\title{
CALIFORNIA ACADEMY OF SCIENCES
}

The Coral Triangle

The 2011 Hearst Philippine Biodiversity Expedition

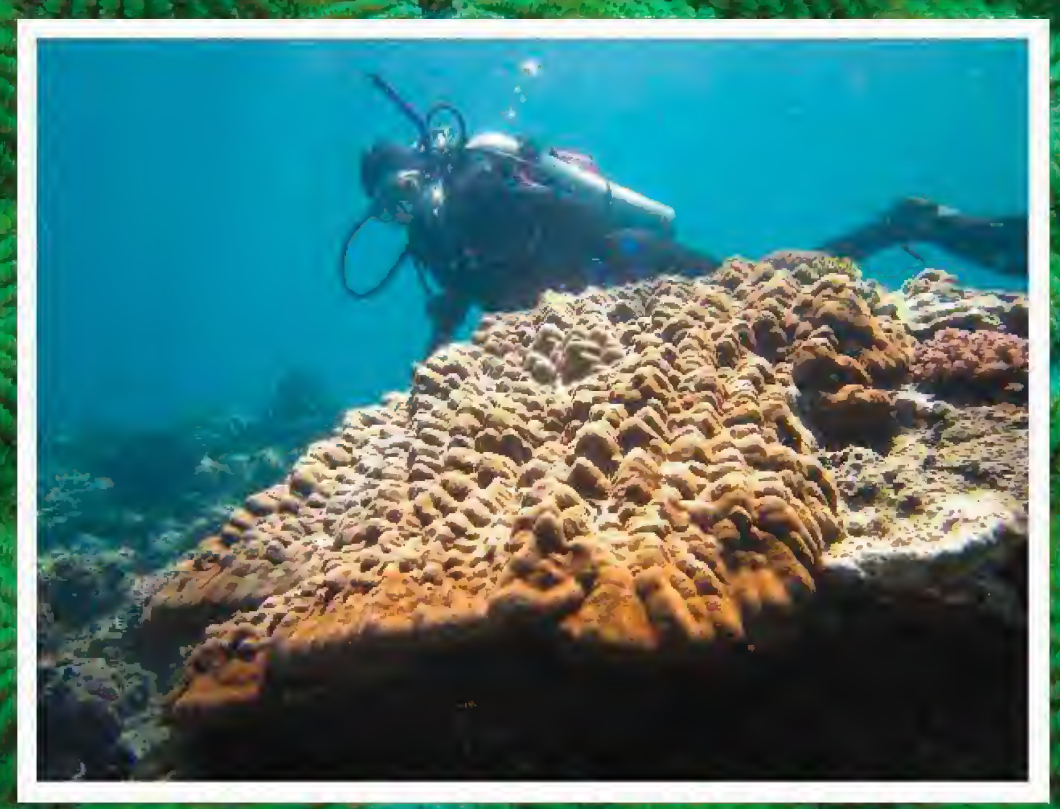

Arranged and edited by

Gary C. Williams and Terrence M. Gosliner

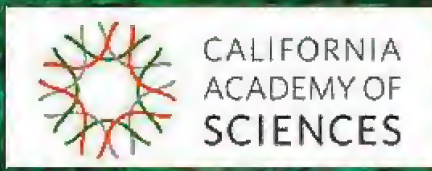




\section{THE CORAL TRIANGLE}

\section{The 2011 Hearst Philippine Biodiversity Expedition}

Arranged and edited by

Gary C. Williams and Terrence M. Gosliner California Academy of Sciences 
Copyright (C) 2014 by the California Academy of Sciences

All rights reserved. No part of this publication may be reproduced or transmitted in any form or by any means, electronic or mechanical, including photocopying, recording, or any information storage or retrieval system, without permission in writing from the publisher.

\section{SCIENTIFIC PuBlications}

Alan E. Leviton, Ph.D., Editor

Gary C. Williams, Ph.D., Associate Editor

Michael T. Ghiselin, Ph.D., Associate Editor

Michele L. Aldrich, Ph.D., Consulting Editor

ISBN 0-940228-75-0

Date of publication: April 15, 2014

Published by the California Academy of Sciences

55 Music Concourse Drive, Golden Gate Park,

San Francisco, California 94118 U.S.A.

Printed in the United States of America by Allen Press Inc., Lawrence, Kansas 66044 


\section{Table of Contents}

Terrence M. Gosliner And Meg Burke: Foreword: The 2011 Hearst Philippine Biodiversity

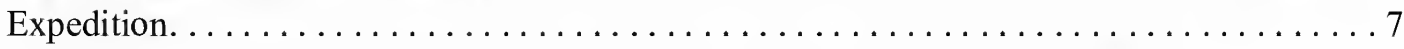

Terrence M. Gosliner and Meg Burke: Expedition Participants and Logistics . . . . . . . . . 9

Terrence M. Gosliner And Meg Burke: From Parachutes to Partnerships: An "Integrated” Natural History Museum Expedition in the Philippines . . . . . . . . . . . . . 19

RICHARD Ross: 2011 Philippine Biodiversity Expedition Summary . . . . . . . . . . . . . 39

GARY C. WILliams: The Three Research Components of the Hearst Biodiversity Expedition

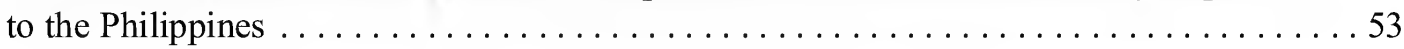

\section{Shallow-water Component}

Gary C. Williams and Jei-Ying Chen: Illustrated Key to the Shallow-Water Gorgonians and Pennatulaceans of the Verde Island Passage, Northern Philippines, Including Synopses of the Taxa and a Glossary of Terms (Cnidaria: Anthozoa: Octocorallia) . . . . . . . 67

Vanessa L. Knutson and Terrence M. Gosliner: Three New Species of Gymnodoris

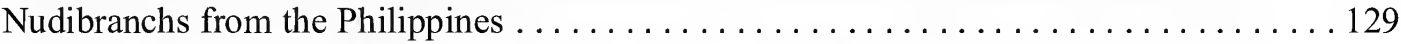

Patricia Álvarez-Campos, Guillermo San Martín, and Christina Piotrowski: A New Species of Myrianida Milne Edwards, 1845 (Autolytinae: Syllidae: Annelida), from

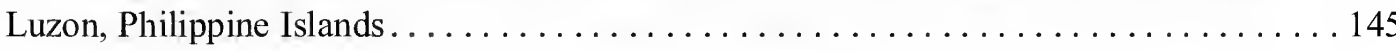

Christina N. Piotrowski: A New Scaleworm, Iphione malifera (Polychaeta: Iphionidae),

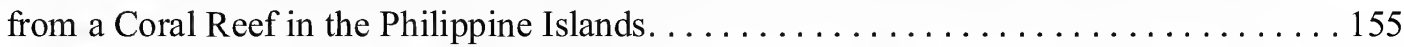

Sergio I. Salazar-ValleJo: Sternaspis piotrowskiae sp. nov. (Polychaeta: Sternaspidae)

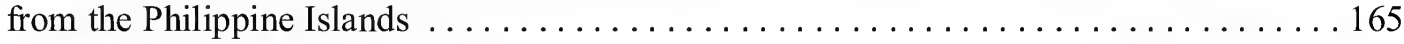

Robert J. Van Syoc, Dana Carrison-Stone, Liezl Madrona, and Gary C. Williams: Barnacle Symbionts of Gorgonian Sea Fans Description of Seven New Species (Archaeobalanidae: Cirripedia) from the Philippines

Rich Moor And Angelica Munguia: Sea Urchins of the Philippines $\ldots \ldots \ldots \ldots \ldots \ldots \ldots 213$

Bart Shepherd, Richard Ross, and Marisa Avila: Collection, Transport and Husbandry of the Coconut Octopus, Amphioctopus marginatus (Taki, 1964), from the Philippines . . 237

\section{Deep-water Component}

томіо Iwamoтo: Two New Hemerocoetine Trichonotidae Fishes (Teleostei, Perciformes)

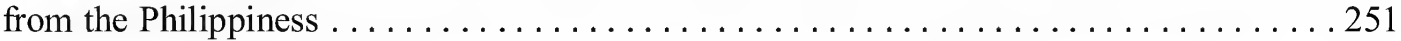

Tomio Iwamoto And John E. McCosker: Deep-Water Fishes of the 2011 Hearst Philippine Biodiversity Expedition of the California Academy of Sciences $\ldots \ldots \ldots \ldots \ldots \ldots \ldots 3$

JoHn McCosker: A Gigantic Deep-Water Worm Eel (Anguilliformes: Ophichthidae) from the Verde Island Passage, Philippine Archipelago . . . . . . . . . . . . . . . . . 333 
Michael Maia Mincarone and John E. McCosker: Redescription of Eptatretus luzonicus Fernholm et al., 2013, a Replacement Name for Eptatretus fernholmi McMillan and Wisner, 2004 (Craniata: Myxinidae), Based on the Discovery of the Holotype and Additional

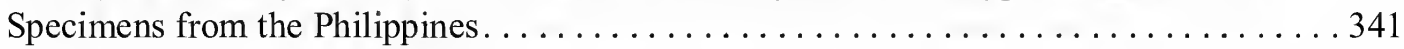

Clatre Gonzales and Terrence Gosliner: Six New Species of Philine (Opisthobranchia:

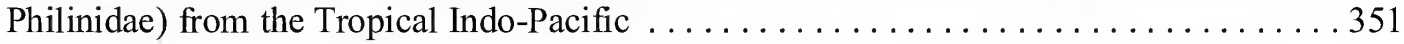

Mary K. Wicksten: Deep-Water Lobsters (Astacidea, Polychelida), Shrimps (Caridea, Penaeoidea) and a Lophogastrid from the California Academy of Sciences' Hearst Philippine Biodiversity Expedition, 2011

\section{Terrestrial Component}

James R. Shevock, Ivy Amor F. Lambio, and Benito C. Tan: Collection and Preparation Techniques of Bryophyte Specimens in Biodiversity Inventories. . . . . . . . . 395

Facundo M. Labarque and Charles E. Griswold: New Ray Spiders from Southeast Asia: Male and Female Evidence to Define the New Philippine Genus Tagalogonia gen. nov. and Continental Genus Coddingtonia Miller, Griswold, and Yin, 2009 (Araneae:

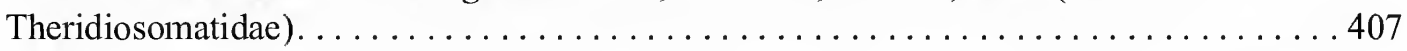

Facundo M. Labarque, Veverled A. San Juan, Ireneo L. Lit, Jr., and Charles E. Griswold: Redescription of the Flatbacked Millipede Ilodesmus margaritiferus (Gervais, 1836) (Diplopoda: Polydesmida: Platyrhacidae) from the Philippines . . . . . . . . . . . 427

David H. Kavanaugh, Victor G. Smith, and Michael Krasnobrod: An Annotated and Illustrated List of the Carabid Beetles (Insecta: Coleoptera: Carabidae) from the California Academy of Sciences' 2011 Hearst Philippine Biodiversity Expedition

Alan E. Leviton, Rafe M. Brown, and Cameron D. Siler: The Dangerously Venomous Snakes of the Philippine Archipelago, with Identification Keys and Species Accounts. . . 473

\section{Medical Perspective}

Matthew Lewin: How Expeditions Drive Clinical Research

\section{Outreach Component}

Meg Burke and Roberta Brett: The Education Log of the 2011 Hearst Philippine

Biodiversity Expedition . . . . . . . . . . . . . . . . . . . . . 539

\section{Epilogue}

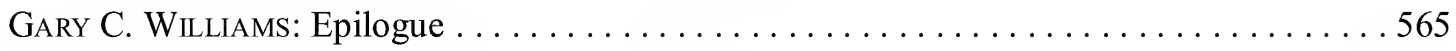

\section{Index}

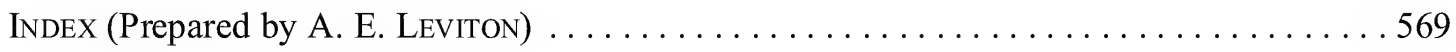




\section{THE CORAL TRIANGLE}

The 2011 Hearst Philippine Biodiversity Expedition 


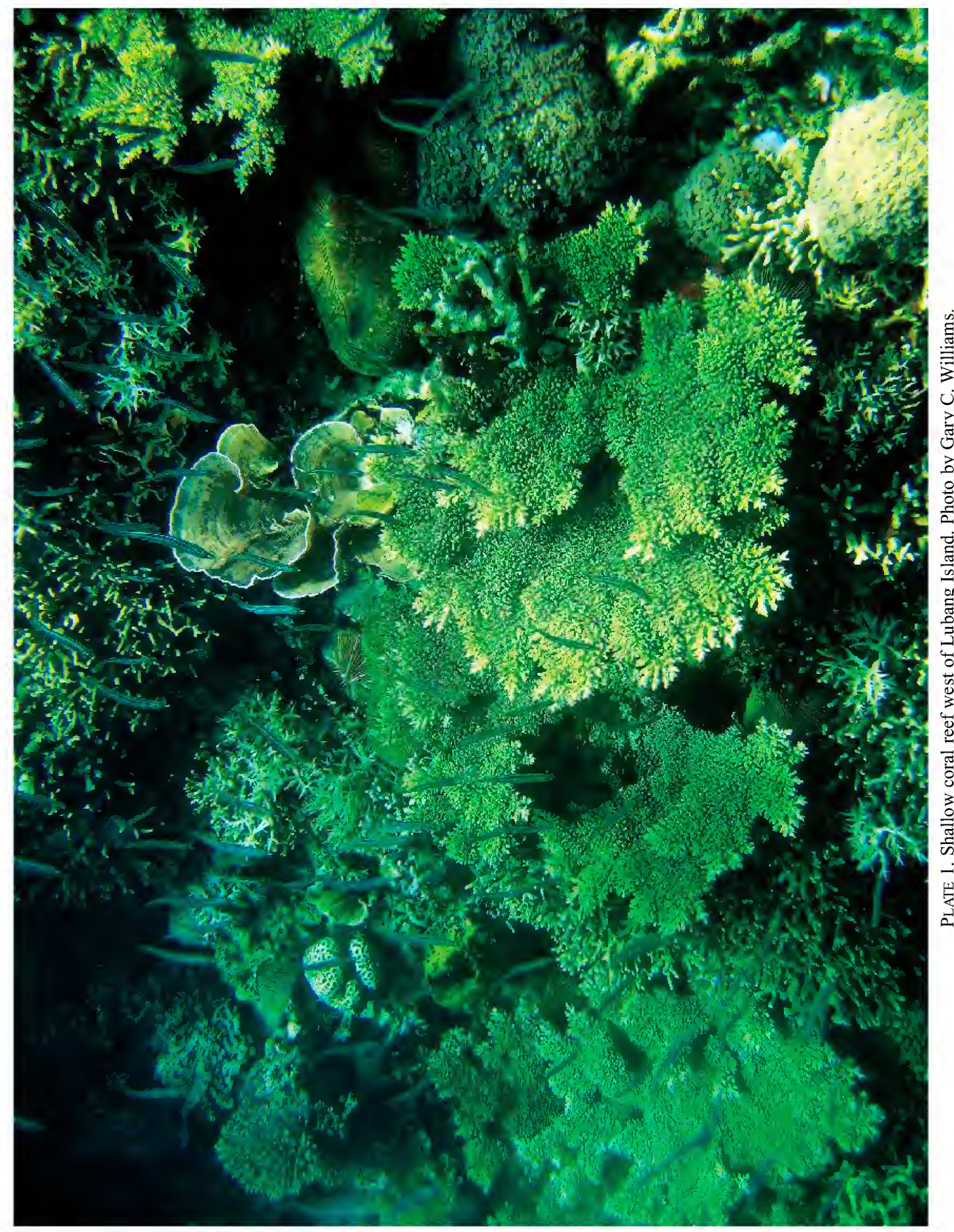




\section{Foreword}

\section{The 2011 Hearst Philippine Biodiversity Expedition}

Expeditions are the life-blood of scientific exploration and the source for most natural history collections. The romantic escapades of the likes of Roy Chapman Andrews' explorations for dinosaurs in the Gobi Desert in the 1920s have provided the inspiration for exploration and adventure-seeking Indiana Joneses for the better part of a century. Andrews got his expeditionary start on the 1909 U.S. Fisheries Albatross Expedition to the Philippines, during which he studied cetaceans.

The California Academy of Sciences began its work in the Philippines in 1907-08, when Joseph Cheesman Thompson, a naval surgeon and an Assistant Curator in the Academy's Department of Herpetology, was stationed in Manila Bay. He collected reptiles and amphibians rather extensively in the Philippines as well as elsewhere in eastern Asia. The Academy's herpetological work in the Philippines continued in the 1950s through collaborations with Walter Brown, an Academy Research Associate, and continues today with Professor Angel Alcala of Silliman University, who is also an Academy Fellow and former Secretary of the Department of the Environment and Natural Resources of the Philippines.

The Academy's marine research in the Philippines began in 1992, with a preliminary survey by Gosliner of parts of the Verde Island Passage that separates southern Luzon Island from northern Mindoro Island. That marine research has been the continued focus of consistent Academy work in the Philippines over the last two decades, and since 2006 has included the participation of staff from the Steinhart Aquarium of the Academy and staff from the Academy's Teacher and Youth Education Department.

As stated in Gosliner and Burke (2013), which is reprinted in this volume, the 2011 Hearst Philippine Biodiversity Expedition had 94 participants (this volume, Expedition Participants and Logistics, Appendix 1, pp. 9-12), over half of whom were Filipino scientists and university students. It became the largest biodiversity expedition in Academy and Philippine history. From its onset, the expedition was designed to be integrative, with terrestrial, shallow-water marine, and deep-sea scientific components integrated with an educational outreach component, two media teams, and a team of aquatic biologists from the Academy's Steinhart Aquarium. The significant achievements of the expedition were directly related to the integration, as well the strength of the partnerships with our Philippine partner institutions. Two planning trips to the Philippines prior to the expedition were critical in ensuring that partnerships, memos of understanding, and permits were all in place prior to launching the expedition. Coordinating the expedition travel logistics with field teams simultaneously in different places and changing locations at different times was complex and challenging. Because one goal of the expedition was to have educational outreach in each of the communities where scientists were conducting research, Burke developed a master calendar (this volume, Expedition Participants and Logistics, Appendix 2, pp. 13-17) that was critical to coordinating the detailed logistics.

This special volume documents the scientific findings to date and educational outreach impact of the 2011 Hearst Philippine Biodiversity Expedition. Over 500 new species were discovered during the expedition, many of which are described in articles in this volume. Because the whole approach of the expedition was to integrate scientific research and public engagement, and share results as quickly and widely as possible, this volume also includes an article detailing how more than 900 people participated in numerous outreach events in the Philippines, including the capstone symposium at the University of the Philippines, which was attended by high-level U.S. and Filipino dignitaries. 
This historic expedition continues to bear fruit. Fieldwork and educational outreach are ongoing, and additional memoranda have been signed, bringing in new Filipino and international partners. The model of an integrated approach to expeditions, with authentic partnerships and embedded outreach, has proven highly successful and will continue to be the Academy way.

Terrence M. Gosliner and Meg Burke

December 13, 2013 


\section{Expedition Participants and Logistics}

Terrence M. Gosliner and Meg Burke

California Academy of Sciences, 55 Music Concourse Drive, San Francisco, California 94118

Email:tgoslineer@calacademy.org; mburke@calacademy.org

\section{APPENDIX 1}

Expedition participants, expertise on the expedition, and expedition components covered.

BFAR $=$ Philippine Bureau of Fisheries and Aquatic Resources

\begin{tabular}{|c|c|c|c|c|c|}
\hline Participant & Expertise & $\begin{array}{c}\text { Shallow } \\
\text { water }\end{array}$ & $\begin{array}{c}\text { Deep } \\
\text { water }\end{array}$ & Terrestrial Symposium \\
\hline
\end{tabular}

California Academy of Sciences

\begin{tabular}{|c|c|c|c|c|c|}
\hline Almeda, Frank & Melastomes & & & $\checkmark$ & \\
\hline Brett, Roberta & Education & $\checkmark$ & $\checkmark$ & $\checkmark$ & $\checkmark$ \\
\hline Burke, Meg & Education & $\checkmark$ & $\checkmark$ & $\checkmark$ & $\checkmark$ \\
\hline Catania, Dave & Fishes & $\checkmark$ & $\checkmark$ & Taal Lake & $\checkmark$ \\
\hline Chousou Polydouri, Natalia & Arthropods & & & $\checkmark$ & $\checkmark$ \\
\hline Farrington, Greg & Exec. Dir. & & & & $\checkmark$ \\
\hline Fritsch, Peter & Ericales & & & $\checkmark$ & \\
\hline Gosliner, Terry & Mollusks & $\checkmark$ & $\checkmark$ & & $\checkmark$ \\
\hline Griswold, Charles & Arthropods & & & $\checkmark$ & $\checkmark$ \\
\hline Hamilton, Healy & Sygnathid fishes & $\checkmark$ & & & $\checkmark$ \\
\hline Horn, Tim & Video & $\checkmark$ & & & \\
\hline Iwamoto, Tomio & Fishes & & $\checkmark$ & & $\checkmark$ \\
\hline Jessup, Elliot & Dive safety & $\checkmark$ & & & \\
\hline Knutson, Vanessa & Mollusks, arthropods & $\checkmark$ & & $\checkmark$ & $\checkmark$ \\
\hline Lewin, Matt & Physician & $\checkmark$ & & $\checkmark$ & \\
\hline McCosker, John & Fishes & & $\checkmark$ & & $\checkmark$ \\
\hline Mooi, Rich & Echinoderms & $\checkmark$ & $\checkmark$ & & $\checkmark$ \\
\hline Moore, Beth & Sygnathid fishes & $\checkmark$ & & & $\checkmark$ \\
\hline Penneys, Darin & Melastomes & & & $\checkmark$ & \\
\hline Piotrowski, Chrissy & Polychaetes & $\checkmark$ & $\checkmark$ & & $\checkmark$ \\
\hline Ross, Rich & Aquarium animals & $\checkmark$ & & & \\
\hline Shepherd, Bart & Aquarium animals & $\checkmark$ & & & \\
\hline Shevock, Jim & Bryophytes & & & $\checkmark$ & \\
\hline Simison, Brian & Gastropods, zooxanthellae & $\checkmark$ & & & $\checkmark$ \\
\hline Stone, Stephanie & Media & $\checkmark$ & $\checkmark$ & $\checkmark$ & \\
\hline Van Syoc, Bob & Crustaceans & $\checkmark$ & $\checkmark$ & & $\checkmark$ \\
\hline Wandell, Matt & Aquarium animals & $\checkmark$ & & & \\
\hline Williams, Gary & Octocorals & $\checkmark$ & $\checkmark$ & & $\checkmark$ \\
\hline Wood, Hannah & Arthropods & & & $\checkmark$ & $\checkmark$ \\
\hline
\end{tabular}




\begin{tabular}{|c|c|c|c|c|c|}
\hline Participant & Expertise & $\begin{array}{c}\text { Shallow } \\
\text { water }\end{array}$ & $\begin{array}{c}\text { Deep } \\
\text { water }\end{array}$ & Terrestrial & Symposium \\
\hline \multicolumn{6}{|l|}{ University of Kansas } \\
\hline Brown, Rafe & Herpetology & & & $\checkmark$ & \\
\hline Siler, Cameron & Herpetology & & & $\checkmark$ & \\
\hline Stirling, Dave & Herpetology & & & $\checkmark$ & \\
\hline \multicolumn{6}{|l|}{ Old Dominion University } \\
\hline Carpenter, Kent & Fishes & $\checkmark$ & & & \\
\hline \multicolumn{6}{|l|}{ Smithsonian Institution } \\
\hline Williams, Jeffrey & Fishes & $\checkmark$ & & & \\
\hline \multicolumn{6}{|c|}{ University of California Los Angeles (UCLA) } \\
\hline Weber, Michele & Zooxanthellae & $\checkmark$ & & & \\
\hline \multicolumn{6}{|l|}{ U.S. media } \\
\hline Isaacson, Andy & Print and stills & $\checkmark$ & $\checkmark$ & $\checkmark$ & \\
\hline McGuire, David & Stills and video & $\checkmark$ & $\checkmark$ & $\checkmark$ & \\
\hline Olney, Jennifer & KGO TV producer & $\checkmark$ & $\checkmark$ & $\checkmark$ & \\
\hline \multicolumn{6}{|l|}{ U.S./Philippines } \\
\hline Salcedo, Mary Lou & Project Manager & $\checkmark$ & & $\checkmark$ & $\checkmark$ \\
\hline \multicolumn{6}{|l|}{$B F A R$} \\
\hline Ampoyos, Riczneth & Crustaceans & & $\checkmark$ & & \\
\hline Bacordo, Rhoda & Mollusks & & $\checkmark$ & & \\
\hline Borja, Val & Invertebrates & $\checkmark$ & & & $\checkmark$ \\
\hline Cadapan, Peter & Corals & & $\checkmark$ & & $\checkmark$ \\
\hline De La Cruz, William & Fishes & & $\checkmark$ & & \\
\hline Escriba, Robin & Crustaceans & & $\checkmark$ & & \\
\hline Fortaliza, Roger & Echinoderms & & $\checkmark$ & & \\
\hline Labe, Ludivina & Echinoderms & $\checkmark$ & $\checkmark$ & & $\checkmark$ \\
\hline Nepomuceno, Laureana & Mollusks & & $\checkmark$ & & \\
\hline Ramiscal, Rafael & Chief Scientist, M/V & & $\checkmark$ & & \\
\hline Tanongonan, Isidro & Crustaceans & & $\checkmark$ & & \\
\hline Viron, Jennifer & Echinoderms & & $\checkmark$ & & \\
\hline Yleana, Joeren & Fishes & & $\checkmark$ & & \\
\hline
\end{tabular}




\begin{tabular}{|c|c|c|c|c|c|}
\hline Participants & Expertise & $\begin{array}{c}\text { Shallow } \\
\text { water }\end{array}$ & $\begin{array}{l}\text { Deep- } \\
\text { water }\end{array}$ & Terrestrial & Symposium \\
\hline \multicolumn{6}{|c|}{ National Museum of the Philippines } \\
\hline Comendador, Joseph & Sponges & $\checkmark$ & & & $\checkmark$ \\
\hline Diesmos, Arvin & Herpetology & & & $\checkmark$ & $\checkmark$ \\
\hline Domingo, Aisa & Illustrator, photographer & & $\checkmark$ & & \\
\hline Dumale, Don & Fishes & $\checkmark$ & $\checkmark$ & & $\checkmark$ \\
\hline Manuel Santos, Marivene & Crustaceans & & $\checkmark$ & & $\checkmark$ \\
\hline Mendoza, Evelyn & Crustaceans & & $\checkmark$ & & \\
\hline Salazar, Zenaida & Echinoderms & & $\checkmark$ & & \\
\hline \multicolumn{6}{|c|}{ University of the Philippines, Diliman } \\
\hline Castilagan Inggat, Laya & Echinoderms & $\checkmark$ & & & $\checkmark$ \\
\hline Dumalan, Rafael & Echinoderms & $\checkmark$ & & & $\checkmark$ \\
\hline Duya, Mariano Roy & Mammals & & & $\checkmark$ & $\checkmark$ \\
\hline Norievill, España & Scleractinians & $\checkmark$ & & & \\
\hline Gorospe, Jay & Echinoderms & $\checkmark$ & & & $\checkmark$ \\
\hline Gotanco, Rachel & Molecular ecology & & $\checkmark$ & & $\checkmark$ \\
\hline Maboloc, Elizaldy & Echinoderms & $\checkmark$ & & & \\
\hline Ong, Perry & Vertebrates & & & & $\checkmark$ \\
\hline Rodriguez, Bryan & Echinoderms & $\checkmark$ & & & \\
\hline \multicolumn{6}{|c|}{ University of the Philippines, Los Baños } \\
\hline Alviola, Phillip & Vertebrates & & & $\checkmark$ & \\
\hline Cajano, Mary Ann & Plants & & & $\checkmark$ & $\checkmark$ \\
\hline Cosico, Edison & Vertebrates & & & $\checkmark$ & \\
\hline De Guzman, Sean Patrick & Arthropods & & & $\checkmark$ & $\checkmark$ \\
\hline Eres, Eduardo & Vertebrates & & & $\checkmark$ & \\
\hline Eusebio, Orlando L. & Arthropods & & & $\checkmark$ & $\checkmark$ \\
\hline Fernando, Edwino & Angiosperms & & & $\checkmark$ & $\checkmark$ \\
\hline James & Vertebrates & & & $\checkmark$ & \\
\hline Lambio, Ivy & Plants & & & $\checkmark$ & $\checkmark$ \\
\hline Larona, Ariel & Plants & & & $\checkmark$ & $\checkmark$ \\
\hline Russell & Vertebrates & & & $\checkmark$ & \\
\hline San Juan, Veverle & Arthropods & & & $\checkmark$ & $\checkmark$ \\
\hline Vacarizas, Joshua & Arthropods & & & $\checkmark$ & $\checkmark$ \\
\hline Yap, Sheryl & Arthropods & & & $\checkmark$ & $\checkmark$ \\
\hline Yugete, Mark & Arthropods & & & $\checkmark$ & $\checkmark$ \\
\hline
\end{tabular}




\begin{tabular}{|c|c|c|c|c|c|}
\hline Participants & Expertise & $\begin{array}{c}\text { Shallow- } \\
\text { water }\end{array}$ & $\begin{array}{l}\text { Deep- } \\
\text { water }\end{array}$ & Terrestrial & Symposium \\
\hline \multicolumn{6}{|l|}{ De La Salle University } \\
\hline Licuanan, Wilfredo & Scleractinians & $\checkmark$ & & & $\checkmark$ \\
\hline Luzon, Katrina & Scleractinians & $\checkmark$ & & & $\checkmark$ \\
\hline \multicolumn{6}{|l|}{ Silliman University } \\
\hline Reboton, Clarissa & Scleractinians & $\checkmark$ & & & $\checkmark$ \\
\hline \multicolumn{6}{|l|}{ University of Singapore } \\
\hline Tan, Benito & Bryophytes & & & $\checkmark$ & \\
\hline \multicolumn{6}{|l|}{ Pusod } \\
\hline Edrial, Jennifer & Plants & & & $\checkmark$ & \\
\hline Javier, Ann Hazel & Education & $\checkmark$ & & $\checkmark$ & $\checkmark$ \\
\hline Luna, Ipat & Education & & & $\checkmark$ & $\checkmark$ \\
\hline Castillo, Jovell & Education & $\checkmark$ & & $\checkmark$ & $\checkmark$ \\
\hline Malubag, Arvell & Education & $\checkmark$ & & $\checkmark$ & $\checkmark$ \\
\hline Reyes, Jennette & Education & $\checkmark$ & & $\checkmark$ & $\checkmark$ \\
\hline \multicolumn{6}{|l|}{ Philippine Science Centrum } \\
\hline Pagsinohin, May & Education & & & & $\checkmark$ \\
\hline \multicolumn{6}{|l|}{ Philippine media } \\
\hline Atienza, Kim & ABS-CBN documentary & $\checkmark$ & $\checkmark$ & & $\checkmark$ \\
\hline Ifurung, Jeanette & ABS-CBN documentary & $\checkmark$ & $\checkmark$ & & $\checkmark$ \\
\hline Magsanoc-Alikpala, Kara & ABS-CBN documentary & $\checkmark$ & $\checkmark$ & & $\checkmark$ \\
\hline
\end{tabular}


APPENDIX 2

\section{Philippine Biodiversity Expedition Master Calendar}

\section{Key to Appendix 2}

\section{Places}

$\mathrm{MNL}=$ Manila

$\mathrm{QC}=$ Quezon City

$*=$ community outreach presentation

\section{People}

$\begin{array}{ll}\text { FA = Frank Almeda } & \text { TH = Tim Horn } \\ \text { RB = Roberta Brett } & \text { AI = Andy Isaacson } \\ \text { MB = Meg Burke } & \text { TI = Tomio Iwamoto } \\ \text { DC = Dave Catania } & \text { EJ = Elliott Jessup } \\ \text { NCP = Natalia Chousou Polydouri } & \text { VK = Vanessa Knutson } \\ \text { JC = Joseph Comendador } & \mathrm{ML}=\text { Matt Lewin } \\ \text { DD = Don Dumale } & \mathrm{JM}=\text { John McCosker } \\ \text { GF = Greg Farrington } & \mathrm{DM}=\text { David McGuire } \\ \text { EF = Edwino Fernando } & \mathrm{RM}=\text { Rich Mooi } \\ \text { PF = Peter Fritsch } & \mathrm{BM}=\text { Beth Moore } \\ \text { TG = Terry Gosliner } & \mathrm{JO}=\text { Jennifer Olney } \\ \text { CG = Charles Griswold } & \mathrm{DP}=\text { Darin Penneys } \\ \text { HH = Healy Hamilton } & \mathrm{CP}=\text { Chrissy Piotrowski }\end{array}$

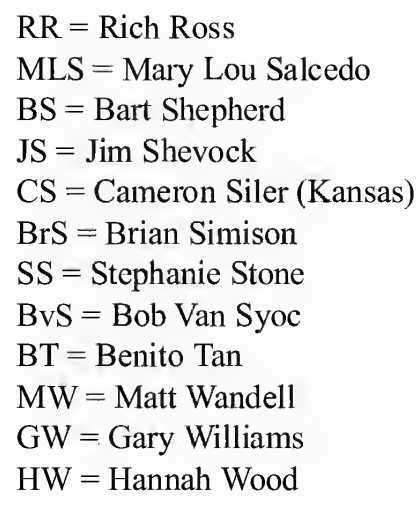

\section{Color code}

Blue $=$ shallow-water marine team

Grey $=$ media team

Purple/magenta $=$ education team

Green $=$ terrestrial team
Brownish-green $=$ medical (Matt Lewin)

Yellow $=$ deep-water marine team

Bright red $=$ CAS Executive Director 


\begin{tabular}{|c|c|c|c|c|c|c|}
\hline Sunday & Monday & Tuesday & Wednesday & Thursday & Friday & Saturday \\
\hline $\begin{array}{l}4 / 24 \\
\text { Dpt SFO } \\
\text { TG, DC, } \\
\text { RM, CP, } \\
\text { BvS, VK. }\end{array}$ & $\begin{array}{l}4 / 25 \\
\text { DptSF0: El. }\end{array}$ & $\begin{array}{l}4 / 26 \\
\text { Arr MNL: TG, DC, RM } \\
\text { CE. BVS, VK } \\
\text { Dpt SFO: TH, DM. }\end{array}$ & $\begin{array}{l}4 / 27 \\
\text { ATT MNL; EJ } \\
\text { MNL: TG, } \\
\text { DC, RM, CP, } \\
\text { BVS,VK }\end{array}$ & $\begin{array}{l}\text { 4/28 } \\
\text { Arr MNL; } \\
\text { TH, DM. } \\
\text { To Anilao: } \\
\text { TG, DC } \\
\text { RM, CP, } \\
\text { BvS, VK, } \\
\text { EJ, TH, } \\
\text { DM: }\end{array}$ & $\begin{array}{l}4 / 29 \\
\text { Anilao: TG, } \\
\text { PC, RM, CP, } \\
\text { BuS, VK, EJ } \\
\text { TH, DM. } \\
\text { Dpt SFO: } \\
\text { MLS. }\end{array}$ & $\begin{array}{l}4 / 30 \\
\text { Anilao, TG, DC, } \\
\text { RM, CP, BVS, } \\
\text { VK, EJ, TH, DM. } \\
\text { DptSFO:PE } \\
\text { DP, JS }\end{array}$ \\
\hline $\begin{array}{l}\text { 5/1* } \\
\text { Anilao: TG, } \\
\text { DC, RM, } \\
\text { CP, BvS, } \\
\text { VK, EJ, TH, } \\
\text { DM. } \\
\text { Cluh O } \\
\text { outreach } \\
\text { RM, CW, } \\
\text { BvS, DM, } \\
\text { TH. } \\
\text { To MNL: } \\
\text { TG, } \\
\text { Arr MNL } \\
\text { MLS }\end{array}$ & $\begin{array}{l}\text { 5/2 } \\
\text { Anilao: TG, DC, } \\
\text { RM, CP, BvS, VK, } \\
\text { EJ, TH, DM. } \\
\text { Arr MNL: PE, DP, } \\
\text { IS. } \\
\text { MNL: MLS, } \\
\text { UP Press } \\
\text { Conference: PF, } \\
\text { DP. JS, TG, MLS. } \\
\text { To Anilao: TG. }\end{array}$ & $\begin{array}{l}\text { 5/3 } \\
\text { Anilao: TG, DC, RM, CP } \\
\text { BvS, VK, EJ, TH, DM. } \\
\text { MNL: PF, DP, JS, MLS, }\end{array}$ & $\begin{array}{l}\text { 5/4 } \\
\text { Anilao: TG, } \\
\text { DC, RM, CP, } \\
\text { BvS, VK, EJ, } \\
\text { TH, DM. } \\
\text { MNL: PE, } \\
\text { DP,IS, MLS, } \\
\text { Dpt SFO: CS }\end{array}$ & $\begin{array}{l}\text { 5/5 } \\
\text { Anilao: } \\
\text { TG, DC, } \\
\text { RM, CP, } \\
\text { BvS, VK, } \\
\text { EJ, TH, } \\
\text { DM. } \\
\text { To } \\
\text { Makiling } \\
\text { (UPLB) } \\
\text { PE, DP, IS } \\
\text { MNL } \\
\text { MLS } \\
\text { CAS Gala } \\
\text { (5/6 am, } \\
\text { PI time) }\end{array}$ & $\begin{array}{l}\text { 5/6 } \\
\text { Arr MNL, } \\
\text { to UPLB: } \\
\text { CS } \\
\text { Anilau: TG, } \\
\text { DC, RM, CP, } \\
\text { BVS, VK, EJ, } \\
\text { TH, DM. } \\
\text { Makiling, } \\
\text { PE, DP, JS } \\
\text { CS } \\
\text { MNL: MLS, } \\
\text { Dpt SFO } \\
\text { MB, RB }\end{array}$ & $\begin{array}{l}\text { 5/7 } \\
\text { Anilao: TG, DC, } \\
\text { RM, CP, BvS, } \\
\text { VK, EJ, TH, DM. } \\
\text { Makiling: PE } \\
\text { DP.IS,CS, } \\
\text { MNL: MLS, } \\
\text { Dpt SFO: HH, } \\
\text { BrS, BM, CG } \\
\text { NCP,HW ML. }\end{array}$ \\
\hline $\begin{array}{l}\text { 5/8 } \\
\text { Arr MNL, } \\
\text { MB, RB. } \\
\text { MNL: MLS, } \\
\text { Anilao: TG, } \\
\text { DC, RM, } \\
\text { CP, BvS, } \\
\text { VK, EJ, TH, } \\
\text { DM: } \\
\text { To MNL; } \\
\text { TG, RM, }\end{array}$ & $\begin{array}{l}\text { 5/9* } \\
\text { Arr MNL, to } \\
\text { Anilao: HH, Brs, } \\
\text { BM; plus TG, RM, } \\
\text { Arr MNL, to } \\
\text { UPLB: CG, NCP, } \\
\text { HW, ML. } \\
\text { Anilao: TG, DC, } \\
\text { RM, CP, BvS, VK, } \\
\text { EJ, HH, BrS, BM, } \\
\text { TH, DM. } \\
\text { Makiling: PF, DP } \\
\text { JS, CS, CG, NCI } \\
\text { HW, ML: } \\
\text { PUST outreach } \\
\text { (MNL): MB, RB } \\
\text { MLS. }\end{array}$ & $\begin{array}{l}\text { 5/10 } \\
\text { Anilao: TG, RM, VK, EJ, } \\
\text { HH, BrS, BM, DM, } \\
\text { To Talisay, from } \\
\text { Anilao: BvS, DC, CP, } \\
\text { VK, DD, DM, TH ; ABS- } \\
\text { CBN. } \\
\text { Tis Talisay, from Dusit } \\
\text { MB, RB, MLS: Ann. } \\
\text { Makiling: PF, DP, JS, } \\
\text { CS, CG, NCP. HW, ML, }\end{array}$ & $\begin{array}{l}\text { 5/11* } \\
\text { Anilao: TG, } \\
\text { RM, EJ, HH, } \\
\text { BrS, BM, } \\
\text { DM, } \\
\text { "Taal } \\
\text { oulreath at } \\
\text { Talisay:MB, } \\
\text { RB, ML.s } \\
\text { Amn;BvS, } \\
\text { DC, CP, VK } \\
\text { Filipino, } \\
\text { DM. } \\
\text { Makiling: } \\
\text { PF, DP, IS } \\
\text { CS, CG, NCP } \\
\text { HW, ML. }\end{array}$ & $\begin{array}{l}\text { 5/12* } \\
\text { Arr MNL, } \\
\text { go to } \\
\text { Anilao: } \\
\text { GW, BS, } \\
\text { RR, MW, } \\
\text { Anilao; } \\
\text { TG, DC, } \\
\text { RM, CP, } \\
\text { BVS, EJ, } \\
\text { HH, BrS, } \\
\text { BM, CW, } \\
\text { BS, RR, } \\
\text { MW, DM } \\
\text { ABS-CBN } \\
\text { To } \\
\text { Makiling } \\
\text { (UPLB) }\end{array}$ & $\begin{array}{l}\text { 5/13* } \\
\text { Anilao: TG, } \\
\text { DC, RM, CP, } \\
\text { BvS, EJ, HH, } \\
\text { BrS, BM, } \\
\text { GW, BS, } \\
\text { RR, MW, } \\
\text { DM, ABS- } \\
\text { CBN. } \\
\text { To } \\
\text { Banahaw } \\
\text { (Lucena) } \\
\text { PF, DP, JS } \\
\text { CS, CG, } \\
\text { NCP, HW } \\
\text { VK, len, } \\
\text { ML. } \\
\text { To }\end{array}$ & $\begin{array}{l}\text { 5/14 } \\
\text { Anilao: TG, DC, } \\
\text { RM, CP, BvS, } \\
\text { HH, BrS, BM, } \\
\text { GW, BS, RR, } \\
\text { MW, DM, ABS- } \\
\text { CBN. } \\
\text { Bankahaw; PF } \\
\text { DP, JS, CS, CG } \\
\text { NCP, HW, VK } \\
\text { Jen, ML, MB } \\
\text { RB, MLS, Anu, } \\
\text { ABS-CBN. }\end{array}$ \\
\hline
\end{tabular}




\begin{tabular}{|c|c|c|c|c|c|c|}
\hline & & & $\begin{array}{l}\text { Back tó } \\
\text { Anilao from } \\
\text { Talisay: } \\
\text { BvS, DC, CP, } \\
\text { Don } \\
\text { Dumale, } \\
\text { DM. }\end{array}$ & $\begin{array}{l}\text { from } \\
\text { Talisiy: } \\
\text { VK, MB, } \\
\text { RB, MLS } \\
\text { Ami, } \\
\text { "Makiling } \\
\text { PF, DP, IS, } \\
\text { CS, CG } \\
\text { NCP, HW } \\
\text { VK, MI } \\
\text { MB, RB. }\end{array}$ & $\begin{array}{l}\text { Batangas } \\
\text { City from } \\
\text { UPLB: MB } \\
\text { RB, } \\
\text { Univ, } \\
\text { Batangas } \\
\text { outreach } \\
\text { To Luccina } \\
\text { from } \\
\text { Batangas, } \\
\text { via Cluh o } \\
\text { MB, RB } \\
\text { MIS, Ann }\end{array}$ & \\
\hline $\begin{array}{l}\text { 5/15 } \\
\text { Anilao: TG, } \\
\text { DC, RM, } \\
\text { CP, BvS, } \\
\text { HH, Brs, } \\
\text { BM, GW, } \\
\text { BS, RR, } \\
\text { MW, DM, } \\
\text { Banahaw } \\
\text { PF, DP, IS } \\
\text { CS, CG, } \\
\text { NCP, HW, } \\
\text { VK, Jen } \\
\text { ML: } \\
\text { To } \\
\text { Banahaw, } \\
\text { from } \\
\text { Anilao: } \\
\text { ABS-CBN } \\
\text { MNL: MB, } \\
\text { RB, MLS, }\end{array}$ & $\begin{array}{l}\text { 5/16 } \\
\text { Anilao: TG, DC, } \\
\text { RM, CP, BVS, HH, } \\
\text { BrS, BM, GW, BS, } \\
\text { RR, MW, DM. } \\
\text { Banahaw: PF } \\
\text { DP, JS, CS, CG } \\
\text { NCP, HW, VK, } \\
\text { len, ML,ABS- } \\
\text { CBN, } \\
\text { To Lucban, from } \\
\text { MNL: MB3, KB) } \\
\text { MLS } \\
\text { (MB, RB day trip } \\
\text { Banahaw). }\end{array}$ & $\begin{array}{l}\text { 5/17* } \\
\text { Anilao: DC, RM, CP, } \\
\text { HH, BrS, BS, RR, MW, } \\
\text { DM. } \\
\text { To Calatagan, from } \\
\text { Anilao: TG, BM, GW, } \\
\text { BuS } \\
\text { Banahaw: PF, DP, IS, } \\
\text { CS, CG, NCP, HW, VK } \\
\text { Len, ML. } \\
\text { l.uchan/Banaliaw } \\
\text { outreach: MB, RB } \\
\text { MLS,Ann, CG, EF } \\
\text { To Calatagan, from } \\
\text { Lucban: MB, RB, MLS, } \\
\text { Ann. }\end{array}$ & $\begin{array}{l}\text { 5/18* } \\
\text { Anilao: DC, } \\
\text { RM, CP, HH, } \\
\text { BrS, BS, RR, } \\
\text { MW, DM, } \\
\text { "Calatagan; } \\
\text { TG, BM, GW, } \\
\text { BvS, MB, RB } \\
\text { MLS, Ann } \\
\text { Banahaw; } \\
\text { PF, DP, IS, } \\
\text { CS, CG, NCP, } \\
\text { HW, VK, Jen } \\
\text { ML. }\end{array}$ & $\begin{array}{l}\text { 5/19 } \\
\text { To Anilao, } \\
\text { from } \\
\text { Calatagan, } \\
\text { TG, BM, } \\
\text { GW, BvS, } \\
\text { To Anilao, } \\
\text { from } \\
\text { Banahaw; } \\
\text { ML. } \\
\text { Anilao: } \\
\text { TG, DC, } \\
\text { RM, CP, } \\
\text { BvS, HH, } \\
\text { BrS, BM, } \\
\text { GW, BS, } \\
\text { RR, MW } \\
\text { DM, ML, } \\
\text { Banahaw: } \\
\text { PE, DP, JS, } \\
\text { CS, CG, } \\
\text { NCP, HW } \\
\text { VK, Jen, } \\
\text { ML. } \\
\text { To MNL } \\
\text { from } \\
\text { Calatagan, } \\
\text { MB, RB } \\
\text { MLS. } \\
\text { MNL: MB, } \\
\text { RB, MLS, }\end{array}$ & $\begin{array}{l}\text { 5/20* } \\
\text { Anilao: TG, } \\
\text { DC, RM, CP } \\
\text { BvS, HH, } \\
\text { Brs, BM, } \\
\text { GW, BS, } \\
\text { RR, MW, } \\
\text { DM, ML. } \\
\text { Banahaw: } \\
\text { PF, DP, JS } \\
\text { CS, CG, } \\
\text { NCP, HW } \\
\text { UK, len } \\
\text { ML: } \\
\text { 'Philippine } \\
\text { Science } \\
\text { Centrum: } \\
\text { MB, RB } \\
\text { MNL: MB } \\
\text { RB } \\
\text { MLSLCS }\end{array}$ & $\begin{array}{l}5 / 21 \\
\text { Anilao: TG, DC, } \\
\text { RM, CP, BVS, } \\
\text { HH, BrS, BM, } \\
\text { GW, BS, RR, } \\
\text { MW, DM, ML } \\
\text { Banahaw: PF, } \\
\text { DP, JS, CS, CG, } \\
\text { NCP, HW, VK } \\
\text { len, ML } \\
\text { MNL: MB, RB } \\
\text { MLS CS, }\end{array}$ \\
\hline $\begin{array}{l}5 / 22 \\
\text { Arr MNL.: } \\
\text { SS, J0, AI }\end{array}$ & $\begin{array}{l}\text { 5/23* } \\
\text { Anilao; TG, DC, } \\
\text { RM, CP, BVS, HH, } \\
\text { BrS, BM, GW, BS, }\end{array}$ & $\begin{array}{l}\text { 5/24 } \\
\text { An MNL, to UPLB:FA } \\
\text { Anilao: TG, DC, RM, CP, }\end{array}$ & $\begin{array}{l}5 / 25 \\
\text { Anilao: TG, } \\
\text { DC, RM, CP } \\
\text { BvS, HH, }\end{array}$ & $\begin{array}{l}5 / 26 \\
\text { Arr MNL. } \\
\text { to } \\
\text { Batangas }\end{array}$ & $\begin{array}{l}5 / 27^{*} \\
\text { Anilao: DC } \\
\text { CP, BvS } \\
\text { HH, Brs }\end{array}$ & $\begin{array}{l}5 / 28 \\
\text { To Batangas } \\
\text { City, from } \\
\text { Anila: DC, CP, }\end{array}$ \\
\hline
\end{tabular}




\begin{tabular}{|c|c|c|c|c|c|c|}
\hline $\begin{array}{l}\text { To Anilao: } \\
\text { SS, JO, AI, } \\
\text { MB, RB, } \\
\text { Anilao: TG, } \\
\text { DC, RM, } \\
\text { CP, BvS, } \\
\text { HH, BrS, } \\
\text { BM, GW, } \\
\text { BS, RR, } \\
\text { MW, MB, } \\
\text { RB, DM, } \\
\text { SS, JO, AI, } \\
\text { ML, } \\
\text { Banaliaw } \\
\text { PF, DP, JS, } \\
\text { CS, CG, } \\
\text { NCP, HW } \\
\text { VK, Jen, } \\
\text { Dpt SFO } \\
\text { FA. } \\
\text { DPt MNL } \\
\text { CS, }\end{array}$ & $\begin{array}{l}\text { RR, MW, MB, } \\
\text { RB,DM, SS, IO, AI, } \\
\text { "Mabini/Tingloy: } \\
\text { MB, RB, MLS, } \\
\text { Ann, HH, IC, IO, } \\
\text { SS, AI. } \\
\text { To UPLB: PF, DP, } \\
\text { IS, CG, NCP, HW, } \\
\text { VK, Jen; ABS- } \\
\text { CBN. } \\
\text { To MNL, From } \\
\text { Anilao, dpt MNL: } \\
\text { ML. }\end{array}$ & $\begin{array}{l}\text { BvS, HH, BrS, BM, GW, } \\
\text { MB, RB, MLS, Ann? } \\
\text { DM, SS, JO, AI. } \\
\text { UPLB: PF, DP, JS, CG, } \\
\text { NCP, HW, VK, FA, Jen, } \\
\text { Dpt SFO: TI, JM. }\end{array}$ & $\begin{array}{l}\text { BrS, BM, } \\
\text { GW, MB, RB, } \\
\text { MLS, Ann? } \\
\text { DM, SS, JO, } \\
\text { AI. } \\
\text { UPLB: PF } \\
\text { DP, JS, CG, } \\
\text { NCP, HW } \\
\text { UK, FA, Jen, } \\
\text { To MNL: BS, } \\
\text { RR, MW }\end{array}$ & $\begin{array}{l}\text { City: TI, } \\
\text { JM, } \\
\text { To } \\
\text { Batangas } \\
\text { City, from } \\
\text { Anilao: } \\
\text { RM. } \\
\text { Anilao: } \\
\text { DC, CP } \\
\text { BvS, HH } \\
\text { BrS, BM, } \\
\text { GW: } \\
\text { UPLB: PF, } \\
\text { DP, JS, CG, } \\
\text { NCP, HW } \\
\text { VK, FA } \\
\text { Jen } \\
\text { To MNL, } \\
\text { from } \\
\text { Anilao,: } \\
\text { DM. SS, } \\
\text { JO, Al, TG } \\
\text { MB, RB, } \\
\text { MLS, } \\
\text { Dpt MNL: } \\
\text { BS, RR, } \\
\text { MW }\end{array}$ & 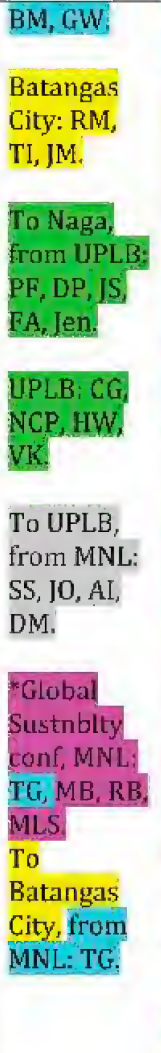 & $\begin{array}{l}\text { BvS, GW, BM, } \\
\text { BrS } \\
\text { Embark } \\
\text { vessel: RM, TI, } \\
\text { JM, TG, DC, CP, } \\
\text { BvS, GW. } \\
\text { Day trip to } \\
\text { Dusit from } \\
\text { Anilao, return } \\
\text { to Batangas } \\
\text { City: HH. } \\
\text { Naga/Isarog } \\
\text { PE, DP. IS, Jen, } \\
\text { UPLB: CG, } \\
\text { NCP } \\
\text { To MNL then } \\
\text { Naga, from } \\
\text { UPLB: SS, JO, } \\
\text { AI, DM } \\
5 / 28 \text { (cont'd) } \\
\text { MNL: MB, RB } \\
\text { MLS } \\
\text { To MNL, from } \\
\text { UPLB, dpt } \\
\text { MNL: HW, VH }\end{array}$ \\
\hline $\begin{array}{l}\text { 5/29 } \\
\text { On vessel: } \\
\text { RM, TI, JM, } \\
\text { TG, DC, CP, } \\
\text { BvS, GW, } \\
\text { To Puerto } \\
\text { Galera ol } \\
\text { Batangas } \\
\text { Ferry: HH, } \\
\text { BM, BrS }\end{array}$ & $\begin{array}{l}\text { 5/30 } \\
\text { On vessel: RM, } \\
\text { TI, JM, TG, DC, } \\
\text { CP, BvS, GW. } \\
\text { Puerto Galera: } \\
\text { HH, BM, BrS. } \\
\text { Isarog (Naga): } \\
\text { PF, DP, IS, FA, } \\
\text { len, SS, JO, AI, } \\
\text { DM. } \\
\text { To Naga, from } \\
\text { UPLB: CG, NCP } \\
\text { To Legazpi, then } \\
\text { Naga, from MNL: } \\
\text { MB, RB, MLS. }\end{array}$ & $\begin{array}{l}\text { 5/31* } \\
\text { On vessel: RM, Tl, JM, } \\
\text { TG, DC, CP, BvS, GW, } \\
\text { Puerto Galera; III, } \\
\text { BM, BrS, } \\
\text { Isarog; PF, DP, JS, CG, } \\
\text { NCP, FA, Ien, SS, JO, } \\
\text { DM. } \\
\text { To Puerto Galera, via } \\
\text { MNL, from Naga: AI. } \\
\text { Naga outreach: MB, } \\
\text { RB, MLS, FA, BT, SS, JO. }\end{array}$ & $\begin{array}{l}\text { 6/1 } \\
\text { On vessel: } \\
\text { RM, TI, JM, } \\
\text { TG, DC, CP, } \\
\text { BvS, GW. } \\
\text { Embark } \\
\text { (from } \\
\text { Calatagan): } \\
\text { Lubang } \\
\text { officials, } \\
\text { ABS-CBN. } \\
\text { Puerto } \\
\text { Galera: HH, } \\
\text { BM, BrS, AI, } \\
\text { Isarog } \\
\text { (Naga): PF) } \\
\text { DP, CG, NCP } \\
\text { Ien, SS, JO, } \\
\text { DM. }\end{array}$ & $\begin{array}{l}\text { 6/2 } \\
\text { On vessel: } \\
\text { RM, TI, } \\
\text { JM, TG, } \\
\text { DC, CP, } \\
\text { BvS, GW, } \\
\text { Lubang } \\
\text { officials, } \\
\text { ABS-CBN. } \\
\text { Puerto } \\
\text { Galera: } \\
\text { HH, BM, } \\
\text { BrS. } \\
\text { To } \\
\text { Batangas } \\
\text { City, from } \\
\text { Puerto } \\
\text { Galera: AI. } \\
\text { Isarog }\end{array}$ & $\begin{array}{l}\text { 6/3 } \\
\text { Anr. MINL } \\
\text { Gr } \\
\text { On vessel: } \\
\text { RM, TI, JM, } \\
\text { TG, DC, CP, } \\
\text { BvS, GW. } \\
\text { Embark } \\
\text { (from } \\
\text { Calatagan); } \\
\text { MB, RB, SS, } \\
\text { JO, DM, AI. } \\
\text { Disembark: } \\
\text { Lubang } \\
\text { officials, } \\
\text { ABS-CBN. } \\
\\
\text { Puerto } \\
\text { Galera: HH, } \\
\text { BM, BrS }\end{array}$ & $\begin{array}{l}6 / 4 \\
\text { On vessel: RM, } \\
\text { TI, JM, TG, DC, } \\
\text { CP, BvS, GW, } \\
\text { MB, RB, SS, JO, } \\
\text { AI, DM. } \\
\text { Disembark } \\
\text { vessel, go to } \\
\text { MNL: } \\
\text { Puerto Galera: } \\
\text { HH, BM, BrS, } \\
\text { UPLB: PF, DP } \\
\text { IS, CG, NCP } \\
\text { MNL, GE. MLS. }\end{array}$ \\
\hline
\end{tabular}




\begin{tabular}{|c|c|c|c|c|c|c|}
\hline & & & $\begin{array}{l}\text { To UPLB, } \\
\text { from Naga, } \\
\text { FA, IS, BT, } \\
\text { MNL; MB, } \\
\text { RB, MLS, } \\
\text { Dol SFQ; GII }\end{array}$ & $\begin{array}{l}\text { (Naga) } \\
\text { PF, DP, IS, } \\
\text { CG, NCP } \\
\text { len. } \\
\text { To MNL, } \\
\text { from } \\
\text { Naga: SS, } \\
\text { JO, AI, DM. } \\
\text { To MNL, } \\
\text { Trom } \\
\text { UPLB, dpt } \\
\text { MNL:FA } \\
\text { MNL,: MB, } \\
\text { RB, MLS. }\end{array}$ & $\begin{array}{l}\text { To UPLB, } \\
\text { from Naga: } \\
\text { PF, DP, IS } \\
\text { CG, NCP } \\
\text { Len. } \\
\text { MNL: GE } \\
\text { MLS }\end{array}$ & \\
\hline $\begin{array}{l}6 / 5 \\
\text { Disembark } \\
\text { vessel in } \\
\text { MNL, to } \\
\text { Dusit via } \\
\text { Nat. Mus.: } \\
\text { RM, TI, JM, } \\
\text { TG, DC, CP, } \\
\text { BvS, GW, } \\
\text { MB, RB, } \\
\text { SS, JO, AI, } \\
\text { DM. } \\
\text { UPLB: PF, } \\
\text { DP, IS, CG, } \\
\text { NCP } \\
\text { MNL: GE, } \\
\text { RM, TL, JM, } \\
\text { TG, DC, CP, } \\
\text { BVS, GW, } \\
\text { MB, RB, } \\
\text { SS, JO, Al, } \\
\text { DM, MLS. }\end{array}$ & $\begin{array}{l}\text { 6/6 } \\
\text { To Batangas City } \\
\text { from Puerto } \\
\text { Galera: continue } \\
\text { to MNL: HH, BM, } \\
\text { BrS, } \\
\text { Ta MNI, from } \\
\text { UPLB: PF, DP, JS } \\
\text { (Lo airport); CG, } \\
\text { NCP (to Dusit) } \\
\text { MNL: RM, TI, JM, } \\
\text { TG, DC, CP, BvS, } \\
\text { GW, HH, BM, BrS, } \\
\text { CG, NCP, MB, RB, } \\
\text { HH, BM, BrS, Gi, } \\
\text { MLS. } \\
\text { 6/6 (cont'd) } \\
\text { 1:30 pm: SEA } \\
\text { Inst meeting, } \\
\text { MNL Polo Club } \\
\text { (Gif TG, MB, } \\
\text { MLS, RM, RB) } \\
\text { 6:00 pm: Dinner } \\
\text { \& medal } \\
\text { ceremony with } \\
\text { Congressman } \\
\text { Palmones, QC } \\
\text { Dpt MNL: SS, JO, } \\
\text { AI, DM PE, DP } \\
\text { IS }\end{array}$ & $\begin{array}{l}\text { 6/7 } \\
\text { MNL: RM, TI, JM, TG, } \\
\text { DC, CP, BvS, GW, HH, } \\
\text { BM, BrS, CG, NCP, MB, } \\
\text { RB, GP, MLS. } \\
\text { Early morning } \\
\text { interview with Howie } \\
\text { Severino. QC (GA, TG, } \\
\text { MB) } \\
\text { 5:00 pm Dusit Hotel } \\
\text { Thanksgiving/farewell } \\
\text { cocktail reception for } \\
\text { expedition (Fiesta San } \\
\text { Miguel Room) }\end{array}$ & $\begin{array}{l}\text { 6/8* } \\
\text { * 8:00 am; } \\
\text { Symposium } \\
\text { at UP: RM, } \\
\text { TL, JM, TG, } \\
\text { DC, CP, BvS, } \\
\text { GW, HH, } \\
\text { BM, BrS, CG, } \\
\text { NCP, MB, } \\
\text { RB, GE, MLS. } \\
\text { ABS-CBN } \\
\text { MNL: RM, } \\
\text { TI, JM, TG, } \\
\text { DC, CP, BvS, } \\
\text { GW, HH, } \\
\text { BM, BrS, CG, } \\
\text { NCP, MB, } \\
\text { RB, GI, MLS. }\end{array}$ & $\begin{array}{l}\text { 6/9 } \\
\text { MNL: RM, } \\
\text { TI, JM, TG, } \\
\text { DC, CP, } \\
\text { BvS, GW, } \\
\text { HH, BM, } \\
\text { BrS, CG, } \\
\text { NCP, MB, } \\
\text { RB, MLS, } \\
\text { Gf } \\
\text { Morning } \\
\text { tour of } \\
\text { MNL and } \\
\text { lunch, } \\
\text { courtesy } \\
\text { of DoT, } \\
\text { Dpt MNL: } \\
\text { Dif }\end{array}$ & $\begin{array}{l}\text { 6/10 } \\
\text { 8:00-10:00 } \\
\text { am: Pusod } \\
\text { Board } \\
\text { meeting, } \\
\text { Dusit (TG, } \\
\text { MB, MLS, } \\
\text { others?) } \\
\text { Dpt MNL: } \\
\text { RM, TI, JM, } \\
\text { TG, DC, CP, } \\
\text { BvS, GW, } \\
\text { HH, BM, } \\
\text { BrS, CG, } \\
\text { NCP, MB, } \\
\text { RB }\end{array}$ & $\begin{array}{l}\text { 6/11 } \\
\text { Dpt MNL: MLS. }\end{array}$ \\
\hline
\end{tabular}




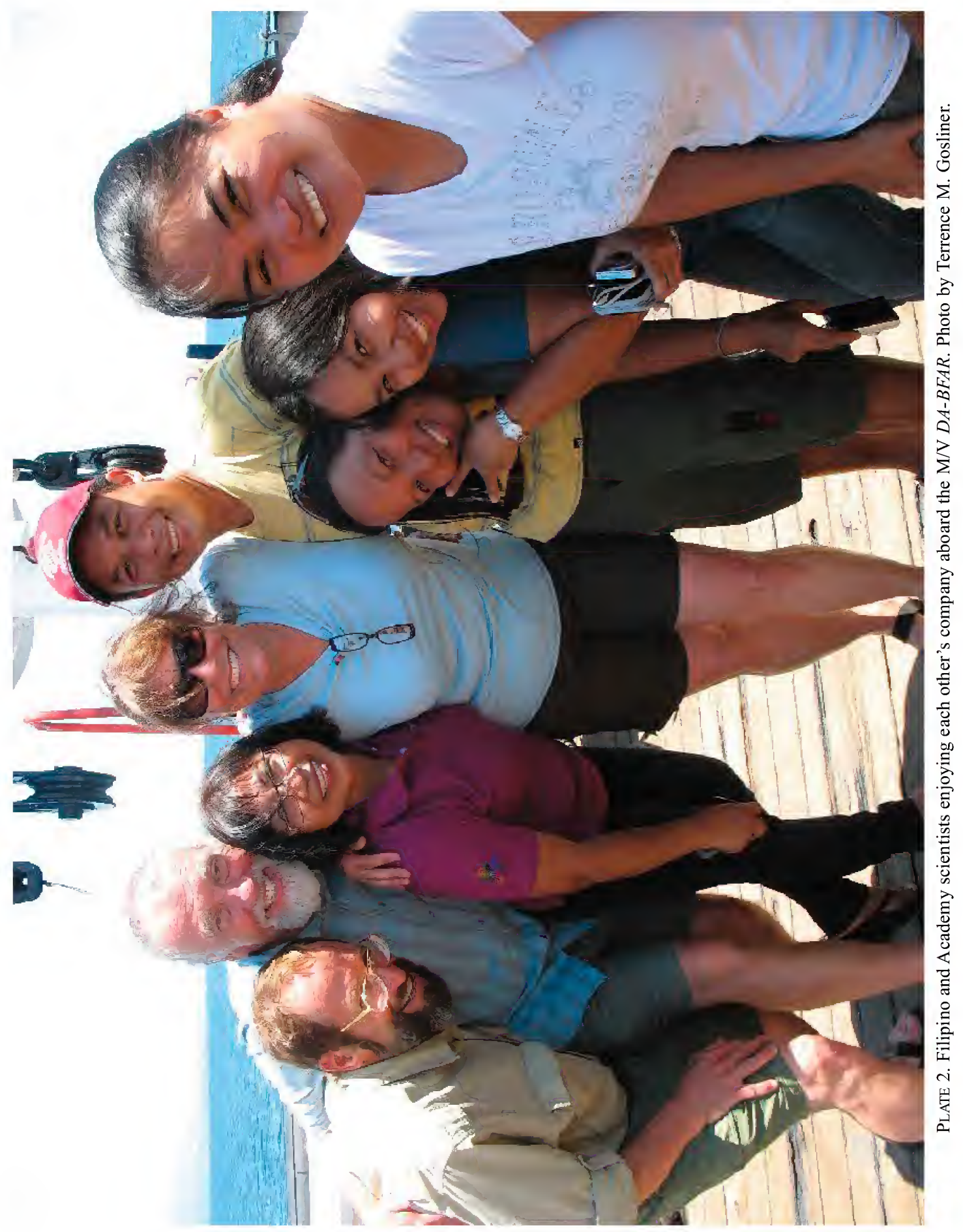




\title{
From Parachutes to Partnerships: An "Integrated" Natural History Museum Expedition in the Philippines*
}

\author{
Terrence M. Gosliner ${ }^{1}$ and Meg Burke 2 \\ 1 Terrence M. Gosliner, Harry W. and Diana V. Hind Senior Curator and Dean of Science and \\ Research Collections, California Academy' of Sciences, San Francisco, California 94118, \\ Email: tgosliner@calacademy.org; ${ }^{2}$ Meg Burke,Director of Teacher and Youth Education, \\ California Academy of Sciences, San Francisco, California 94118; Email: mburke@calacademy.org.
}

The 2011 Hearst Philippine Biodiversity Expedition was the largest ever launched by the California Academy of Sciences, and was also the largest and most diverse expedition to ever take place in the Philippines. Filipino collaboration and participation were vitally important from the outset. Scientists of both nations documented biodiversity in a variety of habitats and across multiple biological disciplines, identifying more than 500 species new to science. The expedition also modeled a new way of embedding substantial educational outreach and media coverage, and promoting conservation actions. More than 900 people attended educational events in the Philippines. Extensive television, radio, online, and print media coverage occurred both in the Philippines and in the U.S. during the expedition and after. A conference at the end shared preliminary results among scientists, educators, policy makers, and media, before the Academy team even left the country.

One of the most cherished and venerable activities of museums is to conduct expeditions of exploration around the world. The "golden age" of expeditions in the late nineteenth to the midtwentieth centuries often led to remarkable discoveries and captured public imagination, but also generated controversy as the developed countries frequently extracted cultural and biological treasures from the less-developed world. Modern natural history expeditions have broadly expanded the mutually beneficial aspects of the explorations, reduced the prospect of exploitation, and created new expectations of interaction. Scientific institutions these days still seek, however, to explore and discover in foreign lands, and return with specimens and new knowledge. A successful contemporary expedition must have a clearly articulated plan for collection of specimens and dissemination of scientific results, a program outlining desired impacts, and inclusion of partners from the host country in the process of planning, implementation, and post-expeditionary interactions and follow-up. These elements are industry standards today, but are often relegated to just the biological aspects of the expedition. It is the authors' view that expeditions, to have truly broader and lasting impact, must also address key societal issues such as education, conservation, and building a more sustainable future. ${ }^{1}$ These broader societal aspects of an expedition are rarely documented in the literature, if they are occurring at all.

A hundred and fifty years ago, scientists would often arrive in a country, conduct their research and extract specimens, all in the absence of interaction with local researchers or institutions. In the Philippines, this brand of foreign researcher is referred to as a "parachute scientist" because the scientist drops in and then disappears.

In the modern world, "partnership" is the name of the game and the only reasonable strategy. It is also the strategy that will most likely achieve the greatest results.

The California Academy of Sciences — the oldest cultural institution west of the Mississippi,

* This article was first published in Curator $(2013,56(1): 47-67)$ and with minor modifications is reprinted here with permission. 


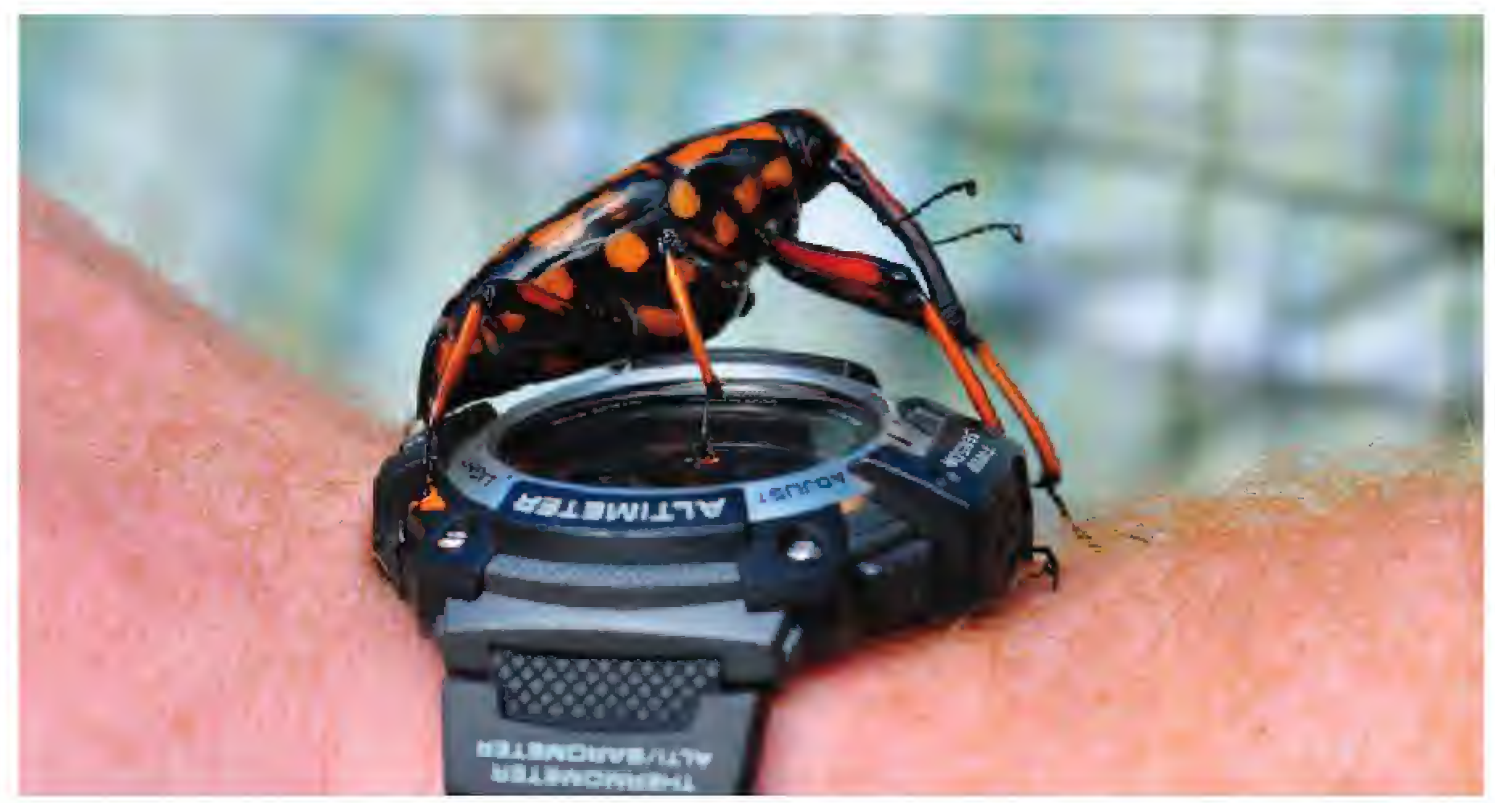

Рното 1. Weevil from the rainforests of southern Luzon Island. Photo by M. Lewin. All photos in this article are courtesy of the California Academy of Sciences.

the fourth-largest natural history museum in the U.S., and the only one to include an aquarium and planetarium - shares with its sister institutions a commitment to the emerging industry-standard elements, but also desires to promote the societal aspects as much as possible. In 2011, the Academy undertook a biological research and education expedition that, from its inception, was designed to include educational outreach, media coverage, and conservation policy conferences as well as biotic surveys. It also invited host country scientists, educators, and conservationists to join as expedition planners, participants, and partners. This article outlines how the 2011 Philippines Biodiversity Expedition came into being, how it was conducted, its results, its impacts before, during and after, and significant lessons learned.

The intent of the expedition from the beginning was to not only conduct groundbreaking research and discovery of novel biodiversity, but also to bring the day-by-day activities of the expedition to life for diverse public audiences in the Philippines and in the San Francisco Bay Area, and to help them understand the larger environmental context. It was hoped that this effort to reach out via local and international media, as well as educational sessions, would create an atmosphere in which local community members, museum visitors, and virtual visitors could participate in the expedition. Public audiences would be receiving information as the science was occurring. A final goal was that the expedition would use education and science in the Philippines to create awareness about environmental issues, in the expectation that awareness - when combined with scientific results - could foster more sustainable conservation outcomes.

Modern expeditions have varied greatly in their degree of involvement with host-country scientists and students, but most have not been designed from inception to maximize the local, incountry impact of the scientific results. Similarly, back at the home institution, the focus in the past has been more on the scientific objectives rather than leveraging a breadth of interactions to engage museum visitors, teachers, students, and the media with the science.

A new integrated model for expeditions that includes scientists, students, educators, animal husbandry experts, and media teams reflects an ethic that contemporary scientific information has to be more than knowledge for knowledge's sake. This new model operates on an understanding 


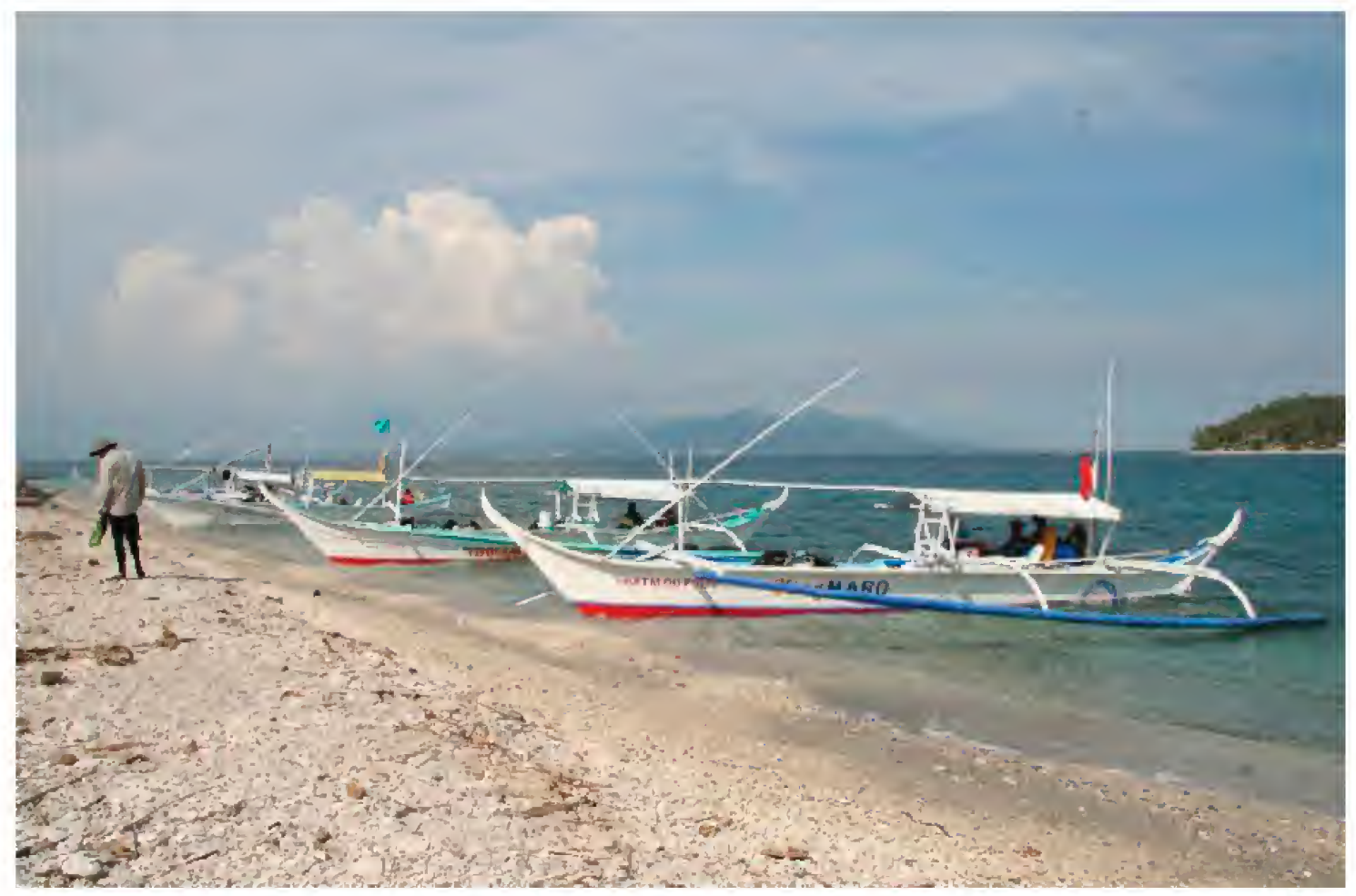

Рното 2. Bankas are the traditional outrigger canoes commonly used by fisherfolk and scuba divers in the Philippines. Photographer unknown.

that there is an urgent need to rapidly transmit and translate new scientific information beyond the audience of fellow scientists. The model clearly accelerates the process of discovery, distillation, and dissemination of information to a global community and underscores the role of local and global partnerships in developing shared knowledge about the natural world in the twenty-first century.

With its 2011 Philippine Biodiversity Expedition, the Academy set out to maximize partnerships with the host country. Partners included Filipino scientists and students, educators, journalists, cultural and environmental institutions, policy and regulatory agencies, and local community leaders. Academy scientists had been working closely with scientific, educational, and conservation partners in the Philippines for many years, but wanted to achieve greater impact by making scientific results more accessible and meaningful in relation to conservation impacts. The Academy was also interested in leveraging expedition results back home to enrich its Living Philippine Coral Reef exhibit and to experiment with more effective and compelling ways of disseminating scientific results in its public floor and educational programs. Another strong desire was to test whether scientists would be willing to report their observations immediately to scientific and general audiences. This idea represented a huge departure from the traditional model in which scientists spend years analyzing data before being willing to speculate in public on the significance of their findings. We planned on intentionally stepping outside of our "comfort zone" by presenting preliminary observations and results at a capstone symposium in the Philippines immediately after the expeditionary teams emerged from their field sites. To extend the impact, we wanted policy makers and other partners to be included at the symposium, as well as the press and other media. Pushing the envelope in this way provided an opportunity to experiment with how to accelerate the dissemination and translation of new scientific knowledge for diverse key stakeholders. 
Natural history museums tend to be siloed institutions. Their research and collections functions are often not well integrated with the public engagement and education areas. For a view of the silo effect, go to any natural history museum's website and navigate from area to area. Even within major sub-units, Web pages will have different appearances and different approaches. Great content exists on websites, but it is frequently buried and not organized in a visitor-centric manner. While scientists may be asked to participate in exhibit development or public or donor events, there is insufficient attention given to designing programs that - from their inception - are intended to integrate the science and the public engagement and maximize the synergy that can be derived from teams with different perspectives working jointly to achieve common goals.

The 2011 expedition was an opportunity for the Academy to create a new model for planning broadly, inclusively, and collaboratively from inception to implementation. If successful, this approach would help us achieve greater institutional relevance by more effectively integrating current scientific findings and impacts into public programs and educational materials, with the science and impacts themselves actually becoming the hook that captures the public's interest and engages them.

\section{PLANNING THE EXPEDITION}

It's rare when one's executive director walks into a room full of scientists, announces that two generous donors want to fund an expedition, and asks "Where would you like to go?" In March 2010, the donors, Will and Margaret Hearst, recognized the importance and power of the Academy's research in such sites as the Galapagos Islands in 1905-1906 (California Academy of Sciences 1907), and felt the time was ripe for another large, multi-disciplinary expedition. Research curators had approximately six weeks to prepare competitive proposals. The size of the gift allowed the scientists to think large-scale and take a team approach. The mission of the Academy and its scientific research, as well as the realities of doing field research these days, set some parameters: The expedition would focus on documenting biodiversity in a biological "hot spot" facing serious threats (Meyers, Mittermeier, Mittermeier, da Fonseca, and Kent 2000). And, given the extensive work and collaborations required to secure the necessary permits and organize logistical support within a year, the site should be one in which the Academy already had well-established contacts and in-country partnerships.

Three proposals were submitted: biological diversity of São Tome and Principé, ant diversity in the Seychelles, and marine and terrestrial diversity in the Philippines. The Philippines project was chosen due to its larger scope, scale, and multi-disciplinarity, as well as the fact that the necessary collaboration infrastructure between the Academy and the host country already existed. This would become the largest and most diverse expedition in the Academy's 159-year history of exploration - and the largest and most heralded expedition of its kind ever mounted in the Philippines. The first author of this article was the Principal Investigator, overall leader of the expedition, and leader of the shallow-water research component. The second author was a Co-PI on the proposal, and leader of the educational outreach component.

\section{The Lead-up to the Expedition}

The Academy began working in the Philippines in the early twentieth century. The Philippines became a U.S. colony at the end of the Spanish American war in 1898, and early exploration of the new lands was a priority for the United States. The U.S. Fish and Fisheries Commission sent the steamer Albatross to explore the waters surrounding the Philippines in 1907-1910. Many new species of fishes, represented in a multitude of specimens, were collected during the expedition, 
and well documented by Japanese artist Kumataro Ito. ${ }^{2}$ Ito also made a series of drawings of nudibranch mollusks. These drawings were rediscovered by Diane Tyler in 1982, in the Mollusk Division library of the National Museum of Natural History. By then, the actual specimens could not be located in the collections, but Ito had drawn the figures so well that the species were readily identifiable from the pictures he created decades earlier (Gosliner 2006).

In 1992, the Academy led an expedition to the Mabini/Tingloy area of Batangas Province, in southern Luzon Island, just three hours south of Manila. Marine life abounded, and more than half of the species found were new to science. Not only was marine life everywhere, but so too were unsustainable fishing practices such as using dynamite and cyanide. On one of the first dives, an underwater explosion all but blew out Gosliner's eardrums and left dead and dying fish all around him. Fortunately, all the divers were okay, but the incident graphically reinforced that this spectacular place was facing serious environmental challenges.

This first trip also initiated a long-standing collaboration with the Philippines Bureau of Fisheries and Aquatic Resources (BFAR) and rekindled the relationship with Edgardo Gomez, director of the Marine Science Institute (MSI) at the University of the Philippines (UP). These relationships would prove to be pivotal. BFAR is the national agency responsible for the regulation of fisheries and the one that issues permits to collect and export marine specimens. UP is the premier university of the Philippines and MSI has a great cadre of marine research scientists. These early connections and collaborations provided the foundations for launching the 2011 expedition.

Shallow-water marine research, which brought two or three Academy scientists to the Philippines on periodic visits, became an almost annual event after 1992. The scientific partnerships expanded in 1997, when three research scientists from BFAR participated in the Academy's annual Summer Systematics Institute, a program funded by the National Science Foundation (NSF). This helped build systematic and evolutionary biological expertise in the Philippines and continued to solidify this key partnership.

A more integrated model for expeditions began to emerge in 2003 during the planning to replace the Academy's structurally challenged, aging facility in Golden Gate Park with a new stateof-the art, sustainably designed, visitor-centric building and exhibits. The leadership team, which included the authors, articulated several core values for the new exhibits: They would be grounded in the science in which the Academy has unique expertise and experience; would highlight areas of high biological diversity around the world; would describe both conservation challenges and success stories; and would be designed to attract new and more diverse audiences.

These precepts led us to plan for a living Philippine coral reef as one of the major exhibits in the new aquarium. Marine life in the Philippines is among the richest of any habitat in the world. Both conservation challenges and success stories abound there. And the San Francisco Bay Area has a large Filipino community, self-described as not having a tradition of visiting museums. We wanted to create a Philippine reef exhibit that would be a source of pride and interest for the Bay Area Filipino community, but we weren't quite sure how to connect with the community or what the result might look like. In 2003, the authors received an Informal Science Education grant from the National Science Foundation: Water is Life: Immersing the Public in Aquatic Diversity (ESI0229918). This grant not only provided critical support to help create the cornerstone exhibits for the Steinhart Aquarium in the new California Academy of Sciences, but it also provided opportunities for building Filipino partnerships beyond our greatest expectations.

In 2004, serendipity brought us a Filipino high school summer intern, Beatrice Romero, whose mother, Marie, ran the local Filipino bookstore, which was also a major Filipino social hub in San Francisco. We explained our project to Marie Romero and expressed our desire to have members of the Filipino community advise us on how to make the reef exhibit more accessible and mean- 

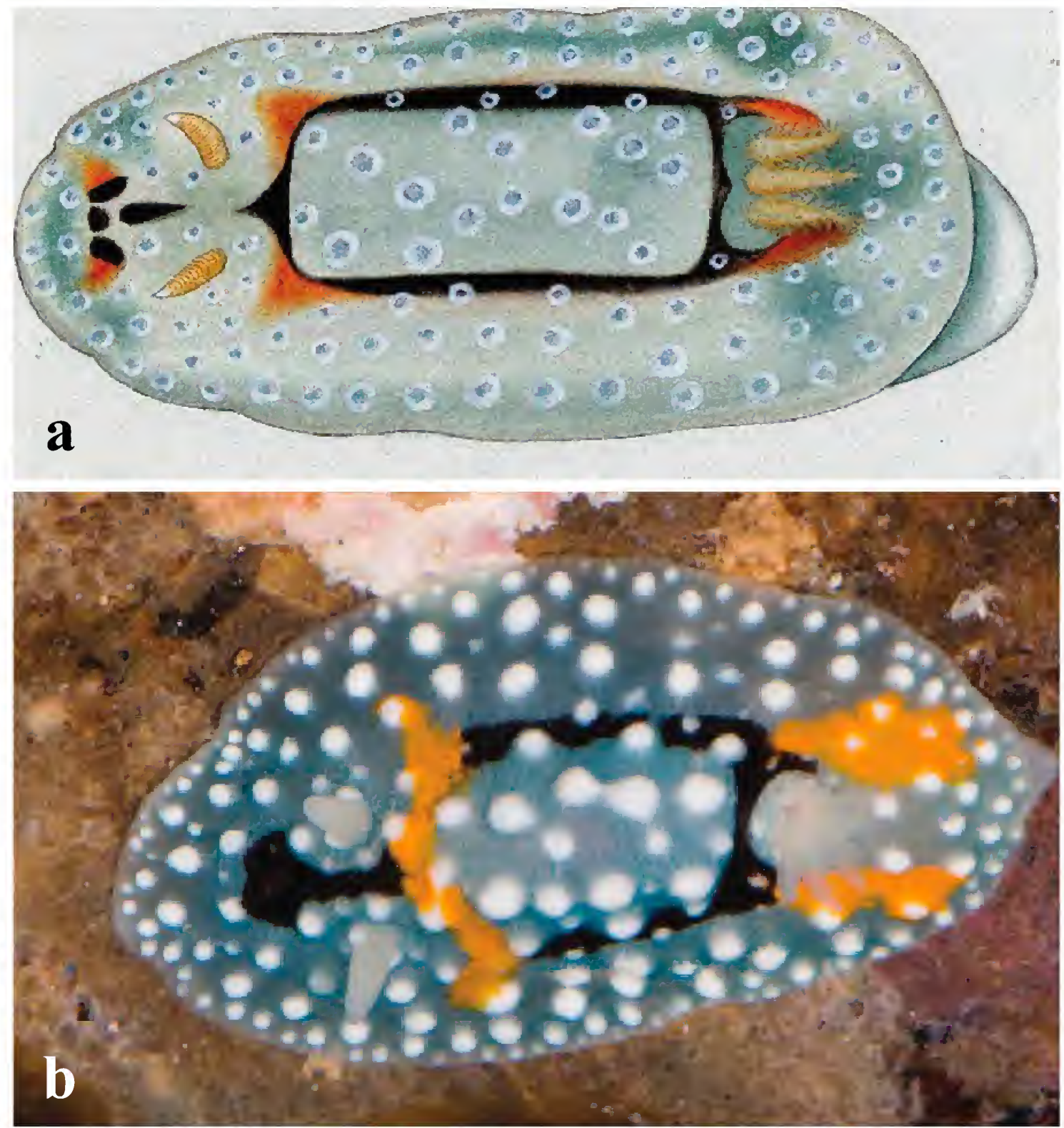

Рното 3a. A nudibranch mollusk, Aldisa albratossae, drawn by Japanese illustrator Kumataro Ito in 1907-1910.

Рното 3b. The living animal, photographed by Terrence Gosliner during the Academy's Philippines expedition in 2011.

ingful to the community. She offered to bring local Filipino leaders together to help with the project and assured us they would be excited to have Filipino voices included. A few weeks later we had the first meeting of what was originally called the Filipino Focus Group, and which later became the REEF group (Reaching out through Environmental Education to Filipinos). We met some 20 Bay Area Filipino leaders, including Mary Lou Salcedo, a board member of Pusod, an environmental organization with offices in the Bay Area and in Lipa, Batangas Province, Philippines. Pusod has worked to promote conservation in Batangas since its founding in 1996. With Mary Lou Salcedo and her daughter Malou Babilonia, we explored additional ways we could collaborate beyond the reef exhibit, to enhance community outreach and conservation in the Batangas 
area. This was a critical turning point in being able to achieve the kind of integration of science, education, and conservation impact that we had been hoping for, since Pusod provided the local expertise and connections we knew we would need. The Academy and Pusod now share a Memorandum of Understanding (MOU) to advance coral reef conservation, education, and research in the Philippines.

The future expedition also benefited from the connections and efforts of one of our most committed REEF members, Susan Po-Rufino, who personally knew the then-president of UP, Emerlinda Roman. President Roman was enthusiastic about expanding Academy interactions and collaborations to other areas of UP beyond our existing relationship with the Marine Science Institute, and helped facilitate the signing of the MOU between the Academy and UP.

\section{Communities and networks}

Between 2006-2009, the Water is Life grant allowed the authors and several Aquarium staff members, a graduate student, and another science educator to travel to the Philippines three times for the combination of research, educational outreach, and animal husbandry work that were the forerunners of the 2011 expedition. During this time we also began a connection with the Philippine Consulate in San Francisco, which involved the Academy in community events sponsored by the Consulate and vice versa. In planning the 2011 expedition, both the Consulate and Pusod provided invaluable logistical support, and Mary Lou Salcedo became the expedition project manager.

By the fall of 2010 it was clear that we would need to make one or two planning and permit acquisition trips prior to the actual expedition. We already had significant recent experience with securing permits and conducting shallow-water fieldwork in the Batangas area. Our relationship with BFAR facilitated our being able to charter their research vessel for the expedition, so we could include a deep-sea survey of the biota in the Verde Island Passage at the southern end of Luzon Island. Pusod already had contacts with most of the key players in the conservation arena and regulatory agencies, so it helped coordinate local educational and resource management contacts that were critical to establishing community partnerships and educational outreach, and to securing permits. We had no equivalent recent experience in developing the terrestrial component of the expedition and were not as certain how to start making necessary connections and obtaining permits.

Fortunately, serendipity struck again. Gosliner was in Chicago in September 2010 to give two presentations about Philippine biodiversity to the Chicago Shell Club and the Shedd Aquarium. He found himself in a conversation with Larry Heaney, a Field Museum mammalogist, who has been working in the Philippines for many years and has discovered dozens of new Philippine mammals. Heaney dropped everything to provide great insight on the specifics of conducting terrestrial expeditions in the Philippines and suggested key folks to meet in Manila as well as some potential sites to explore.

The authors and Academy botanist Peter Fritsch made the first planning trip to the Philippines in September-October 2010, and serendipity intervened once again. While we were heading to Manila, Susan Po-Rufino was on another flight to Manila and met the UP Vice Chancellor for Research and Development. He suggested we connect with Perry Ong, the director of UP's Institute of Biology and one of the leading terrestrial biologists in the Philippines. Other great connections were made by Pusod's former executive director and current board member, Ipat Luna, one of the Philippines's preeminent environmental attorneys. She set up an appointment for us with Mundita Lim, the director of the Protected Areas and Wildlife Bureau (PAWB) of the Department of the Environment and Natural Resources (DENR) to discuss the permit process for conducting 


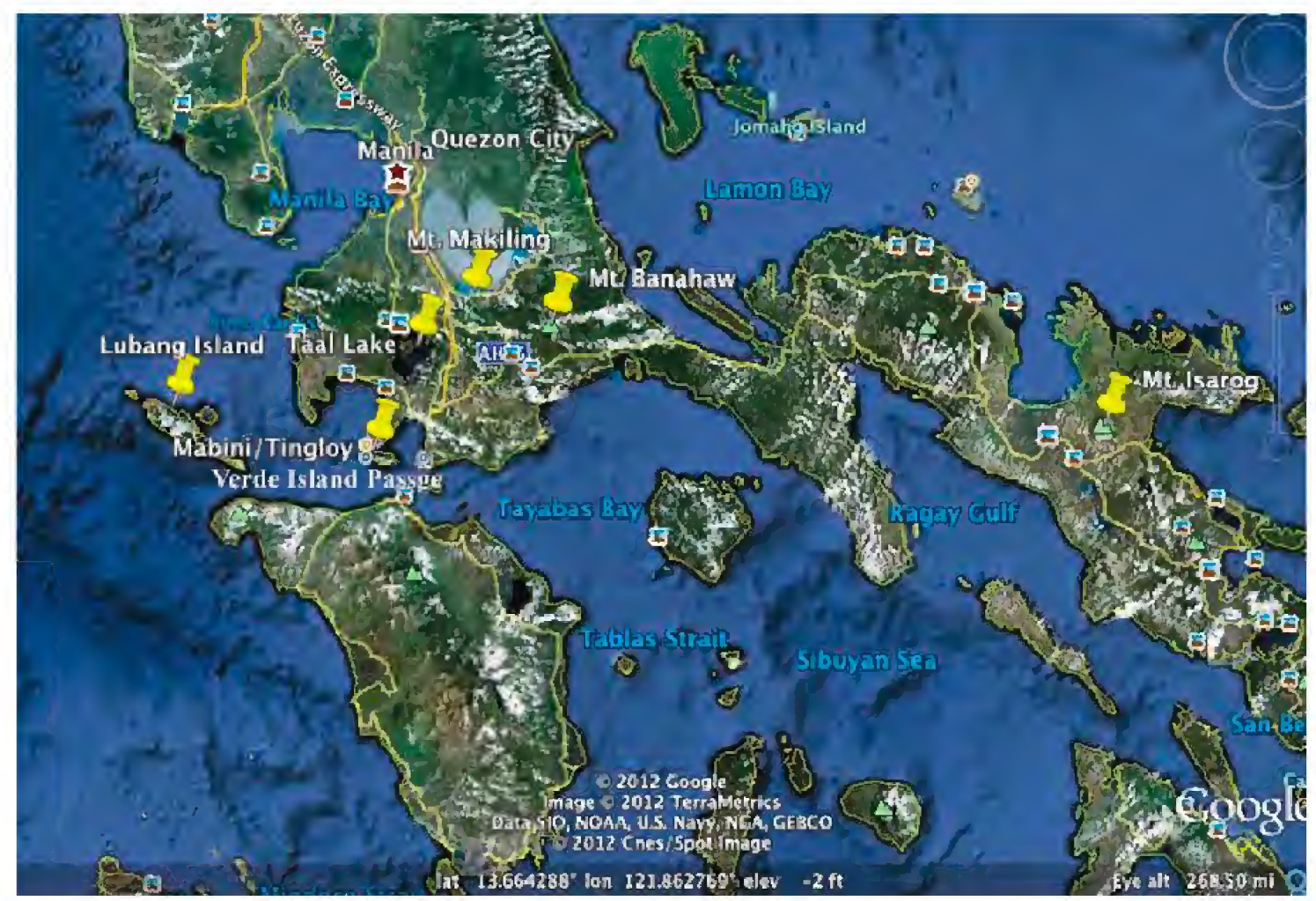

Рното 4. Map of expedition study sites, Google Earth.

research in terrestrial environments in the Philippines. Thus began a whirlwind of meetings, travel, and operational and logistical problem solving.

We learned that our desire to do educational outreach for the local communities at each of the research sites, and to have a capstone symposium with all participants at the end of the expedition, was something unheard of in the prior experience of the various agency personnel and something that was greatly appreciated and desired by the officials. In fact, in several instances we were told that the outreach would help ensure that we would be able to secure the necessary local permits to conduct the research.

We went to Mabini to check in with the owner of the resort where we hoped to base the shallow-water portion of the expedition. This also gave us an opportunity to re-visit a couple of the key dive sites that we had been studying for many years. The first dive brought an unwelcome surprise. We had heard that coral bleaching was occurring in the region, and as soon as we entered the water, we could see the immediate evidence of bleaching in about a quarter of the corals we encountered.

Elevated seawater temperatures cause living corals to expel the symbiotic algae, which give corals their color. When the algae are expelled, the corals are still alive but are ghostly white, looking as if they have been bleached, hence the name of the condition. This is not just a cosmetic change. Corals obtain about half of their nutrition from the photosynthetic activity of their algal partners. In 20 years of studying these reefs, significant bleaching like this was something we had never seen. This was a new threat and added even more meaning and urgency to the integrated research, education and conservation work we were planning to launch.

As we were headed back to San Francisco, we were buoyed by the prospects for great collaborations and the progress we had made at outlining the shape of the expedition. Not more than a 
month later, however, we received the shocking news that Leonardo Co, one of the leading botanists in the Philippines, and two other members of his research team had been shot and killed while conducting their own research in the central part of the country. Leonardo was an amazing storehouse of knowledge about Philippine flora and had agreed to participate in the 2011 expedition. The official, though controversial, report on his death concluded that he had been caught in crossfire between rebels and Philippine soldiers. Others claimed that there was no sign of insurgents, and that inexperienced soldiers most likely panicked and opened fire when they heard noise from the botanical party. Whatever the cause, this was a great tragedy not only for friends and family, but also for Philippine science, and a real blow for the expedition, as well as a harsh reminder that fieldwork can be dangerous. The next day the second blow fell when we learned that our colleague and expedition collaborator, Dan Lagunzad, had succumbed to liver cancer. In less than 24 hours, the Philippines lost two of its leading botanists.

A second planning trip was made in January 2011, by Gosliner, Fritsch, and Rich Mooi, the leader of the deep-sea component. At the end of this trip, the third blow fell. Gerry Ortega, an inspiring environmental leader we had met on the October trip, was murdered in Puerto Princesa, Palawan. He had been vocal in opposing mining interests in Palawan and a gunman was hired to silence him - another tragic reminder that environmentalism in the Philippines is a heroic and often dangerous proposition. His death brought this shocking reality into the stark light of day and left us reeling.

Despite the sadness and sense of loss, the planning continued and we finalized specific dates, sites and events for the expedition.

\section{THE EXPEDITION}

The 2011 expedition included a shallow-water component, a deep-sea component, a montane rainforest component, animal husbandry research and live animal collection, educational outreach, media coverage, and conservation actions. The expedition started at the end of April and ran seven weeks, concluding in early June with a symposium of preliminary findings held at UP. There were three major scientific teams: a shallow-water and a deep-sea marine team with different participants but considerable overlap, and a terrestrial team. More than half of the 94 participants were Filipino. There were undergraduate and graduate students, aquarium biologists, educators, and members of the media, along with the scientists. The number of participants, diversity of scientific disciplines, and research sites are what qualify this 2011 Philippine Biodiversity Expedition as the largest such expedition ever conducted by the Academy and the largest ever in the Philippines.

The expedition's logistics were exceedingly complex to organize and coordinate. The shallowwater team ( 38 participants) operated out of a single base. The deep-sea team (36 participants) occupied the research vessel, but moved from place to place every day, and was joined at sea midway by educators and media. The terrestrial team ( 39 participants) covered four major sites, one of which was located a long day's travel away from the other localities. Four aquatic biologists from the Academy's Steinhart Aquarium were part of the shallow-water team. The media teams (10 persons) and the educational outreach team (four persons) moved from locality to locality to participate in all three scientific components. The Academy participants arrived in the Philippines over the span of four weeks.

Participants were in the field for differing times, teams moved to different sites, and some participants moved between teams - plus all teams had a tremendous amount of gear, supplies, and (eventually) specimens that had to be transported with them and often required special treatment. This remarkably complex schedule could have been a transportation and logistical nightmare. 

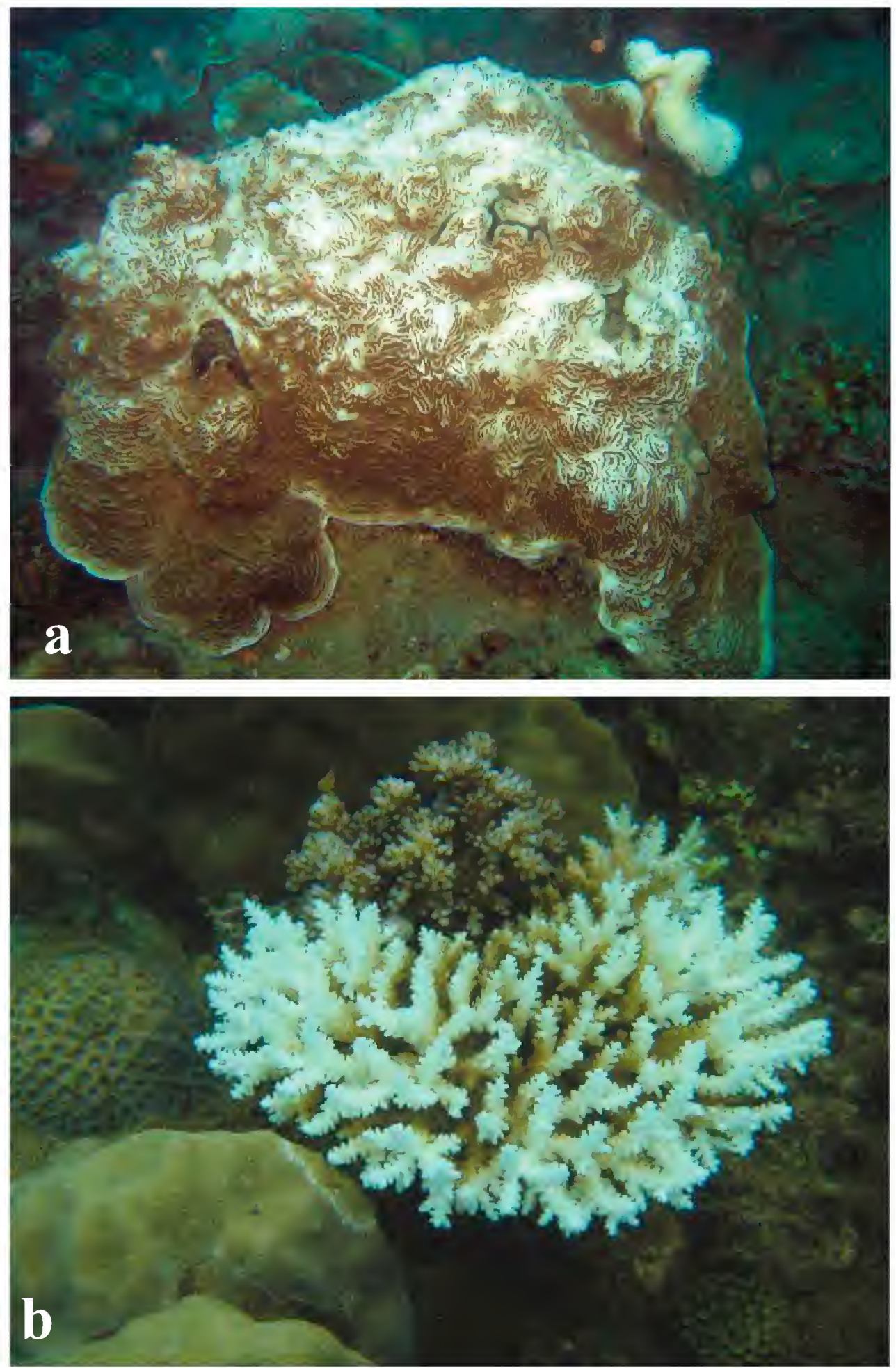

Рнотоs 5a and 5b. Coral bleaching observed on the California Academy's Philippines expedition, 2011. Photos by T. Gosliner, California Academy of Sciences. 
Detailed planning and coordination between the Academy and local experts, effective project management, and exquisitely organized ground transportation made it all work almost seamlessly.

\section{Shallow-water Marine Component}

At Club Ocellaris Dive Resort, the shallow-water team's home base, a typical morning began at 6:00 or 6:30 a.m. and included two dives to photograph and collect specimens. Following the second dive, we would return to Club Ocellaris, have a quick lunch, and then process the specimens from the morning dives. In the afternoon, those individuals who were done documenting and processing specimens were ready for a third dive. Often there would be a night dive, since a completely different set of animals is active at night. The night dives usually started around 6:30 p.m. and lasted several hours.

We would usually make it back to Club Ocellaris around 9:30 or 10:00 p.m., have a very late dinner, and then document and process the specimens from the night dive. Bedtime was usually some time after midnight. For safety reasons, every seventh day was a mandatory "dry day" in which each individual could rest or catch up on specimen documentation. Over the 30 days of shallow-water work, 119 dives were made, representing about 1,000 person-dive-hours, exploring coral reef, sandy and muddy debris substrates ranging in depth from less than a meter to over 35 meters.

The aquatic biologists joined the shallow-water team for 12 days to collect living specimens of fishes, corals, and other invertebrates and transport them to Manila to ship back to the Academy's Steinhart Aquarium. Part of their intent was to develop new animal husbandry techniques to share with Filipino partners to ensure more sustainable use of marine resources, especially for the aquarium trade.

To store animals such as living coral fragments under water until the team headed back to Manila, the aquatic biologists invented a new method they called a "coral clothesline." They suspended a nylon line off the surface of the reef with empty plastic water bottles as floats and tied the coral fragments to the line.

On two successive night dives, the entire shallow-water team witnessed mass spawning of corals. Little information is currently available on the timing or frequency of coral spawning in most parts of the Philippines, and the aquatic biologists are now planning a return trip at spawning time to do animal husbandry research to eventually be able to successfully rear coral in captivity through their whole life cycle, thus decreasing collecting pressure on wild populations.

The shallow-water component was highly successful. At least 100 new (to science) species of marine animals were collected in the 30 days of diving. The team was also able to make observations of the same corals that had shown signs of bleaching during the October 2010 planning trip. By January, corals had begun to acquire new zooxanthellae algae, and by May, almost all corals appeared to have virtually normal levels of pigmentation. This was a very encouraging sign as it indicated that this region of the Verde Island Passage, owing to its deep waters and strong currents, shows greater resilience to the effects of climate change on corals than do other parts of the Philippines or Southeast Asia. ${ }^{3}$

The shallow-water team also compared bio-diversity levels in Marine Protected Areas (MPAs) and nearby unprotected areas to determine the impact of the protected status. The existing MPAs were the only places where we observed schools of large fish or the largest of the seven species of giant clam. We made specific recommendations for reducing damage to MPAs and other reefs by creating permanent moorings rather than having boats drop their anchors on live coral; for better enforcement of MPAs; for expansion of existing MPAs; and for proposed designation of six new MPAs in areas that had particularly unique biodiversity. These recommendations were presented in 
various venues by us and partners at Conservation International and have been shared with the Provincial Governor of Batangas and all local municipal mayors. The recommendations are in the process of being considered and implemented and in fact have led to discussion of extending the protected area well beyond the six proposed additions.

\section{Terrestrial Component}

The land-based team explored several dormant volcanoes on southern Luzon that still had a large percentage of intact forest. (It is estimated that only five to eight percent of the primary forest of the Philippines remains.) The four peaks studied, Mt. Malarayat, Mt. Makiling, Mt. Banahaw, and Mt. Isarog, had all been explored previously to some extent, but never by an integrated team of botanists, entomologists, and (for some of the sites), vertebrate zoologists.

Entomologists set pitfall traps, wielded nets, and set up sheets with lights after dark to attract nocturnal insects. Academy arachnologist Charles Griswold sprayed cornstarch on spider webs to better photo-document the shape of the webs, which is an important characteristic for differentiating among groups of spiders. The botanists collected specimens from a variety of elevations and transferred them into field presses before bringing them back to the herbarium on the UP Los Baños campus, which served as headquarters for the terrestrial team. Academy scientist Jim Shevock and the Filipino bryophyte specialists collected mosses, placing them in individual packets for drying. The herpetologists and mammalogists turned over logs and rocks in search of animals, and set traps to collect small mammals.

After 30 days in the field, the terrestrial component also yielded great success, discovering at least 100 new species of plants and animals. For example, there had been only one species of goblin spider known from the Philippines before the expedition, and the arachnology group found at least 60 different species, so at least 59 represent species new to science or at least new for the Philippines. Post-expedition analysis will determine the exact status of all 60 . The entomology team was surprised that they had some of their best collecting success in the lower-elevation, disturbed forests near the university campus.

\section{The Deep-sea Component}

The deep-sea team boarded the BFAR research vessel on May 28 for eight days of intensive sampling using trawls and traps. The team included scientists from BFAR, UP, the National Museum of the Philippines, and the Academy. The first trawl collected some remarkable corals, worms, crustaceans, mollusks, echinoderms, and fish, boding well for the success of the deep-sea component. At the end of each day's cruise and trawling, the team would set an overnight line of 20-30 plastic-mesh fish traps at various depths, to be retrieved at first light. The traps inevitably contained a rich variety of crustaceans, fish, and mollusks. Some of the most impressive discoveries included a new species of swell shark, two new snake eels, two new hagfish species, and a recently named giant isopod that looks like one of its pillbug cousins on steroids, with the face of an alien. During the eight days of deep sea trawling and trapping, the team collected at 39 stations ranging in depth from 40 to 2,300 meters, setting new depth records for BFAR and Verde Island Passage research. Approximately 100 new species of marine animals were collected, including six new species of nudibranchs, at least five new species of fish, at least three new species of crabs, several new worms, a wood-eating starfish, and several new barnacles. In addition to the remarkable new organisms found, one of the most consistent and disturbing aspects of our studies was the prevalence of plastic and other trash in every trawl that was brought to the surface - even from the deepest stations sampled. In some trawls, there was actually a greater volume of trash than of living organisms. Based on some of the labels on the trash, much of it had come from metropolitan 


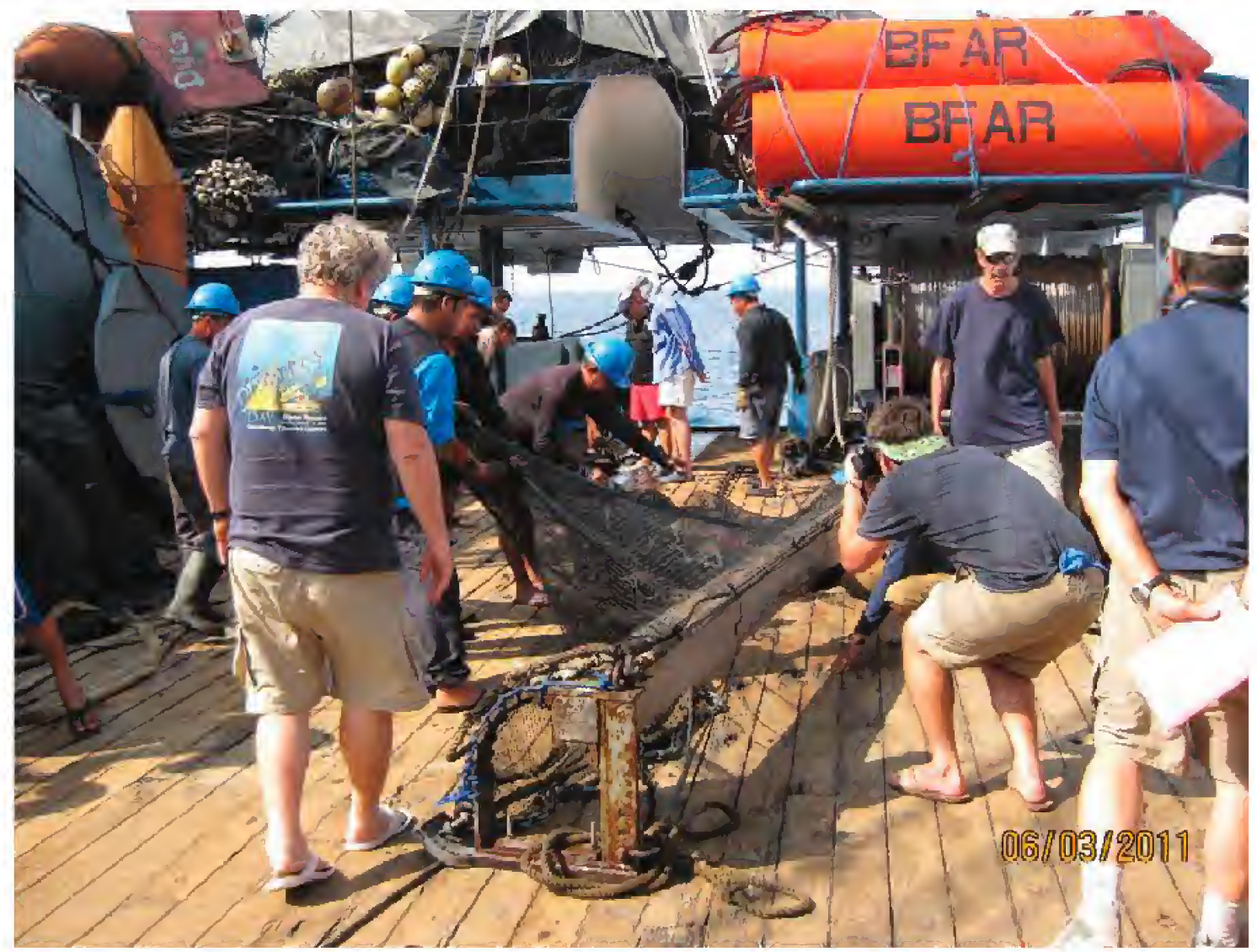

Рното 6. Bringing the beam trawl aboard the MV DA/BFAR. Photo by M. Burke.

Manila, 125 kilometers to the north up the coast.

On the way back to Manila Harbor, the deep-sea team stopped at Corregidor Island, where U.S. and Philippine troops jointly made their last stand against an overpowering Japanese invasion in 1942. This is where Douglas MacArthur promised: "I shall return." Having the collaborative Filipino/American expedition visit Corregidor was a fitting end to the shared expedition experience. Like MacArthur, we all hoped to return and enjoy the riches of this form of collaboration in the

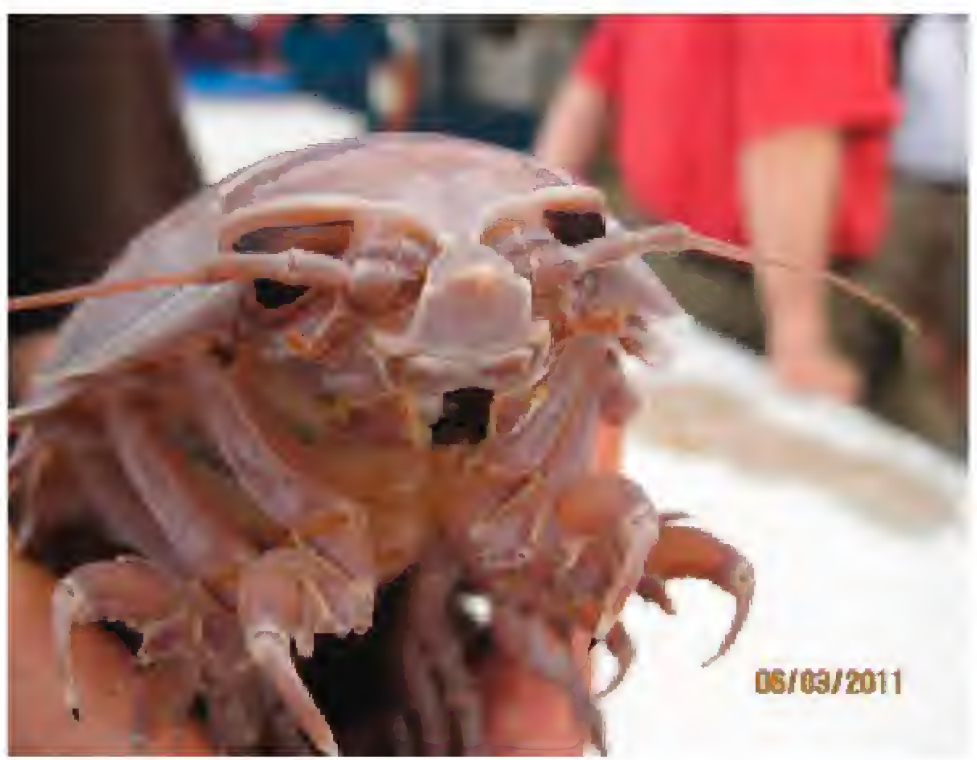

Рното 7. The giant isopod, Bathynomus kensleyi, which reaches more than a foot $(30 \mathrm{~cm})$ in length. Photo by M. Burke. near future. 


\section{The OUTREACH}

Local community outreach was embedded in the plans for the expedition from the outset. The goal was to have presentations, with specimens, by Filipino and Academy scientists, as well as the science educators. The intent was to show what the scientists were doing, why this type of research and biodiversity are important, and how local people could contribute to conservation efforts. Presentations described a critical time with serious challenges facing the Philippines with regard to conservation and climate change. Speakers also urged that it was not too late to make a difference - individually, as a community, and at the provincial and national level.

Teacher professional development workshops explored the same themes and added hands-on activities related to biodiversity, the carbon cycle, and climate change, for teachers to use in their classrooms. Copies of the activities plus bibliographies were given to participants along with digital links to those and other resources that could be downloaded for free. With the help of Academy herpetology curator Alan Leviton, we also distributed to the entire terrestrial team, their research partners, and government officials, pre-publication copies of a manuscript titled "Identification Keys to the Species of Dangerously Venomous Snakes of Luzon and the Sea Snakes of the Whole Philippine Archipelago."4

Meg Burke and Roberta Brett, the Academy's Senior Science Content Specialist, were incountry five weeks; changed localities 14 times; used eight different modes of transportation (including an exciting at-sea transfer onto the research vessel); led seven community outreach events with over 350 attendees including mayors and other local government officials, teachers, students, Sea Scouts, conservationists, and interested members of the public; and led two all-day teacher workshops with 168 attendees. As part of the integrated model, 11 different Academy and four Filipino scientists participated in multiple outreach programs.

\section{The Media Component}

In addition to these media participants and events, the Academy created a website with background information and maps. More than 40 blogs were eventually posted by Academy expedition members during preparations and in the field. Rich Mooi, echinoderm specialist, leader of the deep-sea component and participant in the shallow-water component, also contributed four blogs from the field to the New York Times Scientist at Work column. During the expedition, Gosliner and Mooi also did a live Skype feed from the shallow-water research site, talking with and answering questions from people attending one of the Academy's weekly, Thursday night, adults-only, after-hours social and science evenings called NightLife, which proved to be the perfect venue given the 15-hour time difference between California and the Philippines.

There was a tremendous media buzz in the Philippines during the expedition, including numerous radio and TV interviews with the researchers (both Filipino and Academy), aquatic biologists, and educators. More radio, TV and Web interviews were done when the expedition members and the specimens returned to the Academy. Over 900 people attended outreach events in the Philippines during the expedition, but there is no way of measuring how many people in the Philippines, the Bay Area, and beyond heard or saw the various interviews or documentaries.

\section{AFTER THE EXPEDITION}

Our first evening back in Manila, we were invited to a dinner hosted by Philippine Congressman Angelo Palmones. Expedition participants, both Filipino and American, were presented with congressional medals of excellence, acknowledging our contributions to Philippine science. We 


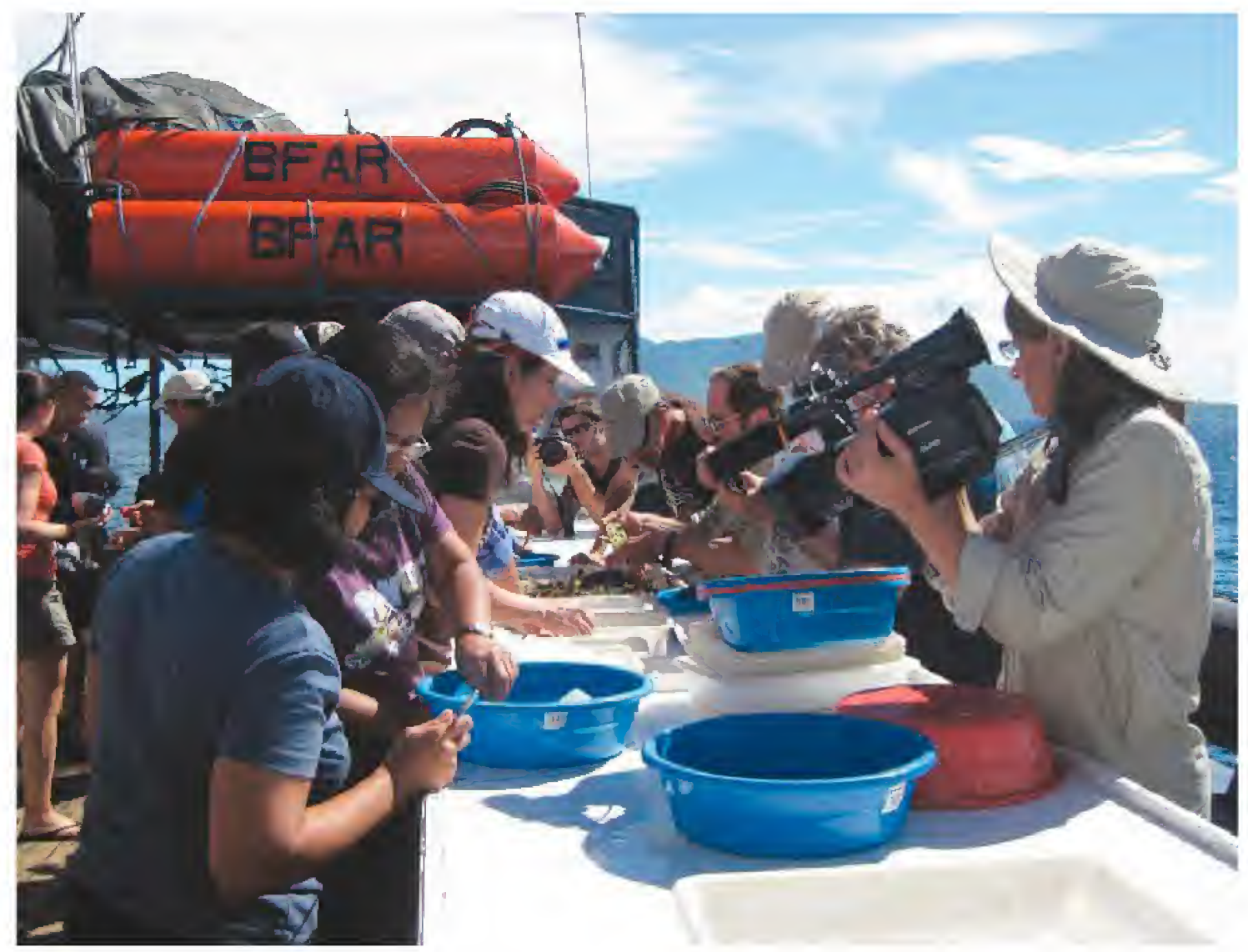

Рното 8. Media team documenting specimens collected from deep-sea trawling. Photo by M. Burke.

couldn't help but note the refreshing contrast to interactions with the U.S. Congress where one could be vilified for wasting taxpayers' money through frivolous research — as happened to one of our Academy colleagues.

The next morning, we all assembled at the UP campus for the capstone symposium, which was intended to present the expedition's preliminary findings. Traditionally, most scientific symposiums are geared to academic audiences and take place months or years after expedition results are known. We wanted this symposium to be different. We would be bringing immediate results to a variety of Filipino audiences, while the impressions were fresh and we had the attention of the local news media. We hoped to demonstrate that dissemination of scientific information should be a rapid process and could prompt immediate calls for action.

In the audience and among the speakers were Filipino resource managers, conservationists, political leaders, educators, students, and scientists. Members of each expedition component reported their key findings and observations.

The marine shallow-water team also presented key recommendations for more sustainable management and expansion of existing Marine Protected Areas. Asis Perez from BFAR and Mundita Lim from PAWB - the directors of the two primary agencies responsible for environmental regulation in the Philippines - made presentations. The symposium generated great excitement about the discovery of more than 300 new species in the Philippines and also much discussion as well as a call to action to manage the unique biological richness of the Philippines more effectively. 


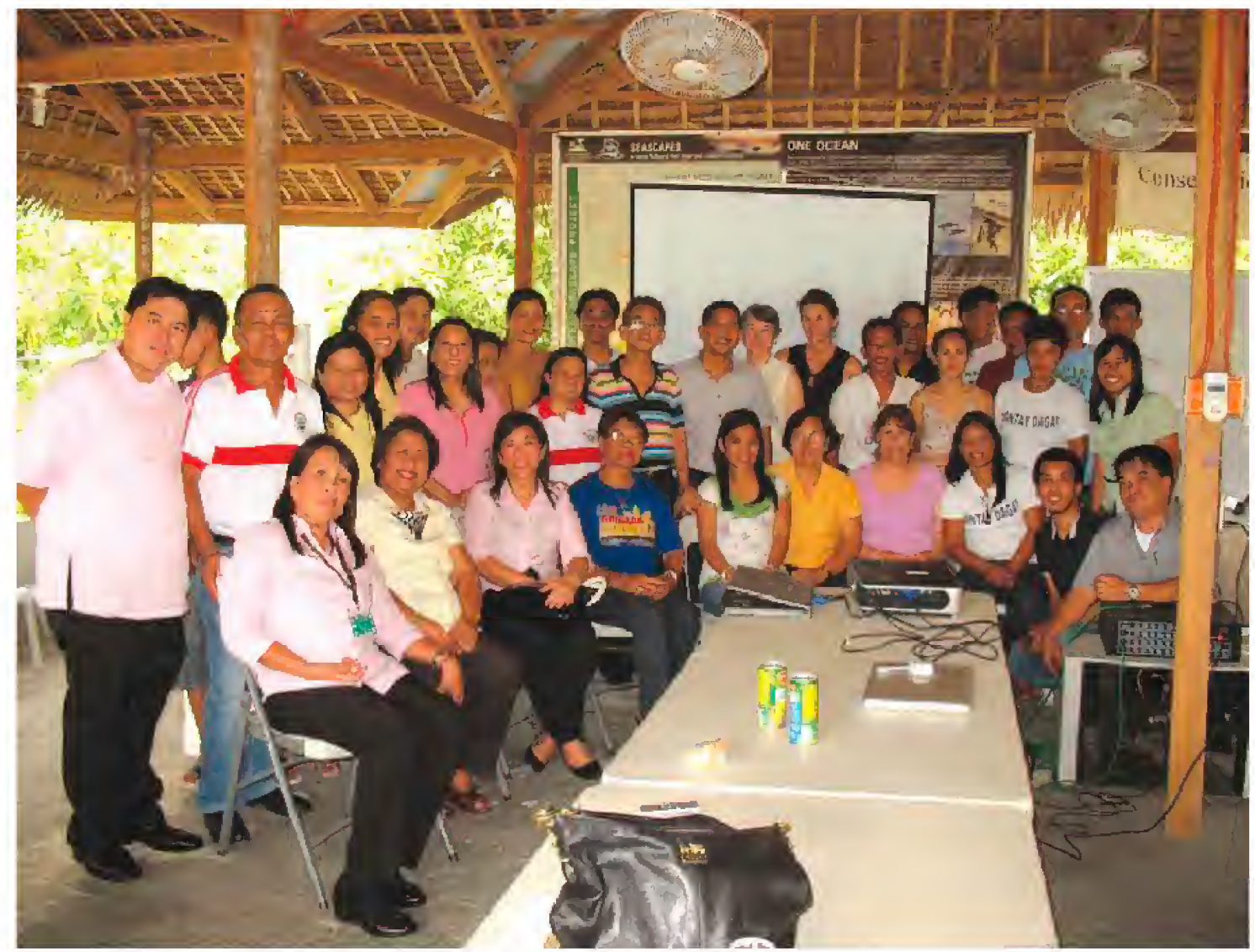

Photo 9. Outreach with community leaders in Mabini, Batangas, May 26, 2011. Photographer unknown, California Academy of Sciences.

Once specimens arrived back at the Academy, more in-depth study, including DNA sequencing of specimens, was initiated. In virtually every case, field identifications of new species were upheld by the morphological and molecular studies. In the case of some of the shallow-water nudibranchs, we had collected what we thought represented at least four new species in one genus from just one locality. When we sequenced their DNA, we discovered that in fact there were eight new species. Total estimate of new species for the expedition has been increased from the initial 300 to 500 currently. John McCosker, Academy ichthyologist, published the first new species name from the expedition, a snake eel (Myrichthys paleracio) named for Club Ocellaris dive guide, Peri Paleracio, who collected the specimens during the expedition (McCosker and Allen 2012).

Personnel exchanges and interactions continue. Two of the expedition's Philippine entomologists have visited the Academy to continue their collaborative interactions, and other visits are being planned for Filipino botanists, invertebrate zoologists, and ichthyologists in 2013. In November 2012, at the invitation of UP, a group of nine Academy scientists, educators, and exhibit staff will participate in a week-long workshop at the university on integrating research, education, exhibits, and conservation.

Shortly after Academy scientists returned from the Philippines, the REEF group and the Philippine Consulate General joined the Academy in a Thursday NightLife celebration of the expedition, with scientists, specimens, and lectures, as well as demonstration stations by local Bay Area Filipino companies and cultural groups. Almost 3,000 visitors attended, mostly members of the 
Bay Area Filipino Community, including the San Francisco consular staff and the Secretary of Tourism of the Philippines, who was visiting from Manila.

Presentations in the Bay Area about the expedition's findings and the integrated expedition model continue. Meg Burke gave a keynote presentation in February 2012 at the second Asian Children's Museum Conference at Museo Pambata in Manila. The theme of the conference was Children and Climate Change. Terry Gosliner was invited to make a presentation about the expedition as a model for conservation action to the directors of all the international marine programs for Conservation International. The conference was held February 2012, in Mabini, the site of the shallow-water expedition.

KGO TV's expedition documentary Reefs to Rainforests: the Great Expedition aired in the Bay Area on October 22, 2011 and re-aired again November 20, 2011. The special won a regional Emmy for Best Informational Educational Program for Northern California. ${ }^{5}$

\section{LESSONS LEARNED}

The 2011 Philippines Biodiversity Expedition helped document tremendous diversity of life in a biologically critical and understudied area of the world. It distributed results in a timely fashion to many types of audiences: scientists, educators, students, conservationists, government officials, and interested citizens. It employed and deepened authentic partnerships with Filipinos in all aspects of the expedition and strengthened the scientific, educational, and conservation infrastructure in the host country. It resulted in new opportunities for further integration of research, educational outreach, and conservation, and it enriched the public experience at the Academy.

Other Academy expeditions and those by our peer institutions have accomplished portions of what this expedition achieved in terms of broader impact beyond the scientific discoveries. For example, our colleagues at the Field Museum have helped establish networks of terrestrial scientists in the Philippines and have developed educational materials and trail guides to the mammals of Philippine National Parks. ${ }^{6}$ But for most expeditions, the emphasis has generally been most heavily directed to achieving the scientific research. Some of the other elements of outreach and conservation have also been accomplished, but were of secondary importance to the organizers and participants.

We wanted the Academy expedition to give equal importance to all aspects. That meant that many scientists did not go collecting every day, because field days were interrupted by trips to Manila to local television stations, by radio interviews, or by participating in educational outreach events. Sometimes participation in a conference was the order of the day - or walking down to the shoreline with local Sea Scouts became more important than logging another dive or collecting an additional new species. It also meant that — rather than looking at the environment through the lens of only one particular group of organisms - teams of specialists created a more comprehensive view of the environment. The emphasis was on functioning truly as a collaborative team rather than as a group of specialists working in the same place but seeing themselves as free agents. It became a great source of pride to make a new discovery for one of the other participants. This larger view allowed us to make more general conclusions about the state of the health of the environments where we were working, and these types of observations ultimately had more utility. By interacting with local community groups at each site, we learned much about their understanding of the environment and the challenges they faced. This was a critically important experience for helping ensure that the outreach messages about developing more sustainable practices and recognizing short-term versus long-term trade-offs were locally relevant.

Fundamentally, the expedition's success rested on the support and untiring efforts of many Fil- 
ipino partners operating side by side with Americans in a spirit of mutual respect and trust. The number of Filipino scientists exceeded the number of Academy scientists. There are multiple benefits for inviting partnership at such an extensive level. The great locality-specific expertise of Filipino partners allowed for much greater scientific success. Having Filipino scientists, students, educators, and media involved with outreach brought immediate local credibility. The audaciously large scale of the expedition, in terms of the number of participants and the taxonomic and habitat diversity, led to unique discoveries, but also necessitated Filipino expertise and help with logistics. Last but not least, the Filipino partnerships facilitated obtaining necessary collecting permits. Inability to secure permits is a deal breaker for any expedition. It should be noted that, when we wrote the original proposal and budget, we underestimated Filipino interest and desire to participate and how much support they expected and needed, which in turn had logistical and budgetary implications.

This expedition clearly changed the model - not "parachute scientists" but full partners with an integrated approach to research, animal husbandry, education, and conservation, with intentional communications between and among multiple stakeholders. We hope it becomes a model that is adopted broadly, not only because it is the right thing to do, but also because it is the only way that the research, education and conservation work of museums can fundamentally alter the path to mass extinctions on which we are currently embarked.

\section{The Power of Collaboration}

A meaningful demonstration of the collaborative significance of the 2011 Hearst Philippine Biodiversity Expedition can be found in the following list of people who were indispensable to the origination, implementation, and successful conclusion of the expedition.

First acknowledgments go to Margaret and Will Hearst, without whose generosity the expedition would not have occurred. We also received generous in-kind support from Philippines Airlines, the Dusit Thani Hotel in Manila, and Wayfair Tours of Manila. All of the friends and partners who helped make the expedition a success are literally too numerous to mention here, but special acknowledgment must be given to: Secretary of Agriculture Proceso J. Alcala; Philippine Consul General Marciano Paynor and the Consular staff in San Francisco; BFAR directors Malcom I. Sarmiento and Attorney Asis G. Perez; BFAR colleagues, especially Attorney Analiza Vitug, Ludivina Labe, Alma Dickson, Captain Ernaldo T. Cawaling, Rafael Ramiscal, and Loida Cainglit; PAWB director Mundita Lim; U.S. Embassy staff, especially Dovas Saulys and Maria Theresa N. Villa; staff of the Department of Foreign Affairs; UP administrators and colleagues including UP Presidents Emerlinda Roman and Alfredo Pasqual, Vice President Giselle Concepcion, Doctors Malou McGlone, Perry Ong, Edwino Fernando, Daniel Lagunzad, Jun Ireneo Lit, Jr., and Marilou Nicolas; staff of the National Museum of the Philippines, especially, Director Jeremy Barns and Marivene Manuel Santos; Benito Tan; Jessie de los Reyes; Marites Pastorfide; Sol Solleza; Boy Venus; Joy Napeñas; Peri Paleracio; Alexis Principe; Ditto de la Rosa; Darwin Raymundo; May Pagsinohin; Susan Po-Rufino; Ipat Luna; Enrnique Nuñez; Jen Edrial; Anne Hazel Javier; Jayo Castilla; Arvel Malubag; Malou Babilonia; Mada Rivera; and certainly not least of all, Mary Lou Salcedo. We also thank our colleagues at the Academy and friends and families who picked up the slack while the expeditioners were expeditioning. And lastly, we thank our fellow Academy teammates on the expedition. This article and the partnerships of the expedition are dedicated to the memories and life works of Dan Lagunzad, Leonardo Co, and Gerry Ortega, our fallen comrades. 


\section{Notes}

1. See http://archive.fieldmuseum.org/expeditions/heaney_expedition/about.html; http://www.calacademy.org/ science/hearst/.

2. See http://vertebrates.si.edu/fishes/albatross/ ito_illustrations.html.

3. For example, reefs to the west, in Palawan, did not fair as well from the same bleaching event and had significant die-off of reefs that were too stressed to recover.

4. The authors were Alan E. Leviton, Rafe M. Brown, Maren Gaulke, and Arvin C. Diesmos. Both Rafe and Arvin participated in the expedition.

5. It is available on YouTube at: http://www.youtube. com/watch?v=T-RUpL_1Eoo. As mentioned previously, the Philippine ABS-CBN documentary aired in the Philippines on Earth Day 2012.

6. See http://archive.fieldmuseum.org/expeditions/ heaney_expedition/video.html.

\section{REFERENCES}

California Academy of Sciences. 1907. Expedition of the California Academy of Sciences to the Galapagos Islands, 1905-1906. Proceedings of the California Academy of Sciences, ser. 4, 1:1-435.

Gosliner, T. 2006. Marine Gastropoda collected by the Steamer Albatross from the Philippines in 1908. Records of the Western Australian Museum, Supplement 69:83-93.

McCosker, J., AND G Allen. 2012. Description of a new snake eel (Pisces: Ophichthiuridae: Myrichthys) from the Philippines. Aqua International Journal Ichthyology 18(1):35-40.

Meyers, N, R. Mittermeier, C. G. Mittermeier, G. DA FonsecA, and J. Kent. 2000. Biodiversity hotspots for conservation priorities. Nature 403:853-858. 


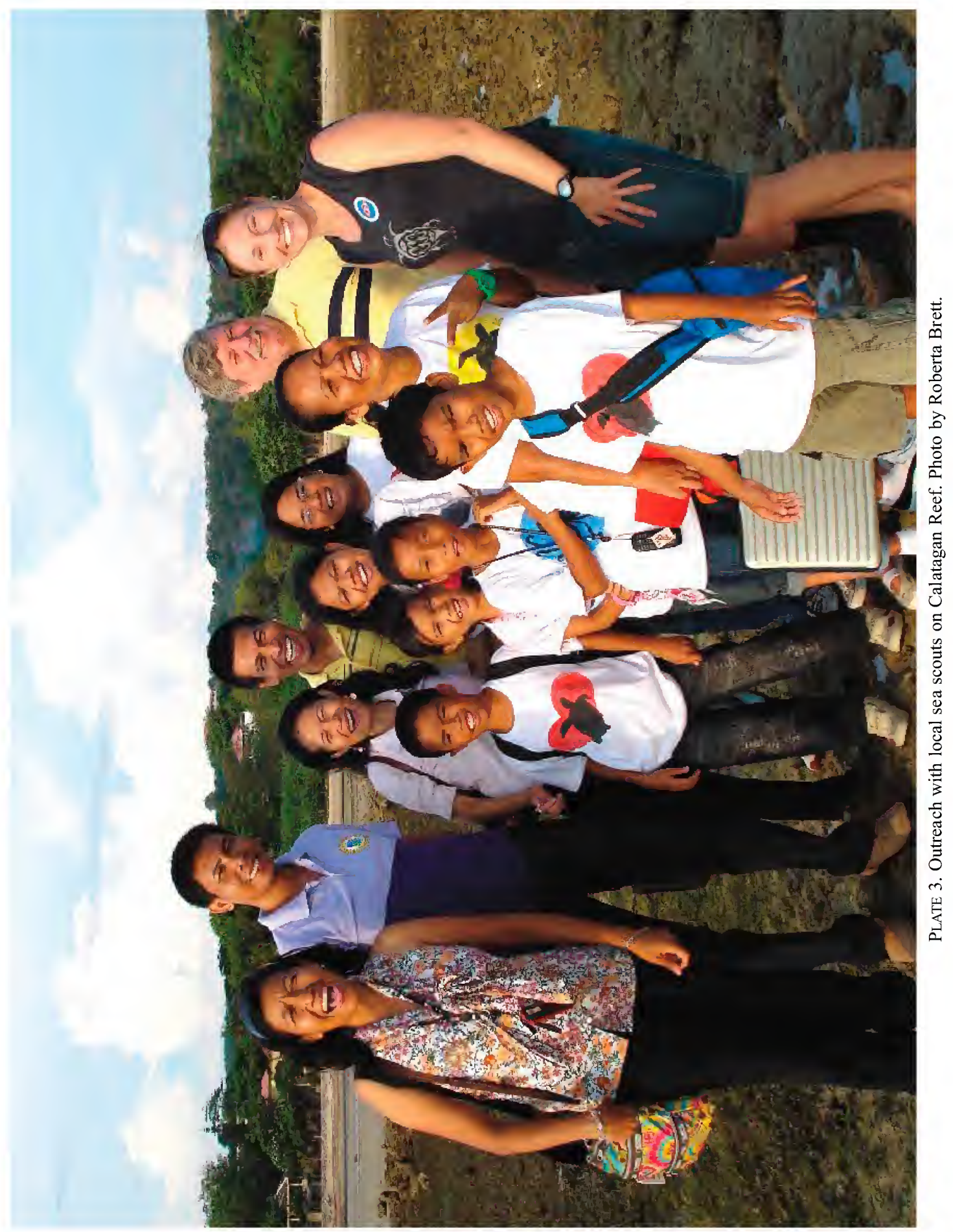




\title{
2011 Philippine Biodiversity Expedition*
}

\section{Part 1: Planning, Science and Surreality}

\author{
Richard Ross \\ Steinhart Aquarium, California Academy of Sciences, 55 Music Concourse Drive, \\ San Francisco, CA 94118. Email: rross@calacademy.org
}

\begin{abstract}
Researchers from the California Academy of Sciences have been visiting an area called the Verde Island Passage off the coast of Batangas Province on Luzon Island, Philippines for almost 20 years. Research by scientists during that period suggested that this area is the "center of the center" of marine biodiversity, and perhaps home to more documented species than any other marine habitat on Earth; there can be more species of soft corals at just one dive site in this area than in all of the Caribbean. Thus it was only natural that when the Steinhart's 212,000 gallon reef tank was designed, the Academy decided to represent the reefs of Luzon. Ever since, Steinhart biologists have traveled to this area in small groups with the objective of acquiring first hand knowledge of the environments they hope to recreate in San Francisco.

The 2011 Philippine Biodiversity Expedition, however, was a trip of a completely different magnitude: the largest expedition in the Academy's history covering both land and sea. Consisting of a Shallow Water team, Deep Water team and a Terrestrial/Fresh Water team, the 2011 Philippine Biodiversity expedition, funded by a generous gift from Margaret and Will Hearst, was the most comprehensive scientific survey effort ever conducted in the Philippines. Joining the expedition were over eighty scientists from the Academy, the University of the Philippines, De La Salle University, the National Museum of the Philippines and the Philippines Bureau of Fisheries and Aquatic Resources, as well as a team of Academy educators whose mission was to share the expedition's findings with local community and conservation groups as the Expedition was happening.

As part of the Shallow Water team Bart Shepherd, Matt Wandell and I surveyed and further documented the underwater sites that served as the inspiration for the Steinhart's Philippine Coral Reef exhibit. We also responsibly collected coral, cephalopods and other invertebrates for captive propagation, research and display at our Golden Gate Park facility. As the only public aquarium permitted to collect stony corals in the Philippines, we were to obtain these unique species for study, captive culture research, distribution to other institutions as well for display at the aquarium. ${ }^{1}$
\end{abstract}

\section{PlANNING}

On previous trips to the Philippines, Steinhart biologists had been given special permission to collect and export small numbers of small coral fragments, most of them collected as 'found frags'. The 2011 Expedition would continue this tradition, albeit with some modifications. In order to reduce stress on the organisms, we planned to adopt Ken Nedimyer's work with the Coral Restoration Foundation (http://www.coralrestoration.org/) to create a system for holding our coral fragments offshore until transport. We mocked up the system using materials that we could travel easily with, or that we could find in the field - silicone airline tubing, zip ties, dive weights and empty

* This article was first published in Reefs Magazine and with minor modifications is reprinted here with permission. The original publication is available online: http://www.reefsmagazine. com/forum/reefs-magazine/117948-phillipine-biodiversity-expedition-part-2-a.html

1 http://www:youtube.com/watch?feature= player_embedded\&v=2_lswEIAcIU. This video by Bart Shepherd shows some of the reefscapes we encountered on the 2011 Philippine Biodiversity Expedition 


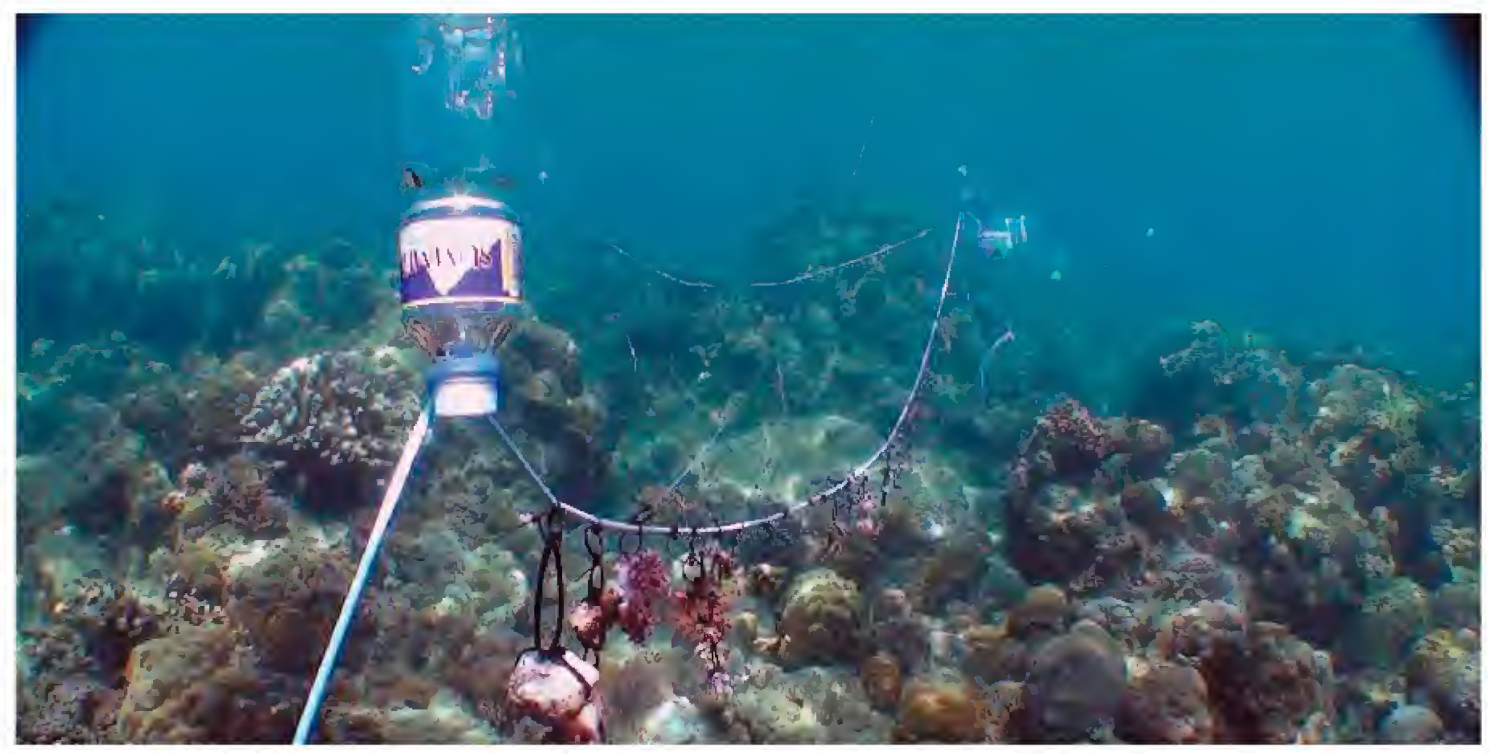

FIGURE 1: The 'Coral Clothesline', inspired by the Coral Restoration Foundation, in action about 50 meters offshore.

plastic water bottles as floats (after all, you can sadly find empty plastic water bottles on just about any beach in the world). The mock up went into our big reef tank for testing and was immediately dubbed 'the coral clothesline' by the aquarium's docents.

In addition to our clothesline supplies, we packed everything else we could think that we might possibly need. Some highlights: six large, low style plastic tanks that could be weighted and sunk offshore for holding larger fish and other inverts, as well as smaller plastic tanks that could be hung from the clothesline to hold small fish and other inverts. A backpack kit for harvesting jelly gonads (as removing the gonads doesn't impact the jellies long term and the gonads ship better than adult jellies). Fiberglass window screen to make lids for impromptu holding containers, as well as the rubber bands to hold those lids on. Dozens of tubes of super glue and rolls of duct tape. LCD microscope just in case we needed to look at something close up. Sharpies for note taking. Scissors for cutting everything. Needle nose pliers for coral fragmenting. Plastic rulers for scale in photographs. Deli cups for transport, collection and shipping or animals. All this stuff and more went into one fish shipping box and filled every empty space in our luggage.

After flying all night to Manila, all this gear, along with some very tired biologists, hit the ground running at $5 \mathrm{am}$, finding our checked items, finding our ride and driving 3 hours to Club Ocellaris, a world renowned SCUBA resort, which would be the base of operations for the shallow water team

\section{SCIENCE WAS EVERYWHERE}

When we arrived at Club Ocellaris, we found it had already been completely taken over by the Expedition. Science was everywhere. Across the resort, any flat space had already become some sort of makeshift lab, with equipment and apparatus piled all over the place. Every electrical outlet had a computer, camera, light or batteries charging. Containers of every conceivable kind from plastic bags, to lidded jars, to 5 gallon buckets waited everywhere to be filled with hunks of science. While all of that was exciting, we really wanted to get in the water. Within an hour of arriving our Diving Safety Officer, Elliott Jessup, got us suited up and on a boat for our first dive of the trip - we saw sea snakes, corals and fish galore. After our afternoon dive, we assembled our offshore holding about 50 meters offshore so we would be ready for whatever collecting we would do 


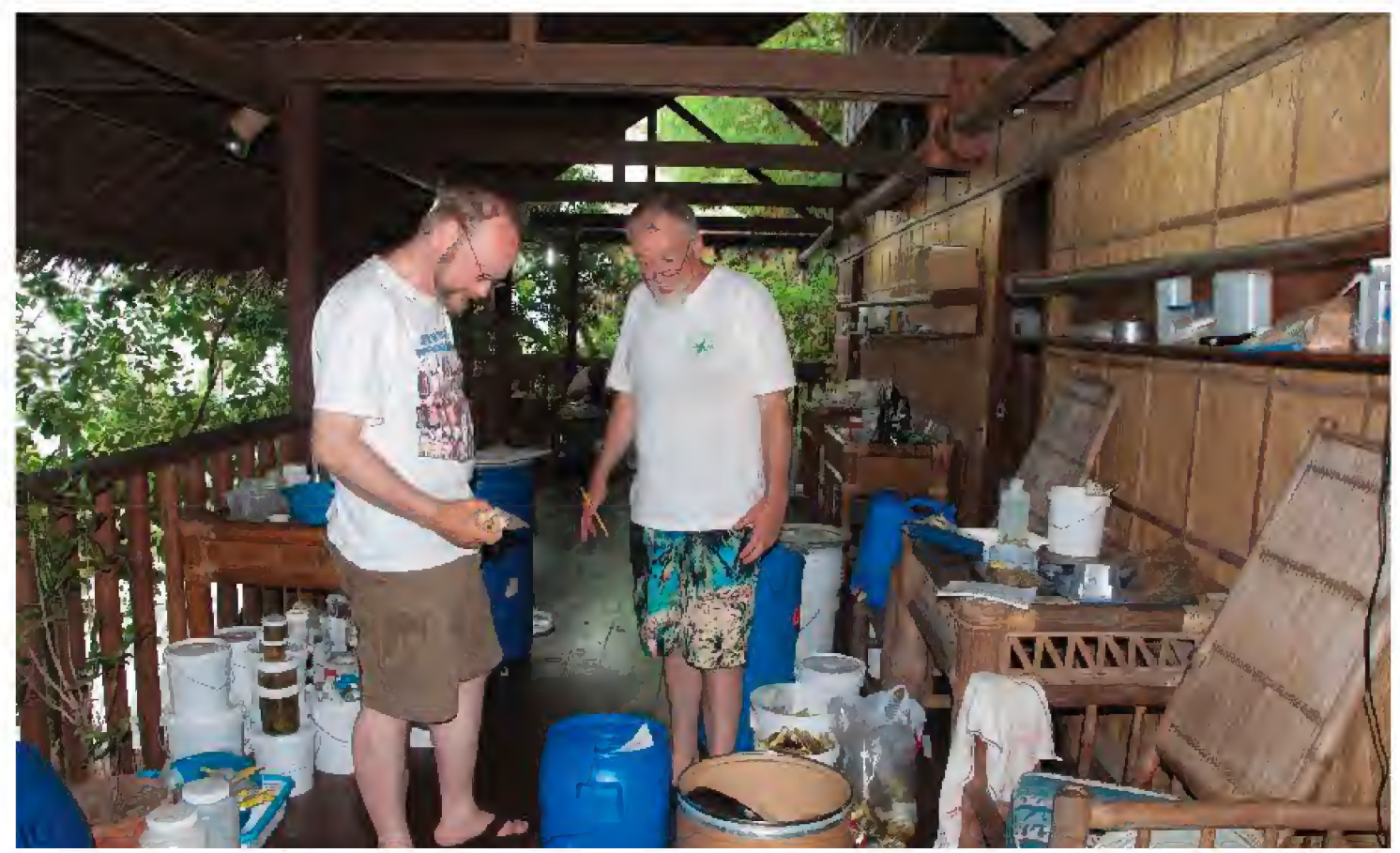

FIGURE 2: Rich Mooi and Bob Van Syoc stand surrounded by the science that took over Club Ocellaris.

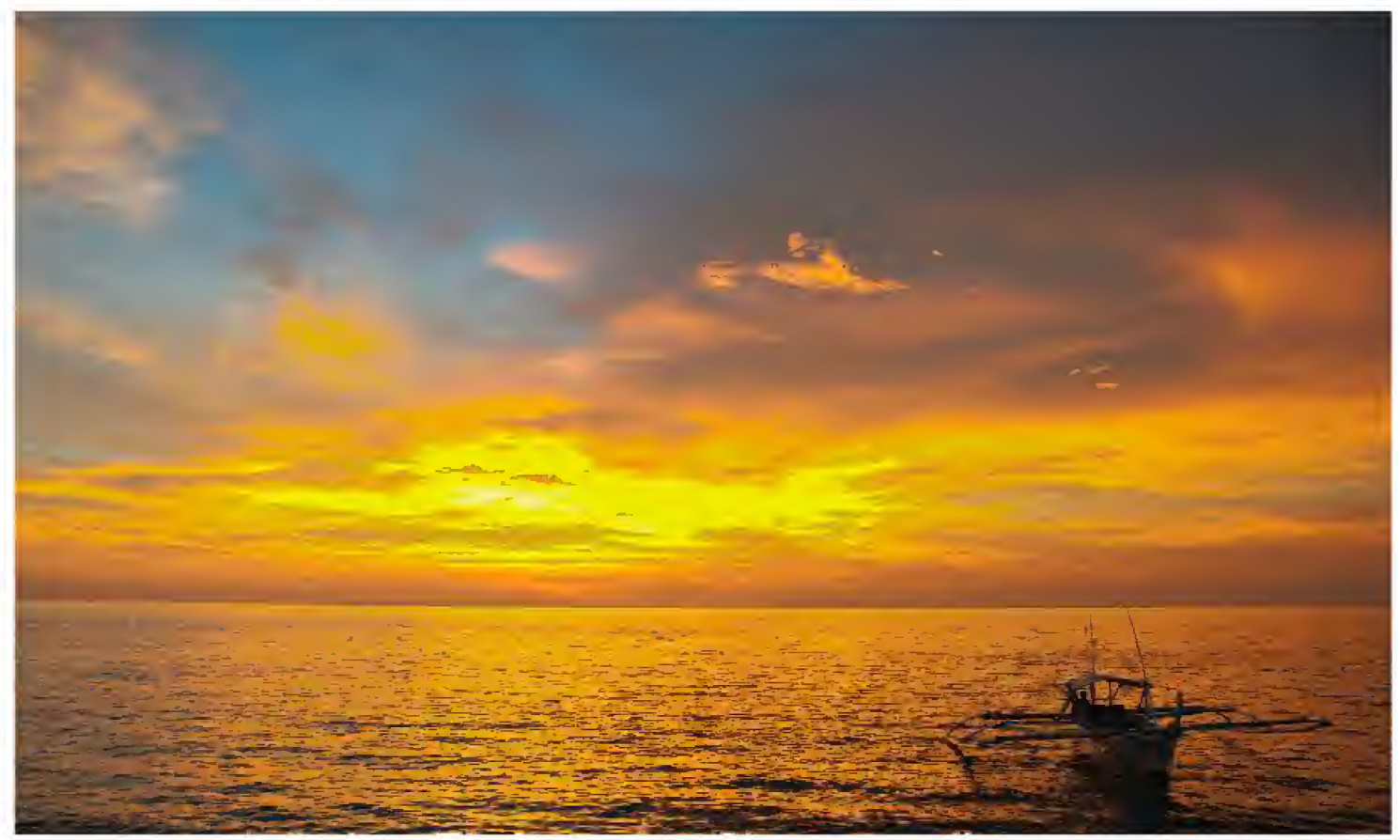

FIGURE 3: Sunset our first night at Club Ocellaris.

the next day. When we were done, we were treated to the most spectacular sunset I have seen in a long time. Not a bad way to start off the expedition.

The overall dive plan for the Steinhart Biologists was to dive and collect for 6 days, then drive 
the animals we had obtained back to Manila for ship out on our 'dry day' (to give our bodies a chance to off gas Nitrogen in our tissues from diving), drive right back to Club Ocellaris for another 6 days of diving and collecting, then back to Manila for packing and shipping then fly home the next day. The daily schedule of activities would be a grueling marathon, but we couldn't wait to get started.

\section{LIFE IN THE EXPEDITION}

Every morning, we woke at around 6 am for coffee and Skype video calls to home and work where it was $2 \mathrm{pm}$ the previous day. Breakfast (ummm, mango shakes) and our dive briefing started at $7 \mathrm{am}$. With up to five dive boats going out each day, coming to agreement on where we would be diving was no small act of coordination. After breakfast we would collect and test our NITROX tanks for the day, get our cameras and collecting gear ready, and assemble \& check our dive gear and load it onto the boats. Then we would suit up and zoom out to a good place to get under the wanter.

On each dive, we not only collected animals, but also completed multiple steps designed to track each specimen - every coral fragment was photographed and assigned a number that provided information on when it was collected, from what dive site and depth it was harvested, as well as the name of the biologist who collected it. Each coral got a tag attached to it so we would, in theory, be able to ID it later. The tagging was a learning experience and morphed over time, so much so, that next year we will most likely use heat stamped numbered zip ties as tracking id's, but attach those zip ties to the coral with 20 gauge coated wire the tips of which are sealed with a rubberized plastic dip because the wire will be easier to manipulate and create less waste than other methods we tried.

After the second dive, we would head back to land and offload our animals. From the dock, we would change our scuba equipment for snorkels,

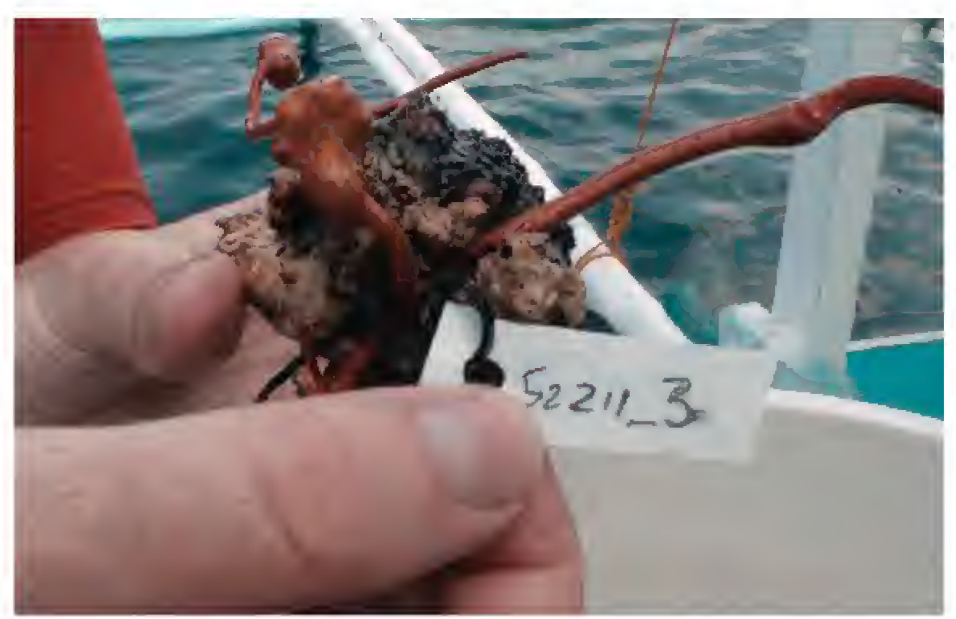

FIGURE 4: A red Junceella sp., tagged and ready to be placed on the Coral Clothsline. This coral is now on display in the Steinhart's Philippine Coral Reef Exhibit

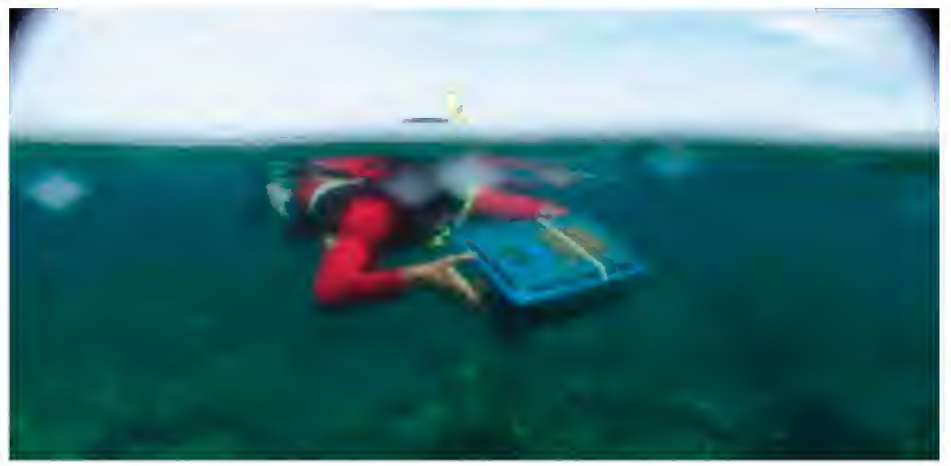

FIGURE 5: Matt Wandell swimming a plastic tank filled with collected animals out to our offshore holding site

and then swim our new specimens to the off shore holding facility, often making multiple trips. Then we would eat ravenously, then turn around and repeat the same process for the afternoon dives. 


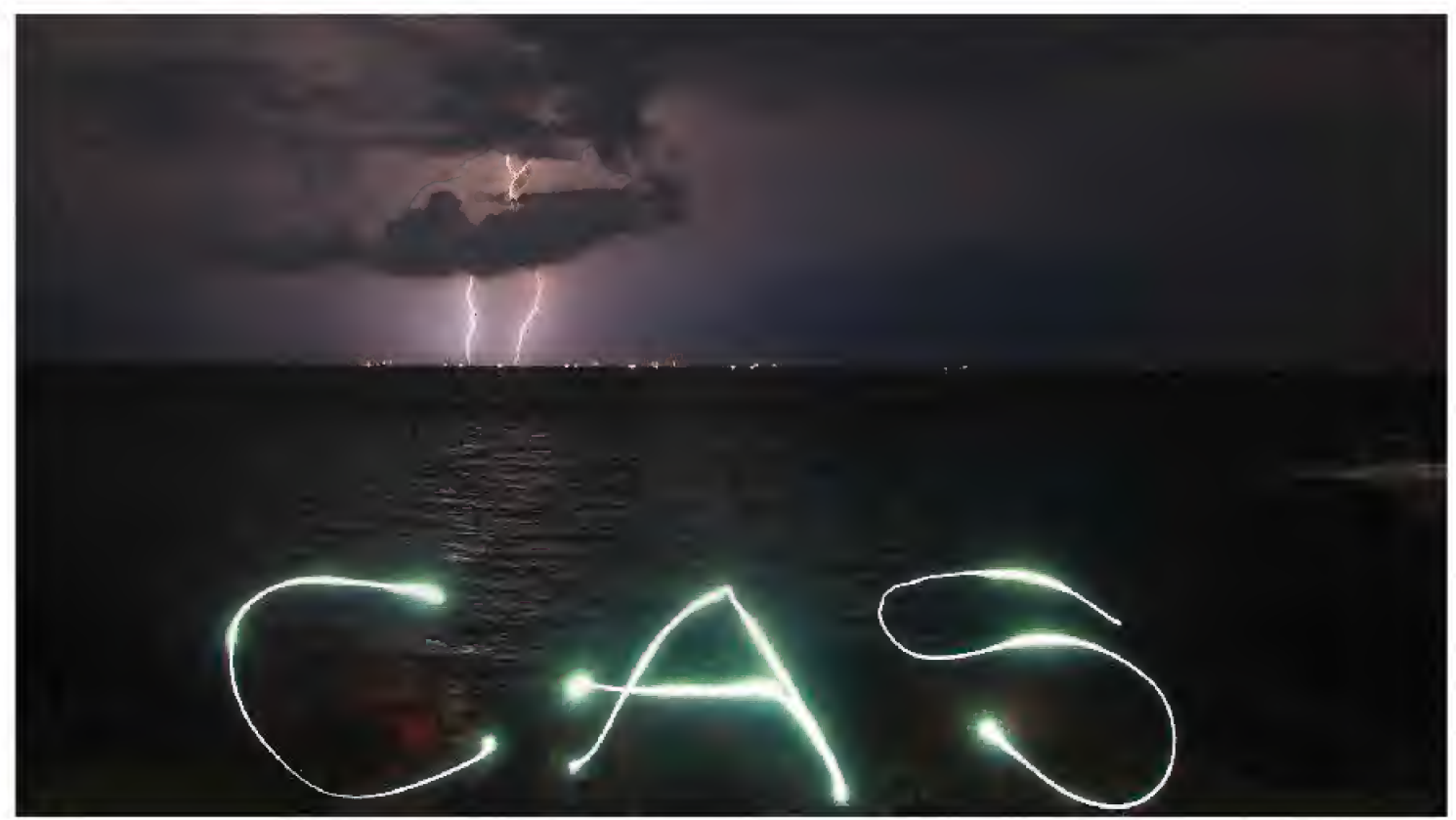

FIGURE 6: Even when bad weather kept us from diving, instead of relaxing, we were still science geeky. This is a time lapse shot of lightning and Matt Wandell writing CAS (California Academy of Sciences) in the air with a dive light.

We would finally climb out of the water at 6 pm for dinner . . unless we were doing a night dive. On night dive days, dinner and dry-off was often as late as $10 \mathrm{pm}$.

After dinner, there was more sciencing to be done. The spreadsheet detailing what we had collected needed to be brought up to date, the Coral ID software needed to be consulted to identify each SPS coral to species. Paperwork for permits for export, and shipment/arrival details needed to be initiated and updated. When that was done, we were often drafted to help the researchers on other teams process specimens they had collected, take pictures, be all around helpful, and tend to whatever animals we were keeping onshore. Sometimes we even had a moment to geek out with Philippine scientists, or have a drink of the local rum (which I still think also contained Formalin). We were lucky if we fell into bed by 11:30.

\section{THE SECOND NIGHT}

Our first night dive was something special. The moon was full and the dive site was called Dead Palm. We hit the water just after the sun set to swim over stands of Acropora of all different kinds and Turbinaria colonies as large as a car. It was an SPS lover's dream dive. About halfway through the dive the particulate in the water started to gradually become noticeably thicker, and virtually at the same time the three of us looked at each other and yelled SPAWN through our regulators.

Many corals reproduce in coordinated mass orgies where they release millions of gametes into the water. None of us had ever seen a coral spawn in the wild, and it really is as cool as it looks in the documentaries. We traced the spawn to a huge thicket of Acropora nobilis, and watched in amazement as each egg/sperm bundle emerged from the branches and floated towards the surface where fertilization takes place. Within a few days the fertilized eggs change into a coral planula, coral larvae, which swim around (yes, swim!), until they find a suitable place to settle and develop into a mature coral. 
Coral spawning is one of the new frontiers in captive coral reproduction, because collecting spawn instead of coral fragments can yield many more corals in captivity in an incredibly sustainable collection method. A group of public aquarists and coral scientists formed SECORE (SExualCOralREproduction - http://www.secore.org/) and they have been holding workshops in the Caribbean for the last several years to perfect spawning, fertilization and settling procedures. Building on the success of the Caribbean workshops the Steinhart Aquarium hopes to hold a SECORE workshop in the Philippines in the next few years. The most important part of such a workshop is of course timing it with the coral spawn. There is not much information on the timing of Philippine coral spawns, and none of the previous trips to the area had ever come across one, so actually observing coral spawning in the Philippines is a good and necessary start to bringing SECORE to the area.

We, along with some of the other California Academy of Sciences researchers and a Philippine television crew, returned to Dead Palm the next night where the coral spawn was in full swing yet again. We were able to find a colony of Acropora willisae when it was beginning to release gametes and set up around the coral to both collect some of the spawn and to document the event. I'll never forget filming Matt collecting gametes in a plastic bag while the television crew was filming me film him. We were able to collect several hundred sperm and egg bundles, and though completely unprepared for the labor intensive process of fertilization and settlement, we gave it a go.

\section{A SURREAL NIGHT}

After years of having the privilege of diving around the world practicing no impact diving, after collecting for the trade practicing and teaching having as little impact as possible, and after planning to take 'found frags' when possible, watching a scientific survey on the move takes a bit of getting used to. The researchers were collecting everything - worms, urchins, fish, nudibranchs - and just about every dive on the Expedition yielded at least one animal that seemed to be undescribed by science. The animals were being collected and preserved for scientific description, genetic analysis and as a way to be comprehensive in the survey, and being in the midst of a full on scientific survey lead to the Steinhart biologists to try to take advantage of the situation, and alter our plan regarding what we would try to bring back to San Francisco for our living collection.

On the third evening of our diving, Dr. Healy Hamilton showed us some ghost pipefish, Solenostomus cyanopterus, and some pygmy seahorses, Hippocampus bargibanti, that had been collected that day. These animals were going to be sacrificed for their genetic material. I know some people have a visceral reaction to that idea, but as Dr. Gerald Allen once said during a MACNA talk "It's a necessary part of science". Of course when we saw the ghost pipefish, a species that we had always wanted to work with but hadn't because of their dismal record of surviving collection and shipping through the trade, we immediately suggested that we try to keep them alive and that we try to ship them home and put them on display — if they didn't make it, we would still have their genetic material available for science. Though we weren't prepared for holding these kinds of animals, Bart, Matt and I had been trained in the ultimate McGyver proving ground - the reefkeeping hobby. We got to work setting up buckets aerated by scuba tanks, faux gargonian hitching posts for the seahorses made from zip ties, and prepared ourselves to do water changes as often as needed by slogging 5 gallon buckets up and down 2 flights of stairs.

Of course, the third night of diving was also the night we collected coral spawn, so while we were preparing to try to keep these amazing fish alive, we were also preparing to attempt to keep the coral spawn healthy and fertilized which included 'stirring' the gametes every hour or two. This led to the most surreal night of the trip. We had coral out on the clothesline, ghost pipefish in the offshore holding tanks, trays of coral eggs and sperm, and a bucket with two pygmy seahorses next 
to our beds. Throughout the night we kept waking up and tending to these animals - a strange, wonderful and exhausting time.

In the end, we were successful keeping the ghost pipefish alive, and getting them home to the aquarium in Golden Gate Park. Sometime in the night we noticed that the pygmy seahorses were no longer living, and we preserved them. The coral spawn failed to thrive, and it seems that we were simply too unprepared and understaffed to have succeeded in that labor intensive realm. We learned a lot and helped move science forward. Of course, we plan that for next year's trip, we will be much more prepared for new surprises and opportunities.

In the next installinent - coral collecting, octopus wrangling, shipping \& packing for the trip home, and 300-500 new species discovered.

Special thanks to Bart Shepherd, Matt Wandell and Elizabeth Palomeque

\section{Philippine Biodiversity Expedition \\ Part 2: Collecting, Getting Stuff Home and New Discoveries ${ }^{3}$}

Researchers from the California Academy of Sciences have been visiting the Verde Island Passage area off the coast of Batangas Province on Luzon Island, Philippines for almost 20 years. Research by scientists during this period has suggested that this area may be the "center of the center" of marine biodiversity, and perhaps home to more documented species than any other marine habitat on Earth; there can be more species of soft corals at just one dive site than in all of the Caribbean.

Funded by a generous gift from Margaret and Will Hearst, the 2011 expedition was not only the most comprehensive scientific survey effort ever conducted in the Philippines, but also the largest expedition in the history of the California Academy of Sciences. Over eighty scientists from the Academy, the University of the Philippines, De La Salle University, the National Museum of the Philippines, and the Philippines Bureau of Fisheries and Aquatic Resources came with a mission to survey and document various aspects of the various ecosystems in the area.

A further team of Academy educators attended with a mission to share the expedition's findings with local community and conservation groups as the Expedition was happening. As part of the expedition's shallow water team based at the renowned Club Ocellaris, Bart Shepherd, Matt Wandell and I focused upon the underwater sites that served as the inspiration for the Steinhart Aquarium in the California Academy of Sciences 212,000 gallon Philippine Coral Reef exhibit.

In part one of this series, we covered getting the the Philippines, the realities of being on an expedition and our lucky observation of hard coral spawning. In part two we'll look at how we collected octopus and corals, how we shipped those animals back home, and more.

\section{ARMEd COCONUTS 4}

In stark contrast to the beautiful obstreperous coral reefs of the Philippines, muck diving is like being on the moon. You float over seemingly endless plains of desolate grey substrate. But unlike the lunar landscape, the muck habitat is full of life; in the 'center of the center of marine biodiversity' the silty muck is packed with animals of all shapes and sizes. Commensal shrimp use tube anemonie tentacles for protection. Flatfish, perfectly camouflaged in plain sight, become visible only when spurred into motion by your passing. Feather Stars move their arms in slow motion,

${ }^{3}$ http://vimeo.com/36865036. This video from the 2011 Philippine Biodiversity Expedition give you a good idea why the Verde Island Passage has been called 'the center of the center of marine biodiversity'.

${ }^{4}$ http://vimeo.com/24176960. The Octopus in this video refuses to eat a crab that we generously caught for it. 
revealing their own commensal shrimp and squat lobsters hiding amongst the 'feathers'. Venomous predators like Lionfish, Stonefish and Seagoblins hide in the muck waiting patiently for their next meal. Ambush predators like the Stargazer lie mostly buried in the silt, with only their skeletal face showing as they wait for an unlucky fish to swim over their vacuum-like mouths.

One of the major goals for the Steinhart Aquariums during the expedition was the collection of the Coconut, or Veined Octopus, Amphioctopus marginatus that inhabits these shallow muck areas. The Coconut octopus captured media attention twice in the last few years, first walking only on two legs across the bottom of the sea while looking like a coconut, and more recently, as a candidate for possible tool use due to the octopus spreading itself over coconut shell "bowls," raising the whole assembly to amble on eight 'stilted' arms across the seafloor. This little octopus is plentiful in the Philippines. Furthermore, it's personable, tenacious, and has an amusing habit of using found objects as temporary homes, making it a great display animal. Clay pots, bottles, tin cans, clam and scallop shells are all used as mobile homes for these octopus, complete with doors to close themselves in tightly and safely. These eight armed mollusks also will defend their homes, batting away anything that comes too close; even pushing a probing finger away with surprising strength. Sometimes they extend their arms and crawl around in the muck with their temporary home on their back, as if they are transforming into snails. This octopus has never been on display before in the US, and perhaps not anywhere in the world (though it may be possible that is has been displayed in Japan) and is not available from commercial collectors, so we were very eager to collect specimens, put them on public view, and work on captive breeding behind the scenes.

It is important to mention that as a cephalopod enthusiast, I have been wanting to work with this species for well over a decade. They aren't available in the trade, but I had been lucky enough to have observed them in the wild, and the idea of being able to work with them in captivity made giddy. So, when we entered the water around Anilao Pier just as the sun was going down I was brimming with anticipation. After 15 minutes we found no sign of octopus and I started to get depressed. This is the love hate relationship I have with muck diving — it is really like a safari because it is very possible that you will not see what you are looking for . . . even if it's only a few feet away from you. When you dive to look at reefs, well, the reefs are kind of hard to miss. The muck, however, is by nature a more challenging landscape, and everything there is trying to not be seen. We kept searching. After another 15 minutes or so, we adjusted, and suddenly we saw Coconut octopus everywhere. We found sizes, as small as my thumb nail all the way to the size of a soft ball. We collected a variety of specimens and then enjoyed the dive by catching crabs and feeding them to other octopus.

There were some recreational divers in the area looking a little lost in the dark and muck. Matt and I, flushed with success, led one one of them over to a coconut octopus that had made its home in some shells. We figured that we would catch a crab and feed the octopus so this diver could get some interesting video. We motioned for him to stay with the octopus and went searching for prey. Turns out we were gone about 10 minutes, but the diver was still where we left him. Good! His wait would be worth

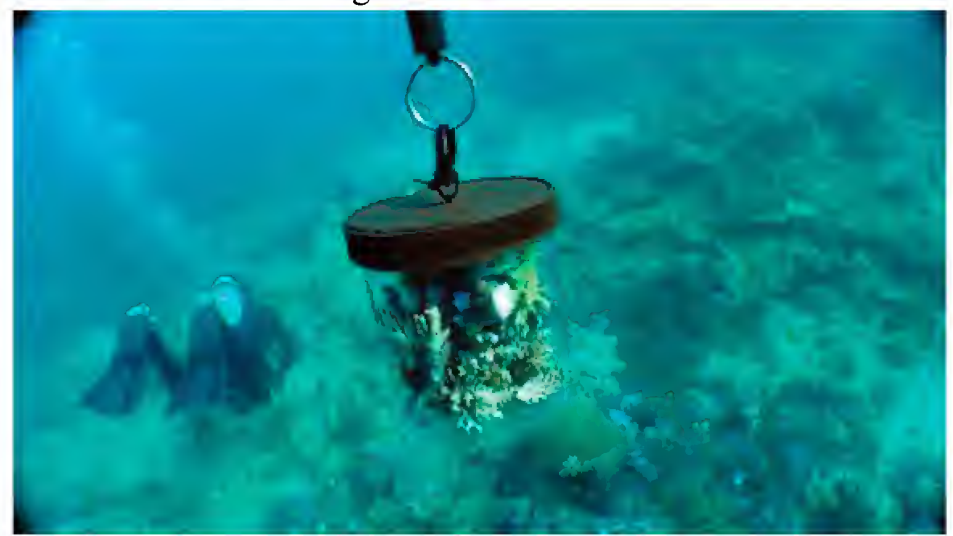

FIGURE 7: So many Acros, so little time. 
it. We proudly showed him the crab, and, he obligingly began to film. Of course, as you might guess, the octopus wouldn't have anything to do with it and kept pushing it away. We shrugged our shoulders at the diver in apology and swam on.

\section{KIDS IN A CORAL STORE}

Our cephalopod duties complete, our focus shifted back to corals. Philippine coral reefs have long been in jeopardy due to human activities including dynamite and cyanide food fishing, overcollection for the curio trade, collection for the aquarium trade (this may only be a small percentage of the damage to Philippine coral reefs compared to other factors, but it is some of the most visible activity and thus comes under intense scrutiny) as well as a host of other impacts including development, sedimentation, run off, climate change and more. As a result, the Philippines has become very protective of their coral reef natural resources and has been working over the last several decades to make that protection more robust and more intelligent for economic and environmental reasons. All Philippine stony corals are protected by inclusion in CITES (the Convention on International Trade in Endangered Species of Wild Fauna and Flora) and there is currently no export of live corals from the area - unless permitted. As you can imagine those permits are not often approved. The Philippine government is interested in looking into what it would take to empower responsible and sustainable local aquaculture and mariculture efforts and granted the Steinhart Aquarium in the California Academy of Sciences CITES and Philippine permits for the export of live coral in order to help explore those efforts. On future trips to the area, The Academy hopes to present workshops on coral culturing techniques as well as coral sexual reproduction workshops as part of SECORE in order to facilitate the sustainable production of corals for research, restoration and perhaps one day to bring responsibly farmed corals to market.

Bart, Matt and I are all reef geeks, so being set loose to collect corals in an area where collection is prohibited was both a treat and a terrific responsibility. As the only public aquarium legally permitted to collect stony corals in the Philippines, the California Academy of Sciences wanted to obtain unique species for study, captive culture research, distribution to other institutions as well for display at the Steinhart aquarium. To support our efforts at sustainable collection building, the plan was to collect 'found fragments' (fragments that were naturally broken off the mother colony) of hard corals whenever possible. Fragments from larger mother colonies would be carefully harvested when there were no found fragments available. Our approach to soft corals was similar, focusing on found fragments, fragments taken from the growing margins of larger colonies, or, in the case of whip corals, taking small specimens from areas with many instances of the same coral. We tried to focus on corals that were exceptionally colored, oddly shaped, or animals generally unseen in captivity.

As we swam along the reefs we carefully collected corals that caught our eye, gently stacking hard corals into the easily accessible frag containers that Bart fabricated for us on site from empty plastic drink mix and ice cream containers. Due to the penchant for releasing toxins when disturbed, soft corals were collected into individual deli cups or plastic bags. There seemed to be corals that fit our collection criteria every few feet, so we were forced to be selective.

As soon as each dive was over each fragments was tagged, rinsed and separated into 5 gallon buckets filled with fresh sea water for the boat ride back to Club Ocellaris where they were strung on our offshore 'coral clothesline' apparatus covered in part one of this series. ${ }^{5}$

\footnotetext{
$5_{\mathrm{http}} / / \mathrm{www}$.youtube.com/watch?v=7K8feG_8bRM. This video explains our hard coral collecting methods
} 


\section{THE TRIP HOME}

With all the collecting done, the only thing left was to ship all the animals home. Luckily for us the Academy has a great relationship with an exporter in the Manila, Aquascapes Philippines Co, a company that early on embraced the idea of responsible and sustainable collection evidence by their becoming one of the first companies to be MAC certified in 2002. This relationship really streamlined our exporting process. Using their facilities meant we didn't need to procure our own shipping boxes, shipping bags, rubber bands, oxygen, heat packs or any of the other essential supplies associated with successful shipping of live saltwater animals. They also arranged flights, getting boxes to the airport, and did all the running around to make sure all the export permits had their i's dotted and their t's crossed. All we had to do was arrange the stateside paperwork, state side inspections and get the animals from the collection spot to Manila.

The morning of our final pack out of the Expedition, we needed to hit the road by $9 \mathrm{am}$. Since many of the researchers were not going home yet, we enlisted them to help us pack up the seemingly infinite number of live specimens we had collected. Of course we had to pack up our personal stuff and our dive gear as well, so the morning was really go go go. We swam out to the offshore holding just after dawn, disassembled it and brought all the animals to shore. There we quickly packed them up in collecting bags for the 3-hour car ride to Manila. But before we could start our ride, we had to get everything to the cars: heavy boxes of animals, and luggage heavy with wet dive gear all needed to be lugged up the 4 flights of stairs from the living area of Club Ocellaris to the road. The locals, who are short even compared to me, made the exercise look easy; they flew up the stairs with several boxes and suitcases each as we huffed and puffed with our comparably teeny loads. Finally, every tub bag and box made it to the van. After a short stop at McDonalds for a McDo (a hamburger with some sort of brown sauce on it), we were on our way to Manila.

Once we arrived at Aquas-

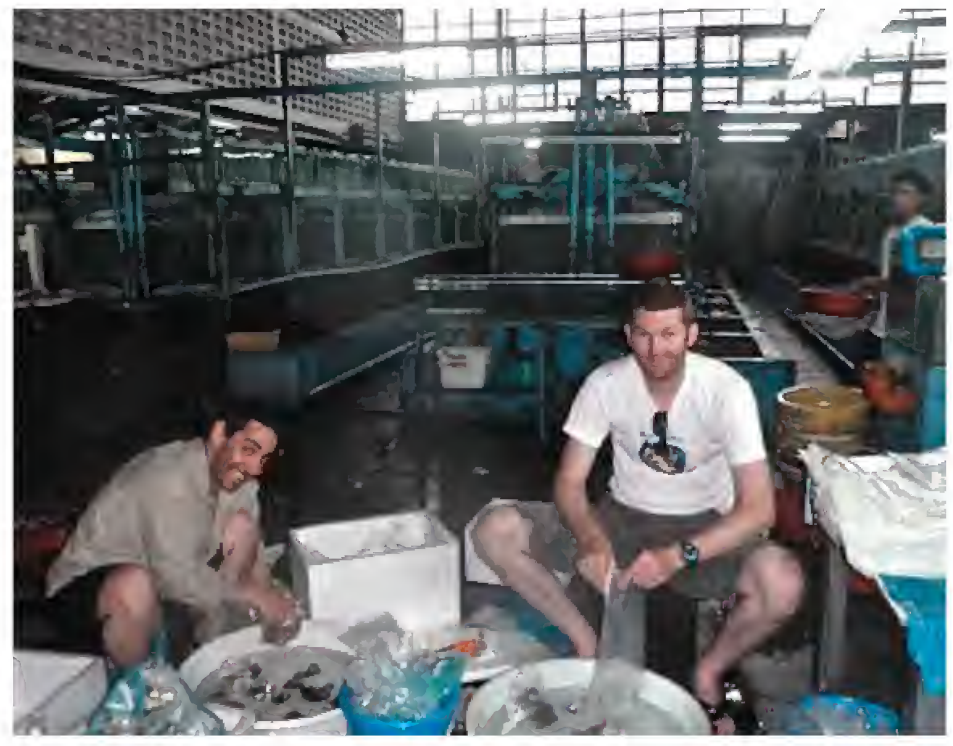

FIGURE 8: Sitting on little wood blocks for hours at the Aquascapes facility as the rain beats on the roof

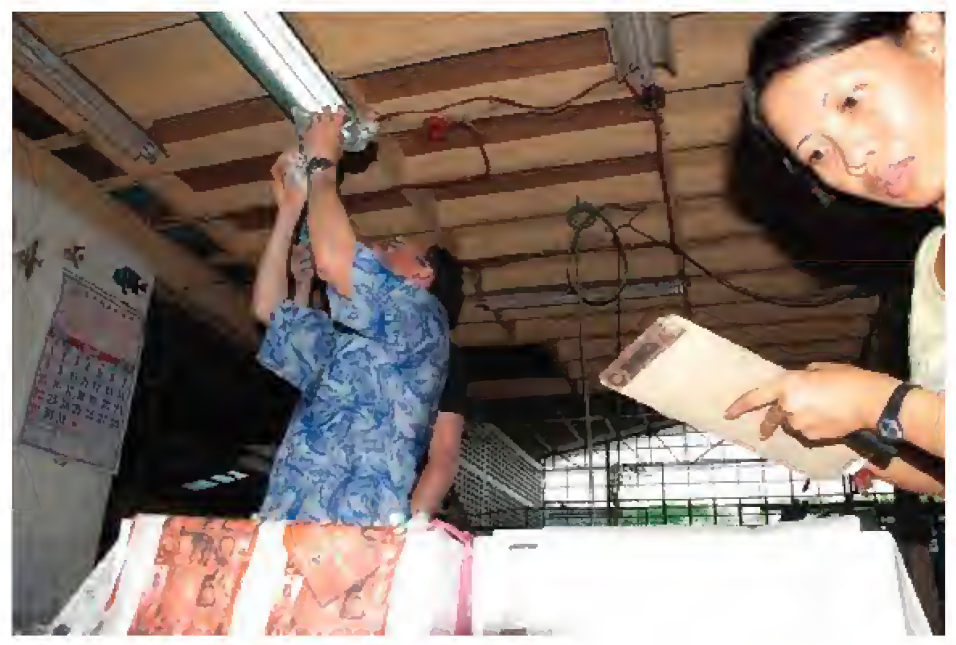

FIGURE 9: Bart and Flor check and double check the paperwork 


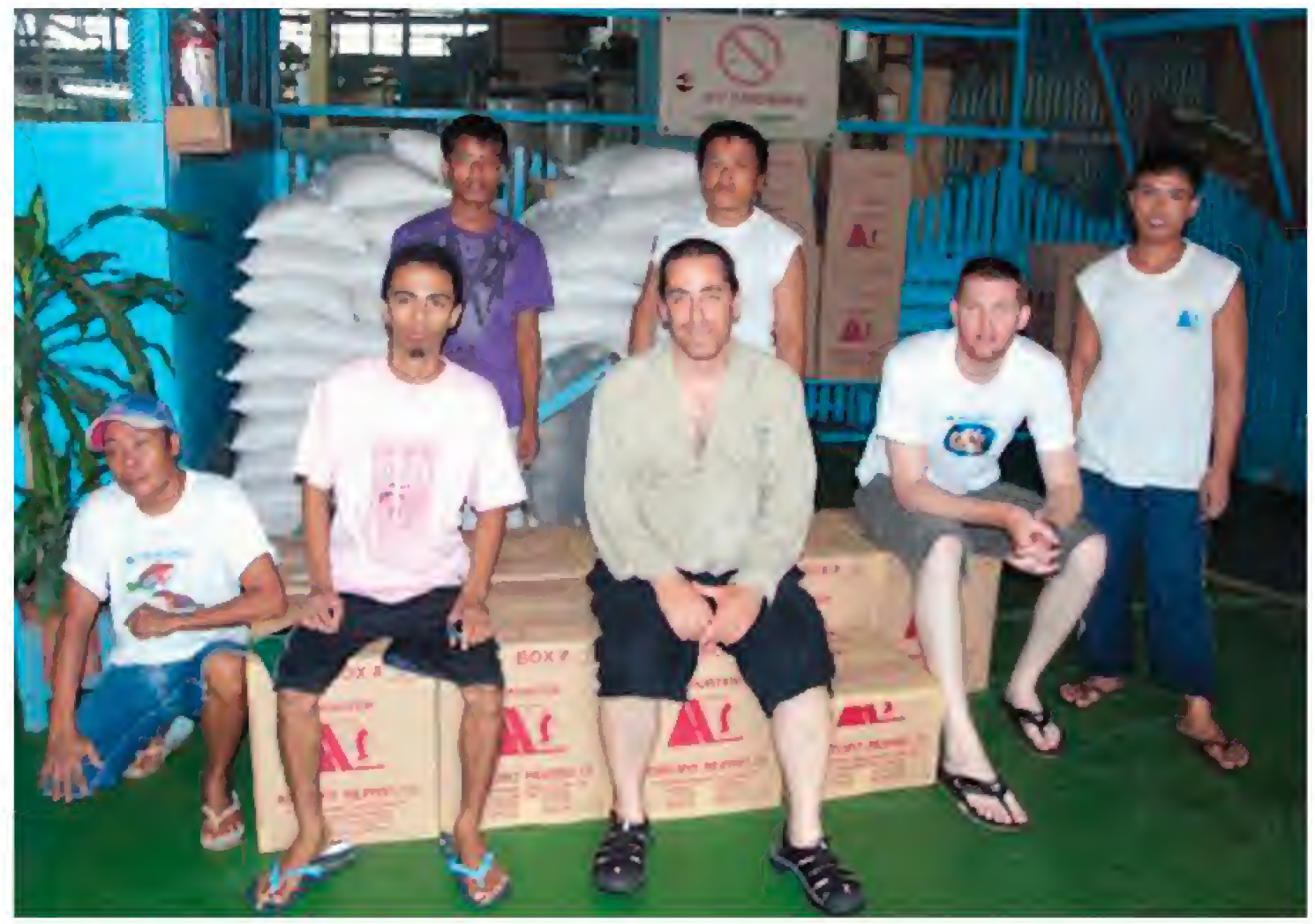

FIGURE 10: Matt, Rich and the Aquascapes crew

capes, we sprung back into action. Since we had already packed up a shipment the week before, everyone knew the drill. The Aquascapes staff had everything ready for us including water at the right salinity and temperature as well styrofoam floats for the corals. Since they don't normally export corals, the staff and owners of Aquascapes were very interested in what we were packing, how we packed it and why we were doing what we were doing - they took copious notes and photographs. As a huge rainstorm let loose on the city, we got into a packing rhythm - Matt and I bagged everything while sitting on tiny stools, the Aquascapes crew would seal the bags with, or without, an air gap depending on the animal, and Bart worked with the office staff to make sure everything was packed and documented correctly. Three hours later we were done and on our way to the Dusit Manila for our first real shower in 16 days, and then the the airport the next day for the flight home.

\section{PerI's SNAKE EEL}

Back in the States, the researchers are still processing and classifying specimens. The estimate of species new to science discovered on the Expedition is currently between 300 and 500. That list includes sharks, fish, polychetes, nudibranchs, corals and echinoderms. Personally, the new discovery that really stands out for me involves a new species of snake eel, and it stands out because we were directly involved in its collection.

Near the beginning of the Expedition, Matt, Bart and I were diving the shallows a a a site call LiagLiag, while some Academy researchers were deeper and further out on the reef slops. The site had seemingly acres of non Acropora SPS corals in 2 to 15 feet of water. Excited over collecting a Soft Coral Anemone (Heterodactyla hemprichii) we were taking in the expansive site including the 
incredible and visable change in water densities at the thermocline/heliocline (called a Schlieren) at about 4 feet when a lone diver appeared from deeper below us, swimming oddly. Fearing something had gone wrong the three of us made our way over to him. His hands were out in front of him and he seemed to be holding something in them. As we got closer we saw that the diver was one of the incredible local dive guides (seriously, these guys can find almost anything under water), Peri Paleracio. In Peri's hand was some sort of eel. Not really knowing what was going on, but knowing it was important, we opened one of the large collecting bags we were carrying and carefully helped get the eel into the bag and sealed it shut. Peri was excited, and quickly returned to the depths to rejoin

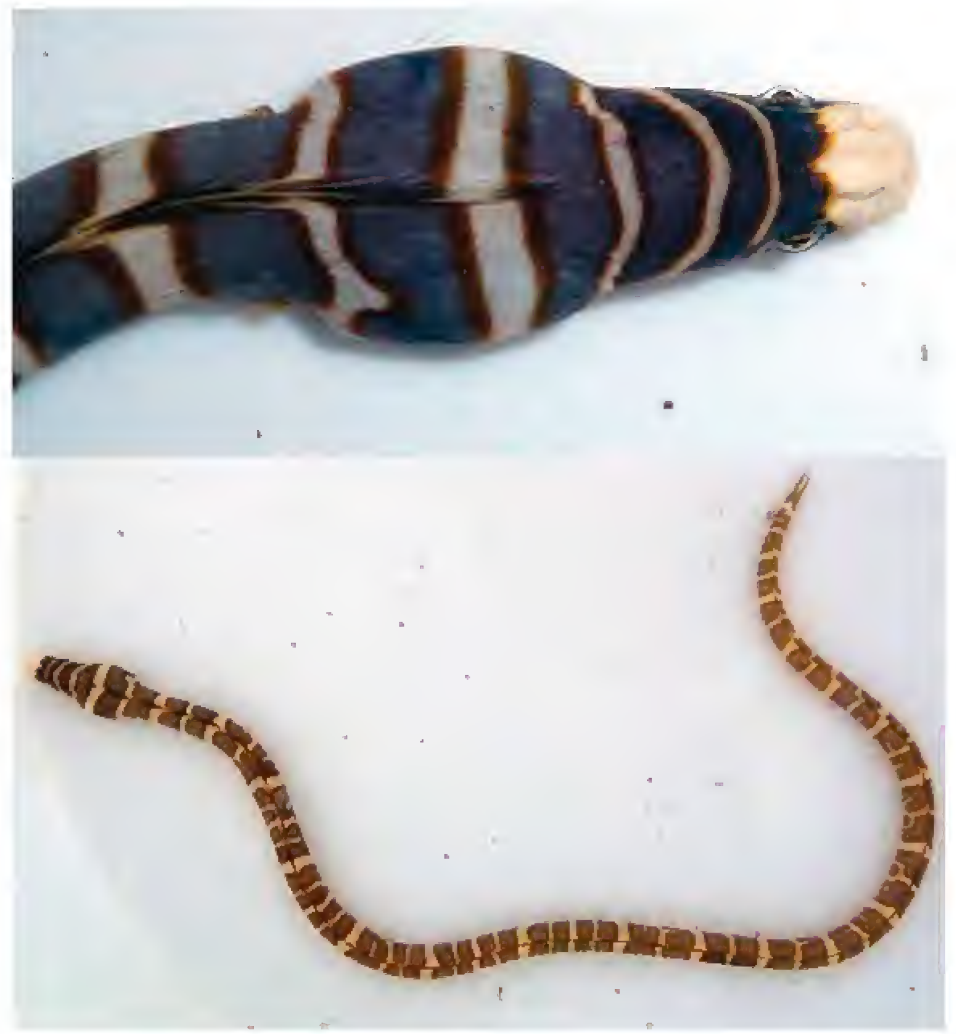

FIgure 11: The newly described Peri's Snake Eel. the group he was diving with. Because the eel was important enough to be caught by hand and brought up from deeper water, we quickly got the animal onto the boat to make sure we didn't lose it.

Back at Club Ocellaris, as everyone oohhd and aahhd over the bucket containing the eel, the backstory unfolded. As it turns out, this was a suspected new species of Snake Eel that had been seen on a previous trip, and had actually been seen earlier in the expedition, but eluded collection. Peri had spotted it, grabbed and and knew that we had a collection bag big enough to put it in. Dr. John McCosker and Dr. Gerald Allen named the fish Peri's Snake Eel, Myrichthys paleracio, in honor of Peri for this feat of SCUBA and icthyological dexterity.

\section{WhAT ABOUT THE FisHES?}

The areas we visited on the trip had corals reefs in great shape - healthy and growing with almost no signs of bleaching, which is very exciting given the steps that the Philippines has taken to protect those animals. The fish populations in the area were a more complicated story. While the small fishes were swimming thick and diverse, there was a noticeable lack of anything larger than a foot or so. The reason for this absence was made clear when we dove on several of the protected areas where food fishing is prohibited. Only in these areas did we see larger fish including huge schools of jacks magnificent above the reef scape and sharks lurking in caves waiting for dusk. Currently, these protected areas are in place to drive eco tourism, but it is hoped that the future will see more of these fish safe havens, and that enough of them in close enough proximity to each other will not only boost the economy of tourism, but will allow these larger animals a safe place to live and breed, and ultimately result in the sustainable harvest of food fish by local peoples. 
My job at the Steinhart Aquarium is pretty dreamy, and hardly a day goes by that I don't sit back with a big grin after diving in the 212,000 gallon tank, mating cephalopods, or hearing someone on the public floor of the aquarium say something like 'That's a Nautilus, they're my favorite but I've never seen one before' and think 'Wow, this is my job'. Being part of the 2011 Philippine Biodiversity Expedition was something special and hardly a moment went by - the late nights, the grueling days, or floating over rarely visited reefs - that I didn't think 'Wow, this is my job". I look forward to the continued collaboration between the research and aquarium departments of the California Academy of Sciences, the chance to work with amazing animals from the Philippines, and hopefully more opportunities for me and my fellow aquarium biologists to experience the majestic Phillippine reefs in person. 


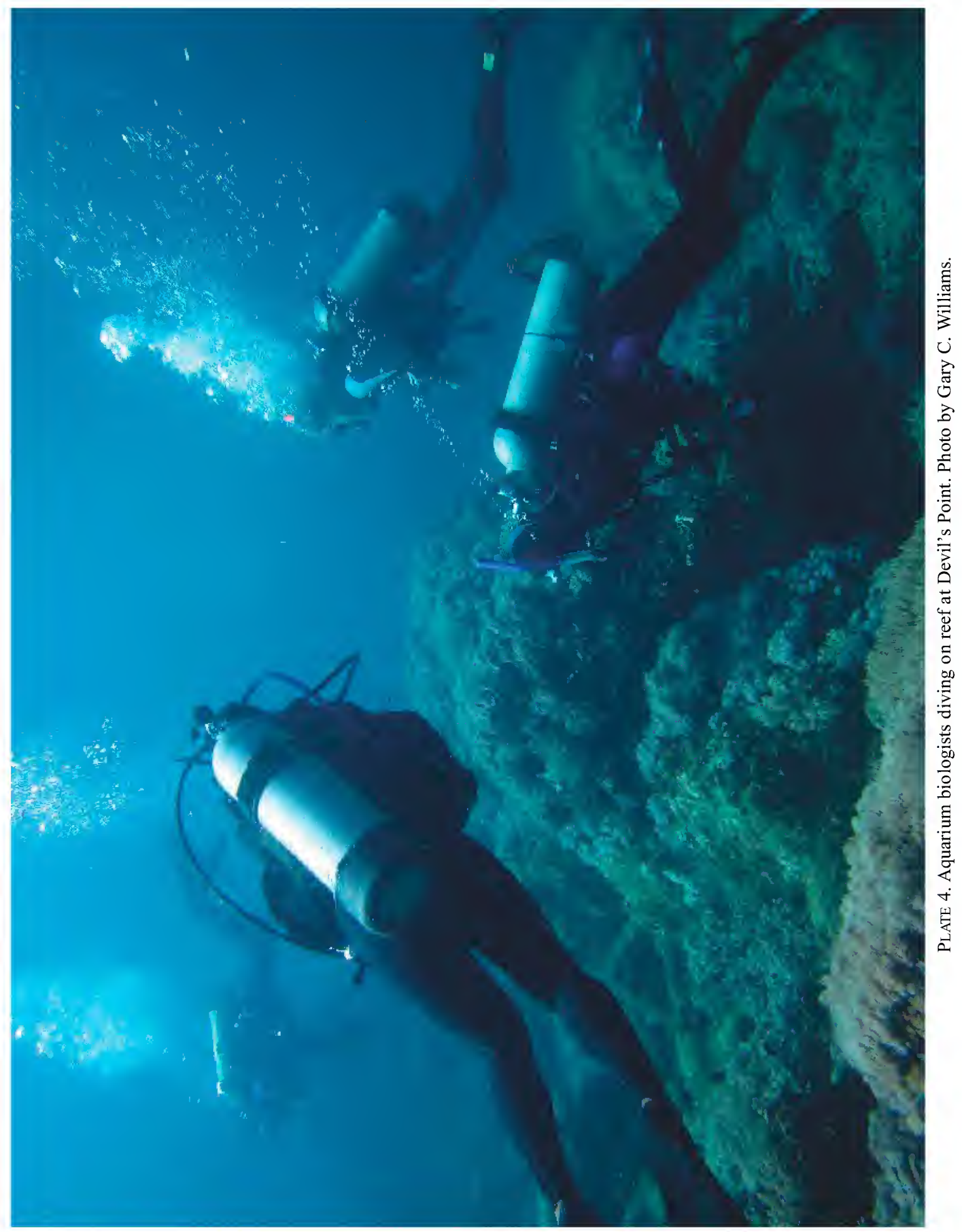




\title{
The Three Research Components of the 2011 Hearst Biodiversity Expedition to the Philippines
}

\author{
Gary C. Williams \\ Department of Invertebrate Zoology and Geology, California Academy of Sciences, \\ 55 Music Concourse Drive, San Francisco, California 94118 USA; Email: gwilliams@calacademy.org
}

\begin{abstract}
The field research of the 2011 Hearst Biodiversity Expedition to the Philippines, was composed of three phases or components - a shallow-water component that explored the coral reefs of the Verde Island Passage primarily by snorkeling and SCUBA diving, a deep-water component on board the Philippine's government ship $M / V D A-B F A R$ in the region of Batangas and Balayan Bays and the Lubang Islands that explored the deep benthic environment primarily by trawling and fish traps, and a terrestrial component by teams of botanists and entomologists that explored the forests of four mountainous regions in southern Luzon.

KeYwords: Phases or Components of the Expedition, Three Research Components, Shallow-Water Component, Deep-Water Component, Terrestrial Component
\end{abstract}

The Hearst Biodiversity Expedition to the Philippines took place between 24 April and 11 June 2011, and apart from the 1905/06 Galápagos Expedition, it was the largest expedition undertaken by the California Academy of Sciences in its 160-year history. The multidisciplinary expedition was divided into several components or phases, each composed of different complements of individuals in different geographic regions, which took place during time periods that did not necessarily overlap (Gosliner and Burke 2013). These components consisted of three research components (Figs. 1-10), educational outreach (Fig. 11 A), and a large, well-attended symposium at the end of the expedition that was conducted at the University of the Philippines on 8 June 2011 (Fig. 11B). All of the components of the expedition not only included scientists, field researchers, media personnel, and educators from the California Academy of Sciences, but also from several institutions in the Philippines and the United States.

\section{THE THREE RESEARCH COMPONENTS}

\section{The Shallow-Water Component}

Figures 1-4

Shallow-water research took place on coral reefs (Fig. 2) and associated habitats primarily through the use of SCUBA using Nitrox technology (Fig. 4). Thirty-eight dive sites were explored in the Verde Island Passage region around Maricaban Island and the Calumpan Peninsula, Calatagan in Balayan Bay, and Puerto Galera on northern Mindoro (Fig 1A). Research activities took place between 28 April and 27 May, involving thirty-three individuals from a variety of institutions in the Philippines and the United States, including research biologists, aquarium biologists, students, dive safety personnel, and dive guides. SCUBA diving and snorkeling took place between surface waters and approximately $40 \mathrm{~m}$ in depth. One hundred seventeen dives were logged, with a wealth of marine invertebrates (Fig. 3) and fishes collected. All material was subsequently transported, curated, and housed at the California Academy of Sciences in San Francisco. Several diurnal dives and a night dive were conducted each day, with periodic rest periods scheduled for particular divers. Headquarters of the operation and field laboratories were located at Club Ocellaris on the Calumpan Peninsula just southwest of the village of Anilao. In addition, the inland fresh- 


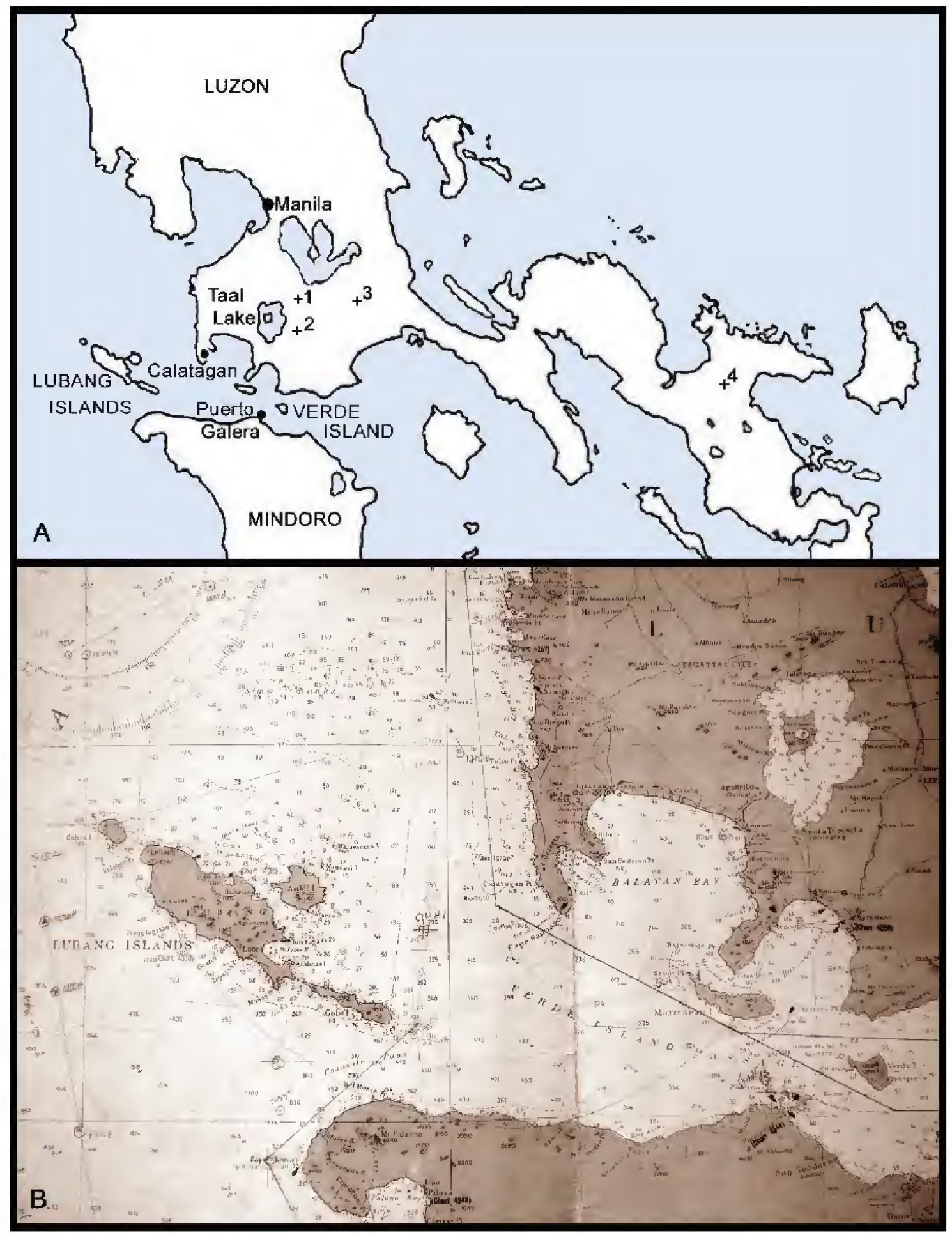

FIGURE 1. A. Map of research areas. Shallow-water component: Verde Island Passage, Puerto Galera, Calatagan, Taal Lake. Deep-water component: Luban Islands. Terrestrial component: 1 - Mt. Makiling, 2 - Mt. Malarayat, 3 - Mt. Banahaw, 4 - Mt. Isarog. B. Nautical chart showing the Lubang Islands group, the Verde Island Passage, and Taal Lake. 
water environment of Taal Lake, a crater lake of volcanic origin (Figs. 10E-F), was also explored and fish and invertebrates were collected by a subset of researchers from the shallow-water operations.

Since 1992, varying degrees of severity regarding coral bleaching (Fig. 2F; compare with the appearance of unbleached scleractinians, figs. 2B, C, E) have been observed during field operations by Academy researchers on the coral reefs of the Verde Island Passage region. Coral bleaching is here defined as the sparsity or absence of zooxanthellae in normally zooxanthellate scleractinians. Prior to 1995, bleaching in scleractinian corals was only occasionally encountered, the incidents of detection ranging from rare to infrequent. By contrast, after 1995, observation of coral bleaching was far more frequent. Reflecting on this, the mid-1990s can be regarded as a pivotal period concerning changing conditions responsible for the prevalence of coral bleaching in the region. A significant variance in degree of bleaching can be seen if one compares the severe bleaching incident of 2010 with observations made during the Hearst expedition in 2011. A major bleaching event occurred in mid-2010 throughout much of the tropical Indo-west Pacific from the eastern Indian Ocean to the Philippines (Sundt 2010). By May through June 2011, during the Hearst expedition in the Verde Island Passage, bleaching was occasionally observed as isolated examples, but the severe conditions of the previous year and any residual effects of a mass mortality or coral damage were not observed.

\section{The Deep-Water Component}

Figures 1B, 5-6

The second marine research component explored the deep sea benthos in the vicinity of the Lubang Islands to the west of the Verde Island Passage region of the shallow-water component. This phase took place took place during an eight day period form 29 May to 5 June 2011, on board the government of the Philippines research ship, M/V DA-BFAR. Sampling of the biota from the sea bottom was conducted between 60 and 2195 meters in depth by trawl nets that included standard trawls, otter trawls and bottom trawls. Fish traps were also employed, which were used at night and brought up on deck each morning before the day's trawling operations commenced. Participants included a large compliment of biologists and marine resource managers from BFAR (Bureau of Fisheries and Aquatic Resources), University of the Philippines, National Museum of the Philippines, as well as the California Academy of Sciences (Departments of Ichthyology and Invertebrate Zoology and Geology).

One unsuspected and unfortunate outcome of the benthic collecting during this phase was the prodigious amount of sunken plastic material and other un-decomposed garbage that was brought up from the sea floor in the majority of trawls. In some instances, the amount of plastics was far greater than that of the biotic material that was encountered.

\section{The Terrestrial Component}

Figures 1A, 7-10

It is generally accepted that the Philippine archipelago has had an extensive period of human occupation dating back to the late Pleistocene (Jocano 2001). Primary forests are now mostly restricted to higher montane regions, such as on the upper slopes of volcanic peaks. Four of these regions in southern Luzon were selected for field research as part of the Hearst biodiversity expedition: Mt. Makiling, Mt. Malarayat, Mt. Banahaw, and Mt. Isarog.

The terrestrial research component was conducted from 6 May to 5 June 2011 by four groups of researchers from the California Academy of Sciences along with colleagues from the University of the Philippines and Pusod (a non-profit organization whose mission is to protect and enhance 
the ecosystems of the Philippines). The groups worked separately for the most part and consisted of a botany section (mosses and flowering plants), an entomological section (primarily spiders and millepedes), herpetologists led by Cameron Siler and Rafe Brown from the University of Kansas, and mammalogists from the University of the Philippines.

\section{ACKNOWLEDGMENTS}

Gratitude is here extended to the chief scientists for each of the three research components of the expedition: Terrence Gosliner (shallow-water component and overall expedition chief scientist), Rich Mooi (deep-water component), and Peter Fritsch (terrestrial component), to all the participants and support staff that made the expedition a reality, and for the generous gift by Margaret and William Hearst that made it all possible. Identifications of the amphibians and reptiles (Figs. 10A-D) were graciously provided by Dr. Rafe Brown (Univ. Kansas).

The photographs reproduced in this article are by members of the expedition and are in the Hearst Biodiversity Expedition archives at the California Academy of Sciences.

\section{LITERATURE CITED}

Gosliner, Terrence M., And Meg Burke. 2013. From parachutes to Partnerships: An "Integrated" Natural History Muscum Expedition in the Philippines. Curator 56(1):47-67.

Jocano, F. LANDA. 2001. Filipino Prehistory: Rediscovering Precolonial Heritage. Punlad Research House, Inc., Quezon City, Philippines. 240 pp.

SuNDT, NICK. 2010. Scientists Report One of the Worst Coral Bleaching Events on Record in Southeast Asia and the Indian Ocean. Climate Change Blog, World Wildlife Fund. <http://www.wwfblogs.org/climate/ content/coral-bleaching-se-asia-and-indian-ocean-20oct2010> 

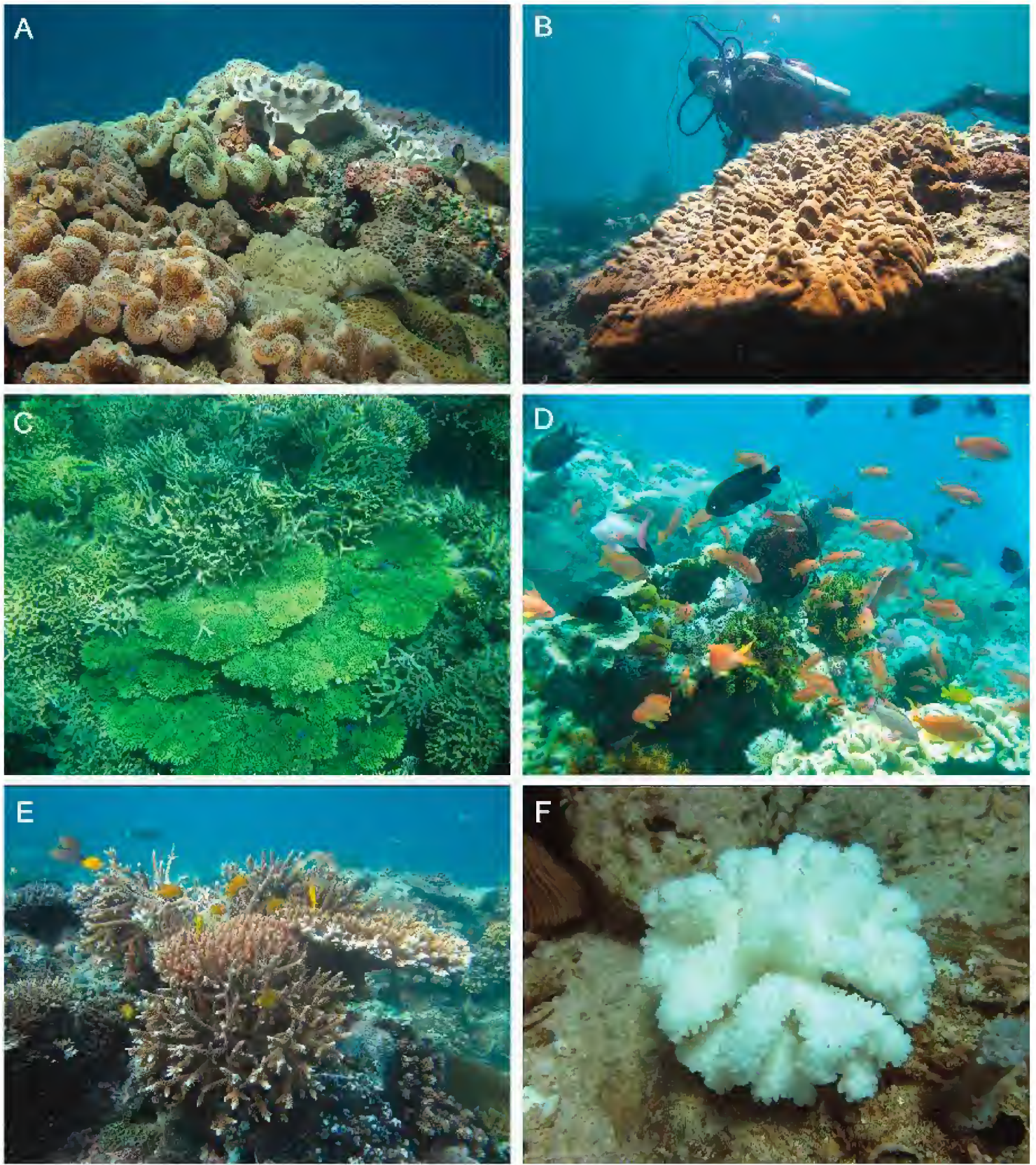

FIGURE 2. Shallow-water component. Underwater photographs of coral reefs. A. Reef area dominated by various species of soft corals. B. A large coral head of the scleractinian, Porites sp. C. Dense populations of Acropora spp. D. A shallow-water coral reef slope. E. Reef area dominated by hard corals, primarily Acropora spp. F. An example of coral bleaching in Pocillopora sp. Photos by G. C. Williams. 

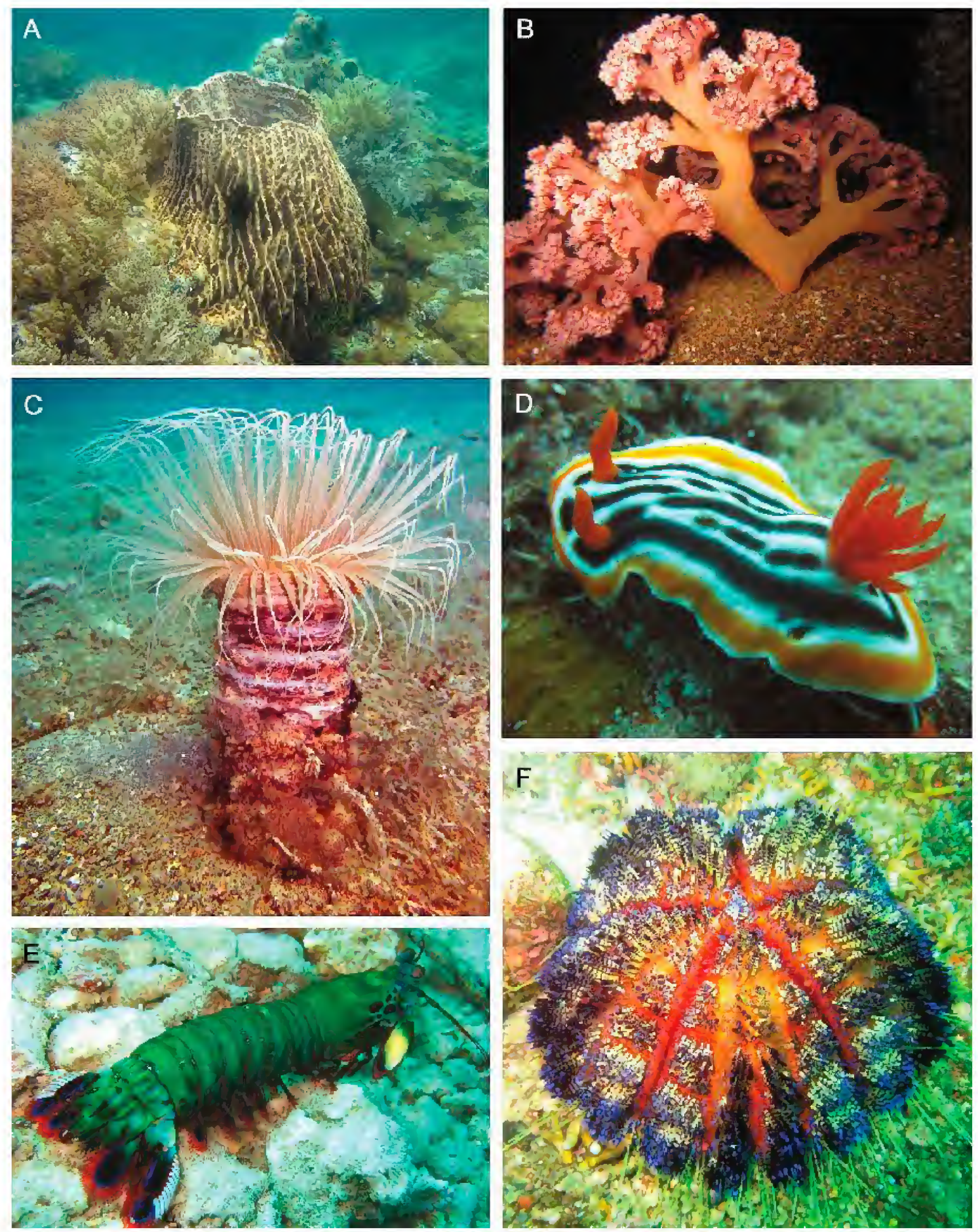

FIGURE 3. Shallow-water component. Underwater photographs of marine invertebrates. A. Barrel sponge, Xestospongia testudinaria. B. Soft coral, Umbellulifera sp. C. Cerianthid tube anemone. D. Dorid nudibranch, Chromodoris magnifica. E. Mantis shrimp, Odontodactylus scyllarus. F. Fire Urchin, Asthenosoma varium. Photos by G. C. Williams. 

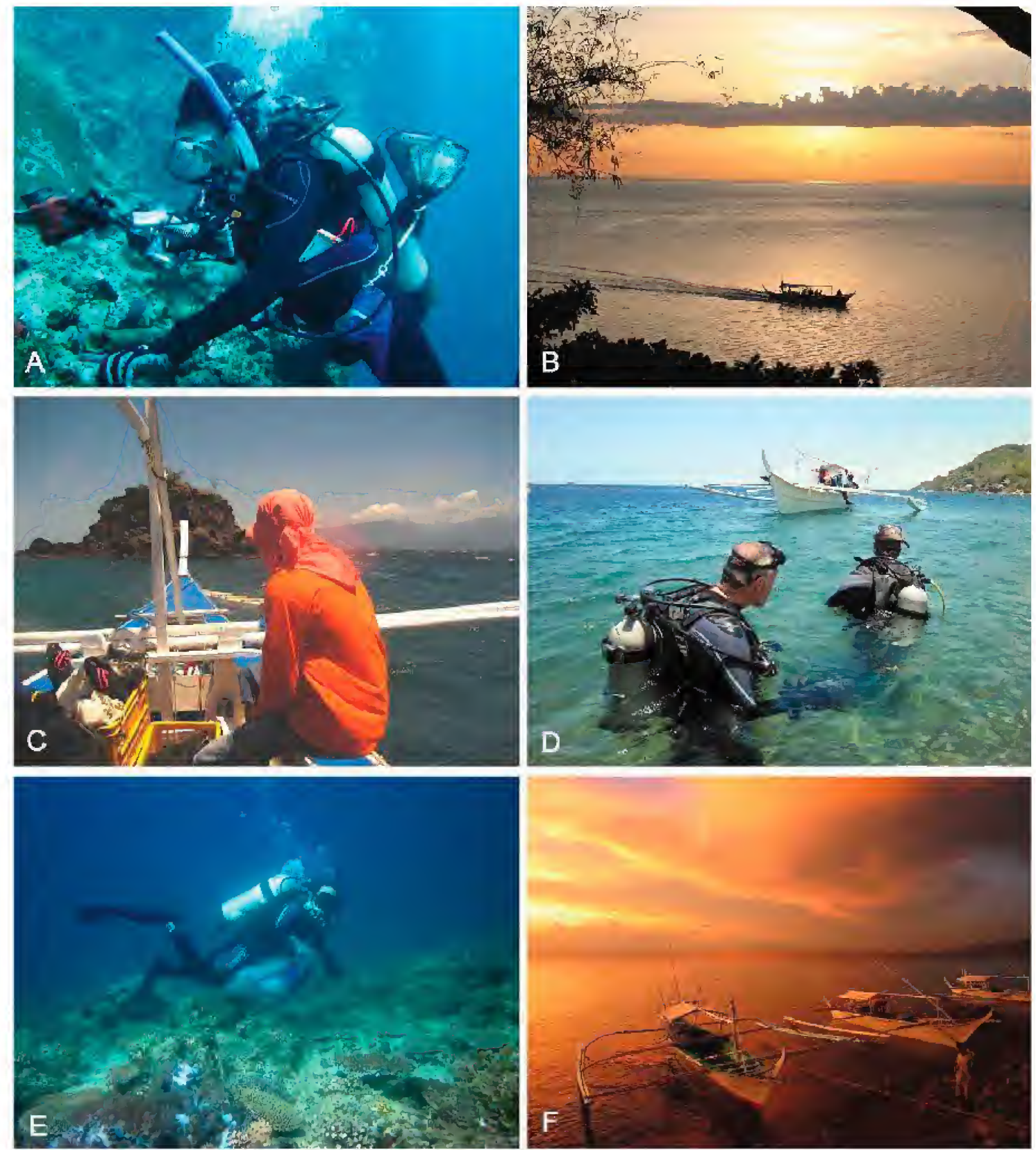

FIGURE 4. Shallow-water component, marine field research, Verde Island Passage. A. Kirby's dive site, Caban Island. B. A returning dive boat, Calumpan Peninsula. C. Dive boat approaching Devil's Point dive site, Maricaban Island. D. Divers and dive boat, Basketball dive site, Calumpan Peninsula. E. Diver on a scleractinian-dominated reef flat, Gemou Point, Maricaban Island. F. Dive boats at sunset, Calumpan Peninsula. Photos by G. C. Williams. 

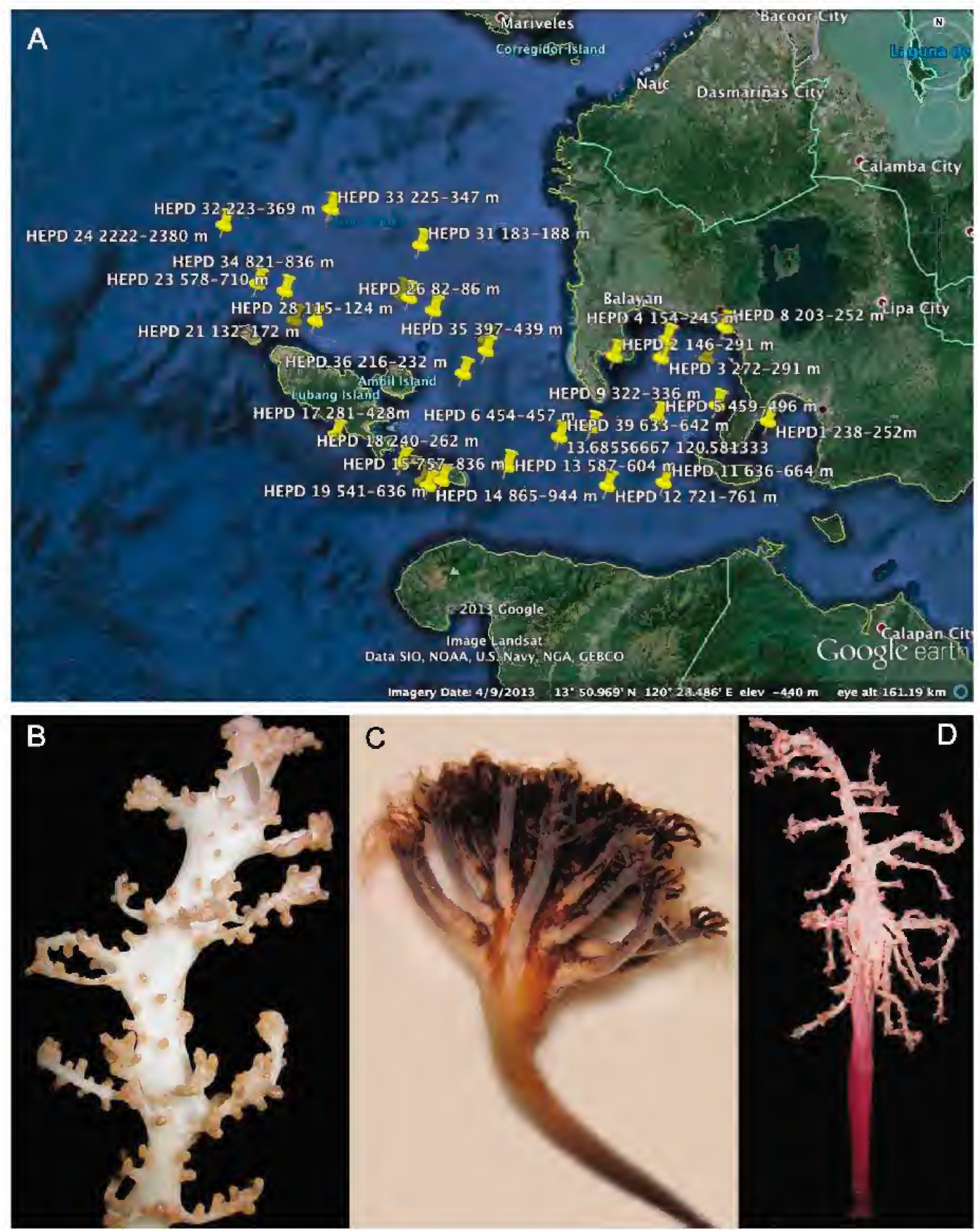

FIGURE 5. Deep-water component, Verde Island Passage and Lubang Islands. A. Map of the deep-sea collection stations by HEPD station number (Hearst Expedition Philippines Deep-sea) and depth; information for Google map by T. M. Gosliner. B. Scleraxonian gorgonian octocoral, Solenocaulon sp. (HEPD 26). C. Sea pen (pennatulacean), Umbellula sp. (HEPD 9). D. Soft coral, Chironephthya sp. (HEPD 26). Photos by G. C. Williams. 

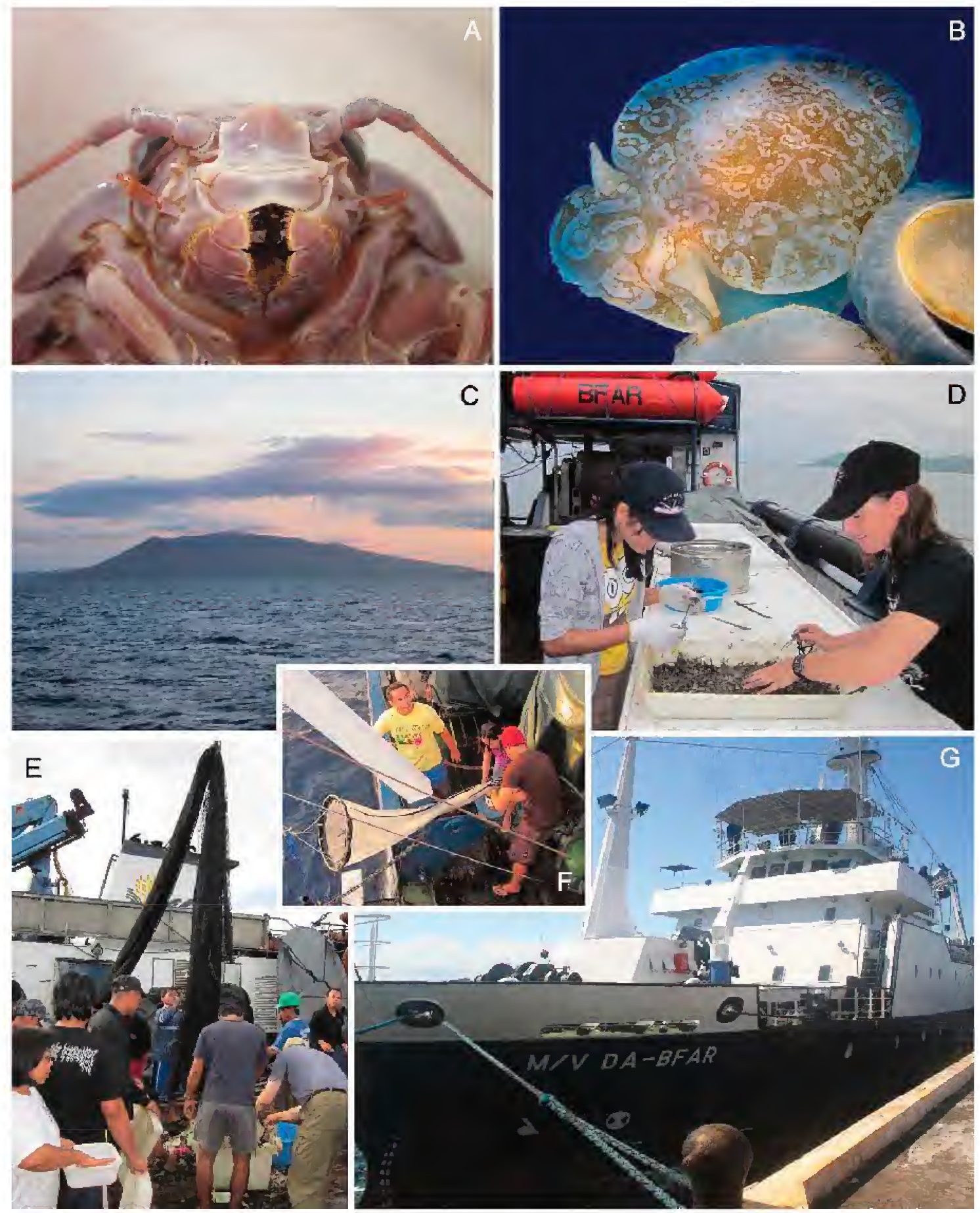

FiguRE 6. Deep-water component, Verde Island Passage and Lubang Islands. A. Giant isopod, Bathynomus kensleyi. B. Pleurobranchoidean opisthobranch, Pleurobranchella nicobarica. C. Ambil Island, Lubang Islands Group. D. Sorting trawl samples. E. Emptying the trawl net on the deck of M/V DA-BFAR. F. Collecting plankton samples. G. The research ship M/V DR-BFAR. Photos by G. C. Williams. 

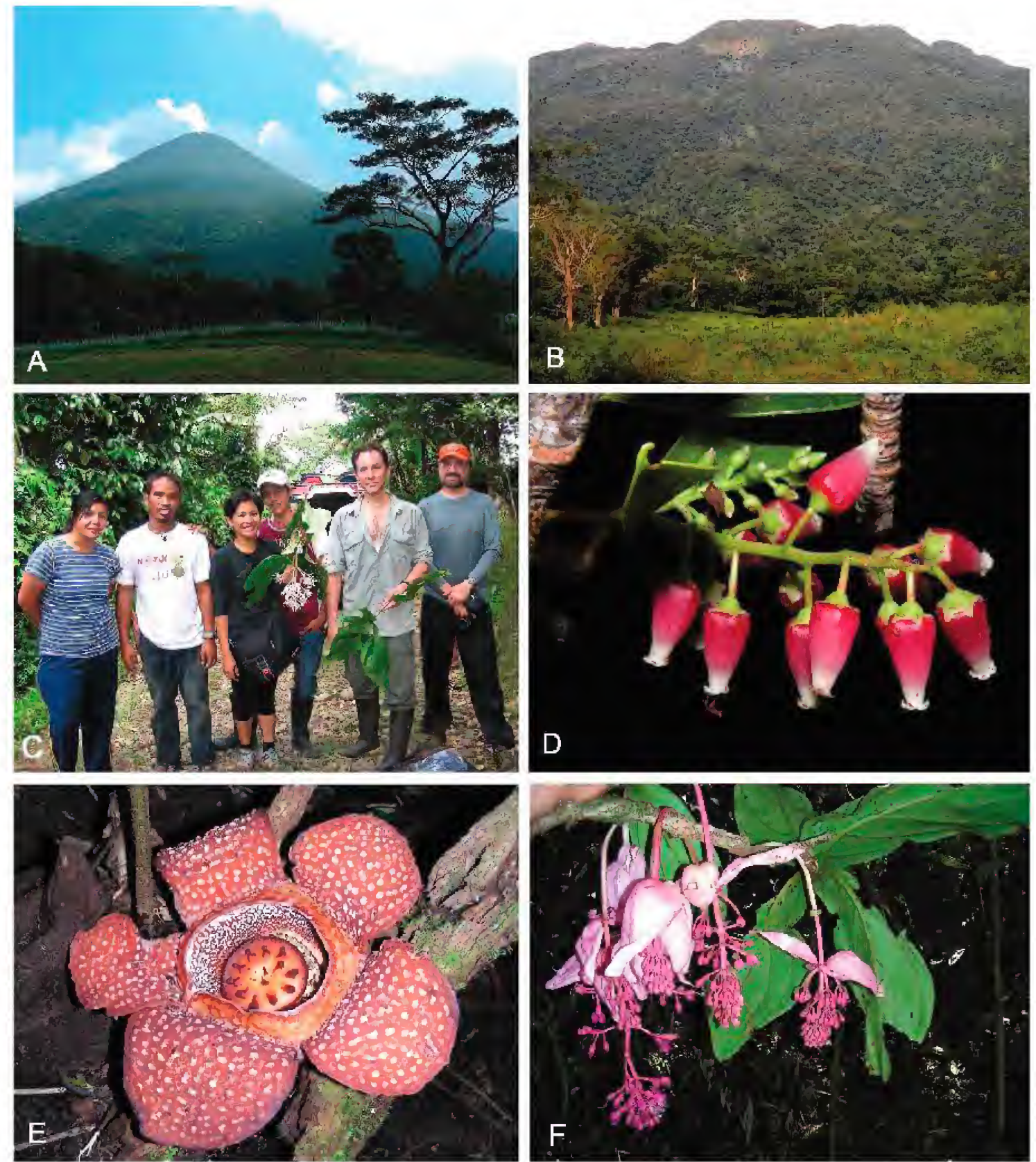

Figure 7. Terrestrial component - Botany. A. Mt. Banahaw de Lucban; photo by D. S. Penny. B. Primary forest, Mt. Isarog National Park; photo by P. W. Fritsch. C. Botanical research team on Mt. Isarog (left to right, Isarog National Park administration representative, Steve (field/lab assistant for Dr. Eduino Fernando), Jen Dimas-Edrial (project manager for Pusod - a non-profit organization whose mission is to protect and enhance the ecosystems of the Philippines), Jin (field assistant and tree-climber for Dr. Eduino Fernando); Darin S. Penneys, Peter W. Fritsch; photo by D. S. Penneys. D. Vaccinium sp, family Ericaceae; photo by P. W. Fritsch. E. Rafflesia maniliana, family Rafflesiaceae. F. Medinilla teysmanii, family Melastomataceae; photo by D. S. Penneys. 

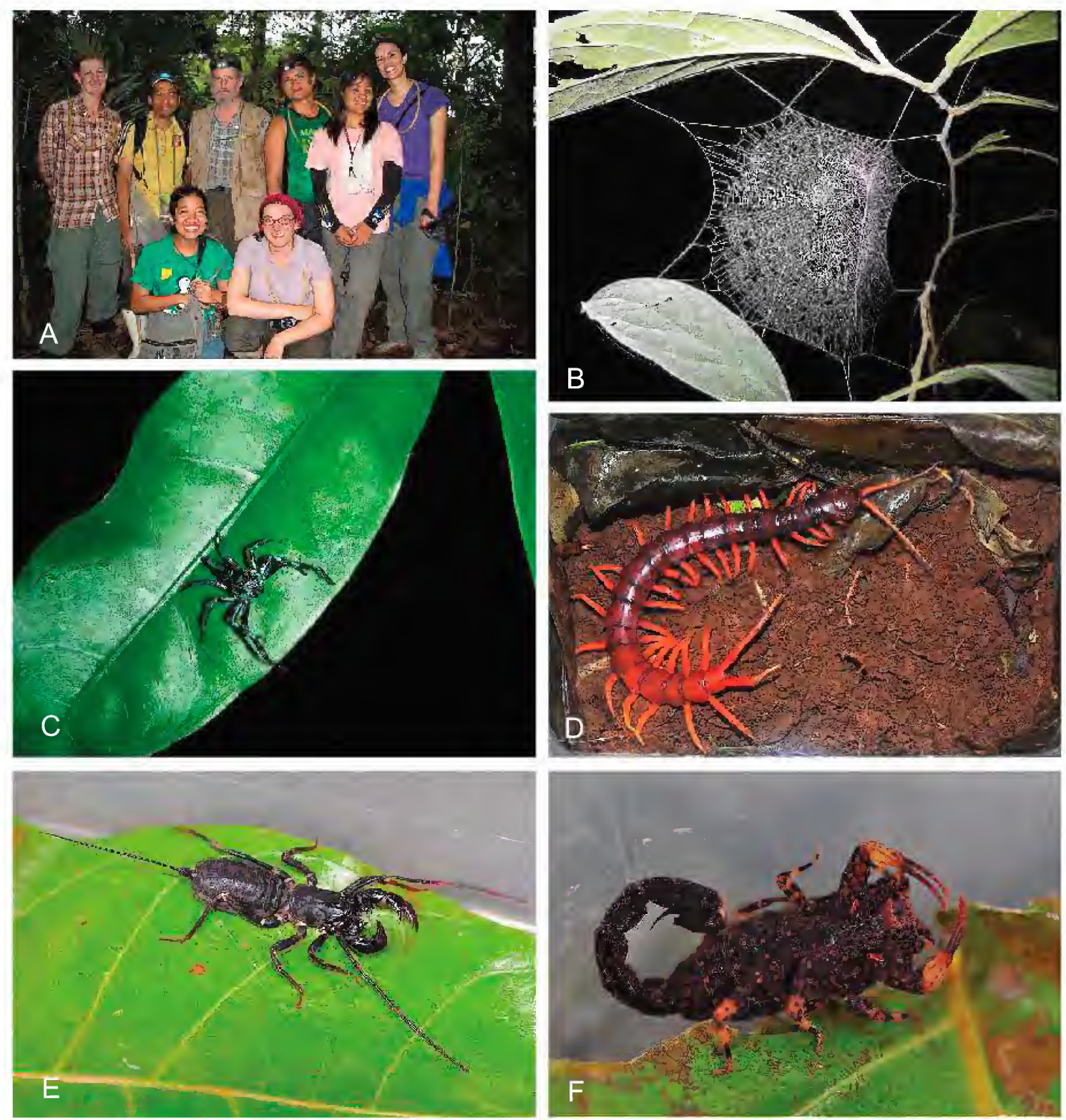

FIGURE 8. Terrestrial component - Entomology. A. Entomological research team (left to right: [standing] Hanna Wood, Orlando "Daddyboy" Eusebio, Charles Griswold, Mark Yngente, Sheryl "Sheng" Yap, and Vanessa Knutson; [kneeling] Veverle San Juan and Natalia Chousou Polydouri). B. Web of Nephila (Araneae, Nephilidae), UP Los Banos. C. Jumping spider (Araneae, Salticidae). D. Centipede (Chilopoda, Scolopendra), IP Los Banos. E. "Vinegaroon" (Arachnida, Thelephonida). F. Unidentified scorpion. Photos by members of the Hearst Expedition. 

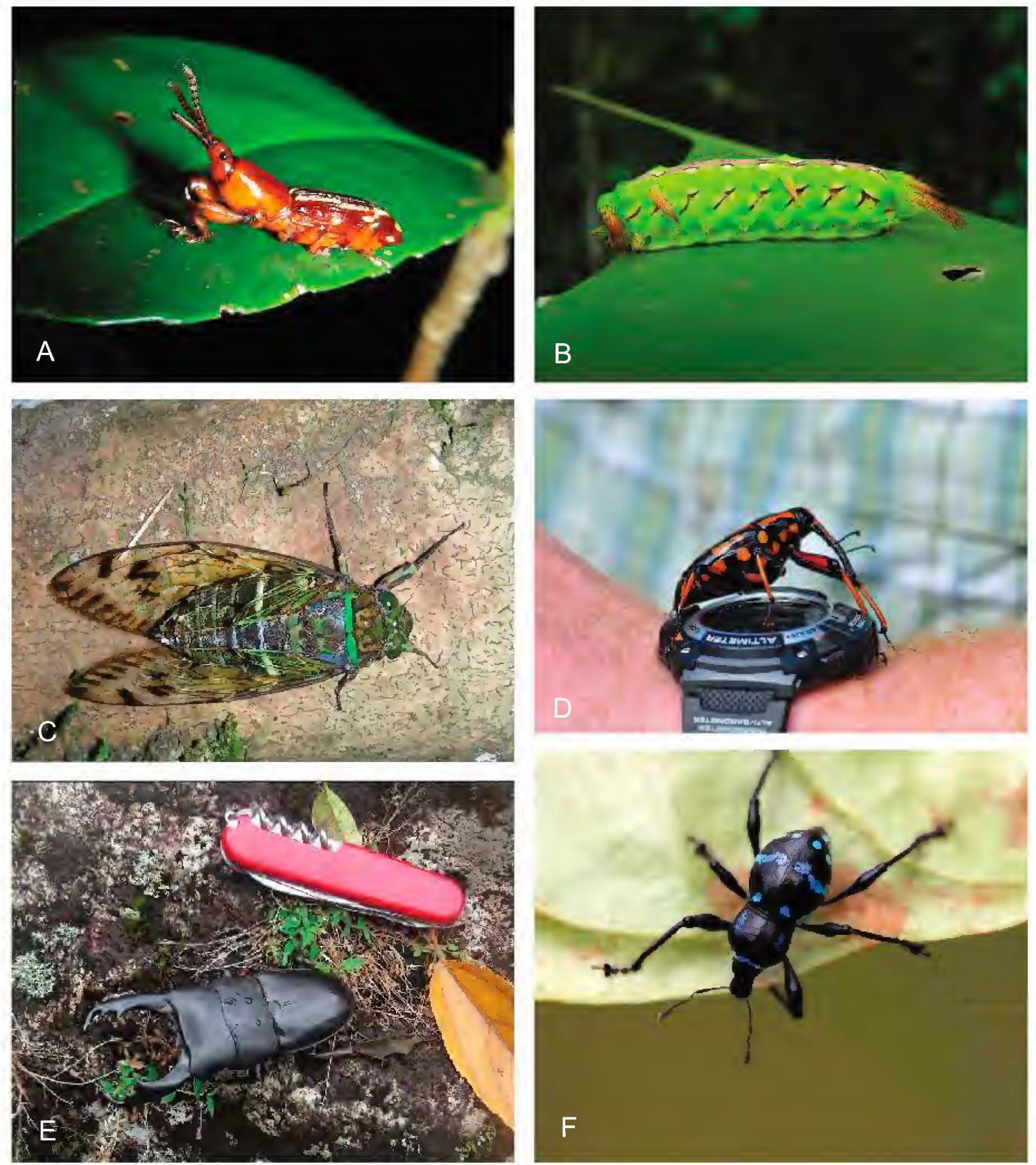

FIGURE 9. Terrestrial component - Entomology. A. Stick weevil (Coleoptera, Brentidae). B. Caterpillar (Lepidoptera, $c f$ Limacodidae). C. Cicada (Homoptera, Cicadidae). D. Weevil (Curculionidae, Coleoptera, Mt. Banahaw. E. Stag beetle (Lucanidae, Coleoptera). F. :Easter egg" weevil (Platyrhynchine, Curculionidae, Coleoptera), Mt. Banahaw. Photos by members of the Hearst Expedition. 

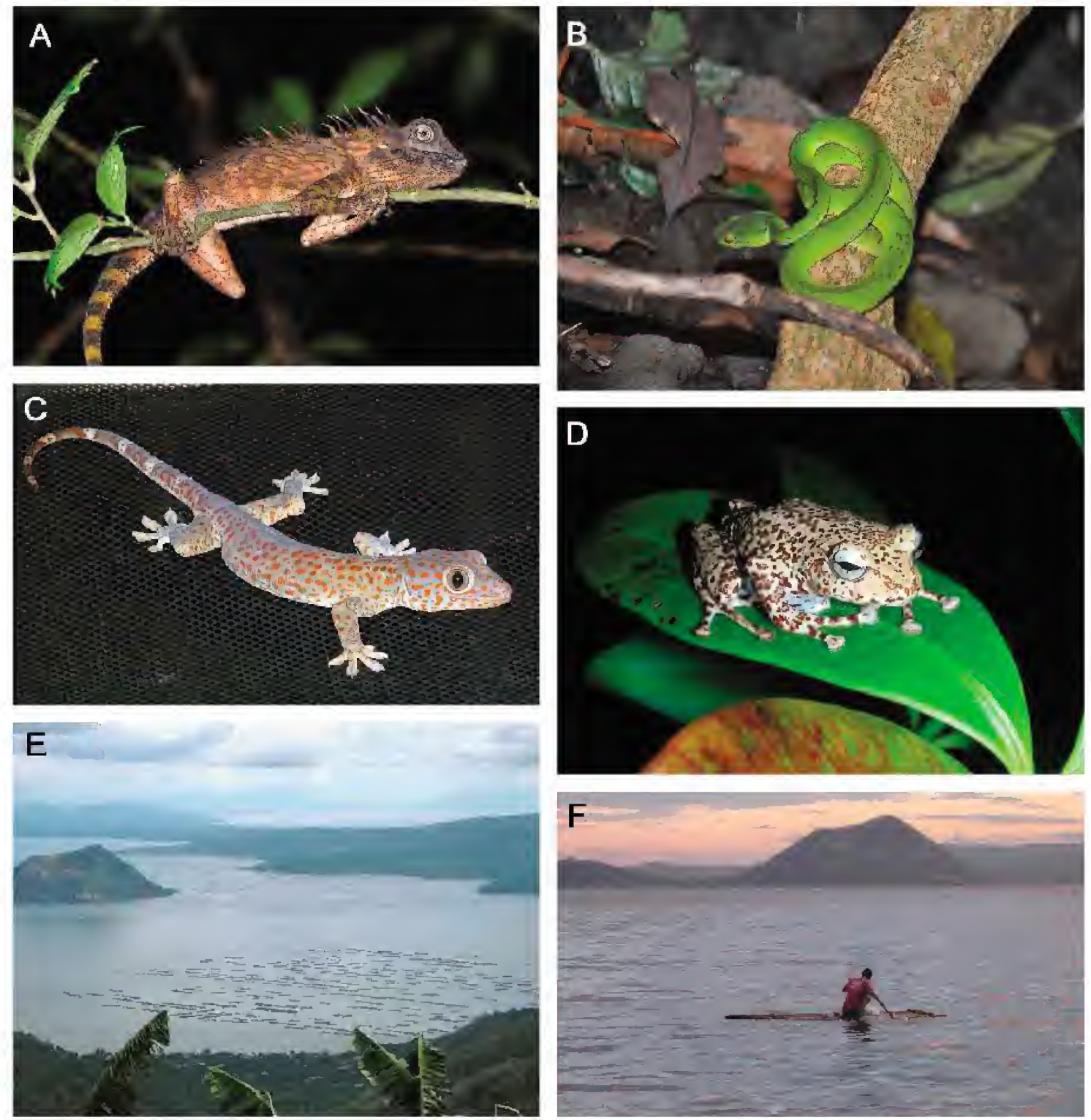

FIGURE 10. Terrestrial component - Herpetology; and Taal Lake. A. Agamid lizard, Gonocephalus sophiae. B. Pitviper snake, Trimeresurus (Parias) flavomaculatus. C. Gecko lizard, Gecko gecko. D. Tree frog, Platymantis isarogi. E-F. Taal Lake showing the central volcanic peak within the surrounding inundated caldera. Photos by members of the Hearst Expedition. 

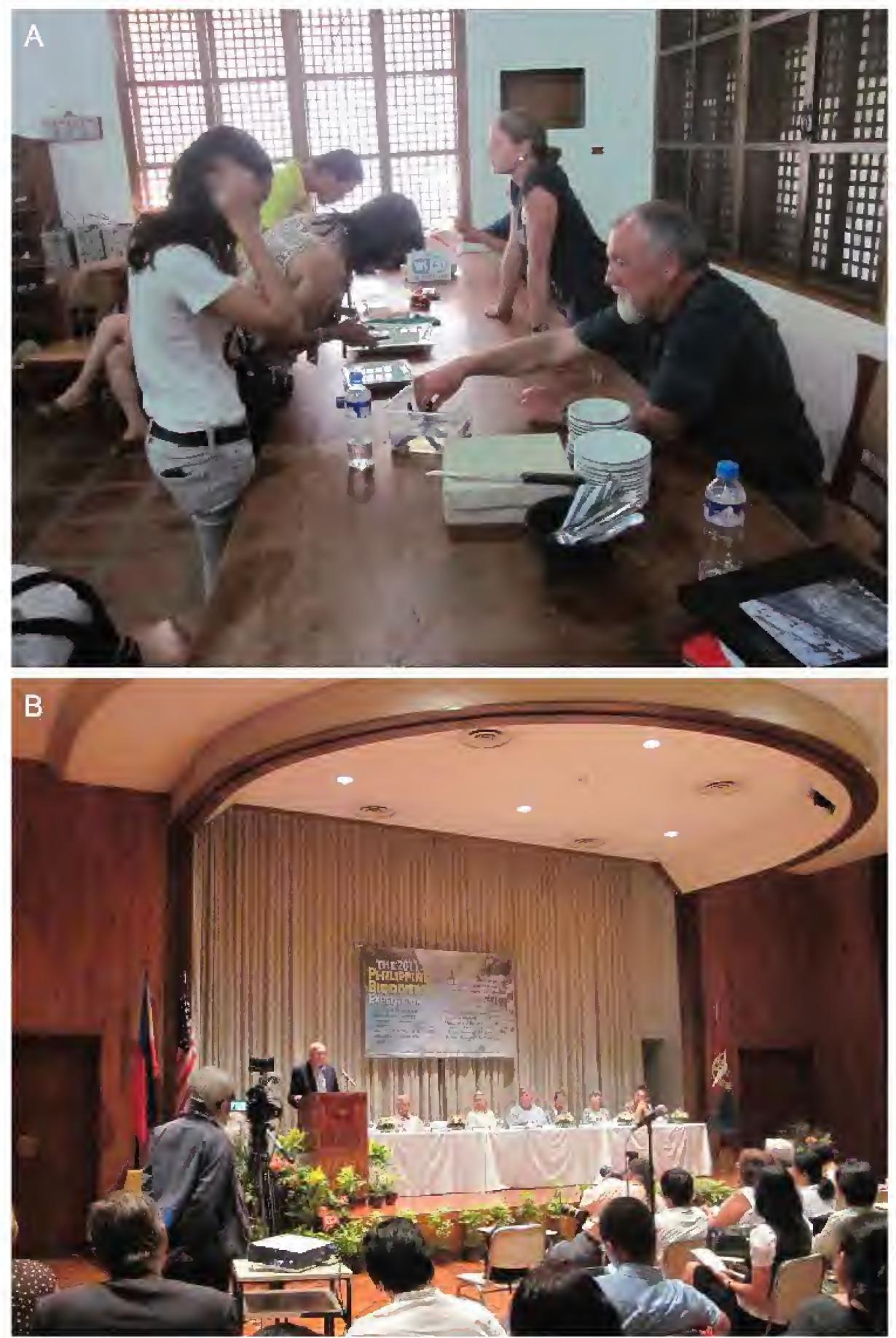

Figure 11. A. Educational outreach, Calatagan, 19 May 2011; Academy scientists with Philippine sea scouts and Conserve and Protect (CAP) - a local community oceans conservation foundation; photo by T. M. Gosliner. B. The 2011 Philippine Biodiversity Symposium, University of the Philippines, Manila, 8 June 2011.; photo by G. C. Williams. 


\title{
Illustrated Key to the Shallow-Water Gorgonians and Pennatulaceans of the Verde Island Passage, Northern Philippines, Including Synopses of the Taxa and a Glossary of Terms (Cnidaria: Anthozoa: Octocorallia)
}

\author{
Gary C. Williams and Jei-Ying Chen \\ Department of Invertebrate Zoology and Geology, California Academy of Sciences, \\ 55 Music Concourse Drive, San Francisco, California 94118 USA \\ Email: gwilliams@calacademy.org; cchen@calacademy.org
}

\begin{abstract}
A guide is here presented to twenty-six genera of gorgonian and pennatulacean octocorals that are commonly seen by divers on the coral reefs of the Verde Island Passage region of the northern Philippines, between southern Luzon and northern Mindoro. Ten of these are identified to species level. Each taxon is illustrated with color photographs either in situ or of preserved specimens, as well as with scanning electron micrographs or drawings of sclerites that are crucial for identification purposes. All material used in the study was collected during eighteen years of field work by Academy scientists, including the Hearst Biodiversity Expedition of 2011, and is housed in the marine invertebrate collections of the California Academy of Sciences. A glossary of technical terms used in the key is appended to the end of the main body of text.
\end{abstract}

Key words: Illustrated Key, Gorgonians, Pennatulaceans, Sea Fans, Sea Whips, Sea Pens, Shallow Water, Verde Island Passage, Philippines, Glossary of Terms

Between 1993 and 2012, field researchers from the California Academy of Sciences made extensive collections of octocorallian cnidarians (soft corals, gorgonians, and sea pens) that are frequently encountered from the shallow water (0-40 meters in depth) coral reefs and adjacent habitats of the Philippine archipelago.

This paper provides an illustrated identification key to common taxa of the gorgonian and pennatulacean faunas that are known to inhabit the coral reef region between southern Luzon and northern Mindoro - the area known as the Verde Island Passage, which comprises an oceanic link between The South China Sea on the east, the Sibuyan Sea in the central Philippines, and the Philippine Sea to the west. Such updated identification guides have proved valuable as guides to local or global faunal composition and biodiversity assessments, as shown by the examples of such guides to soft corals and sea fans (Fabricius and Alderslade 2001), sea pens (Williams 1995), and azooxanthellate hard corals (Cairns and Kitahara 2012).

Biogeographic Setting. - The Philippine archipelago comprises over 7100 islands (Dr. Cathy Lagunzad, Ateneo de Manila University and University of the Philippines, pers. comm.) and occupies the northern part of the Coral Triangle in the tropical western Pacific Ocean, between approximately 5 and 20 degrees north latitude (Fig. 1A).

The Coral Triangle is the region of the tropical western Pacific Ocean that has been recognized as having the world's highest shallow-water marine species diversity with regard to scleractinian corals (Hoeksema 2007; Veron et al. 2009), and similarly for fishes (Carpenter and Springer 2005; Gaither and Rocha 2013).

This region as here recognized includes eastern Indonesia, The Philippines, northern New Guinea, the Bismarck Archipelago, and the Solomon Islands (Fig. 2A). 


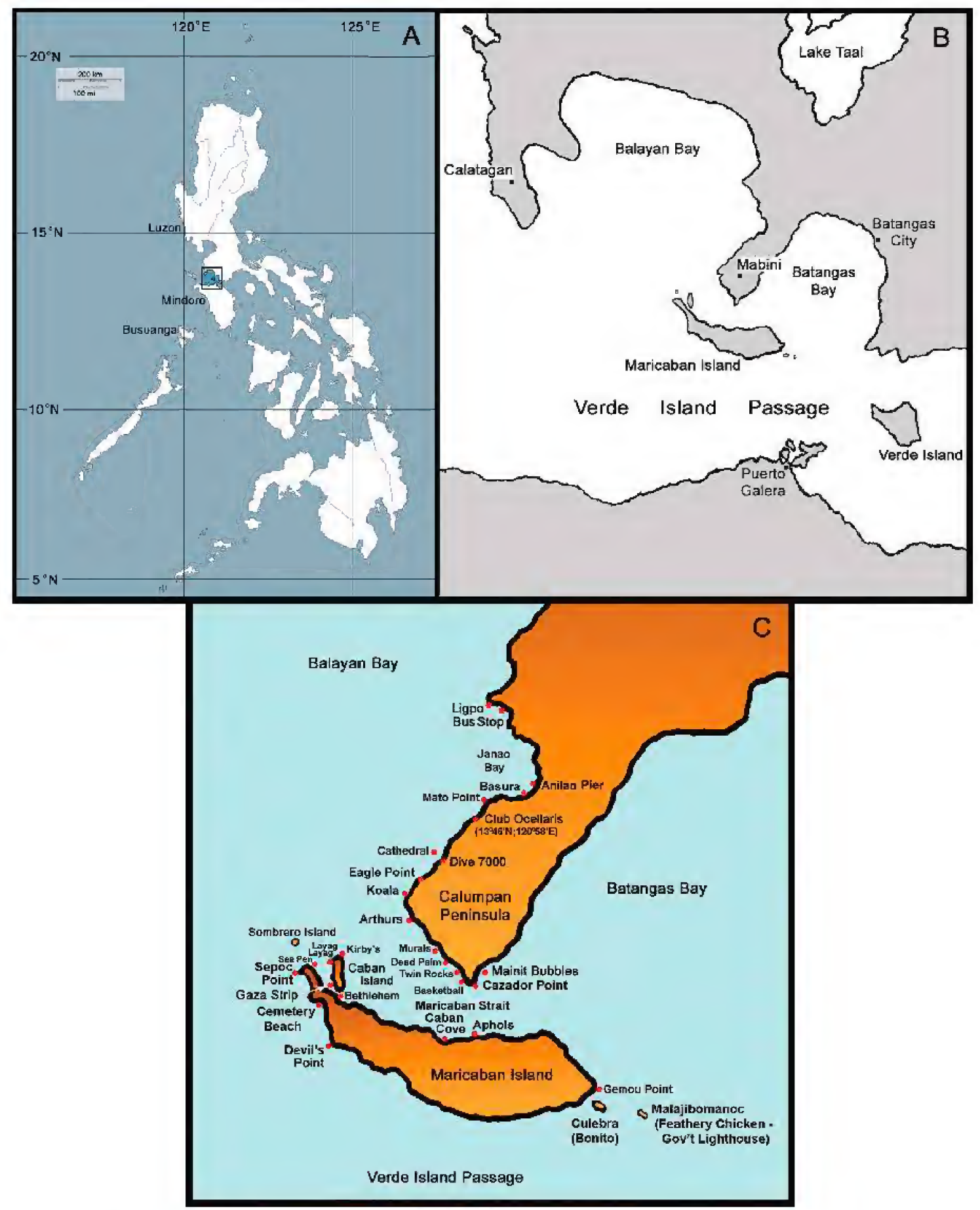

Figure 1. Maps of the Philippines. A. The Philippine Archipelago. B. The study area in the Verde Island Passage. C. Dive sites in the regions of the Calumpan Peninsula and Maricaban Island. 


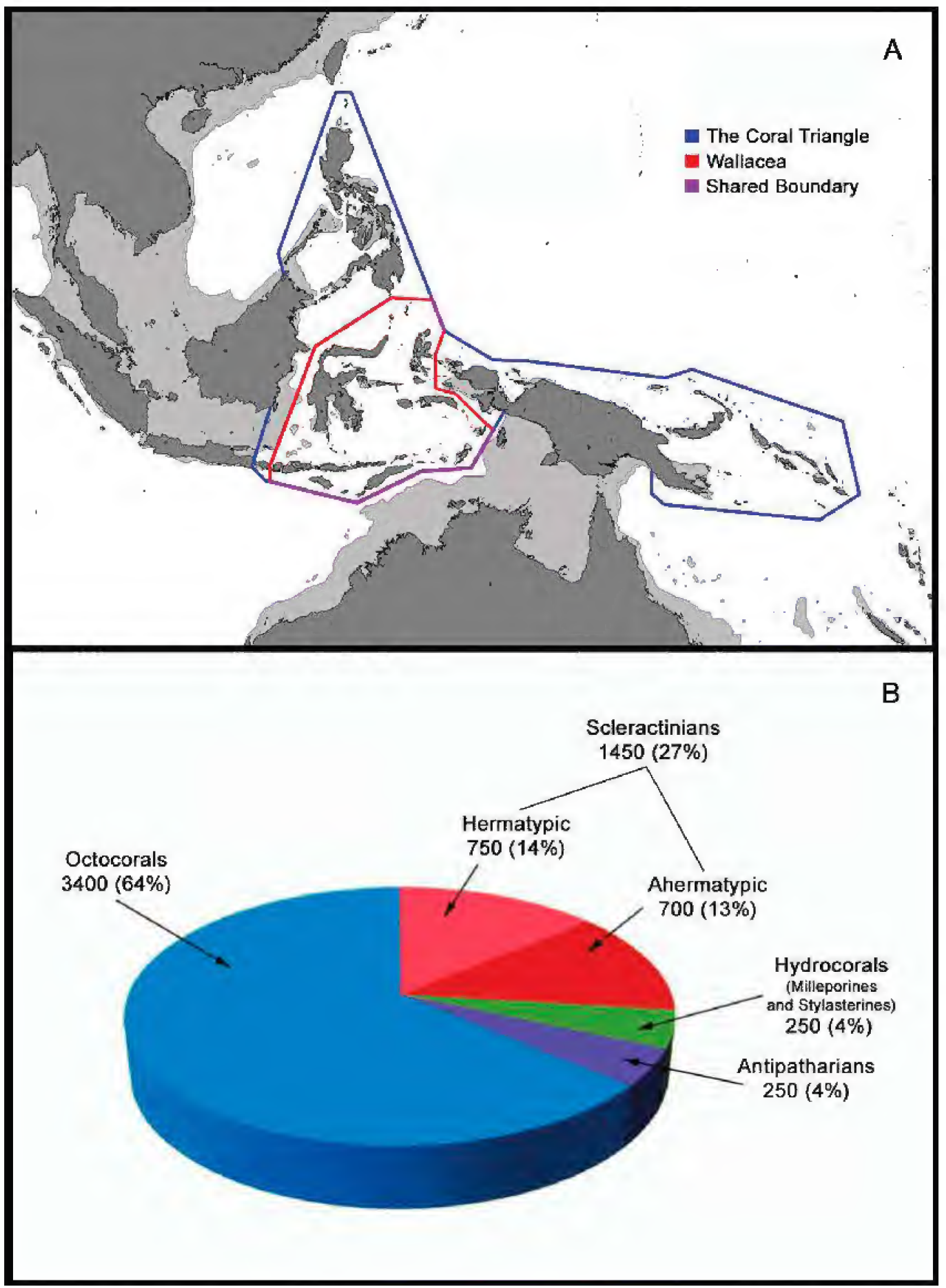

FIGURE 2. A. Map of the tropical western Pacific showing delineation of Wallacea and the Coral Triangle. Boundaries adapted from Conservation International (2010), Hoeksema (2007), and Veron et al. (2009). B. Pie chart showing comparative species diversity of extant corals, estimated 5350 total species of corals worldwide. Adapted from Williams and Cairns, 2013 
During his travels in the Malay Archipelago and based largely on his careful observations of bird and mammal distributions, Alfred Russel Wallace (1860) first postulated a biogeographic line defining a faunal discontinuity that "abruptly separates two of the great Zoological regions of the globe." Subsequently, Wallace (1880) perceptively deduced that varying degrees of isolation resulted from profound geological changes in the past. Subsequent biogeographers showed that the nature of ocean depths in the region and former deviations from the present sea levels, were responsible for Wallace's striking demarcation (Quammen 1996). The line which separates Bali from adjacent Lombok in Indonesia, and Sulawesi (The Celebes) from Borneo to its west, was later called "Wallace's Line" by Thomas Henry Huxley (Raby 2001). In the same paragraph Huxley (1868:313) not only names the line after Wallace, but also modifies Wallace's boundary to include the Philippines, "...the boundary in question would coincide with what may be called "Wallace's line,' between the Indian and the Papuan divisions of the Malay archipelago. But it would run northward as far as the Philippines, and passing between them and Formosa, would trend southward and eastward to the Samoan archipelago" Huxley (1868:294) provides a map to illustrate his alteration.

Our modern concept of the biogeographic region known as "Wallacea" (Conservation International 2010; Beccaloni 2012) does not recognize Huxley's modification, but rather agrees with Wallace's original boundary delineation. Wallacea encompasses a group of islands in "the heart of Indonesia" that are separated by areas of deep water from the Asian and Australian continental shelves (Beccaloni 2012). These islands were thus never connected to either of these continental regions, and are entirely included within the boundary of the coral triangle (Fig. 2A). In 1860, Wallace viewed the zoogeography of the Philippines as somewhat problematic since the archipelago at the same time resembled and differed from either the Asian or Australian regions, but nevertheless, he aligned them as a whole with the Asian region. By 1880, significant additions to the Philippine's fauna had been recorded by various researchers.

Wallace (1880) then reasoned that the peculiarities of isolation of the islands can be explained by the deep seas surrounding the archipelago, but that the archipelago was connected with Borneo by shallow arms of the Asian continental shelf, referred to by him as two narrow submarine banks. These represent southwestern extensions of Palawan and the Zamboanga Peninsula of Mindanao. He further deduced that as a consequence, the Philippines were once part of what he called "the great Malayan extension of Asia." He maintained that the Philippines have experienced prolonged isolation in the past and were later fragmented by extensive volcanic activity, which produced his observed faunal peculiarities. Although his observations and conclusions were for the most part based on terrestrial vertebrate distributions, our contemporary tectonic knowledge of ocean floor bathymetry and topography largely verifies his writings of the latter half of the nineteenth century.

CORAL BIODIVERSITY.- An additional consideration to be noted when studying aspects of the world's coral faunas, is the widely varying perception of comparative coral diversity. Contrary to a popular belief assumed by many individuals that all corals are inhabitants and builders of coral reefs, it is currently estimated that hermatypic corals (reef-building corals) represent only about $15 \%$ of total coral species diversity, as the majority of corals are non-hermatypic (Fig. 2B). This small percentage is comprised of approximately $14 \%$ by hard corals (scleractinians) and perhaps $1 \%$ by others including several species of the hydrocoral genus Millepora, and two monotypic octocoral genera - Heliopora and Tubipora (Williams and Cairns 2013).

OCTOCORAL BiologY.- Gorgonians and pennatulaceans are octocorals that have a central axis in the interior of the colony - composed of consolidated sclerites, or hard proteinaceous and/or calcareous material. In addition, unconsolidated skeletal components composed of calcium carbonate in the form of numerous minute sclerites are present in the thin tissues surrounding the 
axis (Williams 1992). Sclerites are highly diverse in shape, size, and ornamentation. The comparative microscopic examination of sclerites is necessary for the identification of octocoral taxa.

Zooxanthellae are single-celled dinoflagellates (Symbiodinium microadriaticum plus an undetermined number of similar species) that act as the photosynthetic endosymbionts in numerous organisms from various invertebrate groups including corals, sea anemones, sponges, flatworms, mollusks, foraminiferans, and ciliates.

Gorgonians are divided into three groups based on axial structure and composition: scleraxonians (in which the axial structure, the medulla, is composed of sclerites), holaxonians (internal axis composed of scleroproteinacous concentric layers around a hollow core), and calcaxonians (with a solid, largely calcareous axis) (Grasshoff 1999). Pennatulaceans, on the other hand, are a specialized and morphologically distinct group of octocorals with a muscular peduncle for anchoring in unconsolidated benthic substrata (Williams 2011).

Notes ON The Current Status of Knowledge. - Bayer (1981:7-9) reviewed the status of knowledge of octocorals in major geographic regions of the world. He proposed four levels of taxonomic knowledge: essentially complete, moderately well-known, poorly known, and minimally known. He assigned the Philippines to the third category, poorly known, "where the literature is sparse and incomplete. Here the major part of the fauna remains to be described and a large number of species will inevitably be new to science. The major faunal relationships can be deduced, but distributional patterns are not clearly understood."

Bayer's assessment is still considered a valid evaluation of the regional situation at present (more than thirty years later). The abbreviation "cf." used between the words of some binomens stands for the Latin word conferre (to compare or compare with). It is used for provisional or tentative identifications at the species level, as opposed to definitive or conclusive ones.

Throughout the text of this paper, an unidentified species of a particular genus is denoted by "sp." whereas "spp." refers to more than one species of the genus. Species level identifications in Indo-Pacific octocorals remains largely problematic for several reasons. Many genera require thorough taxonomic revisions before an identification can be made with confidence, a particular species can be considered valid, or the number of valid species can be accurately ascertained. In many genera, a large number of species have been described, some of which may have been described in other genera or are conspecific with other named species, while others have been described in the wrong genus. Confusion in a good deal of the relevant literature persists. Many taxa have been described or illustrated insufficiently or inadequately for positive identification purposes. Also, the type specimens that represent a particular taxon may be unknown or not designated, unobtainable, damaged, lost, or otherwise not suitable for comparative purposes.

The relatively few taxonomic papers treating Philippine octocorals include Light (1913, 1914, 1915a, 1915b, 1915c, 1921), Mai-Bao-Thu and Domantay (1970, 1971), Roxas (1932, 1933a, 1933b), Stiasny (1940, 1941), and Williams and Alderslade (1999).

\section{Materials And Methods}

All material used in this study was collected via SCUBA during field operations between 1994 and 2012. The Philippine Archipelago and the Verde Island Passage region are shown in Figs. 1A and 1B. Collecting stations (SCUBA diving sites) of material used in this study from the region of the Calumpan Peninsula and Maricaban Island are shown in Fig. 1C. All material is catalogued and housed in the marine invertebrate collections of the California Academy of Sciences, San Francisco.

Octocoral sclerites were isolated and prepared following standard protocols (Williams and Mattison, 2013). SEM images of sclerites were taken on a LEO 1450VP scanning electron micro- 
scope with Everhart-Thornley detector (SE1) under $10 \mathrm{kV}$ accelerating voltage and $30 \mu \mathrm{m}$ aperture size at Optibeam mode. All specimens were sputter-coated with gold/palladium using a Denton Vacuum Desk II sputter coater prior to imaging.

Other abbreviations used in the text are: CASIZ (California Academy of Sciences, Invertebrate Zoology), and WoRMS (World Register of Marine Species). Photographs are by the first author (GCW) unless otherwise indicated. Scanning electron micrographs are by the second author $(\mathrm{J}-\mathrm{YC})$.

\section{Key to the shallow-water genera of Gorgonians and Pennatulaceans of the Verde Island Passage}

(An asterisk indicates genera that contain some or all zooxanthellate species)

1a. Unbranched octocorals composed of a sterile stalk and a polyp-bearing rachis, imbedded in unconsolidated sediment by a muscular peduncle. Calcified central axis of variable length or absent with varying amounts of proteinaceous material. Sclerites are smooth three-flanged

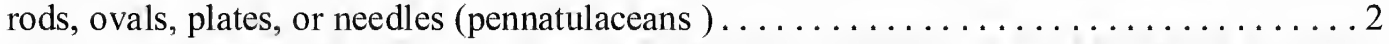

1b. Mostly branching octocorals, sometimes whiplike, encrusting, or lobate, attached to hard substrata by basal holdfast. Axial material highly variable, composed of a purple medullar zone, consolidated sclerites, hard protein, or predominantly calcareous material. Sclerites are mostly conspicuously tubercated, highly variable in shape (gorgonians) $\ldots \ldots \ldots \ldots \ldots 6$

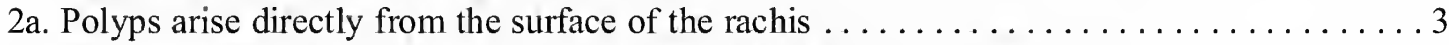

2b. Polyps arise from polyp leaves that emanate laterally from the rachis $\ldots \ldots \ldots \ldots \ldots \ldots 4$

3a. Sclerites are smooth spindles, rods, or ovals, sometimes with bilobed ends . . . . . . . . .

*Cavernulina, Figs. 36A, 40A

3b. Sclerites are truncated plates either with smooth, uneven, or denticulated ends . . . . . . . .

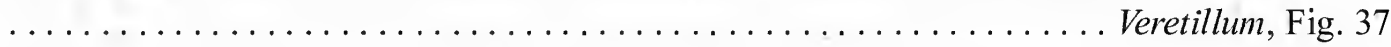

4a. Polyps united basally to form thin polyp leaves, peduncle slender $\ldots \ldots \ldots \ldots \ldots \ldots \ldots$

4b. Polyps are contained on large thick polyp leaves, peduncle thick ... Pteroeides, Figs. 39, 40C

5a. Sclerites absent in rachis and polyp leaves .............. *Virgularia, Fig. 38

5b. Sclerites present in rachis and polyp leaves ............. Scytalium, Figs. 36B, 40B

6a. Colony form highly variable - membranous and encrusting, knobby to tall lobate, or form masses of tangled hollow branches. Axis not highly developed - composed of two layers, an outer cortex and inner medulla. Medullar sclerites often deep magenta in color . . . . . . . . .

*Briareum, Figs. 3, 4

6b. Colony form arborescent, upright and branching, rarely filiform. Axial material composed of consolidated sclerites, hard proteinaceous and/or calcareous material $\ldots \ldots \ldots \ldots \ldots \ldots 7$

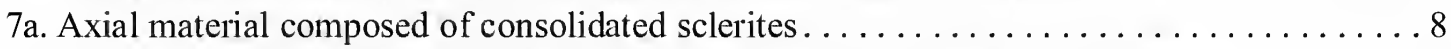

7b. Axial material composed of hard proteinaceous and/or calcareous material . . . . . . 12

8a. Axis segmented, composed of alternating swollen, rounded nodes and straight, elongate internodes. Branching occurs at the nodes. Axial sclerites smooth . . . . . . . . . . . 9

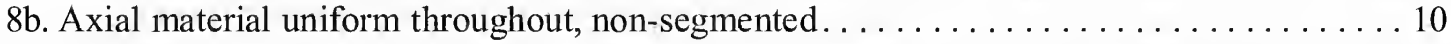

9a. Sclerites include capstans often modified as birotulates (double discs) and club-like forms ..

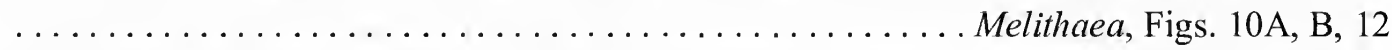

9b. Sclerites are mostly spindles, often modified or curved.......... Acabaria, Figs. 10C, 11

10a. Most branches are hollow, tubular, or openly channeled (interior open to the outside) ....

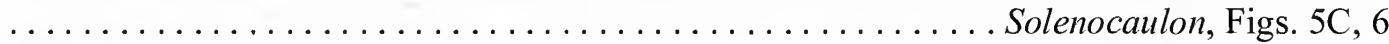

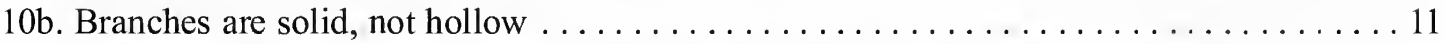

11a. Branching is densely reticulated (netlike), forming closed cells . . . . Annella, Figs. 7, 8 
11b. Branching is open, dichotomous to lateral .......... Subergorgia, Figs. 5A, B, 9

12a. Polyps non-retractile, forming hemispherical to cylindrical projections when contracted. Sclerites mostly spindles, often curved, bent, or hockeystick-shaped, arranged en chevron along

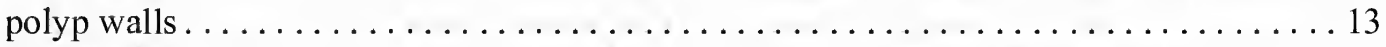

12b. Polyps fully retractile into permanent calyces or form small mounds or short lobes, or retract flush with branch surfaces. Polyp wall sclerites not arranged en chevron . . . . . . . . . 14

13a. Polyps tall cylindrical, perpendicular to branches. Sclerites always colorless . . . . . . . . .

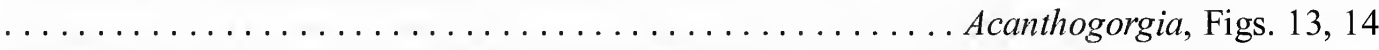

13b. Polyps low, rounded, hemi-spherical to moundlike. Sclerites often colored . Muricella, Figs. 13, 15

14a. Calyx and surface sclerites are rooted leaves (also called leaf-scales) with broad terminal

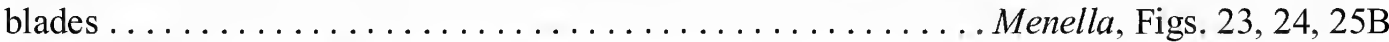

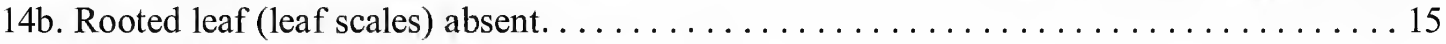

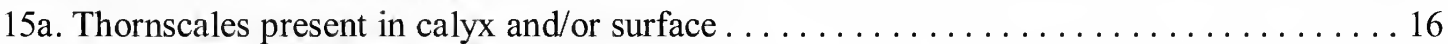

15b. Thornscales absent altogether. . . . . . . . . . . . . . . . . . . . . . . . 19

16a. Thornscales with rootlike or finely tubercated bases $\ldots \ldots \ldots \ldots \ldots \ldots \ldots \ldots \ldots$

16b. Thornscales with deltoid, wing-like extensions on the bases, which are smooth or sparsely

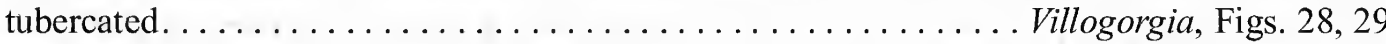

17a. Thornscales with a single long, central spine emanating from a broad rootlike base ......

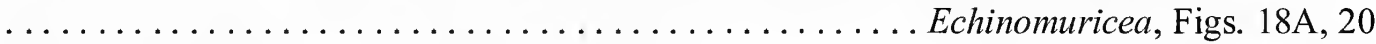

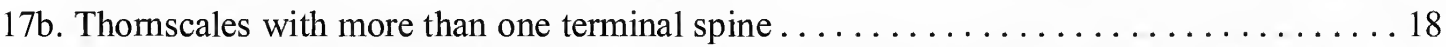

18a. Thornscales somewhat thick with broad terminal spines, present in both calyx and colonial

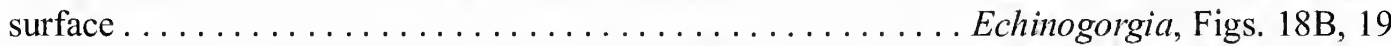

18b. Thornscales are variable in shape, surface sclerites include somewhat robust globular forms that are differentiated between finely tuberculated basal portions, and cobblestone-like or variously thorny upper portions................ Paraplexaura, Figs. 25A, 26, 27

19a. Surface sclerites include conspicuous tuberculate spheroids, often ovoid to subspherical in

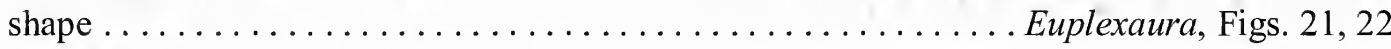

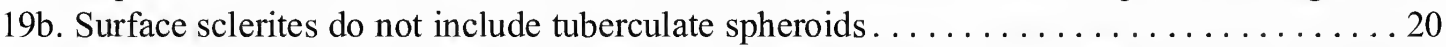

20a. Sclerites are spindles, many long and narrow with pointed ends . . Astrogorgia, Figs. 16, 17

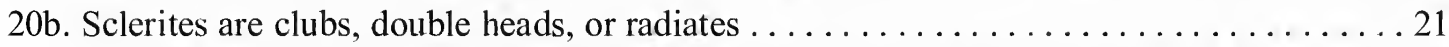

21a. Colonial growth form usually abundantly branched. Contracted polyps retract flush with branch surfaces or less often appear as bumps or low mounds. Surface sclerites are clubs, subsurface sclerites are capstans and/or partly tubercated spindles. Sclerites always colorless.

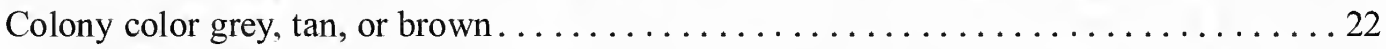

21b. Colonial growth form variable - copiously branched to sparsely branched or filiform and whiplike. Contracted polyps form mounds or short lobe-like projections. Surface sclerites are double heads or clubs, subsurface sclerites are capstans or waisted spindles. Sclerites often colored. Colony color red, orange, yellow, pink, or white................. 23

22a. Axis dark brown to black, composed mostly of concentric layers of proteinaceous material (gorgonin), with a narrow hollow core............. Rumphella, Figs. 30A, 31A

22b. Axis segmented; elongated, white calcareous internodes with ring-like, dark, proteinaceous nodes; solid, without hollow core ................ Isis, Figs. 30B, C, 31B

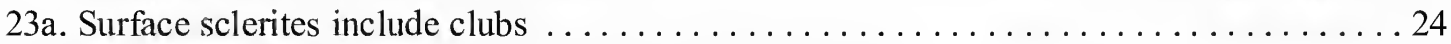

23b. Surface sclerites are double heads and waisted spindles $\ldots \ldots \ldots \ldots \ldots \ldots \ldots \ldots \ldots \ldots \ldots$

24a. Unbranched and whiplike.................. Junceella, Figs. 34, 35C

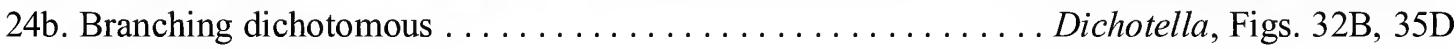


25a. Unbranched and whiplike, rarely with two or three terminal branches

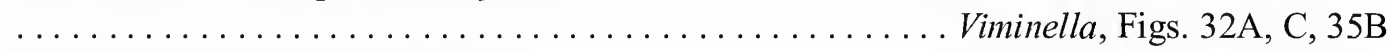

25b. Sparsely to abundantly branched Ellisella, Figs. 33, 35A

\title{
Synopses of the Genera of Pennatulaceans and Gorgonians FROM THE VERDE IsLAND PASSAGE
}

\author{
Alcyonacea Lamouroux, 1816 \\ (Gorgonians) \\ Family Briareidae Gray, 1859 \\ Genus Briareum Blainville, 1834
}

\section{Briareum spp.}

Figures 3-4

Material Examined.- CASIZ 180158, Philippines, Luzon, Batangas Province, Maricaban Island, Devil's Point; < 15 m depth, 23 April 2008, coll. G. C. Williams, one specimen wet-preserved 75\% ethanol; CASIZ 180159, Philippines, Luzon, Batangas Province, Maricaban Island, Aphol's Rock, 18.3 m depth, 23 Apr 2008, coll. G C. Williams, 6 colonies wet-preserved 75\% ethanol; CASIZ 104004, Philippines, Luzon, Batangas Province, Maricaban Island, Culebra (Bonito), 27 February 1995, coll. G. C. Williams, one wet-preserved specimen $75 \%$ ethanol.

RemaRKs. - Often seen as large mat-like, encrusting masses covering dead coral heads, sometimes knoblike or with finger-like projections (Fig. 3A). The tentacles are usually green to gray in color, narrow and elongate, with significantly-reduced pinnules that are mostly unseen underwater, making the tentacles appear smooth, not pinnate (Fig. 3B).

The basal layer of encrusting colonies is usually a distinct deep purple or magenta in color. Some of the more robust, spindle-like sclerites have more-or-less parallel, transverse rings of conspicuous tubercles (Fig. 4). The outer surface of colonies with retracted polyps may be tan, grey, pink-brown, or most commonly red-purple. In the Indo-West Pacific, Briareum is fed upon by the aeolid nudibranch Phyllodesmium briareum.

SPECIES.- Eight species are recognized (Appeltans et al. 2013).

The name Pachyclavularia is junior synonym of Briareum and was previously used in some literature sources for mostly red-purple species of the genus.

Distribution.- - Indo-Pacific (East Africa, Red Sea, Northwestern Australia, Great Barrier Reef, New Guinea, Solomon Islands, Indonesia, Malaysia, Philippines, Taiwan, Palau, Palmyra Atoll); Tropical Western Atlantic (Florida, Caribbean Sea).

References. - Fabricius et al. (2007:90); Fabricius and Alderslade (2001); Gosliner, Behrens, and Williams (1996:50); Grasshoff and Bargibant (2001:110-113).

\section{Family Anthothelidae Broch, 1916}

\section{Genus Solenocaulon Gray, 1862}

\section{Solenocaulon cf. rubra (Kölliker, 1870)}

Figures 5C, 6

Material Examined.- CASIZ 95361; Philippines, Luzon, Batangas Province, Maricaban Island, Sepok Point; <26 m depth; 14 March 1994; coll. G C. Williams; one specimen wet pre- 
served 75\% ethanol; CASIZ 103904, Philippines, Luzon, Batangas Province, Maricaban Island, Devil's Point, 36.6 m depth, 24 Feb 1995, coll. G. C. Williams, 1 whole colony wet-preserved $75 \%$ ethanol.

REMARKS. - In this species that is frequently found on coral reefs of the Batangas region, branching is in one plane. The terminal parts of the branches are spatulate and fistulose, whereas the main stem and basal parts of the branches are mostly solid.

The exterior surface of the colonies is usually red-orange to red-brown, while the colony interior is pure white.

SPECIES. - Eleven species are recognized (Appeltans et al. 2013).

Distribution.- Indo-West Pacific (East Africa, Persian Gulf, Madagascar, Maldives, Taiwan, Philippines, Indonesia, New Guinea, Solomon Islands, Northwestern Australia, Great Barrier Reef, Palau).

References. - Fabricius et al. (2007:91); Fabricius and Alderslade (2001); Gosliner, Behrens, and Williams (1996:50, as Semperina); Grasshoff and Bargibant (2001:106-109).

\section{Family Subergorgiidae Gray, 1859}

\section{Genus Annella Gray, 1858}

\section{Annella reticulata (Ellis and Solander, 1786) and Annella mollis (Nutting, 1910)} Figures $7-8$

Material Examined- - CASIZ 185458; Philippines, Luzon Island: Batangas Province, Murals (GPS coordinates $13.69927^{\circ} \mathrm{N}, 120.8824^{\circ} \mathrm{E}$ ); <31 m depth; 13 May 2011; coll. G. C. Williams; one whole colony wet-preserved $95 \%$ ethanol.

REMARKs.- Species in the genus Annella are unlike other Indo-Pacific gorgonians in that the colonies have a net-like appearance - they are conspicuously reticulated due to numerous anastomosing branches.

At least two species of a pygmy sea horse (family Syngnathidae), which are generally $<20$ $\mathrm{mm}$ in height, are known to inhabit the branches of two genera of gorgonians found in the Coral Triangle - Hippocampus denise Lourie and Randall, 2003, has been encountered on Annella mollis and $A$. reticulata, while $H$. bargibanti is associated with Muricella spp. (family Acanthogorgiidae) (Reijnen et al. 2011:5).

SPECIES.- Two species of Annella, A. mollis and A. reticulata, are known to occur in the Philippines - A. reticulata has finer, more gracile branches, larger closed cells or spaces between the surrounding branches, and colonies usually less than $0.3 \mathrm{~m}$ in height. Annella mollis, on the other hand, has thicker, more robust, branches, narrower spaces between the surrounding branches, and colonies up to $1.5 \mathrm{~m}$ tall (Figs. 7A and 7B).

Distribution.- The genus has an Indo-West Pacific distribution - East Africa to the Eastern Indian Ocean (Keeling Island); Western and Central Pacific (Okinawa, Great Barrier Reef, Indonesia, Philippines, New Guinea, Solomon Islands, New Caledonia, Palau, Marshall Islands).

REFERENCES.-Fabricius et al. (2007:91); Gosliner, Behrens, and Williams (1996:51, as Subergorgia mollis); Grasshoff and Bargibant (2001:72-79); Appeltans et al. (2013).

\section{Genus Subergorgia Gray, 1857}

\section{Subergorgia suberosa (Pallas, 1766)}

Figures 5A, 5B, 9

Material EXamined.- CASIZ 104074, Philippines, Luzon, Batangas Province, Maricaban 
Island, Devil's Point, 6-21 m depth, 23 Feb 1995, coll. G. C. Williams, 1 whole colony wet-preserved 75\% ethanol; CASIZ 103912; Philippines, Luzon, Nasugbu, Pinnacle Rock; 7 m depth; 04 March 1995; coll. G. C. Williams; two specimens wet-preserved 75\% ethanol.

REMARKS. - Branches are often somewhat flattened with a longitudinal line or furrow running along both sides of the branches. Subergorgia appressa (Nutting, 1911) and S. pulchra (Nutting, 1911) are junior synonyms of $S$. suberosa.

SPECIES.- Ten species of the genus Subergorgia are recognized and listed (Appeltans et al. 2013).

Distribution. - The genus has an Indo-West Pacific distribution (Zanzibar, Madagascar, Mauritius, Sri Lanka, Great Barrier Reef, Malaysia, Indonesia, Philippines, China, Taiwan, Japan, Palau, New Guinea, Solomon Islands, New Caledonia).

REFERENCES.-Fabricius et al. (2007:91); Gosliner, Behrens and Williams (1996:51); Grasshoff and Bargibant (2001:68-72).

\section{Family Melithaeidae Gray, 1870}

\section{Genus Acabaria Gray, 1859}

Acabaria spp.

Figures 10C, 11

Material Examined.- CASIZ 186644, Philippines, Luzon, Batangas Province, Maricaban Island, Devil's Point, 29.6 m depth, 20 May 2011, coll. G. C. Williams, one whole colony wet-preserved $95 \%$ ethanol.

REMARKs.- The family Melithaeidae contains five currently recognized genera (Acabaria, Clathraria, Melithaea, Mopsella, and Wrightella), which are not easily distinguished morphologically (Fabricius and Alderslade 2001). If a future revision shows that only one genus in the family is valid, then Melithaea would have priority as the first described genus (Reijnen et al. 2013). Currently, the species that have been assigned to Acabaria are highly variable with regard to sclerite form. Included here are spindles, as well as various foliate forms such as leafy spindles, clubs, and spheroids. A remarkable amount of color variation can also be seen in species of Acabaria, including those found in the Philippines. Many are brightly colored - yellow, red, violet, white, or tanbrown are commonly encountered colors that are observed in the various species. Individual colonies may even be bicolored.

SPECIES.- Forty-seven species are recognized (Appeltans et al. 2013).

Distribution. - The genus is broadly distributed in the Indo-Pacific (East Africa to Hawaii).

REFERENCES. - Fabricius et al. (2007:91); Fabricius and Alderslade (2001); Gosliner, Behrens and Williams (1996:52). Grasshoff and Bargibant (2001:90-97); Williams (1993:50-51).

\section{Genus Melithaea Milne Edwards and Haime, 1857}

\section{Melithaea sp.}

Figures 10A, 12

Material Examined.- CASIZ 103805, Philippines, Luzon, Batangas Province, Maricaban Island, Bonito Island, $16.8 \mathrm{~m}$ depth, 27 February 1995, coll. G. C. Williams, one whole colony wetpreserved $75 \%$ ethanol.

REMARKS. - Species of Melithaea can form large fans and often attain a height of over one meter in localities with strong currents where abundant food is available. The nodes often produce 
exaggerated swollen areas along the thicker branches. Sclerite complements include clubs with rounded or knbby heads, spindles, foliate spheroids, and birotulates. Color most commonly includes red, orange, or yellow.

SPECIES.- Thirty-one recognized species (Appeltans et al. 2013).

Distribution. - Many parts of the Indo-Pacific from East Africa to Japan, Palau, Fiji, and New Caledonia.

REFERENCES.- Fabricius et al. (2007:91); Fabricius and Alderslade (2001:172); Gosliner, Behrens and Williams (1996:53); Grasshoff and Bargibant (2001:82-89).

\section{Family Acanthogorgiidae Gray, 1859}

\section{Genus Acanthogorgia Gray, 1857}

\section{Acanthogorgia sp.}

Figures 13-14

Material Examined.- CASIZ 180180, Philippines, Luzon, Batangas Province, Maricaban Island, Sepok Wall, $21.3 \mathrm{~m}$ depth, 19 Apr 2008, coll. G. C. Williams, 1 whole colony wet-preserved $75 \%$ ethanol.

REMARKS.- The polyps are contractile but not retractile and are covered with elongate often curved spindles with numerous small tubercles. The polyps are tubular or cylindrical in shape and are situated perpendicular to the branches. Colonies are often brightly-colored, commonly yellow, orange, or red to pink or purple.

SPECIES.- Sixty-four nominal species (Appeltans et al. 2013).

Distribution.- Many species are known from colder or deeper regions of all world seas except the Arctic Ocean. In addition, shallow-water species of the tropical Indo-Pacific are known from the Red Sea, Malaysia, Australian Great Barrier Reef, Philippines, Taiwan, Palau, Japan, Indonesia, Papua New Guinea, Solomon Islands, and New Caledonia.

Whether these two groups belong to the same genus or not is yet to be determined.

References.-Fabricius et al. (2007:91); Fabricius and Alderslade (2001:184); Gosliner, Behrens, and Williams (1996:53, as Acalycigorgia); Grasshoff and Bargibant (2001:131-144); Williams (1992:208).

\section{Genus Muricella Verrill, 1869}

\section{Muricella sp.}

Figures 13, 15

Material Examined.- CASIZ 109526, Philippines, Luzon, Batangas Province, Maricaban Island, Sepok Wall, 9-25 m depth, 20 April 1997, coll. G. C. Williams, 1 whole colony wet-preserved $75 \%$ ethanol.

REMARKS. - The polyps are contractile but not retractile and are covered with robust or blunt spindles with prominent tubercles. The polyps are usually rounded or hemispherical and appear as numerous bumps along the branches. Colonies are commonly pink to magenta, but brown, yellow or white have also been recorded. The pygmy sea horse Hippocampus bargibanti, is reported to be associated with perhaps three species of Muricella in the Indo-West Pacific (Reijnen et al. 2011:5), including at least one species in the Philippines (Fig. 13B).

SPECIES.- Thirty-five species recorded (Appeltans et al. 2013).

Distribution. - Indo-West Pacific, Indian Ocean to throughout much the western Pacific.

References.-Fabricius et al. (2007:91); Gosliner, Behrens, and Williams (1996:54); Grasshoff and Bargibant (2001:148-153). 


\title{
Family Plexauridae Gray, 1859
}

\author{
Genus Astrogorgia Verrill, 1868
}

Astrogorgia spp.

Figures 16-17

Material Examined- - CASIZ 168899, Philippines, Calamian Group, Busuanga Island, Coral Gardens Reef $\left(11.98550^{\circ} \mathrm{N}, 120.07668^{\circ} \mathrm{E}\right), 14 \mathrm{~m}$ depth, 24 February 2010, coll. G. C. Williams, several partial colonies wet-preserved 95\% ethanol; CASIZ 185465, Philippines, Luzon, Batangas Province, Maricaban Island, Bonito Island, $31.1 \mathrm{~m}$ depth, 16 May 2011, coll. G. C. Williams, 1 whole colony wet-preserved 95\% ethanol; CASIZ 190428, Philippines, Kuzon, Batangas Province, Maricaban Isalnd, Devil's Point, $15 \mathrm{~m}$ depth, 18 November 2012, coll. G. C. Williams, one partial colony wet-preserved $95 \%$ ethanol.

REMARKS. - The branches are somewhat flattened with polyps usually placed oppositely in two longitudinal rows.

The polyps are retractile into mound-like or cylindrical calyces. The prominent sclerites are robust spindles ornamented sparsely with mostly small tubercles. The color of the colonies is often red, magenta or purple, but orange, yellow, cream or tan are also recorded.

SPECIES.- Fifteen species are recognized (Appeltans et al. 2013). However, confusion in the literature regarding the definition of the genus has led to many taxa described in different genera, thereby making an actual determination difficult regarding the total number of species in the genus.

Distribution.- Widely distributed in the Indo-Pacific: the Red Sea and western Indian Ocean to as far to the east as Tuvalu in the central Pacific.

REFERENCES.- Fabricius et al. (2007:91); Grasshoff and Bargibant (2001:164-175).

\section{Genus Echinogorgia Kölliker, 1865}

\section{Echinogorgia sp.}

Figures 18B, 19

Material Examined. - CASIZ 109537; Philippines, Luzon, Batangas Province, Caban Island, Kirby's Rock; < 31 depth; 22 April 1997; coll. G. C. Williams.

REMARKS. - Branching is planar and mostly lateral. Some branches may anastomose, but colonies only rarely form net-like fans. Branches are often thick and rounded at the terminal ends. The colonies do not harbor zooxanthellae. The color of colonies is often vivid red or orange, but can vary from brown to white or yellow; or they can also be bicolored. The polyps are completely retractile and often form conspicuous, mound-like or spiny calyces. This often gives the surface of the colonies a somewhat rough-to-the-touch texture. Characteristic sclerites of the calyces are thornscales with tuberculated root-like bases and usually three (or sometimes more) thorn-like projections at the opposite end.

SPECIES.- Thirty-six species are recognized (Appeltans et al. 2013), although a substantial amount of confusion appears in the literature regarding the differentiation of this genus with others such as Menella, Paraplexaura, and Echinomuricea.

Distribution.- Widespread in the Indo-West Pacific: Madagascar, Red Sea, India, Sri Lanka, Thailand, Singapore, Taiwan, Australia, Indonesia, Philippines, New Guinea, New Caledonia, and Palau.

ReFERENCES.-Fabricius and Alderslade (2001:202-205); Fabricius et al. (2007:91); Grasshoff and Bargibant (2001:187-190). 


\section{Genus Echinomuricea Verrill, 1869}

\section{Echinomuricea sp.}

Figures 18A, 20

Material Examined. - CASIZ 185452, Philippines, Luzon, Batangas Province, Maricaban Island, Devil's Point; < 29 m depth; 17 May 2011; coll. G. C. Williams; one partial specimen wetpreserved $95 \%$ ethanol.

REMARKS. - Terminal branches are elongate and curved. Colonies have a rough or coarse surface texture to the touch.

The calyces contain easily distinguishable sclerites known as thornscales or thornstars. Many of these have a broad, root-like base that gives rise to a single, projecting, strong spine that is straight and sharply tapered, smooth to slightly toothed on the margins.

The colonies do not harbor zooxanthellae. Overall color is often dark red or orange, but can vary from dark purplish brown to white or yellow; some colonies can also be bicolored.

SPECIES. - Twenty-seven species are recognized (Appeltans et al. 2013).

Distribution.- - Indo-West Pacific: South Africa, Madagascar, Red Sea, India, Sri Lanka, Thailand, Singapore, Taiwan, Australia, Indonesia, Philippines, New Guinea, New Caledonia, and Palau.

REFERENCES.-Fabricius et al. (2007:91); Grasshoff and Bargibant (2001:178-181); Williams (1992:209).

\section{Genus Euplexaura Verrill, 1869}

\section{Euplexaura sp.}

Figures 21-22

Material Examined.-CASIZ 109598; Philippines, Luzon, Batangas Province, Ligpo Island, north end at wall; 27-29 m depth; 23 April 1997; coll. G. C. Williams; CASIZ 180166, Philippines, Luzon, Batangas Province, Maricaban Island, Devil's Point, $15.2 \mathrm{~m}$ depth, 23 Apr 2008 , coll. G. C. Williams, 2 whole colonies wet-preserved $75 \%$ ethanol.

REMARKS.- Colonies grow as fans that branch in one plane. The main branches are relatively thick. The terminal branches are short and rounded to slightly swollen at the ends. The diagnostic sclerites are robust ovoid to elliptical or spheroidal spindles, highly ornamented with large knob-shaped tubercles.

SPECIES.- Thirty-six species are currently recognized (Appeltans et al. 2013).

Distribution.- Indo-West Pacific: South Africa to the western Pacific.

REFERENCES. - Fabricius et al. (2007:91); Grasshoff and Bargibant (2001:158-163); Williams (1992:209).

\section{Genus Menella Gray, 1870}

\section{Menella spp.}

Figures 23-24

Material Examined.- CASIZ 109578; Philippines, Luzon, Batangas Province, Caban Island, Kirby's Rock; 6-33 m depth; 22 April 1997; coll. G. C. Williams, two colonies wet-preserved 75\% ethanol; CASIZ 180197; Philippines, Luzon, Maricaban Island, Devil's Point; $24 \mathrm{~m}$ depth; 19 April 2008; coll. G. C. Williams, one partial colony; CASIZ 185448, Philippines, Luzon; Batangas Province, Calumpan Peninsula, Murals; $31 \mathrm{~m}$ depth;13 May 2011; coll. G. C. Williams, one partial colony wet preserved 95\% ethanol; CASIZ 187764, Philippines, Luzon, Batangas Province, Balayan Bay, Ligpo Island, north of Ligpo Dive Site; depth not recorded; 02 May 2011; coll. R. Van Syoc, one partial colony wet-preserved 95\% ethanol. 
REMARKs.- Branching of the colonies is mostly lateral. Some colonies may have overlapping branches that anastomose to a limited degree, but the colonies are not netlike, and do not form intricate networks. The characteristic sclerite of the calyces is a rooted leaf. Colonies do not harbor zooxanthellae and can vary in color from yellow, orange to dull brown, red, or purple.

SPECIES. - Several other gorgonian genera may have a similar growth form and share a superficial resemblance to species of Menella. Included here are Bebryce, Euplexaura, Echinogorgia, Echinomuricea, and Paraplexaura. Only by the determination of sclerites that are shield-like rooted leaves (often shaped like table tennis rackets), can specimens be positively identified as belonging to the genus Menella. Twenty-four species are recognized and listed (Appeltans et al. 2013).

Distribution. - Indo-West Pacific: South Africa, Red Sea, Madagascar, Mauritius, Bay of Bengal, Singapore, Malaysia, Indonesia, the Philippines, Papua New Guinea, Australia, and New Caledonia.

REFERENCES.- Fabricius and Alderslade (2001:206-207); Fabricius et al. (2007:91); Gosliner, Behrens and Williams (1996:54, as Echinogorgia, Menella); Grasshoff and Bargibant (2001: 191-194); Williams (1992:210); Williams (1993:51-53, as Echinogorgia).

\section{Genus Paraplexaura Kükenthal, 1909}

\section{Paraplexaura sp.}

Figures 25A, 26-27

Material Examined.- CASIZ 103947; Philippines, Luzon, Batangas Province, Nasugbu, Pinnacle Rock; 7.6 m depth; 01 April 1995; coll. G. C. Williams; CAS 190431; Philippines, Luzon, Batangas Province, Maricaban Island, Devil's Point; 15 m depth; 18 November 2012; coll. G. C. Williams; CAS 185451; Philippines, Luzon, Batangas Province, Calumpan Peninsula, Murals; $<31 \mathrm{~m}$ depth; 13 May 2011; coll. G. C. Williams.

REMARKS. - Lateral branches curve upward strongly and often appear mostly parallel to the main branches.

The branches are often thick with conspicuously-rounded ends. The polyps are completely retractile and often appear flush with the surface of the branches. Many of the characteristic sclerites have a complex structure that are intricately and finely-tuberculated on one end with several elongate thorn-like projections on the opposite end. Color of the colonies is usually red or rustorange to tan-brown.

SPECIES.- Two species are currently recognized (Appeltans et al. 2013), but due to uncertainly regarding the definition of the species as evident in some literature sources, it is uncertain as to the actual number of valid species.

Distribution. - Indo-West Pacific: from the Red Sea to islands of the western Pacific.

REFERENCES.- Fabricius and Alderslade (2001:208-209).

\section{Genus Villogorgia Duchassaing and Michelotti, 1860}

\section{Villogorgia sp.}

Figures 28-29

Material Examined.- CASIZ 111773, Philippines, Luzon, Batangas Province, Balayan Bay, Ligpo Island, 27-29 m depth, 23 Apr 1997, coll. G. C. Williams, three whole colonies wetpreserved $75 \%$ ethanol.

REMarKs.- The colonies are copiously-branched sea fans with numerous, relatively thin, closely adjacent branches. The polyps retract into small mound-like or cylindrical calyces. The diagnostic sclerites are thornscales with usually two prominent wing-like lateral projections that 
are usually deltoid or narrowly triangular in shape. Colony color is variable: deep red, orange to brown, or yellow.

SPECIES.- Thirty-nine species are recognized (Appeltans et al. 2013), two of these have been described from the western Atlantic.

Distribution.- Widespread in the Indo-West Pacific: western Indian Ocean to New Caledonia.

REFERENCES._- Fabricius et al. (2007:91); Grasshoff and Bargibant (2001:198-204).

\section{Family Gorgoniidae Lamouroux, 1812 \\ Genus Rumphella Bayer, 1955}

Rumphella cf. aggregata (Nutting, 1910)

Figures $30 \mathrm{~A}, 31 \mathrm{~A}$

Material Examined-C CASiZ 180896, Philippines, Sibuyan Sea, Romblon Province, Cobrador Island, $21.9 \mathrm{~m}$ depth, $20 \mathrm{Feb} 2010$, coll. G. C. Williams, 1 whole colony wet-preserved 95\% ethanol; CASIZ 186635, Philippines, Luzon, Batangas Province, Maricaban Island, Sepok Point, 15 May 2011, coll. G. C. Williams, two partial colonies wet-preserved $95 \%$ ethanol.

REMARKS.-Zooxanthellate coral reef gorgonians, usually grey to tan or yellow-brown in color, with alcohol-soluble chlorophyll pigments in wet-preserved material. Branches are thick with rounded ends. Retracted polyps leave conspicuous polyp openings on the branches. Characteristic sclerites are broadly-flaring clubs with a terminal appendage and a sub-terminal whorl of three large tuberculated appendages. Rumphella aggregata is known from the Moluccas and other parts of Indonesia and the Philippines, while Rumphella antipathes (Linnaeus, 1758) was originally described from the Malaysian Peninsula. Colonies of Rumphella are known to harbor four species of parasitic copepods in three genera, Acanthomolgus, Doridicola, and Enalcyonium (Ofwegen 2013).

SPECIES.- Three species of the genus are recognized (Appeltans et al. 2013).

Distribution. - The genus has an Indo-West Pacific distribution: South Africa, the Red Sea, Malaysia, Indonesia, Philippines, Palau, New Guinea, Solomon Islands, New Caledonia.

ReFerences. - Fabricius and Alderslade (2001:214-215); Fabricius et al. (2007:91); Gosliner, Behrens, and Williams (1996:54); Grasshoff and Bargibant (2001:120-122); Williams (1992:250); Williams (1993:55-57).

\section{Family Ellisellidae Gray, 1859}

\section{Genus Dichotella Gray, 1870}

\section{Dichotella gemmacea (Milne Edwards and Haime, 1857)}

Figures 32B, 35D

Material Examined.- CASIZ 186642, Philippines, Luzon, Batangas Province, Calumpan Peninsula, Murals $\left(13.69927^{\circ} \mathrm{N}, 120.88244^{\circ} \mathrm{E}\right), 13$ May 2011, coll. G. C. Williams, one partial colony wet-preserved 95\% ethanol; CASIZ 103948, Philippines, Luzon, Batangas Province, Maricaban Island, Bethlehem, $20.7 \mathrm{~m}$ depth, 26 Feb 1995, coll. G. C. Williams, two whole colonies wet-preserved $75 \%$ ethanol.

ReMARKS.-Conspicuously dichotomously-branched gorgonians, usually less than $0.5 \mathrm{~m}$ in height, rarely up to a one meter tall. Some sclerites are clubs with congested clustered of smooth rounded tubercles at the widest end, while other sclerites are waisted spindles. Colonies are usually bright red or orange in color, but sometimes yellow, yellow-brown, or white. 
SPECIES.- Only one species is considered valid.

Distribution.- Eastern Indian Ocean and western Pacific to New Caledonia.

ReFERENCES.- Fabricius et al. (2007:91); Grasshoff and Bargibant (2001:232-233).

\section{Genus Ellisella Gray, 1858}

\section{Ellisella ssp.}

Figures 33, 35

Material Examined.- CASIZ 185472, Philippines, Luzon, Batangas Province, Calumpan Peninsula, Dead Palm dive site $\left(13.69569^{\circ} \mathrm{N}, 120.88472^{\circ} \mathrm{E}\right), 25$ May 2011 , coll. G. C. Williams, several partial specimens wet-preserved 95\% ethanol; CASIZ 095385, Philippines, Luzon, Batangas Province, Maricaban Island, Sepok Point, 26.5 m depth, 14 Mar 1994, coll. G. C. Williams, 1 whole colony wet-preserved $75 \%$ ethanol.

REMARKS. - Colonies under one meter in height. Branching is dichotomous and the end branches are often long, slender, and whip-like. Polyps are contractile but not retractile. Polyps form numerous mounds or lobe-like projections along the branches. Sclerites are waisted spindles and double heads with large rounded knob-like tubercles. Color of colonies mostly red to orange, but also can be pink, white, or bicolored.

SPECIES.- Forty-one species are recognized but actual number of species that are considered valid is not known (Appeltans et al. 2013).

Distribution.- Circumglobal distribution in both tropical and warm temperate waters: IndoWest Pacific and Atlantic as well as the Mediterranean Sea.

REFERENCES.- Fabricius et al. (2007:91); Fabricius and Alderslade (2001:224-225); Gosliner, Behrens and Williams (1996:55, as Ctenocella, Ellisella), Grasshoff and Bargibant (2001:240-255).

\section{Genus Junceella Valenciennes, 1855}

\section{Junceella fragilis (Ridley, 1884)}

Figures 34, 35C

Material Examined.- CASIZ 180160, Philippines, Luzon, Batangas Province, Maricaban Island, Aphol's Rock, 23 April 2008, coll. G. C. Williams, one whole specimen wet-preserved 75\% ethanol; CASIZ 103838, Philippines, Mindoro, Medio Island, NW Passage of Puerta Galera, 6-19 m depth, 28 Feb 1995, coll. G. C. Williams, one whole colony wet-preserved $75 \%$ ethanol.

REMARKs.-Colonies unbranched, whiplike, filiform, and threadlike, or sometimes thicker and more robust, up to two meters in height. The polyps of this species contain numerous brown cells of zooxanthllae, unlike other species of the genus which apparently are azooxanthellate (Williams et al. 2010). Numerous colonies that are in close proximity sometimes form undersea clusters or fields of sea whips, appearing like aggregations of garden eels (Fig. 34C).

SPECIES.- Nine recognized species (Appeltans et al. 2013).

Distribution.- Widespread Indo-Pacific distribution: the Red Sea and South Africa to Micronesia and New Caledonia.

REFERENCES.-Fabricius et al. (2007:91); Gosliner, Behrens, and Williams (1996:55); Grasshoff and Bargibant (2001:226-231); Williams (1992:251); Williams (1993:57-58); Williams, et al. (2010). 


\section{Genus Viminella Gray, 1870}

\section{Viminella sp.}

Figures 32A, C, 35B

Material Examined.- CASIZ 103820, Philippines, Luzon, Batangas Province, Maricaban Island, Devil's Rock, 6 m depth, 23 February 1995, coll. G. C. Williams, one whole colony wetpreserved 75\% ethanol; CASIZ 104027, Philippines, Luzon, Batangas Province, Maricaban Island, Gamao Point, 22 m depth, 27 February 1995, coll. G. C. Williams, one whole colony wet-preserved 75\% ethanol; CASIZ 185478, Philippines, Luzon, Batangas Province, Murals, $31.1 \mathrm{~m}$ depth, 13 May 2011, coll. G. C. Williams, 1 whole colony wet-preserved $95 \%$ ethanol.

REMARKs.- Sea whips up to two meters tall. Colonies are mostly unbranched, but colonies with two or three terminal branches are occasionally encountered. Sclerites are either double heads or waisted spindles. Colony color is variable: red, orange, yellow, white, pink, or bicolored.

SPECIES.- Fifteen species are listed (Appeltans et al. 2013).

Distribution. - Widespread with a circumglobal distribution: Indo-Pacific, Atlantic, and Mediterranean Sea.

ReferenCES.- Fabricius et al. (2007:91); Grasshoff and Bargibant (2001:236-240).

\section{Family Isididae Lamouroux, 1812}

\section{Genus Isis Linneaus, 1758}

\section{Isis hippuris Linnaeus, 1758}

Figures 30B-C, 31B

Material Examined.- CASIZ 192749, Philippines, Sibuyan Sea, Romblon Province, Cobrador Island, $21.9 \mathrm{~m}$ depth, 20 Feb 2010, coll. G. C. Williams, 1 whole colony wet-preserved $95 \%$ ethanol.

REMARKS.-Zooxanthellate coral reef gorgonians, yellow to green or brown in color, with alcohol-soluble chlorophyll pigments in wet-preserved material. The axis is conspicuously segmented with alternating dark proteinaceous nodes and white calcareous internodes. Characteristic sclerites are broadly-flaring clubs without a terminal medial appendage, but with a terminal whorl or crown composed of large tuberculated appendages. Living colonies superficially resemble those of the genus Rumphella as well as some species of Euplexaura.This species is often encountered in areas of quiet water such as lagoons that are protected from high energy wave action.

SPECIES. - Eight species are described, but only one is currently recognized as valid (Appeltans et al. 2013).

Distribution. - Indo-West Pacific: western Indian Ocean to Taiwan and Palau.

REFERENCES.- Fabricius et al. (2007:91); Fabricius and Alderslade (2001:248-249).

\section{Pennatulacea Verrill, 1865}

\section{Family Veretillidae Herklots, 1858}

\section{Genus Veretillum Cuvier, 1798}

\section{Veretillum spp.}

Figure 37

Material Examined. - CASIZ 186636, Philippines, Luzon, Batangas Province, Calumpan Peninsula, Dead Palm South $\left(13.694^{\circ} \mathrm{N}, 120.884^{\circ} \mathrm{E}\right), 13$ May 2011, coll. G. C. Williams, one whole colony wet-preserved $95 \%$ ethanol. 
REMARKS. - Sol Felty Light - the author of the first edition of what was later to become known as Light's Manual (Light 1941) — as a young professor at the University of the Philippines during the World War I period, published widely on the Octocorallia of the region in six papers (Light, 1913-1921). In one of these papers (Light 1921), he described four new species of the sea pen genus Lituaria, which appear to be more correctly placed in the genus Veretillum, due to the possession of numerous, minute, otolith-like sclerites in the peduncular interior (Williams, 1995:98).

Light's type material, collected from Puerto Galera on the north coast of Mindoro, is cited as being housed in the "zoological collection, College of Liberal Arts, University of the Philippines." Light (1921:253; in reference to Lituaria breve), states, "This species, like the others described in this paper, was described some time ago. Since then, unfortunately, the type specimens have been misplaced. In view of the very distinct characters of the species, however, I have considered it permissible to publish the description, in spite of the loss, temporary it is to be hoped, of the type specimens."

Whether these specimens were ever located is not known, but a subsequent story possibly relates to the disappearance of Light's types. The first author and T. M. Gosliner visited the marine collections of the Marine Science Institute of the University of the Philippines in March of 1994 to look for the types and were told by a collections staff member that they were possibly destroyed in a 1970's student rebellion, when several alcohol-filled jars from the collections were taken from the collection shelves and used as Molotov cocktails in street demonstrations.

Colonies of the genus are cylindrical and sausage-shaped, sometimes slightly club-shaped, up to $200 \mathrm{~mm}$ in length. Polyps are distributed all around the rachis and are retractile, not forming calyces. The sclerites of the rachis are either variably-shaped plates or absent altogether. Species of Veretillum in the region of the Verde Island Passage have been observed only during night dives.

SPECIES.- Eighteen species have been described, of which perhaps seven may be valid (Williams 1995:105).

Distribution. - Indo-West Pacific, eastern Atlantic, and the Mediterranean Sea.

REFERENCES.- Fabricius et al. (2007:91); Gosliner, Behrens, and Williams (1996:56-58); Williams $(2011: 3,6,9)$.

\section{Genus Cavernulina Kükenthal and Broch, 1911}

\section{Cavernulina cf. cylindrica Kükenthal and Broch, 1911}

Figures $36 \mathrm{~A}, 40 \mathrm{~A}$

Material Examined.- CASIZ 186569; Philippines, Luzon, Batangas Province, Maricaban Island, Sepok Point $\left(13.69^{\circ} \mathrm{N}, 120.83^{\circ} \mathrm{E}\right) ; 25$ May 2011; coll. Peri Paleracio; one entire specimen wet-preserved $95 \%$ ethanol.

REMARKS.-Colonies are cylindrical to somewhat club-shaped. Sclerites of the rachis are rods that commonly have branched or bilobed ends. The polyps do not contain sclerites. The one species of Cavernulina that is known in the Verde Island Passage region is diurnal - the polyps are brown due to the presence of zooxanthellae.

SPECIES.- Four species are considered valid (Williams 1995:103).

Distribution.- Indo-West Pacific (southeastern Africa to the Ryukyu Islands and New Caledonia) and the eastern Pacific (Baja California to Ecuador and the Galápagos Islands).

References.-Fabricius et al. (2007:91); Gosliner, Behrens, and Williams (1996:56); Williams (1993:59-60); Williams (2011:3, 6, 9). 


\section{Family Virgulariidae Verrill, 1868 \\ Genus Scytalium Herklots, 1858}

\section{Scytalium cf. sarsi Herklots, 1858}

Figures 36B, 40B

Material Examined.- CASIZ 185443, Philippines, Luzon, Batangas Province, Calumpan Peninsula, Maricaban Strait, Basketball dive site $\left(13.68594^{\circ} \mathrm{N}, 120.89172^{\circ} \mathrm{E}\right), 14$ May 2011 , coll. G. C. Williams, one specimen wet-preserved $95 \%$ ethanol.

REMARKs.- Colonies in life often take on the appearance of dark red to violet-colored feathers. The sclerites are abundant, oval-shaped plates $(<0.05 \mathrm{~mm}$ in length) throughout most of the near-surface tissues of the colonies. Members of two of the fifteen families of pennatulaceans (Virgulariidae and Pennatulidae) give the group its names due to their resemblance to feathers or feather pens.

This appearance is provided by the presence of conspicuous polyp leaves in two longitudinal rows that emanate from the lateral margins of the rachis.

SPECIES.- Six species have been described, of which perhaps only two or three are valid (Williams, 1995:124).

Distribution.- Indo-West Pacific: the Red Sea and southeastern Africa to Indonesia, the Philippines, Taiwan, China, and Japan.

References.- Gosliner, Behrens, and Williams (1996:58); Williams (2011:3, 6, 9).

\section{Genus Virgularia Lamarck, 1816}

\section{Virgularia spp.}

Figure 38

Material Examined.- CASIZ 180146, Philippines, Luzon, Batangas Province, Calumpan Peninsula, Batangas Bay, Mainit Bubbles dive site $\left(13.7615972^{\circ} \mathrm{N}, 121.3834889^{\circ} \mathrm{E}\right), 19 \mathrm{~m}$ depth, 22 April 2018, coll. G. C. Williams, one whole specimen wet-preserved $75 \%$ ethanol.

RemarKs.-Colonies have a conspicuous feather-like appearance in life. Sclerites are absent throughout the tissues of the colonies except for minute oval bodies $(<0.01 \mathrm{~mm}$ in length) that are present in the interior of the peduncles. Color is variable: cream white or milky white with semitransparent polyp leaves, to brown, red, violet, or multicolored.

SPECIES. - Fifty-six species are described, of which twenty-one are currently recognized (Williams 1995:125); WoRMS 2013).

Distribution.- The distribution of the genus is circumglobal: throughout the Pacific and Indian Oceans, as well as the Atlantic Ocean including the Mediterranean Sea.

REFERENCES.- Fabricius et al. (2007:91); Gosliner, Behrens, and Williams (1996:58-59); Williams $(2011: 3,6,9)$.

\section{Family Pennatulidae Ehrenberg, 1834 Genus Pteroeides Herklots, 1858}

\section{Pteroeides spp.}

Figures 39, 40C

Material Examined.- CASIZ 190421, Philippines, Luzon, Batangas Province, Calumpan Peninsula, Batangas Bay, Mainit Bubbles, $19 \mathrm{~m}$ depth, 17 November 2012, coll. G. C. Williams, one whole specimen wet-preserved 95\% ethanol; CASIZ 185934, Philippines, Luzon, Batangas Province, Maricaban Island, Sepok Point $\left(13.688^{\circ} \mathrm{N}, 120.827^{\circ} \mathrm{E}\right), 15$ May 2011, coll. G. C. 
Williams, one whole specimen wet-preserved 95\% ethanol; CASIZ 179462, Philippines, Luzon, Batangas Province, Maricaban Island, Sepoc Point, 25 May 2011, 18 m depth, coll. Joseph Comendador, one whole colony wet-preserved $95 \%$ ethanol.

Remarks.- Many species of Pteroeides have been described from Indonesia and the Philippines, but unfortunately, many of these are poorly described or insufficiently illustrated, and type material for comparative study is often not obtainable.

The genus is in need of revision before most Indo-Pacific species can be confidently identified or the number of valid species in the genus can be ascertained. More original descriptions of species of Pteroeides appear in the literature than any other pennatulacean genus.

SPECIES. - Thirty-one species are currently recognized (Appeltans et al. 2013).

Distribution.- The genus is circumglobal: Indian, Pacific, and Atlantic Oceans, as well as the Mediterranean Sea.

REFERENCES.-Fabricius et al. (2007:91); Gosliner, Behrens, and Williams (1996:59-60); Williams (1995:130); Williams (2011:3, 6,9).

\section{DISCUSSION AND CONCLUSION}

Somewhat differing species compositions, as encountered in various island groups of the Philippine Archipelago, are evident in a complex geographic region of over 7000 islands spread over approximately $15^{\circ}$ of north latitude in the Indo-Pacific tropics. The additive effects of these differing faunal components result in a complex mosaic of overall high diversity in the archipelago, and no doubt is a major contributing factor to the recognition of the region as having certainly one of the highest levels of marine biodiversity in the world.

In the late 1980s and 1990s, the concept of the Coral Triangle of high marine biodiversity came about through the efforts of various scientists working largely independently in Papua New Guinea, Indonesia, and the Philippines. The three points of the Coral Triangle came to be defined as the northern tip of the Philippines, the eastern end of New Guinea, and Indonesia between the islands of Java and Bali. Subsequently, a team of scientists and conservationists declared the Philippine Archipelago to be the center of global marine biodiversity and the Verde Island Passage as the center of the center (or epicenter of marine biodiversity) based on the diversity of shorefishes (Carpenter and Springer 2005). In addition, the Bismarck Archipelago and the Solomon Islands were later included as extensions of the Coral Triangle based on zooxanthellate coral diversity (Veron et al. 2009).

Accumulative field observations since the early 1990s by invertebrate zoologists from the California Academy of Sciences, have revealed that the Verde Island Passage shows remarkably high levels of diversity in both opisthobranch mollusks and octocoral cnidarians (T. M. Gosliner and G. C. Williams, pers. comm.).

\section{ACKNOWLEDGMENTS}

We express our gratitude to Margaret and William Hearst for their generous gift to the California Academy of Sciences that made the Hearst Biodiversity Expedition to the Philippines a reality. We thank Terry Gosliner, Bob Van Syoc, Joseph Comendador, Peri Paleracio, and Alexis Principe for field observations and collection of specimens, and Christina Piotrowski, Elizabeth Kools, Dana Carrison, and Kelly Markello for curation of collected material. 


\section{Literature Cited}

Appeltans, Ward, et Al. 2013. World Register of Marine Organisms, WoRMS Taxon Search. $<$ http://www. marinespecies.org/aphia.php? $p=$ search>. Cited 12 November 2013.

Bayer, Frederick M. 1981. Status of knowledge of octocorals of the world seas. Seminários de Biologia Marinha. Academia Brasileira de Ciências :3-102.

BecCAloni, George, ED. 2012. Another important Wallace anniversary approaches! In The Alfred Russel Wallace Website <http://wallacefund.info/another-important-wallace-anniversary-approaches $>$. Cited 27 March 2013.

Cairns, Stephen D., and Marcelo V. Kitahara. 2012. An illustrated key to the genera and subgenera of the Recent azooxanthellate Scleractinia (Cnidaria, Anthozoa), with an attached glossary. ZooKeys (227):1-47.

CARPENTER, Kent E., AND Victor G. Springer. 2005. The center of the center of marine shore fish biodiverstiy: the Philippine Islands. Environmental Biology of Fishes 72:467-480.

Conservation International. 2010. Biological diversity in Wallacea. In The Encyclopedia of Earth <http://www.eoearth.org/article/Biological_diversity_in_Wallacea>. Cited 12 March 2013.

Fabricius, Katharina E, and Philip Aldderslade. 2001. Soft Corals and Sea fans - a Comprehensive Guide to the Tropical Shallow-water Genera of the Central-West Pacific, the Indian Ocean and the Red Sea. Australian Institute of Marine Science, Townsville, Australia. 264 pp.

Fabricius, Katharina E, Phil Alderslade, Gary C. Williams, Patrick L. Colin, and Yimnang Golbuu. 2007. Octocorallia in Palau, Micronesia: effects of biogeography and coastal influences on local and regional biodiversity. In H. Kayanne, et al., eds., Coral Reefs of Palau. Palau International Coral Reef Center (PICRC), Koror, Republic of Palau. 238 pp.

Gaither, Michelle R., And Luiz A. Rocha. 2013. Origins of species richness in the Indo-Malay-Philippine biodiversity hotspot: evidence for the centre of overlap hypothesis. Journal of Biodiversity 40:1638-1648.

Gosliner, Terrence M., David W. Behrens, and Gary C. Williams. 1996. Coral Reef Animals of the IndoPacific - Animal Life from Africa to Hawai'i Exclusive of the Vertebrates. Sea Challengers, Monterey. California, USA. 314 pp.

GRASSHOFF, MANFRED, 1999. The shallow water gorgonians of New Caledonia and adjacent islands (Coelenterata, Octocorallia). Senckenbergiana biologica 78(1/2):1-121.

Grasshoff, Manfred, and Georges Bargibant. 2001. Coral Reef Gorgonians of New Caledonia. Institut de Recherche pour le Développement, Collection Faune ct Flore tropicales 38, Paris. 335 pp.

Hoeksema, Bert W. 2007. Delineation of the Indo-Malayan Centre of Maximum Marine Biodiversity: The Coral Triangle. Pages 117-178 in W. Renema, ed., Biogeography, Time and Place: Distributions, Barriers and Islands. Springer, The Netherlands.

Huxley, Thomas H. 1868. On the classification and distribution of the Alectromorphae and Heteromorphae. Proceedings of the Zoological Society, London: 294-319.

Light, Sol Felty. 1913. Notes on Philippine Alcyonaria, Part 1. The Philippine species of the genus Capnella. Philippine Journal of Science 8D(6):435-453.

Light, Sol Felty. 1914. Notes on Philippine Alcyonaria, Part 2. Lemnalioides kïkenthali, a new genus and spccics of Alcyonaria from the Philippines and a discussion of the systematic position of the genus. Philippine Journal of Science 9D(3):233-246.

Light, Sol Felty. 1915a. Notes on Philippine Alcyonaria, Part 3. Two new species of Lithophytum Forskål from the Philippines. Philippine Journal of Science 10D(1):1-10.

Light, Sol Felty. 1915b. Notes on Philippine Alcyonaria, Part 4. Notes on Philippine Stolonifera and Xeniidae. Philippine Journal of Science 10D(2):155-167.

Light, Sol Felty. 1915c. Notes on Philippine Alcyonaria, Part 5. Cornularia minuta, new species. Philippine Journal of Science 10D(3):203-213.

Light, Sol Felty. 1921. Notes on Philippine Alcyonaria, Part 6. New Philippine Pennatularia (sea pens) of the genus Lituaria. Philippine Journal of Science 19(2):247-255. 
Light, Sol Felty. 1941. Laboratory and Field Text in Invertebrate Zoology. Assocatied students of the University of California, Berkeley, Californbia, USA. $232 \mathrm{pp}$.

Mai-Bao-Thu, Francis, and Jose S. Domantay, 1970. Taxonomic studies of the Philippine gorgonaceans in the collections of the University of Santo Tomas, Manila. Acta Manilana (A) 6(11):25-73.

Mai-Bao-Thu, Francis, and Jose S. Domantay. 1971. Taxonomic studies of the Philippine Gorgonaceans in the collections of the University of Santo Tomas, Manila (Con't). Acta Manilana (A) 7(12):3-77.

Ofwegen, Leen P. van. 2013. Rumphella antipathes (Linnaeus, 1758). Accessed through: World Register of Marine Species (WoRMS) at <http://www.marinespecies.org/aphia.php?p=taxdetails\&id $=288448>$. Cited 3 September 2013.

Quammen, David. 1996. The Song of the Dodo - Island Biogeography in an Age of Extinction. Touchstone, New York, New York, USA. 702 pp.

Raby, Peter. 2001. Alfred Russel Wallace - a life. Princeton University Press, Princeton and Oxford. 340 pp.

Reijnen, Bastin T., Catherine S. McFadden, Yoselhine T. Hermanlimianto, and Leendert P. van OfweGEN. 2013. A molecular and morphological exploration of the generic boundaries in the family Melithaeidae (Coelenterata: Octocorallia) and its taxonomic consequences. Molecular Phylogenetics and Evolution 2013, pp. 1-38, <doi; <http://dx.doi.org/10.1016/j.ympev.2013.09.028>.

Reijnen, Bastin T., S. E. T. Van der Meis, and Leen P. van Ofwegen. 2011. Fish, fans and hydroids: host species of pygmy seahorses. ZooKeys 103:1-26.

Roxas, Hilario A. 1932. Two new species of Sarcophyton Less. from the Philippines. Natural and Applied Science Bulletin 2(1):73-81.

Roxas, Hilario A. 1933a. Philippine Alcyonaria. The families Cornulariidae and Xeniidae. Philippine Journal of Science 50(1):49-110.

Roxas, Hilarıo A. 1933b. Philippine Alcyonaria, II. The families Alcyoniidae and Nephthyidae. Philippine Journal of Science 50(4):345-470.

Stiasny, Gustav. 1940. Gorgonaria von Tropisch-Westafrika aus dem Zoologischen Museum in Hamburg. Zoologische Jahrbücher, Abteilung Systematik 73(4):339-368.

Stiasny, Gustav. 1941. Octocorallia from Philippine waters. Philippine Journal of Science 76(1):67-72.

Veron, J. E. N., Lyndon M. Devantier, Emre Turak, Alison L. Green, Stuart Kininmonth, Mary Stafford-Smith, and Nate Peterson. 2009. Delineating the Coral Triangle. Galaxea, Journal of Coral Reef Studies 11:91-100.

WALlaCe, Alfred Russel. 1860. On the zoological geography of the Malay Archipelago. The Proceedings of the Linnean Society, Zoology 4:172-184.

Wallace, Alfred Russel. 1880. Island Life: or, The Phenomenon and Causes of Insular Faunas and Floras, Including a Revision and Attempted Solution of the Problem of Geological Climates. Part 2, Insular Faunas and Floras. MacMillan and Company, London, UK. 526 pp.

WiLliams, GARY C. 1992. The Alcyonacea of southern Africa. gorgonian octocorals (Coelenterata, Anthozoa) South Africa. Annals of the South African Museum 101(8):181-296.

Williams, Gary C. 1993. Coral Reef Octocorals, and Illustrated Guide to the Soft Corals, Sea Fans and Sea Pens Inhabiting the Coral Reefs of Northern Natal. Durban Natural Science Museum, Durban, South Africa. $64 \mathrm{pp}$.

Williams, Gary C. 1995. Living genera of sea pens (Coelenterata: Octocorallia: Pennatulacea): illustrated key and synopses. Zoological Journal of the Linnean Society 113:93-140.

Williams, Gary C. 2011. The Global Diversity of Sca Pens (Cnidaria: Octocorallia: Pennatulacea). PLoS ONE 6(7):1-11.

Williams, Gary C. and Philip Alderslade. 1999. Revisionary systematics of the western Pacific soft coral genus Minabea (Octocorallia: Alcyonacea), with descriptions of a related new genus and species from the Indo-Pacific. Proceedings of the California Academy of Sciences, ser. 4, 51(7):337-364.

Williams, Gary C. and Stephien D. Cairns. 2013. Biodiversity myth busters. Octocoral Research Center Website. <http://researcharchive.calacademy.org/research/izg/Biodiversity\%20Myth\%20Busters.htmb. Cited 3 September 2013.

Williams, Gary C., J. Charles Delbeek, Bart Shepherd, and Seth Wolters. 2010. Zooxanthellae in 
ellisellid gorgonians of the Philippines. Proceedings of the California Academy of Sciences, ser. 4, 61(18):647-648.

Williams, Gary, and Courtney Mattison. 2013. Microscoope slide or SEM stub preparation for octocoral sclerites or other invertebarate spicules. In: Octocoral Research Center Website, Research Techniques. $<$ http://researcharchive.calacademy.org/research/izg/Biodiversity\%20Myth\%20Busters.html $>$. Cited 6 September 2013.

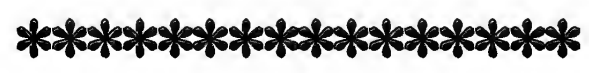

\section{Appendix}

\section{Glossary}

Anastomosis: In gorgonian corals, the union or cross fusion of branches. Sometimes there is only one or a few examples on a colony, but if a colony has common and abundant anastomosing branches the colonial growth form may appear as a network.

Autozooid: The largest kind of polyp in octocorals, with eight pinnate tentacles surrounding the mouth; for feeding, reproduction, and protection.

Axial: Referring to the central axis of a gorgonian, sea pen, or black coral; see Axis.

Axis: The rod-like structure in the center of a gorgonian or pennatulacean colony that runs throughout most or all of the length of the colony, composed of sclerites, hard protein, or consolidated calcium carbonate with varying amount of proteinaceous material.

Birotulate: A capstan-like sclerite, with the tubercles of two parallel whorls fused into disks; also called double discs or double wheels (Fig. 8, center and bottom right).

Calcareous: Referring to a structure that is composed of calcium carbonate $\left(\mathrm{CaCO}_{3}\right)$.

Calyx: The wart-like, rigid base of some polyps that does not retract below the surface of the colony.

Capstan: A capstan-like sclerite; see Radiate (Fig. 31, top left and bottom right).

Clubs: Unbranched, club-like sclerites that are enlarged at one end, and tapered to form a thinner handle at the other end.

Contractile: A polyp that may reduce in size but cannot be withdrawn.

Coral Triangle: A biogeographical region of maximum marine biodiversity based primarily on the high species diversity of zooxanthellate corals; encompassing the entire Philippines, eastern Indonesia, and western, northern and eastern New Guinea, to the Bismarck Archipelago and the Solomon Islands (Fig. 2A).

Cortex: The outer layer of a central axis that is composed of consolidated sclerites; as opposed to the medulla - the inner core.

Denticulated: Toothed or serrated.

Dichotomous branching: Branching pattern in which a single branch gives rise to only two branches at each branching point, giving a Y-shaped axil.

Double heads: Sclerites with narrow, smooth waists and terminal clusters of tubercles that are not radiallyarranged (See Fig. 35, top row).

en chevron: Sclerites arranged in an inverted V-shape, sometimes found on the walls or calyces of autozooids.

Filiform: Unbranched, threadike, or whiplike, as in Junceella.

Fistulose: Hollow with open widened grooves where the white interior is exposed toward the ends of branches, gutter-like, as in Solenocaulon.

Holdfast: The basal portion of a colony that adheres a gorgonian to a hard substratum.

Lateral branching: Irregular branching in octocorals - neither dichotomous or pinnate.

Lobate: Growth form with several prominent lobes, as in some colonies of the genus Briareum. 
Medulla: The inner supporting structure of scleraxonian gorgonians that is composed of consolidated sclerites, as in Subergorgia (Fig. 9, bottom row).

Needle: A long, thin, unbranched sclerite.

Oval: A short rodlike sclerite, rounded or ovoid in shape, often somewhat flattened.

Peduncle: The muscular lower (proximal) portion of a sea pen colony that is devoid of polyps and serves to anchor the colony into sediments of the sea bottom.

Planar: Branching pattem that is only in onc planc.

Plate: A flattened, relatively thick sclerite of diverse form — ovoid, polygonal, or irregularly-shaped.

Polyp: Any individual of an octocoral colony, but usually refers to an autozooid.

Polyp leaf: In some sea pens, a lateral projection emanating from the rachis that contains multiple numbers of autozooids, often giving the colony a feather-like appearance.

Proteinaceous: Partially or wholly composed of a protein or combination of several proteins, often part of a matrix associated with other substances such as calcium carbonate.

Rachis: The upper portion of a sea pen that contains the polyps; as opposed to the peduncle in the lower portion of the colony that is smooth and docs not contain polyps.

Radiate: A spindle-like sclerite with two parallel whorls of tubercles separated by a smooth waist, also called capstan in some literature accounts.

Reticulated: Branching pattcrn that forms a netlike structure; see Anastomosis.

Retractile: A polyp that can completely withdraw or retract into the coenenchyme of the coral colony.

Rod: An unbranched sclerite that has blunt edges at both ends.

Rooted leaf: A clublike sclerite with a rootlike base and a broad, flattened, shieldlike blade; also sometimes referred to as a leaf scale (Fig. 24, top row).

Rosette: A sclerite with a funnel-shaped, projecting, often somewhat spiny crown.

Sclerite: Minute skeletal components in octocorals (commonly $<0.25 \mathrm{~mm}$ in length), primarily comprised of calcium carbonate; combined with varying amounts of protein that often provides permanent coloration in axooxanthellate gorgonians; also called "spicule."

Spatulate: Widened or spatula-shaped toward the end of branches, as in Solenocaulon.

Spheroid: A ball-like or sphcrc-shaped sclcrite.

Spindle: An unbranched sclerite that is pointed at both ends.

Stalk: The proximal part of a gorgonian or pennatulacean colony that is devoid of polyps.

Thornscale: A flattened scleritc with a single spine-like or scveral thorn-like projecting processes. Derivations of this kind of sclerite have been called thornstars (Figs. 19-20).

Tuberculated: Refers to a sclerite that is ornamented with several or many rounded nodules or pointed knobs or wart-like structures (Fig. 35).

Waisted spindle: A spindle-like sclerite that has a medial, smooth waist that is narrower than the rest of the sclerite, and the tubercles on each end are not radially-arranged (Fig, 35C-D, last three sclerites on the right in each row)

Wallacea: A group of islands in eastern Indonesia that arc scparated by regions of deep watcr from the Asian and Australian continental shelves. They were never connected to either of these continental regions, are entirely included within the coral triangle, and share common faunistic characteristics (Figure 2A); named for $19^{\text {th }}$ century naturalist and zoogcographer, Alfred Russel Wallace.

Zooxanthellate: An adjective that is used to describe corals and other organisms that harbor symbiotic, photosynthetic zooxanthellae (single-celled organisms that are dinoflagellates of the genus Symbiodinium) in their tissues. 


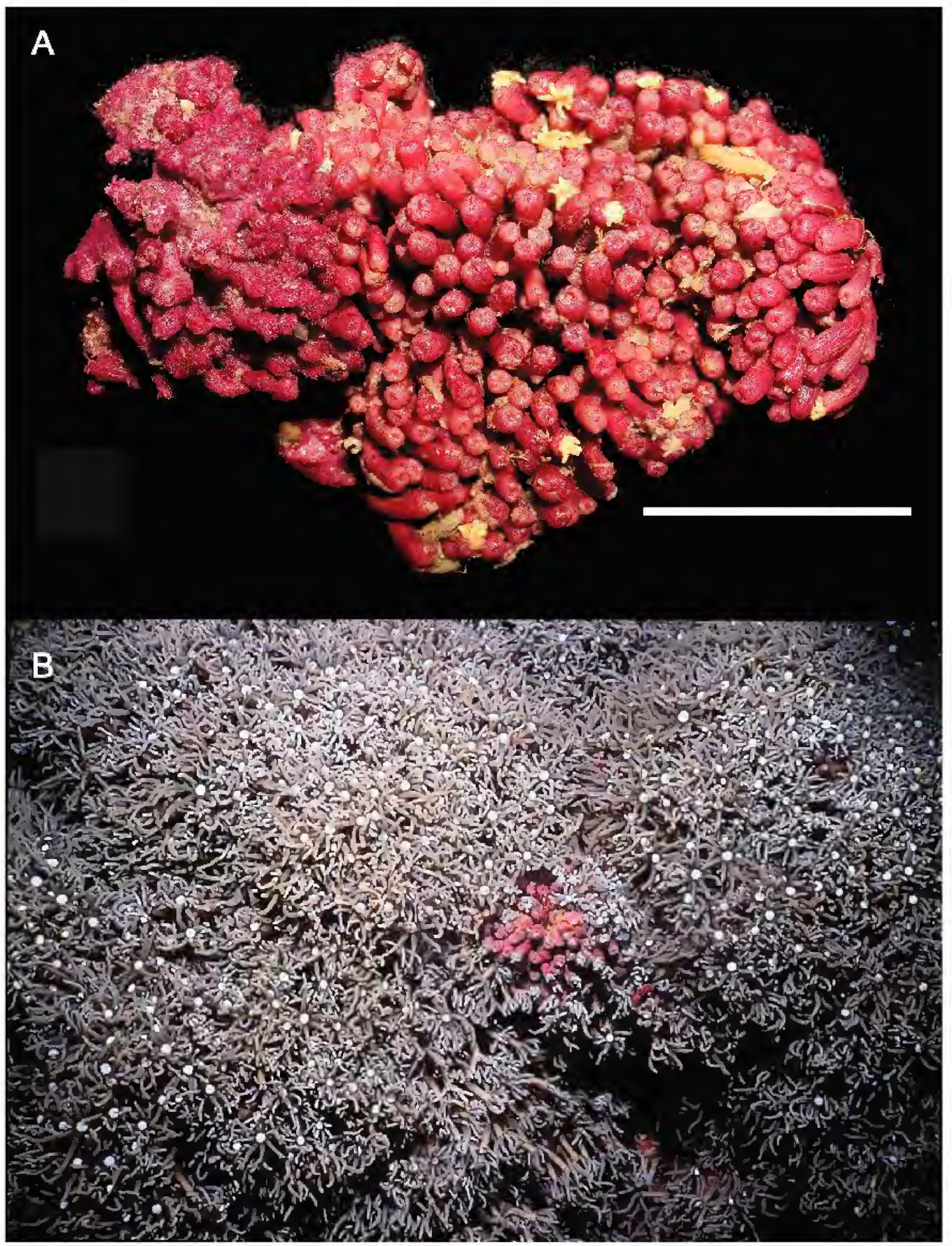

FIGURE 3. Briareum sp. A. Wet-preserved specimen (CASIZ 104004); scale bar $=20 \mathrm{~mm}$. B. Underwater photograph of a species of Briareum with extended polyps in which the tentacles are gray in color, the oral discs are white, and the moundlike or cylindrical polyp bases are red-purple. 


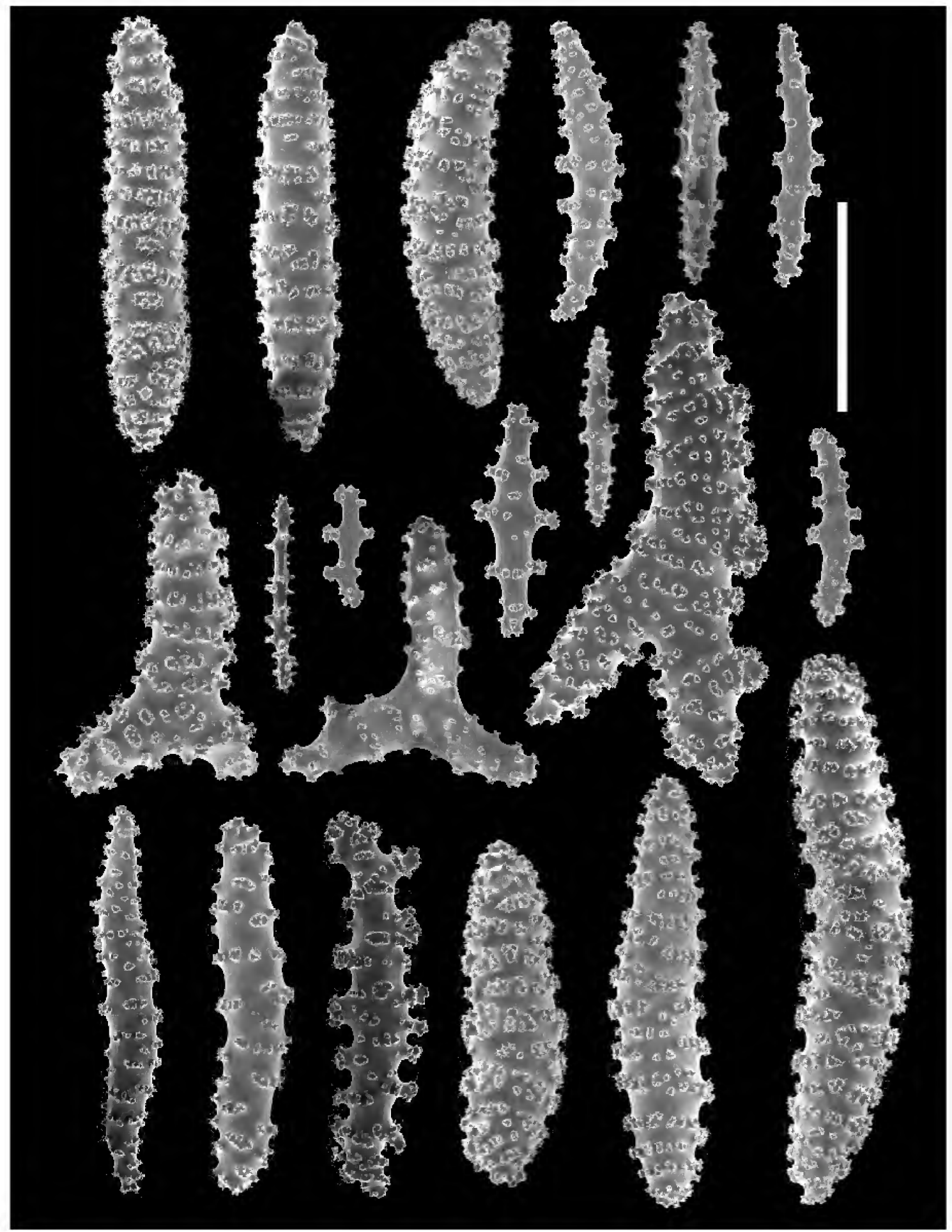

FIGURE 4. Briareum sp., scanning electron micrographs of sclerites from the polyp bases of retracted polyps. Scale bar $=0.2 \mathrm{~mm}$. 


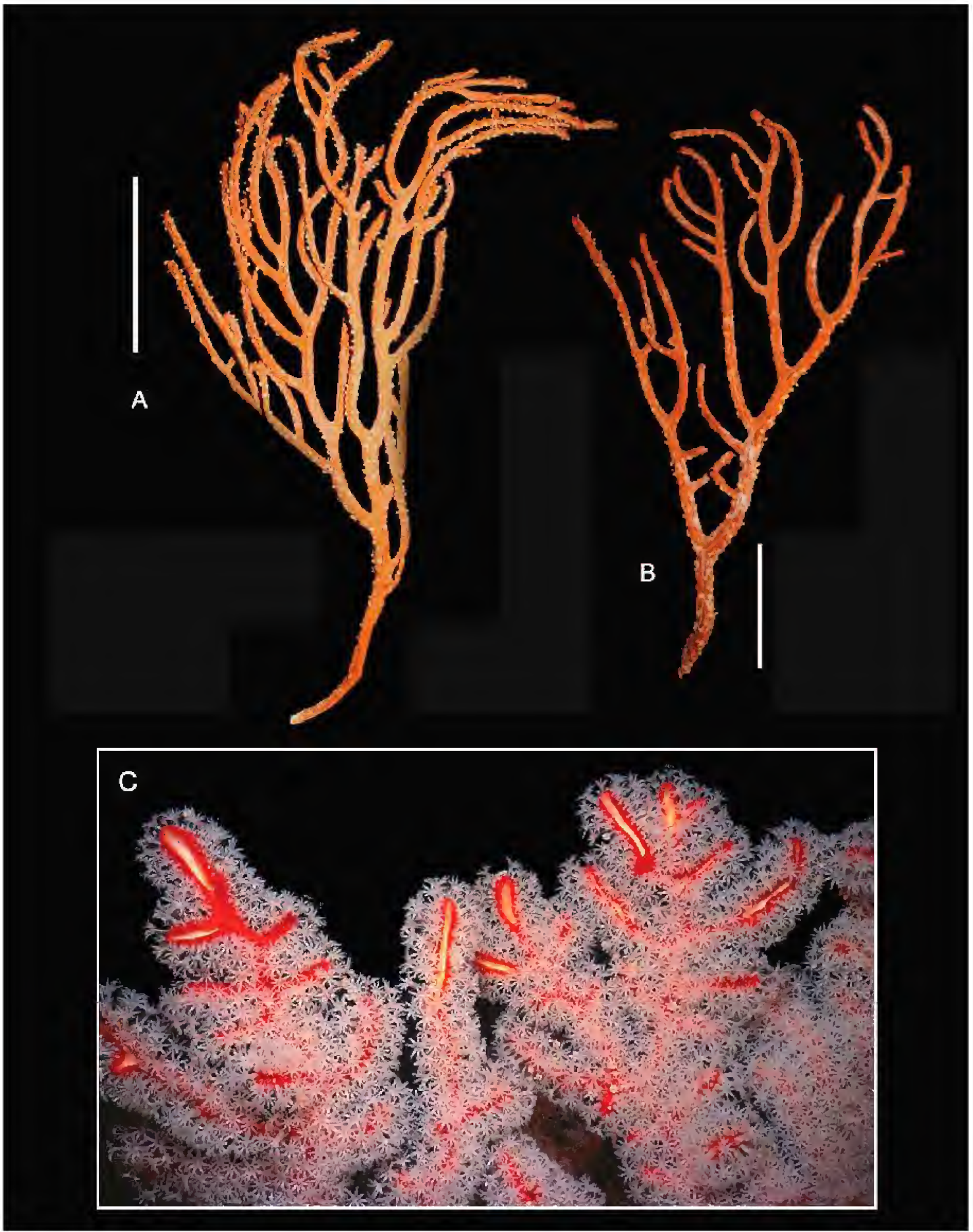

FIGURE 5. A-B. Wet-preserved specimens of Subergorgia suberosa (CASIZ 103912), scale bars $=40 \mathrm{~mm}$. C. Underwater photograph of Solenocaulon cf. rubra, with polyps extended showing fistulose branch ends. 


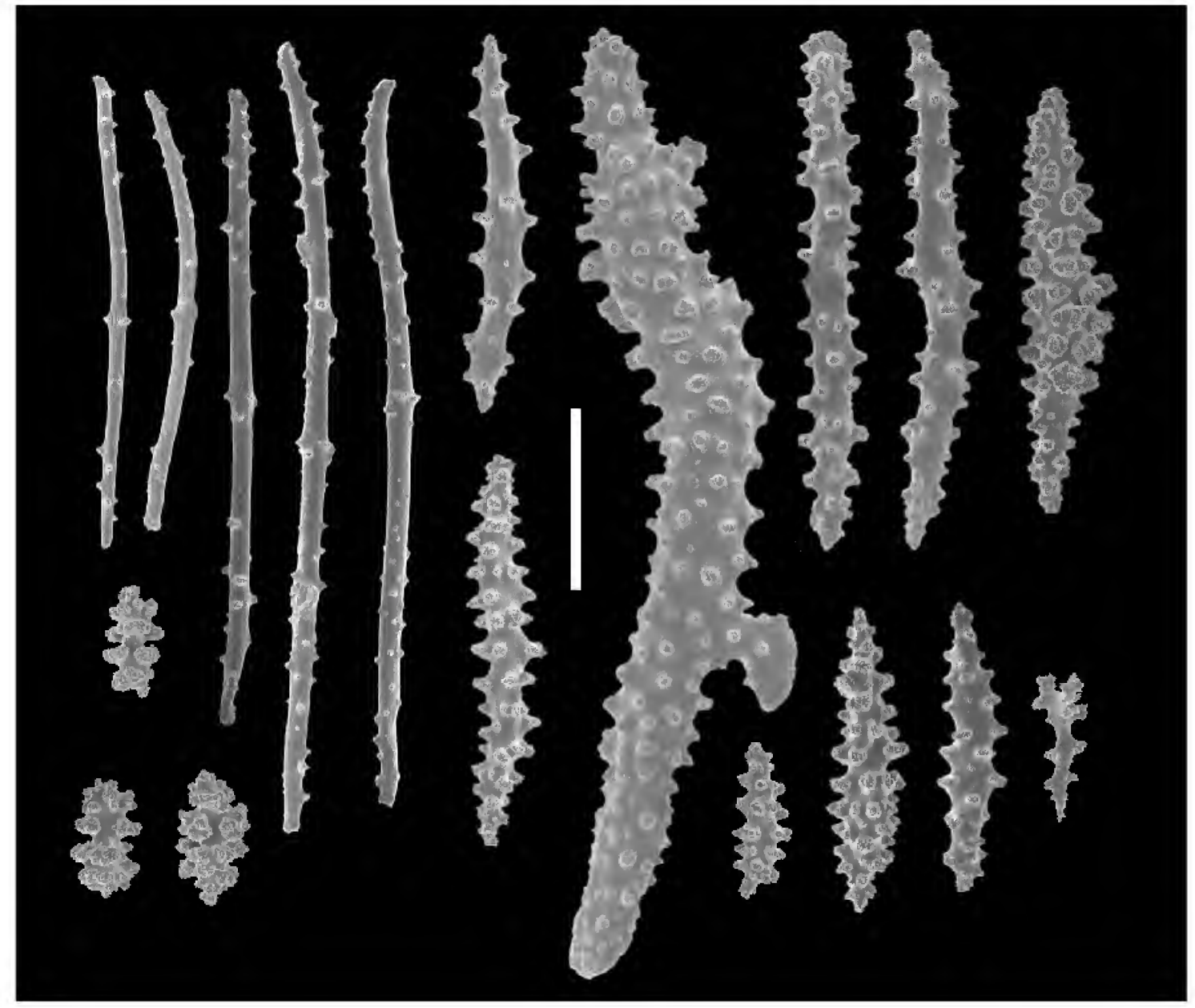

FIGURE 6. Solenocaulon cf. rubra, scanning electron micrographs of sclerites from CASIZ 103904. Scale bar $=0.10$ $\mathrm{mm}$. 


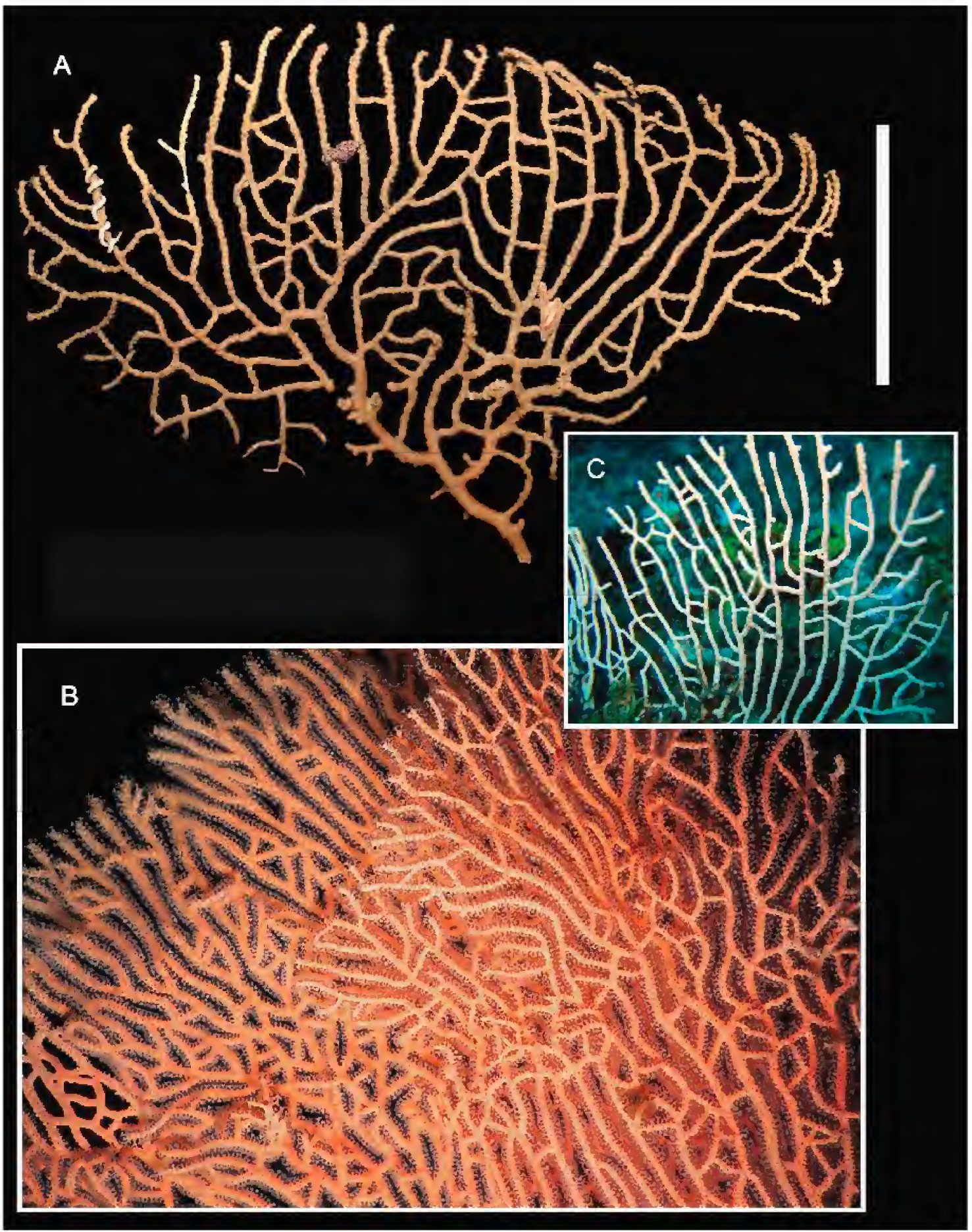

FIGURE 7. A. Wet-preserved specimen of Annella reticulata (CASIZ 185458), scale bar $=50 \mathrm{~mm}$. B. Underwater photograph of Annella mollis, with minute extended polyps arranged biserially in opposite longitudinal rows. C. Underwater photograph of Annella sp. showing reticulated branching pattern. 


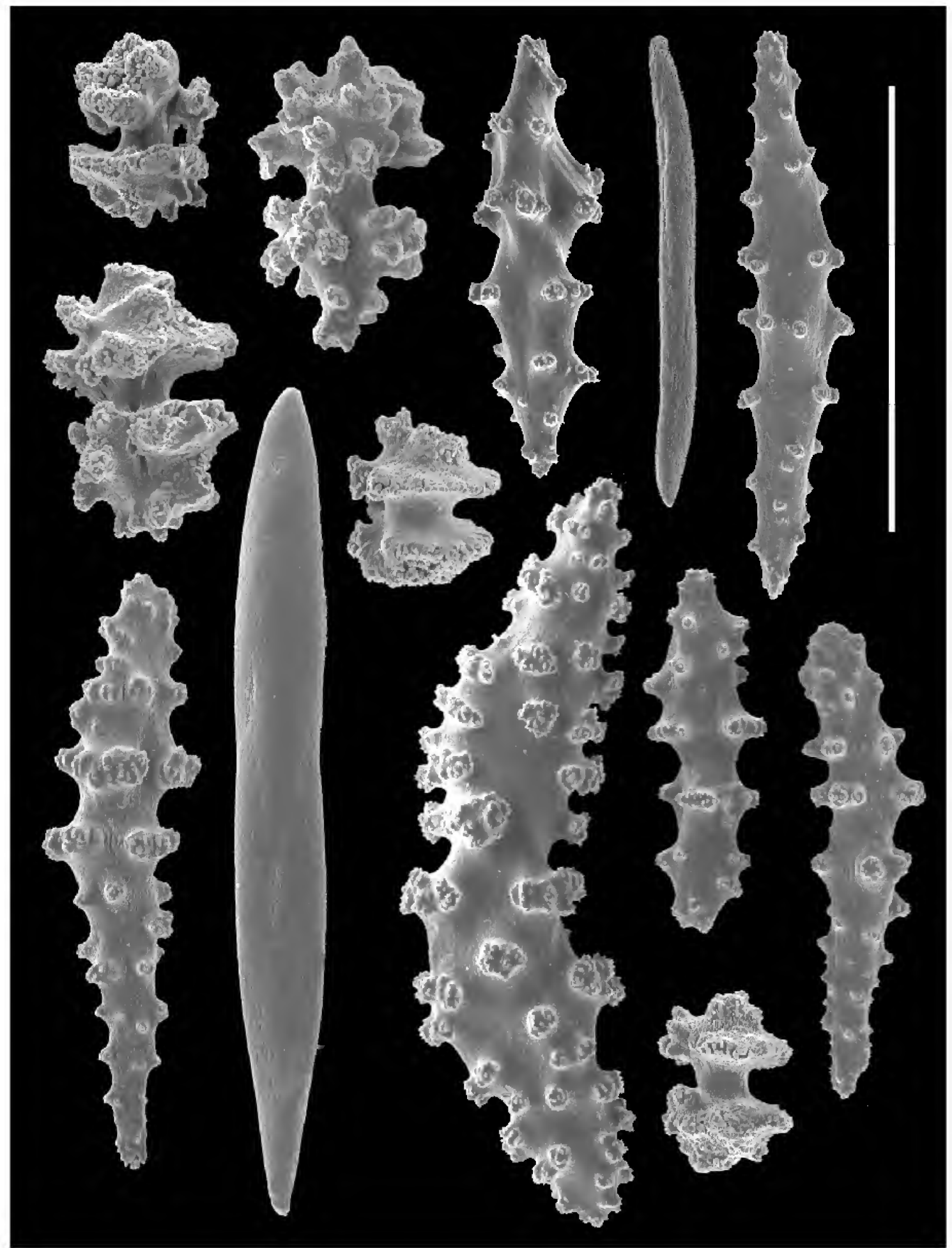

FIGURE 8. Annella reticulata, scanning electron micrographs of sclerites from CASIZ 185458. Scale bar $=0.10 \mathrm{~mm}$. 


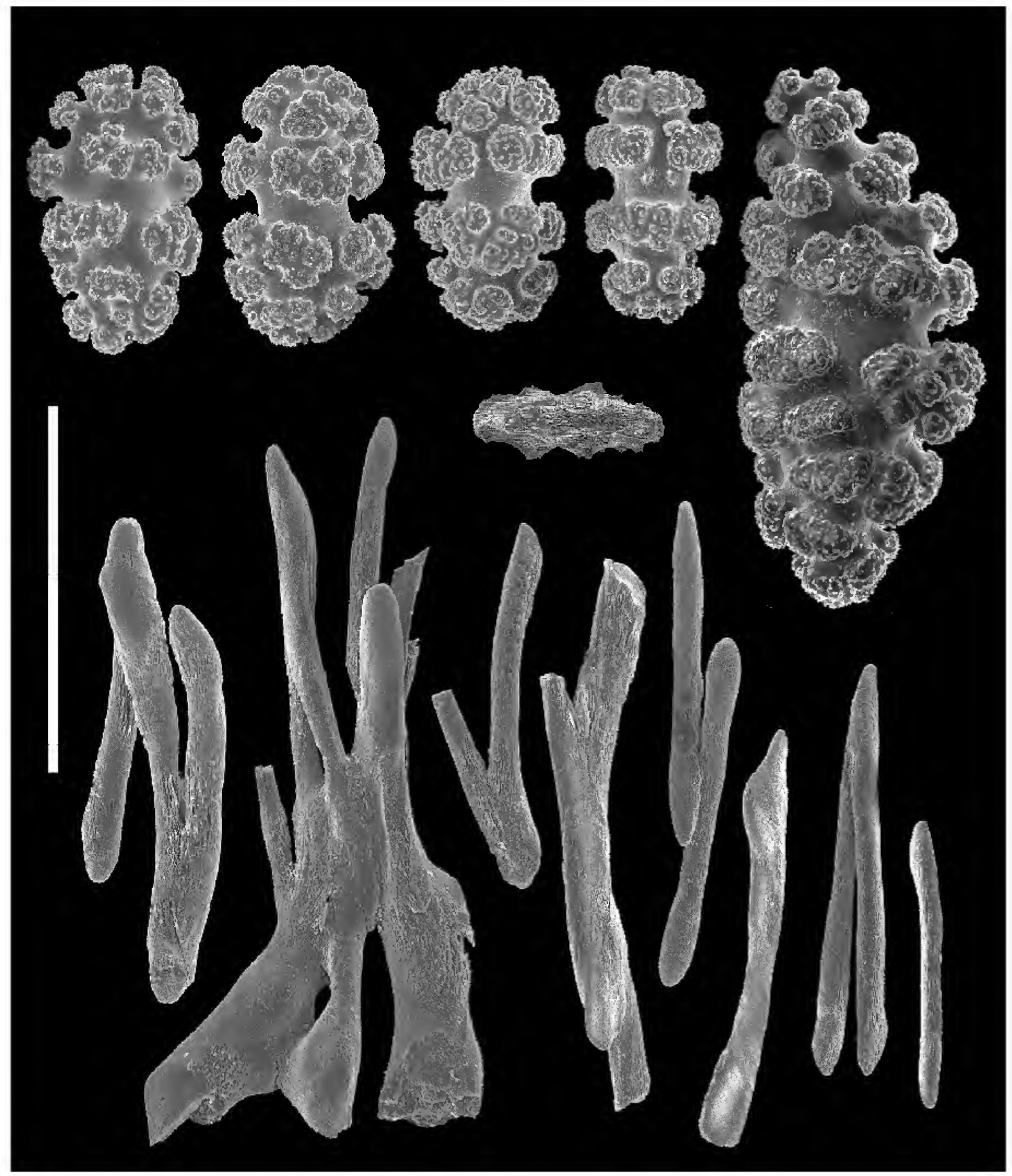

FIGURE 9. Subergorgia suberosa, scanning electron micrographs of sclerites from CASIZ 104074. Scale bar $=0.10 \mathrm{~mm}$. 


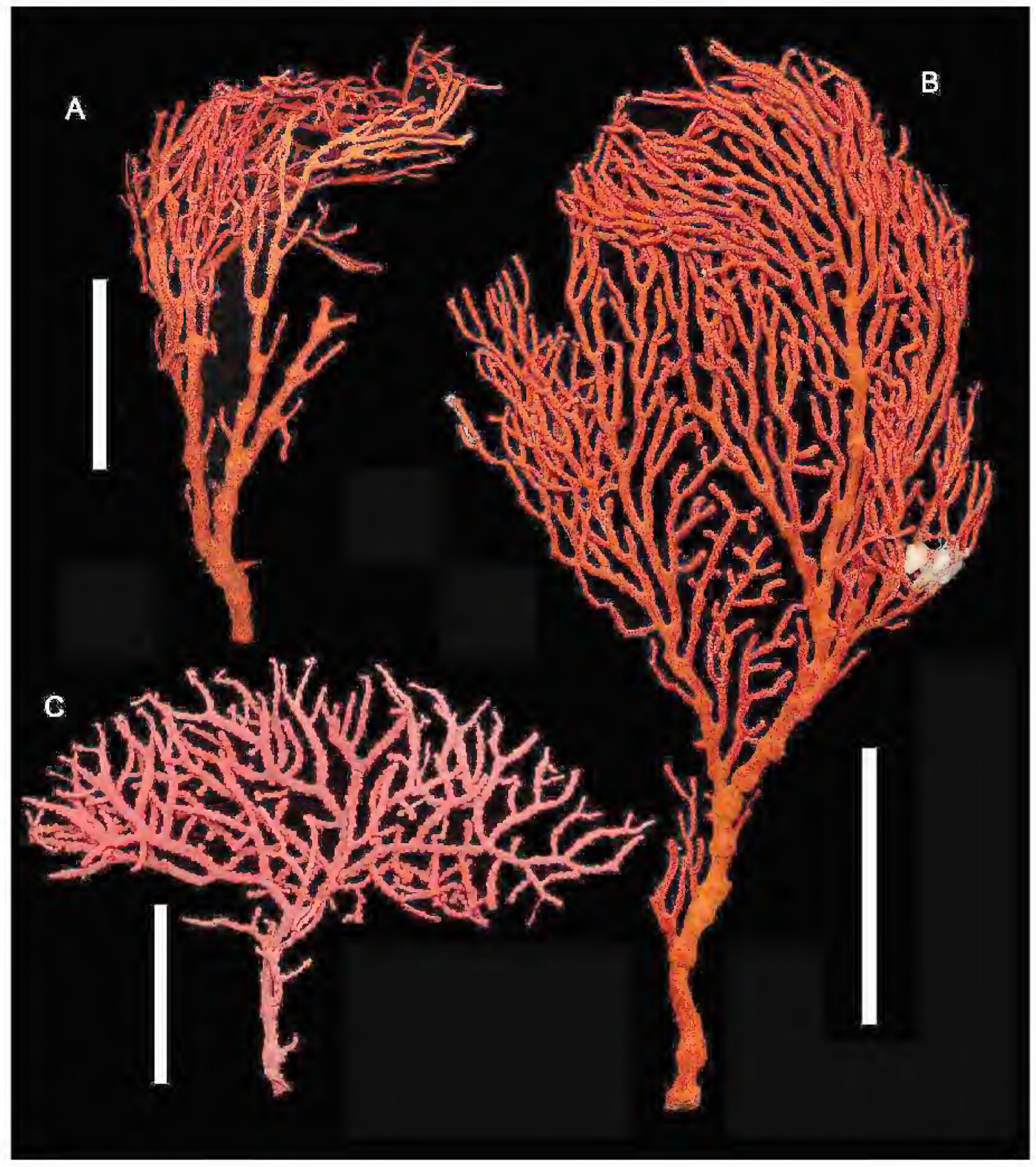

FIGURE 10. A. Melithaea sp., CASIZ 185441, wet-preserved specimen; scale bar $=50 \mathrm{~mm}$. B. Melithaea sp., CASIZ 103805, wet-preserved specimen; scale bar $=50 \mathrm{~mm}$. C. Acabaria sp., 186644, wet-preserved specimen; scale bar $=25$ $\mathrm{mm}$. 


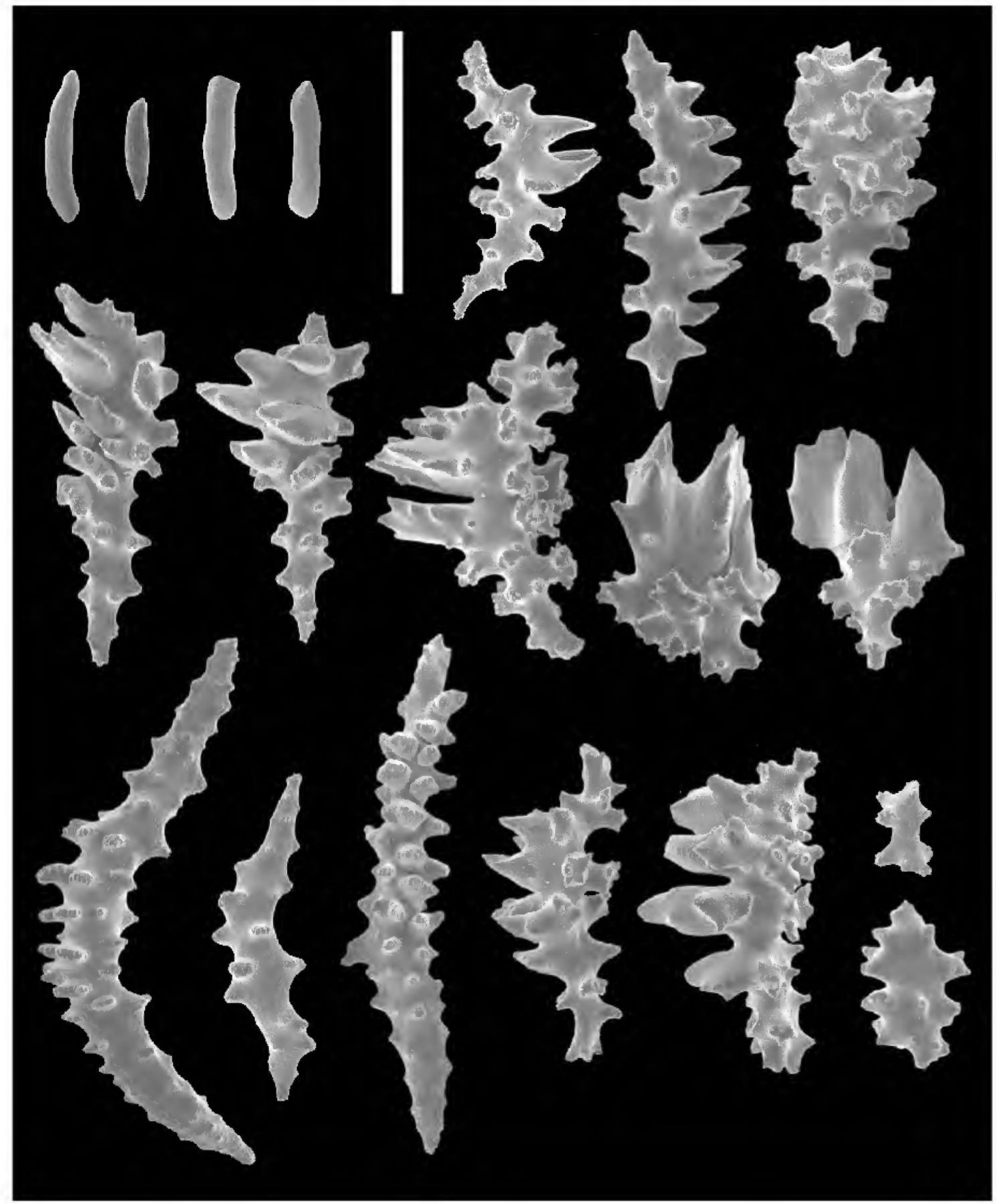

FIGURE 11. Acabaria sp., scanning electron micrographs of sclerites from CASIZ 186644. Scale bar $=0.10 \mathrm{~mm}$. 


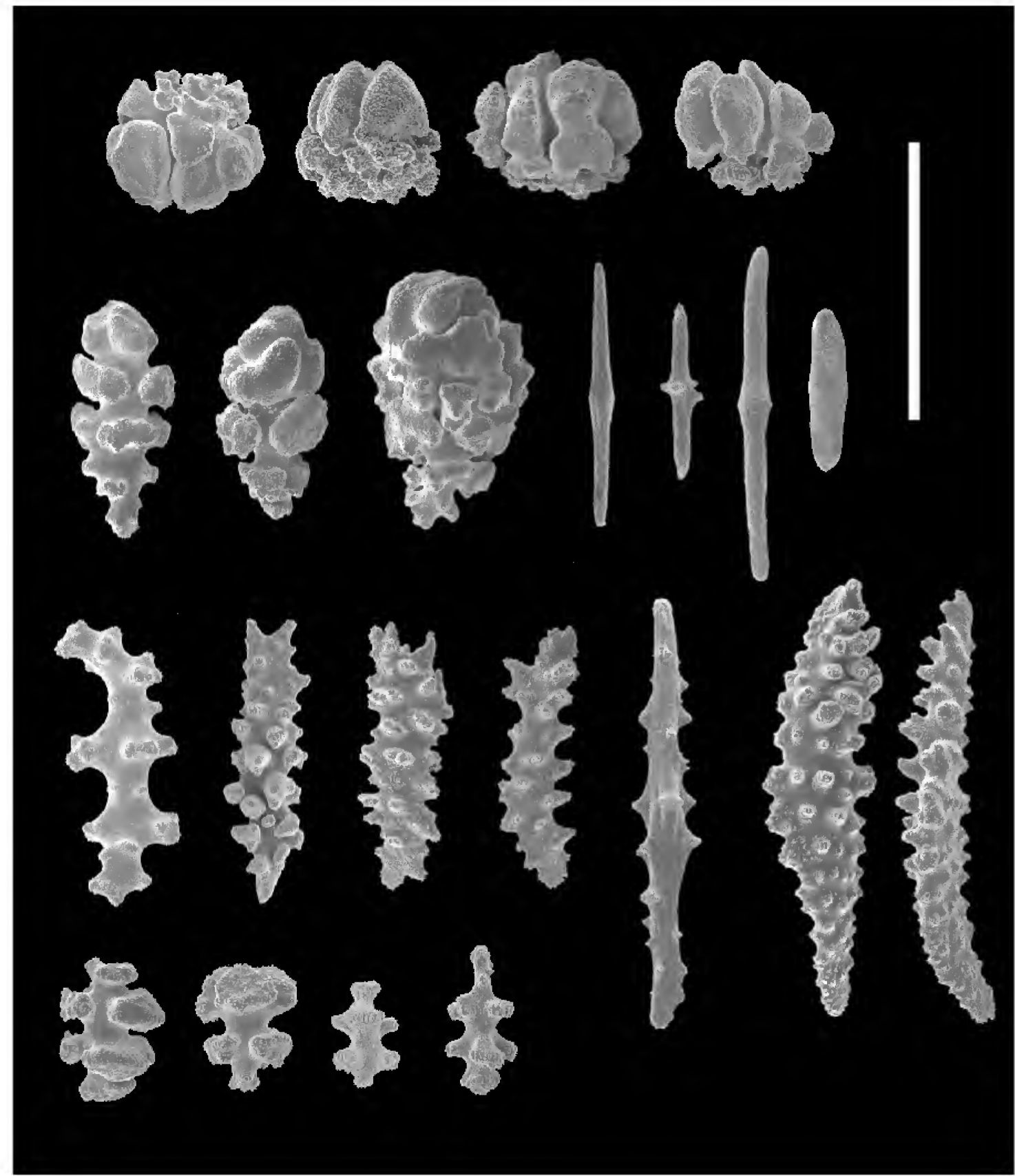

FIGURE 12. Melithaea sp., scanning electron micrographs of sclerites from CASIZ 103805. Scale bar $=0.10 \mathrm{~mm}$. 

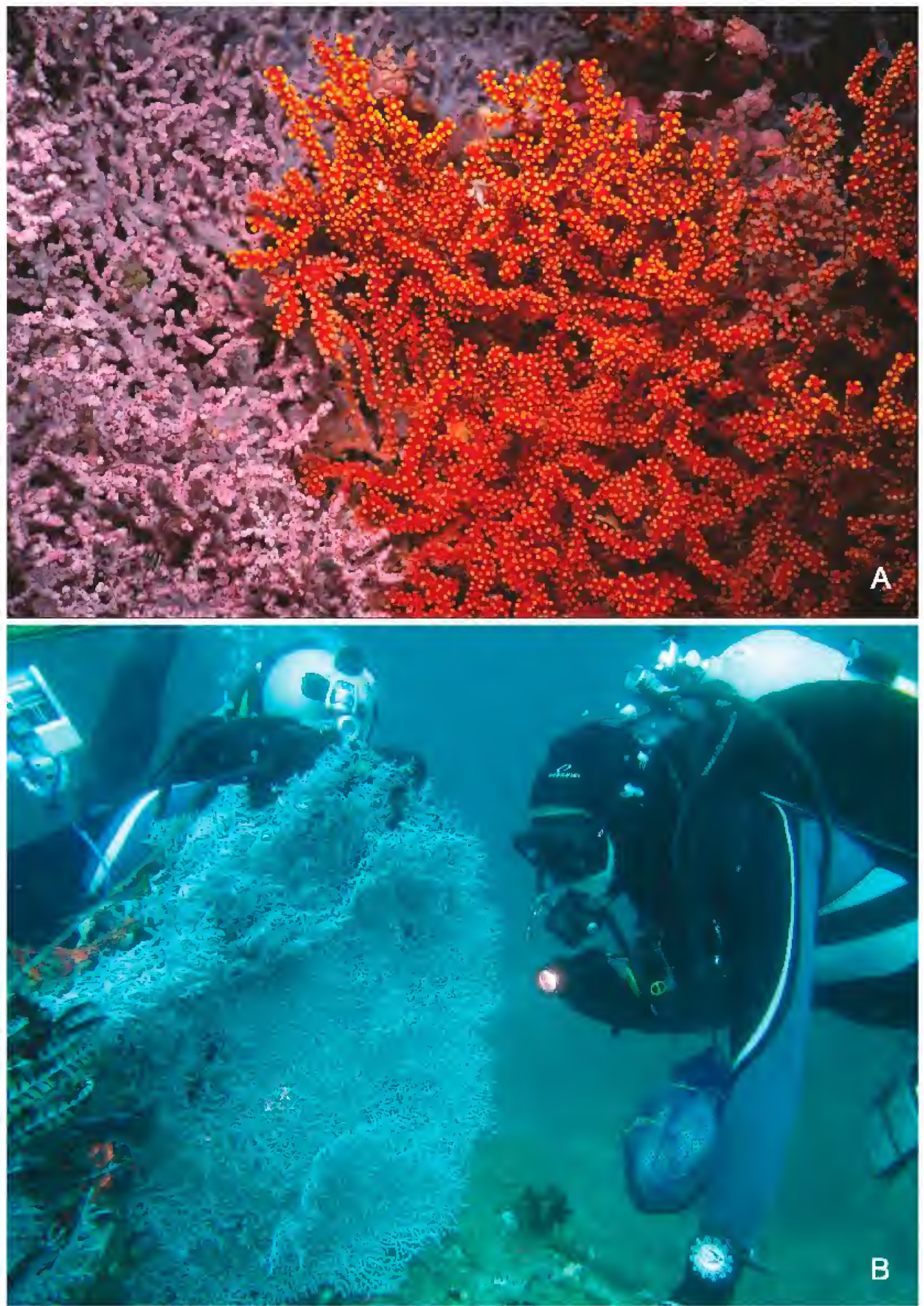

Figure 13. A. Muricella sp. (left) and Acanthogorgia sp. (right). B. Divers inspecting the branches of a large colony of Muricella sp. for pygmy sea horses during the Hearst Philippines expedition, Devil's Point, Maricaban Island, ca. $24 \mathrm{~m}$ depth, 26 May 2011. 


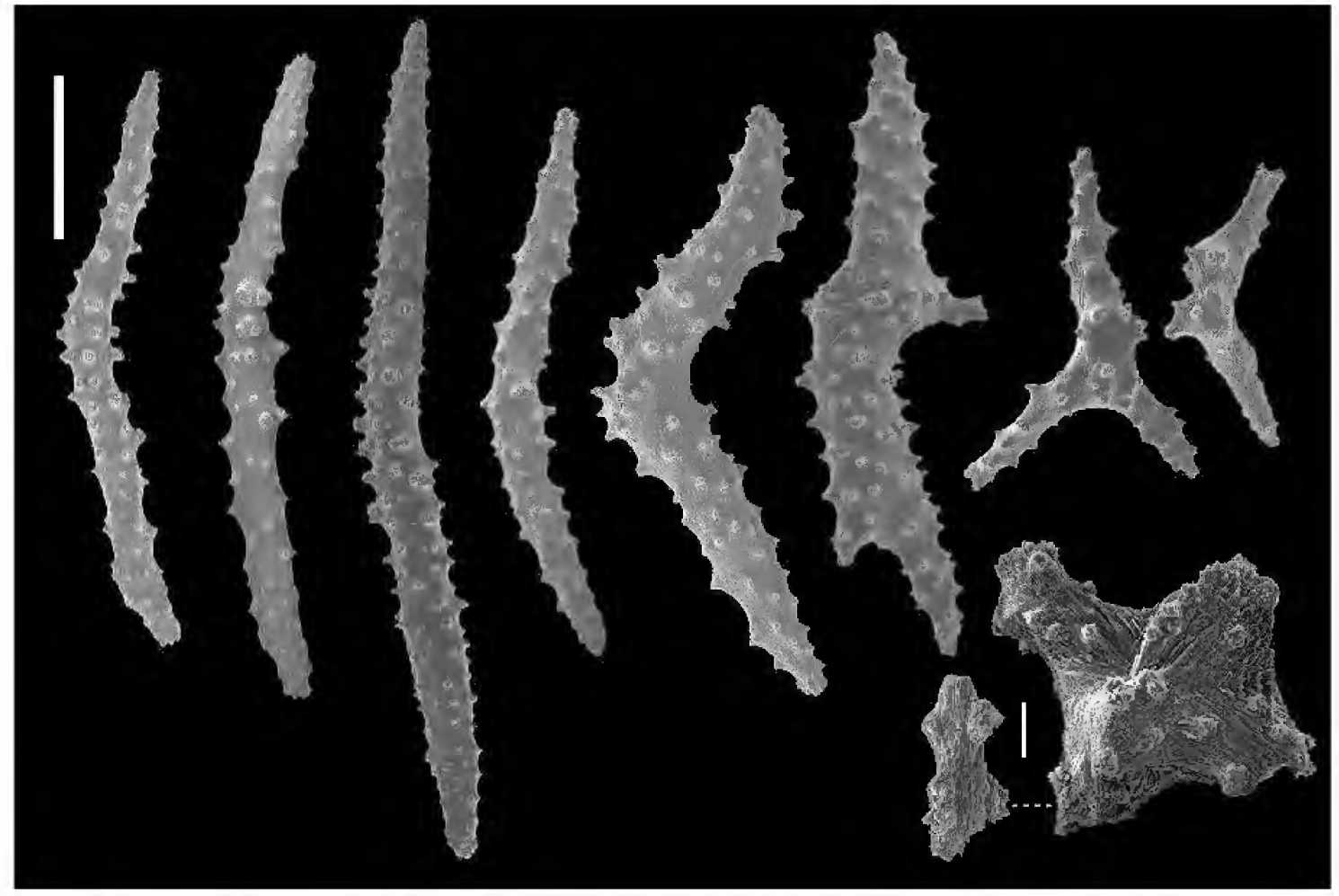

FIGURE 14. Acanthogorgia sp., scanning electron micrographs of sclerites from CASIZ 180180. Scale bar on left $=0.10$ $\mathrm{mm}$; scale bar on right $=0.01 \mathrm{~mm}$. 


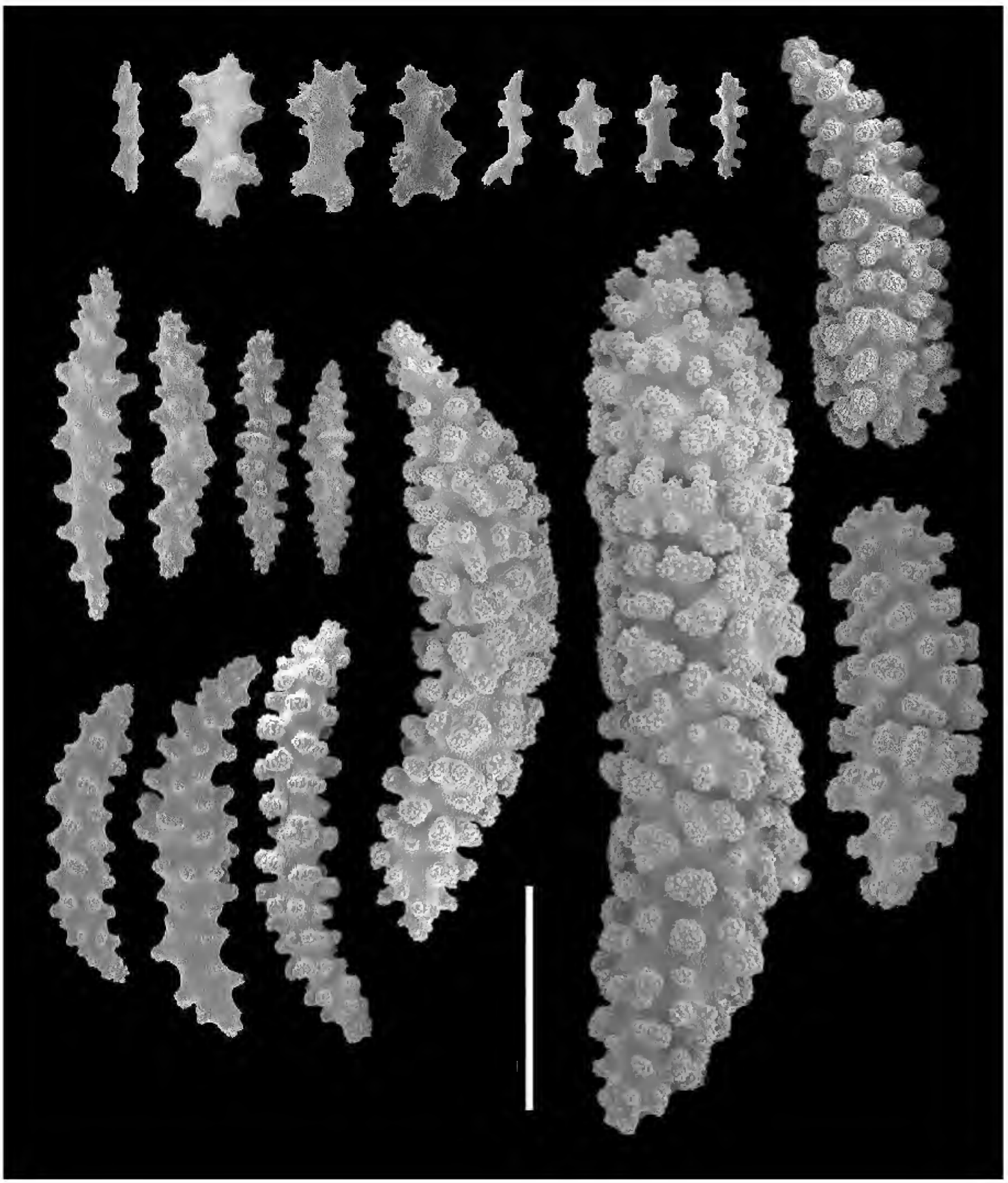

FIGURE 15. Muricella sp., scanning electron micrographs of sclerites from CASIZ 109526. Scale bar $=0.10 \mathrm{~mm}$. 


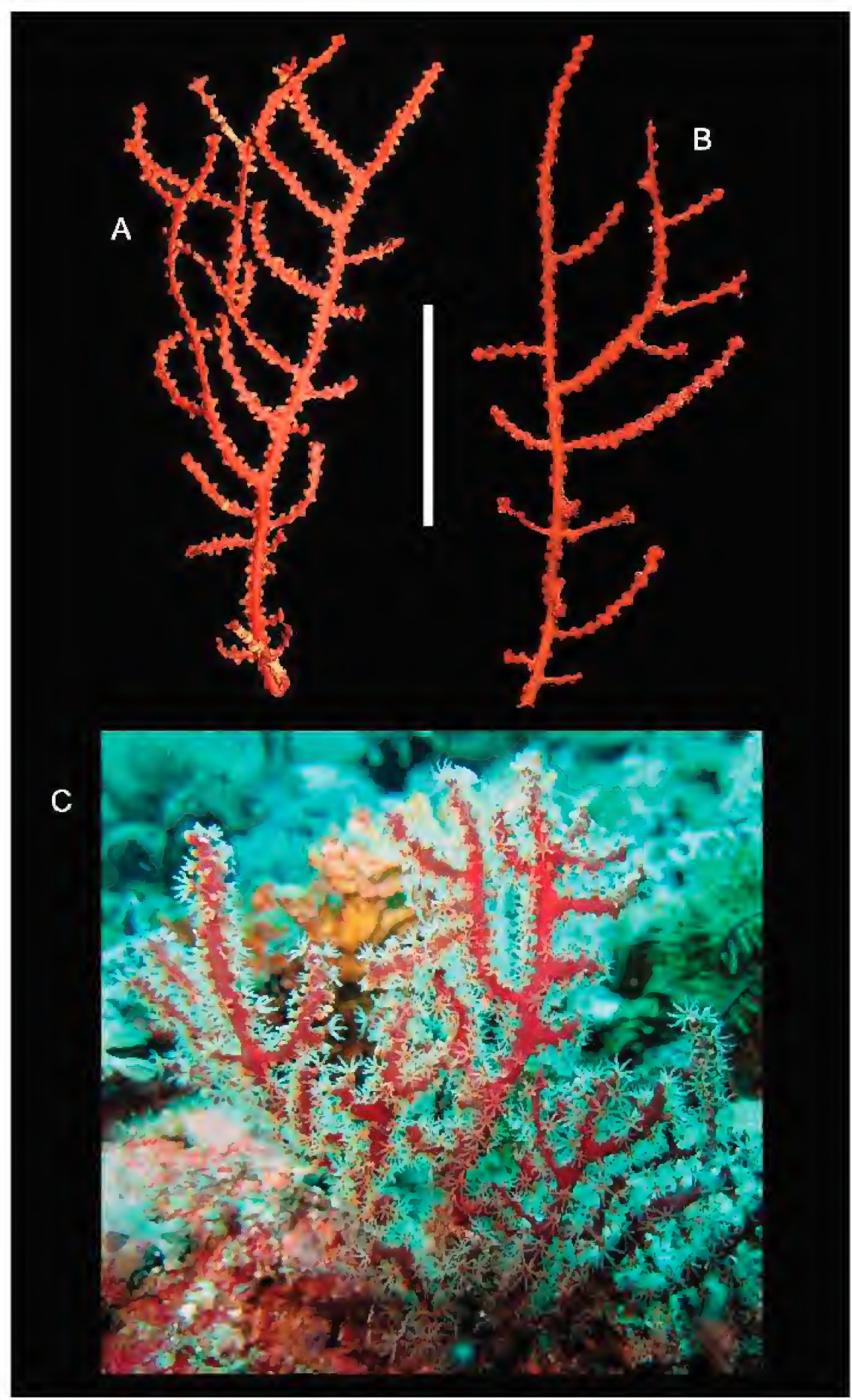

FIGURE 16. Astrogorgia sp. A. Wet-preserved specimen (CASIZ 168899). B. Wet-preserved specimen (CASIZ 190428). Scale bar for A and B $=30 \mathrm{~mm}$. C Underwater photograph of a colony with polyps extended. 


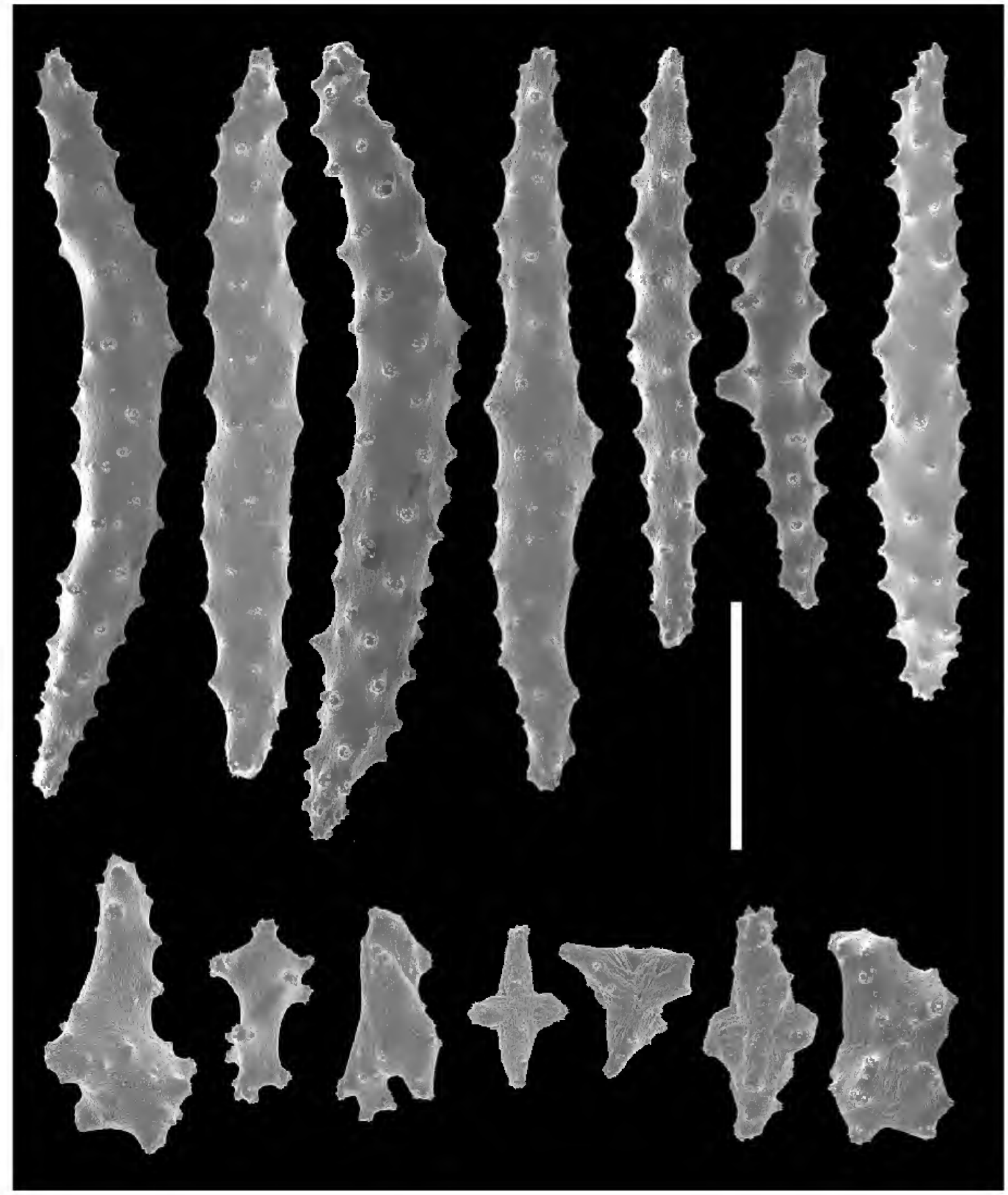

FIGURE 17. Astrogorgia sp., scanning electron micrographs of sclerites from CASIZ 185465. Scale bar $=0.10 \mathrm{~mm}$. 


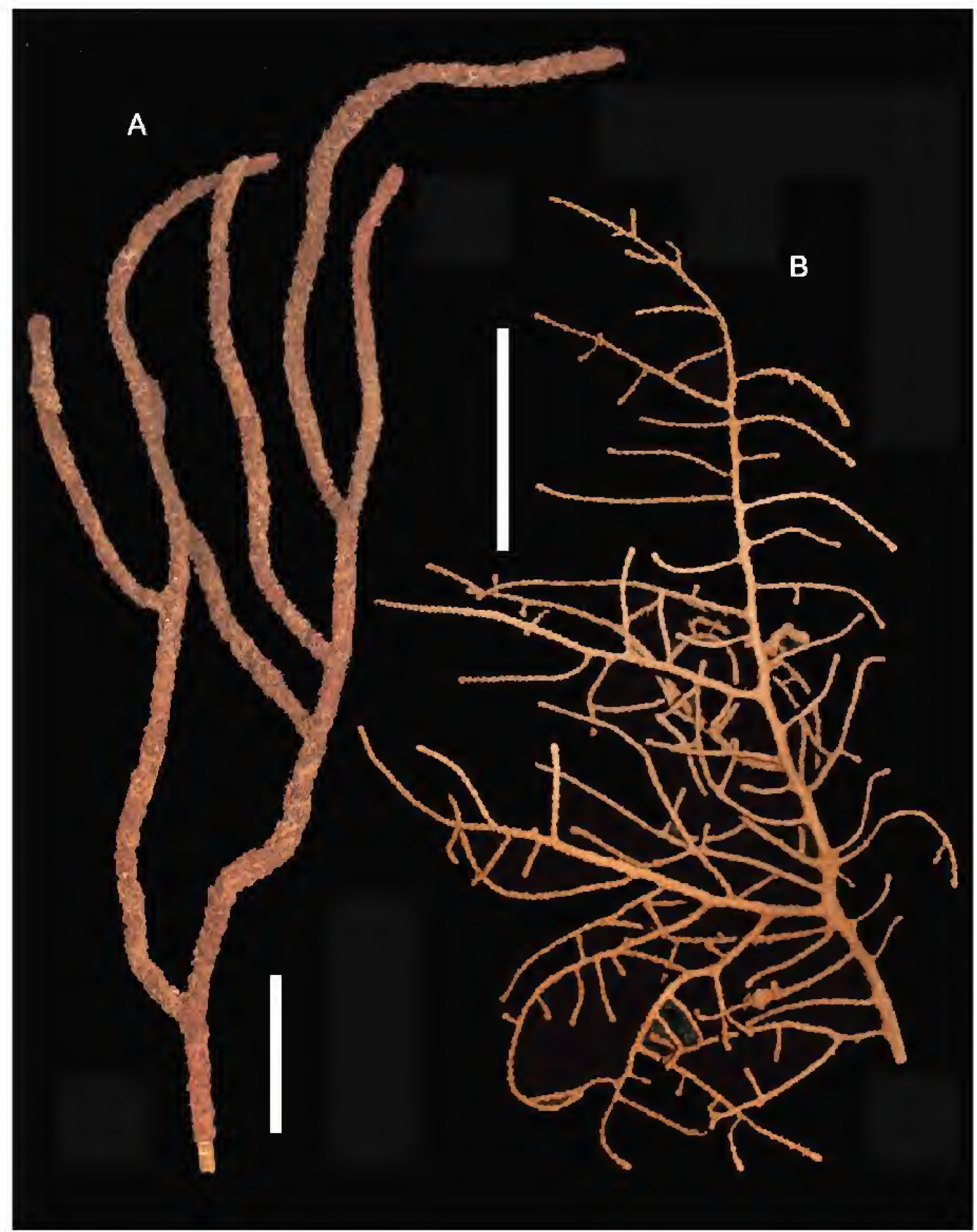

FIGURE 18. A. Wet-preserved specimen of Echinomuricea sp. (CASIZ ******); scale bar $=25 \mathrm{~mm}$. B. Wet-preserved specimen of Echinogorgia sp. (CASIZ 109537); scale bar $=40 \mathrm{~mm}$. 


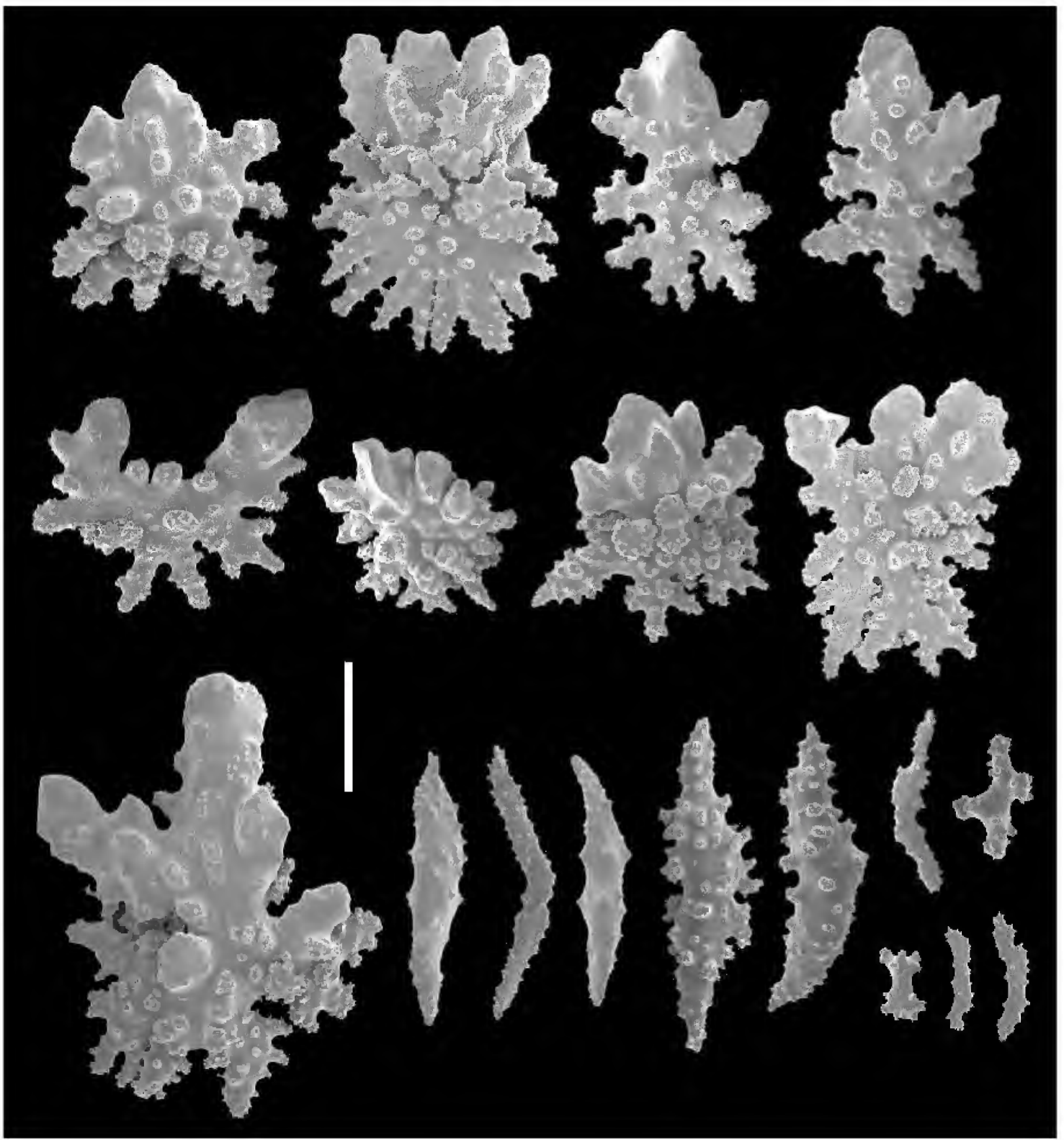

FIGURE 19. Echinogorgia sp., scanning electron micrographs of sclerites from CASIZ 109537. Scale bar $=0.10 \mathrm{~mm}$. 


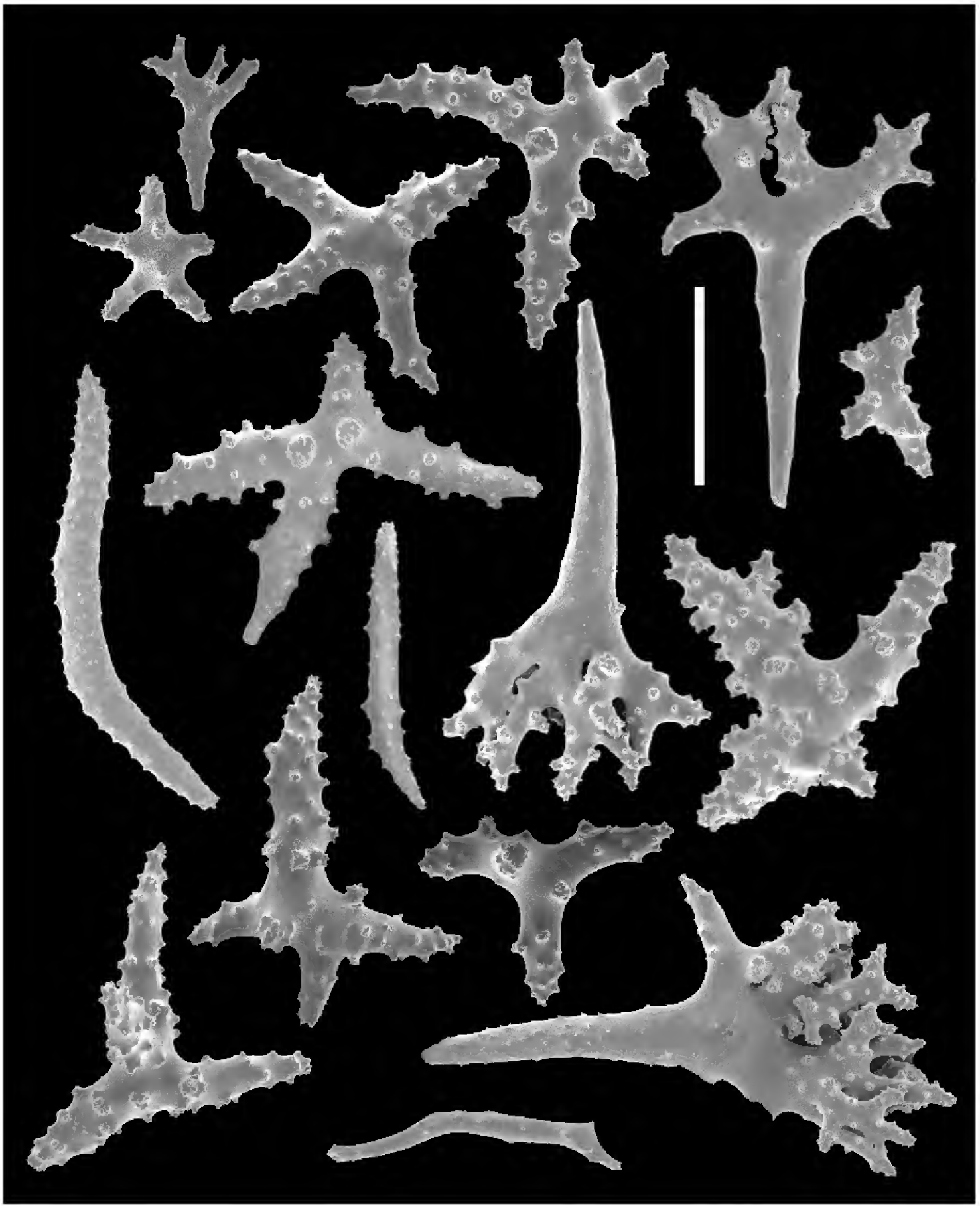

FIGURE 20. Echinomuricea sp., scanning electron micrographs of sclerites from CASIZ 185452; scale bar $=0.20 \mathrm{~mm}$. 


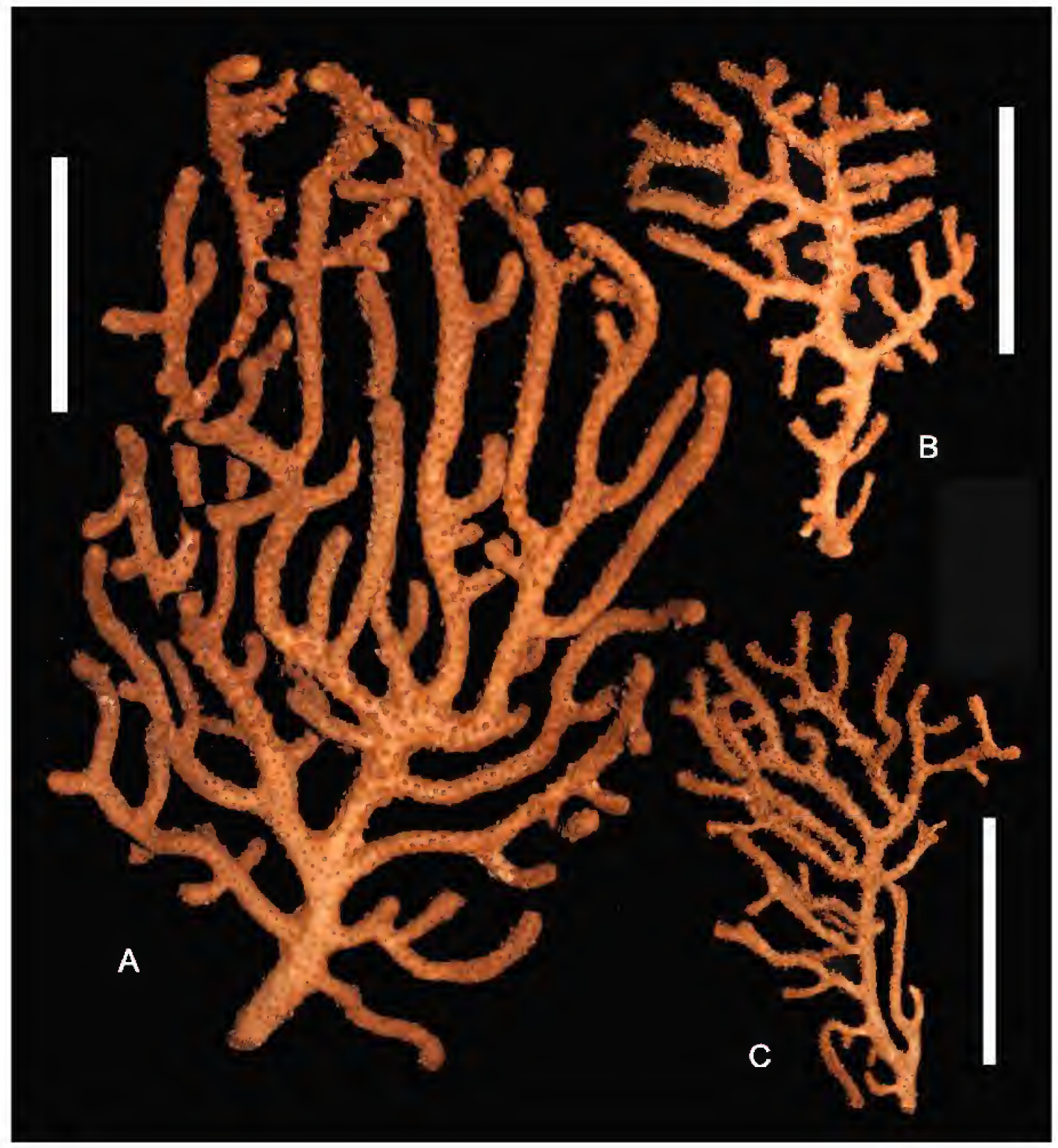

FigurE 21. Euplexaura sp. Wet-preserved specimens (CASIZ 109598); scale bars, A = $40 \mathrm{~mm}, \mathrm{~B}=60 \mathrm{~mm}, \mathrm{C}=65 \mathrm{~mm}$. 


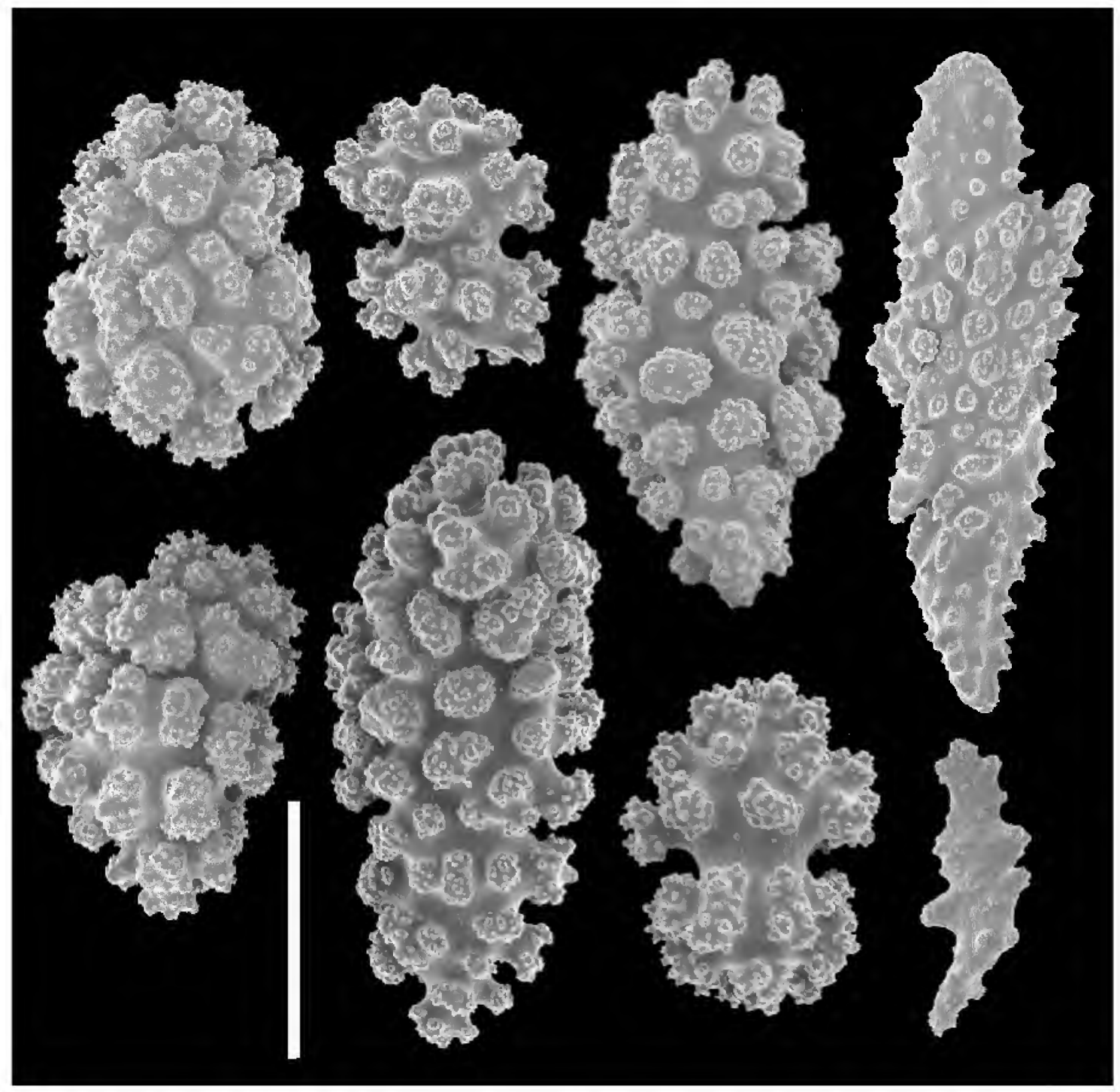

FIGURE 22. Euplexaura sp., scanning electron micrographs of sclerites from CASIZ 180166; scale bar $=0.10 \mathrm{~mm}$. 


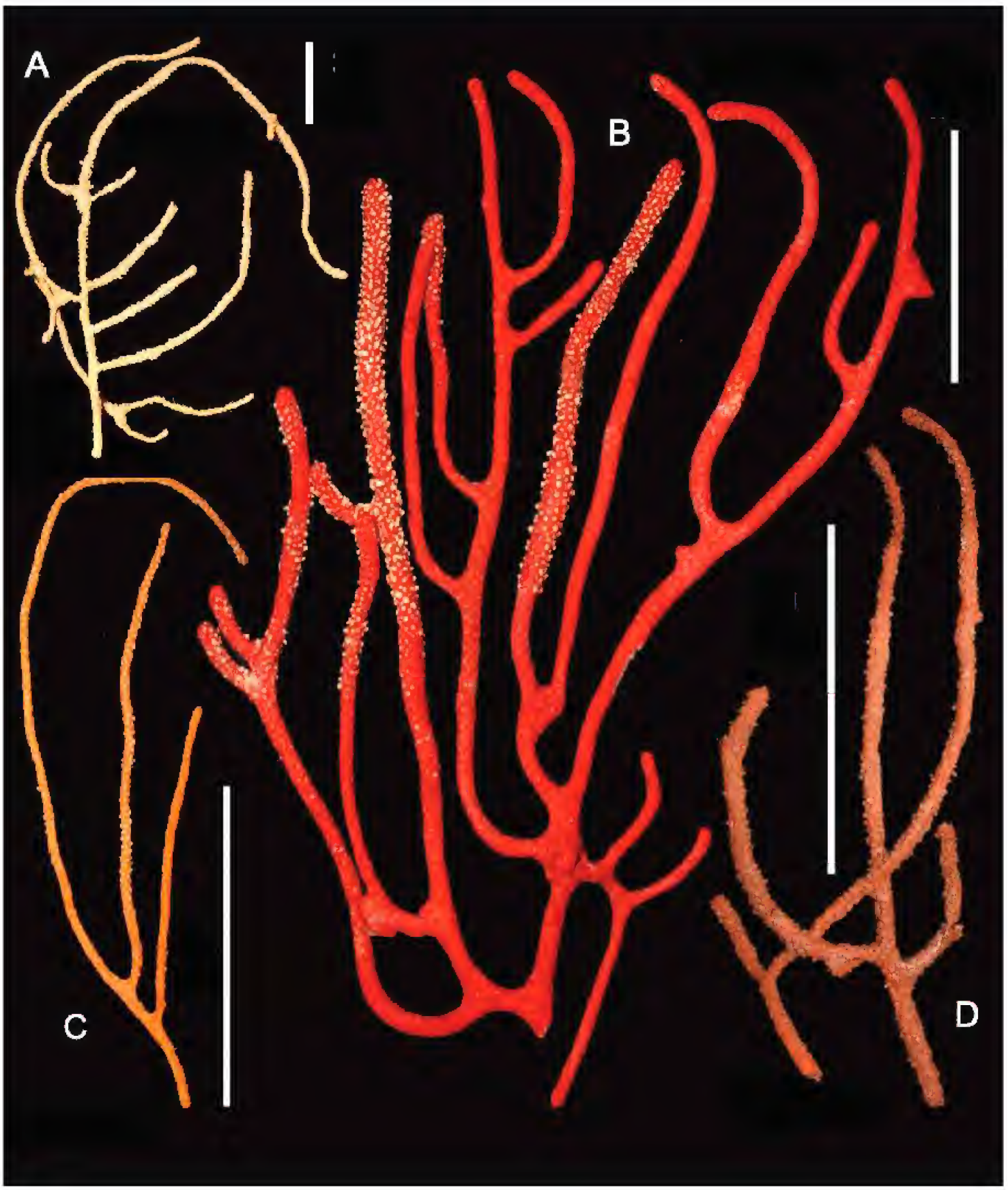

Figure 23. Menella spp. A. CAS 187764; scale bar $=30 \mathrm{~mm}$. B. CAS 185448 ; scale bar $=35 \mathrm{~mm}$. C. CAS 180197 scale bar $=60 \mathrm{~mm}$. D. CAS 109578; scale bar $=70 \mathrm{~mm}$. 


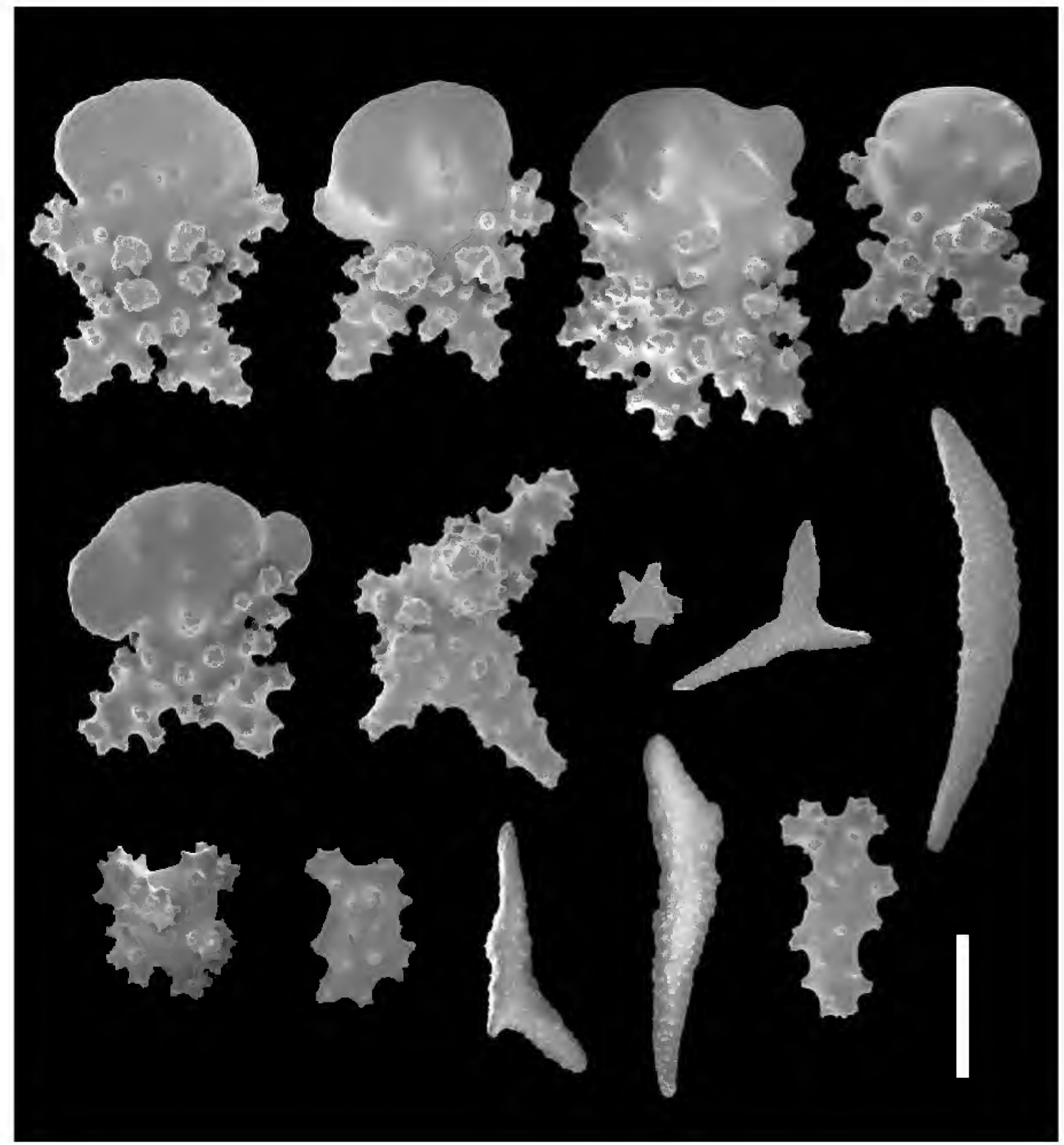

FIGURE 24. Menella sp. scanning electron micrographs of sclerites from CASIZ 109578; scale bar $=0.10 \mathrm{~mm}$. 


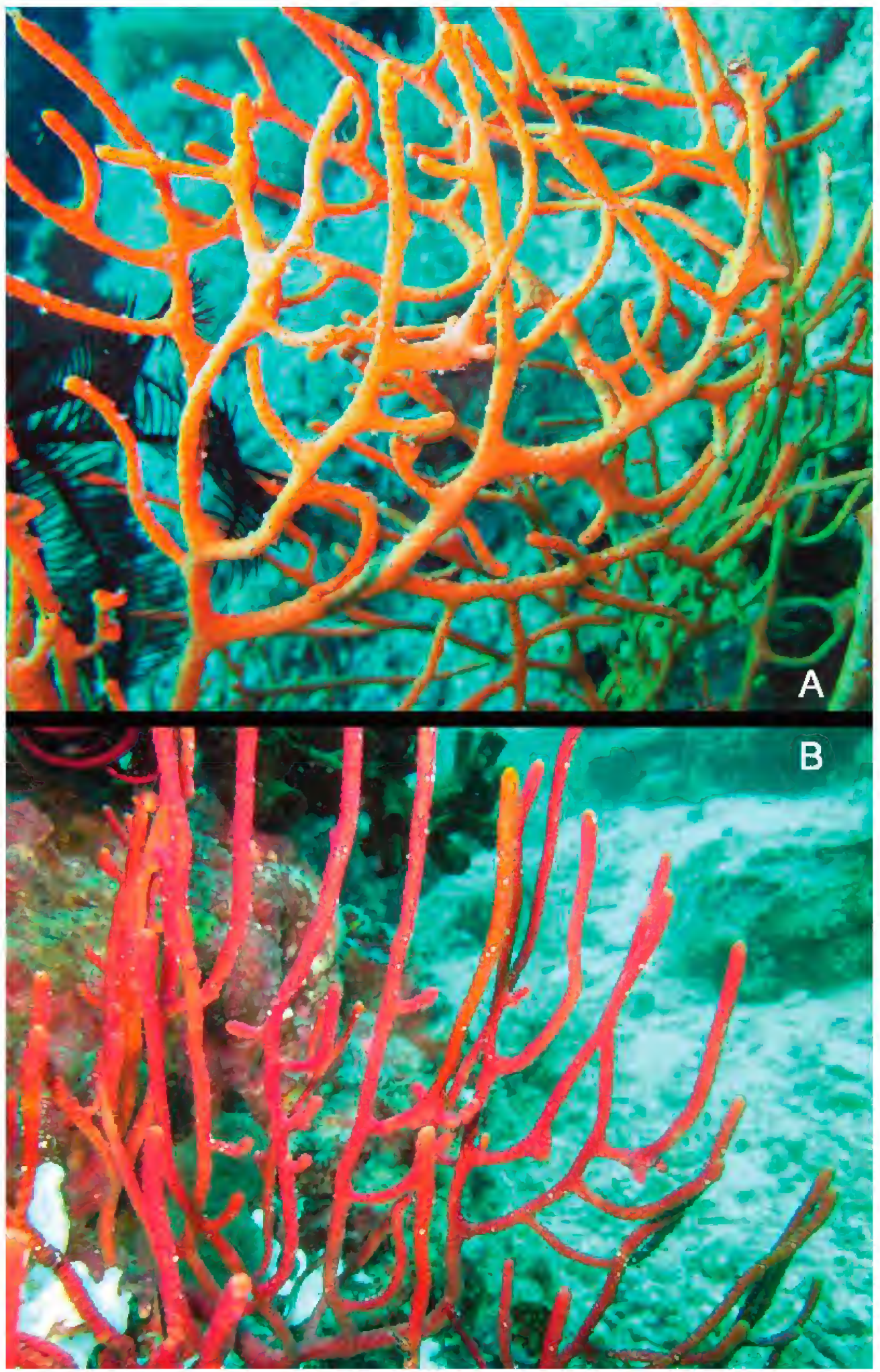

Figure 25. Underwater photographs of plexaurid gorgonians. A. Paraplexaura sp. B. Menella sp. 


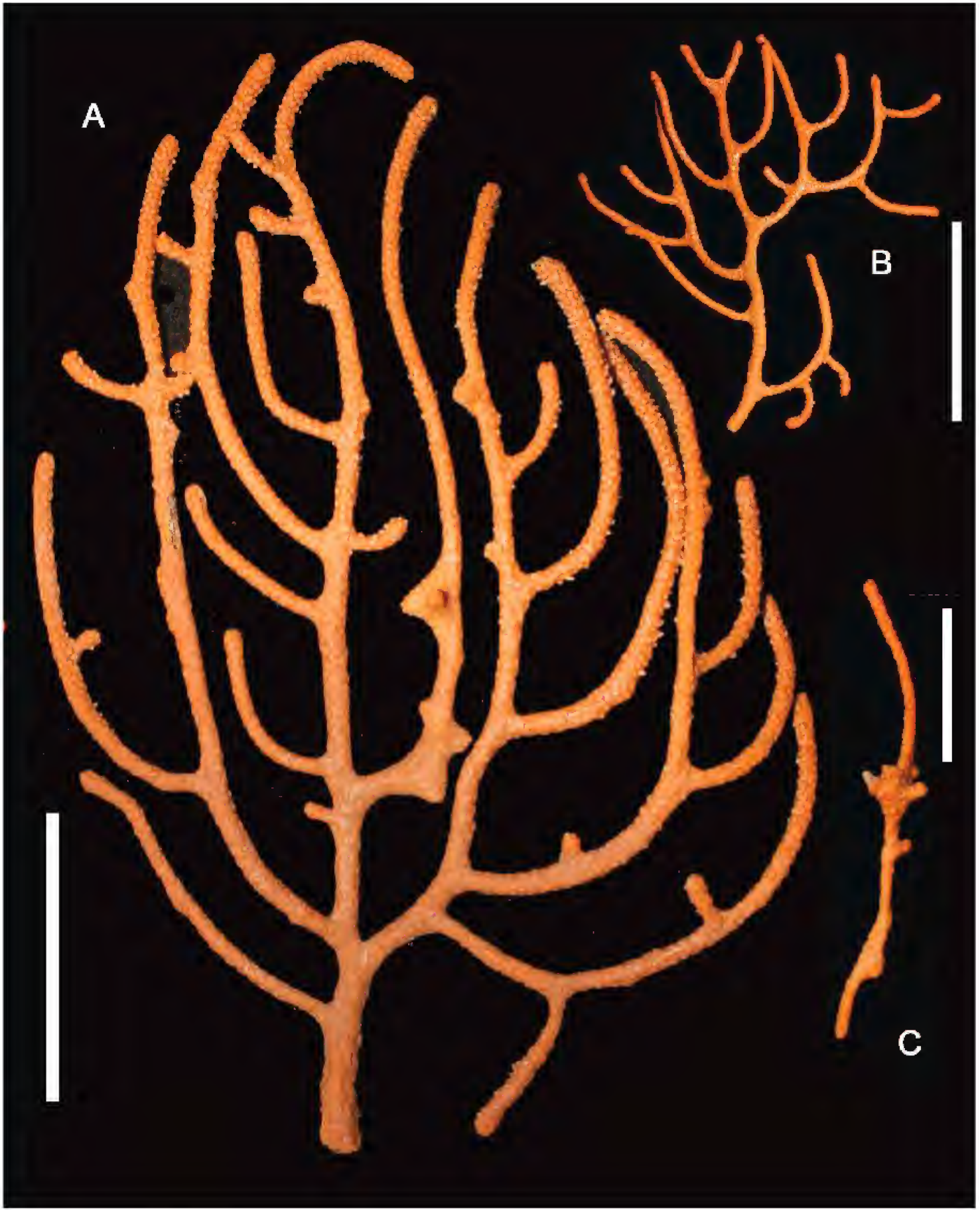

FIgURE 26. Paraplexaura sp., wet-preserved specimens. A. CASIZ 185451; scale bar $=40 \mathrm{~mm}$. B. CASIZ 190431; scale bar $=50 \mathrm{~mm}$. C. CASIZ 190431, scale bar $=25 \mathrm{~mm}$ 


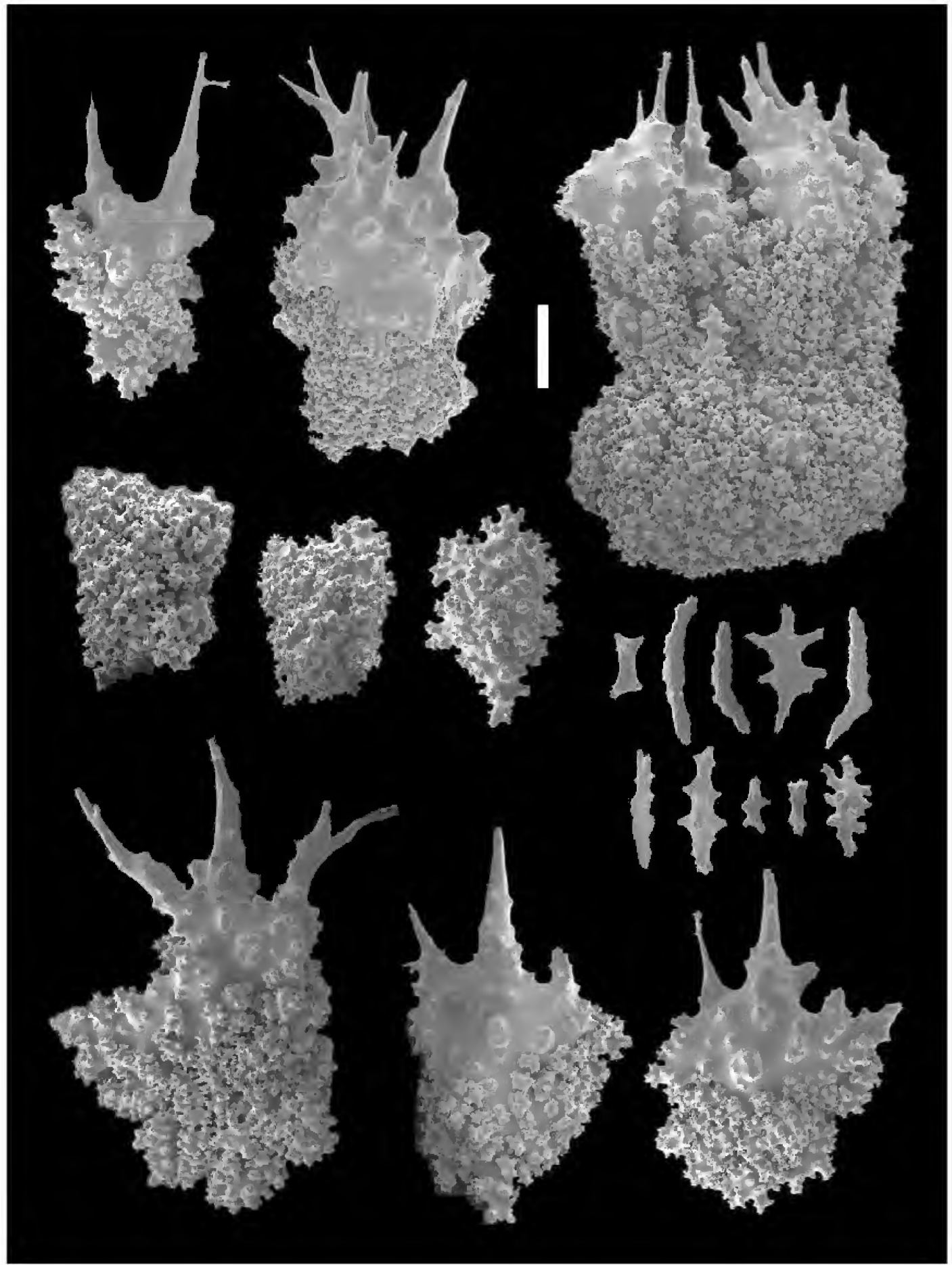

FIGURE 27. Paraplexaura sp. scanning electron micrographs of sclerites from CASIZ 103947; scale bar $=0.10 \mathrm{~mm}$. 


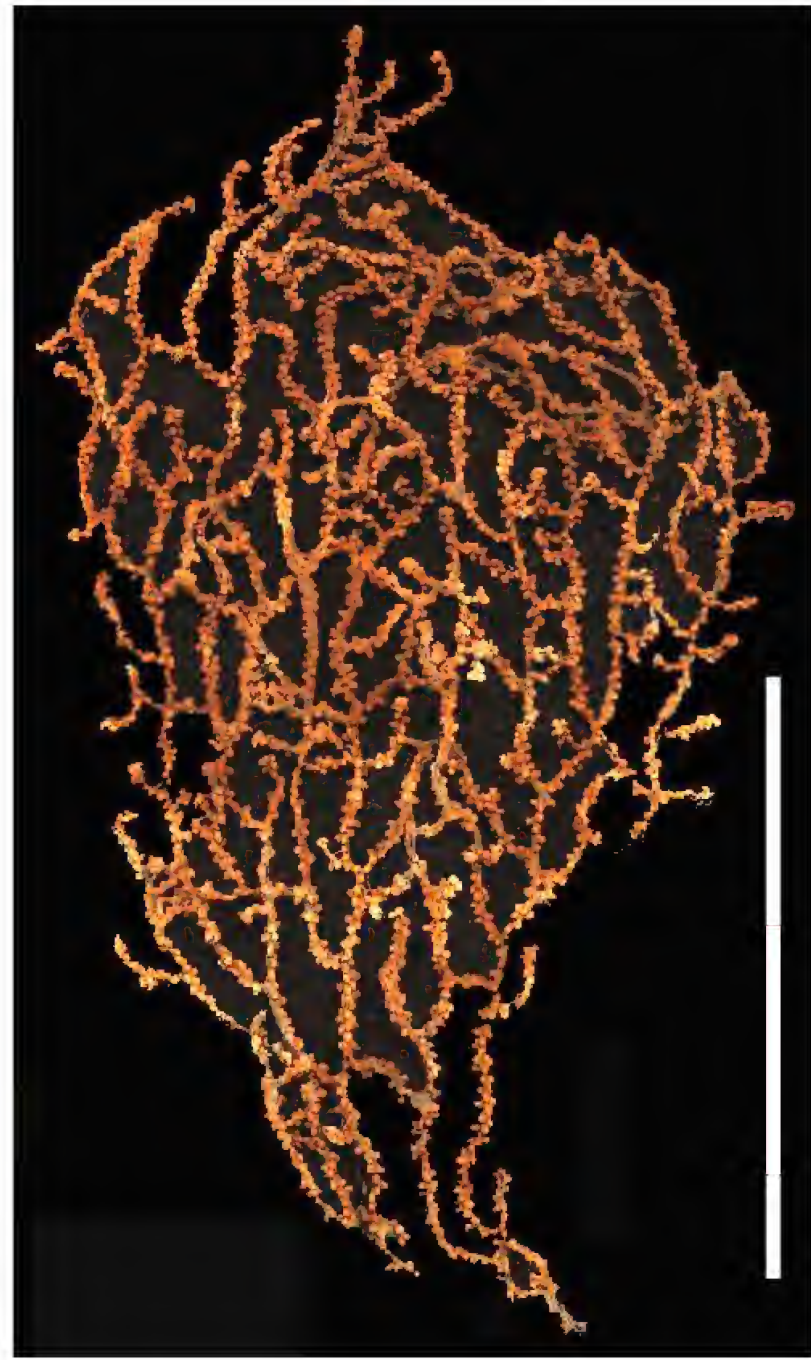

FIGURE 28. Villogorgia sp., CASIZ 111773, wet-preserved specimen; scale bar $=50 \mathrm{~mm}$. 


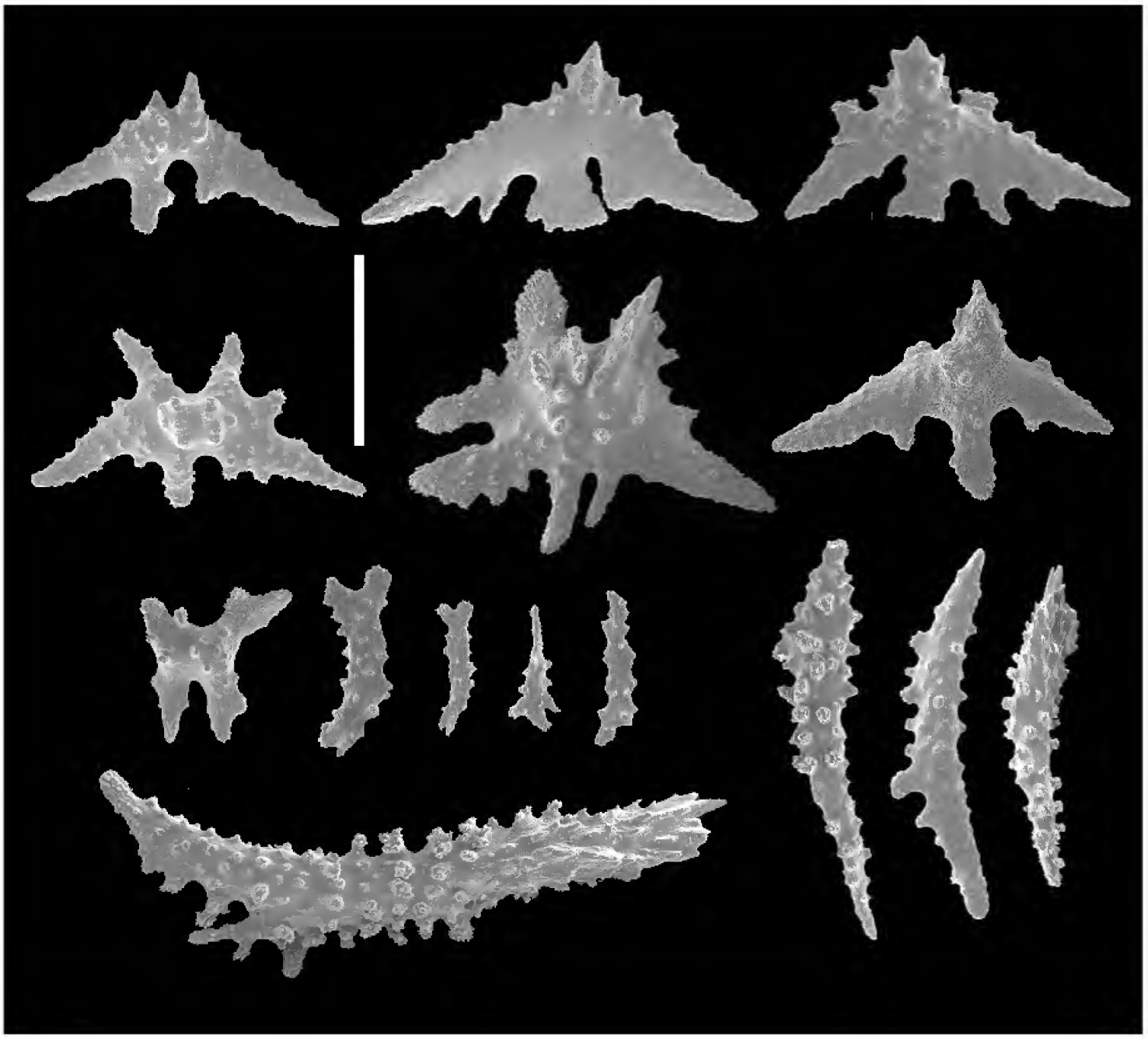

FIGURE 29. Villogorgia sp., scanning electron micrographs of sclerites from CASIZ 111773; scale bar $=0.10 \mathrm{~mm}$. 


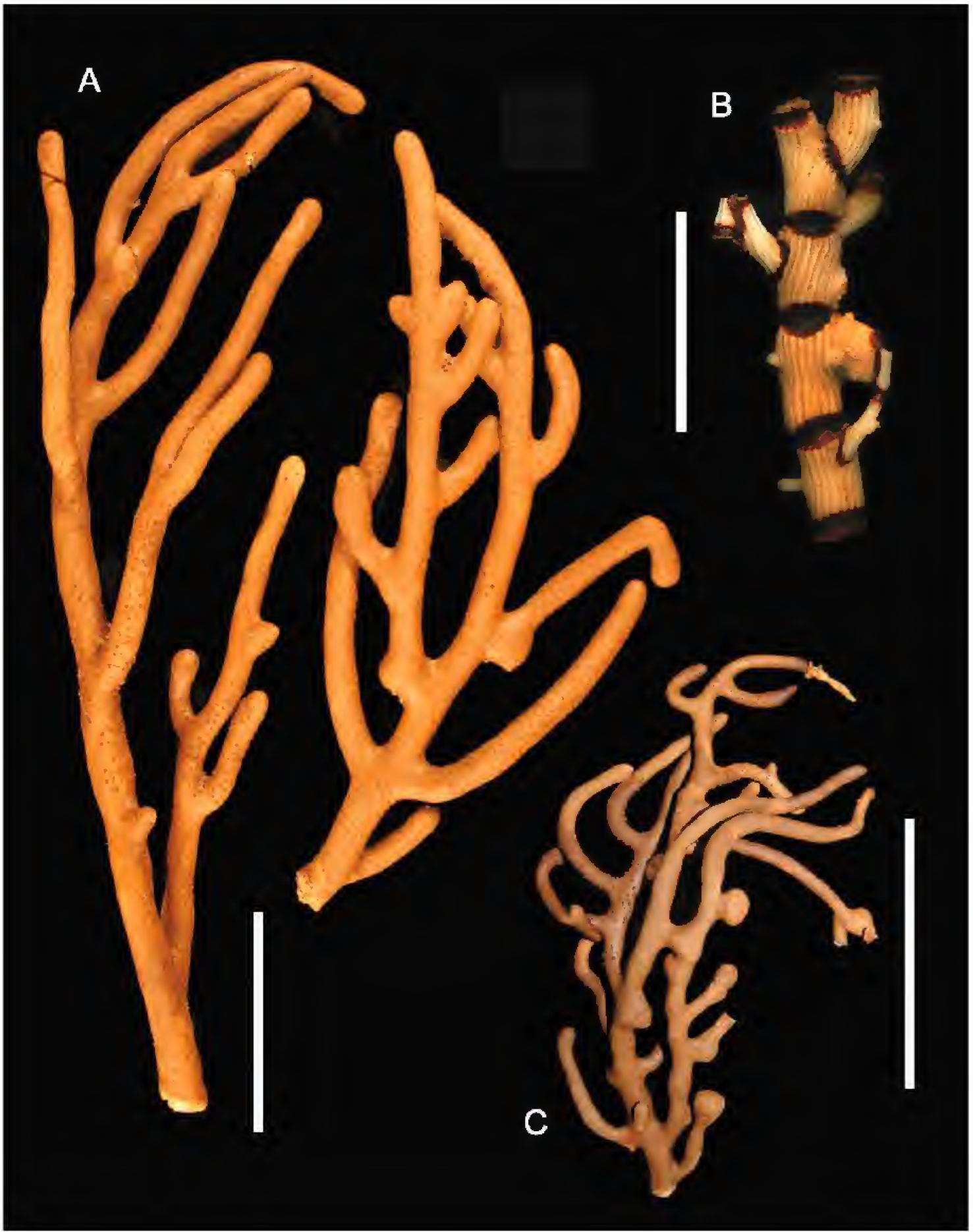

FIGURE 30. Rumphella cf. aggregata and Isis hippuris. A. Rumphella cf. aggregata, wet-preserved specimen (CASIZ 186635); scale bar $=35 \mathrm{~mm}$. B. Segmented axis of Isis hippuris (dried specimen, not catalogued, no collection data); scale bar $=25 \mathrm{~mm}$. C. Isis hippuris, wet-preserved specimen (CAS 192749); scale bar $=55 \mathrm{~mm}$. 


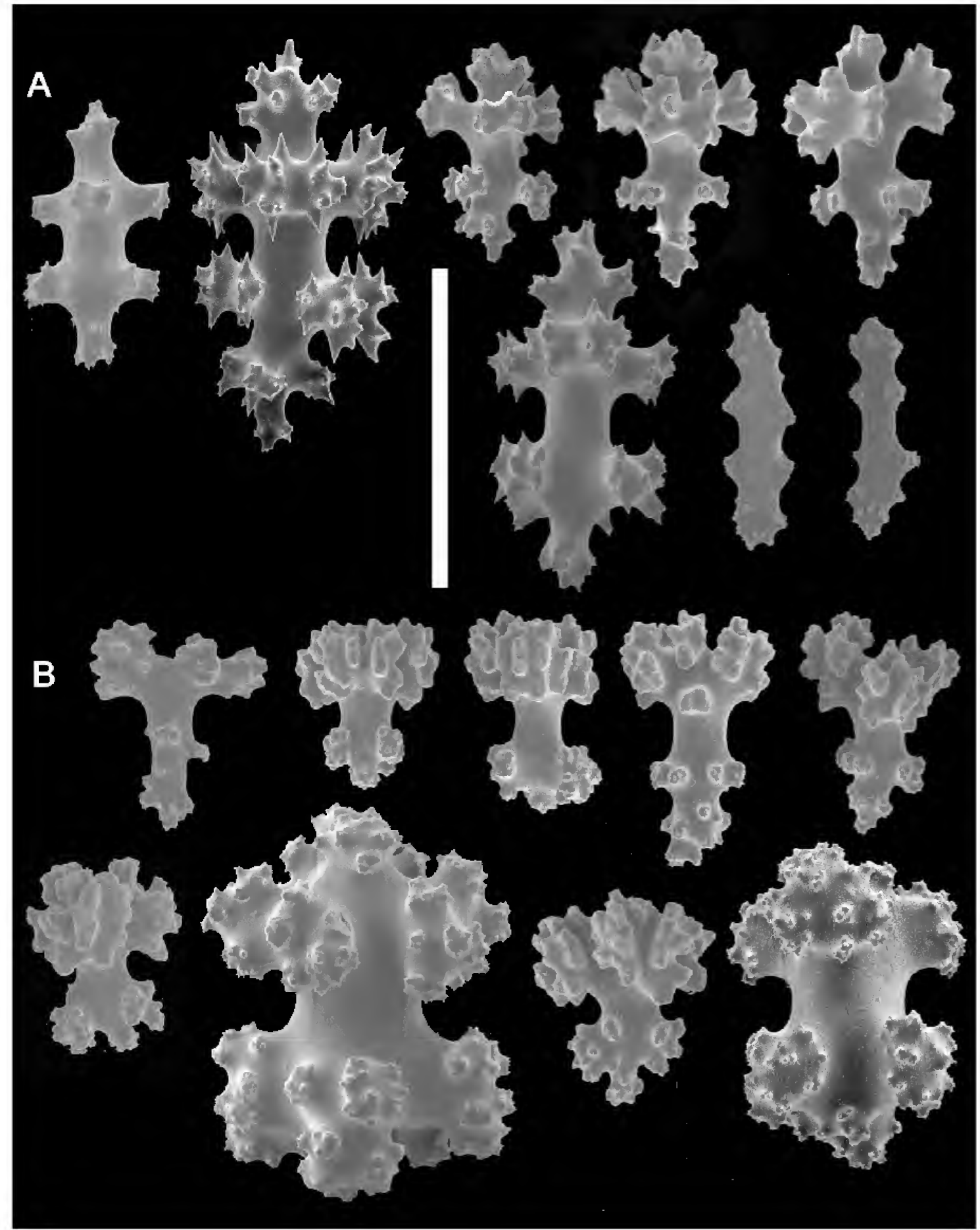

FIGURE 31. Rumphella cf. aggregata and Isis hippuris, scanning electron micrographs of sclerites. A. Rumphella cf. aggregata (CASIZ 180896). B. Isis hippuris (CASIZ 192749). Scale bar for A and B = $0.10 \mathrm{~mm}$. 


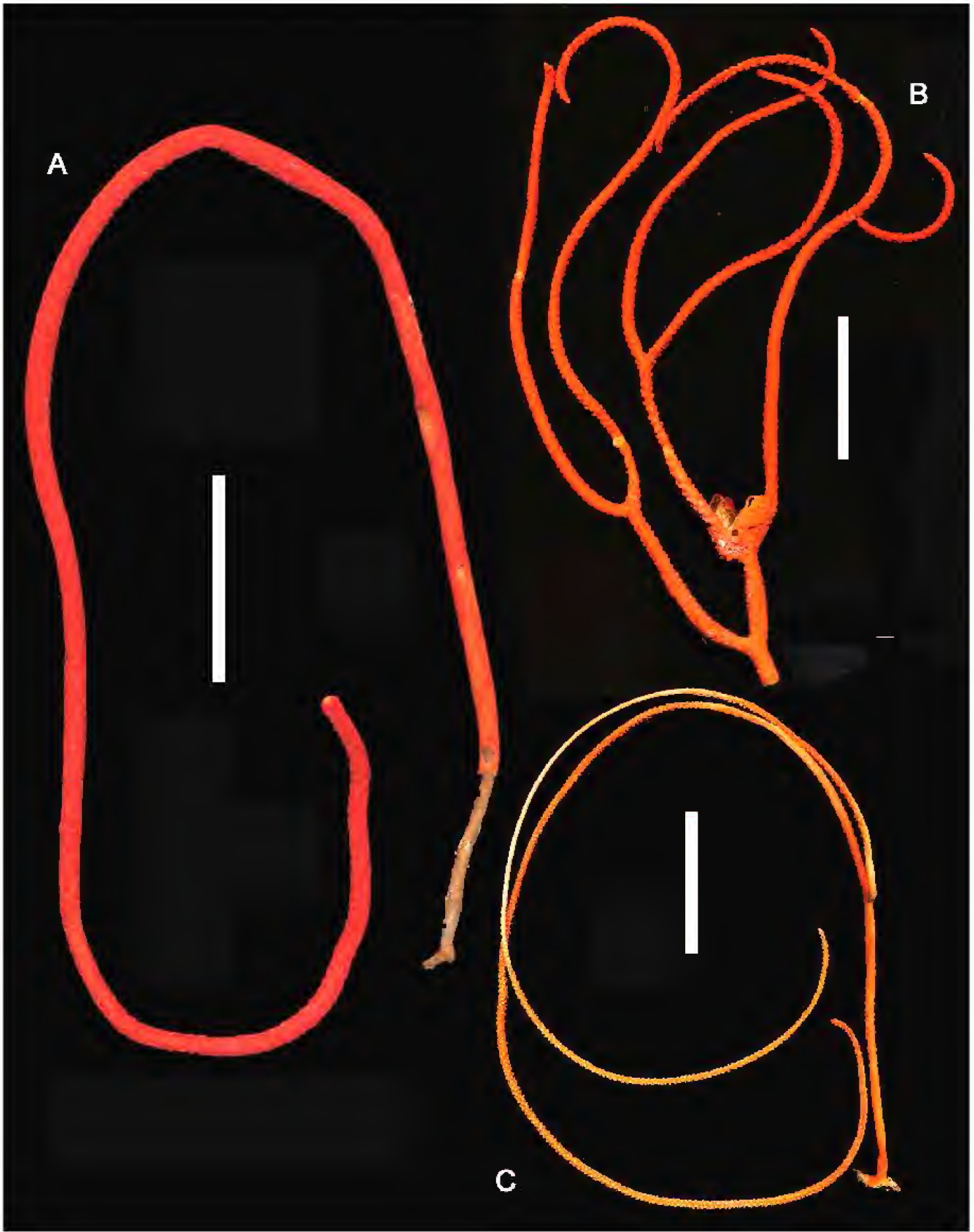

FIGURE 32. A. Viminella sp. unbranched sea whip, CAS 104027; scale bar $=35 \mathrm{~mm}$. B. Dichotella gemmacea CASIZ 186642; scale bar $=35 \mathrm{~mm}$. C. Viminella $\mathrm{sp}$. with two terminal branches, CASIZ 103820; scale bar $=50 \mathrm{~mm}$. 


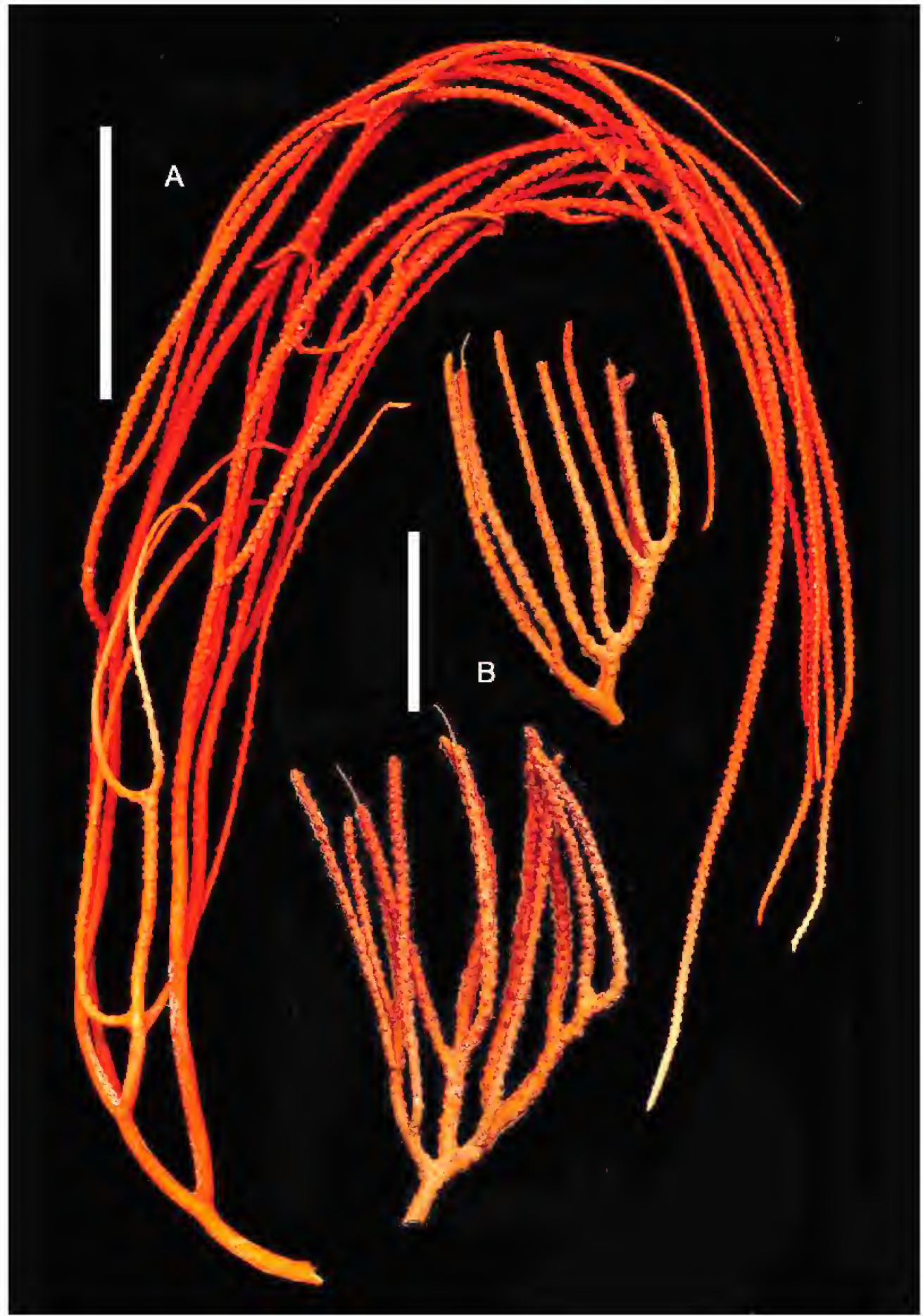

FIGURE 33. Ellisella spp. Wet-preserved specimens. A. CASIZ 985385; scale bar $=30 \mathrm{~mm}$. B. CASIZ 185472, two partial specimens; scale bar $=20 \mathrm{~mm}$. 


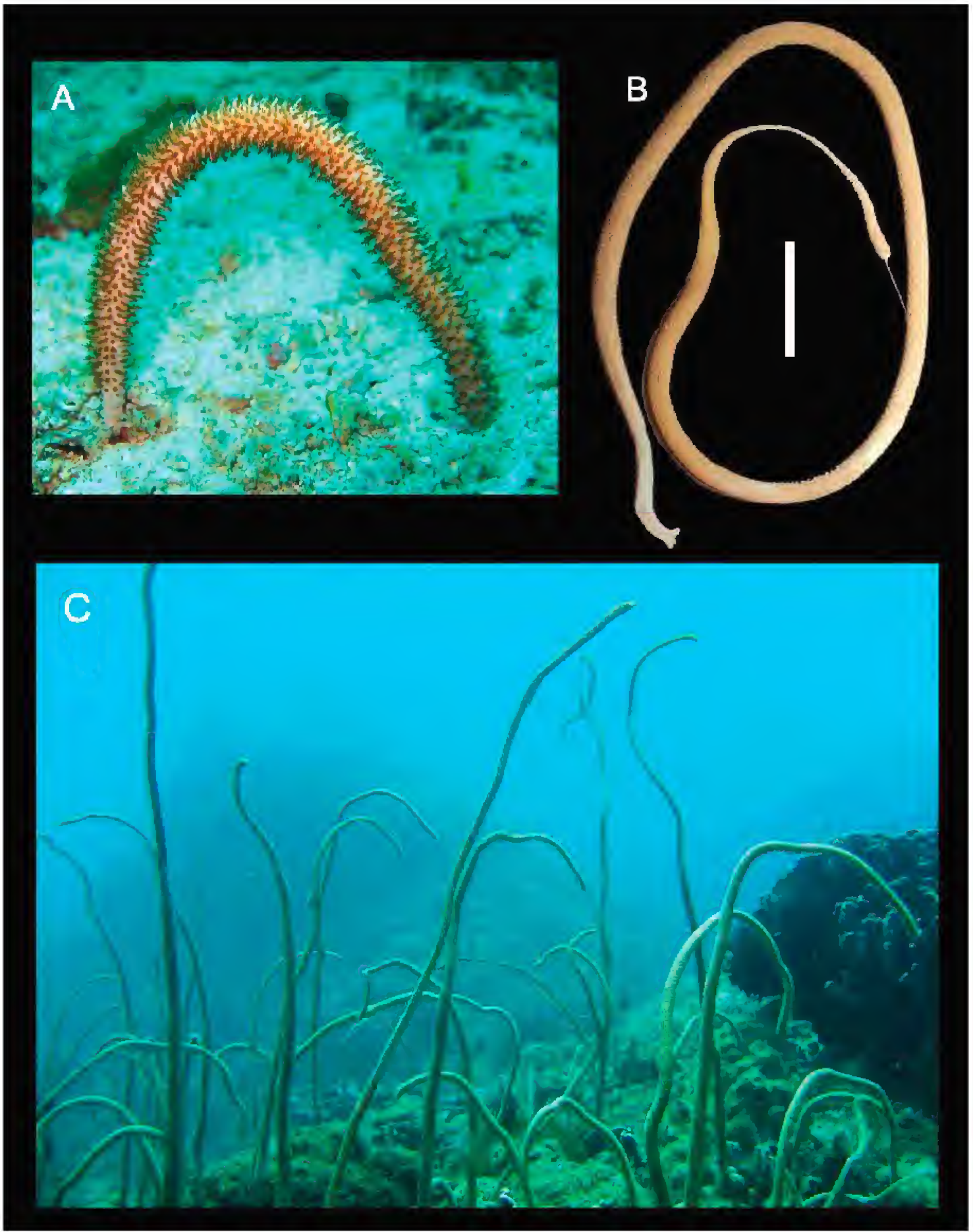

FIGURE 34. Junceella $\mathrm{cf}$. fragilis: A. Underwater photograph of a single colony showing extended polyps that are brown in color due to the presence of zooxanthellae, Maricaban Island. B. Wet-preserved specimen (CASIZ 180160); scale bar= $40 \mathrm{~mm}$. C. Underwater photograph of many colonies displayed as a dense field of sea whips, Maricaban Island. 


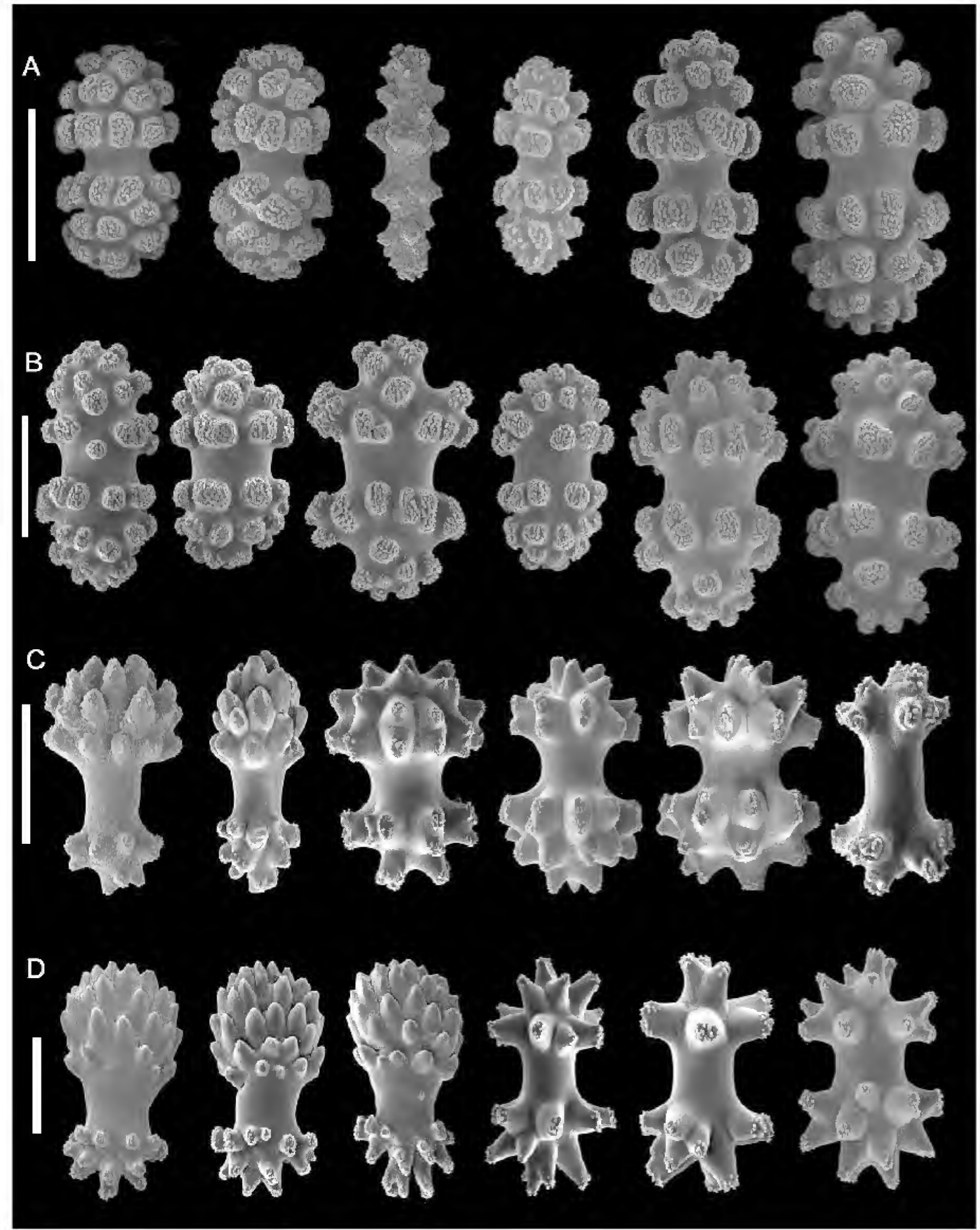

FIGURE 35. Ellisellid gorgonians, scanning electron micrographs of sclerites. A. Ellisella sp. (CASIZ 095385). B. Viminella sp. (CASIZ 185478). C. Junceella fragilis (CASIZ 103838). D. Dichotella gemmacea (CASIZ 103948). Scale bars $=0.03 \mathrm{~mm}$. 

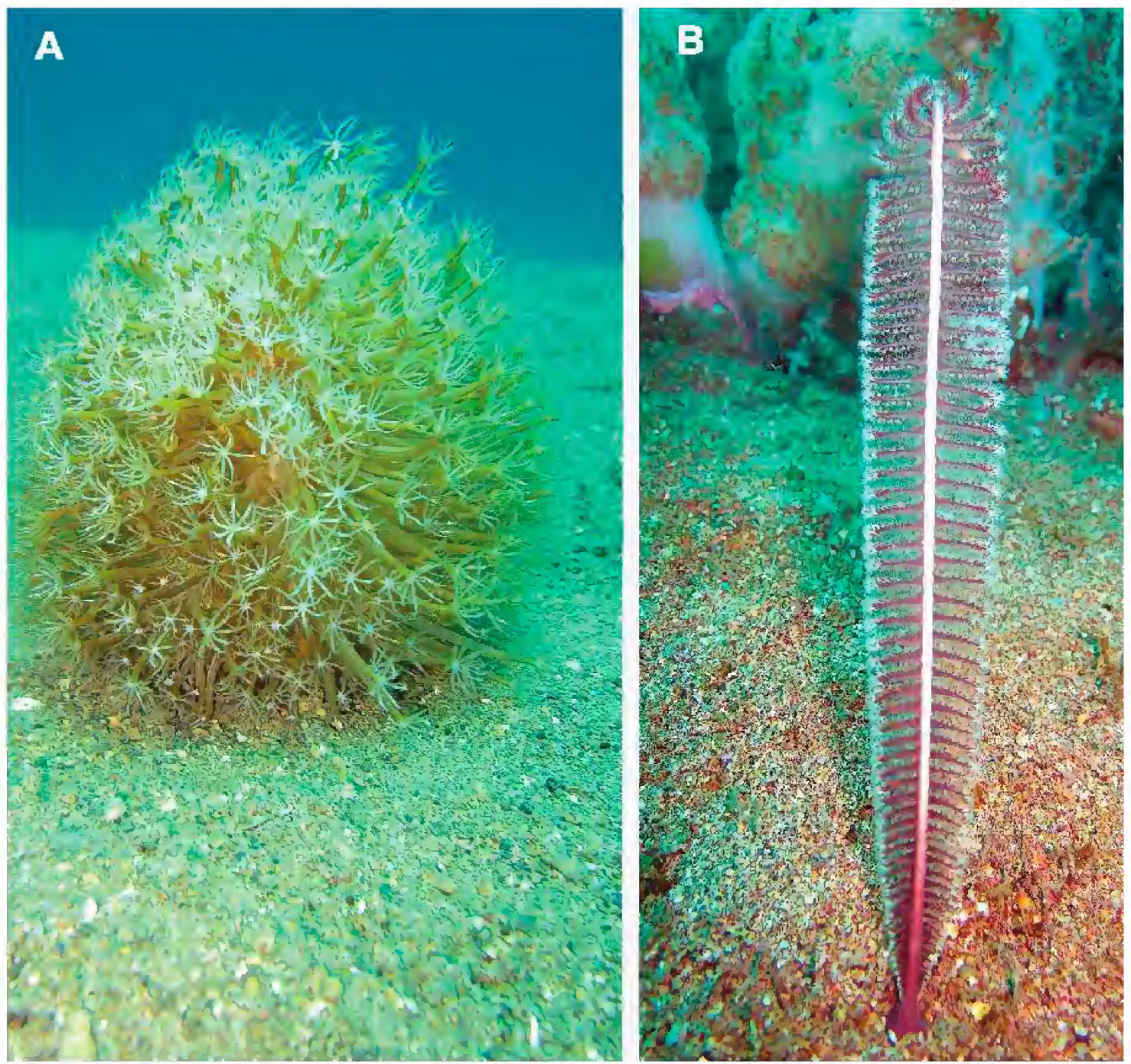

FIGURE 36. Underwater photographs of pennatulaceans, in situ during daylight hours. A. Cavernulina cf. cylindrica showing brown pigmentation in the polyps due to the presence of zooxanthellae; photo by T. M. Gosliner. B. Scytalium cf. sarsi. 

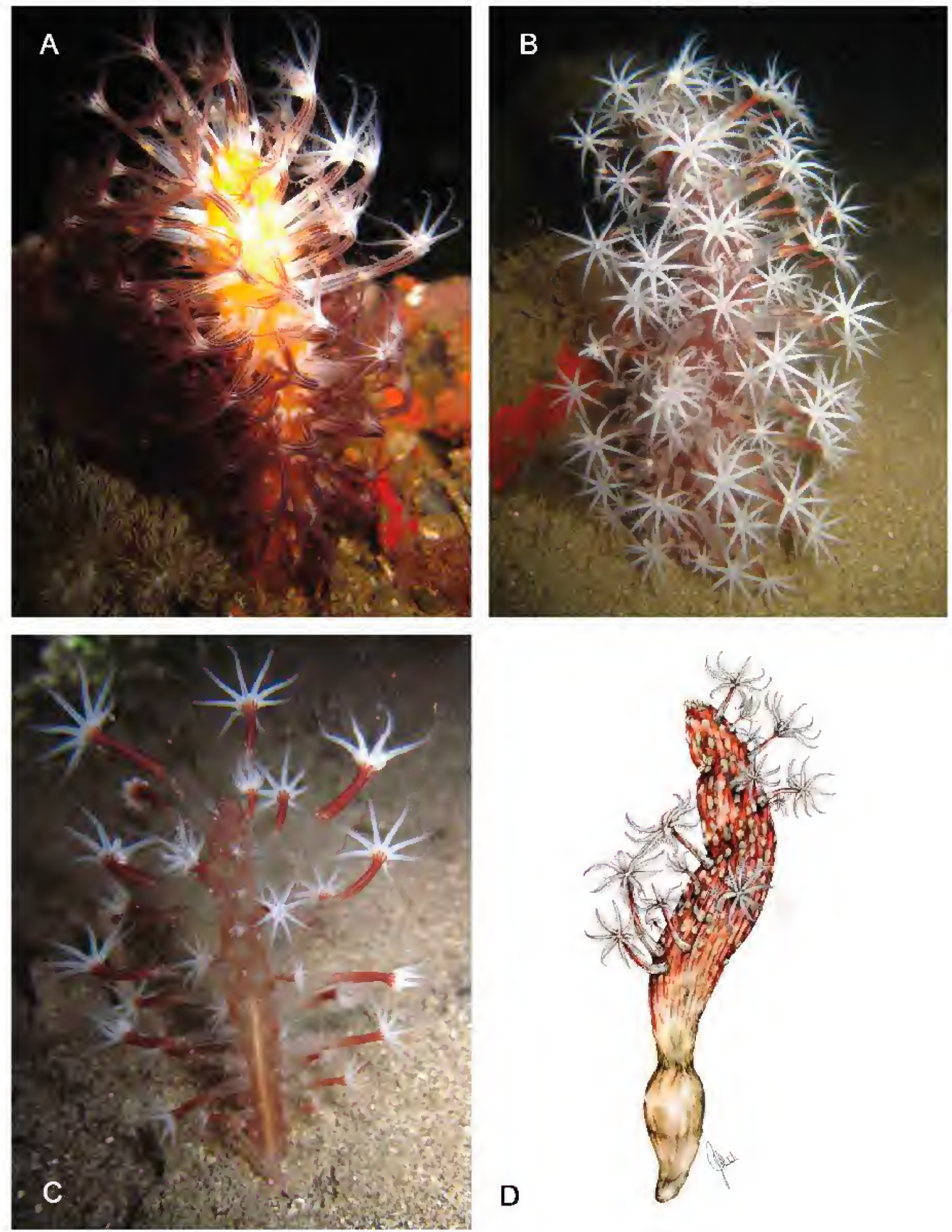

FIGURE 37. Veretillum spp. A-C. Underwater photographs of colonies, in situ at night; photo in B by T. M. Gosliner. D. Illustration of Veretillum sp. from the Batangas region, Luzon, Philippines, by Jessica Machnicki, California Academy of Sciences. 

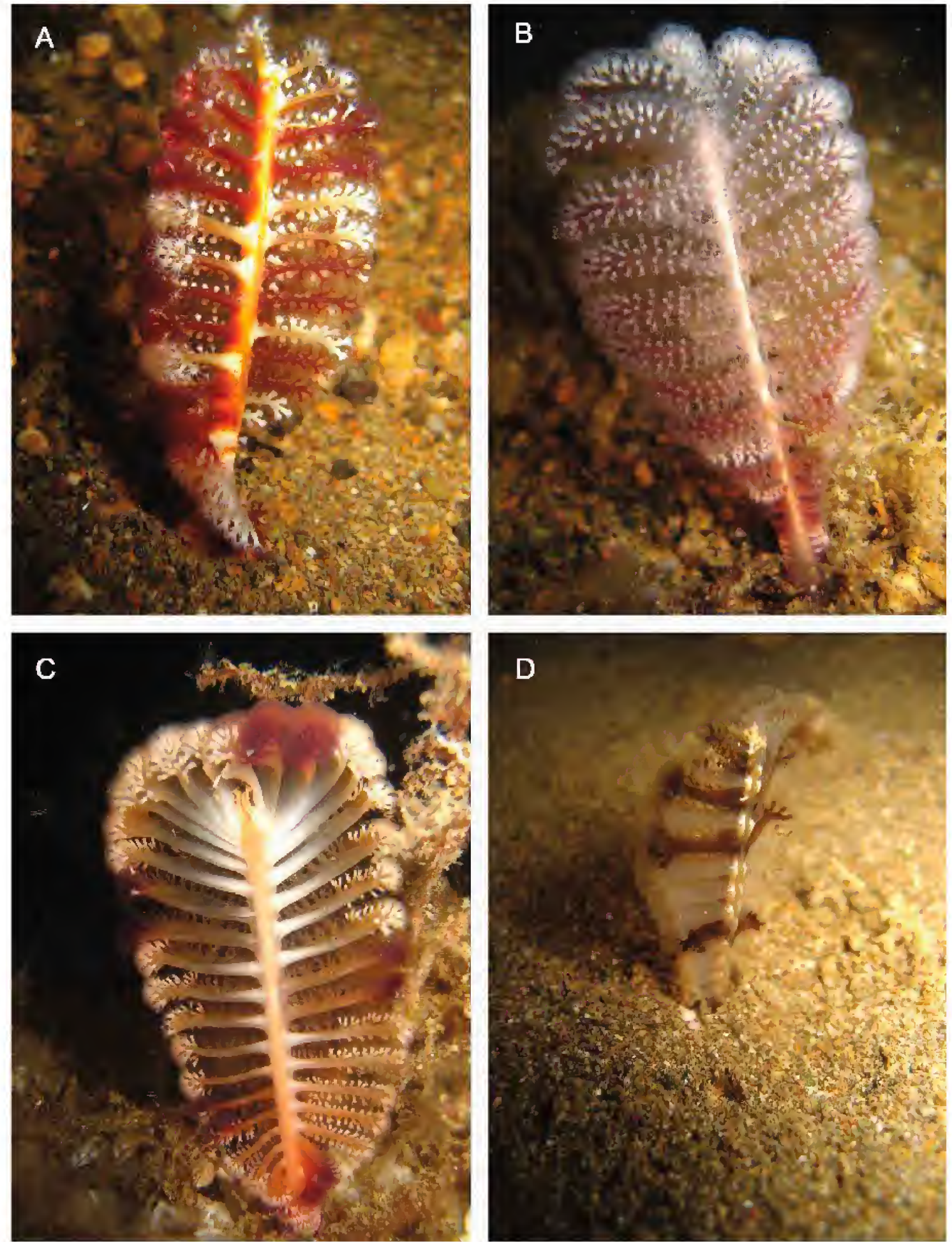

FIGURE 38. Underwater photographs of Virgularia spp. (photos in C and D by T. M. Gosliner). 

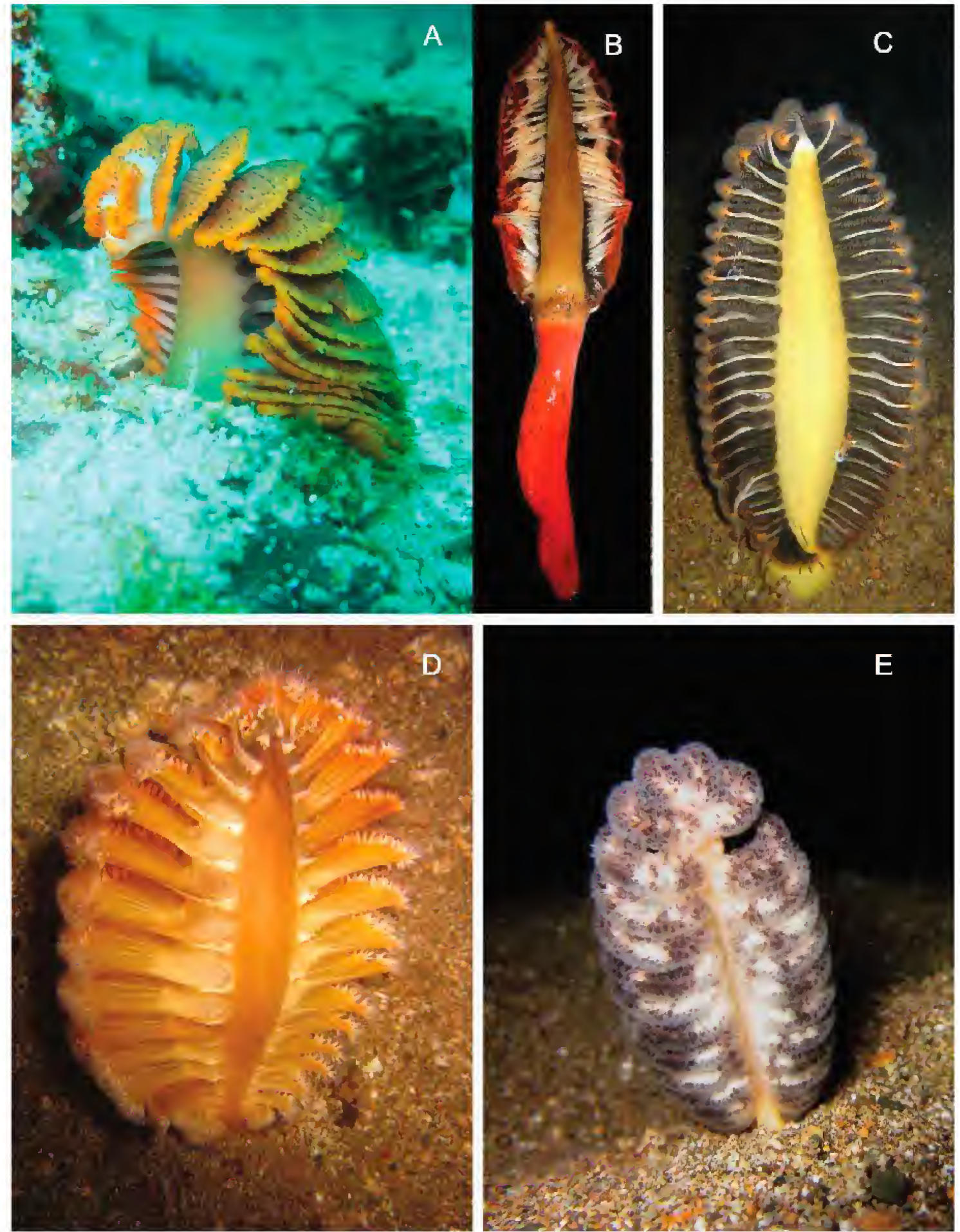

FIgURE 39. Pteroeides spp. A, C-E. Underwater photographs of colonies in situ (photo in A was taken during daylight hours; those in C-E were taken at night); photo in C by T. M. Gosliner. B. Wet preserved specimen of colony shown in A, CAS $185934,220 \mathrm{~mm}$ in length. 

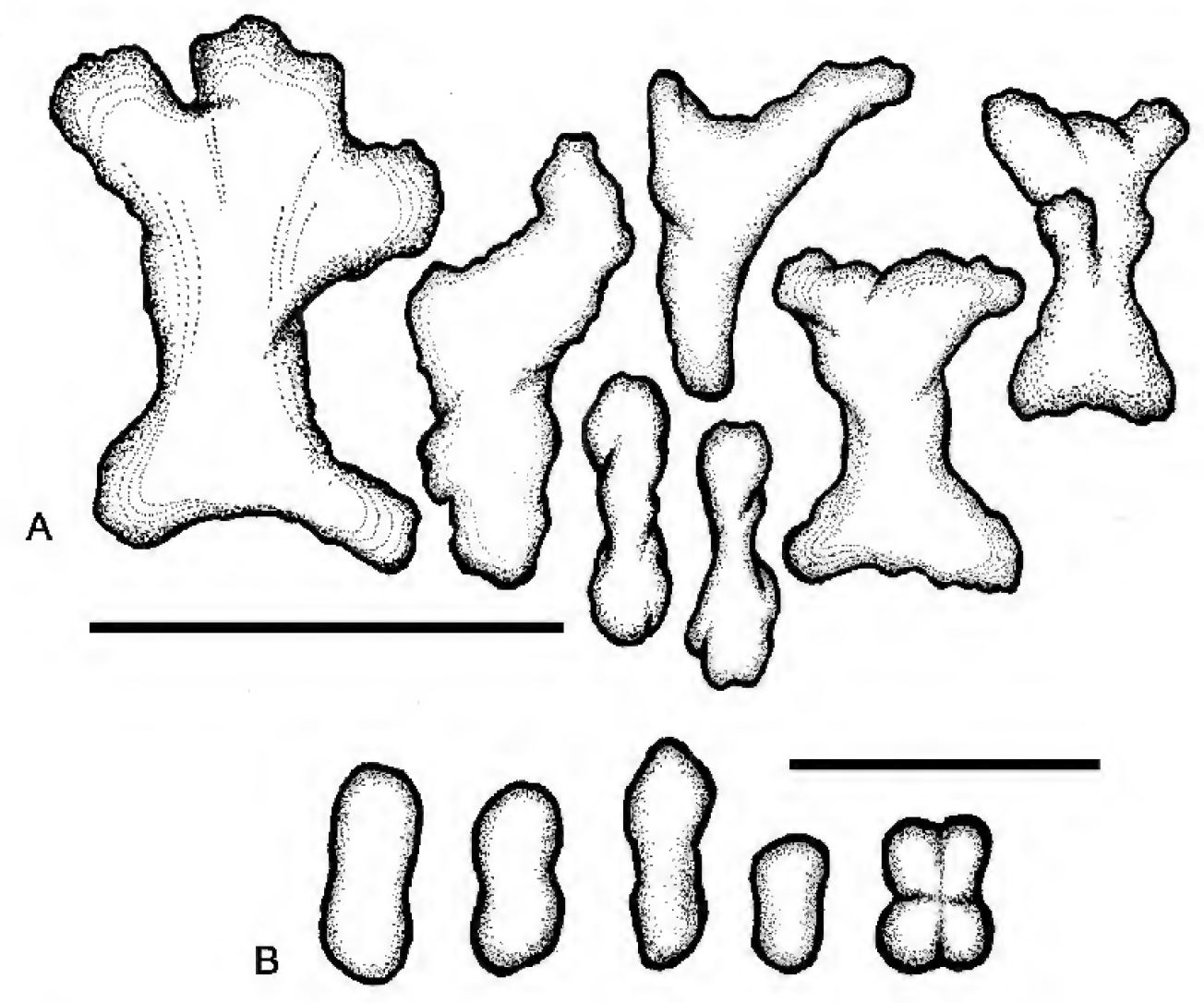

C

FIGURE 40. Pennatulacean sclerites. A. Cavernulina cf. cylindrica (CAS 186569); scale bar $=0.1 \mathrm{~mm}$. B. Scytalium cf. sarsi $($ CAS 185443); scale bar $=0.05 \mathrm{~mm}$. C. Pteroeides sp. (CAS 190421). Scale bar $=2.0 \mathrm{~mm}$. 


\title{
Three New Species of Gymnodoris Stimpson, 1855 (Opisthobranchia, Nudibranchia) from the Philippines
}

\author{
Vanessa L. Knutson and Terrence M. Gosliner \\ Department of Invertebrate Zoology and Geology, California Academy of Sciences, 55 Music Concourse \\ Drive,San Francisco,CA 94118; email:vknutson@calacademy.org,tgosliner@calacademy.org
}

\begin{abstract}
Three new species of nudibranchs in the genus Gymnodoris are described. All three have radulae typical of the genus, with no rachidian tooth and featuring hookshaped, pointed lateral teeth. Gymnodoris brunnea, sp. nov. is translucent with a brownish tinge, covered in small, deep-orange, conical pustules and has gills arranged in a linear row. It can also be distinguished from all other Gymnodoris species that possess a linear gill by a short, broad, triangular second lateral tooth with a bitid cusp. Gymnodoris tuberculosa, sp. nov. differs in pigment from all previously described Gymnodoris species by its uniformly translucent white coloration, including the tubercles that cover the body and a gill arranged in a complete circle. Gymnnodoris pseudobrunnea, sp. nov. externally resembles G. brunnea, sp. nov., with small, deep-orange, conical pustules, and gills arranged in a linear row, though it does not always have a brownish tinge. These two species can be differentiated externally by the shape of a white patch seen dorsally through the skin, the outline of which is more irregularly shaped in G. pseudobrunnea, sp. nov. than in G. brunnea, sp. nov., and by the dark intestine that can be seen through the skin in $G$. brunnea, but not in $G$. pseudobrunnea, sp. nov.. Internally, they are differentiated by the radula, the radula of $G$. pseudobrunnea, sp. nov. lacks a bicuspid second inner lateral tooth, and by the position of the receptaculum seminis duct,which enters the middle of the vagina in G. pseudobrunuea, sp. nov. rather than the at the proximal end as in G. brunnea, sp. nov, Additionally, G. brunnea, sp. nov. specimens sequenced for a fragment of the COI gene differed from a $G$. pseudobrunnea, sp. nov. specimen by an uncorrected p-distance of $10.3 \%$ to $11.1 \%$, further supporting these as two distinct species. All three species are found in the Anilao region of the Philippines, while G. tuberculosa, sp. nov. has been additionally recorded from Madang, Papua New Guinea and the Marshall Islands.
\end{abstract}

KEY Words: Gymnodoris, Gymnodorididae, new species, Philippines

Following the trend of many marine taxa, the opisthobranch diversity of the Coral Triangle in the Indo-Pacific is exceptionally rich, with the Philippines being home to over 700 species (Gosliner et al. 2008). New species continue to be found in this region. On the recent Hearst Philippine Biodiversity Expedition to the "Anilao" region of the Philippines, the team of scientists found 25 species of "opisthobranchs" that are new records for the region, and at least 50 additional species that are new to science. A taxon that was especially well-represented by collections on the expedition was the nudibranch genus Gymnodoris.

There has been some disagreement over the placement of Gymnodoris, whether it belongs in an independent family, Gymnodorididae and whether this family should be treated as a subfamily, Gymnodoridinae, within Polyceridae (summarized in Macnae 1958). The current generally accepted classification recognizes Gymnodorididae Odhner, 1941 (Bouchet and Rocroi 2005) including Gymnodoris along with several other genera (Bouchet 2014; McDonald 2009), though there has been no comprehensive review of the family. A recent molecular phylogenetic study found that Gymnodoris, represented by G. alba and G. striata, nests within the polycerid subfamily Polycerinae with high support (Palomar et al. 2013). However, the study also suggested that additional taxa need to be sampled to clarify the issue, and no taxonomic change was made. The taxonomic status of this family is beyond the scope of this paper, and until there is a formal change in the taxonomy, we follow the current accepted taxonomy here. 
With respect to its taxonomy and identification, Gymnodoris is a particularly challenging genus of nudibranchs. Plagued by inadequate descriptions and little variation of external color patterns, the true diversity of this group has remained poorly documented in the literature.

We have found that molecular techniques have been useful in identifying putative undescribed species and have further highlighted the difficultly of reconciling old descriptions with the true diversity of this group of voracious predators. While there are approximately 30 described species of Gymnodoris, several of these have descriptions that are inadequate for matching species to them, and most of these species names likely lack associated type material. Few Gyminodoris species have been described in recent years. Most recently, Hamatani and Osumi (2003) described Gymnodoris inariensis, a small, blackish, gill-less species from Japan, and Swennen (1996) described Gymnodoris pattani, a translucent greenish species from Thailand. Here we describe three new taxa and compare them to known species of Gynnodoris. Because two of these new taxa were difficult to tell apart in the field, in addition to looking at morphological details, we sequenced specimens for a fragment of the cytochrome oxidase subunit I (COI) gene and calculated uncorrected $\mathrm{p}$-distances to see if this was consistent with the differences seen in morphology.

The material was deposited in the Department of Invertebrate Zoology and Geology of the California Academy of Sciences, San Francisco (CASIZ), and sequences for the COI gene were uploaded to GenBank.

\section{METHODS}

Morphological Examination.- We subsampled many of the specimens for DNA prior to morphological analysis or measurement, resulting in lengths that are smaller than the intact preserved specimens.

We dissected specimens by making an incision with forceps near the foot. Reproductive structures were drawn initially using a drawing tube attached to a dissecting microscope and subsequently scanned, traced and rendered digitally using Adobe Illustrator CS4 or CS6 and Photoshop CS4 or CS6.

To examine the radulae, we placed the buccal masses of specimens in a $10 \% \mathrm{NaOH}$ solution until the tissue surrounding the radulae had dissolved sufficiently. We subsequently placed these radulae in deionized water to remove residual salt and mounted them on SEM stubs using double sided adhesive or no adhesive at all. The radulae were imaged using a scanning electron microscope (LEO $1450 \mathrm{VP}$ ). To assess whether the penis of specimens was armed with spines, the distal portion of the vas deferens was excised and cleared and stained by first dehydrating in a series of increasing concentrations of ethanol, then placed in acid fuchsin stain, then placed in xylene, removed and mounted on a glass microscope slide. The slides were photographed using a Spot FLEX Mosaic Model 15.2 digital camera mounted on a Leica DMRB microscope. Scale bars were applied in SPOT Software 5.0.25. Adobe Photoshop CS4 was used to get a rough approximation of the length and width of penial spines, by measuring and averaging the lengths of four different visible spines andwidths of four visible spine bases using the scale bar for measurement calibration.

Molecular Methods. - In this paper we were interested in comparing COI sequences for two taxa that had a similar external appearance that were difficult to tell apart in the field. We subsampled several specimens for DNA analysis by taking a small piece of tissue from the foot or tip of the "tail." We were careful to avoid subsampling digestive tissue since some gymnodorids are known to eat other nudibranchs including congeners and conspecifics, in some cases.

Polymerase chain reaction (PCR) was used to amplify a partial COI gene fragment using the standard "Folmer" COI primers (Folmer et al. 1994). Each $25 \mu \mathrm{L}$ reaction contained: $15.0 \mu \mathrm{L}$ ster- 
ile water, $2.5 \mu \mathrm{L}$ 10X USB buffer, $1.0 \mu \mathrm{L} 25 \mathrm{mM} \mathrm{MgCl}_{2}, 1.0 \mu \mathrm{L}$ each of $10 \mu \mathrm{M}$ forward and reverse primer, $0.5 \mu \mathrm{L} 10 \mathrm{mM}$ dNTPs, $1.5 \mu \mathrm{L}, 10 \mathrm{mg} / \mathrm{mL}$ BSA, $0.5 \mu \mathrm{L} 1.25$ units $/ \mu \mathrm{L}$ HotStart Taq and between $2 \mu \mathrm{L}$ to $5 \mu \mathrm{L}$ of template DNA, depending on the concentration of the sample. Cycling parameters were generally as follows for COI: an initial denaturation step at $94^{\circ} \mathrm{C}$ for $3 \mathrm{~min}$, followed by $94^{\circ} \mathrm{C}$ for $30 \mathrm{~s}, 47^{\circ} \mathrm{C}$ for $30 \mathrm{~s}, 72^{\circ} \mathrm{C}$ for $60 \mathrm{~s}$ for 35 cycles and a final extension step at $72^{\circ} \mathrm{C}$ for $10 \mathrm{~min}$. Following PCR, we visualized products on $1 \%$ agarose gel containing ethidium bromide. For reactions that successfully amplified the target gene fragment, we used an Exo-SAPIT protocol ExoSAP-IT (usb.affymetrix.com) to purify products for cycle sequencing.

Purified PCR products were cycle-sequenced using a $\sim 10 \mu \mathrm{L}$ reaction that contained $5.7 \mu \mathrm{L}$ sterile water, $1.5 \mu \mathrm{L} 5 \mathrm{X}$ Big Dye buffer, $0.3 \mu \mathrm{L} 10 \mu \mathrm{M}$ primer, $0.5 \mu \mathrm{L}$ Big Dye 3.1, and 1-5 $\mu \mathrm{L}$ of purified PCR product, depending on the sample's PCR band brightness during visualization. We cycle-sequenced all genes using a STeP Program (Platt et al. 2007) using an annealing temperature of $50^{\circ} \mathrm{C}$.

Cycle-sequencing products were precipitated using a standard ethanol precipitation protocol and resuspended them in formamide. Samples were sequenced on the ABI Prism $3130 \times 1$ Genetic Analyzer at the Center for Comparative Genomics and the California Academy of Sciences.

Sequence trace files were then assembled into contigs and edited them using the program Geneious version 6.0 (Drummond et al. 2011). We aligned the resulting consensus sequences in Geneious using the MAFFT Multiple Alignment v1.1 (Biomatters Ltd) plugin with default settings. Geneious was then used to calculate the uncorrected p-distances between all the sequences.

The COI sequences were uploaded to GenBank and the accession numbers appear in Appendix, Table 1.

\section{RESULTS}

We were able to get COI sequences for 8 specimens of the two similar-looking taxa, 7 individual sequences for one taxon and one of the second taxon. The uncorrected COI p-distances for the individuals within one taxonranged from $0.0 \%$ to $0.5 \%$. Only one specimen amplified for the other taxon. The p-distances between this specimen and the other specimens ranged from $10.3 \%$ to $11.1 \%$.

\section{SPECIES DESCRIPTIONS}

\section{Gymnodorididae Odhner, 1941}

Genus Gymnodoris Stimpson, 1855

\section{Gymnodoris brunnea Knutson and Gosliner, sp. nov.}

Figures 1A-B, 2-4

Material examined.- Holotype: CASIZ 185943, one specimen, Anilao Pier, Anilao Harbor, Balayan Bay, Batangas Province, Luzon Island, Philippines, $13^{\circ} 45^{\prime} 35.78^{\prime \prime} \mathrm{N} 120^{\circ} 55^{\prime} 33.56^{\prime \prime} \mathrm{E}$ collected on April 30, 2011 by the members of the Hearst Philippine Biodiversity expedition, preserved specimen $9.5 \mathrm{~mm}$ length. PARATYPES: CASIZ 185946, one specimen, subsampled for DNA, preserved specimen $7.0 \mathrm{~mm}$ length with part of the "tail" missing, CASIZ 185968 one specimen dissected, subsampled for DNA, preserved specimen $9.2 \mathrm{~mm}$ length with part of the "tail" missing, CASIZ 185971, one specimen, preserved specimen $5.0 \mathrm{~mm}$ length, CASIZ 185972, one specimen, subsampled for DNA, preserved specimen $6.5 \mathrm{~mm}$ length with part of the "tail" missing, CASIZ 185973, one specimen, dissected, CASIZ 185976, one specimen subsampled for DNA, preserved specimen $\sim 8.0 \mathrm{~mm}$ length with part of the "tail" missing, all collected at the Anilao Pier, Anilao Harbor, Balayan Bay, Batangas Province, Luzon lsland, Philippines, $13^{\circ} 45^{\prime} 35.78^{\prime \prime} \mathrm{N}$ $120^{\circ} 55^{\prime} 33.56^{\prime \prime} \mathrm{E}$ on April 30, 2011 by the members of the Hearst Philippine Biodiversity expedition.CASIZ 185979, one specimen, Matotonngil Point, Balayan Bay, Batangas Province, Luzon 
Island, Philippines, 134ㄴ $18.997^{\prime \prime} \mathrm{N} 120^{\circ} 54^{\prime} 24.19^{\prime \prime} \mathrm{E}$ collected May 1, 2011 by Vanessa Knutson and Michele Weber, subsampled for DNA, preserved specimen $5.2 \mathrm{~mm}$ length with part of the "tail" missing. CASIZ 185963, one specimen, dissected, subsampled for DNA, CASIZ 185966, one specimen dissected subsampled for DNA, preserved specimen $6.0 \mathrm{~mm}$ length with part of the "tail" missing, CASIZ 185975, one specimen, subsampled for DNA, preserved specimen $5.0 \mathrm{~mm}$ length with part of the "tail" missing, all collected on May 04, 2011 at the Anilao Harbor, Anilao, Balayan Bay, Batangas Province, Luzon Island, Philippines, $13^{\circ} 45^{\prime} 35.70^{\prime \prime} \mathrm{N} 120^{\circ} 55^{\prime} 34.20^{\prime \prime} \mathrm{E}$ by Michele Weber.

There are a couple of photos on the Nudipixel website of this species $(<h t t p: / / w w w . n u d i p i x e l$. net/photo/00034049/> and <http://www.nudipixel.net/photo/00034646/>). These photos were taken from Anilao within approximately one month of when the specimens described here were collected.

GEOGRAPHICAL DISTRIBUTION.- Currently known only from Balayan Bay, in the Anilao region of the Philippines.

ETYMoLoGY.- Gymnodoris brunnea is named for its brownish coloration.

EXTERNAL MORPHOLOGY.- Several preserved specimens were subsampled for DNA before being measured and ranged between 5.0 and $8.0 \mathrm{~mm}$ in length with a subsection of the posterior end of the "tail" missing. Two intact preserved specimens were about $9.5 \mathrm{~mm}$ in length. The living animals (Fig. 1A, B) are translucent with a brownish tinge. Upon close inspection of the preserved specimens, this brownish hue appears to come from elongate dark particles present throughout the tissue of the animal. These dark particles appear to be generally concentrated on the dorsal side of the animal. The sides and dorsum of the body are covered in deep orange, conical pustules. These pustules are present on the anterior portion of the notal margin. Starting from the anterior margin, these pustules are situated in two rows following the mantle margin posteriorly and converge to a point roughly halfway between the gills and the tip of the posterior end of the foot. From here, the pustules continue in a row to the tip of the foot. Pustules can also be found between the rhinophores. In some of the preserved specimens, the very tip of the foot is keeled.

The foot is broad, widest anteriorly beneath the rhinophores. The foot has a thick anterior margin with a deep groove that separates the foot from the rest of the head. The anterior margin is tinged in deep orange. The rhinophores are perfoliate with approximately 8-9 lamellae and are tipped with orange. In some specimens, the orange runs down the anterior portion of the rhinophores, and wraps slightly around the sides, where it gradually fades. In some of the preserved specimens, the rhinophores were partially retracted and thus some lamellae were not visible.

The genital opening is located on the right side of the body, just anterior to the gill plume. The gill branches are arranged in a linear row or slight arc with between 4-7 unipinnate filaments. The filaments are tinged with a deep orange color with deeper pigmentation apically, when present. This coloration varies between specimens. In some specimens, the orange pigment is quite concentrated and may cover much of the gills; in others, the orange pigment covers only the apical portion of the gills. One specimen had a negligible amount of orange on the gills. The length of the gill filaments also varies.

Due to the translucent nature of the skin, the internal organs can be viewed externally. There is a white-colored patch visible just below the skin that extends forward and behind the gill, covering a portion of the dorsal side of the digestive gland. The function of this white patch is unknown. The ovotestis appear to be a light orange in color and appear to be located in various parts of the animal, including a section towards the posterior tip of the foot, approximately halfway between the gills and tip of the foot. The intestine is also visible through the skin as a dark colored arch anterior to the gill. 


\begin{abstract}
InTERnal ANATOMY.Gland-like structures are present at the base of the gill (one specimen had 6 of them), which may be defensive glands. In the preserved material, we were unable to locate the white patch that was visible in the living specimen.
\end{abstract}

Radular morphology: As is typical within Gymnodoris, the radula lacks a rachidian row of teeth (Fig. 2A). This species has very large, broad, inner lateral teeth, roughly hook-shaped, with very long bases (Fig. 2B). The inner lateral teeth are much larger and longer than the rest of the teeth. The second inner lateral teeth are much shorter in length than the first inner laterals (Fig. 2B). The second inner lateral teeth are broad and bicuspid with the second cusp smaller than the first and situated on the outer side of the main cusp. In a couple of specimens, a few of the inner laterals have the second cusp reduced to a small bump. There is a notch in the middle of the base of the second inner laterals as well as the other laterals. The mid and outer lateral teeth are much narrower than the second inner laterals and come to a sharp point. The outer laterals are gradually reduced in size approaching the outer margin of the radula. In some specimens, the third inner lateral teeth are slightly differentiated from the rest of the outer laterals and appear to have a wider base. In one specimen, one side of the radula had third inner laterals that were bicuspid, though this is likely a developmental abnormality. The outermost laterals are straighter in shape and the shortest of all of the teeth (Fig. 2C). The radular formulas of four specimens were counted as follows: $17 \times$ 21.1.1.0.1.1.21 (CASIZ 185966), 19 x 21.1.1.0.1.1.21 (CASIZ 185968), 18 x 20.1.1.0.1.1.20 (CASIZ 185973), 22 x 21.1.1.0.1.1.21 (CASIZ 185963).

Reproductive system: There are four primary ovotestis follicles, three of which are united posteriorly with a single mass situated anteriorly. A hermaphroditic duct extends from the posterior mass of ovotestis follicles and unites with the hermaphroditic duct from the anterior mass (Fig. 3). Just anterior to their junction, the hermaphroditic duct widens into the curved ampulla. The ampulla then bifurcates into a short oviduct which enters the albumen gland within the female gland mass. The second branch widens into the curved prostate, which surrounds the bursa copulatrix and 
then narrows into the muscular vas deferens. The vas deferens consists of several convolutions before entering the penis, adjacent to the vagina. The uterine duct emerges from the female glands near the oviduct and enters the small pyriform receptaculum seminis. The receptaculum duct enters the vagina just below the large, spherical, thinwalled bursa copulatrix. The vagina is curved and opens into the genital aperture. The albumen and membrane glands are small and not well differentiated. The mucous gland comprises the majority of the female gland mass. The penis of one specimen (CASIZ 185973) was cleared and stained (Fig 4A). The penis is densely armed with long spines, roughly $40 \mu \mathrm{m}$ length, with a base of approximately $11 \mu \mathrm{m}$ width.

NatURal history.- Specimens were collected subtidally in 3-5 meters depth at night on a sandy bottom. Due to their sandy habitat, these animals may burrow into the sand.

Discussion.- Although some authors place gymnodorids that have a linear arrangement of gills into a separate genus, Analogium, Risbec 1928, (Hamatani 1995; Yonow 2011) there has never been a comprehensive phylogenetic study of this group to support the separation of these species into a separate genus (Jensen 1998). The radula of this specimen, along with the conical pustules that cover the body are more reminis-

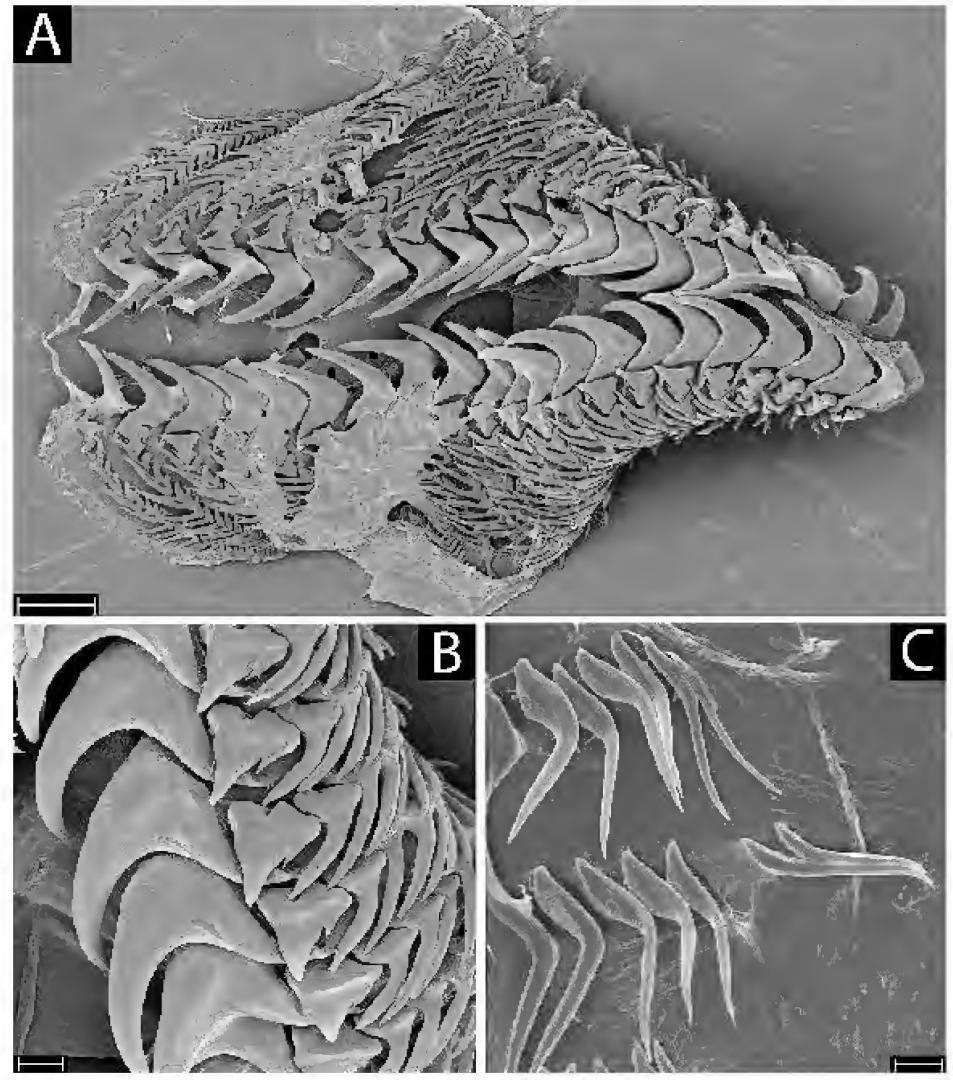

FIGURE 2. Gymnodoris brunnea sp. nov. scanning electron micrographs of the radula. A. View of entire radula. (Note that portionsof the radula on the right side of the image are folded underneath), CASIZ 185963, scale $=90 \mu \mathrm{m}$. B. Inner lateral teeth, note bicuspid second inner lateral, CASIZ 185963 , scale $=20 \mu \mathrm{m}$. C. Outer lateral teeth, CASIZ 185968, scale $=10 \mu \mathrm{m}$.

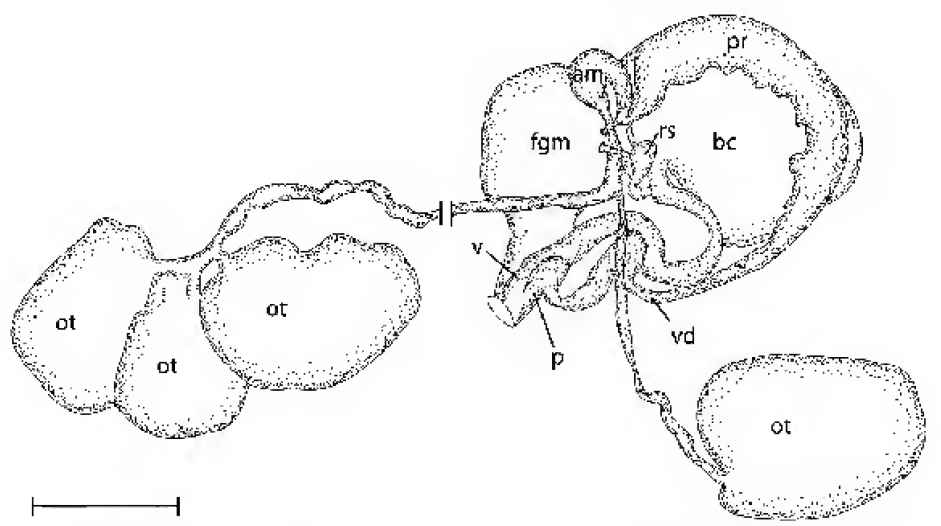

FIGURE 3. Gymnodoris brunnea sp. nov. reproductive system: scale bar = $1 \mathrm{~mm}$. Abbreviations: am, ampulla; bc, bursa copulatrix; fgm, female gland mass; p, penis; pr, prostate; rs, receptaculum seminis; v, vagina; vd, vas deferens; ot, ovotestis. cent of Gymnodoris citrina (Bergh, 1877) than of either of the two described species that have been placed in Analogium. Because of this, we place this species within Gymnodoris. 
The overall body profile of G. brunnea is similar to the species depicted as Gymnodoris marginata (Odhner, 1917). Gymnodoris marginata also has gills arranged in a linear "bow." A major difference, however, is the position of the genital aperture, which is located well forward of that in G. brunnea. The radular teeth depicted in the G. marginata description are also very different in shape to those of G. brunnea, as the inner lateral of $G$. marginata looks nearly identical to the outer lateral depicted, whereas in G. brunnea the first and second inner lateral teeth are clearly differentiated from the outer laterals.

This species has only been documented from the Anilao region of the Philippines and it is unclear if it is restricted to this region or has a wider distribution. We have a photo of a Gymnodoris specimen from Japan that has a similar appearance to G. brunnea. This specimen appears to have a broader foot. It also does not seem to have the same dark brownish pigment to the skin and more subtle orange on the front margin of the foot. These animals would have to be further investigated via DNA or dissections to confirm if they belong to the same or a different, closely-related species.

\section{Gymnodoris tuberculosa Knutson and} Gosliner, sp. nov.

Figures 1 C-D, 5, 6, 7

Gymnodoris sp. 3. Gosliner, et al., 2008: 149.

Type Material. - Holotype: CASIZ 191190, one specimen, "Kranket Fish Market Cove," near Madang Resort, Madang Province, Papua New Guinea, 5²1'28.4148"S, $145^{\circ} 48^{\prime} 31.9896^{\prime \prime} \mathrm{E}$, collected at night, November 13, 2012 by Vanessa Knutson, preserved specimen $6.0 \mathrm{~mm}$ length. PARATYPES: CASIZ 083765, one specimen, dissected, $18.6 \mathrm{~m}$ depth, Bonito Island, Batangas, Luzon Island,

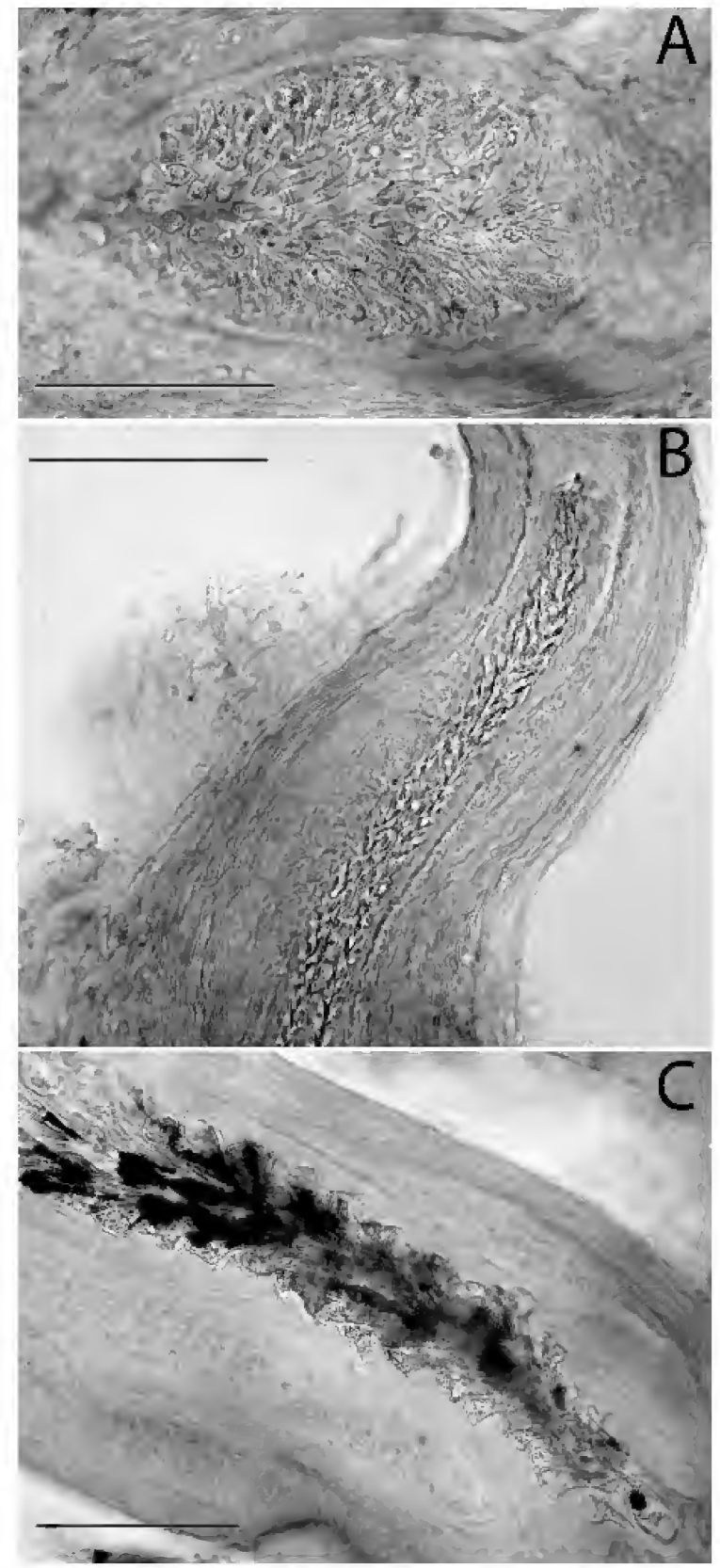

FIGURE 4. Light micrographs of the penial spines: scale bar $=100 \mu \mathrm{m}$. A. G. brunnea sp. nov., CASIZ 185973B. G. tuberculosa sp. nov., CASIZ 185954. C. G. pseudobrunnea sp. nov., CASIZ 185967.

Philippines, collected February 22, 1992 by T.M. Gosliner, preserved specimen $8.3 \mathrm{~mm}$ length. CASIZ 086418, one specimen, dissected, $5.2 \mathrm{~m}$ depth, S. side of Rasch Passage, Madang, Papua New Guinea, collected June 17, 1992 by T.M. Gosliner, preserved specimen $11.0 \mathrm{~mm}$ length. CASIZ 177268, one specimen, $14.2 \mathrm{~m}$ depth, Layag Layag, Caban Island, Maricaban Island, Batangas Province, Luzon, Philippines, collected March 16, 2008, preserved specimen $4.0 \mathrm{~mm}$ 
length with part of the "tail" missing. CASIZ 185954, one specimen, dissected, Cemetery Beach, Maricaban Island, Batangas Province, Luzon, Philippines, collected May 19, 2011 by Ditto de la Rosa, preserved specimen 9.0 mm length with part of the "tail" missing. CASIZ 191207, one specimen, Sek Island, Madang Province, Papua New Guinea, collected November 14, 2012 by Vanessa Knutson, preserved specimen $6.0 \mathrm{~mm}$ length with part of the "tail" missing. CASIZ 191461, one specimen, 6m depth, Lighthouse Point, Madang Province, Papua New Guinea, collected at night, November 28, 2012 by Anthony Berberian, preserved specimen $6.0 \mathrm{~mm}$ length with part of the "tail" missing. CASIZ 191294, two specimens, near Madang Resort, Madang Province, Papua New Guinea, $5^{\circ} 12^{\prime} 27.63^{\prime \prime} \mathrm{S} 145^{\circ} 48^{\prime} 32.45^{\prime \prime} \mathrm{E}$, collected at night November 17, 2012 by Vanessa Knutson, preserved specimen "A" $5.2 \mathrm{~mm}$ length with part of the "tail" missing, preserved specimen "B" 3.5 mm length. CASIZ 191397, one specimen, Madang Province, Papua New Guinea, $5^{\circ} 12^{\prime} 1.08^{\prime \prime} \mathrm{S} 145^{\circ} 48^{\prime} 45.66^{\prime \prime} \mathrm{E}$, collected at night, November 22, 2012 by Vanessa Knutson, preserved specimen $5.0 \mathrm{~mm}$ length. CASIZ 191477, one specimen, Tab Island, Madang Province, Papua New Guinea, collected November 30, 2012, by Vanessa Knutson, preserved specimen 1.7 mm length. CASIZ 191094, one specimen, Kranket Fish Market Cove, near Madang Resort,

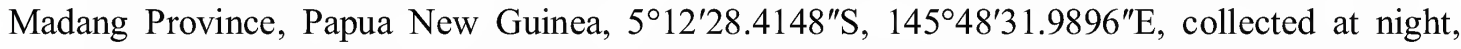
November 9, 2012 by Anthony Berberian, preserved specimen $5.0 \mathrm{~mm}$ length with part of the "tail" missing. CASIZ 191518, one specimen, dissected,1.5 m depth, SW Kranket Island, Madang Province, Papua New Guinea, collected on December 4, 2012 by T.M. Gosliner, preserved specimen $8.0 \mathrm{~mm}$ length with part of the "tail" missing.

EтYMology.- This species is named for the tubercles covering its body.

Distribution. - This species has been found in Papua New Guinea, the Philippines and documented from the Marshall Islands (Gosliner et al. 2008). There is also a photo on the Nudipixel website showing this species from Raja Ampat, Indonesia.

EXTERNAL MORPHOLOGY.- The length of the preserved specimens varies from $1.6 \mathrm{~mm}$ to $11.0 \mathrm{~mm}$. Some of these were subsampled for DNA analysis prior to measurement (CASIZ 177268, CASIZ 185954, CASIZ 191207, CASIZ 191461, CASIZ 191294A, CASIZ 191094, CASIZ 191518). The living animals (Fig. 1C, D) are uniformly translucent white in color and covered in small, rounded tubercles. While these tubercles are obvious in the living animal, they are not always apparent in preserved specimens, depending on the method of preservation. The tubercles seem to preserve well when fixed with Bouin's solution, but not always when fixed with alcohol. The internal organs can be seen through the translucent skin. The color of the digestive gland varies and has been observed as bright orange to pink to brown, perhaps due to the diet of the animal.

The rhinophores are lamellate with between 8 and 13 lamellae and range in color from translucent white to cream or pale yellow. The gill branches are the same color as the body of the animal and consist of approximately 9-13 main branches arranged in a complete circle with the anus located at the center. They are located close to the center of the length of the animal in the posterior half of the body. In preserved specimens, the gill may appear to be in the posterior third of the body. The genital opening (Fig 5) is located on the right side of the animal approximately one third of the length of the distance between the back of the rhinophores to the gills. There is a deep groove in the anterior portion of the foot, ventral to the mouth.

The specimens examined have spicules

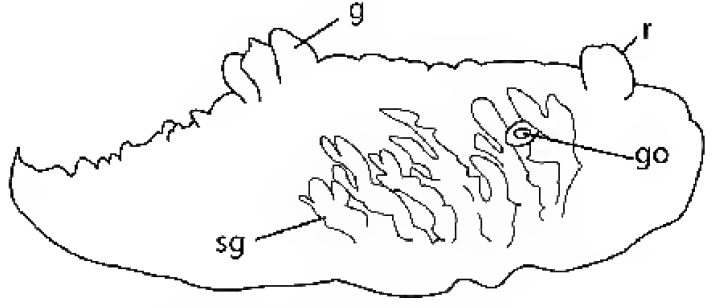

FIGURE 5. Gymnodoris tuberculosa sp. nov. arrangement and position of subcutaneous glands in preserved specimen, CASIZ 086418. Abbreviations: g, gills; go, genital opening; r, rhinophores; sg, subcutaneous glands. 
embedded in the skin. The spicules can be seen through the skin in some of the photos and are present in the preserved specimens. These spicules vary greatly, in one specimen, CASIZ 191461 there are spicules that have a pink tinge to them while others appear colorless. There also appears to be different morphologies for the spicules within a specimen. Some of the larger spicules were " $T$ " or "Y"-shaped and approximately $0.2 \mathrm{~mm}$ long, others were smaller and rod-shaped.

INTERNAL ANATOMY.- - On the ventrum and sides of the animal there are slightly branched, thickened glandular structures (Fig. 5). These structures are white to pale yellow in color and appear to originate at the foot and come up the sides of the animal. Although these structures are subcutaneous, they are clearly visible through the translucent skin in the living animal and in preserved specimens. These structures seem to be concentrated anterior to and at the level of the gills. The structures do not appear to be present in the posterior portions of the foot of the living animals. These structures are more pronounced in some specimens than in others. They resemble the subcutaneous glandular tubes described for Gymnodoris aurita (Gould, 1852), (Gosliner 1997), and presumably serve a defensive function.

Buccal and radular morphology: The buccal mass is muscular and has long strap-like salivary glands. Typical of the genus, the radula lacks a rachidian row of teeth (Fig. 6A). The inner lateral tooth (Fig. 6B) is a curved hook with a thickened, relatively straight base. The mid lateral teeth (Fig. 6C) are hook shaped with an elongate cusp. The outermost laterals (Fig. 6D) are thinner than the mid laterals and have a less pronounced base and a more elongate cusp. The radular formulas of four specimens were counted as follows: $20 \times$ 20.1.0.1.20 (CASIZ 185954), $21 \times$ 21.1.0.1.21 (CASIZ 191518), 21 x 20.1.0.1.20 (CASIZ 083765), 18 x 15.1.0.1.15 (CASIZ 086418).

Reproductive system: There are two ovotestis masses located anterior to the digestive gland and posterior to the genital mass. A hermaphroditic duct extends from each of the ovotestis follicles (Fig. 7). Just anterior to their junction, the hermaphroditic duct widens into the ampulla. The ampulla then bifurcates into a short oviduct which enters the female gland mass. The second branch widens into the curved prostate, which surrounds the bursa copulatrix and then narrows into the muscular vas deferens. The vas deferens consists of several convolutions and coils before entering the penis, adjacent to the vagina. The uterine duct emerges from the female glands near the oviduct and enters the small pyriform receptaculum seminis. The elongate receptaculum duct enters the vagina at the beginning of a
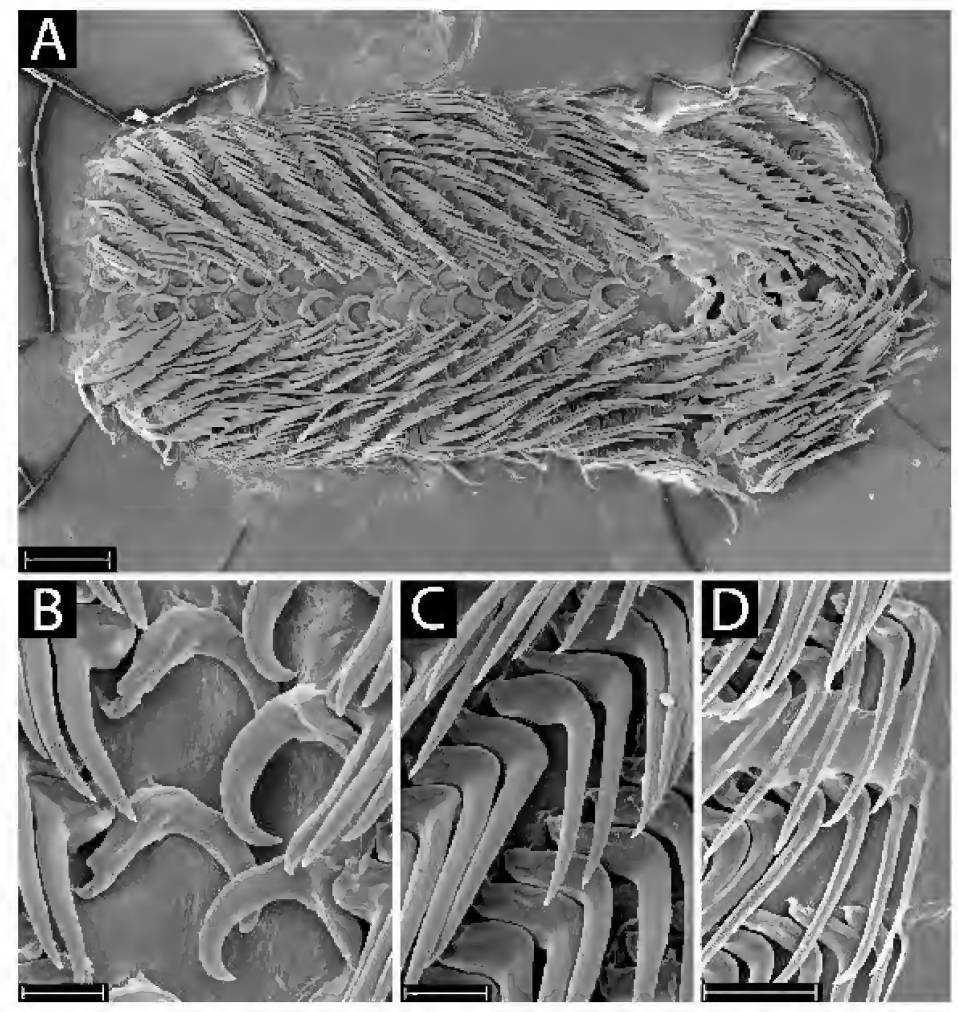

FIGURE 6. Gymnodoris tuberculosa sp. nov. scanning electron micrographs of the radula. A. View of the entire radula, CASIZ 185954, scale $=90 \mu \mathrm{m}$. B. Inner lateral teeth, CASIZ 185954, scale $=20 \mu \mathrm{m}$. C. Mid lateral teeth, CASIZ 185954, scale $=20 \mu \mathrm{m}$. D. Outer laterals, CASIZ 086318 scale $=20 \mu \mathrm{m}$. 
greatly expanded, bulbous portion of the vagina just below the spherical, bursa copulatrix. The vagina again narrows and curves slightly before joining the genital opening. The albumen and membrane glands are small and not well differentiated. The mucous gland comprises the majority of the female gland mass. The penis of one specimen (CASIZ 185954) was cleared and stained (Fig 4B). The penis of this specimen is armed with small spines. The spines were difficult to distinguish due to their small size. These spines are estimated at a length of approximately $12 \mu \mathrm{m}$.

Natural HISTORY.- This species appears to be active at night, but is often found on the undersurface of coral rubble during the day.

Discussion.-Gymnodoris tuberculosa differs from other described species of Gymnodoris by its general translucent white

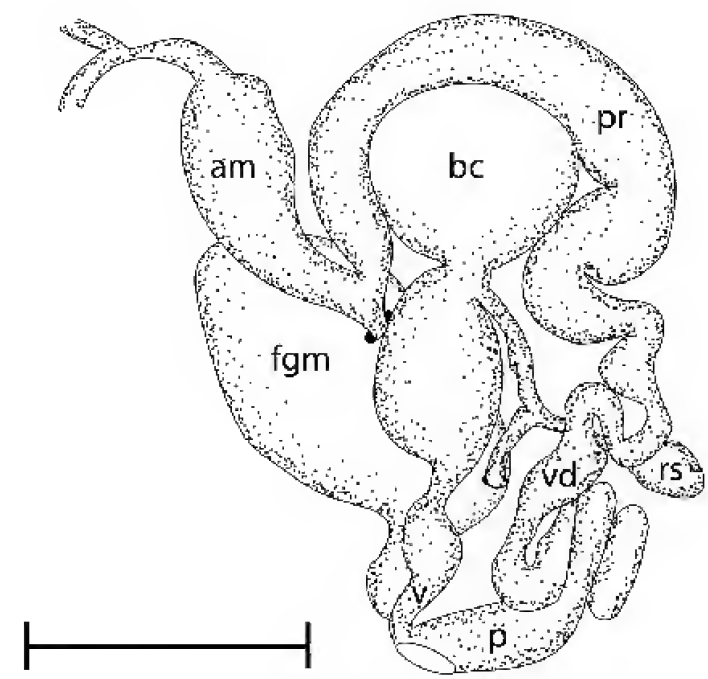

FIGURE 7. Gymnodoris tuberculosa sp. nov. reproductive system: scale bar $=1 \mathrm{~mm}$. Abbreviations: am, ampulla; bc, bursa copulatrix; fgm, female gland mass; p, penis; pr, prostate; rs, receptaculum seminis; v, vagina; vd, vas deferens.

color, and the presence of translucent white tubercles. The other species of Gymnodoris that possess prominent tubercles have tubercles that are pigmented, often from yellow to orange to red in color such as Gymnodoris aurita (Gould, 1852), or Gymnodoris ceylonica (Kelaart, 1858). The vagina of this species has a wide bulbous portion similar to that depicted for Gymnodoris inorna$t a$, (Bergh, 1880). The depiction of part of the reproductive system of Gymnodoris alba (Bergh, 1877) has a smaller, less pronounced, but similar structure.

\section{Gymnodoris pseudobrunnea Knutson and Gosliner, sp. nov.}

Figures $8,9,10$

TyPe MATERIAL. - HolotyPe: CASIZ 185974, one specimen, Anilao Harbor, Anilao, Balayan Bay, Batangas Province, Luzon Island, Philippines, collected May 4, 2011, by Michelle Weber, subsampled for DNA, preserved specimen $5.0 \mathrm{~mm}$ in length with part of the "tail" missing. PARATYPES: CASIZ 185960, one specimen, subsampled for DNA, preserved specimen $5.0 \mathrm{~mm}$ length with part of the "tail" missing, CASIZ 185962, one specimen, dissected, subsampled for DNA, preserved specimen $4.5 \mathrm{~mm}$ length with part of the "tail" missing, CASIZ 185967, one specimen, dissected, DNA subsampled, CASIZ 185969, one specimen, dissected, DNA subsampled, preserved specimen $6.2 \mathrm{~mm}$ in length with part of the "tail" missing, CASIZ 185981, one specimen, subsampled for DNA, preserved specimen $3.0 \mathrm{~mm}$ length with part of the "tail" missing, all collected at Anilao Harbor, Anilao, Balayan Bay, Batangas Province, Luzon Island, Philippines, May 4, 2011, by Michelle Weber, except CASIZ 185981, which was collected by Alexis Principe.

ETYMOLOGY.- This species is named for its similarity in appearance to G. brunnea.

Geographical Distribution.- Currently known only from the type locality, the Anilao region in the Philippines.

EXTERNAL MORPHOLOGY.- Preserved specimens were subsampled for DNA before they were measured and ranged $3.0-6.2 \mathrm{~mm}$ in size with a portion of the tail missing. Living G. pseudobrunnea (Fig. 8A,B) are translucent and may have a slight brownish tinge, but the brownish coloration is relatively subtle, if present. The foot is broad. The sides and dorsum of the body are cov- 
ered in deep orange, conical pustules. These pustules are present on the anterior portion of the notal margin. Starting from the anterior margin, these pustules are situated in two diffuse rows following the mantle margin posteriorly and converge towards the posterior tip of the foot. It is difficult to tell from some of the photos of specimens where the pustules converge and it may be that the pustules do not converge in some of the specimens. None of the living specimens observed appeared to have pustules between the rhinophores, which have approximately $7-8$ lamellae and vary in coloration. Some

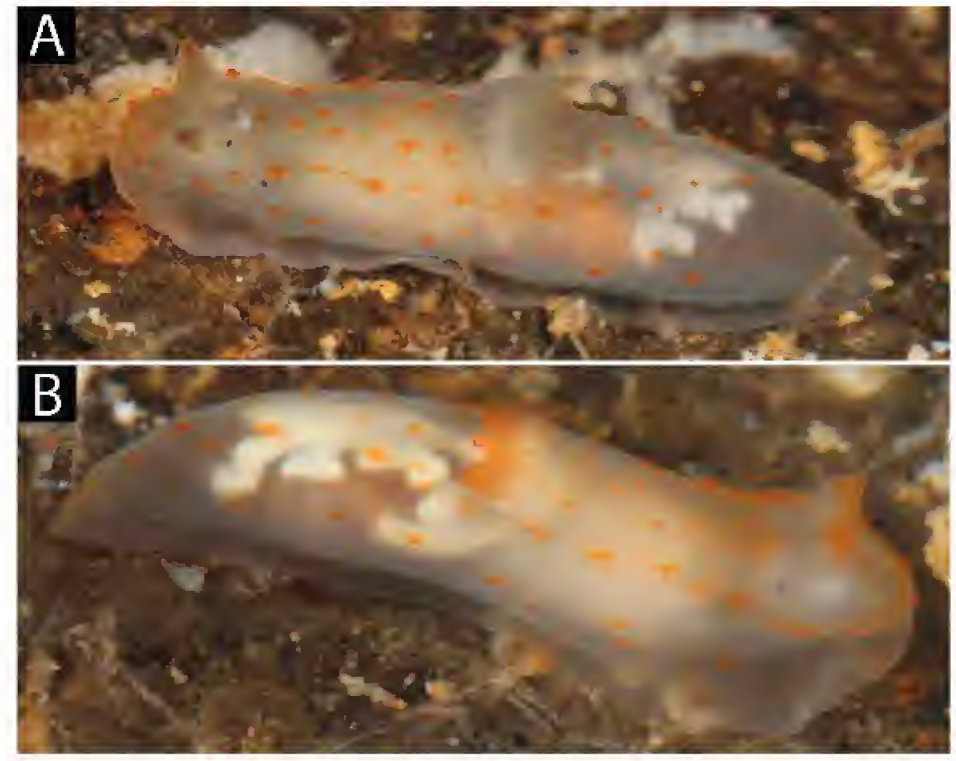

FIGURE 8. Photographs of living animals. A-B. Gymnodoris pseudobrunnea sp. nov.

specimens had rhinophores with a brownish tinge with orange at the tip, others were orange on the upper half of the rhinophore or nearly the whole rhinophore. One specimen had rhinophores that were deep orange-brown.

Specimens had between 7 and 11 unipinnate gill filaments arranged in a linear row or in as light arc anterior to the anus. The filaments may be tinged with a deep orange color, though this coloration varies between specimens. In some specimens, the orange pigment is highly concentrated and may cover much of the gills; in others, the orange pigment covers only the apical portion of the gills. In others, there is a negligible amount of orange on the gills. The length of the gill filaments also varies.

Due to the translucent nature of the skin, the internal organs are visible externally. A bright white patch can be viewed below the skin and is located from the gill to about halfway to the posterior end of the foot. The margin of this white patch is irregular in shape and varies between specimens. No dark brown intestine can be seen through the skin in this species. The genital aperture is located forward of the gills at approximately the same level as the pericardium.

INTERNAL ANATOMY.- Buccal and radular morphology: The buccal mass is muscular and the salivary glands are strap-like. Typical of the genus Gymnodoris, the radula has no rachidian row of teeth (Fig. 9A). The innermost lateral teeth are large and hook shaped with a long base (Fig. 9B). The second inner lateral is not differentiated from the rest of the mid-laterals, which are long and pointed (Fig. 9B). The laterals decrease in size very gradually and the outer laterals are the smallest of the teeth (Fig. 9C). The radular formulae of two specimens were counted and approximated as follows: $14 \times$ 15.1.0.1.15 (CASIZ 185962), $16 \times 14.1 .0 .1 .14$ (CASIZ 185969). A third radula was prepared, but not all of the rows were visible, at least 9 rows could be counted $x$ 12.1.0.1.12 (CASIZ 185967).

Reproductive system: There are two large main ovotestis masses, one located ventral-laterally on the right side to the digestive gland and the other on the left, posterior to the genital mass. A hermaphroditic duct (Fig. 10) extends from each of the ovotestis follicles; these unite into a single duct that widens into the swollen ampulla. The ampulla bifurcates into a short oviduct that enters the female gland mass. The second branch widens into the curved prostate, which surrounds the large 
bursa copulatrix and narrows into the muscular vas deferens. The vas deferens consists of a convolution where it widens and enters the penis, adjacent to the vagina. The uterine duct emerges from the female gland mass and joins with the pyriform receptaculum seminis. The receptaculum duct enters the vagina midway between the bursa copulatrix and the genital aperture. The albumen and membrane glands are small and not well differentiated. The mucous gland comprises the majority of the female gland mass. The penis of one specimen (CASIZ 185967) was cleared and stained (Fig. 4C) and is armed with densely distributed spines that have a broad base (roughly $19 \mu \mathrm{m}$ across). The spines appear to be longer at the base of the penis, roughly $67 \mu \mathrm{m}$, and shorter at the very tip, roughly $31 \mu \mathrm{m}$.

NatURAL History.- This species was collected at night from a sandy bottom and likely
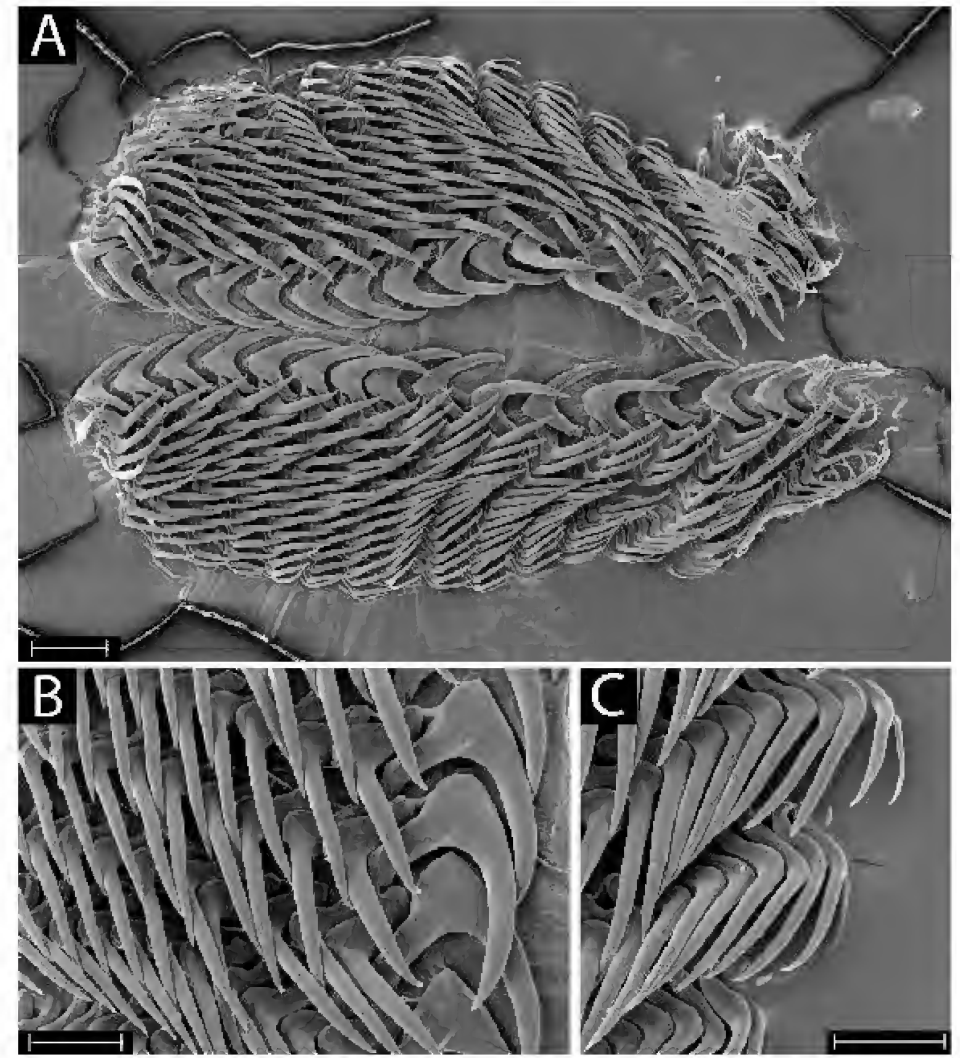

FIGURE 9. Gymnodoris pseudobrunnea sp. nov. scanning electron micrographs of the radula. A. View of the entire radula, CASIZ 185969 , scale $=60$ $\mu \mathrm{m}$. B. Inner and mid lateral teeth, CASIZ 185969, scale $=30 \mu \mathrm{m}$. C. Outer lateral teeth, CASIZ 185969, scale $=30 \mu \mathrm{m}$.

burrows in the sand. One of the specimens dissected (CASIZ 185967) had a minimally digested nudibranch in its stomach. The nudibranch pulled from the stomach had a dark coloration concentrated on the dorsal side, consistent with G. brunnea. After imaging the radula of this nudibranch (Fig. 11) with a scanning electron microscope, it is clear that it is consistent with that of G. brunnea with large, hookshaped inner laterals and distinctive bicuspid second lateral teeth. Due to the early stage of digestion of the stomach contents, it is possible that feeding took place following collection, if the two specimens were placed in the same container at the time of collection. If this is what occurred, one may

FIGURE 10. Gymnodoris pseudobrunnea sp. nov. reproductive system: scale bar $=1 \mathrm{~mm}$. Abbreviations: am, ampulla; bc, bursa copulatrix; fgm, female gland mass; $p$, penis; pr, prostate; rs, receptaculum seminis; v, vagina; vd, vas deferens.

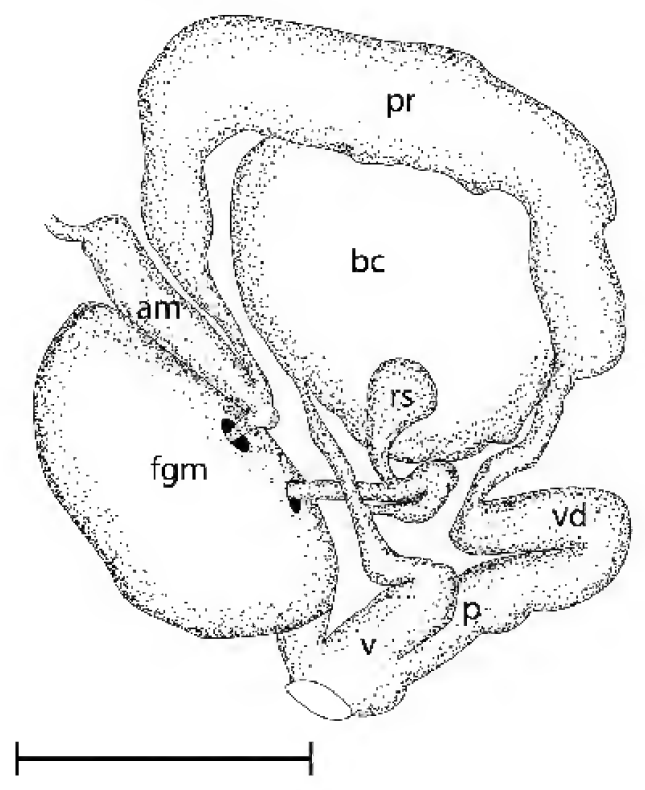


speculate that perhaps the unnatural conditions led to G. pseudobrunnea feeding on $G$ brunnea; however, it is not unusual for gymnodorids to feed upon congeners and even conspecifics (Nakano 2011). Initially, it was thought that cannibalism in Gymnodoris was induced by unnatural laboratory conditions (Young 1967); however, gymnodorids have exhibited cannibalism in their natural habitat (Johnson and Boucher 1983; Johnson 1992; Nakano 2011). This demonstrates that unnatural conditions don't necessarily lead to abnormal feeding behavior. Further, in the field we were careful to keep Gymnodoris specimens separated from each other and other opisthobranchs to prevent loss of specimens. It is therefore likely that G. pseudobrunnea preys upon $G$. brunnea under natural conditions, and that this most likely occurred prior to collection.

Discussion. - Externally, this species looks very similar to G. brunnea. Upon close examination, there are some subtle, but consistent differences in appearance between the two species. The features that best differentiate these species externally include the shape and position of the
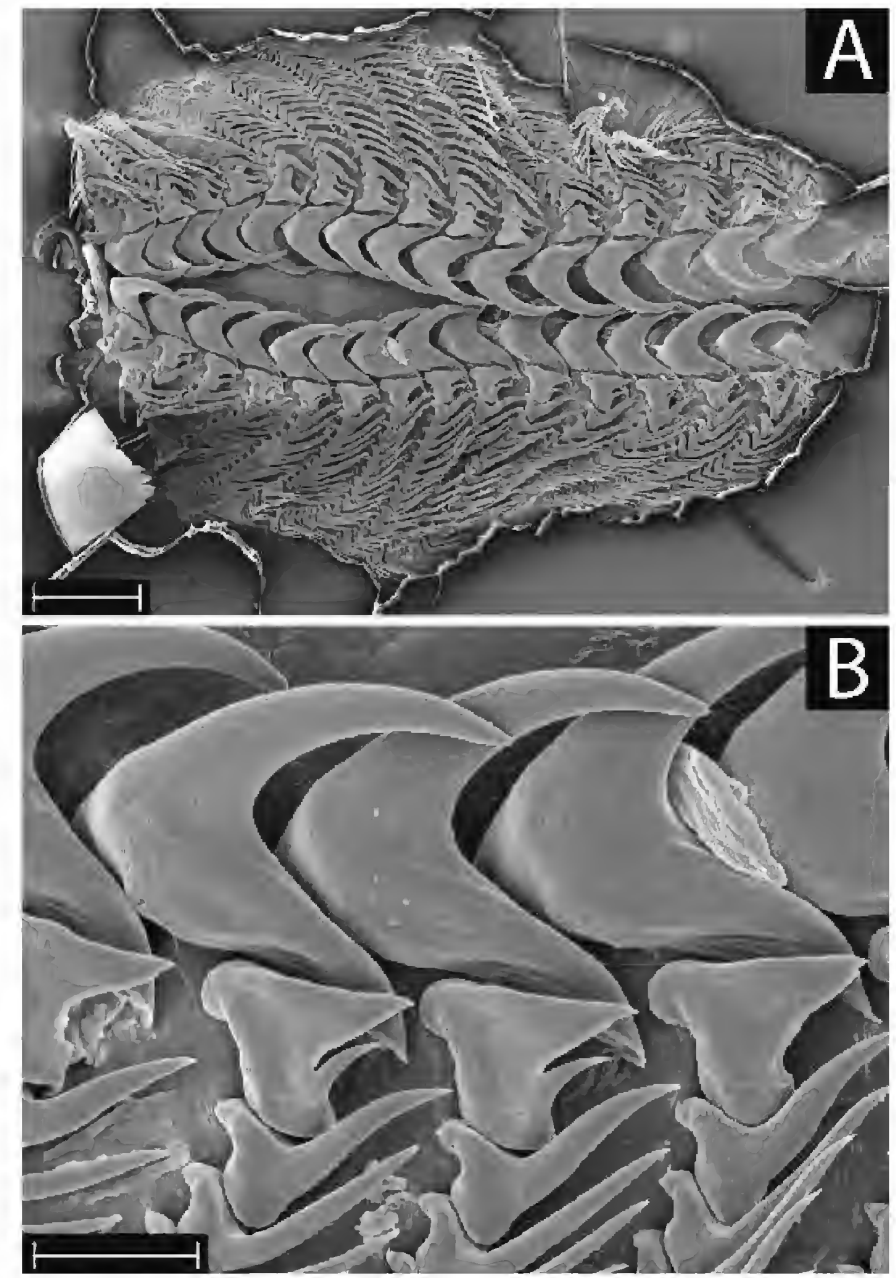

FIGURE 11. Scanning electron micrographs of the radula found inside of the digestive gland of a specimen of G. pseudobrunnea sp. nov. CASIZ 185967. A. View of the entire radula. B. Detail of the inner lateral teeth, note the bicuspid second lateral tooth. white patch visible through the skin on the dorsal side of the animals, and the external visibility of the intestine. The margin of the white patch is far more irregular in shape in G. pseudobrunnea than it is in G. brunnea. Also, in G. pseudobrunnea, the white patch appears at the gills and posteriorly, whereas in G. brunnea, the white can be seen forward of the gill and posteriorly. In G. brunnea, the intestine is visible through the skin as a dark arch; this does not appear to be visible in G. pseudobrunnea.

Internally, there are distinct radular differences and differences in the arrangement of reproductive organs. The inner lateral teeth of $G$ brunnea are much broader than those of G. pseudobrunnea. Also, the second inner lateral teeth of $G$. brunnea are broad and bicuspid, whereas those of $G$. pseudobrunnea are not differentiated from the rest of the middle and outer laterals. Further, in G. pseudobrunnea, the lateral teeth are longer relative to the inner laterals, than those in G. brunnea. The main difference between the reproductive systems is the position of the receptaculum seminis. In $G$. brunnea, the receptaculum seminis duct enters the vagina close to the bursa copulatrix, whereas in $G$. pseudobrunnea the receptaculum seminis enters the vagina approximately halfway between the bursa copulatrix and the genital aperture. 
The morphological differences show clearly that these are two different species, and the molecular data presented here further corroborate their distinctiveness. The uncorrected COI p-distances within G. brunnea specimens ranged from $0.0 \%$ to $0.5 \%$, representing intraspecific diversity. We were only able to successfully amplify the COI fragment for one specimen of G. pseudobrunnea and, although with only one specimen we cannot measure any intraspecific genetic variation for this species, this one specimen ranges from 10.3-11.1\% different in the COI fragment from the G. brunnea specimens. This is well in line with the mean COI divergence of Herbert et al. (2003), which found a mean divergence of $11.1 \pm 5.1 \%$ for congeneric pairs within Mollusca, and above the $5.5 \%$ minimum $\mathrm{p}$-distance cutoff applied in a recent paper that delineated sister species of aeolid nudibranchs (Carmona et al. 2013).

\section{ACKNOWLEDGMENTS}

We would like to thank Michelle Weber for her excellent Gymnodoris spotting skills and Alexis Principe, Peri Palaracio and Ditto de la Rosa for being fantastic dive guides and for their talent of finding interesting specimens. We also acknowledge Will and Margaret Hearst for the funds to be able to survey this region of the Philippines, as well as BFAR for providing us with the permits, and the mayor of Mabini for supporting our efforts. We would further like to acknowledge the 'Our Planet Reviewed' Initiative, Papua New Guinea 2012-2103 Expedition and Philippe Bouchet for including the first author as a part of the shallow water marine portion of the expedition. Further thanks to all the colleagues who have contributed specimens over the course of this project and to the reviewer for suggestions on how to improve the manuscript.

\section{LiTERATURE CiTED}

Bouchet, P. 2013. Gymnodorididae. Accessed through: World Register of Marine Species at http://www.marinespecies. org/aphia.php? $p=$ taxdetails\&id=23049 on 2014-02-16.

Carmona L., M. Pola, T. M. Gosliner, and J. L. Cervera. 2013. A tale that morphology fails to tell: a molecular phylogeny of Aeolidiidae (Aeolidida, Nudibranchia, Gastropoda). PLOS ONE 8(5):e63000. doi:10.1371/journal.pone. 0063000

Folmer, M., M. Black, W. Hoen, R. Lutz, and R. VRijenhoek. 1994. DNA primers for amplification of mitochondrial cytochrome $\mathrm{c}$ oxidase subunit I from diverse metazoan invertebrates. Molecular Marine Biology and Biotechnology 3(5):294-299.

Gosliner, T., AND D. W. Behrens. 1997. Description of four new species of phanerobranch dorids (Mollusca: Nudibranchia) from the Indo-Pacific, with a redescription of Gymnodoris aurita (Gould, 1852). Proceedings of the California Academy of Sciences, ser. 4, 49(9):287-308.

Gosliner, Terrence. M., David. W. Behrens, And Ángel Valdés. 2008. Indo-Pacific Nudibranchs and Sea Slugs, a Field Guide to the World's Most Diverse Fauna, Sea Challengers Natural History Books and California Academy of Sciences. Gig Harbor, USA. 426 pp.

HAMATANI, I. 1995. A record on Analogium striatum (Eliot, 1908) (Opisthobranchia: Nudibranchia: Gymnodorididae) from Southwestern Japan. Venus; Japanese Journal of Malacology 54(3):179-183.

Hamatani, I., AND D. Osumi. 2003. A new gill-less species of Gymnodoris Stimpson, 1855 (Opisthobranchia: Nudibranchia) from Kagoshima Bay, southern Japan. Venus; Japanese Journal of Malacology 62(3-4):125-128.

Hebert, P. D. N., S. RATnASINGHAM, AND J. R. DE WAARD. 2003. Barcoding animal life: cytochrome c oxidase subunit 1 divergences among closely related species. Proceedings of the Royal Society of London, Series B (Biology Letters Supplement) 270:S96-S99.

Jensen, K. R. 1998. Anatomy of some opisthobranch molluscs from Phuket, Thailand, with a list of Opisthobranchia recorded from Thai waters. Phuket Marine Biological Center Special Publication 18(2):243-262. 

FROM THE PHILIPPINES

JoHnson, S. 1992. Cannibalism and mating in Gymnodoris citrina (Bergh, 1877). Hawaiian Shell News 40:3-6.

Johnson, S. AND L. M. Boucher. 1983. Notes on some Opisthobranchia (Mollusca: Gastropoda) from the Marshall Islands, including 57 new records. Pacific Science 37(3):251-291.

MCDonald, Gary R. 2009. Nudibranch Systematic Index, second edition. UC Santa Cruz: Institute of Marine Sciences. Retrieved from: http://escholarship.org/uc/item/93c42364

NaKano, R., AND E. Hirose. 2011. Field experiments on the feeding of the nudibranch Gynmodoris spp. (Nudibranchia: Doridina: Gymnodorididae) in Japan. The Veliger 51(2):66-75.

Palomar, G., M. Pola and E. Garcia-VÁzquez. 2013. First molecular phylogeny of the subfamily Polycerinae (Mollusca, Nudibranchia, Polyceridae). Helgoland Marine Research (DOI: 10.1007/s10152-0130374-x).

Swennen, C. 1996. "Gymnodoris pattani, a New dorid nudibranch from Pattani Bay, Gulf of Thailand (Gastropoda, Nudibranchia)." Bulletin Zoologisch Museum, Universiteit van Amsterdam 15(6):41-46.

Yonow, N. 2011. Results of the Rumphius Biohistorical Expedition to Ambon (1990). Part 15. The suborder Doridina (Mollusca, Gastropoda, Opisthobranchia, Nudibranchia). Zoologische Mededelingen 85(17):905-956.

Young, D. K. 1967. New records of Nudibranchia (Gastropoda: Opisthobranchia: Nudibranchia) from the Central and West-Central Pacific with a description of a new species. The Veliger. 10(2):159-173.

\section{APPENDIX}

TABLE 1. Specimens used to compare uncorrected p-distances based on the COI gene for G. brunnea and G. pseudobrunnea.

\section{Species}

Gymnodoris brunnea, sp. nov. Gymnodoris brunnea, sp. nov. Gymnodoris brunnea, sp. nov. Gymnodoris brunnea, sp. nov. Gymnodoris brunnea, sp. nov. Gymnodoris brunnea, sp. nov. Gymnodoris brunnea, sp. nov. Gymnodoris pseudobrunnea, sp. nov.

\section{Voucher}

CASIZ 185963

CASIZ 185966

CASIZ 185968

CASIZ 185973

CASIZ 185975

CASIZ 185976

CASIZ 185979

CASIZ 185967
GenBank Accession number COI

KJ396778

KJ396779

K.J396780

KJ396781

K.J396782

KJ396783

KJ396784

KJ396785 


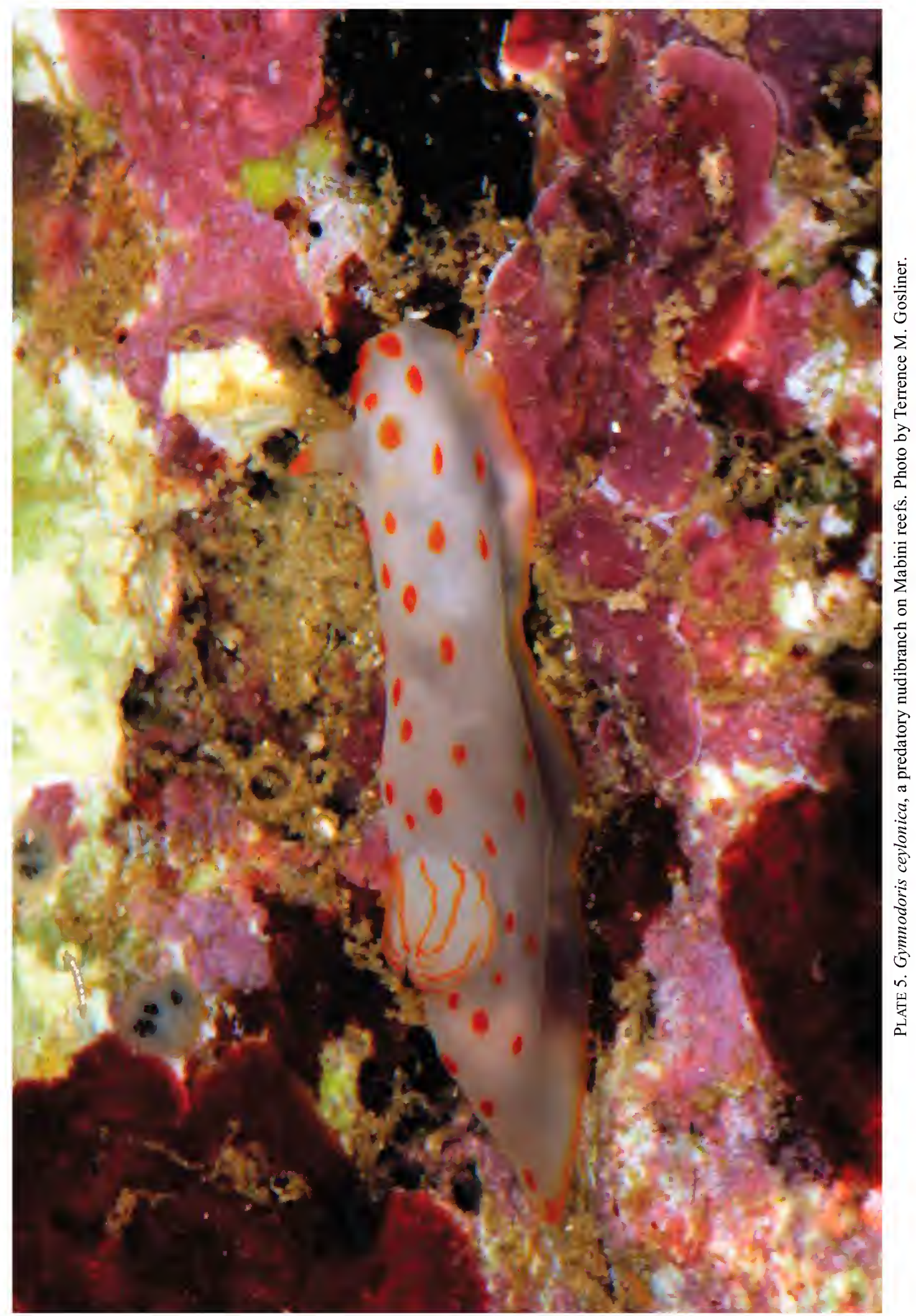




\title{
A New Species of Myrianida Milne Edwards, 1845 (Autolytinae: Syllidae: Annelida) from Luzón, Philippine Islands
}

\author{
Patricia Álvarez-Campos ${ }^{1 *}$, Guillermo San Martín ${ }^{1}$ and Christina Piotrowski ${ }^{2}$ \\ 1 Universidad Autónoma de Madrid, Departamento de Biología (Zoología), \\ Facultad de Ciencias, Cantoblanco, 28049 Madrid, Spain; ${ }^{2}$ California Academy of Sciences, \\ 55 MusicConcourse Drive, Golden Gate Park, San Francisco, CA 94118, USA; E-mails: \\ patricia.alvarez@uam.es; guillermo.sanmartin@uam.es; cpiotrowski@calacademy.org \\ *Corresponding author.E-mail: patricia.alvarez@uam.es
}

\begin{abstract}
A new, brightly colored species of the genus Myrianida Milne Edwards, 1845 from the Philippine Islands is herein described. The new species is characterized by a striking color pattern, with a yellow body and alternating red bands, and with white antennae, tentacular cirri, first dorsal cirri, and anal cirri. The median antenna and nuchal epaulettes are very long. The pharynx exhibits single sinuation, and a trepan with 18-20 equal teeth in a single ring. The reproductive female stolons are described. The phylogenetic position of the species within Myrianida is determined using molecular data, suggesting it is most closely related to the clade containing M. pachycera (Augener, 1913) and M. gidholmi Nygren and Pleijel, 2007. This is the first description of a well-characterized species of Myrianida from the Philippine Islands.
\end{abstract}

Autolytinae is a well-delineated, monophyletic group of Syllidae Grube, 1845 (Nygren 1999; Nygren and Sundberg 2003; Nygren and Pleijel 2007; Aguado and San Martín, 2009; Nygren et al. 2010; Aguado et al. 2012), easily recognizable by a lack of ventral cirri, presence of a sinuous pharynx, square-shaped proventricular muscle cells, and dimorphic sexual reproduction (Nygren 2004; Nygren and Pleijel 2007; Nygren et al. 2010). Currently, the subfamily comprises 12 recognized genera (Nygren 2004; Nygren and Pleijel 2007; Nygren et al. 2010): Myrianida Milne Edwards, 1845, Proceraea Claparède, 1864; Procerastea Langerhans, 1884; Virchowia Langerhans, 1879; Levidorum Hartman, 1967; Paraprocerastea San Martín and Alós, 1989; Epigamia Nygren, 2004; Imajimaea Nygren, 2004; Pachyprocerastea Nygren, 2004; Paraproceraea Nygren, 2004; Planicirrata Nygren, 2004; and Erseia Nygren, Sundkvist, Mikac and Pleijel, 2010. The genus Acritagasyllis, described by Lucas et al. (2010), ressembles the Autolytinae but it is considered as incertae sedis because its reproduction is still unknown. Autolytines reproduce by epitoky, which involves many morphological, physiological, and behavioral changes in ripe individuals (Malaquin 1893; Potts 1911; Franke 1999; Nygren 1999, 2004; Nygren and Sundberg 2003, Nygren and Pleijel 2007; Nygren et al. 2010; Aguado et al. 2012). They present two types of epitoky: Epigamy (the entire animal is transformed) and schizogamy (the posterior segments are transformed into epitokous individuals). Transformation occurs either as a single stolon at a time (scissiparity), or as several successive stolons in a row (gemmiparity) (Pleijel 2001; San Martín 2003; Nygren 2004; Aguado et al. 2007). Some species are brood caring, in which the female stolons carry ventral eggsacs (San Martín 2003; Aguado and San Martín 2009).

Myrianida was redefined by Nygren (2004) as a large genus within the Autolytinae Langerhans, 1879 , comprising 33 valid species. It is characterized by the nuchal epaulettes, completely fused palps, three antennae, two pairs of tentacular cirri, cylindrical or flattened appendages, one or two ciliary bands on each segment, compound chaetae with bidentate blades, the proximal tooth typically larger than the distal one, thin bayonet-shaped dorsal simple chaetae, lack of ventral simple chaetae, a slender pharynx with single or multiple sinuations, and a trepan with several equal 
or unequal teeth. Myrianida is the only genus of Syllidae that reproduces by gemmiparous schizogamy (see Nygren, 2004 for further diagnostic characters).

\section{MATERIAL AND METHODS}

The material examined was collected from less than $20 \mathrm{~m}$ depth in coral rubble at the "Dead Palm" dive site on the Calumpan Peninsula in Batangas Province at $13.69569^{\circ} \mathrm{N}, 120.88472^{\circ} \mathrm{E}$. Rubble was collected by SCUBA during the Hearst Philippine Biodiversity Expedition 2011 by Bryan Rodriguez (University of Philippines Marine Science Institute) and Christina Piotrowski (California Academy of Sciences).

Specimens were removed by soaking rubble in seawater for several hours and were sorted using a Meiji EMZ-13TR stereomicroscope, photographed, and preserved in 95\% ethanol for DNA-sequencing. Specimens were studied under a Nikon Optiphot microscope with a differential interference contrast system (Nomarsky) and an ocular micrometer, and were drawn by employing a camera lucida drawing tube. For scanning electron microscopy (SEM), the specimens were critical point dried with an Emitech K850 Critical Point Dryer, gold-coated with a Q150T-S TurboPumper Sputter Coater, and imaged using a Hitachi S-3000N electron microscope at SIDI (ServicioInterdepartamental de Investigación), Universidad Autónoma de Madrid (UAM). Width, excluding parapodia, was measured at the proventricle region.

Genomic DNA was extracted using a DNeasy Tissue Kit (Qiagen) following protocols supplied by the manufacturer. Gene fragments of COI and 16SrDNA genes were amplified from the paratype specimen (MNCN 16.01/14734) of Myrianida puladilaw sp. nov. Universal primers LCO 1490 (GGTCAACAAATCATAAAGATATTGG) and HCO 2198 (TAAACTTCAGGGTGACCAAAAAATCA) (Folmer et al. 1994) were employed for the COI fragment and the primers 16SarL (CGCCTGTTTATCAAAAACAT) and 16SbrH (CCGGTCTGAACTCAGATCACGT) (Palumbi 1996) were used for 16S. PCR reactions were performed using 3 ul of template DNA in $25 \mathrm{ul}$ reaction volumes using the following recipe for each gene fragment: COI: $2.5 \mathrm{ul} \mathrm{10X}$ USB Buffer, $1.0 \mathrm{ul} 25 \mathrm{mM} \mathrm{MgCl}_{2}, 1.0 \mathrm{ul}$ each of $10 \mathrm{uM}$ primers, $0.5 \mathrm{ul}$ of $10 \mathrm{mM}$ dNTP, $1.25 \mathrm{ul}$ of 1.25 U/ul HotStarTaq DNA Polymerase (Qiagen). 16S: 2.5 ul 10X USB Buffer, 1.5 ul $25 \mathrm{mM} \mathrm{MgCl}_{2}$, $0.2 \mathrm{ul}$ each of $25 \mathrm{uM}$ primers, $0.5 \mathrm{ul}$ of $10 \mathrm{mM}$ dNTP, $1.25 \mathrm{ul}$ of $1.25 \mathrm{U} / \mathrm{ulTaq}$ DNA Polymerase (Invitrogen). Both reactions were run using a BioRad MyCyclerThermocycler. The temperature profile for COI was as follows: $94^{\circ} \mathrm{C} / 180 \mathrm{sec} ;\left(94^{\circ} \mathrm{C} / 30 \mathrm{sec} ; 48^{\circ} \mathrm{C} / 30 \mathrm{sec} ; 72^{\circ} \mathrm{C} / 60 \mathrm{sec}\right)$ x $40 \mathrm{cycles}$; $72^{\circ} \mathrm{C} / 10 \mathrm{~min}$; the temperature profile for $16 \mathrm{~S}$ was: $94^{\circ} \mathrm{C} / 180 \mathrm{sec} ; 50^{\circ} \mathrm{C} / 120 \mathrm{sec} ; 72^{\circ} \mathrm{C} / 120 \mathrm{sec}$; $\left(94^{\circ} \mathrm{C} / 35 \mathrm{sec} ; 50^{\circ} \mathrm{C} / 30 \mathrm{sec} ; 72^{\circ} \mathrm{C} / 40 \mathrm{sec}\right) \times 35$ cycles $)$. Two reactions were run for the template DNA using each recipe and temperature profile; products were then electrophoresed on an agarose gel and resulting bands were excised and combined into a single tube for each gene fragment and cleaned using a Zymoclean Gel DNA Recovery kit (Zymo Research).

Twenty ul cycle sequencing reactions were performed for each primer using $3.0 \mathrm{ul}$ of cleaned template DNA for each primer direction using the following protocols: $\left(9.4 \mathrm{ul}\right.$ ultrapure $\mathrm{H}_{2} 0,3.0$ ul 5X Big Dye Buffer, 0.6 ul $10 \mathrm{uM}$ primer, 4.0 ul of Big Dye 3.1). The sequencing reaction temperature profile was as follows: $96^{\circ} \mathrm{C} / 60 \mathrm{sec} ;\left(96^{\circ} \mathrm{C} / 10 \mathrm{sec} ; 50^{\circ} \mathrm{C} / 5 \mathrm{sec} ; 60^{\circ} \mathrm{C} / 75 \mathrm{sec}\right)$ x $15 \mathrm{cycles}$; $\left(96^{\circ} \mathrm{C} / 10 \mathrm{sec} ; 50^{\circ} \mathrm{C} / 5 \mathrm{sec} ; 60^{\circ} \mathrm{C} / 90 \mathrm{sec}\right) \times 5$ cycles; $\left(96^{\circ} \mathrm{C} / 10 \mathrm{sec} ; 50^{\circ} \mathrm{C} / 5 \mathrm{sec} ; 60^{\circ} \mathrm{C} / 120 \mathrm{sec}\right) \times 5$ cycles. Sequencing products for each primer were precipitated using $125 \mathrm{mM}$ EDTA and ethanol. Precipitated product was denatured, followed by analysis using an ABI 3130 Genetic Analyzer (Applied Biosystems).

Reverse reads of sequence fragments were aligned by eye, trimmed, and edited using Sequencher 4.7 (Gene Codes Corporation). Overlapping sequence fragments were merged into 
consensus sequences with Geneious 6.1.6 (Drummond et al. 2009). In order to establish the phylogenetic position of M. puladilaw sp. nov. within the genus, we used nuclear (18S) and mitochondrial (16S and COI) GenBank sequences of 18 Myrianida species provided by Nygren et al. (2010). Species of Proceraea, Epigamia, Imajimaea, and Vichowia were used as outgroups (Table 1).

The mitochondrial data sets were analysed both separately and combined with nuclear data. RAxML 1.3 (Stamatakis 2006) was used to perform the Maximun likelihood analysis. Bootstrap support values were estimated by 1000 replicates, implementing a thorough bootstrapping algorithm (Stamatakis et al. 2008). The Bayesian Inference analysis was performed in MrBayes 3.2.1 (Ronquist and Huelsenbeck 2003). Four Markov chains were started from a random tree and run simultaneously for one million generations with trees sampled every 500 generations (samplefreq $=500$ ); the initial 25 percent of trees being discarded as burnin (burninfrac $=0.25$ ). The model of

TABLE 1. Species included in phylogenetic analyses, collection localities, voucher and GenBank accession numbers.

\begin{tabular}{|c|c|c|c|c|c|}
\hline & Locality & Voucher & COI & $16 S$ & $18 \mathrm{~S}$ \\
\hline Epigamia alexandri & Kaldbak, Faroe Islands & SMNH 45824 & GQ856183 & AF474262 & AF474308 \\
\hline E. magna & $\begin{array}{l}\text { Friday Harbor, Washin- } \\
\text { ton, USA }\end{array}$ & SMNH 45825 & GQ856185 & AF474263 & AF474309 \\
\hline Myrianida australiensis & Kaikora, New Zealand & GNM Polychaeta 13105 & GQ856187 & EF661834 & EF661838 \\
\hline M. brachycephala & Kristineberg, Sweden & SMNH 45812 & GQ856188 & AF474250 & AF474296.1 \\
\hline M. convoluta & $\begin{array}{l}\text { Santa Catalina, California, } \\
\text { USA }\end{array}$ & SMNH 45817 & GQ856189 & AF474257 & AF474303 \\
\hline M. dentalia & $\begin{array}{l}\text { Friday Harbor, Washin- } \\
\text { ton, USA }\end{array}$ & SMNH 45819 & GQ856190 & AF474301 & AF474301 \\
\hline M. edwardsi & Kristineberg, Sweden & SMNH 45810 & GQ856191 & AF474248 & AF474294 \\
\hline M. flava & $\begin{array}{l}\text { Friday Harbor, Washin- } \\
\text { ton, USA }\end{array}$ & SMNH 45818 & GQ856192 & AF474254 & AF474300 \\
\hline M. gidholmi & Carrie Bow Cay, Belize & GNM Polychaeta 13103 & GQ856193 & EF661835 & EF661839 \\
\hline M. hesperidium & Banyuls, France & SMNH 45815 & GQ856194 & AF474259 & AF474305 \\
\hline M. inermis & La Jolla, California, USA & SMNH 45821 & GQ856195 & AF474256 & AF474302 \\
\hline M. langerhansi & Banyuls, France & SMNH 45813 & GQ856197 & AF474251 & AF474297 \\
\hline M. longoprimicirrata & Banyuls, France & GNM 13214a, b & GU722619 & GU722629 & GU722643 \\
\hline M. pachycera & $\begin{array}{l}\text { Los Angeles, California, } \\
\text { USA }\end{array}$ & SMNH 45816 & GQ856198 & AF474258 & AF474304 \\
\hline M. pentadentata & La Jolla, California, USA & SMNH 45820 & GQ856199 & AF474253 & AF474299 \\
\hline M. pinnigera & Cádiz, Spain & SMNH 45823 & GQ856200 & AF474252 & AF474298 \\
\hline M. puladilaw & Batangas, Philippine Ids & MNCN 16.01/14734 & KJ534506 & KJ534507 & - \\
\hline M. prolifera & Kristineberg, Sweden & SMNH 45811 & GQ856201 & AF474249 & AF474295 \\
\hline M. quindecimdentata & Banyuls, France & SMNH 45814 & GQ856202 & AF474260 & AF474306 \\
\hline M. rubropunctata & Ferrol, Spain & GNM Polychaeta 13106 & GQ856203 & EF661837 & EF661841 \\
\hline Proceraea albocephala & Porto Moniz, Madeira & GNM Polychaeta $13194 a, b$ & GU722607 & GU722640 & GU722646 \\
\hline P. madeirensis & Funchal, Madeira & GNM Polychaeta 13208 & GU722617 & GU722627 & GU722645 \\
\hline P. pleijeli & Cádiz, Spain & SMNH 5947 & GQ856167 & AF474272 & AF474318 \\
\hline Virchowia clavata & Banyuls, France & AN & GQ856171 & AF474268 & AF474314 \\
\hline
\end{tabular}


sequence evolution for each partition was selected implementing the Akaike information criterion (AIC) in Modeltest 3.7 (Posada and Crandall 1998). For the three combined genes, General Time Reversible model was implemented with gamma distributed rate across sites and with a proportion of the sites invariable (GTR $+\mathrm{G}+\mathrm{I}$ ). The holotype has been deposited at the California Academy of Sciences in the Invertebrate Zoology collections (CASIZ), USA, and the paratype in the Museo Nacional de Ciencias Naturales de Madrid (MNCN), Spain.

\section{RESULTS}

\section{Molecular analysis}

The COI data set consists of 658 aligned positions, of which 303 are parsimony-informative and 343 are variable but not parsimony-informative. The 16SrDNA data set consists of 455 aligned positions, of which 237 are parsimony-informative and 272 are variable but not parsimony-informative. All Myrianida nodes of the combined phylogenetic tree (Fig. 4) including both mitochondrial and nuclear data sets also occur in a separate analysis of only mitochondrial data, each node having posterior probabilities ( $\mathrm{PP} \geq 0.97$, except for the $M$. dentalia (Imajima, 1966) and M. flava (Nygren, 2004) node. The clade comprising M. brachycephala (Marenzeller, 1874), M. edwardsi (Saint Joseph, 1887), M. prolifera (O.F. Mueller, 1788), M. langerhansi (Gidholm, 1967) and M. pinnigera (Montagu, 1808) as a sister group to $M$. dentalia, M. flava, M. inermis (Saint Joseph, 1887), M. longoprimicirrata (López, San Martín, and Jiménez, 1997) and M. pentadentata (Imajima, 1966) presents a PP of 0.59 and a bootstrap of 51 in analyses of both mitochondrial and combined data sets.

\section{Taxonomy}

\section{Genus Myrianida Milne Edwards, 1845}

\section{Myrianida puladilaw sp. nov.}

Material eXamined.- Holotype: (CASIZ 185700) and one paratype mounted for SEM (MNCN 16.01/14734). Philippines: Luzón Island, Batangas Province: Calumpan Peninsula: Dead Palm dive site, hidden in coral rubble. Hearst Philippine Biodiversity Expedition 2011. Station HEP-26. 13.69569 N 120.88472 E. Coll: Bryan Rodriguez and Christina Piotrowski by SCUBA 3 May 2011.

Diagnosis.- Characteristicred and yellow pattern, long median antenna, long nuchal epaulettes, and a trepan with 18-20 equal teeth.

DESCRIPTION.- HolOTYPE: $4.5 \mathrm{~mm}$ long, $0.3 \mathrm{~mm}$ wide, 39 chaetigers, one large female with stolon attached (Fig. 1A). PARATYPE: $3.5 \mathrm{~mm}$ long, $0.3 \mathrm{~mm}$ wide, 38 chaetigers, 4 female stolons attached (Fig. 1B, 3G-H). Living specimens with anterior three segments brightly red, remaining body with yellow background and successive groups of four to six red bands (Fig. 1A-C). Prostomium yellow, ovate, with four small, red eyes in trapezoidal arrangement (Fig 1C); antennae, tentacular cirri and dorsal cirri of chaetiger 1 white; parapodia and remaining dorsal cirri yellow (Figs. 1A-C). Stolons with similar color pattern (Figs 1A, 1B). Ciliation on prostomium, nuchal epaulettes, on one dorsal band per segment reaching cirrophores and on antennae, tentacular cirri and dorsal cirri (Figs. 2A, 2B, 2C; 3A-C). Palps fused, not visible in dorsal view (Fig. 1A-C, 2A). Nuchal epaulettes strongly red in vivo, extending to end of chaetiger 4 (Figs. 1C, 2A, C). Median antenna very long, reaching chaetiger 11-12 (Fig. 1B, 2B), missing in holotype. Lateral antennae shorter, $1 / 2$ of median antennae. Dorsal tentacular cirri similar in length to lateral antennae; ventral 

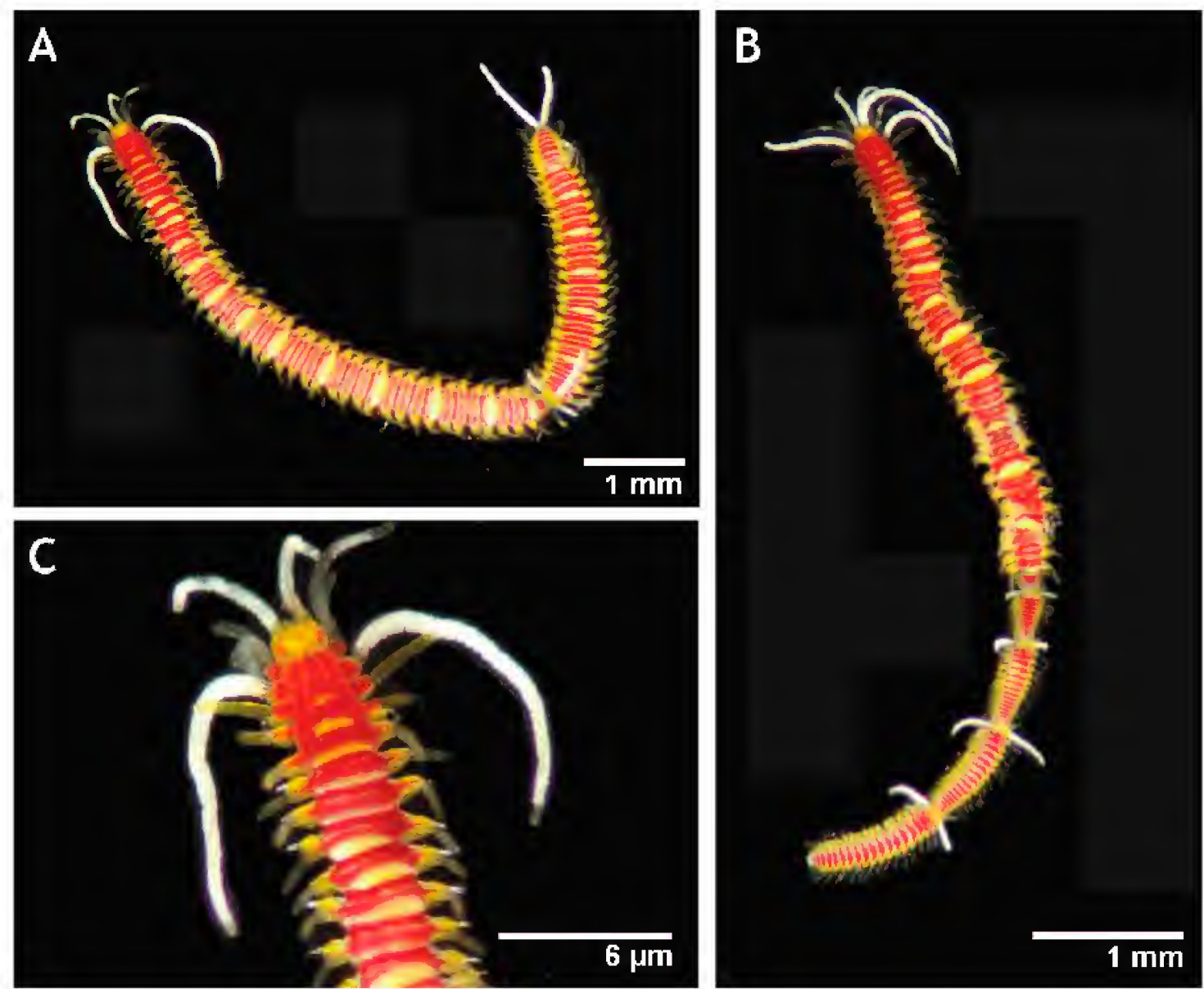

FIGURE 1. Myrianida puladilaw sp. nov. A: Holotype (CASIZ 185700) complete specimen, with a single stolon; B: paratype (MNCN 16.01/14734) complete specimen, with four developing stolons; C: anterior end, dorsal view of holotype.

tentacular cirri $2 / 3$ of dorsal ones. Cirri on first chaetiger as long as median antennae (Figs. 1A-C, 2A). Cirri on chaetiger 2 equal in length to body width. Dorsal cirri from chaetiger 3 onwards, alternating in length; short cirri about half longer than body width, long cirri $3 / 4$ longer than body width (Fig. 2A, C). Alternation in cirri orientation not seen. Cirrophores present on tentacular cirri and all dorsal cirri. Cirrophores and cirrostyles unequal; short cirrostyles $2 / 3$ longer than long ones; cirrophores of short cirrostyles $1 / 2$ longer than those of long ones; cirrophores slightly shorter than parapodial lobes and shorter than cirrostyles. Appendages cylindrical. Parapodial lobes rounded. Single aciculum in all chaetigers. Chaetal fascicle with 11 compound chaetae in anterior, 8 in median, and 5-7 in posterior chaetigers. Shafts of compound chaetae with distal spines; blades bidentate, with serration on cutting edge; proximal tooth distinctly larger than distal one; posterior falcigers shorter and wider than anterior ones (Figs. 2D, F; 3D-E). Single narrow bayonet chaetae beginning at chaetiger 25-28 (Fig. 2E, 3F). Pharynx with one sinuation anterior to proventricle (Fig. 2G). Trepan in chaetiger 2, with 18-20 equal teeth (Fig. 2H), arranged in single ring. Proventricle from chaetiger 9 to 11, with 36-38 rows of muscle cells (Fig. 2G). Anal cirri twice longer than tentacular cirri (Fig. 1A).

Reproduction and morphology of epitokous stage: Schizogamy is by gemmiparity. The holotype of M. puladilaw sp. nov. has a single stolon with 28 chaetigers, $2.5 \mathrm{~mm}$ long, without swim- 


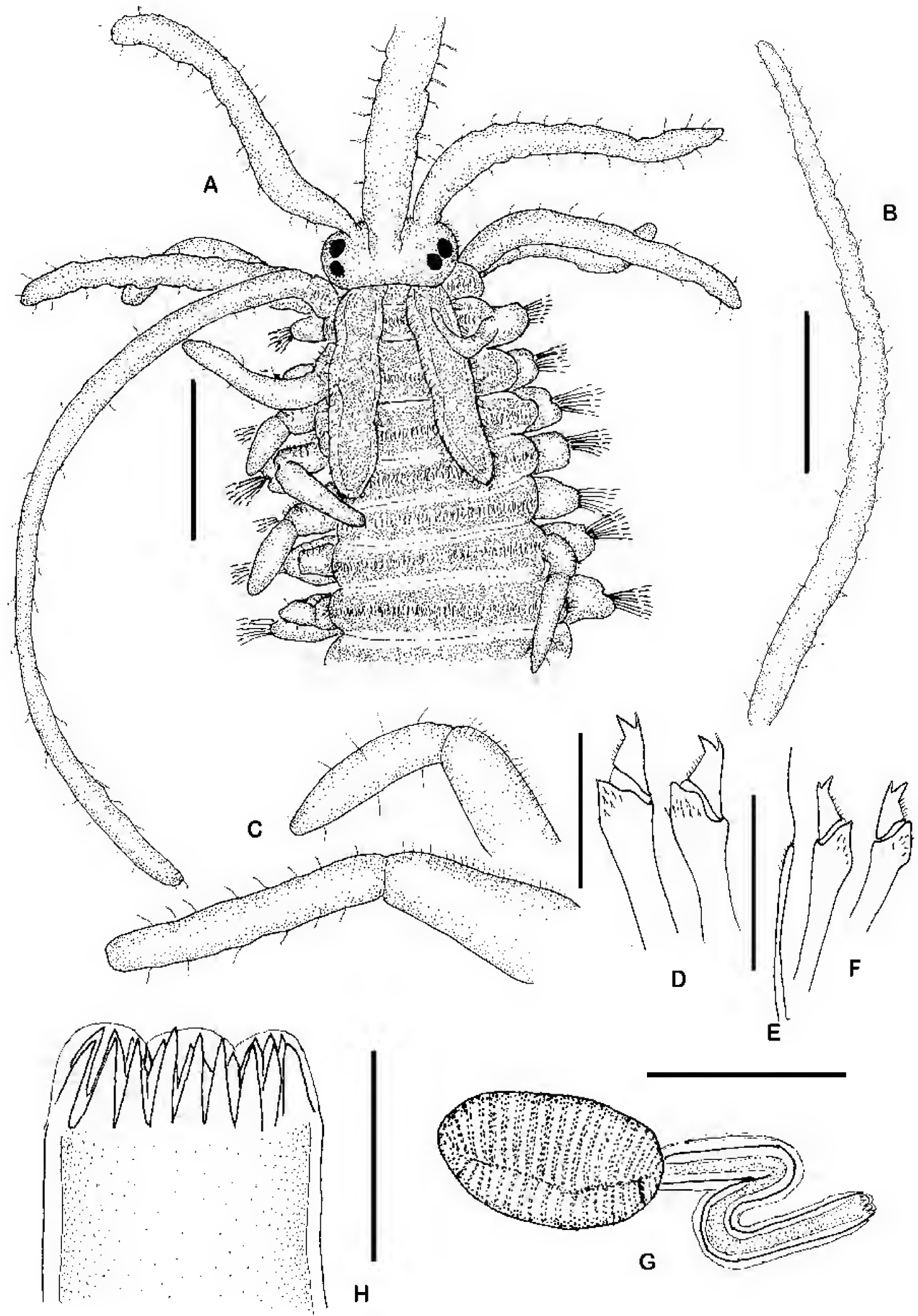



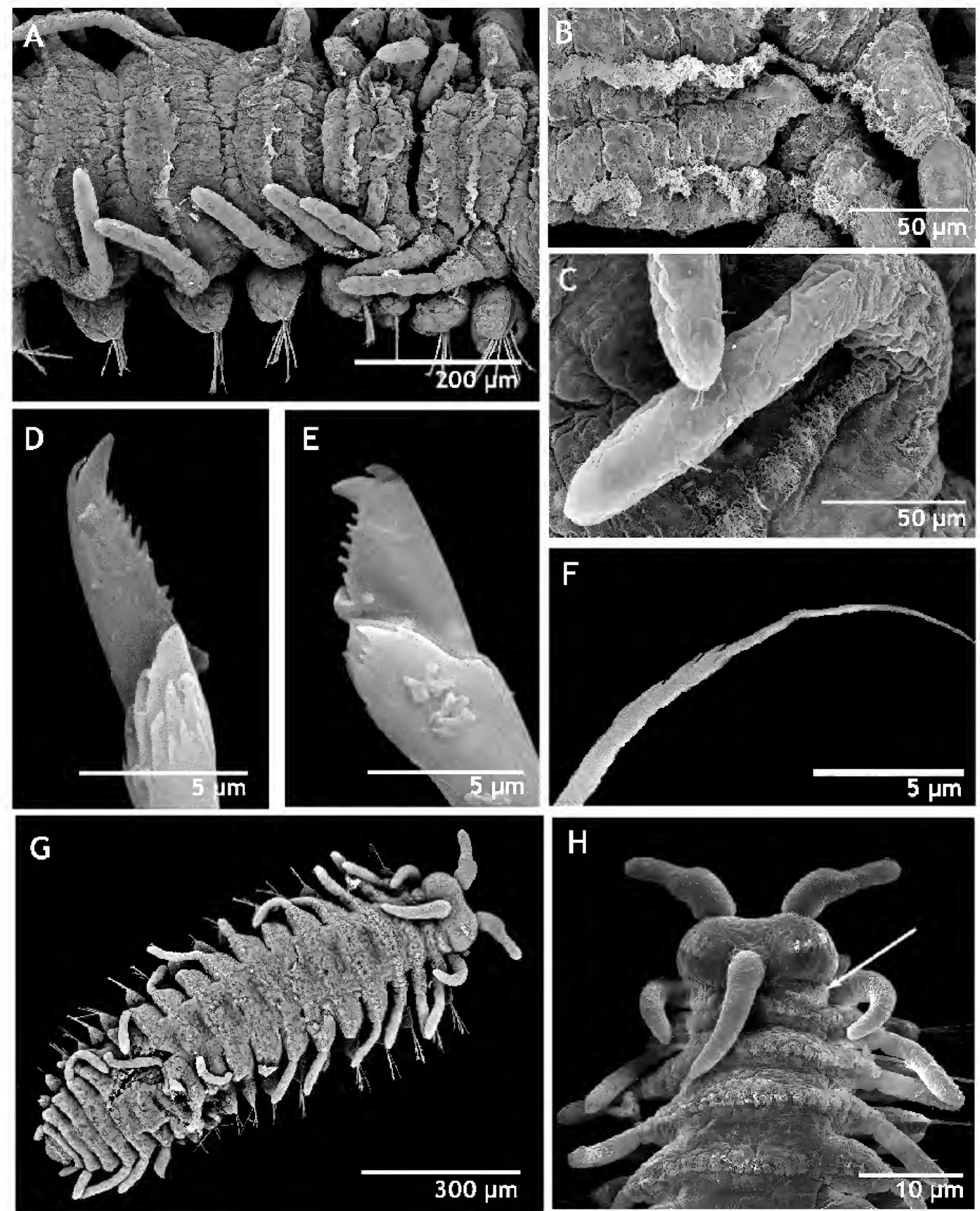

FIGURE 2 (left). Myrianida puladilaw sp. nov. Paratype (MNCN 16.01/14734) A: anterior end, dorsal view. B: central antennae. C: detail of short cirrostyles; D: chaetae, anterior parapodium; E: single bayonet chaetae, posterior parapodium; F: chaetae, posterior parapodium; G: Pharynx and proventriculus; H: Trepan.

FIGURE 3 (above). Myrianida puladilaw sp. nov. Paratype (MNCN 16.01/14734) SEM. A: midbody segments, dorsal view. B: detail of ciliary bands on midbody segments; C: detail of ciliary bands on cirrophores; D: dorsal chaetae, midbody parapodium E: ventral chaetae, midbody parapodium. F: single bayonet chaetae, posterior parapodium; G: complete stolon, dorsal view; $\mathrm{H}$ : detail of ciliary bands on anterior end of stolon. 
ming capillary chaetae (Fig. 1A). The paratype has four stolons with $9+15+17+20$ chaetigers, $0.4+0.6+0.8+1.2 \mathrm{~mm}$ long, respectively, and five regenerating posterior chaetigers on atokous form (Fig. 1B, 3G-H) with the same color pattern as the adult (Fig. 1A, B) and possibly representing another developing stolon. These chaetigers lack swimming chaetae (Fig. 3G) and exhibit a row of cilia on each segment (Figs. 3G-H); nuchal ciliated organs as two pits between prostomium and peristomium; some ciliary bands over the eyes (Fig. 3H).

ETYMology.- The name of the species is derived from the Tagalog language: pula, meaning red and dilaw, meaning yellow, and refers to the striking color pattern of this species.

HABitat. - Coral rubble near shallow coral reef

Distribution.- Only known from the type locality in Luzón Island, Philippine Islands.

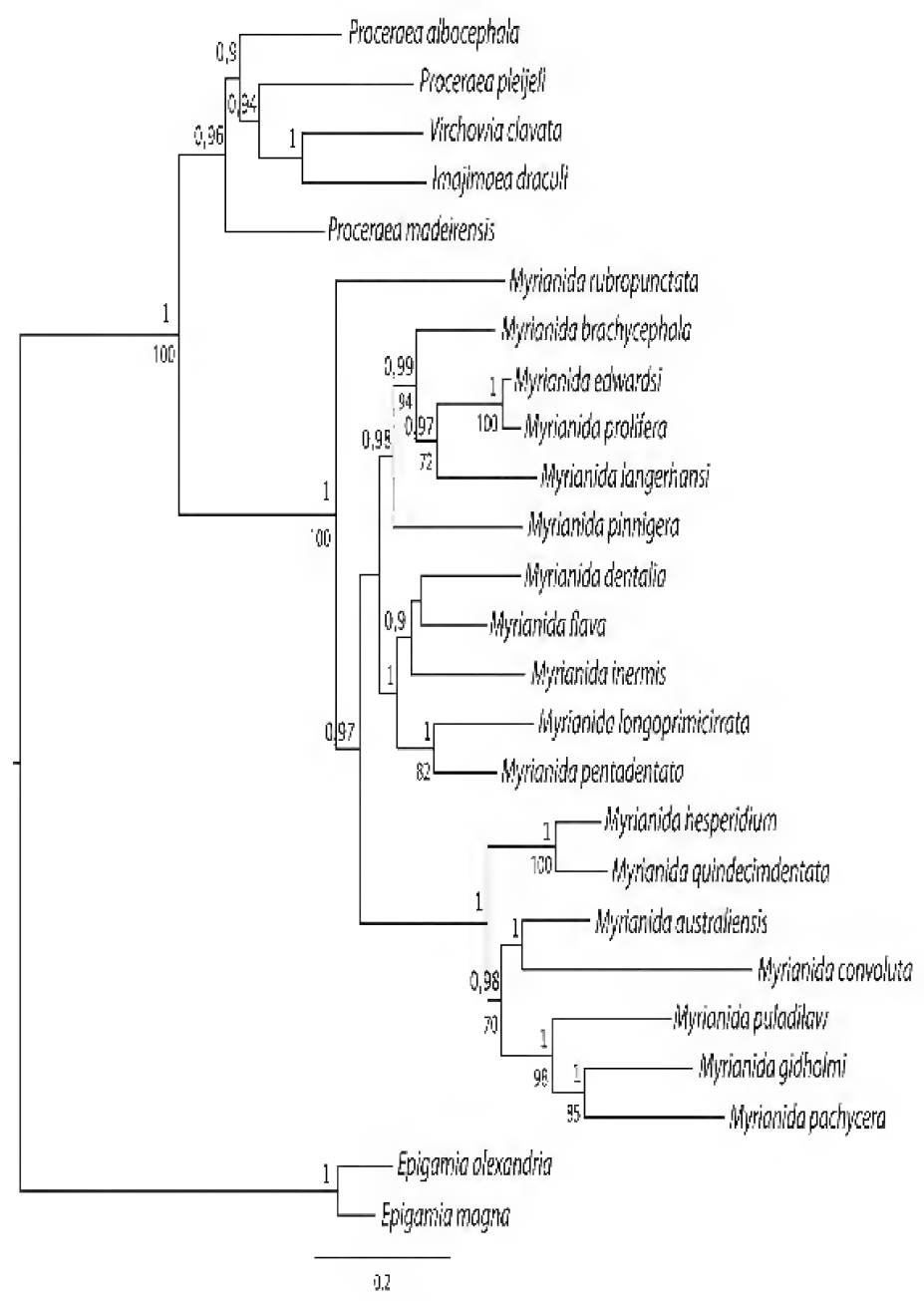

FIGURE 4. Majority rule consensus tree of Bayesian analyses from combined mitochondrial and nuclear data sets including COI, 16SrDNA and 18SrDNA. Maximun Likelihood analysis is congruent with this analysis. Bayesian posterior probabilities are shown above branches; boostrap values below branches except for nodes for which boostrap value is $<70$ (see material and methods for further explanation).

\section{DisCUSSION}

Both morphological and molecular data sets support M. puladilaw sp. nov. as belonging to Myrianida, within a well supported clade including M. australiensis (Hartmann-Schröder, 1982), M. convoluta (Cognetti, 1953), M. hesperidium, M. quindecimdentata (Langerhans, 1884) $M$. pachycera (Augener, 1913), and M. gidholmi (Nygren and Pleijel, 2007) (Fig. 4). The two latter taxa are the sister group of the new species. The unique character that unites this clade is reproduction by gemmiparity.

Myrianida puladilaw sp. nov. ressembles $M$. quindecimdentata and $M$. hesperidium in the length of median antennae, the number of chaetae in anterior segments and the unique sinuation of the pharynx. However, the former lacks long nuchal epaulettes and the latter exhibits different chaetal morphology than M. puladilaw sp. nov., with a much larger subdistal tooth. Both species 
present trepans with fewer and much shorter teeth than the new species. Myrianida pachycera and M. puladilaw sp. nov. share the presence of a single bayonet chaeta in the posterior parapodia. Myrianida gidholmi has the antennae similar in length to the new species. Myrianida arborea (Westheide, 1974) and M. puladilaw sp. nov. share a unique sinuation of the pharynx and the number of teeth in the trepan, yet $M$. arborea has shorter nuchal epaulettes and a single thin bayonet chaeta in all segments. None of these species presents a similar striking color pattern or the long nuchal epaulettes observed in M. puladilaw sp. nov. (Nygren 2004; Nygren and Sundberg 2007).

Only two Autolytinae, Autolytus triangulifer Grube, 1878, and Myrianida tereseta (Hoagland, 1920), were previously reported from the Philippines. Both are incompletely described from stolons and were considered as "incertae sedis" (Nygren 2004). Therefore, M. puladilaw sp. nov. is the first valid Autolytinae described from Philippines.

\section{ACKNOWLEDGMENTS}

This study was supported by the project: Caracterización Taxonómica y Sistemática de la familia Syllidae (Polychaeta) basada en datos moleculares y morfológicos. El problema de las especies cosmopolitas y Biodiversidad en el Pacífico. Project number CGL2009-12292 BOS was founded by the Ministerio de Ciencia e Innovación of the Spanish Government. Collection and curation of specimens and processing of molecular data was made possible by funding from the Hearst Foundation and the California Academy of Sciences (CAS). The authors wish to thank Bryan Rodriguez (University of the Philippines Diliman), Anna Sellas and Cerise Chen (CAS Center for Comparative Genomics), Ana Riesgo (Universidad de Barcelona), and Aida Verdes (City University of New York) for their invaluable assistance to this project. It should be noted that the three coauthors contributed equally to this project. Furthermore, the comments of an anonymous referee helped greatly to improve the quality of the paper.

\section{LiTERATURE CITED}

Aguado M. T., A. Nygren, and M. Siddall. 2007. Phylogeny of Syllidae (Polychaeta) based on combined molecular analysis of nuclear and mitochondrial genes. Cladistics 23:552-564.

Aguado M. T., and G. San Martin. 2009. Phylogeny of Syllidae (Annelida, Phyllodocida) based on morphological data. Zoologica Scripta 38(4):379-402.

Aguado M. T., G. San Martín, and M. Siddall. 2012. Systematics and evolution of syllids (Syllidae, Annelida). Cladistics 28:234-230.

Drummond, A. J., B. Ashton, M. Cheung., J. Heled, M. Kearse, R. Moir, S. Stones-Havas, T. Thierer, AND A. Wilson. 2009. Geneious v4.8. Available from <http://www.geneious.com/ (accessed 2 February 2010).

Folmer, O., M. Black, W. Hoeh, R. Lutz, and R. VRijenhoek. 1994. DNA primers for amplification of mito-chondrial cytochrome $\mathrm{c}$ oxidase subunit I from diverse metazoan invertebrates. Molecular Marine Biotechnology 3:294-299.

Franke, H. D. 1999. Reproduction of the Syllidae. Hydrobiologia 402:39-55.

Lucas, Y., G. San Martín, AND A. Sikorsky. 2010. A new genus and species of Syllidae (Annelida: Polychaeta) from off the coast of Norway with unusual morphological characters and uncertain systematic position. Proceedings of the Biological Society of Washington 123(4):251-257.

Malaquin, A. 1893. Recherches sur les syllidiens. Mémoires de la Société des Sciences, de l'Agriculture et des Arts de Lille, 4ème série, 18:1-477.

Nygren, A., And P. SundBerg. 2003. Phylogeny and evolution of reproductive modes in Autolytinae (Syllidae, Annelida). Molecular Phylogenetics and Evolution 29:235-249.

Ny gren, A. 2004. Revision of Autolytinae (Syllidae, Polychaeta). Zootaxa (680):1-314. 
Nygren, A., And F. PleiJel. 2007. A new species of Myrianida (Syllidae, Polychaeta) from Belize. Zootaxa (1595): 17-29.

Nygren, A., T. Sundkkvist, B. Mikac, And F. Plejuel. 2010. Two new and two poorly known autolytines (Polychaeta: Syllidae) from Madeira and the Mediterranean Sea. Zootaxa (2640):35-52.

Palulmbi, S. R. 1996. Nucleic acids II: The polymerase chain reaction. Pages 205-247 in D. M. Hillis, C. Moritz, and B. K. Mable, eds., Molecular Systematics, 2nd ed. Sinauer, Massachusetts, USA.

PleiJel, F. 2001. Syllidae Grube, 1850. Pages 102-105 in G. E. Rouse and F. Pleijel, eds., Polychaetes. Oxford University Press, New York, New York, USA.

Posada, D., AND K. A. CRANDAll. 1998. Modeltest: testing the model of DNA substitution. Bioinformatics 14:917-918.

Роттs, F. A. 1911. Methods of reproduction in the syllids. Ergebnisse und Fortschritte der Zoologie $3(1): 1-72$.

Ronquist, F., AND J. HuelsenBeck. 2003. MrBayes3: Bayesian phylogenetic inference under mixed models. Bioinformatics 19:1572-1574.

San Martin, G. 2003. Familia Syllidae. In: M.A. Ramos, ed., Annelida, Polychaeta II. Fauna Ibérica, vol. 21. Museo Nacional de Ciencias Naturales, CSIC, Madrid, Spain. 554 pp.

StAMATAKIS, A. 2006. RAxML-VI-HPC: maximum likelihood-based phylogenetic analyses with thousands of taxa and mixed models. Bioinformatics, 22:2688-2690.

Stamatakis, A., P. Hoover, and J. Rougemont. 2008. A rapid bootstrap algorithm for the RAxML web servers. Systematic Biology 57:758-771. 


\title{
A New Scaleworm, Iphione malifera (Polychaeta: Iphionidae), from a Coral Reef in the Philippine Islands
}

\author{
Christina N. Piotrowski \\ Department of Invertebrate Zoology and Geology, California Academy of Sciences, \\ 55 Music Concourse Drive, San Francisco, California, USA 94118 \\ Email:cpiotrowski@calacademy.org
}

\begin{abstract}
A new species of scaleworm, Iphione malifera, was collected from a shallow coral reef during the Hearst Philippines Biodiversity Expedition 2011. A morphological description is provided along with figures and comparisons are made with previously described congeneric species. Iphione reticulata Amoureux, Rullier, and Fishelson, 1978 is re-established as a valid species based on examination of the holotype. A key is provided to currently recognized Iphione species.
\end{abstract}

It has long been acknowledged that the taxonomy and systematics of the Indo-Pacific polychaete fauna are in dire need of targeted study (Natividad and Palpal-Latoc 1986; Fauchald 1976). Despite recent recognition of the Coral Triangle biogeographic region as the "the global epicenter for marine biodiversity" (Barber 2009) and at least one study having demonstrated unusually high polychaete diversity in this region (Wallace et al. 2000), a relative dearth of taxonomic literature exist for its reef worm fauna. This has led to the application of species names described from geographically separate faunal regions, and has inhibited estimation of the extent of reef species yet to be described. One recently published study (Stella et al. 2011) indicated that approximately 8000 coral-associated annelid species are known to occur in coral reef ecosystems. High incidence of cryptic and morphologically convergent polychaete taxa globally (Nygren 2013), coupled with a high rate of reported cosmopolitan species both globally (Glasby and Alvarez 1999) and from coral reef and other tropical environments (Fauchald 1976), have contributed to numerous erroneous reports of species distributed within the Indo-Pacific. Knox (1957) surveyed 212 published reports of polychaete species records in the Indo-Pacific and found some sub-regions with a proportion of "cosmopolitan" species as high as $40 \%$. In this same study, an evaluation of 1,989 taxa reported for the Philippine Islands yielded $20 \%$ "cosmopolitan species", whereas $36 \%$ of species examined were classified as endemic. Glasby and Alvarez (1999) pointed out that traditional assumptions regarding cosmopolitanism in this region have resulted from insufficiently resolved polychaete taxonomy. Given our deficient taxonomic understanding of this frequently dominant faunal group within reef habitats (Klumpp et al. 1988; Grassle 1973), it is perhaps not surprising that even large, morphologically unique polychaete species remain undiscovered in near-shore Philippine coral reef systems. One such species of the scaleworm genus Iphione is described herein.

Iphione is the only shallow water genus within the Iphionidae, a family recently resurrected and split from the highly speciose and paraphyletic family Polynoidae on the basis of compelling molecular evidence (Norlinder et al. 2012). Iphione superficially resemble chitons in their compact, stiffened appearance and exhibit convergent behavior to these armored mollusks, including comparable defensive responses such as their tendency to clamp onto hard surfaces using muscular contraction, retraction of soft appendages under their protective scales, and a propensity to curl their bodies ventrally when disturbed rather than attempting to swim in escape (Pettibone 1986; Storch 1967). In great contrast to chitons and like many other errant polychaete taxa, these carnivorous annelids are equipped with an eversible pharynx armed with chitinous jaws and lateral parapodia from which bundles of chaetae arise. As with all other scaleworms (Aphroditoidea), iphionids are equipped with two longitudinally arranged rows of dorsal elytra. 
Iphione consists of seven currently accepted species, two of which are of questionable validity (Pettibone 1986) due to a lack of type material (Iphione hirta Quatrefages, 1866) and/or inadequate species descriptions (I. hirta and Iphione reticulata Amoureux, Rullier, and Fishelson, 1978). Iphione muricata (Savigny in Lamarck, 1818) and Iphione ovata Kinberg, 1856, the two most common and widespread species in the genus, are both reportedly distributed across numerous biogeographic regions (Wehe 2006; Barnich et al. 2004; Yun et al. 1999; Hanley and Burke 1991; Pettibone 1986; Uschakov 1982; Day 1967; Fauchald 1977a; Wu et al. 1975; Murty et al. 1968; Wu 1968; Fauvel 1953; Hartman 1939). Considering the number of recent papers separating cryptic reef taxa (Glasby et al. 2013; Wu et al. 2013; Barroso et al. 2010), it is likely that some of these widespread populations represent genetically distinct populations in need of closer scrutiny. Morphological characters traditionally compared for diagnosis of species of Iphione include the shape and size of spines and tubercles on elytral surfaces, presence or absence of fringe papillae at elytra margins, shape of neurochaetae tips, and length of papillae along the neuropodial lobe margins.

\section{MetHODS}

Type materials of Iphione species from the Smithsonian Institution National Museum of Natural History (USNM), the Swedish Museum of Natural History (SMNH), and the Muséum national d'Histoire naturelle (MNHN) were examined for comparison. Additional materials were compared from the National Museum of Wales (NMW). New specimens were collected from the Batangas Province of the Philippines.

Collections were taken by SCUBA from coral reef and neighboring habitats off southern Luzon during the shallow-water component of the 2011 Hearst Philippine Biodiversity Expedition by the California Academy of Sciences and its partner institutions in the Philippines. Sampling was carried out at depths of less than 36 meters by a team of researchers and collaborators over a five week period. Two species of Iphione were collected during this effort, the first fitting descriptions for Iphione muricata and the second species new to science. Specimens were narcotized in a solution of $8 \% \mathrm{MgCl}_{2}$, photographed, and preserved in $95 \%$ ethanol. Examinations were made of the preserved specimen with stereo (Nikon SMZ-U) and transmitted light (Leica DMRB) microscopes. The specimen was photographed using a Big Kahuna (BK) Lab System (Visionary Digital) equipped with a Canon 5D camera and a photomicroscopy apparatus (Leica M165C with attached DFC550 camera). Both systems were used in conjunction with Zerene Stacker (Zerene Systems LLC) for automontage focus stacking, and a Spot Imaging System was used for transmitted light photomicroscopy. Scanning electron microscopy (LEO/Zeiss $1450 \mathrm{VP}$ ) was employed to examine the ultrastructure of chaetae. The holotype (and sole specimen) of the new species is deposited at the California Academy of Sciences, Department of Invertebrate Zoology and Geology (CASIZ).

The species is described in a similar format to that of Hanley and Burke's (1991) descriptions of Iphione from the Chesterfield Islands in an attempt to standardize Iphione species descriptions. New characters and several mentioned in Pettibone (1986) and Wehe (2006) are also addressed.

SPECIES DESCRIPTION

\section{Family Iphionidae Kinberg, 1856 \\ Genus Iphione Kinberg, 1856}

\section{Iphione malifera Piotrowski, sp. nov.}

Figures 1-3

TyPe MATERIAL.- Holotype: CASIZ 187234 Philippines, Luzon, Batangas Province, Maricaban Island, "Sea Pen" dive site, coral reef rubble, less than 33 m, 2011 Hearst Philippines Bio- 
diversity Expedition, sta. HEP-42, $13.68736^{\circ} \mathrm{N} 120.83283^{\circ} \mathrm{E}, 07$ May 2011, coll: Alicia Hermosillo. Holotype deposited at the California Academy of Sciences, Department of Invertebrate Zoology and Geology.

MATERIAL COMPARED.- Paratype of I. fustis Hoagland, 1920 (=I. muricata): USNM 18969; Holotype I. ovata: SMNH Type-388; I. muricata Rodriguez, Indian Ocean [near type locality of Mauritius]: NMW.Z.2001.060.0001; 3 specimens I. muricata from Batangas Province, Luzon: CASIZ 187238, CASIZ 187240, CASIZ 187246; Holotype I. reticulata Amourex, Rullier, and Fishelson, 1978: MNHN POLY TYPE 1430; Holotype I. spinosa Kinberg, 1858: SMNH Type-392.

DESCRIPTION.- Holotype (CASIZ 187234): Body short, broad, oval, flattened ventrally, arched dorsally, strongly tapered at anterior and posterior ends. Length $17 \mathrm{~mm}$; width including parapodia $11 \mathrm{~mm} ; 29$ segments. Dorsal and ventral surfaces of body creamy white lacking dark pigment, lateral ventrum with wrinkled texture.

Thirteen pairs large, stiff, tightly imbricating elytra (Figs. 1a, b) cover body completely; elytrophores segments 2, 4, 5, 7, then alternate segments to 21, 23, and 27. Elytra pigmented with
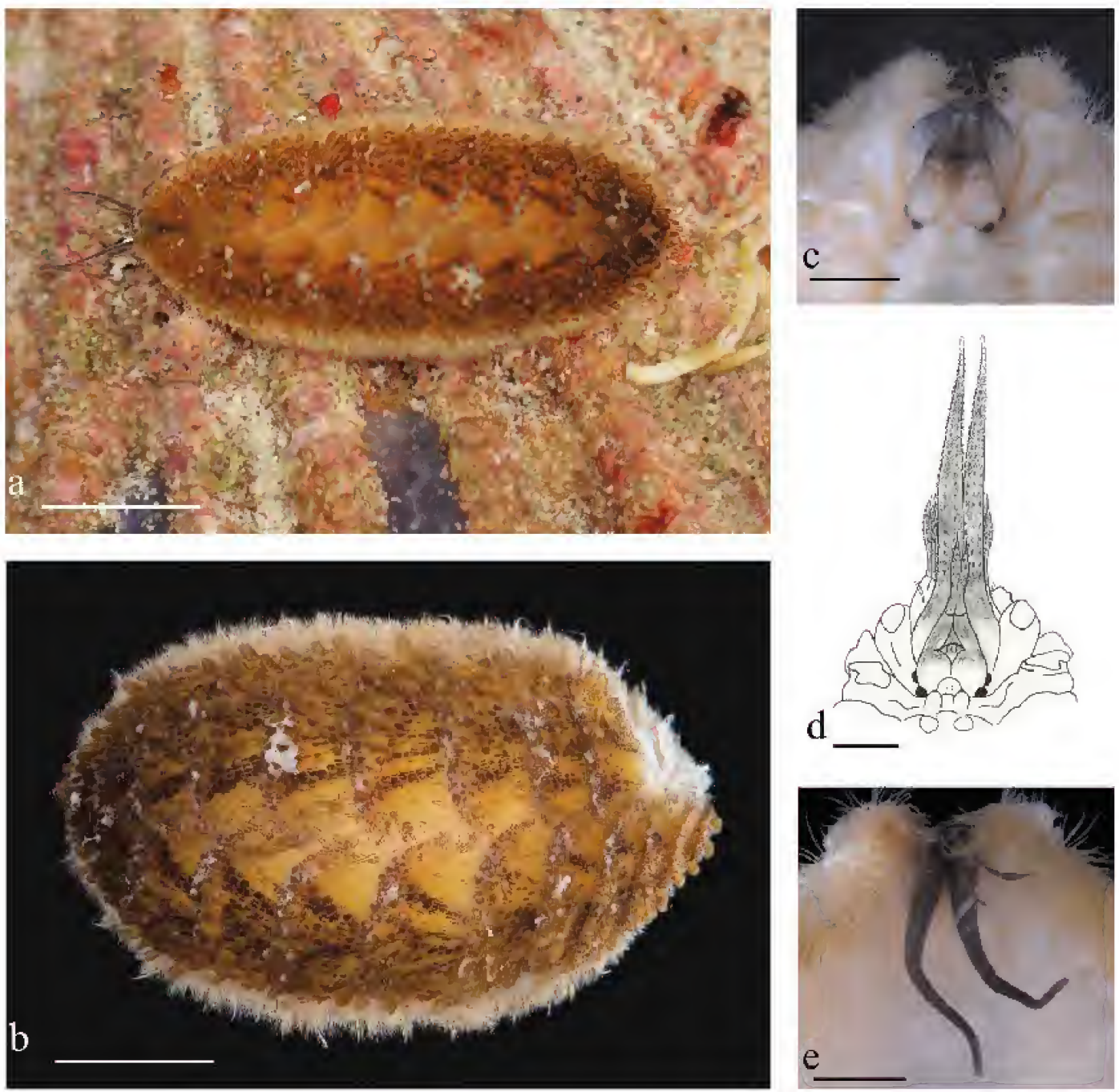

FIGURE 1. Iphione malifera sp. nov., holotype (CASIZ 186700), a. Dorsal view in life; b. Same, preserved with three anterior-most left elytra removed. c. Dorsal anterior preserved. d. Illustrated dorsal anterior with appendages extended. e. Ventral anterior. Scalebars.- a,b: $5 \mathrm{~mm}$; c,d,e: $1 \mathrm{~mm}$. 
variable longitudinal fanned brown streaks against yellow/cream background; anterior and median elytra with less pigmentation medially, producing lightened dorsal region; posterior segments with heavier pigment coverage. Elytra vary in shape along body; anterior (Fig. 2c) and posterior elytra smaller; first elytron triangularly oval, median elytra (Fig. 2b) larger, boomerang-shaped with broad anterior notch. Last pair elytra small, triangular, with median notch leaving dorsal anus uncovered. Posterior elytral surfaces with encrusting debris and epibionts.

Anterior and lateral margins of elytra narrow, transparent. Anterior and medial elytral surface a mosaic of regularly arranged hexagonal areas; numerous longitudinal rows oval-shaped pigmented areolae fill each hexagon (Fig. 2f.4); hexagonal areas in anterior and medial elytral surfaces arranged in honeycomb pattern; each hexagon slightly raised with respect to adjacent hexagon to posterior; posterior hexagonal areas more visibly raised than anterior areas.

Hexagonal areas transition to smaller, irregularly arranged polygons near posterio-lateral elytral margins where smaller polygons surround two rows inflated, round-tipped, cylindrical macrotubercles (Figs. 2b, d, f.3) near posterior margin; medial region of anterior diagonal row with pointed and/or smaller tubercles in variable stages of development (Fig. 2f.3); large rounded tubercles form nearly complete line in posterior row adjacent to lateral margin; macrotubercles in medial and lateral regions inflated, those in proximal region lower in profile; some flattened irregularly arranged microtubercles near posterior-lateral corners; one or two tubercles near lateral margin of most median elytra with little pigmentation.

Macrotubercles are modified distended hexagonal areas lacking spination; secondary areolae similar to flattened hexagonal areas cover macrotubercle surface. Some macrotubercles and posterior hexagonal areas with irregularly arranged hair-like papillae, possibly epibionts rather than papillae. Cylindrical macrotubercles appear hollow; small elongate hole subdistally at tip (Fig. 2f.3) near proximal posterior tip; subdistal holes packed with white debris, possibly adhered to solidified mucus.

Spinous lateral papillae subdistal to elytral margin; papillae with cylindrical columns, short radiating spines; four or more longer papillae subdistally (Figs. 2d, f.2). Segment 2 elytra with spinous papillae laterally and one or more at anterior margin.

Prostomium iridescent, bilobed, wider than long, lacking cephalic peaks (Figs. 1c-d). Prostomium, lateral antennae lightly tinted grey. Eyes two pairs; anterior pair larger oval, raised, placed laterally at widest part on posterior half of prostomium; posterior pair slightly smaller ovals close behind first pair at posteriolateral corner of prostomium.

Palps long, slender, iridescent at base, dark grey to black with longitudinal rows short papillae, gently tapering to fine pigment-free tips (Figs. 1d-e). Palps more than twice as long as tentacular cirri. Occipital antenna a short cirriform papilla at midline near rear edge of prostomium (Fig. 1d), obscured from view by nuchal fold. Lateral antennae inserted terminally on long, slender lateral extensions of prostomium; styles dark grey, long, slender, papillated, with slight subterminal swelling, filiform pigment-free tip.

Tentacular segment not visible dorsally; tentaculophores ventrolateral to prostomium with short, unpigmented acicular lobe, styles similar to lateral antennae, slender, dark, finely papillated, gently tapering, with slight subterminal swelling and filiform unpigmented tip. Facial tubercle tinted grey, clearly visible low, broad ridge between cirrophores of lateral antennae.

Rounded nuchal fold of second segment covering posterior prostomium. Large, elongate elytrophores with excavate lateral margins; ventral buccal cirri long, unpigmented (Fig. 1e), arise from bulbous bases; buccal cirri similar length to tentacular cirri, longer and more proximally inserted than subsequent ventral cirri.

Segments 4 and 5 with paired dorsal nodules (Fig. 1d), most prominent on segment 4. Dorsal 

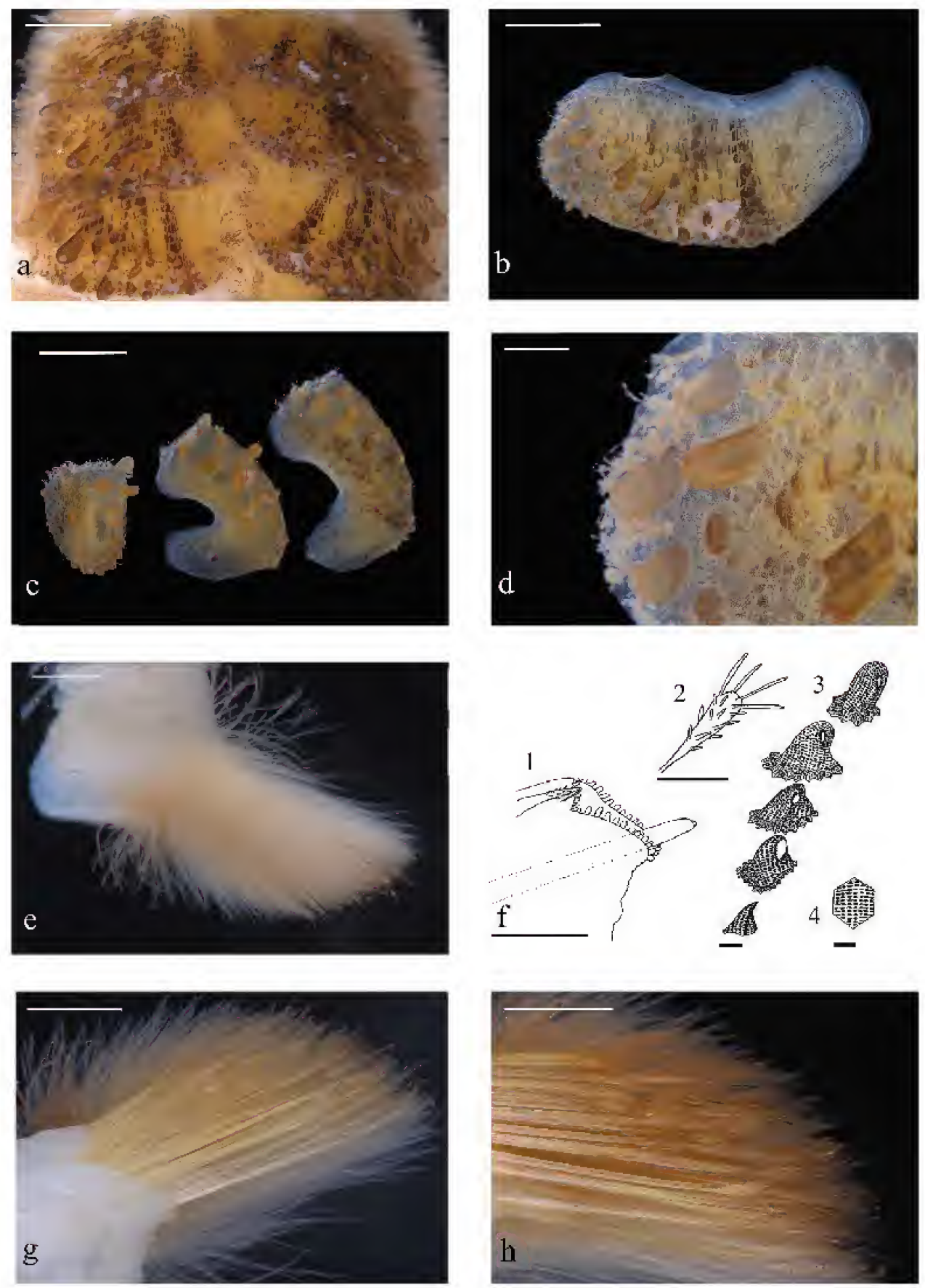

FIGURE 2. Iphione malifera sp. nov., holotype (CASIZ 186700), a. Dorsal mid-anterior elytra of segments 7, 8 , and 9 . b. Left elytron from segment 15. c. Anterior elytra of segments (from left) 2, 4, and 5. d. Lateral margin of left elytron, segment 15. e. Anterior view of left notopodium, segment 15. fl. Illustrated posterior view of segment 15 neuropodium demonstrating distal papillae and acicular process. f2. Lateral papillae from elytral margin, median elytra. f3. Posteriolateral view of macrotubercles bearing subterminal holes. Series includes variable stages of development in anterior row of macrotubercles; medial and proximal macrotubercles are illustrated from center to bottom of the figure respectively. f4. Medial hexagonal area of median elytral surface with secondary aereolae. g. Posterior view of left neuropodium from segment 15. h. Same at magnified view. Scalebars. - a,b,c: $2 \mathrm{~mm}$; $11 \mathrm{~mm}$; e: $1 \mathrm{~mm}$; f1: $400 \mu \mathrm{m}$; f2,f3: $500 \mu \mathrm{m}$; f4: 250 $\mu \mathrm{m} ; \mathrm{g},: 1 \mathrm{~mm} ; \mathrm{h}: 400 \mu \mathrm{m}$. 
tubercles transversely elongated, swollen, thin walled, with medial lateral swelling. Delicate, transverse folds extend between dorsal tubercles on segments 6 and 8 .

Dorsal cirri (Fig. 1d) with cylindrical cirrophores, lacking pigment, bulbous basally; styles elongate, slender, papillate, with filiform tips, styles extend beyond elytra margins and longest neurochaetae when preserved. Ventral cirri long, gently tapering, finely papillated; style length equivalent to distance between parapodium base and neurochaetae insertion. Nephridial papillae small.

Parapodia biramous. Notopodia small, neuropodium larger with digiform acicular process (Fig. 2f.1). Presetal and postsetal lobes low, rounded, with distinct ventral notch between lobes in line with posterior edge of ventral cirrus insertion when viewed posteriorly. Lobes with small digitiform papillae distally (Fig. 2f.1).

Notochaetae in plume-like white bundles, numerous, fine, pinnate, flexible capillaries (Figs. 2e, 3a), ventral-most notochaetae collect debris; ultrastructure (Figs. 3b-d) a series of fine, cirriform projections, combining longitudinally forming nested cups along length of chaetal shaft; projections most visible when chaeta bent to expose cross-section (Fig. 3d); viewed laterally cups appear as pinnate leaves; leaves more detached and pointed towards chaetal shaft base (Fig. 3a).

Eight horizontal rows stout, light yellow-gold neurochaetae (Fig. $2 \mathrm{~g}-\mathrm{h}$ ), subdistally expanded; close set spinous rows cover expanded region below entire, slightly hooked bare tips (Figs. 3e-i). Upper neurochaetae (Figs. 3e-f) with most spinous rows; lower neurochaeetae (Figs. 3h-i) with fewer rows. Segment 2 neurochaetae and lower neurochaetae of segments 3 slender, with longer region of close set spinous rows; neurochaetae taper to sharp curved unidentate tip. Dorsal neurochaetae extend slightly beyond notochaetae and elytra in preserved specimen.

No distinct pygidium; anal cirri absent. Anus dorsal on segments 27-29.

Distribution.- Known only from holotype specimen from Maricaban Island, Philippines.

ETYMOLOGY.- The name malifera (Latin= apple-bearing) refers to the presence of large round-tipped macrotubercles on all elytra, and is similar to melas (Greek = black) which describes the darkly pigmented palps. The specific epithet also plays upon a similarity between the genus name and that of a modern mobile device.

REMARKS.- The new species can readily be distinguished from all other Iphione species by the presence of exceptionally large, cylindrical, round-tipped macrotubercles. I. malifera differs from I. muricata specimens collected from Philippine reefs and from the Indian Ocean by the presence of inflated, cylindrical macrotubercles rather than spinous conical tubercles near posterior elytral margins as in I. muricata. I. malifera has a more drastically tapered body, narrow and elongate dark palps, dull yellow neurochaetae rather than dark gold as in I. muricata, and buccal cirri approximately equivalent in length to the tentacular cirri.

The holotype of I. ovata was examined, from which the new species differs by the presence of cylindrical, round-tipped macrotubercles and the presence of papillae on lateral edges of elytra. The cylindrical macrotubercles of I. malifera also markedly differ from the more conical, spiny tubercles on the elytra of the holotype of Iphione fustis, a taxon described from the Philippines by Hoagland (1920) as bearing "cudgel-like" spines [tubercles] and which has since been synonymized with $I$. muricata by Pettibone (1986). The paratype of I. fustis examined in this study bears macrotubercles similar to those of I. muricata, supporting Pettibone's synonymy. The new species differs markedly from the holotype of Iphione reticulata examined. The latter species bears

FIGURE 3. Iphione malifera sp. nov., holotype (CASIZ 186700), a. Middle notochaeta from segment 15 . b. Same as magnified SEM image of midshaft section. c. SEM of notochaetae segment 15 featuring ultrastructure of papillae cups. $d$. Bent notochacta segment 15 featuring ultrảstructure of papillae cups. e. Lower neurochaeta from segment 15. f. Same magnified distal region. g. SEM of same, opposite perspective h. Upper neurochaeta from segment 15. i. Same magnified, distal region. j. SEM of same, subdistal expanded region with spinous rows. Scalebars.- a: $100 \mu \mathrm{m} ; \mathrm{b}: 2 \mu \mathrm{m}$; c,d,f,g,i: $20 \mu \mathrm{m}$; e,h: $40 \mu \mathrm{m}$; j: $6 \mu \mathrm{m}$. 

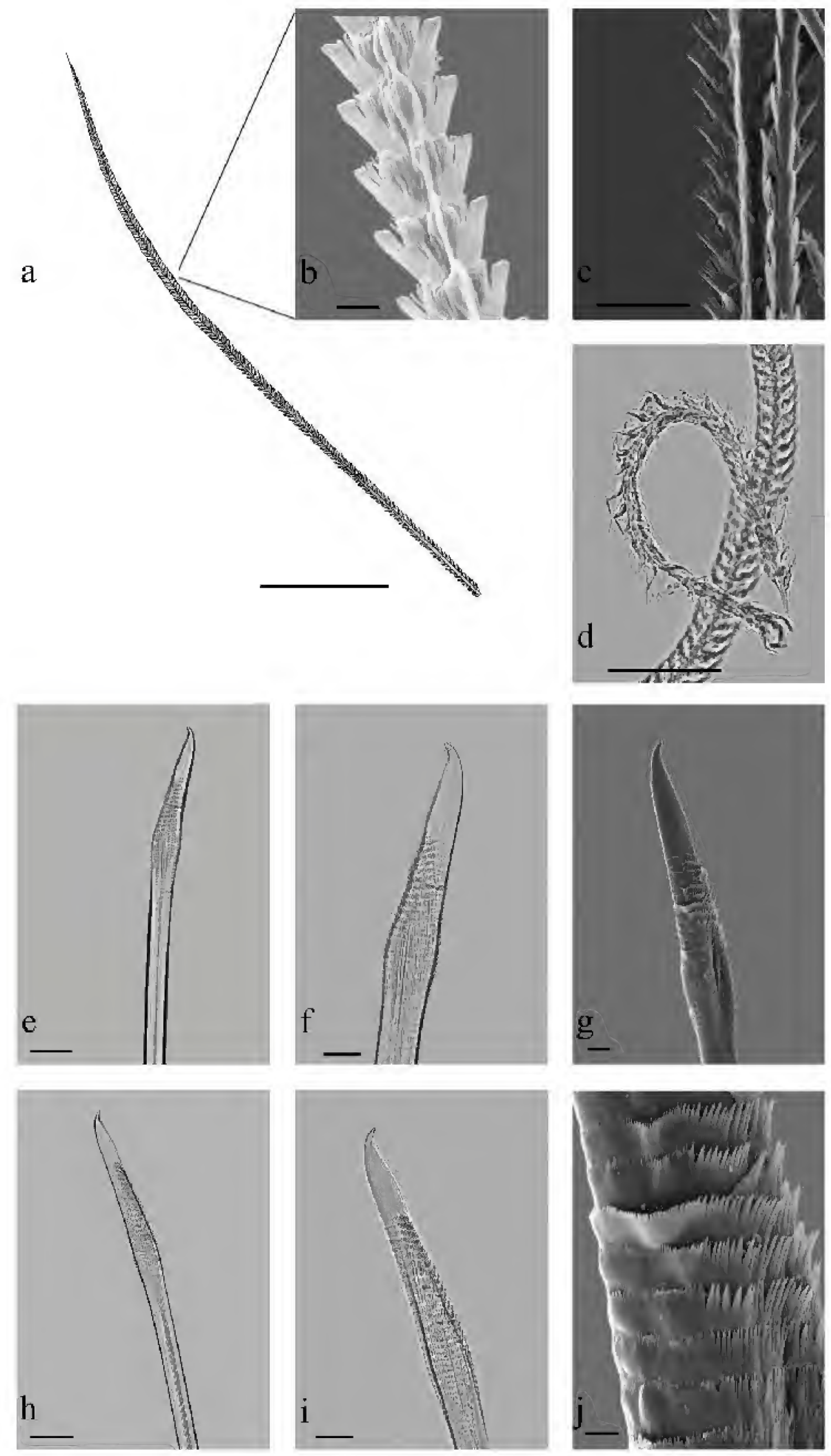
elytra with fewer and greatly enlarged polygonal areas; it bears low, spinous macrotubercles along widened transparent posterior margins and no lateral spinous papillae are present unlike the new species. I. reticulata is considered herein to be a valid species no longer of questionable status and will be re-described in a later paper.

Iphione malifera differs from descriptions of Iphione treadwelli Pettibone, 1986 in lacking raised oval thickened areas of the elytra and from Iphione henshawi Pettibone, 1986 by lacking conical tubercles with long distal papillae. The species differs from Iphione coriolos (Hanley and Burke, 1991) by the absence of bidentate neurochaetae and long papillae on neuropodial lobes. Iphione malifera differs from the original description of Iphione hirta Quatrefages, 1866 in lacking bristly spines on posterior surfaces of elytra; however this species was poorly described without illustrations, and no type materials exist, hence the taxon was considered questionable by Pettibone (1986).

Although only a single specimen of $I$. malifera has been collected to date, an image (photo id 900075) of a very similar species was made by photographers Philippe and Guido Poppe in 2004 from Caubian Island, Philippines of a specimen with similar appearance and was posted on their underwater image website $<$ http://www:poppe-images.com/?t=17\&photoid=900075>. Although the subject is identified as Paralepidonotus indicus, it bears dark elytral streaks typical of I. malifera, fewer elytral pairs than a Paralepidonotus should have, and may be this species. No specimen or high-resolution image is available.

\section{Key to currently valid species of Iphione}

Compiled based on the following references: Rullier and Fishelson, 1978; Pettibone, 1986; Hanley and Burke, 1991; Wehe, 2006. Where species descriptions in these references conflict, original descriptions and previous descriptions of specimens from the type region have been applied.

1a Median elytra with fewer than 70 enlarged polygonal areas; smooth wide transparent posterior elytra margins; lacking lateral papillae .................. Iphione reticulata [type locality Red Sea]

1b Median elytra with greater than 200 small polygonal areas; lacking smooth wide transparent posterior

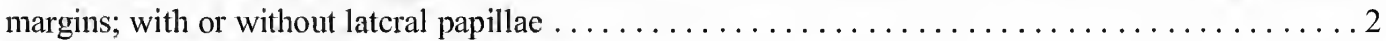

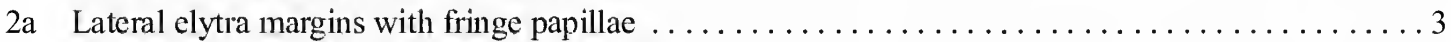

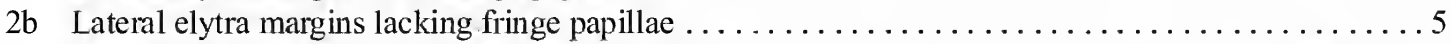

3a Postcrolateral and postcromedial surfaces of median elytra with 2 or more diagonal rows of tall conical spinous or smooth round-tipped macrotubercles; long cylindrical lateral papillae with flexible bases

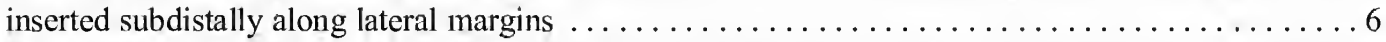

3b Posterolateral surfaces of elytra with several to numerous short conical macrobutercles or low oval thickened areas; short club-shaped, rounded, or digitate lateral papillae $\ldots \ldots \ldots \ldots \ldots \ldots \ldots \ldots$

4a Surfaces of elytra with up to 6 raised oval thickened areas near posterior borders; bead like fringe of distally wide scaly lateral papillae with short stems............ Iphione treadwelli [type locality Hawaii]

$4 \mathrm{~b}$ Postcrolateral corners of elytra with several rows of numerous short conical macrotubercles variablc in form, bearing raised overlapping areolae and few distal papillae; numerous spinous lateral papillae with

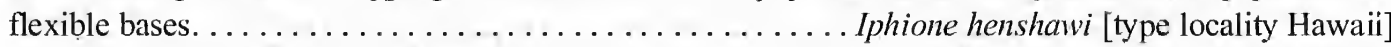

5a Several clongate slender distal neuropodial papillae near base of acicular lobe; neurochactae bidentate; low blunt tubercles in some polygonal areas, some with offset distal spine and/or papillae; short clavate papillae near elytra lateral edge .............. Iphione coriolis [type locality New Caledonia]

5b Neuropodial papillae distal and short; neurochaetae unidentate or with split tips; several rows large spinous tubercles with distal spines. .................. Iphione ovata [type locality Hawaii]

6a Elytra with diagonal rows of large, conical macrotubercles in posterior and lateral regions; tubercle columns bearing small triangular spines and longer spines distally; neurochaetae dark gold; palp length less than twice tentacular cirri................. Iphione muricata [type locality Mauritius] 
6b Posterior and lateral regions of elytra with diagonal rows of very large, inflated, round-tipped macrotubercles; conical shorter tubercles in medial regions; neurochatae dull yellow; dark palps, length greater than twice tentacular cirri ................... Iphione malifera [type locality Philippines]

\section{ACKNOWLEDGEMENTS}

The discovery of this new species would not have been possible without the generous support of the Hearst Foundation. Special thanks and acknowledgement to the collector, Alicia Hermosillo and to Dr. Terrence Gosliner as Principle Investigator of the expedition. Dr. Andy Mackie (National Museum of Wales), Elin Sigvaldadottir (Swedish Museum of Natural History), Dr. Karen Osborn (United States National Museum Smithsonian Institution), Dr. Tarik Meziane (Muséum National d'Histoire Naturelle), and Dr. Patrick Gillet (Catholic University of the West) are acknowledged for the kindly arranged loans of type and comparative materials. Leslie Harris (Natural History Museum of Los Angeles County) is thanked for invaluable consultation and taxonomic support, helpful conversations, advice, and review of the manuscript.

\section{BIBILIOGRAPHY}

AmoureuX, L., F. Rullier, and L. Fishelson 1978. Systematique et ecologie d'annelides polychetes de la presqu'il du Sinai. Israel Journal of Zoology 27(2-3):57-163.

BARBER, P. H. 2009. The challenge of understanding the Coral Triangle biodiversity hotspot. Journal of Biogeography 36(10): 1845-1846.

Barnich, R., D. Fiege, and R. SUn: 2004. Polychaeta (Annelida) of Hainan Island, South China Sea Part III. Aphroditoidea. Species Diversity 9(4):285-329.

Barroso, R., M. Klautau, A. M. Solé-Cava, and P. C. Paiva. 2010. Eurythoe complanata (Polychaeta: Amphinomidae), the 'cosmopolitan' fireworm, consists of at least three cryptic species. Marine Biology 157(1):69-80.

DAY, J.H. 1967. A monograph on the Polychaeta of southern Africa, Part I. Trustees of the British Museum (Natural History), London, England. 458 pp.

FaUChald, K. 1976. A review of the need for work on polychaete systematics on Indo-Pacific coral reefs. Micronesica 12(1):165-167.

Fauchald, K. 1977a. Polychaetes from intertidal areas in Panama, with a review of previous shallow-water records. Smithsonian Institution Press, Washington, D.C., USA. 81 pp.

FaUCHALD, K. 1977b. The polychaete worms, definitions and keys to the orders, families and genera, Science Series 28. Natural History Museum of Los Angeles County, Los Angeles, USA. 188 pp.

Fauvel, P. 1953. Annelida Polychaeta. The Indian Press, Allahabad, India. 507 pp.

Glasby, C. J., N. V. Wei, AND K. S. Gibb. 2013. Cryptic species of Nereididae (Annelida: Polychaeta) on Australian coral reefs. Invertebrate Systematics 27:245-264.

Glasby C. J., AND B. Alvarez . 1999. Distribution patterns and biogeographic analysis of Austral Polychaeta (Annelida). Journal of Biogeography 26(3):507-533.

Grassle, J. F. 1973. Variety in coral reef communities. Pages 247-270 in O.A. Jones and R. Endean, eds. Biology and Geology of Coral Reefs, vol. II. Biology. Academic Press, New York, USA.

Hanley, J. R., AND M. Burke. 1991, Polychaeta, Polynoidae: Scaleworms of the Chesterfield Islands and Fairway Reefs, Coral Sea. Memoirs du Museum National D'Histoire Naturalle, Serie A Zoologie, Tome 151, Resultats des Campagnes MUSTROM 8:9-82.

HARTMAN, O. 1939. New species of polychaetous annelids from southern California. Allan Hancock Pacific Expeditions 7:159-171.

Hoagland, R. A. 1920. Polychaetous Annelids Collected by the United States Fisheries Steamer Albatross during the Philippine Expedition of 1907-1909. Bulletin of the United States National Museum 1(9):603-635.

KinBeRG, J. G. H. 1856. Nya slägten och arter af Annelider, Öfversigt af Kongl. Vetenskaps-Akademiens Förhhandlingar Stockholm 12(9-10):381-388. 
Kinberg, J. G. H. 1858. Part 3: Annulater. Kongliga Svenska Fregatten Eugenies Resa omkring jorden under befal af C.A. Virgin aren 1851-1853. Vetenskapliga Iakttagelser. Almquist \& Wicksells, Uppsala \& Stockholm, Sweden. $32 \mathrm{pp}$.

KLumpp, D. W., A. D. McKinnon, And C. N. Mundy. 1988. Motile cryptofauna of a coral reef: abundance, distribution and trophic potential. Marine Ecology Progress Series 45(1):95-108.

Knox, G. A. 1957. The distribution of polychactes within the Indo-Pacific. Proceedings of the $8^{\text {th }}$ Pacific Science Congress of the Pacific Science Association 3:403-411.

Murty, V. S., D. C. V. Easterson, A. B. Fernando, K. K. Appukuttan, and K. M. S. Ameer Hamsa. 1968. Bibliography of Marine Fisheries and Oceanography of the Indian Ocean 1962-67. Central Marine Fisheries Research Unit Bulletin 1:1-218.

Natividad, F., and V. S. Palpal-Latoc. 1986. Philippine Annelids. Guide to the Philippine Flora and Fauna. Natural Resources Management Center and University of the Philippines, Manila, Republic of the Philippines. $356 \mathrm{pp}$.

Norlinder, E., A. Nygren, H. Wiklund, And F. Pleidel . 2012. Phylogeny of scale-worms (Aphroditiformia, Annelida), assessed from 18SrRNA, 28SrRNA, 16SrRNA, mitochondrial cytochrome $c$ oxidase subunit I (COI), and morphology. Molecular Phylogentetics and Evolution. 65:490-500.

Nygren, A. 2013. Cryptic polychaete diversity: a review. Zoologica Scripta 43(2):172-183.

Pettibone, M. H. 1986. Review of the Iphioninae (Polychaeta: Polynoidae) and revision of Iphione cimex Quatrefages, Gattyana deludens Fauvel, and Harmothoe iphionelloides Johnson (Harmothoinae). Smithsonian Institution Press, Washington, D.C., USA. 43 pp.

Poppe-Images. 2004. Paralepidonotus indicus. In: Marine Iconography of the Philippine Archipelago <http://www.poppe-images.coml >. Cited 25 July 2013.

Quatrefages, M. A. 1866. Histoire naturelle des anneles marins et d'eau douce: Annelides et gephryriens. Librairie Encyclopedique de Roret, Paris, France. 588 pp.

Salazar-Vallejo, S. I., AND M. H. Londono. 2009. Lista de especies y bibliografía de poliquetos (Polychaeta) del Pacífico Oriental Tropical. Anales del Instituto de Biología Serie Zoología 75(1):9-97.

Savigny, J. C. 1818. Les Annelides Pages 302-374 in J.B.D. Lamarck, ed. Histoire naturelle des Animaux sans Vertèbres. Déterville and Verdiére, Paris, France.

Stella, J. S., M. S. Pratchett, P. A. Hutchings, and G. P. Jones. 2011. Coral-associated invertebrates: Diversity, ecological importance and vulnerability to disturbance. Oceanography and Marine Biology: An Annual Review 49:43-104.

Storch, V. 1967. Iphione muricata (Savigny), ein den Chitonen ähnlicher Lebensformtyp unter den Polychaeten. Kieler Meeresforschungen 23(2):148-155.

Uschakov, P. V. 1982. Polychaeta of the Suborder Aphroditiformia of the Arctic Ocean and the Northwestern part of the Pacific, Families Aphroditidae and Polynoidae. Fauna of the USSR Polychaete. Fauna SSSR, Mnogoshchetinkovyye chervil 2(1):1-272.

Wallace, C. C., G. Paulay, B. W. H. Hoeksema, D. R. Bellwood, P. Hutchings, P. Barber, M. Erdman, And J. Wolstenholme. 2003. Nature and origins of unique high diversity reef faunas in the Bay of Tomini, Central Sulawesi: the ultimate "centre of diversity". Proceedings of the $9^{\text {th }}$ International Coral Reef Symposium. Bali, Indonesia 1:185-192.

WeHE, T. 2006. Revision of the scaleworms (Polychaeta: Aphroditoidea) occurring in the seas surrounding the Arabian Peninsula. Part I: Polynoidae. Fauna of Arabia 22:23-197.

Wu, B. L., S. SHen, AND M. ChEN. 1975. Preliminary report of polychaetous annelids from Xisha Islands, Guandong Province, China. Studia Marina Sinica 10:65-104.

Wu, S-K. 1968. On some polychaete worms from the northern coast of Taiwan. Bulletin of the Institute of Zoology Academia Sinica 7:27-48.

Wu, X., R. Sun, R. Liu, And K. Xu. 2013. Two new species of Eunice Cuvier, 1817 (Polychaeta, Eunicidae) from the coral reefs of Hainan Island with a key to 16 species of Eunice from China seas. Zootaxa 3652(2):249-264.

YUn, S. G., S.-G. PAIK, AND E.-I. PAIK. 1999. New record of Iphione muricata (Savigny, 1818) (Polychaeta: Polynoidae) in Korea. Journal of the Korean Fisheries Society 32(1):5-9. 


\title{
Sternaspis piotrowskiae sp. nov. (Polychaeta: Sternaspidae) from the Philippine Islands
}

\author{
Sergio I. Salazar-Vallejo \\ Depto. Sistemática y Ecología Acuática, El Colegio de la Frontera Sur \\ Chetumal, Quintana Roo, México \\ E-mail:ssalazar@ecosur.mx,savs551216@hotmail.com
}

\begin{abstract}
A new species of Sternaspidae Carus, 1863, was collected during the 2011 Hearst Philippine Biodiversity Expedition, and it is being named after Christina Piotrowski, a member of the expedition and Collections Manager of Invertebrate Zoology. Sternaspis piotrowskiae sp. nov. has a reddish ventro-caudal shield, with anterior keels reaching anterior margins, fan truncate, margin barely crenulated or smooth, and posterior corners variably prominent.
\end{abstract}

The polychaetes from the Philippine Islands have systematically been studied since the 1870 s. The first major contribution was the monograph on the polychaete materials collected by Semper (Grube 1878) in shallow water bottoms; it contained 70 genera and almost 160 newly described species; most materials were deposited in the museums of Berlin (Hartwich 1993) or Wroclaw (Wiktor 1980). The Challenger Expedition collected at several stations in the archipelago; a total of 15 species of marine annelids were collected at four stations $(201,205,209,214)$, whereas before the Challenger, only two species had been reported from the archipelago (McIntosh 1885).

In the early Twentieth Century, and as part of the reports about an American expedition to the Philippine Islands, Hoagland and Treadwell made a series of contributions; their illustrations are schematic and the type materials are in the Smithsonian Institution, Washington. Hoagland (1920) reported 53 species and 22 out of them were new; Treadwell $(1920,1939 a, 1939 b, 1942,1943)$ recorded 48 species and 10 were newly species and one genus was proposed. Holly $(1934,1935)$ made two contributions to the Philippine polychaete fauna by recording 25 species including the proposal for a new genus and descriptions for two new species; the latter of these two publications is remarkable because he was the first to use photographs, instead of line drawings, albeit it was restricted to one of his new species.

Pillai (1965) reported 32 species in 30 genera from the Philippine Islands; two genera were newly proposed and 14 species and 3 varieties were newly described. His illustrations are highqualityline drawings, and his collections were deposited in the now University of Sri Lanka, Colombo. The largest compilation about Philippine polychaetes was made by Natividad and Palpal-Latoc (1986). It contains synonymies, diagnosis, illustrations and distribution data for 49 species in 30 genera and 15 families. They also provided keys to families, to genera and to species making it a useful reference, despite the fact they only included errant polychaetes. There are several other, mostly ecological publications made on Philippine polychaetes, and the only checklist was made by Palpal-latoc (2001). The only sternaspid polychaete heretofore recorded from the Philippine Islands was Petersenaspis palpallatoci (Sendall and Salazar-Vallejo, 2013).

\section{METHODS}

Specimens were carefully cleaned and photographed. Illustrations were made by combining a series of photographs with HeliconFocus. The specimens are deposited in the Invertebrate Zoology and Geology Department, California Academy of Sciences (CAS). 


\section{RESULTS}

\section{Sternaspis piotrowskiae Salazar-Vallejo, sp. nov.}

Figure 1

Type Material.- Philippine Islands, Hearst Philippine Biodiversity Expedition 2011. HoloTYPE (CAS 186700), Luzon Island, Balayan Bay, M/V DA-BFAR, Sta. HEPD-003 (13.82 ${ }^{\circ} \mathrm{N}$, $120.75^{\circ} \mathrm{E}$ ), 272-291 m, mud, 29 May 2011, Mooi et al., coll. PARATYPES: One paratype (CAS 186736), Verde Island Passage, $\mathrm{S}$ off Golo Island, M/V DA-BFAR, Sta. HEPD-019 (13.60 ${ }^{\circ} \mathrm{N}$, $120.38^{\circ} \mathrm{E}$ ), 541-636 m, sandy mud with pebbles, 1 Jun. 2011, Mooi et al., coll. (27 mm long, $6 \mathrm{~mm}$ wide; left shield plate $4.9 \mathrm{~mm}$ long, $5.3 \mathrm{~mm}$ wide). One paratype (CAS 186927), Lubang Islands, off Ambil Island, M/V DA-BFAR, Sta. HEPD-035 (13.82 $\left.{ }^{\circ} \mathrm{N}, 120.46^{\circ} \mathrm{E}\right), 397-439 \mathrm{~m}$, mud, 4 June 2011, Mooi et al., coll. (body $24 \mathrm{~mm}$ long, $10 \mathrm{~m}$ wide; left shield plate $8 \mathrm{~mm}$ long, $9 \mathrm{~mm}$ wide). One paratype (CAS 186945), Luzon Island, Balayan Bay, M/V DA-BFAR, Sta. HEPD-006 $\left(13.70^{\circ} \mathrm{N}, 120.68^{\circ} \mathrm{E}\right), 454-457 \mathrm{~m}$, mud with coralline sand, 29 May 2011, Mooi et al., coll. (body extremely dehydrated; introvert damaged, detached from; body $21 \mathrm{~mm}$ long, $8 \mathrm{~mm}$ wide; left shield plate $6.0 \mathrm{~mm}$ long, $6.5 \mathrm{~mm}$ wide). Three paratypes (CAS 187017), Luzon Island, Balayan

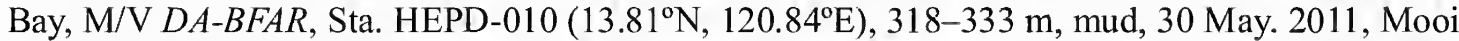
et al., coll. (body 21-30 mm long, 7-9 $\mathrm{mm}$ wide; left shield plate $6.5-8.0 \mathrm{~mm}$ long, $8.5-9.0 \mathrm{~mm}$ wide).

DesCriPTION.- Holotype (CAS 186700) complete, body wall whitish, integument pale brown (Fig. 1A), variably eroded exposing paler body wall areas. Introvert exposed, parapodial ridges variable damaged, some chaetae broken; introvert body wall broken on the right side; ventro-caudal shield dark reddish, fading towards its margins, anterior keels paler. Body papillae and integument mostly eroded. Body $25 \mathrm{~mm}$ long, $9 \mathrm{~mm}$ wide; left shield plate $6.9 \mathrm{~mm}$ long, $7.0 \mathrm{~mm}$ wide; about 30 segments.

Prostomium whitish, globose, projected from body wall, without eyespots (Fig. 1B). Peristomium rounded, papillae eroded. Mouth circular, markedly wider than prostomium, papillae eroded, some remain in mouth opening.

First three chaetigers with 20-22 thick, golden, almost straight hooks, with subdistal darker areas. Genital papillae pale, tapered, barely widened medially, protrude ventrally from intersegmental groove between segments 7 and 8 . Pre-shield region with 7 segments, capillary chaetae mostly broken, segment 9 with 4-5 thin capillary chaetae.

Ventro-caudal shield with radiating ribs and concentric lines, anterior keels completely exposed, reaching anterior margins, separated; suture indistinct (Figs. 1A, C). Anterior margins rounded; anterior depression deep but obscured by exposure of anterior keels. Lateral margins expanded medially, slightly reduced posteriorly. Fan truncate, slightly expanded reaching posterior corners, margin barely crenulated; median notch indistinct.

Marginal chaetal fascicles include 10 lateral ones, chaetae in a tight fascicle (apparently ovally arranged before dehydration), and 7 posterior fascicles, chaetae in a slightly curved arrangement. Peg chaetae broken, one fascicle with a few delicate long chaetae folded behind shield.

Branchiae and interbranchial filaments abundant, curled; branchial plates parallel, anteriorly widened, rounded.

TYPE LOCALITY.- Balayan Bay, Luzon Island, Philippines, 272-291 m.

Eтyмology.- The species name is after Christina Piotrowski, Collections Manager of Invertebrate Zoology, California Academy of Sciences, in recognition of her efforts during sampling, sorting and cataloguing polychaete materials of the Hearst Expedition. The epithet is a noun in the genitive case. 


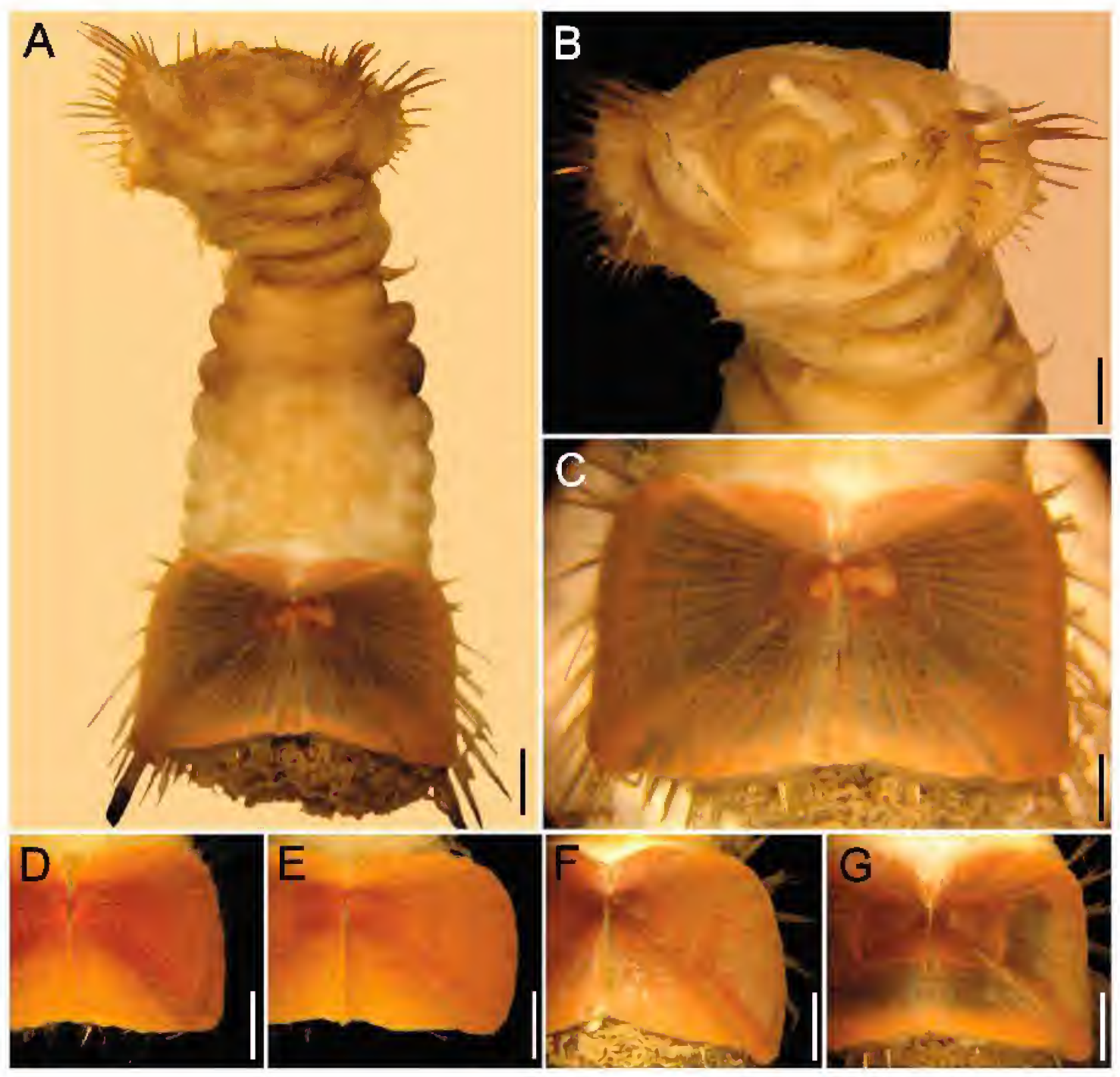

FIGURE 1. Sternaspis piotrowskiae sp. nov., holotype (CAS 186700), A. Ventral view; B. Same, anterior end, frontal view. C. Same, ventro-caudal shield, frontal view. D. Paratype (CAS 186736), shield, frontal view. E. Paratype (CAS 186945), shield, frontal view. F. Paratype (CAS 187017), shield, frontal view. G. Paratype (CAS 187017), shield frontal view. Scale bars.- A, E: 3 mm, B: $1.6 \mathrm{~mm}, \mathrm{C}-\mathrm{D}: 2.2 \mathrm{~mm}, \mathrm{~F}: 3.4 \mathrm{~mm}, \mathrm{G}: 2.9 \mathrm{~mm}$. [CAS1/ New2/ 186700]

VARIATION: There are some variations in the ventro-caudal shield regarding shape and pigmentation (Figs. 1D-G). The general shape is generally stable with two variations. First, the anterior keels might be separated medially or they can be fused (Fig. 1E). Second, the posterior corners can be variably developed, being wide, short projections (Figs. 1D-E), or larger, better defined structures (Figs. 1F-G) in larger specimens. The fan's margin, however, was barely crenulated to smooth (Fig. 1E), but because dredging could have eroded this region, these differences are not regarded as diagnostic. Likewise for any difference in pigmentation. The pigmentation is usually darker in the central shield areas, and it can be orange reddish (Figs. 1D-E), or reddish brown (Figs. 1C, F-G), but because there are gradients in their intensity and because this differences in intensity do not seem to be size-related, they could depend on fine variations in the sediment chemical composition. 
REMARKS: Sternaspis piotrowskiae sp. nov. resembles S. rietschi Caullery, 1944 from Indonesia, found in about $1790 \mathrm{~m}$ depth, and recently redescribed by Sendall and Salazar-Vallejo (2013). However, they differ in body wall pigmentation and on the relative development of shield's anterior keels; in S. piotrowskiae the body wall is whitish and anterior keels are very long, its central regions are often as long as the shield's anterior margins, whereas in S. rietschi the body wall is brownish, and the anterior keels are very short.

On the other hand, S. piotrowskiae resembles S. thorsoni Sendall and Salazar-Vallejo, 2013 from the Arabic Sea, and found in 3-110 m depth, because both have posterior corners and a variable developed fan. These two species differ by the relative shape of the shield because the anterior keels are longer in S. piotrowskiae, surpassing the anterior margins, whereas they are shorter in $S$. thorsoni, and the fan margin is barely crenulated in S. piotrowskiae, whereas it is markedly crenulated in $S$. thorsoni.

DistriBution: Philippine Islands, found in muddy bottoms, 272-636 m depth.

\section{ACKNOWLEDGMENTS}

This contribution was made possible by the kind support of Christina Piotrowski, Collections Manager of Invertebrate Zoology, CAS, and by Leslie Harris and David Ocker that due to their unconditional and typical hospitality, provided a home during a part of my sabbatical leave. Funds for this work were given by ECOSUR, and CONACYT (sabbatical leave scholarship, 176535).

\section{REFERENCES}

Grube, E. 1878. Annulata Semperiana. Beiträge zur Kenntniss der Annelidenfauna der Philippinen nach den von Herrn Prof. Semper mitgebrachten Sammlungen. Mémoires de l'Académie Impériale des Sciences de Saint Pétershourg, 7ème série, 25(8): 1-300, 15 pls.

HaRtwich, G. 1993. Die Polychaeten-Typen des Zoologischen Museums in Berlin. Mitteilungen aus dem Zoologisches Museum, Berlin 69:73-154.

Hoagland, R.A. 1920. Polychaetous annelids collected by the United States Fisheries Steamer Albatross during the Philippine Expedition. Bulletin of the United States National Museum 100(1, 9):603-635.

Holly, M. 1934. Polychäten von den Philippinen, 1. Erste Mitteilung über Polychäten. Zoologischer Anzeiger 105:147-150.

Holly, M. 1935. Polychäten von den Philippinen, 2. Zweite Mitteilung über Polychäten. Zoologischer Anzeiger 111:96-100.

McIntosh, W. C. 1885. Report on the Annelida Polychaeta collected by H.M.S. Challenger during the years 1873-76. Challenger Reports 12:1-554.

Natividad, F. and V. S. Palpal-Latoc. 1986. Philippine Annelids. Pages 267-342 in Guide to Philippine Flora and Fauna. Vol. 6: Gastropods, Pelecypods, Annelids. Natural Resources and Management Center, Ministry of Natural Resources and University of the Philippines, Manila. $356 \mathrm{pp}$.

Palpal-Latoc, V. S. 2001. Checklist of the polychaetous annelids of the Philippines. National Museum Papers, Manila 11:1-79.

Pillai, T. G. 1965. Annelida Polychaeta from the Philippines and Indonesia. Ceylon Journal of Science (Biological Sciences) 5:110-177.

Sendall, K., And S. I. Salazar-Vallejo. 2013. Revision of Sternaspis Otto, 1821 (Polychaeta: Sternaspidae). ZooKeys 286:1-74.

Treadwell, A. L. 1920. Polychaetous annelids collected by the United States Fisheries Steamer Albatross in the waters adjacent to the Philippine islands in 1907-1910. Bulletin of the United States National Museum 100(1, 8):589-602.

Treadwell, A. L. 1939a. Additions to the polychaetous annelids collected by the United States Fisheries Steamer Albatross, 1907-1910, including one new genus and three new species. Bulletin of the United States National Museum 100(6, 2):183-193. 
TREadwell, A. L 1939b. Four new species of polychaetous annelids collected by the United States Fisheries Steamer Albatross, during the Philippine Expedition of 1907-1910. Bulletin of the United States National Museum 100(6, 5):313-321.

Treadwell, A. L. 1942. Polychaetous Annelids from Lower California and the Philippine Islands in the collections of the American Museum of Natural History. American Museum Novitates (1172):1-5.

Treadwell, A. L. 1943. Polychaetous annelids from the Philippine Islands in the collections of the American Museum of Natural History. American Museum Novitates (1220): 1-4.

WiKtoR, J. 1980. Type-specimens of Annelida Polychaeta in the Museum of Natural History of the Wroclaw University. Annales Zoologici 35:267-283. 


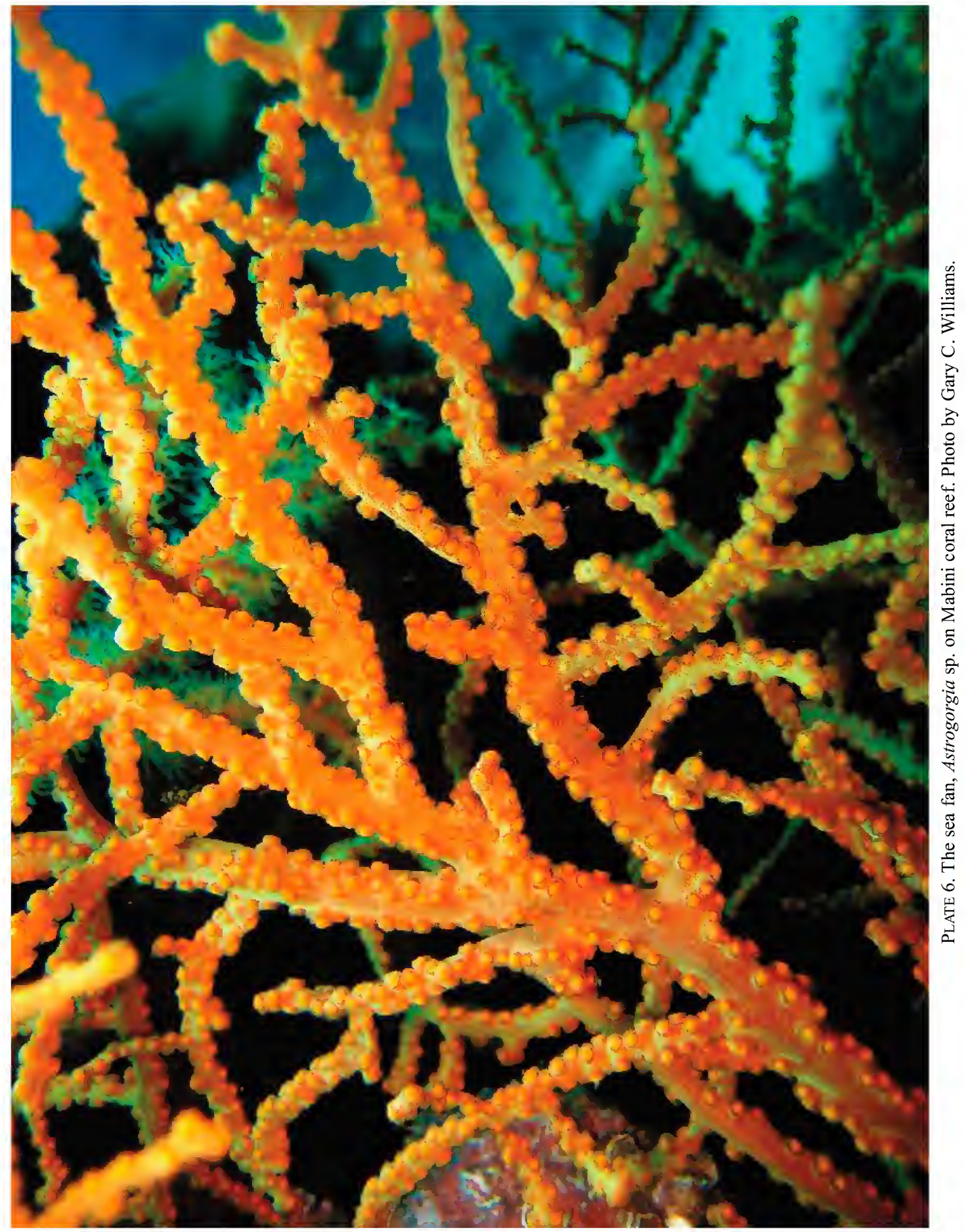




\title{
Barnacle Symbionts of Gorgonian Sea Fans Description of Seven New Species (Archaeobalanidae: Cirripedia) from the Philippines, Including a Key to Western Pacific Species of Conopea
}

\author{
Robert J. Van Syoc 1, Dana Carrison-Stone, Liezl Madrona, and Gary C. Williams \\ Department of Invertebrate Zoology and Geology, California Academy of Sciences, \\ San Francisco, California 94118. \\ ${ }^{1}$ Corresponding author: bvansyoc@calacademy.org
}

\begin{abstract}
Seven new species of barnacle symbionts of gorgonian sea fans are described, six species in the genus Conopea and one in the genus Acasta (Archaeobalanidae: Cirripedia). Host gorgonians of the new species are generally identified to genus level and to species where possible. Conopea sabangensis sp. nov. and $C$. willhearsti sp. nov. are found only on gorgonians in the family Melithaeidae. Gorgonians in the family Ellisellidae are hosts for $C$. basicuneata sp. nov., $C$. margaretae sp. nov., $C$. minyrostrum sp. nov. and $C$. exothobasis sp. nov. The description of these new species increases the known western Pacific Ocean species of gorgonian symbiotic Conopea from 12 to 18. Acasta vipensis sp. nov. is found only on hosts in the family Plexauridae. Sequence data for a portion of the eytoch rome $\mathrm{C}$ oxidase subunit I (COI) gene correlates with the morpho-species and host data. Conopea species clades in the COI tree suggest the invasion and expansion into different host family taxa, with the greatest barnacle species richness appearing within the host gorgonian family Ellisellidae. A key to the octocoral symbiotic species of western Pacific Conopea is presented.
\end{abstract}

The Philippines Archipelago, comprised of over 7000 islands, is arguably the most species diverse ocean environment on Earth. In 2011, the California Academy of Sciences (CAS) partnered with colleagues at institutions in the Philippines to study a few small portions of this rich environment. Two of us (RVS, GW) were among those collecting specimens of marine species in the Verde Island Passage area, southwest of Luzon, for further study and inclusion in the scientific collections at CAS and the National Museum of the Philippines in Manila. Although it will take more time to complete our studies of the several thousand specimens of marine invertebrates resulting from the expedition, we have already discovered a large number of new species. In fact, a majority of the barnacle species collected appear to be new to science.

Among our early discoveries are several new species of barnacle symbionts of gorgonian octocorals. Most of these are in the barnacle genus Conopea. Species in the genus Conopea are obligate symbionts of gorgonian octocorals (sea fans and sea whips) or antipatharians (black corals). There are currently 23 described species of Conopea. Although the genus has a global distribution in tropical and warm temperate seas, only 15 species are known from the western Pacific Ocean. These 15 species range from Japan in the north to Indonesia and northwestern Australia in the south. Three of the 15 western Pacific species are symbionts of antipatharians, the remaining 12 live in association with gorgonians. The current paper considers only those Conopea symbionts of gorgonian hosts.

The 12 known western Pacific gorgonian symbionts in the genus Conopea are: C. acuta (Nilsson-Cantell, 1921), C. canaliculatus Ren and Liu, 1978, C. cornuta (Hoek, 1913), C. dentifer (Broch, 1922), C. fragilis (Broch, 1931), C. investita (Hoek, 1913), C. longibasis (Hiro, 1937), 
C. mjobergi (Broch, 1916), C. proripiens (Hoek, 1913), C. pygmaea (Broch, 1931), C. scandens (Pilsbry, 1916), and C. squamosa Rosell, 1991. Many of these names are associated only with the type material. One, C. proripiens, is listed by Newman and Ross (1976) as having been synonymized with $C$. cymbiformis (Darwin, 1854) by Broch (1922). However, Broch's actual conclusion was only that the two species are very similar in description and "a reexamination of Darwin's type specimens will have to settle this question." Therefore, he stopped short of actually synonymizing $C$. proripiens with $C$. cymbiformis. For that reason, and because we find several morphological differences in the original descriptions of these two species, and the fact that the type localities are in distinct biogeographic regions (the coast of India for C. cymbiformis and the Banda Sea coast of Indonesia for $C$. proripiens), we consider $C$. proripiens a currently valid name.

In addition to the genus Conopea, five species of the subfamily Acastinae are known as symbionts of gorgonians. Most species of Acastinae live in association with sponges, a few others are symbionts of antipatharians. The acastine species living in gorgonians differ from Conopea species in several ways, the most obvious is the form of their attachment to the host. Conopea species are cemented directly, and firmly, to the surface of the gorgonian axis. The coenenchyme of the gorgonian overgrows the shell of Conopea species, but the proteinaceous axis generally does not. On the other hand, individuals of Acastinae become completely embedded in the proteinaceous axis rather than living attached to the surface of the gorgonian axis. The wall plates of most Conopea are heavily cemented to each other at the contact sutures, whereas those of acastines are loosely attached to each other and disarticulate very easily with handling or treatment in dilute sodium hypochlorite.

Here we describe seven barnacles with gorgonian hosts, a new species of Acasta (Acastinae) and six new species of Conopea, and examine their specificity in hosts for comparison with other known gorgonian/barnacle symbiotic relationships.

\section{METHODS}

Molecular methods. Genomic DNA was extracted from adductor muscle tissue using the Qiagen DNeasy Blood and Tissue kit (Valencia, CA). The cytochrome c oxidase subunit I (COI) primers COI-N: TGAGAAATTATTCCGAAGGCTGG (Van Syoc 1994, 1995) and LCO 1490: GGTCAACAAATCATAAAGATATTGG (Folmer et al. 1994) were used to amplify approximately 700 base pairs of the mitochondrial genome (mtDNA). Sequence alignments were performed initially with Geneious Pro 5.6.4 (created by Biomatters, available at http://www.geneious.com) and then edited by hand. Molecular phylogeny was determined by both PHYML likelihood analysis and Mr. Bayes Bayesian analysis in Geneious Pro 5.6.4. The topologies for the two analyses were identical, so only the Bayesian tree is illustrated herein. All sequence data used in the analysis has been deposited at GenBank for archival with cross-references to CASIZ catalog numbered type specimens as vouchers.

Morphology methods. Barnacle cirri, mouthparts and opercular plates were dissected for morphological comparisons. The cirri and mouthparts were mounted on microslides and photographed with a Leitz microscope imaging system. Opercular plates were treated with $5.25 \%$ sodium hypochlorite (common household bleach) to remove remaining tissues prior to coating for imaging with a scanning electron microscope (SEM, LEO/Zeiss 1450VP).

Identification of host gorgonians was based on external and sclerite morphology. Branching patterns, polyp shape, color and sclerite types were examined. Sclerites were isolated by dissolving small amounts of gorgonian tissue in a $5.25 \%$ sodium hypochlorite solution, followed by rinsing with water and then $75 \%$ ethanol. All gorgonians harboring barnacles were identified using Grasshoff $(1988,1992)$. 


\author{
SYSTEMATICS \\ Subclass Cirripedia Burmeister, 1834 \\ Superorder Thoracica Darwin, 1854 \\ Order Sessilia Lamarck, 1818 \\ Suborder Balanomorpha Pilsbry, 1916 \\ Superfamily Balanoidea Leach, 1817 \\ Family Archaeobalanidae Newman and Ross, 1976
}

\title{
Genus Conopea Say, 1822
}

Obligate symbionts of octocorals or antipatharians. Basis of shell firmly attached to the axis of the host by direct calcification on and around part of the axis. Shell overgrown by coenenchyme of the octocoral or antipatharian host. However, the shell is not overgrown by the proteinaceous axis material of the host. Shell composed of 4-6 wall plates.

Conopea willhearsti Van Syoc, Carrison-Stone, Madrona, and Williams, sp. nov. Figures 1-4, Table 1

Material examined.- Holotype: CASIZ 191932, whole specimen attached to host Melithaea sp. in 95\% EtOH. Locality: Philippines, Batangas Province, Culebra Island. $13.60000^{\circ} \mathrm{N} ., 120.94700^{\circ} \mathrm{E}$. Attached to Melithaea sp. HEP-74. Depth: 6 meters Collector: Robert Van Syoc, 16 May 2011. PARATYPES: CASIZ 185242, 12 whole, 2 dissected specimens in 95\% EtOH. Locality: Philippines, Batangas Province, Culebra Island. $13.60000^{\circ}$ N., $120.94700^{\circ} \mathrm{E}$. Attached to Melithaea sp. HEP-74. Depth: 6 meters Collector: Robert Van Syoc, 16 May 2011;CASIZ 104031, 3 whole, 2 dissected specimens in 95\% EtOH. Locality: Philippines, Mindoro, Sabang, Escarceo Point. Attached to Acabaria sp. Depth: 23 meters. Collector: Gary Williams, 1 March 1995; CASIZ 111792, 2 whole, 3 dissected specimens in 95\% EtOH. Locality: Philippines, Batangas Province, Maricaban Island, "Bethlehem" dive site. Attached to Acabaria sp. Depth: 5-21 meters. Collector: Gary Williams, 21 April 1997; CASIZ 111822, 7 whole, 8 dissected specimens in $95 \%$ EtOH, SEM stub with opercular plates, microslide with cirri and mouthparts. Locality: Philippines, Batangas Province, Maricaban Island, Kirby's Rock dive site. Attached to Acabaria sp. Depth: 9-30 meters Collector: Gary Williams, 19 April 1997; CASIZ 185241, 14 whole, 1 dissected specimens in 95\% EtOH, SEM stub with opercular plates, microslide with cirri and mouthparts. Locality: Philippines, Batangas Province, Maricaban Island, Devil's Point dive site. $13.65084^{\circ}$ N., $120.84145^{\circ}$ E. Attached to Acabaria sp. HEP-41 Depth: 24 meters. Collector: Robert Van Syoc, 7 May 2011; CASIZ 185882, 2 whole, 4 dissected specimens in 95\% EtOH. Locality: Philippines, Batangas Province, Maricaban Island, Devil's Point dive site. $13.65084^{\circ} \mathrm{N}$., $120.84145^{\circ}$ E. Attached to Acabaria sp. HEP-41 Depth: 24 meters. Collector: Robert Van Syoc, 7 May 2011; CASIZ 185884, 1 dissected specimen in 95\% EtOH. Locality: Philippines, Batangas Province, Ligpo Island, "Ligpo South" dive site. $13.81920^{\circ}$ N., $120.90043^{\circ}$ E. Attached to Mopsella sp. HEP-97 Depth: 21 meters. Collector: Robert Van Syoc, 22 May 2011; CASIZ 185899, 1 dissected specimen in 95\% EtOH. Locality: Philippines, Batangas Province, Calumpan Peninsula, Balayan Bay, "Koala" dive site. $13.71682^{\circ}$ N., $120.87236^{\circ}$ E. Attached to Mopsella sp. Collector: Dito de la Rosa, 22 May 2011; CASIZ 185900, 2 whole, 2 dissected specimens in 95\% EtOH. Locality: Philippines, Batangas Province, Culebra Island. $13.62978^{\circ}$ N., $120.94738^{\circ}$ E. Attached to Acabaria sp. HEP-95 Collector: Robert Van Syoc, 21 May 2011; CASIZ 187665, about 30 whole, 2 dissected specimens in 95\%EtOH. Locality: Philippines, Batangas Province, Maricaban Island, 
Kirby's Rock dive site. $13.69202^{\circ}$ N., $120.84308^{\circ}$ E. HEP-37. Collector: Michelle Weber, 6 May 2011; CASIZ 187689, 3 whole, 1 dissected specimens in 95\%EtOH. Locality: Philippines, Batangas Province, Maricaban Island, Devil's Point dive site. $13.65058^{\circ} \mathrm{N}$., $120.84162^{\circ} \mathrm{E}$. Attached to Acabaria sp. HEP-90 Depth: 21 meters Collector: Robert Van Syoc, 20 May 2011; CASIZ 187718, 3 whole, 1 dissected specimens in 95\% EtOH. Locality: Philippines, Batangas Province, Maricaban Island, Layag Layag dive site. $13.69178^{\circ}$ N., $120.84130^{\circ}$ E. Attached to Acabaria sp. HEP-91 Depth: 12 meters. Collector: Robert Van Syoc, 20 May 2011; CASIZ 187720, 6 whole, 2 dissected in 95\% EtOH. Locality: Philippines, Batangas Province, Maricaban Island, Devil's Point dive site. $13.65092^{\circ}$ N., $120.84137^{\circ} \mathrm{E}$. Attached to Acabaria sp. HEP-59. Depth: 15 meters Collector: Robert Van Syoc, 13 May 2011; CASIZ 187721, 6 whole, 2 dissected specimens in 95\% EtOH. Locality: Philippines, Batangas Province, Maricaban Island, Devil's Point dive site. $13.65084^{\circ} \mathrm{N}$, $120.84145^{\circ}$ E. Attached to Acabaria sp. HEP-41 Depth: 24 meters. Collector: Robert Van Syoc, 7 May 2011; CASIZ 187765, 6 whole, 2 dissected in 95\% EtOH, SEM stub with opercular plates, microslide with cirri and mouthparts. Locality: Philippines, Batangas Province, Balayan Bay, Ligpo Island. $13.81964^{\circ} \mathrm{N}, 120.90078^{\circ} \mathrm{E}$. Attached to Melithaea sp. HEP-18 Collector: Robert Van Syoc, 2 May 2011; CASIZ 187766, 3 whole, 3 dissected specimens in 95\% EtOH. Locality: Philippines, Batangas Province, Maricaban Island, Kirby's Rock dive site. $13.69202^{\circ} \mathrm{N}, 120.84308^{\circ} \mathrm{E}$. HEP-37. Collector: Michelle Weber, 6 May 2011; CASIZ 187768, 10 whole, 3 dissected specimens in 95\% EtOH. Locality: Philippines, Batangas Province, Balayan Bay, "Koala" dive site. $13.71656^{\circ} \mathrm{N}, 120.87217^{\circ} \mathrm{E}$. Attached to Acabaria sp. HEP-14 Collector: Robert Van Syoc, 1 May 2011. OTHER MATERIAL: CASIZ 187769, 17 whole, 3 dissected specimens in 95\% EtOH. Locality: Philippines, Batangas Province, Maricaban Island, Devil's Point dive site. $13.65092^{\circ}$ N., 120.84137 ${ }^{\circ}$ E. HEP-77. Depth: 32 meters. Collector: Robert Van Syoc, 17 May 2011; CASIZ 189827, 2 whole, 3 dissected specimens in 95\% EtOH. Locality: Philippines, Batangas Province, Maricaban Island, "Bethlehem" dive site. Depth: 5-21 meters. Collector: Gary Williams, 21 April 1997.

DiAgnosis.- Shell wall and basis elongated along axis of host; basis with elongated "boatshape", upturned laterally and extended along host axis to sharp edges at carinal and rostral ends, about same depth along entire length with small variations, not tapering toward axis from center to tips; carina sloping steeply from summit, then gradually to basal margin, not in contact with host axis; rostrum elongated, sloping gradually from summit to basal margin, not in contact with host axis; latus nearly equilateral triangle-shape; carino-latus about same width from summit to basal margin; summit of shell wall even, radii parietal with diametric growth, not jagged. Scutum slightly wider than high.

DESCRIPTION. - Shell wall and basis elongated along axis of host; basis with elongated "boatshape", upturned laterally and extended into points at ends, about same depth along entire length with small variations, not tapering from center to tips; carina sloping steeply from summit, then gradually to basal margin, not in contact with host axis; rostrum elongated, sloping gradually from summit to basal margin, not in contact with host axis; latus nearly equilateral triangle-shape; carino-latus about same width from summit to basal margin. Basis and parietes with longitudinal tubes, secondarily filled. Summit of shell wall even, radii parietal with diametric growth, not jagged. Scutum width greater than height, apex acute, articular ridge extending over $3 / 4$ length tergal margin, basal margin curved, steep slope to depressor muscle pit at tergal/articular margin, articular ridge fairly to moderately convex, adductor muscle pit present, inner surface pebbled, tergal and occludent margins fairly straight. Tergum height slightly greater than width; apex acute; spur broad, furrow shallow, spur sloping downward to rounded end near scutal margin; basiscutal angle shallow, obtuse; inner surface pebbled; 3-6 depressor muscle crests; basal margin concave, carinal margin 


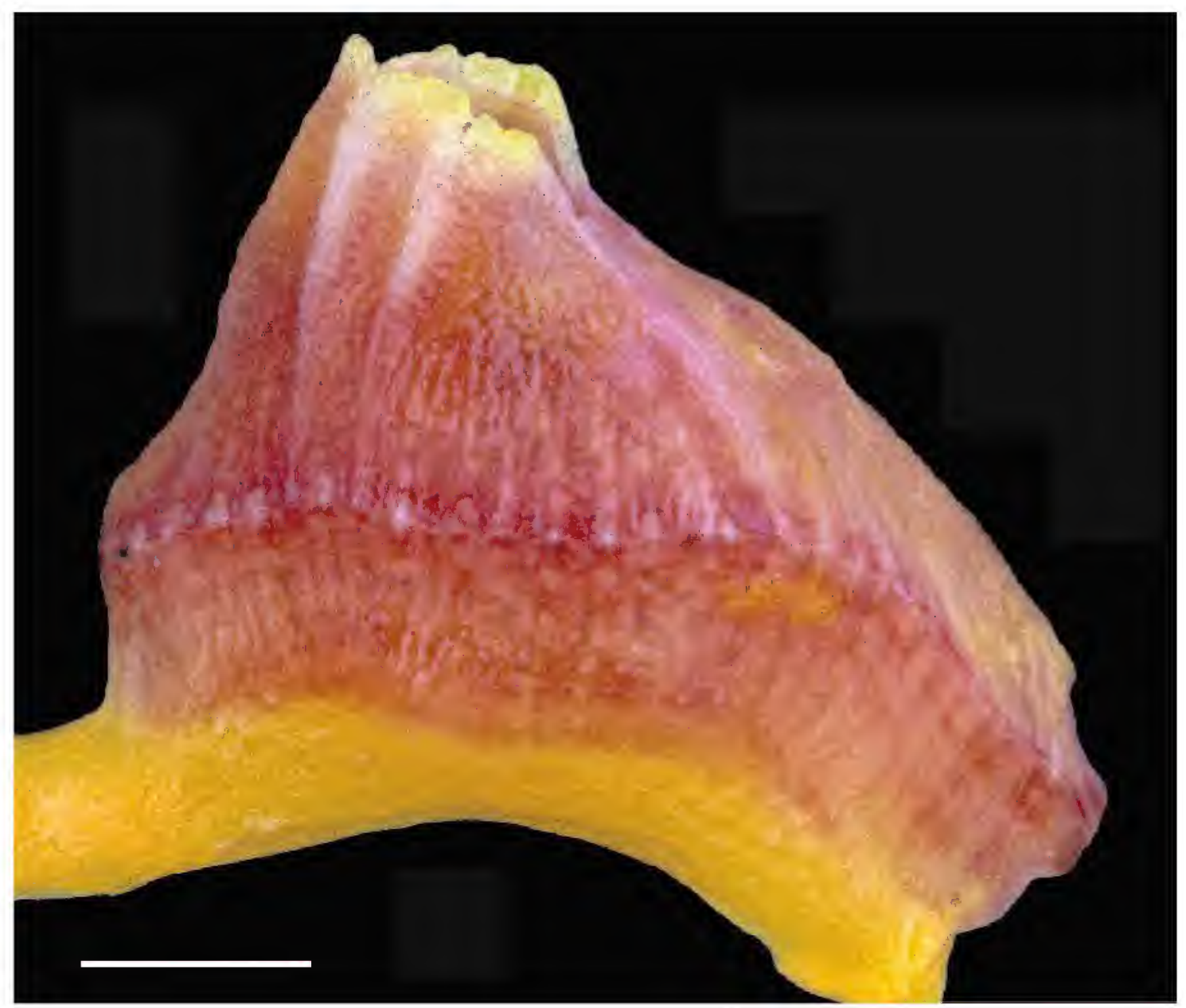

FIGURE 1. Conopea willhearsti, whole shell of paratype, CASIZ 185241. Scale bar $=200 \mathrm{~mm}$.

straight to convex, scutal margin fairly straight. Labrum with 2 teeth either side of notch; notch moderately deep, opening shallow, triangular; cutting margins convex. Mandible with 5 teeth, 1 st $2^{\text {nd }}$ and $3^{\text {rd }}$ large, about equal distance from each other, distance may be greater between $1^{\text {st }}$ and $2^{\text {nd }}$, $4^{\text {th }}$ and $5^{\text {th }}$ smaller, closer together; medium length, fine setae along inferior, superior, cutting margins. Maxilla with 9-11 large spines along cutting edge; cutting edge, inferior and superior margins covered in long fine setae; cutting edge with small notch two spines in from superior angle. $2^{\text {nd }}$ Maxilla oblong; small secondary lobe at base; many long setae distally and along inferior margin. Palp oblong; superior margin more strongly convex than inferior; long fine setae distally, shorter setae along inferior margin. Cirrus I anterior ramus twice as long as posterior ramus; anterior ramus distinctly tapered; obvious segmentation in both rami; rami covered in long setae. Cirrus II anterior ramus about $1 / 4$ longer than posterior ramus; rami thick, mildly tapered, inferior margins rounded, protruding; inferior margin setae long, dense; superior margin setae shorter, grouped at segment junctions. Cirrus III anterior ramus $1 / 3$ to $1 / 4$ longer than posterior ramus; anterior ramus with minute sharply pointed armature along inferior margin, armature grouped near upper margin of individual segments; tufts of setae formed on each segments upper margin, inferior setae long, superior setae shorter. Cirrus IV rami similar in length; anterior ramus with armature grouped near upper margin of individual segments; inferior setae longer and more abundant than superior setae. 

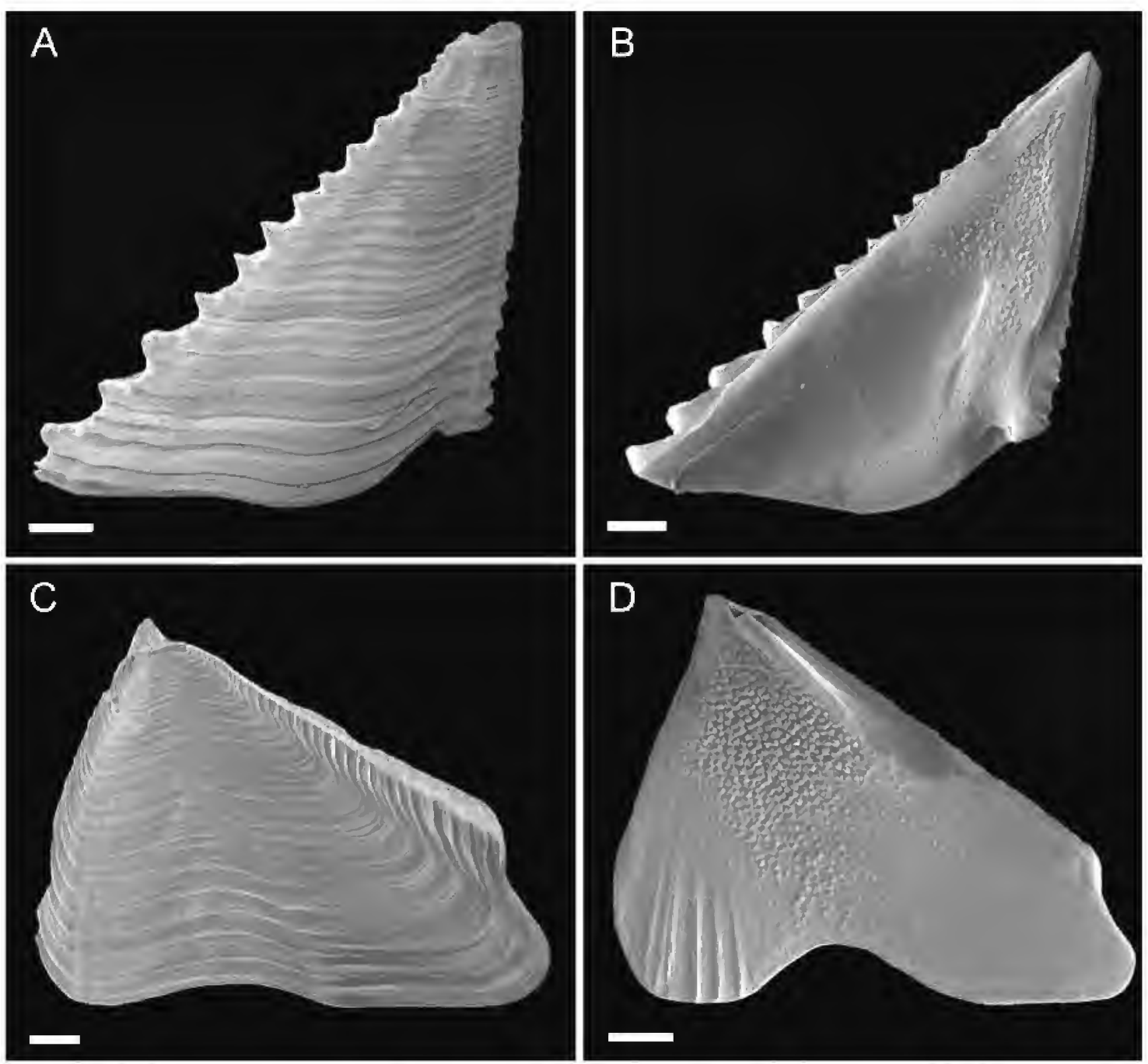

FIGURE 2. Conopea willhearsti, opercular plates of paratypes. A scutum exterior (CASIZ 111822); B scutum interior (CASIZ 111822); C tergum exterior (CASIZ 111822); D tergum interior (CASIZ 111822). Scale bar $=200 \mu \mathrm{m}$.

Cirrus V rami similar in length, tapered; inferior setae longer and more abundant than superior setae, superior setae grouped at upper margin of segment junctions. Cirrus VI rami similar in length, longer than $\mathrm{CV}$, tapered; inferior setae longer and more abundant than superior setae, superior setae grouped at upper margin of segment junctions. Penis long, tapered, very sparsely covered in fine setae. All cirral setae simple.

TABLE 1. Cirral formula for Conopea willhearsti sp. nov. Segment counts from paratypes, CASIZ 111822 and 187765.

$\begin{array}{lllllll}\text { Cirrus } & \text { I } & \text { II } & \text { III } & \text { IV } & \text { V } & \text { VI } \\ \text { Anterior ramus } & 6 & 6-7 & 6-7 & 7-10 & 12-14 & 14-15 \\ \text { Posterior ramus } & 9-11 & 10-14 & 10-13 & 11-13 & 14-16 & 16-17\end{array}$

ЕтомоLOGY.- This species is named in honor of Will Hearst, philanthropist and benefactor of the California Academy of Sciences and funder of the 2011 joint expedition to the Philippines. 


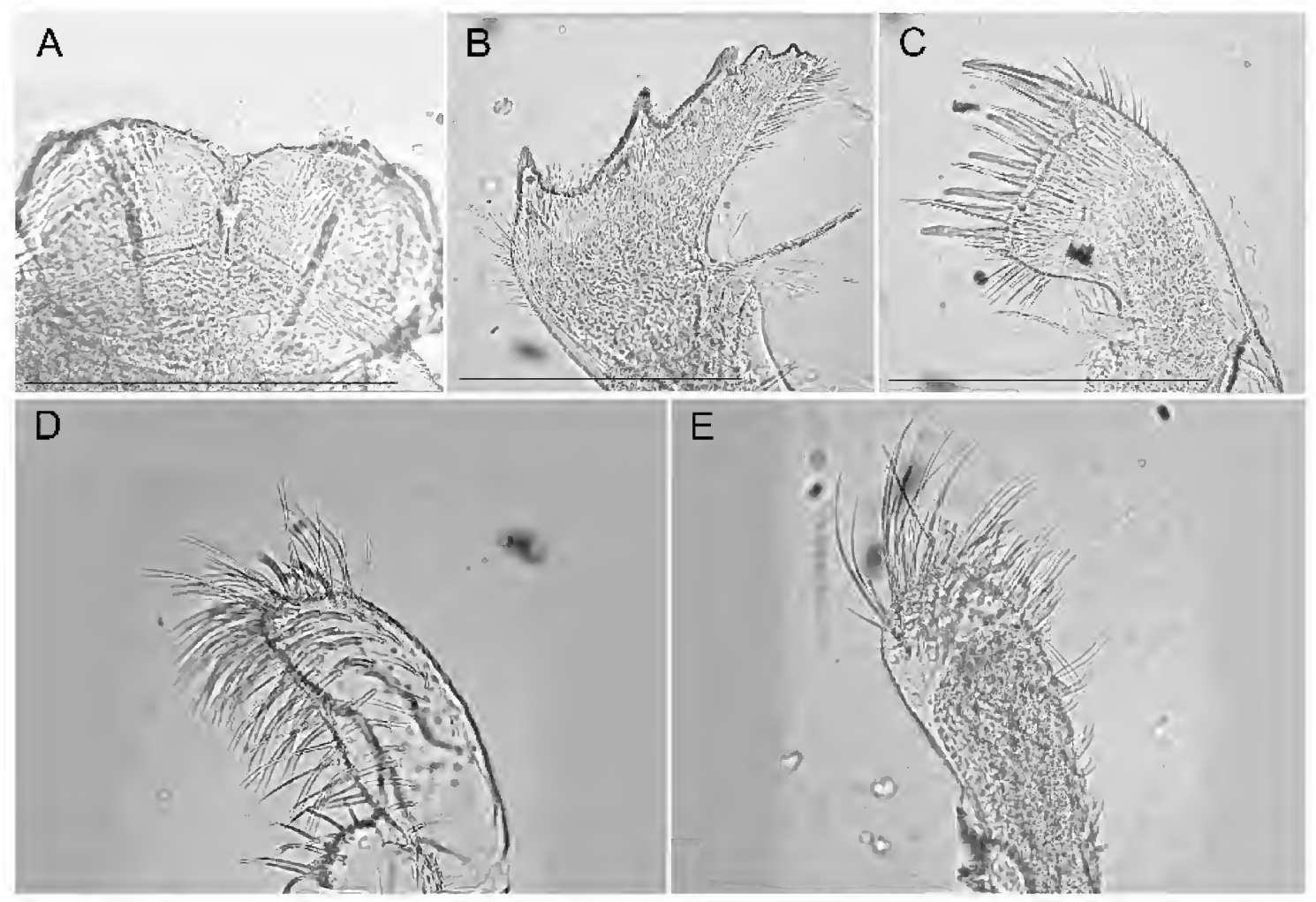

FIGURE 3. Conopea willhearsti, mouth parts of paratypes. A labrum (CASIZ 187765); B mandible (CASIZ 185241); C maxilla I (CASIZ 111822); D maxilla II (CASIZ 111822); E mandibular palp (CASIZ 111822). Scale bar $=200 \mu \mathrm{m}$.

Distribution. - Known only from the type locality in the Verde Island Passage, Philippines.

SPECIES COMParisons. - Conopea willhearsti has morphological affinities to C. sabangensis, C. margaretae, and C. proripiens. The external morphology is particularly similar, with basis, rostrum and carina extended longitudinally along the axis of the host. In both species, the extension of these plates is extreme to the point of converting the typical conical shell wall shape into a spindle shape. However, the basis of $C$. willhearsti is much deeper, especially at the carinal and rostral ends, than that of $C$. sabangensis, $C$. margaretae and C. proripiens. The bases of $C$. margaretae and $C$. proripiens taper from their thickest point, just below the carinolateral sutures, to the carinal and rostral ends. In these two species, at the carinal and rostral ends, the basis is nearly flat, with no depth. Although the basis of $C$. sabangensis is about as deep as that of $C$. willhearsti for much of its length, the rostral and carinal ends taper down such that the rostrum and carina nearly contact the host axis in $C$. sabangensis. The basis remains well above the host axis in $C$. willhearsti. The scutum of $C$. willhearsti has a well developed lateral depressor muscle pit, this is lacking in C. proripiens. The $3^{\text {rd }}$ mandibular tooth of $C$. willhearsti is not massive as described for C. proripiens. In the specimens we examined, the basal width of the scutum of $C$. willhearsti is greater than the height at the articular margin, it is wider than high. The scutum of $C$. sabangensis is higher than 


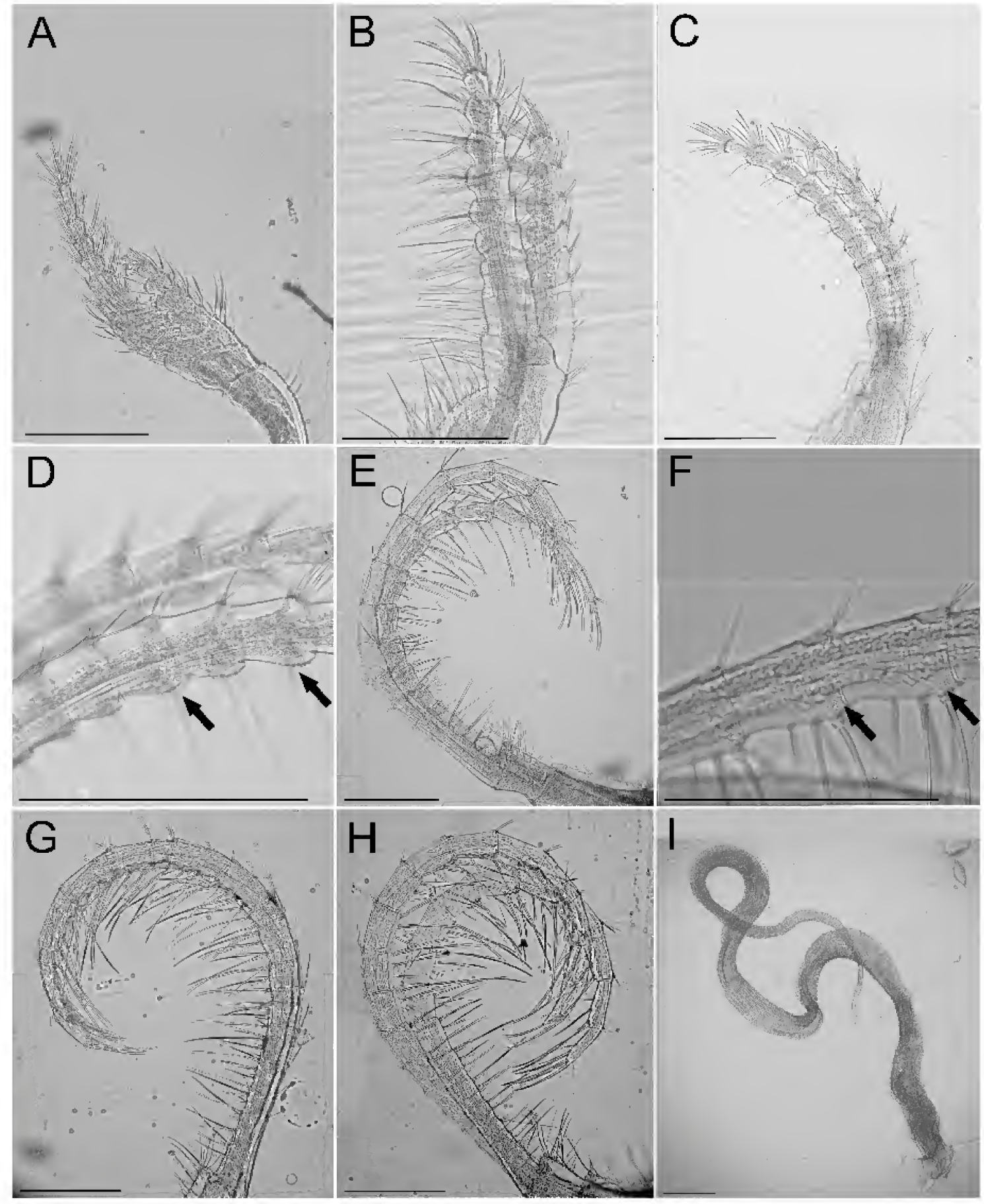

Figure 4. Conopea willhearsti, cirri and penis of paratypes. A CI (CASIZ 185241); B CII (CASIZ 111822); C CIII (CASIZ 111822); D CIII spines (CASIZ 111822); E CIV (CASIZ 187765); F CIV spines (CASIZ 111822); G CV (CASIZ 187765); H CVI (CASIZ 187765); I penis (CASIZ 111822). Scale bar $=200 \mu \mathrm{m}$. 
wide, it has a basal width that is smaller than the height at the articular margin.

Conopea sabangensis Van Syoc, Carrison-Stone, Madrona, and Williams, sp. nov. Figures 5-8, Table 2

Material eXamined- - Holotype: CASIZ 191928. One whole specimen attached to Acabaria sp. Locality: Philippines, Mindoro, Sabang, Escarceo Point. Depth: 23 meters. Attached to Acabaria sp. (CASIZ 103922). Collector: Gary Williams, 1 March 1995; PARATYPES: CASIZ 104032, 3 specimens. Locality: Philippines, Mindoro, Sabang, Escarceo Point. Depth: 23 meters. Attached to Acabaria sp. (CASIZ 103922). Collector: Gary Williams, 1 March 1995; CASIZ 103822, 1 whole specimen, 1 dissected specimen, and 2 scuta. Locality: Philippines, Mindoro, Sabang, Escarceo Point. Depth: 23 meters. Attached to Melithaea sp. (CASIZ 103825). Collector: Gary Williams, 1 March 1995.

Diagnosis.- Shell wall and basis elongated along axis of host; basis tapering from center to tips; rostrum gently sloping down from summit to base, touching or nearly touching host axis at basal margin; carina dropping steeply from summit to about half wall height then sloping gradually to basal margin where it touches or nearly touches host axis; scutum slightly higher than wide; tergum only slightly higher than wide, four low lateral depressor crests; no spine or other armature on basal segments of Cirrus 4.

DESCRIPTION.- Shell wall elongated along axis of host, basis, carina and rostrum extended out along axis with basis depth narrowing from greatest depth beneath carino-latera and latera to nearly flat at carinal and rostral ends of shell wall where rostrum and carina are closest to host axis; radii not broadening greatly from basal margin to summits, summits even; carina not quite as long as latera at basal margin, sloping steeply near apex, then at about a $45^{\circ}$ angle to tip; rostrum sloping at a shallower angle from apex to tip; carino-latus nearly same width from summit to base; latera nearly triangular with apex and summit, broadening at about $45^{\circ}$ angle along sutures to basal margin; carino-latera paries about same width from basal margin to summits. Basis and parietes

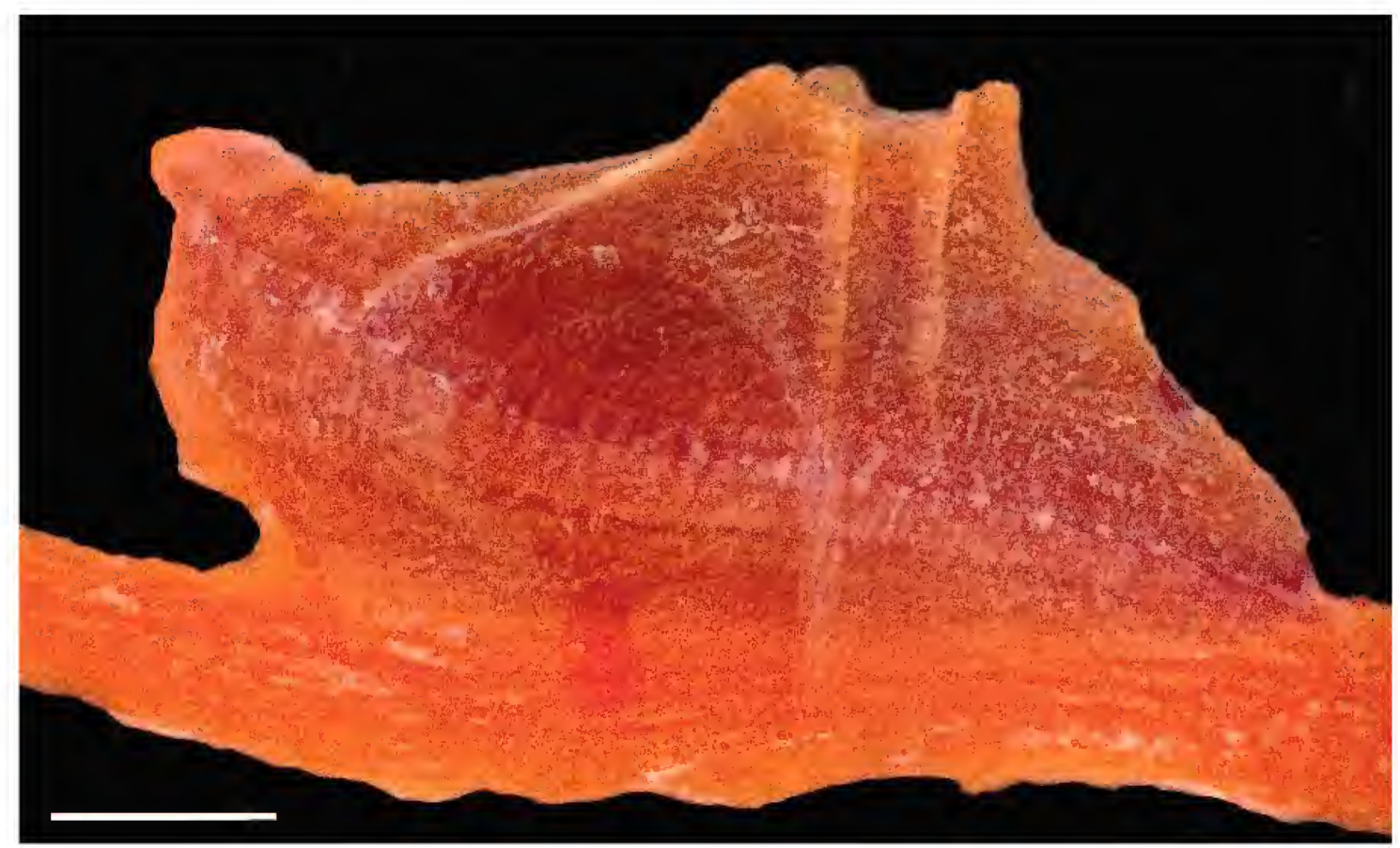

FIGURE 5. Conopea sabangensis, whole shell of paratype, CASIZ104032. Scale bar $=200 \mathrm{~mm}$ 

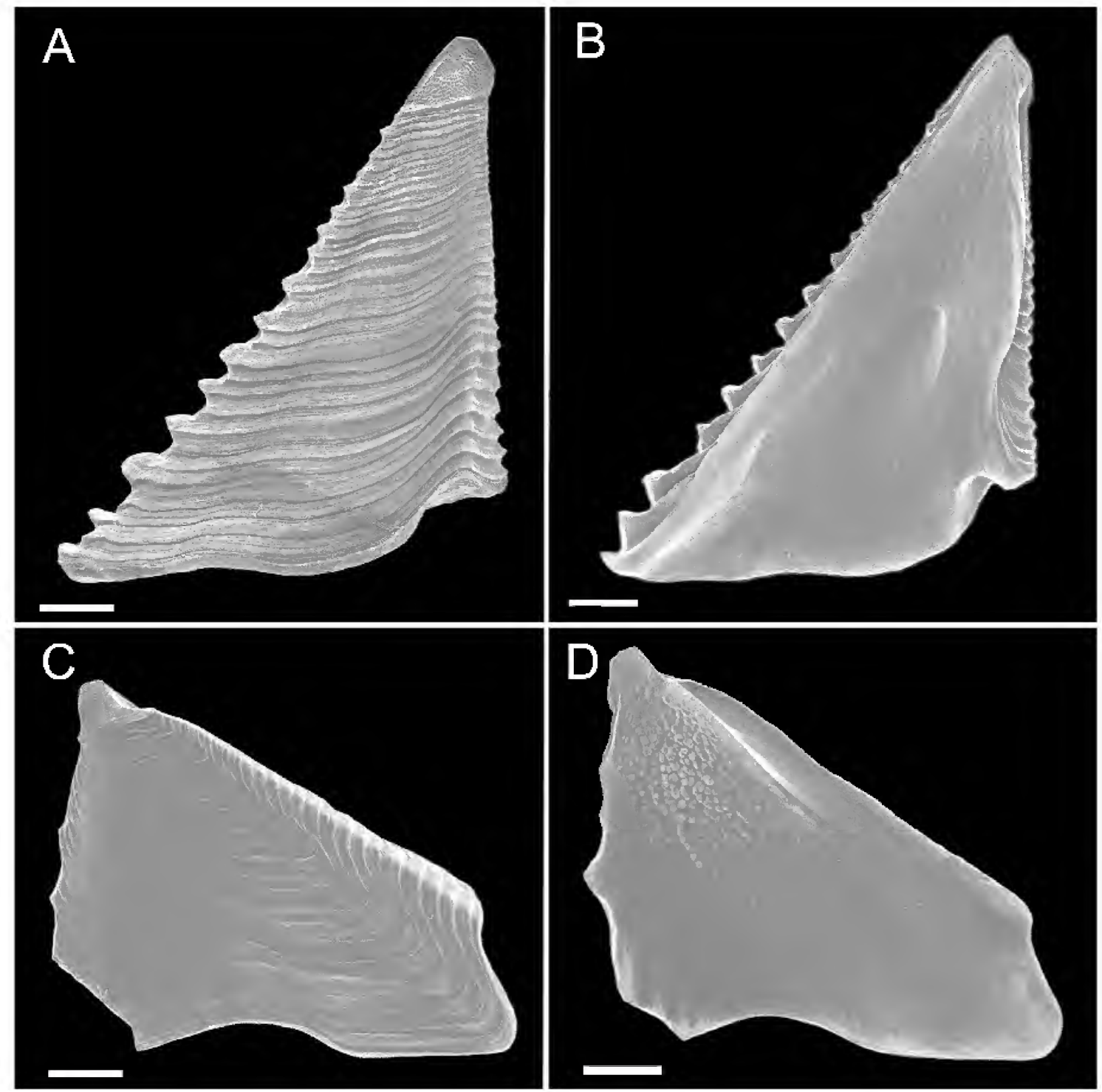

FIGURE 6. Conopea sabangensis, opercular plates of paratype, CASIZ 103822. A scutum exterior; B scutum interior; $\mathrm{C}$ tergum exterior; D tergum interior. Scale bar $=200 \mu \mathrm{m}$. Tergal margins and basicarinal margins chipped.

solid, lacking tubes. Scutum height slightly greater than width; basal margin curved, angling up sharply at tergal margin; small lateral depressor muscle pit, shallow to moderately deep; adductor muscle pit medium size, moderately deep; articular ridge slightly less than $1 / 2$ length of tergal margin; interior surface lightly textured; exterior at apex distinct texture change from rest of surface, no ridges, covered in small shallow pits; articular furrow narrow; tergal and occludent margins fairly straight. Tergum height only slightly greater than width; apex acute, not beaked; spur broad, about $1 / 2$ the width, spur short, barely extending beyond basal margin; 3-4 shallow depressor crests; interior surface pebbled; scutal and carinal margins straight to slightly convex, basal margin straight to mildly curved. Labrum with triangular shaped notch opening; 3 teeth on both sides of notch, teeth rounded, set into tissue in slight depressions. Mandible with 4-5 teeth, $5^{\text {th }}$ tooth may be part of inferior angle, $3^{\text {rd }}$ tooth may be bi-dentate; $1^{\text {st }}, 2^{\text {nd }}$, and $3^{\text {rd }}$ teeth largest and spaced well 


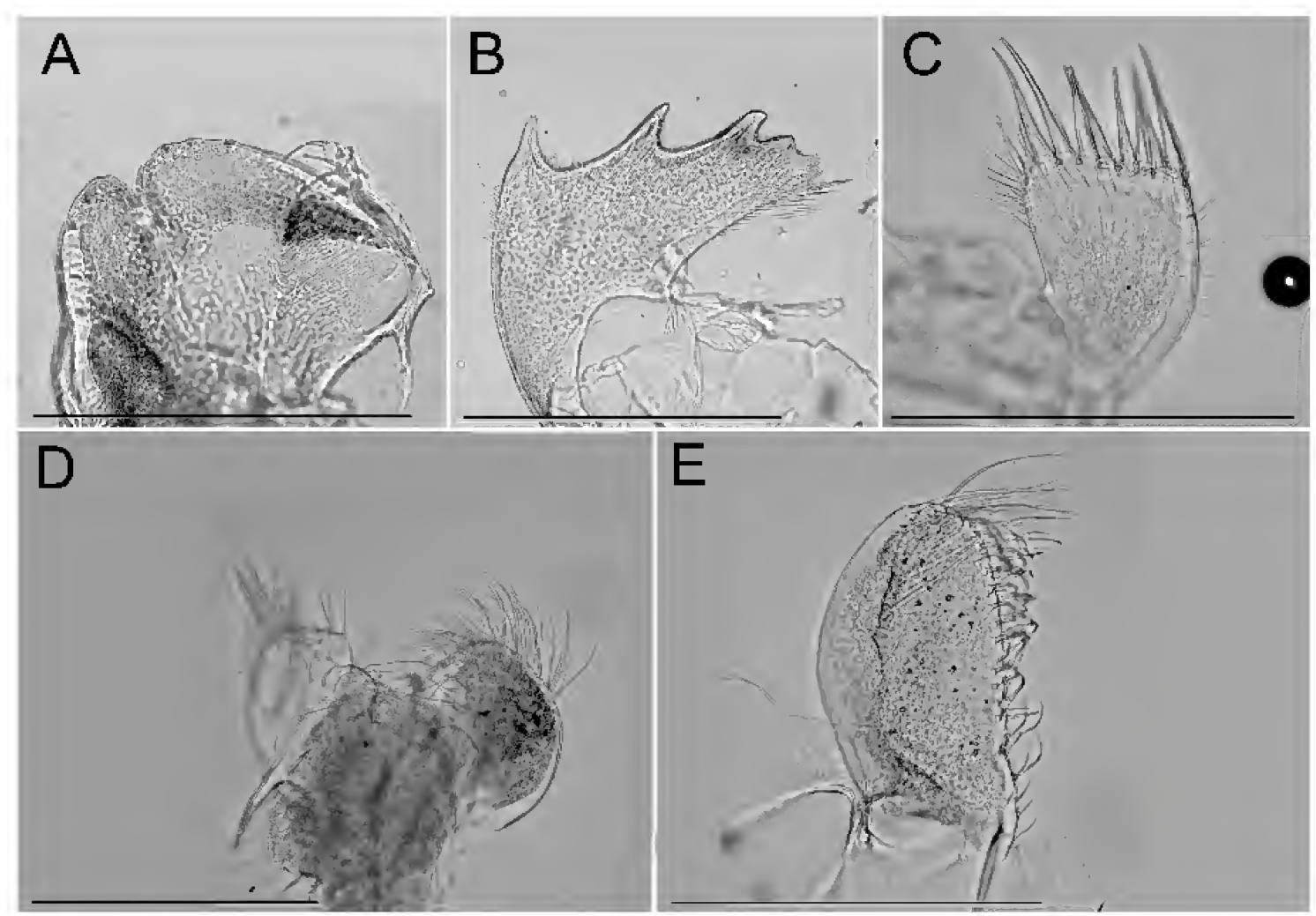

FIGURE 7. Conopea sabangensis, mouth parts of paratype, CASIZ 104032. A labrum; B mandible; C maxilla I; D maxilla II; E mandibular palp. Scale bar $=200 \mu \mathrm{m}$.

apart, $3^{\text {rd }}, 4^{\text {th }}$, and $5^{\text {th }}$ teeth close together; $4^{\text {th }}$ and $5^{\text {th }}$ teeth small, lumpy; medium length fine setae along superior, inferior and just below cutting margins. Maxilla with 8-12 large spines along cutting edge; medium length fine setae along superior, inferior and just below cutting margins. $2^{\text {nd }}$ Maxilla small; rounded egg shape; fine, dense setae. Palp elongate; setae along inferior margin, apex; superior margin convex, inferior margin fairly straight. Cirrus I anterior ramus $1 / 4$ longer than posterior ramus, rami tapered; segmentation distinct; setae dense, medium length. Cirrus II anterior ramus $1 / 4$ to $1 / 5$ longer than posterior ramus, rami thick, slightly tapered; setae dense, shorter along superior margin, longer along inferior margin. Cirrus III armature present, spines small and sparse; anterior ramus $1 / 4$ longer than posterior ramus; setae simple, dense, bushy, may or may not be longer along inferior margin and shorter along superior margin; inferior segment margin may or may not be more bulbous than superior margin. Cirrus IV without armature; rami slightly unequal in length; rami longer and setae less dense and longer than CI, CII, and CIII. Cirrus V rami similar in length, long; setae similar to CIV, setae longer along inferior margin, shorter along superior margin. Cirrus VI similar to CV. Penis long; large spine at base; sparsely covered in small fine setae.

All cirral setae simple.

TABle 2. Cirral formula for Conopea sabangensis sp. nov. Segment counts from paratype CASIZ 104032.

$\begin{array}{lllllll}\text { Cirrus } & \text { I } & \text { II } & \text { III } & \text { IV } & \text { V } & \text { VI } \\ \text { Anterior ramus } & 4-5 & 6 & 5-8 & 12 & \text { 16-Missing } & \text { Missing } \\ \text { Posterior ramus } & 5 & 7 & 9-10 & 13-14 & \text { 19-Missing } & \text { Missing }\end{array}$




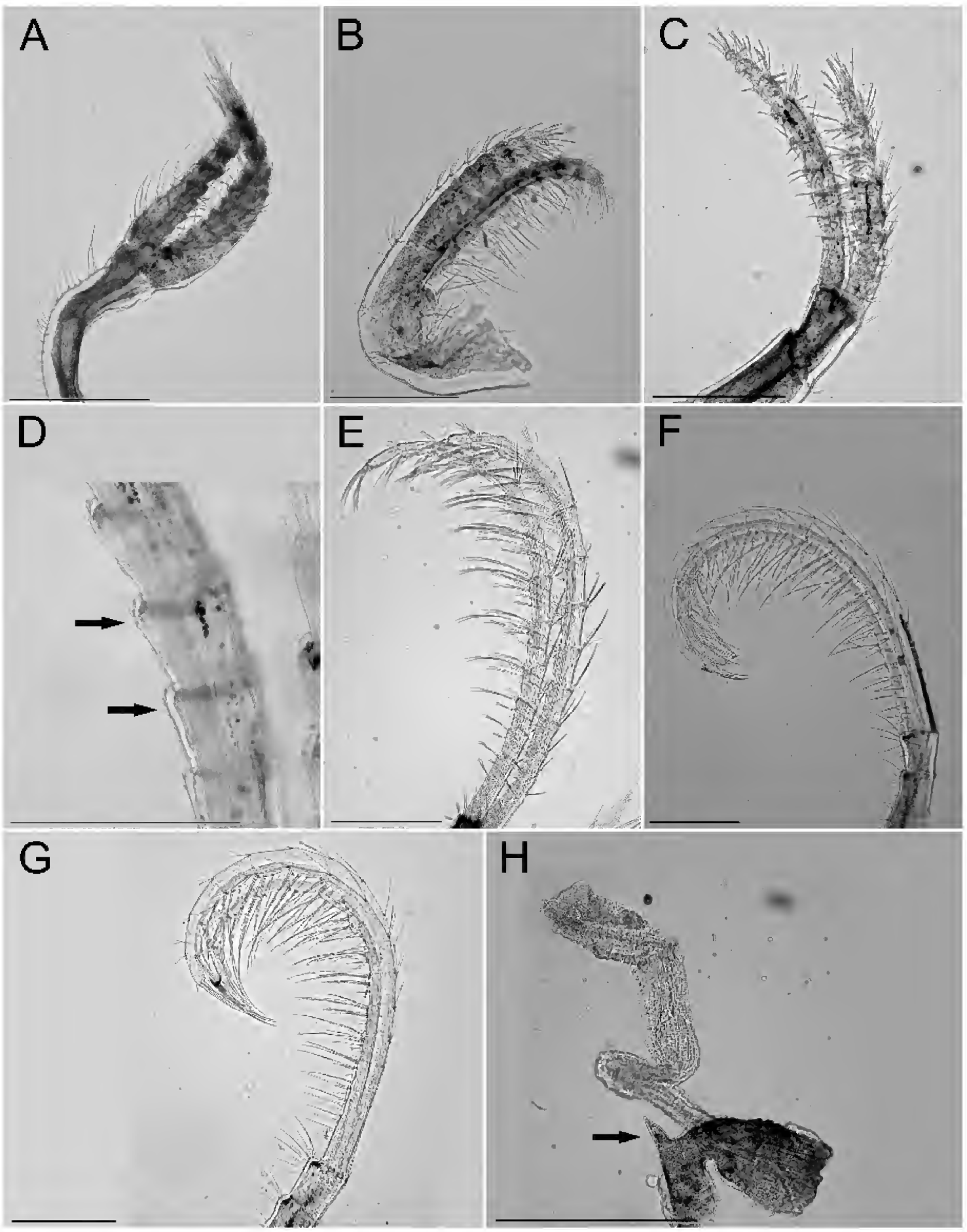

FIGURE 8. Conopea sabangensis, cirri and penis of paratype, CASIZ 104032. A CI; B CII; C CIII; D CIII spines; E CIV; F CV; G CVI; H penis. Scale bar $=200 \mu \mathrm{m}, 100 \mu \mathrm{m}$ D. 
ЕтомоцоGY.- All of the material examined was collected near Sabang. Hence, Conopea sabangensis, from Sabang and the Latin -ensis, belonging to or from, literally Conopea from Sabang.

Distribution. - Known only from the type locality near Sabang in the Verde Island Passage, Philippines.

SPECIES COMPARISONS. - The species most similar in external appearance to C. sabangensis is $C$. willhearsti. The differences between the two species are described in detail in the description of $C$. willhearsti, herein.

Conopea margaretae Van Syoc, Carrison-Stone, Madrona, and Williams, sp. nov. Figures 9-12, Table 3

Material eXamined.- Holotype: CASIZ 191929, one whole specimen. Locality: Philippines, Luzon Island, Batangas Province, "Murals" dive site. $13.69936^{\circ}$ N., $120.88224^{\circ}$ E. HEP-104. Attached to Viminella sp. Depth: 30 meters Collector: Robert Van Syoc, 23 May 2011. PARATYPES: CASIZ 185864, 3 dissected specimens, microslide of cirri and mouthparts. Locality: Philippines, Luzon Island, Batangas Province, "Murals" dive site. $13.69936^{\circ} \mathrm{N} ., 120.88224^{\circ} \mathrm{E}$. HEP-104. Attached to Viminella sp. Depth: 30 meters. Collector: Robert Van Syoc, 23 May 2011; CASIZ 185865, 2 whole, 2 dissected specimens. Locality: Philippines, Luzon Island, Batangas Province, "Ligpo South" dive site. $13.81920^{\circ}$ N., $120.90043^{\circ}$ E. HEP-97. Attached to Viminella sp. Depth: 21 meters. Collector: Robert Van Syoc, 22 May 2011; CASIZ 187649, 4 whole, 2 dissected specimens. Locality: Philippines, Luzon Island, Batangas Province, Balayan Bay, Matotonngil Point. $13.75528^{\circ}$ N., $120.90672^{\circ}$ E. HEP-28. Depth: 2 meters. Collector: Robert Van Syoc, 3 May 2011. CASIZ 185862, 2 whole, 1 dissected specimens. Locality: Philippines, Luzon Island, Batangas Province, Calumpan Peninsula, Maricaban Strait, "Twin Rocks" dive site. $13.68996^{\circ} \mathrm{N}$, $120.88965^{\circ}$ E. HEP-87. Attached to Viminella sp. Depth: 21 meters. Collector: Robert Van Syoc, 19 May 2011; CASIZ 185243, 7 whole, 2 dissected specimens, wall plates, basis and prosoma in $95 \%$ EtOH, 2 SEM stubs with opercular plates, microslide with cirri and mouthparts. Locality: Philippines, Luzon Island, Batangas Province, Calumpan Peninsula, "Dead Palm" dive site. $13.69569^{\circ}$ N., $120.88472^{\circ}$ E. HEP-23. Attached to Ellisella sp. Depth: 29-33 meters. Collector: Robert Van Syoc, 3 May 2011; CAS 106068, 2 specimens. Locality: Philippines, Mindoro, Medio Island, northwest passage of Puerto Galera. Depth: 6-20 meters. Collector: Gary Williams, 22 May 1996. Attached to Viminella sp. (CASIZ 103813).

Diagnosis.- Shell elongated in basis, rostrum and carina; basis white, greatest depth beneath carino-latera, tapering to no depth at basal tips of carina and rostrum, or even slightly short of carina and rostrum basal tips; carina gently sloping from summit to basal margin where it contacts host axis, about same length as carino-latus and latus width combined, shorter than rostrum; rostrum white, sloping gently from summit to basal margin where it contacts host axis, about 1.5 length of carina.

DeSCRIPTION.- Shell wall elongated along host axis, radii red, broadening near summits, summit even; basis white, sinuous margin along base of wall plates, edges raised with greatest depth beneath carino-latera, edges tapering to nothing at basal tips of carina and rostrum, or even slightly short of carina and rostrum basal tips, resulting in flat basis at extreme ends of shell; carina gently sloping from summit to basal margin where it contacts host axis, about same length as carino-latus and latus width combined, shorter than rostrum, pink and white vertical and horizontal stripes; rostrum white, sloping gently from summit to basal margin where it contacts host axis, 


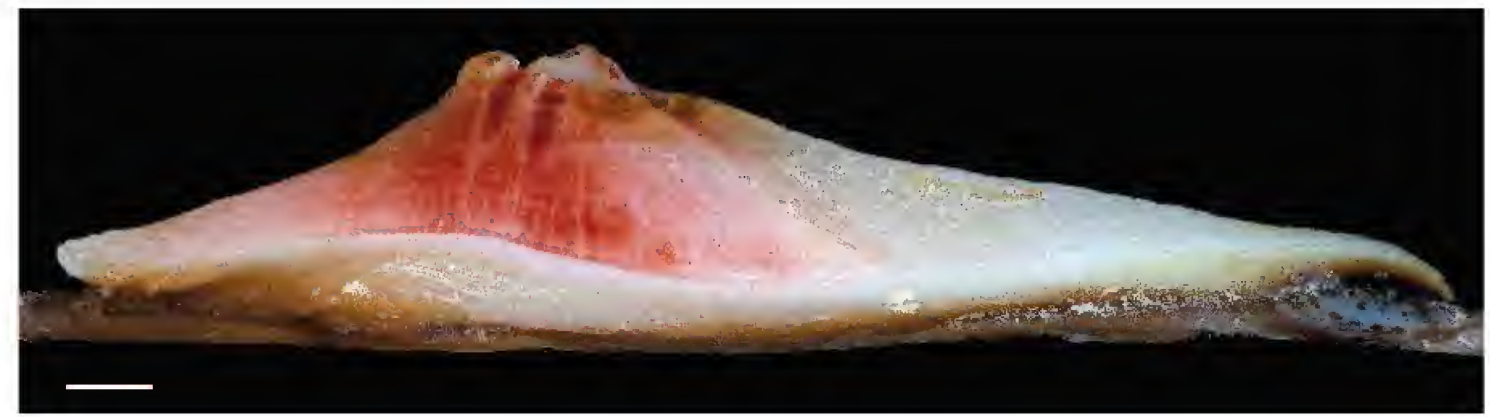

FIGURE 9. Conopea margaretae, whole shell of paratype, CASIZ 185865. Scale bar $=200 \mathrm{~mm}$.

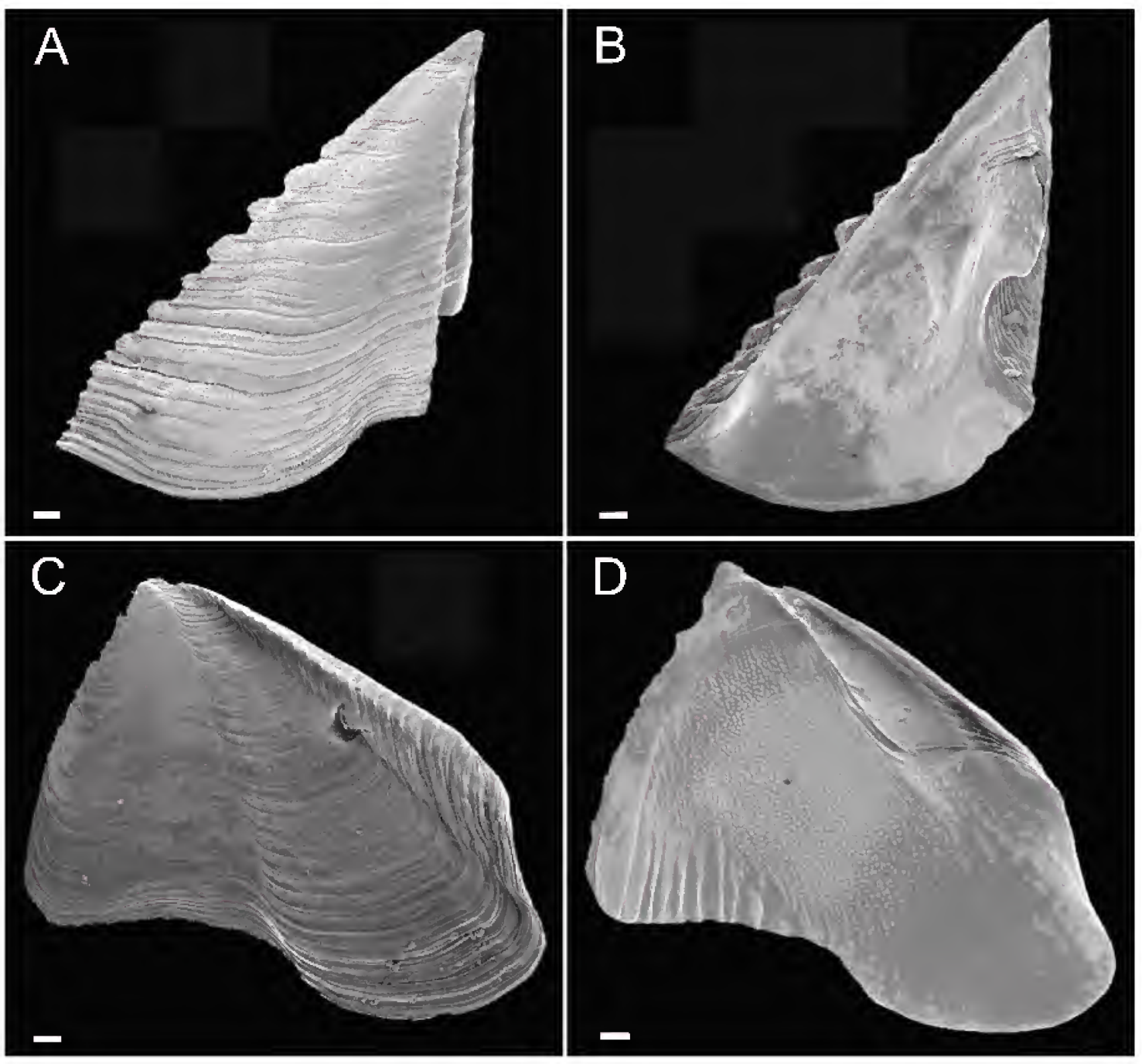

FIGURE 10. Conopea margaretae, opercular plates of paratype, CASIZ 185243. A scutum exterior; B scutum interior; $\mathrm{C}$ tergum exterior; D tergum interior. Scale bar $=200 \mu \mathrm{m}$. 


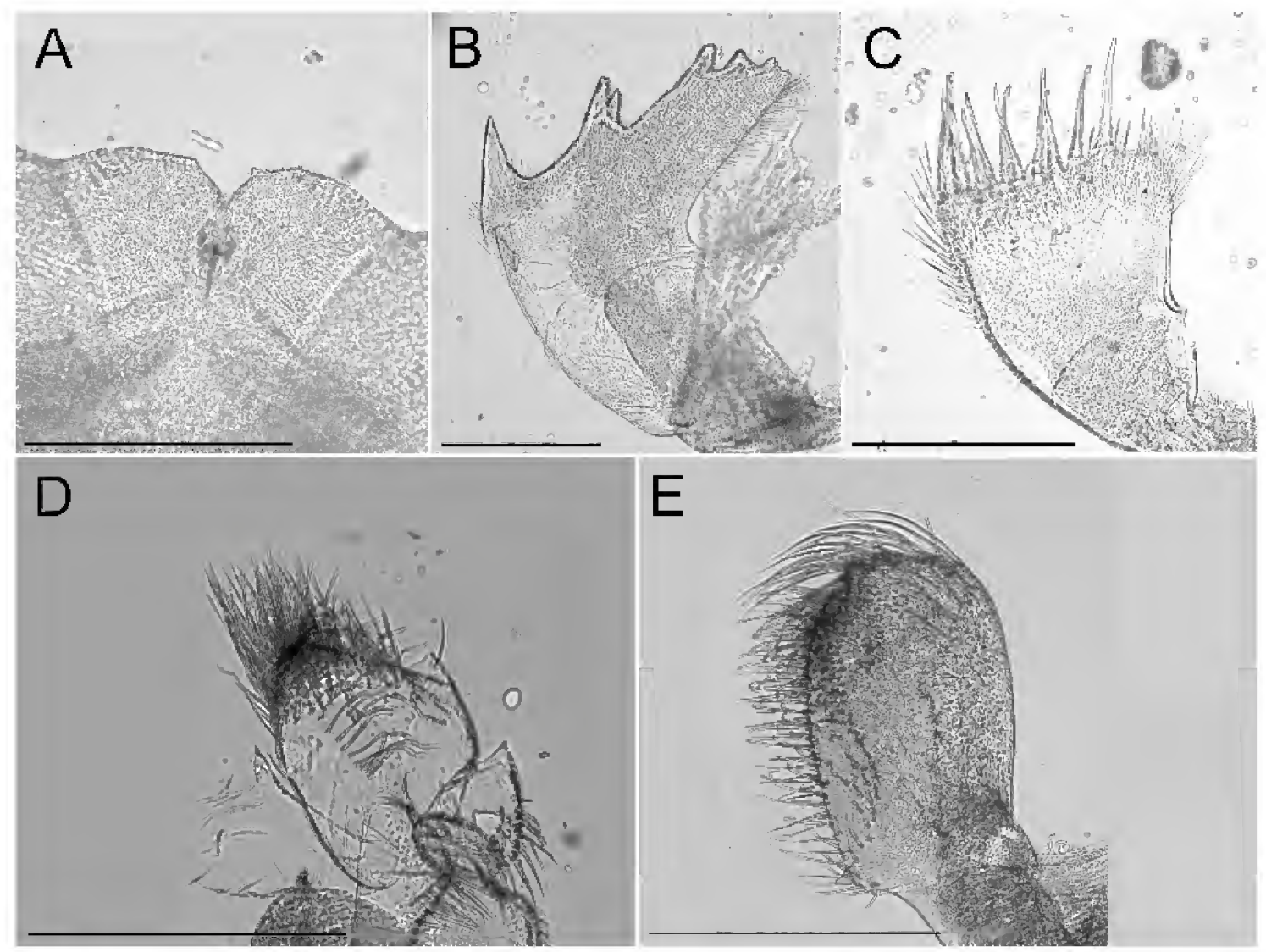

FIGURE 11. Conopea margaretae, mouth parts of paratypes. A labrum (CASIZ 185243); B mandible (CASIZ 185864); C maxilla I (CASIZ 185243); D maxilla II (CASIZ 185864); E mandibular palp (CASIZ 185864). Scale bar $=200 \mu \mathrm{m}$.

about 1.5 length of carina; carino-latus broader at basal margin, narrowing to summit, pink and white longitudinal stripes interrupted by white lines; latus rostral margin long and sloped, carinolateral margin nearly vertical, pink and white longitudinal stripes interrupted by white lines; wall summit smooth and even, radii parietal, deep red in color, closed at basal margin, broadening toward summit. Basis and parietes with longitudinal tubes, secondarily filled. Scutum height greater than width; depressor and adductor muscle pits shallow; high articular ridge about one-half length of tergal margin, straight to mildly convex; external growth ridges, no radial ridges; apex acute, reddish brown, shows growth ridges internally; interior surface lightly textured; basal margin curved, tergal and occludent margins relatively straight. Tergum width similar to height; spur wider than long, about one-half of basal margin; 7-9 depressor muscle crests; spur furrow shallow, broad; base of spur rounded; basiscutal angle obtuse, shallow; articular furrow wide; articular ridge mild; interior surface pebbled. Labrum with $0-2$ teeth on either side of notch; notch triangular, opening shallow; very small fine setae along cutting margin. Mandible with 5 teeth; $2^{\text {nd }}$ tooth may by bi-dentate; $1^{\text {st }}$ and $2^{\text {nd }}$ teeth largest, $3^{\text {rd }}$ slightly smaller, $4^{\text {th }}$ and $5^{\text {th }}$ much smaller, closer together; fine setae along superior and inferior margins, below and along cutting margin. Maxilla with 10-11 large spines, small spines, and setae along cutting margin; last large spine set in from inferior margin angle; cutting margin straight or lower in space between spine and inferior margin angle; fine, dense, medium length setae along superior, inferior margins and below cutting margin. $2^{\text {nd }}$ Maxilla bi-lobed, small, egg shaped; tuft of fine, medium to long apical setae, setae extend 


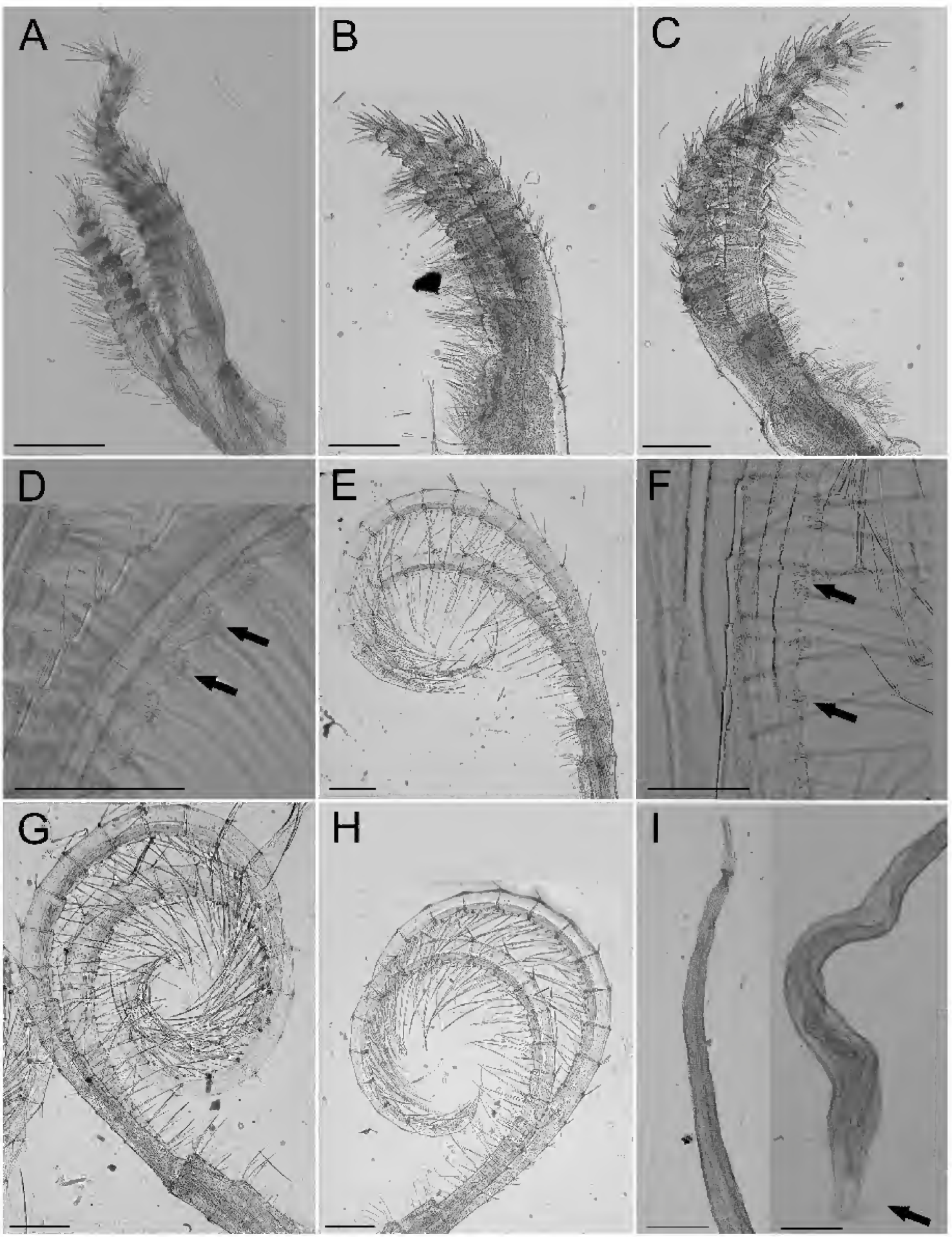

FIGURE 12. Conopea margaretae, cirri and penis of paratypes. A CI (CASIZ 185864); B CII (CASIZ 185243); C CIII (CASIZ 185243); D CIII spines (CASIZ 185864); E CIV (CASIZ 185243); F CIV spines (CASIZ 185864); G CV (CASIZ 185243); H CVI (CASIZ 185243); I penis (CASIZ 185864). Scale bar $=200 \mu \mathrm{m}$. 
along ridge between inferior and superior margins. Palp elongate rectangular shape, corners rounded; dense, long, fine setae distally and along inferior surface; inferior and superior margins fairly straight to convex. Cirrus I anterior ramus about twice as long as posterior; rami tapered; setae bushy, medium length. Cirrus II anterior ramus $1 / 3$ to $1 / 4$ longer than posterior, rami thick, slightly tapered apically; inferior margin of segments more pronounced and rounded than superior margin; segments encircled with setae, inferior margin setae longer, superior margin setae shorter. Cirrus III anterior ramus slightly tapered apically, almost twice as long as posterior; inferior margin of segments more pronounced and rounded than superior margin; setae similar to $\mathrm{CII}$; anterior rami with armature along inferior margin, spines dense. Cirrus IV rami similar in length, tapered, much longer than CI, CII, CIII; setae longer and more sparse than CI, CII, CIII , setae longer on inferior margin, shorter on superior margin; inferior margin slightly more rounded than superior; inferior margin of anterior rami with armature, spines less dense than CIII, spines extend to basal segment. Cirrus V rami longer than CIV; inferior margin setae fine, long; superior margin setae short, concentrated at segment junctions. Cirrus VI similar to CV. Penis long, annulated; sparsely covered in short fine setae; large spine at base, spine apically rounded. All cirral setae simple.

TABLE 3. Cirral formula for Conopea margaretae sp. nov. Segment counts from paratypes, CASIZ 185864A and 185864B.

$\begin{array}{lllllll}\text { Cirrus } & \text { I } & \text { II } & \text { III } & \text { IV } & \text { V } & \text { VI } \\ \text { Anterior ramus } & 7-9 & 8-9 & 9-11 & 17-20 & 18-20 & 21-25 \\ \text { Posterior ramus } & 13-16 & 11-14 & 9-12 & 22-23 & 22-23 & 23-26\end{array}$

ЕтомоLоGY.- This species is named in honor of Margaret Hearst, philanthropist and benefactor of the California Academy of Sciences and funder of the 2011 joint expedition to the Philippines.

Distribution.- Known only from the type locality in the Verde Island Passage, Philippines.

SPECIES COMPARISONS. - The species of Conopea that is most similar externally to C. margaretae is $C$. proripiens. Both species have extremely elongated basis and rostrum. However, the carina of $C$. margaretae is much more elongate than that of $C$. proripiens. The carina of $C$. margaretae also slopes gradually from the summit to the basal margin. In $C$. proripiens it is nearly vertical from the summit to $3 / 4$ down toward the basis where it sharply breaks to a much lower and gradual slope to the basal margin. In both the basis and rostrum are white, with vertical/longitudinal red stripes on the carina, carino-latera and latera. Both have visible, white, radii open from basal margin to summits. The basal margin of the shell wall has a sinuous appearance in both species, generally higher in the oldest part in the middle, sloping down gently toward the tips. The scutum of $C$. margaretae lacks a lateral depressor pit, whereas it is present, though barely visible in $C$. proripiens. The tergum of $C$. margaretae has 7-8 depressor muscle crests, there are 6 in the illustration of the type of $C$. proripiens. Both species live on hosts in the family Ellisellidae.

Conopea margaretae is also similar to Conopea minyrostrum and clusters most closely with it in the tree derived from $\mathrm{CO} 1$ nucleotide sequence data. It differs from $C$. minyrostrum in the much more elongated rostrum, the rostrum of $C$. minyrostrum is more steeply sloped and less elongated in relation to the carina. The rostrum of $C$. margaretae is much more elongated than the carina. It slims gradually down to a fine point at the end. The rostrum of $C$. minyrostrum is much shorter and 
attenuates abruptly at the distal end.

Conopea minyrostrum Van Syoc, Carrison-Stone, Madrona, and Williams, sp. nov. Figures 13-16, Table 4

Material EXamined.- Holotype: CAS 191925, shell wall, basis and prosoma in 95\% EtOH, opercular plates on SEM stub, cirri and mouthparts on microslide. Locality: Philippines, Luzon Island, Batangas Province, "Ligpo South" dive site. $13.81920^{\circ}$ N., 120.90043 ${ }^{\circ}$ E. Depth: 21 meters. Attached to Viminella sp. Collector: Robert Van Syoc, 22 May 2011. Paratype: CAS 191924, 1 dissected specimen. Locality: Philippines, Batangas Province, Balayan Bay, Matotonngil Point. $13.75528^{\circ}$ N., $120.90672^{\circ}$ E. HEP-28. Depth: 2 meters. Attached to Ellisellidae. Collector: Robert Van Syoc, 3 May 2011.

DiAGNOSIS. - Shell wall elongated along host axis, carina about same width as all other wall plates combined; rostrum short and not greatly elongated, rostral basal margin about same length as latera basal margin; carino-latera near mid-point of shell wall; basis gently sinuous with greatest depth at mid-point beneath carino-latera, then narrowing in depth toward rostral and carinal ends.

DESCRIPTION.- Shell wall forming a spindle shape along host axis, carina, mid-point of shell wall at carino-latera, carino-latera and latera with red and white longitudinal stripes interrupted by white lines, rostrum and basis white; carina about same width as all other wall plates combined; rostrum wider than only carino-latera; basis highest under carino-latera, then tapering down toward carinal and rostral ends. Basis with tubes, secondarily filled. Parietes solid, lacking tubes. Scutum height greater than width; apex acute; tergal and occludent margins fairly straight, basal margin convex with steep rise up towards articular furrow; articular ridge prominent, length slightly less than total height; interior mildly textured; depressor muscle pit small, shallow; adductor muscle pit medium sized, moderately deep. Tergum height and width similar; apex acute, mildly beaked; scutal and carinal margins straight to mildly convex, basal margin slightly convex; spur furrow wide; spur wide, short; basiscutal angle shallow, obtuse; articular ridge short, about $1 / 3$ length scutal margin; articular furrow narrow; interior surface pebbled to smooth; moderate depressor crests present. Labrum with shallow triangular notch; 1-3 teeth either side of notch, teeth well spaced out

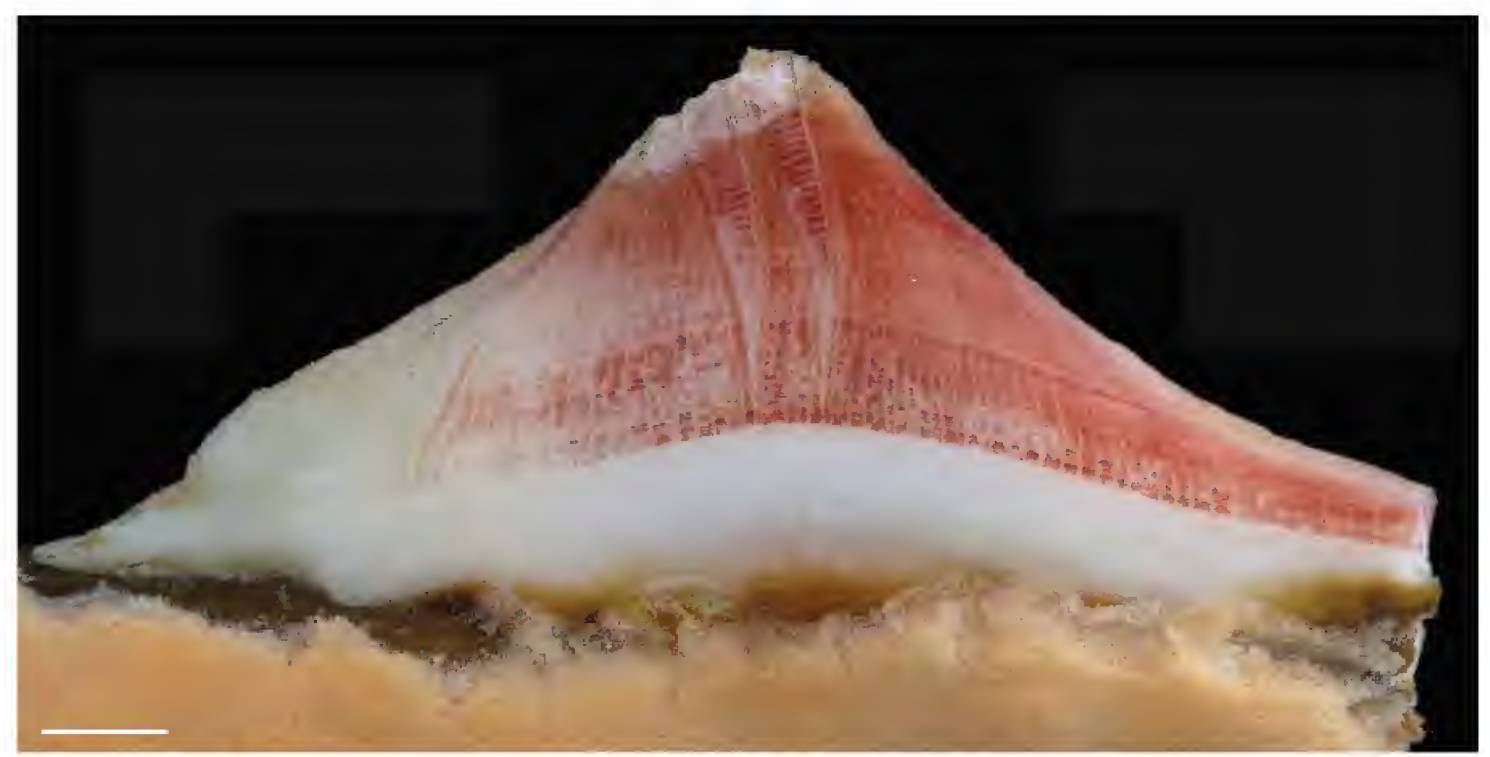

FIGURE 13. Conopea minyrostrum, whole shell of holotype, CASIZ 191925. Scale bar $=200 \mathrm{~mm}$. 

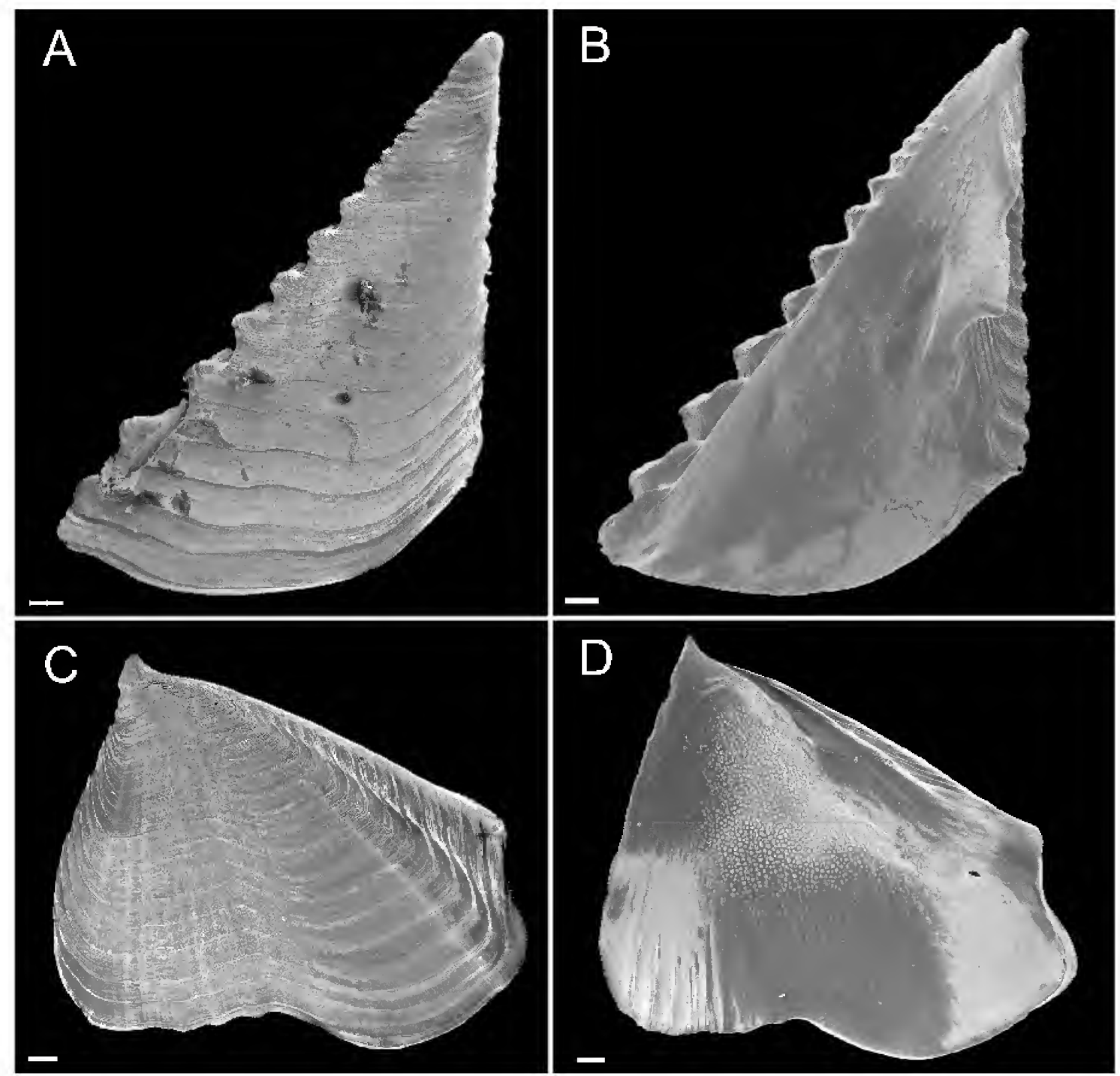

FIGURE 14. Conopea minyrostrum, opercular plates of holotype, CASIZ 191925. A scutum exterior; B scutum interior; $\mathrm{C}$ tergum exterior; D tergum interior. Scale bar $=200 \mu \mathrm{m}$.

from notch along cutting margin. Mandible with 5 teeth; $1^{\text {st }}$ may be bi-dentate, $1^{\text {st }}, 2^{\text {nd }}$, and $3^{\text {rd }}$ large, well spaced apart, $4^{\text {th }}$ and $5^{\text {th }}$ small, close together; fine setae along inferior and cutting margins. Maxilla with 10-12 large spines along cutting margin, large spine near inferior angle set in from inferior margin; fine, dense, medium length setae along superior margin, inferior angle and surface below cutting edge. $2^{\text {nd }}$ Maxilla oblong, tapered distally; bi-lobed, secondary lobe smaller, rounder; long fine setae apically and along inferior margin. Palp oblong, rectangular; inferior margin relatively straight, superior margin convex; long fine setae along inferior margin and distally. Cirrus I rami tapered; anterior ramus thicker, about $1 / 3$ longer than posterior; inferior margin setae long, superior margin setae short. Cirrus II rami short, thick; anterior ramus $1 / 3$ to $1 / 4$ longer than posterior; inferior segment margin rounded, protruding, superior straight; inferior margin setae long, superior margin setae medium length. Cirrus III rami similar but longer than CII; anterior ramus about $1 / 4$ longer than posterior; inferior margin of anterior ramus with dense armature. Cirrus IV 


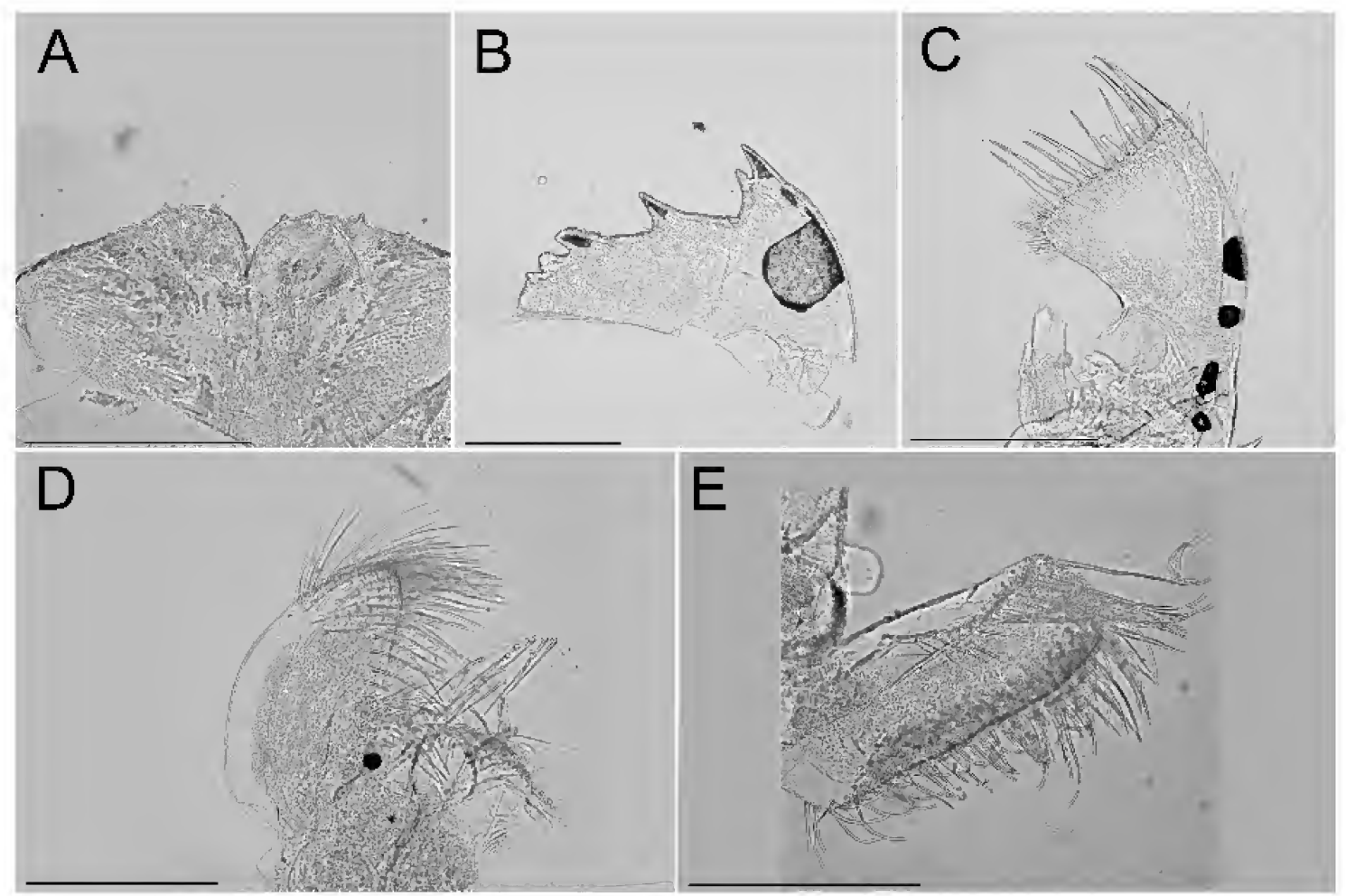

FIGURE 15. Conopea minyrostrum, mouth parts of paratype CASIZ 191924. A labrum; B mandible; C maxilla I; D maxilla II; E mandibular palp. Scale bar $=200 \mu \mathrm{m}$.

rami longer than CI, CII, CIII; inferior margin of both rami covered with long fine setae, superior margins with medium to short length setae at segment nodes; inferior margin of anterior rami segments rounded, protruding, inferior margin of posterior rami slightly convex, both with straight superior margins; inferior margin of anterior ramus with armature, fairly dense, begins on basal segment. Cirrus V rami slightly longer than CIV; inferior margin setae fine, long, dense, superior margin setae medium length, grouped at segment nodes; inferior segment margins slightly convex, superior segment margin fairly straight. Cirrus VI similar to CV; rami slightly longer or same length. Penis long, annulated; very sparsely covered in short fine setae; large spine at base, spine mildly rounded. All cirral setae simple.

TABle 4. Cirral formula for Conopea minyrostrum sp. nov. Segment counts from paratypes CASIZ 187649A and 185865.

$\begin{array}{lllllll}\text { Cirrus } & \text { I } & \text { II } & \text { III } & \text { IV } & \text { V } & \text { VI } \\ \text { Anterior ramus } & 7-9 & 6-9 & \text { Missing } & 16 & 17 & 19-20 \\ \text { Posterior ramus } & 10-12 & 9-12 & \text { Missing } & 17 & 17-19 & 19-20\end{array}$

EтомоLOGY.- A combination of the Latin miny- small and rostrum, in reference to the small rostrum, especially in comparison to the carina.

Distribution. - Known only from the type locality in the Verde Island Passage, Philippines.

SPECIES COMPARISONS. - The three species of Conopea that are most similar externally to C. minyrostrum are C. proripiens, $C$. willhearsti, and C. margaretae. It differs from all three of these species in the presence of a much shorter rostrum. All of the other species have much more 


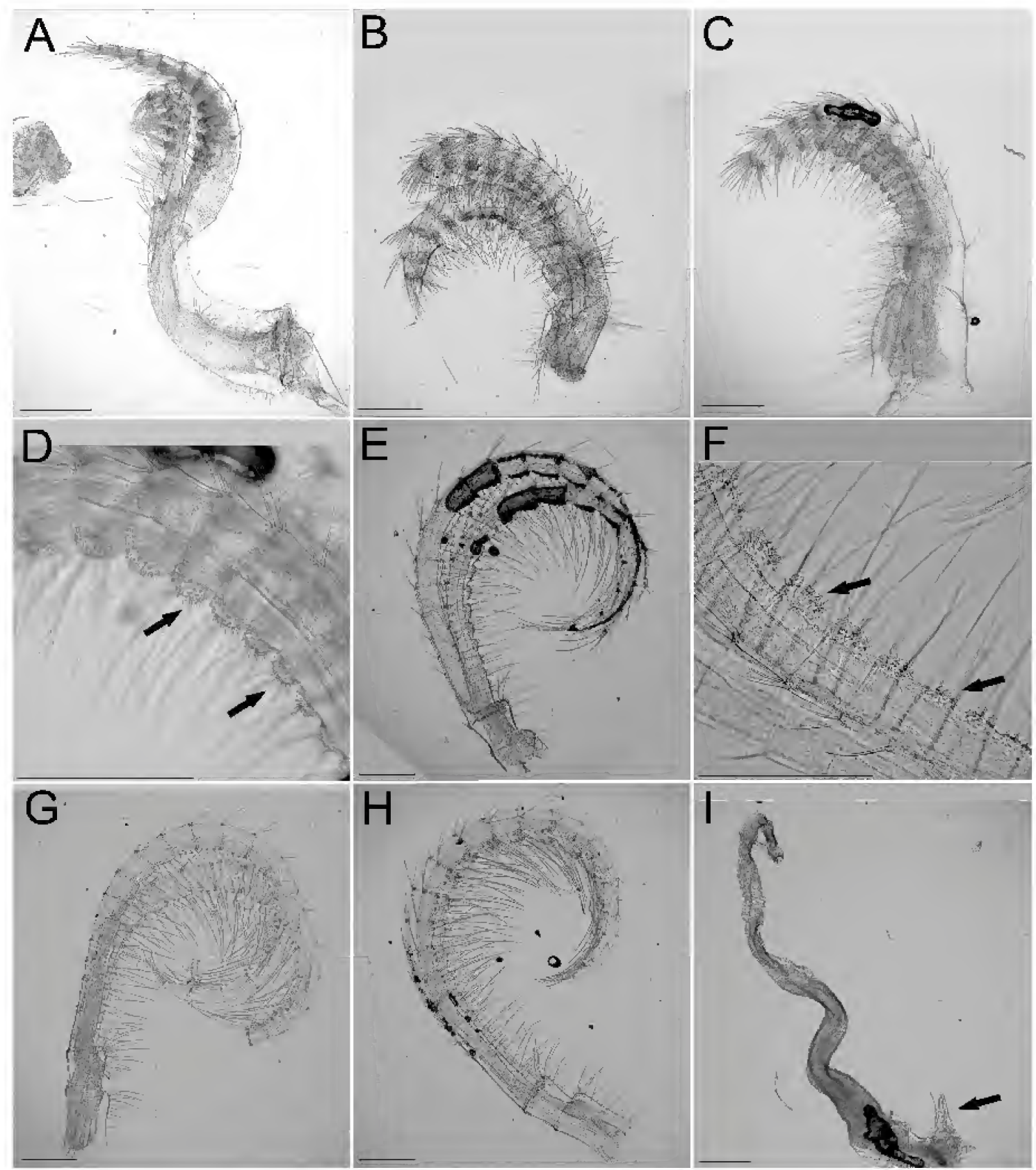

FIGURE 16. Conopea minyrostrum, cirri and penis of paratype, CASIZ 191924. A CI; B CII; C CIII; D CIII spines; E CIV; F CIV spines; G CV; H CVI; I penis. Scale bar $=200 \mu \mathrm{m}$. 
elongated rostra in comparison to their carina lengths.

Conopea basicuneata Van Syoc, Carrison-Stone, Madrona, and Williams, sp. nov. Figures 17-20, Table 5

Material EXAmined.- Holotype: CASIZ 191931, whole specimen in 95\% EtOH. Locality: Philippines, Luzon Island, Batangas Province, Calumpan Peninsula, "Dead Palm" dive site. $13.69569^{\circ}$ N., $120.88472^{\circ}$ E. Attached to Junceella sp. HEP-23. Depth: 29-34 meters. Collector: Robert Van Syoc, 3 May 2011. PARATYPES: CASIZ 187655, 6 whole, 2 dissected specimens in 95\% EtOH. Locality: Philippines, Luzon Island, Batangas Province, Calumpan Peninsula, "Dead Palm" dive site. $13.69569^{\circ} \mathrm{N} ., 120.88472^{\circ} \mathrm{E}$. Attached to Junceella sp. HEP-23. Depth: 29-34 meters. Collector: Robert Van Syoc, 3 May 2011; CASIZ 187654, 4 whole specimens in 95\% EtOH. Locality: Philippines, Luzon Island, Batangas Province, Calumpan Peninsula, "Dead Palm" dive site.

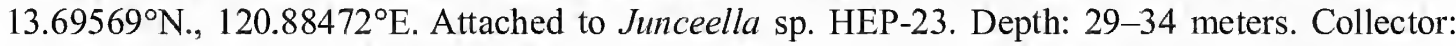
Michelle Weber, 3 May 2011; CASIZ 187719, 3 whole specimens in 95\% EtOH. Locality: Philippines, Batangas Province, Maricaban Island, Devil's Point dive site. $13.65084^{\circ}$ N., $120.84145^{\circ} \mathrm{E}$. Attached to Junceella sp. HEP-41. Collector: Robert Van Syoc, 7 May 2011; CASIZ 187653, 3 whole, 2 dissected specimens in 95\% EtOH. Locality: Philippines, Batangas Province, Maricaban Island, Devil's Point dive site. $13.65092^{\circ} \mathrm{N} ., 120.84137^{\circ} \mathrm{E}$. Attached to Junceella fragilis HEP-77. Depth: 12 meters. Collector: Robert Van Syoc, 17 May 2011; CASIZ 191960, 2 whole specimens in 95\% EtOH. Locality: Philippines, Luzon Island, Batangas Province, Calumpan Peninsula, "Basketball" dive site. $13.68594^{\circ}$ N., $120.89172^{\circ}$ E. HEP-47. Collector: Elliott Jessup, 11 May 2011; CASIZ 179509, 1 whole, 2 dissected specimens in 95\% EtOH, SEM stub with opercular plates, microslide with cirri and mouthparts. Locality: Philippines, Romblon Province, Tablas Island, Biaringan Island, next to Long Beach. $12.62562^{\circ} \mathrm{N} ., 122.16280^{\circ} \mathrm{E}$. Attached to Ellisella sp. Depth: 6 meters. Collector: Robert Van Syoc, 19 Feb 2010; CASIZ 179510, 10 whole, 10 dissected specimens in 95\% EtOH, SEM stub with opercular plates, microslide with cirri and mouthparts. Locality: Philippines, Sibuyan Sea, Romblon Province, Tablas Island, Blue Hole, NE corner of island, outlet tunnel through reef wall. $12.61599^{\circ} \mathrm{N} ., 122.25231^{\circ} \mathrm{E}$. Attached to Dichotella sp. Depth: 12-24 meters. Collector: Robert Van Syoc, 19 Feb 2010; CASIZ 185887, 4 whole, 2 dissected in 95\% EtOH. Locality: Philippines, Luzon Island, Batangas Province, Calumpan Peninsula, "Dead Palm" dive site. $13.69569^{\circ} \mathrm{N} ., 120.88472^{\circ} \mathrm{E}$. Attached to Dichotella gemmacea. HEP-105. Depth: 30 meters Collector: Robert Van Syoc, 23 May 2011; CASIZ 187631, 9 whole, 2 dissected in 95\% EtOH, SEM stub with opercular plates. Locality: Philippines, Luzon Island, Batangas Province, Calumpan Peninsula, "Dead Palm" dive site. $13.69569^{\circ}$ N., $120.88472^{\circ} \mathrm{E}$. Attached to Dichotella gemmacea. HEP-105. Depth: 30 meters Collector: Robert Van Syoc, 23 May 2011; CASIZ 187630, 1 whole, 2 dissected specimens in 95\% EtOH. Locality: Philippines, Luzon Island, Batangas Province, Calumpan Peninsula, "Dead Palm" dive site. $13.69569^{\circ} \mathrm{N} ., 120.88472^{\circ} \mathrm{E}$. Attached to Dichotella gemmacea. HEP-105. Depth: 30 meters Collector: Robert Van Syoc, 23 May 2011; CASIZ 187681, 4 whole, 1 dissected specimens in 95\% EtOH. Locality: Philippines, Batangas Province, Maricaban Island, Aphol's Point dive site. $13.65835^{\circ} \mathrm{N} ., 120.90144^{\circ} \mathrm{E}$. Attached to Junceella fragilis. HEP-33 Collector: Robert Van Syoc, 5 May 2011; CASIZ 185863, 4 whole, 2 dissected specimens in 95\% EtOH, SEM stub with opercular plates. Locality: Philippines, Luzon Island, Batangas Province, Calumpan Peninsula, "Twin Rocks" dive site. $13.68996^{\circ} \mathrm{N}$, $120.88965^{\circ}$ E. Attached to Dichotella sp. HEP-87. Depth: 21 meters. Collector: Robert Van Syoc, 19 May 2011; CASIZ 187651, 2 whole 1 dissected in 95\% EtOH. Locality: Philippines, Batangas Province, Maricaban Island, Devil's Point dive site. $13.65092^{\circ} \mathrm{N} ., 120.84137^{\circ} \mathrm{E}$. Attached to Ellisellidae. HEP-59 Depth: 18 meters. Collector: Robert Van Syoc, 13 May 2011;CASIZ 187682, 8 whole, 2 dissected in 95\% EtOH. Locality: Philippines, Batangas Province, Maricaban Island, 
Aphol's Point dive site. $13.65835^{\circ}$ N., $120.90144^{\circ} \mathrm{E}$. Attached to Junceella fragilis. HEP-33 Collector: Robert Van Syoc, 5 May 2011; CASIZ 179528, 4 dissected specimens in 95\% EtOH, SEM stub with opercular plates. Locality: Philippines: Sibuyan Sea, Romblon Province, Cobrador Island, Arequita. $12.62563^{\circ} \mathrm{N}$., $122.16274^{\circ} \mathrm{E}$. Attached to Ellisella sp. Depth: 23 meters. Collector: Gary Williams, 20 Feb 2010; CASIZ 106069, 1 dissected specimen in 95\% EtOH, microslide with cirri and mouthparts. Locality: Philippines, Mindoro, Medio Island, NW Passage of Puerta Galera. Attached to Ellisella sp. Depth: 6-20 meters. Collector: Gary Williams, 28 Feb 1995.

Diagnosis. - Shell wall and basis forming distinct wedge shape in side view; rostrum and basis elongated along host axis, carina not elongated along host axis, carina and carino-latera nearly vertical in aspect; latera sloping at an increasing angle toward rostral margin; summits or radii even, not disparietal; basis wedge-shaped in side view, widest at carinal margin, tapering evenly to rostral end where rostrum comes into contact with host axis.

DESCRIPTION.- Shell wall conical except for greatly elongated rostrum; parietes, except for rostrum, with reddish brown and white longitudinal stripes interrupted by white horizontal lines; radii with dark red horizontal lines, summits even; rostrum white, some with very faint red and white stripes nearest latera, elongated to a width about the same as or greater than all other wall plates combined; basis white, elongated along host axis, not raised or raised only very slightly above the axis at extreme rostral end, tapering upward gradually to carina basal margin, then sloping steeply down to host axis again, together with shell wall shape forming a wedge shaped shell. Basis and parietes lacking longitudinal tubes. Scutum height slightly greater than width; strong articular ridge more than $1 / 2$ length tergal margin; basal margin curved, slope toward tergal margin steeper in larger specimens, milder in smaller specimens; adductor muscle pit shallow; depressor muscle pit shallow to moderately deep; apex acute, growth ridges visible apex interior; tergal and occludent margins fairly straight; interior surface textured near apex and articular ridge. Tergum width slightly greater than height; apex beaked unless eroded; carinal and basal margins slightly convex, scutal margin fairly straight; spur short, wider in older specimens, narrower in younger specimen; basiscutal angle very shallow; broad and shallow spur furrow, 6-10 depressor muscle crests, faint to high ridges; articular furrow wide; articular ridge prominent; interior surface pebbled. Labrum with 2-4 teeth either side of notch; notch triangular; cutting margin with short fine setae. Mandible with 5-6 teeth; $2^{\text {nd }}$ and/or $3^{\text {rd }}$ tooth may be bi-dentate; $1^{\text {st }}$ and $2^{\text {nd }}$ teeth furthest apart, $2^{\text {nd }}$ and $3^{\text {rd }}$ slightly closer, $3^{\text {rd }}, 4^{\text {th }}$, and $5^{\text {th }}$ very close together; $4^{\text {th }}, 5^{\text {th }}$, and occasional $6^{\text {th }}$ teeth small; fine dense setae along superior, inferior, and just below cutting margins. Maxilla cutting edge notch may or may not be present, located two large spines in from superior angle; 9-13 large spines along cutting margin; medium length fine setae along superior and inferior margins as well as below and along cutting margin. $2^{\text {nd }}$ Maxilla small, elongate or egg shaped, bi-lobed; apex, infe-

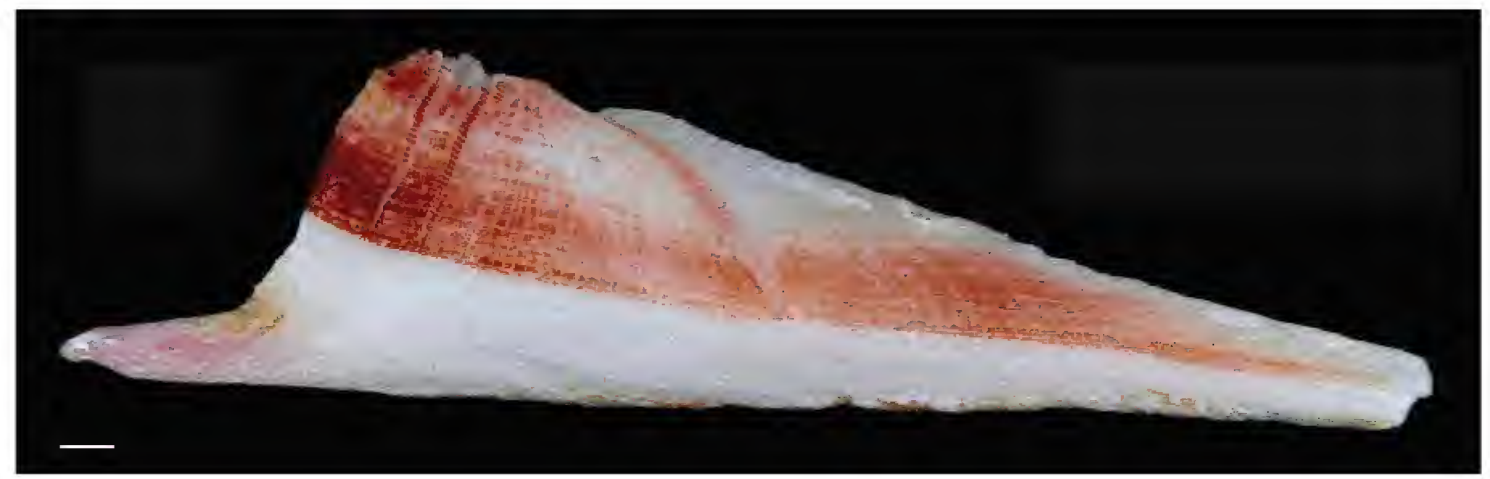

FIGURE 17. Conopea basicuneata, whole shell of paratype, CASIZ 187631B. Scale bar $=200 \mathrm{~mm}$. 

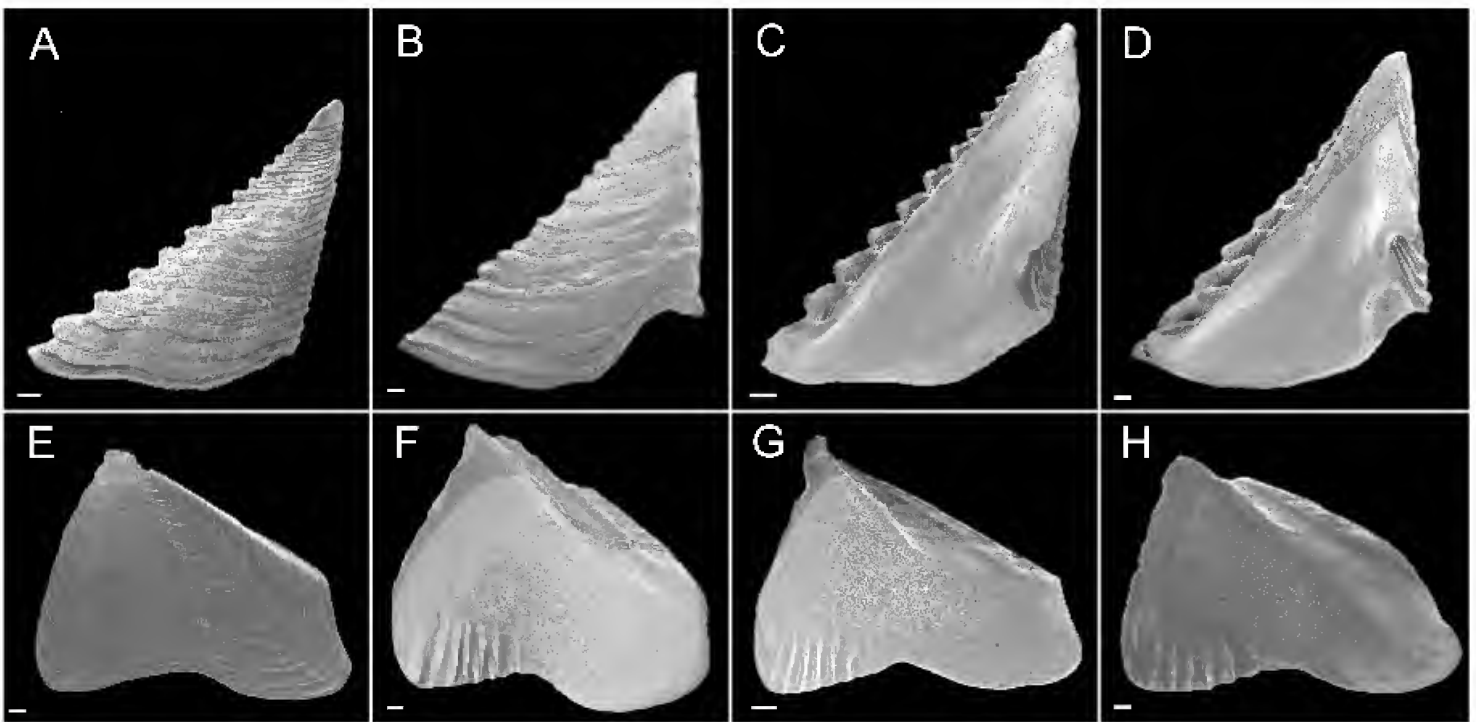

FIGURE 18. Conopea basicuneata, opercular plates of paratypes showing some variation in tergal spur and scutum lateral depressor muscle pit. A scutum exterior (CASIZ 179510); B scutum exterior (CASIZ 187630); C scutum interior (CASIZ 179510); D scutum interior (CASIZ 187630); E tergum exterior(CASIZ 187652); F tergum interior (CASIZ 187630); G tergum interior (CASIZ 179510); H tergum interior (CASIZ 187652). Scale bar $=200 \mu \mathrm{m}$.

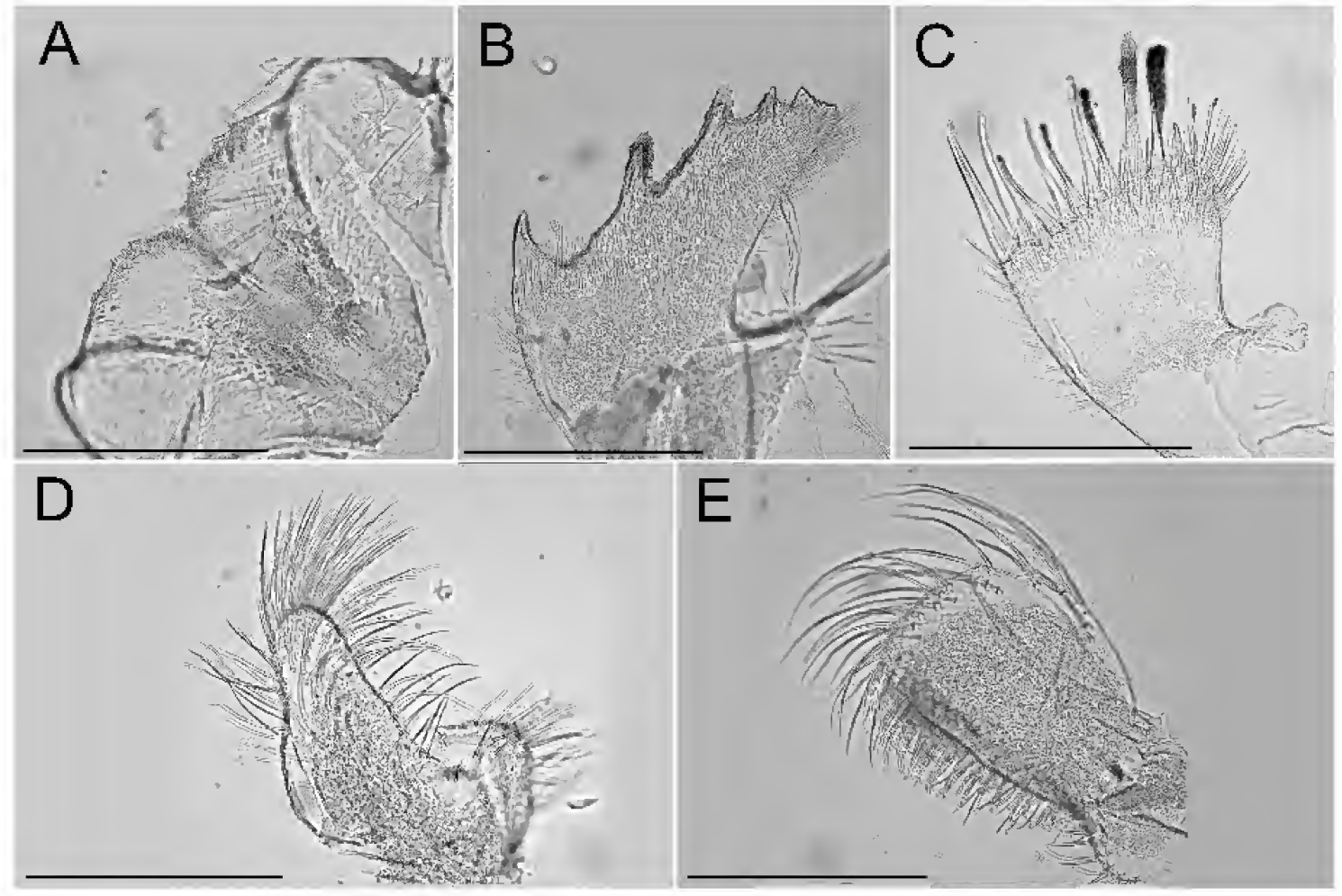

FIGURE 19 (above). Conopea basicuneata, mouth parts of paratype, CASIZ 179510. A labrum; B mandible; C maxilla I; D maxilla II; E mandibular palp. Scale bar $=200 \mu \mathrm{m}$.

FIGURE 20 (right). Conopea basicuneata, cirri and penis of paratype, CASIZ 179510. A CI; B CII; C CIII; D CIII spines; E CIV; F CIV spines; G CV; H CVI; I penis. Scale bar $=200 \mu \mathrm{m}$. 


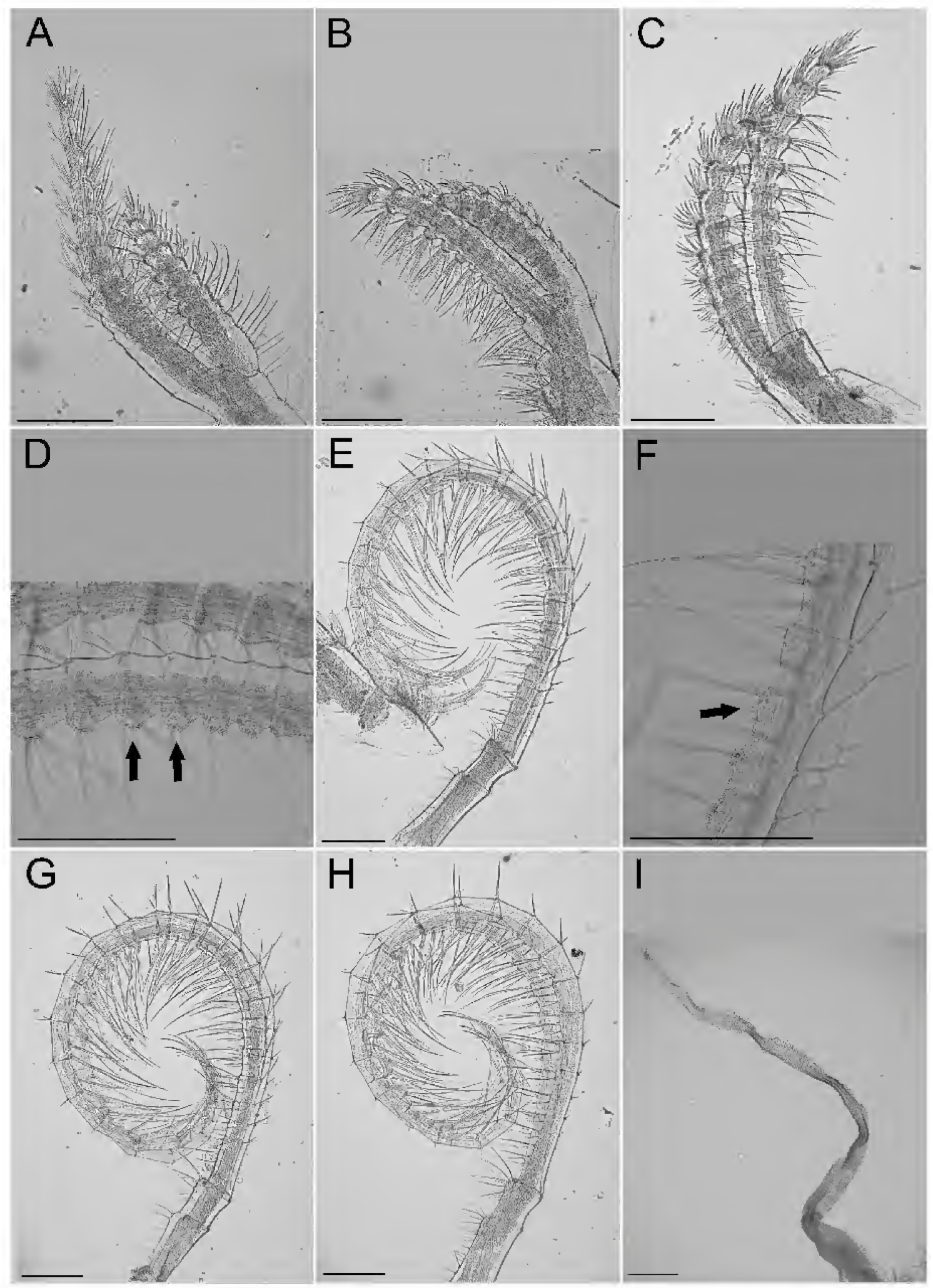


rior, and superior margin surfaces with long fine setae; apex rounded; base may be bulbous. Palp squat, rectangular with rounded corners; superior margin mildly convex; long sparse setae along superior margin, denser setae distally, medium length dense setae along inferior margin. Cirrus I anterior ramus $1 / 3$ to $1 / 2$ longer than posterior ramus, both rami tapered, anterior more so, both rami covered in long, dense, simple, setae, segmentation distinct. Cirrus II anterior ramus $1 / 4$ to $1 / 3$ longer than posterior ramus, inferior segment margins bulbous, superior segment margins smoother, setae simple, dense, inferior setae longer, superior setae shorter. Cirrus III anterior ramus $1 / 3$ to $1 / 4$ longer than posterior ramus; inferior segment margins bulbous, superior segment margins smoother; armature present along inferior margin of anterior ramus; setae simple, dense, shorter along superior margin, longer along inferior margin. Cirrus IV rami slightly unequal in length, tapered; armature present along inferior margin of anterior ramus, less dense than CIII armature; segmentation not as distinct as CI, CII, and CIII; setae simple, long along inferior margin, short and less dense along superior margin. Cirrus V rami similar in length, slightly longer than CIV, setae simple, long along inferior margin, short and less dense along superior margin. Cirrus VI similar to CV. Penis long, very fine short sparse setae, spine at base. All cirral setae simple.

TABLE 5. Cirral formula for Conopea basicuneata sp. nov. Segment counts from paratypes CASIZ 187652 and 106069.

$\begin{array}{lllllll}\text { Cirrus } & \text { I } & \text { II } & \text { III } & \text { IV } & \text { V } & \text { VI } \\ \text { Anterior ramus } & 7-9 & 5-8 & 7-9 & 14-17 & 19 & 16-20 \\ \text { Posterior ramus } & 13-16 & 9-10 & 9-13 & 15-16 & 21 & 18-24\end{array}$

ЕтомоцоGY.- Uniquely, this species has a wedge-shaped basis. From the Greek, basis and the Latin cuneatus, wedge-shaped.

Distribution.- Known from reef areas around Romblon Island and the Verde Island Passage, Philippines.

SPECIES COMPARISONS.- The carina and rostrum morphology of $C$. basicuneata is similar to C. acuta, $C$. investita, and C. mjobergi. All of these have elongated rostra with nearly vertical carinas. However, none has a similarly low wedge-shaped basis. Instead, they all possess a cup-shaped basis. The basis of $C$. mjobergi is somewhat extended under the rostrum, but in a very limited fashion that cannot compare with the more pronounced elongation of the basis in $C$. basicuneata. The basis of $C$. exothobasis is also wedge-shaped, but it has less depth underneath the rostrum, where it becomes almost flat and is almost level with the host axis. The basis of $C$. basicuneata tapers gradually and completely from a high wedge at the carinal end to a tapering point at the rostral end. The basis of $C$. exothobasis also extends far beyond the carinal margin, about the same distance as the width of the shell wall excluding the rostrum.

\section{Conopea exothobasis Van Syoc, Carrison-Stone, Madrona, and Williams, sp. nov.} Figures 21-24, Table 6

Material eXAmined.- Holotype: CASIZ 191927, dissected, wall plates, basis, and prosoma in 95\% EtOH, opercular plates on SEM stub, cirri and mouthparts on microslide. Locality: Philippines, Luzon, Batangas Province, Calumpan Peninsula, "Dead Palm" dive site. $13.69569^{\circ}$ N., 120.88472 ${ }^{\circ}$ E. HEP-23. Attached to Ellisella sp. Depth: 30 meters. Collector: R. Van Syoc, 3 May 2011. Paratype: CASIZ 187770, 1 specimen, dissected, in 95\% EtOH. Locality: Philippines, Luzon, Batangas Province, Calumpan Peninsula, "Dead Palm" dive site. $13.69569^{\circ} \mathrm{N}$., 120.88472 ${ }^{\circ}$ E. HEP-23. Attached to Ellisella sp. Depth: 30 meters. Collector: R. Van Syoc, 3 May 2011. 


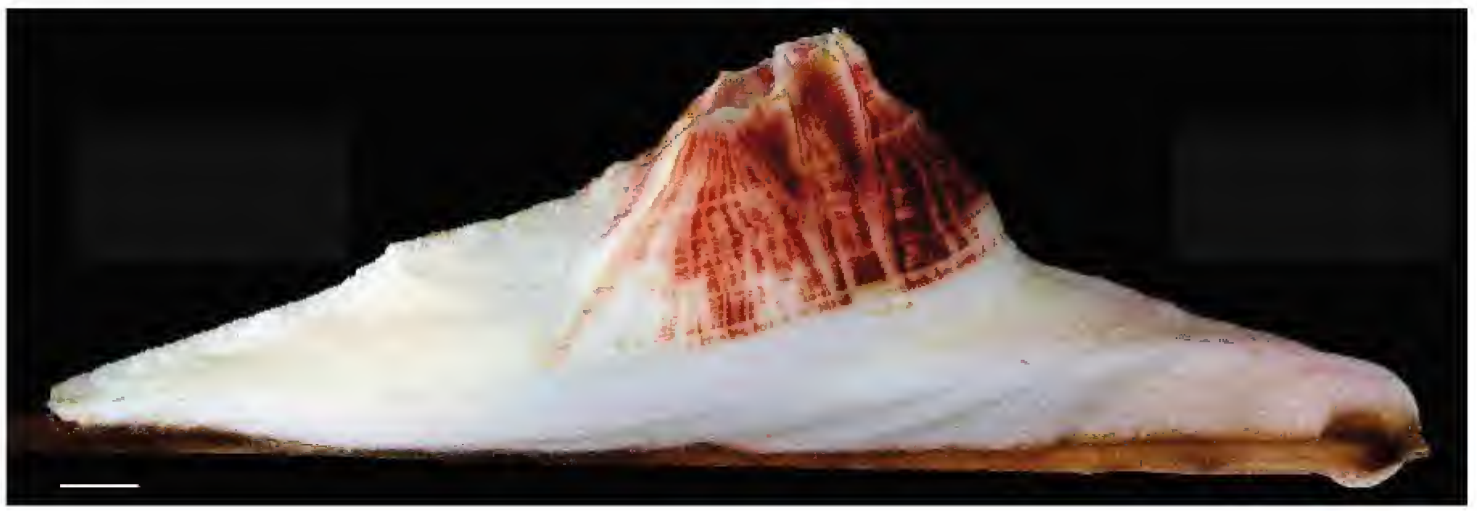

FIGURE 21. Conopea exothobasis, whole shell of paratype, CASIZ 187770 . Scale bar $=200 \mathrm{~mm}$.

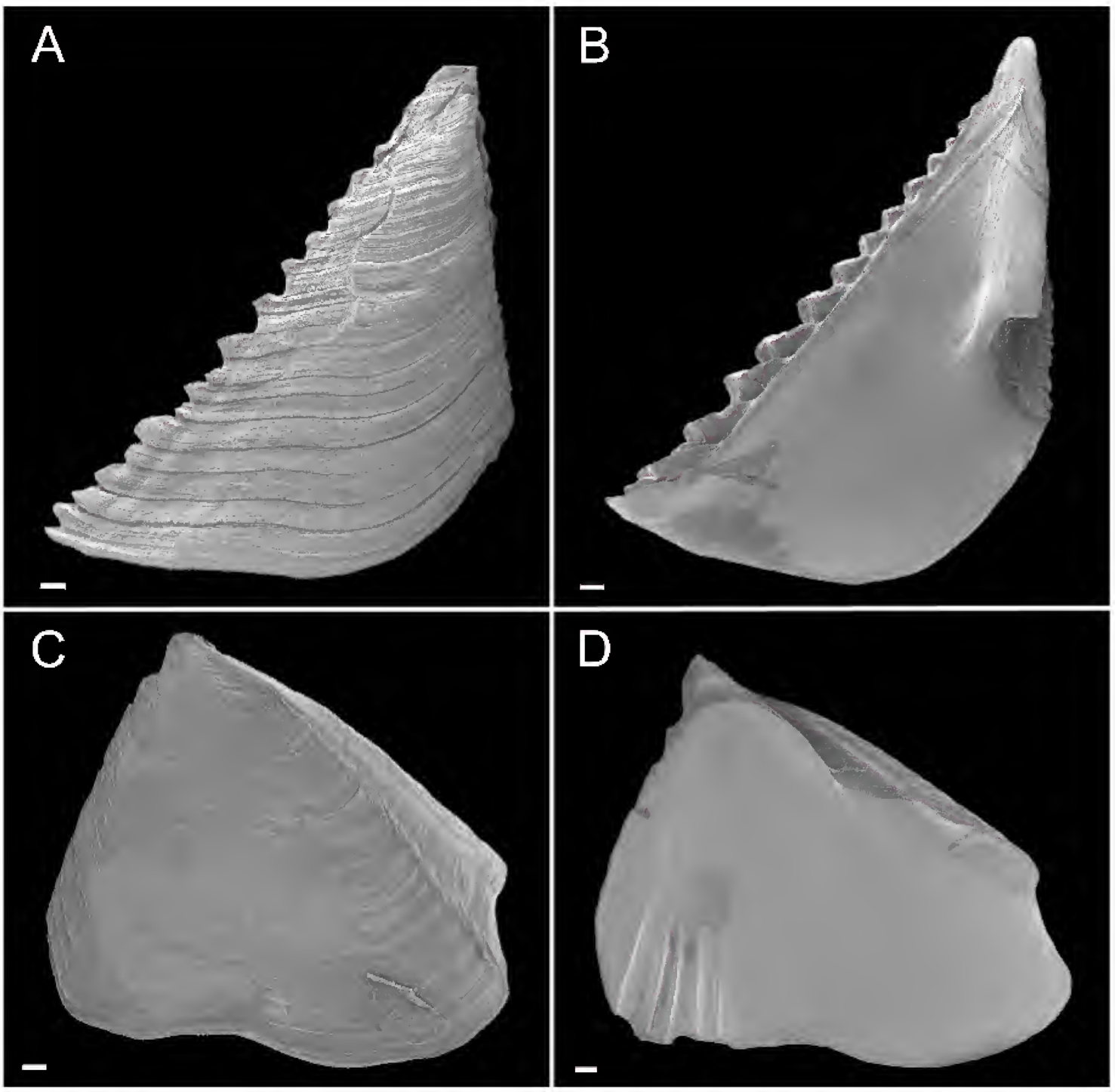

Figure 22. Conopea exothobasis, opercular plates of holotype, CASIZ 191927. A scutum exterior; B scutum interior; C tergum exterior; D tergum interior. Scale bar $=200 \mu \mathrm{m}$. 


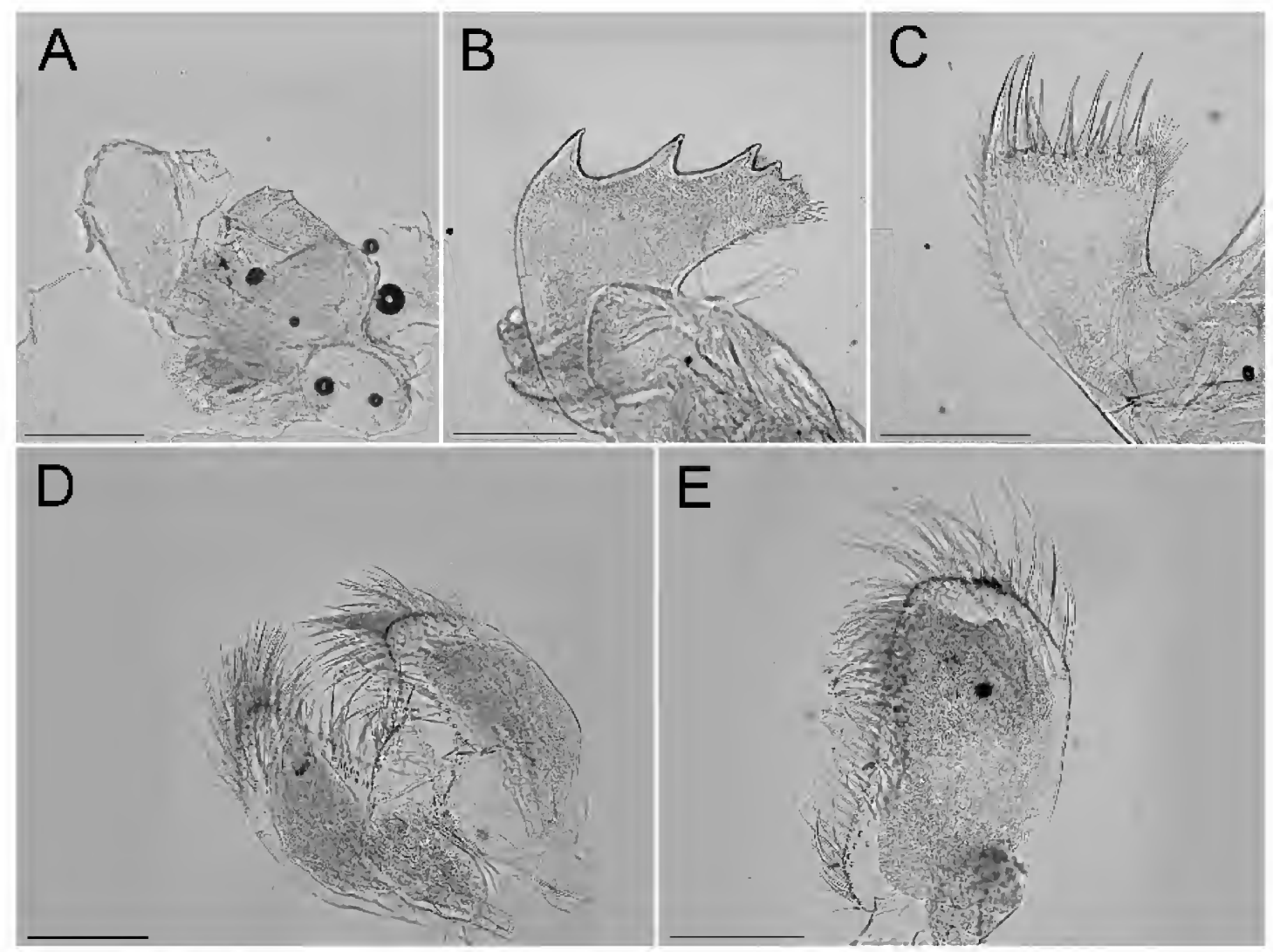

FIGURE 23. Conopea exothobasis, mouth parts of paratype CASIZ 187770. A labrum; B mandible; C maxilla I; D maxilla II; E mandibular palp. Scale bar $=200 \mu \mathrm{m}$.

Diagnosis. - Shell wall elongated on rostral end only, entire shell wall at angle to host axis, tipping from the carina down toward the rostrum at about a $20-30^{\circ}$ angle; basis white, extending along host axis far beyond basal margin of carina, length of basis along host axis beyond carinal margin about same as width of shell wall excluding the rostrum, basis deepest (highest) at the carina basal margin, tapering to a tip at the far end of the carina end, but tapering down to, or below, the host axis at the latera-rostral suture; carina not sloping down to host axis, dark red vertical stripes with some white horizontal stripes; rostrum white with faint red vertical and horizontal stripes over most of external surface, sloping gradually from summit to basal margin, nearly level with host axis at basal margin for nearly entire width of margin, not just at tip.

DESCRIPTION.- Shell wall plates forming conical shape with exception of rostrum which is greatly elongated along the host axis, summits even and sloping from carina down to rostrum; all wall plates, except rostrum, with dark red and white longitudinal stripes interrupted by horizontal white lines; radii red, broad with even summits; rostrum white or with very pale red and white longitudinal stripes interrupted by horizontal white lines, longer than width of all other plates combined, entire length of basal margin in contact or nearly in contact with host axis; basis white, not raised above host axis under rostrum, sloping upward from rostral margin to carina margin, then sloping back down at tip beyond carinal margin, extending along host axis beyond carinal margin by nearly same distance as width of shell wall excluding the rostrum. Basis with tubes, secondarily filled. Parietes solid. Scutum base convex, rises steeply towards articular furrow; articular furrow about $1 / 3$ total height; articular ridge about $1 / 2$ total height; occludent and tergal margins fairly 


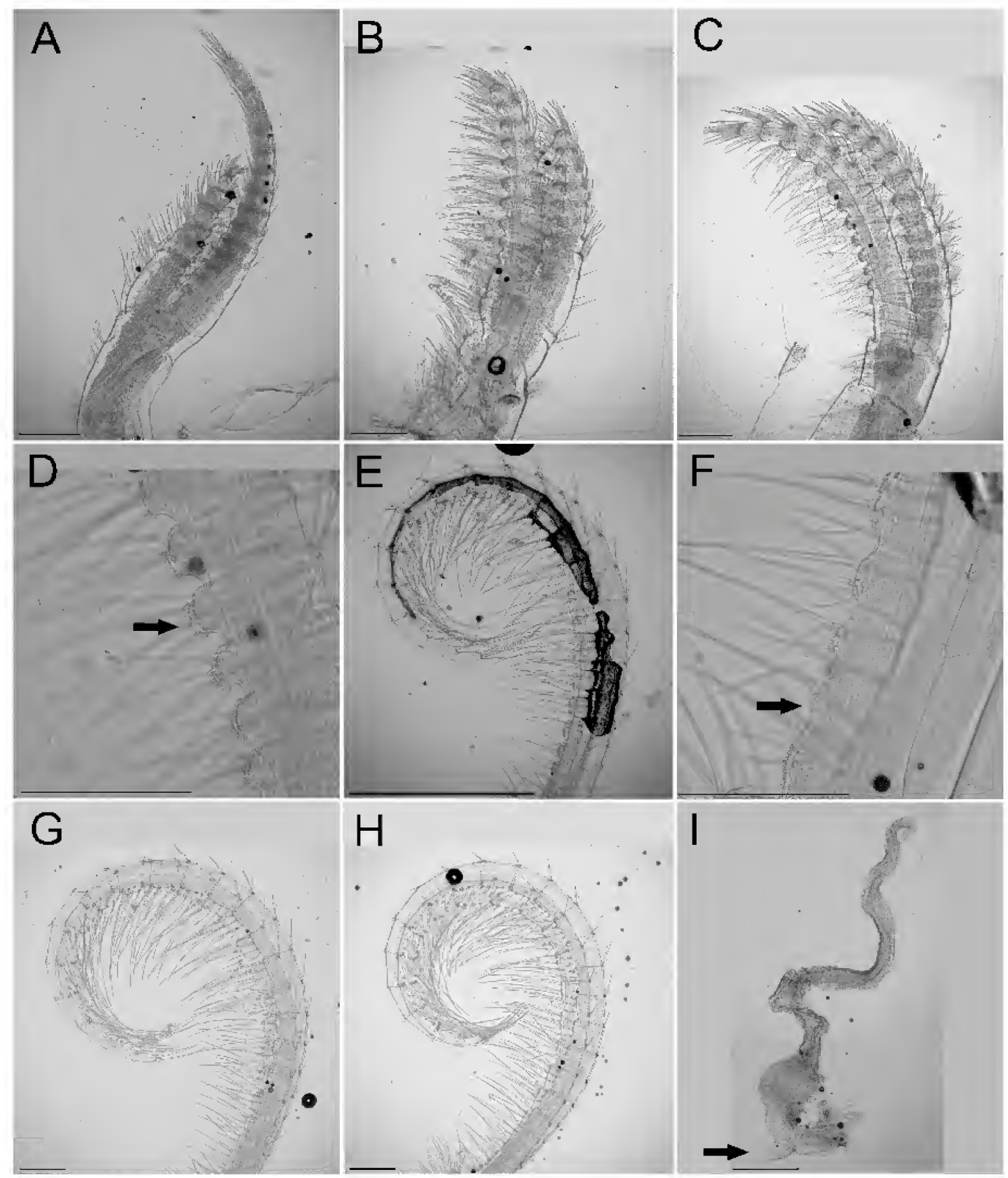

FIGURE 24. Conopea exothobasis, cirri and penis of paratype, CASIZ 187770. A CI; B CII; C CIII; D CIII spines; E CIV; F CIV spines; G CV; H CVI; I penis. Scale bar $=200 \mu \mathrm{m}$.

straight; apex acute; depressor muscle pit shallow, difficult to distinguish; adductor muscle pit present, shallow. Tergum spur wide, short; depressor crests present, ridged; articular ridge convex, about $1 / 4$ length of scutal margin; basi-scutal angle wide, shallow; basal, carinal and scutal margins slightly convex; spur furrow wide, shallow. Labrum with 2 teeth either side of notch. Mandible with 5 teeth; $1^{\text {st }}, 2^{\text {nd }}$, and $3^{\text {rd }}$ teeth largest, well spaced apart, $4^{\text {th }}$ and $5^{\text {th }}$ small, close together; dense, 
fine, short setae along inferior, superior, and cutting margins. Maxilla with 10-11 large spines along cutting margin, last spine set in from inferior angle; fine, short, dense setae along superior, inferior, and cutting margins. $2^{\text {nd }}$ Maxilla oblong; apex covered in dense, long, fine setae. Palp oblong, blunt apex; fine dense setae along inferior margin; long setae apically and along part of superior margin. Cirrus I anterior ramus $1 / 2$ to $1 / 3$ longer than posterior ramus; rami covered in dense, medium length setae; rami thick, tapered; segmentation distinct. Cirrus II anterior ramus $1 / 4$ longer than posterior ramus; rami thick; segmentation distinct, inferior margins bulbous; setae dense, inferior setae long, superior setae medium length. Cirrus III similar to CII, longer; anterior ramus with inferior margin armature, spines dense. Cirrus IV anterior ramus with dense armature along inferior margin; rami tapered, longer, segment margins smoother than $\mathrm{CI}, \mathrm{CII}$, and CIII; inferior margin setae dense, long, superior margin setae only at segment junctions, medium length. Cirrus V rami similar in length; inferior margin setae dense, long, superior margin setae only at segment junctions, medium length. Cirrus VI similar to CV. Penis long; large spine at base; covered in sparse, fine, short setae. All cirral setae simple.

TABLE 6. Cirral formula for Conopea exothobasis sp. nov. Segment counts from holotype, CASIZ 191927.

$\begin{array}{lllllll}\text { Cirrus } & \text { I } & \text { II } & \text { III } & \text { IV V V V } & \text { VI } & \\ \text { Anterior ramus } & 6-8 & 7-10 & 11-13 & 12-\text { Missing } & \text { 19-Missing } & 17-21 \\ \text { Posterior ramus } & 13-15 & 11-12 & 8-13 & \text { 13-Missing } & \text { 21-Missing } & 23-22\end{array}$

EтомоLOGY.- From the Greek exotho- to protrude, and basis, for the basis protruding far beyond the carina along the host axis.

Distribution.- Known only from the type locality in the Verde Island Passage, Philippines.

SPECIES COMParisons. - Conopea exothobasis is most similar to C. basicuneata, they both have a non-elongated carina, with a greatly elongated rostrum. However the basis of $C$. exothobasis does not taper evenly as it does in $C$. basicuneata. The basis of $C$. exothobasis beneath the rostrum is nearly flat, not tapered. The other gorgonian-inhabiting western Pacific species of Conopea with elongated rostra with nearly vertical carinas, C. acuta, C. investita, and C. mjobergi, all possess a cup-shaped basis, not the greatly elongated and protruding, tapered basis of C. exothobasis.

\section{Key to the western Pacific octocoral symbiont species of Conopea}

The following key includes only those taxa with type localities in the west Pacific Ocean. Type localities and host taxa from the original descriptions are noted following species level taxa.

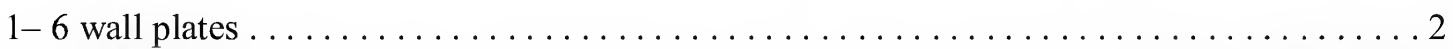

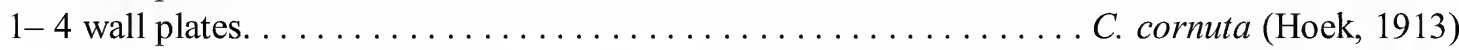

(Indonesia, Ceram Sea, $1^{\circ} 42.5^{\prime} \mathrm{S}, 130^{\circ} 47.5^{\prime} \mathrm{E}$; type host "brown stem, which, perhaps is that of a species of Gorgonia")

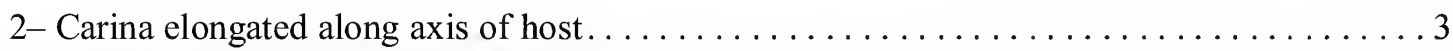

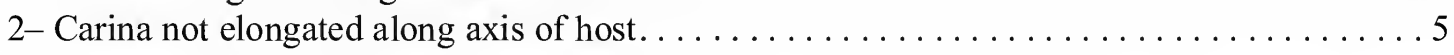

$3-$ Rostrum greatly elongated along axis of host $\ldots \ldots \ldots \ldots \ldots \ldots \ldots \ldots \ldots$

3 - Rostrum not greatly elongated along axis of host, carina longer than rostrum. . . . . . . . .

C. minyrostrum Van Syoc, Carrison-Stone, Madrona, and Williams sp. nov.

(Philippines, Verde Island Passage; type host Viminella sp.)

4 - Basis, carina and rostrum greatly elongated, more than 4 times height of shell . . . . . . . 
C. margaretae Van Syoc, Carrison-Stone, Madrona, and Williams sp. nov. (Philippines, Verde Island Passage; type host Viminella sp.)

4 - Basis, carina and rostrum less elongated, less than 3 times height of shell

(Indonesia, Sulawesi, Banda Sea; type host "Scirpearella gracilis" = Viminella gracilis)

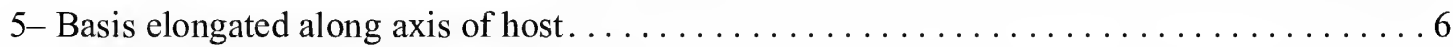

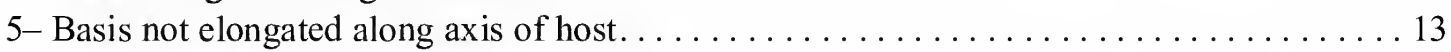

6 - Basis not flat, margins of basis clearly raised above axis of host . . . . . . . . . . . 7

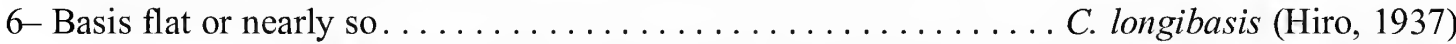

(Palau, Koror Island, Iwayama Bay; type host "Melitodes (?)" = Melithaea sp.)

7- Paries tightly fused, not disarticulating in 5-6\% sodium hypochlorite (bleach) . . . . . . 8

7- Paries not tightly fused, disarticulating in 5-6\% sodium hypochlorite (bleach) . . . . . 18

8 - Basis not extended far beyond basal margins of carina or rostrum . . . . . . . . . . 9

8- Basis extended out beyond basal margin of carina, length of basis along host axis beyond carinal margin about same as width of shell wall excluding the rostrum . .

........... C. exothobasis Van Syoc, Carrison-Stone, Madrona, and Williams sp. nov. (Philippines, Verde Island Passage; type host Viminella sp. or Ellisella sp.)

9- Basis greater depth at one end than the other end $\ldots \ldots \ldots \ldots \ldots \ldots \ldots \ldots \ldots \ldots \ldots \ldots \ldots \ldots \ldots$

9- Basis about same depth along entire length. . . . . . . . . . . . . . . . . . .

C. willhearsti Van Syoc, Carrison-Stone, Madrona, and Williams sp. nov. (Philippines, Verde Island Passage; type host Acabaria sp. or Mopsella sp. or Melithaea sp.)

$10-$ Basis greater depth below carina than below rostrum $\ldots \ldots \ldots \ldots \ldots \ldots \ldots \ldots \ldots$

$10-$ Basis greater depth below rostrum than below carina . . . . . . . . . . . . . . . .

C. sabangensis Van Syoc, Carrison-Stone, Madrona, and Williams sp. nov.

(Philippines, Verde Island Passage, Sabang; type host Acabaria sp.)

11- Rostrum greatly elongated, width about the same as or greater than all other wall plates combined......... C. basicuneata Van Syoc, Carrison-Stone, Madrona, and Williams sp. nov.

(Philippines, Romblon Island and Verde Island Passage; type host Junceella sp. or Ctenocella sp. or Dichotella sp.)

11 - Rostrum not greatly elongated, basis deeply cupped beneath carina $\ldots \ldots \ldots \ldots \ldots 12$

12- Carina white or light pink ................. acuta (Nilsson-Cantell, 1921) (Japan, Goto-Inseln; type host "Acanthogorgie"= Acanthogorgia)

12- Carina dark violet. ....................... mjobergi (Broch, 1916) (Australia, Western Australia, Cape Jaubert; type host Echinogorgia)

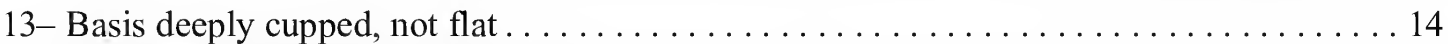

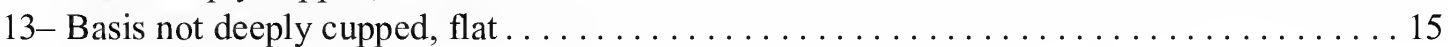

14- Paries faintly light blue in color, exterior surface smooth, ungrooved .......... C. scandens (Pilsbry, 1916) (Japan, Honshu, off Ose-Zaki; type host unknown)

14 Paries white or yellowish in color, exterior surface grooved longitudinally . . . . . . . . . C. canaliculatus Ren and Liu, 1978 (China, South China Sea; type host "gorgonians") 
15- Upper margins of carina and latera without teeth or projections $\ldots \ldots \ldots \ldots \ldots \ldots$

15- Upper margin of carina and latera with tooth-like projections . . . . C. dentifer (Broch, 1922)

(Japan, East China Sea; type hosts Isiidae and "Muricaeidae"= Plexauridae)

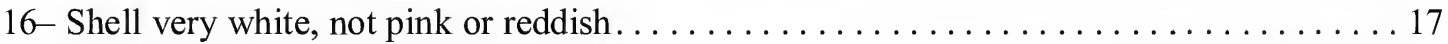

16- Shell pink to deep red in color . .................... fragilis (Broch, 1931)

( Indonesia, Amboina Bay; type host "gorgonian")

17- Basis with radiating grooves aligned with wall plate sutures,external surface of wall plates rough, wall plates and basis thin and easily disarticulated ....... C. pygmaea (Broch, 1931)

(Indonesia, east of Pulau-Kai-besar, $5^{\circ} 43^{\prime}$ S., $132^{\circ} 55^{\prime} \mathrm{E}$; host "slender Gorgonian")

17- Basis without radiating grooves aligned with wall plate sutures, basis external surface of wall plates smooth . ............................ squamosa Rosell, 1991

(Philippines, South China Sea, Mindoro Strait; type host "white gorgonian")

18- Basis firmly attached to host axis, growing around the axis to form a groove or furrow at the

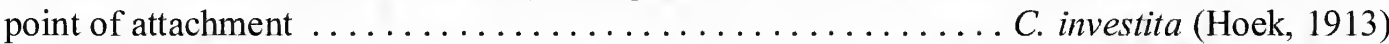

(Indonesia, Flores Sea, $8^{\circ} 30^{\prime} \mathrm{S}, 119^{\circ} 7.5^{\prime} \mathrm{E}$; type host Acanthogorgia truncata)

18- Basis not attached to host axis, or attached only at center of basis, proteinaceous material of

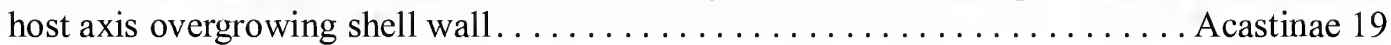

\section{Subfamily Acastinae Kolbasov, 1993}

\section{Genus Acasta Leach, 1817}

Acasta vipensis Van Syoc, Carrison-Stone, Madrona, and Williams, sp. nov. (B)

Figures 25-28, Table 7

Material eXamined.- Holotype: CASIZ 191930, 1 whole specimen attached to host. Locality: Philippines, Luzon Island, Batangas Province, Calumpan Peninsula Maricaban Strait, "Murals" dive site. $13.69936^{\circ}$ N., $120.88250^{\circ} \mathrm{E}$. HEP-25. Attached to Menella sp. Collector: Michelle Weber, 3 May 2011. PARATYPES: CASIZ 187687, 3 whole 1 dissected specimens, in 95\% EtOH. Locality: Philippines, Luzon Island, Batangas Province, Calumpan Peninsula Maricaban Strait, "Murals" dive site. $13.69936^{\circ}$ N., $120.88250^{\circ} \mathrm{E}$. HEP-25. Attached to Menella sp. Collector: Michelle Weber, 3 May 2011; CASIZ 187686, 11 whole, 2 dissected specimens, in 95\% EtOH, SEM stub of opercular plates, microslide of cirri and mouthparts. Locality: Philippines, Luzon Island, Batangas Province, Calumpan Peninsula Maricaban Strait, "Murals" dive site. $13.69902^{\circ}$ N., $120.88270^{\circ}$ E. HEP-30. Attached to Menella sp. Collector: Dito dela Rosa, 3 May 2011; CASIZ 187706, 5 whole, 2 dissected specimens in 95\% EtOH. Locality: Philippines, Luzon Island, Batangas Province, Calumpan Peninsula Maricaban Strait, "Basketball" dive site. $13.68594^{\circ}$ N., $120.89172^{\circ}$ E. HEP-47. Collector: Elliott Jessup, 11 May 2011; CASIZ 185883, 4 dissected specimens in $95 \% \mathrm{EtOH}$, SEM stub of opercular plates, microslide of cirri and mouthparts. Locality: Philippines, Luzon Island, Batangas Province, Calumpan Peninsula Maricaban Strait, "Murals" dive site. $13.69936^{\circ}$ N., $120.88250^{\circ} \mathrm{E}$. HEP-25. Attached to Menella sp. Collector: Michelle Weber, 3 May 2011; CASIZ 187717, 12 whole, 3 dissected specimens in 95\% EtOH. Locality: Philippines, Luzon Island, Batangas Province, Balayan Bay, "Ligpo" dive site. $13.81964^{\circ} \mathrm{N} ., 120.90078^{\circ} \mathrm{E}$. HEP-18 Attached to Menella sp. Collector: Robert Van Syoc, 2 May 2011; CASIZ 187767, 1 whole, 3 dissected specimens in 95\% EtOH. Locality: Locality: Philippines, Luzon Island, Batangas Province, Calumpan Peninsula Maricaban Strait, "Murals" dive site. $13.69936^{\circ} \mathrm{N}$., $120.88250^{\circ} \mathrm{E}$. HEP-25. Attached to Menella sp. Collector: Robert Van Syoc, 3 May 
2011; CASIZ 187667, 3 whole, 1 dissected specimens in 95\% EtOH. Locality: Philippines, Batangas Province, Maricaban Island, Devil's Point dive site. $13.65092^{\circ}$ N., $120.84137^{\circ}$ E. Depth: 37 meters. HEP-59. Attached to Menella sp. Collector: Robert Van Syoc, 13 May 2011; CASIZ 187764, 1 dissected specimen in 95\% EtOH. Locality: Philippines, Luzon Island, Batangas Province, Balayan Bay, Ligpo Island, north of "Ligpo" dive site. 13.82231 ${ }^{\circ} \mathrm{N}$., $120.90106^{\circ} \mathrm{E}$. HEP19. Collector: Robert Van Syoc, 2 May 2011; CASIZ 185885, 3 dissected specimens in 95\% EtOH. Locality: Philippines, Batangas Province, Maricaban Strait, "Murals" dive site. $13.69936^{\circ}$ N., $120.88250^{\circ}$ E. Attached to Menella sp. HEP-25. Collector: Michelle Weber, 3 May 2011; CASIZ 185886, 4 dissected specimens in 95\% EtOH, microslide of cirri and mouthparts, SEM stub of opercular plates. Locality: Philippines, Batangas Province, Maricaban Strait, "Murals" dive site. $13.69936^{\circ} \mathrm{N}, 120.88250^{\circ} \mathrm{E}$. Attached to Menella sp. HEP-25. Collector: Robert Van Syoc, 3 May 2011.

Diagnosis. - Conical shell wall, not elongated along host axis, not only covered by the coenenchyme tissues containing the gorgonian polyps, but entirely embedded in the proteinaceous axis of the gorgonian, forming a gall around the shell wall such that only the opercular opening is not encased by extensions of the proteinaceous axis material; basis nearly flat with radial grooves aligning with plate sutures; summit of plates uneven, summit sloping from high end at top of carina down to low end at top of rostrum; radii disparietal and wide; parietes covered in short calcareous spines.

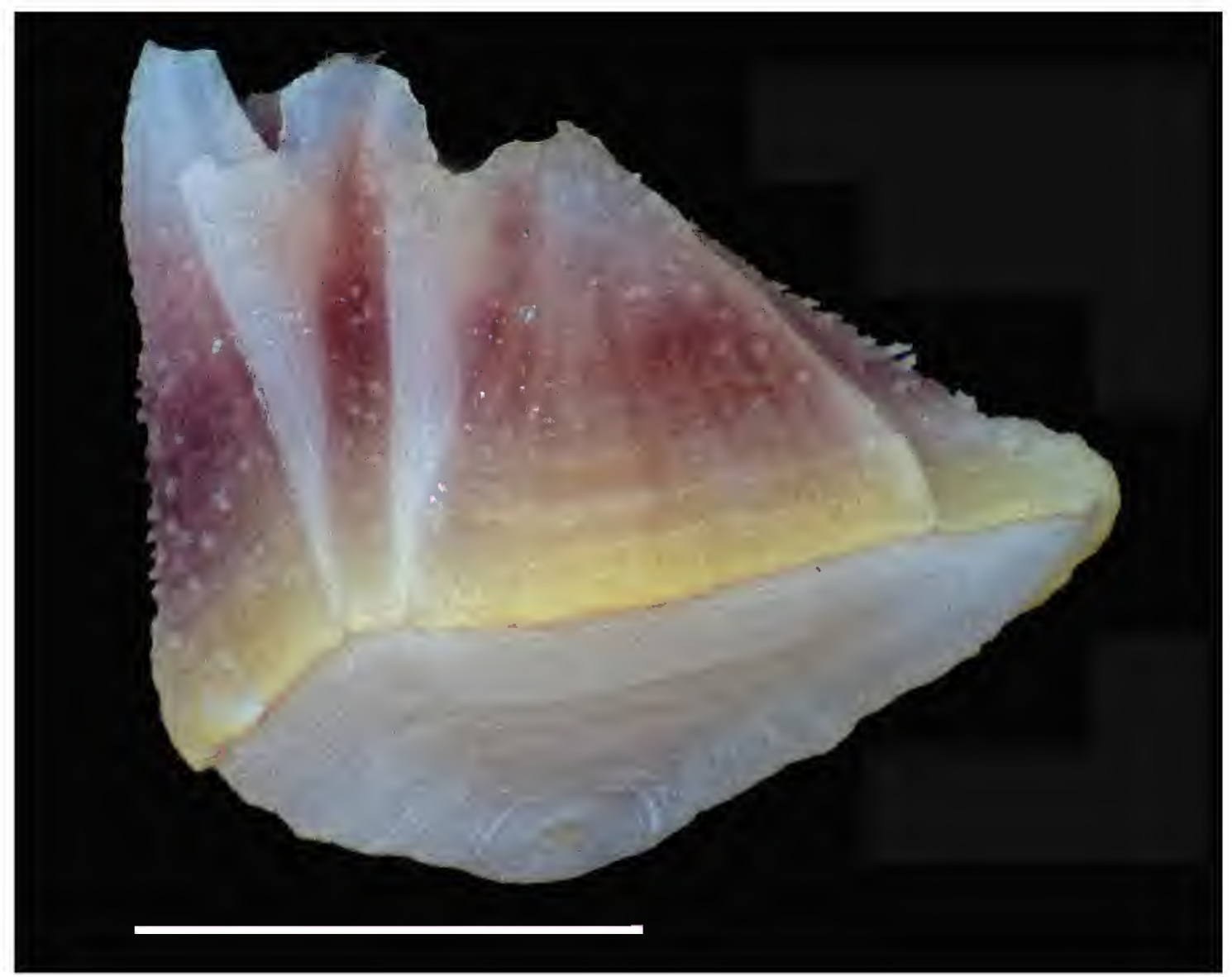

FIGURE 25. Acasta vipensis, whole shell of paratype, CASIZ 185883. Scale bar $=200 \mathrm{~mm}$. 

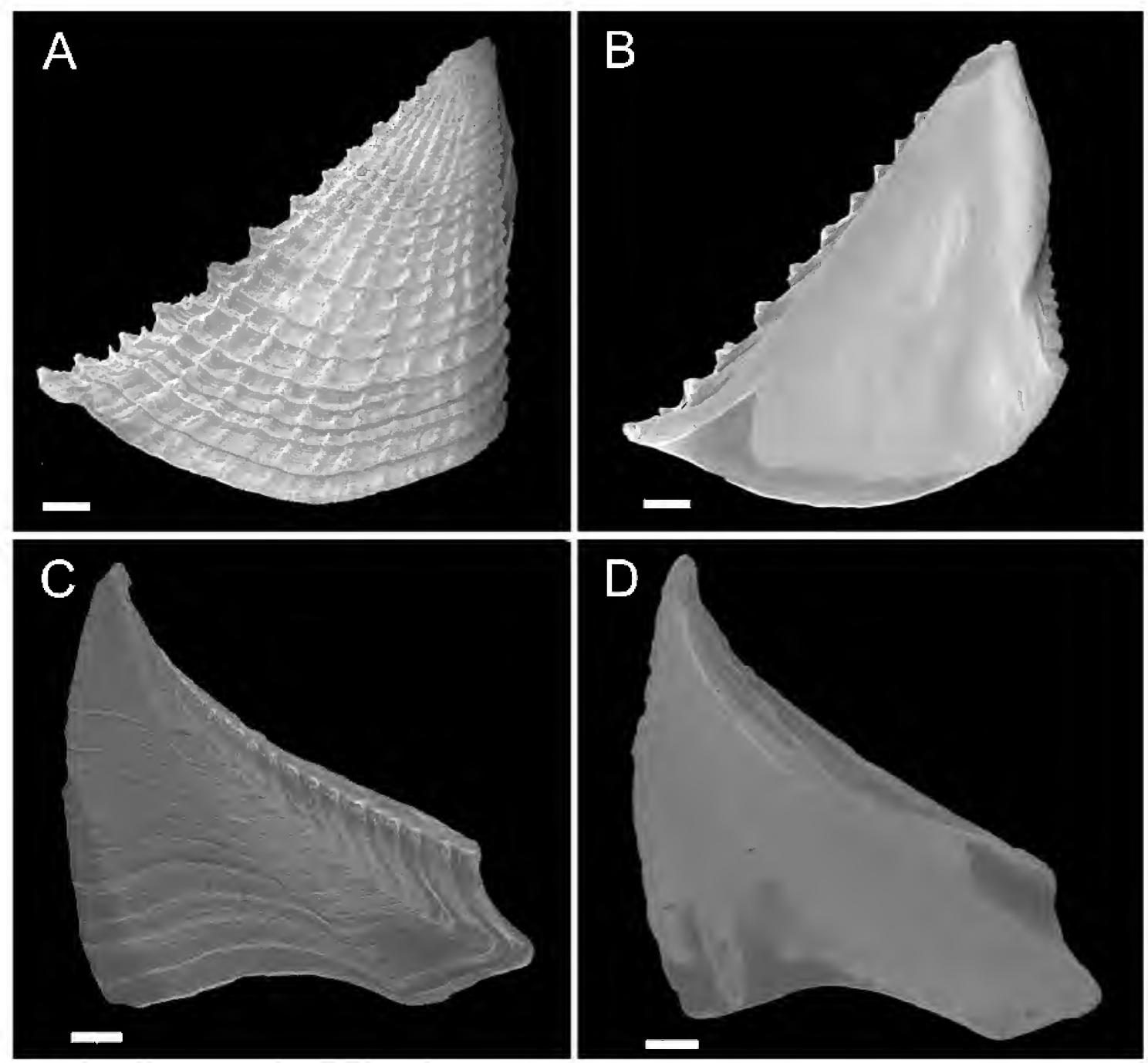

FIGURE 26. Acasta vipensis, opercular plates of paratype, CASIZ 185883. A scutum exterior; B scutum interior; C tergum exterior; D tergum interior. Scale bar $=200 \mu \mathrm{m}$.

DESCRIPTION.- Shell conical with short calcareous spines protruding from parietes, radii broad and disparietal, orifice with jagged summits, orifice sloping from carina to rostrum. Carina highest wall plate, carino-latera next highest, then latera, with rostrum about one half height of carina. Basis flat, oval, with shallow grooves aligned with the six wall plate sutures. Scutum exterior with latticed appearance due to longitudinal ridges crossing growth ridges; apex acute; adductor and depressor muscle pits shallow to not visible; articular ridge convex, approximately $1 / 2$ length of scutum; basal margin broadly convex, tergal and occludent margins fairly straight; interior smooth. Tergum with short truncated spur, rounded point on basal margin of spur near articular margin; apex mildly beaked; depressor crests very faint or not present; scutal margin concave; carinal margin convex; interior smooth; articular ridge mild, concave; basicutal angle moderate to shallow, wide. Labrum with deep narrow notch, $2-4$ teeth either side of notch. Mandible with 5 teeth, $1^{\text {st }}$ and $2^{\text {nd }}$ slightly farther apart than $2^{\text {nd }}$ and $3^{\text {rd }} ; 2^{\text {nd }}$ and $3^{\text {rd }}$ teeth may be bifurcated; $4^{\text {th }}$ and $5^{\text {th }}$ teeth clumped together near inferior angle; inferior and superior margins with long fine setae, shorter setae along cutting edge. Maxilla cutting edge with 8-9 large spines; last large spine may or may 


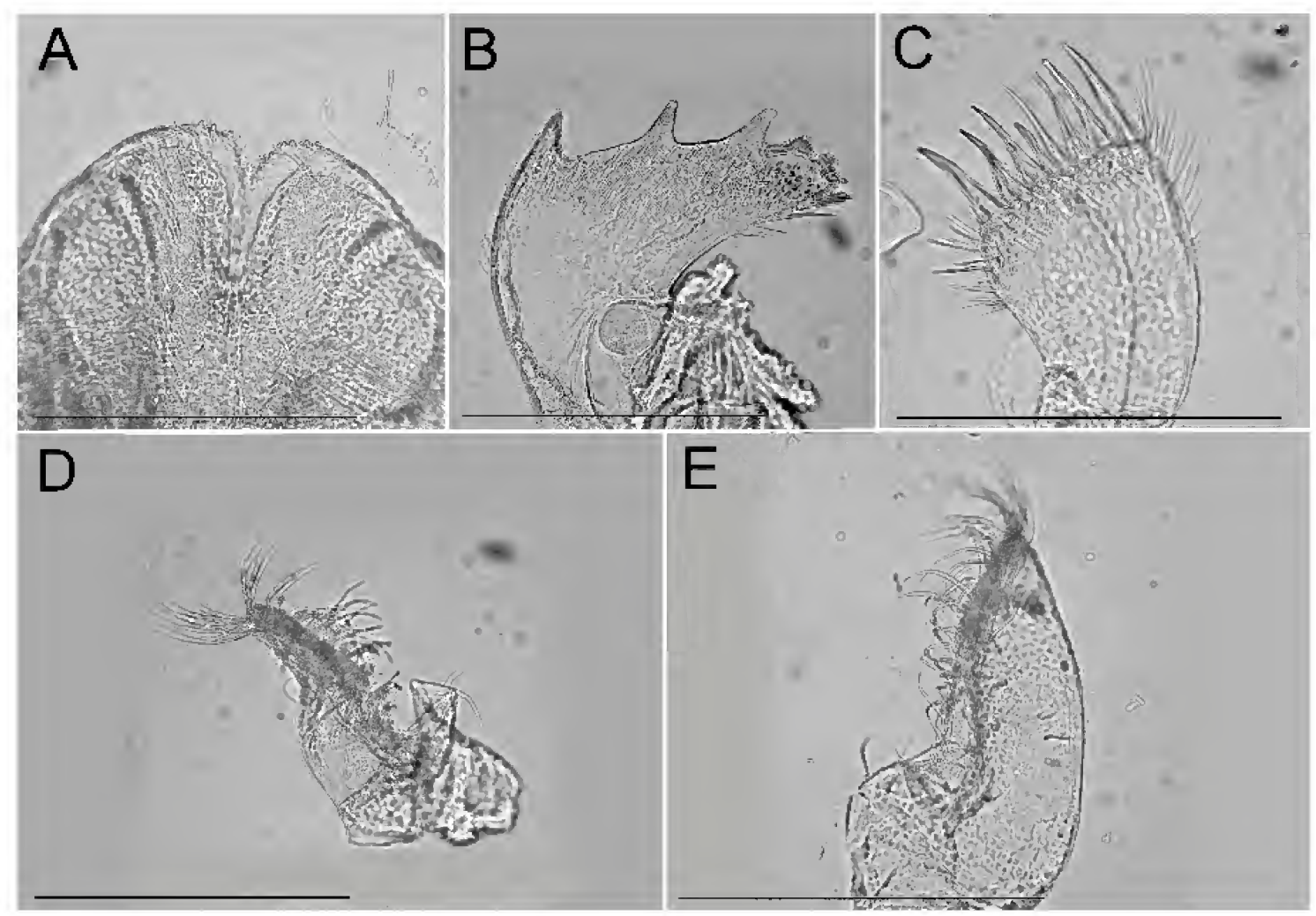

FIGURE 27. Acasta vipensis, mouth parts of paratypes. A labrum (CASIZ 185885) B mandible (CASIZ 185886) C maxilla I (CASIZ 185886) D maxilla II (CASIZ 185886) E mandibular palp (CASIZ 185886). Scale bar $=200 \mu \mathrm{m}$.

not be set in from inferior angle; inferior, superior, and cutting edges with long fine setae. $2^{\text {nd }}$ Maxilla small, elongate; bi-lobed; apical setae long. Palp oblong, tapered; superior edge convex, occasionally angled; long setae on superior margin and distally. Cirrus I anterior ramus long, tapered, at least twice as long as posterior ramus; posterior ramus short thick; rami with long fine setae; rami curved in opposite directions, inferior margins facing. Cirrus II anterior ramus about $1 / 3$ longer than posterior ramus; rami thick; long fine setae. Cirrus III anterior and posterior rami thick; anterior ramus 1-2 segments longer than posterior; long fine setae; anterior rami with inferior margin armature, spines grouped near upper segment margin. Cirrus IV rami long, tapered distally, similar length; inferior setae long, less dense than CI, II, III; superior setae short and sparse; anterior rami with small spines on inferior margin of each segment. Cirrus V similar to CVI; no armature; inferior setae long, superior setae short and sparse; rami close to equal in length. Cirrus VI similar to $\mathrm{CV}$; inferior setae long, superior setae short and sparse; rami close to equal in length. Penis long; sparsely covered with short fine setae, difficult to tell if basal spine is present. All cirral setae simple.

TABLE 7. Cirral formula for Acasta vipensis sp. nov. Segment counts from paratypes, CASIZ 185885 and $185883 \mathrm{~A}$.

$\begin{array}{lllllll}\text { Cirrus } & \text { I } & \text { II } & \text { III } & \text { IV } & \text { V } & \text { VI } \\ \text { Anterior ramus } & 5-6 & 7-8 & 9-12 & 16 & 24-26 & 25-26 \\ \text { Posterior ramus } & 12-13 & 10-12 & 12-13 & 20 & 24-26 & 25-26\end{array}$




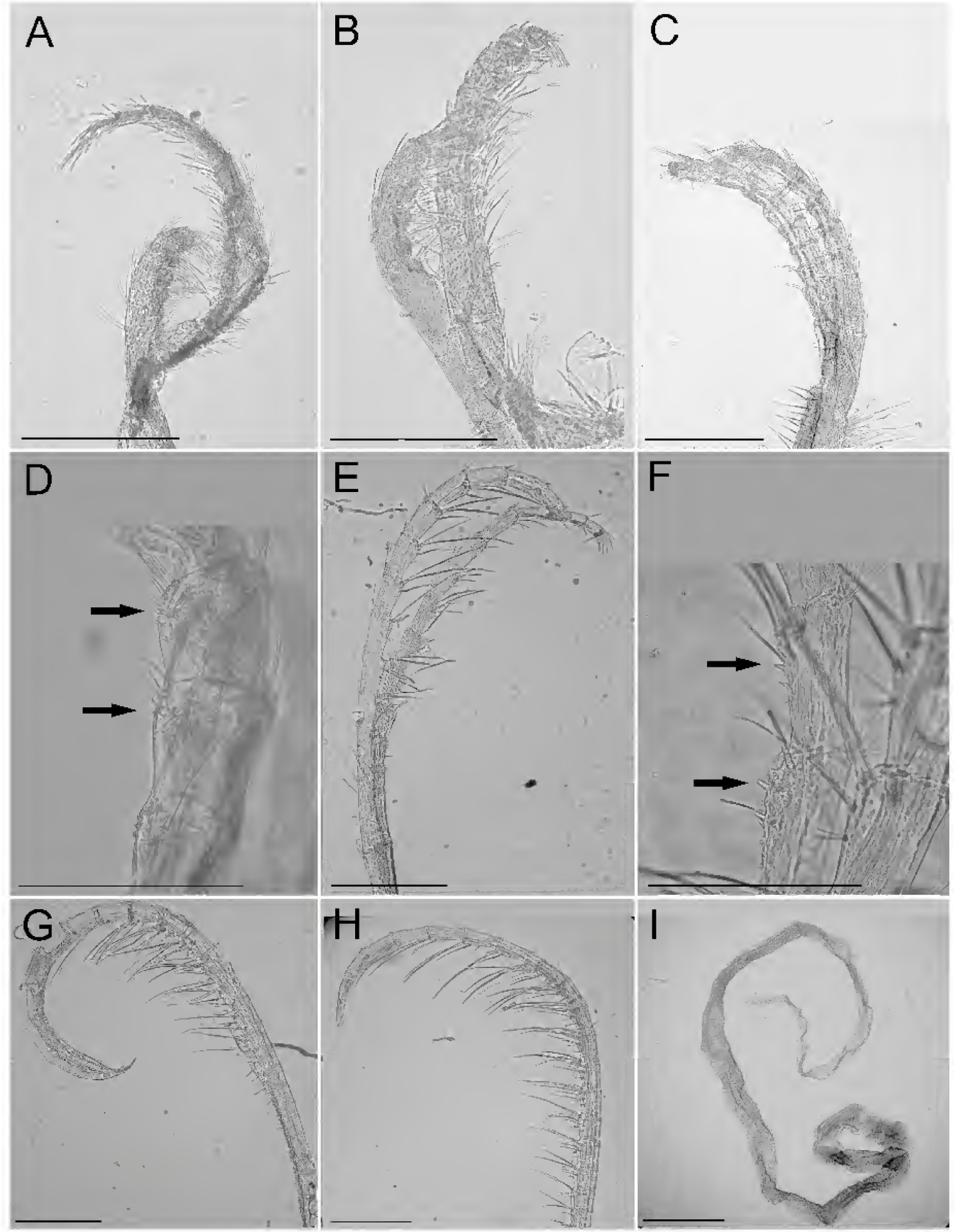

FIGURE 28. A casta vipensis, cirri and penis of paratypes. A CI (CASIZ 185883); B CII (CASIZ 185883); C CIII (CASIZ 185883); D CIII spines (CASIZ 185883); E CIV (CASIZ 185886); F CIV spines (CASIZ 185886); G CV (CASIZ 185886) H CVI (CASIZ 185886); I penis(CASIZ 185883). Scale bar $=200 \mu \mathrm{m}, 100 \mu \mathrm{m}$ D and F. 
EтомоLogY.- Named for the type locality, the Verde Island Passage (VIP) and the Latin -ensis, belonging to or from, literally Acasta from VIP (Verde Island Passage).

Distribution. - Known only from the type locality in the Verde Island Passage, Philippines.

SPECIES COMPARISONS.-Acasta hirsuta Broch, 1916, A. purpurata Darwin, 1854, A. gregaria Utinomi, 1959, Euacasta microforamina Rosell, 1970, and Archiacasta spinitergum Broch, 1931 are Acastinae species known from the western Pacific which have been recorded living on gorgonian hosts and are similar to A. vipensis morphologically with a flat basis with shallow grooves aligned with plate sutures. The plates also have small, short spines, similar to those of A. vipensis. However, A. purpurata and Euacasta microforamina have fenestra, small openings at the basal end of wall plate sutures, which are lacking in the other species.

The scutum of $A$. vipensis has a more rounded basi-tergal angle than $A$. hirsuta and it lacks an adductor muscle pit which is quite obvious, though shallow, in $A$. hirsuta. The latticed external surface of the scutum of $A$. vipensis is also much more pronounced than the less obvious longitudinal ribs in $A$. hirsuta. The scutum exterior of $A$. gregaria has growth ridges with fluted margins, rather than the latticed appearance. In addition, the tergal spur of $A$. vipensis is longer and slightly narrower (less than half the width of the basal margin) than that of A. hirsuta, A. gregaria, and Archiacasta spinitergum (about half the width of the basal margin).

Both $A$. hirsuta and A. vipensis have small spines or "teeth" on the three basal segments of cirrus IV, these are absent in Archiacasta spinitergum, however the spines in A. hirsuta are arranged in a more or less linear fashion, horizonally across the segments, whereas those in A. vipensis are less organized and spread down most of the face of the segments. Euacasta microforamina has much larger spines. Spines are lacking in Archiacasta spinitergum. Utinomi (1959) did not have a body in the type material of $A$. gregaria, so he could not determine the details of the cirral morphology.

Darwin (1854) listed the host of A. purpurata as the gorgonian genus Isis, in the family Isididae. Rosell noted the host taxon of Euacasta microforamina as a "plexaurid gorgonian". Broch (1916) identified the host of $A$. hirsuta as Euplexaura, a plexaurid genus. He noted the host of Archiacasta spinitergum only as a gorgonian (Broch 1931). Acasta vipensis has only been found on hosts in the genus Menella, in the family Plexauridae.

\section{MOLECULAR RESULTS}

The phylogenetic tree resulting from the $\mathrm{COl}$ sequence data for 84 barnacle individuals had seven clades representing new species (Fig. 29). Although we intended the CO1 sequence to simply serve as an independent line of evidence to the morphological data for the new species, we found that the host families map onto the tree covering sets of 1,2 and 4 species clades of barnacles sequenced for this study. Two of the new species from the Philippines, $C$. sabangensis sp. nov. and $C$. willhearsti sp. nov. are found living with gorgonians in the family Melithaeidae. Four species, $C$. exothobasis sp. nov., C. basicuneata sp. nov., C. margaretae sp. nov., and C. minyrostrum sp. nov., live only on gorgonians in the family Ellisellidae. Acasta vipensis sp. nov. inhabits gorgonians in the genus Menella (Plexauridae). The tree shows these data in an obvious graphical fashion.

\section{DISCUSSION}

Clearly, there is host specificity at the family level for the barnacle species described in our study. However, species-level host specificity of gorgonian-inhabiting barnacles is not resolved. Carrison-Stone et al. (2013) have presented data that indicates species-level host specificity for Conopea calceola (Ellis, 1758) from Portugal (in Eunicella verrucosa, Gorgoniidae) and Conopea 


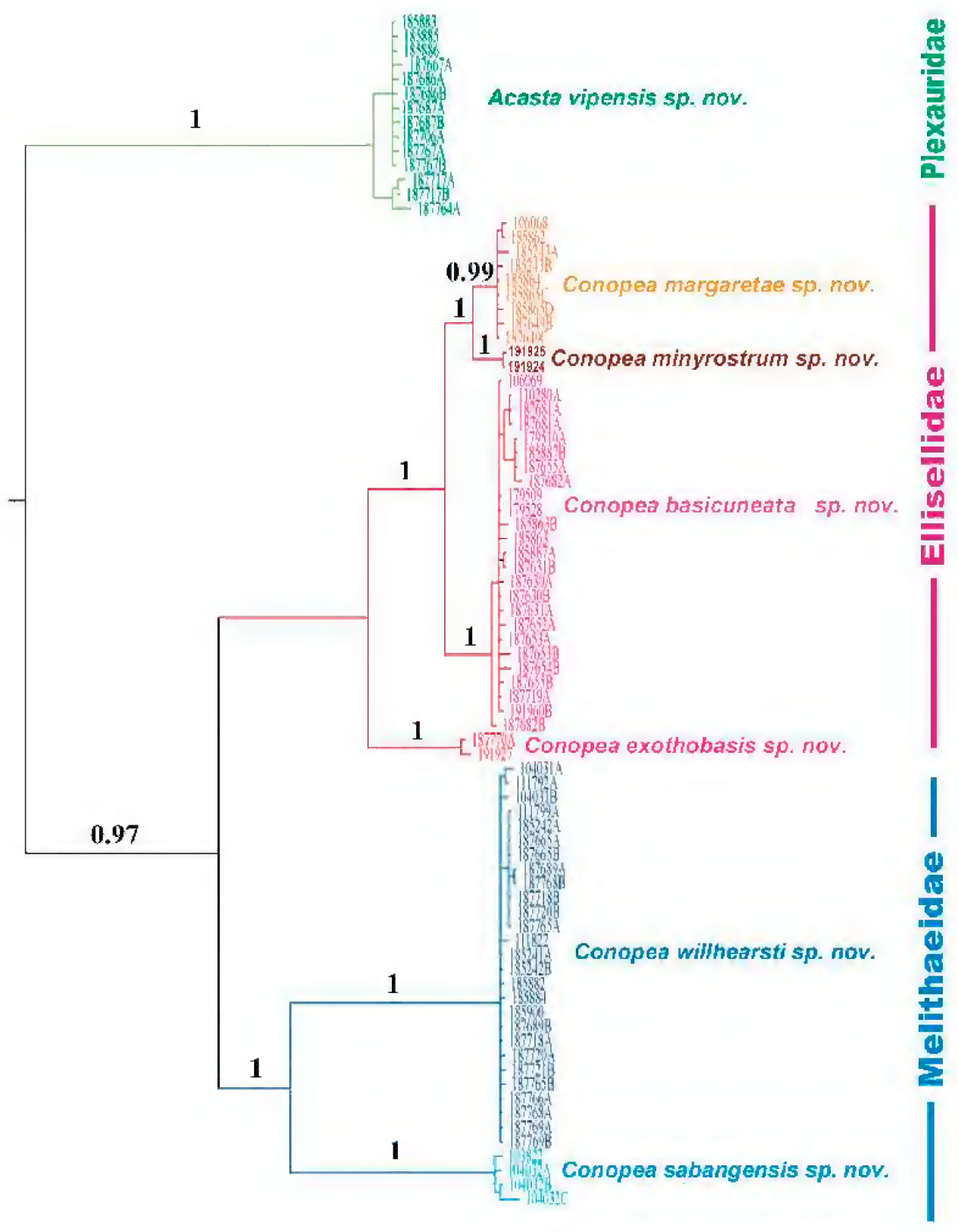

\subsection{9}

FIGURE 29. Tree resulting from a Bayesian analysis of nucleotide sequence data from COI for some Philippines octocoral-dwelling barnacles. Octocoral host families for barnacle clades are noted on the rigfht side of the tree. 
fidelis (Carrison-Stone et al. 2013) from Sao Tome and Principe (in Muriceopsis tuberculata, Plexauridae). However, they also found that Conopea saotomensis (Carrison-Stone et al. 2013) is symbiotic with seven species in the family Gorgoniidae, living on six gorgonian species in the genus Leptogorgia and Eunicella kochi. Similarly, the Philippines Conopea exhibit host specificity to varying degrees as well (Table 8). Unfortunately, taxonomic uncertainty in the Alcyonacea at the genus and species level inhibits taking the issue of host specificity to a level much finer than family, for now. We suspect that as the taxonomy of the Alcyonacea is refined, several barnacle species will be discovered to have species-level host specificity. Perhaps the further refinement of barnacle taxonomy will help to inform taxonomy within the Alcyonacea.

The invasion of octocoral and antipatharian hosts by barnacles in the family Archaeobalanidae does appear to have patterns of speciation by barnacle clades as various host taxon relationships evolved. In our admittedly small data set, some families of octocorals harbor more species of Conopea than others, and acastines have only found plexaurid octocorals to be suitable hosts. The reasons for these restrictions and specialization in host family taxa are not yet clear. It may be due to chemical cues from the hosts that attract or repeal barnacle larvae. Carrison-Stone et al. (2013) presented a synopsis of previous literature documenting evidence for attraction or repulsion of larvae by various host taxa.

TABLE 8. Western Pacific gorgonian-inhabiting barnacle species and their host taxa, as published in the original species descriptions and in this study.

\begin{tabular}{|c|c|c|c|c|c|}
\hline Barnacle name & Published host & Gorgoniidae & Plexauridae & Melithaeidae & Ellisellidae \\
\hline C. willhearsti sp. nov. & & & & $\begin{array}{l}\text { Acabaria, } \\
\text { Mopsella, } \\
\text { Melithaea }\end{array}$ & \\
\hline C. sabangensis sp. nov. & & & & Acabaria & \\
\hline С. basicuneata sp. nov. & & & & & $\begin{array}{l}\text { Junceella, Ctenocel- } \\
\text { la, Dichotella }\end{array}$ \\
\hline C. margaretae sp. nov. & & & & & Viminella \\
\hline C. minyrostrum sp. nov. & & & & & Viminella \\
\hline C. exothobasis sp. nov. & & & & & Viminella or Ellisella \\
\hline C. arcuata & "Acanthogorgie" & & & & \\
\hline C. canaliculatus & "gorgonian" & & & & \\
\hline C. comuta & Gorgonia & Gorgonia & & & \\
\hline C. dentifer & Isiidae, "Muricaeidae" & & "Muricaeidae" & & \\
\hline C. fragilis & "gorgonian" & & & & \\
\hline C. investita & Acauthogorgia truncata & & & & \\
\hline C. longibasis & "Melitodes?" & & & Melithaea & \\
\hline C. mjoebergi & Echinogorgia & & Echinogorgia & & \\
\hline C. proripiens & "Scirpearclla gracilis" & & & & Viminella gracilis \\
\hline C. pygmaea & "slender Gorgonarian" & & & & \\
\hline C. scandens & none & & & & \\
\hline C. squamosa & "white gorgonian" & & & & \\
\hline Acasta vipensis sp. nov. & & & Menella & & \\
\hline A. gregaria & Euplexaura & & Euplexaura & & \\
\hline A. hirsuta & Euplexaura & & Euplexaura & & \\
\hline A. purpurata & Is is & & & & \\
\hline Archiacasta spinitergum & gorgonian & & & & \\
\hline Euacasta microforamina & plexaurid & & Plexauridae & & \\
\hline
\end{tabular}




\section{ACKNOWLEDGEMENTS}

We gratefully acknowledge the donation by Will and Margaret Hearst that entirely funded the CAS 2011 Hearst Philippines Biodiversity Expedition and much of the laboratory work following our return from the field. Without their generous gift our work would not be possible. Special thanks also go to Terry Gosliner for originally conceptualizing and then heading up the Expedition. We are grateful to all of our colleagues in the field and here at CAS for helping us with everything from collecting specimens, shipping specimens to San Francisco, curating them at the museum, and analyzing them in detail in our laboratories. We would specifically like to thank: Rich Mooi, Christina Piotrowski, David Catania, Elizabeth Kools, Christina Cordova, Elliott Jessup, and Anna Sellas at CAS; and Marivene Manuel and Joseph Comendador from the National Museum of the Philippines. Michelle Weber and Dito de la Rosa helped with specimen collection in the Philippines.

\section{LiTERATURE CITED}

BRoch, H. 1916. Cirripedien. Results of Dr. E. Mjoberg's Swedish scientific expedition to Australia 1910-1913, No. 8. Kungliga Svenska Vetenskapsakademiens Handlingar 52(8):1-16.

BRoch, H. 1922. Studies on Pacific cirripeds. Papers from Dr. Th. Mortensen's Pacific Expedition 1914-1916, No. X. Videnskabelige Meddelelser Dansk Naturhistorisk Forening 73:215-358.

BRoch, H. 1931. Indomalayan Cirripedia. Papers from Dr. Th. Mortensen's Pacific Expedition 1914-1916, LVI. Videnskabelige Meddelelser Dansk Naturhistorisk Forening 91:1-146.

Burmeister, H. 1834. Beitrage zur Naturgeschichte der Rankenfusser (Cirripedia). G Reimer, Berlin, Germany. 68 pp.

Carrison-Stone, D., R. Van Syoc, G. Williams, and W. B. Simison. 2013. Two new species of the gorgonian inhabiting barnacle, Conopea (Crustacea, Cirripedia, Thoracica), from the Gulf of Guinea. Zookeys 270:1-20. Doi:10.3897/zookeys.270.3736.

DARwin C.R. 1854. A Monograph on the Sub-Class Cirripedia, with Figures of All the Species.The Balanidae (or Sessile Cirripedes); the Verrucidae, etc. The Ray Society, London, England. $30 \mathrm{pp}$.

ELLIS, J. 1758. An account of several rare species of barnacles. In a letter to Mr. Isaac Romilly, F.R.S. from John Ellis, Esq: F.R.S. Philosophical Transactions 50:845-855.

Folmer, O., M. Black, W. Hofh, R. LutZ, and R. VRiJENHOEK. 1994. DNA primers for amplification of mitochondrial cytochrome c oxidase subunit I from diverse metazoan invertebrates. Molecular Marine Biology and Biotechnology 3:294-299.

Grasshoff, M. 1988. The genus Leptogorgia (Octocorallia: Gorgoniidae) in West Africa. Atlantide Report 14:91-147.

GRASSHOFF, M. 1992. Die Flachwasser-Gorgonarien von Europa and Westafrika (Cnidaria, Anthozoa). Courier Forschungsinstitut Senckenberg 149:1-135.

HiRo, F. 1937. Cirripeds of the Palao Islands. Palao Tropical Biological Station Studies 1:37-72.

Hoek, P. P. C. 1913. Cirripedia of the Siboga-Expedition: B. Cirripedia Sessilia. Siboga-Expeditie 21:129-275, pls. 11-27. Brill, Leyden, Netherlands.

Kolbasov, G. A. 1993. Revision of the genus Acasta Leach (Cirripedia: Balanoidea). Zoological Journal of the Linnean Society. 1009:395-427.

Lamarck, J. B. P. A. DE 1818. Histoire Naturelle des Animaux san Vertebres, vol. 5. Paris, France. 612 pp.

LEACH, W.E. 1817. Distribution systematique de la classe des Cirripedes. Journal de Physique, de Chimie et d'Histoire Naturelle 85:67-69.

Newman, W. A., AND A. Ross. 1976. Revision of the balanomorph barnacles; including a catalog of the species. San Diego Society of Natural History Memoir 9:1-108.

Nilsson-Cantell, C. A. 1921. Cirripeden Studien. Zur Kenntnis der Biologie, Anatomie und Systematik dieser Gruppe. Zoologiska Bidrag fran Uppsala 7:75-390. 
Pilsbry, H.A. 1916. The sessile barnacles (Cirripedia) contained in the collections of the U.S. National Museum. Bulletin of the United States National Museum 93:1-366.

Ren, X. and J. Y. Liu 1978. Studies on Chinese Cirripedia (Crustacea). I. Genus Balanus. Studia Marina Sinica 13:119-196, pls. I and XI (including English summary).

Rosell, N. 1970. A gorgonacean inhabiting barnacle genus Acasta from Cebu. Natural and Applied Science Bulletin 22:103-111.

Roselt, N. C. 1991. Crustacca Cirripedia Thoracica: MUSORSTOM 3 Philippines collection. In: A. Crosnier, ed., Résultats des Campagnes MUSORSTOM. Vol. 9. Mémoires du Muséum national d'Histoire naturelle, (A), 152:9-61.

SAY, T. 1822. An account of some marine shells of the United Statcs. Journal of the Academy of Natural Sciences, Philadelphia 2(2):221-248, 302-325.

Utinomi, H. 1959. A new gall-forming barnacle imbedded in the bark of a gorgonacean colony (Acasta gregaria n. sp.). Publication of the Seto Marine Biological Laboratory VII(3):313-318, pl. XXV.

VAN Syoc, R. J. 1994. Genetic divergence between subpopulations of the eastern Pacific goose barnacle Pollicipes elegans: mitochondrial cytochrome c subunit 1 nucleotide sequences. Molecular Marine Biology and Biotechnology 3(6):338-346.

VAN SYOC, R. J. 1995. Barnacle mitochondrial DNA: Determining genetic relationships among species of Pollicipes. Pages 269-296 in F. R. Schram and J. T. Høeg, eds., New Frontiers in Barnacle Evolution, Crustacean Issues 10. A. A. Balkema, Rotterdam, Netherlands. 


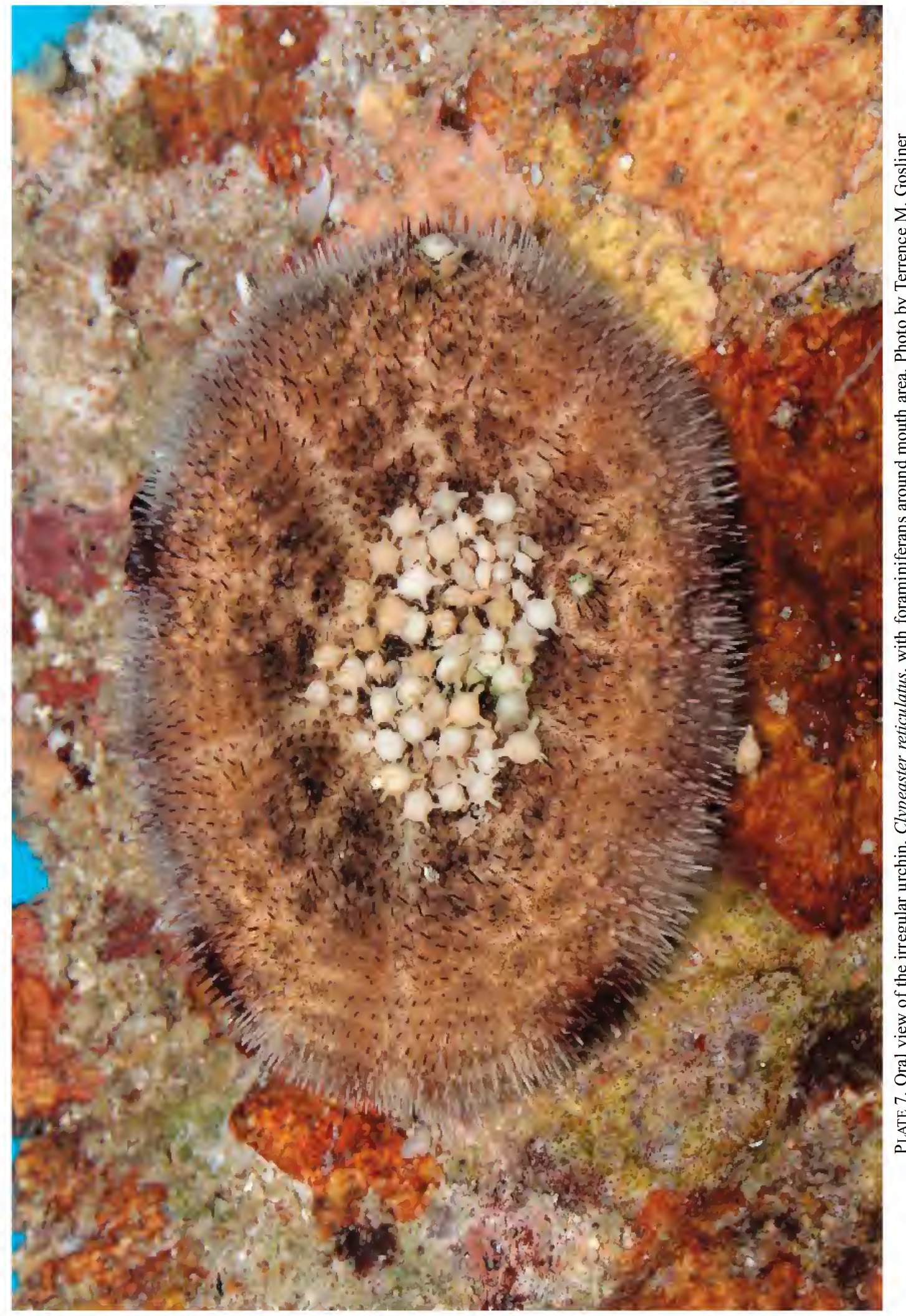




\title{
Sea Urchins of the Philippines
}

\author{
Rich Mooi ${ }^{1}$ and Angelica Munguia 2 \\ ${ }^{1}$ Department of Invertebrate Zoology \& Geology, California Academy of Sciences, \\ 55 Music Concourse Drive, San Francisco, CA 94118; Email: rmooi@calacademy.org \\ 2 University of California at Davis, Davis, CA 95616; Email: anmunguia@ucdavis.edu
}

\begin{abstract}
A list of 210 species of echinoids recorded from the Philippines was developed using data from the literature, the 2011 Hearst Philippine Biodiversity Expedition, and ancillary sources such as collections at the California Academy of Sciences and the National Museum of Natural History at the Smithsonian Institution. The list was then taxonomically updated using the World Echinoidea Database. The Philippines is home to more species of echinoids than any other comparable region in the world. Ongoing discovery of new Philippine records and species new to science indicate that present species richness estimates for the Philippines are conservative. Analysis of the list suggests that the unsurpassed Philippine echinoid diversity is best explained by the center of overlap hypothesis. Several of the echinoid species encountered during the Expedition have the potential of dramatically increasing our understanding of their evolution, behavior, and ecological significance.
\end{abstract}

KeYwords: Echinoidea, species list, systematics, center of overlap hypothesis, biodiversity, bathymetry

Accurate estimates of species richness are crucial to arguments made in favor of policies intended to protect specific marine regions, and for analyzing the status of species in threatened areas. However crucial these inventories might be, the value of their contribution to both science and policy-making remain at the mercy of data quality. Resources such as GBIF, iNaturalist, postings by underwater photographers, and even commercial websites such as eBay allow data to accumulate, but require vetting by taxonomists. For these reasons, collaborative expeditions and surveys in which specialists in a variety of taxa are represented will continue to provide important data. These data act as a sort of "ground-truthing" for the scientific and lay community alike because their dependability is higher than what is often encountered in relatively unreviewed, secondary resources such as those listed above.

The Echinodermata (sea lilies, starfish, brittlestars, sea cucumbers, and sea urchins) comprises an entirely marine clade of about 6,500 species. Most members of the group are relatively large, usually common, and conspicuous members of the marine biota. Among these, the sea urchins (Echinoidea) are arguably the best-known and most thoroughly studied of the major extant clades. In spite of this, and the fact that they are often reported by divers, photographers, amateurs, and professionals visiting or working in the Indo-Pacific, they are frequently misidentified or their reported nomenclature is not congruent with current usage. Nevertheless, with appropriate taxonomic quality control, echinoids can be useful indicators of relative species richness among different oceanic ecoregions, particularly as their nomenclature and taxonomy are now starting to be better understood through efforts such as those represented by the World Echinoidea Database (2011).

Echinoids are morphologically disparate and ecologically diverse. The familiar epibenthic, rocky substrate "regular" sea urchins constitute a polyphyletic assemblage (Kroh and Smith 2011) that includes slate pencil urchins (cidaroids), fire urchins (echinothurioids), and other "true" sea urchins (diadematoids, camarodonts and other carinacean forms) with large spines and a subspherical body, or test. All of these groups possess an Aristotle's lantern, a large, heavily muscled jaw apparatus equipped with five hard, sharp teeth used for chewing and rasping at food sources, or for 
cutting up plant material or sessile organisms that form the primary food sources of these echinoids.

Less familiar, usually burrowing echinoids with a dense, almost hair-like covering of thin, sometimes very short spines are placed in a monophyletic group known as the Irregularia (Kroh and Smith 2011). The term "irregular" refers to the fact that the anus is no longer found at the top of the animal, but at the posterior end, giving these forms a secondarily derived anterior-posterior axis that disturbs the "regular" pentaradial symmetry of most other urchins. Among these, the heart urchins (spatangoids) can be strongly bilateral, capable only of moving forward in substrates ranging from soft muds to relatively clean sands of varying particle size ranges. Being sediment-swallowers, they lack the Aristotle's lantern. However, other Irregularia such as sand dollars, sea biscuits, sea pancakes, pea urchins, and keyhole urchins (all clypeasteroids) retain the lantern into adulthood. Sand dollar-like taxa have extremely miniaturized spines that they use for locomotion through relatively clean, fine sands. Their tube feet are likewise miniaturized, adapted to handling individual, nutrient-bearing particles that are passed to the mouth, ingested, and crushed by the lantern. A much rarer group of Irregularia, lamp urchins (cassiduloids and echinolampadoids), once dominated in the Mesozoic and early Cenozoic. These are cryptic forms, "nestling" in coral rubble or burrowing into coarser sands. Although seldom seen today, several unusual lamp urchins are known from the Philippines.

Echinoids can be found in every ocean, from the upper intertidal to the deepest parts of the abyss. Almost every major echinoid clade contains deep-sea forms, and many of these are represented in the Philippines. However, coral reefs and soft substrates in lagoons and among the coral cover itself harbor the majority of Philippine echinoid taxa. Sea urchins, particularly the "regular" forms that are important herbivores, are crucial to the ecology of reefs (e.g. Ostrander 1999, Bellwood et al. 2004), often filling roles left vacant by local extirpation of fish species. It is also becoming increasingly clear that bathymetry has important effects on the overall significance of echinoids in reef ecology (e.g. Hughes 1996), making it crucial that accurate depth data are recorded for all species. In addition, echinoids are themselves important food sources for fish and crustaceans, not only as adults, but as larvae.

Sea urchins exert significant influence on the environments in which they live, in shallow water as well as at extreme depths. For example, the activities of large numbers of subtidal "regular" urchins can greatly alter the physical environment, particularly through bioerosion. Camarodont "regular" urchins such as Echinometra (Fig. 1A) alter their environment by actually chewing into the coral rock in which they live (Hiratsuka and Uehara 2007). Interestingly, juvenile Echinometra were seldom found in burrows or channels of their own construction, but were instead commonly ensconced in the empty shells of dead barnacles (Fig. 1B). Our shallow water work in the Verde Island Passage provided abundant evidence for the environment-altering activities of these urchins (Figs. 1C, D).

Urchins themselves support a wide variety of benthic invertebrates that find shelter and sometimes food among the spines. Certain species of fish also use the spines of larger urchins such as Diadema for protection. Large species of deep-sea heart urchins can act as hosts for internal bivalve commensals, and as a substrate for different species of brittlestars (see below). Cidaroid slate pencil urchins actually encourage settlement of other organisms onto their large spines. These urchins frequently carry around a rich epizoic community made up of bryozoans, sponges, barnacles, polychaetes, and other groups, particularly in the deep sea. As such, a single specimen of deep-sea urchin can represent a mobile, highly diverse sampling of the community all on its own.

In addition to their ecological importance, some urchins can inflict injury if not approached with respect. Forms such as the echinothurioids have a flexible test in which the component stere- 

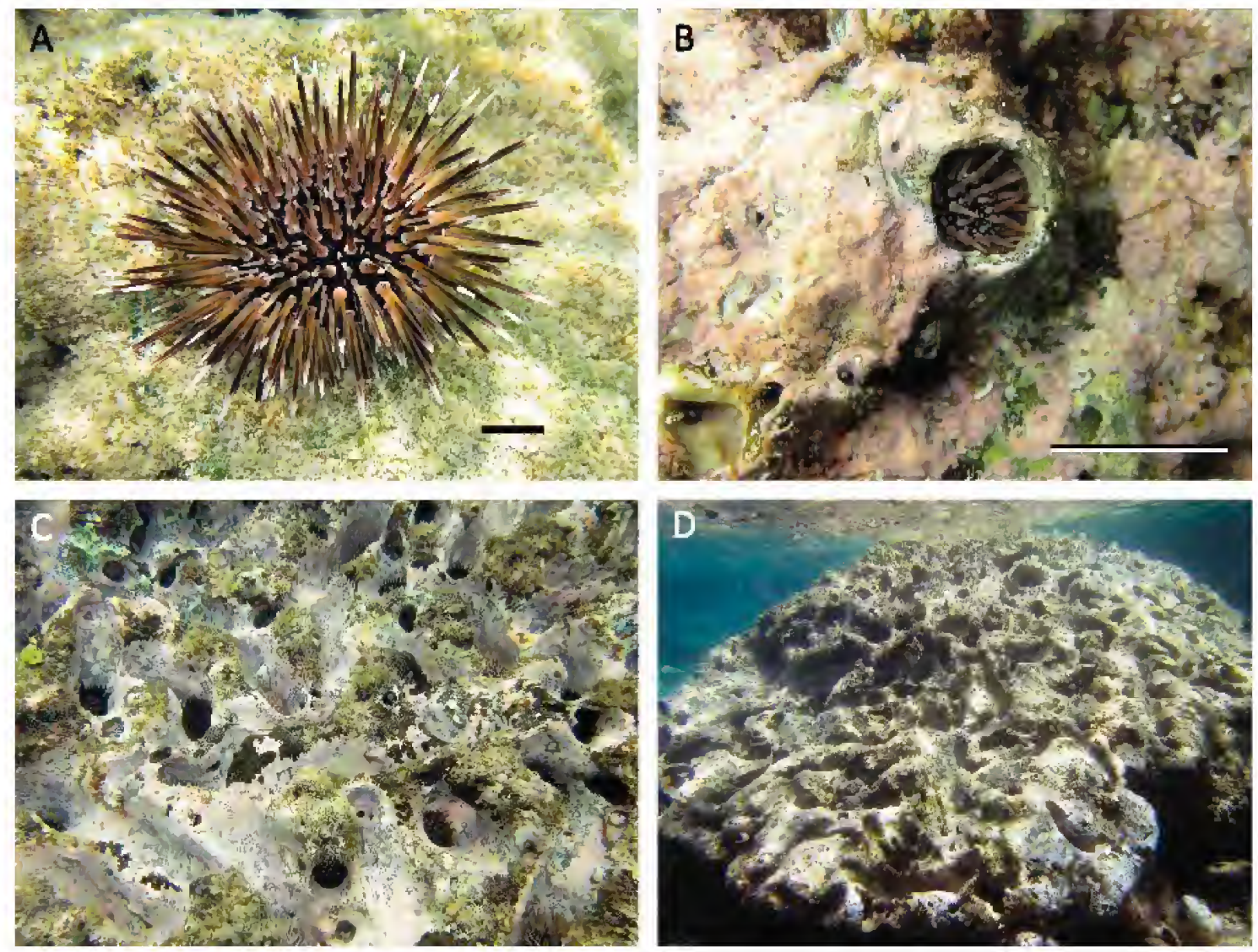

FIGURE 1. Echinometra mathaei in the Verde Island Passage. A. Live adult specimen extracted from its burrow. B. Live juvenile inhabiting a dead barnacle shell. C. Adults in burrows and channels in coral rock caused by chewing action of the Aristotle's lantern and spine abrasion. D. Large coral boulder being deeply channeled and eroded by feeding activities of Echinometra. Scale bars $10 \mathrm{~mm}$ long.

om plates are not tightly sutured together. These animals protect their thin, soft test with venomous spines. Although the vast majority of echinothurioids are deep-sea (Mooi et al. 2004) and almost never encountered by laypersons, shallow water echinothurioid taxa such as Asthenosoma can be common in coral reefs, and are known as "fire urchins". Diadematids have long, very sharp primary spines that, although not themselves venomous, can cause injury to unwary swimmers or divers that brush up against them. Because diadematids occur in large numbers in some areas, the potential for multiple injuries can be high. Most divers never encounter the layer of shorter, venomous spines known to occur in diadematids because they never get beyond the initial pain of the longer spines. However, some diadematids such as Echinothrix also bear well-exposed, venomous spines. In contrast, the so-called "flower urchin" (Toxopneustes) can deliver powerful stings not through its spines, but with its greatly enlarged pedicellariae (Fig. 2).

\section{A LIST OF PHILIPPINE SPECIES OF ECHINOIDEA}

The ecological importance of and general interest in echinoids of the Philippines are rooted in the biology summarized above, as well as in their diversity. Here, we develop a comprehensive list of all sea urchin species known from the Philippines. These efforts should provide a reliable baseline for future, comparative analyses of echinoid biodiversity within the Philippines and indeed, 

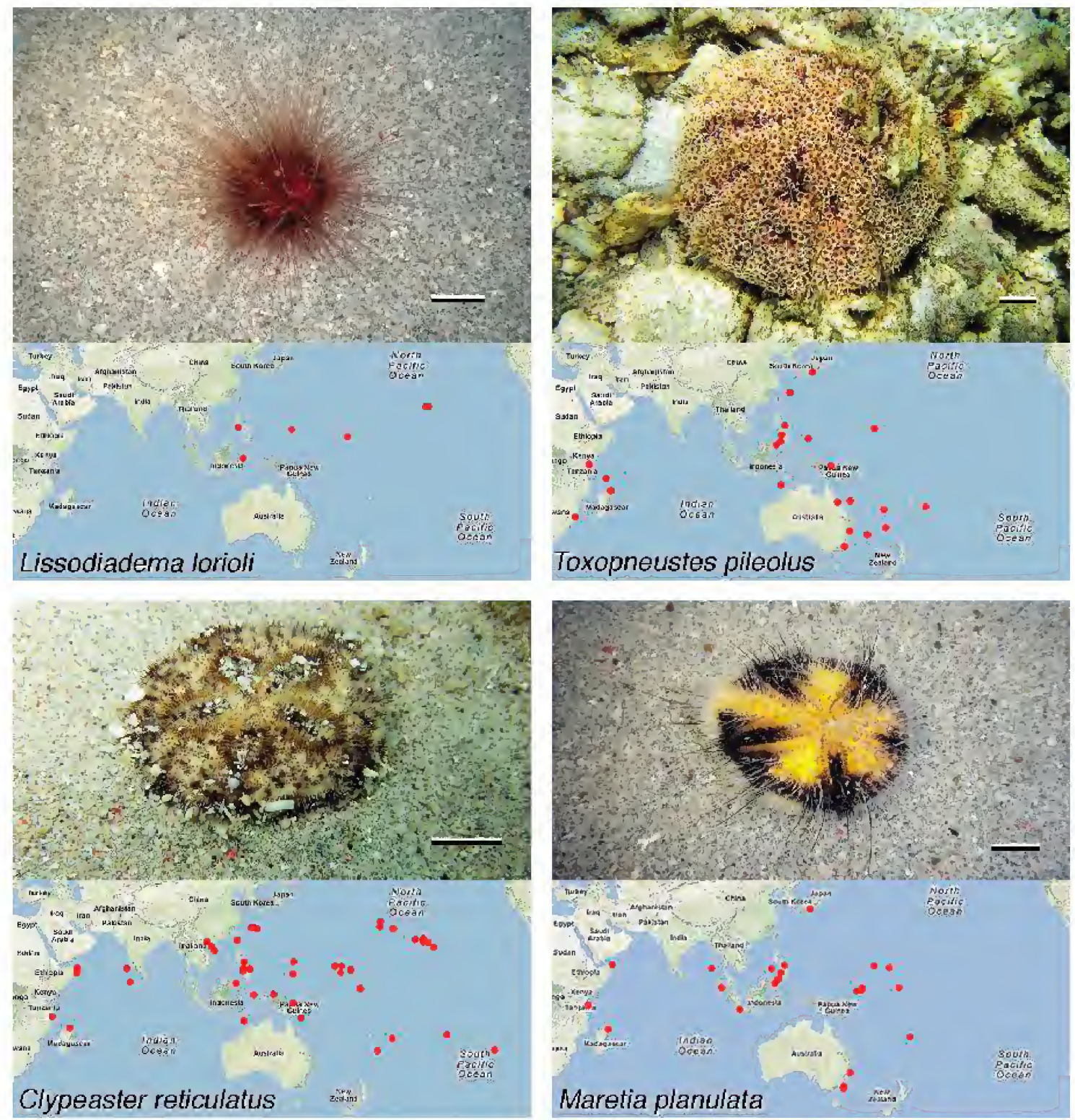

FIGURE 2. Four exemplars of major Philippine echinoid taxa and their corresponding distributions. Scale bars in animal images are $10 \mathrm{~mm}$ long. Range maps are edited from the Encyclopedia of Life (EoL), with red dots indicating EoL records as well as new data from the 2011 Hearst Philippine Biodiversity Expedition.

throughout the Indo-Pacific. Our list includes 210 species so far verifiably recorded from the Philippine region (see Appendix). We regard this estimate of echinoid diversity in the Philippines as conservative, given that there are several undescribed species of clypeasteroids and spatangoids either listed in van Noordenburg (2008) or presently being worked on by the senior author and his colleagues. We also do not separately enumerate subspecies, some of which might turn out to be full species. Finally, we note that there will likely be new material coming out of work such as that described by Bouchet et al. (2004), potentially adding to our compilation.

To build the list, we relied on a variety of literature and collections-based sources. In his monumental Monograph of the Echinoidea, Mortensen (1928, 1935, 1940, 1943a, 1943b, 1948a, 
1948b, 1950, 1951) laid the groundwork for our understanding of echinoid biodiversity, providing many of the best-documented records of species occurring in the Philippines. Mortensen's work remains a primary source for other biogeographic and bathymetric data as well. Many of the echinoid species he listed as occurring in the Philippines were collected during surveys conducted by the United States Fisheries Steamer "Albatross" between 1907 and 1910. The majority of this material is housed at the Smithsonian Institution in the National Museum of Natural History (NMNH). In its catalog, the NMNH has 139 of the species known to occur in the Philippines. This material is of particular significance because until the 21 st century, it represented nearly all the sampling in the region done below depths of about 50 meters. For some species, the "Albatross" specimens are the only ones known.

For these reasons alone, the 2011 Hearst Philippine Biodiversity Expedition was significant in shining new light on echinoids from deeper waters around the Philippines. The deep-sea component of the Expedition led to verification of many records, and provided additional data on bathymetry. Specimens from the shallow water component clarified many aspects of the distribution of taxa down to scuba depths, and also revealed new records of some taxa within the Philippines. A total of 106 Philippine echinoid species are cataloged into the Invertebrate Zoology collections of the California Academy of Sciences (CASIZ). Of these, 52 were identified from the collections made during the Hearst Expedition, and 65 are held in common in the CASIZ and NMNH collections, constituting a combined total of 180 species represented by the collections of both institutions. In other words, 30 species are not known in either institution's holdings, but were recorded in works such as Fell (1963), Lane et al, (2000) and van Noordenburg (2008). In two instances, Philippine species were identified from websites constructed by private collectors. All these sources are noted in the table presented in the Appendix. The contents of the species list are summarized by higher taxon in Table 1 .

\section{SignifiCANCE OF THE PHILIPPINE ECHINOID FAUNA}

Our results indicate, as has been found in studies of other taxa in the Coral Triangle, that there are more echinoid species in the Philippines than in other comparable ecoregion in the world. For example, in comparing records compiled from sources such as Dollfus and Roman (1981), the Philippines is home to nearly four times as many species as occur in the entire Red Sea. Preliminary estimates compiled from Mortensen's Monograph and other sources suggest that only half the number of species seen in the Philippines have been recorded from India, Malaysia, and Indonesia combined. This is partially a reflection of the lack of detailed knowledge of the faunas of these regions. Inspection of collections at the California Academy of Sciences and the NMNH, along with counts made from Mortensen's Monograph indicate that it is unlikely that future surveys of these regions will push species richness numbers beyond what is found in the Philippines. According to estimates compiled from similar sources, there are more than twice as many echinoid species in the Philippines as in the Gulf of Mexico and Caribbean Sea together.

Almost 130 species of Philippine echinoids occur at depths less than 100 meters, and just over 80 of these can be encountered at depths of 10 meters or less. However, 11 are restricted to depths greater than 500 meters, and of these, 5 are restricted to depths greater than 1,000 meters. Therefore, the Philippine echinoid fauna is well represented not only in terms of taxonomy, but also in terms of bathymetry.

Table 1 shows that among the major clades of echinoids, the group contributing the single highest number of species is the heart urchins (Spatangoida), with nearly $27 \%$ of the total. The cidaroids, camarodonts, and clypeasteroids contribute similar numbers of species, and combine to 
make up just over half of the total number of echinoid species. These numbers are comparable to world-wide taxonomic representations for the Echinoidea, particularly in tropical regions (see, for example, Lessios 2005). Remarkably, every extant order and over $70 \%$ of the extant families of echinoids listed in Kroh and Smith (2011) are represented in Philippine waters.

\section{Origins OF PhILIPPINE ECHINOID DIVERSITY}

The unsurpassed diversity of the Echinoidea in the Philippines is not primarily due to high levels of endemism. About 13\% of the species have so far been recorded only from the Philippines. Nearly half of these "endemics" are cidaroids that are not only notoriously difficult to identify, but from depths over 100 meters (all but two from over 200 meters). Only three of the remaining species recorded to occur in the Philippines do so at depths shallower than 100 meters, and only two of those can be found at what might be considered depths that collectors could reach with conventional scuba gear. Our overall knowledge of the seemingly endemic species, most of which occur at depths greater than are normally sampled, prevents us from stating unequivocally that they do not occur elsewhere in the Indo-Pacific.

Over $60 \%$ of all the known Philippine species occur at depths shallower than 100 meters, and of these, nearly $64 \%$ occur between 0 and 10 meters.
TABLE 1. Contents of the species list (see Appendix table) are summarized by higher taxon.

\begin{tabular}{|c|c|c|c|}
\hline Order & Family & $\begin{array}{c}\text { \# of Species } \\
\text { in Philippines }\end{array}$ & $\begin{array}{c}\text { Total } \\
\text { by Order }\end{array}$ \\
\hline \multirow{3}{*}{ Cidaroida } & Cidaridae & 30 & \multirow{3}{*}{35} \\
\hline & Histocidaridae & 4 & \\
\hline & Psychocidaridae & 1 & \\
\hline \multirow{2}{*}{ Echinothurioida } & Echinothuriidae & 11 & \multirow{2}{*}{13} \\
\hline & Phormosomatidae & 2 & \\
\hline Micropygoida & Micropygidae & 2 & 2 \\
\hline Diadematoida & Diadematidae & 10 & 10 \\
\hline Aspidodiadematoida & Aspidodiadematidae & 2 & 2 \\
\hline Pedinoida & Pedinidae & 3 & 3 \\
\hline Salenioida & Saleniidae & 1 & 1 \\
\hline Stomopneustoida & Stomopneustidae & 1 & 1 \\
\hline Arbacioida & Arbaciidae & 4 & 4 \\
\hline \multirow{5}{*}{ Camarodonta } & Echinometridae & 7 & \multirow{5}{*}{39} \\
\hline & Parasaleniidae & 2 & \\
\hline & Temnopleuridae & 19 & \\
\hline & Toxopneustidae & 7 & \\
\hline & Trigonocidaridae & 4 & \\
\hline Echinoneoida & Echinoneidae & 2 & 2 \\
\hline \multirow{2}{*}{ Cassiduloida } & Neolampadidae & 1 & \multirow{2}{*}{2} \\
\hline & Cassidulidae? & 1 & \\
\hline Echinolampadoida & Echinolampadidae & 7 & 7 \\
\hline \multirow{5}{*}{ Clypeasteroida } & Astriclypeidae & 4 & \multirow{5}{*}{33} \\
\hline & Clypeasteridae & 8 & \\
\hline & Echinocyamidae & 5 & \\
\hline & Fibulariidae & 6 & \\
\hline & Laganidae & 10 & \\
\hline \multirow{2}{*}{ Holasteroida } & Corystusidae & 1 & \multirow{2}{*}{2} \\
\hline & Plexechinidae & 1 & \\
\hline \multirow{14}{*}{ Spatangoida } & Brissidae & 14 & \multirow{14}{*}{56} \\
\hline & Eupatagidae & 3 & \\
\hline & Eurypatagidae & 6 & \\
\hline & Hemiasteridae & 1 & \\
\hline & Loveniidae & 7 & \\
\hline & Macropneustidae & 1 & \\
\hline & Maretiidae & 6 & \\
\hline & Micrasteridae & 1 & \\
\hline & Palaeostomatidae & 1 & \\
\hline & Palaeotropidae & 1 & \\
\hline & Paleopneustidae & 4 & \\
\hline & Pericosmidae & 4 & \\
\hline & Schizasteridae & 3 & \\
\hline & Spatangidae & 2 & \\
\hline Total & 42 & 210 & \\
\hline
\end{tabular}


The fact that there are so few endemics among the taxa occurring in more accessible, shallower waters strongly suggests that the vast majority of Philippine echinoid taxa from any depth will also be found to occur outside the region.

This provides support for the idea that the Philippines is a center of overlap for many species ranges (Gaither and Rocha 2013). The center of overlap hypothesis suggests that the distinct faunas of the Pacific and Indian Oceans overlap in the Indo-Malay-Philippine biodiversity hotspot, which is bounded by the Philippines, Malay Peninsula, and New Guinea. For echinoids, the overlap hypothesis is exemplified by the ranges of four echinoids that figured prominently during the shallow water component of the Hearst Expedition, and that typify the distributions of the major taxa to which they belong (Fig. 2). The species are characterized by relatively large, disparate ranges, but all have the Philippines as a common region of overlap.

\section{ECHINOID HIGHLIGHTS OF THE EXPEDITION}

During approximately 35 days of collecting, the 2011 Hearst Philippine Biodiversity Expedition found nearly as many echinoid species in the Verde Island Passage (VIP) region as have been recorded over the entire history of biodiversity work in the Red Sea. These findings are summarized in Figure 3, which shows bathymetry, by family, of all 52 of the species found during the Expedition. Although more species (about 65) have been recorded from the Philippine parts of the Sulu Sea and Archipelago, this region is vastly larger than the VIP. Present data indicate that the

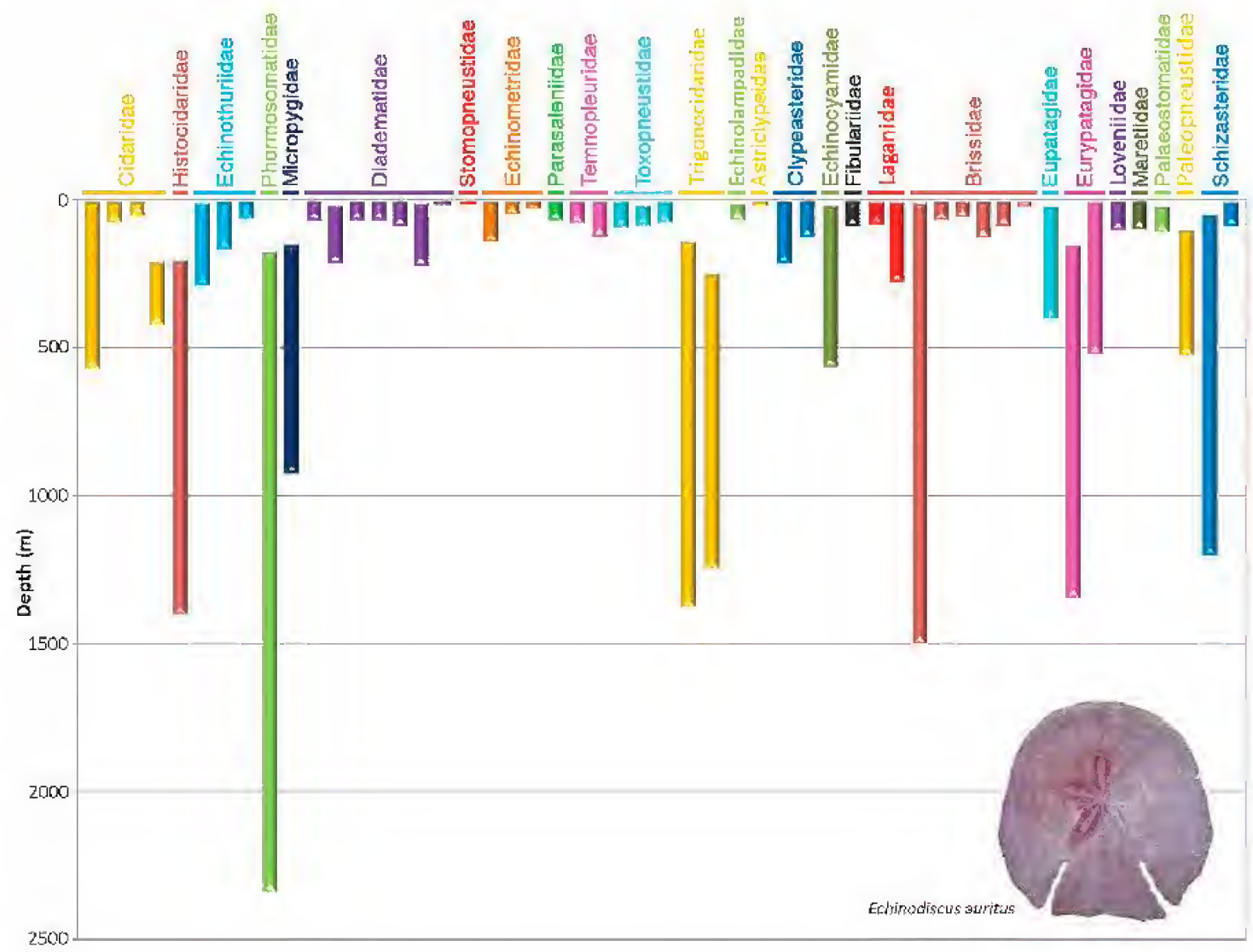

FIGURE 3. Bathymetry of all 52 species collected during the 2011 Hearst Philippine Biodiversity Expedition. 
VIP is the "center of the center" (sensu Carpenter and Springer 2005) of diversity in the Coral Triangle in terms of echinoids, and that diversity is high at all depths.

A major contribution of the Expedition was the discovery of five taxa never before seen in the Philippines, and a sixth (Stomopneustes variolaris) suspected to occur there, but not hitherto verified in published records. Although none of these is new to science, they reinforce the inference that the VIP is among the most diverse regions of the world's oceans. Many other taxa remain to be discovered even within a group of echinoderms in which a year or more can go by without the discovery of new extant species. For example, at least six species of Philippine Irregularia alone (van Noordenburg 2008) are suspected to be new to science (although not all of them have been found in the VIP as yet).

Another significant find during the shallow-water component of the expedition includes the most westerly occurrence of the "hair-spined urchin", Lissodiadema lorioli (Fig. 4A). The phylogenetic systematics of this poorly-known, relatively rare diadematid remain equivocal because of a lack of analysis, potential synonymy with the Hawaiian species Leptodiadema purpureum, and poor quality of the type material of both taxa. However, it is clear that Lissodiadema ranges widely throughout the Pacific and is being more frequently seen by divers interested in cryptic species with cavernicolous tendencies. The spines of this urchin are striking, being as fine or finer than a human hair - so thin that they can be bent easily en masse in the living animal (Fig. 4B).

During the trawling by the M/V "DA-BFAR", several minute specimens of "wood urchins" representing two species in the genus Prionechinus were discovered (Figs. 4C, D). Neither of these species were previously known to occur in the Philippines. Wood urchins are members of a poorly known family of camarodonts currently known as the Trigonocidaridae. As noted by Mortensen (1943a), several species of trigonocidarids are known to be xylophagous, and are found exclusively on sunken wood derived from deciduous trees (i.e. not on coconut or other palm tree fragments). Trigonocidarids species are known to harbor gut flora capable of digesting cellulose (Becker et al. 2009). Wood-falls are sometimes regarded as "stepping stone" habitats representing alternative energy sources for deep-sea taxa that have evolved to exploit whale-falls and deep-sea thermal vents (Kiel and Goedert 2006). The study of echinoids that can live exclusively on wood will lead to many lines of inquiry ranging from the phylogenetic origins and diversification of trigonocidarids to the ecological significance of forest-derived outfall in deep ocean adjacent to the Philippines coast, where some of the steepest and deepest drop-offs in the Indo-Pacific can be found.

Trawling work also recovered several specimens of very large heart urchins. Each of these specimens in turn yielded other parts of deep-sea biodiversity because of the fact that they bore commensals from widely disparate taxonomic groups. For example, one specimen of Plesiozonus hirsutus was home to what appear to be two different species of brittlestar (Fig. 4E), and a bivalve mollusk living just inside the test in the anal region (A. Kroh, personal communication). Other trawling events of the Expedition resulted in several specimens of Chaetodiadema granulatum. Although most of these were damaged, the tissues were sufficiently undisturbed to reveal the remarkable structural colors caused by isolated spots of iridophores arranged in rows in the aboral interambulacra (Fig. 4F). This phenomenon was carefully described by Mortensen (1940a), but his black and white illustrations do not do justice to the nearly $100 \%$ reflectance of these spots. Iridescent lines and spots in a variety of colors are commonly photographed in diadematids from shallow water such as Diadema, Astropyga, and Echinothrix. Although de Meijere (1904) illustrated the spots in a color drawing of $C$. granulatum, to the best of our knowledge, Figure $4 \mathrm{~F}$ is the first published color photo of these spots in a deep-sea echinoid.

During work on the M/V "DA-BFAR", it was discovered that Micropyga violacea (Fig. 5A) was one of only two echinoid species to enter commonly the baited fish traps (the other being the 

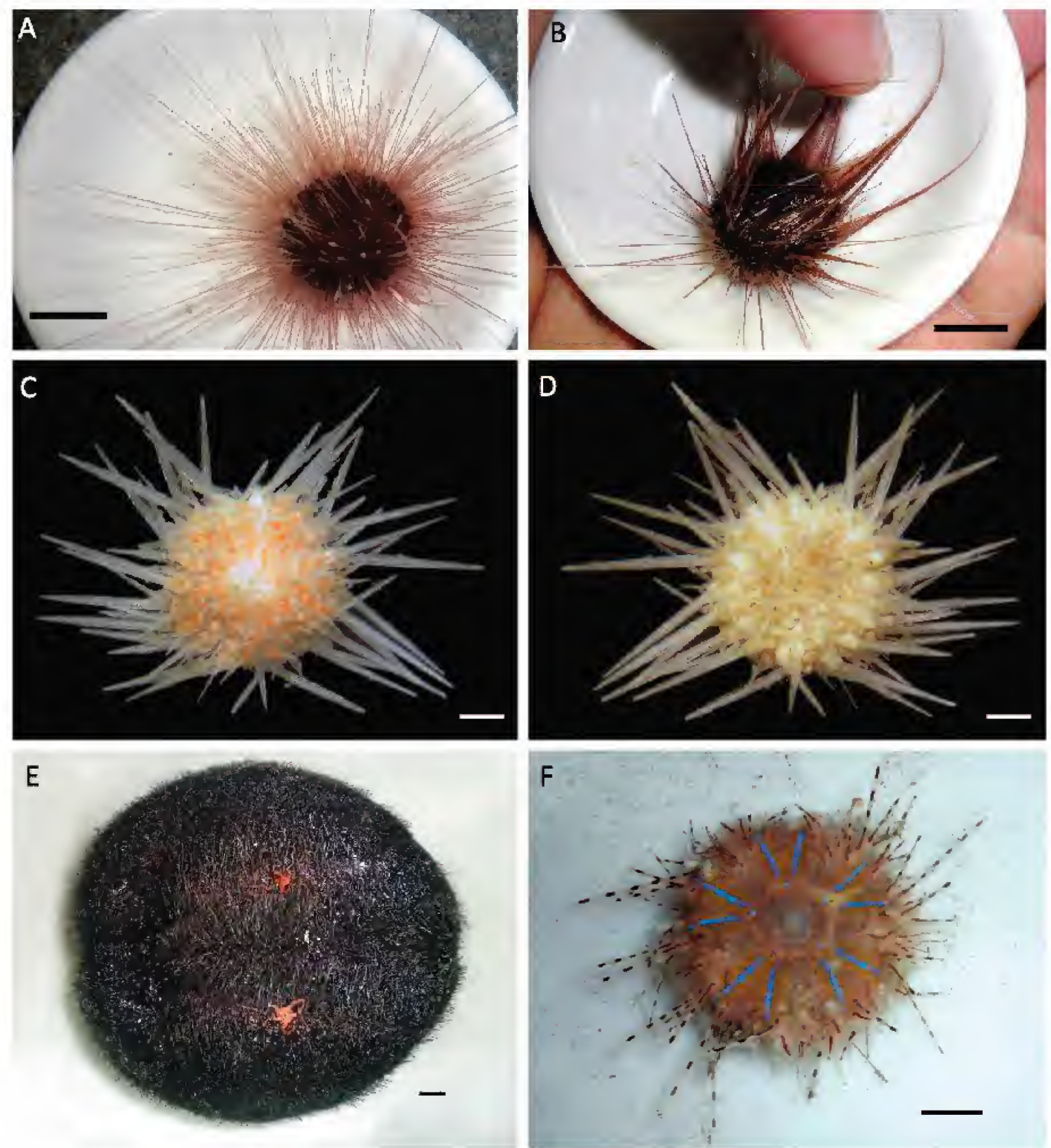

Figure 4. A. Live Lissodiadema lorioli collected in the Verde Island Passage, spines undisturbed and fully spread. B. Same specimen as in A showing extreme flexibility of very fine primary spines. C. Aboral view of Prionechinus forbesianus collected in the Verde Island Passage aboard the M/V "DA-BFAR". D. Oral view of specimen in C. E. Oral surface of live specimen of Plesiozonus hirsutus with two ophiuroids among spines in ambulacra flanking plastron. Mouth of echinoid is to left. Mouths of both ophiuroids are directed downwards away from echinoid and towards substrate. F. Photograph using flash of live Chaetodiadema granulatum showing pattern of iridophores on aboral surface. Scale bars in A, B, E, and F $10 \mathrm{~mm}$ long, bars in C and D $1 \mathrm{~mm}$ long. 

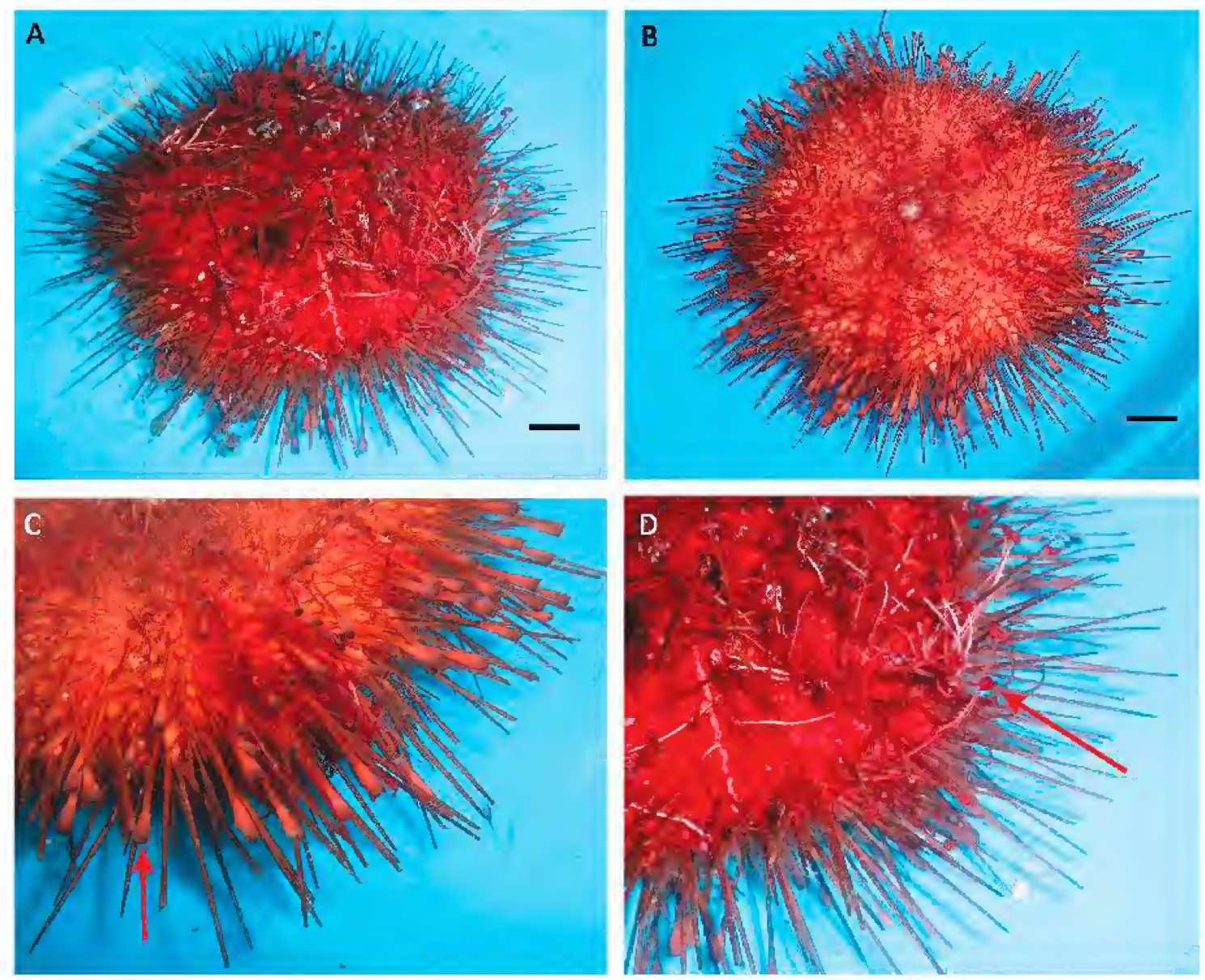

FIGURE 5. Micropyga violacea. A. Aboral view of live specimen on board the M/V "DA-BFAR". B. Oral view of same specimen. C. Hoof-like tips of oral locomotory spines (arrow). D. Slightly magnified view of specimen in A showing long, string-like, white shafts of aboral tube feet terminating in sticky, umbrella-like tips (arrow). Scale bar $10 \mathrm{~mm}$ long.

detritivore and adventitious carnivore, Eucidaris metularia). Micropyga is characterized not only by peculiar, hoof-shaped oral spine tips (Figs. 5B, C), but by the strangest tube feet known in any echinoid (Fig. 5D). The aboral tube feet of Micropya are extremely long, and tipped with very sticky, umbrella-like expansions (Mortensen 1940a). The stickiness of the tips results in their wholesale removal from specimens during trawling operations, as illustrated by Burch (2001: Fig. 1) - although she mistakenly attributed the tube feet to a spatangoid, not a micropygid. The functions of these peculiar tube feet are unknown, but one hypothesis advanced during observations of the living, relatively undamaged animals from the fish traps was that the tube feet were extended upwards into the water column as "fishing lines" capable of capturing living prey such as small crustaceans. This would agree well with the apparent attraction of Micropyga to the protein bait of the traps. However, work by Mortensen (1940a), and subsequent dissection of specimens on board the $\mathrm{M} / \mathrm{V}$ "DA-BFAR" revealed only fragments of plant material and spicules of sponges - a diet typical of many deep-sea echinoids lacking any specialized tube feet. Therefore, the function of the bizarre tube feet remains obscure, although it cannot yet be ruled out that they are used in food gathering.

Work on Philippine echinoids continues at the Academy, and findings of the Expedition have 
so far contributed to the research programs of undergraduates such as those in our NSF-funded Reseach Experiences for Undergraduates (REU) Site. The second author of this paper was an REU student in the summer of 2012. A high school student in the Academy's Student Science Fellows program is working on heart urchins from the Philippines collected during the Expedition, and several graduate students are using Philippines material for their research. Our outreach and collaborations during the the 2011 Hearst Philippine Biodiversity Expedition also helped to train students from the University of the Philippines, Diliman, laying the groundwork for future joint research on diversity in the region. Therefore, the Expedition is yielding rich scientific dividends alongside the goal of training the next generation of systematists who will inherit the challenges of preserving marine biodiversity for their own generation and those that will follow.

\section{ACKNOWLEDGMENTS}

We would first like to acknowledge Margaret and Will Hearst, without whose generosity the 2011 Hearst Philippine Biodiversity Expedition would not have existed. We also received generous in-kind support from Philippines Airlines, the Dusit Thani Hotel in Manila, and Wayfair Tours of Manila. The work of AM was funded by the National Science Foundation's Research Experiences for Undergraduates initiative, grant DBI 0754804 to RM. Malou Babilonia and Mary Lou Salcedo receive our thanks for their friendship and help along so many steps of the way. Ludivina Labe, Alma Dickson, Captain Ernaldo T. Cawaling, Rafael Ramiscal, and Loida Cainglit were instrumental to our work on during the deep-sea component. All of the friends, partners, and collaborators on various aspects of the shallow-water and deep-sea components of the Expedition are too numerous to mention here by name. Most have been acknowledged in other reports on the Expedition. This leaves me to mention individuals who contributed directly to the discovery, collection, and identification of echinoids during our shallow water work off southern Luzon in the Verde Island Passage, and on board the M/V "DA-BFAR". Sharp-eyed Philippine colleagues who brought to our attention so many fascinating specimens include Peter Cadapan, Joseph Comendador, Don Dumale, Aissa Domingo, Rachel Gotanco, Luvi Labe, Marivene Manuel Santos, Evelyn Mendoza, and Zenaida Salazar. We also tip our hats to the excellent student and scientist support crew on the ship. Our dive guides in the VIP were no less alert and we would like to thank Peri Paleracio, Alexis Principe, and Ditto de la Rosa in finding many echinoids that might otherwise have escaped our notice. RM would like to single out the Philippine students from the University of the Philippines, Diliman who enthusiastically worked alongside him both on shore and in the sea. In part, this paper is dedicated to them because they represent the future of marine research in the Philippines: Inggat Casilagan, Jay Gorospe, Elizaldy Maboloc, and Bryan Rodriquez. And last, but of course not least, we thank our Academy teammates on the Expedition, and all the collections support staff who cataloged and/or identified material forming the basis of the echinoid list, notably Bob Van Syoc, Christina Piotrowski, and Kelly Markello.

\section{LiTERATURE CiTED}

Becker, P. T., S. Samadi, M. Zbinden, C. Hoyoux, P. Compére, and C. de Ridder. 2009. First insights into the gut microflora associated with an echinoid from wood falls environments. Cahier de Biologie Marine, 50:343-352.

Bellwood, D. R., T. P. Hughes, C. Folke, and M. Nystrom. 2004. Confronting the coral reef crisis. Nature, 429(6994):827-833.

Bouchet, P., P. K. L. NG, D. Largo, And S. H. TAN. 2004. PANGLAO 2004 - Investigations of the marine species richness in the Philippines. The Raffles Bulletin of Zoology, Supplement 20:1-19. 
BurCH, B. L. 2001. Dr. Frederick M. Bayer. A fine zoologist with rare depth of knowledge, memory, and great follow-through in literature. Bulletin of the Biological Society of Washington, 10:363-364.

CARPENTER, K. E., AND V. G. SPRING ER. 2005. The center of the center of marine shore fish biodiversity: the Philippine Islands. Environmental Biology of Fishes, 72:467-480.

Dollfus, R.-P., ANd J. Roman. 1981. Les Échinides de la mer Rouge. Ministère des Universités, Comité des Travaux Historiques et Scientifiques, Mémoires de la Section des Sciences, 9:1-145.

ENCYClopedia of Life. <http://www.eol.org>. Cited December 12, 2011.

FelL, H. B. 1963. The spatangid echinoids of New Zealand. Zoology Publications from Victoria University of Wellingston, 32:1-8.

Gaither, M. R., AND L. A. Rocha. 2013. Origins of species richness in the Indo-Malay-Philippine biodiversity hotspot: evidence for the centre of overlap hypothesis. Journal of Biogeography, 40(9):1638-1648.

Hiratsuka, Y., and T. Uehara. 2007. Feeding ecology of four species of sea urchins (genus Echinometra) in Okinawa. Bulletin of Marine Science, 81(1):85-100.

Hughes, T. P. 1996. Approaches to community dynamics: A coral reef example. Ecology, 77(7):2256-2260.

Kiel, S., AND J. L. GoEDERT. 2006. Deep-sea food bonanzas: Early Cenozoic whale-fall communities resemble wood-fall rather than seep communities. Proceedings of the Royal Society B, Biological Sciences, 273(1601):2625-2632.

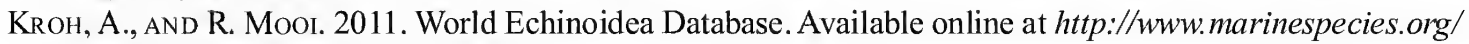
echinoidea [accessed 2013-12-06]

KROH, A., AND A. B. Smith. 2011. The phylogeny and classification of post-Palaeozoic echinoids. Journal of Systematic Palaeontology, 8(2):147-212.

Lane, D. J. W., L. M. Marsh, D. VandenSpiegel, and F. W. E. Rowe. 2000. Echinoderm fauna of the South China Sea: An inventory and analyis of distribution patterns. The Raffles Bulletin of Zoology, Supplement 8:459-493.

Lessios, H. 2005. Echinoids of the Pacific waters of Panama: Status of knowledge and new records. Revista de Biología Tropica, 53 (Suppl. 3):147-170.

MeIJere, J. C. DE. 1904. Die Echinoidea der Siboga -Expedition. E. J. Brill, Leiden. 251 pp.

Mool, R., H. Constable, S. Lockhart, and J. Pearse. 2004. Echinothurioid phylogeny and the phylogenetic significance of Kamptosoma (Echinoidea: Echinodermata). Deep-Sea Research II, 52:1903-1919.

Mortensen, T. 1928. A Monograph of the Echinoidea. I. Cidaroidea. C. A. Reitzel \& Oxford University Press, Copenhagen \& London. 551 pp.

Mortensen, T. 1935. A Monograph of the Echinoidea. II. Bothriocidaroida, Melonechinoida, Lepidocentroi$d a$, and Stirodonta. C. A. Reitzel \& Oxford University Press, Copenhagen \& London. 647 pp.

Mortensen, T. 1940a. A Monograph of the Echinoidea. IIl, I. Aulodonta, with Additions to Vol. II (Lepidocentroida and Stirodonta). C. A. Reitzel, Copenhagen. 370 pp.

Mortensen, T. 1940b. Contributions to the biology of the Philippine Archipelago and adjacent regions. Report on the Echinoidea collected by the United States Fisheries Steamer "Albatross" during the Philippine Expedition, 1907-1910. Part 2: The Echinothuridae, Saleniidae, Arbaciidae, Aspidodiadematidae, Micropygidae, Diadematidae, Pedinidae, Temnopleuridae, Toxopneustidae, and Echinometridae. United States National Museum Bulletin 100, 14(1):1-52.

Mortensen, T. 1943a. A Monograph of the Echinoidea. IIl. 2. Camarodonta. I. Orthopsidae, Glyphocyphidae, Temnopleuridae and Toxopneustidae. C. A. Reitzel, Copenhagen. 553 pp.

Mortensen, T. 1943b. A Monograph of the Echinoidea. Ill, 3. Camarodonta. II. Echinidae, Strongylocentrotidae, Parasaleniidae, Echinometridae. C. A. Reitzel, Copenhagen. $446 \mathrm{pp}$.

Mortensen, T. 1948a. A Monograph of the Echinoidea. IV, I Holectypoida, Cassiduloida. C. A. Reitzel, Copenhagen. $371 \mathrm{pp}$.

Mortensen, T. 1948b. A Monograph of the Echinoidea. IV, 2. Clypeasteroida. Clypeasteridae, Arachnoidae, Fibulariidae, Laganidae and Scutellidae. C. A. Reitzel, Copenhagen. 471 pp.

Mortensen, T. 1950. A Monograph of the Echinoidea. V, I. Spatangoida I. Protosternata, Meridosternata, Amphisternata I. Palaeopneustidde, Palaeostomatidae, Aeropsidae, Toxasteridae, Micrasteridae, Hemiasteridae. C. A. Reitzel, Copenhagen. 432 pp.

Mortensen, T. 1951. A Monograph of the Echinoidea. V, 2. Spatangoida II. Amphisternata II. Spatangidae, 
Loveniidae, Pericosmidae, Schizasteridae, Brissidae. C. A. Reitzel, Copenhagen. 593 pp.

Ostrander, G. K., K. M. Armstrong, E. T. Knobbe, D. Gerace, and E. P. Scully. 2000. Rapid transition in the structure of a coral reef community: The effects of coral bleaching and physical disturbance. Proceedings of the National Academy of Sciences, 97(10):5297-5302.

van Noordenburg, H. 2008. Sea Urchins of the Philippines. Part I. The Irregulars. Artificial Harmonics, Utrecht. 153 pp. 


\section{Appendix}

\section{A List of Philippine Species of Echinoidea}

List of echinoid taxa recorded from the Philippines, with higher classification and bathymetry. Families, genera, and species listed alphabetically within each order. Species collected during the 2011 Hearst Philippine Biodiversity Expedition are in bold. Species so far known only from the Philippines are marked with an asterisk (*). For authorities and dates for all taxa, see Kroh and Mooi (2011). 


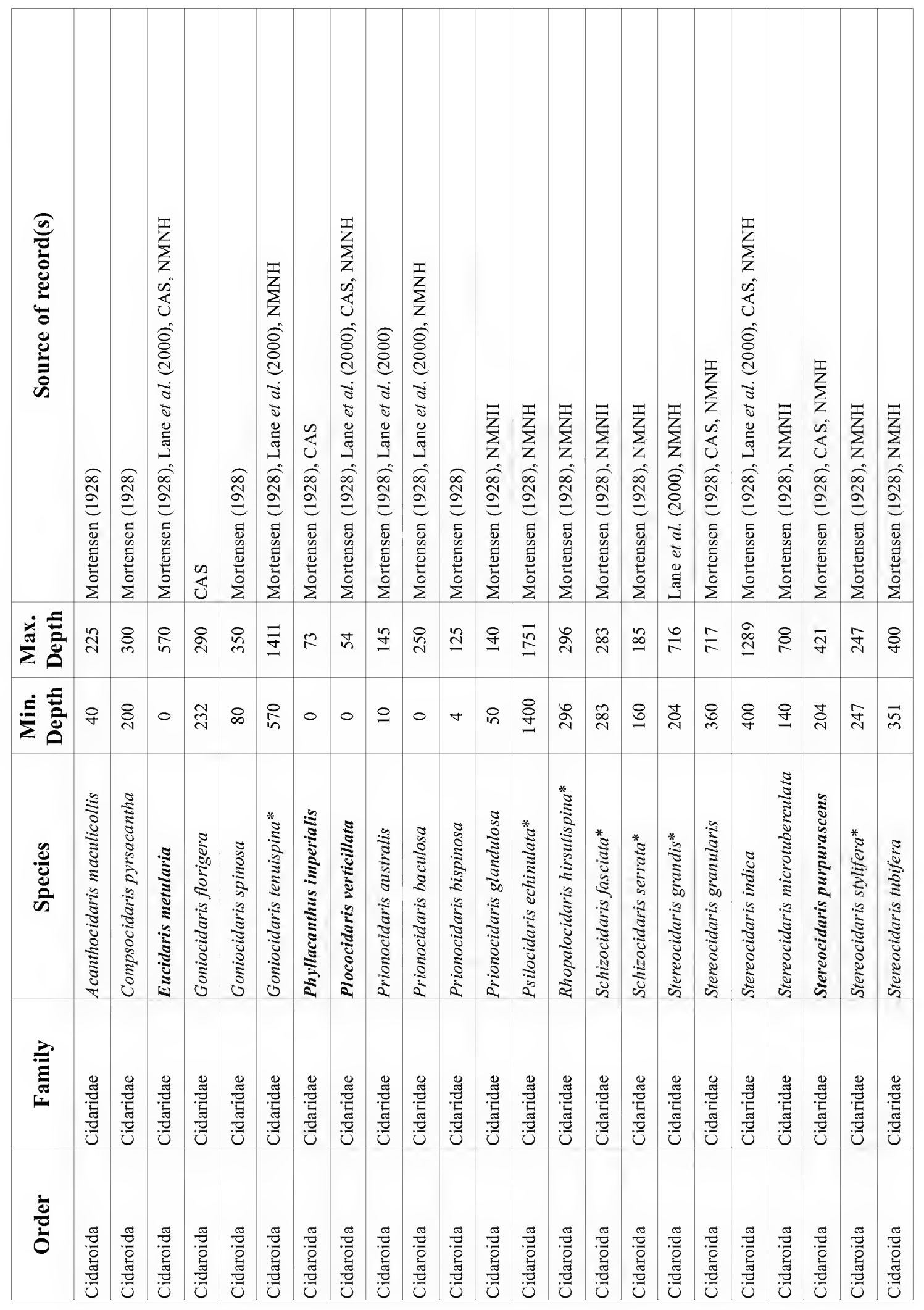




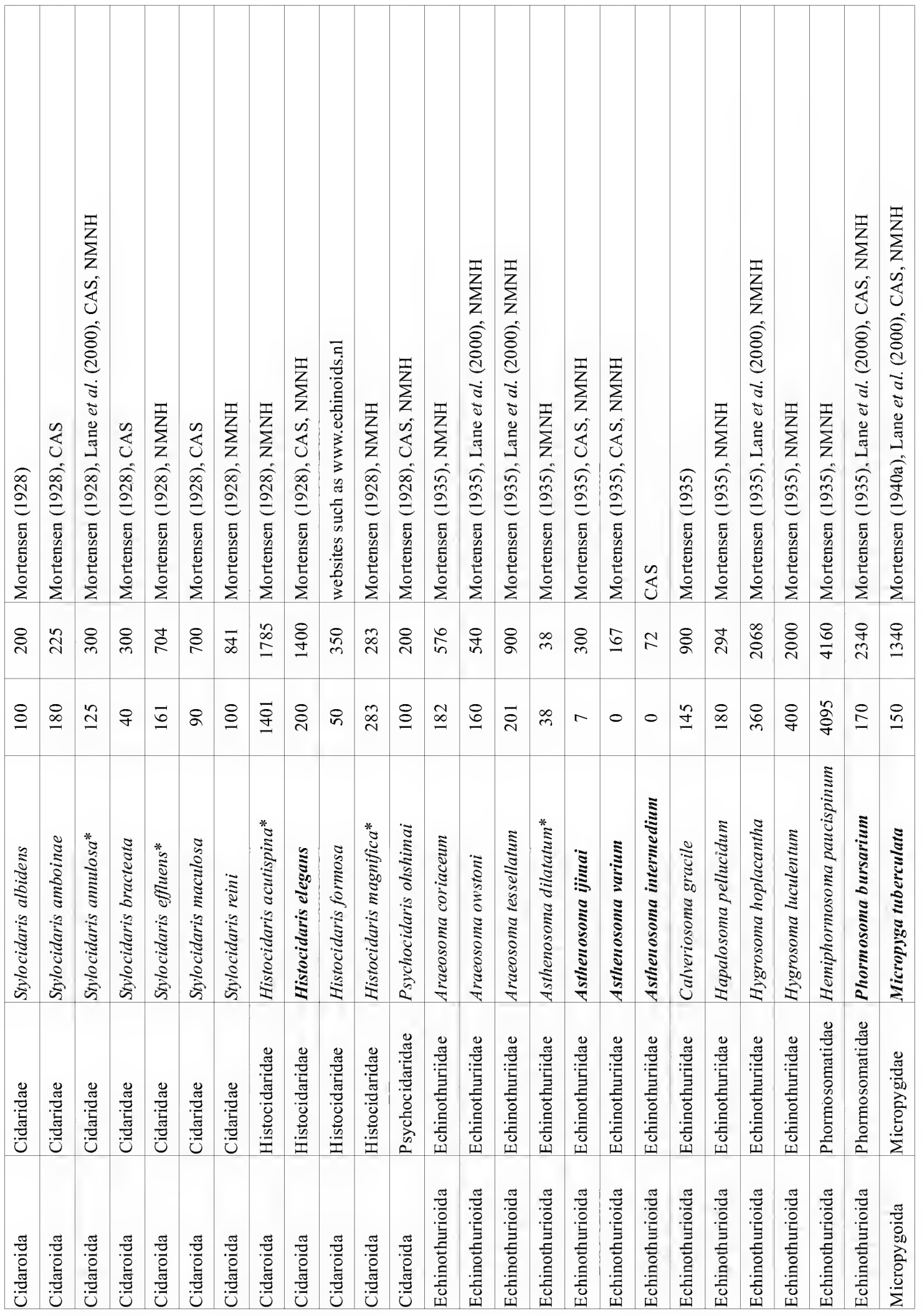




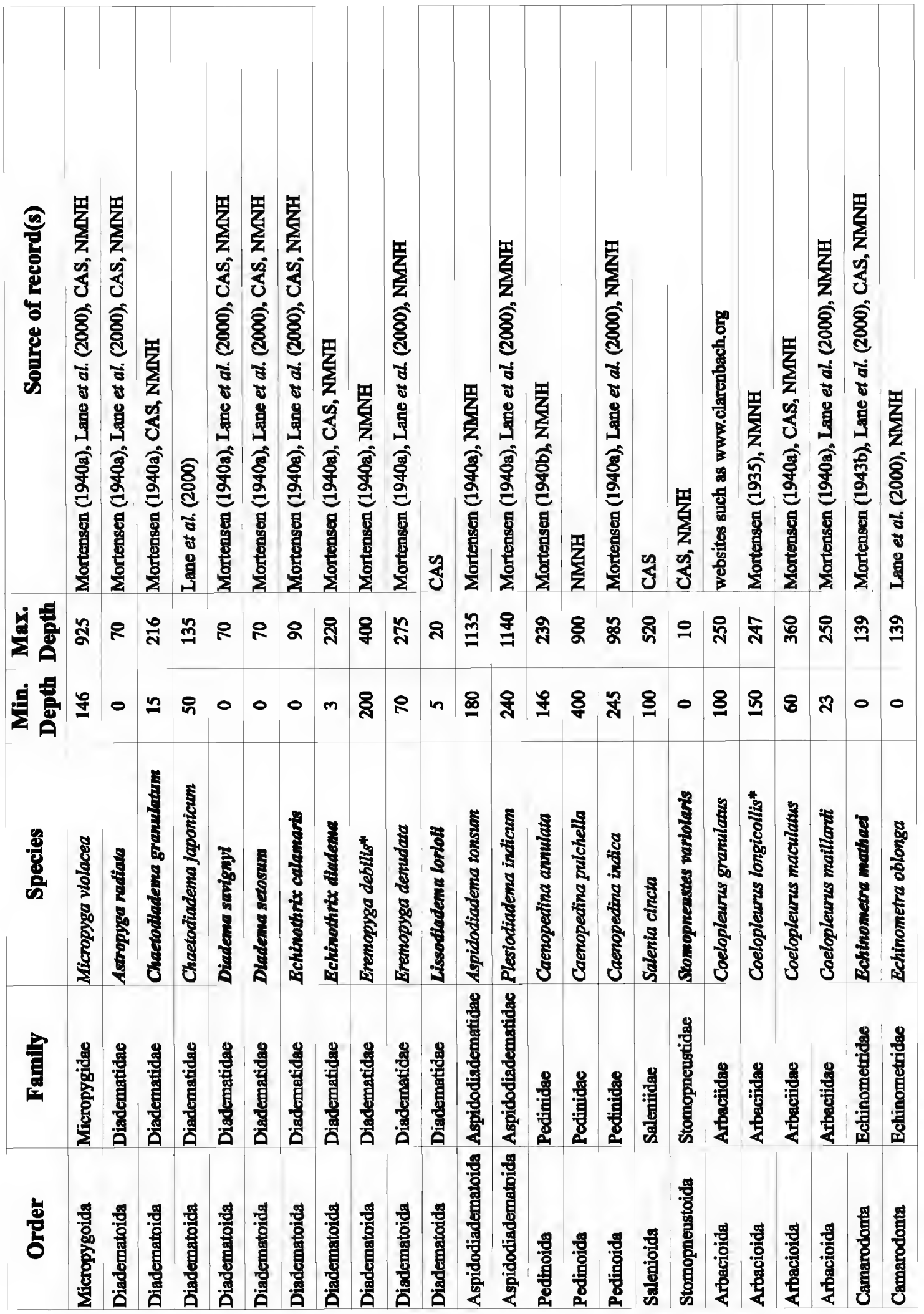




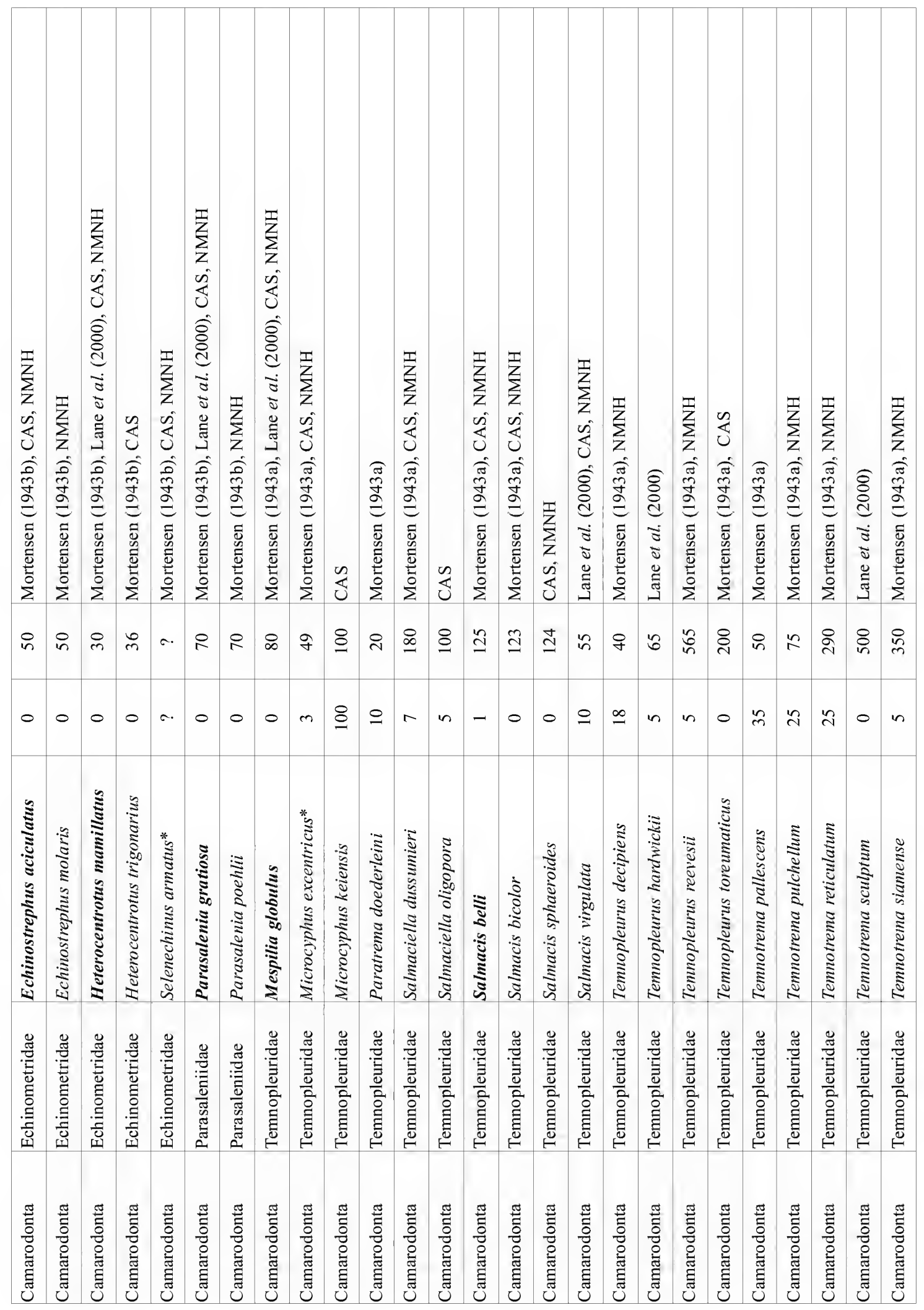



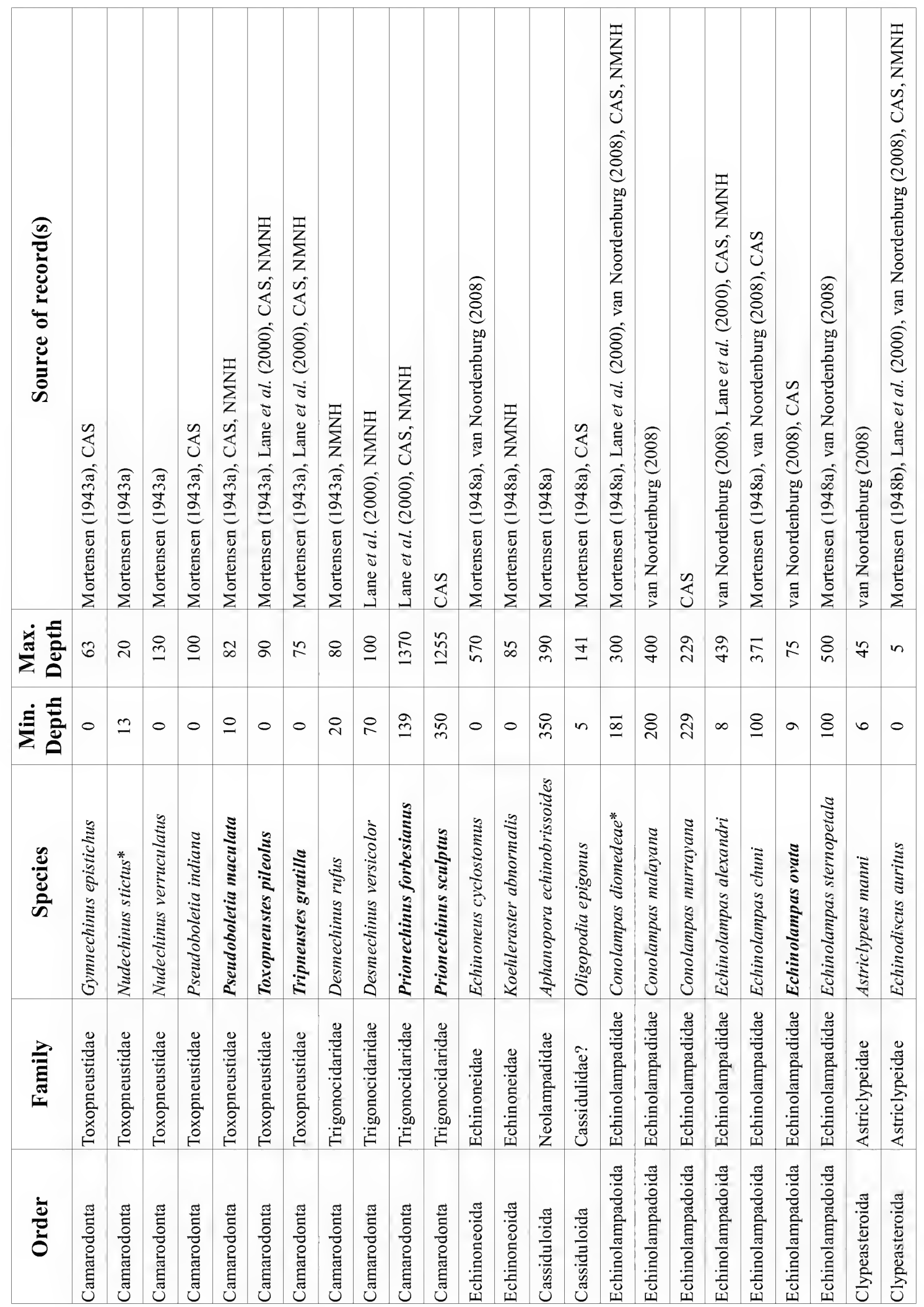

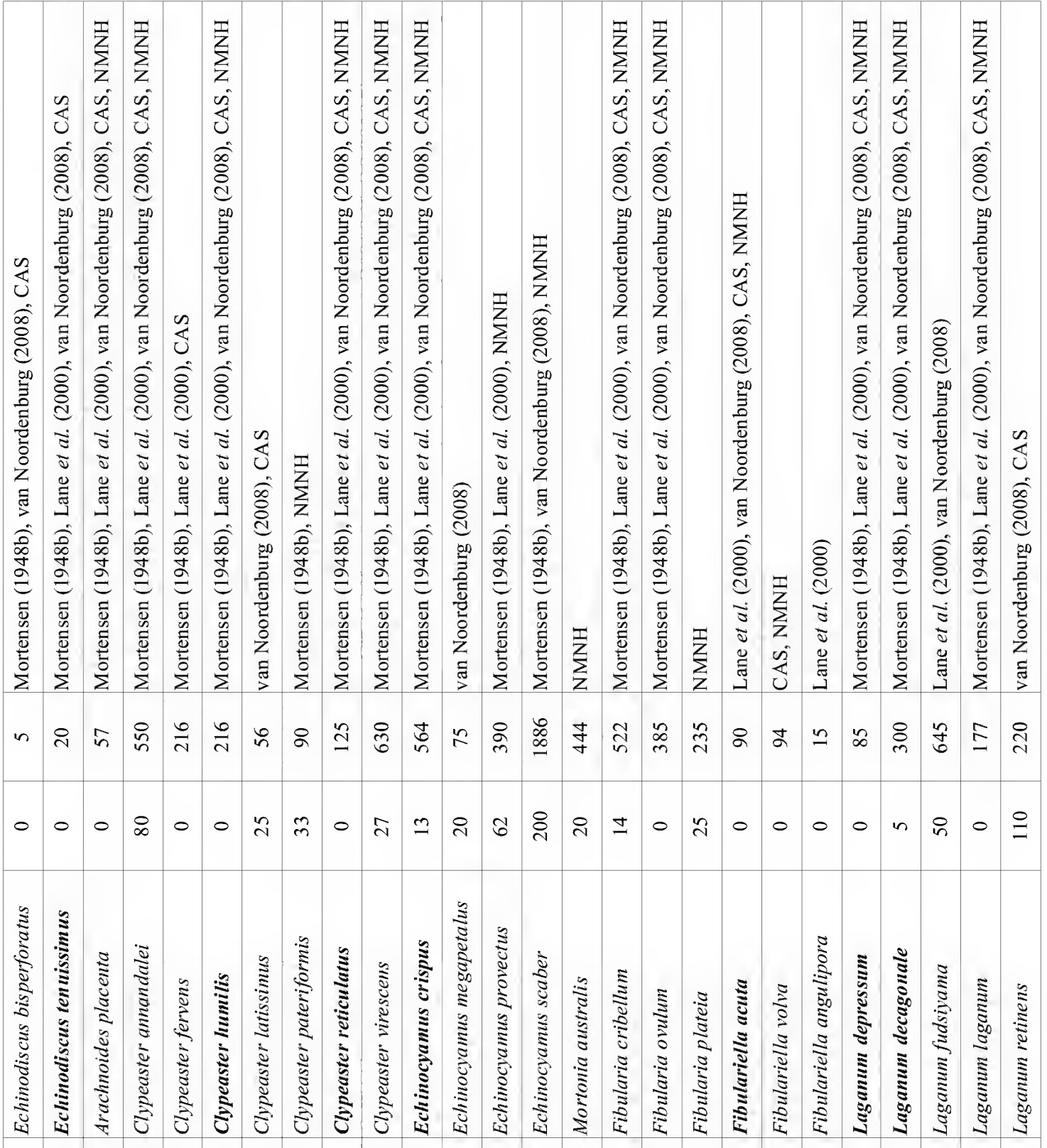

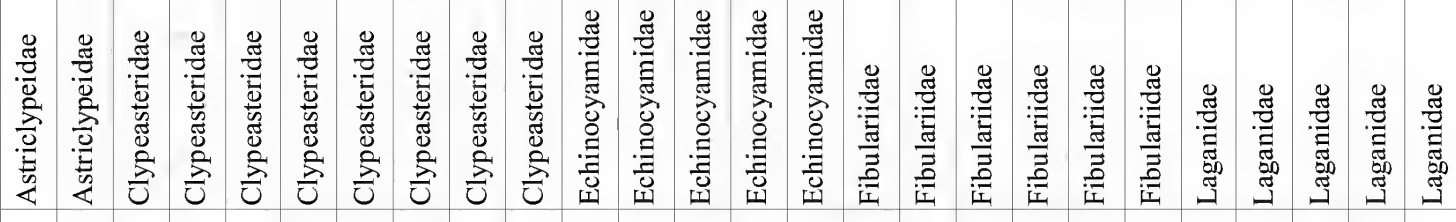

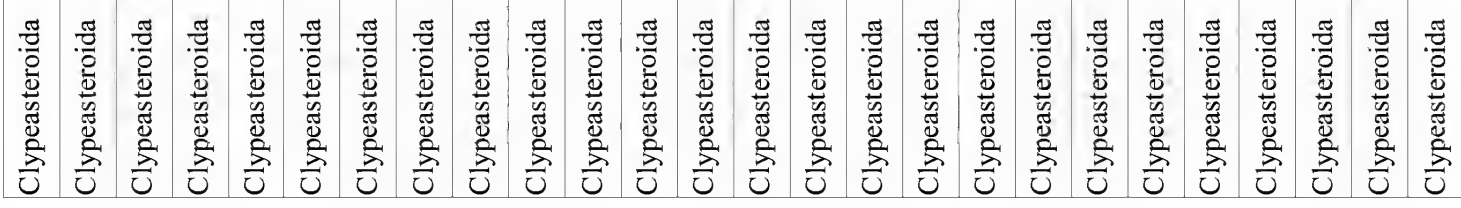



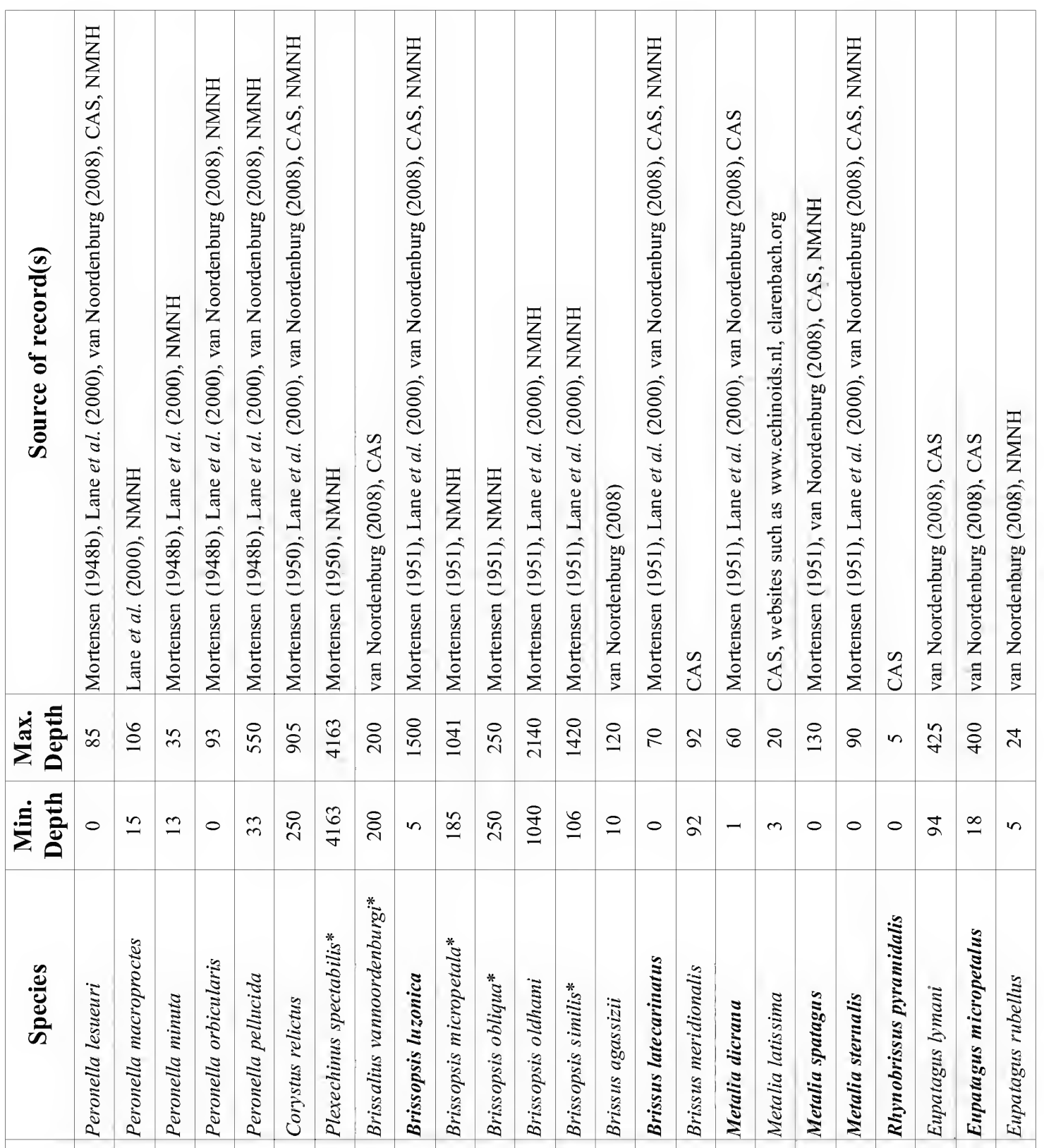

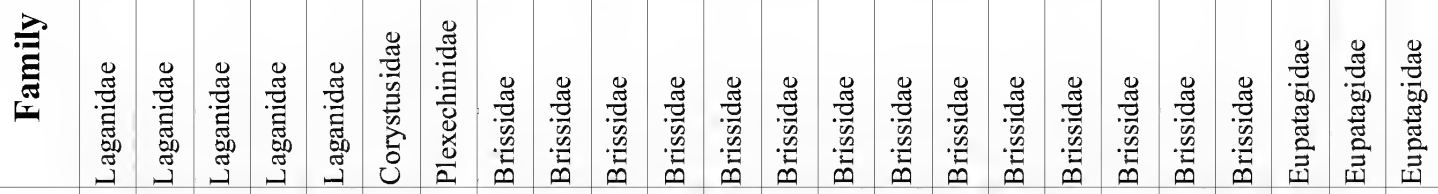

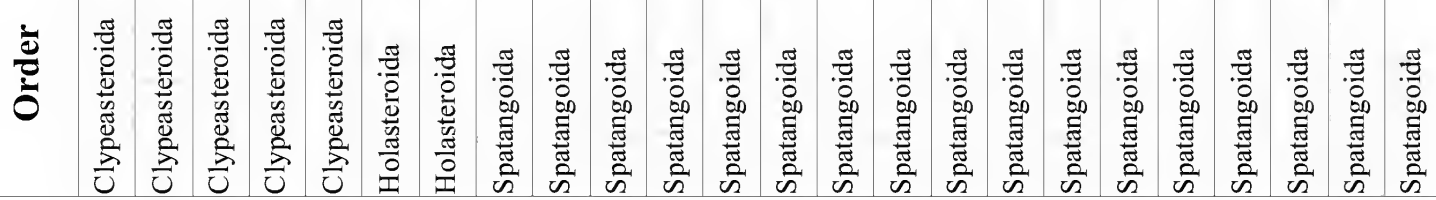




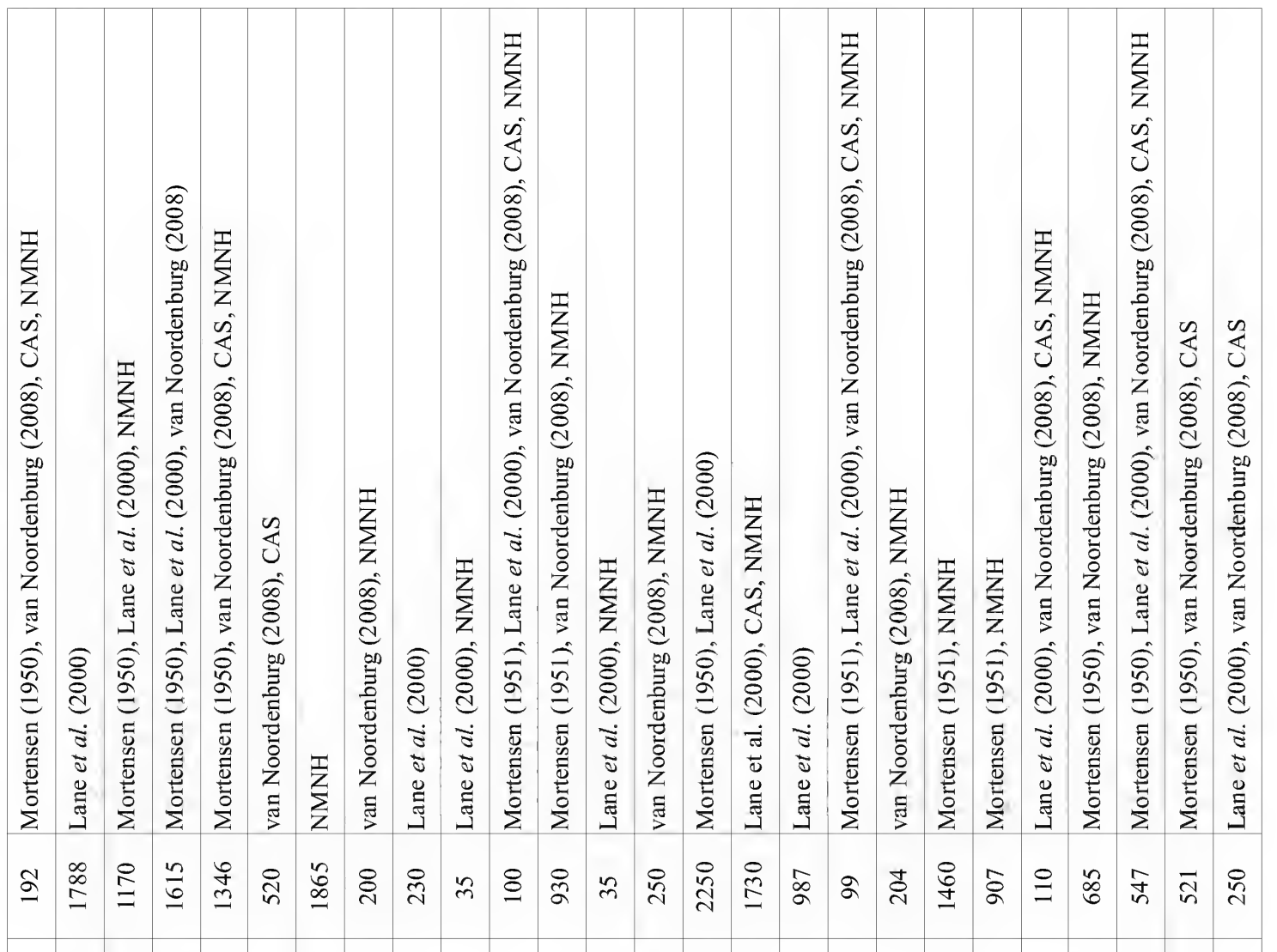

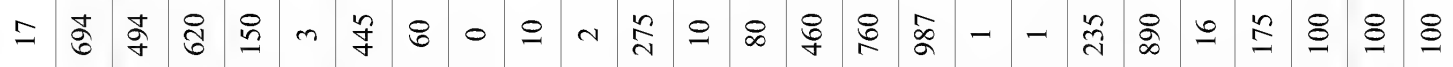

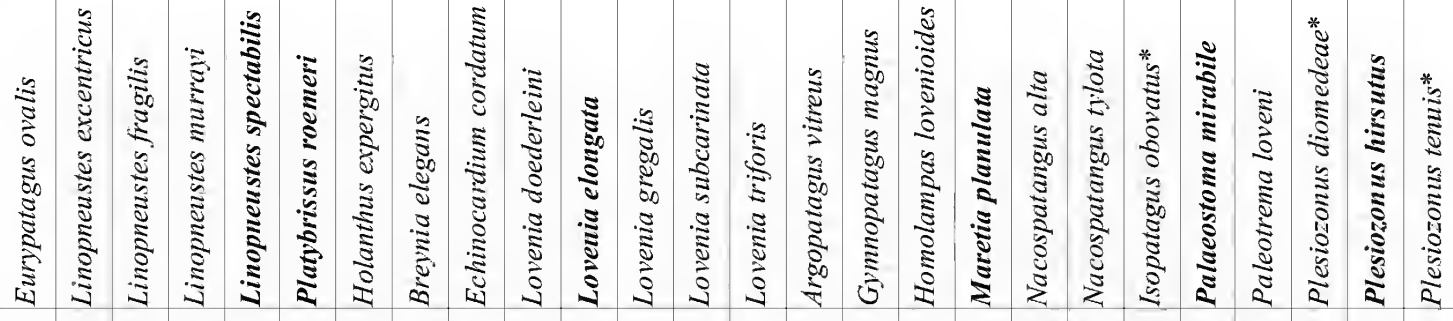

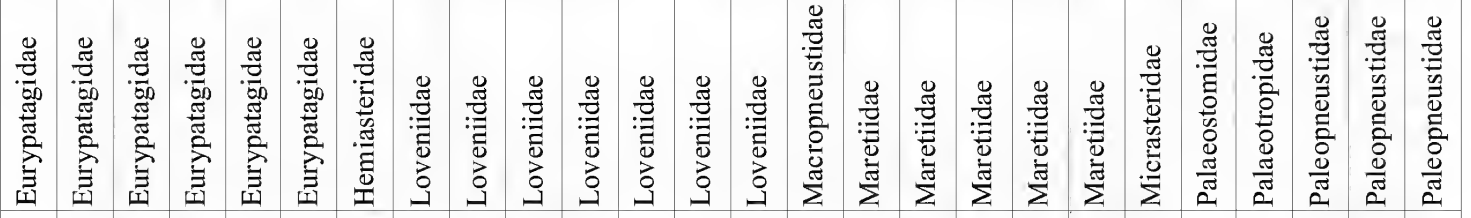

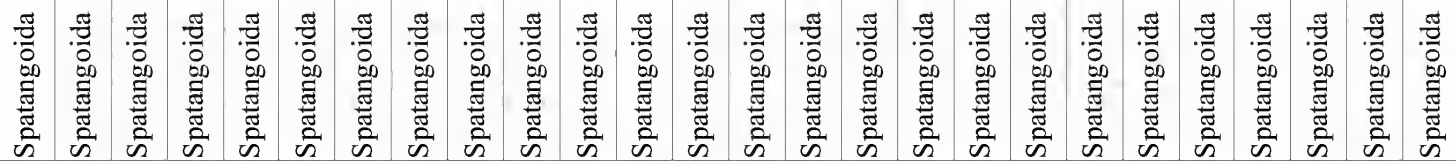




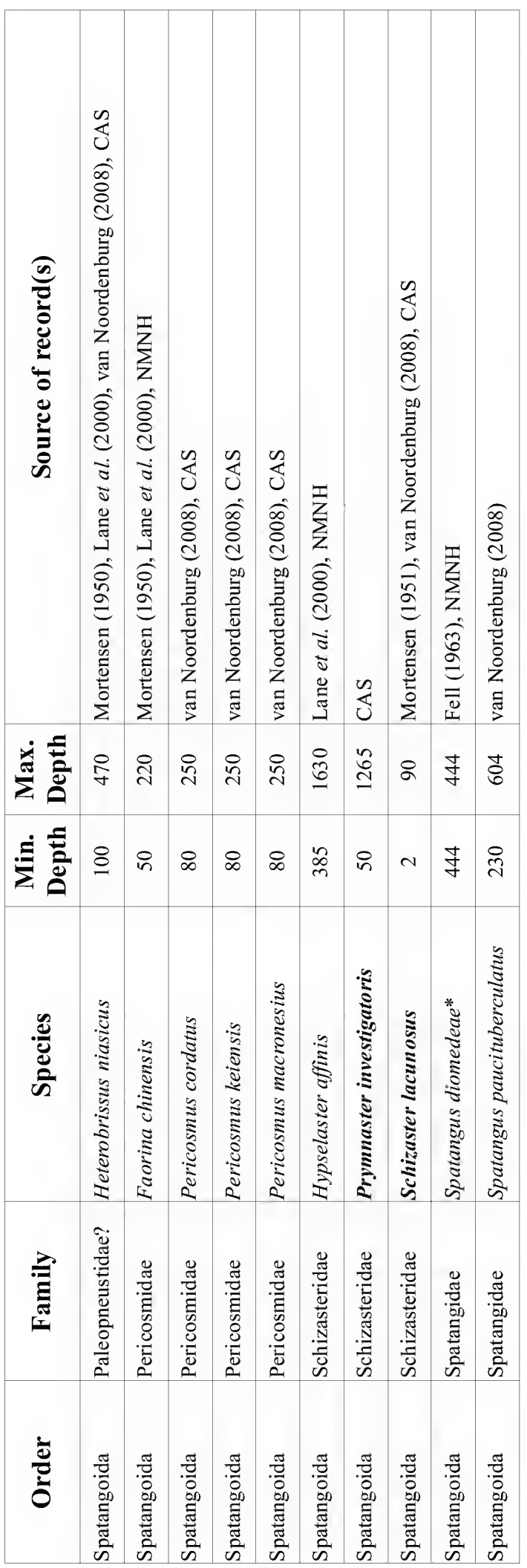




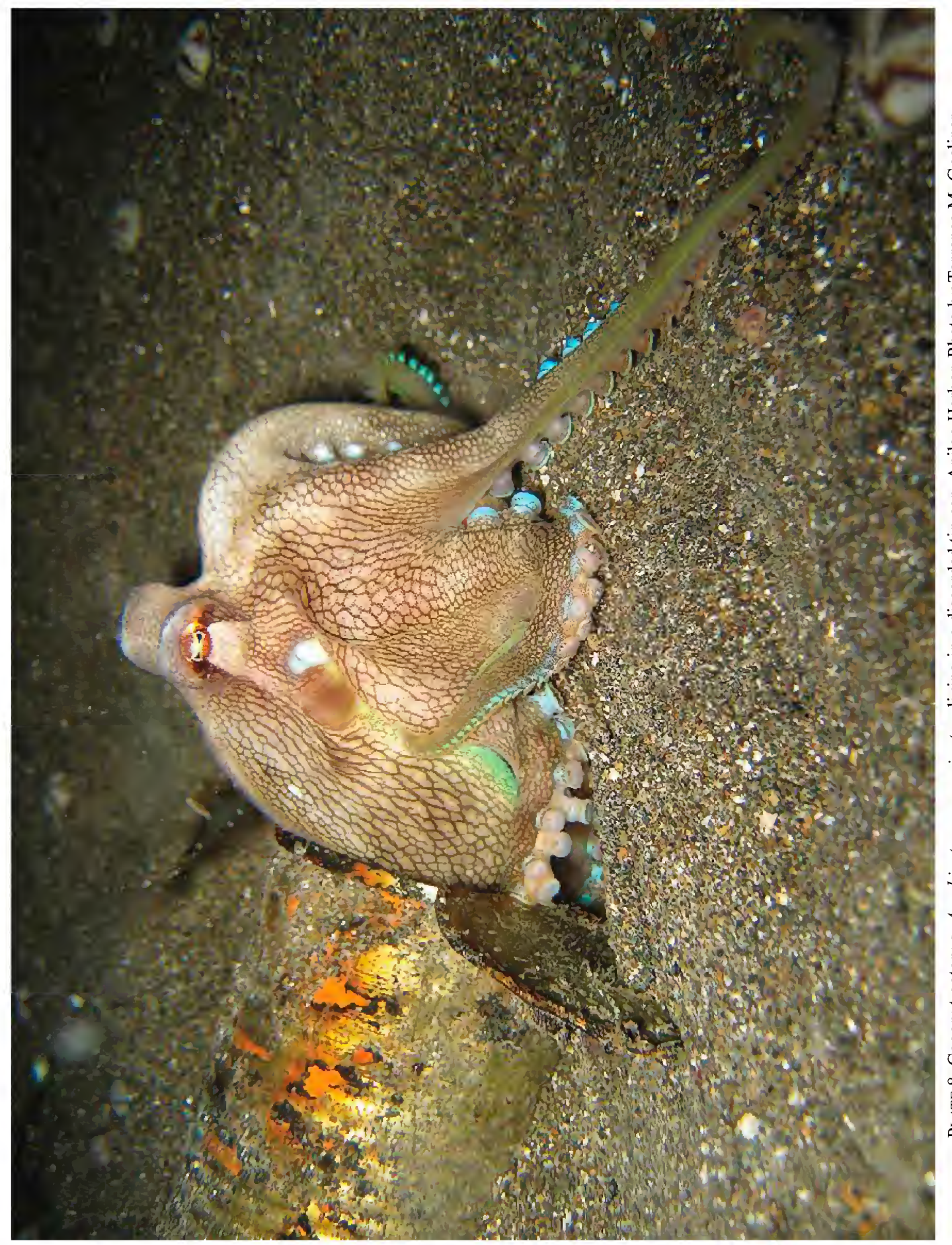




\title{
Collection, Transport and Husbandry of the Coconut Octopus, Amphioctopus marginatus (Taki, 1964) from the Philippines
}

\author{
Bart Shepherd, Richard Ross, and Marisa Avila \\ Steinhart Aquarium, California Academy of Sciences \\ 55 Music Concourse Drive, San Francisco CA 94118
}

\begin{abstract}
The coconut octopus, Amphioctopus marginatus (Taki, 1964), is a small, charismatic, tropical, day-active species of octopus that is well suited for aquarium display. Despite this, they are never seen in the marine aquarium hobby and have never been displayed in public aquariums. As part of the California Academy of Sciences' longterm scientific collaboration in the Philippines, we collected 25 individuals of $A$. marginatus on two occasions (May 2011 and November 2012) and transported a total of 18 coconut octopuses to Steinhart Aquarium for research and display. We developed techniques that support $100 \%$ survival of specimens during 3 critical stages: (1) collection via SCUBA, (2) temporary staging in the field and (3) international air-cargo transport. At Steinhart Aquarium, we successfully displayed $A$. marginatus in two separate exhibits. In aquaria, coconut octopuses lived their presumed natural lifespans (longevity up to 375 days post-collection, average of 195 days), exhibited typical behaviors observed in the wild, such as constructing dens and hiding in containers, and proved to be exceptionally popular with museum guests. The coconut octopus is a small-egged species with tiny paralarvae, complicating the development of aquarium-based captive breeding programs. In addition, commercial collectors have proven to be an unreliable source for this species. Thus, for the time being, successful aquarium display programs will likely involve targeted collecting trips.
\end{abstract}

The coconut octopus, Amphioctopus marginatus (Taki, 1964), is an engaging, relatively small species of octopus, reaching a maximum mantle length (ML) of $80 \mathrm{~mm}$ and weight of 400 grams (Huffard and Hochberg 2005). Amphioctopus marginatus is also a benthic octopus occurring in the shallow tropical seas of the Indo-West Pacific, ranging from the tropical waters of Indian and Western Pacific oceans in continental coastal waters (Norman 2000). We have observed numerous individuals of coconut octopuses living in close proximity to each other in sandy habitats in the Philippines, especially at sites with large numbers of discarded bottles, cans, ceramic pots or coconut shells: all of which are readily used as octopus dens (Fig. 1). These sites include areas heavily impacted by human activities, such as piers and shallow water near municipal centers. The coconut octopus has been observed to be active both in the day and at night, "exploiting" bright dive lights for opportunistic feeding during night dives as well as actively exploring surroundings and socially interacting with conspecifics during the day.

These characteristics make it a fantastic candidate for display in public aquariums. Many other species of octopus traditionally displayed in public aquaria are either nocturnal, extremely cryptic, or both, making them difficult to observe and enjoy. It is not uncommon for octopus displays to fail to engage public aquarium guests, either because the animals are out of view, hiding under tank decor, in rocks or crevices, or simply because they are so perfectly camouflaged as to be invisible in plain sight, By comparison, the coconut octopus is almost always in view due to its affinity of using bottles, cans or coconut shells as dens. Within aquaria, coconut octopuses tend to pick a den and stay positioned in it in such a way that at least part of their bodies remain visible to guests.

In popular literature and on the web, the common name has been changed from the veined octopus to coconut octopus based on descriptions of this species using empty coconut shells as 


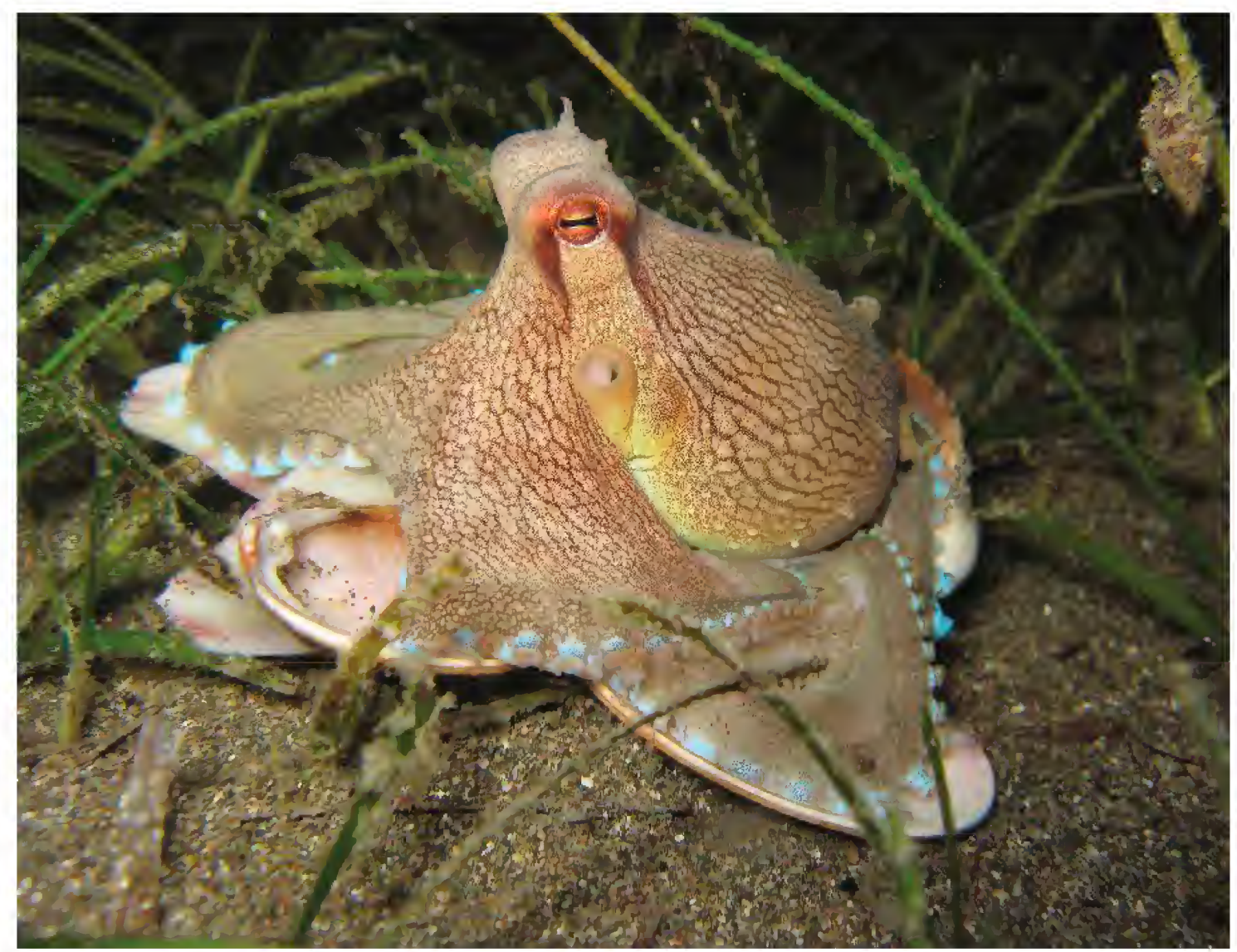

FIGURE 1. The coconut octopus, Amphioctopus marginatus (Taki, 1964), in its natural habitat in the Philippines. Note the "veined" appearance and the opalescence along the suction cups (defining characters used to identify appropriate specimens for collecting), as well as this individual's use of multiple (empty) bivalve shells as a portable den. Photo by Bart Shepherd.

tools as a portable defense mechanism (Finn et al. 2009). Amphioctopus marginatus have been observed carrying coconut shells under their bodies, 'stilt-walking' on the tips of their arms, and bringing two halves of a coconut shell together while hiding inside and rolling the shells across the sediment. Because it is presumed that the shell is being carried by the octopus for future (rather than immediate) use, and due to the complexity involved with correctly manipulating two different coconut shells into a single functioning "tool", these unique behaviors may satisfy the definition of tool use. However, it may be the case that the use of coconut shells by these octopuses is indeed for immediate use as protection from substrate dwelling predators. Amphioctopus marginatus is also one of several species of octopuses known to exhibit bipedal locomotion (Huffard et al. 2005).

There have been very few in situ research studies on this species. Huffard and Godfrey-Smith (2010) documented the details of Amphioctopus marginatus mating behavior. The male and female were observed to be in close proximity during mating, with periods of crawling along the open sand by both sexes. During mating, the male was observed 'reaching' his hectocotylus, a modified tentacle used to pass spermatophores into the female mantle cavity, and holding it horizontally above the substratum. It is unknown whether the 'reaching' behavior is necessary for mating, or how many spermatophores were passed to the female during mating. 
Ex situ research has also been scant. Amphioctopus marginatus are 'small-egged' octopuses; they produce copious amounts of very tiny eggs. Sreeja and Bijukumar (2013) observed a female that laid approximately 20,000 eggs. Their specimen ate the day she laid the eggs, but did not eat again after laying, and died on the eighth day following laying. Amphioctopus marginatus eggs are less than $6 \mathrm{~mm}$ in diameter, and laid in festoons of 33-45 eggs per centimeter of festoon. They were cemented to the inside of a coconut shell den, and the female tended the eggs for around 16 days, until they hatched as planktonic paralarvae (Sreeja and Bijukumar 2013). The paralarvae of $A$. marginatus, like in other paralarval octopuses, are very tiny (ML approximately $2 \mathrm{~mm}$ ). It has proven difficult to find first-foods to sustain them through the early life stages. Although there has been some reported success feeding primarily crab zoea, the survival and settlement rates remain low (Carrasco, Arronte and Rodríguez, 2006).

The California Academy of Sciences has a long-term research program focused in the Philippines. Two of our primary goals are to (1) study and document the tremendous marine biodiversity present in the more than 7,000 islands that define the Philippines, and (2) to use this knowledge to help inform and enhance conservation through education, social and scientific outreach - in the Philippines, online and in our facility in Golden Gate Park. Over the past twenty years, a particular focus for marine invertebrate biodiversity surveys is the area known as the Verde Island Passage (Fig. 2). This region has been called the "center of the center" of marine biodiversity due to the presence of more species of reef fishes than anywhere else on Earth (Carpenter and Springer 2005). In addition, more species of nudibranchs exist in this area than anywhere else on Earth (Gosliner, pers. comm.) and there is exceptionally high biodiversity in octocorals, with a single site, Devil's Rock, hosting more species of soft corals than the entire Caribbean basin (Williams, pers. comm.). Scientists from the Academy have visited this area since the early 1990s, documenting species diversity and collaborating with in-country partners such as the Bureau of Fisheries and Aquatic Resources (BFAR), the National Fisheries Research and Development Institute (NFRDI), and the University of the Philippines (UP).

In the mid 2000s, the Academy signed a memorandum of understanding (MOU) with BFAR and NFRDI to foster international collaboration on documenting marine biodiversity, to create a framework for the continued training of Filipino students and scientists, and for the development of novel animal husbandry techniques. The latter component supports one of Steinhart Aquarium's core strategic goals: to both increase the sustainability of the marine aquarium trade in the Philippines and to foster the development of new economic incentives to protect and steward Philippine coral reefs (e.g., through jobs created by the aquaculture of marine aquarium species). Our work with the coconut octopus directly supports this aspect of the MOU through the development and dissemination of new techniques for the collection, transport, husbandry and captive management of a charismatic species that is not currently traded within the international marine aquarium industry.

\section{Materials AND Methods}

Collecting.- Coconut octopuses were collected on two occasions in the Verde Island Passage area of the Philippines, Batangas Province, Luzon Island, near the municipality of Mabini (Fig. 2). On both occasions, gratuitous collecting permits were secured through our MOU with BFAR and NFRDI. In addition, we obtained Mayor's permits granting us permission from the local government to collect on reefs located within the municipal waters of Mabini and Tingloy. All animals were collected in shallow water (2-8 meters depth), at night, using SCUBA, at the dive site "Anilao Pier" $\left(13^{\circ} 45.62^{\prime} \mathrm{N}, 120^{\circ} 55.56^{\prime} \mathrm{E}\right)$. Dives were conducted from local boats, called "bankas", based at the dive resort Club Ocellaris $\left(13^{\circ} 46^{\prime} \mathrm{N}, 120^{\circ} 58^{\prime} \mathrm{E}\right)$, with local SCUBA dive guides assist- 


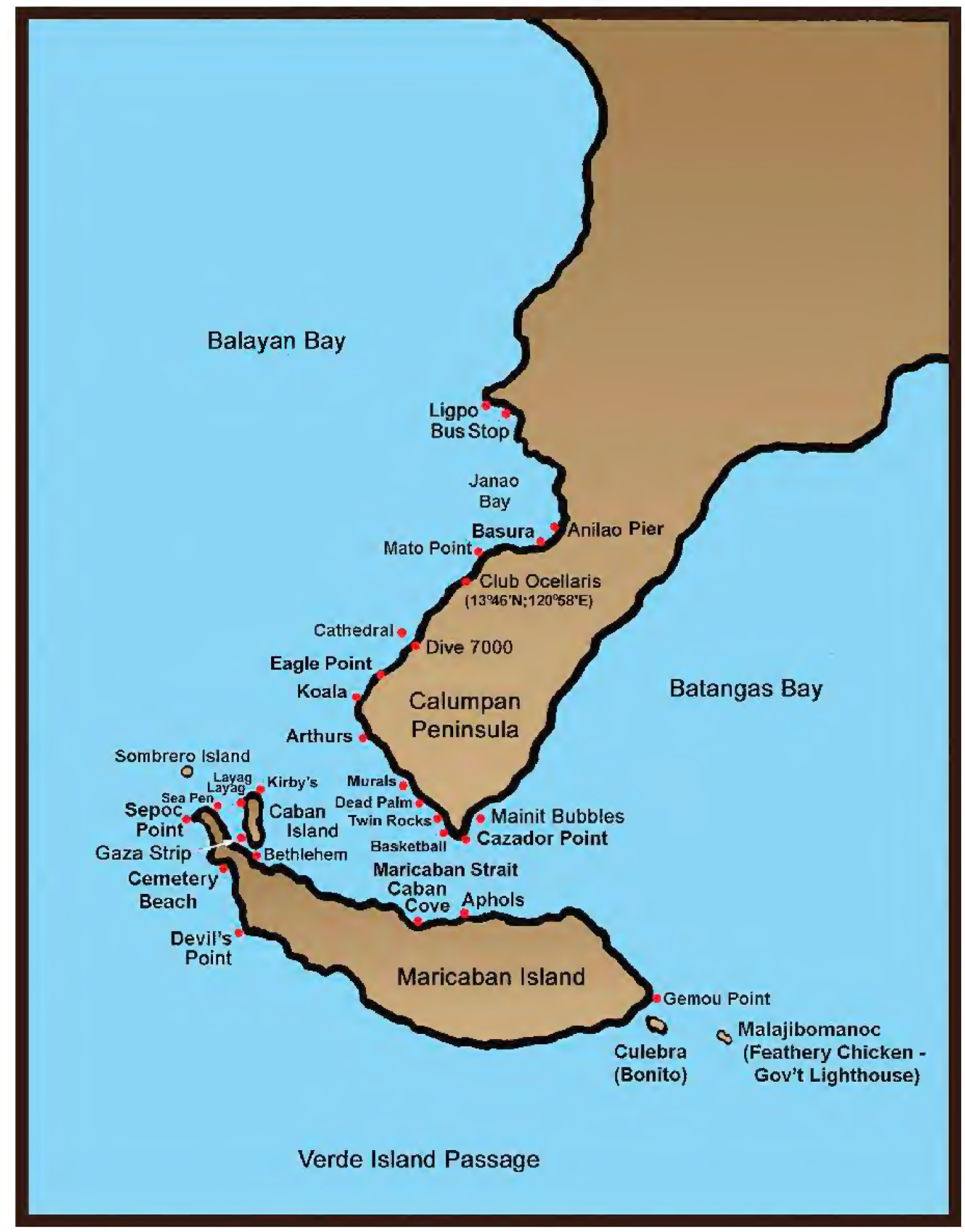

FIGURE 2. The Verde Island Passage area traditionally known as "Anilao". This region features numerous dive sites of varying composition: reefs, "muck diving", sea grass beds and rubble habitats. The Coconut Octopus, Amphioctopus marginatus, was collected at Anilao Pier, just north of our field station, Club Ocellaris, Mabini, Batangas, Philippines. Map by Gary Williams. 
ing in the identification of appropriate sites and individual specimens. In this area, A. marginatus is relatively easy to identify underwater, even at night, due to the conspicuous opalescence along the suction-cups, as well as their typical behavior of hiding within bivalve shells, small cans, bottles or broken coconut shells (Fig. 1).

Our first attempts at collecting coconut octopuses occurred during the shallow-water component on the Academy's Philippine Biodiversity Expedition in late May 2011, funded by William Randolph and Margaret Hearst. Smaller sizes were preferentially chosen for ease of transport and longevity, as small specimens were presumed to be the youngest specimens. All animals were collected in clear plastic bags or rigid plastic jars with mesh lids. Whenever possible, each octopus was collected with its den in order to reduce stress and give the specimens cover and structure during the transport. In these cases, octopus dens consisted of small bivalve shells, cans or bottles. Following collection, specimens were returned to our field station by banka (approximately 30 minute transit time) and immediately staged in holding containers placed in shallow water just offshore of our field station. The next morning the animals were removed from the ocean and transported to Manila (approximately 120 minutes by car) where they were prepared and exported to the Steinhart Aquarium.

The second collecting trip occurred at the end of a Steinhart Aquarium led expedition focused on developing our coral conservation efforts in the Philippines. We were joined on this trip by biologists from the SECORE Foundation (Bremen, Germany), The Florida Aquarium (Tampa, Florida, USA) and Moody Gardens (Galveston, Texas, USA). Florida Aquarium and Moody Gardens staff assisted in the collecting, transport and documentation of these efforts and we are very grateful for their contributions. Our methods closely resembled the initial collecting trip, except for two major differences. First, as an attempt to eliminate death by "rigor" during collection (see results and discussion), we decided to use only rigid plastic jars rather than clear plastic bags (Fig. 3). Second, to increase longevity and reduce the size of our transport container, we focused our collecting efforts on extremely small specimens $(<2$ cm ML).

Square-sided plastic jugs constructed of FDA-approved PVC were purchased from TAP

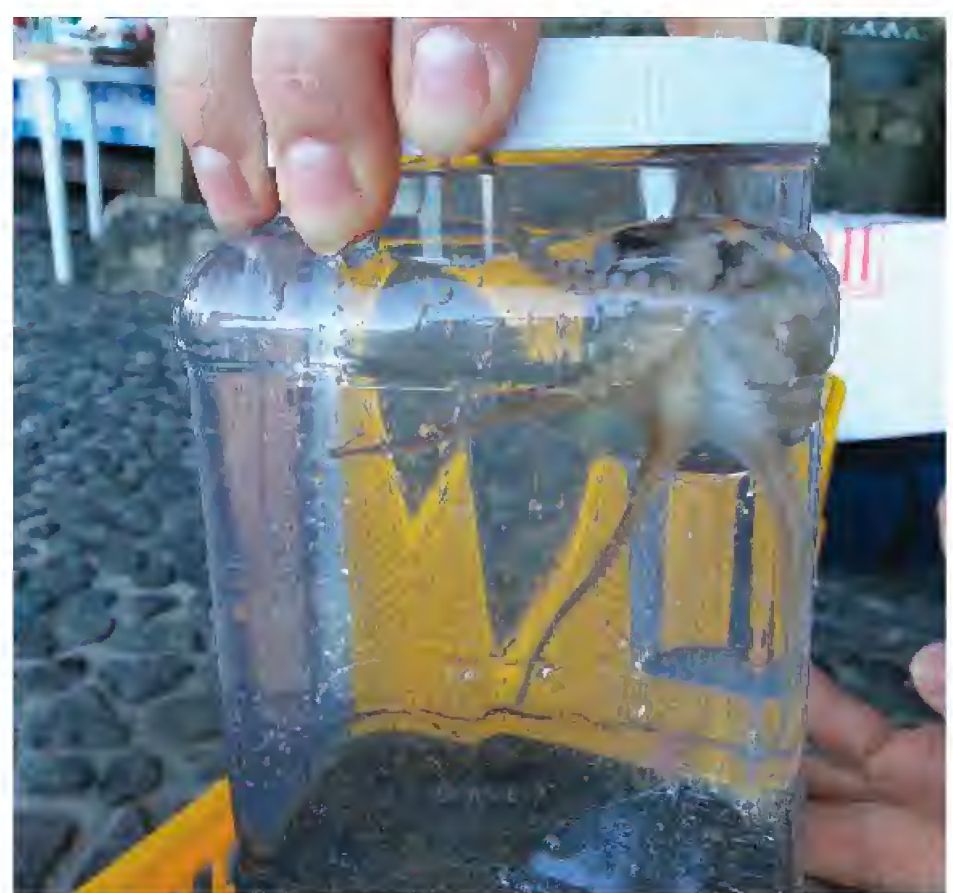

FIGURE 3. Clear, food-safe plastic jars with tight fitting screw top lids were used for collecting, staging and both short and long-distance transports with a high degree of success (100\% survival). Photo by Eric Hovland.

Plastics (Easy Grip Plastic Jugs, www.tapplastics.com, USA). The uniform size and cube-like shape of these containers facilitated packing in Styrofoam aquarium shipping boxes, while the plastic protected the octopuses during the collecting dive (40-60 minute bottom time), transport back to the field station ( 30 minute boat ride) and transport to the shipping facility (2-3 hour car ride). 
Two sizes of containers were selected: 1 liter $(32 \mathrm{oz})(\mathrm{n}=8)$ and 2 liter $(64 \mathrm{oz})(\mathrm{n}=2)$. Both sizes have tight-fitting screw-on lids that are easy to manipulate under water. To prepare the jars for our purposes, a $5.08 \mathrm{~cm}(2$ inch) hole was drilled into each lid, and $1 \mathrm{~mm}$ fiberglass window screen was glued over the opening with cyanoacrylate glue. These containers were used to both collect and ship the coconut octopuses collected on the second expedition. Following collection, specimens were returned to our field station by banka (approximately 30 minute transit time) and immediately staged in holding containers placed in shallow water just offshore of

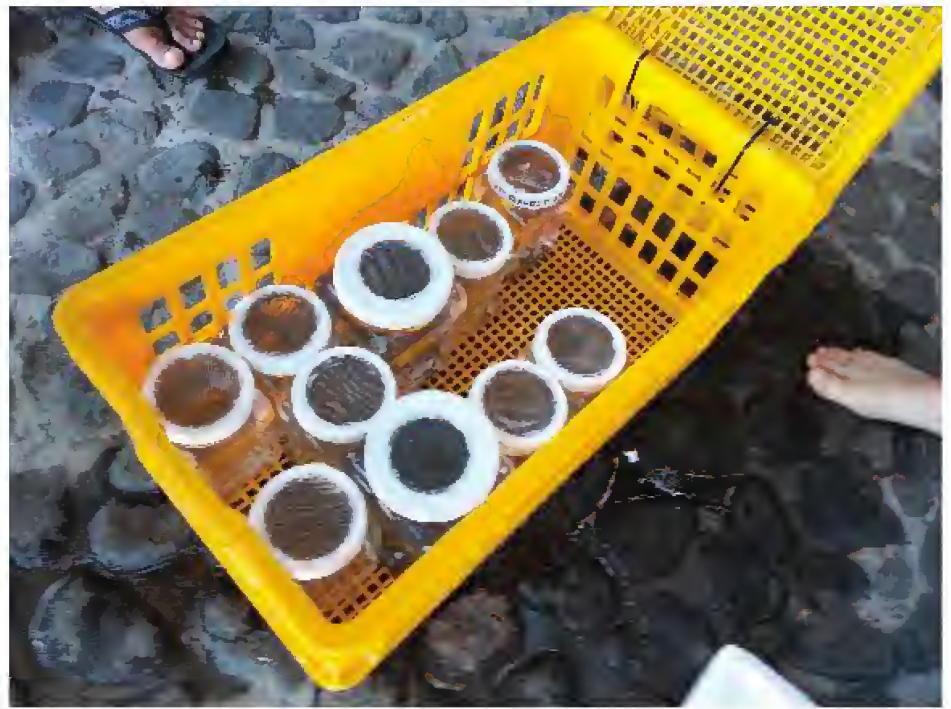

FIGURE 4. Plastic collecting containers and storage crates were used for temporarily staging the coconut octopus. The collecting containers were secured between the two crates, weighted down with large stones and placed in shallow water off of our field station in between collecting and shipping. Photo by Eric Hovland.

our field station. The 11 specimens were held overnight in the plastic collecting containers,locked between two heavy plastic milk crates, and secured on the bottom using large round stones (Fig. 4). The next morning the animals were removed from the ocean and transported to Manila where they were prepared and exported to the Steinhart Aquarium.

SHIPPING.- The coconut octopuses we collected in May 2011 were professionally packed at an aquarium export facility (Aquascapes Philippines, Manila) with oversight by Steinhart Aquarium biologists. Animals collected in metal dens (cans) were removed from their dens prior to shipping to avoid the risk of the corroding metal contaminating the transport water. All specimens were shipped in clear plastic deli cups with $1 \mathrm{~mm}$ mesh window screen tops to protect them from being trapped in the corners of the shipping bag, while still allowing access to well-oxygenated water. The deli cups created a den-like, contained space for the animals, and prevented them from biting through the shipping bag. Each individual deli cup was placed in a large, clear, plastic shipping bag filled with a total volume of approximately 2 liters, consisting of $50 \%$ seawater and $50 \%$ oxygen. The salinity of the shipping water was adjusted to match the salinity of the water with which the octopus were collected. Shipping bags were placed inside a second bag (double-bagged) with a newspaper liner in between the two layers, and then packed tightly inside Styrofoam coolers with cardboard outer liners. Small pieces of ice were used to keep the temperature inside the shipping boxes cool for the time between packing and when they were loaded on to the aircraft. All eight specimens of coconut octopus were shipped on a direct flight from Manila to SFO (total transit time of 14 hours). Export permits were arranged with BFAR and coordinated with Aquascapes Philippines and our stateside customs broker (Service Express, San Francisco, California, USA).

As with the first collection, the animals from our second collection were professionally packed at an aquarium exporter (Aquascapes Philippines, Manila) and the salinity of the shipping water was adjusted to match the water in which the octopuses were collected. This time, however, all specimens were shipped inside the plastic collecting jars. The jars were placed inside a large plastic shipping bag with a ratio of approximately $50 \%$ seawater and $50 \%$ oxygen (Fig. 5). In contrast 
to a typical international aquarium fish shipment, where water volumes are minimized to reduce shipping costs, we shipped these containers "heavy"; each specimen was shipped with approximately 2-3 liters of seawater. Again, this approach allowed animals access to an abundance of high-quality, well-oxygenated water, increased the stability of the temperature during the long duration of the air transport, protected the octopuses from being trapped in the 'corners' of a flexible shipping bag, gave them a secure den-like space during shipping and eliminated the possibility of them puncturing the shipping bag with their beaks. As

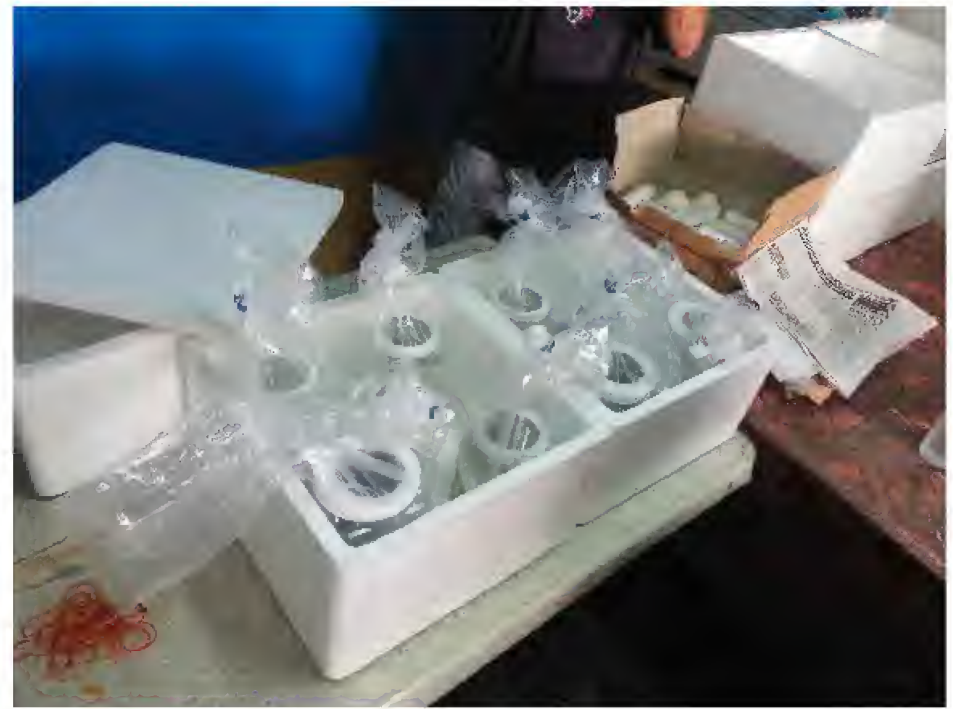

FIGURE 5. Successful shipping was accomplished by packing the coconut octopus in individual hard plastic containers within plastic bags. Doublebagged specimens were tightly packed in styrofoam coolers with outer cardboard shells. Photo by Eric Hovland. with our first collection, the animals were double-bagged with newspaper liners in Styrofoam coolers with cardboard outer liners, and ice packs were used. The boxes were then shipped air cargo on a direct flight from Manila to SFO, with a total transit time of 14 hours. Export permits were arranged with BFAR and coordinated with Aquascapes Philippines and our stateside customs broker (Service Express, San Francisco, CA, USA).

AQUarium Display.- We displayed single individuals of coconut octopus in two separate aquaria over a period of 2.5 years. The first (Animal Attraction gallery, May 2011-March 2013) was a 350-liter acrylic aquarium (122 $\mathrm{cm} \times 60 \mathrm{~cm} \times 46 \mathrm{~cm}$ ), the second (Water Planet gallery, March 2013-present) is a 240-liter acrylic aquarium (60 $\mathrm{cm}$ cube). These exhibits have very tight fitting lids made from twin-wall polycarbonate greenhouse material held in place by plastic coated lead weights. The exhibits were set up as 'natural systems' where biological filtration is provided by live rock. Mechanical filtration, oxygenation and off gassing of carbon dioxide is provided via foam fractionation (ASM protein skimmer, model G4). Lighting consists of a combination of blue and white, 3 x 1 watt MR-16 LED lamps (EcoGreen Solutions, Laguna Niguel, CA, USA). Water parameters are maintained at standard levels for delicate marine invertebrates (Table 1).

Tank decor consists of a few coral rubble rocks, small bivalve shells, coconut shells, glass bottles and jars. The tank substratum was initially "Mineral Mud" (CaribSea, Florida, USA), which closely mimics the muck substrata in which these octopuses are found. This was later replaced with silica sand for maintenance reasons and the animals showed no behavioral changes when substratum was switched. Chocolate Chip Starfish, Protoreaster nodosus (Linnaeus, 1758) were sporadi- 
cally used as a scavenger to keep uneaten food from degrading water quality. Live algae, Caulerpa prolifera (Lamouroux, 1809), was grown in the exhibit to assist with maintaining high water quality and guest visual interest.

FeEding.- At Steinhart Aquarium, Amphioctopus are fed live freshwater ghost shrimp enriched with CYCLOP-EEZE (Argent Chemical Laboratories, Redmond, WA, USA), live Crangon shrimp, frozen Crangon shrimp, locally collected crabs (Hemigrapsus spp.), and live Manila clams (Venerupis philippinarum). Crangon shrimp are commonly used as bait for recreational fishing, and are purchased from a fishing supply store. Manila clams are purchased from a restaurant seafood industry supplier. In the rare instances that live shrimp were not available, frozen prawn was accepted and eaten by the octopus. Food was often given in jars (see below) and inside wiffle balls as part of a formal behavioral enrichment program.

Attempts to Acquire Specimens Through Commercial Sources. - As the animals from our May 2011 collecting trip began to get old and undergo senescence, we made several attempts to obtain replacement octopuses through the normal public aquarium channels of commercial collectors and suppliers. None of these attempts were successful. Instead of receiving Amphioctopus, we received several shipments of Abdophus or Macropus. The second author has experienced this trend for the last 10 years. We postulate that because octopus are rarely collected for the marine aquarium trade, it is very difficult to find collectors that can tell the difference between the various octopus species. Also, Amphioctopus occur in areas that are not often visited by commercial collectors, and most are unwilling to do special trips to selected areas for only one kind of animal as such trips are not cost effective. It is unknown whether Amphioctopus are targeted or opportunistically caught in traps used by traditional fishers, or whether this method could be used to collect specimens without requiring SCUBA.

On our November 2012 collecting trip, we invited a commercial collector working for Aquascapes Philippines to join us on the expedition to learn how to identify the species, where to find it, and to learn appropriate collecting techniques. This was an attempt to create a reliable source for future acquisitions of Amphioctopus marginatus. The fisherman joined us on the boat, saw the collecting sites and snorkeled with us while we collected the specimens. Challenges here revolved around a language barrier (all communication was through a translator) and limited access to equipment (everything from SCUBA equipment and underwater flashlights to the plastic collecting jars). It remains to be seen whether or not this will be an effective strategy for future acquisitions of coconut octopus.

\section{RESULTS AND DisCUSSION}

Collecting AND ShipPing.- On May 24, 2011, as part of the Hearst expedition, Steinhart Aquarium biologists collected a total of 14 specimens exhibiting a range of sizes from $0.75 \mathrm{~cm}$ to $5.0 \mathrm{~cm}$ ML. During collection, three larger octopuses died of what we now call "rigor": a stiffening of arms and mantles. These three individuals were all larger animals. Two died almost immediately (before the collection dive was over). The third specimen was inactive but still alive when we returned to our holding area; this individual died during the night.

The cause of this sudden mortality is unknown, but we postulate that this may be a "fear" reflex, and is perhaps a result of collecting larger animals without dens and placing them in clear plastic bags. An alternate explanation is that the larger specimens experienced a sudden decrease in water quality while enclosed in the plastic bags for the duration of the collecting dive. This rapid decrease in water quality could be caused by increased physiological activity resulting from the stress associated with collecting, or perhaps due to the animal inking in the bag. A drop in dissolved oxygen or an accumulation of carbon dioxide or ammonia could cause sudden mortality in the min- 
imal water volume in a sealed collecting bag. No water quality tests were conducted in the field, so we have no data to substantiate this hypothesis.

During the night, three specimens secured in individual small containers inside of a 20 liter opaque plastic bucket went missing. We assume that local fishers, who are regularly seen out on the reef at night, took the bucket. Our other temporary holding containers, "Kritter Keepers" (Lee's Aquarium and Pet Products, San Marcos, California, USA) were not taken, presumably because the clear boxes were less visible or because the "Kritter Keepers" are less desirable than the opaque plastic buckets. This was the first and only time we used plastic buckets as an offshore holding container.

We were only able to ship eight specimens out of the 14 that we collected on our first expedition, as three were lost, and three died of rigor. Initial mortality resulting from collecting on our first expedition was $21 \%$. This is significantly higher than expected, and higher than we have experienced when collecting other species for aquarium research and display. During shipping, an additional specimen died in transit, bringing the total mortality rate for our first collecting and shipping trial to $29 \%$. In total, only seven of the 14 specimens collected on this first trip made it to Steinhart Aquarium for display, representing a $50 \%$ success rate from field collection to exhibit. If we exclude the three specimens that went missing with their bucket, this success rate climbs to $64 \%$.

A total of 11 octopuses were collected on our second expedition (November 19,2012). Despite the presence of fishers, heavy currents and surge in the area, all 11 specimens were alive the following morning when they were removed from the ocean for packing and transport to Manila to be exported back to Steinhart Aquarium. Because our export permit only allowed us to ship 10 specimens to Steinhart Aquarium, a single specimen was released the morning following collecting. No animals died during transit. The $0 \%$ mortality rate on our second collecting and shipping trial was likely the result of our collecting only small individuals, collecting the animals with their dens, and using the rigid plastic containers for all stages of the operation: collection, temporary staging and shipping. The screened tops of these containers allow for continuous water exchange and thus prevent rapid degradation of water quality due to physiological processes or inking. This is a model that we will use for any future collections of small octopuses.

SEASONALITY, SYMPATRY, AND LIFESPAN.-Amphioctopus marginatus were readily available during the months of May and November when these collecting expeditions occurred. During both of these times, a wide range of sizes was visible, and small specimens were targeted for collecting. This suggests that eggs of this species may hatch during the spring or early summer. The presence of many individuals of several sizes is likely a result of the individuals' success rate with capturing food, as animals that feed more frequently will grow more rapidly (Wells and Wells 1977).

The second collecting trip (November 2012) yielded two to three different species of Amphioctopus. These animals were impossible to distinguish from each other while collecting, but differences in coloration and behavior that were observed in aquaria suggest that we were dealing with at least two species among the ten specimens exported successfully to the Academy. Further research at the collection site will be useful in determining whether different species of Amphioctopus are sympatric all year round, for only part of the year, or if our experience was an outlier event.

Like most small tropical octopuses, $A$. marginatus is estimated to have a short lifespan. We tracked the lifespan, post-collection, for five of seven specimens from the May 2011 collecting trip and all 10 specimens from the November 2012 trip. Longevity of $A$. marginatus held at Steinhart Aquarium varied between 33 days and 375 days (Fig. 6). The average longevity post collection was 195.4 days ( \pm 116.2 days standard deviation). Longevity varied between the collections, with the animals from the first collection (May 2011) living an average of 173.6 days ( \pm standard deviation 
of 126.9 days), while the animals from our second collection lived an average of 206.3 days ( \pm standard deviation of 116.0 days). A $\mathrm{t}$-test was performed on the data set, and there was no statistical difference between the longevity from the two collecting trips (independent samples, unequal variance, $p=0.642$ ). The longest lifespan that we witnessed at Steinhart Aquarium was 375 days following collection (specimen 1.5, collected May 24, 2011, death on June 2, 2012).

Senescence was observed in both large and small animals and followed the general pattern seen in other octopuses: lethargy, unwillingness to leave a den, spiraling arm tips, dulling of skin

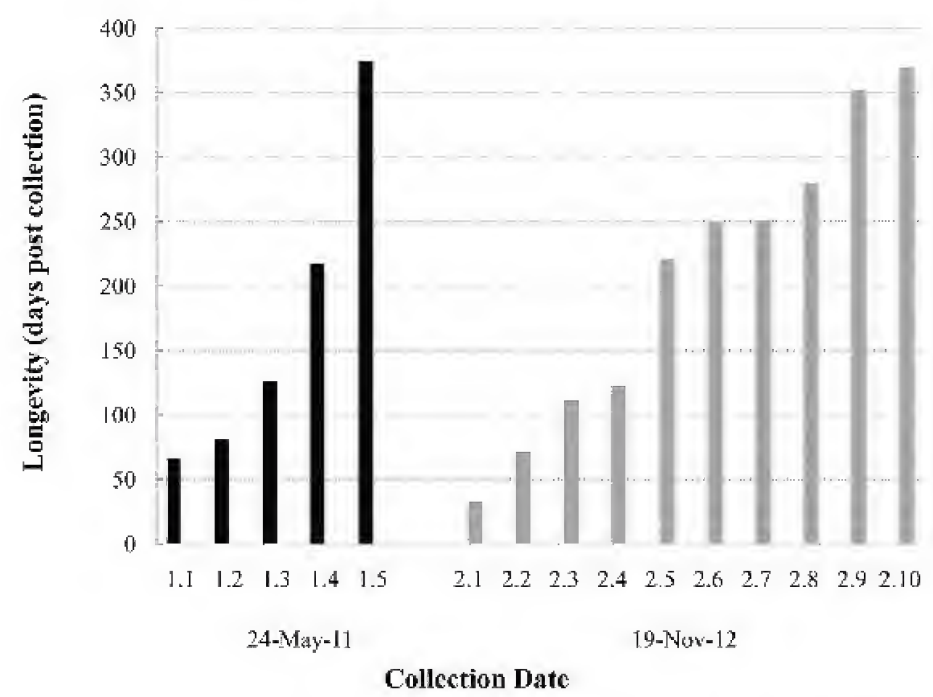

FIGURE 6: Longevity data from both groups of Amphioctopus marginatus collected in the Philippines. Black bars are 24 May 2011; grey bars are 19 November 2012. Longevity was highly variable, but the second collection lived longer on average $(206.3+116.0$ days, as compared to $173.6+126.9$ days). So far, our longest-lived specimen (1.5) was 375 days post collection. color, refusal to feed. Like other species of small, warm-water octopuses, it is likely that in the wild, A. marginatus grows very rapidly, is semelparous (breeds a single time), and then dies within 1 to 2 years (Wells and Wells 1977).

Display Techniques.- Steinhart Aquarium at the California Academy of Sciences has been successful in displaying Amphioctopus judged on the basis that (1) the animals are living to their presumed natural lifespan ( $>1$ year post collection), and (2) we are achieving positive educational engagement with aquarium visitors. Guests are often crowded around the exhibit to observe the octopus. Our displays are simple and are based on the environments where we collected Amphioctopus. They accurately represent the animals native habitat: soft, sandy substrate with a small amount of rock and stemmed algae, and included various items to be utilized as dens. Periodically we have added "toys", such as legos, and plastic squid or octopus figures, but none of the animals showed much interest in these items.

Initially, the octopuses were given pve fittings, flowerpots, and coconut shells to use as dens. The display of Amphioctopus was further enhanced by giving the animals clear glass bottles to use, so that they are visible even when they retreat into their dens. Steinhart Aquarium Senior Biologist Richard Ross created several hand-blown glass dens of different sizes and shapes. We have found that a den slightly larger than the octopus, with an inner fold (a lip of glass that projects inside the den) seems to be preferred by these animals (Fig. 7). These hand blown glass dens have also been used with other species of octopus (larger Pacific striped octopus, an undescribed species) with great success for both the animals and the viewing public. We are planning further research to determine what makes one type of artificial den more preferable to another.

At Steinhart Aquarium, Amphioctopus were only displayed singly. Given the natural population density of these animals, research on displaying multiple animals in larger exhibits (750 liters or more) might yield interesting results, including successful mating or observations of other social behaviors.

Captive Behavior.- Amphioctopus is a very visible display animal, usually nestled in some 


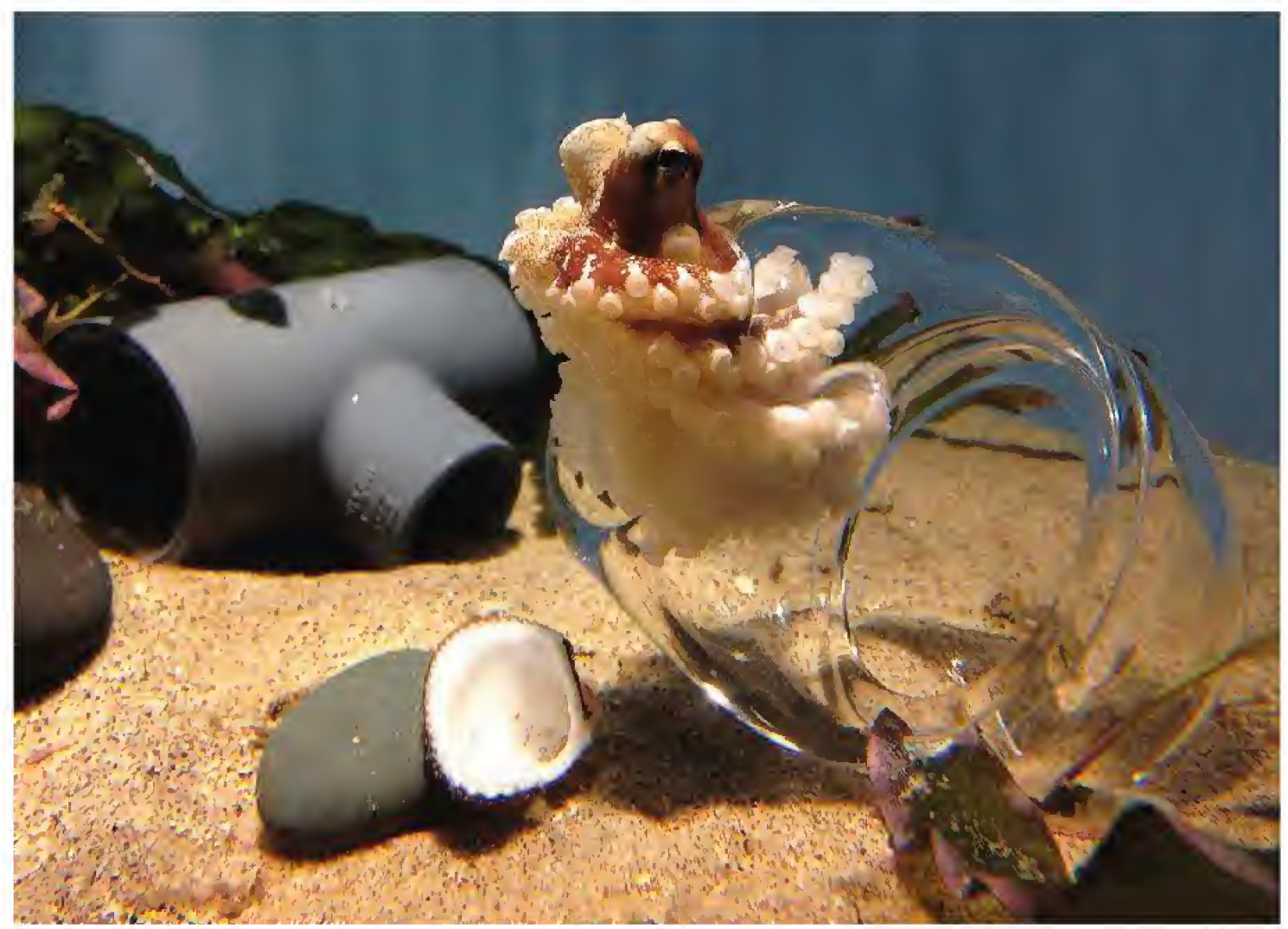

FIGURE 7: Amphioctopus marginatus on display at the California Academy of Sciences, peering out of a hand-blown clear glass den. This approach to display fosters a successful and engaging cephalopod-guest interaction. Photo by Richard Ross.

type of decor right in the center of the exhibit. Individuals will use all available materials to partially enclose themselves into their den. These octopuses are very active and regularly venture around their exhibit when they have been fed. We have witnessed display specimens swimming across the entire length of the exhibit to chase down prey. Sometimes an octopus would elongate its body and have just the tips of the arms in contact with its den in a type of "lookout" position (Fig. 8). It is also common to see them sitting in their dens with their arms folded in tightly to the mantle so their suckers and mouth area exposed (Fig. 7).

These octopuses are also very curious and tactile; when they spot an aquarist taking the lid off of their enclosure they will usually swim up, reach out their arms and try to make contact with that person, perhaps rushing to get food. Unlike many octopus species that shy away from people and remain hidden, Amphioctopus are often out in the open, staying aware of their surroundings and looking for a new interaction. This tendency to remain active makes Amphioctopus a very engaging animal to care for and for guests to see on display.

On display Amphioctopus were taught to open clear glass screw top jars to access prey inside the jars. The behavior was trained by starting with a prey item in an open jar. When we first began to add the lid, it was left very loose. As the training progressed, the lid was tightened more and more on subsequent feedings. Within two weeks, animals learned to open jar lids that were fully closed and hand tight. Amphioctopus were also offered prey items inside of plastic wiffle balls as an enrichment activity, as it takes time for the octopus to figure out there is food in the ball and how to remove it. 
On exhibit, we have not seen the 'stilting' or 'rolling' behaviors with coconut shells that have been observed in the wild, nor have we observed the bipedal locomotion that has also been documented for Amphioctopus (Finn et al. 2009). We have observed Amphioctopus defending food from its tank mate, the chocolate chip starfish, Protoreaster nodosus. After a coconut octopus had been fed a Manila clam, the starfish was attracted to the open clam and attempted to take it. The coconut octopus responded by using one of its arms to push the starfish away while using the remaining seven arms to stabilize itself on the bottom, secure itself in its den (small glass bottle) and hold on to the open clam shell. Ultimately the starfish was repelled and the octopus was able to feed in peace.

Observations of mating behavior and captive breeding were limited, as we were almost

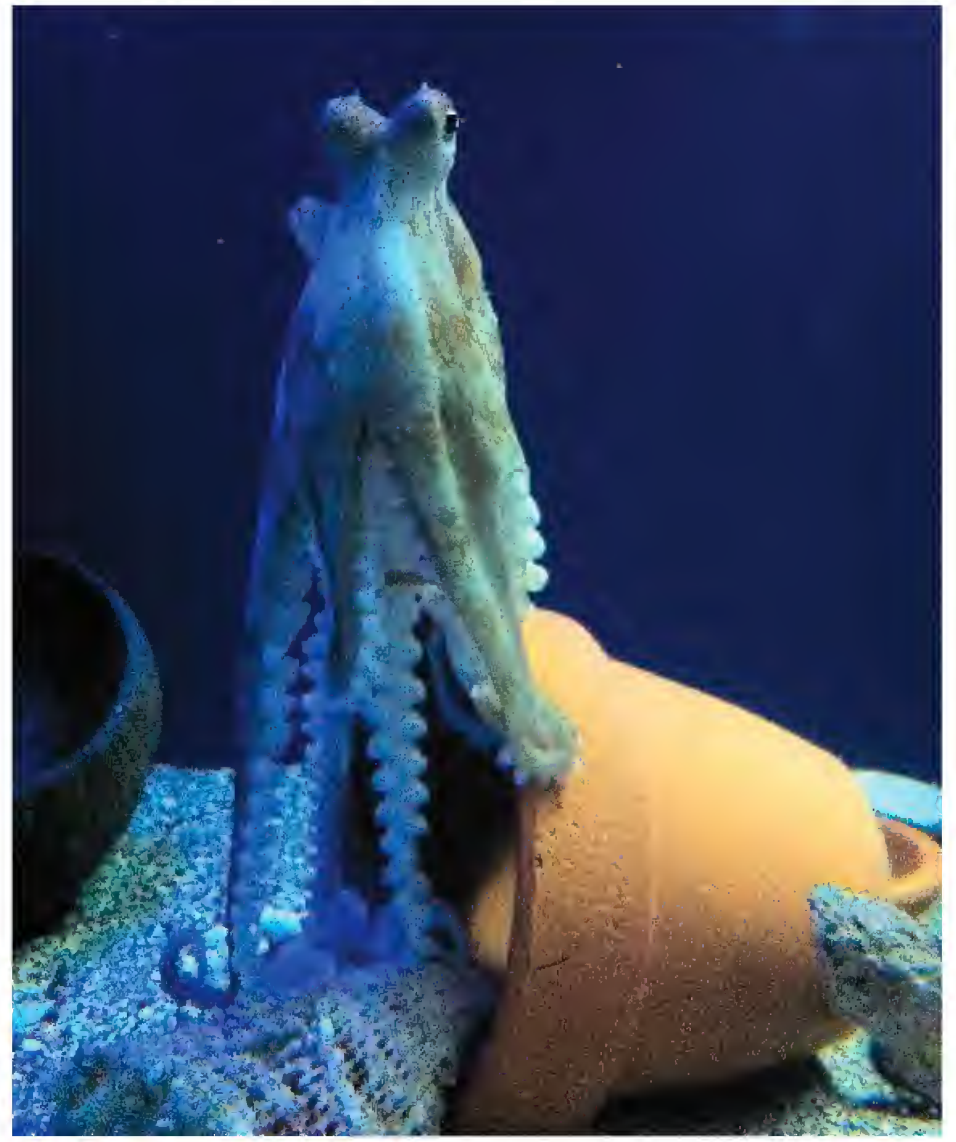

FIGURE 8: Amphioctopus marginatus on display in the "lookout" pose. Note the use of a clay flowerpot as a den, and a coral skeleton as an operable "door" to the den. Photo by Richard Ross.

exclusively displaying single specimens in our exhibits. On one instance, we did attempt to put two animals together for mating. The larger specimen quickly engulfed the smaller in its arm webbing. These two individuals were allowed to stay in this position until we observed inking, at which point they were separated. On display and in holding, three Amphioctopus marginatus each laid a single clutch of eggs; two of these three were fertile. Unfortunately, hatchings were not observed, so we did not have an opportunity to attempt to raise the paralarvae.

Amphioctopus marginatus is an ideal candidate for public aquarium display. It is an engaging species with minimal space needs, and most facilities will be able to meet the minimum requirements for successfully caring for the animal for the duration of its natural lifespan. It is popular with guests due to its interesting behaviors and it has a tendency to be active during daylight hours. The major challenges with this species surround acquisition. It will likely remain difficult to acquire specimens through regular commercial collectors and exporters. We have developed collecting techniques that minimize stress and eliminate mortality. Future research is needed to develop captive-breeding and larval-rearing protocols, and to examine whether populations within the Philippines are robust enough to support repeated collections of aquariums specimens in a sustainable manner. 


\section{ACKNOWLEDGEMENTS}

The authors wish to thank the staff and leadership of the California Academy of Sciences for supporting these efforts, as well as the other strategic research and conservation initiatives at Steinhart Aquarium. We are also indebted to Matt Wandell (Steinhart Aquarium, San Francisco, California, USA) and the staff of Club Ocellaris, especially Alexis Principe, Peri Paleracio and the captain and crew of the boat, Yolly Bert for their assistance with collecting. Nick Yim (Steinhart Aquarium, San Francisco, California, USA), Eric Hovland (The Florida Aquarium, Tampa, Florida, USA) and Roy Drinnen (Moody Gardens, Galveston, Texas, USA) greatly assisted with the second collecting trip, including providing photographic documentation, and Denis Ty and the staff of Aquascapes assisted with packing and shipping. The authors also wish to thank Dr. Christine Huffard (Monterey Bay Aquarium Research Institute, Monterey, California, USA) for sharing her general knowledge of Amphioctopus, and Dr. John H. Long, Jr. (Vassar College, Poughkeepsie, New York, USA) for assistance with longevity data analysis. This work was partially supported by the Kingfisher Foundation, and The City and County of San Francisco provides significant financial support for Steinhart Aquarium operations.

\section{REFERENCES}

CARPenter, Kent E., AND Victor G. Springer. 2005. The center of the center of marine shore fish biodiversity: the Philippine islands. Environmental Biology of Fishes 72:467-480.

Carrasco, José Francisco, Juan Carlos Arronte, and Carmen Rodríguez. 2006. Paralarval rearing of the common octopus, Octopus vulgaris (Cuvier). Aquaculture Research 37(15):1601-1605.

Finn, Julian K., Tom TregenzaAnd, and Mark D. Norman. 2009. Defensive tool use in a coconut-carrying octopus. Current Biology 19(23):R1069-R1070.

Huffard, Christine L., And Peter Godfrey-Smith. 2010. Field observations of mating in Octopus tetricus Gould, 1852 and Amphioctopus marginatus (Taki, 1964) (Cephalopoda: Octopodidae). Molluscan Research 30(2):81-86.

Huffard, Christine L., Roy L. Caldwell, and Farnis Boneka. 2008. Mating behavior of Adopuls aculeatus (d'Orbigny 1834) (Cephalopoda: Octopodidae) in the wild. Marine Biology 154:353-362.

Huffard, Christine L., Farnis Boneka, and Robert J. Full. 2005. Underwater bipedal locomotion by octopuses in disguise. Science 307:1927.

Huffard, Christine L., AND F. G. Hochberg. 2005. Description of a new species of the genus Amphioctopus (Mollusca: Octopodidae) from the Hawai'ian Islands. Molluscan Research 25(3):113-128

Norman, M. D. 2000. Cephalopods: A World Guide-Octopuses, Argonauts, Cuttlefish, Squid, Nautilus. Conchbooks, Hackenheim, Germany, 320 pp.

Sreeja, V., And A. Bijukumar. 2013. Ethological studies of the Veined Octopus Amphioctopus marginatus (Taki)(Cephalopoda: Octopodidae) in captivity, Kerala, India. Journal of Threatened Taxa 5(10):4492-4497.

TAKI, I. 1964. On eleven new species of the Cephalopoda from Japan, including two new genera of Octopodinae. Journal of the Factlty of Fisheries and Animal Husbandry, Hiroshima University 5(2):277-343.

Wells, M. J., AND J. Weles. 1977. Cephalopoda: Octopoda. Pages 291-337 in Arthur C. Geise and John S. Pearse, eds., Reproduction in Marine Invertebrates, Volume IV: Molluscs, Gastropods and Cephalopods. Academic Press, New York, New York, USA. 


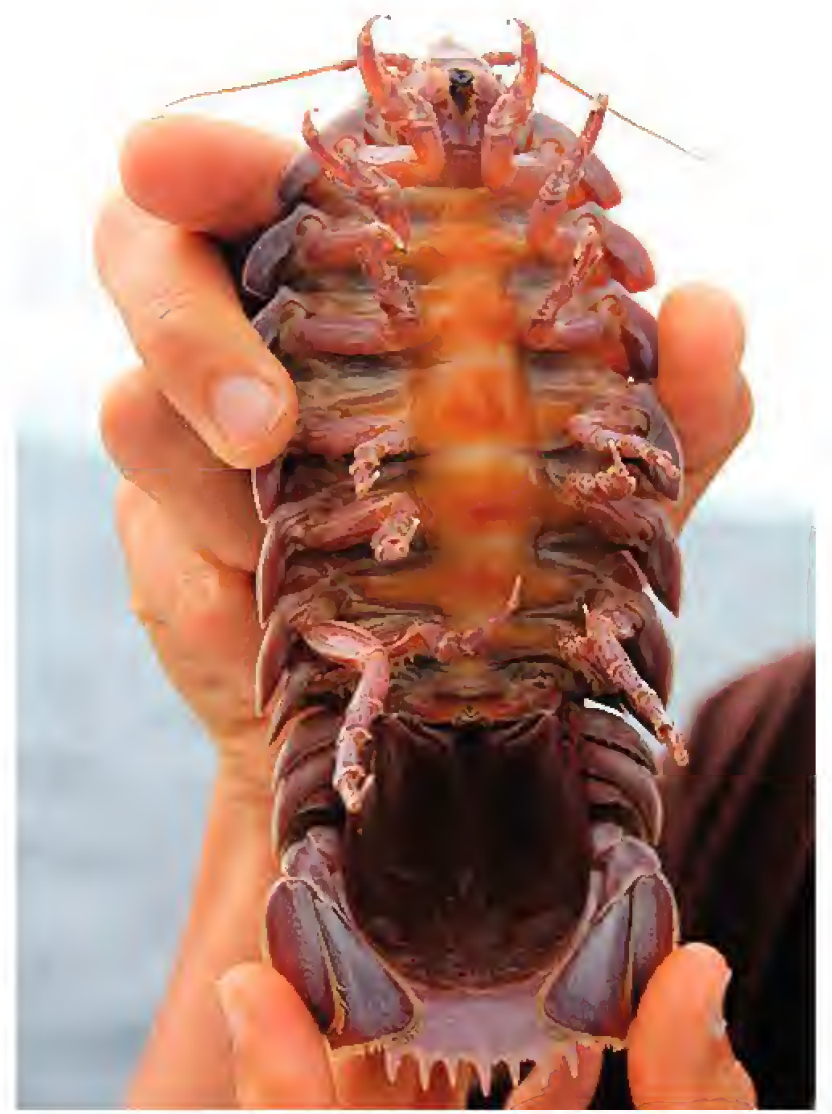

Plate 9. The deep sea isopod, Bathynomus kensleyi, commonly collected in fish traps. 


\title{
Two New Hemerocoetine Trichonotidae Fishes (Teleostei, Perciformes) from the Philippines
}

\author{
Tomio Iwamoto \\ Section of Ichthyology, California Academy of Sciences, 55 Music Concourse Drive, \\ San Francisco, California 94118; Email: tiwamoto@calacademy.org.
}

The California Academy of Sciences Hearst Philippine Expedition of 2011 included a deepsea phase aboard the 60-m long Philippine Bureau of Fisheries and Aquatic Resources research ship M/V DA-BFAR. Beam trawls, otter trawls, and fish traps were used during this phase to collect in off-shore waters between the islands of Luzon and Mindoro in the Verde Island and Calavite passages, around the Lubang Islands, and out to the continental shelf of the South China Sea. At station HEPD-026 northeast of Lubang Island, a highly successful drag was made with the beam trawl in 82-86 m over a sandy-rocky bottom. Among the many fishes collected were 12 small specimens of trichonotid fishes belonging to an enigmatic group, the "Pteropsaron-like" Hemerocoetinae, as defined by Smith and Johnson (2007). One of the collected specimens was identified as Pteropsaron springeri Snith and Johnson, 2007. The others could not be readily categorized into a genus because they displayed characters that appeared to bridge the gap between genera. Three of the specimens were brightly colored males of what appear to be representatives of either Pteropsaron or Acanthaphritis Günther, 1880.

Acanthaphritis Günther, 1880 is represented by four species (Suzuki and Nakabo 1996) and is distinguished from other Pteropsaron-like hemerocoetines by having scaled cheeks, short dorsal spines, well-developed maxillary spines, and a fleshy barbel at the tip of the snout. The three brightly colored HEPD specimens have greatly elongated dorsal spines, no scales on cheeks, strong maxillary spines, and a snout barbel. The other eight specimens appear to be most similar to Pteropsaron natalensis (Nelson, 1982) in morphometry and meristic values, but their cheeks are scaled, the relative lengths of their dorsal spines and rays are slightly shorter, and the upper jaw extends to below the posterior margin of the pupil (vs. below posterior margin of orbit). Based on the character mix in these newly collected specimens, it is apparent that this distinctive group of Hemerocoetinae is greatly in need of revision. As stated by Smith and Johnson (2007:370), "A definitive solution to the generic placement of these species will require further morphological and phylogenetic analysis." For the purposes of this paper, the two new species are placed in the genus Pteropsaron.

\section{MATERIAL AND METHODS}

Specimens are deposited in the ichthyology collections of the California Academy of Sciences (CAS). In addition to the type specimens of the two new species, the following specimens of other hemerocoetine Trichonotidae were examined for comparison: Pteropsaron evolans Jordan and Snyder (CAS 1017158, 2 paratypes, 57.0-59.9 mm SL, Owari Bay, Japan); P. incisum Gilbert (CAS 120166, paratype, 30.5 mm SL; Laysan I., Philippines); Spinapsaron barbatus Okamura and Kishida (CAS 88795, 3 spec., 81.0-91.2 mm SL; San Bernardino Strait, e. coast Luzon I., Philippines, 382-376 m); Matsubaraea setouchiensis Taki ([as recorded in Iwamoto 1980] CAS 32846, 10 spec., 50.8-66.7 mm SL; CAS 34695, 4, 54.4-67.4 SL; Gulf of Thailand; CAS 35531, 3 paratypes, 46.1-55.5 min SL; Takamatsu Fish Market, Japan).

The reader is referred to Eschmeyer's Catalog of Fishes website for complete reference to genera and species names used here: http://research.calacademy.org/research/ichthyology/catalog/ fishcatmain.asp 


\section{Family Trichonotidae Subfamily Hemerocoetinae}

\section{Genus Pteropsaron Jordan and Snyder, 1902}

Pteropsaron dabfar Iwamoto sp. nov.

Figures 1-3, Table 1.

Type SPecimens.- Holotype: CAS 236400 (33.6 mm SL); Philippines, $13.905833^{\circ} \mathrm{N}$, $120.35433^{\circ} \mathrm{E}$, between Luzon and Mindoro islands; 45-47 fm $(82-86 \mathrm{~m})$ over hard, sandy, rocky bottom; M/V DA-BFAR; beam trawl; 2 June 2011; Hearst Philippines Expedition sta. HEPD-026. PARATYPES: CAS 236667 (33.0 mm SL, DC-1508, preserved in 95\% ethyl alcohol) and CAS 236560 (30.0 mm SL, body damaged, slightly squashed), collected with holotype.

Diagnosis.- D V + 20; A 24; P 17-19; V I,5. Spinous-dorsal-fin spines closely set creating a narrow base, first spine greatly elongated, reaching to middle of caudal fin; dorsal lobe of caudal fin with filamentous tip. Tubed lateral-line scales about 33, their posterior margin narrowly incised or crenulated. A short, curved spine (maxillary spine) at anterior end of each maxilla. Short rostral barbel.

DESCRIPTION OF HOLOTYPE. - (paratype characters in parentheses, if different).- Head cylindrical, slightly depressed, body long and slender, compressed posteriorly (Figs. 1, 2) Snout sharply pointed in lateral view, about $2 / 3$ orbit diameter; barbel short, $0.6 \mathrm{~mm}$ long (Fig. 3) at tip of upper jaw (a male character). Orbits large, deeply incised into top of skull, pupil with a prominent aphakic space anteriorly, and a slightly developed pupillary lappet (= dorsal operculum); bony interorbital very narrow, about 1/10 orbit diameter. Upper jaw projecting slightly beyond lower jaw; maxilla extending to below posterior $1 / 3$ of orbit. Maxillary spine (Fig. 3) curved ven-

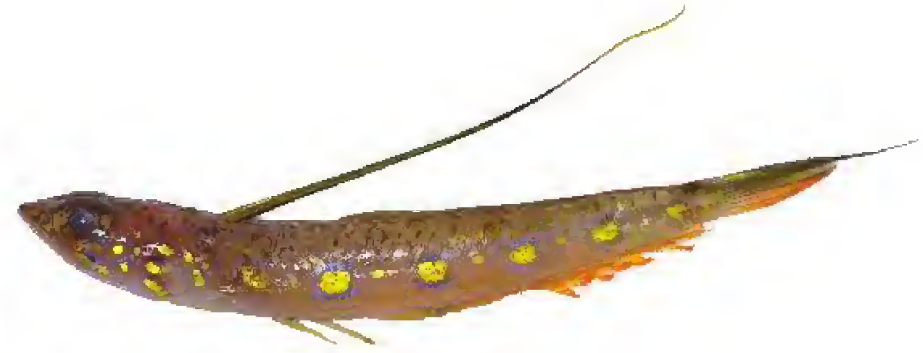

FigURE 1. Fresh coloration of Pteropsaron dabfar sp. nov. CAS 236400 (holotype, $32.6 \mathrm{~mm} \mathrm{SL}$ ); Philippines: between Luzon and Mindoro islands in 82-86 m. (Photograph by T. Iwamoto.) trally, $0.4 \mathrm{~mm}$ long. Anterior nostril a short raised tube; posterior nostril a simple pore, no cirri or flaps on margin of nostrils. Opercular flap membranous, overlapping entire base of pectoral fin; a narrow bony ridge without protruding spine dorsally on opercle; margins of opercular bones entire. Tongue long, narrow, with spatulate tip. Gill rakers short, broad based, 9 or 10 on lower limb of first arch (8 or 9 in paratypes); pseudobranchs well developed. Branchiostegal rays 7.

Scales: Scales cycloid, absent on head except dorsally posterior to orbits. Lateral-line scales about 33 (35); tubed, with posterior margin incised or irregularly crenate, partly to accommodate the raised lateral-line tube midlaterally. Other body scales with entire margins, lacking any projections or serrations.

Fins: First dorsal fin short-based, 5 spinous rays, tightly clustered at base; first three spines elongated, the first spine longest, extending to caudal fin; fin origin about on same vertical as that of pectoral fin and between those of pelvic and anal fins. Second dorsal fin well separated from first, long-based with 20 rays, last split to base, all rays unbranched, none prolonged, longest rays at posterior third of fin, slightly longer than postorbital length of head. Anal fin long-based with 24 


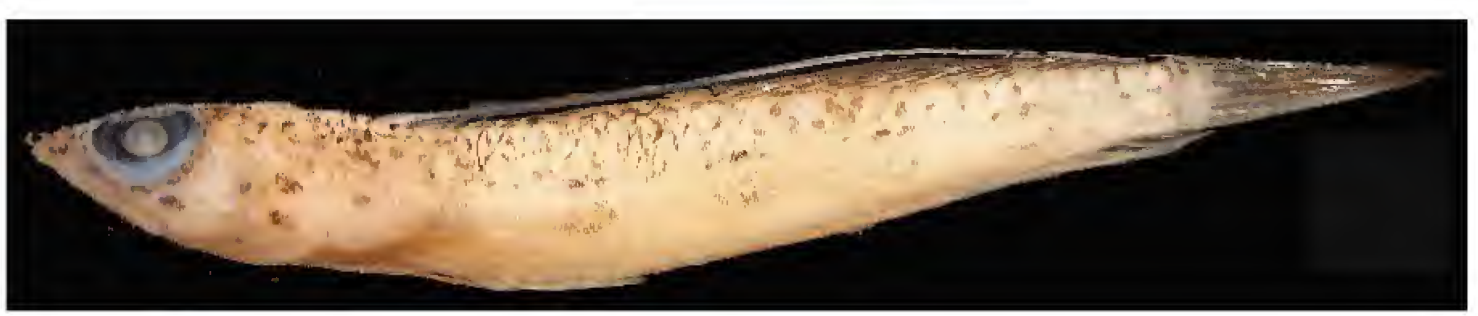

FIGURE 2. Pteropsaron dabfar sp. nov. Holotype (CAS 236400) after preservation in alcohol. (Photograph by Alan E. Leviton.)

rays (last split to base), all but first and last ray branched; no elongated rays, height of fin less than that of second dorsal fin. Pectoral fin broad based, rounded; rays 19 (left) and 17 (right) (17 for all fins in paratypes). Pelvic fin thoracic, origin about under preopercle, well anterior to that of pectoral fin, a short fleshy spine and 5 segmented rays, first 4 rays branched, $4^{\text {th }}$ ray longest, its tip extending to between $3^{\text {rd }}$ and $4^{\text {th }}$ anal rays. Caudal fin with 8 branched rays, posterior margin somewhat emarginate, upper rays longer, first branched ray of dorsal lobe filamentous ( $13 \mathrm{~mm}$ long).

Dentition: Small conical teeth in 2 or 3

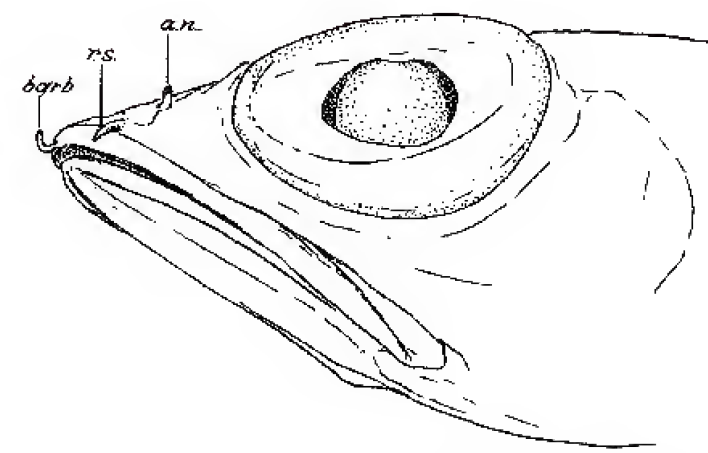

Figure 3. Pteropsaron dabfar sp. nov. Holotype (CAS 236400) ventrolateral view of snout region to show barbel (barb), anterior nostril (a.n.), and maxillary spine (r.s.). rows in both jaws; inner row of dentary teeth larger than those of outer row(s), retrose anteriorly, highly recumbent and directed inwardly along lateral and posterior parts of jaw. Small patch of teeth on each side of vomer, the two patches broadly separated mesially.

Color in life: Body pale olive with margins of scale pockets on dorsal half irregularly and thinly outlined in black. Small black spots scattered on snout and interorbital and parts of head and dorsal body surfaces. Side of body just below midlateral line with six bright metallic-yellow oval spots, each spot somewhat larger than eye pupil with bright blue streaks or dashes above and below spots. Sides of head marked with bright spots and short dashes of metallic yellow and a dash of bright blue under posterior half of orbit and smaller, fainter spots on preopercle. Elongated first spinous dorsal ray dull chartreuse near base, becoming black along middle of ray, then bright orange distally to tip. Inter-radial membranes of first dorsal fin black. Anal fin more or less chartreuse anteriorly, becoming orange along posterior two-thirds, with tips of rays dark reddish-orange and chartreuse near posterior end of fin. Pectoral fin clear. Second dorsal fin chartreuse on interradial membranes, but rays themselves blackish. Caudal fin chartreuse at base of fin, dorsal lobe blackish, distal tip of uppermost branched rays and filamentous tip black; ventral lobe chartreuse at base blending to orange, with distal tips reddish.

ETYMOLOGY.- The new species is named for the research vessel M/V DA-BFAR of the Philippine Bureau of Fisheries and Aquatic Resources, Department of Agriculture.

REMARKS AND COMPARISONS.- The generic placement of this beautiful little fish is problematic and symptomatic of the confused state of the generic classification within this hemerocoetine group. The genus Hemerocoetes Valenciennes, 1837 has been well characterized by Nelson (1979) and can be eliminated as closely related to the new species based on Hemerocoetes lacking a spinous dorsal fin, and having a flap or cirri on the anterior nostril and more rays in the second dorsal and anal fins. The genus Acanthaphritis, revised by Suzuki and Nakabo (1996), agrees relatively 
well with the new species in having in common a barbel on the snout tip, maxillary spines present, anterior nostril in a raised tube, posterior nostril simple, lateral-line scales with an incised ("serrated") posterior margin, vomerine teeth present, five dorsalfin spines, and seven branchiostegal rays. Acanthaphritis disagrees in having cheek scales and a short spinous dorsal fin, longest spine when depressed not or barely extending to second dorsal fin. Suzuki and Nakabo (1996) synonymized Spinapsaron Okamura and Kishida, 1963, and Branchiopsaron McKay, 1971, with Acanthaphritis. The apparent absence of cheek scales in Pteropsaron dabfar may be misleading owing to the thin cycloid scales in this species and the shallow scale pockets on the cheek, which could result in easy loss of scales without subsequent detection of their former presence. The holotype and one paratype, CAS 236667 , are, however, in good condition with most body scales intact and scale pockets visible in most places where scales are missing.

Two other genera that are closely related to Acanthaphritis are Pteropsaron Jordan and Snyder, 1902 and Osopsaron Jordan and Starks, 1904. Nelson (1982) characterized these two genera in his paper describing two new species, Pteropsaron heemstrai and Osopsaron natalensis. Pteropsaron dabfar agrees closely with $P$. heemstrai in general features, including absence of scales on the head, exposed margin of body scales entire (except for those of lateral line, which have short projections or crenulations posteriorly), short rostral spine, and elongated dorsal fin spines. The new species differs in having five, not six, dorsal spines, and the first spine is the longest (vs. fourth spine in $P$. heemstrai and $P$. evolans Jordan and Snyder, 1902 from Japan), tip of pelvic fin reaching past anal-fin origin (vs. not reaching anal fin), no elongated rays in anal fin (vs. middle rays elevated), presence of a pupillary lappet, snout barbel, and filamentous tips in dorsal lobe of caudal fin (all absent in $P$. heemstrai and $P$. evolans). Pteropsaron dabfar agrees in most characters with P. natalensis (Nelson, 1982), especially in meristic characters and in those features that are not in agreement with $P$. heemstrai, aside from the last two characters listed (snout barbel and filamentous caudal-fin lobe). The shorter, blunter snout, shorter maxillary spines, and the absence of a snout barbel serve to differentiate $P$. natalensis from the new species. There may be other characters (especially fresh coloration) that would allow better differentiating the two 
species, but the poor state of the known specimens of $P$. natalensis and the three specimens of $P$. dabfar preclude any statement as such until additional specimens of both species can be compared. Pteropsaron formosensis (Kao and Shen, 1985) also agrees in many respects with the new species. The major differences appear to be in the absence in that species of a snout barbel, shorter dorsal spines, and a rounded caudal fin (vs. emarginated with upper lobe elongated). Fresh coloration is also quite different between the two species, most notably with $P$. formosensis having a bright longitudinal yellow stripe along the midbody bordered above and below with blue stripes and a broken yellow stripe dorsolaterally (see Suzuki, Senou, and Nomura 1996: figs. 1-2).

\section{Pteropsaron levitoni Iwamoto, sp. nov.}

Figures 4-6, Tables 2, 3.

TyPe SPECIMENS.-Holotype: CAS 236401 (23.7 mm SL); HEPD-026 (data as for P. dabfar). PARATYPES: CAS 236399 (6, 19.8-27.9 mm SL); same data as for holotype. Non-type specimen: CAS 236402 (1, $24.5 \mathrm{~mm} \mathrm{SL}$; cleared and stained); same data as for holotype.

Diagnosis.- D IV-V + 19-20; A 24-25; P 19; V I,5; vertebrae 33 including hypural, gill rakers on lower limb of first arch 9 or 10 . Spinous dorsal fin elongated, first spine reaching to middle of second dorsal fin or somewhat beyond. None of soft-dorsal or anal-fin rays elongated. Tubed lateral line scales about 30-32; slightly crenulated or incised above and below lateral-line tube. Short obtuse spine at anterior end of each maxilla scarcely or not protruding through skin; no barbel at tip of upper jaw. Small patch of teeth laterally at tip of vomer, separated mesially by a large gap; palatine teeth absent.

DESCRIPTION.- Body moderately compressed anteriorly over trunk, becoming more compressed towards tail (Figs. 4-6); head cylindrical, slightly depressed, wider than deep. Snout pointed, $0.5-0.6$ of orbit diameter. Orbits large, deeply incised into top of skull, pupil with narrow aphakic space anteriorly, and a small pupillary lappet; bony interorbital very narrow, at narrowest point about $1 / \mathrm{t}^{\text {th }}$ of orbit diameter. Upper and lower jaws about equal; maxilla extending to below middle of orbit. Anterior nostril a short raised tube; posterior nostril a simple pore. Opercular flap membranous, overlapping entire base of pectoral fin; two narrow bony ridges dorsally on opercle converging posteriorly in a tiny spine, scarcely if at all piercing skin; posterodorsal margin of opercular bones minutely or scarcely fringed. Tongue narrow with spatulate tip. Gill rakers short, broad based, about 9 or 10 on lower limb of first arch; pseudobranchs well developed. Branchiostegal rays 7 .

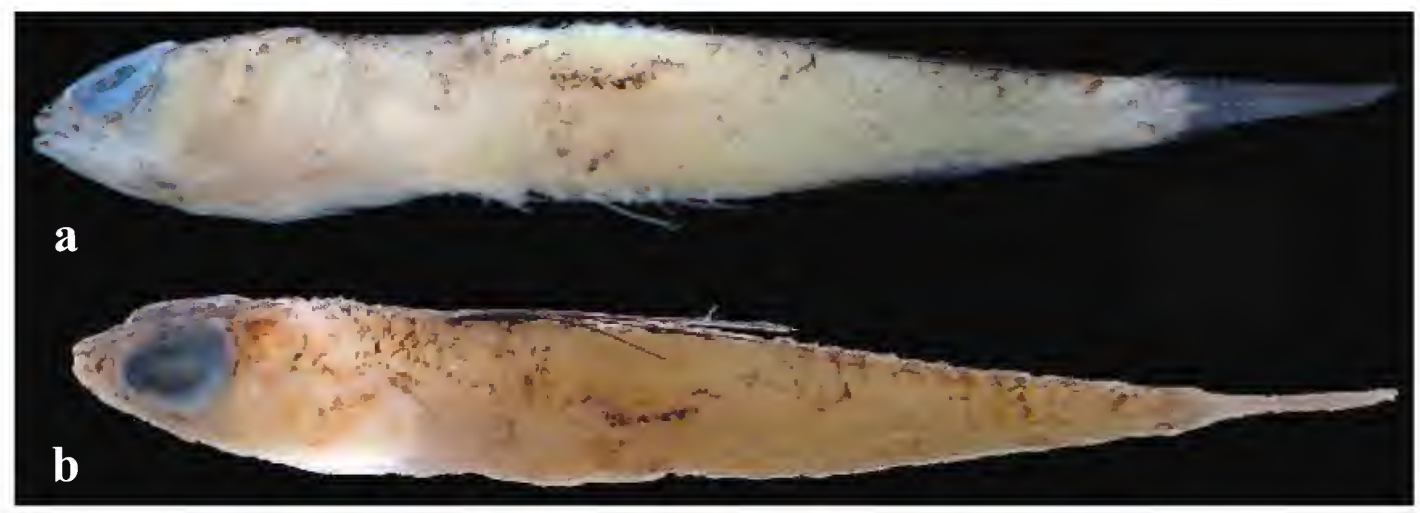

FIGURE 4. Pteropsaron levitoni sp. nov. CAS 236401 (holotype, $23.7 \mathrm{~mm} \mathrm{SL}$ ); Philippines: between Luzon and Mindoro islands in 82-86 m. (Upper) Lateral view (photograph by Jon D. Fong); (lower) dorsolateral view (photograph by Alan E. Leviton) 

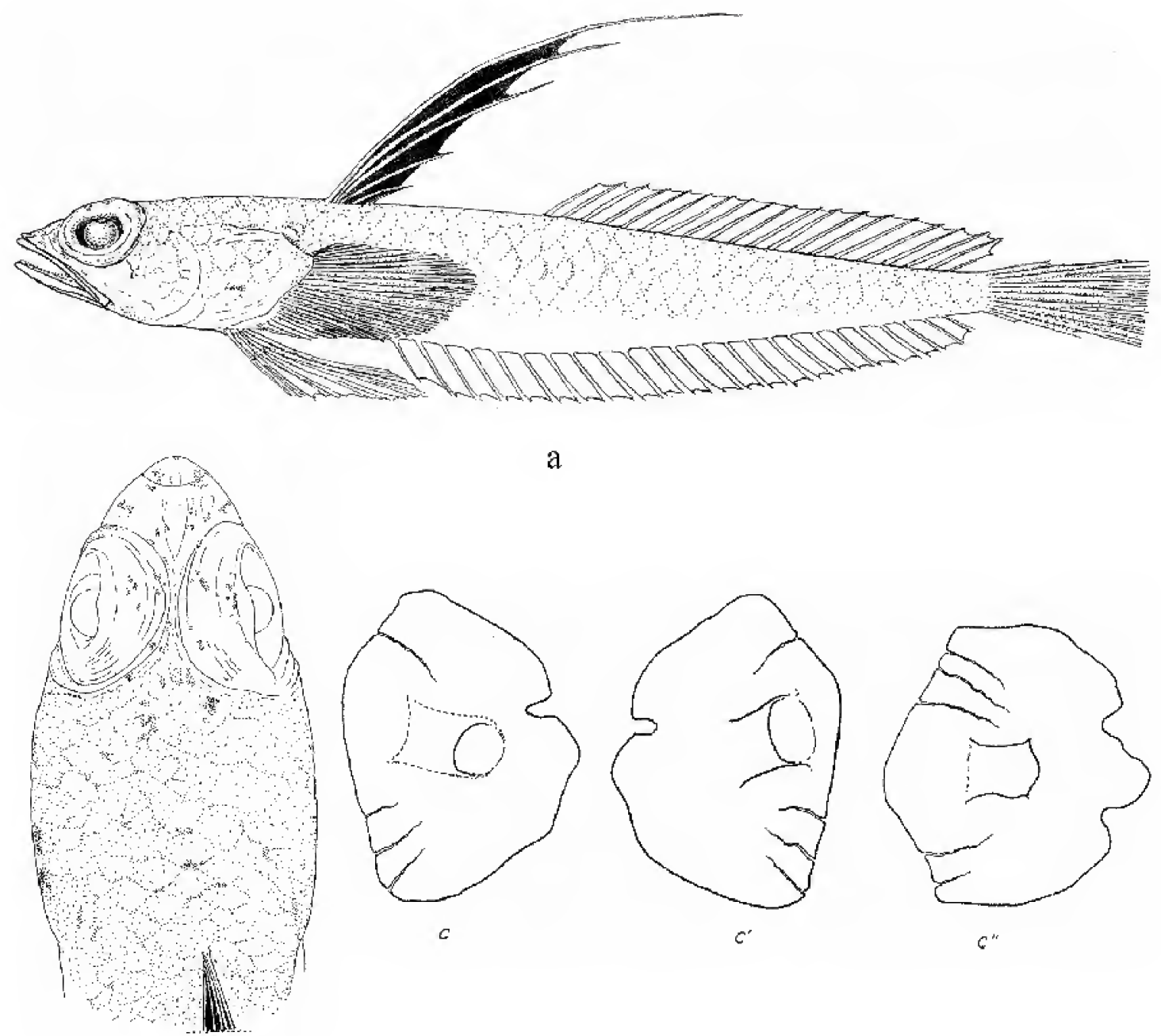

a

b

Figure 5. Pteropsaron levitoni sp. nov. (a) Composite drawing using specimens 1, 3 \& 5 (as numbered in Table 2) (scales and fin rays partially reconstructed); (b) dorsal view of head of holotype; (c) lateral-line scales of cleared-andstained specimen CAS 236402: c — lateral view of scale, anterior to left; c'-medial view of same scale, anterior to right; c" - lateral view of another scale, anterior to left.

Scales: Scales large, cycloid, some large scales dorsally on preopercle and opercle; snout and ventral parts of head lacking scales; scales present on chest and isthmus. Lateral-line scales about 30-32; tubed, with midlateral parts of posterior margin incised or irregularly crenate (Fig. 5). Other body scales with margins entire, lacking any projections or serrations.

Fins: First dorsal fin short-based, 5 spinous rays, tightly clustered at base; first three spines elongated, the first spine longest, extending about to middle of soft dorsal fin; fin origin slightly behind vertical of pectoral-fin origin and between those of pelvic and anal fins. Second dorsal fin well separated from first, long-based with 19-20 rays, last split to base, all rays unbranched, none prolonged. Anal fin long-based with 24-25 rays (last split to base), all but first ray branched; no elongated rays, height of fin less than that of second dorsal fin. Pectoral fin broad based, rounded; with 19 rays. Pelvic fin thoracic, origin about under preopercle, well anterior to that of pectoral fin, 
TABLE 2. Counts and measurements of type specimens of Pteropsaron levitoni sp. nov.

\begin{tabular}{|c|c|c|c|c|c|c|c|c|}
\hline Spec. number & \#1(holotype) & $\# 2$ & $\# 3$ & $\# 4$ & $\# 5$ & $\# 6$ & $\# 7(\mathrm{C} \& S)^{*}$ & $\# 8$ \\
\hline SL & 23.7 & 21.8 & 23.2 & 23.7 & 27.9 & 21.5 & 24.5 & 19.8 \\
\hline \multicolumn{9}{|c|}{$\% \mathrm{SL}$} \\
\hline HL & 38 & 36.7 & 37.5 & 35 & 33.3 & 34.9 & 39.6 & 35.4 \\
\hline Head width & 20.3 & 21.1 & 21.1 & 19 & 19 & 19.1 & 18.4 & 25.8 \\
\hline Orbit diam & 12.7 & 11.5 & 11.6 & 10.5 & 10.8 & 11.6 & 11 & 11.6 \\
\hline Snout len & 0 & 6.9 & 6.9 & 6.3 & 5.7 & 6 & 6.5 & 5.6 \\
\hline Postorbital & 21.5 & 18.8 & 19.4 & 18.1 & 19 & 17.7 & 18 & 20.2 \\
\hline Interorb width & 1.3 & 1.8 & 1.7 & 1.3 & 1.1 & 0.9 & 1.2 & 1 \\
\hline Up jaw len & 16 & 16.1 & 15.5 & 15.2 & 13.6 & 18.6 & 15.1 & 13.6 \\
\hline Body depth & 14.3 & 15.6 & 15.1 & 15.6 & 13.6 & 14 & 15.5 & 14.1 \\
\hline Pre-D & 34.6 & 34.4 & 36.6 & 34.6 & 33 & 32.6 & 32.7 & 35.4 \\
\hline Pre-2D & 54.4 & 53.2 & 52.6 & 52.3 & 53 & 48.4 & 49 & 50.5 \\
\hline Pre-A & 48.5 & 44.5 & 43.1 & 43.9 & 42.7 & 42.8 & 44.5 & 40.4 \\
\hline C ped depth & 6.8 & 6.4 & 6.5 & 6.8 & 6.8 & 6.5 & 6.9 & 7.1 \\
\hline Ht 1D & 49.8 & 29.8 & 34.5 & 32.5 & 51.3 & 26.5 & 35.5 & 25.8 \\
\hline Ht A & 15.2 & 10.1 & 9.5 & 11.4 & 9.7 & 11.6 & 10.2 & \\
\hline P len & 22.4 & 21.1 & 20.7 & 21.1 & 22.2 & 24.7 & 21.2 & 21.2 \\
\hline $\mathrm{V}$ len & 21.9 & 19.7 & 22.4 & 20.3 & 21.5 & 19.5 & 21.6 & 20.7 \\
\hline longest 2D ray & 13.5 & 12.8 & 13.4 & 13.9 & 13.6 & 12.6 & 12.2 & 12.1 \\
\hline \multicolumn{9}{|c|}{ COUNTS } \\
\hline $\mathrm{D}$ & $V+20$ & $V+20$ & $\mathrm{~V}+20$ & $\mathrm{~V}+19$ & $\mathrm{IV}+20$ & $\mathrm{~V}+19$ & $\mathrm{~V}+20$ & $\mathrm{~V}+20$ \\
\hline A & 24 & 24 & 24 & 24.5 & 24.5 & 25 & 24 & 24.5 \\
\hline $\mathrm{P}$ & 19 & 19 & 19 & 19 & 19 & 19 & 19 & 19 \\
\hline Caudal rays & iv4+4ii & iv4+4ii & iv $4+4 \mathrm{ii}$ & iii4+4ii & iii4+4ii & 0 & 0 & iii4+4ii \\
\hline Lateral-line scales & 30 & & & 31 & & & 32 & 31 \\
\hline GR lower limb & 10 & 9 & 9 & 9 & & 9 & & \\
\hline * _ Cleared \& sta & ained & & & & & & & \\
\hline
\end{tabular}

a short spinous ray and 5 segmented rays, first 4 rays branched, $4^{\text {th }}$ ray longest, extending to $4^{\text {th }}$ anal rays. Caudal fin with 8 branched rays, posterior margin emarginate.

Dentition: Small conical teeth in 2 or 3 rows in both jaws; inner teeth slightly larger than outer teeth. Small band of teeth on each side of vomer, the two bands separated mesially, each band followed by a row of what appears to be papillae.

Color pattern: Live coloration not available. Ventral half of body and head almost entirely pale. About six small clusters of melanophores along lateral midline of body. Some irregular brown blotches on dorsum of head and body. Margins of scale pockets usually marked with brownish pigmentation. Tips of premaxillaries with two dark spots, ventral orbital margin with one small dark 
spot; blackish spots or dashes on top of snout and interorbital space, including dorsal aspect of cornea of eye. Dark brownish spots on occipit immediately behind orbits. Mouth and gill cavities pale. First dorsal fin black except pale at immediate base of first spine and distal tip of same. All other fins without pigmentation.

ETYMology.- It is a pleasure to name this fish after Alan E. Leviton, Curator Emeritus of the California Academy of Sciences, who strongly promoted this Hearst Expedition volume, used his considerable technical knowledge of desk-top publishing to produce this work, and who pro-
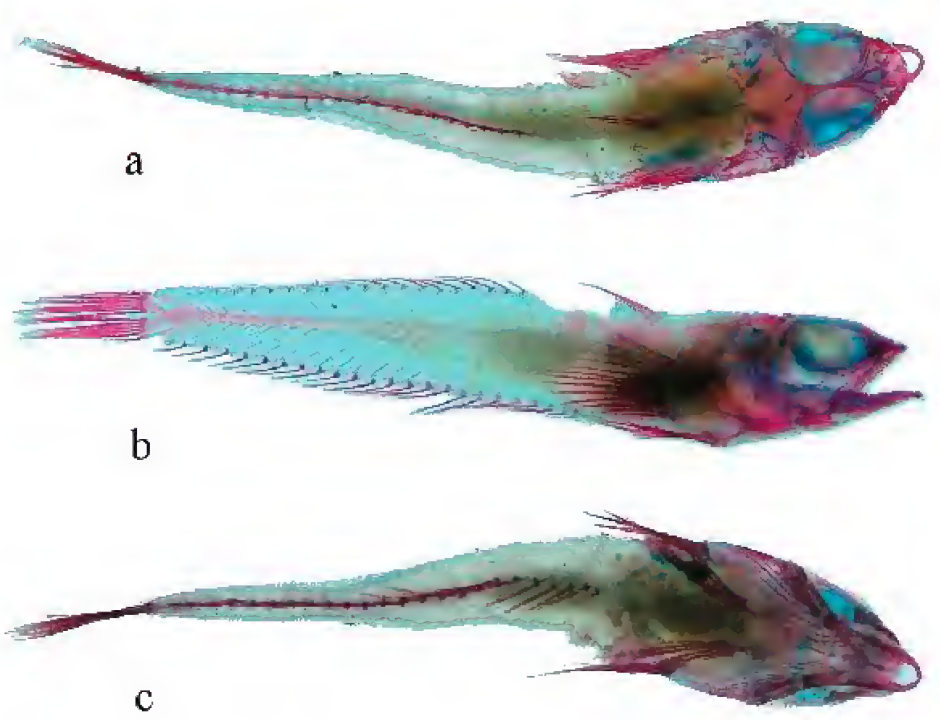

FiguRE 6. Pteropsaron levitoni sp. nov. Photographs of cleared-and-stained specimen, CAS 236402 (24.5 mm SL). (a) dorsal view; (b) lateral view); (c) ventral view.

vided much advice and support with this paper.

REMARKS AND COMPARISONS.- These specimens are closely similar in most characters to $P$. natalensis, with only a few morphometric differences noted in caudal-peduncle depth, and pectoral and pelvic fin lengths (Table 3). The type specimens of $P$. natalensis were not in the best shape: fins were damaged and not fully intact, and no scales or color pattern remained. Three other specimens recorded by Smith and Johnson (2007:374) have provided information on lengths of median-fin rays and expanded the range of counts of second dorsal-fin and anal-fin rays. The HEPD specimens are, in all likelihood, subadults and thus may not display features characterizing mature individuals.

\section{DISCUSSION}

The genera of hemerocoetine Trichonotidae have been inadequately defined and a further shuffling of taxa within this group is likely, but it is beyond the scope of this paper to attempt such an undertaking. Nelson (1982:7) recognized a close relationship among the three genera, Acanthaphritis, Pteropsaron, and Osopsaron, and discussed the relationships of that clade to other percophids. Smith and Johnson (2007) further developed his concept of relationships and removed the Hemerocoetinae and Creediidae from the Percophidae and recognized them as subfamilies in the expanded family Trichonotidae.

That three different species of Hemerocoetinae, two of which are new, were collected in a single haul of a beam trawl in the Philippines makes it appear likely that many more species will be discovered in the Indo-West Pacific with more collecting at appropriate depths and bottom substratum. Because of their small adult size, cylindrical body shape, and probable cryptic sand-dwelling habits, they have avoided capture and are possibly much more abundant and wide-spread than is apparent from museum specimens alone. Current developing efforts in collecting in deeper waters with SCUBA should add markedly to the number of known species in this group. 
TABLE 3. Comparison of counts and measurements of species of Osopsaron and Pteropsaron. Data for $P$. natalensis and P. heemstrai from Nelson (1982), with additions to counts of second dorsal and anal-fin rays from Smith and Johnson (2007). Data for other species taken from literature (P. evolans, $P$. formosensis, $P$. incisum, and $O$. verecundum) or specimens examined.

\begin{tabular}{|c|c|c|c|c|c|c|c|}
\hline \multirow{2}{*}{\begin{tabular}{l}
\multicolumn{1}{c|}{ Genus } \\
Species
\end{tabular}} & \multicolumn{6}{|c|}{ Pteropsaron } & \multirow{2}{*}{\begin{tabular}{|c|} 
Osopsaron \\
verecundum $^{* * * *}$
\end{tabular}} \\
\hline & levitoni & natalensis* & formosensis & incisum $^{* *}$ & heemstrai & evolans & \\
\hline & 8 & 3 & 20 & 1 & 2 & 2 & $2 ?$ \\
\hline \multirow[t]{2}{*}{ SL } & $19.8-34.5$ & $21.4-29.6$ & $35.9-47.8$ & $30.5-52.0$ & $38.3-44.7$ & $57.4-59.3$ & $40.6-00 ?$ \\
\hline & \multicolumn{6}{|c|}{$\% \mathrm{SL}$} & \multirow{3}{*}{32.3} \\
\hline HL & $33.3-39.6$ & $32.8-36.0$ & $27.2-30.8$ & $34.6-35.0$ & $32.6-34.0$ & $31.5-31.5$ & \\
\hline Head width & $18.4-25.8$ & $18.9-20.9$ & $13.3-15.4$ & 18 & $16.4-17.8$ & $15.3-16.5$ & \\
\hline Orbit diam & $10.5-12.7$ & $10.0-11.4$ & $8.8-11.3$ & $11.0-12.4$ & $10.2-10.3$ & $9.1-9.6$ & 9.2 \\
\hline Snout len & $5.6-6.9$ & $5.2-5.6$ & $4.1-4.9$ & $9.0-9.2$ & $7.8-8.5$ & $8.5-10.1$ & 8.5 \\
\hline Postorbital & $17.7-21.5$ & $17.7-19.3$ & & 16 & $15.7-15.9$ & $15.7-15.9$ & \\
\hline Interorb width & $0.9-1.8$ & $0.5-0.6$ & $0.5-0.6$ & $0.7-1.0$ & 1.5 & 1.7-1.9 & \\
\hline Up jaw len & $13.6-18.6$ & $13.0-13.8$ & $10.9-12.3$ & $15.0-15.0$ & $14.0-15.2$ & 13.1-13.8 & \\
\hline Body depth & $13.6-15.6$ & $13.4-15.9$ & $11.6-13.6$ & $12.0-17.6$ & 13.2 & $13.1-13.5$ & 13.9 \\
\hline Pre-D & $32.6-36.6$ & $32.5-34.3$ & $25.9-28.6$ & $40.0-41.5$ & $32.5-32.9$ & $30.3-30.9$ & \\
\hline Pre-2D & $48.4-54.4$ & $47.8-54.2$ & $41.4-46.8$ & 53.9 & $46.7-47.7$ & $44.1-44.4$ & \\
\hline Pre-A & $40.4-48.5$ & $38.5-45.8$ & $33.1-38.2$ & 50 & $45.7-46.6$ & $42.7-42.8$ & \\
\hline C ped depth & $6.4-7.1$ & $5.9-6.3$ & $4.6-5.7$ & $5.0-5.9$ & $5.2-5.5$ & $5.2-5.6$ & 5.4 \\
\hline Ht 1D & $25.8-51.3$ & $12.0-22.5$ & $40.2-54.9$ & & 13.4-49.2 & $51.4-51.4$ & \\
\hline $\mathrm{Ht}$ A & $9.5-15.2$ & $9.6-10.5$ & $7.1-9.5$ & & $10.7-34.9$ & $24.4-38.8$ & \\
\hline P len & $20.7-24.7$ & 19.6-21.9 & & 20 & $19.1-20.8$ & 21.1 & 19.2 \\
\hline V len & $19.5-22.4$ & $18.9-19.6$ & & 27 & $15.1-17.0$ & $17.4-19.2$ & 23.1 \\
\hline longest $2 \mathrm{D}$ ray & $12.1-13.9$ & $9.3-12.6$ & $15.2-22.1$ & & $11.5-25.7$ & $19.2-50.8$ & 9.2 \\
\hline \multicolumn{7}{|c|}{ COUNTS } & \\
\hline $\mathrm{D}$ & $\mathrm{IV}-\mathrm{V}+19-20$ & $\mathrm{IV}-\mathrm{V}+19-20$ & $\mathrm{~V}+20-22 \mathrm{I}$ & IV-V+17-19 & $\mathrm{VI}+21-22$ & $\mathrm{VI}+20$ & $\mathrm{IV}-\mathrm{V}+18-19$ \\
\hline A & $24-25$ & $23-25$ & $24-27$ & $22-23$ & 25 & 26 & $22-23$ \\
\hline$P$ & 19 & $18-19$ & $18-19$ & 19 & 19 & $17-18$ & $18-19$ \\
\hline Caudal rays & iii-iv4+4ii & iv4+4ii & 8 to 9 & & & ii4+4ii & \\
\hline Lateral-line scales & 30-32 & & 32.35 & $30-30$ & $32-33$ & $35-36$ & $30-32$ \\
\hline GR lower limb & 9 to 10 & 9 to 10 & 10 to 12 & 9 to 10 & 10 to 11 & 12 & \\
\hline \multirow{2}{*}{\multicolumn{8}{|c|}{$\begin{array}{l}\text { * Smith \& Johnson (2007:374) recorded three other specimens, one Somali specimen had } 18 \text { D rays and } 22 \text { A rays, } \\
\text { otherwise counts were similar (no measurements given). } \\
\text { ** Data from Gilbert (1905:647) and CAS } 120166(30.6 \mathrm{~mm} \mathrm{SL})\end{array}$}} \\
\hline & & & & & & & \\
\hline \multicolumn{8}{|c|}{ *** Data from original description and Okamura in Masuda et al (1984:290) } \\
\hline
\end{tabular}




\section{ACKNOWLEDGMENTS}

My special thanks go to the officers and crew of the M/V DA-BFAR for their superb handling of the ship and collecting gear that resulted in the capture of the new species. I also thank the leaders of the deep-sea phase of the Hearst Philippine Expedition of the California Academy of Sciences, Terrence Gosliner and Rich Mooi, for allowing my participation on the cruise. I am appreciative of the help given by various members of the expedition in the collection of the specimens and preparation of this paper. CAS staff: Jon Fong photographed Fig. 4 and made radiographs of Pteropsaron levitoni, Mysi Hoang cleared and stained the specimen of P. levitoni (Fig. 6), David Catania photographed representatives of $P$. springeri and $P$. dabfari aboard ship and assisted in a variety of technical and curatorial matters; John E. McCosker reviewed the manuscript and provided valuable advice. Don Dumale (Philippine National Museum) helped during collection of the specimens. Alan E. Leviton (CAS) deserves special thanks for his encouragement, patience, editorial advice, photographing Figures 2 and 3, and for digitally enhancing all of the images used here. And, to Dr. M. Aldrich, special thanks for reading proof and catching a number of my unpardonable grammatical errors.

\section{LITERATURE CITED}

Gilbert, Charles H. 1905. The deep-sea fishes of the Hawaiian Islands. Section II, The Aquatic resources of the Hawaiian Islands. Bulletin of the United States Fish Commission 23:577-713.

GÜNTHER, ALBERT. 1880. Report on the shore fishes procured during the voyage of H.M.S. Challenger in the years 1873-1876. Report on the scientific results of the voyage of H.M.S. Challenger; Zoology, 1(6):1-82, pls. $1-32$.

Iшамото, Томго. 1980. Matsubaraea Taki, a senior synonym of Cirrinasus Schultz (Percophididae). Japanese Journal of Ichthyology 27(2):111-114.

Jordan, David S., And John O. Snyder. 1902. A review of the trachinoid fishcs and their supposed allies found in the waters of Japan. Proceedings of the United States National Museum 24(1263):462-497.

JoRdan, DAVID S., AND EDward C. Starks. 1904. List of fishes dredged by the steamer Albatross off the coast of Japan in the summer of 1900, with descriptions of new species and a review of the Japanese Macrouridae. Bulletin of the United States Fish Commission 22:577-630.

Kao, Hsiao-Wei, and Shih-Chieh Shen. 1985. A new percophidid fish, Osopsaron formosensis (Percophidae: Hemerocoetinae) from Taiwan. Journal of the Taiwan Museum 38(1):175-178.

Masuda, Hajime, Kunio Amaoka, Chuichi Araga, Teruyo Uyeno, and Tetsuo Yoshino, eds. 1984. The Fishes of the Japanese Archipelago. Tokai University Press, Tokyo, Japan. Pages 1-437 (text), plates 1-70.

McKay, Roland J. 1971. Two new genera and five new species of percophidid fishes (Pisccs: Percophididac) from Western Australia. Journal of the Royal Society of Western Australia 54(Pt 2): 40-46.

Nelson, Joseph S. 1979. Revision of the fishes of the New Zealand genus Hemerocoetes (Perciformes: Percophididae), with descriptions of two new species. New Zealand Journal of Zoology 6:587-599.

Nelson, Joseph S. 1982. Pteropsaron heemstrai and Osopsaron natalensis (Perciformes: Percophidae), new fish species from South Africa, with comments on Squamicreedia obtusa from Australia and on the classification of the subfamily Hemerocoetinae. J.L.B. Smith Institute of Ichthyology Special Publication (25):1-11.

OKamura, Osamu, and Shuzo Kishida. 1963. A new genus and species of the bembroid fish collected from the Bungo Channel, Japan. Bulletin of the Misaki Marine Biological Institute, Kyoto University 4:43-48.

Parin, Nicholal V. 1985. A new hemerocoetine fish, Osopsaron karlik (Percophidae, Trachinoidei) from the Nazca Submarine Ridge. Japanese Journal of Ichthyology 3:358-361.

Smith, David G., and G. David Johnson. 2007. A new species of Pteropsaron (Teleostei: Trichonotidae: Hemerocoetinae) from the western Pacific, with notes on related species. Copeia 2007(2):364-377.

Suzuki, Toshiyukı, and Tetsunl Nakabo. 1996. Revision of the genus Acanthaphritis (Percophidae) with the description of a new species. Ichthyological Research 43(4):441-454. 
Suzuki, Toshiyuki, and Tetsuji Nakabo. 1997. Notes on the life and fresh colors of Acanthaphritis unoorum and A. barbata (Percophidae). I.O.P. Diving News 8(11):2-4, figs. 1-8

Suzuki, Toshiyuki, Hiroshi Senou, And Tomoyuki Nomura. 1996. New record of a percophid fish Osopsaron formosensis (Perciformes; Percophidae) from Japan. I.O.P. Diving News 7(3):2-4, figs. 1-2.

TAKI, I. 1953. On two new species of fishes from the Inland Sea of Japan. Journal of Science of Hiroshima University, B. Div. 1, 14(1):201-210, pl. 1, figs. 1-7. 


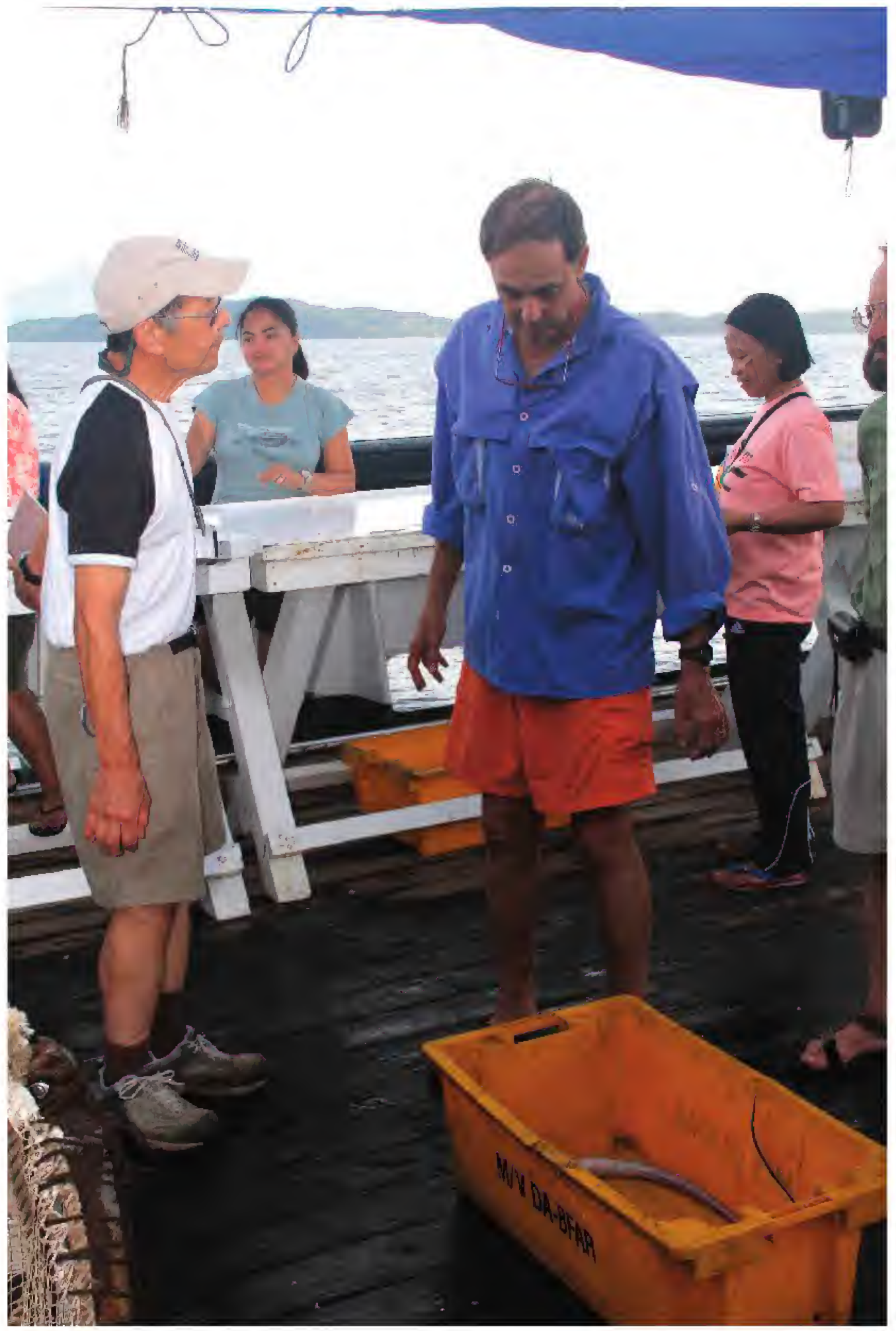

PLATE 10. Tomio Iwamoto (left) and John McCosker (right) aboard the M/V DA-BFAR. Photo by Terrence M. Gosliner. 


\title{
Deep-Water Fishes of the 2011 Hearst Philippine Biodiversity Expedition of the California Academy of Sciences
}

\author{
Tomio Iwamoto and John E. McCosker \\ Institute of Biodiversity Science and Sustainibility, California Academy of Sciences, 55 Music Concourse \\ Drive, San Francisco, California 94118; Email: tiwamoto@calacademy.org; jmccoskeer@calacadermy.org
}

The year 2017 will mark the $100^{\text {th }}$ anniversary of the Albatross Philippine Expedition. Smith and Williams (1999) wrote:

\begin{abstract}
In the history of American maritime exploration, it was the second only to the Wilkes Expedition in terms of time spent and area covered. In terms of the material collected and the pages published, the Philippine Expedition is in a class by itself and stands as one of the greatest of all oceanographic expeditions.
\end{abstract}

Whereas the offshore collecting efforts of California Academy of Sciences Hearst Philippine Expedition (HEPD) of 2011 was much smaller and more limited in duration and locations sampled, it did accomplish similar successes in that the deepwater trawling and trapping along the Verde Island Passage (between Luzon and Mindoro islands) resulted in the capture of several undescribed and many poorly known fishes. Several of the specimens remain to be conclusively identified, however we present here our findings as of this date.

During the period 28 May-4 June 2011, the M/V DA-BFAR of the Philippine Bureau of Fisheries and Aquatic Resources made a series of deepwater collections in waters off Batangas and Mindoro provinces off southwestern Luzon, Philippines (Fig. 1). The collecting began in the Batangas and Balayan bays, then out into the Verde Island Passage between Luzon and Mindoro islands, proceeded west through the Calavite Pasage to the southern shores of the Lubang Islands and out to the shelf edge in the South China Sea before returning along the northern coast of the Lubang Islands to Batangas Bay. A total of 39 stations were occupied (Table 1; station data) of which eight were trap stations, eight otter trawls (including station HEPD-027 where the gear was entirely lost), and 23 beam trawls. In addition, a few fish were captured on hook-and-line during one evening of fishing while the vessel lay-to for the night. Fishes comprised part of the catch at all stations except two where the otter trawl was used, one where the beam trawl was used, and two where traps were used.

The number of fishes captured during this cruise included 78 families, 148 genera, and about 214 species, so far as we have been able to determine. Many of these represent new records for the area and a few represent species new to science and will be described elsewhere. A number of specimens could not be determined as to species, either because of inadequate descriptions in the published literature or because the taxonomy of the group is in need of a thorough revision. Included in this category were badly damaged specimens, and some juveniles and larvae that we made no attempt to identify. Some unidentified specimens may well represent undescribed species.

\section{Methods And Materials}

Traps (Fig. 2) were of a standard design used by the local fishermen. They were cylindrical cage traps approximately $1 \mathrm{~m}$ long and $30 \mathrm{~cm}$ in diameter covered with polyethylene mesh and baited with fish. They were deployed in 40-trap sets, each trap tethered to a mainline at about $50 \mathrm{~m}$ intervals. Depths fished with the traps ranged from as shallow as $60-77 \mathrm{~m}$ to as deep as $821-836 \mathrm{~m}$. Although the number of fishes captured in the traps was generally low, the species rep- 


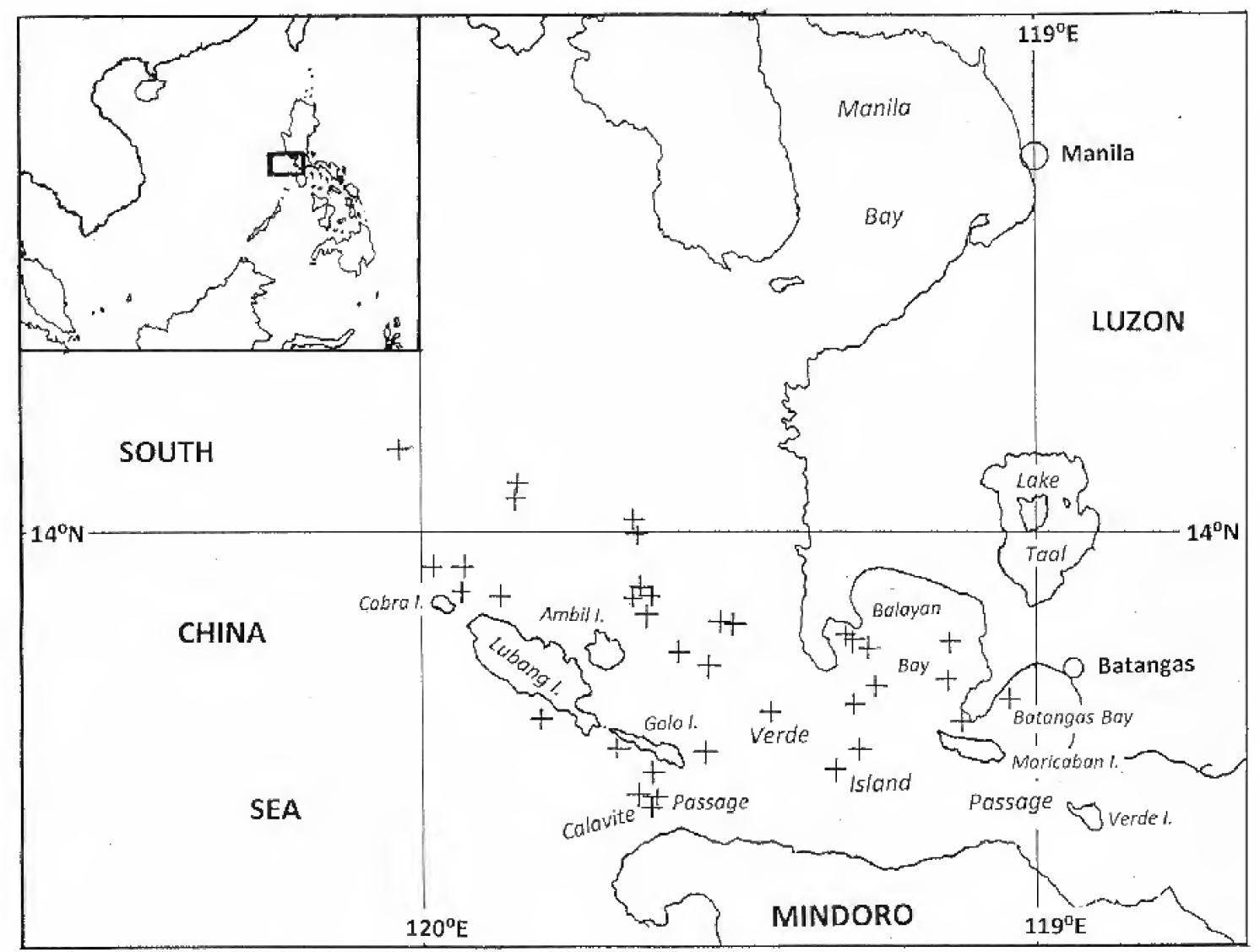

FIGURE 1. Map showing collecting stations of the M/V DA-BFAR during the California Academy of Sciences Hearst Philippines Expedition, 28 May through 4 June 2011.

resented were often not taken by other means: falling into this category were most notably the eels and the catsharks. Traps offer the advantage over trawls in being usable over bottom topography that would otherwise preclude dragging a trawl. The fishes obtained by this method were also in excellent shape: damaged specimens are a frequent problem in trawl catches.

OTTER TRAWLS (Figs. 3, 4).- When successfully fished, the otter trawls were highly productive in terms of biomass and diversity of the catch because of their wide swept area. However, they are susceptible to hang-ups and tears from rough bottoms, making them unsuitable over much of the area surveyed during the HEPD cruise. Because no opening-closing device was used on the trawl, a mixture of midwater and bottom organisms was often taken.

BEAM TRAWLS.- The 4-m beam trawl employed during the cruise was notable in the length of its wooden beams, which exceeded those commonly used in oceanographic work. The wide swept-area of the beam trawl resulted in good catches with high diversity. The relatively tight coverage of the substratum and the fine-mesh liner often captured small epibenthic, subsurface, and burrowing organisms, especially invertebrates, that were not sampled by the otter trawl. The durability of beam trawls in general also makes it much more feasible to deploy over rough bottoms, although on one occasion, the trawl hung up, a beam broke, and most of the gear was lost.

Preservation of SPecimens.- - After capture and a rough sort of the catch on deck, the fish specimens were brought into the vessel's wet lab and further sorted and identified to the lowest level possible with the available literature on board. Representatives of each species were set aside, 
TABLE 1. Station data for M/V DA-BFAR, 28 May to 4 June 2011. Gear abbreviations: BTR beam trawl, OTR — otter trawl, TRA — traps, H\&L — hook and line.

\begin{tabular}{|c|c|c|c|c|c|c|c|}
\hline $\begin{array}{l}\text { Stn. No. } \\
\text { HEPD }\end{array}$ & 2011 date & Gear & Set time & $\begin{array}{c}\text { Set latitude } \\
N\end{array}$ & $\begin{array}{c}\text { Set Longitude } \\
E\end{array}$ & $\begin{array}{c}\text { Capture } \\
\text { depth (m) }\end{array}$ & Bottom type \\
\hline 001 & 28-May & BTR & 1412 & 13.714 & 120.953 & $238-252$ & Sandy-muddy \\
\hline 002 & 28-May & TRA & 1833 & 13.825 & 120.679 & $146-203$ & Sandy-muddy \\
\hline 003 & 29-May & BTR & 0805 & 13.822 & 120.763 & $272-291$ & Muddy \\
\hline 004 & 29-May & OTR & 1000 & 13.854 & 120.772 & $154-245$ & Muddy \\
\hline 005 & 29-May & BTR & 1157 & 13.718 & 120.756 & $459-496$ & Muddy w/pebbles \\
\hline 006 & 29-May & OTR & 1504 & 13.703 & 120.638 & $454-457$ & Muddy w/coraline sand \\
\hline 007 & 29-May & OTR & 1830 & 13.775 & 120.846 & Aborted & \\
\hline 008 & 29-May & TRA & 2005 & 13.876 & 120.876 & $203-252$ & Muddy \\
\hline 009 & 30-May & OTR & 0838 & 13.740 & 120.861 & $322-336$ & Sandy-muddy \\
\hline 010 & 30-May & BTR & 1022 & 13.820 & 120.843 & $318-333$ & Muddy \\
\hline 011 & 30-May & OTR & 1416 & 13.600 & 120.767 & $636-664$ & Muddy \\
\hline 012 & 30-May & BTR & 1642 & 13.601 & 120.667 & $721-761$ & Muddy \\
\hline 012.5 & 30-31-May & $\mathrm{H} \& \mathrm{~L}$ & & 13.601 & 120.667 & 40 & \\
\hline 013 & 30-May & TRA & 1925 & 13.635 & 120.488 & & Muddy \\
\hline 014 & 31-May & BTR & 0850 & 13.602 & 120.348 & $865-944$ & Muddy \\
\hline 015 & 31-May & BTR & 1117 & 13.601 & 120.348 & $757-836$ & Sandy-muddy \\
\hline 016 & 31-May & OTR & 1324 & 13.607 & 120.339 & $892-966$ & Muddy \\
\hline 017 & 31-May & BTR & 1807 & 13.689 & 120.184 & $282-428$ & Muddy w/hard coraline rocks \\
\hline 018 & 31-May & TRA & 1953 & 13.641 & 120.301 & $240-262$ & Sandy-muddy \\
\hline 019 & 1-Jun & BTR & 0815 & 13.610 & 120.372 & $541-636$ & Sandy-muddy w/pebbles \\
\hline 020 & 1-Jun & BTR & 1153 & 13.667 & 120.186 & $311-328$ & Trawl lost \\
\hline 021 & 1-Jun & BTR & 1619 & 13.886 & 120.147 & $72-94$ & Sandy-muddy \\
\hline 022 & 1-Jun & OTR & 1745 & 13.887 & 120.109 & $63-79$ & Muddy \\
\hline 023 & 1-Jun & TRA & 1951 & 13.937 & 120.092 & $578-710$ & Sandy-muddy \\
\hline 024 & 2-Jun & BTR & 0840 & 14.052 & 119.983 & $2107-2350$ & Sandy-muddy \\
\hline 025 & 2-Jun & BTR & 1523 & 13.891 & 120.383 & $82-86$ & Sandy-rocky, hard \\
\hline 026 & 2-Jun & BTR & 1609 & 13.904 & 120.357 & $82-86$ & Sandy-rocky, hard \\
\hline 027 & 2-Jun & OTR & 1721 & 13.899 & 120.365 & & Trawl lost \\
\hline 028 & 2-Jun & BTR & 1911 & 13.927 & 120.314 & $115-124$ & Sandy-rocky, hard \\
\hline 029 & 2-Jun & TRA & 2020 & 13.932 & 120.298 & $60-77$ & Sandy-muddy \\
\hline 030 & 3-Jun & BTR & 0740 & 13.993 & 120.322 & $190-201$ & Sandy-muddy \\
\hline 031 & 3-Jun & BTR & 0928 & 14.017 & 120.334 & $183-188$ & Sandy-muddy \\
\hline 032 & 3-Jun & BTR & 1355 & 14.080 & 120.175 & $223-369$ & Sandy \\
\hline 033 & 3-Jun & BTR & 1620 & 14.080 & 120.172 & $225-347$ & Sandy \\
\hline 034 & 3-Jun & TRA & 1855 & 13.950 & 120.044 & $821-836$ & Muddy \\
\hline 035 & 4-Jun & BTR & 1117 & 13.835 & 120.451 & $397-439$ & Muddy \\
\hline 036 & 4-Jun & BTR & 1330 & 13.795 & 120.410 & $216-262$ & Muddy \\
\hline 037 & 4-Jun & BTR & 1532 & 13.844 & 120.483 & $417-481$ & Muddy \\
\hline 038 & 4-Jun & TRA & 1029 & 13.852 & 120.451 & $355-368$ & Sandy-muddy \\
\hline 039 & 4-Jun & BTR & 2035 & 13.686 & 120.581 & $633-642$ & Muddy \\
\hline
\end{tabular}


a plastic tag with a unique number attached (the number is prefaced with "DC" in the Materials sections), a tissue sample extracted, and a photograph taken. The tissues, usually a slice of body muscle from the right side or a portion of the right pectoral fin, were placed in tissue vials filled with $95 \%$ ethanol. A plastic tag numbered the same as the fish specimen from which it came was also inserted into the vial. The fish specimens to be preserved for the CAS collections were placed in $10 \%$ formalin for initial fixation later to be transferred in stages to $75 \%$ ethanol at CAS. Some of the specimens listed as CAS uncat. were left in the Philippines to be deposited in the Philippines National Museum. A few others will be deposited in other institutions.

The primary references used for the initial identifications include the FAO Species Identification Guide for Fishery Purposes, The Living Marine Resources of the Western Central Pacific

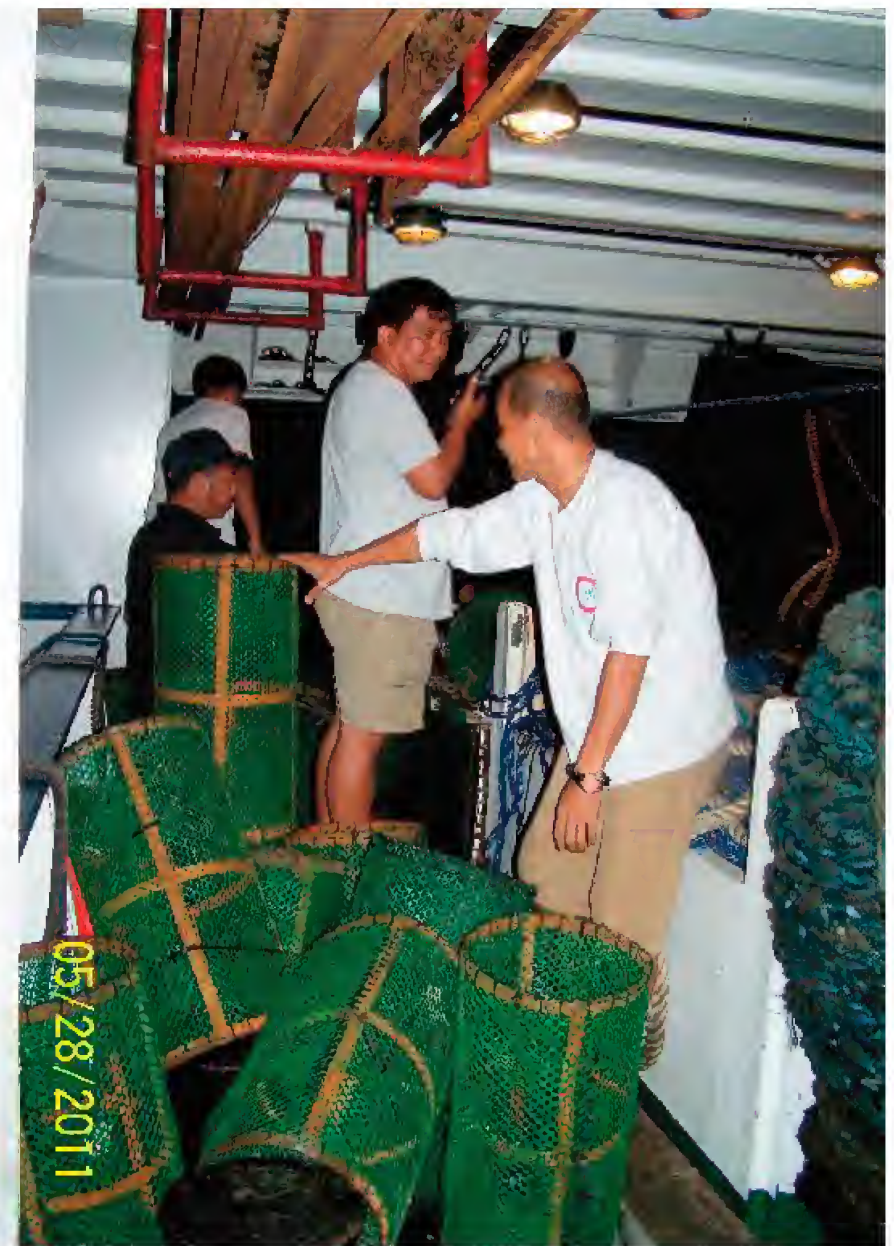

FIGURE 2. Traps used during the Expedition. (Carpenter and Niem 1999 and 2001); Fishes of Japan with Pictorial Keys to the Species (Nakabo 2000); and The Fishes of the Japanese Archipelago (Masuda et at. 1984). More specialized literature as listed in the References, and specimens from the Academy collections, were used to verify our identifications. On occasion, we took advantage of the internet and advice from experts on different fish groups to garner identifications from images taken aboard ship. For the most part, we did not conduct thorough investigations into the literature coupled with comparisons of museum specimens for the HEPD specimens identified, as would be the case were this paper meant to be a full taxonomic treatise. The purpose of this paper is to provide a basic list of specimens procured during the deepwater phase of the Expedition; our tentative identifications and photographs will guide others who wish to follow up with more extensive studies of specimens of interest.

Abbreviations are generally the standard ones used in the taxonomic literature, including SLstandard length, TL — total length, FL — fork length, HL - head length, 1D and 2D-first and second dorsal fin, $\mathrm{A}$ - anal fin, $\mathrm{P}$ - pectoral fin, $\mathrm{V}$ - pelvic fin, $\mathrm{C}$ - caudal fin, GR - gill raker, $\mathrm{m}$ meters, fm-fathom. Photophore abbreviations for Myctophiformes, Stomiiformes, and others can be found in most texts dealing with those fishes. The fishing (gear) depths recorded aboard the M/V $D A-B F A R$ were in fathoms; these were converted in the text to meters using the multiplier 1.8288 . A question mark after a species name in the subheads indicates an uncertainty in the correctness of 


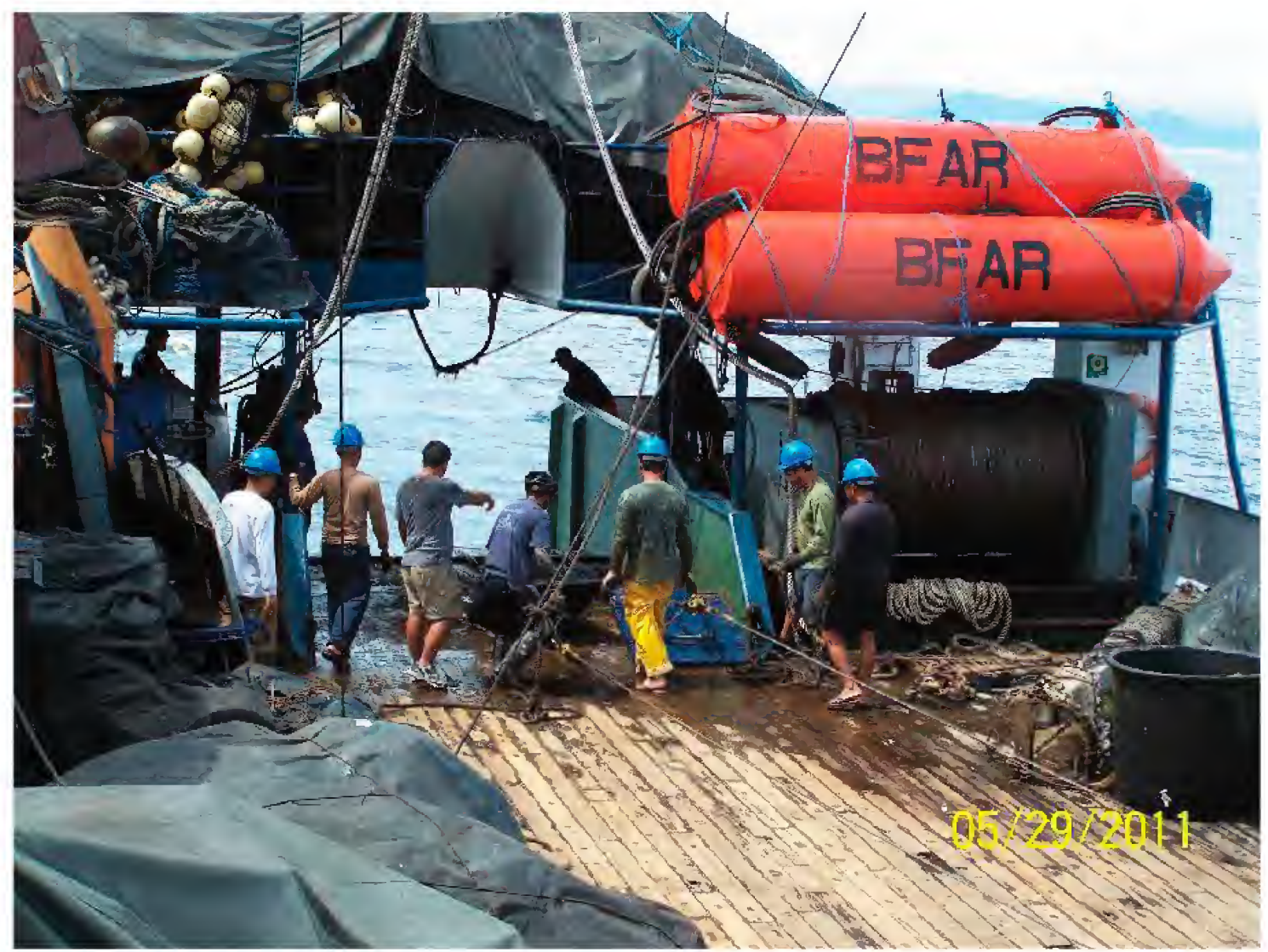

FIGURE 3. The otter trawl during haul-back, otter doors on deck; note beam trawl on right behind black plastic tub.

the specific name; a cf. before the specific name indicates that the fish is similar to, but not the same as, the species indicated.

The list of species and the classification of families largely follow Nelson's (2006) Fishes of the World, Fourth Edition.

\section{DISCUSSION}

The Coral Triangle has long been considered the center of diversity of marine organisms (Allen and Erdman, 2012) and the Philippines are thought by some (Carpenter and Springer 2005) to be the center of the center of diversity. The deepwater fish fauna of this region have yet to be adequately compared with those from other regions, but collections by the former U.S. Fish Commission steamer Albatross in the Philippines and Dutch East Indies during the early part of the 20th century (1907-1910) (see Smith and Williams 1999) provide a broad measure of the diversity of the deepwater fauna. No other expedition to this region has equaled the extent of coverage and resultant new species described from these Albatross collections. The French ORSTOM cruises over the past three decades collected huge numbers of fishes and invertebrates from offshore waters, but the fishes from those cruises have yet to be adequately examined and published on. A short ORSTOM cruise off Lubang Island in 1976 resulted in the collection of 43 deepwater fish species (de la Paz and Interior 1979) that was deposited in the Zoological Museum of the University of the Philippines (UPZM). The list of species in that collection, included only a few species that corresponded with the HEPD list. We were unable to access the UPZM collection and therefore could not check the identifications. Most ORSTOM collections are housed in the Muséum 


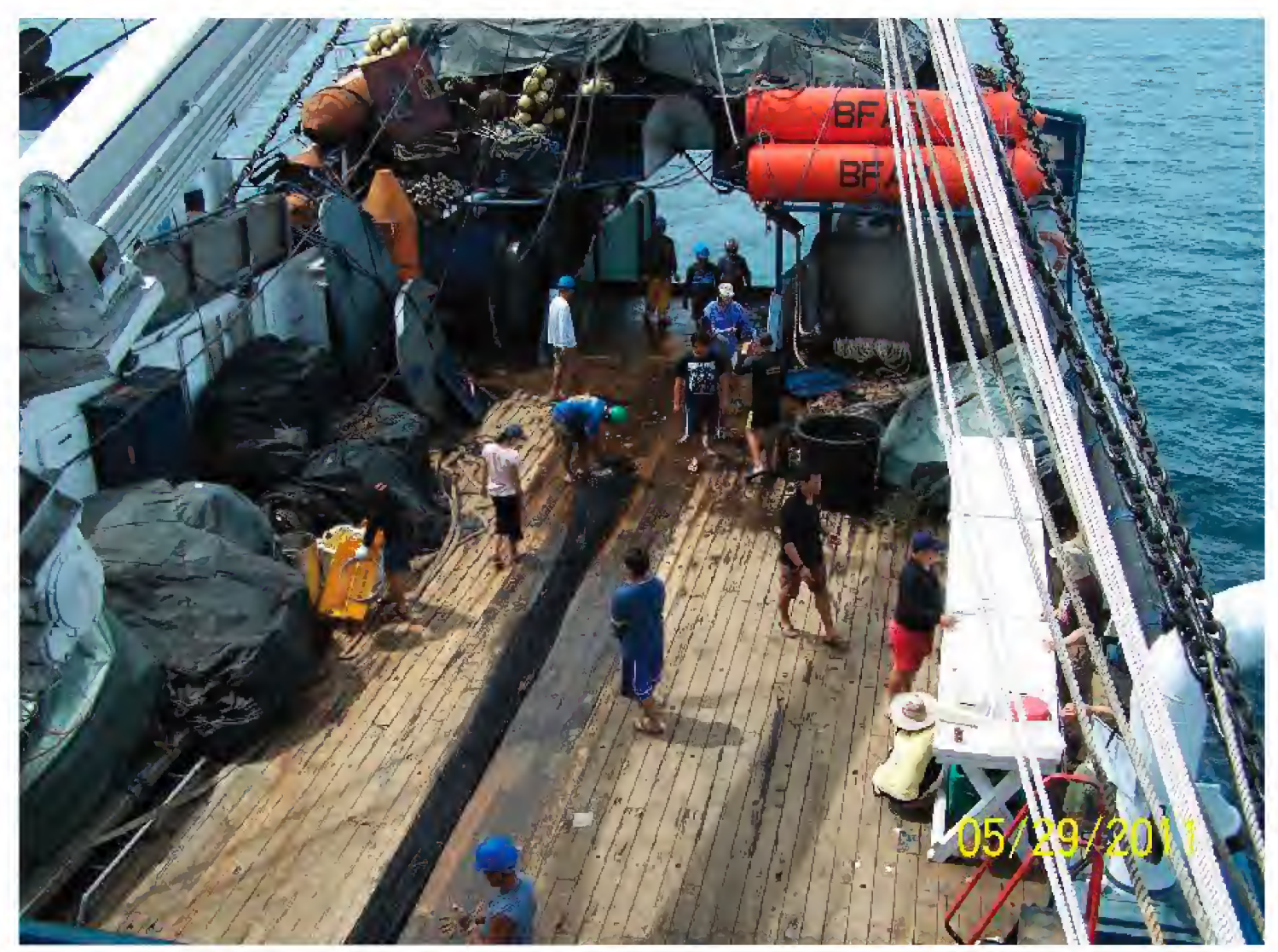

FIGURE 4. The otter trawl on deck.

national d'Histoire naturelle in Paris: they offer a treasure-trove of research material for those willing to dig through the many drums of formalin-preserved fishes.

In September 1995 the Taiwan fishery vessel Fishery Researcher I conducted a short survey off the east coast of Luzon using a large otter trawl and a 2-m ORI ring net. Seven deep bottom hauls were made using the otter trawl at depths from $174 \mathrm{~m}$ to $1053 \mathrm{~m}$, and one shallow haul made in $40 \mathrm{~m}$. Midwater hauls were made between the surface and about $1550 \mathrm{~m}$, four using the otter trawl and two using the ORI ring net. About 300 species were identified from this 1995 survey, a number far exceeding what the HEPD expedition obtained, mostly owing to the larger catches of midwater fishes and perhaps the larger trawl used by the Fishery Researcher I. The fish collections were split among various institutions, including the Philippine Bureau of Fisheries and Aquatic Resources, the Australian Museum, the Peabody Museum of Yale University, the Taiwan Fisheries Research Institute in Kaohsung, and the California Academy of Sciences. Two subsequent cruises sponsored by the Taiwanese government were made in the early part of 2000 , with the collections deposited in the National Museum of the Philippines in Manila and the Academia Sinica in Taiwan.

The extent to which the Chinese have surveyed the South China Sea is unknown to us, but is likely to be substantial. Randall and Lim (2000) recorded 3365 species of marine fishes from the South China Sea. That number continues to grow as more collecting continues, often in areas hitherto untouched, and as new, more-refined techniques tease out previously imperceptible taxa. Randall and Lim acknowledge that the pelagic and deep-sea fauna has not been well studied in the South China Sea and that "these deep-sea habitats are. . . important areas for future exploration" (op. cit. p. 570). 


\section{ACKNOWLEDGMENTS}

We had identification help from numerous ichthyologists who were generous with their time and expertise. These include Abner Bucol (Muraenidae), Kent E. Carpenter and Thomas H. Fraser (Apogonidae), Barry Goldman (Nemipteridae), Martin F. Gomon (Trachichthyidae), Hsuan-Chieh Ho (Ogcocephalidae and deepsea anglerfishes); Doug Hoese (Gobiidae), Helen Larson (Gobiidae), Keiichi Mastuura (Tetraodontidae), Michael Mincarone (Myxinidae); Stuart G Poss (Scorpiniforms), John E. Randall (Nemipteridae), William J. Richards (Triglidae, Peristediidae), and David G. Smith (Congridae). Ichthyology staff of the California Academy of Sciences (CAS) were extremely helpful: David Catania photographed almost all of the species during the expedition and answered continual questions concerning specimens and data; Jon Fong provided radiographs, photographs, and data; Mysi Hoang ensured accurate and timely cataloging of specimens and provided necessary administrative and other assistance; and Anna Sellas and Claudia Rocha provided genomic assistance and advice. Don Dumale (National Museum of the Philippines) provided ichthyological advice and assistance while in the field and identified specimens while at the CAS. We thank expedition leaders Terrence Gosliner and Richard Mooi for their invitation to participate in the expedition and for support of our efforts during and after the cruise. And most importantly, we thank the persons who made it all possible, William and Margaret Hearst, sponsors of the expedition. 


\title{
Annotated list of species collected on the Philippine Bureau of Fisheries and Aquatic Resources research vessel M/V DA-BFAR, 28 May to 5 June 2011
}

\author{
MYXINIDAE (LAMPREYS)
}

Myxine cf. formosana Mok and Kuo, 2001 (Fig. 5)

Material. - CAS 233680 (440 mm TL, female with eggs, DC-1388); HEPD-013, traps in 587-604 m.

ReMarks. - This specimen is tentatively identified by Michael Mincarone and McCosker (this volume) as Myxine formosana. It represents the first Philippine specimen of the species.

Eptatretus luzonicus Fernholm, Norén, Kullander, Quattrini, Zintzen, Roberts, Mok, and Kuo, 2013 (Fig. 6)

Material. - CAS 233675 (563 mm TL); HEPD-023, traps set in 578-710 m. CAS 233676 (3, 334-430 mm TL); HEPD-013, traps set in 587-604 m. NPM 1999 (443 mm TL); collected with CAS 233676.

REMARKs.- Mincarone and McCosker (this volume) have discovered the lost holotype of Eptatretus luzonicus (= Eptatretus fernholmi McMillan and Wisner, 2004), lost prior to its description; they redescribed it along with the five specimens collected during the Hearst Expedition.

\section{CHIMAERIDAe (SHORTNOSE CHIMAERAS OR RATFISHES)}

\section{Hydrolagus deani (Smith and Radcliffe, 1912) (Fig. 7)}

Mate Rial.-CAS 235485 (female, $730 \mathrm{~mm}$ TL, DC-1413); HEPD 016, otter trawl in 892-966 m.

Remarks. - The Philippine Chimaera is known only from the Philippines.

\section{SCYLIORHINIDAE (CAT SHARKS)}

Apristurus platyrhynchus Tanaka, 1909 (Fig. 8)

MATerial.-CAS 234027 (225 mm TL, DC-1405); HEPD-015, beam trawl in 757-836 m.

Remarks. - Distributed from southern Japan, Taiwan, to northern Borneo, the East China Sea, the Philippines and the South China Sea at depths between approximately 600 and $1000 \mathrm{~m}$.

Cephaloscyllium sp. (Fig. 9a-c)

MATERial. - ( 7 specimens trapped and trawled at 355-480 m.)

REMARKS. - McCosker sent pictures and the sequencing map provided by Anna Sellas (CAS) to Peter Last, the CSIRO shark biologist who has done so much work on this group. Last has advised McCosker that he has a market specimen from the Philippines that is most probably the same as ours and was in the process of describing it, and would like our involvement. He now has concerns about separating the Philippine material from another species that John E. Randall (BPBM) described as Cephaloscyllium stevensi Clark and Randall, 2011 from New Ireland, and is trying to get tissue from that species. A juvenile specimen (135 $\mathrm{mm}$ TL) was captured and cataloged as CAS 235500. Measurements of the six larger specimens are here provided: DC-1313 (female, $580 \mathrm{~mm}$ TL); DC-1314 (mature male, $610 \mathrm{~mm}$ TL); DC-1315 (female, 625 $\mathrm{mm}$ TL); CAS 235501, DC-1438 (immature male, $395 \mathrm{~mm}$ ); DC-1576 (mature male, $520 \mathrm{~mm}$ TL); DC1577 (immature male, $410 \mathrm{~mm} \mathrm{TL}$ ).

\section{SQUALIDAE (DOGFISH SHARKS)}

Etmopterus brachyurus Smith and Radcliffe in Smith, 1912 (Fig. 10)

Mate Rial. - CAS 233994 (2, 132-203 mm TL); HEPD-005, beam trawl in 459-496 m.

REMARKS. - Originally described from Jolo Is., Philippines; the species is also known from Japan and Western Australia. 


\title{
HeXATRYGONIDAE (SIXgILl STINGRAYS)
}

\author{
Hexatrygon bickelli Heemstra and Smith, 1980 (Fig. 11)
}

Material. - CAS 233779 (female, $620 \mathrm{~mm}$ TL, DC-1295); HEPD-006, otter trawl in 454-457 m.

REMARKS. - This species was originally described from South Africa, but subsequcntly recorded from Japan, Australia, Hawaii and waters adjoining these areas. It is occasionally sold in fish markets in Taiwan.

\section{Halosauridae (Halosaurs)}

\section{Aldrovandia phalacra (Vaillant, 1888)? (Fig. 12)}

Material. - CAS 236021 (213+ mm TL [tail tip missing], DC-1427); HEPD-016, otter trawl in 892-966 m.

REMARKS.- This specimen agrees fairly closely with Aldrovandia oleosa Sulak, 1977 in its dark overall coloration, but the development of, and interspace betwcen, the palatine tooth patches, and the spacing between them and the pterygoid tooth patches is narrower, the lateral-line scale count appears to be higher (scales all lost and scale pockets not well defined), and the gill-raker count at 24 total $(5+1+18)$ is slightly higher (cf. 19-23). The branchiostegal-ray count of 10 is lower than in A. phalacra (11-13) and agrees more with that in A. oleosa (9-11). A. phalacra has been recorded from the Indian Ocean and the Hawaiian Islands, but so far as we can determine, not in the western Pacific. If the HEPD specimen is correctly identified as that species, it will represent a first record for these waters.

\section{Muraenidae (MORAY EELS)}

\section{Gymnothorax cf. johnsoni (Smith, 1962) (Fig. 13)}

Material. - CAS 236625 (3, 440-620+ mm TL, DC-1310-1312); HEPD-008, traps in 203-252 m.

REMARKS.- The deepwater white-spotted species of Gymnothorax requires proper analysis. Our specimen is closely related to two or more other white-spotted spccics, including G. elegans Bliss, 1883 and G. isingteena (Richardson, 1845), and cannot be identified with certainty. The three CAS specimens are similar to the holotype of Lycodontis johnsoni and have a MVF of 5-59-145, total 141-146. The type of G. johnsoni has 5-55-139. Muraena stellifer (Richardson, 1848) may be a senior synonym of Gymnothorax johnsoni or a junior synonym of Gymnothorax punctatus Bloch and Schneider, 1801; and Gymnothorax albomaculatus Bliss, 1883 may be a synonym of G. elegans (see Böhlke and Smith 2002). This species complex requires revision.

A $585 \mathrm{~mm}$ SL specimen of what appears in a photograph to be this species was purchased in a Dumaguete fish market by a Philippine student, Abner Bucol, who is in contact with McCosker about Philippine eels.

\section{Gymnothorax cf. nuttingi Snyder, 1904 (Fig. 14)}

Material. - CAS 236626 (female, 748 mm TL, DC-1318); HEPD-008, traps in 203-252 m.

REMARKS. - This deepwater moray is currently reported only from the Hawaiian Islands. Our specimen differs in coloration from that of Hawaiian specimens (see Böhlke and Randall 2000:246), but does not differ in morphometrics and dentition. It does differ in its vertebral counts (PI 5-68-148 vs. MVF of 6 specimens from Hawaii 6-71-160, total 157-165). We are hesitant to describe this as a new species until tissue from Hawaiian specimens can be made available for comparison to that of our Philippine specimen.

\section{SYNAPHOBRANCHIDAE (CUTTHROAT EELS)}

\section{Dysomma anguillare Barnard, 1923 (Fig. 15)}

Material.-CAS 235128 (557 mm TL and CAS 235465 (5, 525-540 mm TL); HEPD-002, traps in 146-203 m. CAS 235129 (2, 517-575 mm TL); HEPD-018, traps in 240-262 m. CAS 235465 (2, 525-540 $\mathrm{mm}$ TL); HEPD-038, traps in 355-368 m.

REMARKS. - This is a circumglobal species.

\section{Synaphobranchus kaupii Johnson, 1862 (Fig. 16)}

MATERIAL. - CAS 235497(365 mm SL, DC-1381); HEPD-012, beam trawl in 721-761 m. CAS 235454 (535 $\mathrm{mm}$ SL, DC-1423) and CAS 235499 (535 mm SL, DC-1423); HEPD-016, otter trawl in 892-966 m. CAS 235498 (405 mm SL, DC-1500); HEPD-023, traps in 578-710 m. 
REMARKs.-A mostly circumglobal species, including the Hawaiian Islands, but absent in the eastern Pacific.

\section{SiMENCHELYIDAE (SNUBNOSE PARASITIC EELS)}

\section{Simenchelys parasitica Gill, 1879 (Fig. 17a-b)}

Material.-CAS 235457 (463 mm TL, DC-1341); HEPD-011, otter trawl in 636-664 m.

REMARKS. - The only species in this family. Probably worldwide distribution in deep slope waters below 500 $\mathrm{m}$ to more than $1500 \mathrm{~m}$.

\section{OPHICHTHIDAE (SNAKE EELS AND WORM EELS)}

Pylorobranchus hearstorum McCosker, 2014 (described in this volume) (Fig. 18)

MateriaL.-CAS 235464 (holotype, female, 1218 mm TL, DC-1426); HEPD 016, beam trawl in 892-966 m.

REMARKS. - This, the largest myrophine ophichthid yet known, is described in this volume on the basis of the single specimen collected during the expedition.

Ophichthus cf. urolophus (Temminck and Schlegel, 1846) (Fig. 19)

Material.- CAS 236637 (4, 429-635 mm TL, DC-1445, JM 541-543); HEPD-018, trap in 240-262 m. CAS 236638 (547 mm TL, DC-1269); HEPD-003, beam trawl in 272-291 m. CAS 236639 (3, 508-ca. $630 \mathrm{~mm}$ TL); HEPD-0 10, beam trawl in 318-333 $\mathrm{m}$.

Remarks.- The eight Verde Island Passage specimens trawled and trapped between $240 \mathrm{~m}$ and $332 \mathrm{~m}$ are very similar in appearance and characteristics to Ophichthus urolophus, a deepwater $(40-420 \mathrm{~m})$ ophichthid known from Japan, western Australia, and Indonesia (Sumida and Machida 2000; McCosker 2010). It is also similar in its body proportions, general physiognomy, and vertebral counts (HEPD specimens 134-137 vs. O. urolophus 134-139), but differs in the location of its dorsal-fin origin (slightly in advance of end of pectoral fin in Philippine specimens, slightly behind end of pectoral fin in extralimital O. urolophus specimens).

\section{COLOCONGRIDAE}

Coloconger scholesi Chan, 1967 (Fig. 20)

MATE RIAL. - CAS 235482 (365 mm SL, DC-1301); HEPD-006, otter trawl in 454-457 m.

REMARKS.- Known from western Indian Ocean and in the western Pacific off Australia and in the South China Sea.

\section{CONGRIDAE (CONGER EELS)}

Ariosoma anago (Temminck and Schelgel, 1846) (Fig. 21)

Material. - CAS 235453 (363 mm SL, DC-1480); HEPD-022, otter trawl in 115-144 m.

Remarks. - Widely distributed in the western Pacific and eastern Indian Ocean.

\section{Conger macrocephalus Kanazawa, 1958 (Fig. 22)}

MateriaL-_CAS236635 (785 mm TL, DC-1316) and CAS 236636 (610 mm TL, DC-1317); HEPD-008, traps in 203-252 m. CAS 2366634 (378 mm TL, DC-1441); HEPD-018, trap in 240-262 m.

Remarks.-Kanazawa (1958) described Conger macrocephalus (p. 254) and C. philippinus (p. 255) in his Conger revision. D. G. Smith (in litt. 2012) questions the difference between these species. The vertebrae of our specimens agree with Smith's (1994: 6) listing in his catalogue of eel type specimens in the USNM. Ours have 14-35-134 (DC-1316), 14-36-136 (DC-1317) and 16-38-141 (DC-1441), and the holotype of C. macrocephalus has 15-36-136, that of C. philippinus has 17-38-132.

Parabathymyrus brachyrhynchus (Fowler, 1934) (Fig. 23)

MATERIAL. - CAS 235589 (male, 268 mm TL, DC-1532); HEPD-031, beam trawl in 183-188 m.

REMARKS. - This specimen is in excellent condition and its testes are well developed. It has a vertebral formula of 13-52-171, slightly different than those of the holotype (19-55-166) and the paratype (168 total) 
(Smith 1989:504; 1994:5). The specimen displays a sharp and distinct mid-saggital crest that extends from slightly anterior to the orbit to the rear margin of the orbit. The specimen is not at all dessicated and the crest is quite apparent exteriorly.

\section{Bathycongrus guttulatus (Günther, 1887) (Fig. 24)}

Material.-CAS 235635 (male, $319 \mathrm{~mm}$ TL, DC-1303); HEPD-006, otter trawl in 454-457 m. CAS 235634 (male, $417 \mathrm{~mm}$ TL, DC 1557); HEPD-035, beam trawl in 397-439 m.

REMARKs. - The vertebral formulae of the specimens are 11-42-154 (DC-1303) and 10-41-163 (DC-1557). Several species of Bathycongrus remain undescribed; these specimens were identified using the key in Karmovskaya and Smith (2008).

Bathycongrus retrotinctus (Jordan and Snyder, 1901) (Fig. 25)

Material. - CAS 235455 (224 mm TL); HEPD-001; beam trawl in 238-252 m. CAS 235456 (360 mm TL, DC-1580); HEPD-038, traps in 355-368 m.

REMARKS. - This congrid eel is readily identified by its pointed snout, dentition, D and A fin origins, and pore and color patterns.

\section{BATHYLAGIDAE (DEEP-SEA SMELTS)}

\section{Nansenia ardesiaca Jordan and Thompson, 1914 (Fig. 26)}

Material.-CAS 234013 (135 mm SL, DC-1332); HEPD-010, beam trawl in 318-333 m.

REMARKS.- Widely distributed in the western Pacific.

\section{ALEPOCEPHALIDAE (SLICKHEADS)}

Bajacalifornia erimoensis Amaoka and Abe, 1977 (Fig. 27)

MATERIAL.—CAS 235451 (232 mm SL, DC-1416); HEPD-016, otter trawl in 892-966 m.

REMARKS.-Formerly known only from off Japan. The HEPD specimen extends its known range to the Philippines.

\section{Narcetes kamoharai Okamura, 1984 (Fig. 28)}

Material. - CAS 235450 (276 mm SL, DC-1417); HEPD-016, otter trawl in 892-966 m.

REMARKS. - This species was originally described from off the Okinawa Islands in the Ryukyu Trench; its capture during the HEPD expedition extends its known range to the Philippines. One small ( $78 \mathrm{~mm} \mathrm{SL})$ damaged specimen from HEPD-014 (CAS 234025) is also probably this species.

\section{GonOSTOMATIDAE (BRISTLEMOUTHS)}

\section{Sigmops elongatum (Günther, 1878)}

Material. - CAS 235475 (95 mm SL); HEPD-016, otter trawl in 892-966 m.

REMARKs. - A circumglobal, temperate to tropical species, mostly at bathypelagic depths but often taken in bottom trawls.

\section{PhotichthyidAe (LightFishes)}

\section{Pollichthys mauli Poll, 1953}

Material.-CAS 236663 (4, 40.2-46.9 mm SL); HEPD-004, otter trawl in 154-245 m. CAS 236511 (13, $32.0-42.2 \mathrm{~mm} \mathrm{SL}$ ); HEPD-009, otter trawl in 322-336 m.

REMARKs. - Small, vertically-migrating, mesopelagic fish found in tropical waters of Atlantic, Pacific, and Indian oceans.

\section{Polymetme corythaeola (Alcock, 1900)}

Material.- CAS 235541 (9, 48.8-70 mm SL): HEPD-009, otter trawl in 322-336 m.

REMARKS. - Apparently worldwide in warm seas, commonly in 300-500 m, but sometimes to $>800 \mathrm{~m}$. 


\section{STERNOPTYCHIDAE (MARINE HATCHETFISHES)}

\section{Polyipnus spinifer Borodulina, 1979 (Fig. 29)}

Material. - CAS 235509 (6 spec.); HEPD-003, bcam trawl in 272-291 m. CAS 233991 (46.8 mm SL, DC1281); HEPD-004, otter trawl in 154-245 m. CAS 234000 (21, 15.7-60.0 mm SL, DC-1282); HEPD-009, otter trawl in 322-336 m. CAS 235477 (5, 48.5-58.0 mm SL); HEPD-035, beam trawl in 397-439 m.

ReMarks. - Known from Suruga Bay, Japan, East China Sea, and off Philippines in South China and Sulu Seas. Depth usually about $220-380 \mathrm{~m}$. Previously confused with $P$. tridentifer and $P$. soelae, but distinguishable from these by multidentate $\mathrm{ACB}$ photophore scales.

\section{Polyipnus triphanos Schultz, 1938}

Material.-CAS 235510 (23.7 mm SL); HEPD-009, otter trawl in 322-336 m. CAS 235473 (2, 30.9-35 $\mathrm{mm} \mathrm{SL}$ ); HEPD-016, otter trawl in 892-966 m.

Remarks. - Known from the Philippines and Taiwan in the South China and Indonesian islands south to the Coral Sea. Small adult size, $<50 \mathrm{~mm}$ SL

\section{Polyipnus unispinus Schultz, 1938 ?}

Material.-CAS 235471 (31.4 mm SL); HEPD-014, beam trawl in 865-944 m. CAS 235472 (8, 24.5-27 $\mathrm{mm}$ SL); HEPD-016, otter trawl in 892-966 m.

RemarKs. - A miniature species, not attaining adult size exceeding about $35 \mathrm{~mm}$ SL. The low gill-raker count (11 or 12 total) is characteristic only of $P$. unispinus. The low A-ray count (13-14, rarely 15), absence of lateral pigment bar and the ill-defined pigmentation on dorsum distinguish it from $P$. danae and all other Polyipnus. The HEPD specimens did not fully agree with the description provided by Harold (1994:502-504, fig. 4l) in lacking denticulation on the PV photophore scales, in shape of preopercular and pterygiophore spines, and in characters of the ACB photophores. If these specimens are correctly identified, they represent the first record of the species from the South China Sea. Previous records are from the Sulu Sea south through Indonesia and east and south to the Solomon Islands, Ncw Caledonia, and to north of New Zealand.

\section{Sternoptyx diaphana Herman, 1781}

Material.-CAS 235474 (2, 28.5-29.2 mm SL); HEPD-016, otter trawl in 892-966 m.

REMARKS. - Worldwide in temperate to tropical seas; bathypelagic; depth range usually between 200 and $1800 \mathrm{~m}$, but many records exceeding $1800 \mathrm{~m}$.

\section{STOMIIDAE (SCALY DRAGONFISHES)}

\section{Stomias nebulosus Alcock, 1889 (Fig. 30)}

MATERIAL. - CAS 233992 (106 mm SL, DC-1294); HEPD-005, beam trawl in 459-496 m.

REMARKs.-One of five Stomias species in the area. Absence of a greatly enlarged fanglike premaxillary tooth and the more numerous upper-jaw teeth distinguish the species from its congeners.

\section{Stomias sp.}

Material.-CAS 234024 (123 mm SL, DC-1397); HEPD-014, beam trawl in 865-944 m.

Remarks.- Harold (1999:1908) lists five species from the western-central Pacific (S. affinis, S. boa, S. danae, S. longibarbatus, and S. nebulosus).

\section{AstronesthidAE (SNAGGLETOOTHS)}

\section{Astronesthes chrysophekadion (Bleeker, 1849)}

MATERIAL. - CAS 235748 (98 mm SL); HEPD-006, otter trawl in 454-457 m.

REMARKs. - The HEPD specimen had PV 19, AC 12, OV 18, VAV 19, and OA 37: the last two counts fell outside the range given by Nakabo (2000), but the specimen otherwise closely agrees with his description. 
Astronesthes ijimai Tanaka, 1908 (Fig. 31)

MAte Rial. - CAS 233983 (10, 62.2-116.0 mm SL, DC-1284); HEPD-004, otter trawl in 154-245 m. CAS 235379 (107 mm SL, DC-1336); HEPD-009, otter trawl in 322-336 m.

REMARKS. - The black bar on the caudal peduncle and abruptly raised VAL photophores immediately separate this species from all others except $A$. lucifer Gilbert, 1905, which has a more slender caudal peduncle (depth 1.9-2.3 into length). The CAS specimens agree relatively well with descriptions of the species except for the following counts (P 7 vs. 6; VAV 17 vs. 21-24; AC 15 vs. 11-13; VAL 20 vs. 21-23; OA 39 vs. 40-42), which add a measure of uncertainty.

\section{Astronesthes lucifer Gilbert, 1905 (Fig. 32)}

Material. - CAS 235257 (2, 111-119 mm SL, DC-1335); HEPD-009, otter trawl in 322-336 m.

REMARKS. - The prominent black band on the ventral two-thirds of the caudal peduncle distinguishes the species from all others except $A$. ijimai (see above). Distributed in the western Pacific from the Hawaiian Islands to southern Japan and Indonesia.

\section{Astronesthes sp.}

Material. - CAS 236664 (44 mm SL); HEPD-026, beam trawl in 82-86 m.

REMARKS. - This small specimen was damaged, with part of the abdominal wall torn away and the tip of barbel lost. The capture of this bathypelagic fish at this relatively shallow station is unusual.

\section{Melanostomiatidae (Scaleless Black DRAGONFiShes)}

\section{Photonectes albipennis (Döderlein, 1882) (Fig. 33)}

Material.-CAS 235547 (82.7 mm SL, DC-1428); HEPD-016, otter trawl in 892-966 m. CAS 235558 (ca. $225+\mathrm{mm}$ SL [severely bent vertebral column at thorax]); collection data lost.

REMARKS. - This black dragonfish is readily identified by its curved lower jaw, absence of a $P$ fin, large postorbital photophore, and short barbel with a single filament on its bulbous tip. The CAS specimen has a long chin barbel measuring $64 \mathrm{~mm}$ (about 2x HL) with a filamentous tip (not included in measurement); base of barbel black, but all of remainder, including large, flattened bulb and tip without color. Widespread in the western Pacific from Japan south to Australia, including East and South China seas, off New Caledonia, Hawaii and French Polynesia, and off South Africa.

\section{Argentinidae (Argentines, HERring SMELTS)}

\section{Glossanodon sp. (Fig. 34)}

Material. - CAS 236020 (4, 76-80 mm SL, DC-1492); HEPD-022, otter trawl in 115-144 m.

REMARKS. - Paxton and Cohen (in Carpenter and Niem, 2001:1884) remarked on the need for a comprehensive revision of the family. The HEPD specimen does not agree with any of the known species and likely is undescribed.

\section{SYNODONTIDAE (LIZARDFISHES)}

\section{Saurida sp.}

Material. - CAS 236481 (11, 29.0-39.9 mm SL); HEPD-026, beam trawl in 82-86 m.

REMARKS. - We were unable to identify these juvenile specimens.

\section{Synodus macrops Tanaka, 1917 ?}

Material.-CAS 236482 (110 mm SL); HEPD-022, otter trawl in 115-144 m.

REMARKS. - This specimen agrees in count characters with $S$. macrops, but there are two or three short stripes on the cheek, a character that is found in S. oculeus Cressey and not in S. macrops, which has instead a single short bar immediately behind the eyes.

\section{Synodus oculeus Cressey, 1981? (Fig. 35)}

Material.-CAS 236488 (135 mm SL; DC-1495); HEPD-022, otter trawl in 115-144 m. 
REMARKS.- This specimen agrees relatively well with $S$. oculeus except for the dark peritoneum and the low LL-scale count (54-57 in S. oculeus). Whether these differences are of specific importance is not known. The two or three short stripes on the cheek and the large orbit otherwise appear to distinguish $S$. oculeus from other western Pacific members of the genus.

\section{Synodus sp.}

Mate Rial.—CAS $236478(10,35.3-42.6 \mathrm{~mm}$ SL); HEPD-026, beam trawl in 82-86 m.

REMARKS. - We were unable to identify these juvenile specimens.

\section{Chlorophthalmidae (GreEneyes)}

Chlorophthalmus acutifrons Hiyama, 1940 (Fig. 36)

MateriaL.-CAS 235821 (134 mm SL; DC-1566); HEPD-036, beam trawl in 216-262 m.

Remarks. - This is a common species known from southern Japan, the East China Sea, Taiwan, and the Philippines in $260-435 \mathrm{~m}$.

Chlorophthalmus albatrossis Jordan and Starks, 1904

MATERial. - (91 mm SL); HEPD-003, beam trawl in 272-291 m

\section{IPNOPIDAE (GRIDEYE SPIDERFISHES)}

\section{Bathypterois atricolor Alcock, 1896 (Fig. 37)}

Material.- CAS 2355479 and 236195 (2, 135-150 mm SL); HEPD-016, otter trawl in 892-966 m.

RemarKS. - This species is very similar to $B$. phenax from the Atlantic, and apparently differs only in the placement of its vertical fins.

Bathypterois guentheri Garman, 1889 (Fig. 38)

Material.-CAS235452 (2, 207-226 mm SL, DC-1399, -1400); HEPD-015, beam trawl in 757-836 m.

\section{NeOSCOPELIDAE (BLACKCHINS)}

\section{Neoscopelus microchir Matsubara, 1943 (Fig. 39)}

Material.-CAS 235378 (2, 114.5-115.0 mm SL) and CAS 235504 (4, 75.2-93.5 mm SL); HEPD-003, beam trawl in 272-291 m. CAS 236624 (11, 74.6-114.3 mm SL); and CAS $235506(3,83.0-116.0 \mathrm{~mm}$ SL); HEPD-009, otter trawl in 322-336 $\mathrm{m}$.

REMARKS. - We counted lateromedial photophores as $20-22+3$ separated anteriorly over the pectoral-fin base, the series extending over the anal-fin base. Nafpaktitis (1977:9) gave counts of LO photophores that are low compared with those of our material. His study material included many Philippine specimens.

\section{Neoscopelus porosus Arai, 1969}

MateriaL. - CAS 233995 (11, 77-133.5 mm SL); HEPD-006, otter trawl in 454-457 m. CAS 235492 (139 $\mathrm{mm}$ SL, DC-1571); HEPD-039, beam trawl in 633-642 m.

\section{MYCTOPHIDAE (LANTERNFISHES)}

\section{Benthosema fibulatum (Gilbert and Cramer, 1897)}

Material.-CAS 236518 (2, 56.5-57.0 mm SL; DC-1285); HEPD-004, otter trawl in 154-245 m.

REMARKS.- This species is an exception in the genus in having the supracaudal and infracaudal luminous glands present in both sexes. Widely distributed in the western tropical Pacific and in the Indian Ocean.

\section{Bolinichthys distofax Johnson, 1975}

MATERIAL.-CAS 236516 (58.0 mm SL); HEPD-006, otter trawl in 454-457 m.

REMARKS. - The crescent-shaped white tissue behind the iris is distinguishing for this genus. We are uncer- 
tain if this single specimen from the expedition is $B$. distophax, although it rather well agrees with the account given by Nafpaktitis (1977:234-236, fig. 164). The species is widespread in the Atlantic and Pacific oceans although records of the species are sparse.

\section{Diaphus adenomus Gilbert, 1905 (Fig. 40)}

Material. - CAS 236623 (6, 98-154 mm SL); HEPD-009, otter trawl in 322-336 m.

REMARKS. - This is a large, widely distributed species known from the western Pacific from Hawaii to Japan and in the Atlantic Ocean. The Ant (supraorbital) and Vn (infraorbital) luminous organs are well developed in the largest specimen, but much less developed in the smaller specimens.

\section{Diaphus fragilis Tåning, 1928 (Fig. 41)}

Material. - CAS 233984 (7, 85-123 mm SL, DC-1286); HEPD-004, otter trawl in 154-245 m. CAS 233999 (123 mm SL, DC-1328); HEPD-009, otter trawl in 322-336 m.

REMARKS.-A mesopelagic species found in tropical waters of the Pacific, Atlantic and Indian oceans.

\section{Diaphus garmani Gilbert, 1906}

Material. - CAS 233989 (11, 44.0-61.4 mm SL); HEPD-004; otter trawl in 154-245 m. CAS 236513 (8, $37.2-53.0 \mathrm{~mm} \mathrm{SL}$ ); HEPD-009, otter trawl in 322-336 m.

REMARKS. - This is a common, worldwide species.

\section{Diaphus gigas Gilbert, 1913}

Material. - CAS 233987 (10, 71.2-83.9 mm SL, DC-1287); HEPD-004, otter trawl in 154-245 m.

REMARKS. - Taxonomic uncertainty exists with this species. Wisner (1976:121) suggested that it may be conspccific with D. elucens (Braucr, 1904), and Kawaguchi and Shimizu (1978:68) reported that "according to Nafpaktitis (pers. comm.), D. gigas might be oversized senile expartriates of the warm water $D$. perspicillatus." We know of no records of this species from the Philippines, although Okamura (in Okamura and Kitajima 1984:361) record it from the East China Sea off Okinawa. They give its distribution as southern Japan, East China Sea, and Indian Ocean, but Kawaguchi and Shimizu (1978:68) report it from south to $20^{\circ} \mathrm{N}$, north to off Hokkaido $\left(42^{\circ} \mathrm{N}\right)$, and as far east as $179^{\circ} \mathrm{W}$. Wisner $(1976: 121)$ reported the species in the North Pacific Current eastward to $155^{\circ} \mathrm{W}$.

\section{Diaphus suborbitalis Weber, 1913 (Fig. 42)}

Material.-CAS 234003 (71.3 mm SL, DC-1330); HEPD-009, otter trawl in 322-336 m.

REMARKS. - This species is readily identified from other congeners by the large oval to round $\mathrm{Vn}$ that lies along the ventral rim of the orbit, anterior to a vertical through the posterior margin of the pupil, in combination with other photophore characters. Widely distributed in tropical to subtropical western Pacific and western Indian oceans.

\section{Diaphus watasei Jordan and Starks, 1904 (Fig. 43)}

Material.-CAS 233899 (156 mm SL, DC-1327) and CAS 234002 (112 mm SL, DC-1329); HEPD-009, otter trawl in 322-336 m.

REMARKS. - The larger (CAS 233899) of the two HEPD specimens has a relatively low gill-raker count $(7+1+11=17$ total, vs. 18-23 total recorded by others), but the smaller (CAS 234002) ha a count of $5+1+13+19$ total. The snout of the smaller is damaged and the luminous organs there could not be adequately assessed. The two otherwise agree well with descriptions of the species. Distributed widely in Indo-West Pacific from southern Japan south to southern Australia and west to Africa.

\section{Diaphus sp. (Fig. 44)}

MATERIAL. - CAS 236509 (83.5 mm SL, DC-1435); HEPD-017, beam trawl in 282-428 m.

REMARKS. - We are unable to identify this specimen. The area around the luminous organs in front of the orbit is damaged, and wc cannot determine if it has an Ant or So photophorc. In its gencral morphology and arrangement and numbers of photophores on the body, the specimen appears similar to Diaphus adenomus Gilbert, 1905. 


\section{Diaphus sp.}

Material.-CAS 236510 (34.7 mm SL); HEPD-014, beam trawl in 865-944 m.

REMARKS. - We are unable to identify this small, damaged specimen.

\section{Diaphus sp.}

Material. - CAS 236512 (30.0 mm SL); HEPD-016, beam trawl in 892-966 m.

Remarks. - We are unable to identify this specimen owing to its small size and imperfect condition, especially around the snout and orbit where the luminous organs are situated. The short, deep body and arrangement of the large photophores on the body are somewhat similar to those characters in D. perspicillatus (Ogilby, 1898).

\section{Hygophum proximum Becker, 1965}

Material.-CAS 236514 (41.0 mm SL); HEPD-016, otter trawl in 892-966 m.

REMARKS. - Widespread in tropical waters of the Pacific and Indian oceans.

\section{?Lampanyctus sp.}

Material.-CAS 236507 (46.0 mm SL); HEPD-016, otter trawl in 892-966 m.

REMARKS. - The general morphology and photophore pattern of this single, damaged specimen indicate that it is a Lampanyctus based on the keys provided by Nafpaktitis et al. (1977: 26-29) and Nakabo (2000: 378-399). It agrees closest with L. nobilis Tåning, 1928 in Nakabo’s key.

\section{Myctophum obtusirostre Tåning, 1928}

MATERial.-CAS 236515 (2, 44.3-50.8 mm SL); HEPD-016, otter trawl in 892-966 m.

Remarks. - Worldwide in tropical seas. These specimens agree well with published descriptions of the species except that the luminous supracaudal (male) and infracaudal (female) organs are less developed, probably owing to the subadult size of the specimens.

\section{Taaningichthys sp.}

MateriaL. - CAS 236517 (58.0 mm SL); HEPD-014, beam trawl in 865-944 m.

REMARKS. - We are uncertain of the identification of this single, denuded specimen, in which little evidence of photophores remain. The presence of supra- and infracaudal luminous glands bordered by black tissue and the crescent-shaped whitish tissue on the posterior half of the iris led us to this genus. Bolinichthys also has the whitish tissue on the iris, but the caudal luminous glands consist of overlapping scale-like bodies not bordered by black tissue. Body photophores are apparently absent in T. paurolychnus Davy, but we are uncertain of their absence in this specimen.

\section{PARALEPIDidae (BARRACUdinas)}

\section{Dolichosudis ? (Fig. 45)}

Material. - CAS 236706 (196 mm SL; DC-1424); HEPD-016, otter trawl in 892-966 m.

REMARKs. - We are uncertain of the genus of this barracudine. It has D 9, A 33, LL 73; a long adipose fin between the anus and $\mathrm{A} ; \mathrm{V}$ well anterior to $\mathrm{D}$, which lies about midway between the origins of $\mathrm{V}$ and $\mathrm{A}$; distance between D and C about 3.5 in SL; no light organs; short P; large depressible mandibular teeth in 2 rows; and relatively compressed body. Color uniformly medium brown.

\section{POLYMIXIIDAE (CAS GROUP 115)}

\section{Polymixia berndti Gilbert, 1905 (Fig. 46)}

Material.-CAS 235791 (125 mm SL, DC-1432); HEPD-017, beam trawl in 282-428 m. CAS 235819 (3, 130-147 mm SL, DC-1567); HEPD-036, beam trawl in 216-262 m.

REMARKS. - The HEPD specimens agree for the most part with descriptions in Heemstra (in Smith and Heemstra, 1986:432, fig. 134.1) and Nakabo (2000: 407), although the snout tip does not extend beyond 
the premaxillary as depicted in those works. They more closely resemble P. japonicus in that respect, but the scales are much smaller and the D lobe is intensely black in that species.

\section{MORIDAE (MORID CODS)}

\section{Physiculus longifilis Weber, 1913}

Material. - CAS 235569 (55 mm SL); HEPD-022, otter trawl in 115-144 m.

REMARKS. - The elongated pelvic fin is apparently distinctive among members of the genus; this and the few $\mathrm{D}$ rays (about 60) and the absence of scales on D and gular membranes are diagnostic. So far known only from the Flores and Sulu seas and off southwestern Luzon (HEPD specimen).

\section{Physiculus rhodopinnis Okamura, 1982 (Fig. 47)}

Material. - CAS 235782 (85.0 mm SL, DC-1433); HEPD-017, beam trawl in 282-428 m.

REMARKS. - This very small specimen agrees relatively well with the original description and Paulin's (1989) revised description using more comparative material. The developed gill rakers appeared somewhat longer and more slender than shown in Okamura's (fig. 78C) figure, and the gular membrane completely lacked scales (although Paulin states "...gular scales usually [italics added] present." Furthermore, scales on the mandibular rami were of two sizes, several larger ones posteriorly placed, and most of the remaining surfaces covered with tiny embedded scales that did not taper to one row anteriorly. The size of the HEPD specimen may have a bearing on these character differences. This specimen is the first record of the species from Philippine waters.

\section{BREGMACEROTIDAE (CODLETS)}

\section{Bregmaceros japonicus Tanaka, 1908 (Fig. 48)}

Material.-CAS 236708 (55 mm SL, DC-1293); HEPD-005, beam trawl in 459-496 m. CAS 236480 (3, 81-106 mm SL); HEPD-006, otter trawl in 454-457 m. CAS 236483 (3, 49.8-70.5 mm SL); HEPD-016, otter trawl in 892-966 m.

REMARKS. - This species is one of several that were captured during the Expedition, but we could not identify the others to species.

\section{BATHYGADIDAE (BATHYGADIDS)}

\section{Bathygadus entomelas Gibert and Hubbs, 1920 (Fig. 49)}

Material. - CAS 233710 (38.6 mm HL, 169+ mm TL, DC-1345); HEPD-011, otter trawl in 636-6664 m. CAS 233711 (40.2 mm HL, 178+ mm TL, DC-1380); HEPD-012, beam trawl in 721-761 m.

REMARKS. - The following combination of characters fairly well distinguish this species from its congeners: V 10, GR-I 6+19; gill rakers long, slender, with pointed tips; fins lacking prolonged rays; no chin barbel; interorbital wider than orbit, and pyloric caeca around 36.

Bathygadus spongiceps Gibert and Hubbs, 1920? (Fig. 50)

Material.-CAS 236494 (ca. 27 mm HL, 131+ mm TL, DC-1415); HEPD-016, otter trawl in 892-966 m.

REMARKS.- This single damaged juvenile is tentatively identified as $B$. spongiceps based mainly on the counts of the pelvic fins (9), gill rakers $(5+1+21)$, pyloric caeca (about 14), and dimensions of its orbit $(20 \% \mathrm{HL})$, interorbital (33\%), upper jaw (57\%), and suborbital $(16 \%)$. The genus is in need of revision. Bathygadus spongiceps (or a species very much like it) has been broadly recorded from the Philippines south to Indonesia, Australia, and in the southwestern Pacific (Coral Sea, off New Caledonia and adjacent regions),

\section{Gadomus denticulatus Gilbert and Hubbs, 1920}

Material. - CAS 233712 (33.0 mm HL, $185 \mathrm{~mm}$ TL); HEPD-006, otter trawl in 454-457 m.

REMARKs. - The species is closely similar to $G$. colletti from Japan (the range possibly extends to Western Australia; see Iwamoto and Williams 1999:117) differing in G. colletti having somewhat more GR (4-6+2l-23, total 25-28), more pyloric caeca (95), and longer barbel (3X orbit). 


\section{Gadomus multifilis Günther, 1887 (Fig. 51)}

Material. - CAS 235518 (2, 54.0-61.9 mm HL, 294+-357 mm TL, DC-1351, -1379); HEPD-012, beam trawl in 721-761 m. CAS 235546 (20.0 mm HL, 90+ mm TL), CAS 235376 (1 spee.) and CAS 235799 (35.3 mm HL, 170+ mm TL, DC-1414); HEPD-016, otter trawl in 892-966 m.

REMARKs. - The high gill-raker eount $(6-7+27-28)$ and pointed rakers, the elongated ray in the paired and dorsal fins, and the pyloric-caeca count (12-16) in combination distinguish this speeies from others of the genus (but see Sazonov and Iwamoto 1992:37-38). This species is widespread from Japan south to Indonesia and possibly in the Indian Ocean.

\section{MACROURIDAE (GRENADIERS, MACROURIDS, RATTAILS)}

\section{Coelorinchus acantholepis Gilbert and Hubbs, 1920 (Fig. 52)}

Material.-CAS 233993 (2, 33.8-38.4 mm HL, 120+-160 mm TL, DC-1289 and DC-1290); HEPD-005, beam trawl in $459-496 \mathrm{~m}$.

REMARKS. - These small speeimens agree relatively well with the original deseription exeept for the presence of scales between the orbit and infraorbital ridge, which Gilbert and Hubbs (1920:490) say are absent in C. acantholepis, and the eount of seales below the origin of second dorsal fin $\left(5 \frac{1}{2} v s .41 / 2\right)$. In these eharacters, the specimens agree with $C$. carinifer, but that species has a somewhat longer snout and other proportional differenees. Body-scale features could not be eompared beeause of the absenee of seales on the body of the HEPD speeimens. Coelorinchus acantholepis appears to be an East Indies species and the HEPD specimens may represent the first reeord from the Philippines.

\section{Coelorinch us carinifer Gilbert and Hubbs, 1920 (Fig. 53a-b)}

Material. - CAS 235516 (73.5 mm HL, 287+ mm TL, DC-1384); HEPD-012, beam trawl in 721-761 m.

REMARKs. - This speeies was deseribed only from the holotype; the HEPD speeimen represents the seeond specimen and record of the species. Gilbert and Hubbs (1920) provided a good description and illustration of the species, which the HEPD specimen follows closely except for the size and orientation of the spinules on its body seales. They are arranged in much more divergent rows and are stouter and longer than figured in the original description. Also, the authors (p. 493) record "...branehial eavity lined with brownish black, except on a narrow but abrupt whitish margin along the opercular and branchiostegal membranes," whereas in the HEPD specimen, the membrane is black without a light outer margin.

\section{Coelorinchus kishinouyei Jordan and Snyder, 1900}

Material. - CAS 235540 (26.1 mm HL, $110 \mathrm{~mm}$ TL); HEPD-009, otter trawl in 322-336 m.

REMARKS. - This is a common species in the South China Sea off Taiwan and north to southern Japan. It has been captured in depths from $200 \mathrm{~m}$ to more than $600 \mathrm{~m}$.

\section{Coelorinchus smithi Gilbert and Hubbs, 1920 (Fig. 54)}

Material.-CAS 235519 (2, 113-119 mm HL, 431+-432+ mm TL, DC-1402, -1403); HEPD-015, beam trawl in 757-836 m. CAS 236403 ([head only], $114.5 \mathrm{~mm} \mathrm{HL}$ ); HEPD-023, trap in 578-710 m.

REMARKS -Widely distributed from southern Japan to Indonesia and Australia, in 300-1110 m. The speeimen with only the head and parts of the vertebral eolumn was mostly devoured by deep-sea isopods (Bathynomus). which were also taken in the same traps; the head remains in exeellent eondition allowing ready identifieation.

\section{Coryphaenoides microps (Smith and Radcliffe, 1912) (Fig. 55)}

Material.-CAS 235552 (2, 48.6-75.0 mm HL, 233+-332+ mm TL, DC-1343); HEPD-011, otter trawl in 636-664 m. CAS 235554 (77 HL, 349+ TL, DC-1392); HEPD-012, beam trawl in 721-761 m. CAS 235554 (3, 44.4-71.5 HL, 201+-353 TL); HEPD-015, beam trawl in 757-836 m. CAS $236659(53.0 \mathrm{~mm}$ HL, $257 \mathrm{~mm}$ TL, DC 1569); HEPD-039, beam trawl in 633-642 m.

RemarKs.-Coryphaenoides microps is known from the Philippines, off southwestern Taiwan (Chiou et al., 2004a: table 1; Shao et al. 2008: table 2), and the East Sea (Japan Sea) off South Korea (Kim et al, 2009: 108-110). It is very similar to, and ean be eonfused with, C. macrolophus, $C$. marginatus, $C$. semiscaber, 
and C. tydemani, but can be distinguished from them by a combination of the shape of its preopercle, length of elongated ID ray, orbit-to-preopercle distance, and the relationship of that measurement to size of its orbit (see key in Shcherbachev and Iwamoto 1995:286-287).

\section{Hymenocephalus lethonemus Jordan and Gilbert, 1904}

Mate RIAL. - CAS 233709 (2 spec., 23.8-24.0 mm HL, 112-122 mm TL); HEPD-006, otter trawl in 454-457 m.

Remarks. - Distributed from southern Japan, Kyushu-Palau Ridge, East China Sea, South China Sea off Taiwan to the Philippines.

\section{Hymenocephalus nascens Gilbert and Hubbs, 1920 (Fig. 56)}

Mate RiaL.-CAS 233942 (85+ mm TL, DC-1288); HEPD-005, beam trawl in 459-496 m.

REMarks. - This species is closely similar to H. lethonemus. It has been recorded from the Philippines to the southwestern Pacific off New Caledonia and Australia (QLD, NSW, WA), in about 350-930 m.

\section{Hymenocephalus torvus Smith and Radcliffe in Radcliffe, 1912}

Material.-CAS 234080 (7, 49+-113 mm TL); HEPD-009, otter trawl in 322-336 m. CAS 234076 (9, 21-27 mm HL, 75+-1 $46 \mathrm{~mm}$ TL); HEPD-010, beam trawl in 318-333 m. CAS 234083 (2, 24.5-27.8 mm HL, 370+-370+ mm TL); HEPD 035, beam trawl in 397-439 m. CAS uncat (73.5 mm HL, 287+ $\mathrm{mm} \mathrm{TL}$ ); HEPD-012, beam trawl in 721-761 m.

REMARKs. - This species was recognized as a subspecies of $H$. striatissimus by Gilbert and Hubbs (1920:530), but the V-ray count, barbel length, and body pigmentation appear to distinguish the two species. According to Gilbert and Hubbs (1920: 528) the nominal subspecies ranges from Japan "southward to China, Formosa, and the east coast of Luzon," "intergrading off the northwest coast of Luzon with the subspecies torvus, which inhabits the Sulu Sea and the China Sea off southern Luzon." Those authors corrected the Albatross station number (sta. 5508) for the holotype of $H$. torvus, erroneously given by Radcliffe (1912:110) as station 5548.

\section{Mataeocephalus acipenserinus (Gilbert and Cramer, 1897)}

MateriaL.-CAS 235251 (51.2 mm HL, damaged); HEPD-011, otter trawl in 636-664 m. CAS 235822 ( 47 $\mathrm{mm} \mathrm{SL}, 225+\mathrm{mm}$ TL); HEPD-39, beam trawl in 633-642 $\mathrm{m}$.

REMARKS. - Widely distributed in the tropical Indo-Pacific, from the Sala-y-Gomez Ridge in the southeastern Pacific to Hawaii, southwestem Pacific, Philippines, Indonesia, and South China Sea, across Indian Ocean to east Africa.

Mataeocephalus cristatus Sazonov, Shcherbachev and Iwamoto, 2003) (Fig. 57)

Material.-CAS 234020 (46.2 mm HL, $210 \mathrm{~mm}$ TL, DC-1383); HEPD-012, beam trawl in 721-761 m.

REMARKS. - This species is known from the Indian Ocean (Saya de Malha Ridge, Mascarene Ridge, NinetyEast Ridge), the South China Sea (Paracel Is.), and the Markus-Necker Ridge in the western Pacific. The HEPD specimen is the first record from the Philippines.

\section{Nezumia spinosa (Gilbert and Hubbs, 1916) (Fig. 58)}

MateriaL. - CAS 235798 (44.6 mm HL, 220+ mm TL, DC-1442); HEPD-019, beam trawl in 541-636 m.

REMARKS. - A widespread species known from Japan south and east to Australia (QLD and WA) and New Caledonia, and west to southeastern Africa.

\section{Sphagemacrurus pumiliceps (Alcock, 1894) (Fig. 59)}

Material.-CAS 235732 (29.0 mm HL, 187+ mm TL, DC-1412) and CAS 236022 (28.2 mm HL, $190 \mathrm{~mm}$ TL); HEPD-016, otter trawl in 892-966 m.

REMARKS. - Apparently widespread throughout Indo-West Pacific, but more than one species may be hiding under this name. 


\section{Trachonurus villosus (Günther, 1878) (Fig. 60)}

Material. - CAS uncat. $(1,58.7 \mathrm{~mm} \mathrm{HL}, 340++\mathrm{mm}$ TL); HEPD-012, beam trawl in 721-761 m. CAS 235503 (61.6 mm HL, $345 \mathrm{~mm}$ TL, DC-1411); HEPD-016, otter trawl in 892-966 m.

REMARKs.- Trachonurus has several nominal species; all are closely similar and difficult to distinguish; more taxonomic study is necessary. Numerous specimens werc collected by the Albatross during its 1907-1910 expedition to the Philippine and Indonesian archipelagos. Trachonurus villosus is apparently widespread in the northwestern Pacific.

\section{Ventrifossa longibarbata Okamura, 1982 (Fig. 61)}

Material. - CAS 236398 (62.4 mm HL, 310+ mm TL, DC-1555); HEPD-035, beam trawl in 397-439 m.

Remarks.- Previously known from southern Japan, Okinawa Trough, and Taiwan in 382-1211 m. The HEPD specimens represent the first record of the species from the Philippines.

\section{Ventrifossa macroptera Okamura, 1982}

Material. - CAS 233997 (5, 31.3-43.5 mm HL, 175-207 mm TL); HEPD-006, otter trawl in 454-457 m.

REMARKS. - These HEPD specimens represent the first record of the species from the Philippines and the farthcst south. It was previously known from the Kyushu-Palau Ridge and off Taiwan. Ventrifossa sazonovi Iwamoto and Williams, 1999 from off Vietnam and Western Australia also has a smooth spinous second $1 \mathrm{D}$ ray, but that species has shorter $\mathrm{P}(1.5-1.9$ time in HL vs. 1.3-1.5) and enlarged spinules on scales along the dorsum in adults.

Ventrifossa saikaiensis Okamura, 1984 (Fig. 62)

Material. - CAS 235515 (2, 48.4-58.7 mm HL, 240+-287+ mm TL, DC-1382, -1390); HEPD-012, beam trawl in 721-761 m. CAS 235517 (55.9 mm HL, 295+ mm TL, DC-1406); HEPD-015, beam trawl in $757-836 \mathrm{~m}$. CAS uncat. (61.6 mm HL, $345 \mathrm{~mm}$ TL); HEPD-016, otter trawl in 892-966 m.

Remarks. - Known only from the Okinawa Trough, Taiwan, and the South China Sea off Luzon, in $280-1211 \mathrm{~m}$.

\section{OphididDae (BRotulas AND CUSK-Eels)}

\section{Dicrolene tristis Smith and Radcliffe in Radcliffe, 1913}

Material. - CAS 235740 (2, 116-161 mm SL, DC-1309); HEPD-006, otter trawl in 454-457 m. CAS 235468 (175 mm TL); HEPD-016, otter trawl in 892-966 m.

REMARKs. - Known from southem Japan, Taiwan, and the Philippines in approximately 560-990 m.

Glyptophidium japonicum Kamohara, 1936 (Fig. 63)

Material. - CAS 233982 (123 mm SL, DC-1286); HEPD-003, beam trawl in 272-291 m.

ReMArKs. - The genus was revised by Nielsen and Machida (1988); five of the seven species are known from off the Philippines.

\section{Glyptophidium lucidum Smith and Radcliffe in Smith, 1913 (Fig. 64)}

Material.- CAS 235750 (5, 130+-175+ mm SL); HEPD-006, otter trawl in 454-457 m. CAS 235801 (188 $\mathrm{mm} \mathrm{SL}, \mathrm{DC}-1446$ ); HEPD-0 19, beam trawl in 541-636 $\mathrm{m}$.

Remarks. - This is a common species known from the northern Philippines south to NW Australia, in $395-685 \mathrm{~m}$.

Hoplobrotula armata (Temminck and Schlegel, 1846) (Fig. 65)

Material. - CAS 235795 (207 mm SL, DC-1550); HEPD-033, beam trawl in 225-347 m.

REMARKs. - The HEPD specimen probably represents the first record of the species from the Philippines. The species is known from southern Japan, Okinawa, and Taiwan in upper-slope depths (in approximately $200-350 \mathrm{~m})$. 
Luciobrotula bartschi Smith and Radcliffe in Radcliffe, 1913?

Mate Rial. - CAS 236665 (95.0 mm SL, DC-1306); HEPD-006, otter trawl in 454-457 m.

Remarks. - Widely distributed in the Indo-West Pacific at depths of about 250 to more than $1000 \mathrm{~m}$.

Monomitopus pallidus Smith and Radcliffe in Radcliffe, 1913 (Fig. 66)

Material. - CAS 235275 (2, 185-190 mm SL) and CAS 234015 (207 mm SL, DC-1350); HEPD-011, otter trawl in 636-664 m. CAS 234022 (157 mm SL, DC-1391); HEPD-012, beam trawl in 721-761 m.

REMARKS. - This species appears to have a limited distribution, being known only from the East China Sea and the Philippines.

Neobythites macrops (Günther, 1887) (Fig. 67)

Material. - CAS 235747 (5, 87-124 mm SL, DC-1308); HEPD-006, otter trawl in 454-457 m. CAS 235255 (2, 151-161 mm SL); HEPD-009, otter trawl in 322-336 m.

Remarks.-A common deepwater Neobythites of Philippine waters; also known from Indonesia, Arafura Sea, and Western Australia, in 143-686 m.

\section{Neobythites unimaculatus Smith and Radcliffe in Radcliffe, 1913 (Fig. 68)}

Material. - CAS 235745 (137.56 mm SL, DC-1456); HEPD-021, beam trawl in 132-172 m. CAS 235787 (124 mm SL, DC-1542); HEPD-031, beam trawl in 183-188 m. CAS 235478 (162 mm SL); HEPD-032, beam trawl in 223-369 m. CAS 235753 (232 mm SL); HEPD-036, beam trawl in 216-262 m.

REмARкs. - Neobythites nigromaculatus Kamohara, 1938, recorded from Japan and Taiwan, is considered a synonym of this species. This species supposedly has short pelvic fins that fall well short of the anus, but in the HEPD specimen the outermost ray is quite long, extending to or well beyond the anus. Distributed from Japan to northern Australia and east to Fiji in $146-567 \mathrm{~m}$.

\section{Neobythites sivicola Jordan and Snyder, 1901}

MateriaL. - CAS 235480 (166 mm SL, DC-1520); HEPD-030, beam trawl in 190-201 m.

Remarks. - Known only from the Philippines in the South China Sea and a single specimen from the Arafura Sea in $176-249 \mathrm{~m}$.

\section{Sirembo imberbis (Temminck and Schlegel, 1846) (Fig. 70)}

Material.-CAS $235742(2,124-125 \mathrm{~mm}$ SL, DC-1459, -1460); HEPD-021, beam trawl in 132-172 m. CAS 235534 (2, 108-120 mm SL); HEPD-022, otter trawl in 115-144 m.

ReMarks.- Distribution from Japan south through the East China Sea, Philippines, and northern Australia (QLD, WA).

\section{LOPHIIDAE (GOOSEFISHES)}

\section{Lophiomus setigerus (Vahl, 1797) (Fig. 71)}

Material.-CAS 236404 (142 mm SL, DC-1453); HEPD-021, beam trawl in 132-172 m.

Remarks.- Widespread in the Indian Ocean and western Pacific from Japan to southeastern Australia and well into the southwestern Pacific Ocean. The dark mouth with a pattern of anastomosing lines is distinguishing.

\section{Chaunacidae (SEa Toads)}

Chaunax sp. 1 (not Chaunacops cf. coloratus) (Garman, 1899) (Fig. 72a-b)

Material. - CAS 235683 (33.2 mm SL, DC-1444); HEPD-019, beam trawl in 541-636 m.

REMARKS. - We have been advised by Hsuan-Chieh Ho (National Museum of Marine Biology \& Aquarium, Pingtung, Taiwan) that this specimen should be tentatively identified as Chaunax sp., not Chaunacops cf. coloratus. He added that "when they are small, they tend to be dark and similar to Chaunacops." The species was last treated by Caruso (1989) who found that "coloratus is currently known from the eastern Indian Ocean . . . and the type locality on the Cocos Ridge in the eastern Pacific Ocean . . . In the Indi- 
an Ocean it has been taken between $16^{\circ} \mathrm{S}$ and $32^{\circ} \mathrm{S}$ and $87^{\circ} \mathrm{E}$ and $97^{\circ} \mathrm{E}$ at depths ranging from $1,250-1,733$ m." He cautioned, however, that the lack of adequate eastern Pacific matcrial (only thc holotypc, "which has suffered from ruthless dissection") precludes the recognition of those populations as conspecific.

Chaunax sp. 2 (Fig. 73)

Material.- CAS 236015 (52 mm SL); HEPD-021, beam trawl in 132-172 m. CAS 236014 (69 mm SL, DC-1493); HEPD-022, otter trawl in 115-144 $\mathrm{m}$.

REMARKS. - We were unable to identify these small specimens, which may not be the same species.

\section{OgCocephalidae (BATfishes)}

REMARKS. - The Batfishes have not been thoroughly reviewed and many taxonomic problems remain to be resolved, including the description of new species; as a consequence several of the HEPD specimens are left unidentified except to genus. Hsuan-Ching ("Hans") Ho of the National Museum of Marine Biology and Aquarium, Taiwan, is currently working on the group.

\section{Dibranchus sp. (Fig. 74)}

MateriaL. - CAS 234021 (75mm SL, DC-1385); HEPD-012, beam trawl in 721-761 m. CAS 234026 (53 $\mathrm{mm} \mathrm{SL}$, DC-1407); HEPD-015, beam trawl in 757-836 $\mathrm{m}$.

REMarKS. - We were unable to identify these specimens.

\section{Halicmetus sp. (Fig. 75)}

Material.-CAS 234019 (58 mm SL, DC-1386), HEPD-012, beam trawl in 721-761 m. CAS 236016 (55 $\mathrm{mm} \mathrm{SL}$, DC-1572); HEPD-039, beam trawl in 633-642 $\mathrm{m}$.

REMARKS.-We could not identify this to species.

\section{Halieutaea cf. stellata (Vahl, 1797) (Fig. 76a-b)}

MateriaL. - CAS 236405 (120 mm SL, DC-1525); HEPD-030, beam trawl in 190-201 m.

REMARKs.- Mochizuki (in Masuda et al. 1984:105) gives counts of P 13 and C 9, and also statcs that the ventral surface of the disc is white. Aside from these discrepancies, the HEPD specimen agrees with his description and color figure (pl. 91-H). Gloerfelt-Tarp and Kailola (1984:97, color figure on p. 96) recorded an unidentified Halieutaea that also agrees well with the HEPD specimen, especially in its disc shape (much wider than long), but they describe the ventral surface of the disc as covered with fine spinules or simple spines, in contrast to the minute dermal denticles of the HEPD specimen. Distributed from Japan to the East Indies and west to India.

\section{Halieutaea sp.}

Material.-CAS 235678 (25.7 mm SL) and CAS 236017 (2 spec.); HEPD-022, otter trawl in 115-144 $\mathrm{m}$.

REMARKS.- Bradbury (in Carpenter and Niem 1999:2025) lists five species but does not provide a key to the specics. She notes, "Halieutaea needs revision and most spccies distributions are little known. There are probably 5 or 6 species to bc expected in the area."

\section{Halieutopsis sp. 1 (Fig. 77)}

Material. - CAS 235685 (48 mm SL, DC-1422); HEPD-016, otter trawl in 892-966 m.

Remarks. - This specimen is similar to Halieutopsis vermicularis Smith and Radcliffe, 1912, however, its coloration is much too dark.

\section{Halieutopsis sp. 2 (Fig. 78)}

Material.-CAS 235684 (2, 51-54 mm SL, DC-1420 and DC-1421); HEPD-016, otter trawl in 892-966 $\mathrm{m}$.

REMARKS. - The smaller specimen has black pectorals, the larger has pale pectoral fins. 
Malthopsis annulifera Tanaka, 1908 (Fig. 79)

Material. - CAS 235680 (46.5 mm SL, DC-1546); HEPD-032, beam trawl in 223-369 m.

Remarks. - Widely distributed in the western Pacific, from Japan southward to the Philippines and southeastward to New Caledonia, in 90-360 m.

\section{Malthopsis kobayashii Tanaka, 1916? (Fig. 80)}

Material.-CAS 235679 (76 mm SL, DC-1534); HEPD-032, beam trawl in 223-369 m.

REMARKS. - This specimen keys out to Malthopsis lutea Alcock, 1891 in most references, however, Ho and Shao (2010) show that $\mathrm{m}$. lutea is limited to the Andaman Islands and that $\mathrm{m}$. kobayashii is the widespread Indo-West Pacific species. It has four dorsal-fin rays. The fins are pale and the specimen lacks some of the pigmentation of $\mathrm{m}$. kobayashii. H-C Ho (in litt. 2013) suggests that it might be either Malthopsis tiarella Jordan, 1902 or $m$. asperata Ho, Roberts and Shao, 2013.

\section{HiMANTOLOPHIDAE (FoOTBALLFISHES)}

\section{Himantolophus appelii (Clark, 1878)}

Material. - CAS 235600 (female, $74 \mathrm{~mm} \mathrm{SL}$ ); collection data lost.

REMARKs. - This specimen probably represents a new Philippines record, although the species is circumglobal in the southern hemisphere (except the eastern Pacific).

\section{Ateleopidae (Jellynose)}

\section{Ateleopus japonicus Bleeker, 1853 (Fig. 81)}

Material.-CAS 235514 (638 mm SL, DC-1331); HEPD-009, otter trawl in 322-336 m. CAS 235794 (291 mm SL; DC-1526); HEPD-030, beam trawl in 190-201 m. CAS 235639 (1 spec.); HEPD-030, beam trawl in $190-201 \mathrm{~m}$.

REMarks. - Several species of Ateleopus occur in the region of the South China Sea, East China Sea and Japan, including one that is apparently undescribed (Tatsuya Kaga, in litt. 19 June 2013).

\section{TRACHICHTHYIDAE (SLIMEHEADS)}

\section{Hoplostethus melanopterus Fowler, 1938 (Fig. 82)}

Material._CAS 23998 (82 mm SL, DC-1299); HEPD-006, otter trawl in 454-457 m. CAS 234018 (4, 99-162 mm SL, DC-1346, -1348, -1349); HEPD-011, otter trawl in 636-664 m.

REMARKS.- We have compared our specimens to a paratype of H. melanopterus (CAS-SU 40191, $82 \mathrm{~mm}$ SL). They are conspecific. The $162 \mathrm{~mm}$ SL specimen (DC-1347) agrees in counts and proportions with the species, but differs in having pale rather than black pectoral fins. Martin Gomon (in litt. 11 Nov. 2013) suggests that fin coloration can change with growth in Hoplostethus, however, this species has not been adequately studied. Gomon advises us that Hoplostethus melanopterus should be in another genus. We provisionally include it in Hoplostetlus for this listing.

\section{Hoplostethus sp.}

MATE RIAL. - CAS 233985 (97 mm SL; DC-1277); HEPD-004, otter trawl in 154-245 m.

Remarks. - This specimen appears identical to Hoplostethus ravurictus Gomon, 2008 from Australia in its coloration (body and buccal cavity) and in its counts. We have compared it to the pale CAS paratypes (CAS 227136, 3 paratypes 79-116 mm SL), and they seem to be the same. Martin Gomon (NMV, in litt., 24 Oct. 2013) has advised that such a distribution is unlikely for Hoplostethus and that they are probably not conspecific. We will pursue a comparative analysis of the $\mathrm{CO} 1$.

\section{Hoplostethus sp.}

Material. - CAS 236495 (25.1 mm SL); HEPD-036, beam trawl in 216-262 m.

REMARKS. - We were unable to identify this small individual. 


\section{HolocenTRIDAE (SQUIRRELFISHES)}

Myripristis hexagona (Lacepède, 1802) (Fig. 83)

MATE RIAL.-CAS 235467 (127 mm SL, DC-1396); HEPD-012.5, hook and line in $40 \mathrm{~m}$.

Remarks. - Widespread in Indo-West Pacific.

Ostichthys cf. japonicus (Cuvier in Cuvier and Valenciennes, 1829) (Fig. 84)

Mate Rial. - CAS 235783 (69 mm SL, DC-1478); HEPD-022, otter trawl in 115-144 m.

REMARKs. - This HEPD specimen agrees fairly closely with $O$. japonicus as described by Nakabo (2000: 494) and Randall and Greenfield (in Carpenter and Niem, 1999: 2247) except for the narrower suborbital (height about $1 / 4$ of orbit diameter vs. $1 / 2$ ), slightly lower gill-raker count, and the last $D$ spine not substantially longer than the penultimate spine. The upper jaw also falls well short of a vertical through the hind margin of the orbit, as opposed to well beyond that vertical. The gill-raker counts for the HEPD specimen included only developed rakers and not the one or two rudiments in each limb of the arch. Perhaps these differences may be a result of the small size of the HEPD specimen. Nakabo (2000) gives the following counts: D XII,12-14; A IV,10-12; P 16-17; LL 28-30; GR 7-10+12-14. O. japonicus is widespread in the western Pacific, from Japan to Australia and west to the Andaman Sea.

\section{MACRUROCYTTIDAE (ARMOREYE DORIES)}

\section{Zenion hololepis Goode and Bean, 1896 (Fig. 85)}

Material. - CAS 235741 (41.3 mm SL); HEPD-006, otter trawl in 454-457 m. CAS 235737 (2, 48.8-49.6 mm SL, DC-1431, -1436); HEPD-017, beam trawl in 282-428 m.

REMARKs.- A widespread species in slope waters of most tropical and subtropical seas.

\section{CAPROIDAE (BOARFISHES)}

Antigonia capros Lowe, 1843

Material. - CAS 235578 (52.3 mm SL, DC-1552); HEPD-032, beam trawl in 223-369 m.

REMARKS.-A broadly distributed species in tropical to subtropical waters.

Antigonia rubicunda Ogilby, 1910 (Fig. 86)

MateriaL. - CAS 235575 (25.3 mm SL); HEPD-022, otter trawl in 115-144 m. CAS 235579 (98.5 mm SL); HEPD-032, beam trawl in 223-369 m.

REMARKS. - The lower counts on these specimens, compared to those of A. capros, could place them in A. malayana.

\section{FisTULARIIDAE (CORNETFISHES)}

\section{Fistularia petimba Lacepède, 1803 (Fig. 87)}

Material. - CAS 236412 (639 mm TL, DC-1479); HEPD-022, otter trawl in 115-144 m.

REMARKS. - This species is almost circumglobal in distribution, ranging on both sides of the Atlantic Ocean into the Indian Ocean and the Pacific Ocean to the Hawaiian Islands. It is not found in the eastern Pacific.

\section{SCORPAENIDAE (SCORPIONFISHES, ROCKFISHES)}

Ebosia bleekeri (Döderlein, in Steindachner and Döderlein, 1884) (Fig. 88)

Material.-CAS 235824 (2, 57-96 mm SL, DC-1487, DC-1477); HEPD-022, otter trawl in 115-144 m.

REMARKS. - The high bony crest over the orbits in males of this species is unique in the family. The two HEPD specimens and one collected off Camarines Sur in southeastern Luzon (CAS 41610) are the first records of the species from the Philippines. A third unrecorded specimen (CAS 64871) comes from off Vietnam in the South China Sea. The species is otherwise known from southern Japan, Taiwan, Hong Kong, and Indonesia. 
Ectreposebastes imus Garman, 1899 (Fig. 89)

Material. - CAS 235751 (125 mm SL, DC-1418); HEPD-016, otter trawl in 892-966 m.

REMARKS. - A worldwide bathypelagic species.

\section{Erisphex ariarus (Thomson, 1967)}

Material._CAS 236697 (40.4 mm SL, DC-1324); HEPD-009, otter trawl in 322-336 m.

REMARKS. - This juvenile black-finned belvetfish was identified by S. G. Poss.

\section{Minous pictus Günther, 1880}

MATERIAL. - CAS 235528 (71.2 mm SL); HEPD-022, otter trawl in 115-144 m.

REMARKS. - Widespread from Taiwan and the South China Sea to the Indo-Australian Archipelago.

Minous quincarinatus (Fowler, 1943) (Fig. 90)

Material. - CAS 235738 (2, 72.4-77.2 mm SL, DC-1449, -1461); HEPD-021, beam trawl in 132-172 m. CAS 235595 (75 mm SL, DC-1512); HEPD-028, beam trawl in 115-124 m.

\section{Neocentropogon aeglefinus (Weber; 1913) (Fig. 91)}

Material.-CAS 234641 (8, 60.5-91.0 mm SL) and CAS 235739 (2, 63.6-69.0 SL, DC-1455, -1463); HEPD-021, beam trawl in 132-172 m. CAS 235563 (62.5 mm SL); HEPD-022, otter trawl in 115-144 m.

Remarks.- Distributed from Bali Straits to Timor Sea, Halmahera Sea; Savu Sea, Sumbawa. The HEPD specimens are the first records from the Philippines.

\section{Neocentropogon affinis (Lloyd, 1909) (Fig. 92)}

Material. - CAS 235749 (2, 80.3-81.4 mm SL, DC-1462, -1467) and CAS 235572 (3, 67.5-78.2 mm SL); HEPD-021; beam trawl in 132-172 m. CAS 235562 (3, 52-83 mm SL); HEPD-022, otter trawl in 115-144 m.

REMARKS. - Distributed from Myanmar east through the islands of the Malay Archipelago, and with the HEPD specimens, now first recorded from the Philippines.

\section{Neomerinthe sp. (Fig. 93)}

Material. - CAS 236002 (66.0 mm SL, DC-1447); HEPD-021, beam trawl in 132-172 m.

REMARKS. - This specimen was identified by Stuart G Poss. The genus is much in need of revision.

\section{Ocosia zaspilota Poss and Eschmeyer, 1975 (Fig. 94)}

MATERIAL. - CAS 235825 (67 mm SL, DC-1519); HEPD-030, beam trawl in 190-201 m.

REMARKS. - The holotype (CAS 33069) and all three paratypes were collected off Luzon Is., Batangas, as was the HEPD specimen. These are the only records of the species so far as we know.

\section{Parapterois heterurus (Bleeker, 1856) (Fig. 95)}

Material.-CAS 236010 (53 mm SL, DC-1516); HEPD-028, beam trawl in 115-124 m.

REMARKS. - Distributcd from southern Japan to New Guinea and in Indian Ocean to off South Africa.

\section{Pontin us rhodochrous Günther, 1872) (Fig. 96)}

Material. - CAS 235458 (190 mm SL, DC-1437); HEPD-018, traps in 240-262 m. CAS 235594 (106.3 $\mathrm{mm}$ SL); HEPD-032, beam trawl in 223-369 $\mathrm{m}$.

REMARKs. - This species has been confused in the past with P. tentacularis and P. macrocephalus, but Stuart G. Poss, in Fishbasc, considers the former, and possibly the lattcr, to be synonyms. Masuda ct al. (1984), Goerfelt-Tarp and Kailola (1984), Nakabo (2000), and others have recognized P. macrocephalus from Japanese waters. Okamura (in Okamura et al. 1982) recognized $P$. tentacularis as represcntative of the Indo-West Pacific fauna, and $P$. macrocephalus as confined to Hawaii and adjacent waters. Shao (2014) also used P. tentacularis for his Taiwan specimens. Eschmeyer (1969:24) recognized P. tentacularis and 
P. macrocephalus based on differences in D and P ray counts, but he did not include $P$. rhodochrous in his discussion. If the three nominal species are determined to be a single species, its distribution would be extremely widespread, ranging from the western Indian Ocean to Hawaii and from Japan south to Indonesia and through most intervening areas of the western Pacific.

\section{Pterois antennata (Bloch, 1787) (Fig. 97)}

MateriaL. - CAS 235573 (105.5 mm SL, DC-1503); HEPD-026, beam trawl in 82-86 m.

Remarks.- A common, widespread species from most of the Indo-West Pacific, found in lagoons to outer reefs in depths to about $76 \mathrm{~m}$.

\section{Pterois lunulata Temminck and Schlegel, 1842 (Fig. 98)}

Material.-CAS 235752 (91 mm SL, DC-1448); HEPD-021, beam trawl in 132-172 m.

REMARKS.-Distributed throughout the western Pacific from northern Japan and Korea to northern Australia

\section{Setarches longimanus (Alcock, 1894) (Fig. 99)}

MateriaL.-CAS 236699 (43 mm SL); HEPD-006, otter trawl in 454-457m. CAS 236698 (2, 340-358 mm SL); HEPD-009, otter trawl in 322-33 m. CAS 236696 (37.2 mm SL); HEPD-010, beam trawl in 318-333 $\mathrm{m}$. CAS 235642 (121 mm SL); HEPD-036, beam trawl in 216-262 m.

REMARKS.- A wide-ranging species in tropical to subtropical waters if the Indo-West Pacific.

\section{TRiglidae (SEAROBINS)}

\section{Lepidotrigla abyssalis Jordan and Starks, 1904 (Fig. 100)}

Mate Rial. - CAS 236411 (125 mm SL, DC-1489); HEPD-022, otter trawl in 115-144 m.

Remarks. - Masuda et al. (1984: 334) record the distribution of this species as southern Japan and the East China Sea.

\section{Pterygotrigla hemisticta (Temminck and Schlegel, 1843)}

MateriaL. - CAS 235570 (89 mm SL); HEPD-022, otter trawl in 115-144 m.

Remarks. - A widespread species ranging from Japan south through the Philippines and China coasts to Indonesia and northern Australia, in 10-420 m.

\section{Pterygotrigla sp. (Fig. 101)}

Material.-CAS 234010 (187 mm SL, DC-1320); HEPD-009, otter trawl in 322-336 m. CAS 236479 (96 $\mathrm{mm}$ SL, DC-1560); HEPD-036, beam trawl in 216-262 m.

REMARKS.- The genus has yet to be revised, and according to Richards (1999 in Carpenter and Niem FAO WCP, vol. 4, p. 2360) “. . . includes many species, several of which are undescribed." We were unable to identify this specimen.

\section{Peristididide (ARmored Searobins)}

\section{Peristedion ef. liorhynchus Günther, 1871 (Fig. 102)}

Material.-CAS 233996 (2, 116-166 mm SL, DC-1296, -1297); HEPD-006, otter trawl in 454-457 m. CAS uncat. (154 mm SL); HEPD-009, otter trawl in 322-336 m.

REMARKS. - In the preserved HEPD specimens, the dorsal fins are clear except for the black margins; P pale with broad black band near tip and fainter diagonal black band at mid-fin. Scales of dorsum outlined in black along posterior edges. The HEPD specimens do not agree with Richards's (1999:2370) figure of the species (adapted from Okamura, 1985) in terms of the barbel, the P pigmentation pattern and length of free rays. That figure also shows a large sharp preopercle spine, which is reportedly absent fide Nakabo (2000: 610) and Okamura and Amaoka (1997: 216). 


\title{
Platycephalidae (Flatheads)
}

\author{
Rogadius welanderi (Schultz, 1966)? (Fig. 103a-b)
}

Material. - CAS 235511 (87.6 mm SL, DC-1517); HEPD-028, beam trawl in 115-124 m.

REMARKs. - The HEPD specimen follows Knapp's (1999:2414) description fairly well, except for a few minor items. The right $\mathrm{P}$ has 23 rays ( $c f 22-23$ recorded by Knapp); preopcrcle spine 1 ( $v$ s. 2 or 3 ); a relatively large antrose preopercle spine ( $v s$. small spine); and fin pigmentation patterns of D, P, A. and D diffcr. The maximum size of $13 \mathrm{~cm}$ TL reported is not much larger than the $11 \mathrm{~cm}$ TL of the HEPD specimen, so size may not be a factor in the pigmentation differences. The species has been recorded from the Amcrican Samoas, Marshall Islands, Moluccas, and west into the Indian Occan; it is not known from the Philippines, so the identification of this specimen remains tentative.

\section{Thysanophrys chiltonae (Schultz, 1966) (Fig. 104a-b)}

MATERIAL. - CAS 235508 (94.0 mm SL, DC-1507); HEPD-026, beam trawl in 82-86 m.

REMARKS. - The single juvenile collected during the expedition appeared to lack iris lappets. According to Knapp (1999), the species has "lappets bearing short branches with bifurcate tips." Otherwise, the HEPD specimen agrees well with his description. Widely distributed in the Indo-Wcst Pacific.

\section{HopliChTHYidae (GHOST FLATHEADS)}

\section{Hoplichthys langsdorfi Cuvier in Cuvier and Valenciennes, 1829 (Fig. 105)}

Material.-CAS 235513 (136 mm SL) and CAS 235800 (1, $123 \mathrm{~mm}$ SL, DC-1466); HEPD-021, beam trawl in 132-172 m. CAS 235525 (2, 105-147 mm SL): HEPD-022, otter trawl in 115-144 m.

REMARKS. - Previously recorded from southern Japan to the East China Sea and Taiwan (see Shao 2013); the HEPD specimens extend the range to the west coast of Luzon Is, Philippines.

\section{Psychrolutidae (FAThead Sculpins)}

\section{Psychrolutes cf.. occidentalis Fricke, 1990 (Fig. 106)}

Material.-CAS 234016 (137 mm SL, DC-1342); HEPD-011, otter trawl in 636-664 m.

REMARKS.- The absence of vomerine teeth, no cirri on head or body, D 22, P 23, and dark but not jet-black peritoneum agrees with those diagnostic characters for Psychrolutes occidentalis as given by Nelson ( $\mathrm{p}$. 2428 in Carpenter and Niem, 1999). However, the color pattern does not entirely agree with Fricke's (1990) original description. Fresh coloration of the HEPD spccimen showed an overall uniformly brownish-gray color with blackish posterior part of body, black caudal fin, possibly pale caudal peduncle (but this may be an artifact of preservation with the skin stripped away), black pectoral fin but paler near base, with those fins lacking whitish margins, the eyes were not yellowish, and the belly was not whitish but grayish. Fricke's drawing of the holotype shows traces of diagonal bars on the body, which are lacking in our specimen. The known distribution of $P$. occidentalis is the Rowley Shoals off the northwestern coast of Australia. No member of the genus has hitherto been recorded from the Philippines.

\section{DACTYLOPTERIDAE (FLYING GURNARDS)}

\section{Dactyloptena orientalis (Cuvier, 1829) (Fig. 107)}

Material.-CAS 235790 (101 mm SL, DC-1482); HEPD-022, otter trawl in 115-144 m. CAS 235470 (39.4 mm SL); HEPD-026, beam trawl in 82-86 m.

REMARKS.- A widespread Indo-Pacific species known from Africa to Hawaii, Society Islands, Pitcairn and Rapa, and Japan to Australia.

\section{Dactyloptena tiltoni Eschmeyer, 1997 (Fig. 108)}

Material._CAS 235885 (86.5 mm SL, DC-1498); HEPD-022, otter trawl in 115-144 m. CAS 235469 (72 $\mathrm{mm}$ SL); HEPD-028, beam trawl in 115-124 $\mathrm{m}$.

REMARKS.- A distinctive species of the family; so far known only from the Philippines. 


\section{ACROPOMATIDAE (LANTERNBELLIES)}

\section{Malakichthys elegans Döderlein, 1883}

Material. - CAS 235640 (2, 109.5-118.5 mm SL); HEPD-036, beam trawl in 216-262 m.

REMARKS. - A widely distributed bathypelagic fish found throughout the western Pacific and the eastern Indian Ocean.

\section{Synagrops japonicus (Döderlein, 1883) (Fig. 109)}

Material.-CAS 235380 (2, 70.2-74.1 mm SL, DC-1352), CAS 234012 (124 mm SL, DC-1319) and CAS 236024 (139 mm SL); HEPD-009, otter trawl in 322-336 m. CAS 236023 (85.2 mm SL) and CAS 235743 (44.7mm SL); HEPD-036, beam trawl in 216-262 m.

REMARKs.- Of four Japanese species, S. japonicus is the only one to lack serrations along the leading edge of the pelvcs-fin spine. It is a dark-colored species, with a head that is almost uniformly dark brown; in its color it is similar to Synagrops bellus (Goode and Bean, 1896). Widely distributed in Indo-West Pacific from east Africa to Hawaii.

\section{Synagrops philippinensis (Günther, 1880) (Fig. 110)}

Material- - CAS 236019 (81.9 mm SL, DC-1562); HEPD-036, beam trawl in 216-262 m.

REMARKS. - Widely distributed from India east to the western Pacific, including Japan, south through the Philippines and northern Australia (Arafura Sea).

\section{Synagrops sp. (Fig. 111)}

Material. - CAS 235736 (63.0 mm SL, DC-1430); HEPD-017, beam trawl in 282-428 m.

Remarks. - We could not identify this specimen. It is deeper bodied than $S$. philippinensis and has welldeveloped serrations on the $\mathrm{V}$ spine, but none on the $\mathrm{A}$ or $\mathrm{D}$ spines.

\section{SERRANidAe (SEABASSES)}

\section{Plectranthias sagamiensis (Katayama,1964) (Fig. 112)}

Material.-CAS 235596 (41 mm SL, DC-1502); HEPD-026, beam trawl in 82-86 m.

REMARKS.- Previously known only from southern Japan to Taiwan, and in southern Indonesia. The HEPD specimen represents the first record from the Philippines.

\section{Plectranthias sp. (Fig. 113)}

Material.-CAS 235681 (53 mm SL, DC-1458); HEPD-021, beam trawl in 132-172 m.

REMARKS. - We were unable to identify this specimen.

\section{Cephalopholis aurantia (Valenciennes, 1828) (Fig. 114)}

Material. - CAS 235460 (240 mm SL; DC-1504); HEPD-026, beam trawl in 82-86 m.

REMARKS.- A deepwater grouper usually captured in depths greater than $100 \mathrm{~m}$. Distributed in tropical waters from islands of southcentral and western Pacific into Indian Ocean west to Madagascar and southern Africa.

\section{Epinephelus areolatus (Forsskål, 1775) (Fig. 115)}

Mate RiAL. - CAS 235793 (131 mm SL, DC-1514); HEPD-028, beam trawl in 115-124 m.

Remarks. - Widespread in Indo-West Pacific from southern Japan south to northern Australia, east to New Caledonia, and west to Africa, Red Sea, and Persian Gulf.

\section{Epinephelus fasciatus (Forrskål, 1775)}

Material. - CAS 234023 (144 mm SL); HEPD-012.5, hook and line in $40 \mathrm{~m}$.

REMARKS. - Common, widely distributed grouper, known from islands throughout tropical and subtropical Indo-West Pacific, including the Red Sea, but not the Persian Gulf or the Hawaiian Islands. 


\section{Pricanthidae (Bigeyes, Catalufas)}

Priacanthus fitchi Starnes, 1988 (Fig. 116)

Material.-CAS 235784 (3, 55.3-88 mm SL, DC-1543, -1544, -1545); HEPD-031, beam trawl in 183-188 m.

Remarks. - Distributed from southern Japan and Philippines to northwestern Australia and Sumatra; also known from Mascarene Island in the western Indian Ocean, in 150-400 m.

Priacanthus macracanthus Cuvier, 1829 (Fig. 117)

Mate RiaL. - CAS 235820 (53 mm SL, DC-1518); HEPD-029, trap in 60-77 m.

Remarks.- Distributed from Japan south to Indonesia, northern and eastern Australia, Malaya, and Andaman Sea.

\section{Pristigenys niphonia (Cuvier, 1829) (Fig. 118)}

Material._CAS 236407 (95.2 mm SL); HEPD-02 1, beam trawl in 132-172 m.

Remarks. - A common, widely distributed species in the Indo-West Pacific from southern Japan to eastern Australia and east to Samoa, and Indian Ocean to South Africa and Red Sea, in depths of 80 to $100 \mathrm{~m}$ over rocky bottoms.

\section{Apogonidae (CARDinALFISHES)}

\section{Jaydia carinatus Cuvier, 1828 (Fig. 119)}

Material. - CAS 235746 (100.0 mm SL, DC-1452); HEPD-021, beam trawl in 132-172 m. CAS 235571 (92.0 mm SL); CAS 235789 (88.4 mm SL); HEPD-022, otter trawl in 115-144 m.

REMARKS. - Lives over muddy bottoms; most often taken in trawls to about $50 \mathrm{~m}$. Attains at least $15 \mathrm{~cm}$ TL. Known from Japan south to Taiwan, Hong Kong and the Philippines; also recorded from northwestern Australia. The HEPD specimens had a totally clear A, lacking blackish distal margin; the upper limb of its first gill arch has one or two developed rakers, although the upper of these was considerably smaller than the one nearest the angle.

Jaydia cf. poecilopterus Cuvier in Cuvier and Valenciennes, 1828 (Fig. 120)

Material. - CAS 236504 (2, 50.5-59.4 mm SL, DC-1465); HEPD-021, beam trawl in 132-172 m. CAS $236506(16,30-50 \mathrm{~mm}$ SL); HEPD-022, otter trawl in 115-144 m.

REMARKS. - This species lacks the fin coloration of closely related species of Jaydia (black edging on anal fin, black spot on soft dorsal fin of J. carinatus; dorsal half of spinous dorsal fin black and thin dark stripes on soft dorsal fin of J. poecilopterus).

\section{Ostorhinchus cf. cheni Hayashi, 1990 (Fig. 121)}

Material.-CAS 236505 (52 mm SL, DC-1511); HEPD-028 in 115-124 m.

ReMarks.-Ostorhinchus cheni is a deepwater western Pacific species that is very similar in coloration to CAS 236505; however, $O$. chen $i$ has a fainter snout stripe and lacks a fine black margin on its caudal fin. We follow Thomas H. Fraser (in litt., October 2013) in recognizing Ostorhinchus and Jaydia as valid genera.

\section{EPigonidae (DEEPWATER CARDinAlFishes)}

\section{Epigonus ctenolepis Mochizuki and Shirakihara, 1983 (Fig. 122)}

Material.-CAS 235796 (160 mm SL, DC-1443); HEPD-019, beam trawl in 541-636 m.

REMARKs. - This HEPD specimen is only the fourth recorded of this species and the first from the Philippines (others taken off southern Japan) as well as the largest known. It agrees well with characters given by Okamoto and Fukui (2011) with the exception of having a GR count of $6+1+15$ (22 total) vs. 24-25 total and 8 pyloric caeca (vs. 9-11). 


\section{CARAngidae (Jacks AND Pompanos)}

Decapterus kurroides Bleeker, 1855 (Fig. 123)

Material. - CAS 236410 (165 mm FL, DC-1491); HEPD-022, otter trawl in 115-144 m.

REMARKs.- Widely distributed, deeper-water schooling species usually found in depths of 100 to $300 \mathrm{~m}$. Known distribution from western Indian Ocean and western Pacific from Japan south to Philippines, Indonesia and Australia. Our HEPD specimens were taken in an otter trawl in bottom depths of 63-79 m. It is most likely to be confused with $D$. rilsselli but differs in having slightly fewer gill rakers on first arch (36-41 total vs. 41-53 total) and reddish C (vs. hyaline to dusky brown).

\section{LUTJANIDAE (SNAPPERS)}

Pristipomoides argyrogrammicus (Valenciennes, 1832) (Fig. 124)

Material. - CAS 236418 (87.7 mm SL, DC-1496); HEPD-022, otter trawl in 115-144 m.

Remarks. - A common, wide-ranging species of the Indo-West Pacific; found over rocky bottoms in 70-350 $\mathrm{m}$.

\section{Nemipteridae (ThreAdFIN BREAMS)}

\section{Nemipterus bathybius Snyder, 1911 (Fig. 125)}

Material.-CAS 236018 (100 mm SL, DC-1484) and CAS 236408 (162 mm SL); HEPD-022, otter trawl in 115-144 m. CAS 236025 (134 mm SL, DC-1521); HEPD-028, beam trawl in 115-124 m.

REMARKS.- A common commercial species in the western Pacific, ranging from southern Japan to northern Australia, Indonesia, and into the westernmost Indian Ocean, in depths of 42-300 m. Nemipterus species are often difficult to distinguish because of their overall similarities in counts and proportional measurements. Live color pattern is often the best feature one can use to identify specimens, and we are fortunate that David Catania (CAS) took color photographs of almost all the species collected during the HEPD cruise. His photographs of these specimens allowed us to identify them with high confidence.

\section{Nemipterus peronii (Valenciennes, 1830)}

Material.-CAS 235632 (4, 97.6-143.8 mm SL); HEPD-022, otter trawl in 115-144 m.

Remarks. - Widespread in Indo-West Pacific.

Nemipterus virgatus (Houttuyn, 1782)

Mate Rial.- CAS 235633 (95 mm SL); HEPD-022, otter trawl in 115-144 m.

Remarks.-Distributed in the western Pacific Ocean from southern Japan to northwestern Australia.

Parascolopsis inermis (Schlegel in Temminck and Schlegel, 1843) (Fig. 126)

Material.-CAS 236496 (84 mm SL, DC-1486); HEPD-022, otter trawl in 115-144 m.

REMARKs. - A common fish distributed from southern Japan south through Indonesia and into the eastern Indian Ocean.

\section{MULLIDAE (GOATFISHES)}

\section{Upeneus subvittatus (Temminck and Schlegel, 1843) (Fig. 127)}

Material.-CAS 235576 (5, 128-151 mm SL); HEPD-022, otter trawl in 115-144 m. CAS 236409 (149 $\mathrm{mm} \mathrm{SL}, \mathrm{DC}-1485$ ); HEPD-026, beam trawl in 82-86 m.

REMARKS. - Widespread from southern Japan to Indonesia, Red Sea and Mozambique. Our specimens of this species display a prominent yellow stripe on the body, much as in U. moluccensis (Bleeker, 1855), but the dark stripes on both lobes of the caudal fin in $U$. subvittatus contrast with the dusky orange stripes on the upper lobe only of $U$. moluccensis. Additional differences between the two species include the longer barbel of $U$. subvittatus (barbel falls short of preopercle margin in $U$. moluccensis) and the presence of a black-tipped ID in U. subvittatus (absent in U. moluccensis). 


\title{
Bathyclupeidae (DeEPSEA Herrings)
}

\author{
Bathyclupea argentea Goode and Bean, 1896? (Fig. 128)
}

Material.-CAS 233990 (87 mm SL, DC-1297); HEPD-004, otter trawl in 154-245 m. CAS 234030 (3, 125-136 mm SL); HEPD-009, otter trawl in 322-336 m.

REMARKS. - This group is in need of revision. Dick (1972) provided a cursory review and recognized six species, but provided little new information on them. Our specimens agree relatively well with $B$. argentea Goode and Bean, 1896, described from off Nevis Is. (not Neris sic Goode and Bean, 1896:190, nor Neirs sic Dick, 1973:543), in the Leeward Islands, West Indics. Two specimens (CAS 56867 and CAS uncat.) that we examined for comparison are also from off Nevis. The HEPD specimens, however, have a smaller eye diameter (34-36\% HL cf 39-40\%), slightly shorter upper jaw (41-42\% HL cf $42-45 \%$ ), and a slightly shallower body depth (22-23\% SL $c f 23-27 \%)$. All specimens examincd had the A origin in the anterior half of the body, although the original illustration of $B$. argentea shows the A origin in the posterior half of the body. We have examined numerous specimens of Bathyclupea from the Gulf of Mexico and Caribbean Sea, but none matched B. schroeder Dick, 1962, which was described from the holotype taken off Cal Sal Bank off northern Cuba (not in the Caribbean as stated in the original description) and nine paratypes, four of which were taken with the holotype, another at almost the same locality; one in the Antilles off St Croix I., and two in the wcstem Caribbcan cast-northeast off the Nicaragua-Honduras border.

\section{Champsodontidae (CROCODILE TOOTHFISHES)}

\section{Champsodon atridorsalis Ochiai and Nakamura, 1964}

Material. - CAS 235529 (111.5 mm SL); HEPD-030, beam trawl in 190-201 m. CAS 235785 (100 mm SL, DC-1541); HEPD-031, beam trawl in 183-188 m

REMARKs. - Most similar to Champsodon longipinnis Matsubara and Amaoka, 1964 from Japan and Philippines but lacking forked eye cirrus and body blotches, and the fully scaled belly and sides of that species. Champsodon vorax Günther, 1867 and C. nudivittis (Ogilby, 1895) differ in having only four transverse papillae between posterior margin of pterotic ridges. Distribution from Vietnam, Philippines, south to Indonesian waters and northwestern Australia, in 0-326 m.

\section{Champsodon nudivittis (Ogilby, 1895)}

Material.-CAS 236628 (32, 15.9-42.1 mm SL); HEPD-026, beam trawl in 82-86 m. CAS 235536 (3, 59-84 mm SL); HEPD-030, beam trawl in 190-201 m. CAS 236629 (31.0 mm SL); HEPD-036, beam trawl in 216-262 m.

REMARKS.- The smaller specimens from HEPD-026 and HEPD-036 are tentatively referred to this species because some of the diagnostic characters (notably squamation features) did not appear to be adequately developed. Champsodon nudivittis is most similar to C. guentheri Regan, 1908 but lacks a fully scaled chest and has fewer gill rakers (10-12 on lower limb, vs. 12-14); $C$. vorax and $C$. longipinnis differ in having a branched eye cirrus and the gular and chest regions mostly or fully scaled; $C$. longipinnis also has its 1D black distally. Broadly distributed from Philippines, Indonesia, south to warm waters of Australia and Madagascar, in 0-335 m.

\section{PINGUIPEDIDAE (SANDPERCHES)}

\section{Parapercis sp. (Fig. 129)}

Material. - CAS 236013 (89mm SL, DC-1524); HEPD-030, beam trawl in 190-201 m.

REMARKS. - We could not identify this specimen.

\section{TRICHINOTIDAE (SAND-DIVERS)}

\section{Pteropsaron dabfar Iwamoto, 2014 (Fig. 130)}

Material. - CAS 236400 (holotype, $33.6 \mathrm{~mm}$ SL); HEPD-026, beam trawl in 82-86 m. CAS 236667 (paratype, $33.0 \mathrm{~mm} \mathrm{SL}$; DC-1508; preserved in 95\% EtOH) and CAS 236560 (paratype, $30 \mathrm{~mm} \mathrm{SL}$ ); same data as for holotype.

REMARKS. - This species is described in this volume. 


\section{Pteropsaron levitoni Iwamoto, 2014 (Fig. 131)}

Material. - CAS 236401 (holotype, $23.7 \mathrm{~mm}$ SL), CAS 236399 (6 paratypes, 19.8-28.8 mm SL) and CAS 236402 (24.5 mm SL, cleared and stained); HEPD-026, beam trawl in 82-86 m.

REMARKs.- This species is described in this volume.

Pteropsaron springeri Smith and Johnson, 2007? (Fig. 132)

Material.- CAS 236668 (35.0 mm SL, DC-1 509), HEPD-026, bcam trawl in 82-86 m.

REMARKS. - This specimen is too fragile to allow a conclusive examination of its fin-ray and scale conditions. (Radiographs were attempted but were ineffective for making median fin counts.) It is very similar in appearance and coloration to the female specimen from Florcs, Indonesia, illustrated in the original description (Smith and Johnson, 2007: fig. 5) and even more similar to the female from Bali, Indonesia, illustrated in Allen and Erdman (2012: 759). Our specimen differs in having two fewer slender orange bars along its body. This species is known from Indonesia, Philippines, and Palau in 18-86 m.

\section{PercophidAe (DuCKBILls)}

\section{Bembrops caudimacula Steindachner, 1876 (Fig. 133)}

Material.-CAS 235272 (186 mm SL, DC-1273); HEPD-003, beam trawl in 272-291 m. CAS 235734 (99.0 mm SL, DC-1429); HEPD-017, beam trawl in 282-428 m. CAS 235507 (2, 185-190 mm SL, DC$1548,-1556$ ); HEPD-033, beam trawl in 225-347 m.

REMARKS.-CAS 235272 from HEPD-003 agrees rather well with the description of the species provided by Thompson and Suttkus (2002:287-288), although the P count is slightly higher (27-28 vs. 23-27, $\overline{\mathrm{x}}=25.97$ ) and its spinous $\mathrm{D}$ is black over. most of the first three or four membranes, and with clear membranes posteriorly. The two specimens from HEPD-033 lack black membranes, the 1D is entirely dusky, and only the ventral margin of the $\mathrm{C}$ is black; the lateral-line scale counts are also on the high side (54 and 55 vs. 42-54). Thompson and Suttkus (2002) found variation in populations between the eastern and western Indian Occan in pigmentation and some proportional measurements. The female (CAS 235734) from HEPD-017 agrees in most characters, although its lateral-line scale count is slightly on the high side at 59 .

\section{Bembrops curvatura Okada and Suzuki, 1952 (Fig. 134)}

MATERIAL. - CAS 235735 (94.5 mm SL, DC-1464); HEPD-021, beam trawl in 132-172 m.

REMARKS. - The abrupt dip in the lateral line and the small black caudal spot are distinctive among the Bembrops spp. of the region. Distributed in the western Pacific from southern Japan to Indonesia and northern Australia.

\section{Bembrops nelsoni Thompson and Suttkus, 2002 (Fig. 135)}

Material. - CAS 235272 (2, 90-164 mm SL); HEPD-003, beam trawl in 272-291 m.

REMARKS.-Distributed from the Philippines south to Indonesia (south coast Java) and northern Australia (Arafura Sea) in 265-333 m.

\section{Chrionema chlorotaenia McKay, 1971 (Fig. 136a-b)}

MATERIAL.-CAS 235512 (146 mm SL), HEPD-033, beam trawl in 225-347 m.

REMARKS. - Broadly distributed in the western Pacific from southern Japan to Indonesia and Australia.

\section{URANOSCOPIDAE (STARGAZERS)}

\section{Kathetostoma sp.}

Material.-CAS 236422 (38.6 mm SL); HEPD-022, otter trawl in 115-144 m.

REMARKS. - This little specimen was collected together with one "Uranoscopus sp. 2" and two similar-sized individuals of another unidentifiable Uranoscopus. The narrow interorbital fossa, the absence of a spinous dorsal fin and supracleithral spines differentiate the specimen from members of Uranoscopus. (We do not know if the lack of supracleithral spines in this specimen reflects a juvenile stage.) Three other genera found in the area have members lacking a spinous D, but they differ as follows: in Xenocephalus the lat- 
eral line does not run close to the dorsal-fin base; Genyagnus monopterygius (the only recorded species of the genus in the area) has a small chin barbel; and Ichthyscopus lacks dermal appcndages on the oral valve, has a relatively compressed head and body, has dermal folds on the belly, its basipterygium is not visible,and its upper cleithral spine has fringed dermal flaps. There arc other uranoscopids lacking a spinous D fin that are known from outside the general area. Based on Pietsch's (1989) comprehensive study of phylogenetic relationships of the family, the HEPD specimen agrees most closely with his diagnosis of Kathetostoma, a genus containing seven species from western North Atlantic (2 spp.), tropical eastern Pacific (1 sp.), New Zealand (1 sp.), and southern Australia and Tasmania ( 3 spp.). If the specimen proves to bc a Kathetostoma, it would be the first rccord of the genus in tropical waters of the westcrn Pacific. It is beyond the scope of this report to attempt a species identification based on a single juvenile.

Uranoscopus sp. 2 (of Kishimoto, 2001) (Fig. 137a-b)

Material.—CAS 236423 (98 mm SL, DC-1450); HEPD-016, otter trawl in 892-966 m. CAS 236421 (72 $\mathrm{mm} \mathrm{SL}$ ); HEPD-022, otter trawl in 115-144 m.

ReMARKs.- These spccimens kcy out to "Uranoscopus sp. 2" in Kishimoto's key in the FAO Species Idcntification Guide (Carpenter and Niem, 2001, vol. 6), and they agree rather well with the figure of that species on p. 3529 of that work, especially in the pigmentation pattern of the fins, which, however, are somewhat paler in our specimens. They do not agree with any of the described species from Japan (Kishimoto, 1987; Nakabo 2000). Uranoscopus sp. 2 is known from the Philippines and Indonesia and attains a maximum size of $26 \mathrm{~cm}$ TL.

\section{Uranoscopus sp. 3 (of Kishimoto, 2001) (Fig. 138a-b)}

Material.-CAS 236477 (2, 40-48 mm SL); HEPD-022, otter trawl in 115-144 m. CAS 236487 (2, 39.8-47.5 SL); HEPD-026, beam trawl in 82-86 m. CAS 236476 (58.1 SL, DC-1564); HEPD-036, beam trawl in 216-262 m.

ReMarks.- These specimens key out, more or less, to Uranoscopus sp. 3 in Kishimoto's key (in Carpenter and Nicm, 2001, pp. 3520-3523), although therc are discrepancies, cspecially in terms of color (no bands or minute black spots) and form of appendage on its oral valve. Also, the distribution of the species supposedly lies wcll to the east and south in Micronesia and the Coral and Arafura scas. It is possible that the differences may be attributable to the HEPD specimens being juveniles. The specimens also keyed out closely to U. chinensis Guichenot, 1882 using Nakabo (2000). Other species of Uranoscopus recorded from the Philippines include U. bicinctus Temminck and Schlegcl, 1843, U. cognatus Cantor, 1849, U. japonicus Houttuyn, 1782, U. kaianus Günther, 1880, U. tosa Jordan and Hubbs, 1925, and U. sp. 2 (of Kishimoto, 2001).

\section{GoBIIDAE (GoBIEs)}

\section{Hazeus sp. (Fig. 139a-b)}

Material.—CAS 236631 (3, 32.2-35.5 mm SL); HEPD-026, beam trawl in 82-86 m over a hard-rocky bottom.

ReMarks. - These specimens appcar to be within the genus Hazeus. They arc very similar to Obliquogob$i u s$, however, the anterior spines of the first and second dorsal fin are thicker than the remaining fin spines and the nape and opercles appear to be partly scaled. All three specimens have a distinct V-shaped black mark above their caudal peduncle, vertical spots forming four faint bars along the caudal fin, a black spot at the base of the pectoral fin, a dark black spot between dorsal spines V and VI (much like in $O$. megalops and O. sp. 3 in Shibukawa and Aonuma's [2007] Fig. 3), and numerous black spots symmetrically occurring on the snout and lower lip. We are advised by K. Shibukawa, H. Larson, and D. Hoese that they probably fall within Hazeus, a genus that is currently being revised.

\section{Obliquogobius Koumans, 1941}

REMARKS.- The deepwater goby genus Obliquogobius was until recently known only from one central Indian Ocean and one Red Sea species. Shibukawa and Aonuma (2007) revised the genus, added three additional species from Japan and included in their kcy, but did not describe, three additional specics (from the Gulf of Aden, Fiji, and New Caledonia). They also mentioned specimens of their new species $O$. cirrifer and $O$. yamadai collected from the Philippines, but did not include them as type specimens because of 
minor differences that they possessed. An additional new species from the Ryukyu Islands was subsequently described by Chen, Jaafar and Shao (2012). It is yellowish in coloration and lacks any of the dark pigmentation of our specimens.

\section{Obliquogobius cf. cirrifer Shibukawa and Aonuma, 2007 (Fig. 140)}

Material. - CAS 236632 (36.0 mm SL); HEPD-001, beam trawl in 238-252 m over sandy-mud bottom. CAS 236633 (31.0 mm SL); HEPD-036, beam trawl in 216-262 $\mathrm{m}$ over sandy-mud bottom.

REMARKS. - Our specimens were damaged during their trawl capture and have lost most of their scales. They were not photographed when fresh, however. The dark pigmentation of their body and fins persists. The two specimens are most similar in appearance to Obliquogobius cirrifer Shibukawa and Aonuma, 2007 but differ slightly in their coloration. In their description of $O$. cirrifer, Shibukawa and Aonuma (2007:P145-146) referred to four Philippine and four Fijian specimens that they were hesitant to include among the type material. The Philippine specimens differed in the location of the black spot above the posterior end of the anal-fin base; our specimens are intermediate in the location of the spot. The Fijian specimens had 10 rather than 9 segmented anal rays, ours have 8 and 9 segmented anal-fin rays. Photographs of the larger specimen were sent by email to Shibukawa who has advised us with our identification.

\section{Gemplylidae (SNake Mackerels, Escolars)}

\section{Neoepinnula orientalis (Gilchrist and von Bonde, 1924) (Fig. 141)}

MATE Rial. - CAS 233988 (125 mm SL, DC-127); HEPD-004, otter trawl in 144-245 m.

REMARKS. - Widespread in Indian Ocean from east Africa to India, Indonesia, and western Australia, and western Pacific from Japan south to Taiwan, and the Philippines.

\section{Promethichthys prometheus (Cuvier, 1832) (Fig. 142)}

Material.-CAS 234028 (200 mm SL, DC-1401); HEPD-015, beam trawl in 757-836 m.

REMARKS.-Circumglobal in tropical to temperate waters except eastern Pacific.

\section{NOMEIDAE (DRIFTFISHES)}

\section{Cubiceps whiteleggii (Waite, 1894) (Fig. 143)}

Material. - CAS 233986 (127 mm SL, DC-1276); HEPD-004, otter trawl in 154-245 m.

REMARKs. - The HEPD specimen agrees well with the description by Last (in Carpenter and Niem, 2001: 3776 ) except for the count of lateral-line scales $(51+2 \mathrm{cf} .56-63$ given by Last).

\section{Callionymidae (Dragonets)}

\section{Callionymus (Calliurichthys) japonicus (Houttuyn, 1782)}

Material.-CAS 235543 (4, 29-40.5 mm SL); HEPD-026, beam trawl in 82-86 m.

REMARKs. - The HEPD specimens are juveniles, but readily identified by the diagnostic characters. The species is widespread in the tropical western Pacific, from southern Japan south to the East China Sea and South China Sca, to Malaysia, Indonesia, throughout the Philippines, New Guinea and northern Australia (although those from the last two areas may represent a separate species). The species is treated by Nakabo (2000:1134) in the genus Calliurichthys, which Fricke (1983) recognizes as a subgenus.

\section{CitHARIDAE (CITHARIDS)}

\section{Citharoides macrolepidotus Hubbs, 1915 (Fig. 144)}

MATERIAL.-CAS 235548 (138 mm SL, DC-1529); HEPD-031, beam trawl in 183-188 m

RemarKS. - Known from southern Japan, Korea, and Philippines in 121-240 m. 


\section{BOTHIDAE (LEFTEYE FLOUNDERS)}

Arnoglossus elongatus Weber, 1913?

MATERIAL. - CAS 235544 (2, 85-95 mm SL); HEPD-021, beam trawl in 132-172 m.

REMARKS. - These two HEPD specimens key out rather readily in Hensley and Amaoka's (2001) key to the species of Arnoglossus. Closer comparisons with othcr spccimens, espccially males, must be made before a more-definitive identification can be made. The species is known from Taiwan, Philippines, Madura (in Java Sea), and northwestern Australia, in 100-224 m.

Arnoglossus japonicus Hubbs, 1915 (Fig. 145)

Material. - CAS 235577 (13, 53-101 mm SL) and CAS 2355786 (127 mm SL, DC-1499); HEPD-022, otter trawl in 115-144 m.

REMARKS. - Known distribution from southem Japan to Gulf of Tonkin and New Caledonia; the HEPD specimens represent the first record from the Philippines. Attains $17 \mathrm{~cm}$ TL.

Arnoglossus oxyrhynchus Amaoka, 1969 (Fig. 146)

Material. - CAS 235549 (150 mm SL, DC-1528); HEPD-030, beam trawl in 190-201 m.

REMARKS.- Possibly a junior synonym of A. brunneus (Fowler, 1934). It occurs in depths of about 100-300 $\mathrm{m}$ and is known from southern Japan (Kochi), with an unconfirmed rccord from New Caledonia. Arnoglossus brunneus is known only from the east coast of Luzon in $292 \mathrm{~m}$. (Hensley and Amaoka, in Carpenter and Niem, 2001:3827)

\section{Kamoharaia megastoma (Kamohara, 1936) (Fig. 147)}

Material.-CAS 235542 (89 mm SL, DC-1473); HEPD-021, beam trawl in 132-172 m. CAS 235535 (88.5 $\mathrm{mm}$ SL); HEPD-022, otter trawl in 115-144 $\mathrm{m}$.

REMARKs. - Previously known from southern Japan to Taiwan and in the Indo-Australian Archipelago in $300-500 \mathrm{~m}$. The HEPD specimens are the first recorded from the Philippines, so far as we know.

\section{Laeops clarus Fowler, 1934}

Material.- CAS 235744 (125.2 mm SL, DC-1468); HEPD-021, beam trawl in 132-172 m.

REMARKS. - This specimen appears to be very similar to Laeops sp. from HEPD-036, agreeing rather well in meristic values and most other characters. However, the body is deeper, the eycs larger and have broad black margins along the mesial and posterior borders (light to medium brown in HEPD-036), and the branchiostegal membrane is black (compared with medium brown). The HEPD specimen may be only the second record of the species.

\section{Laeops sp.}

Mate Rial.-CAS 236558 (2, 106-120 mm SL); HEPD-036, beam trawl in 216-262 m.

REMARKS. - These spccimens agree most closely with the Japanese species L. kitaharae (Smith and Pope, 1906) except for the deeper body ( $<3$ time in SL) and the presence of fine spots in that species. Laeops clarus Fowler, 1934, apparently known only from the Philippines, has a slender body but the HL goes 5.7 timcs in SL and there are $10 \mathrm{GR}$ on the lower limb of the first arch. Laeops gracilis Fowler, 1934, also known only from the Philippines, has higher counts of rays in its D (112) and A (93) and the HL goes about five times in SL.

\section{Parabothus taiwanensis Amaoka and Shen, 1993 (Fig. 148)}

MATE RIAL. - CAS 235505 (107 mm SL, DC-1510); HEPD-026, beam trawl in 82-86 m.

REMARKS. - This specimen may represent the first record of the species outside Taiwan. Amaoka and Shen (1993) describe the teeth as biserial in its upper jaw, but that does not appear to be the case in the HEPD specimen; also they describe the body as pale purplish after removal of scales (vs. cream-colored). Otherwise the description fits our specimen rather well. 


\section{Parabothus sp.}

Material.-CAS 236630 (71, 16.0-56.5 mm SL); HEPD-026, beam trawl in 82-86 m.

REMARKS. - We were unable to identify these juvenile specimens.

Psettina gigantea Amaoka, 1963 (Fig. 149)

Material.-CAS 235788 (105 mm SL, DC-1481); HEPD-021, beam trawl in 132-172 m.

Remarks.-Distributed in the western Pacific from southern Japan through the South China Sea, Philippines, and Indonesia to the north coast of Australia.

\section{Taeniopsetta ocellata (Günther, 1880) (Fig. 150)}

Material._CAS 235823 (68.5 mm SL, DC-1554); HEPD-033, beam trawl in 225-347 m.

REMARKS. - This deepwater bothid is recorded from depths of 183-400 m in southern Japan, Western Australia, the Admiralty Islands, western Indian Ocean, and possibly New Caledonia. The HEPD specimen represents the first record from the Philippines and the South China Sea.

\section{Pleuronectidae (Righteye Flounders)}

\section{Poecilopsetta colorata Günther, 1880 (Fig. 151)}

Material. - CAS 235551 (98 mm SL, DC-1535); HEPD-032, beam trawl in 223-369 m.

REMARKS. - Widely distributed from the eastern Indian Ocean to the South China Sea and Indonesia.

Poecilopsetta plinthus (Jordan and Starks, 1904) (Fig. 152)

Material.-CAS 235545 (95 mm SL, DC-1 469); HEPD-021, beam trawl in 132-172 m. CAS 235533 (93 $\mathrm{mm} \mathrm{SL}$ ); HEPD-022, otter trawl in 115-144 m. CAS 235550 (111 mm SL); HEPD-030, beam trawl in 190-201 m.

Remarks. - Distributed from Japan, Taiwan, China mainland, and the Philippines. Hensley (in Carpenter and Niem, 2001:3866) cites an unconfirmed record from Manila Bay, Philippines. The HEPD specimens confirms its presence in the Philippines.

\section{Samarus cristatus Gray, 1831 (Fig. 153)}

Material.-CAS 235527 (3, 67-122 mm SL); HEPD-028, beam trawl in 115-124 m.

Remarks. - Widely distributed from southern Japan, Taiwan, South China Sea, Philippines, Indonesia, northern Australia, New Caledonia, and throughout the Indian Ocean.

\section{Soleidae (Soles)}

\section{Aseraggodes kobensis (Steindachner, 1896) (Fig. 154)}

Material.—CAS 235733 (2, 89-96 mm SL); HEPD-036, beam trawl in 216-262 m.

ReMARKS. - Maximum size attained about $10 \mathrm{~cm}$ SL. Known previously from southern Japan and the South China Sea; the HEPD specimens represent possibly the first record from the Philippines.

\section{Aseraggodes sp. (Fig. 155)}

Material. - CAS 236701 (5, 84-1158 mm SL, DC-1530, -1531, -1538, -1539, -1540); HEPD-031, beam trawl in $183-188 \mathrm{~m}$.

REMARKS.- Munroe's chapter on the soles in FAO-WCP [in Carpenter and Niem, 2001, vol. 6, part 4:3878-3889] does not include a key to the species, and there does not appear to be a synoptic treatment of the taxon. Munroe lists $11 \mathrm{spp}$. of the genus from the WCP.

\section{Cynoglossidae (TONGUEFISHES)}

Cynoglossus cf. gracilis Günther, 1873 (Fig. 156)

MATERIAL.—CAS 23662 (166 mm SL); HEPD-001, beam trawl in 264-278m. 
REMARKS. - This single specimen had counts of D 126, A 106, LL about 133, C about 8; body depth $24 \%$ of SL; upper eyc almost cqually aligned with lower cye, the posterior corner of upper jaw about on same vertical as posterior margin of lower eye. These characters place the specimen in either Cynoglossus abbreviatus (Gray, 1834) or C. gracilis using the keys provided by Nakabo (2000:1390) and Munroe (2001 in Carpenter and Niem, 2001: 3891-3894). Neither of these species has bcen reported from the area, however, we tentatively assign the HEPD specimen to $C$. gracilis because of the more slender body, the relative positions of the eye, and the LL scale count.

\section{Cynoglossus sp. (Fig. 157a-b)}

Mate RiAl. - CAS 236661 (5, 122-160 mm SL); HEPD-021, beam trawl in 132-172 m. CAS 236660 (4, 132-148 mm SL); HEPD-022, ottcr trawl in 115-144 m.

REMARKS. - We could not identify these specimens. Using Munroe's treatment of the family in the FAO Western Central Pacific volume (Carpenter and Niem, 2001: 3890-3901), the specimens keyed out to C. microlepis or $C$. mecullochi based on the presence of 3 lateral lines, pigmented peritoneum and other characters. Specimens from HEPD-022 had somewhat lower counts of D (107-111 vs. 111-115), A (86-87 vs. 86-90. Color on eyed side is light to medium brown with black median fins, and no other markings.

\section{TRIACANTHODIDAE (SPIKEFISHES)}

\section{Triacanthodes ethiops Alcock, 1894 (Fig. 158)}

MAte Rial. - CAS 235886 (73.4 mm SL, DC-1483); HEPD-022, otter trawl in 115-144 m.

REMARKs. - Distribution widespread from Japan, Philippines, Indonesia, and east coast of Africa in depths of about 100-250 fm. Triacanthodes ethiops closely resembles T. anomalus (Temminck and Schlegel, 1850) from Japan and the China coast but differs in having fewer olfactory lamellae, a less convex interorbital space, and slight differences in the pattern of stripes on body.

\section{BALISTIDAE (TRIGGERFISHES)}

\section{Pseudobalistes flavimarginatus (Rüppell, 1829)}

Material. - CAS 236493 (28 mm SL); HEPD-006, otter trawl in 454-457 m.

REMARKS. - This is a widespread coastal, reef, and estuarine species found through most of the Indo-West Pacific, from the coast of Africa east to the Tuamotus in the South Pacific, and north to Japan. The single juvenile taken during the HEPD cruise was likely taken in near-surface waters.

\section{MonACANTHIDAE (Filefishes)}

\section{Cantherhines sp.}

Mate Rial. - CAS 236484 (2, 41-43 mm SL); HEPD-030, beam trawl in 185-190 m.

REMARKS. - The pelvic fin of the smaller specimen is absent (damaged). These specimens cannot be identified with any certainty.

\section{?Cantherhines sp.}

Mate Rial. - CAS 236486 (17 mm SL); HEPD-026, beam trawl in 82-86 m.

REMARKS. - This specimen is too small to identify to genus or species.

\section{Paramonacanthus cf. curtorhynchos (Bleeker, 1855) (Fig. 159)}

Mate RIAL. - CAS 236485 (2, 48.5-54.0 mm SL, DC-1475); HEPD-021, beam trawl in 132-172 m. CAS 233262 (female, $41.3 \mathrm{~mm} \mathrm{SL}$ ); HEPD-022, otter trawl in 115-144 m.

REMARKS. - This juvenile specimen has the proportions and coloration of Paramonacanthus japonicus (Tilesius, 1809)(see Masuda et al, 1984: pl. 3265a), formcrly considcred to be widespread from the Bay of Bengal to Fiji, Australia, the Philippines, and throughout the East Indian Region. Allen and Erdman (2012: 1075) limit the distribution of that species to Japan and recognize previous identifications of individuals extralimital to Japan to be $P$. curtorhynchos (Bleeker, 1855). Our specimen has D II,25, A 25, and P 12 , 
well within the range of $P$. japonicus as listed by Masuda et al, but less than the counts of $P$. curtorhynchos (D II,33-36, A 30-32, and P 11-13) listed by Allen and Erdman.

\section{?Pervagor sp.}

MATERIAL.-CAS 236492 (2, 37-43 mm SL); HEPD-006, otter trawl in 454 $457 \mathrm{~m}$.

REMARKS. - Presuming that these are Pervagor, we are unaware of any species in that genus with a barred tail pattern such as seen in these specimens.

\section{Thamnacornus tesselatus (Günther, 1880)? (Fig. 160)}

Material.-CAS 235682 (45.0 mm SL); HEPD-022, otter trawl in 115-144 m. CAS 236406 (146 mm SL, DC-1536); HEPD-032, beam trawl in 223-369 m.

REMARKS. - The morphological and meristic characters (29 anal fin rays) are correct for the species, but these specimens lack the facial spots. Maximum size about $28 \mathrm{~cm}$. Distributed from Japan to the Philippines and off northwestern and northeastern coasts of Australia, in Indonesia, and New Caledonia. Depth range between 120 and $236 \mathrm{~m}$.

\section{Tetraodontidae (PufFers)}

\section{Arothron immaculatus (Bloch and Schneider, 1801) (Fig. 161)}

Material examined.-CAS 236559 (25.1 mm SL); HEPD-022, otter trawl in 115-144 m.

REMARKs. - This juvenile Immaculate puffer, like several of its congeners, is often melanistic at this size (in litt. Keiichi Matsuura, October 2013). It has the appropriate morphometric features (small spinules on head and body except around eyes, gill openings, fins, and posterior C peduncle) and counts (D 10, A 10, P 17) of this species. Arothron immaculatus lives above silt bottoms near reefs in 3-30 m from East Africa and the Red Sea to the Philippines (Allen and Erdman 2012: 1087). If our specimen was collected by the net when it was on the bottom (115-144 m) rather than during the descent or ascent of the trawl, it would represent a deeper capture than has been previously reported for the species.

\section{Sphoeroides pachygaster (Müller and Troschel, 1848) (Fig. 162)}

Material.-CAS 235459 (147 mm SL, DC-1270); HEPD-003, beam trawl in 272-291 m.

REMARKS. - Widespread in tropical to subtropical waters.

\section{Tylerius spinosissimus (Regan, 1908)}

Material. - CAS 236500 (41.4 mm SL); HEPD-O26, beam trawl in 82-86 m.

Remarks. - Widespread in the Indo-West Pacific. It is the only species in the genus, which is characterized in part by D 8-9, A 7-8, small spinules over all of head and body except the $C$ peduncle, no lateral line ventrolaterally on the $\mathrm{C}$ peduncle, and a mouth situated below the level of the upper edge of the $\mathrm{P}$ base. 


\author{
REFERENCES \\ (*-Note: This is not a literature cited; instead it is a list of many [but not all] \\ of the references we used to arrive at our identifications.)
}

Agafonova, T. B. 1988. New data on the taxonomy and distribution of cigarfishes (Cubiceps, Nomeidae) of the Indian Ocean. Journal of Ichthyology 28(6):46-61.

Allen, G R., and m. V. Erdmann. 2012. Reef fishes of the East Indies. Volumes I-III. Tropical Reef Research, Perth, Australia. 1260 pp.

АмаокA, K. 1969, Studies on the sinistral flounders found in the waters around Japan. Taxonomy, anatomy and phylogeny. Journal of the Shimonoseki University of Fisheries 18(2):65-340

Amaoka, K., And S. C. Shen. 1993. A new bothid flatfish Parabothus taiwanensis collected from Taiwan (Pleuronectiformes: Bothidae). Bulletin of Marine Science 53(3):1042-1047.

Bertelsen, E., AND G. Krefft, 1988. The ceratioid family Himantolophidae (Pisces, Lophiiformes). Steenstrupia 14(2):9-89.

BigelOw, H. B., ET AL., EDS. 1964. Fishes of the Western North Atlantic. Memoirs of the Sears Foundation for Marine Research no. 1 (Pt 4).

BöHLKE, E. B., AND J. E. RANDAll. 2000. A review of the moray eels (Angulliformes [sic]: Muraenidae) of the Hawaiian Islands, with descriptions of two new species. Proceedings of the Academy of Natural Sciences of Philadelphia 150:203-278, pls. 1-9.

BöHlke, E. B., AND D. G. Sмiтн. 2002. Type catalogue of Indo-Pacific Muraenidae. Proceedings of the Acadeny of Natural Sciences of Philadelphia 152:89-172.

Borodulina, O. D. 1979. Composition of the "Polyipnus spinosus complex" (Stcrnoptychidae, Osteichthyes) with a description of 3 new species of the group. Voprosyi Ikhtiologii 19:198-208.

BradbuRY, M. G. 1988. Rare fishes of the deep-sca genus Halieutopsis: a rcview with descriptions of four new species (Lophiiformes: Ogcocephalidae). Fieldiana Zoology (new series) (44): 1-22.

CARPENTER, K. E., AND V.H. Niem, Eds. 1999. FAO Species Identification Guide for Fishery Purposes. The Living Marine Resources of the Western Central Pacific. Vol. 3. Batoid fishes, chimaeras and bony fishes Part 1 (Elopidae to Linophrynidae). FAO: Rome, pp. 1397-2068.

CARPENTER, K. E., AND V.H. Niem, eds. 1999. FAO Species Identification Guide for Fishery Purposes. The Living Marine Resources of the Western Central Pacific. Vol. 4. Bony fishes, Part 2 (Mugilidae to Carangidae). FAO: Rome, pp. 2069-2790.

Carpenter, K. E., AND V.H. Niem, eds. 2001. FAO Species Identification Guide for Fishery Purposes. The Living Marine Resources of the Western Central Pacific. Vol. 5. Bony fishes, Part 3 (Menidae to Pomacentridae). FAO: Rome, pp. 2791-3380.

CARPenter, K. E., And V.H. Niem, EdS. 2001. FAO Species Identification Guide for Fishery Purposes. The Living Marine Resources of the Western Central Pacific. Vol. 6. Bony fishes, Part 4 (Labridae to Latimeriidae), Estuarine Crocodiles, Sea Turtles, Sea Snakes and Marine Mammals. FAO: Rome, pp. 3381-4218.

CARPenter, K. E., AND V.G. SPRinger. 2005. The center of the center of marine shore fish biodiversity: the Philippine Islands. Environmental Biology of Fishes 72:467-480.

CARuso, J. H. 1989. A review of the Indo-Pacific members of the deep-water chaunacid anglerfish genus Bathychaunax, with the description of a new species from the eastern Indian Ocean (Pisces: Lophiiformes). Bulletin of Marine Science 45:574-579.

Caruso, J. H., H.-C. Ho, And T. W. PietsCh, 2006. Chaunacops Garman, 1899, a senior objective synonym of Bathychaunax Caruso, 1989 (Lophiiformes: Chaunacoidei: Chaunacidae). Copeia 2006(1):120-121.

Chen, I-S., Z. JAAFAr,, AND K.-T. Shao. 2012. A new Obliquogobius Koumans, 1941 (Teleostei: Gobiidae) from Kumejima, Ryukyu Islands, Japan. Zootaxa (3367):269-273.

Chiou, M.-L. , K.-T. Shao, ANd T. Iwamoto. 2004. New species of Caelorinchus (Macrouridae, Gadiformes, Teleostci) from Taiwan, with a redescription of Caelorinchus brevirostris Okamura. Copeia 2004 (2): 298-304.

CoHEn, D. M. 1958. A revision of the fishes of the subfamily Argentininae. Bulletin of the Florida State Museum 3(3):93-173. 
Cohen, D. M. 1964. Suborder Argentinoidea. Pages 1-70 in H. B. Bigelow et al., eds., Fishes of the Western North Atlantic. Memoir Sears Foundation for Marine Research (1) (pt. 4).

Cohen, D. M., AND S. P. Atsaides. 1969. Additions to a revision of argentinine fishes. Fishery Bulletin, U.S. 68(1):13-36.

CRessey, R. 1981. Revision of the Indo-West Pacific lizardfishes of the genus Synodus (Pisces: Synodontidae). Smithsonian Contributions to Zoology (342):1-53.

de la Paz, R. M., and R. Interior. 1979. Deep-sea fishes off Lubang Island Philippines. Natural and Applied Science Bulletin 31(3-4):101-175, figs. 1-44.

Eschmeyer, W. N. 1997. A new species of Dactylopteridae (Pisces) from the Philippines and Australia, with a brief synopsis of the family. Bulletin of Marine Science 60(3):727-738.

Fricke, R. 1983. Revision of the Indo-Pacific Genera and Species of the Dragonet Family Callionymidae (Teleostei). Theses Zoologicae 3:1-774.

FRICKE, R. 1990. A new species of psychrolutid fish from Western Australia. Japanese Journal of Ichthyology 36(4):404-409.

Gilbert, C. H., And C. L. HubBs. 1920. Contributions to the biology of the Philippine Archipelago and adjacent regions. The macrouroid fishes of the Philippine Islands and the East Indies. Bulletin of the United States National Museum (100), 1 (pt 7):369-588.

Gloerfelt-Tarp, T., And P. J. Kallola. 1984. Trawled Fishes of Southern Indonesia and Northwestern Australia. Australian Development Assistance Bureau, Directoral General of Fisheries, Indonesia, German Agency for Technical Cooperation. $406 \mathrm{pp}$.

Harold, A. S. 1994. A taxonomic revision of the sternoptychid genus Polyipnus (Teleostei: Stomiiformes) with an analysis of phylogenetic relationships. Bulletin of Marine Science 54(2):428-534.

Ho, H.-C., AND K.-T. Shao. 2010. A review of Malthopsis jordani Gilbert, 1905, with description of a new batfish from the Indo-Pacific Ocean (Lophiiformes: Ogcocephalidae). Bulletin of the National Museum of Nature and Science (Ser. A) Supplement 4:9-19.

Hutchins, J. B.. 1997. Review of the monacanthid fish genus Paramonacanthus, with descriptions of three new species. Records of the Western Australian Museum Supplement 54:1-57.

Iwamoto, T., and A. Williams. 1999. Grenadiers (Pisces, Gadiformes) from the continental slope of western and northwestern Australia. Proceedings of the California Academy of Sciences, ser. 4, 51(3):105-243.

JoRDAN, D. S., AND E. C. STARKS. 1904. List of fishes dredged by the steamer Albatross off the coast of Japan in the summer of 1900, with descriptions of new species and a review of the Japanese Macrouridae. Bulletin of the U.S. Fish Commission 22 [for 1902]:577-638, pls. 1-8.

Kanazawa, R. H. 1958. A revision of the eels of the genus Conger with descriptions of four new species. Proceedings of the United States National Museum 108 (3400):219-267, Pls. 1-4.

Karmovskaya, E. S., And D. G. Smith. 2008. Bathycongrus trimaculatus, a new congrid eel (Teleostei: Anguilliformes) from the southwestern Pacific, with a redescription of Bathycongrus bleekeri Fowler. Zootaxa 1943:26-36.

Kawaguchi, K., AND H. Shimizu. 1978. Taxonomy and distribution of the lanternfishes, genus Diaphus (Pisces, Myctophidae) in the western Pacific, eastern Indian Oceans and the Southeast Asian seas. Bulletin of the Ocean Research Institute, University of Tokyo (10):1-145.

Kısнıмото, H. 1987. A new stargazer, Uranoscopus flavipinnis, from Japan and Taiwan with redescription and neotype designation of U. japonicus. Japanese Journal of Ichthyology 34(1):1-14.

Kotlyar, A. N. 1986. Systematics and distribution of the species of the genus Hoplostethus Cuvier (Beryciformes, Trachichthyidae). Trudy Institute of Oceanology 121:97-140. (In Russian)

MACHIDA, Y. 1990. A new ophidiid species, Hoplobrotula badia, from Sagami Bay, Central Japan. Japanese Journal of Ichthyology 37(3):209-214.

Masuda, H., K, Amaoka, C. Araga, T. Uyeno, and T. Yoshino, 1984. The Fishes of the Japanese Archipelago. Tokai University Press, Tokyo, Japan. Text pp. 1-437; pls. 1-370.

McCosker, J. E. 2010. Deepwater Indo-Pacific species of the snake-eel genus Ophichthus (Anguilliformes: Ophichthidae), with the description of nine new species. Zootaxa (2505):1-39.

McKaY, R. J. 1971. Two new genera and five new species of percophidid fishes (Pisces: Percophididae) from 
Western Australia. Journal of the Royal Society of Western Australia 54(2):40-46.

Mochizuki, K., AND K. Shirakihara. 1983. A new and rare apogonid species of the genus Epigonus from Japan. Japanese Journal of Ichthyology 30(3):199-207.

Morrow , J. E., JR. 1964. Family Stomiatidae. Pages 290-310 in H.B. Bigelow, et al., eds., Fishes of the Western North Atlantic. Memoirs of the Sears Foundation for Marine Research (1)(pt 4).

Nafpaktitis, B. G, R. H. Backus, J. E., Craddock, R. L. Haedrich, B. H. Robison, and C. Karnella. 1977. Family Myctophidac. Pages 13-265 in R.H. Gibbs, Jr., Fishes of the Western North Atlantic. Memoirs of the Sears Foundation for Marine Research (1)(pt. 7).

NaKabo, T. 2000. Fishes of Japan with Pictorial Keys to the Species. Second edition. Tokai University Press, Japan. 2 vol., $1748 \mathrm{p}$.

Nelson, J. S. 1982. Pteropsaron heemstrai and Osopsaron natalensis (Perciformes: Percophidae), new fish species from South Africa, with comments on Squamicreedia obtusa from Australia and on the classification of the subfamily Hemerocoetinae. J. L. B. Sinith Institute of Ichthyology, Special Publication 25:1-11.

Nemeth, D. 1994. Systematics and distribution of fishes of the family Champsodontidae (Teleostei: Perciformes), with descriptions of three new species. Copeia 1994(2):347-371.

Nielsen, J. G. 2009. A revision of the bathyal genus Luciobrotula (Teleostei, Ophidiidae) with two new species. Galathea Report 22:141-156.

Nielsen, J. G, D. M. Cohen, D. F. Markle, and C. R. Robins. 1999. FAO species catalogue. Vol, 18. Ophidiiform Fishes of the World (Order Ophidiiformes). An Annotated and Illustrated Catalogue of Pearlfishes, Cusk-eels, Brotulas and Other Ophidiiform Fishes Known to Date. FAO Fisheries Synopsis (1225) vol. 18. Rome, FAO. 178 pp., 136 figs.

Nielsen, J. G., And Y. Machida. 1988. Revision of the Indo-West Pacific bathyal fish genus Glyptophidium (Ophidiiformes, Ophidiidae). Japanese Journal of Ichthyology 35(3):289-319.

Oкамото, M., AND A. FukUi. 2011. Redescription of a rare deepwater cardinalfish, Epigonus ctenolepis Mochizuki and Shirakihara, 1983, and comparison with related species (Perciformes: Epigonidae). Ichthyological Research 58:388-392.

Okamura, O., And T. Kitajima. 1984. Fishes of the Okinawa Trough and the Adjacent Waters, I. The Intensive Research of Unexploited Fishery Resources on Continental Slopes. Japan Fisheries Resource Conservation Association, $414 \mathrm{p}$.

Parin, N. V., And O. C. Borodulina. 1986. Preliminary review of the benthopelagic fish genus Antigonia Lowe (Zeiformes, Caproidae). Transaction of the P. P. Shirshov Institute of Oceanology 121:141-172.

Parin, N. V., And Y. N. ShCherbachev. 1982. Two new argentinine fishes of the genus Glossanodon from the eastern South Pacific. Japanese Journal of Ichthyology 28(4):381-384.

Paulin, C. D. 1989. Review of the morid genera Gadella, Physiculus, and Salilota (Teleostei: Gadiformes) with descriptions of seven new species. New Zealand Journal of Zoology 16:93-133.

Pietsch, T. W. 1989. Phylogenetic relationships of trachinoid fishes of the family Uranoscopidae. Copeia 1989(2):253-303.

Poss, S. G, ANd W. N. Eschmeyer. 1975. The Indo-West Pacific scorpionfish genus Ocosia Jordan and Starks (Scorpaenidae, Tetraroginae), with description of three new species. Matsya 1: 1-18.

Randall, J. E.,, AND K. K. P. Lim. 2000. A checklist of the fishes of the South China Sea. Pages 569-667 in Peter K. L. Ng, and K. S. Tan, eds., The Biodiversity of South China Sea. The Raffles Bulletin of Zoology, Supplement 8:1-673.

Russell, B. C. 1990. FAO Species Catalogue. Vol. 12. Nemipterid fishes of the world (Threadfin breams, Whiptail breams, Monocle breams, Dwarf monocle breants, and Coral breants). Family Nemipteridae. An annotated and illustrated catalogue of nemipterid species known to date. FAO Fisheries Synopsis (125) 12:1-149, pls. I-VIII. Rome, FAO,

Russell, B. C. 1993. A review of the threadfin breams of the genus Nemipterus (Nemipteridae) from Japan and Taiwan, with description of a new species. Japanese Journal of Ichthyology 39(4):295-310.

Sazonov, Y. I., Y. N. Shcherbachev, And T. Iwamoto. 2003. The grenadier genus Mataeocephalus Berg, 1898 (Teleostei, Gadiformes, Macrouridae), with descriptions of two new species. Proceedings of the 
California Academy of Sciences, ser. 4, 54(17):279-301.

SHao, K. T. 2014. The Fish Database of Taiwan. http://fishdb.sinica.edu.tw

ShCherbacheV, Y. N., AND T. Iwamoto. 1995. Indian Ocean grenadiers of the subgenus Coryphaenoides, genus Coryphaenoides (Macrouridae, Gadiformes, Pisces). Proceedings of the California Academy of Sciences, ser. 4, 48 (14):285-314.

Schultz, L. P. 1964. Family Sternoptychidae. Pages 241-27 in H.B. Bigelow, et al., eds., Fishes of the western North Atlantic. Memoirs of the Sears Foundation for Marine Research (1)(pt. 4).

Shibukawa, K., AND Y. Aonuma. 2007. Three new species of the deep-dwelling goby genus Obliquogobius (Perciformes: Gobiidae: Gobiinac) from Japan, with comments on the limits of the genus. Bulletin of the National Museum of Nature and Science (Ser. A), Supplement 1:137-152.

Sмiтн, D. G. 1989. Family Congridae. Pages 460-567 in E.B. Böhlke, ed., Fishes of the Western North Atlantic. Orders Anguilliformes and Saccopharyngiformes, vol. 1. Memoirs of the Sears Foundation for Marine Research, (1)(pt. 4).

Sмiтh, D. G. 1994. Catalog of type specimens of Recent fishes in the National Museum of Natural History, Smithsonian Institution 6: Anguilliformes, Saccopharyngiformes, and Notacanthiformes (Teleostei: Elopomorpha). Smithsonian Contributions to Zoology (566):i-iii + 1-50.

Smith, D. G., AND G. D. Johnson. 2007. A new species of Pteropsaron (Teleostei: Trichonotidae: Hemerocoetinae) from the western Pacific, with notes on related species. Copeia 2007(2): 364-377.

Smith, D. G., ANd J. T. Williams. 1999. The great Albatross Philippine Expedition and its fishes. Marine Fisheries Review, 61(4):31-41.

STARNES, W. C. 1988. Revision, phylogeny, and biogeographic comments on the circumglobal marine percoid fish family Priacanthidae. Bulletin of Marine Science 43(2):117-203.

SULAK, K. L. 1977. Aldrovandia oleosa, a new species of the Halosauridae, with observations on several other species of the family. Copeia 1977(1):11-20.

Sulak, K. L. 1986. Family No. 53: Halosauridae. Pages 196-197 in m. M. Smith and P. C. Heemstra, eds., Smith's Sea Fishes. Macmillan South Africa, Johannesburg, Soutgh Africa. 1047 pp.

SUMIDA, S., AND Y. MACHIDA. 2000. Revision of the two sympatric snake-eel species of the genus Ophichthus (Ophichthidae, Angilliformes) from Tosa Bay, southern Japan, with comments on O. tsuchidae. Bulletin of Marine Sciences and Fisheries, Kochi University 20:51-69 (In Japanese, English summary).

SuzuKI, T., AND T. NAKabo. 1996. Revision of the genus Acanthaphrities (Percophidae) with the description of a new species. Ichthyological Research 43(4):441-454.

Temminck, C., ANd H. Schlegel. 1846. Pisces. Pages 173-269 in P. F. von Siebold, ed., Fauna Japonica (pt. 5). Lugduni Batavorum, Leiden, Netherlands.

Thompson, B. A., And R. D. Suttkus. 2002. A revision of Indo-Pacific Benbrops, family Percophidae (suborder Trachinoidei). Marine and Freshwater Research 53(2):283-295.

WISNER, R. L. 1976. The taxonomy and distribution of lanternfishes (family Myctophidae) of the eastern Pacific Ocean. U.S. Navy Ocean Research Development Activity, NORDA Report 3: 1-299.

Yeh, H.-M., M.-Y. LeE, AND K.-T. Shao. 2005. Fifteen Taiwanese new records of ophidiid fishes (Pisces: Ophidiidae) collected from the deep waters by the RV Ocean Researcher I. Journal of the Fisheries Society of Taiwan 32(3):279-299. 


\title{
Images of Fishes Collected During the HEPD Deep-Water Cruise of the M/V DA-BFAR
}

\author{
All images are based on freshly \\ preserved specimens. \\ Photographs by David Catania \\ unless otherwise stated.
}




\section{Plate I}

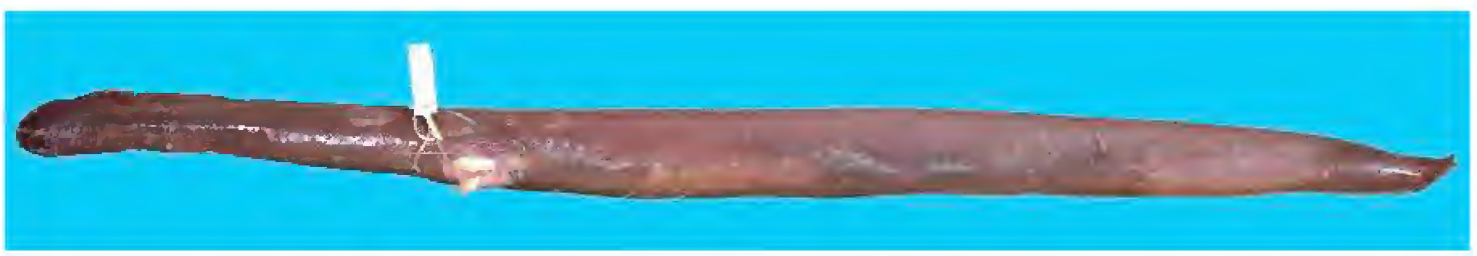

Figure 5. Myxine cf. formosana, CAS 233680, $440 \mathrm{~mm}$ TL.

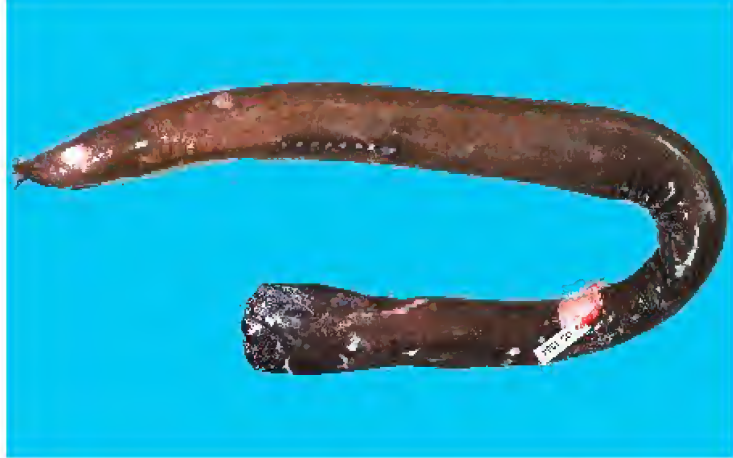

FIGURE 6. Eptatretus luzonicus, CAS 233675, $563 \mathrm{~mm}$ TL.

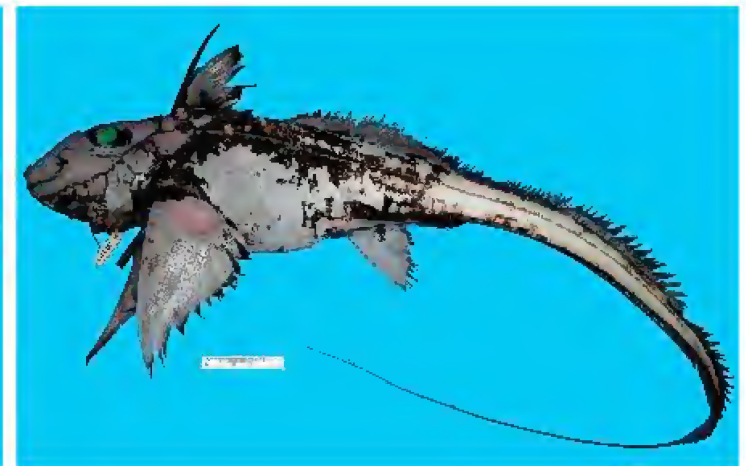

FIGURE 7. Hydrolagus deani, CAS 235485, $730 \mathrm{~mm}$ TL.

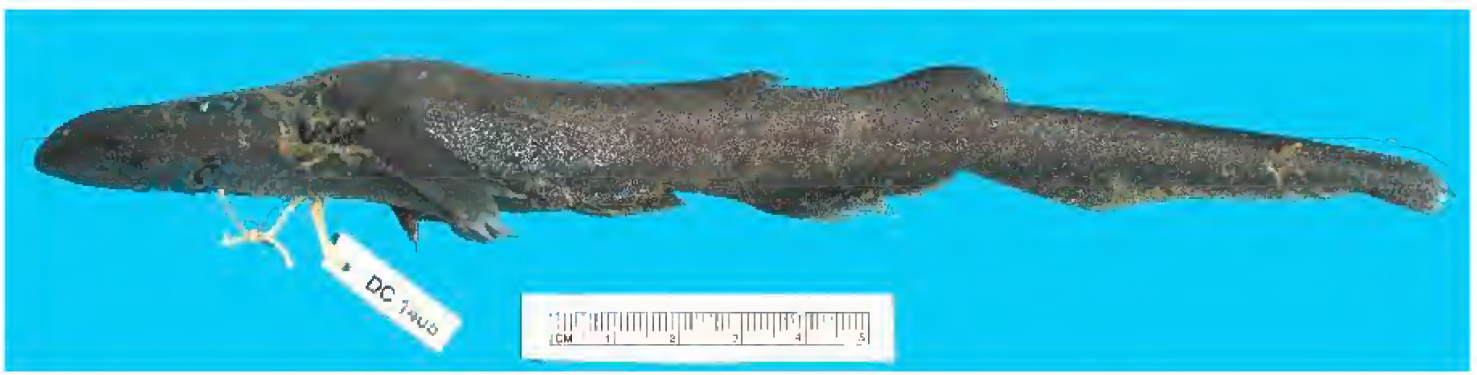

FIGURE 8a. Apristurus platyrhynchus, CAS 234027, 225 mm TL.

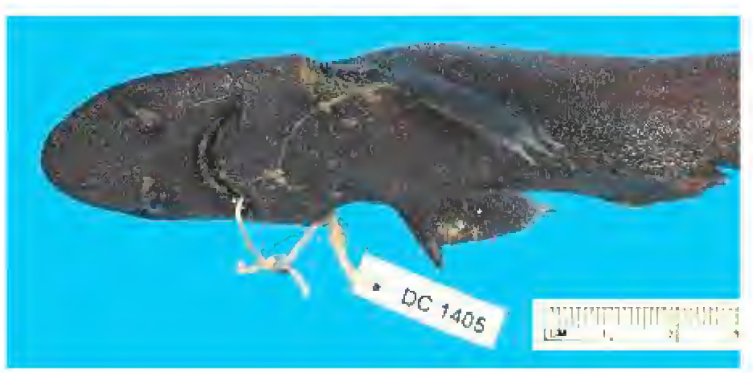

FIGURE 8b. Apristurus platyrhynchus CAS 234027 , $225 \mathrm{~mm}$ TL. 


\section{Plate II}

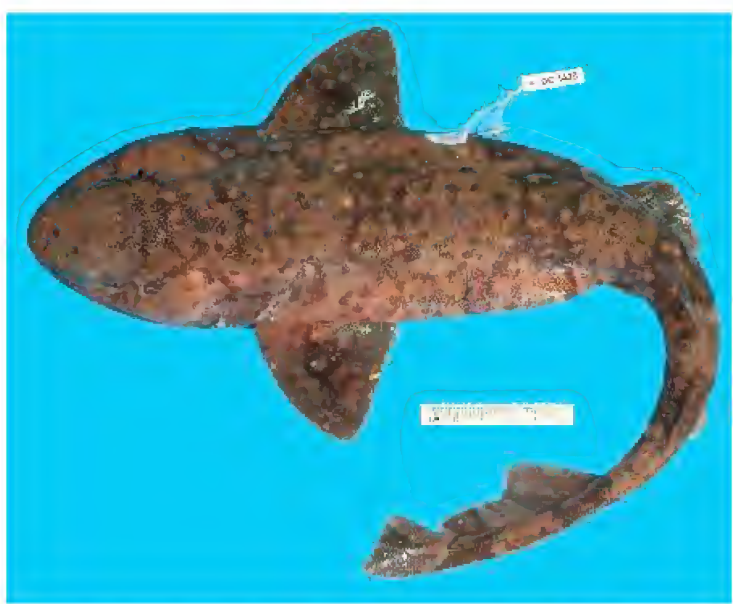

Figure 9a. Cephaloscyllium sp, CAS uncat., female, $625 \mathrm{~mm}$ TL., dorsal view.

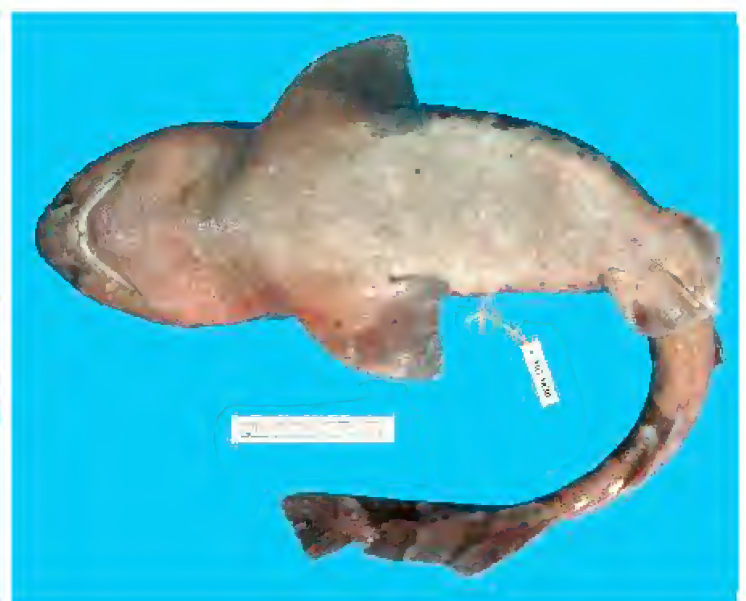

FIGURE 9b. Cephaloscyllium sp, CAS uncat., female, $625 \mathrm{~mm}$ TL., ventral view.

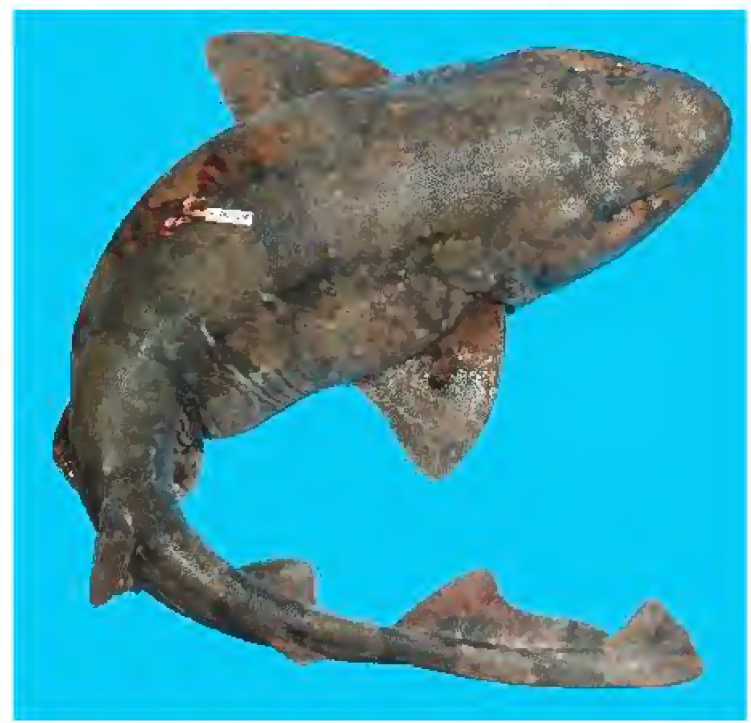

Figure 9c. Cephaloscyllium sp, CAS uncat., immature male, $395 \mathrm{~mm}$ TL.

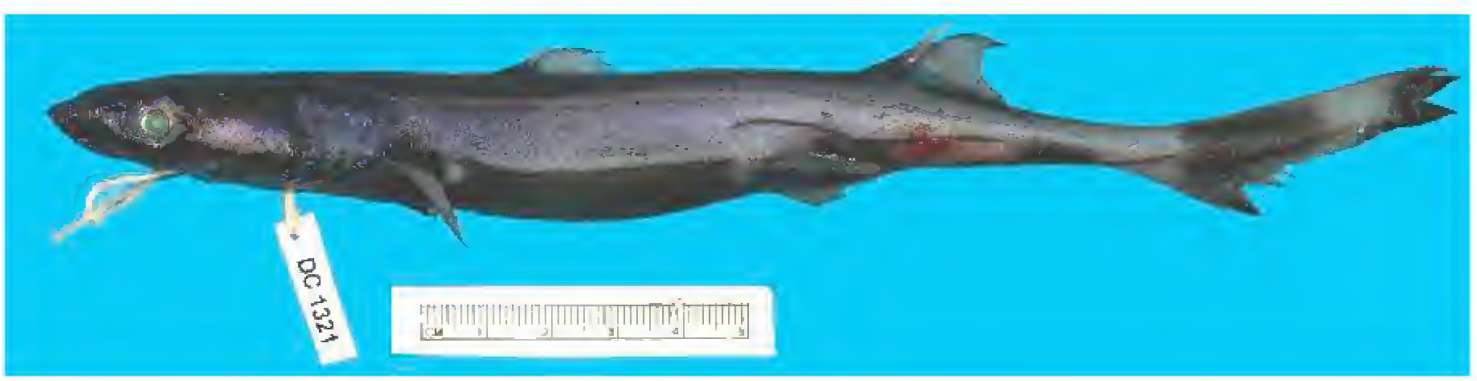

FigURE 10. Etmopterus brachyurus, CAS 233994, 203 mm TL. 


\section{Plate III}

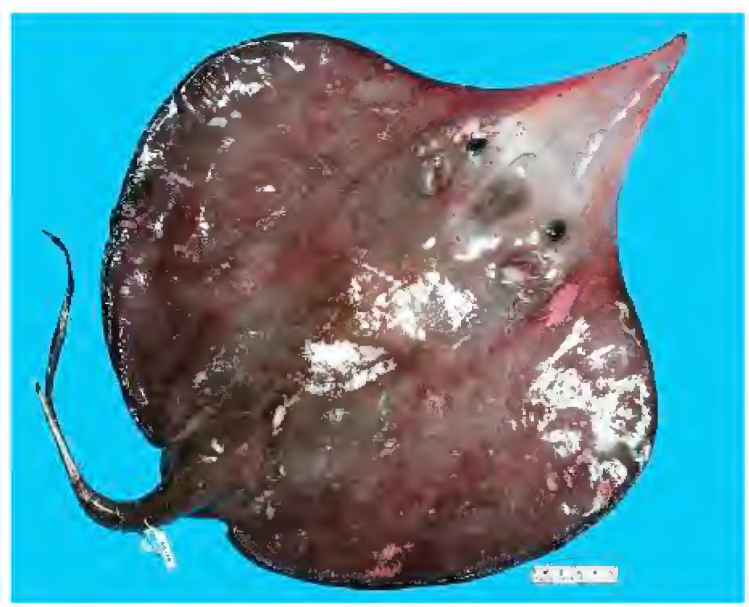

FIGURE 11. Hexatrygon bickelli, CAS 233779, 620 mm TL.

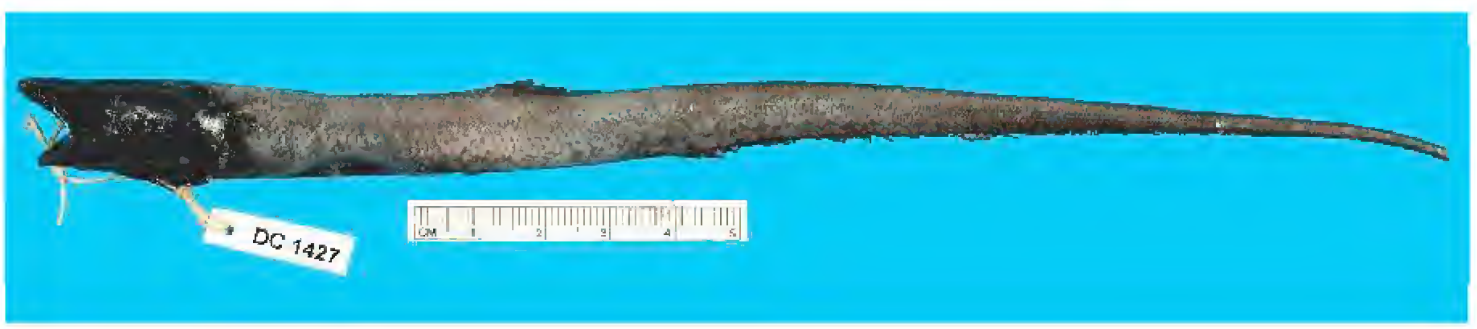

FIGURE 12. Aldrovandia phalacra, CAS 236021, 213+ mm TL.

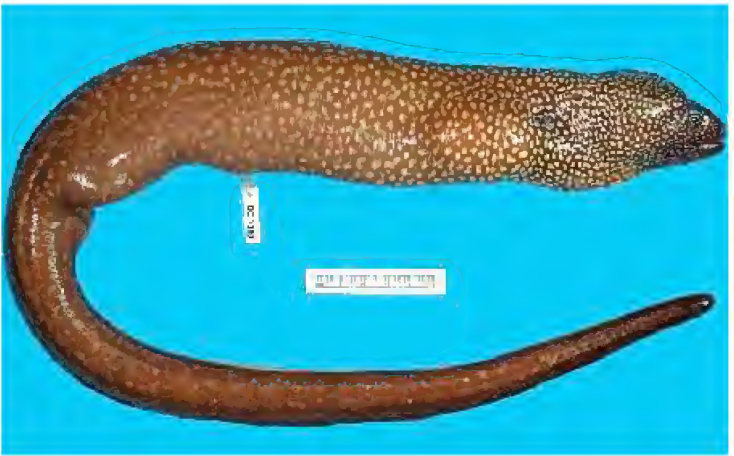

FIGURE 13. Gymnothorax cf. johnsoni, CAS 236625 , $440 \mathrm{~mm}$ TL.

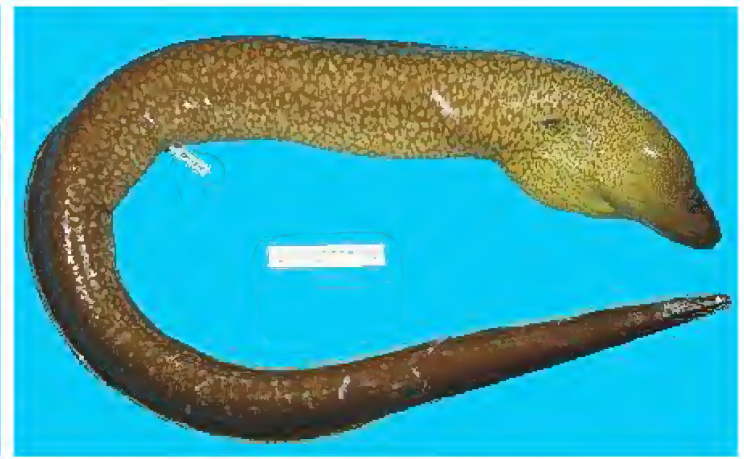

FIGURE 14. Gymnothorax cf. nuttingi, CAS 236626, $748 \mathrm{~mm}$ TL 


\section{Plate IV}

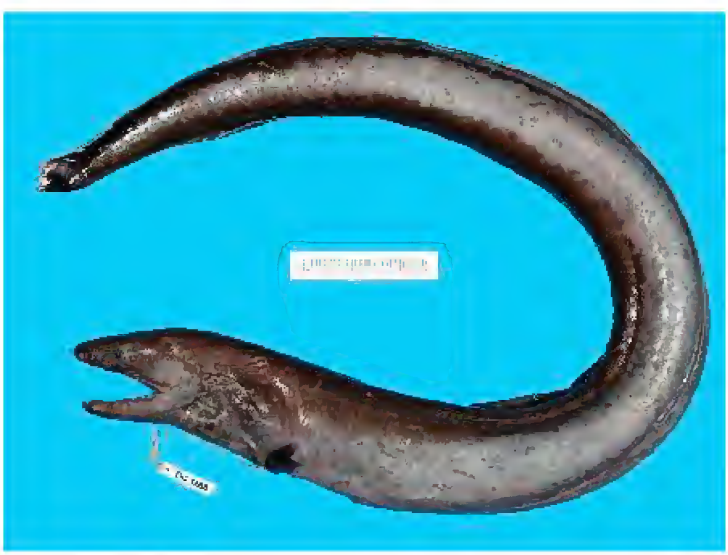

Figure 15. Dysomma anguillare, CAS 235128, $557 \mathrm{~mm}$ TL.

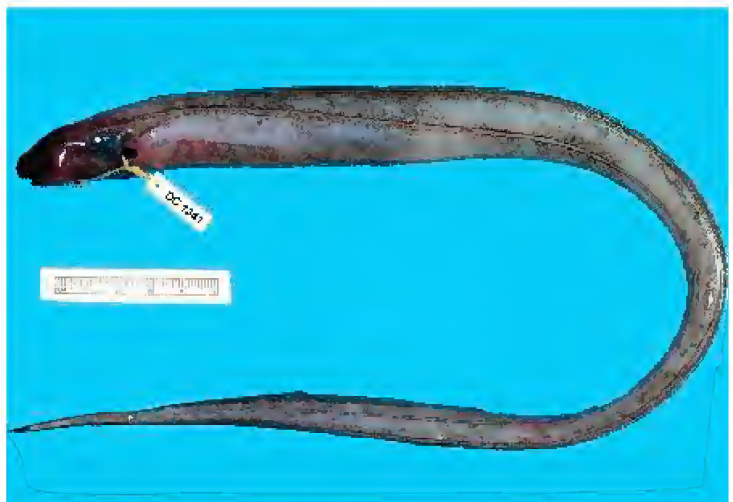

FIGURE 17a. Simenchelys parasitica, CAS 235457, $463 \mathrm{~mm}$ TL, lateral view.

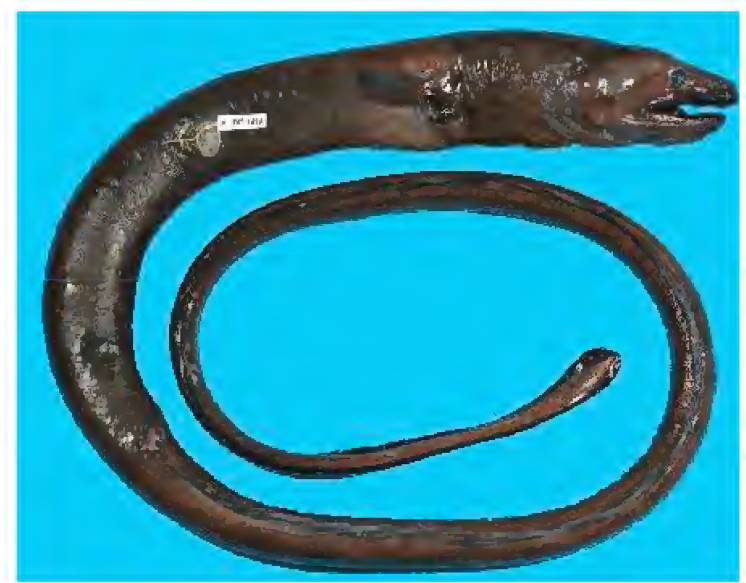

FIGURE 18. Pylorobranchus hearstorum, CAS 235464 , holotype, $1218 \mathrm{~mm}$ TL.

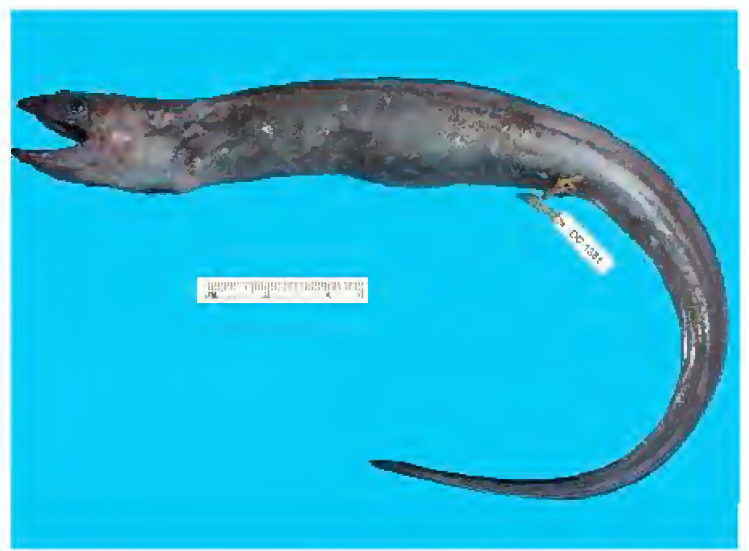

FIGURE 16. Synaphobranchus kaupii, CAS 235497, $365 \mathrm{~mm}$ SL.

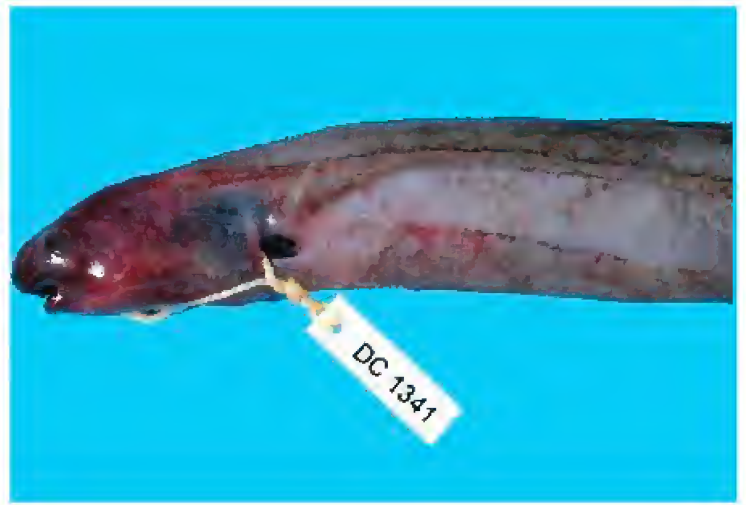

FIGURE 17b. Simenchelys parasitica, CAS 235457 , $463 \mathrm{~mm}$ TL, head and trunk.

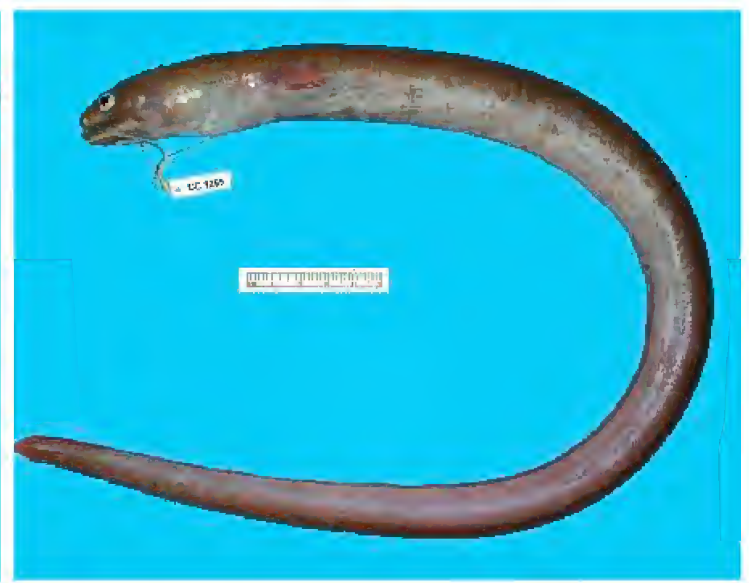

FIGURE 19. Ophichthus $\mathrm{cf}$. urolophus, CAS 236638 , $570 \mathrm{~mm} \mathrm{TL}$ 


\section{Plate V}

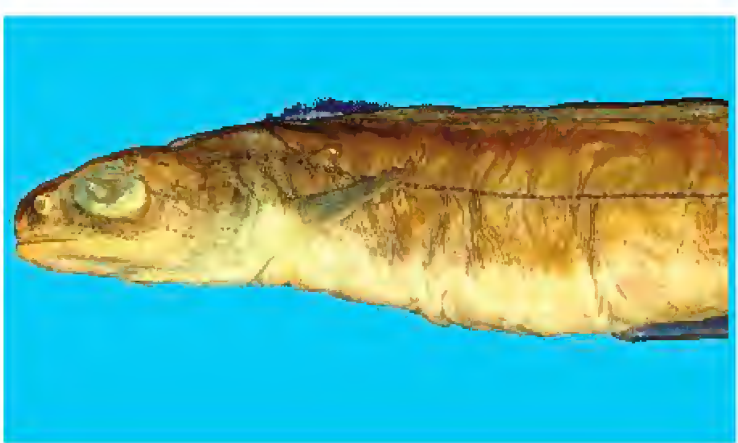

FIGURE 20. Coloconger scholesi, CAS 235482, $365 \mathrm{~mm}$ SL. Photo by John E. McCosker

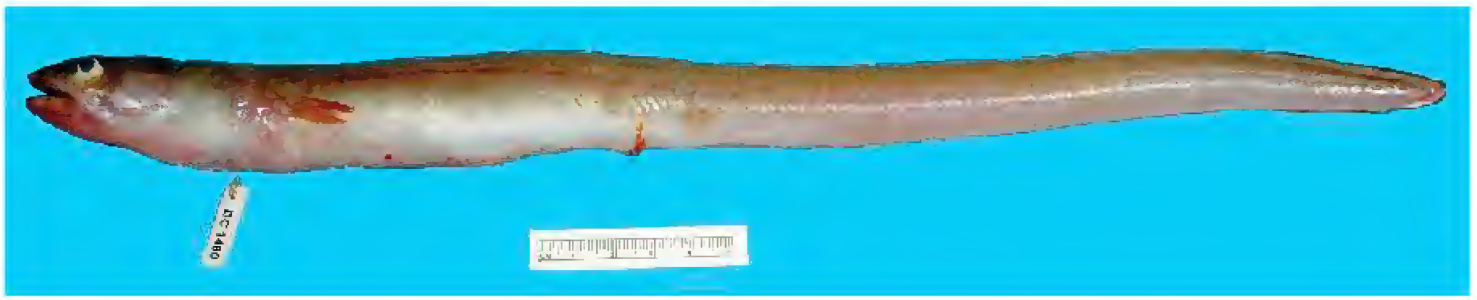

FIGURE 21. Ariosoma anago, CAS 235453, $363 \mathrm{~mm} \mathrm{TL}$.

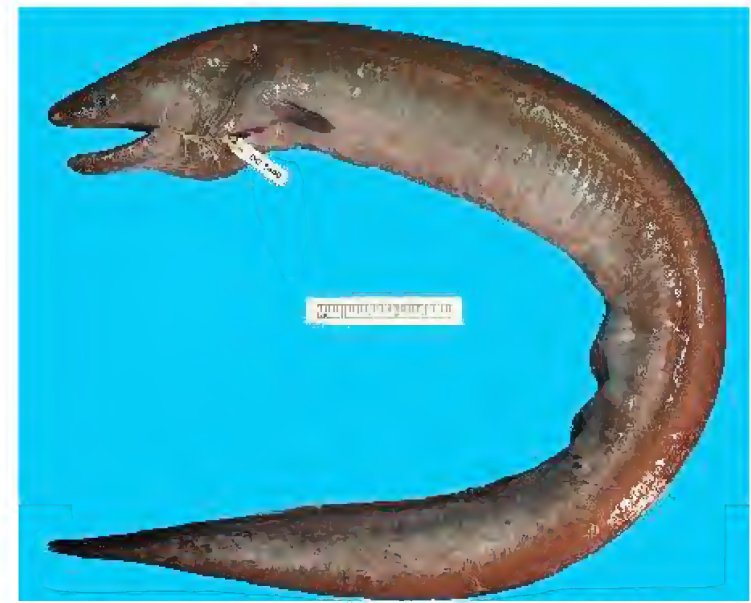

FIGURE 22. Conger macrocephalus, CAS 236634, $378 \mathrm{~mm}$ TL.

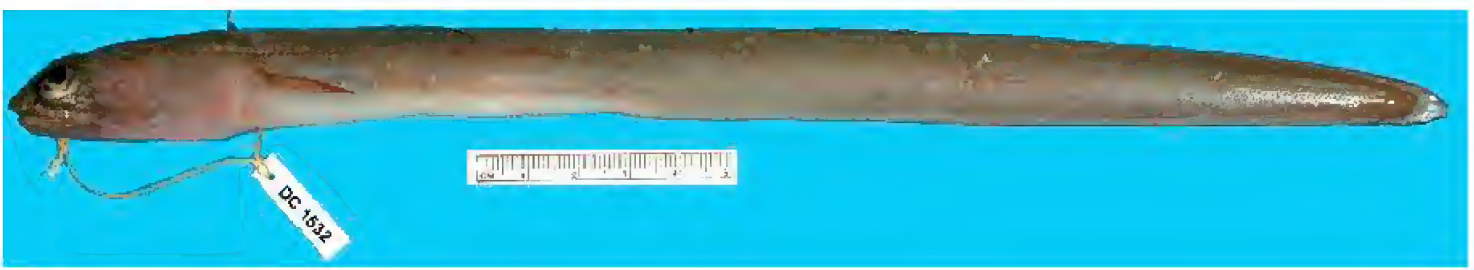

FIGURE 23. Parabathymyrus brachyrhynchus, CAS 235589, 268 mm TL. 


\section{Plate VI}

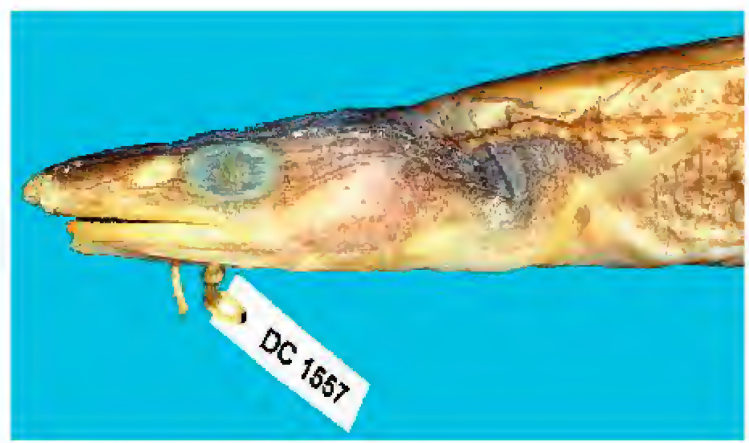

FIGURE 24. Bathycongrus guttulatus, CAS 235634, $417 \mathrm{~mm}$ TL. Photo by John E. McCosker.

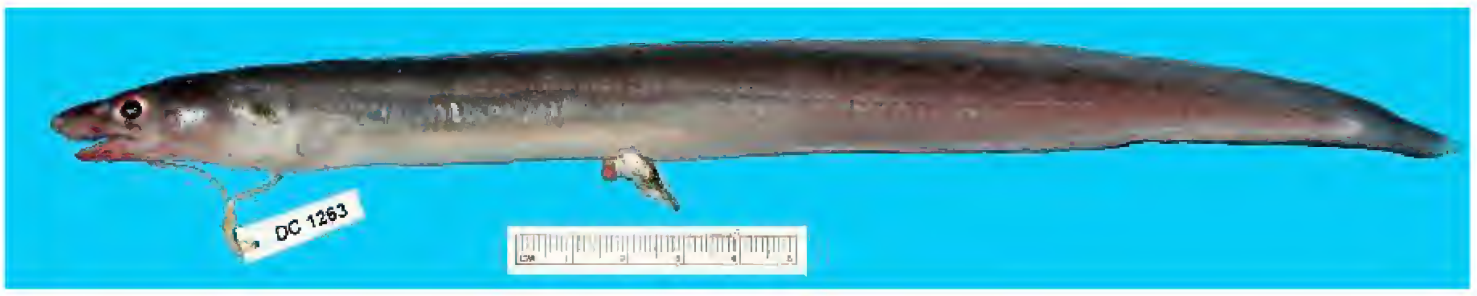

FIGURE 25. Bathycongrus retrotinctus, CAS 235456, $360 \mathrm{~mm}$ TL.

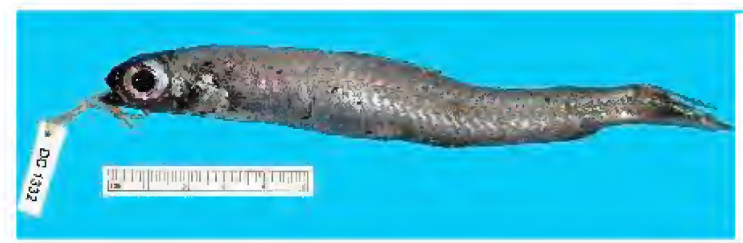

FIGURE 26. Nansenia ardesiaca, CAS 234013, $135 \mathrm{~mm}$ SL.

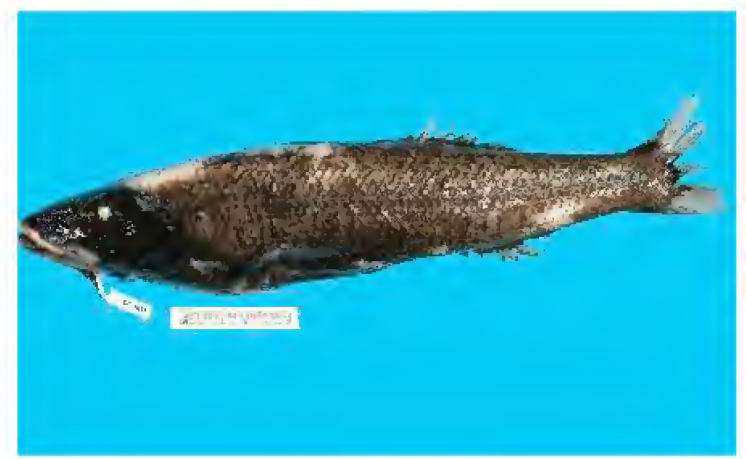

FIGURE 28. Narcetes kamoharai, CAS 235450, $276 \mathrm{~mm}$ SL.

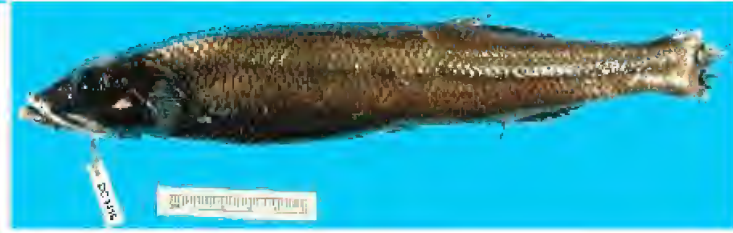

FIGURE 27. Bajacalifornia erimoensis, CAS 235451, $232 \mathrm{~mm}$ SL.

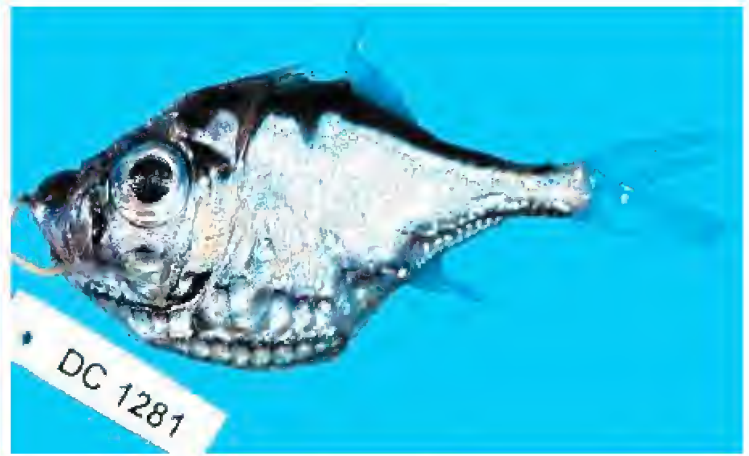

FIgURE 29. Polyipnus spinifer, CAS 233991, $46.8 \mathrm{~mm}$ SL. 


\section{Plate VII}

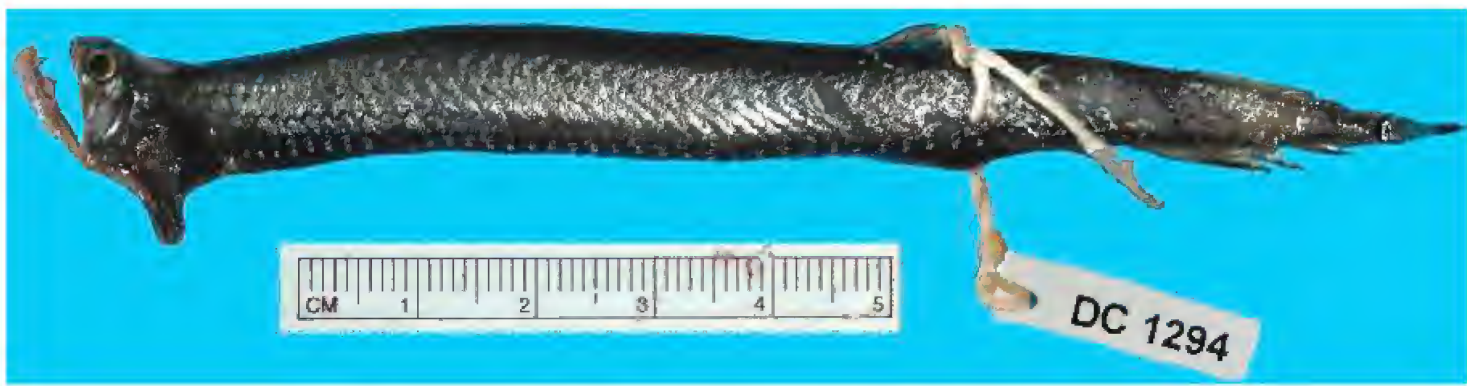

FIGURE 30. Stomias nebulosus, CAS 233992, 106 mm SL.

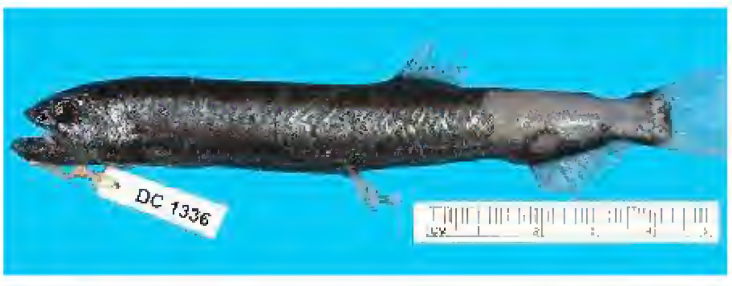

FigurE 31. Astronesthes ijimai, CAS 25379, $107 \mathrm{~mm}$ SL.

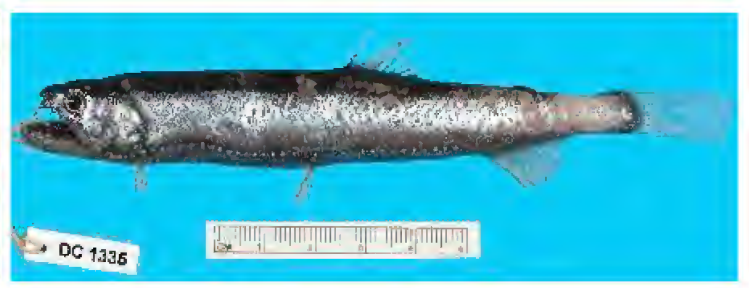

FIGURE 32. Astronesthes lucifer, CAS 235257, $119 \mathrm{~mm}$ SL.

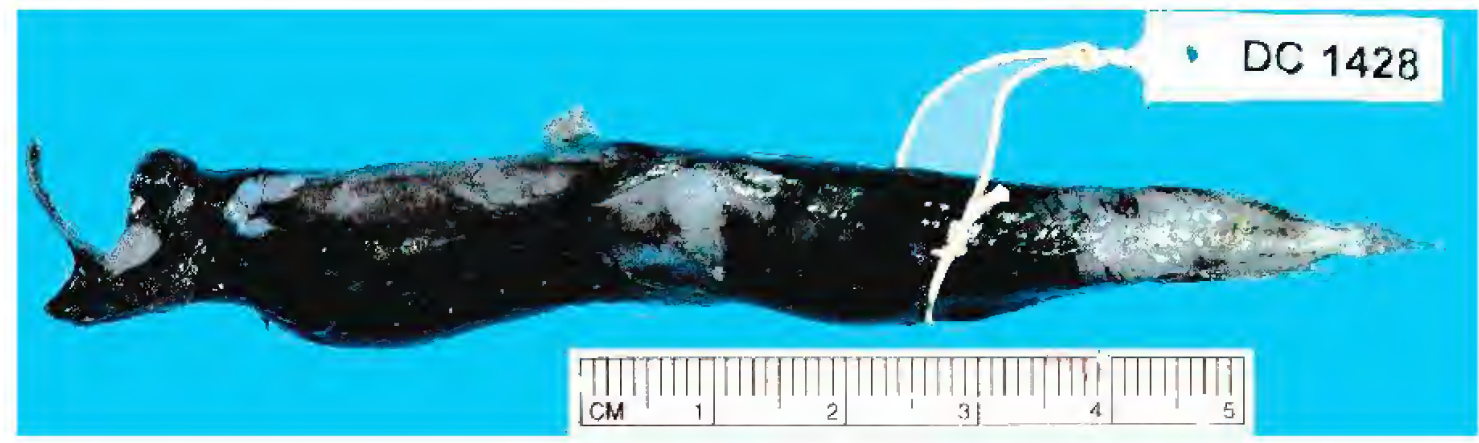

FIGURE 33. Photonectes albipennis, CAS 235547, $82.7 \mathrm{~mm}$ SL.

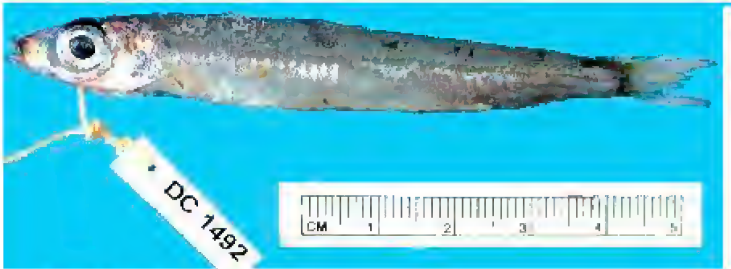

Figure 34. Glossanodon sp., CAS 236020, $77 \mathrm{~mm} \mathrm{SL.}$

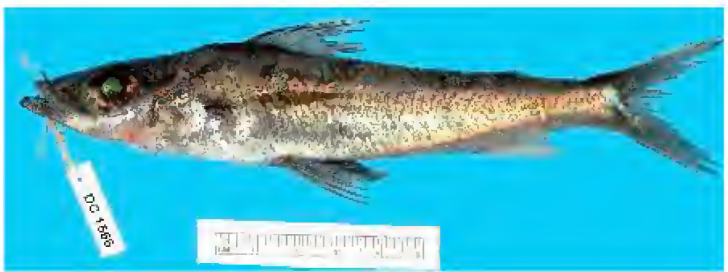

FIGURE 36. Chlorophthalmus acutifrons, CAS 235821, $134 \mathrm{~mm}$ SL.

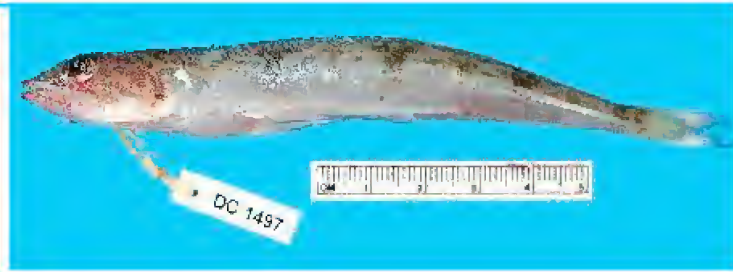

FIGURE 35. Synodus oculeus, CAS 236488, $135 \mathrm{~mm}$ SL.

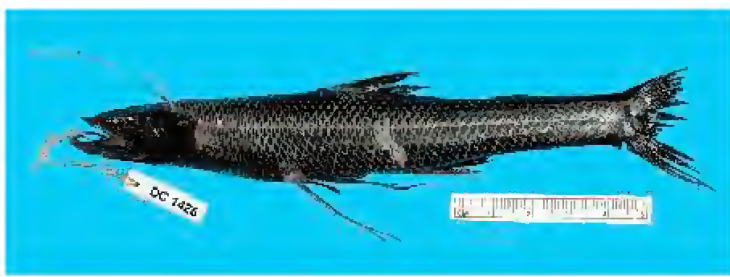

FIGURE 37. Bathypterois atricolor, CAS 2355479 , $150 \mathrm{~mm} \mathrm{SL}$. 


\section{Plate VIII}

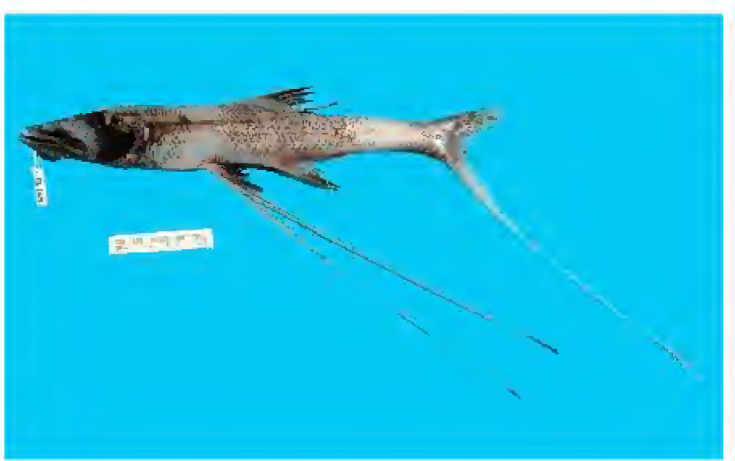

FIGURE 38. Bathypterois guentheri, CAS 235452, $226 \mathrm{~mm}$ SL.

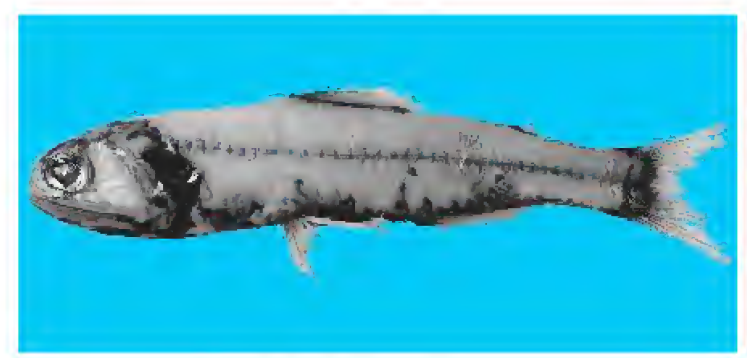

FIGURE 40. Diaphus adenomus, CAS 236623, $153 \mathrm{~mm}$ SL. Photo by Tomio Iwamoto

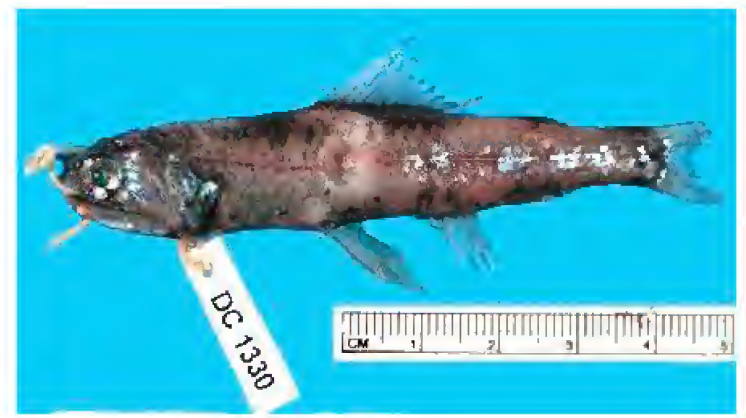

FIGURE 42. Diaphus suborbitalis, CAS 234003 , $71.3 \mathrm{~mm} \mathrm{SL}$.

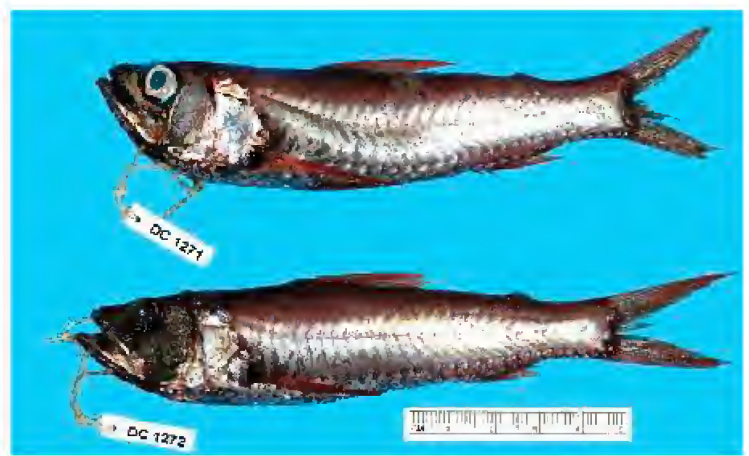

FIGURE 39. Neoscopelus microchir, CAS 235504 , 114.5 and $115.0 \mathrm{~mm}$ SL.

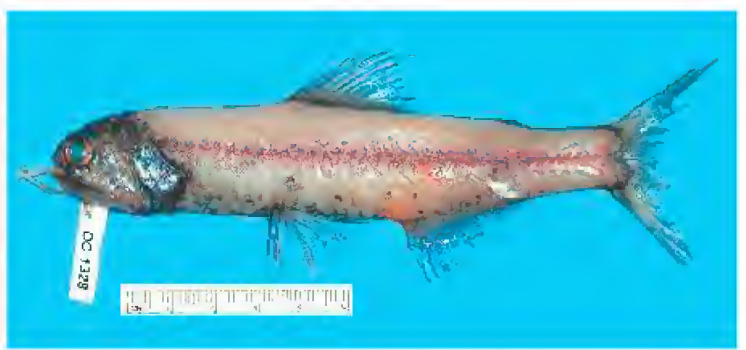

FigURE 41. Diaphus fragilis, CAS 233999, 123 mm SL.

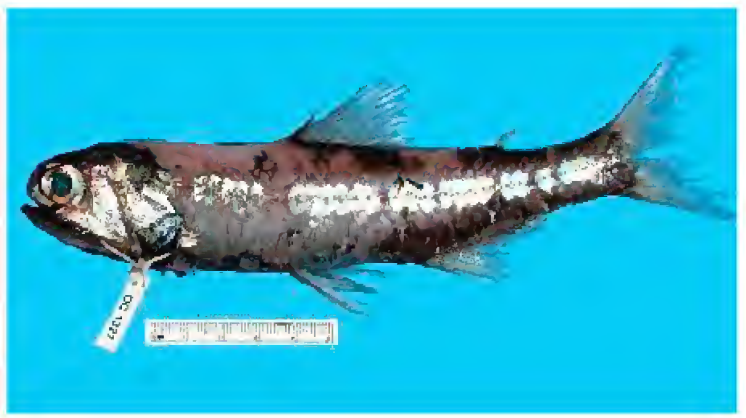

FIGURE 43. Diaphus watasei, CAS 233899 , $156 \mathrm{~mm} \mathrm{SL}$.

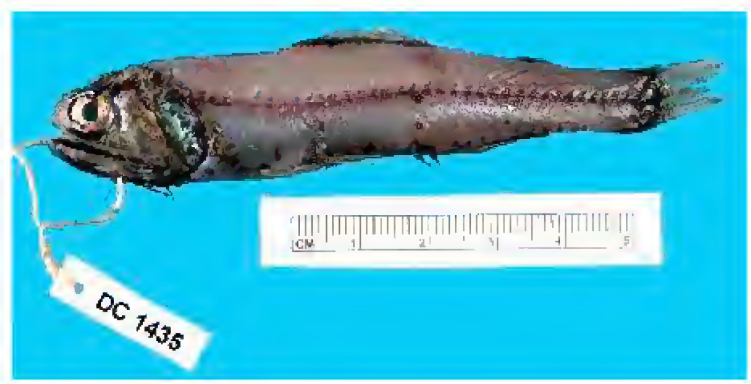

Figure 44. Diaphus sp., CAS 236509, 83.5 mm SL. 


\section{Plate IX}

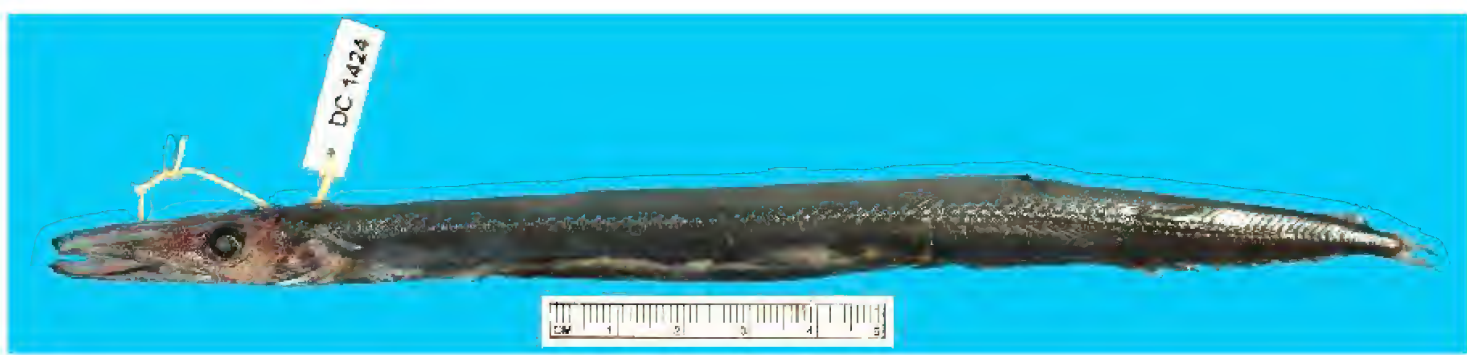

FIGURE 45. Paralepididae, CAS 236706, 196 mm SL.

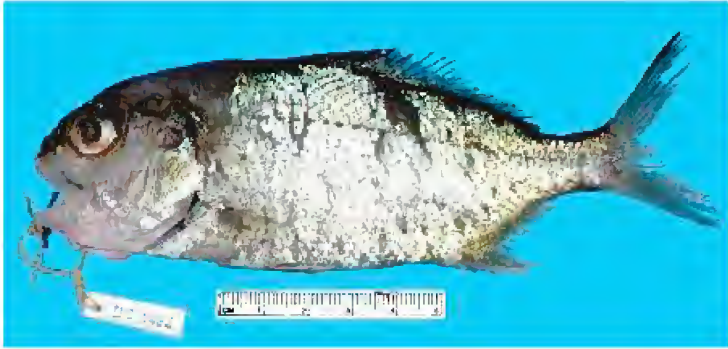

FIgURE 46. Polymixia berndti, CAS 235791, $125 \mathrm{~mm}$ SL.

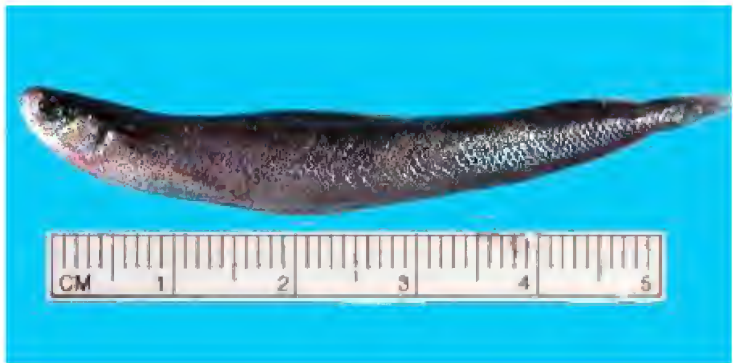

FIGURE 48. Bregmaceros japonicus, CAS 236708, $55 \mathrm{~mm} \mathrm{SL}$.

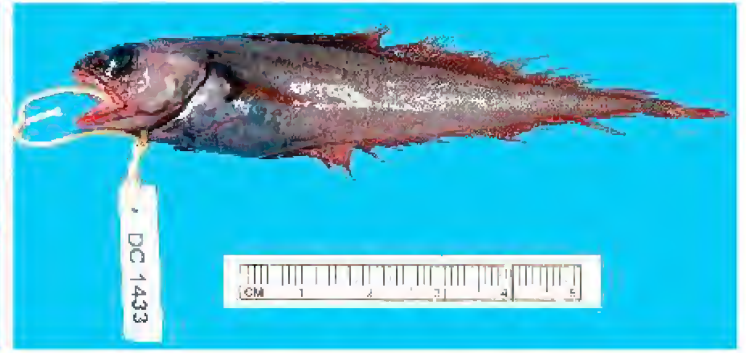

FIGURE 47. Physiculus rhodopinnis, CAS 235782 , $85.0 \mathrm{~mm}$ SL.

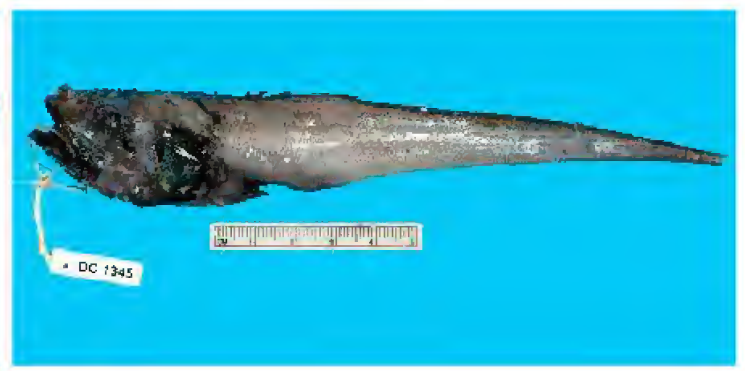

FIGURE 49. Bathygadus entomelas, CAS 233811, $178+\mathrm{mm}$ TL.

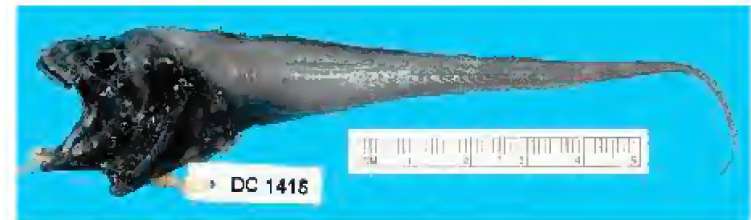

FIGURE 50. Bathygadus spongiceps, CAS 236494 , $131+\mathrm{mm} \mathrm{TL}$

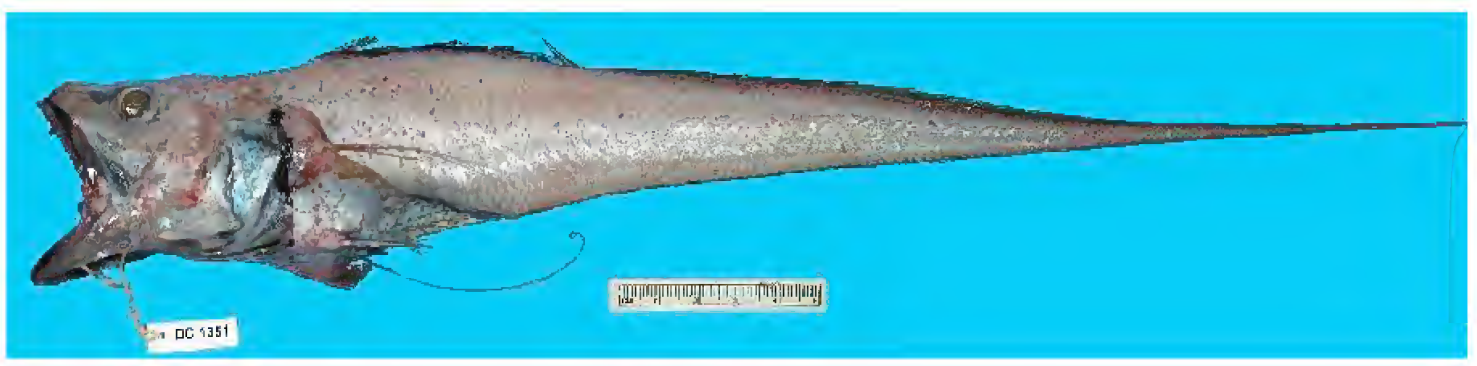

FIGURE 51. Gadomus multifilis, CAS 235518, 294+ mm TL. 


\section{Plate X}

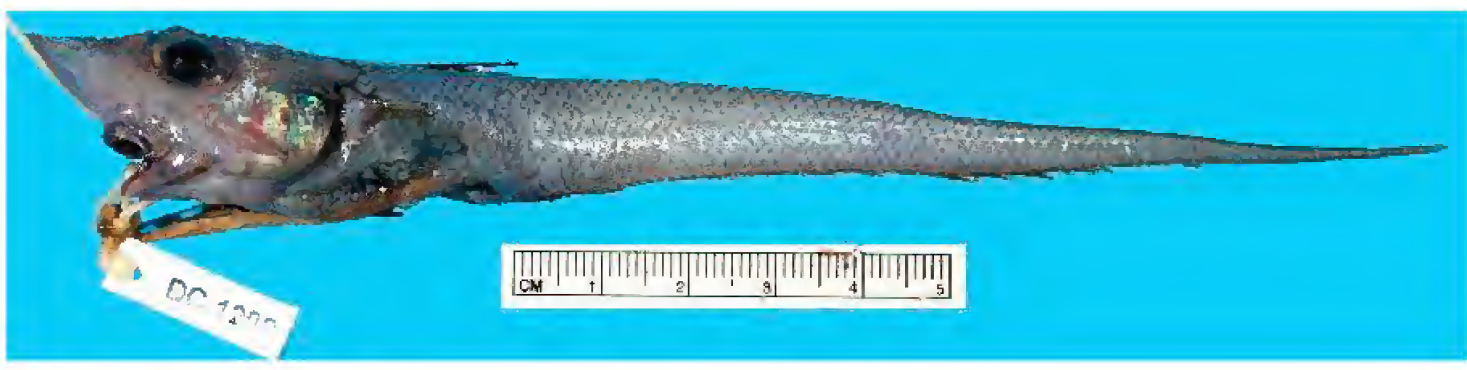

FIGURE 52. Coelorinchus acantholepis, CAS 233993, $160 \mathrm{~mm}$ TL.

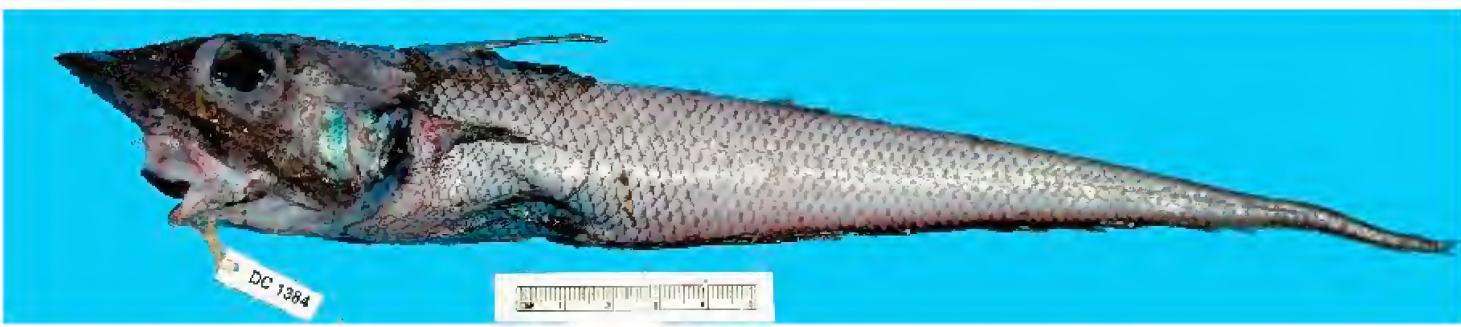

FIGURE 53a. Coelorinchus carinifer, CAS 235516, 287+ mm TL, lateral view.

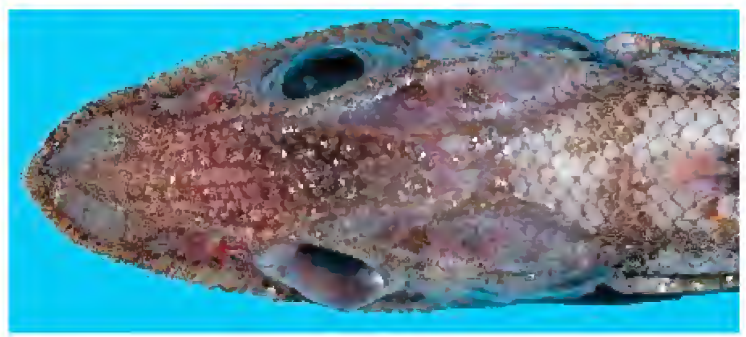

FIGURE 53a. Coelorinchus carinifer, CAS 235516, $287+\mathrm{mm}$ TL, dorsal view of head.

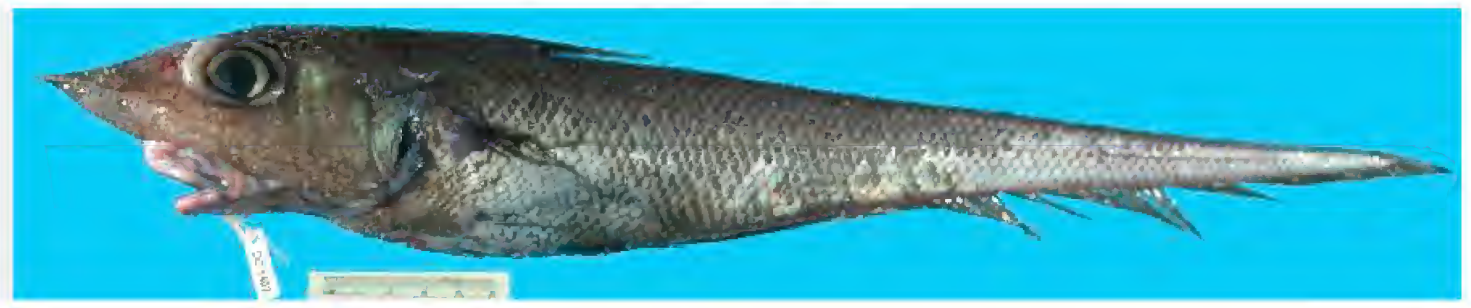

FIGURE 54. Coelorinchus smithi, CAS 235519, 431+mm TL.

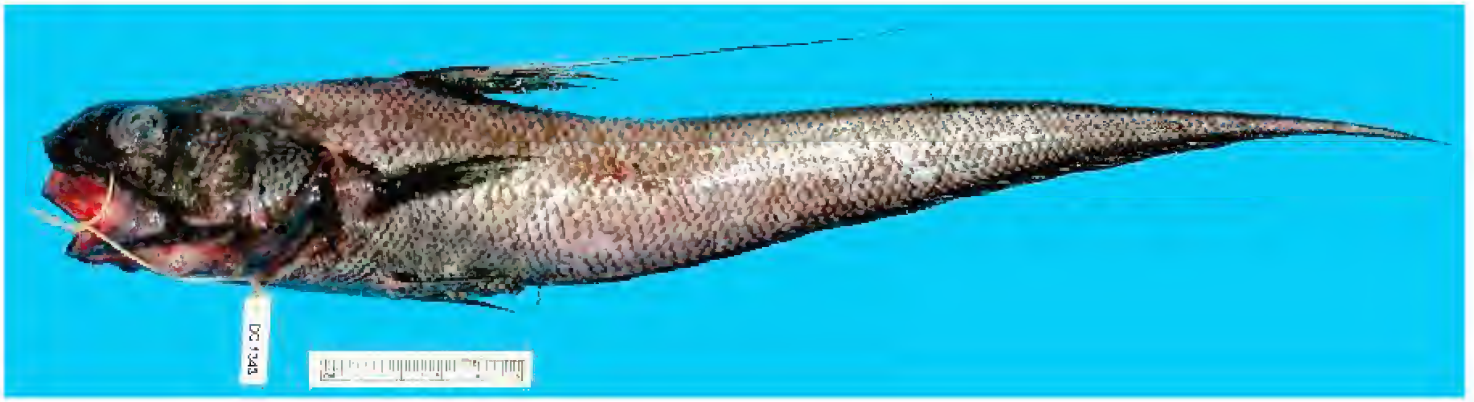

FIGURE 55. Coryphaenoides microps, CAS 235552, 332+ mm TL. 


\section{Plate XI}

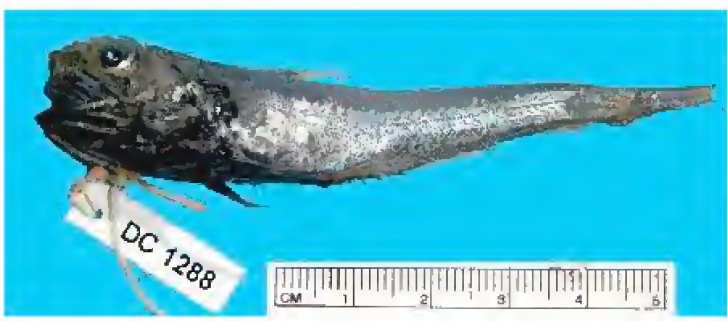

FiguRE 56. Hymenocephalus nascens, CAS 233942 , $85+\mathrm{mm}$ TL.

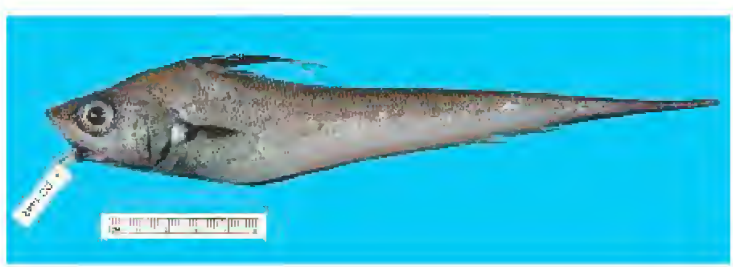

Figure 58. Nezumia spinosa, CAS 235798, 220+ mm TL.

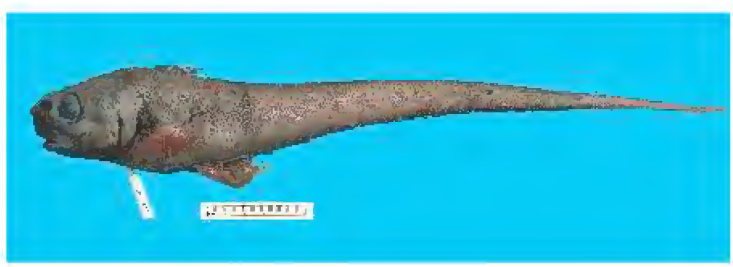

FIGURE 60. Trachonurus villosus, CAS 235503, $345 \mathrm{~mm}$ TL.

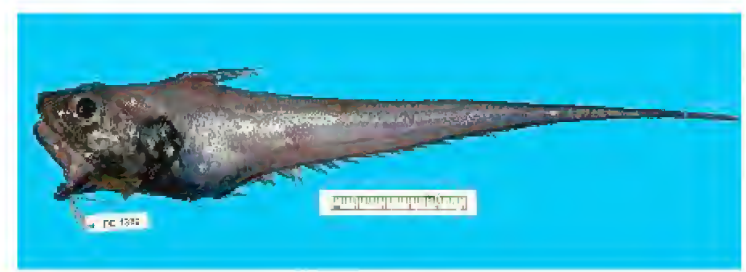

FIGURE 62. Ventrifossa saikaiensis, CAS 235515, 287+ mm TL.

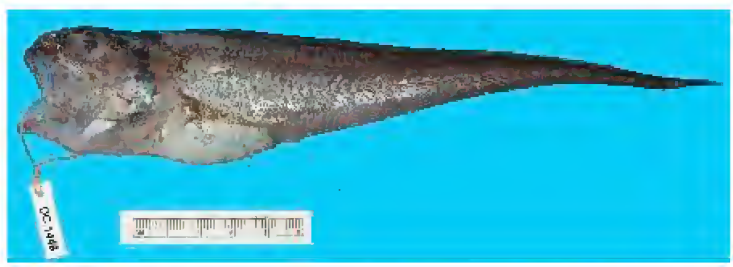

FIGURE 64. Glyptophidium lucidum, CAS 235801, $188 \mathrm{~mm}$ SL.

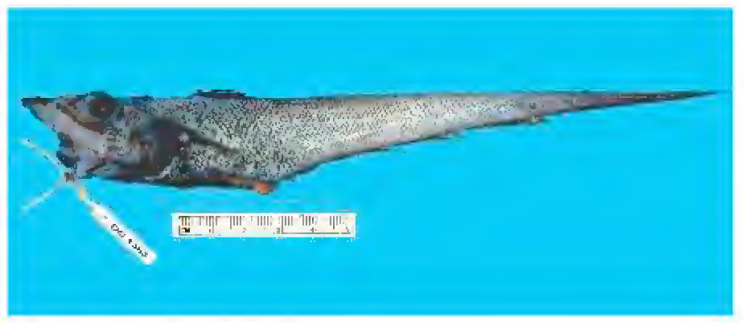

FIGURE 57. Mataeocephalus cristatus, CAS 234020, $210 \mathrm{~mm}$ TL.

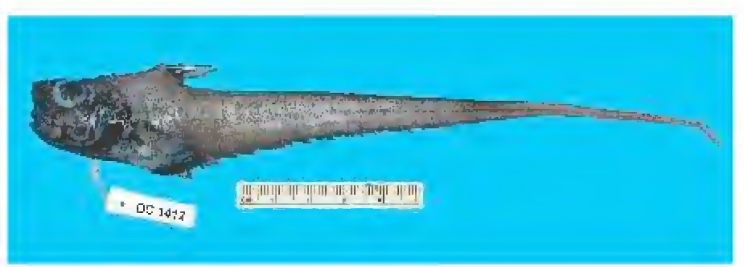

FIGURE 59. Sphagemacrurus pumiliceps, CAS 235732 , $187+\mathrm{mm}$ TL

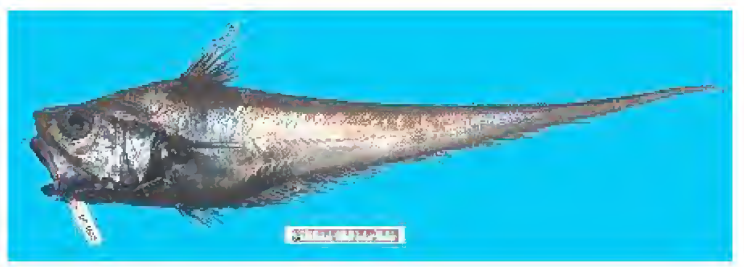

FIGURE 61. Ventrifossa longibarbata, CAS 236398, $310+\mathrm{mm}$ TL.

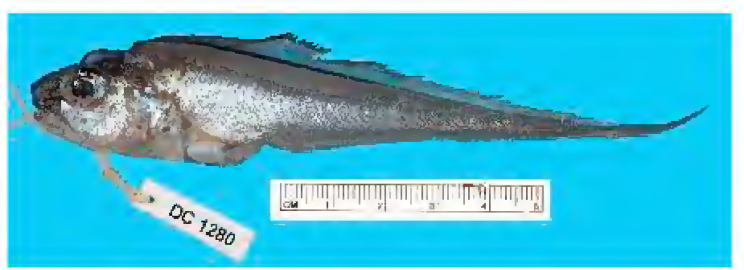

FIGURE 63. Glyptophidium japonicum, CAS 233982, $123 \mathrm{~mm}$ SL.

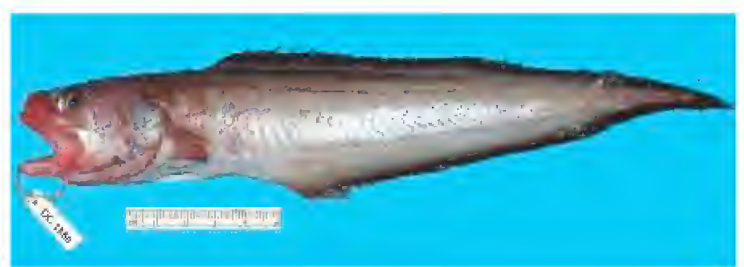

FIGURE 65. Hoplobrotula armata, CAS 235795 , 207 mm SL. 


\section{Plate XII}

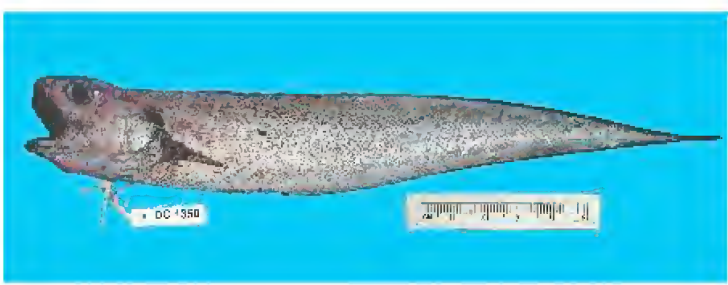

FIGURE 66. Monomitopus pallidus, CAS 234014, $207 \mathrm{~mm} \mathrm{SL}$.

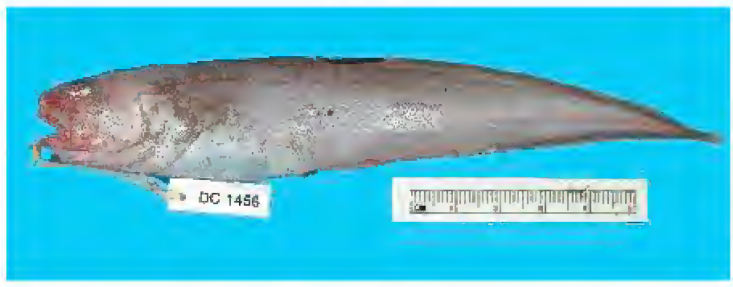

FIGURE 68. Neobythites unimaculatus, CAS 235745, $137 \mathrm{~mm} \mathrm{SL}$

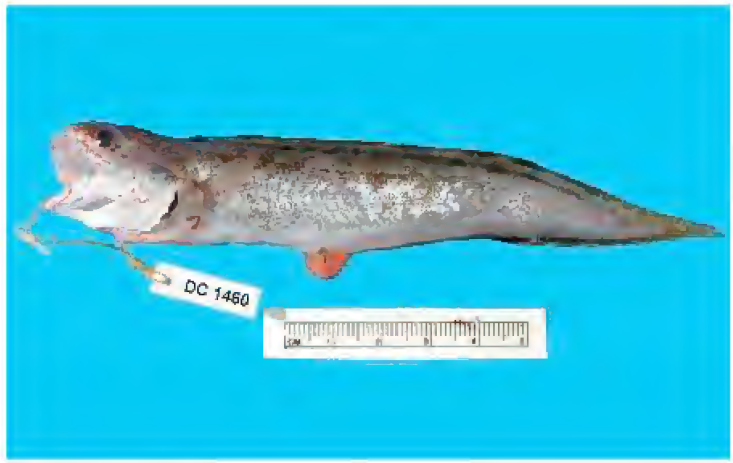

FIGURE 70. Sirembo imberbis, CAS 235742 , 124-125 mm SL.

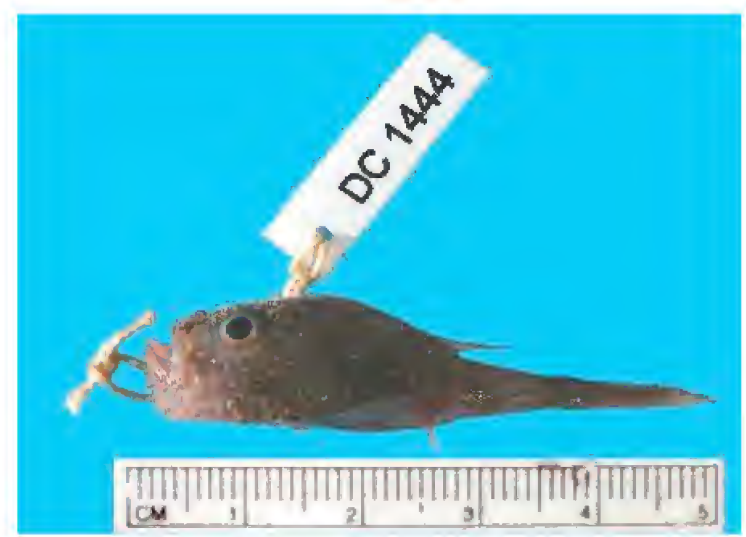

FIGURE 72a. Chaunax sp. 1, CAS 235683, $33.2 \mathrm{~mm}$ SL., lateral view

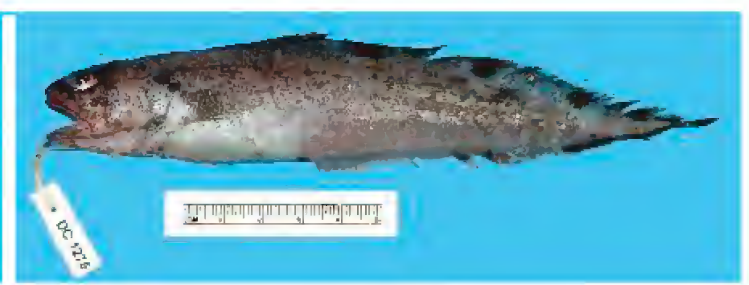

FIGURE 67. Neobythites macrops, CAS235255, $151 \mathrm{~mm}$ SL.

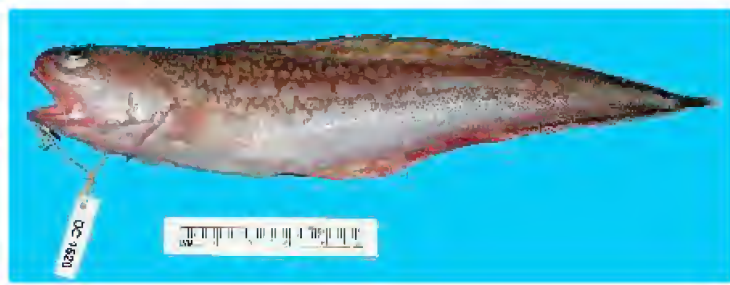

FigURE 69. Neobythites sivicola, CAS 235480, 166 mm SL.

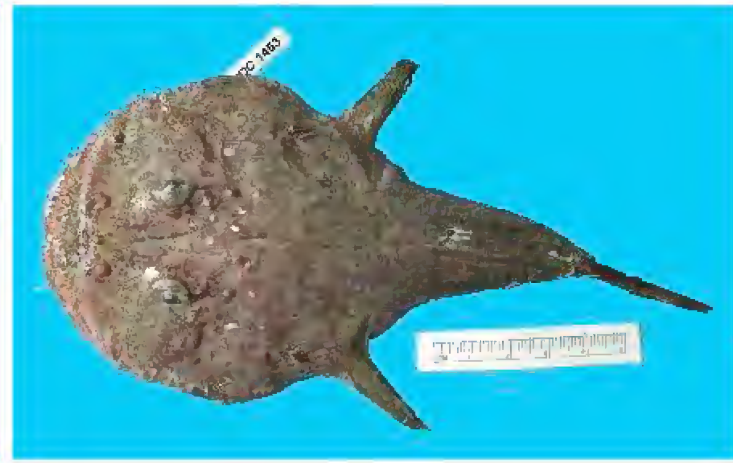

FIGURE 71. Lophiomus setigerus, CAS 236404, 142 mm SL.

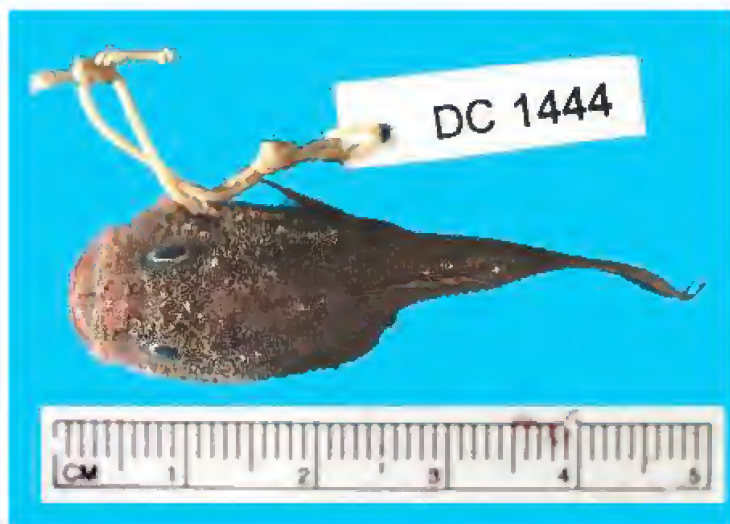

FIGURE 72b. Chaunax sp. 1, CAS 235683, $33.2 \mathrm{~mm}$ SL., dorsal view 


\section{Plate XIII}

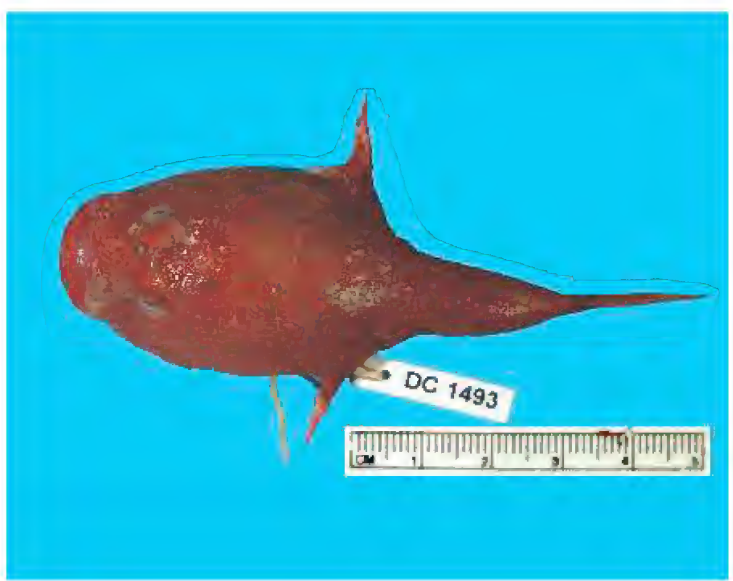

FIGURE 73. Chaunax sp. 2, CAS 236014, $69 \mathrm{~mm} \mathrm{SL}$

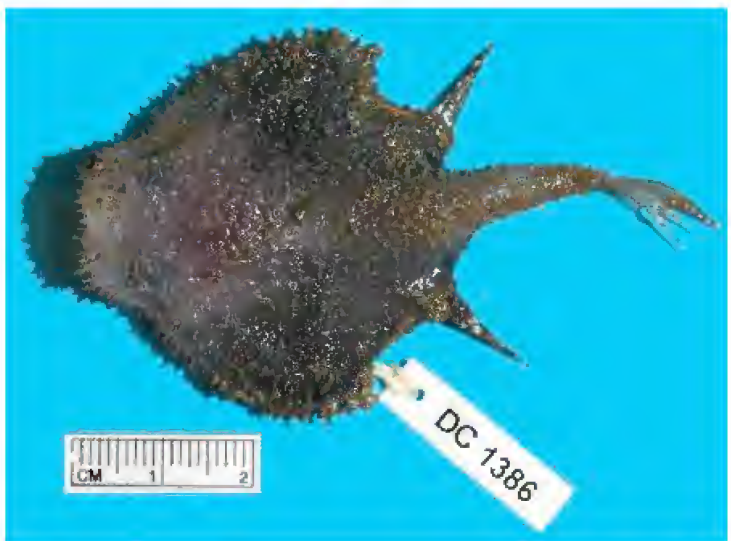

FIGURE 75. Halicmetus sp., CAS 234019, $58 \mathrm{~mm}$ SL.

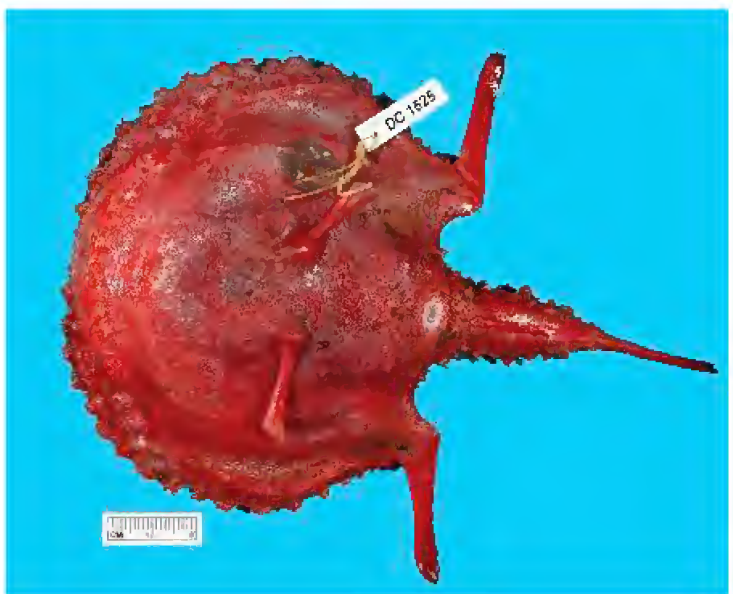

FIGURE 76b. Halieutaea cf. stellata, CAS 236405, $120 \mathrm{~mm}$ SL, ventral view.

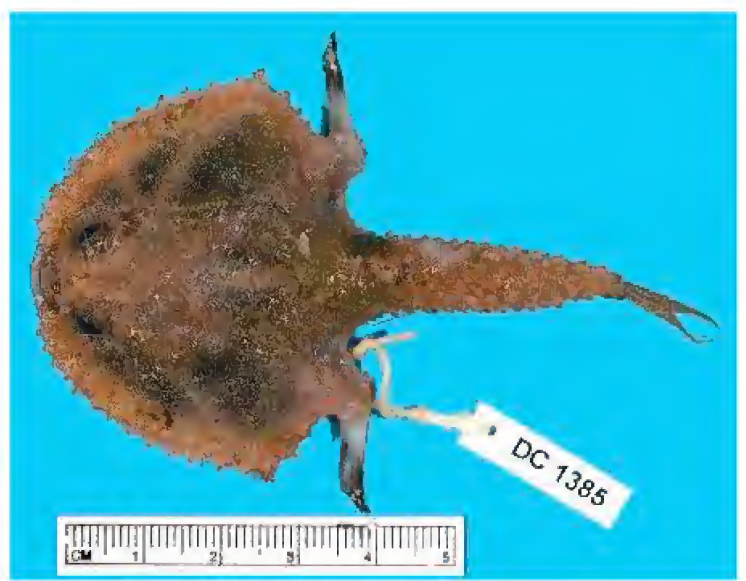

FIGURE 74. Dibranchus sp., CAS 234021, 75 mm SL.

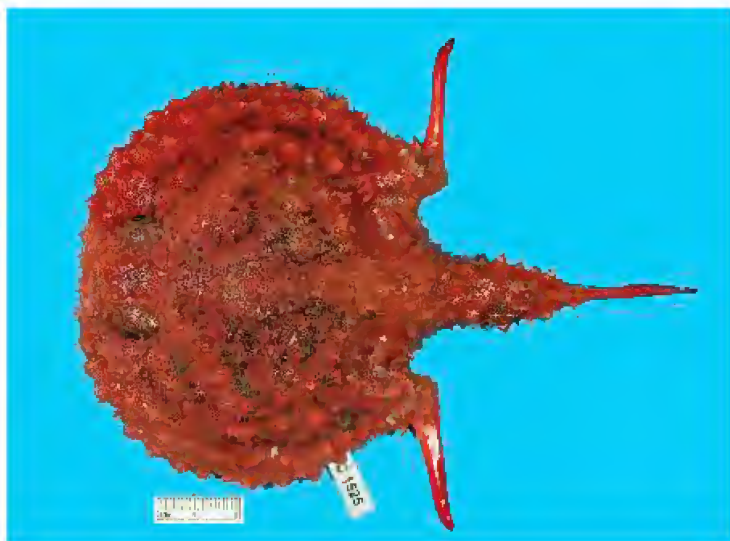

FIGURE 76a. Halieutaea $\mathrm{cf}$ stellata, CAS 236405 , $120 \mathrm{~mm}$ SL, dorsal view.

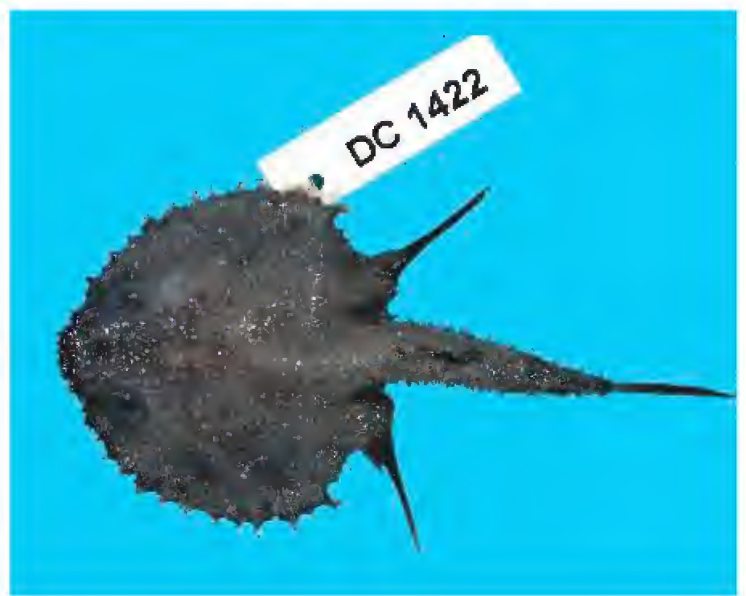

FIGURE 77.Halieutopsis sp. 1, CAS 235685, 48 mm SL. 


\section{Plate XIV}

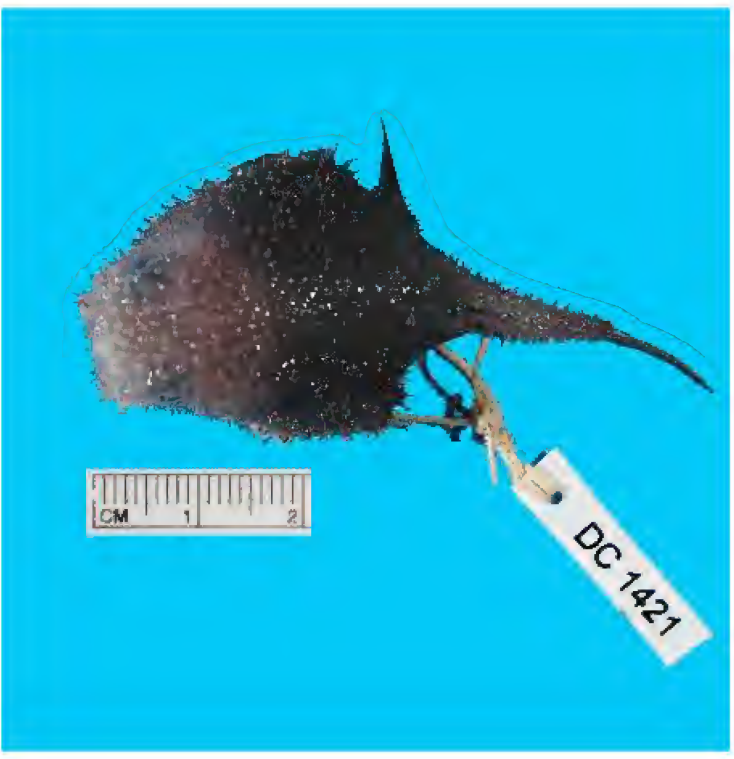

FiguRE 78. Halieutopsis sp. 2, CAS 235684, $51 \mathrm{~mm}$ SL.

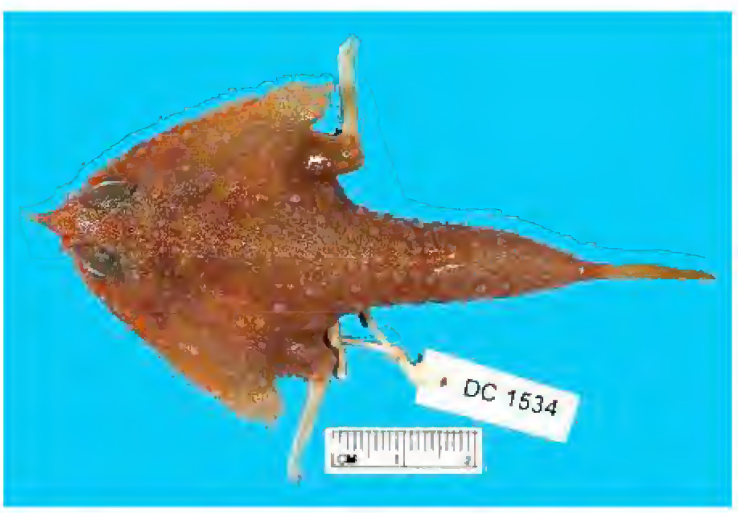

FIGURE 80. Malthopsis kobayashii, CAS 235679 , $79 \mathrm{~mm}$ SL.

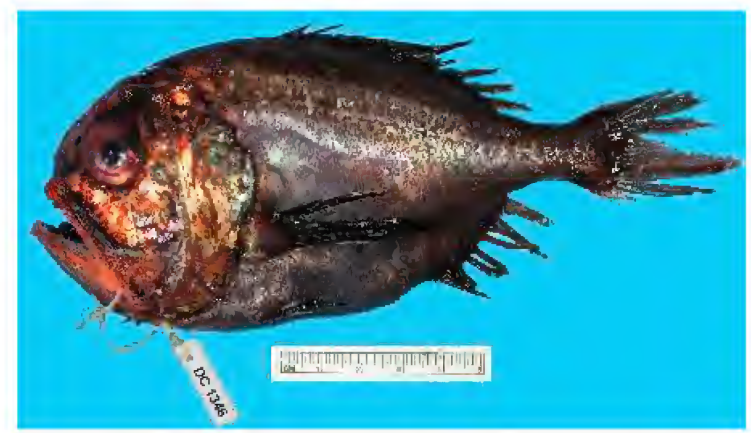

FIGURE 82. Hoplostethus melanopterus, CAS 234018, $00 \mathrm{~mm}$ SL.

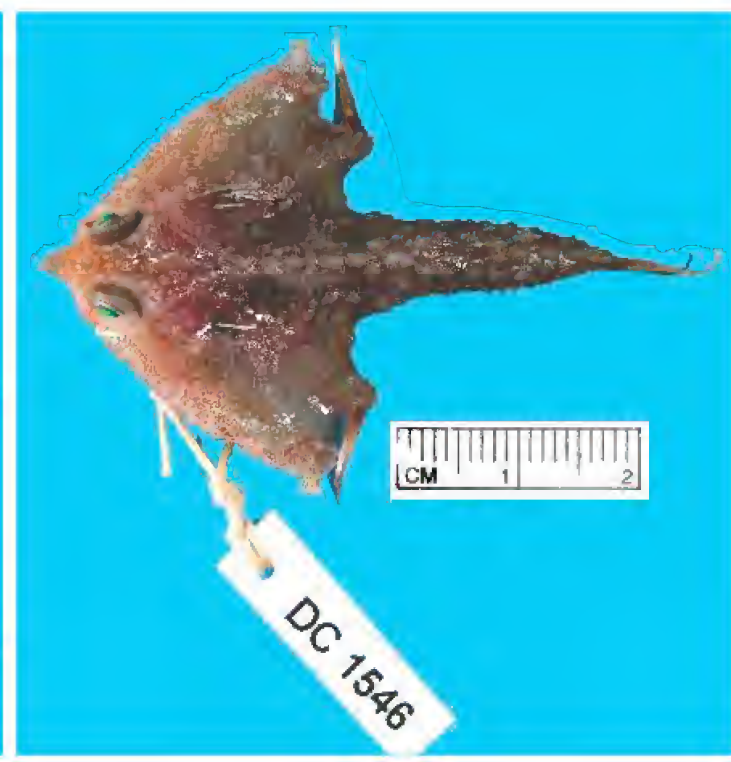

FIGURE 79. Malthopsis annulifera, CAS 235680, $46.5 \mathrm{~mm}$ SL.

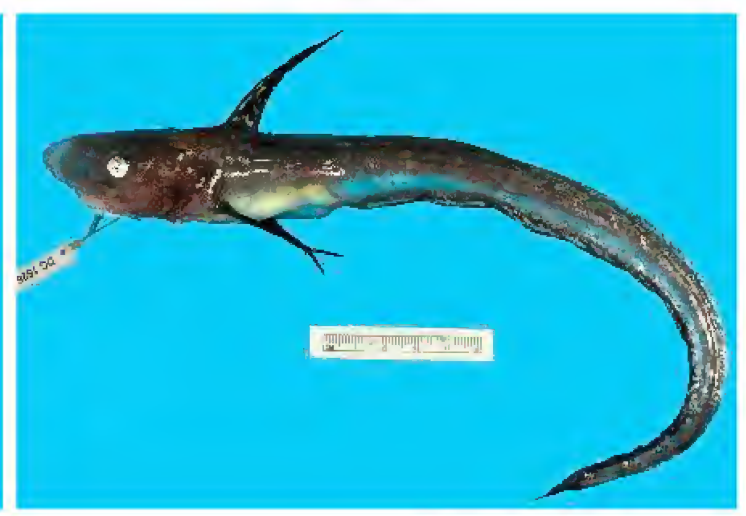

FIGURE 81. Ateleopus japonicus, CAS 235794, $291 \mathrm{~mm}$ TL.

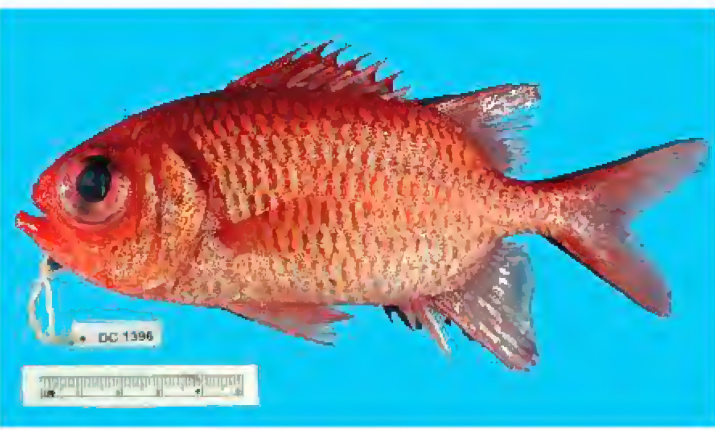

FIGURE 83. Myripristis hexagona, CAS 235467, $127 \mathrm{~mm}$ SL. 


\section{Plate XV}

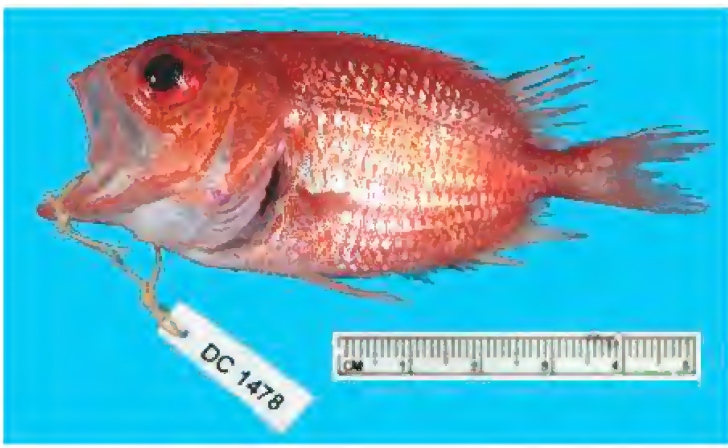

FIGURE 84. Ostichthys ef. japonicus, CAS 2235783, $69 \mathrm{~mm}$ SL.

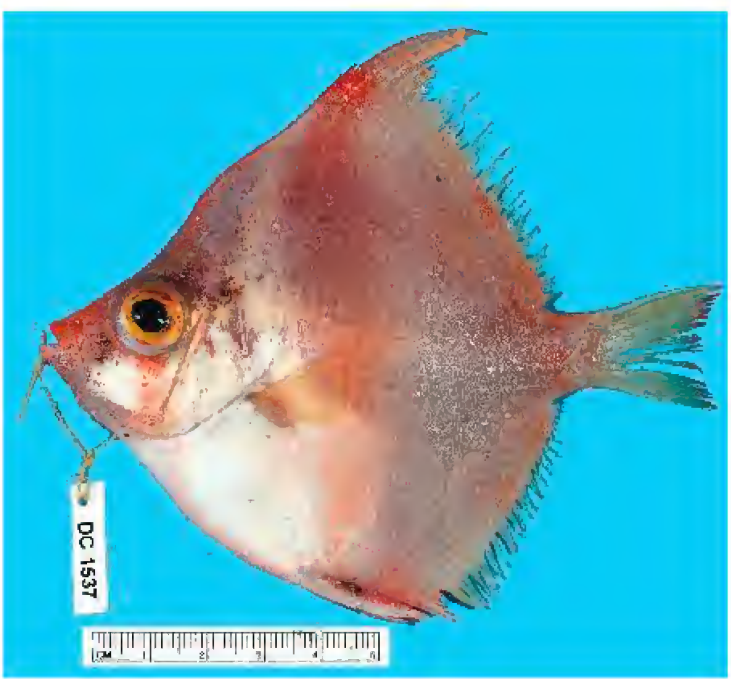

FIGURE 86. Antigonia rubicunda, CAS 235579, $98.5 \mathrm{~mm} \mathrm{SL}$.

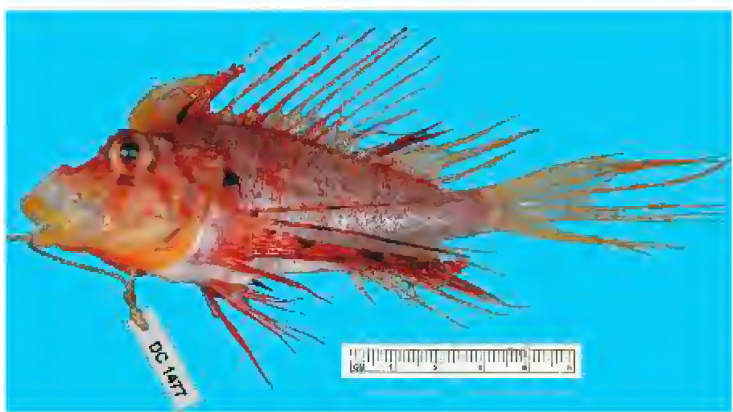

FIGURE 88. Ebosia bleekeri, CAS 235824, $96 \mathrm{~mm}$ SL.

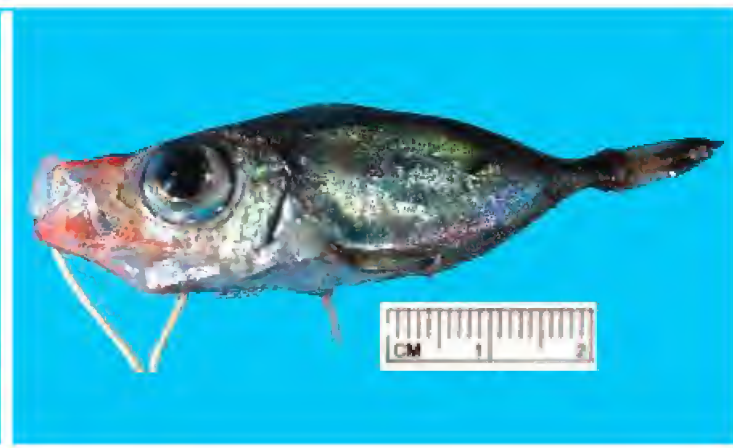

FIGURE 85. Zenion hololepis, CAS 235737, $48.8 \mathrm{~mm} \mathrm{SL}$.

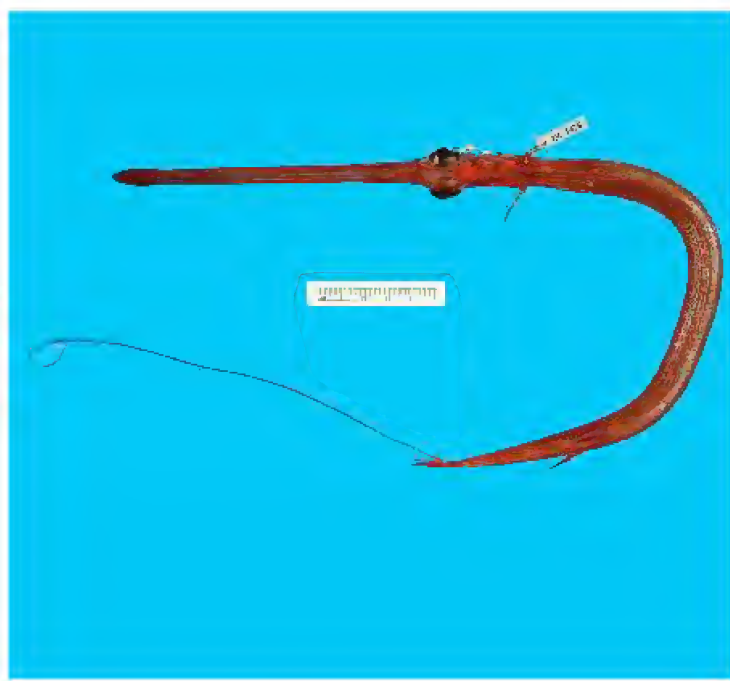

FIGURE 87. Fistularia petimba, CAS 236412, $639 \mathrm{~mm}$ TL.

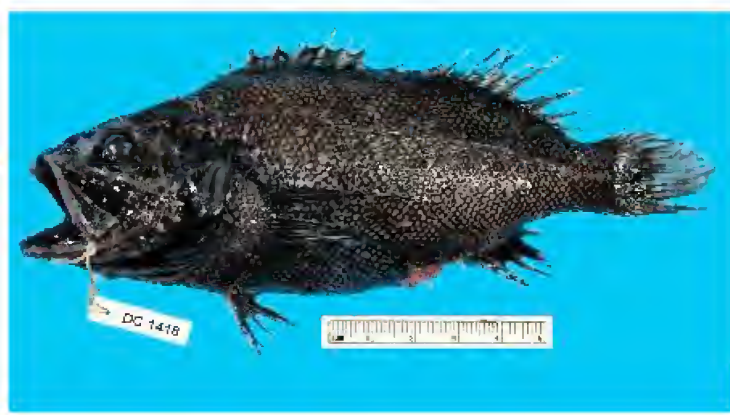

FIGURE 89. Ectreposebastes imus, CAS 235751, $125 \mathrm{~mm}$ SL. 


\section{Plate XVI}

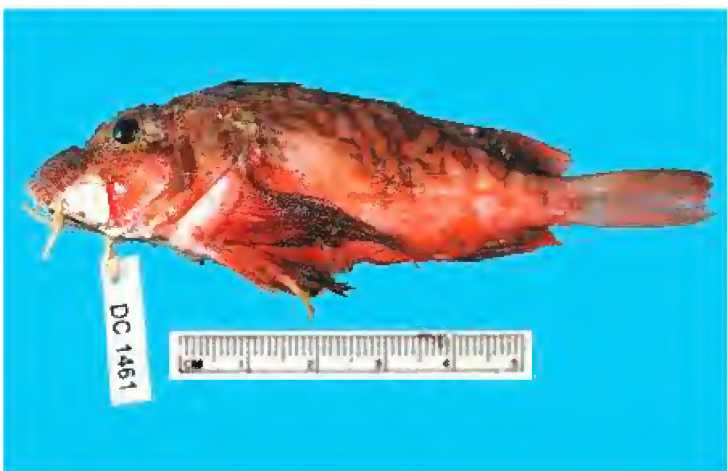

FIGURE 90. Minous quincarinatus, CAS 235738, $77.2 \mathrm{~mm} \mathrm{SL}$

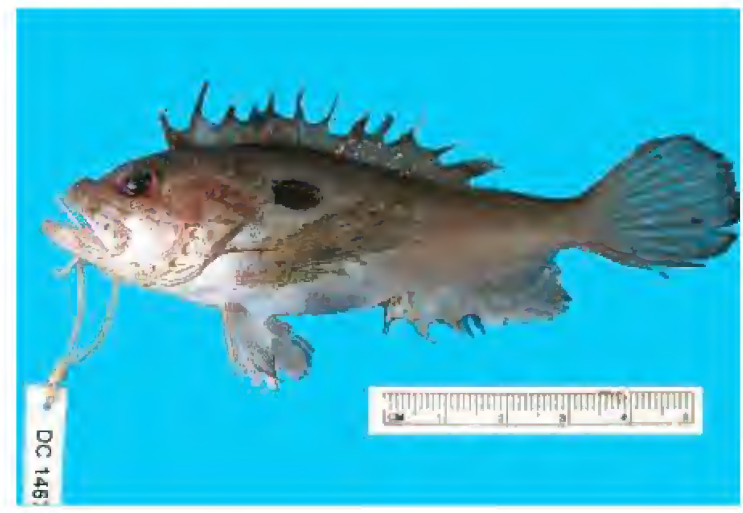

FIGURE 92. Neocentropogon affinis, CAS 235749, $81.4 \mathrm{~mm} \mathrm{SL}$.

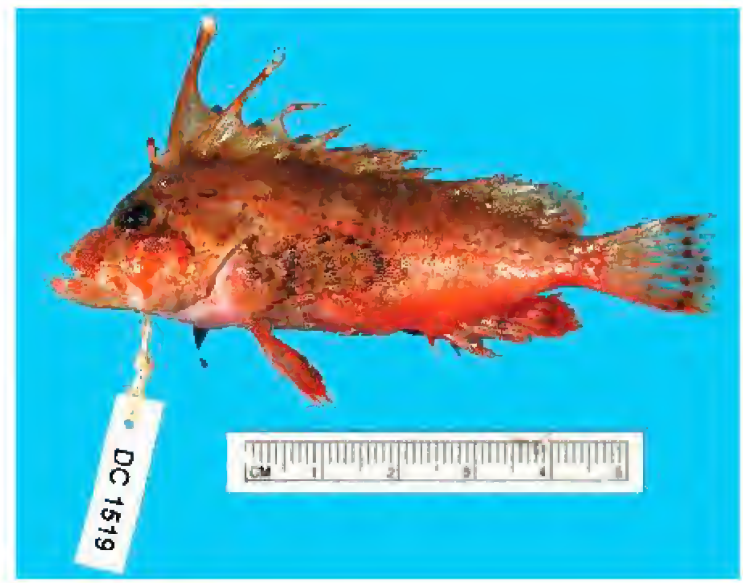

FIGURE 94. Ocosia zaspilota, CAS 235825, 67 mm SL.

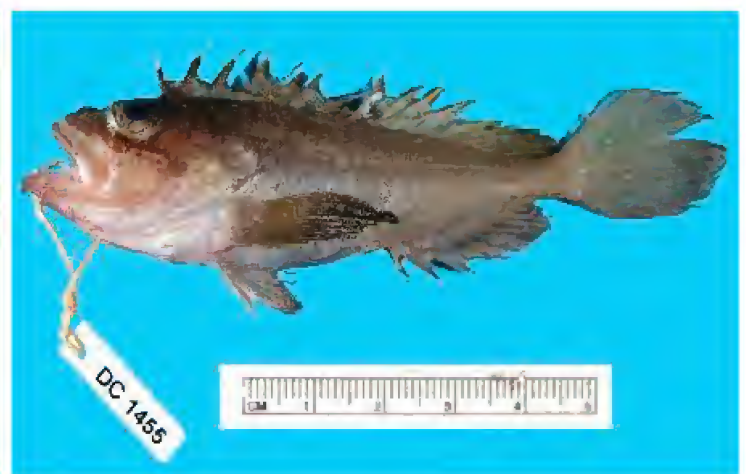

FIGURE 91. Neocentropogon aeglefinus, CAS 235739, $69 \mathrm{~mm} \mathrm{SL}$.

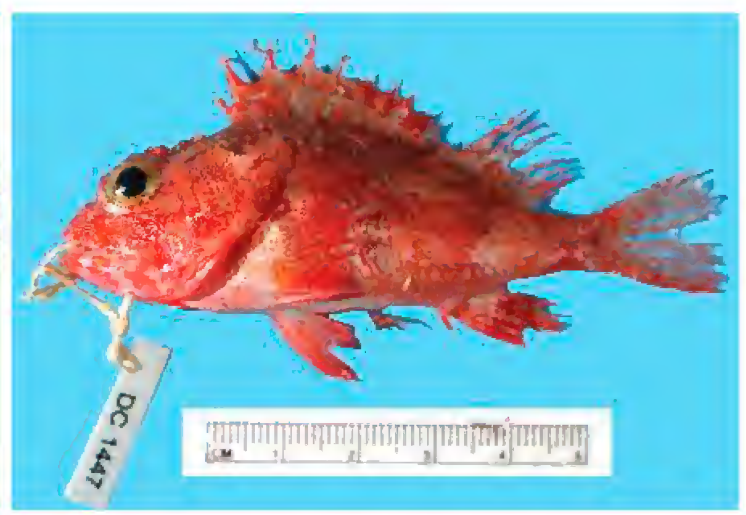

FigURE 93. Neomerinthe sp., CAS 236002, $66.0 \mathrm{~mm} \mathrm{SL}$.

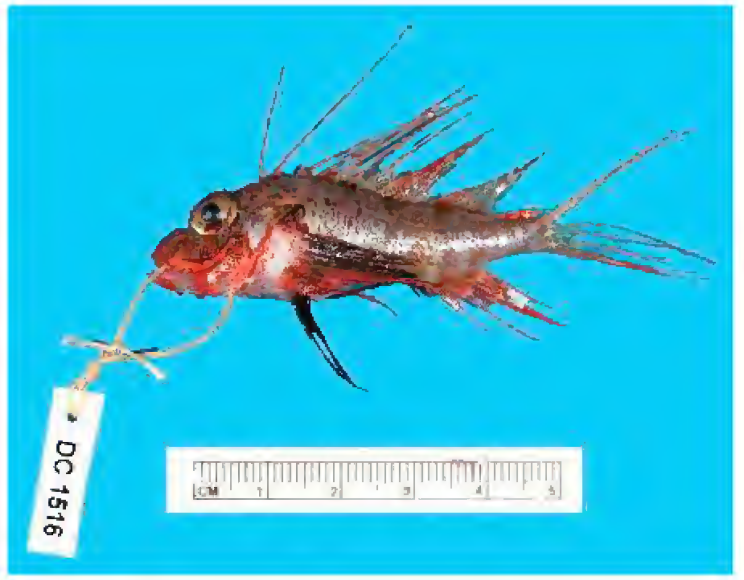

FIGURE 95. Parapterois heterurus, CAS 236010, 53 mm SL. 


\section{Plate XVII}

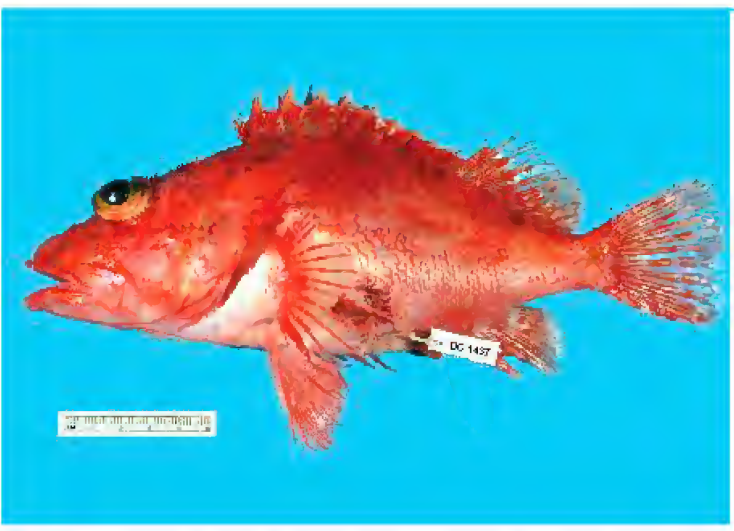

FIGURE 96. Pontinus rhodochrous, CAS 235458 , $190 \mathrm{~mm}$ SL.

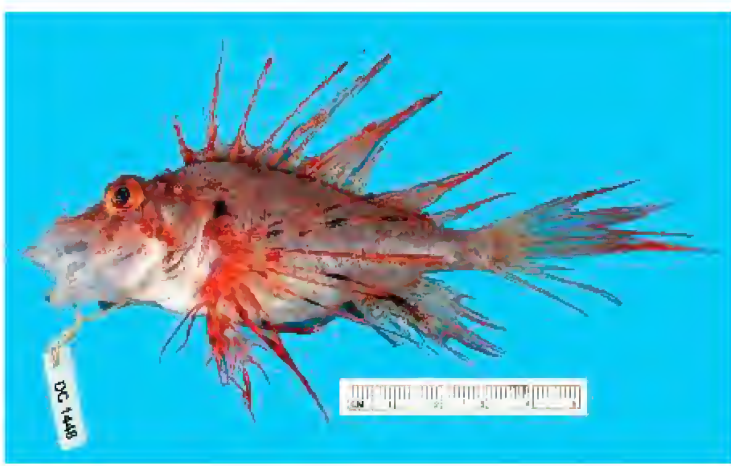

FIGURE 98. Pterois lunulata, CAS 235752, $91 \mathrm{~mm} \mathrm{SL.}$

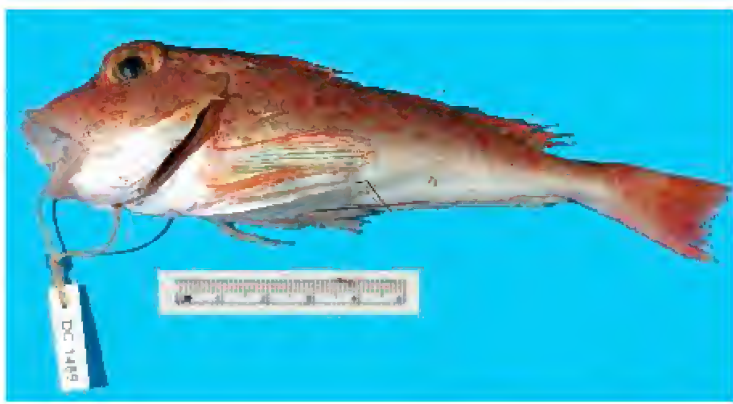

FIGURE 100. Lepidotrigla abyssalis, CAS 236411, $125 \mathrm{~mm}$ SL.

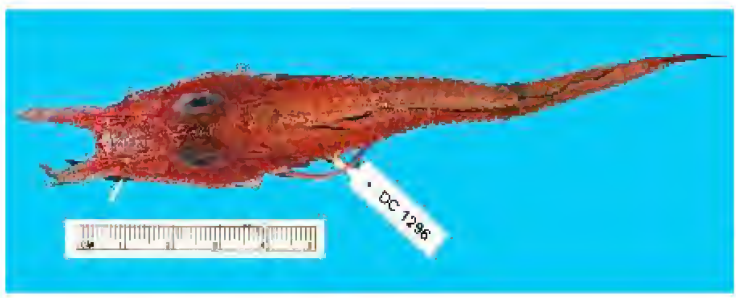

FIGURE 102. Peristedion cf. liorhynchus, CAS 233996, $116 \mathrm{~mm} \mathrm{SL}$.

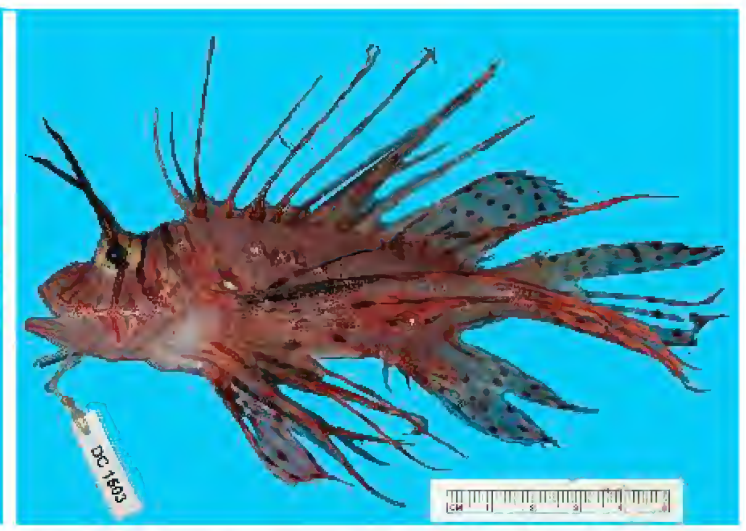

Figure 97. Pterois antennata, CAS 235573, $105.5 \mathrm{~mm}$ SL.

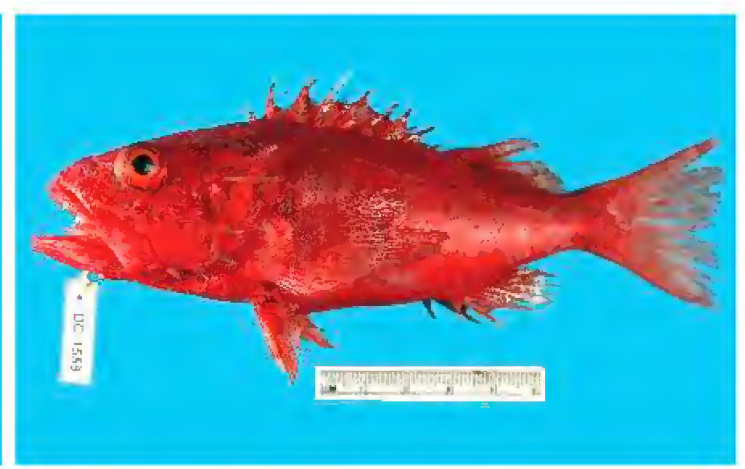

FIGURE 99. Setarches guentheri, CAS 235642, $121 \mathrm{~mm}$ SL.

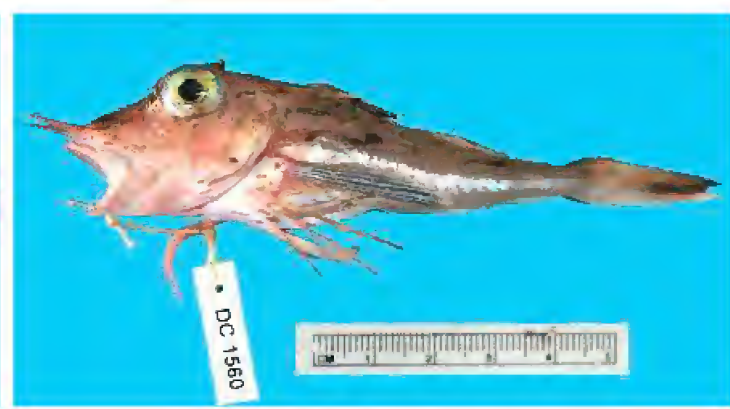

FIGURE 101. Pterygotrigla sp., CAS 236479, $96 \mathrm{~mm} \mathrm{SL}$.

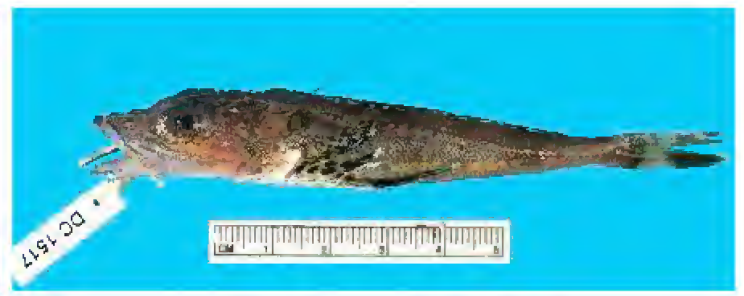

FIGURE 103a. Rogadius welanderi, CAS 235511, $87.6 \mathrm{~mm}$ SL, lateral view. 


\section{Plate XVIII}

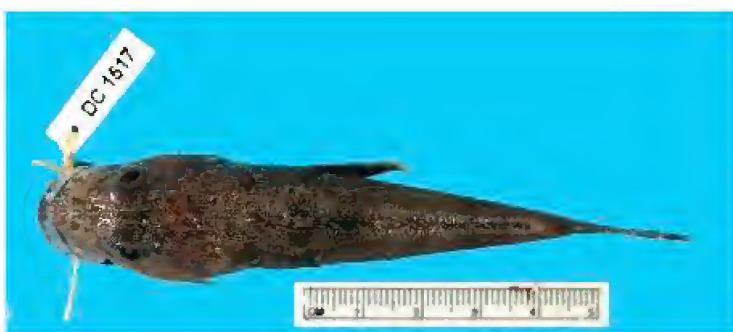

FIGURE 103b. Rogadius welanderi, CAS 235511, $87.6 \mathrm{~mm} \mathrm{SL}$, dorsal view.

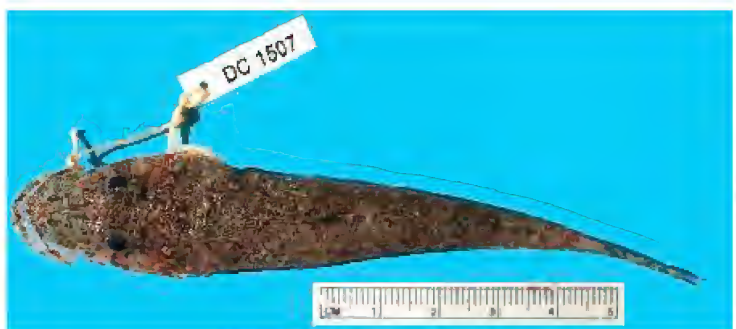

FIGURE 104b. Thysanophrys chiltonae, CAS 235508, 94.0 mm SL, dorsal view.

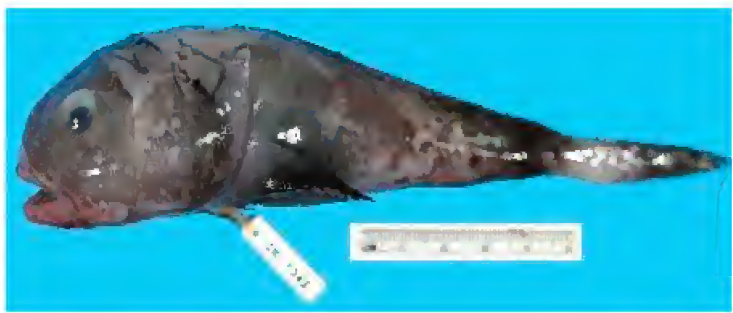

FIGURE 106. Psychrolutes cf. occidentalis, CAS 234016, $137 \mathrm{~mm}$ SL.

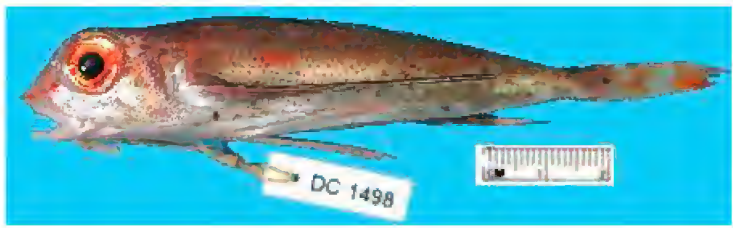

FIGURE 108. Dactyloptena tiltoni, CAS 235885, $86.5 \mathrm{~mm}$ SLmm SL.

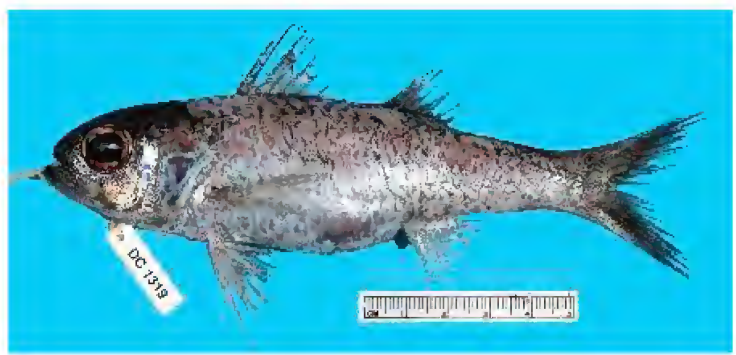

FIGURE 109. Synagrops japonicus, CAS 234012 , $124 \mathrm{~mm}$ SL.

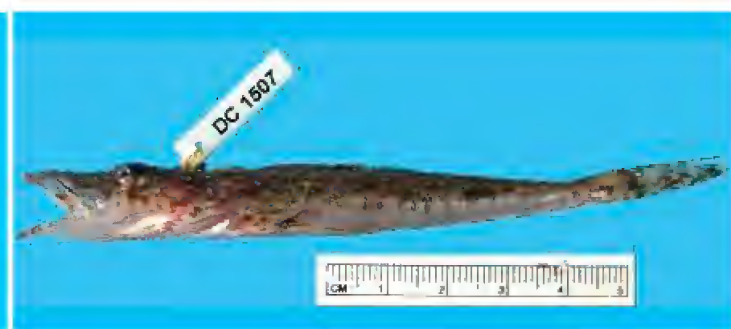

FIGURE 104a. Thysanophrys chiltonae, CAS 235508, $94.0 \mathrm{~mm} \mathrm{SL}$, lateral view.

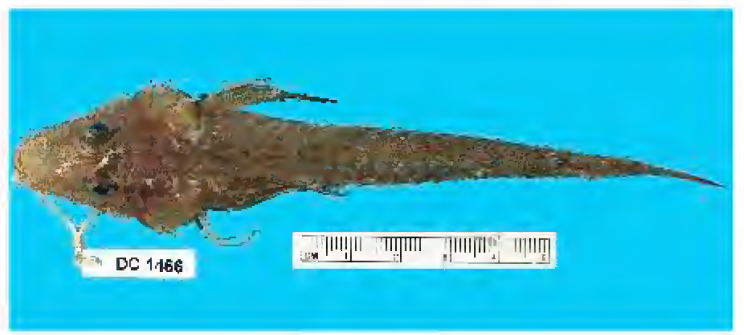

FIGURE 105. Hoplichthys langsdorfi, CAS 135800 , $123 \mathrm{~mm}$ SL.

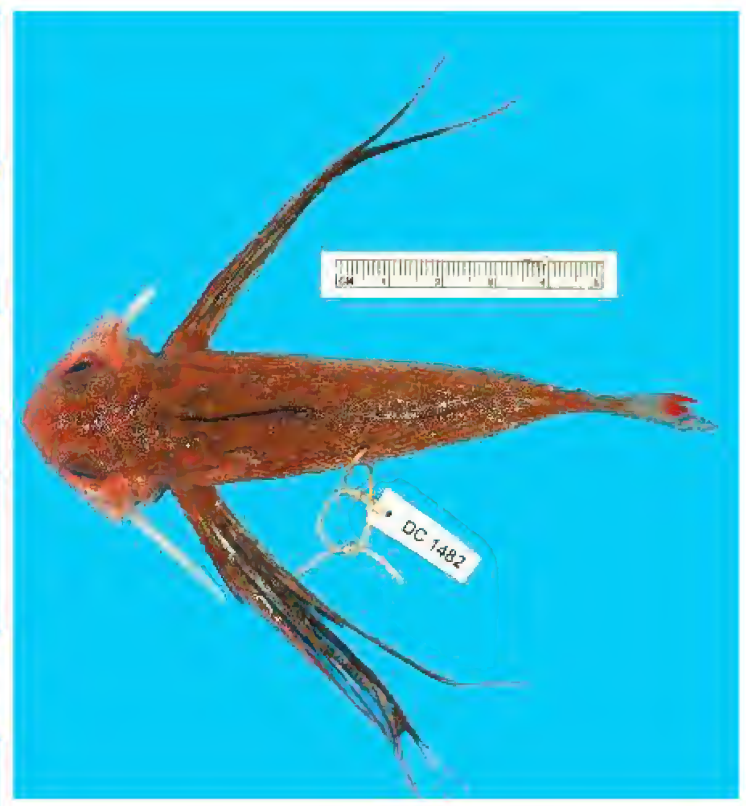

FIGURE 107. Dactyloptena orientalis, CAS 235790 , $101 \mathrm{~mm} \mathrm{SL}$ 


\section{Plate XIX}

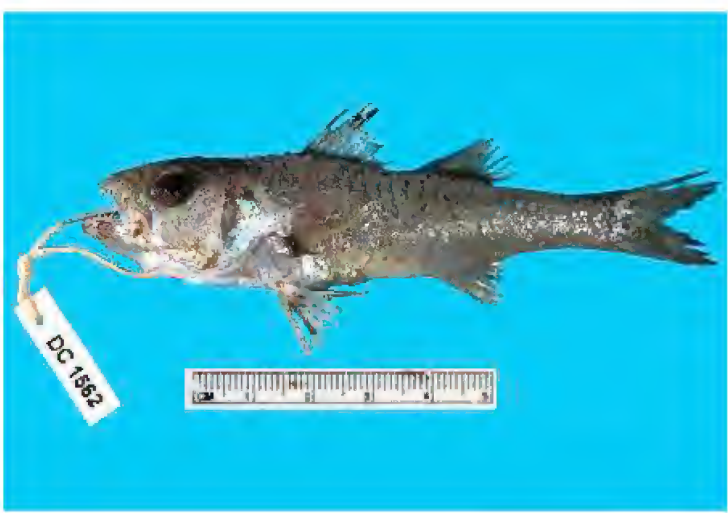

FIGURE 110. Synagrops philippinensis, CAS 236019, $81.9 \mathrm{~mm} \mathrm{SL}$

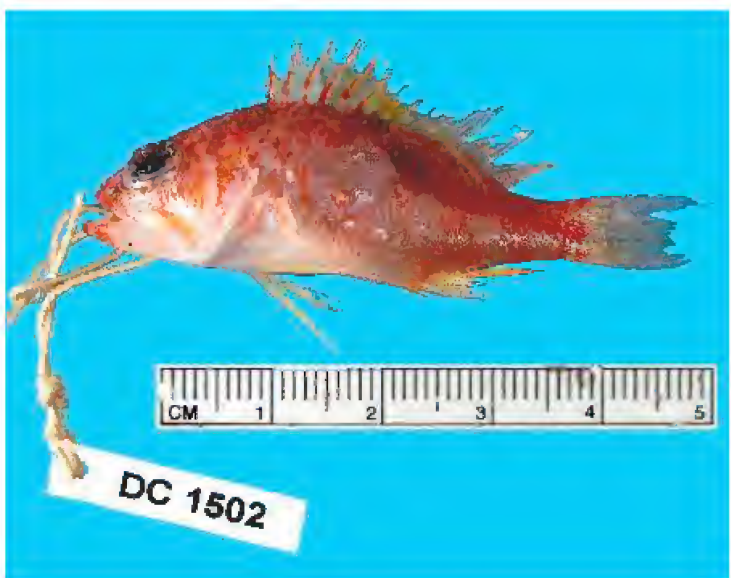

FIGURE 112. Plectranthias sagamiensis, CAS 235596 , $41 \mathrm{~mm}$ SL.

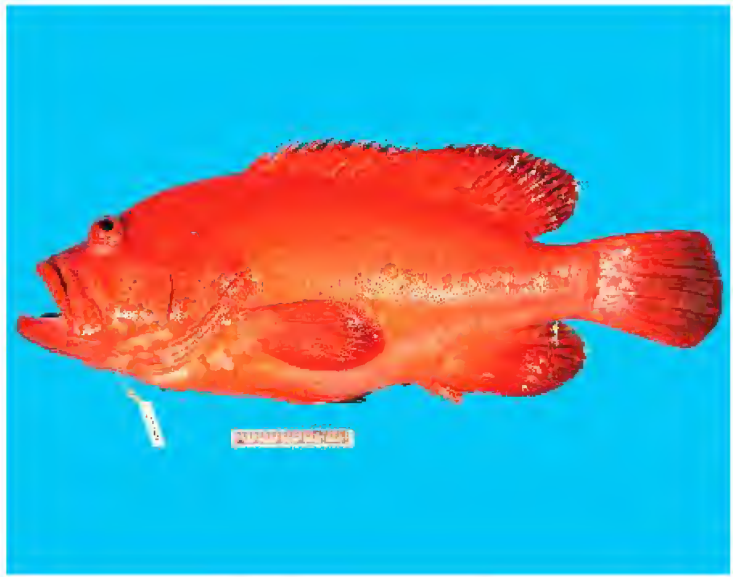

FIGURE 114. Cephalopholis aurantia, CAS 235460 , $240 \mathrm{~mm}$ SL.

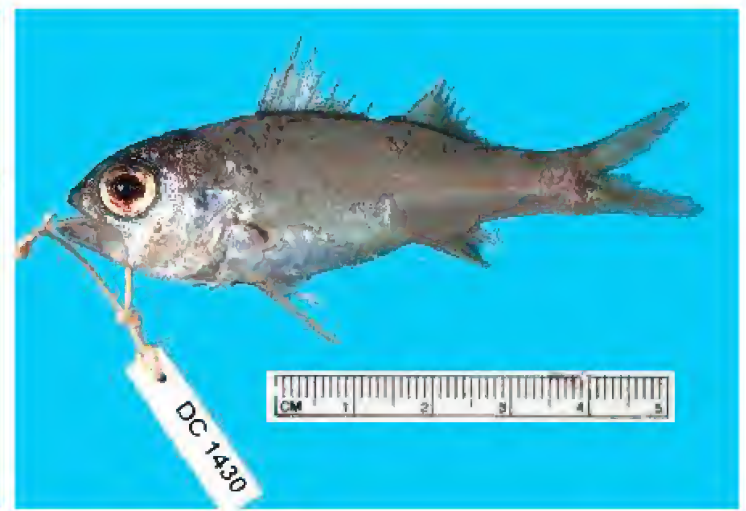

FIGURE 111. Synagrops sp., CAS 235736, $63.0 \mathrm{~mm}$ SL.

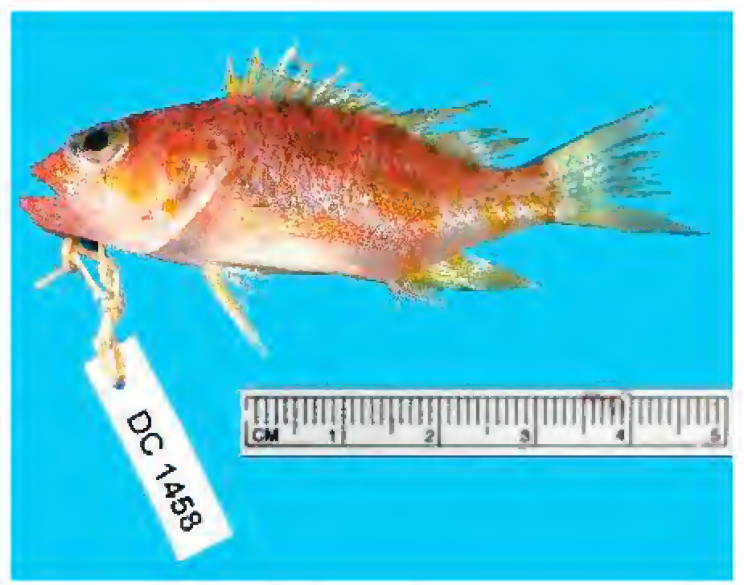

Figure 113. Plectranthias sp., CAS 235681, $53 \mathrm{~mm}$ SL.

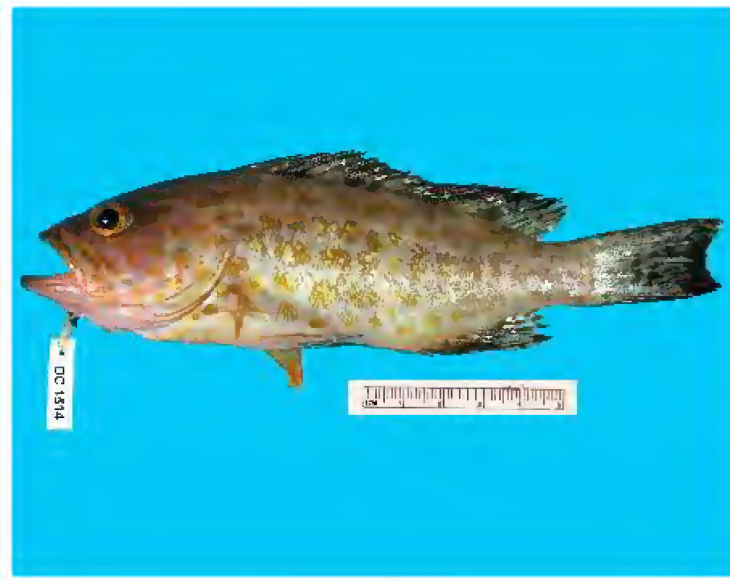

FIGURE 115. Epinephelus areolatus, CAS 235793, $131 \mathrm{~mm}$ SL. 


\section{Plate XX}

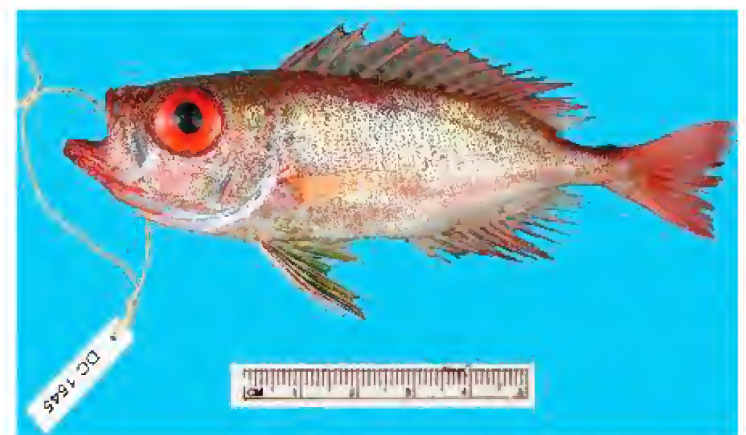

FigURE 116. Priacanthus fitchi, CAS 235784, 88 mm SL.

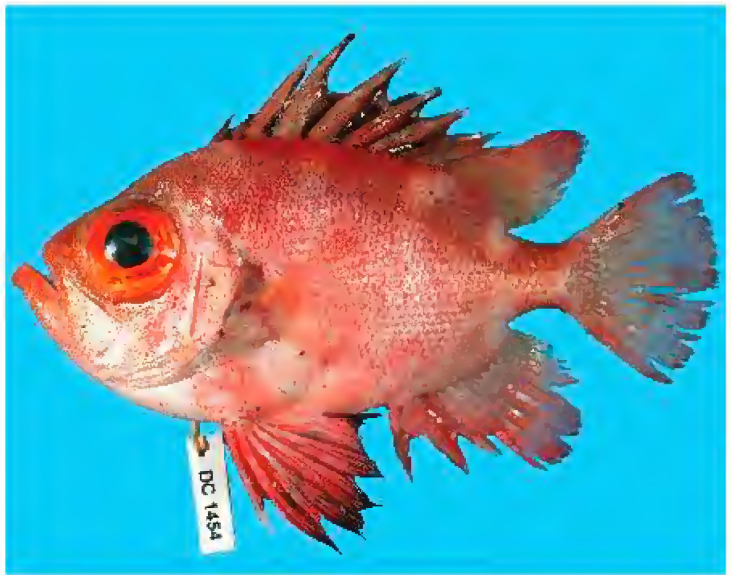

FIGURE 118. Pristigenys niphonia, CAS 236407, $95.2 \mathrm{~mm}$ SL.

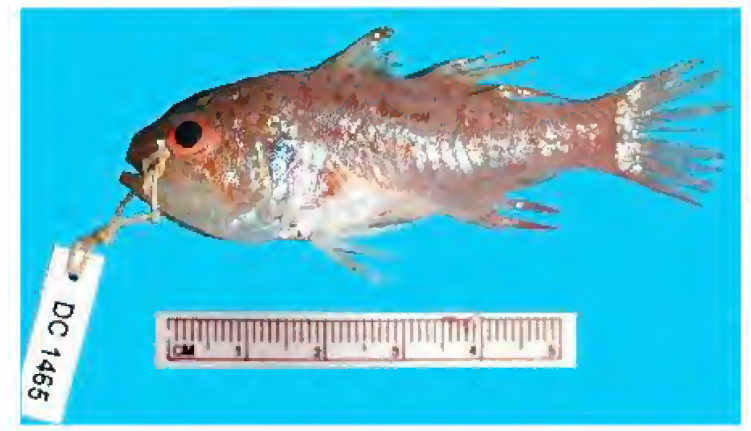

FIGURE 120. Jaydia cf. poecilopterus, CAS 236504 , $59.4 \mathrm{~mm} \mathrm{SL}$

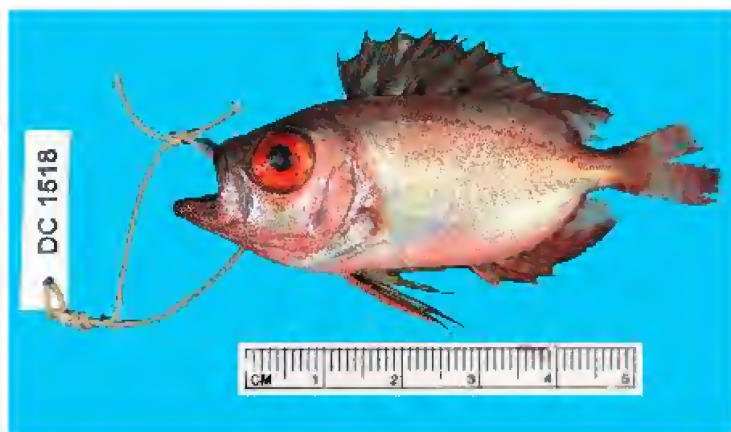

FIGURE 117. Priacanthus macracanthus, CAS 235820, $53 \mathrm{~mm} \mathrm{SL}$

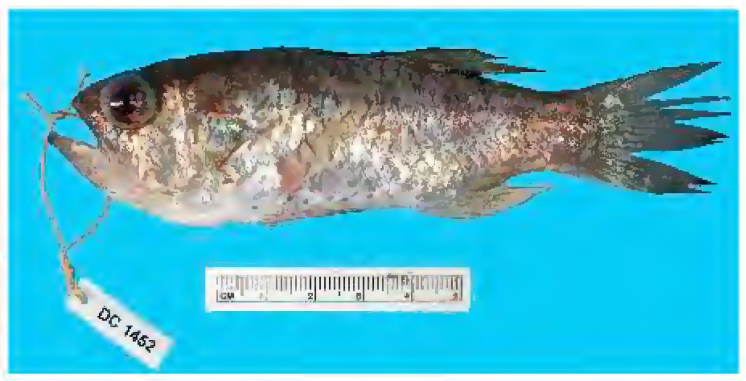

FIGURE 119. Jaydia carinatus, CAS 235746, $100 \mathrm{~mm}$ SL.

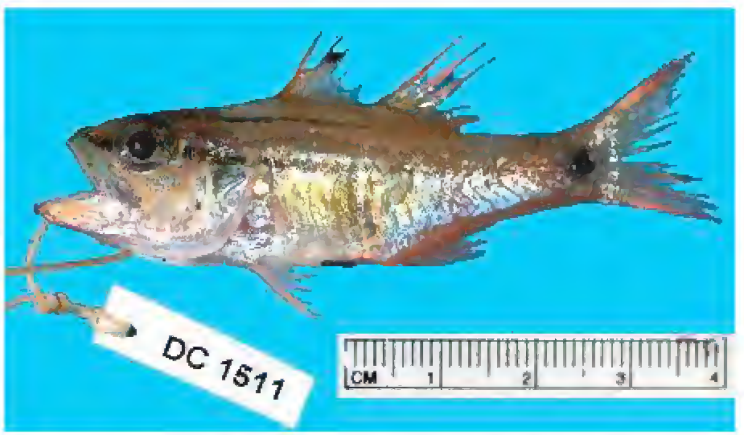

FIGURE 121. Ostorhinchus cf. cheni, CAS 236505, $52 \mathrm{~mm} \mathrm{SL}$

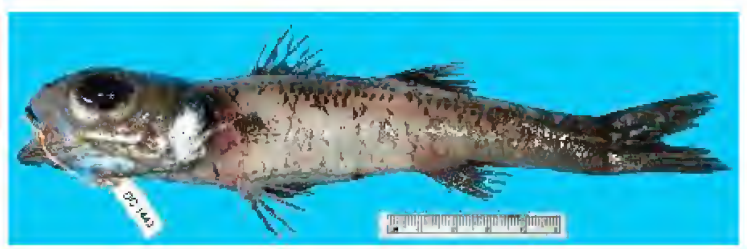

FIGURE 122. Epigonus ctenolepis, CAS 235796, $160 \mathrm{~mm} \mathrm{SL}$. 


\section{Plate XXI}

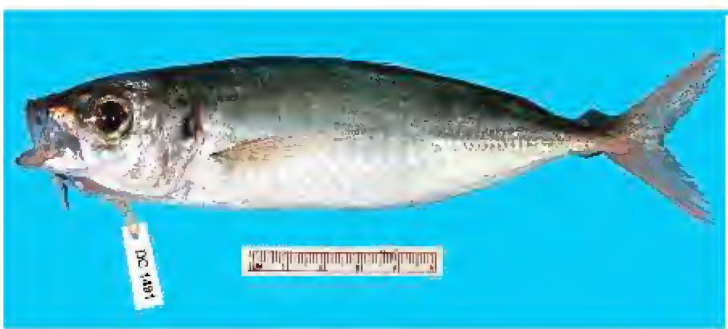

FIGURE 123. Decapterus kurroides, CAS 236410, $165 \mathrm{~mm} \mathrm{SL}$

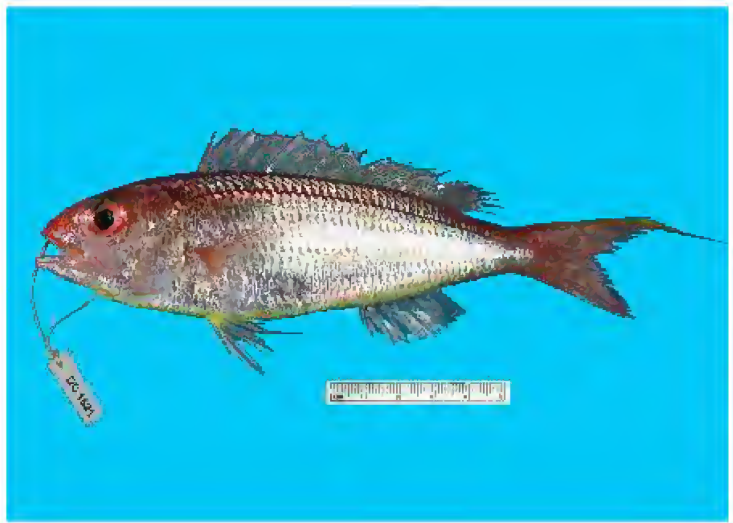

FIGURE 125. Nemipterus bathybius, CAS 236025, $134 \mathrm{~mm} \mathrm{SL}$.

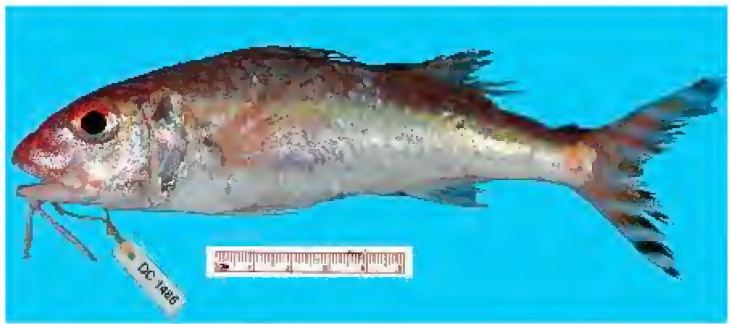

FIGURE 127. Upeneus subvittatus, CAS 235576 , $149 \mathrm{~mm}$ SL.

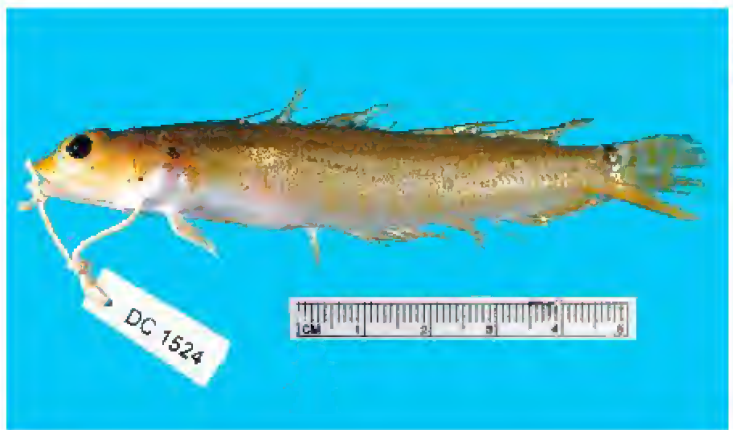

FIGURE 129. Parapercis sp., CAS 236013, 89 mm SL

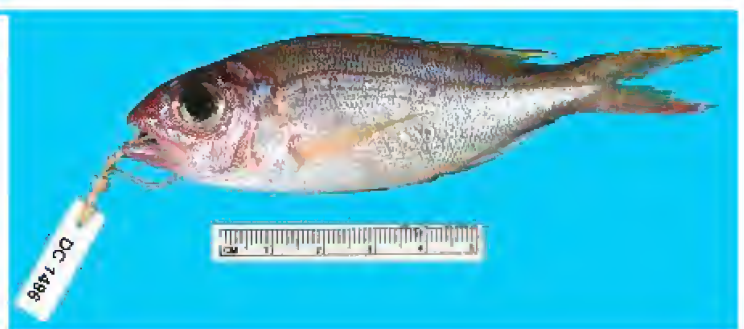

FIGURE 124. Pristipomoides argyrogrammicus, CAS $236418,87.7 \mathrm{~mm} \mathrm{SL}$

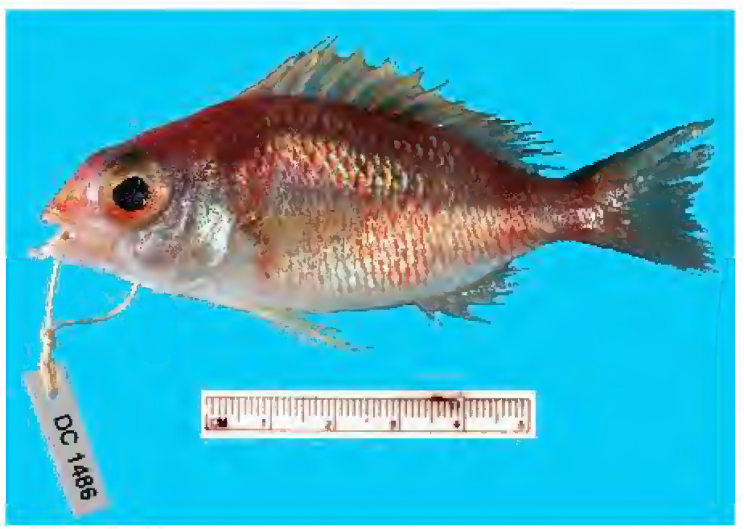

FIGURE 126. Parascolopsis inermis, CAS 236496, 84 m SL.

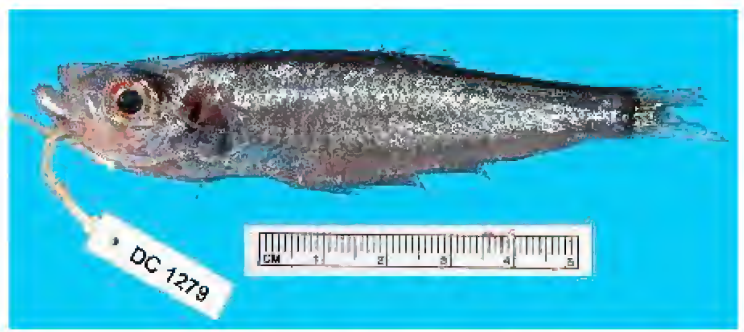

FIGURE 128. Bathyclupea argentea?, CAS 233990 , $87 \mathrm{~mm}$ SL.

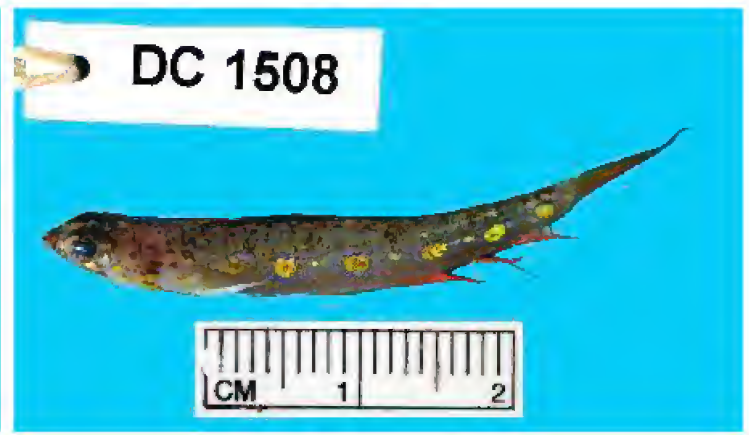

FIGURE 130. Pteropsaron dabfar, CAS 236400, holotype $33.6 \mathrm{~mm}$ SL 


\section{Plate XXII}

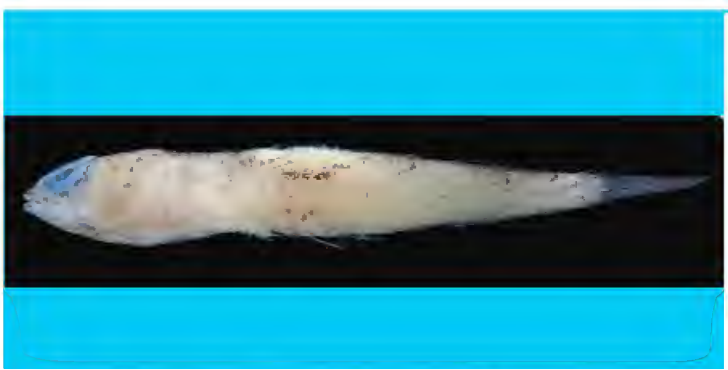

FiguRE 131. Pteropsaron levitoni, CAS 236401, holotype $23.7 \mathrm{~mm} \mathrm{SL}$.

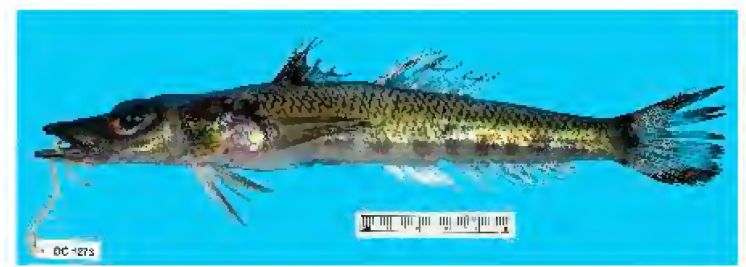

FIGURE 133. Bembrops caudimacula, CAS 235272, 186 $\mathrm{mm}$ SL.

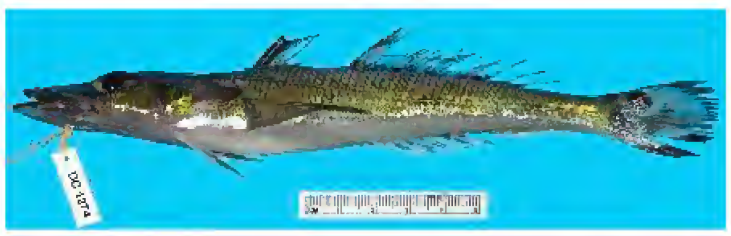

FIGURE 135. Bembrops nelsoni, CAS 235272, $164 \mathrm{~mm} \mathrm{SL.}$

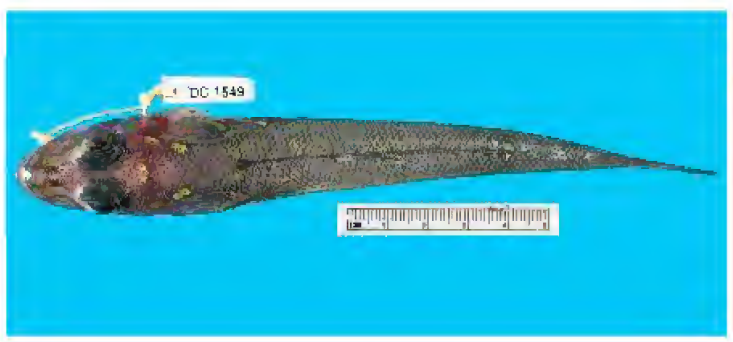

FIGURE 136b. Chrionema chlorotaenia, CAS 235512, 146 $\mathrm{mm} \mathrm{SL}$, dorsal view.

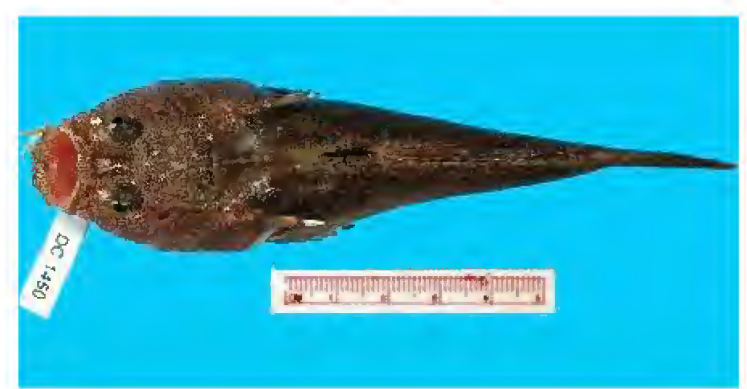

Figure 137b. Uranoscopus sp. 2 (of Kishimoto), CAS 236423, $98 \mathrm{~mm} \mathrm{SL}$, dorsal view.

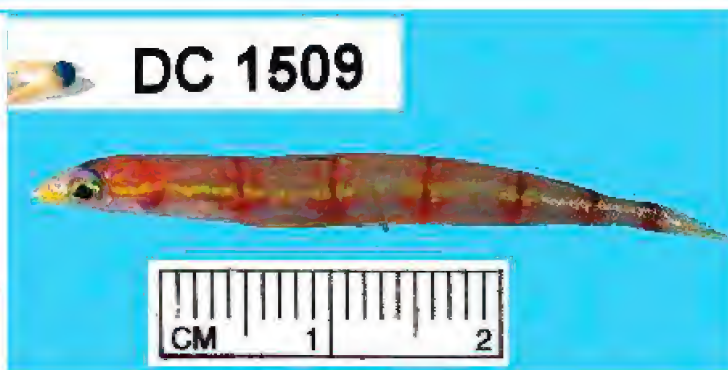

FIGURE 132. Pteropsaron springeri?, CAS 236668 $35.0 \mathrm{~mm}$ SL.

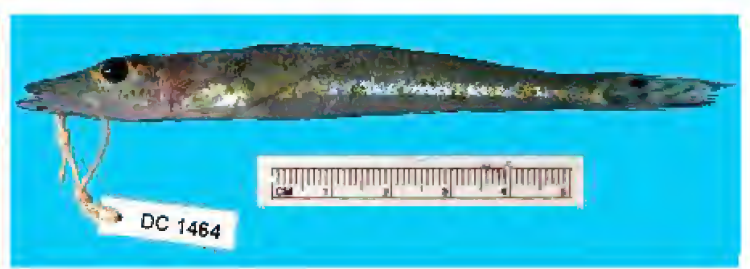

FIGURE 134. Bembrops curvatura, CAS 235735, $94.5 \mathrm{~mm}$ SL.

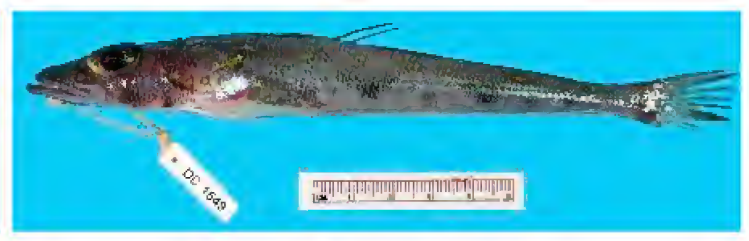

FIGURE 136a. Chrionema chlorotaenia, CAS 235512 , $146 \mathrm{~mm}$ SL, lateral view

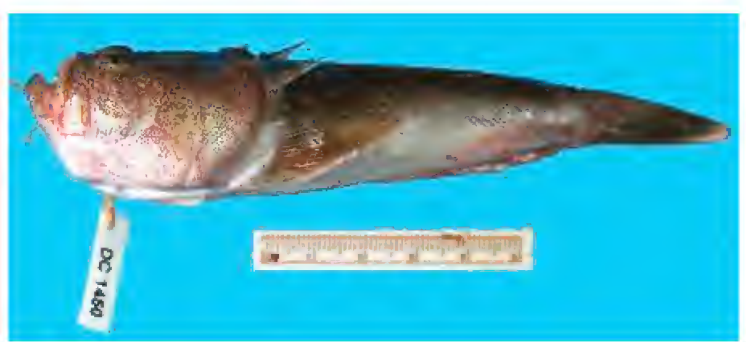

FIGURE 137a. Uranoscopus sp. 2 (of Kishimoto), CAS 236423, $98 \mathrm{~mm} \mathrm{SL}$, lateral view.

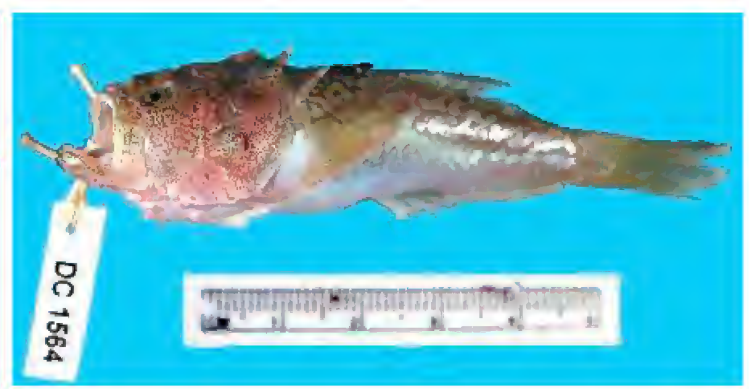

FIGURE 138a. Uranoscopus sp. 3 (of Kishimoto), CAS 236476, $58.1 \mathrm{~mm} \mathrm{SL}$, lateral view. 


\section{Plate XXIII}

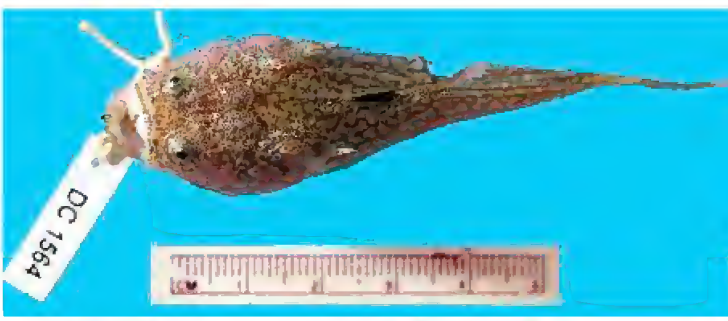

FIGURE 138b. Uranoscopus sp. 3 (of Kishimoto), CAS 236476, $58.1 \mathrm{~mm} \mathrm{SL}$, dorsal view.

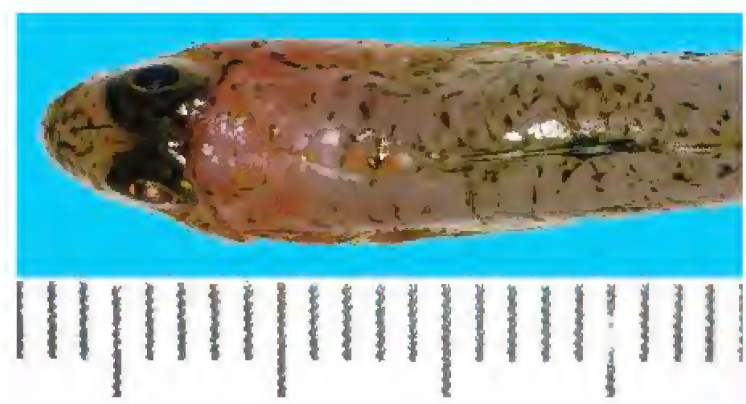

FIGURE 139b. Hazeus sp., CAS 236631, $35.5 \mathrm{~mm} \mathrm{SL}$, dorsal view.Photo by Tomio Iwamoto.

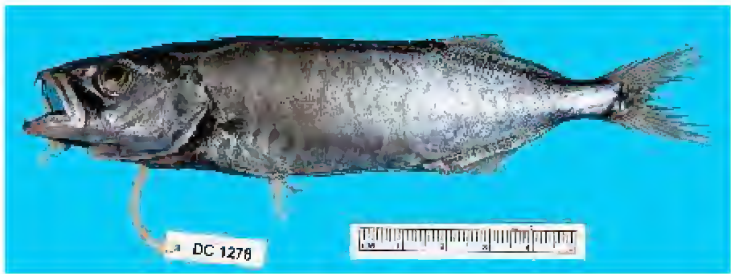

FIGURE 141. Neoepinnula orientalis, CAS 233988, $125 \mathrm{~mm}$ SL.

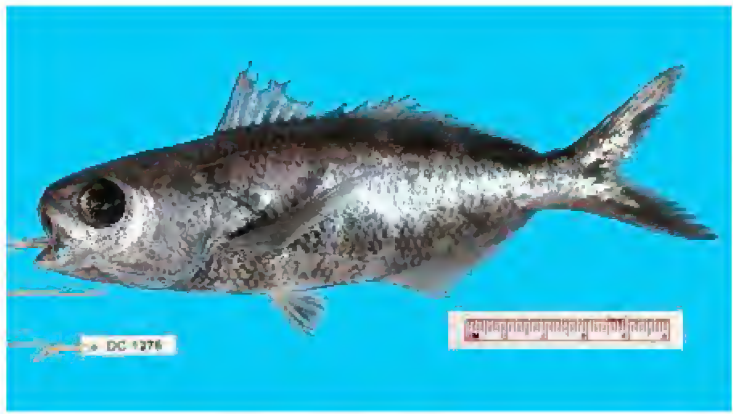

FIGURE 143. Cubiceps whiteleggii, CAS 233986, $127 \mathrm{~mm}$ SL.

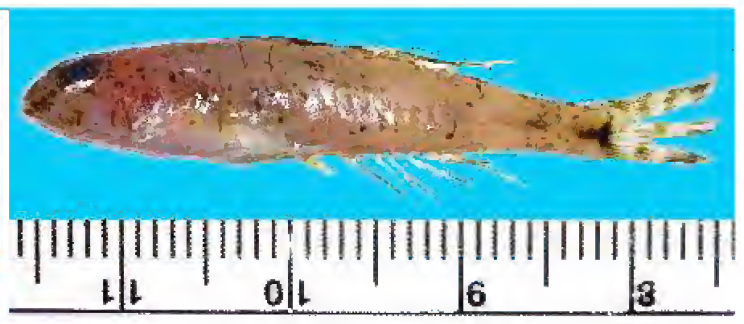

Figure 139a. Hazeus sp., CAS 236631, 35.5 mm SL, lateral view. Photo by Tomio Iwamoto.

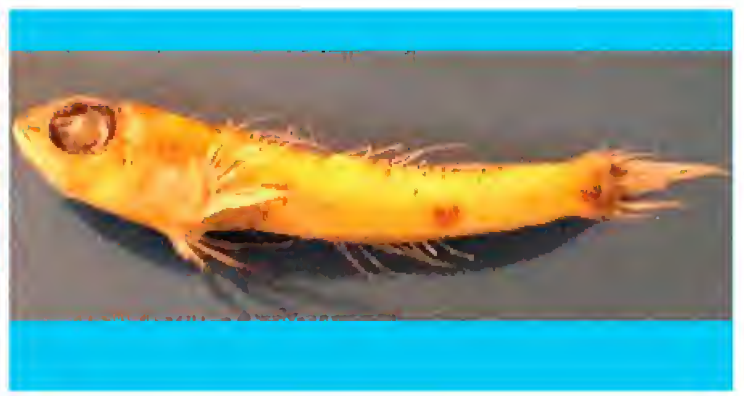

FIGURE 140. Obliquogobius cf cirrifer, CAS 236632. Photo by John McCosker.

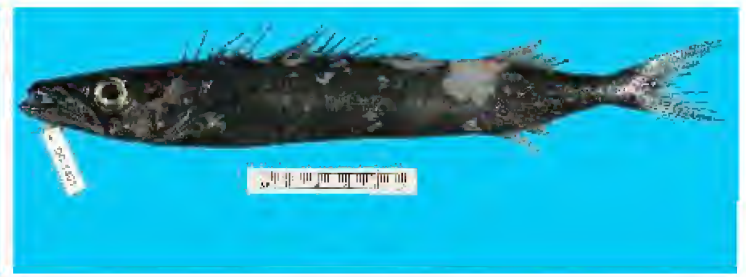

FIGURE 142. Promethichthys prometheus, CAS 234028, $200 \mathrm{~mm}$ SL.

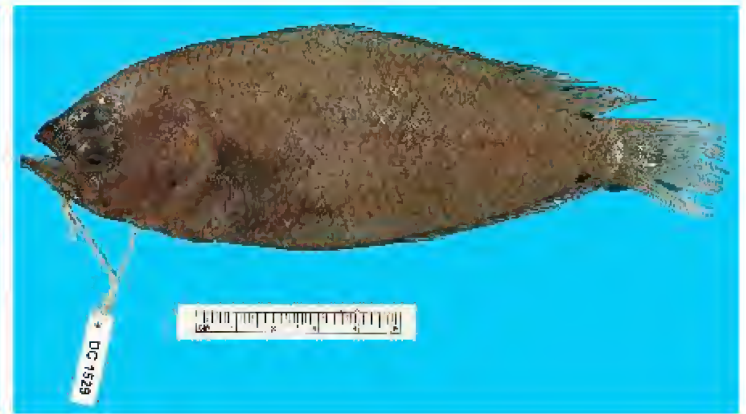

FIGURE 144. Citharoides macrolepidotus, CAS 235548, $138 \mathrm{~mm}$ SL. 


\section{Plate XXIV}

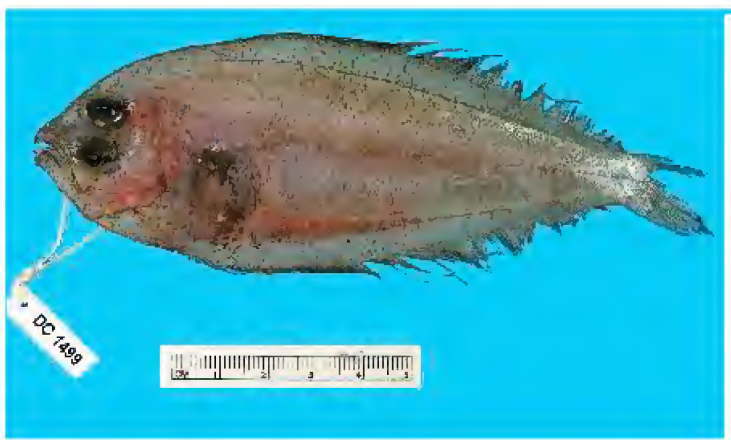

FIGURE 145. Arnoglossus japonicus, CAS 235578, $127 \mathrm{~mm}$ SL.

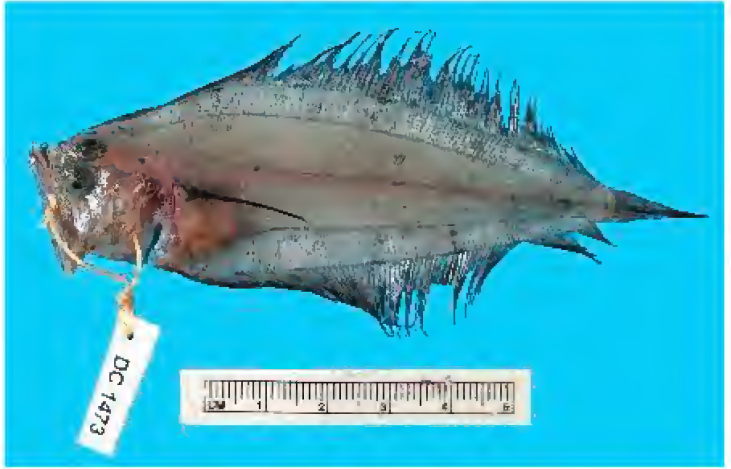

FIGURE 147. Kamoharaia megastoma, CAS 235542 , $89 \mathrm{~mm}$ SL.

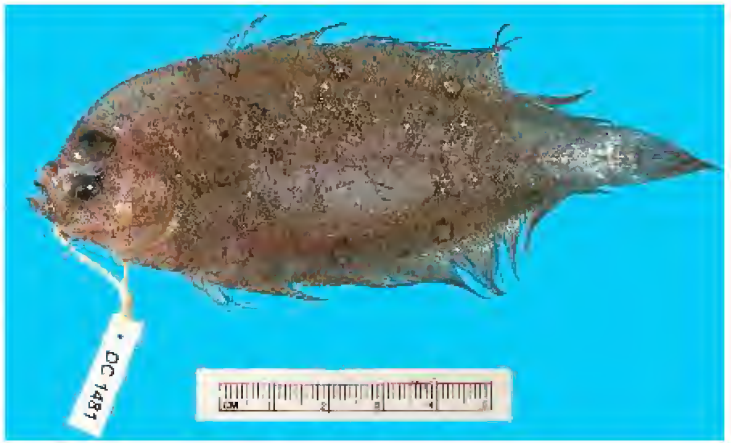

FIGURE 149. Psettina gigantea, CAS 235788, 105 mm SL.

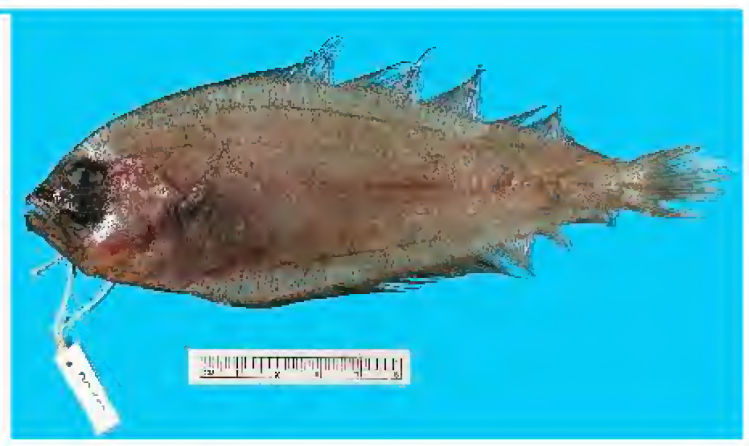

FIGURE 146. Arnoglossus oxyrhynchus, CAS 235549 , $150 \mathrm{~mm} \mathrm{SL}$

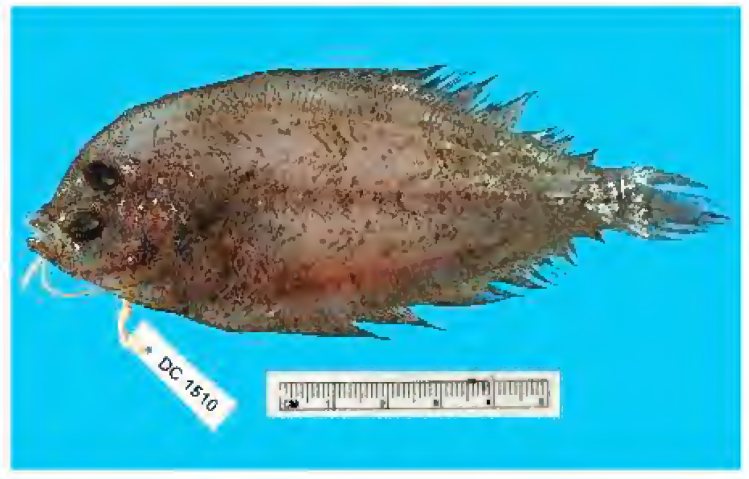

FIGURE 148. Parabothus taiwanensis, CAS 235505, $107 \mathrm{~mm} \mathrm{SL}$

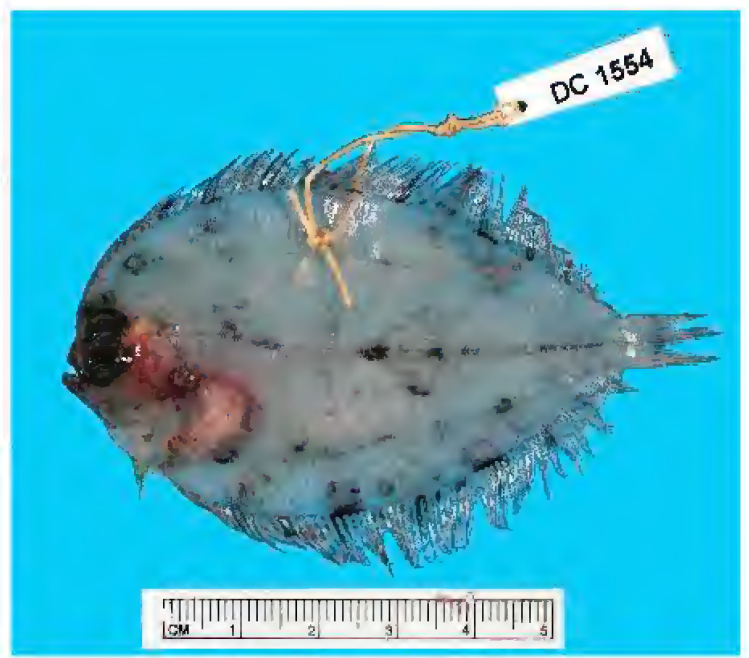

FIGURE 150. Taeniopsetta ocellata, CAS 235823, $68.5 \mathrm{~mm}$ SL. 


\section{Plate XXV}

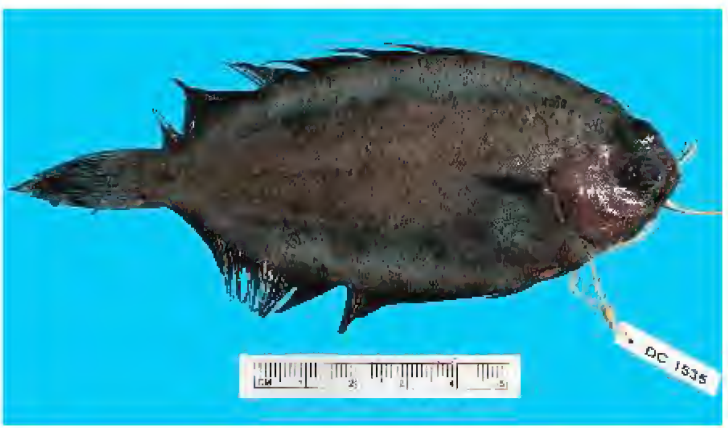

FIGURE 151. Poecilopsetta colorata, CAS 235551, $98 \mathrm{~mm}$ SL.

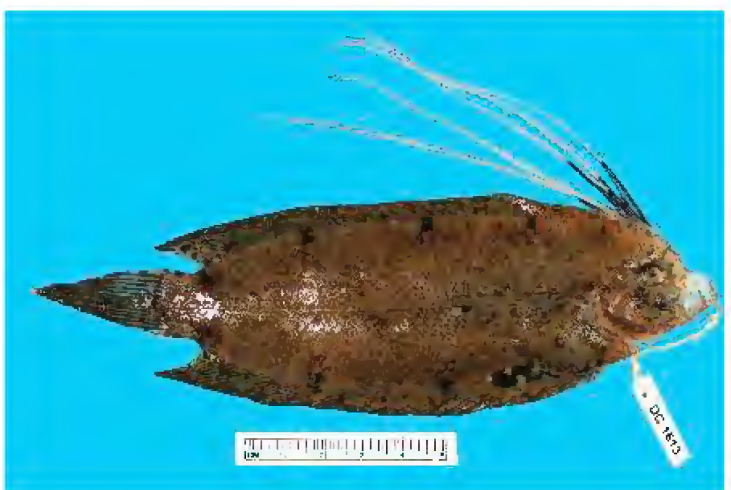

FIGURE 153. Samarus cristatus, CAS 235527, 122 mm SL.

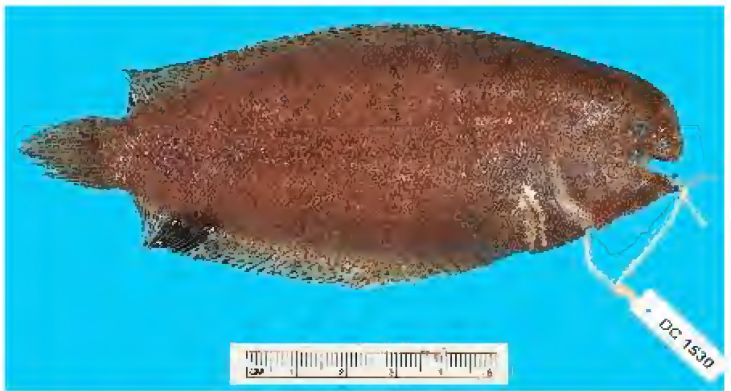

FIGURE 155. Aseraggodes sp., CAS uncat.

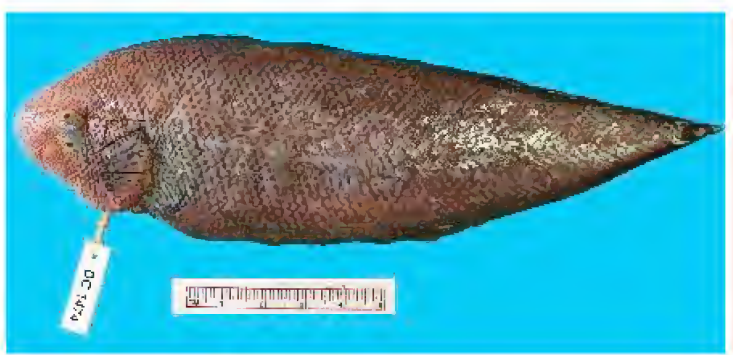

FIGURE 157a. Cynoglossus sp., CAS 236661, $160 \mathrm{~mm} \mathrm{SL,}$ sinistral (eyed) side.

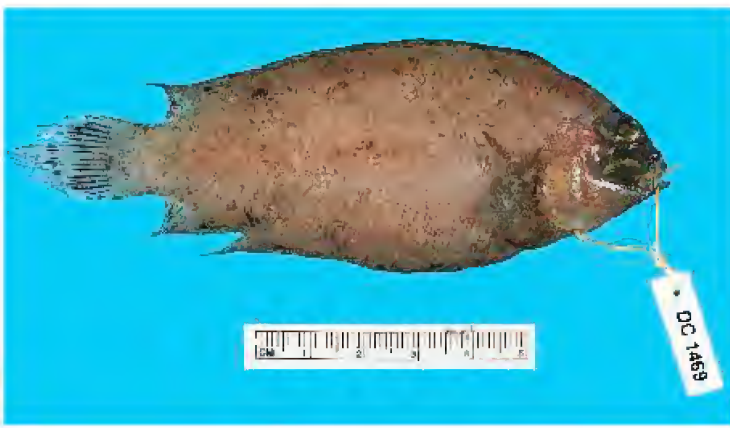

FIGURE 152. Poecilopsetta plinthus, CAS 235545 , $95 \mathrm{~mm}$ SL.

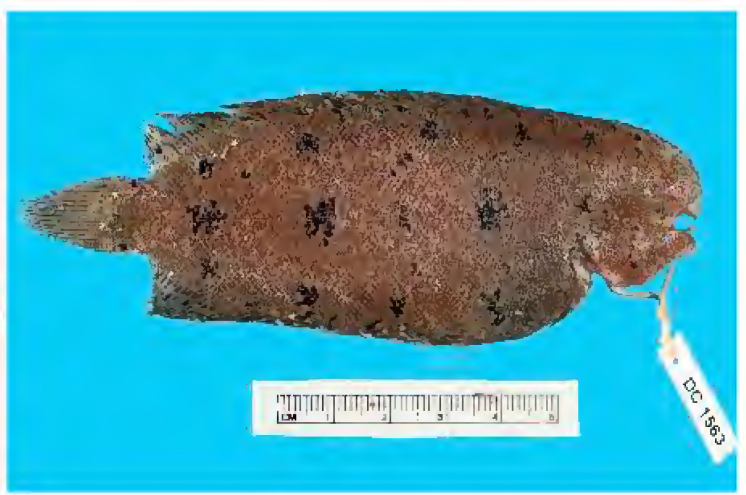

FIGURE 154. Aseraggodes kobensis, CAS 235733, $96 \mathrm{~mm} \mathrm{SL}$

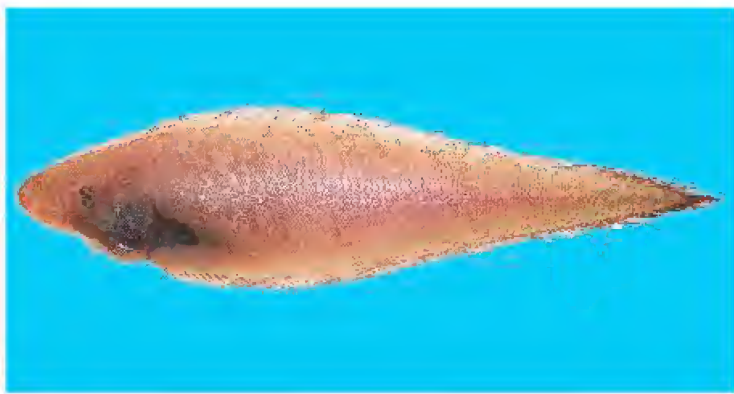

FIGURE 156. Cynoglossus gracilis?, CAS 236662, $166 \mathrm{~mm} \mathrm{SL}$

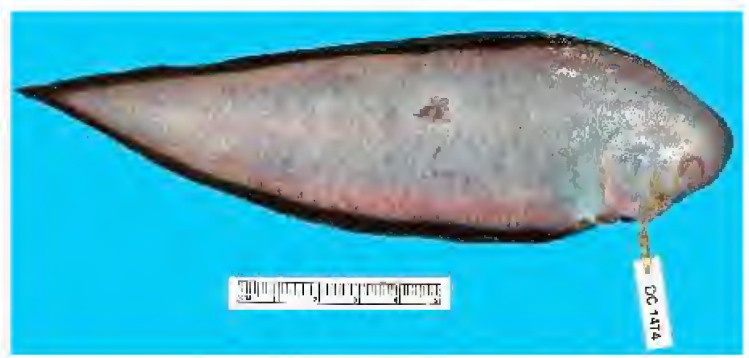

FIGURE 157b. Cynoglossus sp., CAS 236661, $160 \mathrm{~mm} \mathrm{SL}$, dextral (blind) side. 


\section{Plate XXVI}

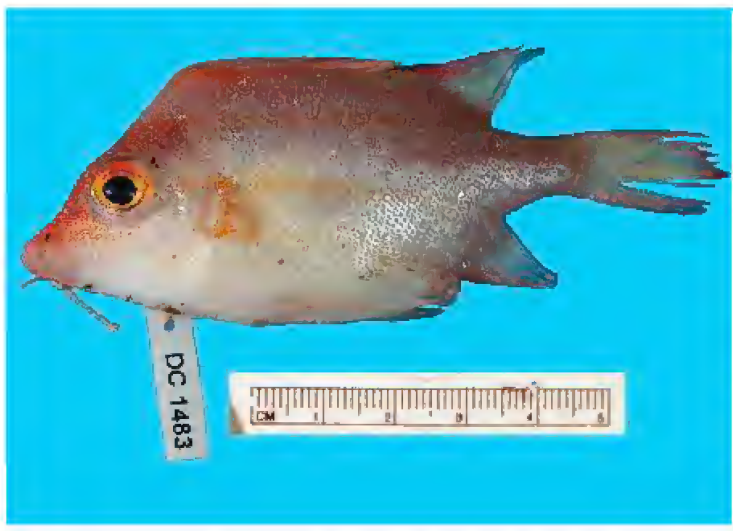

FIGURE 158. Triacanthodes ethiops, CAS 235886, $73.4 \mathrm{~mm} \mathrm{SL}$

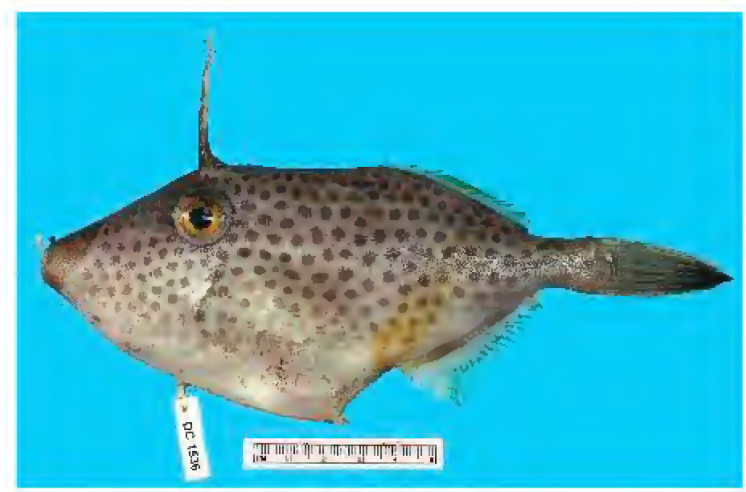

FIGURE 160. Thamnacornus tesselatus, CAS 235682 , $45.0 \mathrm{~mm}$ SL.

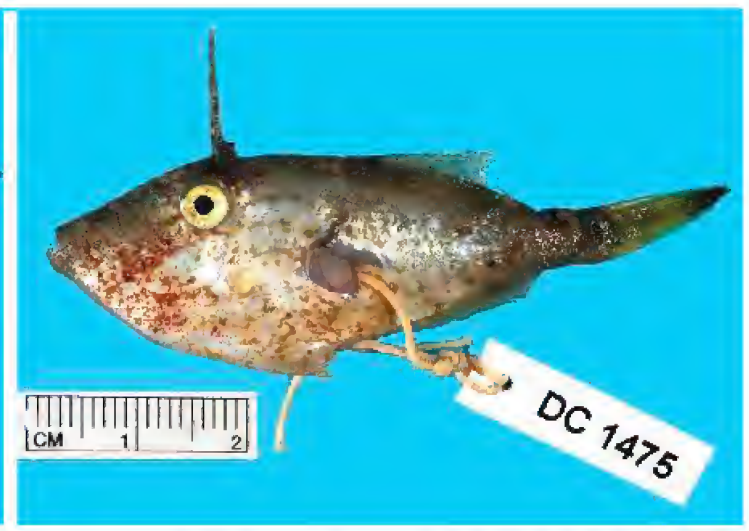

FIGURE 159. Paramonacanthus cf. curtorhynchos, CAS 236485, $48.5 \mathrm{~mm}$ SL.

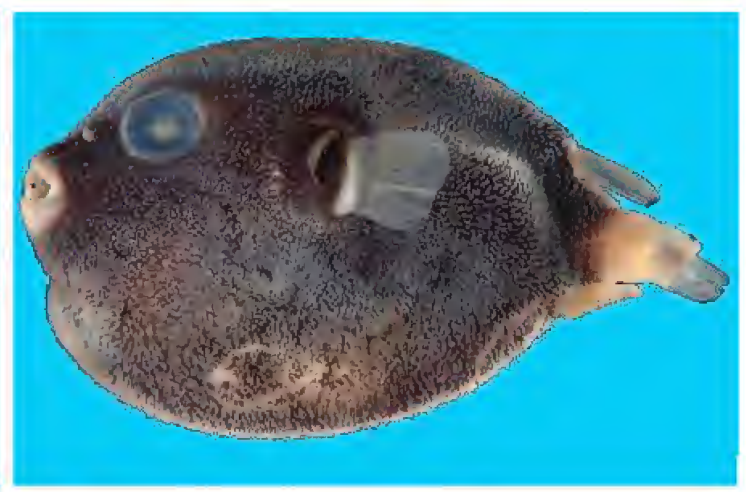

Figure 161. Arothron immaculatus, CAS 236559, $25.1 \mathrm{~mm}$ SL. Photo by Jon D. Fong.

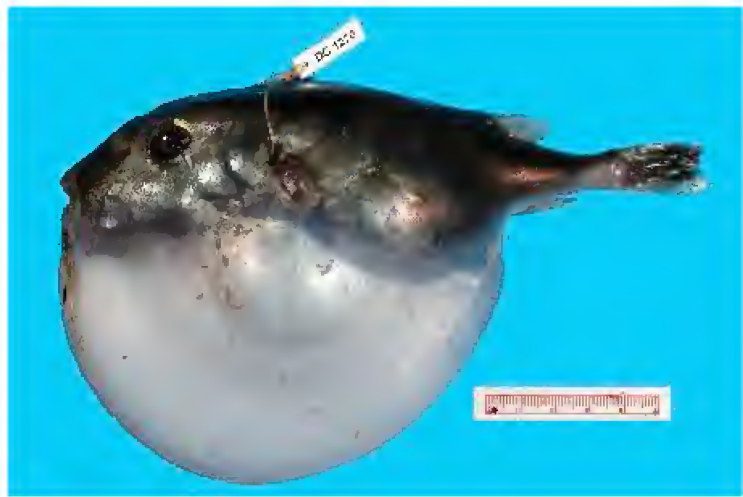

FIGURE 162. Sphoeroides pachygaster, CAS 235459 , $147 \mathrm{~mm}$ SL. 


\title{
A Gigantic Deepwater Worm Eel (Anguilliformes: Ophichthidae) from the Verde Island Passage, Philippine Archipelago
}

\author{
John E. McCosker \\ California Academy of Sciences, San Francisco, California 94118 \\ E-mail: Jmccosker@calacademy.org
}

\begin{abstract}
A new species of a deepwater ophichthid worm eel was collected from the Verde Island Passage of the Philippine Archipelago. Pylorobranchus hearstorum sp. nov., subfamily Myrophinae, is described and illustrated from a specimen trawled in 892-966 $\mathrm{m}$. It is much larger than any known myrophine and differs from its only congener, $P$. hoi, in its longer tail ( $66 \%$ of TL vs. $52-59 \%)$, shorter head $(8.8 \%$ of TL vs. 11.0-11.8\%), body depth (39 times in TL vs. 29-31), dorsal-fin origin (ahead of mid-trunk vs. behind mid-trunk), vertebral number (226 vs. 182-183), and its coloration (brownish black vs. uniform brown). The known ophichthid fauna of the Philippines is discussed and listed.
\end{abstract}

Keywords: Ophichthidae; Pylorobranchus hearstorum sp. nov.; Verde Island Passage, Philippines

The center of diversity of fishes in the Indo-Malay-Philippines archipelago is said to be in the Philippines (Carpenter and Springer 2005). The California Academy of Sciences recently mounted an expedition sponsored by William and Margaret Hearst to further investigate the diversity of plants and animals at several Philippine localities. Shallow water collections were made using scuba and deepwater collections were made aboard the M/V DA-BFAR in the vicinity of the Verde Island Passage, between Luzon and Mindoro islands. Preliminary findings have added several new marine fish species including a shallow water, coral reef-inhabiting snake eel, Myrichthys paleracio, collected from southern Luzon Island and described by McCosker and Allen (2012), and a deepwater myrophine trawled from the Verde Island Passage. Other eels collected, including two deepwater morays, are currently under investigation and may represent either new species or slightly different of rare and poorly known muraenids. The collections, although not comprehensive considering the diversity of habitats and the enormity of space in the Philippines, do indicate that additional unknown taxa remain to be discovered.

The center of diversity of ophichthid eels in the Indo-Malay-Philippines archipelago has not been adequately analyzed such that a confident prediction of comparative insular biodiversity can be made. Unpublished studies by systematists at the California Academy of Sciences (this author), the National Museum of Natural History (David G. Smith), and Silliman University (Abner Bucol) have advanced us toward that goal. The Philippine snake eels and worn eels of the family Ophichthidae were previously treated by Weber and de Beaufort (1916), Fowler (1918), Herre (1923), and subsequent authors including Allen and Erdmann (2012) and my published and unpublished works, resulting in a list comprising approximately 50 valid and six questionable species. ${ }^{1}$ Whereas the Philippine ichthyofauna comprises many ophichthids (Appendix 1), several of which (Muraenichthys philippinensis, M. thompsoni, and Myrichthys paleracio) are known only from the archipelago, there are many species and genera known from Malaysia and Indonesia that have yet

1 The type specimens of Muraenichthys malaboensis and Ophichthus manilensis, destroyed during WWII, have not been subsequently observed and probably are not valid species. 
to be found in the Philippines (Allen and Adrim 2003; Allen and Erdmann 2012; and unpub. data). Included are: Brachysomophis cirrocheilos, B. henshawi, Callechelys catostoma, C. marmorata, C. papulosa. Hemerorhinus heyningi, Phyllophichthus xenodontus, Schultzidia johnstonensis, Scolecenchelys acutirostris, and Xestochilus nebulosus.

Whereas most ophichthids are benthic and occupy 100 m or less, more recent deepwater trawling and trapping have demonstrated that many deepwater ophichthids remain to be discovered (McCosker 2010). I herein describe an additional worm eel known from a single specimen and collected in deep water from the Verde Island Passage. It is closely related to the deep water Pylorobranchus hoi McCosker et al. (2013) from Taiwan and is remarkable in that it is nearly twice as long and three times heavier than any known myrophine.

\section{MATERIALS AND METHODS}

Measurements are straight-line, made either with a $300 \mathrm{~mm}$ ruler with $0.5 \mathrm{~mm}$ gradations (for total length, trunk length, and tail length) and recorded to the nearest $0.5 \mathrm{~mm}$, or with dial calipers (all other measurements) and recorded to the nearest $0.1 \mathrm{~mm}$. Body length comprises head and trunk lengths. Head length is measured fiom the snout tip to the posterodorsal margin of the gill opening; trunk length is taken from the end of the head to mid-anus; maximum body depth does not include the median fins. Head-pore terminology follows that of McCosker et al. (1989:257) such that the supraorbital pores are expressed as the ethmoid pore + pores in supraorbital canal, e.g., $1 \times 3$, and the infraorbital pores are expressed as pores along the upper jaw + those in vertical part of canal behind eye (the "postorbital pores"), e.g., $4 \times 2$, in that frequently the last pore included along the upper jaw is part of the postorbital series. Osteological examination of the gill arches involved clearing and counterstaining with alcian blue and alizarin red dyes (Dingerkus and Uhler 1977). Other osteological examinations were made from radiographs. Vertebral counts, which include the hypural, were taken from a radiograph. Radiographic techniques are described in Böhlke (1989). The vertebral formula (VF) is expressed as the predorsal/preanal/total vertebrae (Böhlke 1982). Institutional abbreviations are as listed at http://asih.org/codons.pdf. The holotype of the new species is deposited in the fish collection of the California Academy of Sciences. Comparative material is despoited at both the CAS and at Taiwan Ocean University (TOU)

\section{Genus Pylorobranchus McCosker \& Chen 2013}

Type species Pylorobranchus hoi McCosker, Loh \& Lin 2013, by original designation

Pylorobranchus hearstorum McCosker, sp. nov.

Figures 1-4

Gigantic worm eel

Material EXAmined.- Holotype: CAS 235464, $1218 \mathrm{~mm}$ TL, female, field number DC1426, from the Verde Island Passage, Philippine Archipelago, captured by beam trawl at 892-966 $\mathrm{m}$ between $13.583^{\circ}-13.575^{\circ} \mathrm{N}, 120.382-120.411^{\circ} \mathrm{E}$ over a muddy substrate, aboard M/V $D A-$ BFAR, Sta. HEPD 016, between 1405-1440 hrs. on 31 May 2011.

DIAGNOSIS.- An elongate myrophine with the following characteristics: tail $66 \%$ of TL; dorsal fin arising in posterior trunk region; dorsal fin slightly elevated, anal fin very elevated; pectoral fin wedge-shaped, developed, about four times eye diameter; eye moderate, 17 in HL; rear margin of orbit above posterior third of upper jaw; cephalic pores small, SO 1 × 3 , IO 5 × 2, POM 7 × 3 ( 2 right), and ST 3 present; teeth needle-shaped, not enlarged, slightly retrorse, uniserial on jaws and vomer; coloration brownish black, median fins grayish black, anal-fin membrane black posteriorly. Vertebral formula 39/66/226.

COUNTS AND MEASUREMENTS OF THE HOLOTYPE (IN MM).- Total length 1218; head length 
139 ; trunk length 278 ; tail length 801 ; body depth at gill openings $\sim 42$; body width at gill openings $\sim 31$; body depth at branchial basket $\sim 48$; body width at branchial basket $\sim 42$; body depth at anus $\sim 35$; body width at anus $\sim 25$; origin of dorsal fin 267 ; pectoral-fin length 32.8 ; pectoral-fin base 11; gill-opening length $\sim 12$; isthmus width $\sim 23$; snout length 27.7 ; tip of snout to tip of lower jaw 5.6; upper-jaw length 44.6; eye diameter 8.3; interorbital distance 18.9. Total left-lateral pores 210 lateral-line pores present, 17 above branchial basket, 59 before anus. Vertebral formula 39/66/ 226. Wet weight after preservation $526 \mathrm{~g}$.

DESCRIPTION. - Body elongate (Fig. 1), depth at gill openings 29 in TL, laterally compressed throughout, more so in tail region. Head and trunk 3.6 and head 8.8 in TL. Snout acute (Fig. 2), rounded but not blunt at tip, without a median groove on its underside. Jaws moderately elongate, slightly curved, incapable of closing completely; center of eye in posterior $1 / 3$ of upper jaw. Lower jaw included, its tip slightly beyond anterior base of anterior nostrils. Anterior nostrils directed anterolaterally, in very short tubes, without marginal extensions; posterior nostril an open horizontal slit along outside of upper lip at level beginning slightly above ventral margin of orbit in advance of anterior margin of eye. Eye moderate, its center at midpoint of upper lip and top of head, its diameter about 2.3 in interorbital distance. Interorbital region slightly elevated. Gill openings below lateral mid-line, larger than orbit, located in advance of ventral base of pectoral-fin. Dorsal fin low in trunk and anterior tail

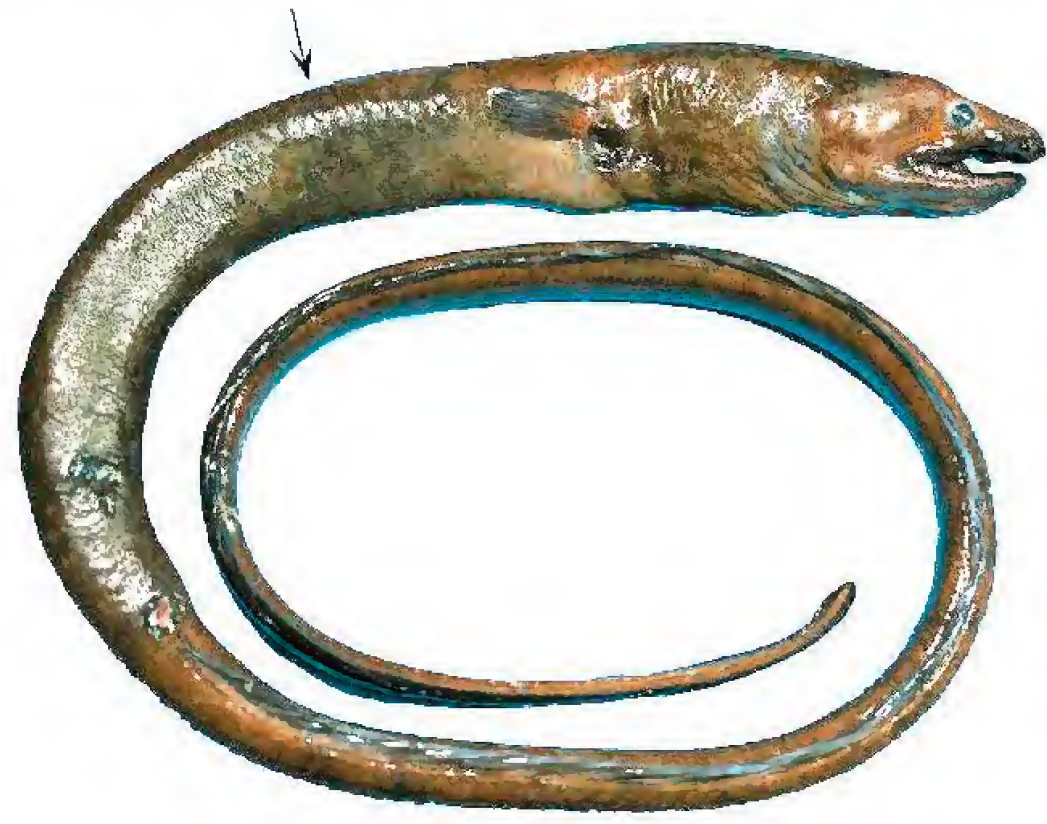

Figure 1. Holotype of Pylorobranchus hearstorum sp. nov., CAS 235464, female, $1218 \mathrm{~mm}$ TL, photographed soon after capture and before preservation by David Catania. Arrow indicates origin of the dorsal fin

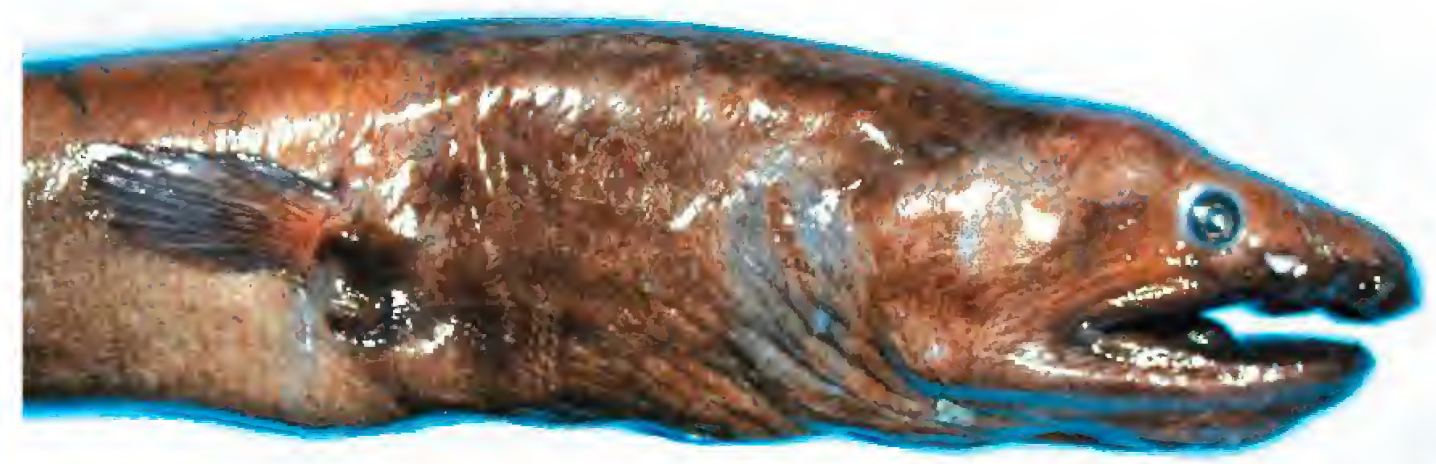

FIGURE 2. Head of holotype of Pylorobranchus hearstorum sp. nov., CAS 235464,female, $1218 \mathrm{~mm}$ TL, photographed soon after capture and before preservation by David Catania. 
region, becomes elevated posteriorly. Dorsal-fin origin in posterior trunk region, arising 2 HL behind snout tip. Anal-fin membrane elongate, twice in body depth when extended, median fins confluent with caudal; caudal fin short. Pectoral fins wedge-shaped,

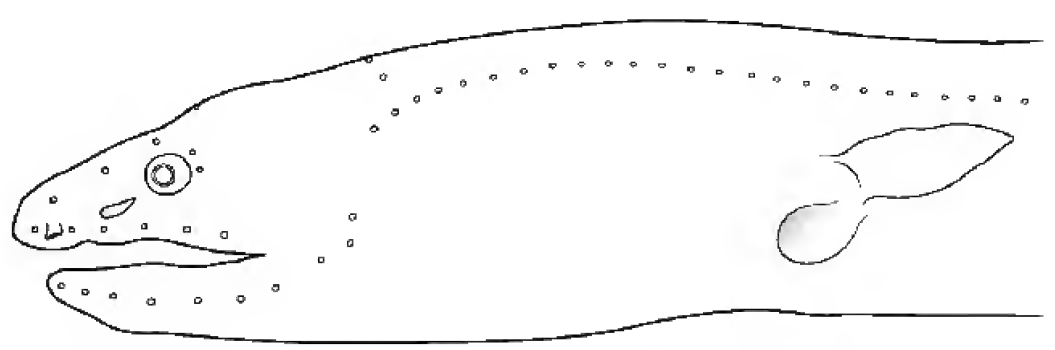

FIgURE 3. Schematic illustratiton of head of holotype of Pylorobranchus hearstorum sp. nov., CAS 235464, female, 1218 mm TL. Illustration prepared by Corlis Schneider. longer than snout, rays of dorsal quarter the longest.

Head pores minute but apparent (Fig. 3); SO 1 x 3, IO 5 x 2, POM $7 \times 3$ (2 right, the dorsalmost pore absent), ST 3 . A single temporal and interorbital pore. Two infraorbital pores between anterior and posterior nostrils. Approximately 210 lateral-line pores present, 17 above branchial basket, 59 before anus, last pore about $0.37 \mathrm{HL}$ before tail tip.

Teeth (Fig. 4) needle-shaped, recurved, all teeth uniserial and widely spaced, becoming slightly smaller posteriorly on jaws and vomer. An anterior intermaxillary horseshoe-shaped band of 4 teeth, followed by 2 pairs of slightly larger teeth, followed by a uniserial linear row of 6 vomerine teeth. Maxillary teeth 11 in a linear row, decreasing in size and irregularly separated by short gaps. Mandibular teeth lack a symphyseal pair, 10 (right) to 15 (left), decreasing in size and irregularly separated by short gaps.

Gill arches moderately developed: basibranchials 1-4 cartilaginous; hypobranchials 1-2 ossified, 3 cartilaginous; ceratobranchials 1-4 ossified, 5 absent; epibranchials 1-4 ossified; infrapharyngobranchials 1-2 ossified; third upper pharyngeal tooth plate with 3 conical teeth, fourth upper pharyngeal tooth plate with 3 longitudinal rows of 8-9 conical teeth, the plates closely sutured but not fused; lower pharyngeal tooth plate with 10-12 conical teeth in 3 irregular longitudinal rows. Teeth are comparable in size and appearance to those of jaws.

Body coloration in ethyl alcohol uniform dark brown. (Coloration of fresh specimen shown in Figures 1-2). Approximately 20 diffuse black saddles overlay trunk and anterior tail area, their interspaces wider than the saddles. Median fins gray anteri-
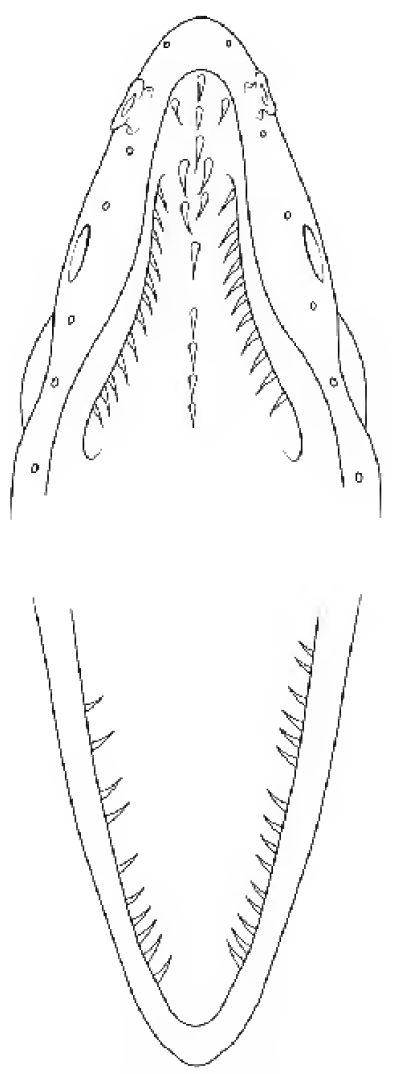

FIGURE 4. Schematic illustration of dentition of holotype of Pylorobranchus hearstorum sp. nov., CAS 235464,female, $1218 \mathrm{~mm}$ TL. Illustration prepared by Corlis Schneider. orly, the anal fin becoming black in posterior half of its length, the dorsal black in posterior quarter of its length. Pectoral fins uniformly brownish gray. Interior surface of posterior nostril white. Palate gray-black, teeth reside in white bands. Gill openings and peritoneum black.

ETYMOLOGY.- I take pleasure in naming this remarkable new species in honor of William and Margaret Hearst, friends and philanthropists.

REMARKS. - The new species might be mistakenly identified as a congrid by someone unfamiliar with the subtle characteristics of myrophine ophichthids. Its enormous size, elongation, tail 
condition, and posterior nostril location above the lip edge are similar in appearance to that of many deepwater congrids. Indeed, the holotype of the new species is remarkable in that it is nearly twice as long as and three times heavier than any known myrophine specimen. The second largest known specimen is the holotype of its conspecific, Pylorobranchus hoi, which is $676 \mathrm{~mm}$ in total length and $176 \mathrm{~g}$ in wet weight. Most myrophines reach no more than $450 \mathrm{~mm}$ TL and many are mature at $100 \mathrm{~mm}$ TL or less (McCosker unpublished data).

The discovery of this, the second species of Pylorobranchus, requires a minor revision of a generic character unique to $P$. hoi. The general osteology of the two species does not differ (as viewed from radiographs). The condition of their gill arches, which were removed and cleared-andstained, is nearly identical; the first ceratobranchial of $P$. hearstorum is cartilaginous whereas that of $P$. hoi appears to be slightly ossified. Such differences exist within species of other ophichthids (Nelson 1966; McCosker 1977). The degree of median fin elevation, pectoral fin shape and size, body elongation and lateral compression, jaw condition, dentition, posterior nostril condition, and cephalic pore number and location are shared by both. The size and location of the gill opening (McCosker et al. 2013) of $P$. hoi ("at lateral midline, reduced, a small opening smaller than eye diameter, preceded anteromedially by a small lappet-like fleshy protuberance"), does not differ; however, the fleshy protuberance is absent in P. hearstorum.

The new species is separable from Pylorobranchus hoi by several meristic and morphometric conditions. It has more vertebrae ( $P$. hearstorum 226 vs. $P$. hoi 182-183) more lateral-line pores (P. hearstorum $\sim 210$ vs. P. hoi 135 ), a longer tail ( $P$. hearstorum $66 \%$ of TL vs. $P$. hoi $52-59 \%$ ), a shorter head ( $P$. hearstorum $8.8 \%$ of TL vs. $P$. hoi $11.0-11.8 \%$ ), a more posterior dorsal-fin origin ( $P$. hearstorum ahead of mid-trunk vs. $P$. hoi behind mid-trunk), a more slender body and tail ( $P$. hearstorum greatest depth 39 times in TL vs. $P$. hoi 29-31 times), shorter anterior nostrils, and it is darker in coloration ( $P$. hearstorum is uniform brownish black vs. $P$. hoi, which is uniform brown, head and trunk gray ventrally). It is unlikely that the new species would be mistaken for any other known myrophine (see the "Key to the Genera of Myrophinae" in McCosker et al. 2013), many of which lack pectoral fins and nearly all of which have their posterior nostril within their upper lip and opening into the mouth.

The holotype is a female with minute undeveloped ova. Based on its dentition and jaw condition it is likely that Pylorobranchus hearstorum, like $P$. hoi, feeds upon crustaceans and small fishes. Other fishes collected by deep water traps and by trawls during the Academy Expedition in the Verde Island Passage are listed and explained by Iwamoto et al. (this volume).

COMPARATIVE MATERIAL EXAMINED.-Pylorobranchus hoi: TOU-AE 5574, $676 \mathrm{~mm}$ TL, holotype; TOU-AE 5525, $568 \mathrm{~mm}$ TL, and CAS 233704, $657 \mathrm{~mm}$ TL, paratypes

\section{ACKNOWLEDGMENTS}

I wish to thank: David Catania (CAS) for the use of his photographs and assistance in the field; Corlis Schneider for preparing figures 3-4; Mysi Hoang (CAS) for preparing figures 1-2 and for staining and clearing the gill arches of the holotype; Terence Gosliner (CAS) for his leadership of the Hearst Expedition; the crew of the M/V DA-BFAR; the staffs of the California Academy of Sciences (CAS), Hsuan-Ching Ho of the Institute of Marine Biodiversity and Evolutionary Biology, Checheng, Taiwan, and the staff of the fish division, National Museum of Natural History (USNM), Washington D. C., for advice and assistance with specimens; and Tomio Iwamoto (CAS) and David Smith (USNM) for reading a draft of this manuscript. And finally, I sincerely thank Margaret and Will Hearst for their generous support of the Academy expedition to the Philippines. 


\section{REFERENCES}

Allen, G. R. And M. Adrim. 2003. Coral Reef Fishes of Indonesia. Zoological Studies 42:1-72.

Allen, G. R. And M. V. Erdmann. 2012. Reef Fishes of the East Indies, Vol. 1. Tropical Reef Research, Bali, Indonesia. $424 \mathrm{pp}$.

BöHlkE, E. B. 1982. Vertebral formulae of type specimens of eels (Pisces: Anguilliformes). Proceedings of the Academy of Natural Sciences of Philadelphia 134:31-49.

BöHLKe, E. B. 1989. Methods and Terminology. Pages 1-7 in E. B. Böhlke, ed., Fishes of the Western North Atlantic, Part Nine, Vol. One: Orders Anguilliformes and Saccopharyngiformes. Sears Foundation for Marine Research, Yale University, New Haven, Connecticut, USA.

Carpenter, K., and V. G. Springer. 2005. The center of the center of marine shore fish biodiversity: the Philippine Islands. Environmental Biology of Fishes 72:467-480.

Dingerkus, G., AND L. D. Uhler. 1977. Enzyme clearing of alcian blue stained whole small vertebrates for demonstration of cartilage. Stain Technology 52:229-232.

Fowler, H. W. 1918. New and little known fishes from the Philippine Islands. Proceedings of the Academy of Natural Sciences of Philadelphia 70:2-71.

Herre, A. W. C. T. 1923. A review of the eels of the Philippine Archipelago. Philippine Journal of Science 23(2):123-236, pls. 1-11.

McCosker, J. E. 1977. The osteology, classification, and relationships of the eel family Ophichthidae. Proceedings of the California Academy of Sciences, ser. 4, 41(1):1-123.

McCosker, J. E. 2010. Deepwater Indo-Pacific species of the snake-eel genus Ophichthus (Anguilliformes: Ophichthidae), with the description of nine new species. Zootaxa (2505):1-39.

McCosker, J. E., AND G. R. Allen. 2012. Description of a New Snake Eel (Pisces: Ophichthidae: Myrichthys) from the Philippines. Aqua 18(1):35-40.

McCosker, J. E., E. B. BöhlKE, AND J. E. BöhlKe. 1989. Family Ophichthidae. Pages 254-412 in E. B. Böhlke, ed., Fishes of the Western North Atlantic, Part Nine, Vol. One: Orders Anguilliforntes and Saccopharyngiformes. Sears Foundation for Marine Research, Yale University, New Haven, Connecticut, USA.

McCosker , J. E., K.-H. LoH, J. Lin, AND H.-M. Chen. 2113. Pylorobranchus hoi, A New Genus and Species of Myrophine Worm eel from Taiwan (Anguilliformes: Ophichthidae. Zoological Studies. 51(7): $1188-1194$

Nelson, G J. 1966. Gill arches of teleostean fishes of the order Anguilliformes. Pacific Science 20(4):391-408.

Weber, M., And L. F. De Beaufort. 1916. Fishes of the Indo-Australian Archipelago, Vol. 3. Ostarophysi: II Cyprinoidea, Apodes, Synbranchi. E. J. Brill, Leiden, Netherlands. 455 pp. 


\section{APPENDIX}

\section{Provisional list of ophichthid eels from the Philippine Islands}

Based on specimens in the fish collections of the California Academy of Sciences (CAS) and the National Museum of Natural History (USNM), and my unpublished data. Those species whose identity or status is unclear or uncertain are marked by "?"

Apterichtus klazingai (Weber 1913)

Bascanichthys myersi (Herre 1932)

Benthenchelys cartieri Fowler 1934

Brachysomophis crocodilinus (Bennett 1833)

Brachysomophis umbonis McCosker \& Randall 2001

Cirrhimuraena chinensis Kaup 1856

Cirrhimuraena playfairii (Günther 1870)

Ichthyapus vulturis (Weber \& de Beaufort 1916)

Lamnostoma kampeni (Weber \& de Beaufort 1916)

? Lamnostoma mindora (Jordan \& Richardson 1908)

Lamnostoma orientalis (McClelland 1844)

Lamnostoma taylori (Herre 1923)

Leiuranus semicinctus (Lay \& Bennett 1839)

Leiuranus versicolor (Richardson 1848)

Muraenichtlys gymnopterus (Bleeker 1853)

? Muraenichthys malaboensis Herre 1923

Muraenichthys philippinensis Schultz \& Woods 1949

Muraenichthys schultzei Bleeker 1857

Muraenichthys thompsoni Jordan \& Richardson 1908

Myrichthys colnbrinus (Boddaert 1781)

Myrichthys maculosus (Cuvier 1816)

Myrichthys paleracio McCosker \& Allen 2012

Myrophis microchir (Bleeker 1864)

Ophichthus altipennis (Kaup 1856)

Ophichthus apicalis (Anonymous [Bennett] 1830)
Oplichthus bonaparti (Kaup 1856)

Ophichthus cephalozona Bleeker 1864

Ophichthus lithinus (Jordan \& Richardson 1908)

Ophichthus macrochir (Bleeker 1853)

? Ophichthus manilensis Herre 1923

Ophichthus mystacinus McCosker 1999

Ophichthus polyophthalmus Blecker 1865

Ophichthus tomioi McCosker 2010

Ophichthus urolophus (Temminck \& Schlegel 1846)

Phyllophichthyus xenodontus Gosline 1951

Pisodonophis boro (Hamilton 1822)

Pisodonophis cancrivorus (Richardson 1848)

? Pisodonophis copelandi Herre 1953

Pylorobranchus hearstorum sp. nov.

Schultzidia retropinnis (Fowler 1934)

? Scolecenchelys godeffroyi (Regan 1909)

Scolecenchelys gymnota (Blceker 1857)

Scolecenchelys laticaudata (Ogilby 1897)

Scolecenchelys macroptera (Bleeker 1857)

Skythrenchelys macrostomus (Bleeker 1864)

Skythrenchelys zabra Castle \& McCosker 1999

Xyrias revulsus Jordan \& Snyder 1901

Yirrkala kaupi (Bleeker 1858)

Yirrkala misolensis (Günther 1872)

? Yirrkala philippinensis (Herre 1936) 


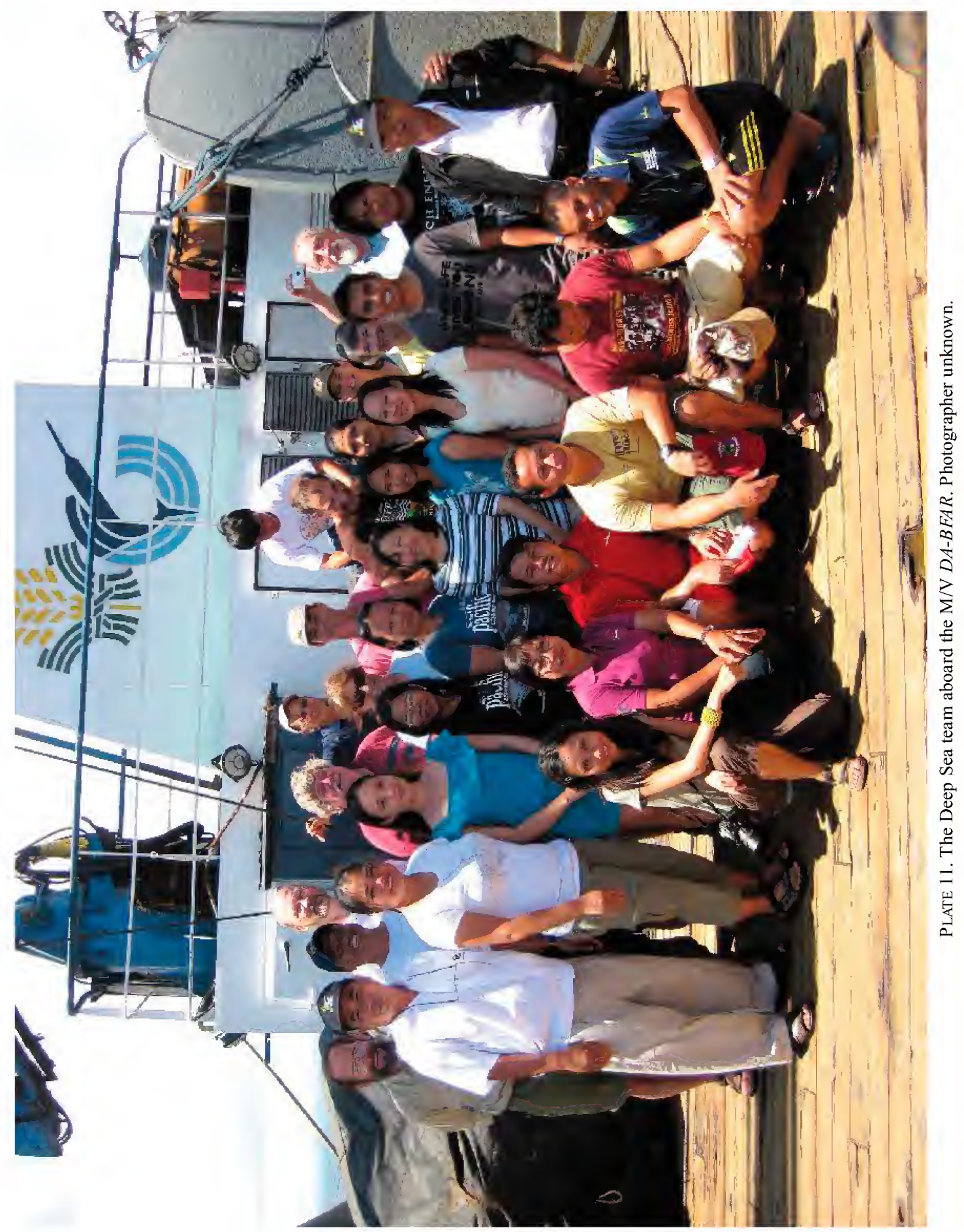




\title{
Redescription of Eptatretus luzonicus Fernholm et al., 2013, a Replacement Name for Eptatretus fernholmi McMillan and Wisner, 2004 (Craniata: Myxinidae), Based on the Discovery of the Holotype and Additional Specimens from the Philippines
}

\author{
Michael Maia Mincarone ${ }^{1}$ and John E. McCosker ${ }^{2}$ \\ ${ }^{1}$ Universidade Federal do Rio de Janeiro (UFRJ), Núcleo em Ecologia e Desenvolvimento Socioambiental \\ (NUPEM), Caixa Postal 119331, Macaé, RJ, 27910-970,Brazil; E-mail: mincarone@macae.ufrj.br; \\ 2 California Academy of Sciences, San Francisco, CA, 94118, USA; E-mail: jmccosker@calacademy.org
}

\begin{abstract}
The holotype of the hagfish Eptatretus luzonicus (= Eptatretus fernholmi) (Myxinidae), lost prior to its description, was found and is redescribed along with five additional specimens trapped at 578-710 $\mathrm{m}$ depth between Luzon and Mindoro islands during the 2011 California Academy of Sciences Hearst Philippine Expedition. In addition, a single specimen of Myxine cf. formosana, previously known from Taiwan, was also trapped at the same location, between 587 and $604 \mathrm{~m}$ depth.

KEYwords: Myxinidae; Eptatretus luzonicus; Eptatretus fernholmi; redescription; taxonomic history; Philippines.
\end{abstract}

On 16 October 1907, the U.S. Fish Commission Steamer Albatross left San Francisco on her way to Manila for the longest and most extensive expedition of the ship's career. It took about 2.5 years before the Albatross crossed the Golden Gate again, bringing in her holds thousands of fishes and invertebrates that were later deposited in the U.S. National Museum, Smithsonian Institution. The number of fishes collected during the Albatross Philippine Expedition is difficult to calculate but it was estimated at about 100,000 specimens (Smith and Williams 1999), including a single hagfish specimen. This specimen remained unnamed for many years until it was described as Eptatretus fernholmi McMillan and Wisner, 2004, a name recently replaced by Eptatretus luzonicus Fernholm, Norén, Kullander, Quattrini, Zintzen, Roberts, Mok, and Kuo, 2013.

Nearly a century later, the California Academy of Sciences Hearst Expedition to the Philippines included a voyage aboard the M/V DA-BFAR in the vicinity of the Verde Island Passage and the Calavite Passage (between Luzon and Mindoro islands). Although the deepwater marine portion of the Hearst Expedition was limited in duration and coverage, it was able to capture, photograph, and study numerous fishes and invertebrates that were poorly known or new to science. From 28 May to 4 June 2011, a total of 29 bottom trawl stations were made between 82 and $2217 \mathrm{~m}$ and eight trap stations were set from 60-841 m depth. Six specimens of hagfishes were trapped: a single specimen tentatively identified as Myxine formosana Mok and Kuo, 2001, previously reported from Taiwanese waters, and five additional specimens of Eptatretus luzonicus, previously known only from the damaged and lost holotype collected from the Philippines. The discovery of the holotype and additional material of E. luzonicus deserve special discussion and that is the purpose of this paper.

\section{MateriaLs AND Methods}

Measurements and counts (Table 1) and the names for anatomical structures follow Fernholm and Hubbs (1981), McMillan and Wisner (1984), Wisner and McMillan (1995), and Mok (2001). 
Length of the specimens (in mm) is given as total length (TL), the distance from the front of the rostrum to the end of the caudal finfold. All other measurements are given as percentage of TL (Table 1). About $7-11 \%$ shrinkage was noted in the TL of four specimens that were measured before preservation. Some shrinkage occurs in all myxinid specimens upon preservation, mainly in the trunk length (McMillan and Wisner 1984).

Counts of gill pouches and cusps were taken from both sides, whereas slime pore counts are from the left side. Details on the deepwater fishes collected during the Hearst Expedition are provided by Iwamoto and McCosker (2014). Specimens examined are deposited in the fish collections of the California Academy of Sciences (CAS), National Museum of Natural History (USNM), and Núcleo em Ecologia e Desenvolvimento Socioambiental, Universidade Federal do Rio de Janeiro (NPM).

\section{TAXONOMIC History OF EPTATRETUS LUZONICUS (= EPTATRETUS FERNHOLMI)}

Eptatretus luzonicus has a convoluted and curious taxonomic history. The holotype was collected in 1909 during the Albatross Expedition to the Philippines and deposited at the USNM fish collection. Like many of the nearly 100,000 specimens collected during the expedition it was apparently shelved and remained unidentified for many decades ( $c f$. Smith and Williams 1999). While at the USNM, on June 29, 1972, Carl Leavitt Hubbs of the Scripps Institution of Oceanography (SIO) examined the hagfish specimen collected by the Albatross Expedition and identified it as Myxine garmani Jordan and Snyder, 1901; it was catalogued as USNM 207761 on July 11,1972. It was then sent to Hubbs on loan at SIO and, after further examination, Hubbs thought that it was an undescribed species of Myxine but did not open the abdominal cavity to count its gill pouches (which would have allowed the proper generic identification). The specimen remained at SIO and was later examined by Bo Fernholm of the Swedish Museum of Natural History during a six-month collaboration that he spent at SIO with Hubbs. At that time they realized that it was a new species of Eptatretus and they gave it the manuscript name "Eptatretus luzonica". They recognized that the specimen was in poor condition and were eager to get more and better material for its description. Fernholm went to the Philippines in an effort to get more specimens but he did not succeed, and they never published the new species (Bo Fernholm pers. comm., February 17, 2012).

Subsequently, Charmion McMillan and Robert Wisner worked in the Hubbs lab at SIO and assisted him with his hagfish studies. In 2004 they published a review of the hagfishes from the northwestern Pacific, in which they described three new species, Eptatretus fernholmi, Paramyxine moki, and Paramyxine walkeri (McMillan and Wisner 2004). They briefly described the Philippine specimen collected by the Albatross Expedition as Eptatretus fernholmi without examination of any specimen. Their description was based on a picture and unpublished notes by Bo Fernholm. They mentioned that Bo Fernholm ". . . planned to describe it as a new species 'E. luzonica' with Carl L. Hubbs, to whom he gave the data and photo, but apparently abandoned the idea when Hubbs died a few years later. The notes and photo came into our possession with other hagfish data when Hubbs' lab was closed." McMillan and Wisner (2004) also stated that “. . . the specimen was left in the National Museum of Natural History", but the specimen was never returned to the USNM fish collection. In February 2012, in response to a request by Michael Mincarone and Bo Fernholm, Philip Hastings and H. J. Walker were able to locate the specimen (Fig. 1) at SIO.

Recently, Fernholm et al. (2013) performed a phylogenetic analysis of the Myxinidae based on molecular data, which resulted in the synonymization of Paramyxine with Eptatretus. This created a homonymy of Paramyxine fernholmi Kuo, Huang, and Mok, 1994 (from Taiwan) with Eptatretus fernholmi McMillan and Wisner, 2004 (from the Philippines). As Eptatretus fernholmi became 
a junior homonym of Paramyxine fernholmi, its name was replaced by Eptatretus luzonicus Fernholm, Norén, Kullander, Quattrini, Zintzen, Roberts, Mok, and Kuo, 2013. A similar name, "Eptatretus luzonica", was mentioned by McMillan and Wisner (2004) in the original description of E. fernholmi, as the name initially intended for the species.

\section{Eptatretus luzonicus Fernholm, Norén, Kullander, Quattrini, Zintzen, Roberts, Mok, and Kuo, 2013}

Figures 1-4; Table 1

Eptatretus fernholmi McMillan and Wisner, 2004:53 (former name).

Material eXamined.- Holoty pe: USNM 207761, tag 8686, $373 \mathrm{~mm}$ TL [now $360 \mathrm{~mm}$ ], R/V Albatross, station D5444: $12^{\circ} 43^{\prime} 51^{\prime \prime} \mathrm{N}, 124^{\circ} 58^{\prime} 50^{\prime \prime} \mathrm{E}$, off Atalaya Point, NW of Batag Island, northern Samar, the Philippines, collected by 12 foot Agassiz beam trawl, at 308 fathoms $(563 \mathrm{~m})$ depth, green mud bottom, 3 June 1909, 0957-1049 h. AdDITIONAL MATERIAL: CAS 233675 (1, 563 $\mathrm{mm}$ TL), M/V DA-BFAR, station HEPD 023: 135'01.1994"N, 120 04'34.2006"E, between Luzon and Mindoro islands, the Philippines, collected by trap, at 316-388 fathoms (578-710 m) depth, sandy-muddy bottom, 1-2 June 2011, 2035-0645 h. CAS 233676-233678 (3, 334-430 mm TL),

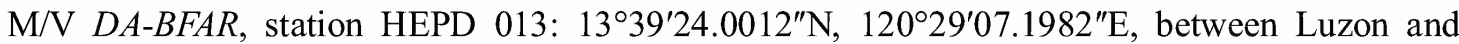
Mindoro islands, the Philippines, collected by trap, at 321-330 fathoms (587-604 m) depth, muddy bottom, 30-31 May 2011, 2010-0715 h. NPM 1999 (1, $443 \mathrm{~mm}$ TL), collected with CAS 233676.

Diagnosis. - Eptatretus luzonicus can be distinguished from all known congeners by the following combination of characters: eight pairs of gill pouches; 3-cusp multicusps on the anterior sets and 2-cusp multicusps on the posterior sets of cusps; 47-51 total cusps; $13-15$ prebranchial pores; $49-55$ trunk pores; $84-88$ total pores; a single nasal-sinus papilla in the middorsal surface of the nasal sinus.

Description.- Based on the holotype and five non-type specimens: Body subcylindrical, slightly deeper than wide at prebranchial and branchial regions, laterally compressed at trunk and strongly compressed at tail. Rostrum bluntly rounded. A single nasal-sinus papilla in the middle of the dorsal surface of the nasal sinus (not seen in the holotype). Three pairs of barbels on head, first two pairs about nearly equal in size $(1.1-1.5 \% \mathrm{TL})$ and adjacent to opening of nasopharyngeal duct; third pair longer (2.0-2.4\% TL) and immediately adjacent to oral cavity. Ventral finfold 1-7 $\mathrm{mm}$ high, beginning within anterior $22-38 \%$ of trunk, extending backward to the cloaca. Caudal finfold thin, its ventral outline nearly straight, beginning immediately posterior to edge of cloaca, extending around tail to dorsal surface, ending nearly over cloaca.

Total length of the six specimens analyzed (including the holotype) range from 334 to 563 $\mathrm{mm}$. Body proportions as a percentage of total length (those of holotype given first, followed by ranges of non-type specimens in parentheses): preocular length 5.8 (5.4-6.3); prebranchial length 21.4 (20.7-22.6); branchial length 8.3 (7.4-7.8); trunk length 55.6 (53.0-55.1); tail length 15.0 (16.0-17.2); body width at prebranchial region 4.7 (4.8-6.7); body depth at mid-trunk including

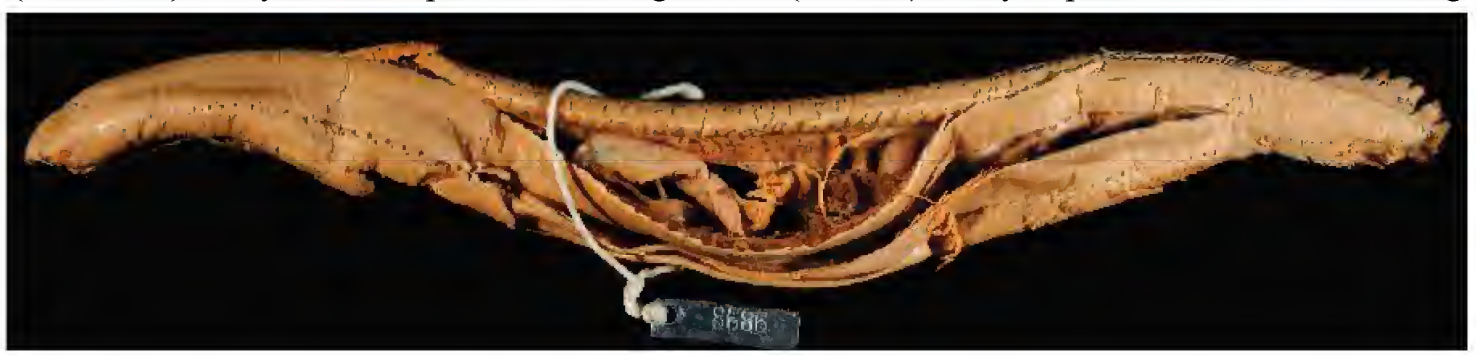

FIGURE 1. Holotype of Eptatretus luzonicus; USNM 207761, 360 mm TL. 
TABLE 1. Proportions and counts for the holotype and non-type specimens of Eptatretus luzonicus from the Philippines.

\begin{tabular}{|c|c|c|c|c|c|c|c|}
\hline \multirow[b]{3}{*}{ Collection number } & \multirow{3}{*}{\begin{tabular}{|c|} 
McMillan and \\
Wisner (2004)
\end{tabular}} & \multicolumn{6}{|c|}{ Present study } \\
\hline & & \multirow{2}{*}{\begin{tabular}{|c|} 
Holotype \\
USNM \\
207761 \\
\end{tabular}} & \multicolumn{5}{|c|}{ Non-types } \\
\hline & & & $\begin{array}{c}\text { CAS } \\
233675\end{array}$ & $\begin{array}{c}\text { CAS } \\
233676\end{array}$ & $\begin{array}{c}\text { CAS } \\
233677\end{array}$ & $\begin{array}{c}\text { CAS } \\
233678 \\
\end{array}$ & $\begin{array}{c}\text { NPM } \\
1999\end{array}$ \\
\hline Tag number & & & DC-1501 & DC-1387 & DC-1389 & DC-1393 & DC-1394 \\
\hline Sex & $?$ & $?$ & Female & $?$ & Female & Female & Female \\
\hline Total length (mm) & 373 & 360 & 563 & $\begin{array}{c}334 \\
\text { (360 fresh) }\end{array}$ & $\begin{array}{c}430 \\
\text { (485 fresh) }\end{array}$ & $\begin{array}{c}404 \\
\text { (453 fresh) }\end{array}$ & $\begin{array}{c}443 \\
\text { (490 fresh) }\end{array}$ \\
\hline \multicolumn{8}{|c|}{ Measurements in \%TL } \\
\hline Preocular length & - & 5.8 & 6.2 & 6.3 & 5.6 & 6.2 & 5.4 \\
\hline Prebranchial length & 21.2 & 21.4 & 21.7 & 21.3 & 20.7 & 21.8 & 22.6 \\
\hline Preventral length & - & $?$ & 48 & 46.4 & 49.3 & 45.8 & 42 \\
\hline Branchial length & 8 & 8.3 & 7.8 & 7.5 & 7.7 & 7.4 & 7.4 \\
\hline Trunk length & 53.6 & 55.6 & 53.3 & 55.1 & 54.7 & 54.5 & 53 \\
\hline Tail length & 14.9 & 15 & 16 & 16.5 & 16.7 & 16.8 & 17.2 \\
\hline Body width & - & 4.7 & 6.7 & 4.8 & 6.3 & 5.9 & 5.2 \\
\hline \multicolumn{8}{|l|}{ Body depth: } \\
\hline Including VFF & 8 & $?$ & 10.7 & 7.5 & 7.4 & 7.9 & 7.1 \\
\hline Excluding VFF & 8 & $?$ & 9.4 & 6.7 & 7 & 7.7 & 7 \\
\hline Over cloaca & - & 6.7 & 8.2 & 6.6 & 6 & 5.9 & 6.1 \\
\hline Tail depth & 8.6 & 8.1 & 9.8 & 8.4 & 8.8 & 8.4 & 9.7 \\
\hline \multicolumn{8}{|l|}{ Barbel length: } \\
\hline First & - & 1.5 & 1.3 & 1.3 & 1.4 & 1.2 & 1.1 \\
\hline Second & - & 1.5 & 1.3 & 1.3 & 1.4 & 1.5 & 1.3 \\
\hline Third & - & 2.4 & 2 & 2.2 & 2.4 & 2.2 & 2 \\
\hline \multicolumn{8}{|c|}{ Counts } \\
\hline \multicolumn{8}{|l|}{ Teeth: } \\
\hline Multicusp pattern & $3 / 2$ & $3 / 2$ & $3 / 2$ & $3 / 2$ & $3 / 2$ & $3 / 2$ & $3 / 2$ \\
\hline Anterior unicusps & $11+11$ & $11+11$ & $10+10$ & $10+9$ & $10+11$ & $9+10$ & $10+10$ \\
\hline Posterior unicusps & $9+10$ & $10+9$ & $9+9$ & $9+9$ & $9+9$ & $9+9$ & $10+9$ \\
\hline Total cusps & 51 & 51 & 48 & 47 & 49 & 47 & 49 \\
\hline \multicolumn{8}{|l|}{ Pores*: } \\
\hline Prebranchial & 15 & $15+15$ & 13 & 14 & 13 & 14 & 14 \\
\hline Branchial & 7 & $7+8$ & 8 & 8 & 7 & 7 & 7 \\
\hline Trunk & 50 & $49+50$ & 52 & 53 & 55 & 53 & 49 \\
\hline Cloacal & - & $3+3$ & 4 & 4 & 3 & 3 & 3 \\
\hline Tail & 9 & $13+13$ & 14 & 13 & 13 & 12 & 14 \\
\hline Total pores & 81 & $84+86$ & 87 & 88 & 88 & 86 & 84 \\
\hline Gill apertures & $8+8$ & $8+8$ & $9+8$ & $8+8$ & $8+8$ & $8+7$ & $8+\mathrm{PCD}$ \\
\hline Gill pouches & $8+8$ & $8+8$ & $9+8$ & $8+8$ & $8+8$ & $8+7$ & $8+8$ \\
\hline
\end{tabular}


ventral finfold (VFF) (holotype not measurable) (7.1-10.7); body depth excluding VFF (holotype not measurable) (6.7-9.4); body depth at cloaca 6.7 (5.9-8.2); tail depth 8.1 (8.4-9.8).

A 3-cusp multicusp on the anterior (outer) sets and a 2-cusp multicusp on the posterior (inner) sets of cusps; 9-11 unicusps on the anterior and 9-10 unicusps on the posterior sets of cusps; total cusps 47-51. Cusps slender and pointed (Fig. 2). A single palatine tooth in the roof of the mouth. A row of slime pores segmentally arranged on each side of body. Slime-pore counts (left + right sides of holotype, followed by ranges for non-type specimens in parentheses): prebranchial pores $15+15$ (13-14); branchial pores $7+8(7-8)$; trunk pores $49+50$ (49-55); tail pores $13+13(12-14)$; total pores 84 $+86(84-88)$.

Eight pairs of gill pouches and gill apertures in the holotype and most non-type specimens; one specimen with 7 gill pouches and apertures on the right side and another specimen with 9 gill pouches and apertures on the left side of the body. One

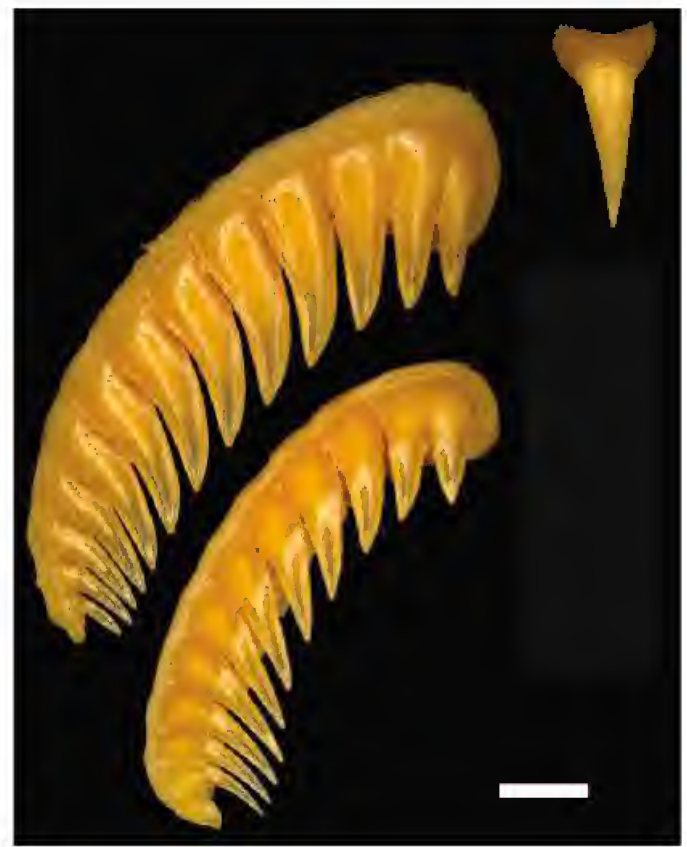

FIGURE 2. Dentition (anterior and posterior left series and palatine tooth) of Eptatretus luzonicus; CAS 233675, $563 \mathrm{~mm}$ TL. Scale $=2 \mathrm{~mm}$. specimen with 8 gill apertures plus the pharyngocutaneous duct (PCD) aperture on the left side. Each gill pouch connected to its own gill aperture by the efferent branchial duct. Last branchial duct usually confluent with PCD, forming a large aperture on the left side of the body. Posterior tip of dental muscle reaches the fourth or fifth pair of gill pouches. Ventral aorta branches at the level of eighth gill pouch; all afferent branchial arteries connected to the branched portion of ventral aorta on both sides.

Body color (Fig. 3) dark chocolate brown; tip of barbels whitish; conspicuous white eyespots; mouth and gill apertures with whitish margins; ventral finfold and caudal finfold the same color as body. Body color slightly lighter in preserved specimens.

Distribution.- Known only from the Philippines (Fig. 4). The holotype was collected at

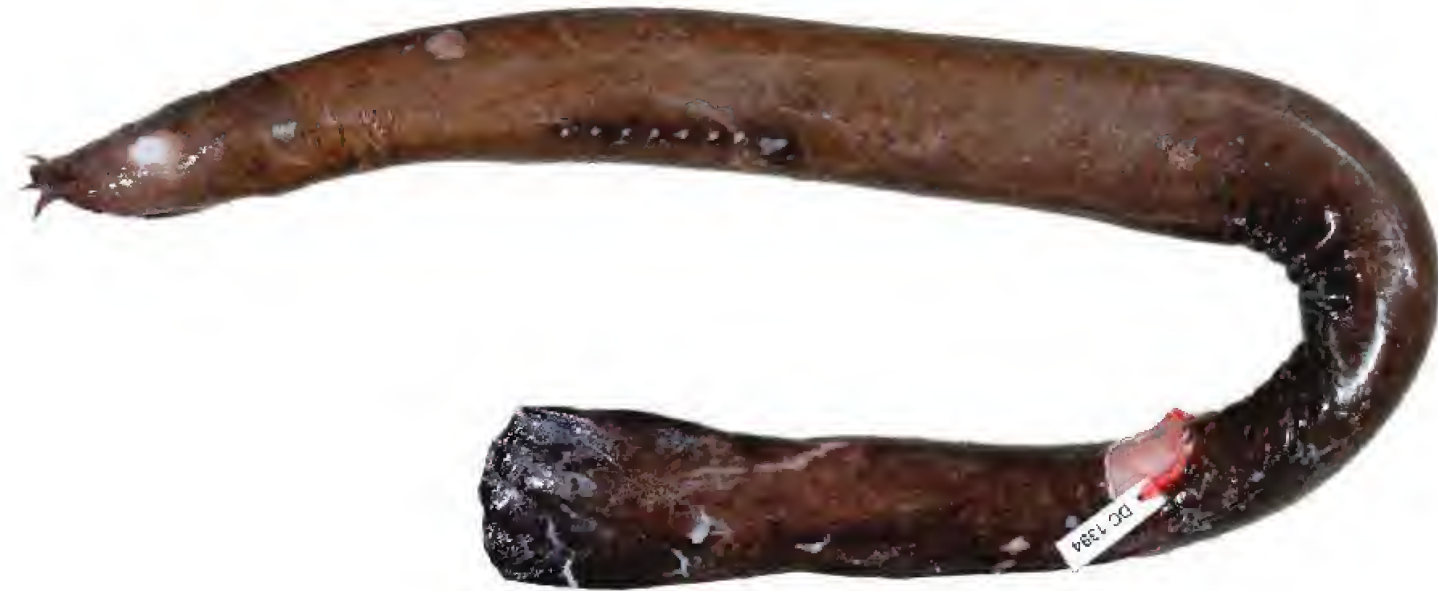

FIGURE 3. Fresh specimen of Eptatretus luzonicus; NPM 1999, 490 mm TL (443 mm after preservation). 


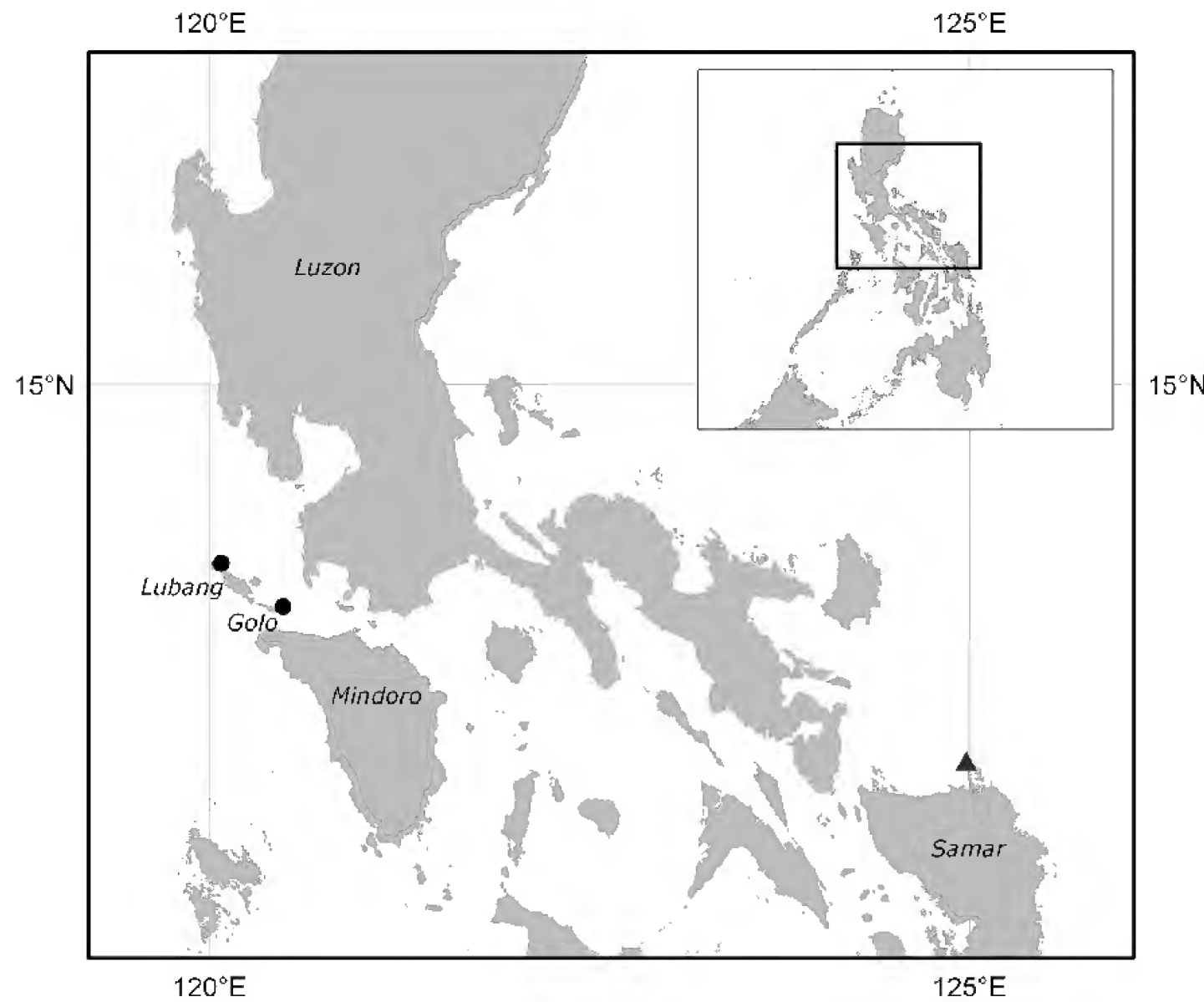

FIGURE 4. Collection sites of the holotype (triangle) and additional specimens (circles) of Eptatretus luzonicus in the Philippines.

$12^{\circ} 43^{\prime} 51^{\prime \prime} \mathrm{N}, 124^{\circ} 58^{\prime} 50^{\prime \prime} \mathrm{E}$, off northern Batag Island (north of Samar). The recent material from Hearst Expedition was collected from two different stations in the western part of Verde Island Passage: one off northern Lubang Island and another off eastern Golo Island. It is likely that E. luzonicus has a wider distribution in the Philippines.

HABITAT. - According to a report of the U.S. Bureau of Fisheries, the Albatross station D5444, where the holotype of E. luzonicus was trawled, was at 308 fathoms $(563 \mathrm{~m})$ depth, on a green mud bottom with a bottom temperature of $44.3^{\circ} \mathrm{F}\left(6.8^{\circ} \mathrm{C}\right)$. The surface water temperature was $83^{\circ} \mathrm{F}\left(28.3^{\circ} \mathrm{C}\right)$ (Anonymous 1910$)$. The additional material from the Verde Island Passage was collected at depths between 578 and $710 \mathrm{~m}$. Sediment type ranged from mud to sand.

\section{DISCUSSION}

The holotype has completely lost its skin, making accurate measurements of the tail length and tail depth, and measurements taken from the ventral finfold impossible (those measurements in Table 1 are approximations). The first two barbels on the left side are shorter than those on the right and appear to have been previously dried. There are deep dissections along the ventral part of the prebranchial and branchial regions and along both sides of the trunk region. Some internal organs are missing, although it is still possible to observe the dental muscle, gill pouches, heart, parts of 
the ventral aorta, and parts of the intestine, which has been dissected along its entire length. The third gill pouch on the left side is missing and the gonads cannot be found. The liver and several unidentified small pieces of muscle tissue are detached from the body. Fortunately, the teeth are in good condition making an accurate tooth count possible. The slime pores can be easily counted, except those of the trunk, which are difficult to observe due to dissections and poor preservation. We are unable to say with certainty whether the poor condition of the specimen resulted from inappropriate preservation and/or multiple dissections after collection. All material collected by the Albatross Philippine Expedition was preserved directly in ethyl alcohol as formalin was not used at that time (Smith and Williams 1999).

In their original description of Eptatretus fernholmi, McMillan and Wisner (2004) briefly compared this species with some western Pacific hagfishes, including Eptatretus strahani McMillan and Wisner, 1984 (Philippines), Eptatretus chinensis Kuo and Mok, 1994 (South China Sea), and Eptatretus okinoseanus (Dean, 1904) (Japan and Taiwan). McMillan and Wisner (2004) stated that Eptatretus fernholmi had no eyespots and a vestigial ventral finfold, and therefore differed from E. okinoseanus, which has prominent eyespots and a well-developed ventral finfold. This statement was based on Bo Fernholm's notes taken from the holotype, which was already in poor condition when he examined it in 1976 (Bo Fernholm pers. comm., February 17, 2012). The badly damaged skin of the holotype makes it impossible to check its eyespot and ventral finfold conditions. The examination of additional specimens, however, revealed that $E$. fernholmi $(=E$. luzonicus $)$ has very conspicuous eyespots (Fig. 3) and a ventral finfold that ranges from $1 \mathrm{~mm}$ (in a 404-mm specimen) to $7 \mathrm{~mm}$ high (in a $563-\mathrm{mm}$ specimen). Therefore, E. luzonicus cannot be distinguished from E. okinoseanus based on the diagnosis proposed by McMillan and Wisner (2004).

The presence of eight pairs of gill pouches and 3-cusp multicusps on the anterior sets and 2-cusp multicusps on the posterior sets of cusps distinguishes Eptatretus luzonicus from all congeners except five: Eptatretus gomoni Mincarone and Fernholm, 2010 from Western Australia, Eptatretus indrambaryai Wongratana, 1983 from Thailand, Eptatretus octatrema (Barnard, 1923) from South Africa, Eptatretus okinoseanus (Dean, 1904) from Japan and Taiwan, and Eptatretus wisneri McMillan, 1999 from the Galápagos Islands. Eptatretus luzonicus differs from these five in having: 47-51 total cusps (vs. 40 in E. octatrema, 44 in E. wisneri); 13-15 prebranchial pores (vs. 23 in E. octatrema, 9-10 in E. wisneri); 49-55 trunk pores (vs. 57-58 in E. gomoni, 65 in E. octatrema, 54-61 in E. okinoseanus, 43-45 in E. wisneri); and 84-88 total pores (vs. 91-93 in E. gomoni, 77-82 in E. indrambaryai, 109 in E. octatrema, 87-97 in E. okinoseanus, 73-75 in $E$. wisneri). In addition, $E$. luzonicus has a single nasal-sinus papilla in the middorsal surface of the nasal sinus, while no nasal-sinus papilla was observed in all these eight-gilled congeners. Another Eptatretus species, E. mccoskeri McMillan, 1999 from the Galápagos Islands also has eight pairs of gill pouches, but it differs from all other eight-gilled congeners in having 3-cusp multicusps on the anterior and posterior sets of cusps and two bilaterally symmetrical nasal-sinus papillae in the dorsal surface of the nasal sinus.

Another species of Eptatretus has been recorded from the Philippines. Eptatretus strahani McMillan and Wisner, 1984 was originally described from five specimens trapped at $14^{\circ} 00^{\prime} \mathrm{N}$, $120^{\circ} 18.2^{\prime} \mathrm{E}$ (near Lubang Island) at $189 \mathrm{~m}$ depth on 21-22 March 1976 (McMillan and Wisner 1984). It has also been recently reported off Western Australia, based on two specimens collected at two locations: $16^{\circ} 54^{\prime} \mathrm{S}, 120^{\circ} 22^{\prime} \mathrm{E}$, at $405 \mathrm{~m}$, and $17^{\circ} 32^{\prime} \mathrm{S}, 118^{\circ} 48^{\prime} \mathrm{E}$, at $430 \mathrm{~m}$ (Mincarone and Fernholm 2010). Eptatretus luzonicus can be easily distinguished from E. strahani by its number of gill pouches ( 8 vs. 7$)$ and its multicusp pattern (3/2 vs. $3 / 3)$.

Also collected during the Hearst Expedition to the Philippines was a single specimen (CAS $233680,393 \mathrm{~mm}$ TL) of the genus Myxine, which was trapped at 587-604 m in the same station 
(HEPD 013) as E. luzonicus. This specimen has been tentatively identified as Myxine formosana Mok and Kuo, 2001, a species known only from off southwestern Taiwan (Mok and Kuo 2001). Despite some differences in color pattern, all measurements and counts are similar to those described for M. formosana. The collection of additional specimens around the Philippines would be helpful to confirm the identity of this species.

Currently, only three species of hagfish are known from Philippine waters, Eptatretus luzonicus, E. strahani, and Myxine cf. formosana. Additional deep-water sampling using trawls and baited traps will likely provide new information on the species composition and distribution of Philippine hagfishes.

\section{ACKNOWLEDGMENTS}

We wish to thank: David Catania (CAS) for the use of his photographs and assistance in the field; Jon Fong (CAS) for taking pictures of the specimens; Arthur Celini, for figure enhancements; Fabio Carocci (FAO) for providing the distribution map; the staff of the California Academy of Sciences (CAS), Jeff Williams (USNM), and Hsuan-Ching Ho (Institute of Marine Biodiversity and Evolutionary Biology, Taiwan) for advice and assistance with specimens; Bo Fernholm for providing historical information on the holotype; Phil Hastings and H.J. Walker (SIO) for finding the holotype; Terence Gosliner (CAS) for his leadership of the Hearst Expedition; the crew of the M/V $D A-B F A R$; and Tomio Iwamoto (CAS) for reading a draft of this manuscript and offering valuable suggestions. And finally, we sincerely thank Margaret and Will Hearst for their generous support to the CAS Expedition to the Philippines.

\section{COMPARATIVE MATERIAL EXAMINED}

Eptatretus gomoni: 2 specimens. Western Australia: WAM 31292-003, holotype, $790 \mathrm{~mm}$, west of Shark Bay-Exmouth (no coordinates given), $260 \mathrm{~m}$, trap, L. Hand, 15 May 1997; NMV A.29719-004, paratype, $1(370 \mathrm{~mm})$, off Cape Leveque, $14^{\circ} 36^{\prime} 53^{\prime \prime} \mathrm{S} ; 121^{\circ} 19^{\prime} 39^{\prime \prime} \mathrm{E}$ to $14^{\circ} 36^{\prime} 15^{\prime \prime} \mathrm{S}$; 121 $20^{\prime} 44^{\prime \prime}$, 698-705 m, RV Southern Surveyor, beam trawl, D. J. Bray, 13 May 2007.

Eptatretus indrambaryai: 2 specimens. Thailand: AMS I.23661001, paratype, 1(188 mm), and BMNH 1983.3.24.1, paratype, $1(175 \mathrm{~mm})$, Eastern Indian Ocean, Andaman Sea, $07^{\circ} 37^{\prime} 02^{\prime \prime} \mathrm{N}$, 97 52'00"E, 267-400 m, RV Nagasaki Maru, deep sea shrimp trap, T. Wongratana, 9-10 Nov. 1981, 19:00-06:30 h.

Eptatretus mccoskeri: 3 specimens. Galápagos Islands (Ecuador): CAS 86431, holotype, 310 $\mathrm{mm}$, Pacific, Ecuador, Galápagos Islands, San Cristobal Island, $01^{\circ} 06^{\prime} 19^{\prime \prime} \mathrm{S}, 89^{\circ} 06^{\prime} 56^{\prime \prime} \mathrm{W}, 660 \mathrm{ft}$ (201 m), RV Johnson Sea Link, baited metallic minnow trap, J. E. McCosker, R. G. Gilmore, 6 Nov. 1995; SIO 97-75 (ex CAS 86431), paratype, 1(290 mm), and USNM 344905, (ex CAS 86431), paratype, $1(284 \mathrm{~mm})$, taken with the holotype.

Eptatretus octatrema: 1 specimen. South Africa: BMNH 1927.12.6.1 (ex SAM 13031), syntype, 1(280 mm), Cape Saint Blaize, West 3/4 North, 4 miles, 27 fm (49 m), RV Pieter Faure, trawl, 25 Jan. 1900.

Eptatretus okinoseanus: 6 specimens. Japan: BSKU 44343, 1(510 mm), Mimase fish market, Kochi, offshore trawl, 26 Nov. 1987; BSKU 44349, 1(515 mm), Mimase fish market, Kochi, off Okitsu, 28 Nov. 1987; MOVI 37392 (ex BSKU 51886), 1(519 mm), Mimase fish market, Kochi, offshore trawl, I Mar. 2000; NSMT-P 65670, 1(324 mm), East China Sea, $31^{\circ} 25.3^{\prime} \mathrm{N}$, $128^{\circ} 24.1^{\prime} \mathrm{E}-31^{\circ} 22.1^{\prime} \mathrm{N}, 128^{\circ} 31.1^{\prime} \mathrm{E}, 461-500 \mathrm{~m}$, RV Yoko-maru, T. Kubodera, H. Namikawa, 8 Nov. 2002, 06:55-08:29 h; NSMT-P 11000, 1(580 mm), Honshu, Boso Peninsula, off Choshi, trawl, 12 Apr. 1971; SU 23522, 1(402 mm), Misaki, Sagami, K. Aoki (obtained by D. S. Jordan in 1911). 
Eptatretus strahani: 5 specimens. Philippines: MNHN 1981-0722, paratype, 1(500 mm), SIO 81-116, paratype, $1(430 \mathrm{~mm})$, and USNM 227442, paratype, $1(435 \mathrm{~mm})$, near Lubang Island, $14^{\circ} 00^{\prime} \mathrm{N}, 120^{\circ} 18.2^{\prime} \mathrm{E}, 189 \mathrm{~m}, \mathrm{RV}$ Vauban, trap, 21-22 Mar. 1976. Australia: NMV A.13506, 1(500 $\mathrm{mm}$ ), Western Australia, west of King Sound, $16^{\circ} 54^{\prime} \mathrm{S}, 120^{\circ} 22^{\prime} \mathrm{E}, 405 \mathrm{~m}$, FV Striker, scampi net, S. Morris, 4 Apr. 1989. NTM S.12589-004, 1(620 mm), Western Australia, off Rowley Shoals, northwest shelf, $17^{\circ} 32^{\prime} \mathrm{S}, 118^{\circ} 48^{\prime} \mathrm{E}, 430 \mathrm{~m}$, bottom trawl, W. Houston, 2 Nov. 1985.

Eptatretus wisneri: 2 specimens. Galápagos Islands (Ecuador): CAS 86429, holotype, 355 mm, Fernandina Island, 0²7'56"S, 91'37'33"W, 1848 ft (563 m), RV Johnson Sea Link, minnow trap, J. E. McCosker et al., 14 Nov. 1995, 11:56-14:01 h; SIO 97-76 (ex CAS 86430), paratype, 1(316 mm), Fernandina Island, $0^{\circ} 17.5^{\prime} \mathrm{S}, 9^{\circ} 38.9^{\prime} \mathrm{W}, 1680 \mathrm{ft}$ (512 m), RV Johnson Sea Link, minnow trap, J. E. McCosker et al., 16 Nov. 1995.

\section{LITERATURE CITED}

Anonymous. 1910. Dredging and hydrographic records of the U. S. Fisheries Steamer Albatross during the Philippine Expedition, 1907-1910. U. S. Bureau of Fisheries Document 741:1-97.

Fernholm, B., And C. L. HubBs. 1981. Western Atlantic hagfishes of the genus Eptatretus (Myxinidae) with description of two new species. Fishery Bulletin (U.S.) 79(1):69-83.

Fernholm, B., M. Norén, S. O. Kullander, A. M. Quattrini, V. Zintzen, C. Roberts, H.-K. Mok, and C.-H. Kuo. 2013. Hagfish phylogeny and taxonomy, with description of the new genus Rubicundus (Craniata, Myxinidae). Journal of Zoological Systematics and Evolutionary Research doi: 10.1111/ jzs.12035.

Iwamoto, T., And J. E. McCosker. 2014. Deep-water fishes of the 2011 Hearst Philippine Biodiversity Expedition of the California Academy of Sciences. Pages 263-332 in G. C. Williams and T. M. Gosliner, eds., Hearst Philippine Biodiversity Expedition of the California Academy of Sciences, California Academy of Sciences, San Francisco, California, USA.

McMillan, C. B., AND R. L. Wisner. 1984. Three new species of seven-gilled hagfishes (Myxinidae, Eptatretus) from the Pacific Ocean. Proceedings of the California Academy of Sciences, ser. 4, 43(16): 249-267.

McMillan, C. B., AND R. L. Wisner. 2004. Review of the hagfishes (Myxinidae, Myxiniformes) of the northwestern Pacific Ocean, with descriptions of three new species, Eptatretus fernholmi, Paramyxine moki, and $P$. walkeri. Zoological Studies 43(1):51-73.

Mincarone, M. M., And B. Fernholm. 2010. Review of the Australian hagfishes with description of two new species of Eptatretus (Myxinidae). Journal of Fish Biology 77:779-801

Мок, H.-K. 2001. Nasal-sinus papillae of hagfishes and their taxonomic implications. Zoological Studies 40(4):355-364.

MoK, H.-K., AND C.-H. Kuo. 2001. Myxine formosana, a new species of hagfish (Myxiniformes: Myxinidae) from the southwestern waters of Taiwan. Ichthyological Research 48:295-297.

Smith, D. G., AND J. T. Williams. 1999. The great Albatross Philippine Expedition and its fishes. Marine Fisheries Review 61(4):31-41.

Wisner, R. L., AND C. B. MCMilLan. 1995. Review of new world hagfishes of the genus Myxine (Agnatha, Myxinidae) with description of nine new species. Fishery Bulletin 93(3):530-550. 


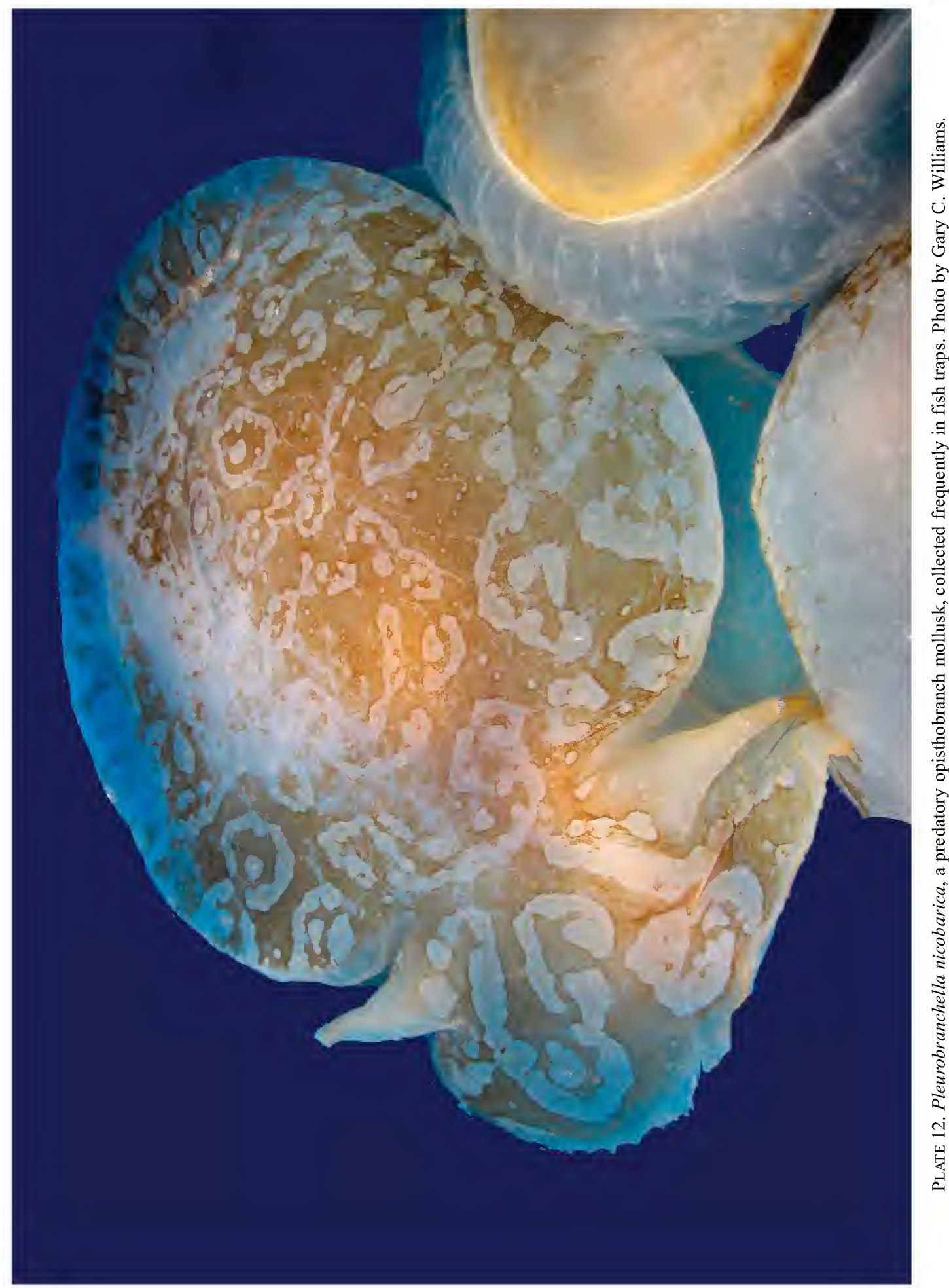




\title{
Six New Species of Philine (Opisthobranchia: Philinidae) from the Tropical Indo-Pacific
}

\author{
Claire Gonzales ${ }^{1}$ and Terrence Gosliner ${ }^{2}$ \\ ${ }^{1}$ Biology Department, Duke University, Box 97567, Duke University, Durham, NC 27708, E-mail: CGonza- \\ les@calacademy.org; 2 Department ofInvertebrate Zoology, California Academy of Sciences, 55 Music Con- \\ course Drive, San Francisco, CA 94118, U.S.A.E-mail: tgosliner@calacademy.org
}

Six new species of philinid opisthobranchs are described from various localities in the tropical Indo-Pacific. Most were collected from deep waters of the Verde Island Passage, Philippines, while one additional species was collected from relatively shallow water from Panglao, Philippines and the second from shallow water in the Hawaiian Islands.

Morphological characters, including anatomical details of the shell, radular morphology, gizzard plates and male and hermaphroditic reproductive systems are entirely congruent with the molecular differences found. Four of these taxa are members of the Philine aperta clade, while two taxa are members of a more basal lineage. Philine acuticauda sp. nov. has an elongate body, has a large, smooth shell, lacks gizzard plates and has a radula with two outer lateral teeth, the outer of which is reduced with a blunt cusp. Philine hearstorum sp. nov. is also elongate but has a series of clearly defined striations on the shell. It also possesses three small gizzard plates with a distinct crystalline structure, has two outer lateral radular teeth with prominent cusps. Philine dentiphallus sp. nov. has residual punctate sculpture lines on the shell, has three equally sized gizzard plates with a prominent medial bar above a single large depression. The radula has a single outer lateral tooth with a prominent cusp. The penis is hammer-shaped with a series of denticles on the outer lobe of the penial papilla. Philine verdensis sp. nov. has a large, smooth shell devoid of striation or other obvious sculpture. The gizzard plates are unequal with two larger plates and a single small plate, all with two prominent pores. The penial papilla is hammer-shaped with an unarmed papilla. Philine pittmani sp. nov. has unequal gizzard plates where the two longer plates each have only a single pore, Philine multipapillata sp. nov., has a smooth shell, devoid of obvious sculpture, has three unequal gizzard plates, all with two large prominent pores. The penis is complex, having a penial papilla densely armed with conical papillae over the entire surface. This study reinforces the view that the diversity of the Indo-Pacific Philinacea still remains incompletely sampled including the Philine aperta clade. Philine acuticauda and $P$. hearstorum appear to be most closely related to $P$. alba and $P$. alboides and represent the first representatives of this group known from the tropical Indo-Pacific. Both morphological and molecular data support the phylogenetic position of these taxa. The more basal members have small gizzard plates or entirely lack them and have a simple penis, while species in the Philine aperta clade have plates with pores or slits and have a complex penis and prostate. In sampling broader outgroup relationships, some members of Philinidae cluster with species of Aglajidae, suggesting that Philinidae as traditionally constructed does not constitute a clade, but represents a paraphyletic assemblage. These relationships need to be further studied with more extensive taxon sampling of philinaceans, but are suggestive that further systematic revision is required to develop a classification consistent with the phylogeny of the Philinacea.

KEYwords: Philinidae, Philinacea, Indo-Pacific, new species, biodiversity 
Many morphological descriptions of Philine species have been undertaken over the past several decades (Marcus 1974; Marcus and Marcus 1966, 1967, 1969; Rudman 1970, 1972a, b; Gosliner 1988), and these studies describe new taxa and review the anatomy of previously identified species. Price et al. (2011) also provided the first morphologically-based phylogenetic study of Philine. More recently, Krug et al. (2012) provided a molecular phylogeny based on the 16S mitochondrial gene, that was used primarily to establish the origin of two introduced species of Philine now found on the Pacific coast of North America. Ohnheiser and Malaquias (2013) reviewed the North Atlantic Philine species, described two additional species from the region and presented a molecular phylogeny of these species based on the COI mitochondrial gene.

The World Register of Marine Species (WORMS: <http://www.marinespecies.org/ aphia.php? $p=$ taxdetails\&id=138339>) lists 117 valid species of Philine from throughout the world's oceans. As noted by Price et al. (2011), the majority of these are known only from shells and their identity remains obscure. The Indo-Pacific tropics and adjacent temperate regions support a diversity of philinid opisthobranchs (Gosliner et al., 2008), with 24 described species documented from the region (Price et al. 2011, WORMS). Several relatively recently described species have been added to the Indo-Pacific region since the systematic reviews cited above (Valdés 2008; Price et al. 2011). These include Philine abyssicola Valdés, 2008, P. babai Valdés, 2008, P. habei Valdés, 2008, P. fenestra Price, Gosliner and Valdés, 2011, P. paucipapillata Price, Gosliner and Valdés, 2011, P. puka Price, Gosliner, and Valdés, 2011 and P. sarcophaga Price, Gosliner and Valdés, 2011. Krug et al. (2012), illustrated that at least one additional Indo-Pacific species from Australia as unidentified and quite likely undescribed.

Recent biodiversity exploration of deeper waters surrounding the Philippines from the 2004 Panglao International Expedition and the 2011 Hearst Philippine Biodiversity Expedition has produced additional material, which is the focus of the present study. Examination of this material plus specimens of a shallow-water species from the Hawaiian Islands reveals the presence of six additional undescribed species. The description of these species and the examination of their molecular phylogenetic relationships formulate the focus of the present review of the genus Philine. In order to compare these species with other species known from the Pacific and Indo-Pacific, our molecular study employs the examination of the $16 \mathrm{~S}$ gene studied by Krug et al. (2012) rather than using the COI gene used by Ohnheiser and Malaquias (2013) for Atlantic taxa. The intent of the present molecular study is to determine the distinctness of the species described here, as well as further assessing the phylogeny and monophyly of Philine.

\section{MATERIALS AND METHODS}

\section{Morphological Methods}

Over the last decade, new specimens of philinds were collected from the Verde Island Passage and Bohol Island, Philippines and the Hawaiian Islands. Specimens collected were preserved in either $10 \%$ formalin for proper preservation of anatomical structures, or preserved entirely in $95 \%$ ethanol for later molecular study. Prior to preservation of any specimen in formalin, a tissue sample was taken from the animal and preserved in $95 \%$ ethanol for later molecular study.

Upon return to the California Academy of Sciences, dissections were completed, and drawings of anatomical structures were accomplished using a Nikon SMZ-U binocular microscope with drawing tube. Buccal mass structures of specimens were dissected and cleaned by placing them in a $10 \% \mathrm{NaOH}$ solution for 4-10 hours, and then prepared for scanning electron microscopy. The radula was separated and cleaned of any remaining tissue. It was then placed on a glass cover slip, air-dried, and then mounted on a stainless steel stub. The same procedure was followed for exam- 
ination of gizzard plates. Specimens of copulatory organs were mounted on stubs and air-dried or were photographed using automontage light microscopy. Hard structures were then coated with gold/palladium using a Denton Desk II vacuum sputter coater. Scanning electron micrographs were produced by a LEO 1450 VP scanning electron microscope. Specimens and dissected structures were deposited at the California Academy of Sciences in the Invertebrate Zoology Department collection (CASIZ).

\section{Molecular Methods}

Taxon sampling: Sampling of Philinidae specimens for the molecular study were all preserved in $70 \% \mathrm{EtOH}$, making it possible to perform molecular work on the tissue obtain sequences of the mithocondrial gene 16S. New molecular sequence data are provided for 21 specimens of 11 species of Philine and outgroup taxa (Table 1). Of the six species described here, five of the species were sequenced. Molecular data were not available for Philine multipapillata, since the single specimen was preserved in formalin. The genus Scaphander was chosen as an outgroup based on its morphological similarity and apparent close relationship to the genus Philine. Additionally, one specimen of Scaphander mundus Watson, 1883, was sequenced to test the monophyly of Philine. The tissues came from specimens collected from various regions in the Indo-Pacific. The majority of specimens were found from deep waters off the Verde Island Passage, Philippines, but one additional species was collected from relatively shallow water from Panglao, Philippines, and another from shallow water in the Hawaiian Islands. Sequences of the 16S gene from 18 specimens of seven species in Philine were obtained from GenBank and were published by Krug etal. (2012) and used in analysis. They are therefore not included in Table 1.

DNA extraction, amplification and sequencing: Genomic DNA was extracted from small pieces of foot tissue for most samples using QiagenDNeasy Tissue Kits. Amplification of DNA was conducted on BioRadsMyCycler ${ }^{\mathrm{TM}}$ Thermocycler (software version 1.065, Bio-Rad Laboratories). Partial sequences of the mitochondrial genes $16 \mathrm{~S}$ rRNA (485 bp) and 16Sar-L and 16Sbr-H (Palumbiet al. 1991) for one specimen for 16S PCR and sequencing we utilized internal primers developed by V. Knutson (personal communication).

PCR amplifications were carried out in a $25 \mathrm{ml}$ reaction volume including $2.5 \mathrm{ml}$ of 10x PCR

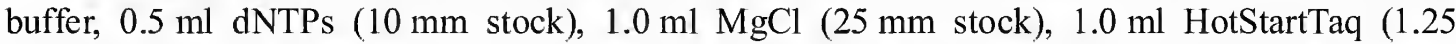
units/ml)-Apex, $1.0 \mathrm{ml}$ of each primer ( $25 \mathrm{~mm}$ stock), $15 \mu 1 \mathrm{H}_{2} \mathrm{O}$, and $2 \mathrm{ml}$ of genomic DNA. The partial 16S amplifications followed the following parameters: an initial denaturing step at $94^{\circ} \mathrm{C}$ for $3 \mathrm{~min} ; 40$ cycles of denaturing at $94^{\circ} \mathrm{C}$ for $30 \mathrm{~s}$, annealing at $48^{\circ} \mathrm{C}$ for $30 \mathrm{~s}$, amplifying at $72^{\circ} \mathrm{C}$; and extension at $72^{\circ} \mathrm{C}$ for $5 \mathrm{~min}$ and $25^{\circ} \mathrm{C}$ for $5 \mathrm{~min}$.

PCR products were visualized on a $1.0 \%$ TBE agarose gel stained with ethidium bromide. PCR products were purified with ExoSAP-IT (USB Scientific) and then EtOH Precipitation. Cycle-sequencing reactions were performed using ABI Prism Big Dye Terminator (Applied Biosystems) (total volume $10 \mathrm{ml}$ ) and analyzed using the automated sequencer ABI 3130 Genetic Analyzer (Applied Biosystems) in the Center for Comparative Genomics at the California Academy of Sciences (San Francisco, USA). All new DNA sequences have been deposited in Genbank (Table 1).

Sequence alignment and analysis: The authenticity of the sequences was verified by BLAST comparisons. The sequences were edited and aligned using Genious 5.5 (Drummond et al. 2009) and checked by eye.

Model selection and phylogenetic analyses: Phylogenetic data were analyzed using Maximum Likelihood with the program RAxML v7.04. RA x ml was employed (Stamatakis, Hoover, and 
TABLE I. Specimens examined for new DNA sequences.

\begin{tabular}{|c|c|c|c|c|c|}
\hline $\begin{array}{l}\text { Catalog } \\
\text { Number }\end{array}$ & Field Station & Genus & Species & Location & GenBank number \\
\hline CAS 192085 & HEPD 005 & Philine & acuticauda & $\begin{array}{l}\text { Verde Island Passage, } \\
\text { Phillipines }\end{array}$ & KJ411886 \\
\hline CAS 192086 & HEPD 005 & Philine & acuticauda & $\begin{array}{c}\text { Verde Island Passage, } \\
\text { Phillipines }\end{array}$ & \\
\hline CAS 192087 & HEPD 019 & Philine & acuticauda & $\begin{array}{c}\text { Verde Island Passage, } \\
\text { Phillipines }\end{array}$ & KJ511781 \\
\hline CAS 189336 & HEPD 035 & Philine & hearstorum & $\begin{array}{l}\text { Verde Island Passage, } \\
\text { Phillipines }\end{array}$ & KJ411892 \\
\hline CAS 192088 & HEPD 019 & Philine & dentiphallus & $\begin{array}{l}\text { Verde Island Passage, } \\
\text { Phillipines }\end{array}$ & KJ411891 \\
\hline CAS 189337 & HEPD 019 & Philine & dentiphallus & $\begin{array}{l}\text { Verde Island Passage, } \\
\text { Phillipines }\end{array}$ & \\
\hline CAS 192089 & HEPD 021 & Philine & verdensis & $\begin{array}{c}\text { Verde Island Passage, } \\
\text { Phillipines }\end{array}$ & KJ411890 \\
\hline CAS 189338 & HEPD 021 & Philine & verdensis & $\begin{array}{c}\text { Verde Island Passage, } \\
\text { Phillipines }\end{array}$ & \\
\hline CAS 192090 & N/A & Philine & pittmani & Black Rock, Maui, HI & KJ411910 \\
\hline CAS 185213 & N/A & Philine & pittmani & Black Rock, Maui, HI & \\
\hline CAS 163775 & N/A & Philine & pittmani & Black Rock, Maui, HI & \\
\hline CAS 166768 & N/A & Philine & pittmani & Black Rock, Maui, HI & \\
\hline CAS 118253 & N/A & Philine & pittmani & Black Rock, Maui, HI & \\
\hline CAS 192091 & N/A & Philine & pittmani & Black Rock, Maui, HI & \\
\hline CAS 172841 & $\mathrm{~T}-2$ & Philine & multipapillata & Panglao, Philippines & \\
\hline CAS 168651 & N/A & Philine & auriformis & San Francisco Bay, CA & \\
\hline CAS 181587 & $\mathrm{~L}-42$ & Philine & orca & Panglao, Philippines & KJ411893 \\
\hline CAS 181478 & S-2 & Philine & rubrata & Panglao, Philippines & KJ411887 \\
\hline CAS 119036 & N/A & Philine & orientalis & San Francisco Bay, CA & \\
\hline CAS 181565 & $\mathrm{~T}-31$ & Philine & habei & Panglao, Philippines & KJ511780 \\
\hline CAS 171499 & $\mathrm{~T}-39$ & Philine & habei & Panglao, Philippines & \\
\hline CAS 186467 & HEPD 012 & Scaphander & mundus & $\begin{array}{c}\text { Verde Island Passage, } \\
\text { Phillipines }\end{array}$ & \\
\hline CAS 185778 & & Philinopsis & sp. 1 & $\begin{array}{c}\text { Verde Island Passage, } \\
\text { Phillipines }\end{array}$ & KJ411888 \\
\hline CAS 185779 & & Philinopsis & sp. 2 & $\begin{array}{c}\text { Verde Island Passage, } \\
\text { Phillipines }\end{array}$ & KJ411889 \\
\hline CAS 17788 & HEPD 026 & Philinopsis & ctenophoraphaga & $\begin{array}{c}\text { Verde Island Passage, } \\
\text { Phillipines }\end{array}$ & KJ411894 \\
\hline
\end{tabular}


Rougemont 2008) random starting trees, using 10,000 rapid bootstraps. The model of analysis was set to GTR + Gamma with Scaphander mundus as the outgroup.

Genetic distances: In order to compare the genetic distances among specimens of Philine from different biogeographic areas, we calculated the mean genetic distances for the molecular marker using PAUP* $4.0 \mathrm{~b}$ 10.0. We followed the criteria applied by Krug et al. (2012) who concluded that mean intraspecific difference for the $16 \mathrm{~S}$ gene was generally less than $0.5 \%$ while intraspecific differences ranged from $1.5 \%-5.9 \%$. We considered any divergences in the $16 \mathrm{~S}$ gene exceeding $2 \%$ to represent distinct taxa.

\section{SPECIES DESCRIPTIONS}

\section{Cephalaspidea Fisher, 1883 Family Philinidae Gray, 1850}

Genus Philine Ascanius, 1772

Type species: Bulla aperta Linnaeus, 1767, by subsequent designation

\section{Philine acuticauda Gonzales and Gosliner, sp. nov.}

Figures 1A-B, 2-3

Material Examined.- Holotype: CASIZ 192085, ST HEPD 05, beam trawl in fine mud, 459-496 m depth, western end of Verde Island Passage, Balayan Bay, Batangas Province, Luzon, Philippines, $13.74833^{\circ} \mathrm{N}, 120.75583^{\circ} \mathrm{E}, 29$ May 2011, Hearst Expedition Deep Sea Team. PARATYPES: CASIZ 192086, ST HEPD 05, dissected, beam trawl in fine mud, 459-496 m depth, western end of Verde Island Passage, Balayan Bay, Batangas Province, Luzon, Philippines, $13.74833^{\circ} \mathrm{N}, 120.75583^{\circ} \mathrm{E}, 29$ May 2011, Hearst Expedition Deep Sea Team. CASIZ 192087, one specimen, partially dissected, ST HEPD 19, beam trawl in beam trawl in muddy sand with pebbles, 541-636 m depth, western end of Verde Island Passage, southeast end of Golo Island, Batangas Province, Luzon, Philippines, $13.5895^{\circ} \mathrm{N}, 120.4155^{\circ} \mathrm{E}, 1$ June 2011 , Hearst Expedition Deep Sea Team.

Geographical Distribution.- Known only from the Verde Island Passage, southern Luzon, Philippines.

Eтymology.- The name "acuticauda" refers to the long tapering posterior end of the body of this species.

Natural History. - This species is in mud and sandy mud in 459-636 m.

DESCRIPTION.- External morphology. The living animals (Figs. 1A, B) are up to $65 \mathrm{~mm}$ in length and $20 \mathrm{~mm}$ wide. The general body color of the living animal is uniformly white with yellowish pigment on the anterior end of the head and in the mantle cavity on the ventral side. The cephalic shield is shorter than the posterior shield and is slightly indented posteriorly. The parapodia are short, not reaching the cephalic shield, leaving the anterior and posterior shields visible (Fig. 2A). The posterior end of the posterior shield tapers to an acutely pointed posterior terminal.

The gill is simply plicate consisting of 12 primary folds and is situated ventrally on the right posterior end of the animal.

Shell (Fig. 2B): The shell is approximately $15 \mathrm{~mm}$ long and is relatively thickly calcified and wide. It occupies the majority of the posterior shield. No obvious sculpture is visible on the surface of the shell. The right posterior extreme of the shell has an elongate extension.

Digestive system (Figs. 3A-B): The buccal mass is relatively large, occupying the anterior half of the anterior shield. The buccal bulb has a relatively large radula. The radular formula in one paratype specimen (CASIZ 192086) is $16 \times 2.1 .0 .1 .2$. (Fig. 2C). The inner lateral teeth are large 

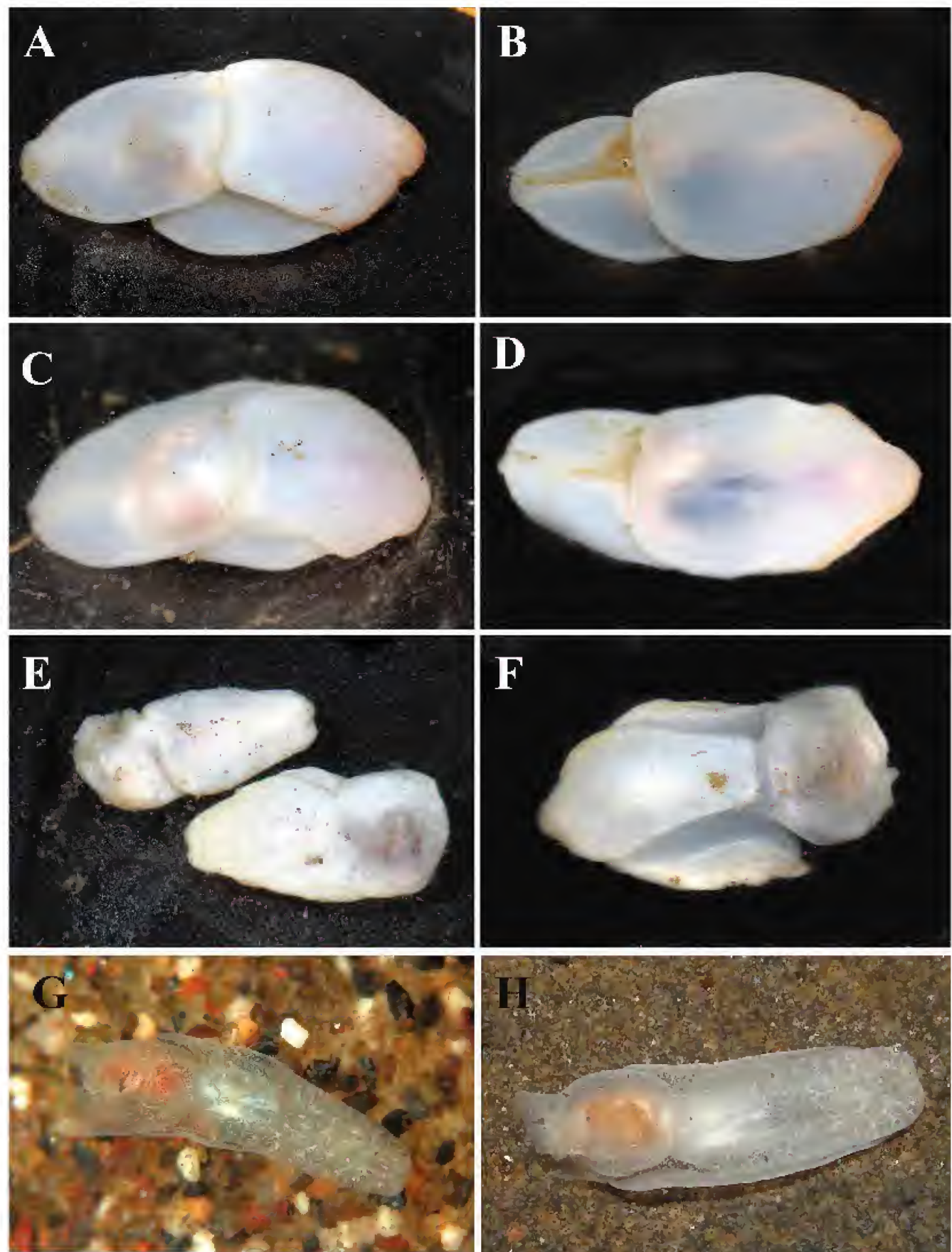

FIGURE 1. Living animals. A. Philine acuticauda sp. nov., dorsal view, paratype, CASIZ 192087, Mindoro Occidental, Philippines. B. Philine acuticauda sp. nov., ventral view, paratype, CASIZ 192087, Mindoro Occidental, Philippines. C. Philine hearstorum sp. nov., dorsal view, holotype, CASIZ 189336, Mindoro Occidental, Philippines. D. Philine hearstorum sp. nov., holotype, ventral view, casiz 189336, Mindoro Occidental, Philippines. E. Philine dentiphallus sp. nov., holotype and paratype, Mindoro Occidental, Philippines. F. Philine verdensis sp. nov., holotype, CASIZ 192089, Mindoro Occidental, Philippines. G. Philine pittmani sp. nov., paratype, CASIZ 192091, Makena Landing, Maui, Hawai'i, Photo by Cory Pittman. H. Philine pittmani sp. nov., holotype, CASIZ 192090, Black Rock, Maui, Hawai'i, Photo by Cory Pittman. all other photos by T. M. Gosliner. 

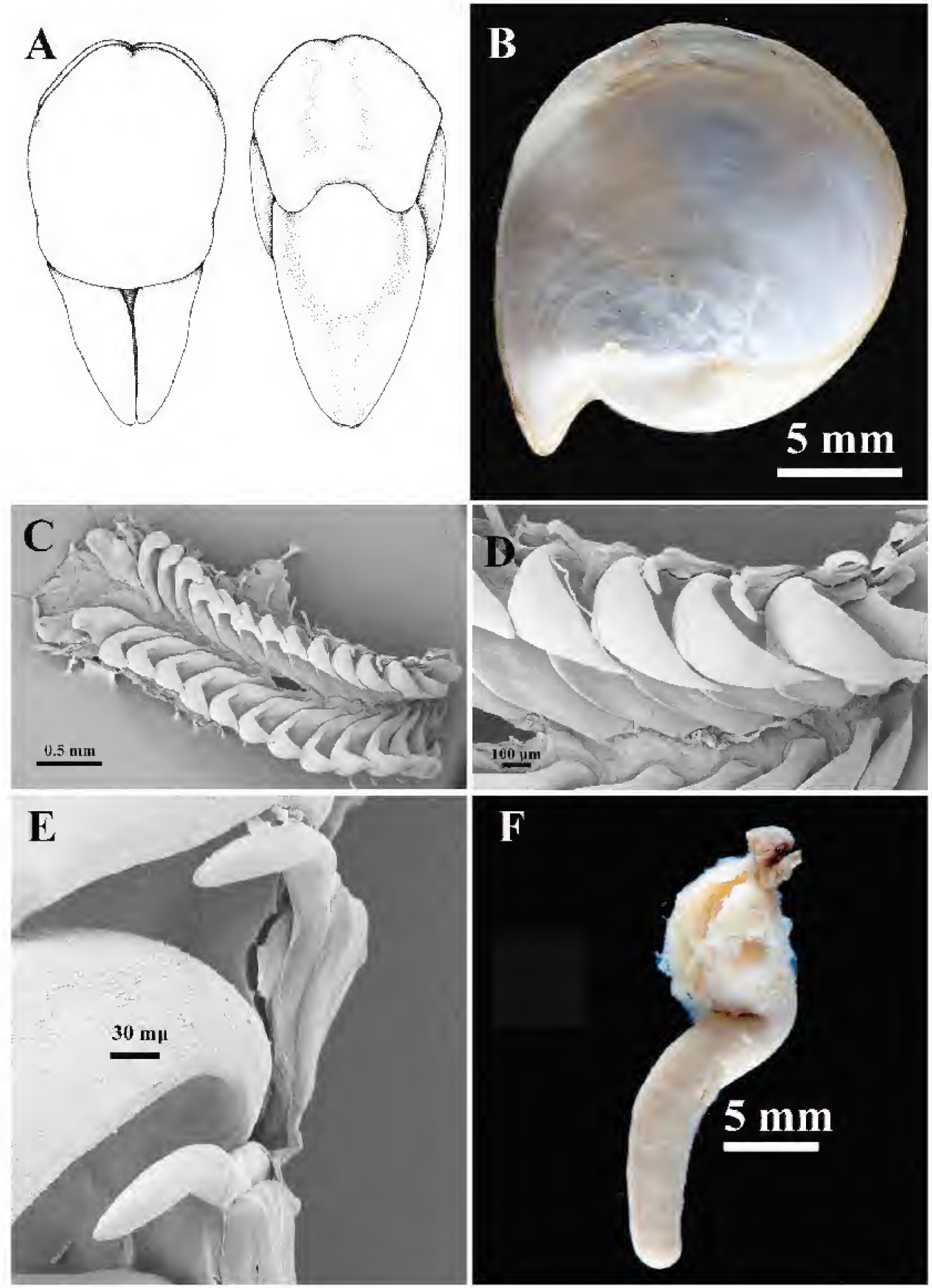

FIgURE 2. Anatomy of Philine acuticauda sp. nov. A. Dorsal and ventral views of holotype, CASIZ 192085, drawings by Emily Eng. B. Shell, paratype, CASIZ 192086. C. Scanning electron micrograph of entire radula, paratype, CASIZ 192086. D. Scanning electron micrograph of half-row of radular teeth, paratype, CASIZ 192086. E. Detail of outer lateral teeth illustrating blunt cusp of outermost outer laterals. F. Light micrograph of penis, paratype, CASIZ 192086. 

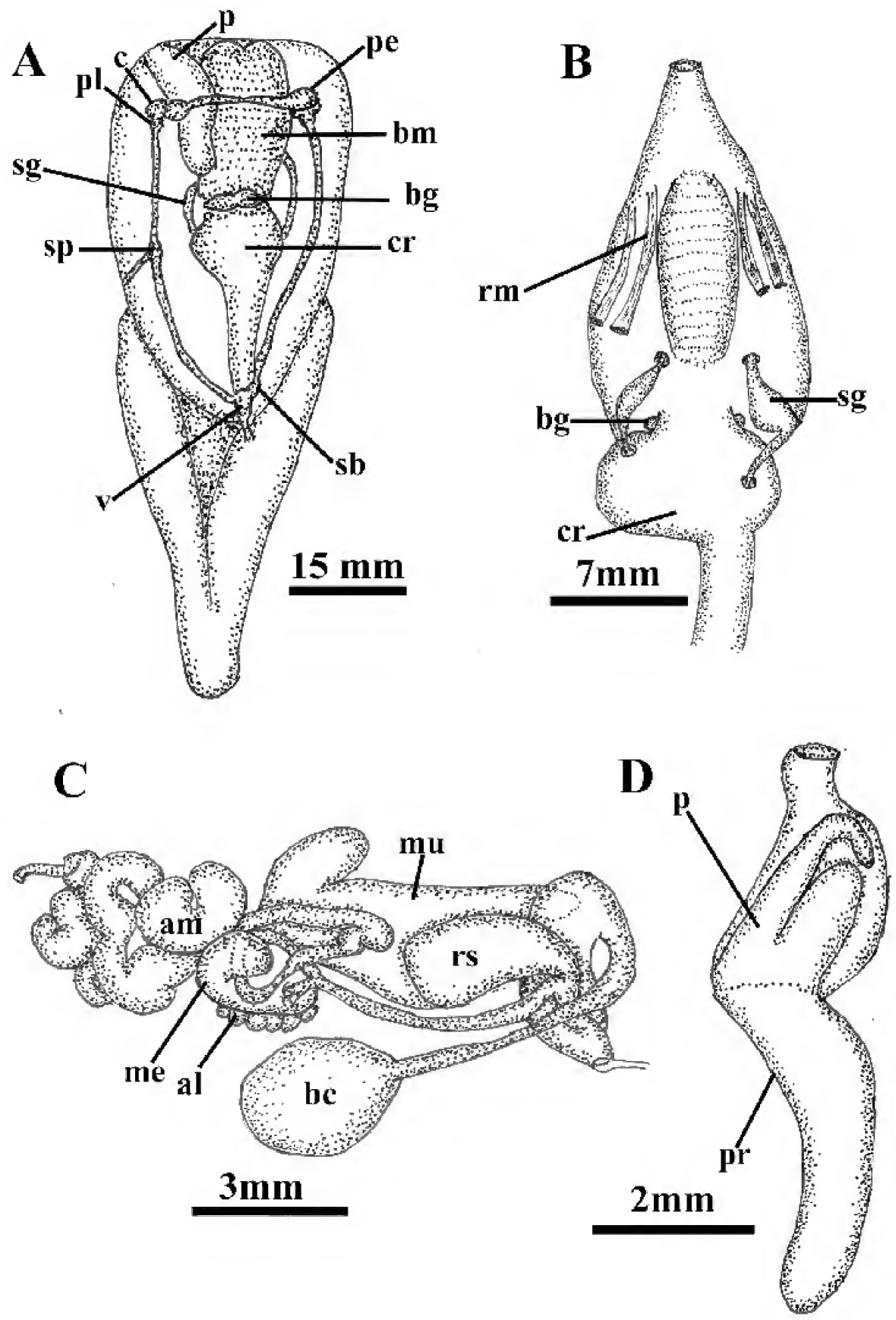

FIGURE 3. Internal anatomy, Philine acuticauda sp. nov. of paratype CASIZ 192086, A. Ventral view of preserved animal showing internal anatomy, $\mathrm{bg}=$ buccal ganglia, $\mathrm{bm}=$ buccal mass, $\mathrm{c}=$ cerebral ganglion, $\mathrm{cr}=\mathrm{crop}, \mathrm{p}=\mathrm{penis}, \mathrm{pe}=$ pedal ganglion, $\mathrm{pl}$, pleural ganglion, $\mathrm{sb}=$ subintestinal ganglion, $\mathrm{sg}=$ salivary gland, $\mathrm{sp}=$ supraintestinal ganglion $\mathrm{v}=\mathrm{vis}-$ ceral ganglion. B. Anterior portion of digestive system, $\mathrm{bg}=$ buccal ganglion, $\mathrm{cr}=\mathrm{crop}, \mathrm{rm}=$ retractor muscle, $\mathrm{sg}=\mathrm{salivary}$ gland. C. Posterior reproductive organs, al = albumen gland, am $=$ ampulla, $b c=$ bursa copulatrix, $\mathrm{me}=$ membrane gland, $\mathrm{mu}=$ mucous gland, $\mathrm{rs}=$ receptaculum seminis. $\mathrm{D}$. Penis and penial papilla, $\mathrm{p}=$ penial papilla, $\mathrm{pr}=$ prostate. 
and broad (Fig. 2D). Their masticatory margin is devoid of denticles. The inner, outer lateral tooth is narrow and elongate with an elongate, curved cusp. The outermost lateral is blunt and curved, lacking an elongate cusp (Fig. 2E). There is a large ventral oral gland and small dorsal oral glands. At the posterior end of the buccal mass, near the junction with the crop, is a pair of elongate salivary glands (Fig. 3A, C). The crop is large and saccate, slightly narrower than the buccal bulb. There are no gizzard plates or muscular thickenings in the crop. The crop narrows posteriorly and enters the digestive gland. The intestine emerges from the right side of the digestive gland and terminates near the posterior end of the body near the base of the gill.

Central Nervous System (Fig. 3A): The circumesophageal nerve ring consists of paired cerebral, pedal and pleural ganglia and a single supraintestinal ganglion on the right side situated well posterior of the nerve ring. The cerebral and pedal commissures are both elongate with well-separated respective ganglia. On the ventral side of the buccal mass near the entrance of the esophagus are the buccal ganglia, which are immediately adjacent to each other. From the posterior end of the anterior nerve ring the right branch of the visceral loop extends posteriorly to the supraintestinal ganglion. The osphradial nerve emerges from supraintestinal ganglion. The two lateral branches of the visceral loop join posteriorly at the posterior ganglia. The left visceral loop enters the subintestinal ganglion, while the right lateral nerve enters the visceral ganglion. The visceral ganglion is larger than the subintestinal ganglion (Fig. 3A). From the visceral ganglion is the genital nerve, which does not appear to have a distinct genital ganglion.

Reproductive System (Figs. 2F, 3C-D): The arrangement of reproductive organs is essentially monaulic (as discussed by Gosliner 1994) but with a single branch of the hermaphroditic duct to the albumen and membrane glands (Fig. 3C). From the large ovotestis, which is intermingled with the digestive gland, emerges the wide, convoluted ampulla. The ampulla narrows into the hermaphroditic duct, which curves around the female glands and enters the short, coiled albumen and membrane glands by means of a single duct. The larger mucous gland is bilobed with a massive primary lobe and smaller secondary one. The hermaphroditic duct is elongate and extends to the genital aperture then joins the short duct of the large, pyriform receptaculumseminis and continues to the genital atrium, where it joins the elongate duct of the bursa copulatrix. The bursa is large and spherical. Its duct is narrow where it joins the bursa and widens and curves until its widest portion at the genital atrium. From the genital atrium the open, ciliated sperm groove leads to the cephalic penis. The penis (Figs. 2F, 3D) consists of a thick penial sac and an elongate, unbranched, posteriorly directed prostate gland that is joined to the penial sac by a narrowed constriction. Within the penial sac is an elongate, curved penial papilla that is devoid of any armature (Fig. 3D).

REMARKS.- Price et al. (2011) described a series of plesiomorphic characteristics found in species of Philine. Philine acuticauda has several plesiomorphic features including a relatively large radula, more than one outer lateral tooth in the radular ribbon, a suprainestinal ganglion situated posterior to the circumesophageal nerve ring and a simple, unarmed penial papilla with a single unbranched prostate. This species also has several derived attributes including a smooth shell, a lack of gizzard plates and an elongate posterior end of the posterior shield.

Philine acuticauda is most similar in its morphology to $P$. alba Mattox, 1958, from the southern California coast and P. alboides Price, Gosliner, and Valdés, 2011, from the Gulf of Mexico and Caribbean. These three species have a large body size with a broad body profile and a broad, smooth, flattened shell with an expanded posterior wing. They also have a large radula with a wide inner lateral tooth that either lacks denticles or has greatly reduced denticles. All three species have two outer lateral teeth and a simple penis and prostate. They all have a supraintestinal ganglion located posteriorly to the nerve ring. Despite these similarities, $P$. acuticauda differs significantly from these taxa in several regards. The posterior end of the body of $P$. alba and $P$. alboides is blunt 
rather than being acutely tapered as $P$. acuticauda. In $P$. acuticauda and $P$. alboides the inner lateral teeth entirely lack denticles, while in $P$. alba, some of the teeth have minute denticles on the masticatory border, while other teeth in the same radula may entirely lack denticles. In both $P$. alba and $P$. alboides the two outer lateral teeth are similar in shape with evenly curved cusps. In $P$. acuticau$d a$, the inner of these two teeth is similar to those found in the other two species but the outer one has a dramatically reduced cusp. Both $P$. alba and $P$. alboides have three small evenly-sized gizzard plates, while no trace of plates was found in the two specimens of $P$. acuticauda examined. The prostate of $P$. acuticauda is only slightly curved as posteriorly directed while in $P$. alba and $P$. alboides, the prostate is sharply curved, with the posterior end being anteriorly directed.

\section{Philine hearstorum Gonzales and Gosliner, sp. nov.}

Figures $1 \mathrm{C}-\mathrm{D}, 4-5$

Material Examined.- Holotype: dissected, CASIZ 189336, ST HEPD 35, beam trawl in fine mud, 397-439 m depth, western end of Verde Island Passage, midway between Ambil Island and Calatagan, Batangas Province, Luzon, Philippines, $13.809^{\circ} \mathrm{N}, 120.46783^{\circ} \mathrm{E}, 4$ June 2011, Hearst Expedition Deep Sea Team.

Geographical Distribution.- Known only from the Philippines (present study).

ETYMOLOGY.- The name "hearstorum" honors Will and Margaret Hearst who generously funded the 2011 Hearst Philippine Biodiversity Expedition.

Natural History. - This species was found in fine mud. The gizzard contained fragments of tissue that when sequenced were found to be mytilid bivavles.

DESCRIPTION.-External morphology: The living animal (Figs. 1C-D) was $25 \mathrm{~mm}$ in length $17 \mathrm{~mm}$ wide. The general body color of the living animal is uniformly white with yellowish pigment on the anterior end of the head and in the mantle cavity on the ventral side. The cephalic shield is shorter than the posterior shield and is slightly indented posteriorly. The parapodia are short, not reaching the cephalic shield, leaving the anterior and posterior shields visible. The posterior end of the posterior shield tapers to an elongate, rounded posterior terminal. The gill is simply plicate consisting of 12 primary folds and is situated ventrally on the right posterior end of the animal.

Shell (Fig. 4A): The shell is approximately $15 \mathrm{~mm}$ long and is relatively thickly calcified and wide. It occupies the majority of the posterior shield. More than 30 radial bands of obvious sculpture are visible on the surface of the shell. The right posterior extreme of the shell has a short extension.

Digestive system (Figs. 4B-E, 5A): The buccal mass is relatively large, occupying the anterior half of the anterior shield (Fig. 5A). The buccal bulb has a relatively large radula. The radular formula of the holotype specimen is $16 \times 2.1 .0 .1 .2$ (Fig. 4D). The inner lateral teeth are large and broad (Fig. 4E). Their masticatory margin is devoid of denticles. The two outer lateral teeth are narrow and elongate with an elongate, curved cusp. There is a large ventral oral gland and small dorsal oral glands. At the posterior end of the buccal mass, near the junction with the crop, is a pair of elongate salivary glands. The crop is large and saccate, about the same diameter as the buccal bulb. Posteriorly the crop narrows to a slightly muscularized gizzard that contains three symmetrical plates (Figs. 4B-C). The gizzard plates are brown and covered with small rhomboidal crystals. The gizzard narrows posteriorly and enters the digestive gland. The intestine emerges from the right side of the digestive gland and terminates near the posterior end of the body near the base of the gill.

Central Nervous System (Fig. 5A): The circumesophageal nerve ring consists of paired cere- 

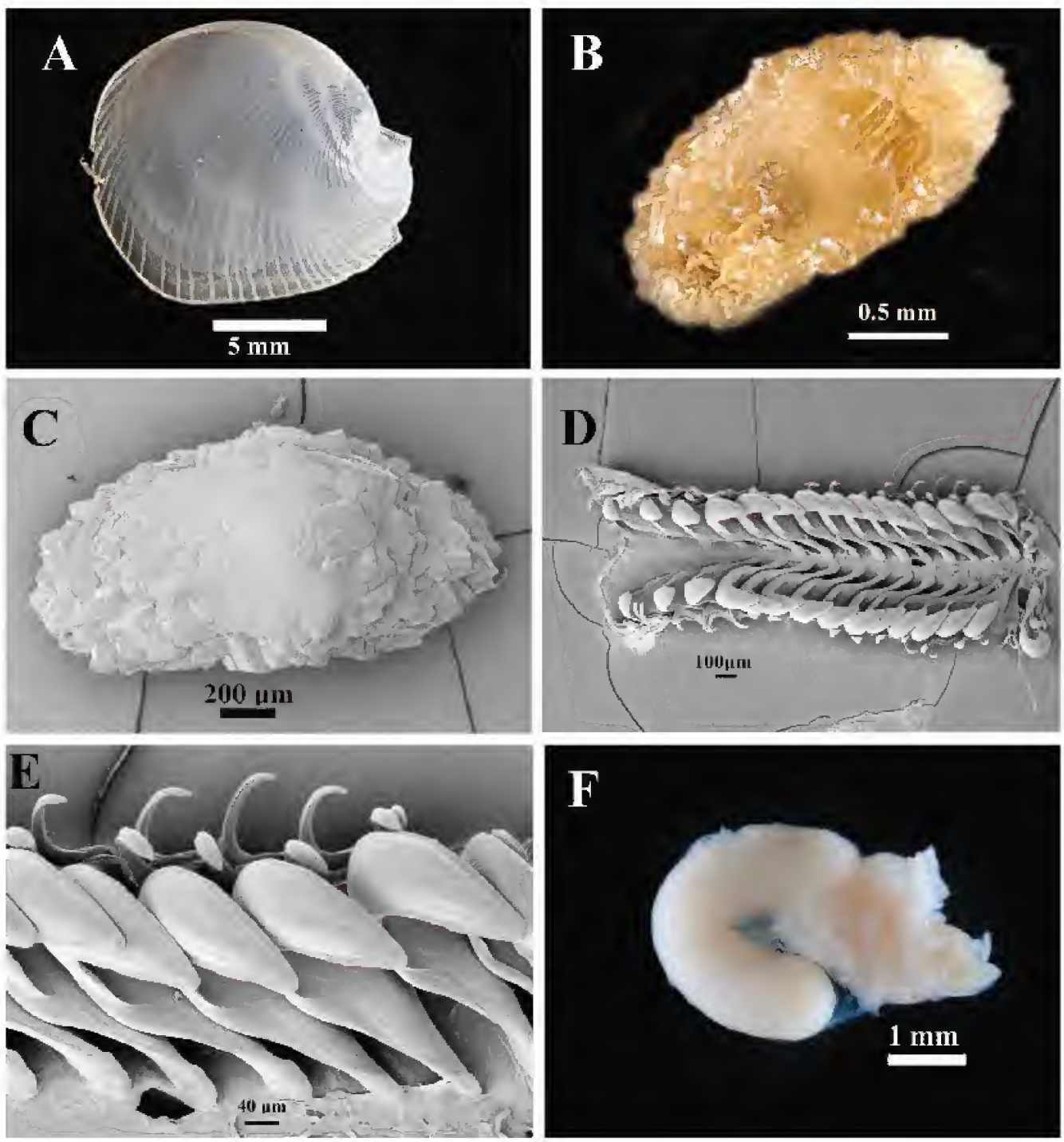

FIGURE 4. Anatomy of Philine hearstorum sp. nov., holotype, CASIZ 189336. A. Shell. B. Light micrograph of gizzard plate showing crystalline structure. C. Scanning electron micrograph of gizzard plate. D. Scanning electron micrograph of entire radula. E. Half-row of radular teeth showing two cuspidate rows of outer lateral teeth. F. Light micrograph of penis.

bral, pedal and pleural ganglia and a single supraintestinal ganglion on the right side situated well posterior of the nerve ring. The cerebral and pedal commissures are both elongate with well-separated respective ganglia. On the ventral side of the buccal mass near the entrance of the esophagus are the buccal ganglia which are immediately adjacent to each other. From the posterior end of the anterior nerve ring the right branch of the visceral loop extends posteriorly to the supraintestinal ganglion. The osphradial nerve emerges from supraintestinal ganglion. The two lateral branches of the visceral loop join posteriorly at the posterior ganglia. The left visceral loop enters the subintestinal ganglion, while the right lateral nerve enters the visceral ganglion. The visceral ganglion is larger than the subintestinal ganglion. From the visceral ganglion is the genital nerve, which does not appear to have a distinct genital ganglion.

Reproductive System (Fig. 4F, 5B-C): The arrangement of reproductive organs is essentially monaulic (as discussed by Gosliner 1994) but with a single branch of the hermaphroditic duct to 

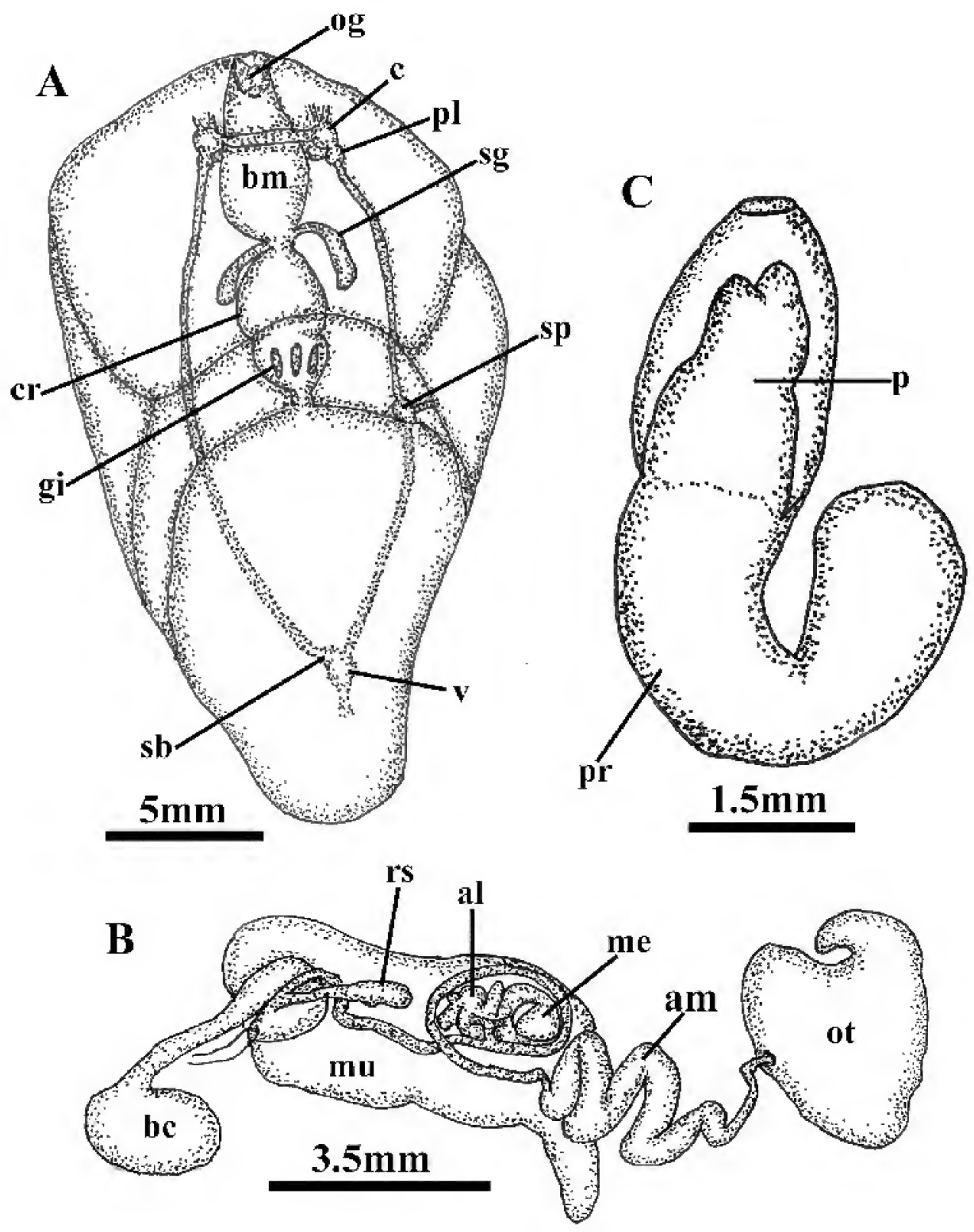

FIGURE 5. Internal anatomy of Philine hearstorum sp. nov., holotype, CASIZ 189336. A. Dorsal view of preserved holotype showing internal anatomy, $\mathrm{bm}=$ buccal mass, $\mathrm{c}=$ cerebral ganglion, $\mathrm{cr}=\mathrm{crop}$, gi $=$ gizzard, $\mathrm{og}=$ oral gland, $\mathrm{p}=$ penis, $\mathrm{pe}=$ pedal ganglion, $\mathrm{pl}=$ pleural ganglion, $\mathrm{sb}=$ subintestinal ganglion, $\mathrm{sg}=$ salivary glands, $\mathrm{sp}=$ supraintestinal ganglion $\mathrm{v}$ $=$ visceral ganglion. B. Posterior reproductive organs, al = albumen gland, am $=$ ampulla, bc $=$ bursa copulatrix, $m e=m e m-$ brane gland, $\mathrm{mu}=$ mucous gland, ot $=$ ovotestis, $\mathrm{rs}=$ receptaculum seminis. $\mathrm{C}$. Penis and penial papilla, $\mathrm{p}=$ penial papilla, $\mathrm{pr}=$ prostate.

the albumen and membrane glands (Fig. 5B). From the large ovotestis, which is intermingled with the digestive gland, emerges the wide, convoluted ampulla. The ampulla narrows into the hermaphroditic duct, which curves around the female glands and enters the short, coiled albumen and membrane glands by means of a single duct. The larger mucous gland is bilobed with a massive primary lobe and smaller secondary one. The hermaphroditic duct is elongate and extends to the genital aperture then joins the short duct of the narrow, saccate receptaculum seminis and continues to the 
genital atrium, where it joins the elongate duct of the bursa copulatrix. The bursa is large and spherical. Its duct is narrow where it joins the bursa and widens and curves until its widest portion at the genital atrium. From the genital atrium the open, ciliated sperm groove leads to the cephalic penis. The penis (Fig. 4F, 5C) consists of a thick penial sac and an elongate, unbranched, anteriorly directed prostate gland that is joined to the penial sac by a narrowed constriction. Within the penial sac is an elongate, lobed penial papilla that is devoid of any armature.

REMARKS.- Price et al. (2011) described a series of plesiomorphic characteristics found in species of Philine. Philine hearstorum has several relatively plesiomorphic features including a relatively large radula, more than one outer lateral tooth in the radular ribbon, a suprainestinal ganglion situated posterior to the circumesophageal nerve ring and a simple, unarmed penial papilla with a single unbranched prostate. This species also has an elongate posterior end of the posterior shield.

Philine hearstorum is most similar in its morphology to $P$. alba Mattox, 1958, from the southern California coast, P. alboides Price, Gosliner, and Valdés, 2011, from the Gulf of Mexico and Caribbean and $P$. acuticauda, with which $P$, hearstorum is sympatric. No molecular data are available for $P$. alba and $P$. alboides, since all material is either fixed in formalin or the alcohol specimens are very old and there was no amplification of DNA (P. Krug, personal communication). The $p$-distance (Table 2) between P. acuticauda and P. hearstorum for the $16 \mathrm{~S}$ gene is $2.7 \%$. This is consistent with the percentages found by Krug et al. (2012) for distinct species of Philine. Morphologically, these four species have a large body size with a broad body profile and a broad, smooth, flattened shell with an expanded posterior wing. They also have a large radula with a wide inner lateral tooth that either lacks denticles or has greatly reduced denticles. All four species have two outer lateral teeth and a simple penis and prostate. They all have a supraintestinal ganglion located posteriorly to the nerve ring. Despite these similarities, $P$. hearstorum differs significantly from these taxa in several regards. It is the only species that has distinct sculpture on the shell. The posterior end of the body of $P$. alba and $P$. alboides is blunt rather than being acutely tapered as in $P$. hearstorum and $P$. acuticauda. The posterior end of the body is more acute in $P$. acuticauda. In $P$. acuticauda, $P$. hearstorum, and $P$. alboides, the inner lateral teeth entirely lack denticles, while in $P$. alba, some of the teeth have minute denticles on the masticatory border, while other teeth in the same radula may entirely lack denticles. In $P$. hearstorum, $P$. alba, and $P$. alboides, the two outer lateral teeth are similar in shape with evenly curved cusps. In $P$. acuticauda, the inner of these two teeth is similar to those found in the other two species but the outer one has a dramatically reduced cusp. Philine hearstorum, $P$. alba, and $P$. alboides have three small evenly-sized gizzard plates, while no trace of plates was found in the two specimens of $P$. acuticauda examined. The gizzard plates of $P$. hearstorum have rhomboidal crystals on their surface, while those of $P$. alba and $P$. alboides are smooth. The prostate of $P$. acuticauda is only slightly curved and is posteriorly directed, while in $P$. hearstorum, $P$. alba, and $P$. alboides, the prostate is sharply curved, with the posterior end being anteriorly directed. The penial papilla of $P$. hearstorum has a bilobed apex, while the papilla of $P$. acuticuada, $P$. alba, and $P$. alboides is undivided.

\section{Philine dentiphallus Gonzales and Gosliner, sp. nov.}

Figures 1E, 6-7

MATERial Examined.- Holotype: body wall opened, but not dissected, CASIZ 192088, ST HEPD 19, beam trawl in beam trawl in muddy sand with pebbles, 541-636 m depth, western end of Verde Island Passage, southeast end of Golo Island, Batangas Province, Luzon, Philippines, $13.5895^{\circ} \mathrm{N}, 120.4155^{\circ} \mathrm{E}, 1$ June 2011 , Hearst Expedition Deep Sea Team. PARATYPE: dissected, 

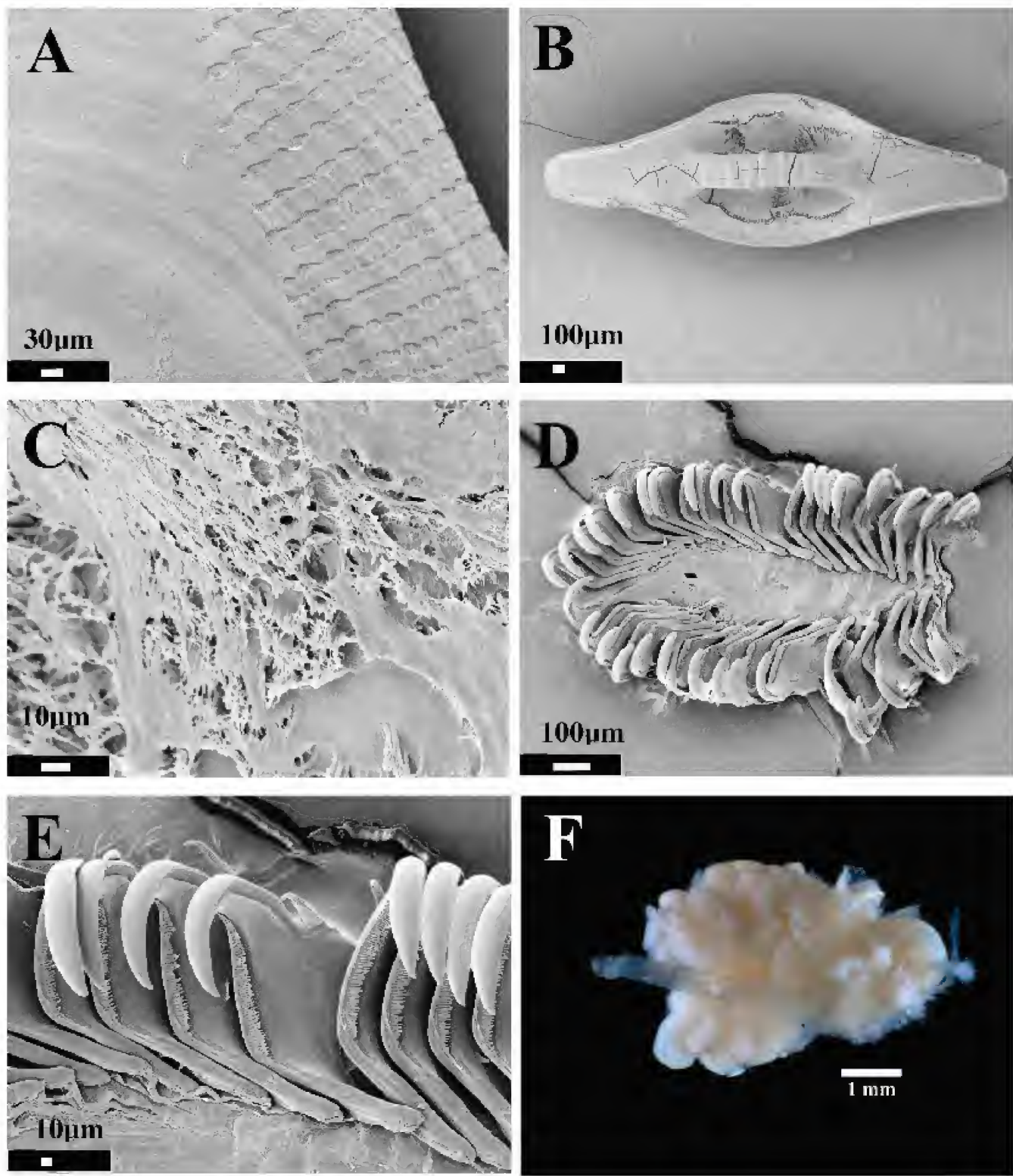

FIGURE 6. Internal anatomy of Philine dentiphallus sp. nov., paratype, CASIZ 1893377. A. Scanning electron micrographs of shell sculpture. B. Scanning electron micrograph of gizzard plate. C. Scanning electron micrograph of microsculpture of gizzard plate. D. Scanning electron micrograph of entire radula. E. Scanning electron micrograph of half-row of radular teeth showing inner and outer lateral teeth. F. Light micrograph of penial papilla and complex prostate. 
CASIZ 189337, ST HEPD 19, beam trawl in muddy sand with pebbles, 541-636 m depth, western end of Verde Island Passage, southeast end of Golo Island, Batangas Province, Luzon, Philippines, $13.5895^{\circ} \mathrm{N}, 120.4155^{\circ} \mathrm{E}, 1$ June 2011 , Hearst Expedition Deep Sea Team.

Geographical Distribution.- Thus far, this species is known only from the western end of the Verde Island Passage separating southern Luzon and northern Mindoro.

ETyMOLOGY.- The name dentiphallus refers to the comb-like row of denticles along the lobe of the penial papilla, a characteristic that distinguishes this species from other members of the Philine aperta clade (sensu Price et al. 2011).

Natural History.- This species has been found in muddy sand with small pebbles. No prey items were found in the gizzard and no other information about its feeding ecology is known.

DESCRIPTION.-External morphology: The living animals (Fig. 1E) are 8 to $9 \mathrm{~mm}$ in length and $5 \mathrm{~mm}$ wide. The body color of the living animal is uniformly white with yellowish pigment in the mantle cavity on the ventral side. The roughly trapezoidal cephalic shield is longer than the posterior shield and is not indented posteriorly. The parapodia are relatively short, reaching the cephalic shield, but leaving the anterior and posterior shields almost entirely visible (Fig. 7A). The posterior end of the posterior shield is blunt and has a rounded posterior terminal. The gill is simply plicate consisting of eight primary folds and is situated ventrally on the right posterior end of the animal.

Shell (Fig.6A): The shell was damaged during collection in the trawl and was fragmented. It was quite broad with a relatively low profile, where it occupies the majority of the posterior shield. Most of the shell lacks sculpture but the innermost whorls show remnants of spiral sculpture that is partially covered by a smooth outer layer of additional calcification.

Digestive system (Figs. 6B-E, 7B): The buccal mass is relatively small, occupying the anterior quarter of the anterior shield. The buccal bulb has a relatively small radula. The radular formula in the paratype specimen is $20 \times 1.1 .0 .1 .1$. (Fig. 6D). The inner lateral teeth (Fig. 6E) are large and broad with a curved prominent cusp. Their masticatory margin has a series of up to 64 elongate, closely crowded denticles. The outer lateral tooth is narrow and elongate with an elongate, curved cusp. There is a large ventral oral gland and small dorsal oral glands. At the posterior end of the buccal mass, near the junction with the crop, is a pair of short salivary glands. The gizzard is large and highly muscular (Fig. 7B), much wider than the buccal bulb. There are three equalsized gizzard plates (Fig. 6B) that are elongate with rounded apices. The central region contains an elongate, narrow longitudinal bar that occupies the central third of the plate. On the outer sides of bar is a pair of large, deep ovoid depressions. There is no organized pattern of fine microscopic network on the gizzard plates, although a fibrous network is evident (Fig. 6C). The gizzard narrows posteriorly and enters the digestive gland. The intestine emerges from the right side of the digestive gland and terminates near the posterior end of the body near the base of the gill.

Central Nervous System (Fig. 7C): The circumesophageal nerve ring consists of paired cerebral, pedal and pleural ganglia and a single supraintestinal ganglion immediately posterior to the right pleural ganglion. The cerebral and pedal commissures are both somewhat elongate with wellseparated respective ganglia. On the ventral side of the buccal mass near the entrance of the esophagus are the buccal ganglia which are immediately adjacent to each other. From the posterior end of the anterior nerve ring the right branch of the visceral loop the osphradial nerve extends posteriorly from the supraintestinal ganglion. The two lateral branches of the visceral loop join posteriorly at the posterior ganglia. The left visceral loop enters the subintestinal ganglion, while the right lateral nerve enters the visceral ganglion. The visceral ganglion is larger than the subintestinal ganglion. From the visceral ganglion is the genital nerve, which does not appear to have a distinct genital ganglion. 

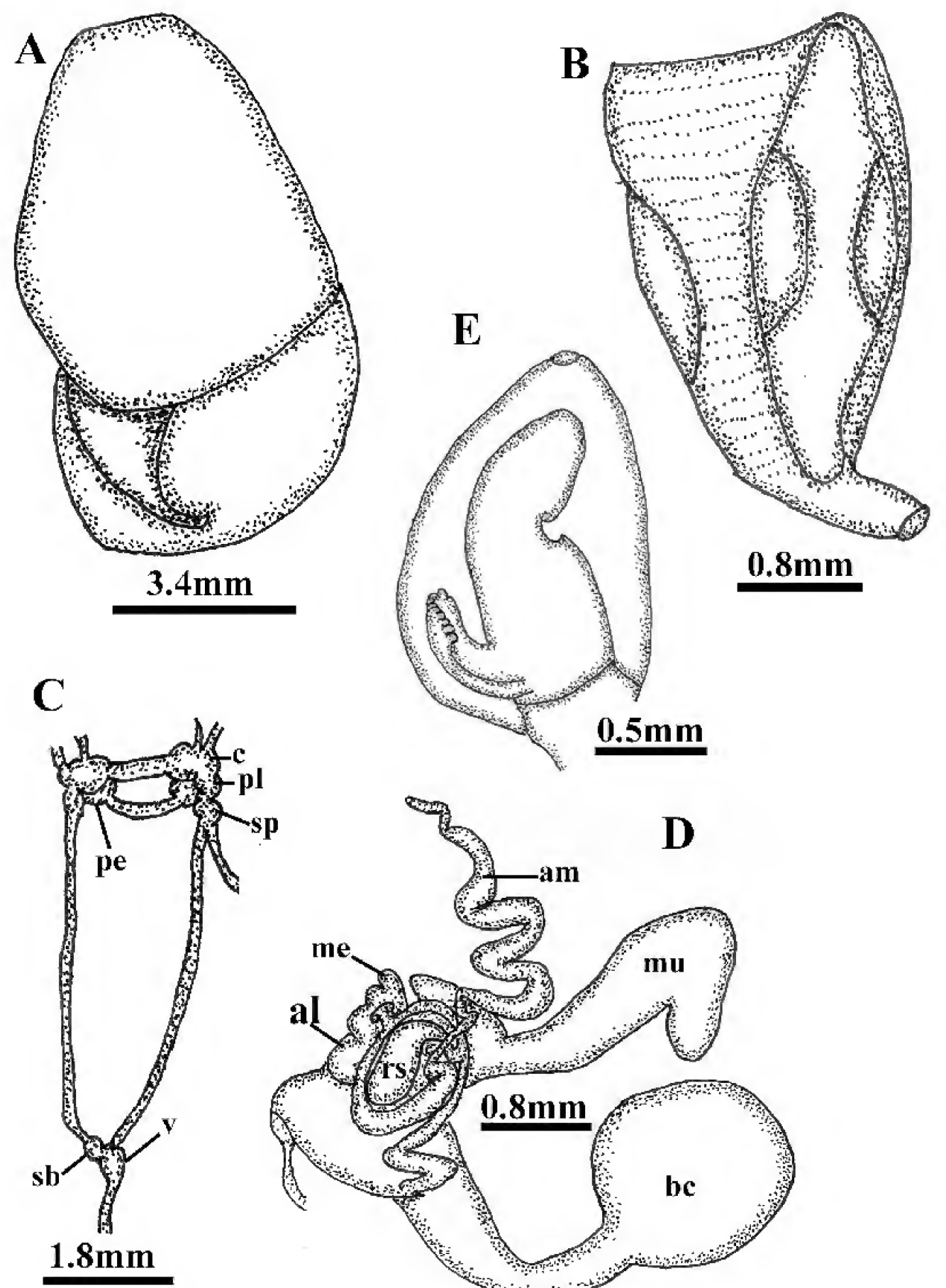

\section{$0.8 \mathrm{~mm}$}

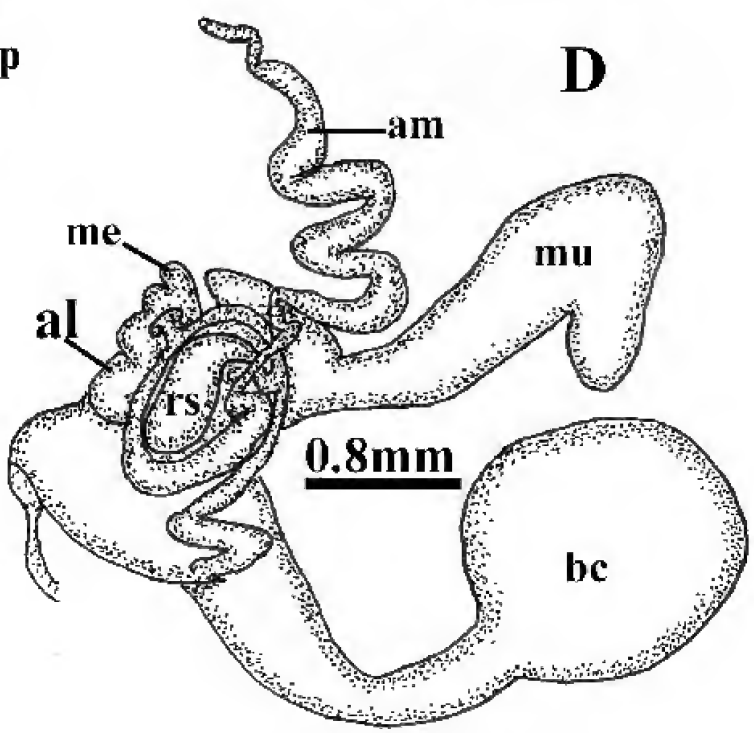

FIGURE 7. Internal anatomy of Philine dentiphallus sp. nov., paratype, CASIZ 1893377. A. Ventral view of preserved animal. B. Muscularized gizzard. C. Central nervous system, $\mathrm{c}=$ cerebral ganglion, $\mathrm{pe}=$ pedal ganglion, $\mathrm{pl}=\mathrm{pleural}$ ganglion, $\mathrm{sb}=$ subintestinal ganglion, $\mathrm{sp}=$ supraintestinal ganglion,, $\mathrm{v}=$ visceral ganglion. $\mathrm{D}$. Posterior reproductive organs, $\mathrm{al}=$ albumen gland, $\mathrm{am}=$ ampul $\mathrm{a}, \mathrm{bc}=$ bursa copulatrix, $\mathrm{me}=$ membrane gland, $\mathrm{mu}=$ mucous gland, $\mathrm{rs}=$ receptaculumseminis. E. Detail of penial sac and penial papilla. 
Reproductive System (Figs. 6F, 7D-E): The reproductive system is fully mature. The arrangement of reproductive organs is essentially monaulic (as discussed by Gosliner 1994) but with a single branch of the hermaphroditic duct to the albumen and membrane glands (Fig. 7D). From the large ovotestis, which is intermingled with the digestive gland, emerges the wide, convoluted ampulla. The ampulla narrows and appears to have a short proximal receptaculum seminis at the point where the hermaphroditic duct again widens and curves around the large distal receptaculum seminis. The duct again narrows at the point where it enters the albumen and membrane glands. The albumen and membrane glands are small. The larger mucous gland is bilobed with a large primary lobe and small secondary one. After branching to the female glands, the hermaphroditic duct is elongate and narrow and extends to the genital aperture where it then joins the short duct of the large, pyriform distal receptaculumseminis and continues to the genital atrium, where it joins the elongate duct of the bursa copulatrix. The bursa is large and spherical. Its duct is wide throughout its length but is widest at the genital atrium. There are no secondary bursae evident in the specimen dissected. From the genital atrium the open, ciliated sperm groove leads to the cephalic penis. The penis (Fig. 6F) consists of a broad penial sac and an elongate, highly branched, posteriorly directed prostate gland and associated ducts that characterize members of the Philine aperta clade. There is a large, wide retractor muscle situated on the ventral surface of the penis. Within the penial sac a large bulbous penial papilla with a large lateral flange that terminates in a curved area that has a series of comb-like denticles along its outer surface (Fig. 7E).

Remarks. - This species is most morphologically similar to Philine auriformis Suter, 1909, and $P$. fenestra Price, Gosliner and Valdés, 2011. All three of these species have three equal-sized gizzard plates with an elongate central bar, flanked by a pair of depressions. The posterior shield of $P$. auriformis has widely distinct lobes that are widely separated by a distinct notch that is not evident in either $P$. dentiphallus or $P$. fenestra. The shell of $P$. dentiphallus is wide and largely smooth as in $P$. auriformis, whereas that of $P$. fenestra is narrower, with punctate sculpture throughout. All three species have radular teeth with rows of denticulate inner lateral teeth and rows of single outer lateral teeth. In P. fenestra (Price et al., 2011), the inner lateral tooth has fewer denticles (35-50) that are more widely spaced than those of $P$. dentiphallus, which has about 64 denticles. In $P$. auriformis there are 30-50 denticles (Gosliner 1995). The outer lateral teeth of P. fenestra are narrow but almost as elongate as the inner lateral teeth, whereas in $P$. auriformis and $P$. dentiphallus the outer laterals are much shorter than the inner laterals. The gizzard plates of $P$. dentiphallus and $P$. auriformis have a narrow bar and two relatively lateral depressions that occupy about a third of the length of the plate, whereas in P. fenestra the central bar is much broader and the depressions are narrower and far more elongate. In both $P$. auriformis and P. fenestra the penial papilla is simple and hammer-shaped, whereas it is bulbous with a lateral denticulate flange in $P$. dentiphallus.

\section{Philine verdensis Gonzales and Gosliner, sp. nov.}

Figures $1 \mathrm{~F}, 8-9$

Material Examined.- Holotype: CASIZ 192089, ST HEPD 21, beam trawl in muddy sand, 132-172 m depth, western end of Verde Island Passage, off northwest tip of Lubang Island, Batangas Province, Luzon, Philippines, $13.888167^{\circ} \mathrm{N}, 120.1075^{\circ} \mathrm{E}, 1$ June 2011 , Hearst Expedition Deep Sea Team. PARATYPE: dissected, CASIZ 189338, ST HEPD 21, beam trawl in muddy sand, 132-172 m depth, western end of Verde Island Passage, off northwest tip of Lubang Island, Batangas Province, Luzon, Philippines, $13.888167^{\circ} \mathrm{N}, 120.1075^{\circ} \mathrm{E}, 1$ June 2011, Hearst Expedition Deep Sea Team. 

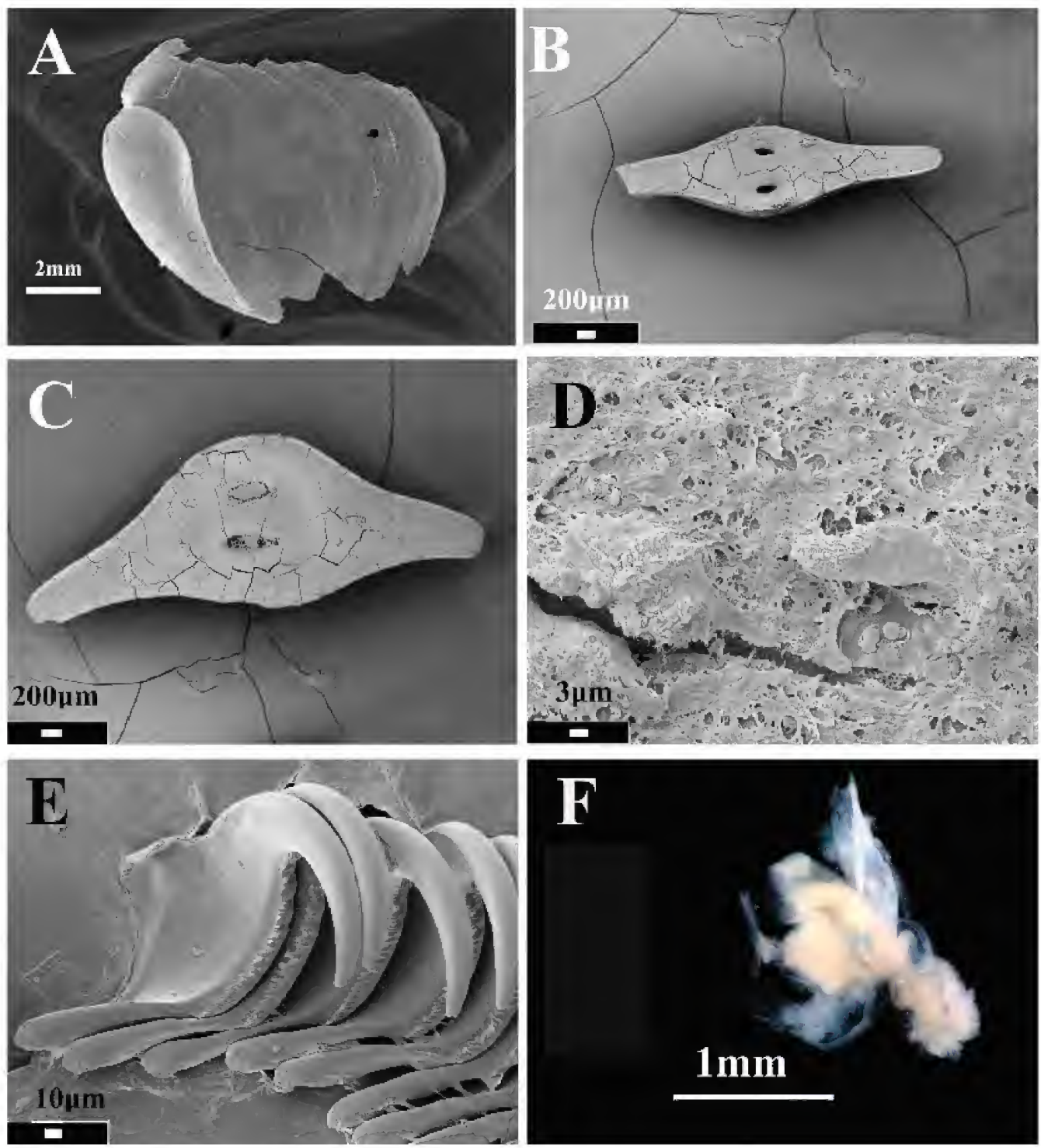

FIGURE 8. Internal anatomy of Philine verdensis sp. nov., paratype, CASIZ 1893378. A. Shell. B. Scanning electron micrograph of unpaired gizzard plate. C. Scanning eletron micrograph of paired gizzard plate. D. Scanning eletron micrograph of gizzard plate microsculpture. E. Radular teeth. F. Light micrograph of penis and prostate. 
Geographical Distribution. - Thus far, this species is known only from the western end of the Verde Island Passage, separating southern Luzon and northern Mindoro.

Eтymology.- The name verdensis refers to the Verde Island Passage, the only locality from which this species is known.

Natural history. - This species has been found in muddy sand in 132-172 m depth. No prey items were found in the gizzard and no other information about its feeding ecology is known.

DESCRIPTION.-External morphology. The living animals (Figs. 1F) are up to $17 \mathrm{~mm}$ in length $10 \mathrm{~mm}$ wide. The body color of the living animal is uniformly white with yellowish pigment on the anterior end of the cephalic shield and in the mantle cavity on the ventral side. The roughly trapezoidal cephalic shield is longer than the posterior shield and is not indented posteriorly. It is widest anteriorly and tapers to a blunt posterior end. The parapodia are relatively short (Fig. 9A), reaching the cephalic shield, but leaving the anterior and posterior shields almost entirely visible. The posterior end of the posterior shield blunt and has a rounded posterior terminal (Fig. 9B). The gill is simply plicate consisting of eight primary folds and is situated ventrally on the right posterior end of the animal.

Shell (Fig. 8A): The shell was slightly damaged during collection in the trawl. It is quite broad with a relatively low profile, where it occupies the majority of the posterior shield.

The shell lacks any obvious sculpture, but spiral growth lines are evident over the shell surface.

Digestive system (Figs. 8B-E, 9C): The buccal mass is relatively small, occupying the anterior quarter of the anterior shield. The buccal bulb has a relatively small radula. The radular formula in the paratype is $18 \times 1.0 .1$. The inner lateral teeth are large (Fig. $8 \mathrm{E}$ ) and broad with a curved prominent cusp. Their masticatory margin has a series of up to 45 elongate, closely-crowded denticles. Outer lateral teeth are absent. There is a large ventral oral gland and small dorsal oral glands. At the posterior end of the buccal mass, near the junction with the crop, is a pair of short salivary glands. The gizzard is large and highly muscular, much wider than the buccal bulb. There are unequal gizzard plates (Fig. 9C) that are elongate with rounded apices. The unpaired plate is smaller (Fig. 8B) than the paired plates (Fig. 8C) and all plates have paired holes that are large in size. There is not an organized pattern of fine microscopic network on the gizzard plates, although a fibrous network is evident (Fig. 8D). The gizzard narrows posteriorly and enters the digestive gland. The intestine emerges from the right side of the digestive gland and terminates near the posterior end of the body near the base of the gill.

Central Nervous System (Fig. 9D): The circumesophageal nerve ring consists of paired cerebral, pedal and pleural ganglia and a single supraintestinal ganglion immediately posterior to the right plcural ganglion. The cerebral and pedal commissures are both somewhat elongate with wellseparated respective ganglia. On the ventral side of the buccal mass near the entrance of the esophagus are the buccal ganglia, which are immediately adjacent to each other. From the posterior end of the anterior nerve ring the right branch of the visceral loop the osphradial nerve extends posteriorly from the supraintestinal ganglion. The two lateral branches of the visceral loop join posteriorly at the posterior ganglia. The left visceral loop enters the subintestinal ganglion, while the right lateral nerve enters the visceral ganglion. The visceral ganglion is larger than the subintestinal ganglion. From the visceral ganglion is the genital nerve, which does not appear to have a distinct genital ganglion.

Reproductive System (Figs. 8F, 9E, F): The reproductive system is not fully mature. The arrangement of reproductive organs is essentially monaulic (as discussed by Gosliner 1994) but with a single branch of the hermaphroditic duct to the albumen and membrane glands (Fig. 9E). From the large ovotestis, which is intermingled with the digestive gland, emerges the narrow, convoluted ampulla. The ampulla narrows further at the point where the hermaphroditic duct again 

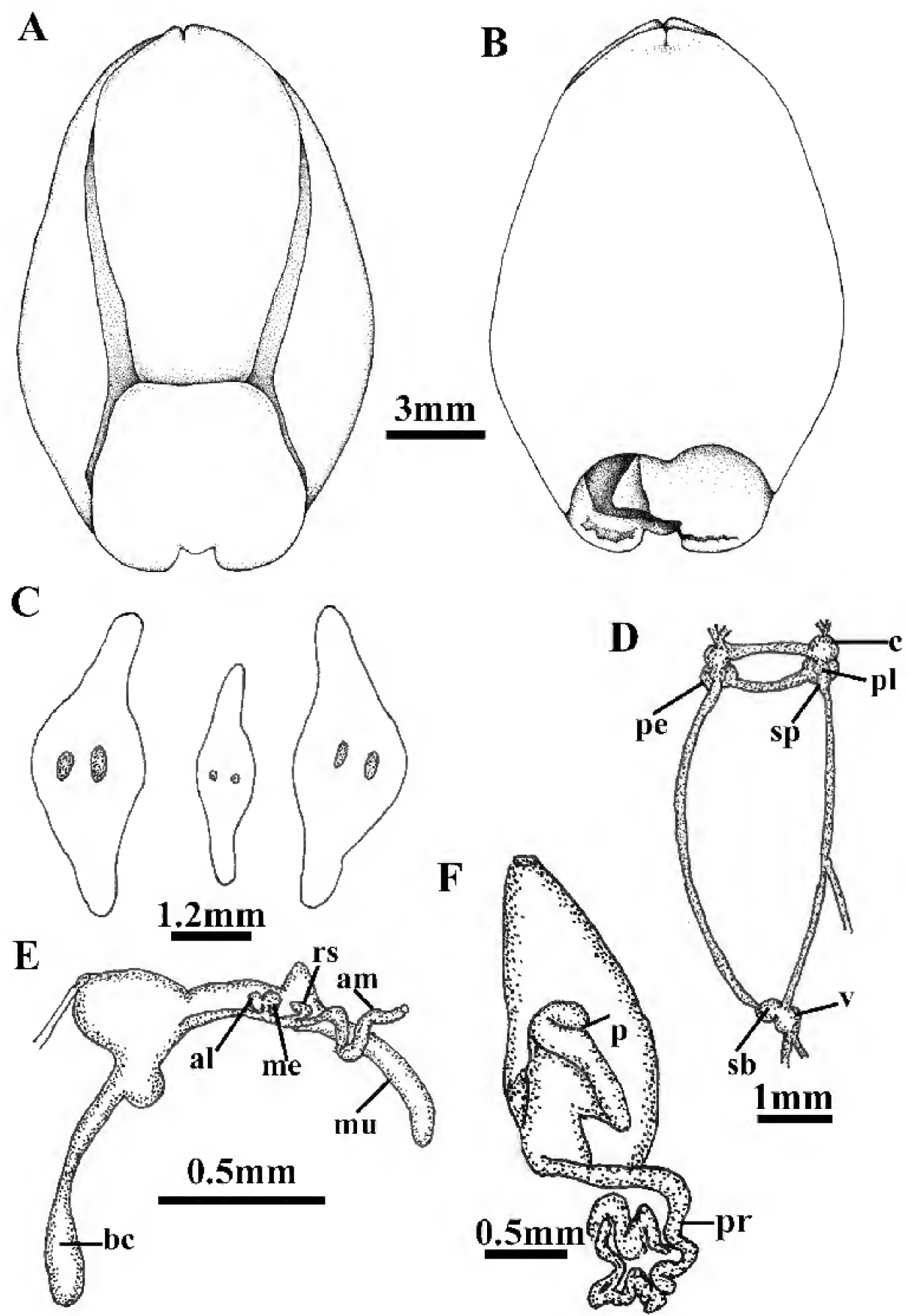

FIGURE 9. Internal anatomy of Philine verdensis sp. nov., paratype, CASIZ 1893378. A. Dorsal view of preserved specimen, drawing by Emily Eng. B. Ventral view of preserved specimen, drawing by Emily Eng. C. Gizzard plates. D. Central nervous system, $\mathrm{c}=$ cerebral ganglion, $\mathrm{pe}=$ pedal ganglion, $\mathrm{pl}=$ pleural ganglion, $\mathrm{sb}=$ subintestinal ganglion, $\mathrm{sp}=\mathrm{suprain}-$ testinal ganglion, $\mathrm{v}=$ visceral ganglion. E. Posterior reproductive organs, al $=$ albumen gland, $a m=$ ampulla, $b c=b u r s a$ copulatrix, $\mathrm{me}=$ membrane gland, $\mathrm{mu}=$ mucous gland, $\mathrm{rs}=$ receptaculum seminis. F. Penis and penial papilla, $\mathrm{p}=$ penial papilla, $\mathrm{pr}=$ prostate. 
widens and curves around the curved distal receptaculum seminis. The duct again narrows at the point where it enters the albumen and membrane glands. The albumen and membrane glands are small. The larger mucous gland is bilobed with a large primary lobe and small secondary one. After branching to the female glands, the hermaphroditic duct is elongate and narrow and extends to the genital aperture where it then joins the short duct of the small, curved distal receptaculum seminis and continues to the genital atrium, where it joins the elongate duct of the bursa copulatrix. The bursa is small and pyriform. Its duct is wide throughout its length but is widest at the genital atrium. There are no secondary bursae evident in the specimen dissected, but there is a swelling at the base of the bursa duct. From the genital atrium the open, ciliated sperm groove leads to the cephalic penis. The penis (Figs. 8E, 9F) is not fully mature and consists of a broad penial sac and a relatively short, compact, highly branched, posteriorly directed prostate gland and associated ducts that characterize members of the Philine aperta clade. Within the penial sac, a large hammer-shaped penial papilla with lobate flap on the anterior side of the lobed papilla (Fig. 9F).The papilla lacks any armature or other ornamentation, but was not entirely mature.

REMARKS.- This species is similar externally to other members of the Philine aperta clade (Price et al. 2011). Of the species known from deep water in the Indo-Pacific, P. habei Valdés, 2008, P. rubra Bergh, 1905, and P. puka Price, Gosliner, and Valdés, 2011, have a radula with no outer lateral teeth and have gizzard plates with a pair of relatively large pits on each gizzard plate. Philine puka has a narrower body shape than does either $P$. habei or $P$. verdensis. The body shape of $P$. rubra is unknown. Also, $P$. puka reaches a maximum length of $10 \mathrm{~mm}$ (Price et al. 2011) and is entirely sexually mature at that size, while a $17 \mathrm{~mm}$ specimen of $P$. verdensis was not fully mature. The inner lateral teeth of $P$. habei were described as lacking denticles, whereas the inner teeth of both $P$. puka and $P$. verdensis have a large number of denticles on the laterals. One specimen identified here as $P$. habei (CASIZ 177499) from the Philippines has a radula where most of the older radular teeth appear quite worn with only rudimentary denticles, whereas the newer teeth have strongly pronounced denticles. Rudimentary denticles also appear to be visible in Valdés' figure of $P$. habei (2008: fig. 64a). Much of the anatomy of $P$. rubra remains undescribed, but the penis is shown as having a distinct vesicle attached to the base of the penial sac that is not evident in the other species. Details of the penial papilla were not described for P. rubra, and it is likely that this species will remain unidentifiable owing to the incompleteness of the original description.

Other morphological differences also appear to differentiate $P$. verdensis, P. habei, and P. puka. In $P$. verdensis, the pores of the paired gizzard plates are oblong with one of the pores being markedly larger than the other. In $P$. puka and $P$. verdensis, the paired holes are very similar in size. The unpaired gizzard plate of $P$. puka and $P$. verdensis is much smaller than the paired plates whereas in $P$. habei all three plates are similar in size. The microstructure of the gizzard plates also differs in the three species. In P. puka, there is a distinct honey-combed pattern present, whereas in $P$. habei (present study) there is some organization of a honeycomb pattern, but it is not as highly organized as in $P$. puka. In $P$. verdensis, there is no indication of any organized microstructural pattern. The penial papilla of $P$. verdensis is hammer-shaped with a prominent flap on the anterior lobe, whereas in $P$. habei the penial papilla is asymmetrical with one lobe larger than the other or more of less equally lobed (present study). The penis of $P$. puka is smaller with markedly unequal lobes and a very short base.

In the molecular phylogenetic analysis (Fig. 14), P. verdensis and P. habei are sister species, but have a p-distance of $4.2 \%$ in their $16 \mathrm{~S}$ mitochondrial genes. This strongly supports them being considered as distinct species. Previously, Krug et al. (2012) found that separate species of Philine have $16 \mathrm{~S} \mathrm{p}$ values greater than $1.0 \%$, while separate populations of members of the same species had $\mathrm{p}$ values between $0.2-0.3 \%$. 


\section{Philine pittmani Gonzales and Gosliner, sp. nov.}

Figures 1G-H, 10, 11

Material Examined. - Holotype: CASIZ, 192090, sand sample, 6-17 m, Black Rock, Maui, Hawai'i, 8 April 2011, Cory Pittman. PARATYPES: CASIZ, 185213, dissected, one specimen, sand sample, 6-17 m, Black Rock, Maui, Hawai'i, 8 April 2011, Cory Pittman. CASIZ 163775, one specimen, dissected, in sample of collected sand dwelling Halimeda, 10-18 m, Airport Beach, Maui, Hawai'i, 9 October 2000, Cory Pittman. CASIZ 166768, two specimens, Halimeda incrasita bed and open sand, 6-11 m depth, Black Rock, Maui, Hawai'i, 14 April 2003, Cory Pittman. CASIZ, 118253, 1 specimen, Halimeda opuntia beds, algal wash, Airport Beach, Maui, Hawai'i, 10 May 1999, T.M. Gosliner and P. Fiene. CASIZ 192091, one specimen, algal wash, 3-8 m, Makena Landing, Maui, Hawai'i, 12 August 2002, Cory Pittman.

Geographical Distribution.- Thus far, this species is known only from the Maui in the Hawai'ian Islands.

ETYMOLOGY.- The name pittmani honors Cory Pittman who has been intensely studying the Hawai' ian opisthobranch fauna for nearly two decades and, together with Pauline Fiene, has documented the diversity of this insular fauna. Cory has discovered many new taxa, including the species described here.

Natural History. - This species has been found in fine sand basins and burrowed in Halimeda kanaloana beds in 3-17 $\mathrm{m}$ depth. No prey items were found in the gizzard and no other information about its feeding ecology is known. This species produces a lozenge-shaped to spherical, white egg mass containing a tangled egg string. The mass has a sticky surface and acquires a coating of strongly adherent sand. Hatching of veliger larvae occurs in 5-6 days in the laboratory.
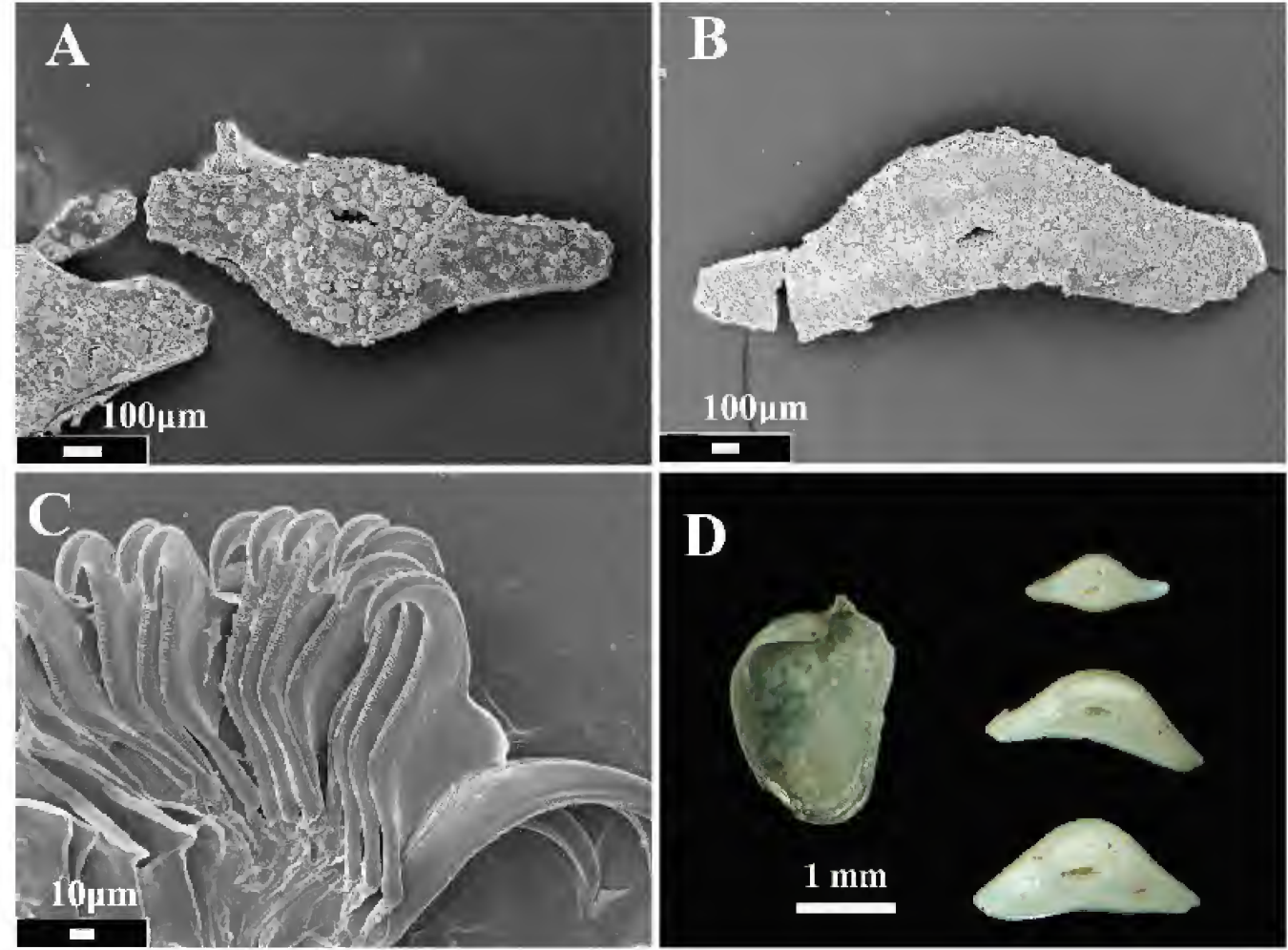

FIGURE 10. Internal anatomy of Philine pittmani sp. nov., paratype, CASIZ 163775. A. Scanning eletron micrograph of unpaired gizzard plate. B.Scanning eletron micrograph of paired gizzard plate. C. Scanning electron micrograph of half-row of radular teeth. D. Shell and gizzard plates, photograph by C. Pittman. 


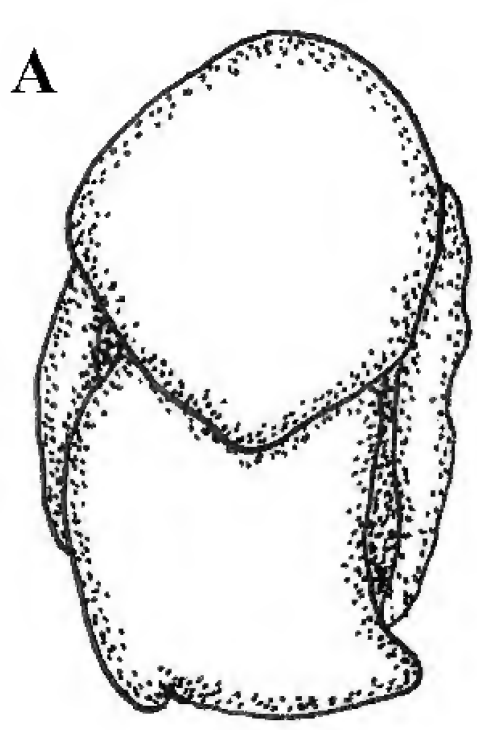

$3 \mathrm{~mm}$

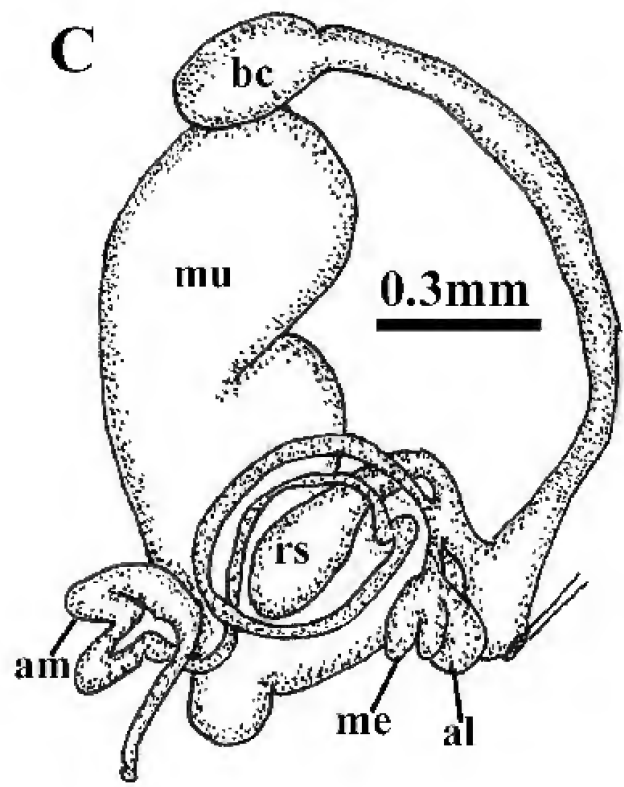

B

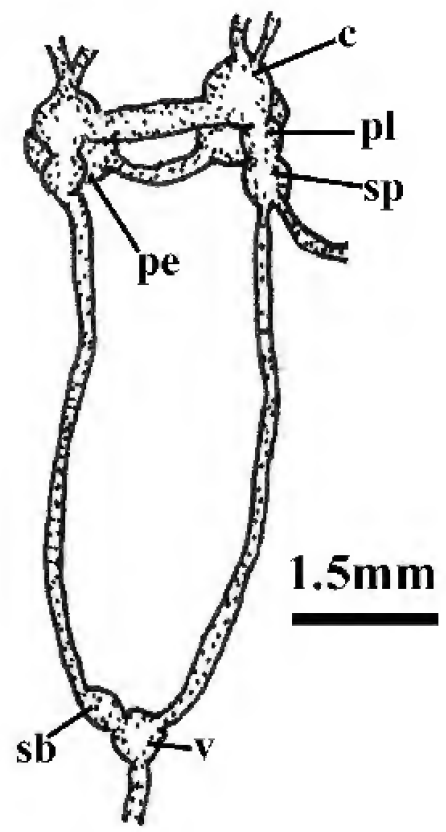

D

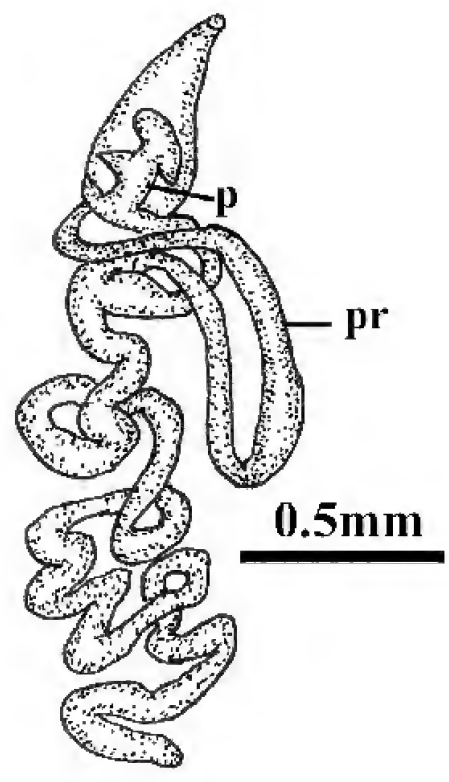

FIGURE 11. Internal anatomy of Philine pittmani sp. nov., paratype, CASIZ 163775. A. Dorsal view of preserved animal. B. Central nervous system, $\mathrm{c}=$ cerebral ganglion, $\mathrm{pe}=$ pedal ganglion, $\mathrm{pl}=$ pleural ganglion, $\mathrm{sb}=$ subintestinal ganglion, $\mathrm{sp}=$ supraintestinal ganglion, $\mathrm{v}=$ visceral ganglion. $\mathrm{C}$. Posterior reproductive organs, al $=$ albumen gland, am $=$ ampulla, $b c=$ bursa copulatrix, $m e=$ membrane gland, $m u=$ mucous gland large, $r s=$ receptaculum seminis. D. Penis, $\mathrm{p}=$ penial papilla, $\mathrm{pr}=$ prostate. 
DESCRIPTION.-External morphology: The living animals (Figs. $1 \mathrm{G}, \mathrm{H}$ ) are narrow and elongate, 3 to $13.5 \mathrm{~mm}$ in length and about $4 \mathrm{~mm}$ wide in the largest specimens. The cephalic shield is two to three times the length of the posterior shield. The parapodia are extremely short (Fig. $11 \mathrm{~A}$ ), and narrow, barely reaching the cephalic shield, and leaving the anterior and posterior shields entirely visible. The posterior end of the posterior shield is blunt and has a pair of elongate extensions. The gill is simply plicate consisting of five primary folds and is situated ventrally on the right posterior end of the animal.

The body color of the living animal is uniformly translucent white with opaque white speckling over the surface of the animal. The opaque white pigment of the gizzard plates is visible through the translucent body, as is the golden brown pigment of the shell.

Shell (Fig. 10D): The shell is wide and open with a thickened posterior margin, where it occupies the majority of the posterior shield.

The shell lacks sculpture but growth lines are evident over its surface. The posterior flange is elongate with a series or irregular denticles along the margin.

Digestive system (Fig. 10): The buccal mass is large and elongate, occupying the anterior twothirds of the anterior shield. The buccal bulb has a relatively small radula. The radular formula in one paratype specimen (CASIZ 163775) is $18-21 \times 1.0 .1$. The inner lateral teeth (Fig. 10C) are large and broad with a curved prominent cusp. Their masticatory margin has a series of up to 52 elongate, closely crowded denticles. Outer lateral teeth are absent. There is a large ventral oral gland and small dorsal oral glands. At the posterior end of the buccal mass, near the junction with the crop, is a pair of short salivary glands. The gizzard is large and highly muscular, much wider than the buccal bulb. There are three unequally-sized gizzard plates that are elongate with rounded apices. The unpaired plate (Figs. 10A, D) is smaller than the two paired plates (Fig. 10B,D). The central region contains two pores, one that is larger and more elongate and a smaller one that is circular (Fig. 10D). The two paired plates differ in size (Fig. 10D) and each of them has only a single elongate pore. There is organized pattern of fine honeycombed microscopic network on the gizzard plates, although it is not well organized. The gizzard narrows posteriorly and enters the digestive gland. The intestine emerges from the right side of the digestive gland and terminates near the posterior end of the body near the base of the gill.

Central Nervous System (Fig. 11B): The circumesophageal nerve ring consists of paired cerebral, pedal and pleural ganglia and a single supraintestinal ganglion immediately posterior to the right pleural ganglion. The cerebral and pedal commissures are both somewhat elongate with wellseparated respective ganglia. On the ventral side of the buccal mass near the entrance of the esophagus are the buccal ganglia, which are immediately adjacent to each other. From the posterior end of the anterior nerve ring the right branch of the visceral loop the osphradial nerve extends posteriorly from the supraintestinal ganglion. The two lateral branches of the visceral loop join posteriorly at the posterior ganglia. The left visceral loop enters the subintestinal ganglion, while the right lateral nerve enters the visceral ganglion. The visceral ganglion is larger than the subintestinal ganglion. From the visceral ganglion is the genital nerve, which does not appear to have a distinct genital ganglion.

Reproductive System (Figs. 11C-D): The arrangement of reproductive organs is essentially monaulic (as discussed by Gosliner 1994) but with a single branch of the hermaphroditic duct to the albumen and membrane glands (Fig. 11C). From the large ovotestis, which is intermingled with the digestive gland, emerges the wide, convoluted ampulla. The ampulla narrows considerably. After the hermaphroditic duct crosses over the receptaculum seminis, it widens and curves around the distal surface of the pyriform receptaculum. The duct completes a circle around the receptaculum and branches to the albumen and membrane glands and also receives the duct of the receptac- 
ulum. The duct widens as it enters the common genital atrium and meets the elongate duct of the bursa copulatrix. The bursa is relatively small and oblong. The genital atrium is relatively wide and somewhat muscular and opens into the ciliated sperm groove. The albumen and membrane glands are small. The larger mucous gland is bilobed with a large primary lobe and small secondary one. From the genital atrium the open, ciliated sperm groove leads to the cephalic penis. The penis (Fig. 11D) consists of a narrow penial sac and an elongate, branched, posteriorly directed prostate gland and associated ducts that characterize members of the Philine aperta clade. There is a large, wide retractor muscle situated on the ventral surface of the penis. Within the penial sac a small, elongate penial papilla with a narrow hammer-shaped papilla that is rounded apically. Below the papilla is a triangular, acutely pointed lobe

REMARKS.- By virture of its gizzard plates with pores and complex penis and prostate, this species is clearly a member of the Philine aperta complex. It is the only member of this complex that has paired gizzard plates with only a single pore. The only other member of this complex with a narrow, elongate body and narrow parapodia is P. elegans Bergh, 1905 (Price et al. 2011, fig. 1D).

This species differs markedly from $P$. pittmani in its internal anatomy. The gizzard plates of P. elegans have a series elongate fibriate extensions along the lateral margins of the plate (Price et al. 2011, figs. 16A-B). Additionally all gizzard plates of $P$. elegans have two pores, while in P. pittmani, the two paired gizzard plates have only a single pore. Also the surface of the gizzard plates of $P$. elegans is tuberculate, while it is smooth in $P$. pittmani. The radula of $P$. elegans also lacks outer lateral teeth but has far fewer denticles (33) than do those of P. pittmani (52). The penial papilla of $P$. pittmani has a relatively small penial papilla with equal lobes of the hammer-shaped papilla, while $P$. elegans has a much larger papilla with markedly unequal lobes. Additionally, P. pittmani has an acutely pointed appendage below the papilla that is absent in P. elegans.

\section{Philine multipapillata Gonzales and Gosliner, sp. nov.}

Figures 12-13

Material Examined.- Holotype: dissected, CASIZ 172841, ST T2, trawl in coarse sand and mud, $150 \mathrm{~m}$ depth, south of Alona Kew, Panglao, Bohol, Philippines, $9^{\circ} 32.4^{\prime} \mathrm{N}, 123^{\circ} 47.8^{\prime} \mathrm{E}$, 31 May 2004, Panglao Expedition team.

GeOgRaPhiCal Distribution. - Thus far, this species is known only from the Visayas region of the Philippines from the coast of Bohol.

EтYMOLOGY.- The name multipapillata refers numerous conical papillae that ornament the surface of the penial papilla.

Natural History. - This species has been found in sand and mud in $150 \mathrm{~m}$ depth. No prey items were found in the gizzard and no other information about its feeding ecology is known.

DESCRIPTION.-External morphology: The living animals have not been observed, but the preserved holotype (Fig. 13A) is $9 \mathrm{~mm}$ in length $4 \mathrm{~mm}$ wide. The cephalic shield is longer that the posterior shield and the parapodia are short and narrow, barely covering the cephalic and posterior shields. The cephalic shield is not indented posteriorly and is blunt and slightly curved. The posterior shield is slightly bilobed posteriorly. The body color of the preserved animal is uniformly white. The posterior shield and is not indented posteriorly. The gill is simply plicate consisting of ten primary folds and is situated ventrally on the right posterior end of the animal.

Shell. The shell was badly fragmented during collection in the trawl and is not illustrated here. It appears that it was quite broad with a relatively low profile, where it occupies the majority of the posterior shield. The shell lacks sculpture but evidence of growth lines can be found on the remaining fragments. 

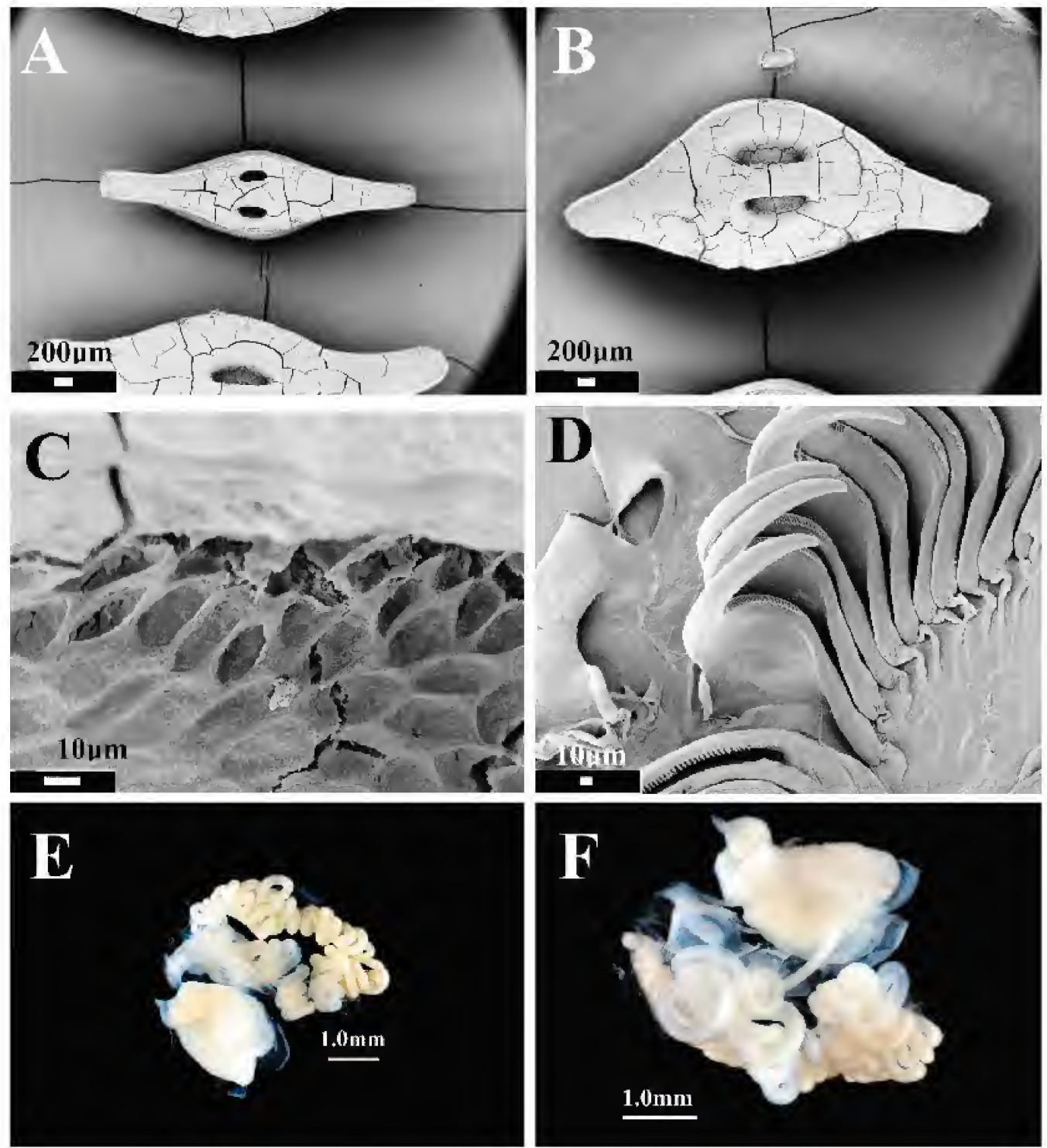

FIGURE 12. Internal anatomy of Philine multipapillata sp. nov., holotype, CASIZ 172841. A. Scanning eletron micrograph of unpaired gizzard plate. B. Scanning electron micrograph of paired gizzard plate. C. Scanning electron micrograph of gizzard plate microstructure. D. Scanning electron micrograph of half-row of radular teeth. E. Dorsal light micrograph of penis. F. Ventral light micrograph of penis.

Digestive system (Fig. 12A-D, 13B): The buccal mass is relatively small, occupying the anterior quarter of the anterior shield. The buccal bulb has a relatively small radula. The radular formula in the holotype is $20 \times 1.0 .1$. The inner lateral teeth (Fig. 12D) are large and broad with a curved prominent cusp. Their masticatory margin has a series of up to 56 elongate, closely crowded denticles. Outer lateral teeth are absent. There is a large ventral oral gland and small dorsal oral glands. At the posterior end of the buccal mass, near the junction with the crop, is a pair of short salivary glands. The gizzard is large and highly muscular, much wider than the buccal bulb. There are unequal gizzard plates (Fig. 13B) that are elongate with rounded apices. The unpaired plate is smaller (Fig. 12A) than the paired plates (Fig. 12B). All plates have paired holes that are elongate and large in size and are relatively equal in size. There is an organized pattern of honeycombed fine 

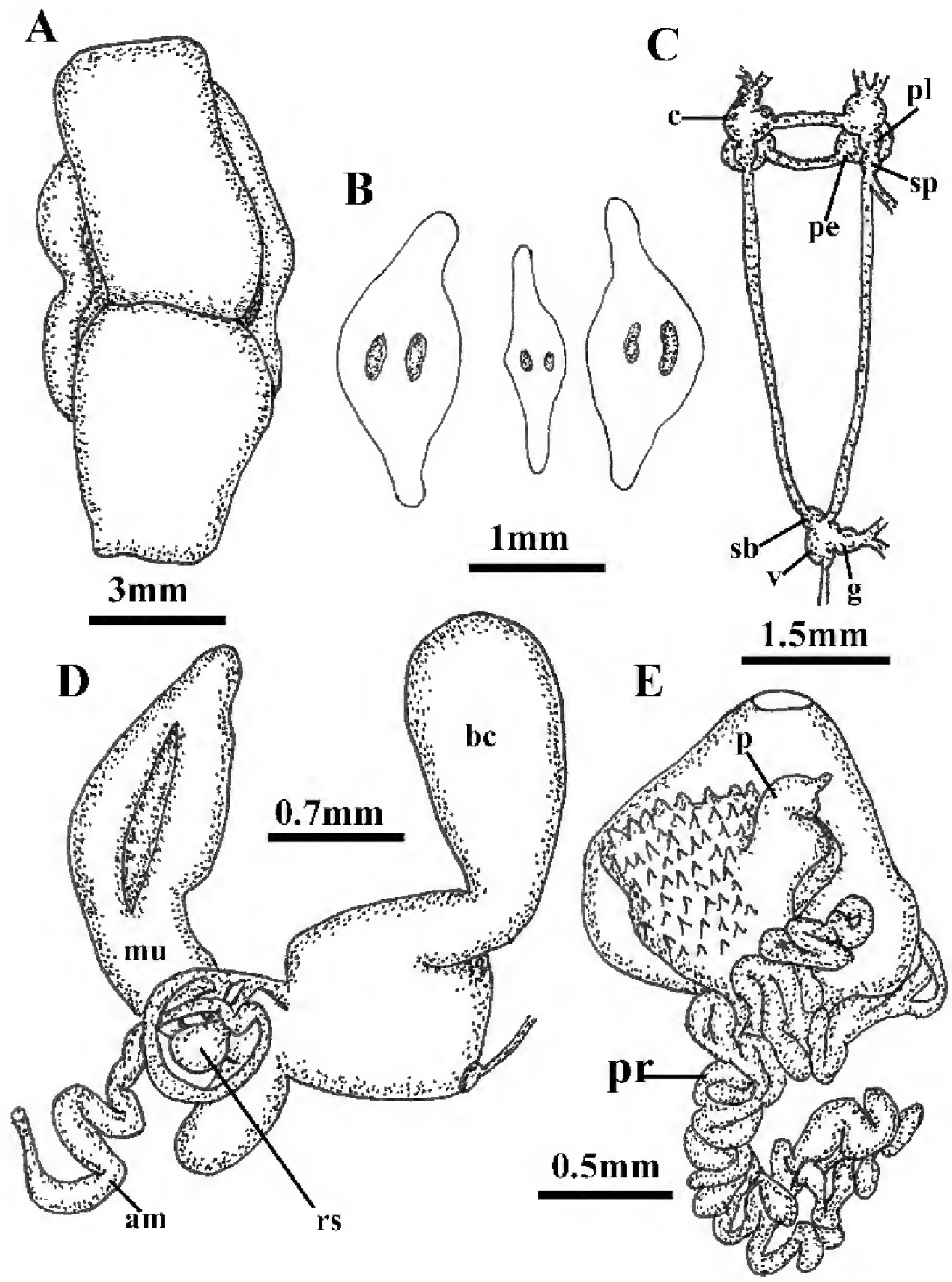

FIGURE 13. Internal anatomy of Philine multipapillata sp. nov., holotype, CASIZ 172841. A. Dorsal view of preserved animal. B. Gizzard plates. C. Central nervous system, $\mathrm{c}=$ cerebral ganglion, $\mathrm{g}=$ genital galion, $\mathrm{pe}=$ pedal ganglion, $\mathrm{pl}=$ pleural ganglion, $\mathrm{sb}=$ subintestinal ganglion, $\mathrm{sp}=$ supraintestinal ganglion, $\mathrm{v}=$ visceral ganglion. $\mathrm{D}$. Posterior reproductive organs, $a m=$ ampulla, $b c=$ bursa copulatrix,$m u=$ mucous gland, $r s=$ receptaculum seminis. E. Penis showing detailed distribution of papillae, $\mathrm{p}=$ penial papilla, $\mathrm{pr}=$ prostate. 
microscopic network on the gizzard plates, although a fibrous network is evident (Fig. 12C). The gizzard narrows posteriorly and enters the digestive gland. The intestine emerges from the right side of the digestive gland and terminates near the posterior end of the body near the base of the gill.

Central Nervous System (Fig. 13C): The circumesophageal nerve ring consists of paired cerebral, pedal and pleural ganglia and a single supraintestinal ganglion immediately posterior to the right pleural ganglion. The cerebral and pedal commissures are both somewhat elongate with wellseparated respective ganglia. On the ventral side of the buccal mass near the entrance of the esophagus are the buccal ganglia, which are immediately adjacent to each other. From the posterior end of the anterior nerve ring the right branch of the visceral loop the osphradial nerve extends posteriorly from the supraintestinal ganglion. The two lateral branches of the visceral loop join posteriorly at the posterior ganglia. The left visceral loop enters the subintestinal ganglion, while the right lateral nerve enters the visceral ganglion. The visceral ganglion is larger than the subintestinal ganglion. From the visceral ganglion is the genital ganglion which bifurcates into a paired gential nerves.

Reproductive System (Figs. 12E-F, 13D-E): The arrangement of reproductive organs is essentially monaulic (Fig. 13D) (as discussed by Gosliner 1994), but with a single branch of the hermaphroditic duct to the albumen and membrane glands. From the large ovotestis, which is intermingled with the digestive gland, emerges the wide, convoluted ampulla. The ampulla narrows considerably. After the hermaphroditic duct crosses over the receptaculum seminis, it widens and curves around the distal surface of the pyriform receptaculum. The duct completes a circle around the receptaculum and branches to the albumen and membrane glands and also receives the duct of the receptaculum. The duct then enters the massive, highly muscularized genital atrium near the wide duct of the bursa copulatrix. The large, ovoid bursa has a thin wall. The entire bursa duct is wide and short and curved. The albumen and membrane glands are small. The larger mucous gland is bilobed with a large primary lobe and small secondary one. There are no secondary bursae evident in the specimen dissected. From the genital atrium the open, ciliated sperm groove leads to the cephalic penis. The penis (Fig. 12E-F, 13E) consists of a broad penial sac and an elongate, highly branched, posteriorly directed prostate gland and associated ducts that characterize members of the Philine aperta clade. There is a large, wide retractor muscle situated on the ventral surface of the penis. Within the penial sac a large bulbous penial papilla with a curved apex is present. The entire surface of the papilla is ornamented with conical papillae (Figs. 12E-F, 13E).

REMARKs.-Morphologically, Philine multipapillata is similar to other members of the Philine aperta clade in that it has gizzard plates with pores and a penial complex with a highly convoluted and branched prostate. It is the only member of this species complex with a penial papilla ornamented with numerous conical papillae. Like P. habei, P. puka, P. rubra, and P. verdensis, it has relatively large pores on the gizzard plates. It is similar to $P$. puka, $P$. verdensis, and $P$. rubra, in that the pores on the gizzard plates are more or less the same size, whereas in $P$. habei, they are markedly unequal. The microstructure of the gizzard plates also differs in the five species. In P. puka, there is a distinct honey-combed pattern present, whereas in P. habei and P. multipapilla$t a$ (present study) there is some organization of a honeycomb pattern, but it is not as highly organized as in P. puka. In P. verdensis, there is no indication of any organized microstructural pattern. The microstructure remains unknown for $P$. rubra. All of these species have only inner lateral radular teeth and lack outer laterals. The denticles on the inner laterals of $P$. verdensis are more uneven than those of $P$. multipapillata, $P$. puka, and $P$. rubra. Philine multipapillata has more denticles on the inner lateral teeth (56) than do P. puka (39-44) or P. verdensis (45). The number of denticles was not described for $P$. rubra, but Bergh's figure seems to indicate there are fewer denticles than 
in P. multipapillata. Philine multipapillata has a distinct genital ganglion present on the visceral loop of the central nervous system, whereas it appears to be absent in P. habei, P. puka, and P. verdensis. It has not been described in $P$. nubra. The penial papilla of $P$. verdensis is hammer-shaped with a prominent flap on the anterior lobe, whereas in $P$. habei the penial papilla is asymmetrical with one lobe larger than the other or more of less equally lobed (present study). The penis of P. pukais smaller with markedly unequal lobes and a very short base. None of these have a large penial papilla with dense conical papillae found in P. multipapillata. The shape of the penial papilla remains unknown for $P$. rubra. Based on these differences, it is clear that $P$. multipapillata is distinct from all other species described within the $P$. aperta clade.

\section{Phylogenetic AnALYSiS}

Our molecular phylogenetic analysis includes five species studied here plus $P$. habei, P. orca, and $P$. rubrata and those studied by Krug et al. (2012) and six other taxa from GenBank (Krug et al. 2012). The resulting maximum likelihood tree (using RAxML) molecular phylogeny is depicted in Figure 14.

In our analysis, Philine verdensis is most closely related to $P$. habei, but that sister group relationship is not strongly supported. The two species have a $p$-distance of just over $4 \%$ (Table 2 ) for the $16 \mathrm{~S}$ gene, strongly supporting their distinctness as separate species. Currently, there are no molecular data for $P$. puka and $P$. rubra, the other two species with large pores on the gizzard plates. Together, $P$, verdensis and $P$. habei form a weakly supported sister-group relationship with P. quadripartita, P. aperta, P. angasi, P. paucipapillata, and an undescribed species from Australia. Philine dentiphallus appears as sister species to $P$. auriformis and $P$. pittmani is sister to both of these species, although these relationships are relatively weakly supported. Philine acuticauda is sister to $P$. hearstorum in our analysis and this relationship is strongly supported. Together these species form the sister group to the Philine aperta clade, but that relationship is weakly supported. The sister group to these Philine species includes seven species of aglajids and Philine orca and P. rubrata. The relationships within this clade are weakly supported.

TABLE 2. Minimum 16S pairwise uncorrected p-distance among Philine species described in this paper. habei verdensis pittmani dentiphallus acuticuada hearstorum

habei verdensis $\quad \overline{0.042}$ pittmani $\quad 0.121$ dentiphallus $\quad 0.160$ acuticauda $\quad 0.169$ hearstorum $\quad 0.168$ anriformis $\quad 0.105$

$\overline{0.116}$
0.122
0.147
0.152
0.104

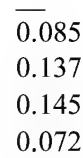

$\overline{0.166}$

0.178 0.067 $\overline{0.027}$

0.155 $\overline{0.1} 62$

\section{DISCUSSION}

This work includes the description of six new species of Philine from the tropical Indo-Pacific. Both morphological and molecular data support the separation of these species. Four of the six species are members of the Philine aperta clade, a group that is already been shown to be well represented in the Indo-Pacific tropics (Price et al, 2011). The other two species, $P$, acuticauda and $P$. hearstorum, have the same radular morphology and gizzard plate morphology as $P$. alba Mattox, 1958, from the Pacific coast of California and $P$. alboides, from the Caribbean. The two new species represent the first members of this group known from the tropical Indo-Pacific.

Krug et al. (2012) conducted the first molecular phylogeny of Philine, but only included Phi- 


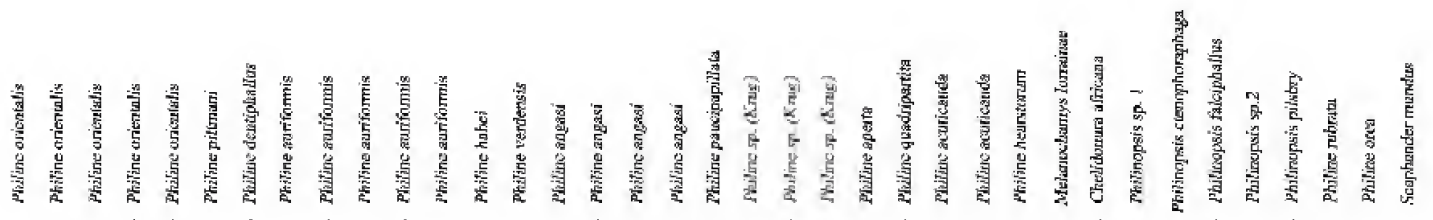

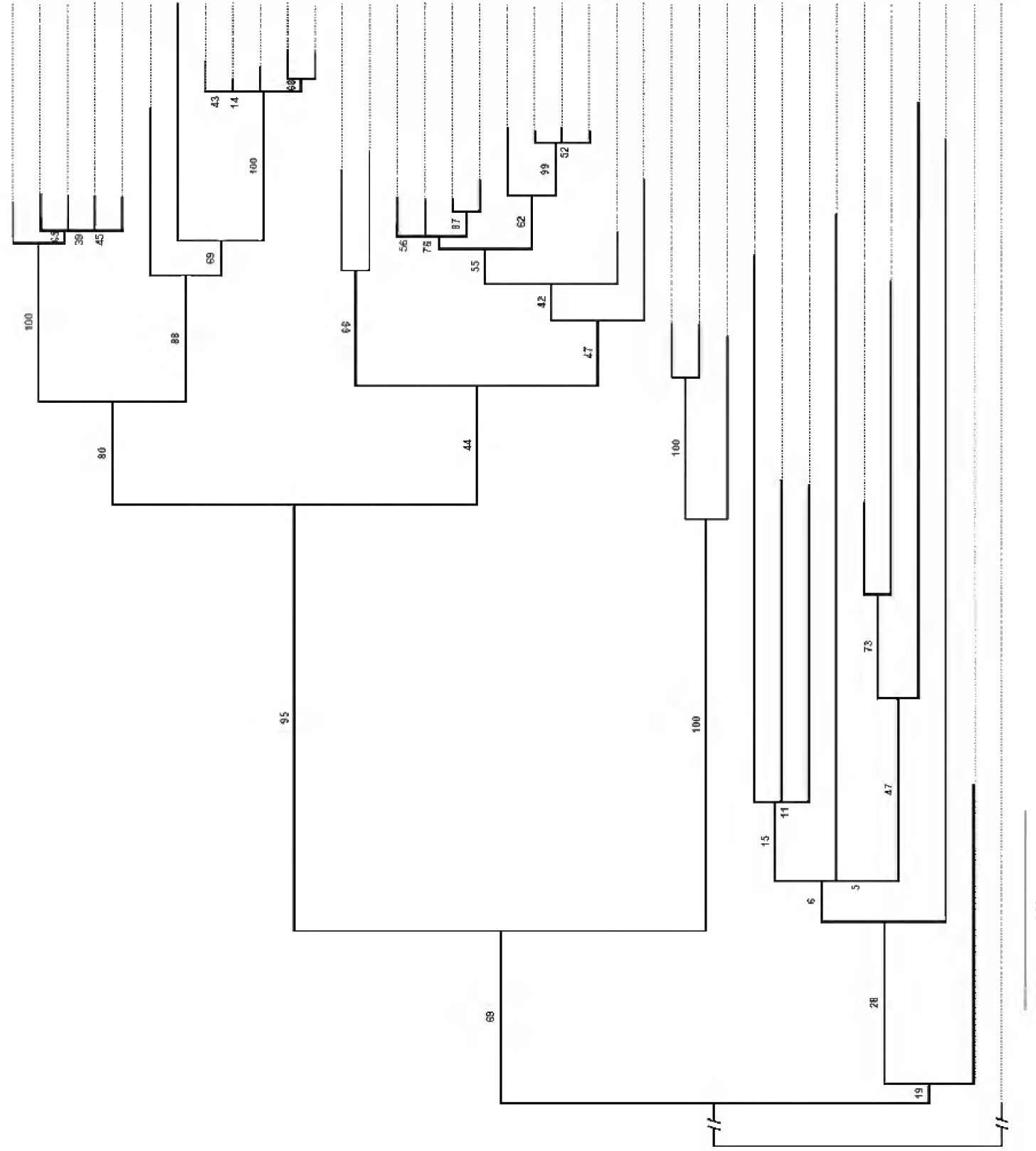

FIgURE 14. Phylogenetic relationships of Philine and other Philinacea. 
line aperta clade members. Our analysis shows strong support for the Philine aperta clade, when additional Philine are included. A second phylogeny was recently published by Ohnheiser and Malaquias (2013) that focused upon COI sequences from North Atlantic species. Their study also shows strong support for the Philine aperta clade, but includes only two members of this group, P. quadripartita Ascanius, 1772 and P. finmarchica (M. Sars, 1859).

The present molecular study includes four additional species in Philine aperta clade: $P$. habei, $P$. verdensis, $P$. pittmani and $P$. dentiphallus. In our analysis, $P$. habei and $P$. verdensis are sister taxa to each other and are collectively the sister taxon to the clade that includes $P$. aperta, $P$. quadripartita, P. paucipapillata, $P$. sp. 1 (from Australia), and $P$. angasi. These taxa also formed a clade in Krug et al.'s (2012) study, but in our study $P$. quadripartita and $P$. aperta are more basally situated than in the previous study. However, these relationships are weakly supported. The two additional species, $P$. pittmani and $P$. dentiphallus, are most closely related to $P$. auriformis, and collectively these three taxa are sister to P. orientalis. In Krug et al. (2012), P. orientalis was sister to the clade containing P. paucipapillata, $P$. sp. 1, P. aperta, P. quadripartita, and $P$. angasi. While there are slight variations in the relationships, the same general patterns of relationship persist in the present study, when additional taxa are added. Morphological studies also support the relationship of $P$. dentiphallus with $P$. auriformis, since both of these species, together with $P$. fenestra Price, Gosliner, and Valdés, 2011, are the only members of the $P$. aperta clade with a radula with an outer lateral tooth and gizzard plates with a solid central bar rather than simple paired pores. No molecular data are available for P. fenestra. Philine pittmani is sister to $P$. dentiphallus and $P$. auriformis. It is unusual for members of this clade in that its paired gizzard plates have only a single pore, but its radula lacks outer lateral teeth, unlike $P$. auriformis and $P$. dentiphallus.

In our analysis, $P$. hearstorum and $P$. acuticuada are sister to each other and collectively are sister to the $P$. aperta clade. As noted above, $P$. alba and $P$. alboides have morphological similarities to $P$. hearstorum and $P$. acuticauda, but no material suitable for molecular sequencing is available for the two former species.

Another weakly supported finding from this study is that $P$. orca Gosliner, 1988 and P. rubrata Gosliner, 1988, are both nested at the base of the Aglajidae rather than within the rest of the Philine species. It is interesting to note that these species have distinctively pigmented bodies, unlike other Philine species, as well as a muscular gizzard that lacks plates. A pigmented body and lack of gizzard plates are also characteristics of the Aglajidae. These features suggest that these species of Philine may be more closely related to Aglajidae than to Philinidae. Another species that has a pigmented body, lacks gizzard plates and has a similar radular morphology to $P$. orca and P. rubrata is P. quadrata (Wood, 1839). Philine quadrata was studied by Ohnheiser and Malaquias (2013), but only its COI mitochondrial sequences were studied and no molecular comparisons can be made at this time.

The phylogeny presented here strongly suggests that gizzard plates have been lost at least twice in independent lineages of Philinacea. Within Philine, $P$. acuticauda lacks gizzard plates while its sister taxon, $P$. hearstorum still has well-developed plates. The species of Philine that are nested with the lineage that also includes the Aglajidae also entirely lack gizzard plates, while the outgroup, Scaphander, has well-developed gizzard plates. This suggests a second loss of plates in this lineage, independently from that found in P. acuticauda.

The present study presents data that further documents the high species richness of the IndoPacific tropics, especially within the deeper waters of the Coral Triangle. The Philine aperta clade, appears to be particular rich in its diversity. Phylogenetically, this clade has been reasonably well studied, but examination of additional genes will hopefullty increase the robustness of support for various lineages within the clade as more of its diversity is discovered. 
Support values are generally low for most basal relationships, but are still presented here to suggest possible relationships and areas for future study.

\section{ACKNOWLEDGMENTS}

First acknowledgments go to Margaret and Will Hearst, without whose generosity the expedition would not have occurred. All of the friends and partners who helped make the expedition a success are literally too numerous to mention here, but special acknowledgment must be given to: Secretary of Agriculture Proceso J. Alcala; Philippine Consul General Marciano Paynor and the Consular staff in San Francisco; BFAR Directors Dr. Malcom I. Sarmiento and Attorney Asis G. Perez; BFAR colleagues, especially Attorney AnalizaVitug, Ludivina Labe, Alma Dickson, Captain Ernaldo T. Cawaling, Rafael Ramiscal, and Loida Cainglit; PAWB Director Dr. Mundita Lim; U.S. Embassy staff, especially Dovas Saulys and Maria Theresa N. Villa; staff of the Department of Foreign Affairs; UP administrators and colleagues including UP Presidents Emerlinda Roman and Alfredo Pasqual, Vice President Giselle Concepción, Dr. Malou McGlone, Dr. Perry Ong, Dr. Edwino Fernando, Dr. Daniel Lagunzad, Dr. Jun Ireneo Lit Jr., Dr. Marilou Nicolas; staff of the National Museum of the Philippines, especially, Dr. Jeremy Barns and Marivene Manuel Santos; Dr. Benito Tan; Jessie de los Reyes; Marites Pastorfide; Sol Solleza; Boy Venus; Joy Napeñas; Peri Paleracio; Alexis Principe; Ditto de la Rosa; Darwin Raymundo; May Pagsinohin; Susan Po-Rufino; Ipat Luna; Enrnique Nuñez; Jen Edrial; Anne Hazel Javier; Jay-o Castilla, Arvel Malubag; Malou Babilonia; Mada Rivera; and certainly not least of all, Mary Lou Salcedo. We also thank our colleagues at the Academy and friends and families who picked up the slack while the expeditioners were expeditioning. And lastly, sincere thanks are extended to our fellow Academy and Filipino teammates on the expedition.

Appreciation is extended to Cory Pittman for his collection of specimens of Philine pittmani. His detailed notes and collection records greatly added to the description of this species. Since thanks are also extended to Philippe Bouchet and his colleagues at the Muséum national d'Histoire naturelle, Paris for making possible the collections from Panglao, Philippines. Emily Eng also produced several drawings of preserved specimens and her work is greatly appreciated.

\section{LiTERATURE CITED}

Bergh, R. (1905) Die Opisthobranchiata der Siboga-Expedition. Siboga Expiditie, 50. E.J. Brill, Leiden, Netherlands. 248 pp.

Colgan, D., A. Mclauchlan, G D. F. Wilson, S. P. Livingston, G. D. Edgecombe, J. Macaranas, G. CasSIS, AND M. R. GRAY. 1998. Histone H3 and U2 snRNA DNA sequences and arthropod molecular evolution. Australian Journal of Zoology 46:419-437.

Drummond, A.J, B, Ashton, M, Cheung, J, Heled, M. Kearse, R, Moir, S. Stones-Havas, T. Thierer, and A. WILSON. 2009. Geneious v4.6. Available from <http://www.geneious.com/s

Folmer, O., M. Black, W. Hoeh, R. Lutz, R., ANd R. VRIJENhOEK. 1994. DNA primers for amplification of mitochondrial cytochrome $\mathrm{c}$ oxidase subunit I from diverse metazoan invertebrates. Molecular Marine Biology and Biotechnology Journal 3:294-299.

GosLINer, T. M. 1980. Systematics and phylogeny of the Aglajidae (Opisthobranchia: Mollusca). Zoological Journal of the Linnean Society 68:325-360.

Gosliner, T. M. 1988. The Philinacea (Mollusca: Gastropoda: Opisthobranchia) of Aldabra Atoll, with descriptions of five new species and a new genus. Bulletin of the Biological Society Washington 8:79-100.

GosLiner, T. M. 1990. Two new species of the aglajid genus Melanochlamys (Gastropoda: Opisthobranchia). Boletimde Zoologia, Universidade de São Paulo 10:211-225. 
Gosliner, T. M. 1994. Gastropoda: Opisthobranchia. Chapter 5. Pages 253-355 in F. W. Harrison, ed., Microscopic Anatomy of Invertebrates, Vol. 5. Mollusca I. Wiley-Liss, Inc, New York, New York, USA.

GosLiner, T. M. 1995. Introduction and spread of Philine auriformis (Gastropoda: Opisthobranchia) from New Zealand to San Francisco Bay and Bodega Harbor. Marine Biology 122:249-255.

Gosliner, T. M., D. Behrens, And Á. Valdés. 2008. Indo-Pacific Nudibranchs and Sea Slugs: a Field Guide to the World's Most Diverse Fauna. Sea Challengers, Gig Harbor, Washington, and California Academy of Sciences, San Francisco, California, USA. 426 pp.

Krug, P. J., J. H. Asif, I. Baeza, M. S. Morley, W. M. Blom, and T. M. Gosliner. 2012. Molecular identification of two species of the carnivorous sea slug Philine, invaders of the U.S. west coast. Biological Invasions 14:2447-2459. (DOI: 10.1007/s10530-012-0242-9)

Marcus, Ev. 1974. On somc Cephalaspidca (Gastropoda: Opisthobranchia) from the western and middle Atlantic warm waters. Bulletin of Marine Science 24:300-371.

Marcus, Ev., AND ER. MArcus. 1966. The R/V Pillsbury deep-sea biological expedition to the Gulf of Guinea, 1964-65. 9. Opisthobranchs from tropical West Africa. Studies in Tropical Oceanography, Miami, 4:152-208.

Marcus, Ev., And Er. Marcus. 1967. American opisthobranch mollusks Part I, Tropical American opisthobranchs. Studies in Tropical Oceanography, Miami, 6:1-137.

Marcus, Ev., AND ER. MARcus. 1969. Opisthobranchian and lamellarian gastropods collected by the Vema. American Museum Novitates (2368): 1-33.

Mattox, N. T. 1958. Studies on the Opisthobranchiata: II. A new tcctibranch of the genus Philine. Bulletin of the Southern California Academy of Sciences 57:98-104.

Nakano, R. 2001. New Philinopsis from Japan. Sea Slug Forum. Australian Museum, Sydney. Available from: <http://www.seaslugforum.net/find/3547> (accessed 29 November, 2010).

Ogden, C. 2005. Odontoglaja guamensis from South Africa. Sea Slug Fornm. Australian Museum, Sydney. Available from: <http://www.seashlugforum.net/find/14101> (accessed 29 November, 2010).

OHNHEISER, L.T., AND M. MALAQUis. 2013. Systematic revision of the gastropod family Philinidae (Mollusca: Cephalaspidea) in the north-east Atlantic Ocean with emphasis on the Scandinavian Peninsula. Zoological Joumal of the Linnean Society 167(2):273-326.

Palumbi, S.R., A. Martin, S. Romano, W. Owen Macmillan, L. Stice, and G Grabowski. 1991. The Simple Fool's Guide to PCR, Department of Zoology, University of Hawaii, Honolulu, Hawaii, USA. 94 pp.

Price, R., T. M. Gosliner, ANd Á. Valdés. 2011. Systematics and phylogeny of Philine (Gastropoda: Opisthobranchia), with emphasis on the Philine aperta clade. The Veliger 51(2):1-58.

Ronquist, F., AND J. P. Huelsen BECK. 2003. MrBayes 3: Bayesian phylogenetic inference under mixed models, Bioinformatics 19:1572-1574.

Rudman, W. B. 1970. A revision of the genus Philine in New Zealand with descriptions of two new species (Gastropoda: Opisthobranchia). Journal of the Malacological Society of Australia 2:23-34.

Rudman, W. B. 1972a. The genus Philine (Opisthobranchia, Gastropoda). Proceedings of the Malacological Society of London 40:171-187.

Rudman, W. B. 1972b. Structure and functioning of the gut in the Bullomorpha (Opisthobranchia) Part 3. Philinidae. Journal of Natural History 6:459-474.

Stamatakis, A., P. Hoover, And J. Rougemont. 2008. A Fast Bootstrapping Algorithm for the RAxML WebServers. Systematic Biology 57(5):758-771.

VALDÉs, A. A. 2008. Decp sea "cephalaspidean" heterobranchs (Gastropoda) from the tropical southwest Pacific. Pagcs 587-792 in V. Hćros, R. H. Cowie, and P. Bouchet, eds., Tropical Deep-Sea Benthos 25. Ménoires du Muséum National d'Histoire Naturelle 196.

Watson, R. B. 1883. Report of the Scientific Results of the Voyage of H.M.S. Challenger during the years 1873-76.Zoology, Part XLII. Scaphopoda and Gasteropoda. 1-756.

ZWICKL, D. 2006. Genetic algorithm approaches for the phylogenetic analysis of large biological sequence datasets under the maximum likelihood criterion. Biology. University of Texas at Austin. 


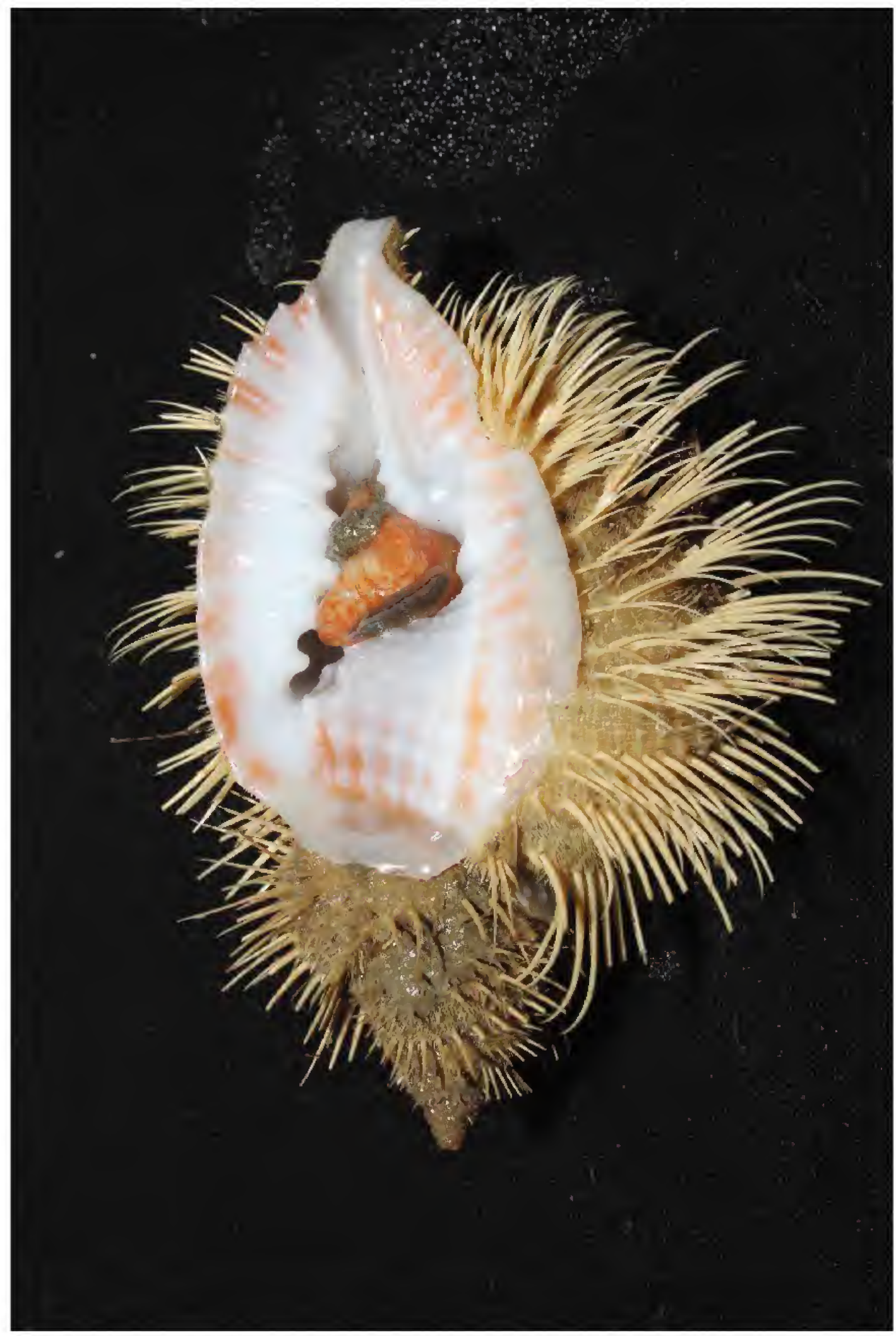

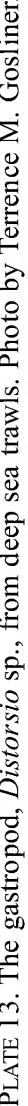




\title{
Deep-Water Lobsters (Astacidea, Polychelida), Shrimps (Caridea, Penaeoidea), and a Lophogastrid from the California Academy of Sciences' 2011 Hearst Philippine Biodiversity Expedition
}

\author{
Mary K. Wicksten \\ Department of Biology, Texas A\&M University, College Station Texas 77843-3258 \\ Email:wicksten@bio.tamu.edu
}

\begin{abstract}
Six species of penaeoid shrimps, 18 carideans, two astacideans and three polychelids were collected at depths of 82-836 m in Balayan Bay, the Verde Island Passage and north of Lubang Island at the southern end of the island of Luzon. Carideans (family Pandalidae) were the most abundant and diverse. Most were benthic species taken on sandy or muddy bottoms, but five species of carideans probably were caught accidentally in mid-water. All of the species have been reported previously from the Philippines or nearby countries.
\end{abstract}

During May-June 2011, members of the team from the California Academy of Sciences (CAS) and colleagues from the National Museum of the Philippines (NMP) collected deep-water species by open trawl at the southern end of Luzon. The specimens were shared between CAS and the NMP.

Previous work on deep-water decapods of the Philippines consists largely of the collections of the U.S. Fisheries Steamer Albatross in 1907-1910, now at the National Museum of Natural History (formerly United States National Museum, Washington, D.C.). The carideans of that expedition were studied in detail by F. A. Chace, Jr. (1984, 1985, 1986, 1988). Useful records of penaeoids and keys to the genera are found in the worldwide work of Pérez Farfante and Kensley (1997) as well as in many papers based on the MUSORSTOM studies of the biota of New Caledonia and other Pacific French territories. Chan (1998) published a good illustrated guide to the astacideans of the Western Pacific and keys to the penaeoids and carideans, especially those of commercial interest. Ongoing studies through the Raffles Museum in Singapore and by researchers in Taiwan and Japan continually add to knowledge of the shrimps of the area.

Many deep-water crustaceans from the Philippines have extensive ranges, some being known from the east coast of Africa across the Indian and Pacific Oceans to Hawaii or even some of the remote eastern Pacific islands. Some midwater species, such as Systellaspis debilis, seem to have worldwide distributions in warm temperate to tropical waters (Chace 1986). Further examination by more refined morphological or molecular methods might distinguish among local populations of these species.

The following report provides lists of species with their CAS catalog numbers by station taken on the continental shelf $(82-185 \mathrm{~m})$ and continental slope (186-836 m). The reported geographic and depth range of each species is provided in a systematic list. "Midwater, accidental" refers to a species that probably was caught in midwater instead of on the sea floor. Because of time constraints and lack of expertise in identification, species of the Sergestidae are not included. Catalogue numbers refer to the California Academy of Sciences, Department of Invertebrate Zoology and Geology (CASIZ). 


\section{STATIONS AND SPECIES}

28 May:

Batangas Bay, $13.7201667^{\circ} \mathrm{N}, 120.958333^{\circ} \mathrm{E}, 238-252 \mathrm{~m}$, sand and mud, HEPD-001.

Plesionika edwardsii: 2 females CASIZ 189899

Plesionika orientalis: 1 female, 1 male CASIZ 187837

29 May:

Pagapas Bay, Luzon: $13.8253333^{\circ} \mathrm{N}, 120.6791667^{\circ} \mathrm{E}, 146-291 \mathrm{~m}$, sand and mud, HEPD-002. Heterocarpus sibogae: 2 females CASIZ 189896

Balayan Bay, $13.697^{\circ} \mathrm{N}, 120.675^{\circ} \mathrm{E}, 454-457 \mathrm{~m}$, mud and coralline sand, HEPD-006. Alpheus macroskeles: 1 female CASIZ 187835 Mesopenaeus mariae: 1 specimen, broken CASIZ 192110

Balayan Bay and Verde Island Passage, $13.67716667^{\circ} \mathrm{N}, 120.8846667^{\circ} \mathrm{E}, 203-252 \mathrm{~m}$, mud, HEPD-008. Heterocarpus sibogae: 3 females, 1 juvenile (juv.) CASIZ 189879; 1 female CASIZ 189804 Plesionika hsuehyi: 1 female ovigerous (ov.) CASIZ 188514 Plesionika edwardsii: 5 females, 1 male CASIZ 189898

30 May:

Balayan Bay, $13.7702^{\circ} \mathrm{N}, 120.8485^{\circ} \mathrm{E}, 322-336 \mathrm{~m}$, sand, HEPD-009.

Heterocarpus gibbosus: 1 male CASIZ 188527

Parapenaeus sextuberculatus: 1 female CASIZ 189862

Pasiphaea japonica: 2 females, 1 juv. CASIZ 188524 (midwater, accidental)

Plesionika orientalis: 7 females ov., 8 females, 4 males, 1 broken CASIZ 189897; female ov. CASIZ 189808; 1 female ov., 1 male CASIZ 188509

Aristaeopsis edwardsiana: 1 female CASIZ 188513; 1 female, 13 juv. CASIZ 189880; 1 female CASIZ 188517

Janicella spinicauda: 3 females, 1 male CASIZ 189883 (midwater, accidental)

Heterocarpus woodmasoni: 3 females CASIZ 187840

Metanephrops sinensis: 1 female CASIZ 189810

Haliporoides sibogae: 1 female CASIZ 189817

Balayan Bay, $13.808^{\circ} \mathrm{N}, 120.8448^{\circ} \mathrm{E}, 318-333 \mathrm{~m}$, mud, HEPD-010.

Heterocarpus gibbosus: 3 females, 1 male, 1 juv. CASIZ 189807

Heterocarpus woodmasoni: 1 female ov, 3 females, 26 juv. CASIZ 189875

Metanephrops sinensis: 1 female, 1 juv. CASIZ 189894

Haliporoides sibogae: 1 female CASIZ 189815

Polycheles baccatus Bate, 1878: 1 female CASIZ 188026

Verde Island Passage, $13.606^{\circ} \mathrm{N}, 120.722^{\circ} \mathrm{E}, 636-664 \mathrm{~m}$, mud, HEPD-011. Acanthephyra eximia: 1 female CASIZ 189813

Polycheles helleri Bate, 1878: 1 female, 1 male CASIZ 187980

South China Sea, Verde Island Passage: $13.659767^{\circ} \mathrm{N}, 120.20 .649667^{\circ} \mathrm{E}, 721-761 \mathrm{~m}$, mud, HEPD-012. Glyphus marsupialis: 1 female (midwater, accidental) CASIZ 188526

Aristaeopsis edwardsiana: 1 female CASIZ 188508

Polycheles sculptus Smith, 1880 ?: 3 females, 1 male, CASIZ 188089 (incomplete specimens)

Lubang Island, $13.65666667^{\circ} \mathrm{N}, 120.4853333^{\circ} \mathrm{E}, 587-604 \mathrm{~m}$, mud, HEPD-013. Heterocarpus dorsalis: 6 spec. CASIZ 189874

Lubang Island, $13.5883333^{\circ} \mathrm{N}, 120.3743333^{\circ} \mathrm{E}, 262-286 \mathrm{~m}$, mud, HEPD-014. Gnathophausia zoea: 2 specimens CASIZ 188512 (midwater, accidental) Systellaspis debilis: 1 female CASIZ 189893 (midwater, accidental)

Verde Island Passage, $13.5968^{\circ} \mathrm{N}, 120.3645^{\circ} \mathrm{E}, 836 \mathrm{~m}$, HEPD-015. Acanthephyra eximia: 1 male CASIZ 189816 Glyphocrangon proxima: 1 female ov. CASIZ 188518, 2 female ov., 1 female CASIZ 188515 
Aristeus virilis: 1 female CASIZ 189809

Hymenopenaeus propinquus: 1 female, 1 male CASIZ 189863

31 May:

Lubang Island, $13.5831667^{\circ} \mathrm{N}, 120.382333^{\circ} \mathrm{E}, 892-966 \mathrm{~m}$, mud, HEPD-016.

Systellaspis debilis: 3 females CASIZ 189819 (midwater, accidental)

Janicella spinicauda: 1 female ov. CASIZ 189821 (midwater, accidental)

Acanthephyra eximia; 1 female, 4 males CASIZ 188528

Acanthephyra quadrispinosa: 1 female CASIZ 191800 (midwater, accidental)

Hymenopenaeus propinquus: 5 females, 1 male CASIZ 189818

Plesionika sp. (broken): 1 CASIZ 187838

South of Lubang Island, $13.833^{\circ} \mathrm{N}, 120.195^{\circ} \mathrm{E}, 281-428 \mathrm{~m}$, mud with coralline rocks, HEPD-017.

Glyphocrangon proxima: 1 female CASIZ 189865

\section{June:}

Verde Island Passage, $\mathrm{S}$ of Golo Island, $13.602^{\circ} \mathrm{N}, 120.384^{\circ} \mathrm{E}, 541-636 \mathrm{~m}$, sand, mud and pebbles, HEPD019.

Heterocarpus gibbosus: 1 ov. female CASIZ 189814

Aristaeopsis edwardsiana: 1 female, 1 male CASIZ 189900

Nematocarcinus bituberculatus: 1 female ov. CASIZ 191799

Nephropsis ensirostris: 1 female ov. CASIZ 189871

South China Sea, E of Cabra Island, N of Lubang Island, $13.8863^{\circ} \mathrm{N}, 120.0565^{\circ} \mathrm{E}, 132-172 \mathrm{~m}$, sand and mud, HEPD-021.

Mesopenaeus mariae: 1 broken spec. CASIZ 192111

Parapontocaris aspera: 4 females, 1 juv. CASIZ 189869

Alpheus macroskeles: 1 specimen, broken CASIZ 189890

Procletes levicarina; 1 female ov. CASIZ 189872, 1 male, CASIZ 188540

North of Lubang Island, $13.88567^{\circ} \mathrm{N}, 120.12983^{\circ} \mathrm{E}, 115-144 \mathrm{~m}$, HEPD-022.

Mesopenaeus mariae: 1 female, I broken spec., CASIZ 189868

Metapenaeopsis stridulans: 2 females, CASIZ 189870

Parapenaeus sextuberculatus: 3 females, 3 males, CASIZ 189881

Parapontocaris aspera: 8 females CASIZ 189886

Stylodactyloides sp.?: 1 broken CASIZ 188536

\section{June:}

Lubang Island, $13.917^{\circ} \mathrm{N}, 120.076^{\circ} \mathrm{E}, 578-710 \mathrm{~m}$, mud, HEPD-023.

Heterocarpus dorsalis: 2 females, 1 juv. CASIZ 189866

Lubang Island, $13.91^{\circ} \mathrm{N}, 120.35^{\circ} \mathrm{E}, 82-86 \mathrm{~m}$, sand-rocky/hard, HEPD-27.

Parapontocaris aspera: 2 females ov., 1 female, 1 male CASIZ 188534.

\section{June:}

Near Simo Banks, $14.074^{\circ} \mathrm{N}, 120.167^{\circ} \mathrm{E}, 223-369 \mathrm{~m}$, sand, HEPD-032.

Parapenaeus sextuberculatus: 1 male CASIZ 189918

Lubang Island, $13.94933^{\circ} \mathrm{N}, 120.05567^{\circ} \mathrm{E}, 449-457 \mathrm{~m}$, mud, HEPD-034.

Parapenaeus sextuberculatus: 1 female CASIZ 189803

\section{June:}

Off Ambil Island, $13.822667^{\circ} \mathrm{N}, 120.460667^{\circ} \mathrm{E}, 397-439 \mathrm{~m}$, mud, HEPD-035.

Plesionika edwardsii: 1 female ov, 1 female, 1 broken CASIZ 188539

Plesionika cf. kensleyi: 1 male CASIZ 193199 (broken)

North of Lubang Island, $13.842^{\circ} \mathrm{N}, 120.452^{\circ} \mathrm{E}, 355-368 \mathrm{~m}$, mud, HEPD-038.

Heterocarpus gibbosus: 3 females CASIZ 189867 


\section{SPECIES LIST}

\section{Order Lophogastrida}

\section{Family Lophogastridae}

Gnathophausia zoea Willemoes-Suhm, 1873

Geographic and depth range: Arctic Ocean to Equator in Atlantic Ocean, Gulf of Mexico, tropical Pacific Ocean, 200-3000 m (Pequegnat 1965).

\section{Order Decapoda \\ Infraorder Penaeoidea}

\section{Family Aristaeidae}

Aristaeopsis edwardsiana (Johnson, 1867)

Geographic and depth range: Eastern and Western Atlantic, Gulf of Mexico, Caribbean Sea, Morocco to South Africa, east coast of Africa, Indian and western Pacific Oceans from Japan to New South Wales, Australia; 274-1850 m (Crosnier and Forest 1973, as Plesiopenaeus edwardsianus; Pérez Farfante and Kensley 1997).

Aristeus virilis (Bate, 1881)

Gcographic and depth range: East coast of Africa, Indian and West Pacific Oceans north to Japan, south to Fiji and New South Wales, 344-800 m (Holthuis 1980, Pérez Farfante and Kensley 1991).

\section{Family Penaeidae}

Metapenaeopsis mogiensis (Rathbun, 1902)

Geographic and depth range: East coast of Africa, Indonesia, Indian and West Pacific Oceans to Philippines, Japan, Australia and Ncw Caledonia, 10-156 m (Chan, 1998).

Metapenaeopis stridulans (Alcock, 1905)

Gcographic and dcpth range: Persian Gulf, Indian and West Pacific Oceans to Philippines, South China Sea and New Caledonia, 9-90 m (Chan, 1998).

Parapenaeus sextuberculatus Kubo, 1949

Geographic and depth range: Madagascar, Indian Ocean to Indonesia, Philippines, and Japan, 140-350

$\mathrm{m}$ (Crosnier 1985). The specimen taken 3 June at $449-457 \mathrm{~m}$ represents a depth extension.

\section{Family Solenoceridae}

Hymenopenaeus propinquus (de Man, 1907)

Geographic and depth range: East coast of Africa, Indian and western Pacific Oceans north to Philippines, south to New South Wales, east to Wallis and Futuna Islands, 450-1200 m (Pérez Farfante and Kensley 1997, Davie 2002).

\section{Family Alpheidae}

\section{Infraorder Caridea}

Alpheus macroskeles Alcock and Anderson, 1894

Geographic and depth range: Indian Ocean in Bay of Bengal and Andaman Sea, Philippines and Indonesia, 251-527 m (Chace 1988).

\section{Family Crangonidae}

Parapontocaris aspera Chace, 1984

Geographic and depth range: Philippine Islands from southern Luzon to southern Mindanao, 247-399 m (Chace 1984).

\section{Family Glyphocrangonidae}

Glyphoerangon proxima Komai, 2004

Gcographic and depth range: Philippines to Banda Sea, Indonesia, 567-809 m (Komai 2004). Previously reported from Philippines by Chace (1984) as G. gilesii Wood-Mason, 1891 (in part, see Komai 2004).

\section{Family Nematocarcinidae}

Nematocarcinus bituberculatus Chace, 1986 
Geographic and depth range: Lagonoy Gulf, east of southern Luzon, to west of Halmahera, Indonesia, 527-567 $\mathrm{m}$ (Chace 1986). The record from the Verde Island Passage at $636 \mathrm{~m}$ represents a slight range and depth extension for this species.

\section{Family Oplophoridae}

Acanthephyra eximia Smith, 1884

Geographic and depth range: Western and Eastern Atlantic, Gulf of Mexico, Caribbean Sea, Indian and

Pacific Oceans from east Africa to Japan, Hawaii, eastern Pacific seamounts; 200-4700 m (Chace 1986). Acanthephyra quadrispinosa Kemp, 1939

Gcographic and dcpth range: Indian and Pacific Occans from east Africa to mid-Pacific, northeastern Pacific, 27-1463 m, undergoes vertical migration (Chace 1986).

Janicella spinicauda (A. Milne-Edwards, 1883)

Geographic and depth range: Pantropical except for eastern Pacific, 300-1500 m (Chace 1986, Pequenat and Wicksten 2006).

Systellaspis debilis (A. Milne-Edwards, 1881)

Geographic and dcpth range: Eastern and western Atlantic from Greenland to South Africa, Gulf of Mexico, Indian and west Pacific Oceans from eastern Africa to Hawaii, not reported from eastern Pacific; $150-800 \mathrm{~m}$, may migrate vertically (Chace 1986 ).

\section{Family Pandalidae}

Heterocarpus dorsalis Bate, 1888

Geographic and depth range: Indian and western Pacific Oceans from eastern Africa to Indonesia, Philippines, Jana, New Caledonia and western Samoa, 185-1400 m (Chace 1985).

Heterocarpus gibbosus Bate, 1888

Geographic and depth range: Indian and western Pacific Oceans from eastern Africa to Indonesia, Philippincs, New Hcbrides, Fiji and Tonga, 247-1280 m (Chace 1985).

Heterocarpus sibogae De Man, 1917

Geographic and depth range: Indian and western Pacific, Andaman Sea to southern Japan, south to Victoria, Australia; east to Fijis and western Samoa, 247-700 m (Chace 1985).

Heterocarpus woodmasoni Alcock, 1901

Geographic and depth range: Indian Ocean from Andaman Sea to South China Sea and Philippines, 291-655 m (Chace 1985).

Plesionika edwardsii (Brandt, 1851)

Gcographic and dcpth range: Western and eastern Atlantic Ocean, Gulf of Mexico, Mediterranean Sea, Indonesia, Philippines (Chace 1985).

Plesionika hsuehyui Chan, 2004

Geographic and depth range: Western Pacific from New Caledonia to Taiwan, east to Tonga, 200-806 m (Chan 2004). Previously reported by Chace (1985) from Philippines as P. rostricrescentis (Bate, 1888) (in part, see Chan 2004).

Plesionika orientalis Chace, 1985

Geographic and depth range: Philippine Islands from north of Luzon to Sulu Archipelago, Indonesia, 247-686 m (Chace 1985).

Procletes levicarina (Bate, 1888)

Geographic and depth range: Indian and western Pacific Oceans from Red Sea to Indonesia, South China Sea and Philippines, 31-393 m (Chace 1985, as Heterocarpoides levicarina).

\section{Family Pasiphaeidae}

Glyphus marsupialis Filhol, 1884

Geographic and depth range: Gulf of Mexico, Caribbean Sea, western Africa, Indo-West Pacific, eastern Pacific, 500-1160 m (Crosnier and Forest 1973, World Register of Marine Species (www.marinespecies.org), Scripps Institution of Oceanography unpubl. records)

Pasiphaea japonica Omori, 1976

Geographic and depth range: Indo-West Pacific from South Africa to Indonesia, Japan, and Taiwan, to $1098 \mathrm{~m}$ (Komai et al. 2012). This is the first report of the species from the Philippines. 


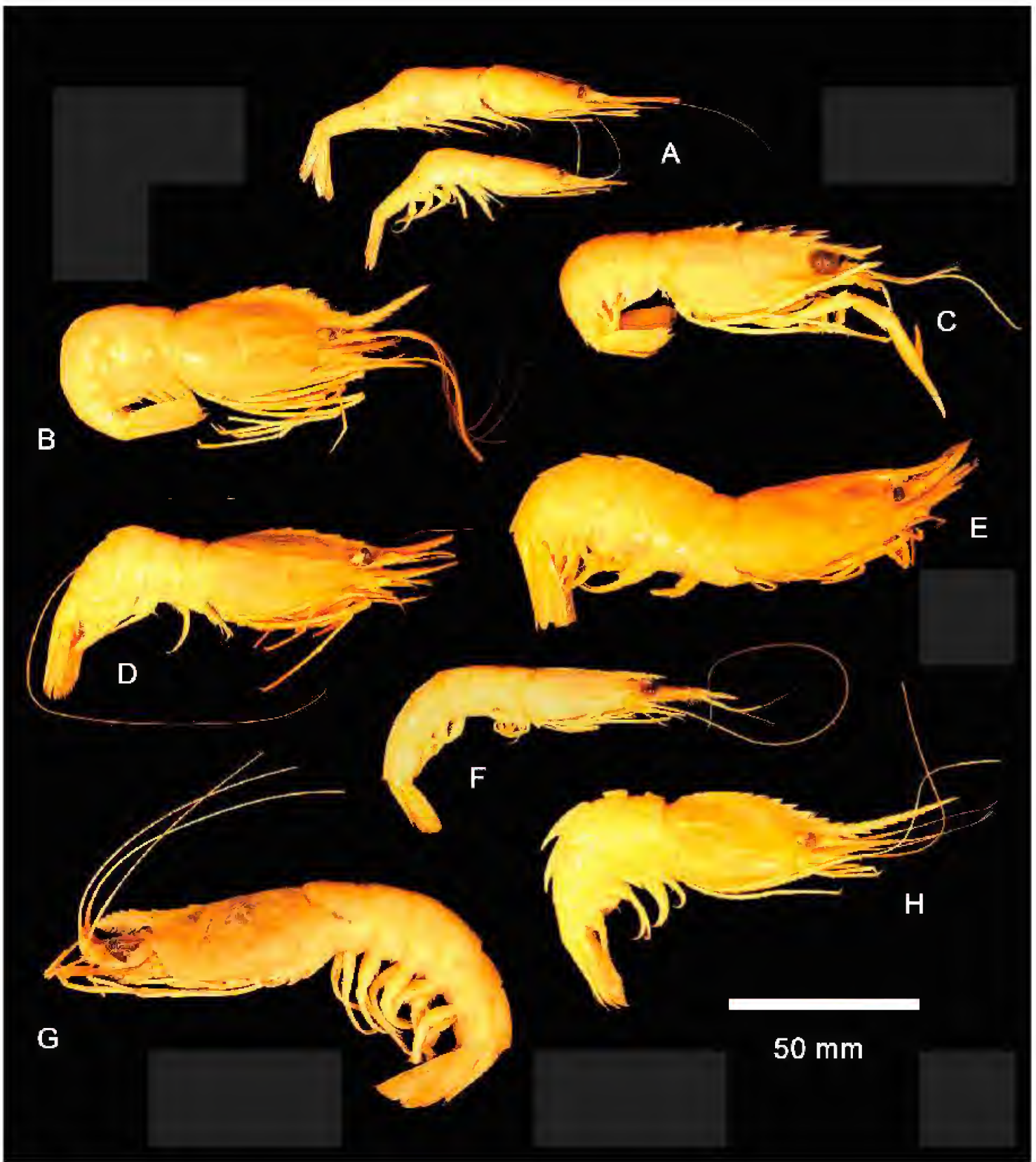

FIGURE 1. Wet-preserved specimens of crustaceans collected during the deep-sea component of the Hearst Biodiversity Expedition, 28 May-4 June 2011. A. Plesionika orientalis, CASIZ 189897. B. Heterocarpus gibbosus, CASIZ 189867. C. Metanephrops sinensis, CASIZ 189810. D. Heterocarpus dorsalis, CASIZ 189866, E. Acanthephyra eximia, CASIZ 189816. F. Parapenaeus sextuberculatus, CASIZ 189918. G. Haliporoides sibogae, CASIZ 189815. H. Heterocarpus sibogae, CASIZ 189892. Scale bar $=50 \mathrm{~mm}$. 

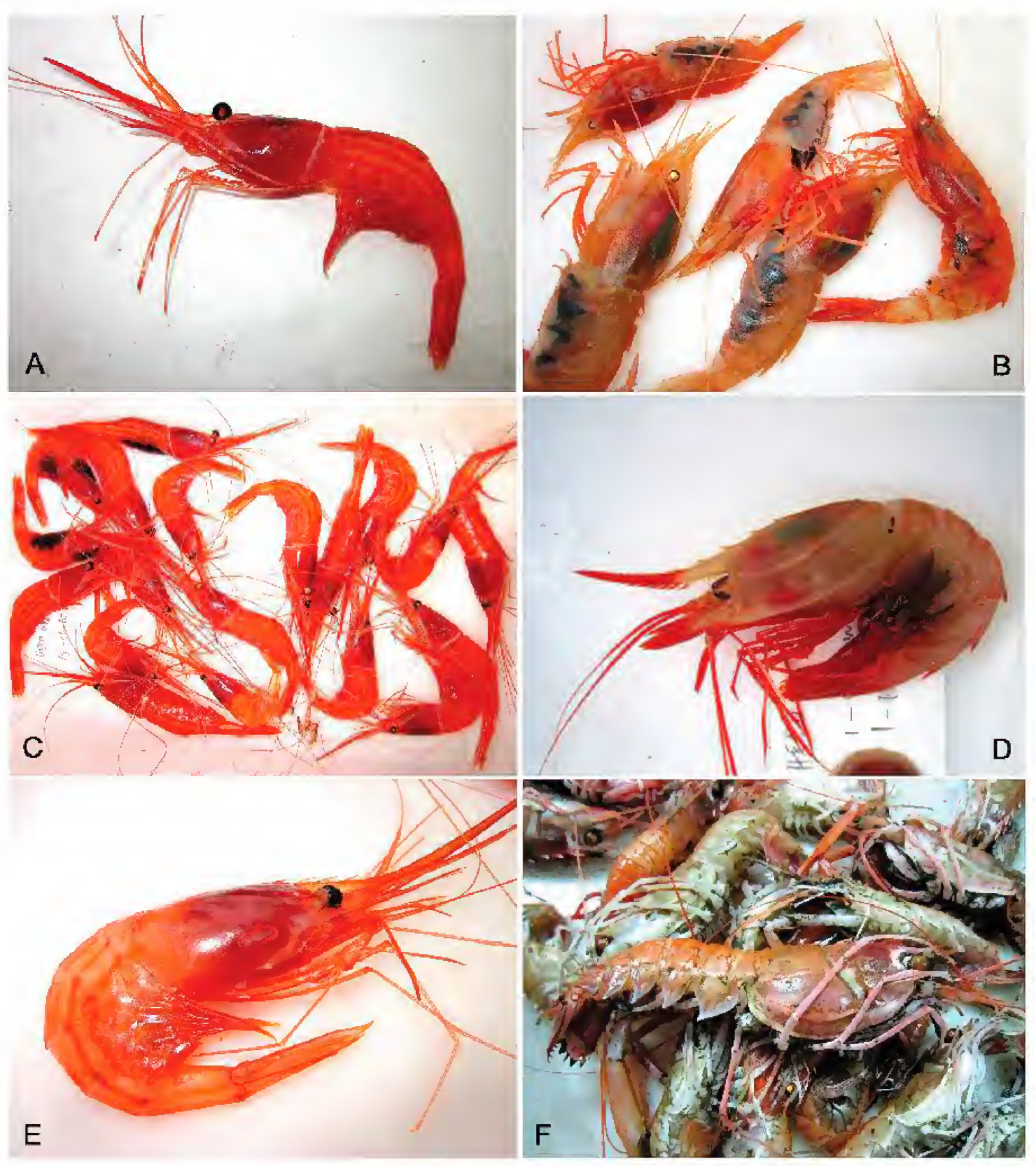

$E$

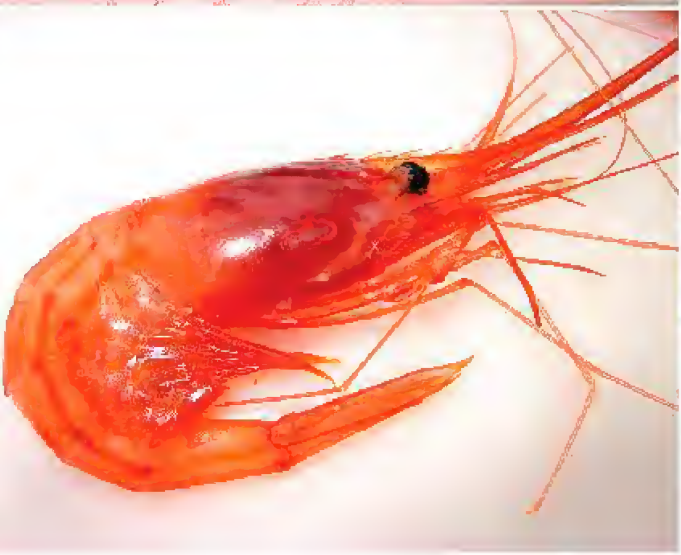

FIGURE 2. Live material of crustaceans collected during the deep-sea component of the Hearst Biodiversity Expedition, 28 May- 4 June 2011. A, C, E. Plesionika edwardsii, HEPD 008. B. Heterocarpus sibogae, HEPD 002. D. Heterocarpus dorsalis, HEPD-13-09. F. Metanephrops sinensis, HEPD 10-10. Photographs A, B, C, and E by Gary Williams; photographs D and F by Robert Van Syoc. 


\section{Family Stylodactylidae}

Stylodactyloides sp.? (badly broken, cannot be identified with certainty).

\section{Infraorder Astacidea}

\section{Family Nephropidae}

Nephropsis ensirostris Alcock, 1901

Geographic and depth range: Indian Ocean from Gulf of Aden, Arabian Sea, Bay of Bengal, Andaman Sea, Indonesia, Philippines, 580-1160 m (Holthuis 1991).

Metanephrops sinensis (Bruce, 1966)

Geographic and depth range: Philippines, Vietnam, Indonesia, 260-373 m (Holthuis 1991, Chan 1998).

\section{Infraorder Polychelida}

\section{Family Polychelidae}

Polycheles baccatus Bate, 1878

Geographic and depth range: Indonesia to Philippines, east coast of Australia, east to Fiji Islands, 300-1250 m (Galil 2000). Polycheles helleri Bate, 1878 Geographic and depth range: Indian and western Pacific Oceans from Madagascar, Indonesia, Japan to New Caledonia, 787-2150 m (Galil 2000).

Polycheles sculptus Smith, 1880

Gcographic and depth range: Geographic and depth range: Western and eastern Atlantic Ocean from Labrador to South Africa, Gulf of Mexico, Caribbean Sea, Indian and western Pacific Oceans from eastern Africa and Gulf of Aden to Japan and Tasman Sea, east to New Zealand; 200-4000 m. Replaced in eastern Pacific by P. pacificus (Faxon, 1893) (Galil 2000).

\section{LiTERATURE CITED}

Chace, F. A. JR. 1984. The caridean shrimps (Crustacea: Decapoda) of the Albatross Philippine Expedition, 1907-1910, Part 2: Families Glyphocrangonidae and Crangonidae. Smithsonian Contributions to Zoology (397):1-63.

Chace, F. A. JR. 1985. The caridean shrimps (Crustacea: Decapoda) of the Albatross Philippine Expedition, 1907-1910, Part 3: Families Thalassocarididae and Pandalidae. Smithsonian Contributions to Zoology (411):1-143.

ChACE, F. A. JR. 1986. The caridean shrimps (Crustacea: Decapoda) of the Albatross Philippine Expedition, 1907-1910, Part 4: families Oplophoridae and Nematocarcinidae. Smithsonian Contributions to Zoolo$g y(432): 1-82$.

CHACE, F. A. JR. 1988. The caridean shrimps (Crustacea: Decapoda) of the Albatross Philippine Expedition, 1907-1910, Part 5: family Alpheidae. Smithsonian Contributions to Zoology (466):1-99.

Chan, T.-Y. 1998. Shrimps, prawns and lobsters. Pages 851-1043 in K. E. Carpenter and V. H. Niem, eds., FAO Species Identification Guide for Fisheries Purposes. The Living Marine Resources of the Western Central Pacific. Volume 2. Cephalopods, Crustaceans, Holothurians and Sharks. United Nations Food and Agriculture Organization, Rome, Italy.

Chan, T.-Y. 2004. The "Plesionika rostricentris (Bate, 1888)" and "P. lophotes Chace, 1985" species groups of Plesionika Bate, 1888, with descriptions of five new species (Crustacea: Decapoda: Pandalidae). Pages 293-318 in B. Marshall and B. Richer de Forges, eds., Tropical Deep-Sea Benthos, vol. 23. Mémoires du Muséum national d'Histoire naturelle, Paris, 191.

Crosnier, A. 1985. Crustacés Décapodes: Penaeidae. Les espèces indo-ouest pacifiques du genre Parapenaeus. Mémoires du Muséum national d'Histoire naturelle, Paris 133:303-353.

Crosnier, A., ANd J. Forest. 1973. Faune Tropicale XIX. Les Crevettes Profondes de l'Atlantique Oriental Tropical. Office de la Recherche Scientifique et Technique Outre Mer, Paris, France. 409 pp.

DAvIE, P. 2002. Zoological Catalogue of Australia, vol, 19.3A: Crustacea: Malacostraca: Phyllocarida, Hoplocarida, Eucarida (Part 1). CSIRO Publishing, Collingwood, Victoria, Australia. 564 pp.

GALIL, B. S. 2000. Crustacea Decapoda: Review of the genera and species of the family Polychelidae Wood- 
Mason, 1874. Pages 285-387 in A. Crosnier, ed., Résultats des Campagnes MUSORSTOM, vol. 21. Mémoires du Muséum national d'Histoire naturelle, Paris, 184.

Holthuis, L. B. 1980. FAO Species Catalogue, vol. 1. Shrimps and Prawns of the World. An Annotated Catalogue of Species of Interest to Fisheries. United Nations Food and Agriculture Organization, Rome, Italy. $271 \mathrm{pp}$.

Holthuis, L. B. 1991. FAO Species Catalogue, vol. 13. Marine Lobsters of the World. An Annotated and Illustrated Catalogue of Marine Lobsters Known to Date. United Nations Food and Agriculture Organization, Rome, Italy. 292 pp.

Komai, T. 2004. A review of the Indo-West Pacific species of the genus Glyphocrangon A. Milne-Edwards, 1881 (excluding the G. caeca species group) (Crustacea: Decapoda: Caridea: Glyphocrangonidae). Pages 375-610 in B. Marshall and B, Richer de Forges, eds., Tropical deep-sea benthos, vol. 23. Mémoires du Muséum national d'Histoire naturelle, Paris, 191.

Komai, T., C. Lin, AND T. Chan. 2012. Bathypelagic shrimp of the genus Pasiphaea (Decapoda: Caridea: Pasiphaeidae) from waters around Taiwan, with descriptions of four new species. Journal of Crustacean Biology 32:295-325.

Pequegnat, L. 1965. The bathypelagic mysid Gnathophausia (Crustacea) and its distribution in the eastern Pacific Ocean. Pacific Science 19:399-421.

Pequegnat, L., And M. K. Wicksten. 2006. Oplophorid shrimps (Decapoda: Caridea: Oplophoridae) in the Gulf of Mexico and Caribbean Sea from the collections of the research vessels Alaminos, Oregon, and Oregon II. Crustacean Research 35:92-107.

Pérez Farfante, I., and B. Kensley. 1999. Penaeoid and sergestoid shrimps and prawns of the world. Keys and diagnoses for the families and genera. Mémoires du Muséunn national d'Histoire naturelle, Paris, $175: 1-233$.

WORLd Register of MARINE SPECIES. 2013. Glyphus marsupialis. In: <http://www.marinespecies.org > Cited 13 March 2013. 


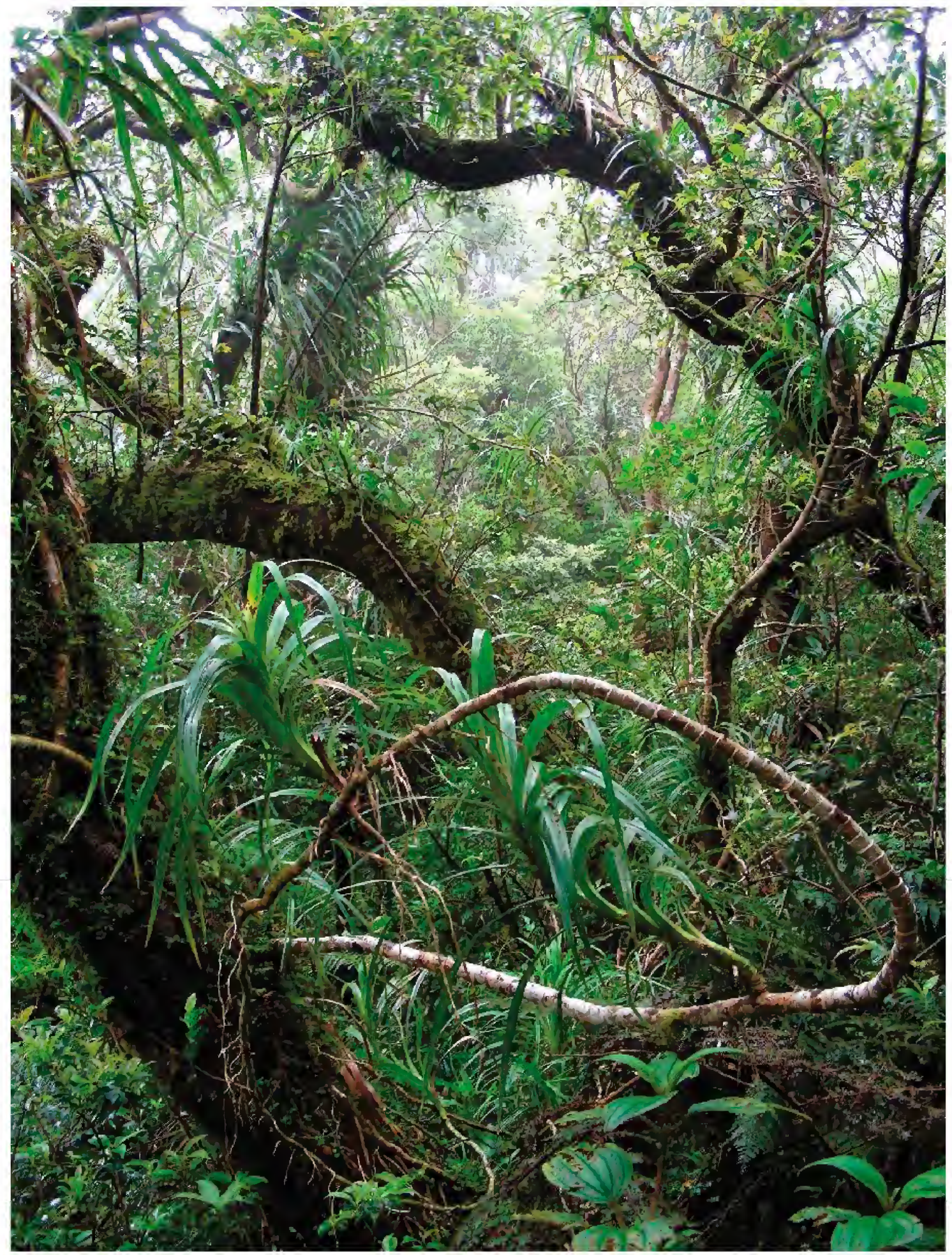

Plate 14. Mossy forest near summit of Mount Banahaw. Photo by Darren Pennys. 


\title{
Collection and Preparation Techniques of Bryophyte Specimens in Biodiversity Inventories
}

\author{
James R. Shevock ${ }^{1}$, Ivy Amor F. Lambio ${ }^{2}$, and Benito C. Tan ${ }^{3}$ \\ ${ }^{1}$ California Academy of Sciences, Department of Botany, 55 Music Concourse Drive, \\ Golden Gate Park, San Francisco, California 94118 U.S.A. Email: jshevock@calacademy.org; \\ 2 Faculty, Environmental Biology Division, Institute of Biological Sciences, Curator, UPLB-Museum \\ of Natural History, University of the Philippines Los Baños, College, Laguna 4031 Philippines, \\ Email:plant_ecologist@yahoo.com; ${ }^{3}$ University Herbarium, 1001 Valley Life Sciences Bldg., \\ University of California, Berkeley, California 94720-2465 U.S.A. Email: btakakia@yahoo.com
}

\begin{abstract}
Biodiversity inventory is a critical step in determining the distribution, abundance, rarity, and conservation priorities of species and their essential habitats. Techniques on inventory sampling and procedures for obtaining and processing high-quality bryophyte museum specimens were implemented during the 2011 Philippines biodiversity expedition. Bryop hytes in the Philippines comprise an extremely species-rich group of land plants and are a key component of ecosystem function in both tropical lowland and montane forest systems. Inventory and specimen acquisition of bryophytes are urgently needed in addition to training of field-oriented biologists in this taxonomic group.
\end{abstract}

KEYWORDS: biodiversity inventory, bryophytes, herbarium specimen acquisition, recordkeeping, sampling techniques

With the current focus on molecular systematics, one would assume that basic natural history inventories have been completed, that all species have been discovered, named, and conservation actions are in place to conserve this biodiversity. Many countries, however, have only basic inventories of their biota (such as checklists or literature reviews), and where inventories do exist, they are considerably less refined below taxonomic groups containing 'fur, feathers, or flowers'. The ongoing interest from governments and conservation organizations continues to focus on biodiversity issues involving human interaction with the natural world and how climate change may impact a nation's biodiversity. For its size, the Philippine archipelago is among the most species-rich areas for bryophytes in Southeast Asia with over 1200 species reported (Tan and Engel 1986; Tan and Iwatsuki 1991; Tan et al. 2000). In this paper, we focus primarily on our experiences in collecting bryophytes (mosses, liverworts, and hornworts) as part of a renewed bio-inventory program in the Philippines. Although the examples used will be based on the effective practices and appropriate procedures needed for the collection of bryological specimens, most of the techniques and field procedures described herein can be easily adapted to other taxonomic groups.

\section{WHAT IS A BRYOPHYTE?}

Bryophytes are considered the first land plants and include three distinct lineages: mosses, liverworts, and hornworts. Collectively they are estimated at 20,000 species worldwide (CrandallStotler et al. 2009; Frey 2009; Goffinet et al. 2009). They differ from the flowering plants primarily by lacking roots, flowers, seeds, and a defined system of internal tissues known as the vascular system (xylem and phlocm) for transporting fluids throughout the plant. In most bryophytes, the leaves are only one cell thick. Bryophytes reproduce not by seeds but by single-celled spores. Many bryophytes can also form new plants by vegetative means (tubers, gemmae, leaf fragments). Bryophytes have two adaptations that make them fairly unique: they are capable of dealing with 
extended periods of desiccation by shutting down all cellular activity and the ability to rapidly come back to life when water again becomes available. Because bryophytes have no roots they are not confined to living on soil and therefore they can grow on rocks, tree trunks, rotten wood, and even colonize leaf surfaces. Bryophytes are frequently used as biological indicators of environmental health because pollutants in water are absorbed directly through the outer cell wall when hydrated (Govindapyari et al. 2010).

\section{THE ROLE OF VOUCHER SPECIMENS IN CONSERVATION BIOLOGY}

Museum specimens are a valuable source of information obtained from conducting inventory efforts and form the foundation for checklists, monographs, and floristic treatments (Bartram 1939; Del Rosario 1967; Linis 2010; Linis and Tan 2008, 2010; Tan 1992; Tan and Iwatsuki 1991). Specimens provide a historical framework and provide insights into species distribution and habitats. Voucher specimens are used to document the following: where species occur, where populations have expanded, or reduced, species now extirpated, and species inadvertently introduced due to habitats being altered or converted by human activities. Properly prepared and identified specimens are also essential for ongoing and future molecular studies so that researchers can examine source materials. In our view, all inventories and checklists should be based on an examination of existing specimens located in museums and herbaria and, where applicable, the acquisition of additional specimens that are properly labeled and curated so they are readily accessible to the scientific community. It is through the ongoing efforts of specimen acquisition that new range distributions are documented, species new to floristic regions are reported, and species new to science are discovered (Linis and Tan 2010; Tan et al. 2000). Herbaria also serve as biological libraries for ecological studies where accurate species identification is paramount (Bortolus 2008) and vouchers aid in determining conservation priorities. Unfortunately, many historic specimens in herbaria have either inadequate or poor label data to answer many basic conservation questions and even contemporary collections can suffer from poor label documentation. The need for detailed and accurate information gathered at the time of collection is therefore critical. Today, with access to high quality topographic maps and global positioning systems (GPS), the location information for a specimen should be quite detailed.

\section{WHY VOUCHER SPECIMENS?}

Among plants, bryophytes offer several inventory challenges since many species are quite small in size and species recognition in the field can be difficult. Species are identified by morphological characters that may be hard to see with the naked eye and most often require greater magnification provided by a dissecting and/or compound microscope. With practice, many species can be identified in the field, but others cannot be named with a high degree of assurance so nothing will substitute for a properly prepared voucher specimen.

Today, the number of bryological specimens residing in Philippine herbaria is still relatively low. Historically much of the bryophyte collecting and inventory work was done by foreign scientists, often before the Philippines became an independent nation. These collections were brought to European or American museums and herbaria. Additionally this under-representation is the result of bryophytes receiving less collection attention among botanists as compared to vascular plants. The inordinate value placed on being vascular has had a detrimental impact on collecting bryophytes and associated inventory efforts to expand the bryological holdings within Philippine

herbaria. In addition, a lack of easy access to a wide variety of the bryological literature has also compounded this situation. There is clearly a need to develop a cadre of resident professional 
botanists and taxonomists to actively pursue the acquisition and identification of bryological specimens through intensive inventory and field work with the long-term goal of developing a bryoflora of the Philippines.

\section{TECHNIQUES AND PROCEDURES FOR MAKING HIGH QUALITY MUSEUM SPECIMENS}

Pre-field Preparation. Before departing on a collection trip or expedition, one should review as much information as possible including: the extent of previous collection for this taxonomic group, who conducted the previous survey, how long ago was the survey done, how intensive the survey was and whether the landscape has changed over the interval. One must also be aware if voucher specimens have been obtained in previous surveys and in which herbaria they reside. Topographic maps are also very useful in planning a collecting inventory event. Maps provide an indication of the complexity and difficulty of the terrain to be surveyed, identify access to the area by roads and trails, and generally indicate physiographic features such as springs, streams, waterfalls and rock outcrops that are likely to provide a suite of microhabitats suitable for the taxonomic group to be surveyed. In addition, taking a simulated over-flight of an area with Google Earth on a computer is a useful adjunct to studying maps. Satellite imagery may reveal interesting geographic features not reflected on maps. One should also have a good overview of the vegetation since this will indicate the bryophyte species likely to be encountered. Collecting routes can be prioritized to maximize sampling on as many different microhabitats as possible. These pre-field assessments will make the time spent in the field considerably more productive. Climatic conditions may also influence when a survey is conducted depending on the project objectives.

Conducting biodiversity inventory work can be an expensive and time intensive enterprise. There are the costs of personnel, the time required to obtain the necessary permits, the associated travel expenses and the actual collection of specimens, the time required to identify specimens, the time required to develop high quality herbarium labels, and the time to properly prepare the collections for permanent museum storage. It is, therefore, essential that the time invested while in the field is spent efficiently and effectively. Pre-field preparation is a key step toward maximizing the time spent collecting specimens and documenting their habitats.

Importance of Collection Numbers. Specimens should always be assigned a collection number at the time of collection. Although many numbering schemes for specimens collected have been utilized by various collectors, the two most frequently used are a chronological numbering sequence $(1,2,3$, etc.) or a combination of the year followed by sequential numbering identifying a collection event. Regardless of the numbering system used, an efficient method of record keeping is essential. As specimens are collected each is assigned the next available number and recorded in a field notebook. This procedure ensures that each specimen is numbered as it is collected and no number can be used more than once.

Recording Field Data. When arriving at a site to begin inventory sampling, one should first enter into the field notebook the country, county (or other land administrative unit), date, specific location, GPS coordinates, overview of the general habitat (vegetation cover, i.e. mixed subtropical hardwood forest), rock type, elevation, date, and of course the name(s) of the collector(s). With these data obtained and written into the field notebook you are now ready to begin the inventory process. Each specimen collected receives the next available number in the field notebook and a quick note about its specific micro-habitat (i.e., aspect, exposure, slope, canopy cover, moisture, etc.) and substrate (i.e., on bark, rotten wood, litter, boulder, etc.) is added next to the collection number (Fig. 1). All of these data will be essential in the creation of detailed and informative herbarium labels for each specimen collected. Record keeping is perhaps the most critical compo- 
nent of conducting any field work. These data need to be gathered in a consistent manner at the time of specimen acquisition. Since collecting events can be impaired by weather such as rain, the person doing inventory voucher sampling needs to have a reliable procedure that can be achieved even when field conditions are less than ideal. In the case of the Philippines, where rain is abundant, a pocket-sized notebook made of paper that does not easily disintegrate when wet is highly recommended.

\section{HOW TO COLLECT BRYOPHYTES}

Bryophyte collecting is generally quite simple. The ideal collection method for bryophytes is to place a sample directly into a small folded paper packet (Fig. 2). Except for liverworts fused to the surface of leaves, bryophytes should not be placed in a plant press. The reason is many species have diagnostic features seen when the plants are dry and these characteristics could be lost when pressed flat. In addition, there is no need to treat bryophytes with alcohol because the leaves will remain intact and mildew is unlikely to form if specimens are dried soon after collection. Bryophyte specimens should not be placed in plastic bags. If bryophytes are collected in plastic bags they will need to be transferred into some type of paper container as soon as possible so the plants can air dry. This transfer is time-consuming and therefore this technique of bryophyte collecting should be avoided. There is a long history of bryologists collecting specimens in small brown paper bags, however, we have concluded that the ideal collection method for bryophytes is to place the sample directly into a small folded paper packet. The problem with collecting in bags, whether it is plas-

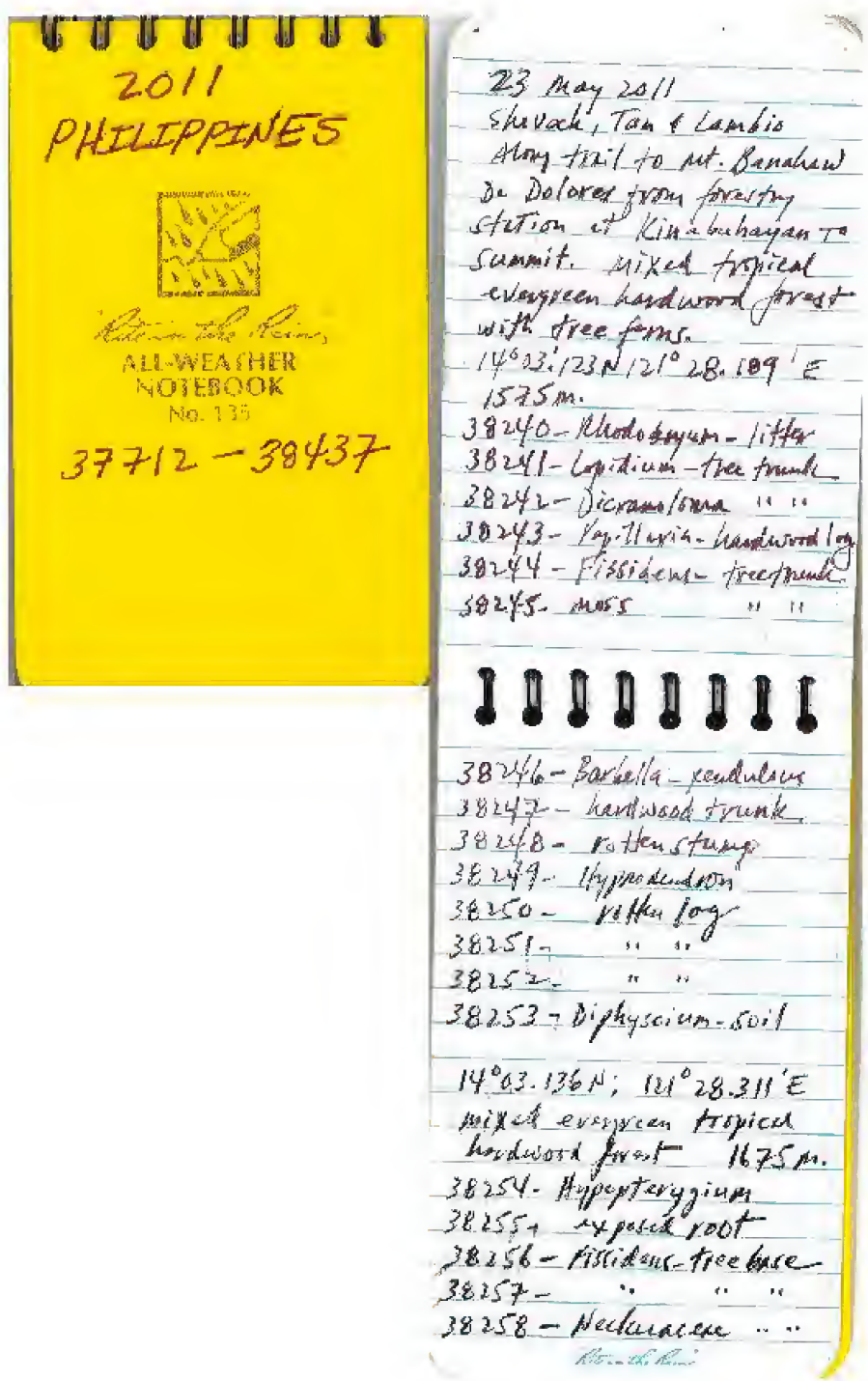

FIGURE 1.The field notebook is a critical piece of equipment. It contains all of the locality data for each collection site recorded at the time of collection and lists the corresponding collection numbers obtained from that location.

tic or paper, is that specimens have to be separated later and transferred into a packet. All of this requires more time and cost and increases the potential for creating errors of data transfer from the 
bags to packets. Therefore, it is best to just start off by developing good collecting habits and techniques and use paper packets for specimen acquisition. A packet can be folded from a sheet of photocopy paper (although a heavier stock weight is required) to provide wet specimens greater support until dried. Standard photocopy paper easily falls apart or tears when wet so it should not be used. In extremely wet climates, we find 'waterrepellent' paper to be ideal although a bit more time will usually be required for the specimens to dry and the unit cost per packet is greater. Other types of paper available in different countries may also be superior to photocopy paper. As long as the paper selected does not readily tear when wet and dries quickly then it can be used for collecting specimens. A folded packet from a sheet of paper is generally around $9.5 \times 14 \mathrm{~cm}$.

In order to consistently obtain the same types of data about each specimen collected, a template form with various ecological attributes is printed on sheets of paper and when folded into a packet becomes the front flap of the collecting packet (Fig. 3 ). This template is an easy way to document various attributes and ecological features regarding a collected specimen. All one has to do is circle all of the appropriate habitat conditions (i.e. available light, moisture, substrate etc.) for that specific collection and place the specimen in the packet. The use of the template form on the front flap of the col-

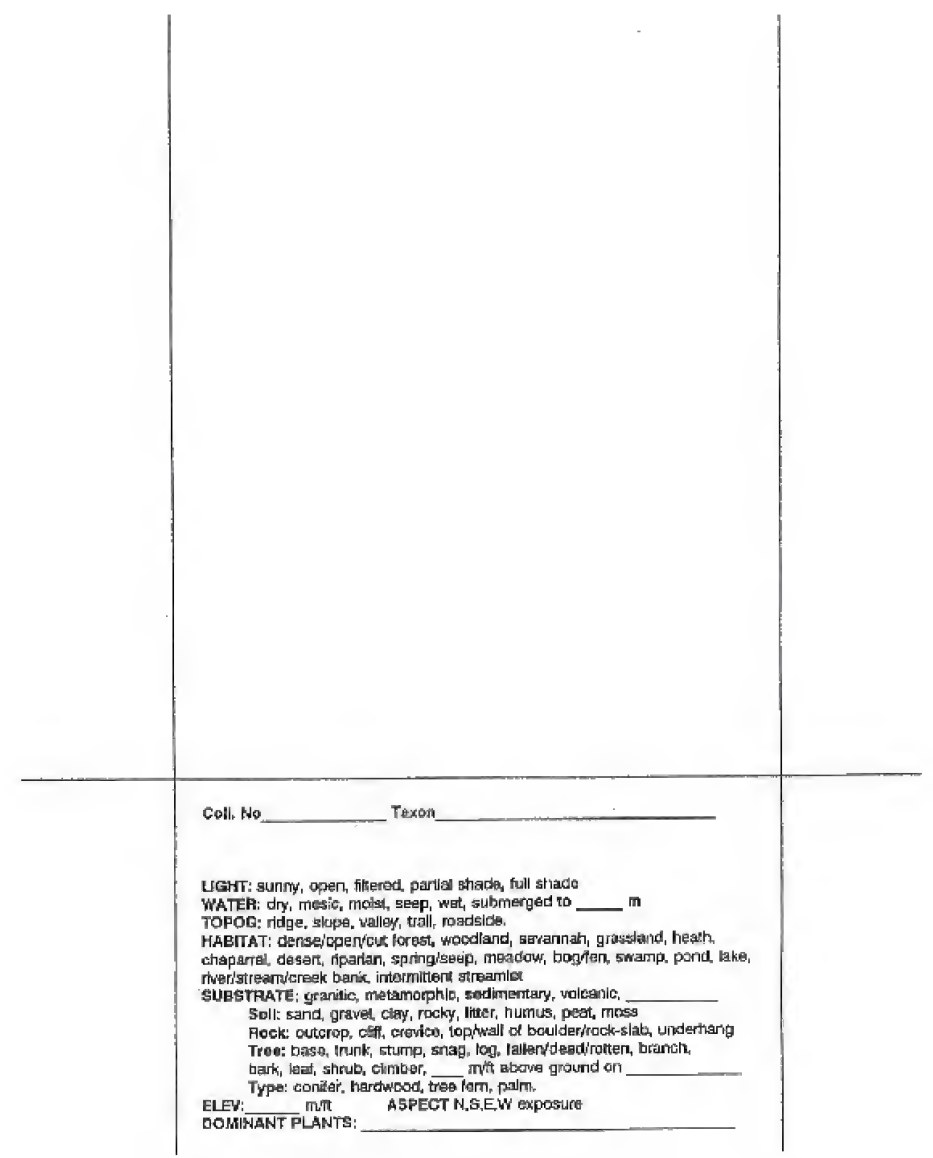

FIGURE 2. Collecting packets are photocopied from $8.5 \times 11$ (short bond paper of heavier weight) that can withstand tearing when wet. Fold along the printed lines to create a uniform sized packet approximately $9.5 \times 14 \mathrm{~cm}$.

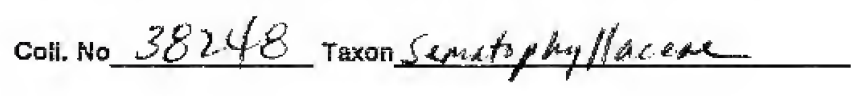

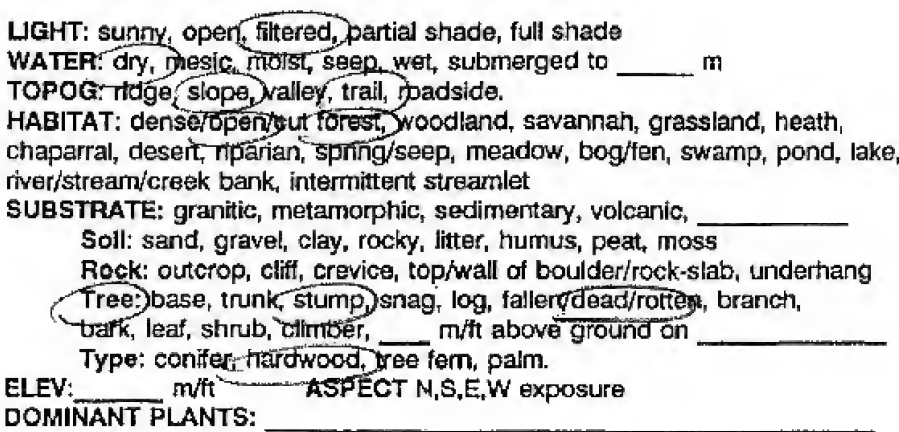

FIGURE 3. The front flap of a bryophyte collecting packet lists a suite of ecological and habitat-specific categories. The collector simply circles all of the appropriate site specific attributes for that collection and then places the sample into the packet. The template provides a simple, easy, and consistent way to record data in the field. 
lecting packet ensures that each collection receives the same level of ecological data obtained directly at the time of collection. It is difficult to consistently write on every brown paper or plastic bag all of these important ecological attributes about a collection, especially if weather conditions in the field are not ideal. Circling the attributes for a collection on the template form takes only a few seconds. Also, once the specimen is dried, identified, and ready for processing into the herbarium, the front flap of the field collecting packet with the circled ecological data becomes part of the specimen record. If there is only a single collection for a particular number, the template with the circled ecological attributes can be cut from the field packet and placed inside the labeled archival quality herbarium packet thercby adding further to the scientific value of the collected specimen. If there are additional duplicates of a particular collection number the ecological data form is simply replicated and a copy of the original data is placed within each duplicate specimen packet of that collection number. Specimens collected and dricd directly in packets have the following advantages:

1) Specimens are much better looking since they dry relatively flat

2) Specimens are handled less frequently before being dried thereby saving valuable time

3) Data is recorded directly on the field collecting packet at the time of collection and remains with the specimen

4) Data recorded for each specimen at a collecting site is more consistently obtained

5) Specimens dried in packets will later fit perfectly into the archival herbarium packets

6) Packets dry faster since there is more exposed surface area available for drying than in bags

7) Draft labels can be stapled directly onto the front flap of the packets once specimens are dry

8) Specimens are easier to store and sort into taxonomic groups until identified.

A small plastic shoe-box sizcd container is ideal for transporting spccimens while in the field. The specimens fit nicely in these inexpensive plastic boxes and they are placed in the box like a row of filing cards. These plastic containers easily fit in a daypack or backpack. This is also especially useful while collecting in wet weather since the samples are protected from the elements plus the packets are less likely to be damaged during transport. A rubber band can be used to keep bulky specimens from moving about. For bryophytes collected from wet habitats (like streams, lakes, rivers, springs), gently place the specimen between your hands and squeeze out any excess watcr. If a water source is nearby bryophytes collected on muddy soil can be rinsed off, squeezed to remove excess water (do not wring) and then placed into the collecting packet. Keeping the collections in numerical order ensures that each collection has been properly numbered as it is collected and is linked back to the field notebook.

In addition to the collecting packets and a container to transport them from the field, we have found that a ficld vest is an essential piece of equipment whilc conducting survcys. The field vest provides a convenient place to store essential items to conduct a survey including collecting packets, a field notcbook, pens, GPS, and a knife or other tool for rcmoving bryophytes from the substrate all neatly fastened to the vest to avoid losing them in the field while collecting.

\section{HOW MUCH PLANT MATERIAL SHOULD BE COLLECTED?}

An ample bryophyte collection is the amount of plant material that fits in the palm of your hand. However, somc species occupy much smallcr-sized colonies. While collection is an essential activity for developing biodiversity inventories, one must also consider the impact of collecting. A good rule to apply in the field is not to remove more than 10 percent of a population from the substrate. Some voucher specimens may be relatively small (a tuft only $25 \mathrm{~mm}$ in diameter) but many species occur in much larger colonies. Under most conditions, a single collecting packet can accommodate 2-3 duplicates depending on the size and amount of the bryophyte collected. To pro- 
vide for additional duplicates (and if doing so would not adversely affect that population) then a more robust packet or additional packets of that collection number can be made. All duplicate packets of the same sample receive the same collection number. Obtaining enough plant material for a duplicate can be of great value. A duplicate specimen can be provided to another specialist to assist in the identification process. This practice is known as a 'gift for determination' and it is a very efficient way to have specimens examined and named by experts within certain taxonomic groups and adds to the value of the collected specimens once placed into an herbarium. Collecting specimens with enough material to provide for a duplicate is desirable for the following reasons:

1) Many agencies, as a requirement of granting a research or specimen collecting permit, will request either a duplicate sample for their herbarium or a synoptic set (one good labeled specimen to represent each species documented)

2) Duplicates placed in a major scientific institution are available to a wider research community

3) A duplicate specimen can be used as a 'gift for determination' and sent to a specialist

4) Extra duplicates can be used for herbarium specimen exchange purposes to increase the reference collection

5) Duplicates become more important when species are documented as new for a particular geographic area (like a country) or when the discovery is a species new to science (isotypes)

\section{HOW ARE BRYOPHYTES DRIED?}

Bryophytes are simply air dried much like one would do for a vascular plant collection except that bryophytes should never be placed in a plant press (except bryophytes fused to the surface of vascular plant leaves) and heat sources should generally be avoided. Once home from the field or at the end of each field day, remove the collections from the plastic shoe box sized containers. The packets are likely to be very wet. The key to drying bryophytes is to have air flow across and between the packets. A small fan works well to provide air circulation and expedite drying. In humid climates, an air conditioned room will greatly aid in specimen drying. Just about any method used for drying vascular plants will work for drying bryophytes as long as the specimens can air dry in a few days. If the packets remain wet for longer periods, they will probably begin to mildew or discolor. Wet packets should be separated and laid out to aid in drying. The paper packets absorb moisture from the bryophyte so placing the packet with the ecological data flap face down will expose the wettest part of the packet first (the portion that was adjacent to the substrate). As the paper dries, flip over the packet and repeat this procedure. Another drying technique is to have each specimen stand up forming a triangle or tent (Fig. 4). Air will flow between the specimens further aiding in the drying process. Hanging packets from a cord secured with clothes pins or binder clips is another technique when floor space for drying specimens is limited. Once dried, bryophytes are nearly indestructible.

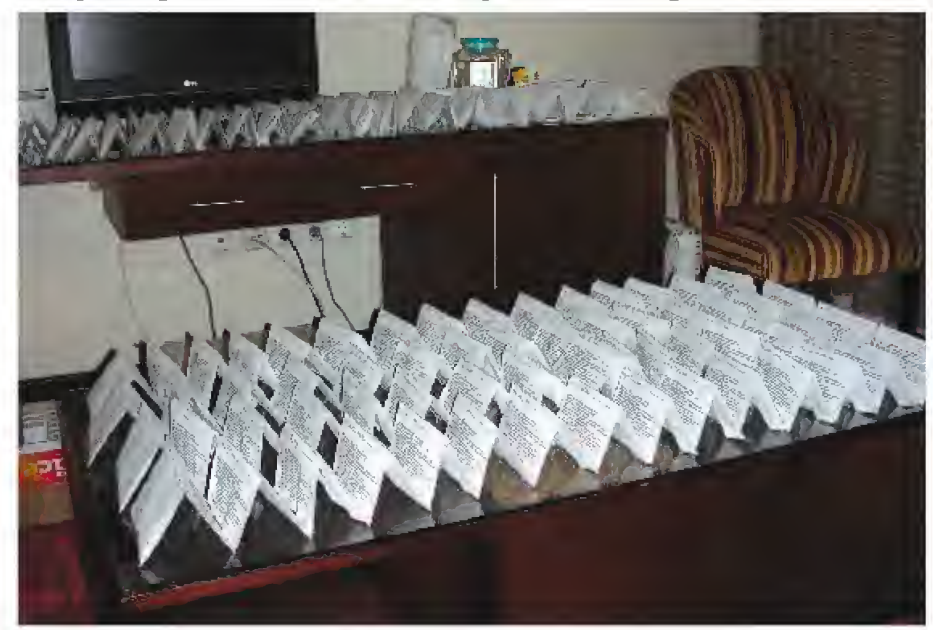

FIGURE 4. Drying bryophyte collecting packets can be enhanced by standing them up like a row of tents. This procedure increases air flow between specimens which expedites drying. 


\section{ARE SPOROPHYTES REQUIRED?}

While reproductive structures are generally essential for the identification of flowering plant specimens, sporophytes (the reproductive structure of a bryophyte) are rarely critical for species identification. However, when sporophytes are present they should be collected as part of the sample. Not all sporophytes are erect on a stalk (called a scta). For some bryophytes, the sporophytes can be hidden among the leaves but these structures can be easily seen with a hand-lens or dissecting microscope. A few bryophyte species have never becn documented with sporophytcs, so do not limit your inventory sampling based on the lack of reproductive structures. There will be cases where a specimen cannot be named with a high level of certainty to the species level without sporophytes, but at least you will have documented that a particular genus is present at a specific locality.

\section{SPECIAL THINGS TO DO WITH LIVERWORT COLLECTIONS}

Liverworts have many important diagnostic features that are either lost in the drying process or are harder to recognize once the specimens are dry. Thallose liverworts and hornworts should always be examined when collected in a fresh condition because once dried they can look considerably different than when obscrved in the field. Liverwort packets can be placed within a plastic bag to keep them moist then placed into the plastic boxes for transport. Once home from the field, liverworts can be kept in their packets for a few days in the refrigerator to keep the material hydrated. Each liverwort collection should be examined under the compound microscope to record key diagnostic features that will then be used later during the identification process. Taking the time to gather these data while the specimen is fresh will expedite the eventual identification of the specimen later. Oil bodies and/or ocelli in many liverwort genera are critical to successful identification; however, thcsc fcaturcs can disappear either during the drying process or be altered substantially. For liverwort collections, examine cells across the leaf and record presence or absence of oil bodies and/or ocelli, their form, number, color, and their distribution in the cell. Under leaves (shape and size) are easier to examine on fresh material and these data should be added to the examination data sct. Other diagnostic fcatures observed on fresh specimens should be recorded to aid in identification of the specimen at a later date. Record the data on a sheet or card and place it within the packet so it is retained with the spccimen. Once the data is recorded, dry the specimens as quickly as possible as described above.

\section{HOW TO PROCESS BRYOPHYTE SPECIMENS}

As soon as possible after returming from a collecting event, a draft label for cach collccted specimen needs to be created. You should get into the habit of doing this at the end of each trip otherwise a backlog is created and the task may later become daunting. In addition to keeping up with your collecting activities, you are likely to have a clearer memory of the collecting sites in the event some particular item was overlooked during data collection. Among botanists the development of labels can be the greatest impediment toward processing collections. Many botanists enjoy the field work component or the identification process but do not follow through with timely label processing. There are several ways to devclop a hcrbarium label but one should strive to have a computer database program so label information can be readily retrieved. First, develop then print a set of draft labels. When the specimens are dried, staple each numbered label to its corresponding numbered field collecting packet. Once the draft labels are attached to the specimen packets they no longer necd to remain in numerical order, but rather, specimens can be organized by various taxonomic groupings to expedite the identification process. It is considerably easier to identify collec- 
tions by grouping specimens by some taxonomic rank rather than attempting to name collections in the order they were collected. Many bryophytes as they are collected are "mixed" meaning that there is another species, sometimes only a few strands intertwined with the dominant taxon. Without the aid of a dissecting microscope some of these intertwined species that rarely grow as a larger colony can be easily overlooked. Yet it is these species occurring as a few strands that are most likely to be either under-collected or were not observed in the field while conducting the inventory. These taxa are also very important to add to the inventory process. Therefore, the collector should carefully examine the dried specimen packets and determine if any collection number has mixed samples that should be separated out and given their own unique identification number. This is achieved by removing the first intertwined item from the dominant numbered sample and giving this extracted specimen the same collection number followed by the letter ' $A$ '. If more than one species is separated from the same collection, then the second species extracted from the packet is given the same collection number followed by the letter ' $\mathrm{B}$ ' and so forth.

The key to processing specimens is to have a high quality draft label attached to each collection so you do not create a backlog of specimens without labels. It is very easy and quick to go from draft to final labels once specimens are named. For really puzzling collections it may be necessary or desirable to contact a bryological expert to examine one or more of your collections. If the specialist is willing then send a small sample of those collections with draft labels to be examined and named as a 'gift for determination'. Once a collection is named, a final label is produced (Fig. 5). The use of archival, acid-free paper is highly recommended. Print labels using a laser printer. Avoid ink jet printers because the ink can smear if moistened. The determination (who named the collection and the month/year) should be a data field on the final label. Additional labels can be printed to accommodate all of the duplicates of a particular collection number that exist. Single dupli-

BRYOFLORA OF THE PHILIPPINES, LUZON, REGION IV-A MT. BANAHAW PROTECTED LANDSCAPE AREA

Worburgiello philippinensis (Williams) Brotherus

det. by lvy Lambio \& Jim Shevock i.2013

\section{QUEZON PROVINCE, PH}

San Pablo Quad. Along trail to Moun Banahaw De Dolores from

Forestry Station at Kinabuhayan. Slopes below the summit. WGS-84: Lat/Long: 14 degrees 03.123' N, 121 degrees $28.189^{\circ}$ E. Elev: $1575 \mathrm{~m}$ Mixed tropical evergreen hardwood forest with tree ferns. On sotten hardwood stump in filtered light.

James R, Slievock 38248

with Benito C. Tan \& Ivy Lambio

23 May 2011

\section{CAS-CAHUP PHILIPPINES BIODIVERSITY EXPEDITION 2011}

FIGURE 5. The final herbarium label is the integration of the locality data for that collection number recorded in the field notebook and the ecological and site specific habitat data circled on the field collecting packet. Labels are glued or can be printed directly onto archival paper and folded into packets for placement in the herbarium. Many herbaria use archival packets that are the same size as the field collecting packet. Although labels can be of various dimensions, they should not exceed $9 \mathrm{~cm}$ tall and $13.5 \mathrm{~cm}$ wide so they will comfortably fit on the archival packet. cates for other herbaria can be sent in the original field collecting packets. If one is splitting a field collection packet into multiple duplicates, additional packets can be folded from standard photocopy paper (even paper already copied can be recycled for this purpose). Place a final label inside the packet with the specimen. A copy of the ecological template data form (the front flap of the collecting packet) should also be enclosed with each duplicate specimen. There is no need to send duplicates to herbaria in archival quality paper since each herbarium has its own procedures and archival packets for adding specimens into its institutional collection. 


\section{HOW SHOULD BRYOPHYTE SPECIMENS BE SENT TO HERBARIA OR TO OTHER BRYOLOGISTS AS GIFT FOR DETERMINATION?}

Once specimens are completely dry, packets (with either a draft or final label) can be mailed at any time. A few dried specimen packets can be placed on a sheet of recycled photocopy paper and wrapped like a small package, using tape to secure the ends. These samples can then be placed in either a padded envelope or a cardboard box for shipment in the mail. If you seek a determination or confirmation of one or more of your bryophyte collections, contact the bryologist before sending any specimens to ensure that person is willing to take the time to examine them on your behalf. Clearly state if the specimens being sent are a 'gift for determination'. Many bryologists will not accept specimens for identification without a draft label attached with the specimen and most are going to want to keep the samples sent for their herbarium in exchange for providing this identification service. Be advised that several countries have special procedures and import forms in order to receive dried plant materials through the mail.

\section{DEVELOPING A SPECIES LIST}

All inventories should clearly state how the species lists were developed. Is the species list based on a literature review, based on existing herbarium specimens, or were additional collections also obtained by the project? These data provide a foundation to assess the quality and completeness of any inventory. All species should be referenced based on literature citation, specimen collection, or field observation. This is especially important in the computer age because once data (as a species checklist) are in electronic formats they can all appear as if of equal quality.

\section{PROFESSIONAL RESPONSIBILITIES WHILE CONDUCTING FOREIGN EXPEDITIONS}

With the use of internet, it is much easier today to stay in professional contact with scientists around the world and develop new partnerships and collaborative ventures. Both the bryological literature and specimens in major herbaria are widely scattered around the globe. It is critical that collaboration occurs and efforts spent on various components of biodiversity can be integrated. Many countries, as a condition of granting collecting permits, require duplicate specimens to be deposited in a herbarium in the country of origin. Sometimes, this arrangement may be simplified by providing a synoptic set. Unfortunately for bryophytes, it is considerably more difficult to divide collections into duplicate sets without the aid of a dissecting microscope. This work usually needs to be done in the lab, versus in the field. If all of the specimens obtained by a foreign scientist are initially taken out of the country then that scientist has a professional responsibility to return as soon as possible a complete duplicate set of specimens (with at least draft labels for each collection) to the host country institution and then provide final labels as specimens are identified.

Collaboration can occur on several fronts from assisting with the actual field work to offering species identification and associated molecular services. Publications are also more likely today to have co-authors residing in different countries. These professional associations should be encouraged and strengthened through biodiversity inventory efforts. There are wonderful opportunities to continue bryophyte collecting throughout the Philippines with the goal of enhancing and expanding the species diversity within local herbaria. However, specimens need to be gathered and subsequently processed in such a way as the data and the actual voucher specimens are readily available to the scientific community. 


\section{ACKNOWLEDGEMENTS}

We thank Will and Margaret Hearst for financial support of the CAS-CAHUP Philippines expedition and to the Department of Environment and Natural Resources of the Republic of the Philippines for providing permits to conduct bryological inventory field work. Comments provided by Judy Harpel and David Wagner during the peer-review process enhanced the final version.

\section{Literature Cited}

Bartram. E. B. 1939. Mosses of the Philippines. Philippine Journal of Science 68:1-437.

BORTOLus, A. 2008. Error cascades in the biological sciences:the unwarranted consequences of using bad taxonomy in ccology. Royal Swedish Academy of Sciences 37:114-118.

Crandall-Stotler, B., R. E. Stotler and D. G. Long. 2009. Morphology and classification of the Marchantiophyta. Pages 1-54 in B. Goffinet and A. J. Shaw, eds., Bryophyte biology. Cambridge University Press, New York.

Del Rosario, R. M. 1967. Liverworts from the Philippines. The Bryologist 70:360-363.

Frey, W. 2009. Part 3. Bryophytes and seedless vascular plants. In W. Frey, ed., Syllabus of Plant Families. Adolf Engler's Syllabus der Pflanzenfamilien. Gebr. Bomtraeger Verlagbuchhandlung. Berlin, Germany. 13th edition [English version]. $419 \mathrm{pp}$.

Goffinet, B., W. R. Buck And A. J. Shaw. 2009. Morphology, anatomy, and classification of the Bryophyta. Pages 55-138 in B. Goffinet and A.J. Shaw, eds., Bryophyte Biology. Cambridge University Press, New York.

Govindapyar, H., M. LeleEkA, M. Nivedita, AND P. L. UniYal. 2010. Bryophytes: indicators and monitoring agents of pollution. $\mathrm{NeBIO} 1: 35-41$.

LinIS, V. C. 2010. The moss flora of Camiguin Island, Philippines and their floristic relations to some adjacent islands in the archipelago. Telopea 12:525-542.

LinIS, V. C., AND B. C. TAN. 2008. Progress of studies on Phytogeography and biodiversity of the Philippine moss flora 1991-2006. Pages 13-22 in H. Mohamed, B.B. Bakar, A.N. Boyce and P.L.K. Yuen, eds., Bryology in the New Millenium. Proceedings of the World Bryology Conference, 2007 Kuala Lumpur, Malysia. Institute of Biological Sciences, University of Malyasia and International Association of Bryologists.

LinIS, V. C., AND B. C. TAN. 2010. Eleven new records of Philippine mosses. Acta Bryolichenologica Asiatica 3:95-100.

TAN, B. C. 1992. Philippine musicology (1979-1989). Bryobrothera 1:137-141.

TAN, B. C., AND J. J. ENGEL. 1986. An annotated checklist of Philippine Hepaticae. Journal of the Hattori Botanical Laboratory 60:283-355.

TAN, B. C., AND Z. IwATSUKI. 1991. A new annotated Philippine moss checklist. Harvard Papers in Botany 3: $1-64$.

TAN, B. C., L Lubos, AND U. Schwarz. 2000. New and biogeographically noteworthy records of Philippine mosses from Mindanao Island. Tropical Bryology 18:27-37 


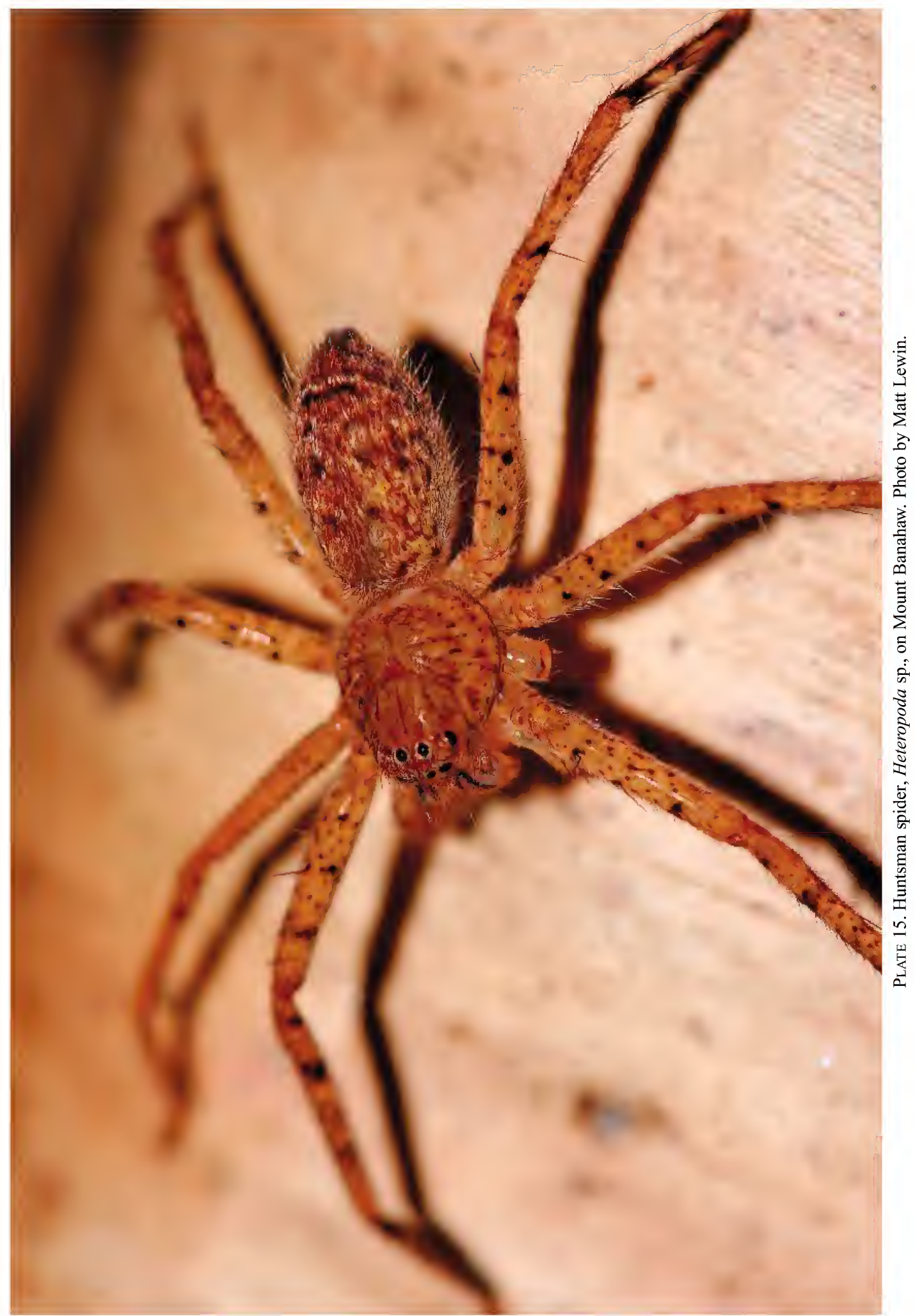




\title{
New Ray Spiders from Southeast Asia: The New Philippine Genus Tagalogonia gen. nov. and Continental Genus Coddingtonia Miller, Griswold and Yin, 2009 (Araneae: Theridiosomatidae), with Comments on Their Intergeneric Relationships
}

\author{
Facundo M. Labarque *,1 and Charles E. Griswold ${ }^{1-4}$ \\ ${ }^{1}$ Arachnology Lab, Entomology Department, California Academy of Sciences, 55 Music Concourse \\ Drive, San Francisco, CA 94118, USA; 2 Biology Department, San Francisco State University, \\ 1600 Holloway Ave, San Francisco, CA 94132, USA: ${ }^{3}$ Environmental Science, Policy and \\ Management, University of California, 101 Sproul Hall, Berkeley, CA 94704, USA; ${ }^{4}$ Biology \\ Department, The George Washington University, 2121 I St NW. Washington, DC 20052, USA. \\ * Address correspondence to facundo.labarque@gmail.com
}

\begin{abstract}
A new genus of Theridiosomatidae from the Philippines is described based on male and female characters: Tagalogonia gen. nov. Two new species are described for the genus: Tagalogonia banahaw sp. nov. and Tagalogonia isarog sp. nov. A new species of Coddingtonia Miller, Griswold and Yin, 2009 is described based on males and females from Malaysia: $C$. anaktakun sp. nov. The monotypic genus Luangnam Wunderlich, 2011 is considered a junior synonym of the monotypic Coddingtonia syn. nov. The female of Coddingtonia discobulbus (Wunderlich, 2011) comb. nov. is illustrated. Discussions on the intergeneric relationships of the Asian Theridiosomatidae are given.
\end{abstract}

KEYwORDS: Symphytognathoids, Indomalaya Region, taxonomy, new species, new synonymy, Luangnam.

The ray spiders, family Theridiosomatidae, are members of a monophyletic group of mostly minute orb-weavers (Griswold et al. 1998; Schütt 2003; Lopardo et al. 2010). Theridiosomatidae area diverse group, currently with 18 genera and 101 species distributed mostly in tropical areas all around the world (Platnick 2014). The family has been reviewed worldwide at the generic level (Coddington 1986), with recent contributions of additional new species from South America (Rodrigues and Ott 2005a-b; Rodrigues and Lise 2008) and Asia (Miller, Griswold and Yin 2009; Ono and Shinkai 2009; Shinkai 2009; Chen 2010; Wunderlich 2011; Dou and Lin 2012; Zhao and Liu 2012).

Several new genera were described from Asia including Karstia Chen, 2010, Chthonopes Wunderlich 2011, the monotypic Coddingtonia Miller, Griswold and Yin 2009, Luangnam Wunderlich 2011, Alaria Zhao and Liu 2012 and Menglunia Zhao and Liu 2012. The main diagnostic character that defines Coddingtonia, the separated spermathecae (Miller et al. 2009), is also shared by Chthonopes, Luangnam and Menglunia (figs. 7, 18f Wunderlich 2011; figs. 16B, 18D Zhao and Liu 2012). In the presence of new evidence, the genus Luangnam is here considered a junior synonym of Coddingtonia (see Systematics and Taxonomy). Coddingtonia was first described based on only one female specimen, and Luangnam was described based in several male and female specimens. However, the Luangnam female illustrations are not detailed enough to provide conclusive evidence of validity. The discovery of a new species of Coddingtonia from Malaysia represented by specimens of both sexes (see Taxonomy) was the key to synonymize Luangnam. Coddingtonia discobulbus (Wunderlich, 2011) comb. nov. is redescribed and the female illustrated based on sev- 
eral paratypes: one male and several females from Tham Pasat Thia, Luang Nam Tha Province, Laos.

Since the descriptions of Andasta cyclosina Simon, 1901 and Theridiosoma nebulosum Simon, 1901 near the beginning of the twentieth century there have been no new records of Malaysian ray spiders. A new species of Coddingtonia from Malaysia is described herein: C. anaktakun sp. nov. based on one male and several females from Bukit Anak Takun, Templer Park, Selangor State. In the case of the Philippines Islands, there are two more recent records of Theridiosomatidae spiders, Ogulnius yaginumai Brignoli, 1981 and Wendilgarda liliwensis Barrion and Litsinger, 1995. During the recent Filipino-American Hearst Biodiversity Expedition (2012) to the Philippines specimens of a new genus, Tagalogonia Labarque and Griswold gen. nov., with two new species, were discovered and these are described herein: Tagalogonia banahaw sp. nov. based on two males and several females from Mt. Banahaw, Quezon Province, Luzon Island, and Tagalogonia isarog sp. nov. based on a male from Mt. Isarog, Camarines Sur Province, Luzon Island.

\section{MATERIALS AND METHODS}

The material examined is deposited in following in institutions (abbreviation and curators in parentheses): California Academy of Sciences, San Francisco, USA (CAS, C. Griswold); University of the Philippines Los Baños, Laguna, Philippines (UPLB, I. Lit, Jr.); Senckenberg Forschungsinstitut und Naturmuseum, Frankfurt, Germany (SMF, P. Jäger); Hunan Normal University, Changsha, China (HNU, X. J. Peng).

Morphological observations and illustrations were made using a Leica M125 stereomicroscope and a Leica DM4000 M compound microscope, both of them with a camera lucida. Pictures were taken with Nikon DXM1200 digital camera mounted on the Leica DM4000 M, and with a Leica DFC 500 digital camera mounted on Leica M216 and M165c stereoscopic microscopes. Extended focal range images were composed with Helicon Focus 4.70 Pro and 5.30 (Khmelik et al. 2006). Preparations were carefully cleaned using fine brushes and a thin jet of alcohol from a thinned pipette. Measurements were taken with an ocular micrometer and are given in millimeters. Female genitalia were digested with contact lens cleaner solution $(\mathrm{ReNu} 囚)$, and observed in lactic acid after dissection. Coloration patterns are described based on specimens preserved in $80 \%$ ethanol.

Coordinates given in brackets were obtained with Google Earth and The World Coordinate Converter (http://twcc:free. fr $/$ ).

Abbreviations used throughout the text are: Habitus: AME, anterior median eyes; PME, posterior median eyes; PT, posterior tubercle. Male palp: C, conductor; $\mathrm{Cy}$, cymbium; E, embolus; EA, embolic apophysis; EB, embolus base; ED, embolic division; MA, median apophysis; O, sperm duct opening; ST, subtegulum; T, tegulum; TS, tegular striae. Epigynum: CD, copulatory ducts; $\mathrm{CDe}$, copulatory duct ending; $\mathrm{CDo}$, copulatory duct opening; $\mathrm{CP}$, central pit; FD, fertilization ducts; GD, gland ductiles; LP, lateral pockets; LW, lateral wings; S, spermathecae; TG, transversal groove; TR, transversal ridges.

\section{SYSTEMATICS}

Coddington (1986) established four subfamilies in Theridiosomatidae: Platoninae, including Plato Coddington, 1986 and Chthonos Coddington, 1986; Epeirotypinae, including Epeirotypus O. P.-Cambridge, 1894 and Naatlo Coddington, 1986; Ogulninae, including Ogulnius O. P.-Cambridge, 1882; and Theridiosomatinae, including Baalzebub Coddington, 1986, Epilineutes Coddington, 1986, Theridiosoma O. P.-Cambridge, 1879 and Wendilgarda Keyserling, 1886. In the last 
five years, many new genera and species of Theridiosomatidae were described for Asia (Miller, Griswold and Yin 2009; Ono and Shinkai 2009; Shinkai 2009; Chen 2010; Wunderlich 2011; Dou and Lin 2012; Zhao and Liu 2012), but the intergeneric and subfamilial relations of those genera were not integrated into the phylogenetic framework proposed by Coddington (1986). Here we present a modified version of the diagnostic characters of Theridiosomatidae genera (fig. 1 Coddington 1986) including all the new genera and several new diagnostic characters (Table 1).

Andasta Simon, 1895, Karstia Chen, 2010, and Zoma Saaristo, 1996 share the characters that defined Ogulninae and Theridiosomatinae; the cymbial lamella, the embolic apophysis, the embolus as a thin lamina, the basal sperm duct opening, the embolic division covered by the conductor, and the convoluted copulatory ducts (figs. 152-156 Coddington 1986; figs. 6, 11-13, 20, 25-27 Chen 2010; figs. 28A-D, 29B Zhao and Liu 2012) and, especially the male characters synapomorphic for Theridiosomatinae including the striated tegulum, the setae row on the cymbial lamella, and the elongated median apophysis with a median groove (figs. 133, 153, 163, 186, 197, 211 Coddington 1986; figs. 10, 24 Chen 2010; figs. 28A-D Zhao and Liu 2012). Chthonopes Wunderlich, 2011, also share most of those characters, except the setae row on the cymbial lamella (figs. 13-14 Wunderlich 2011). Because of those synapomorphies we here include Andasta Simon, Chthonopes Wunderlich, Karstia Chen, and Zoma Saaristo in the subfamily Theridiosomatinae (Table 1). Andasta and Theridiosoma, and Karstia and Baalzebub share the same diagnostic characters respectively, and thus are considered closely related to each other (Table 1). Zoma seem to be closely related to Andasta and Theridiosoma having a striated tegulum, a tegular spur, a setae row on the cymbial lamella, an epigynum with lateral pits, a median apophysis with a dorsal median groove and copulatory ducts inserted mesally on the spermathecae (figs. 28A-D, 29A-B, 30A-D Zhao and Liu 2012; figs. 145-149, 151-156 Coddington 1986). Zoma also share with Epilineutes and Wendilgarda the stripes on the conductor (figs. 28C-D, 30B Zhao and Liu 2012; figs. 189, 197 Coddington 1986). Chthonopes seem to be closely related to Epilineutes and Wendilgarda having a sub-rectangular median apophysis with denticles and an epigynal scape (figs. 17, 18b, 18e Wunderlich 2011; figs. 173, 183, 189, 197 Coddington 1986). Unfortunately, several diagnostic characters are not well documented in Chthonopes (Table 1; Wunderlich 2011). On the other hand, Zoma and Chthonopes share with Platoninae, Epeirotypinae, Menglunia, Ogulninae, Coddingtonia and Tagalogonia gen. nov. a transverse posterior groove on the epigynum (Figs. 1B, D, 3D-F, 6D-F, 7D-F; figs. 25, 37, 50, 78 Coddington 1986; fig. 18f Wunderlich 2011; figs. 16B, 18D, 29B Zhao and Liu 2012), whereas this is absent in the other Theridiosomatidae.

Coddingtonia and Tagalogonia gen. nov. share with Theridiosomatinae and Ogulninae the cymbial lamella, the embolic apophysis, the embolus as a thin lamina, the basal sperm duct opening, the embolic division covered by the conductor, and the convoluted copulatory ducts (Figs. 1A-D, 2D-F, 3D-F, 4D-F, 5D-F, 6D-F, 7D-F; figs. 13-14, 18, 18c, 18f Wunderlich, 2011; figs. 102, 113, 152-153, 164, 184, 191, 211, 215 Coddington 1986; figs. 6, 11, 20, 25 Chen, 2010; figs. 28A-D, 30C-D Zhao and Liu, 2012), and with Theridiosomatinae the mesal insertion of the copulatory ducts on the spermathecae (Figs. 1B, D, 3D, 6E, 7E; figs. 145, 152, 174, 184, 214-215 Coddington 1986; figs. 6, 20 Chen 2010; figs. 29B, 30D Zhao and Liu 2012), whereas other Theridiosomatidae lack the embolic division and its apophysis, the tube like embolus has a distal opening, the copulatory ducts are short and make a simple, acute turn, and the copulatory ducts insert laterally. Coddingtonia and Tagalogonia gen. nov. seem to be closely related to Theridiosomatinae (Table 1), especially Coddingtonia that have a striated tegulum (Fig. 1C). However, both genera lack Theridiosomatinae synapomorphic male characters such as the setae row on the cymbial lamella and the median apophysis with a dorsal median groove (Figs. 2D-F, 4D-F, 5D-F; figs. 3-5 Wunderlich 2011; figs. 133, 153, 163, 186, 197, 211 Coddington 1986). 


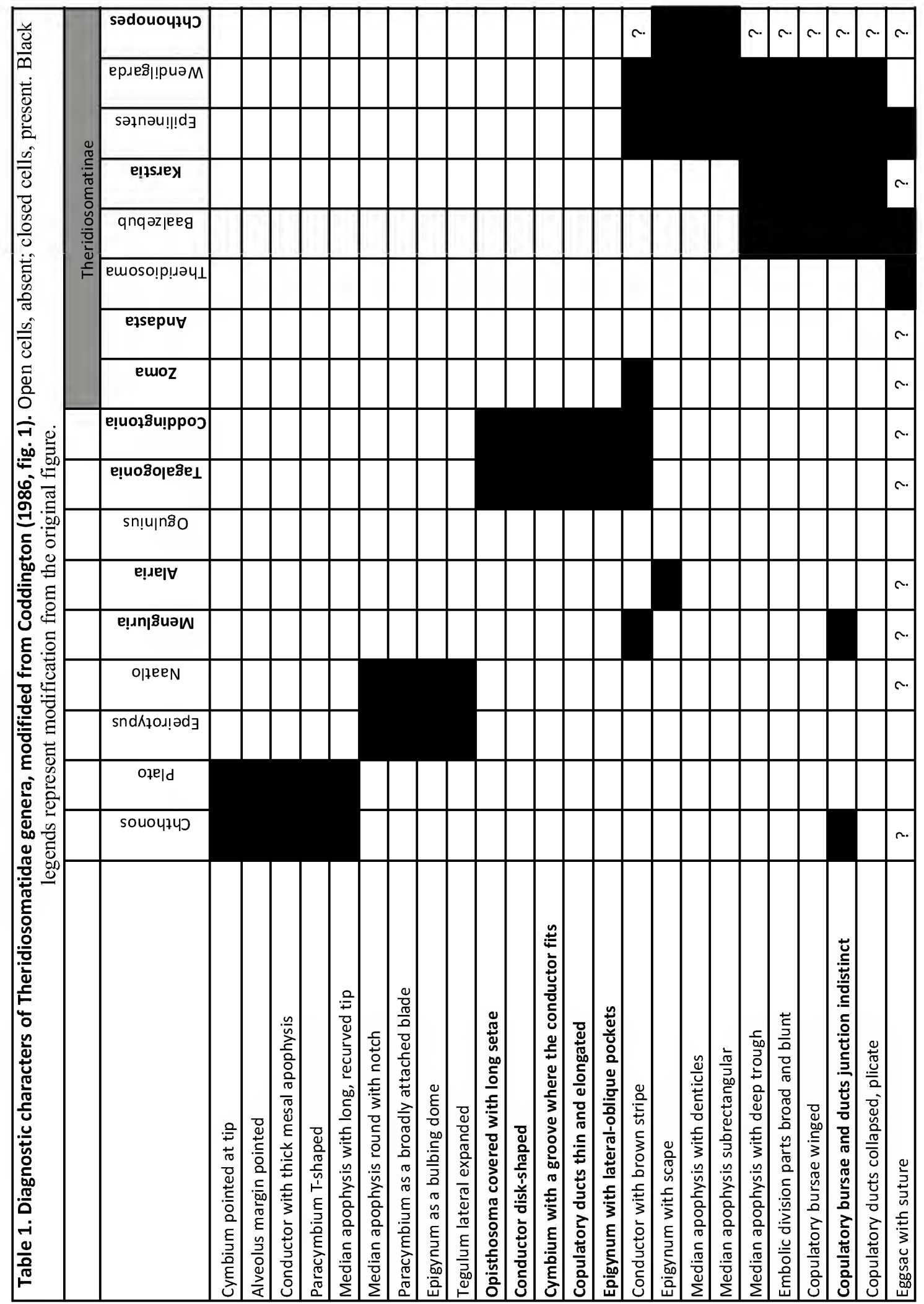



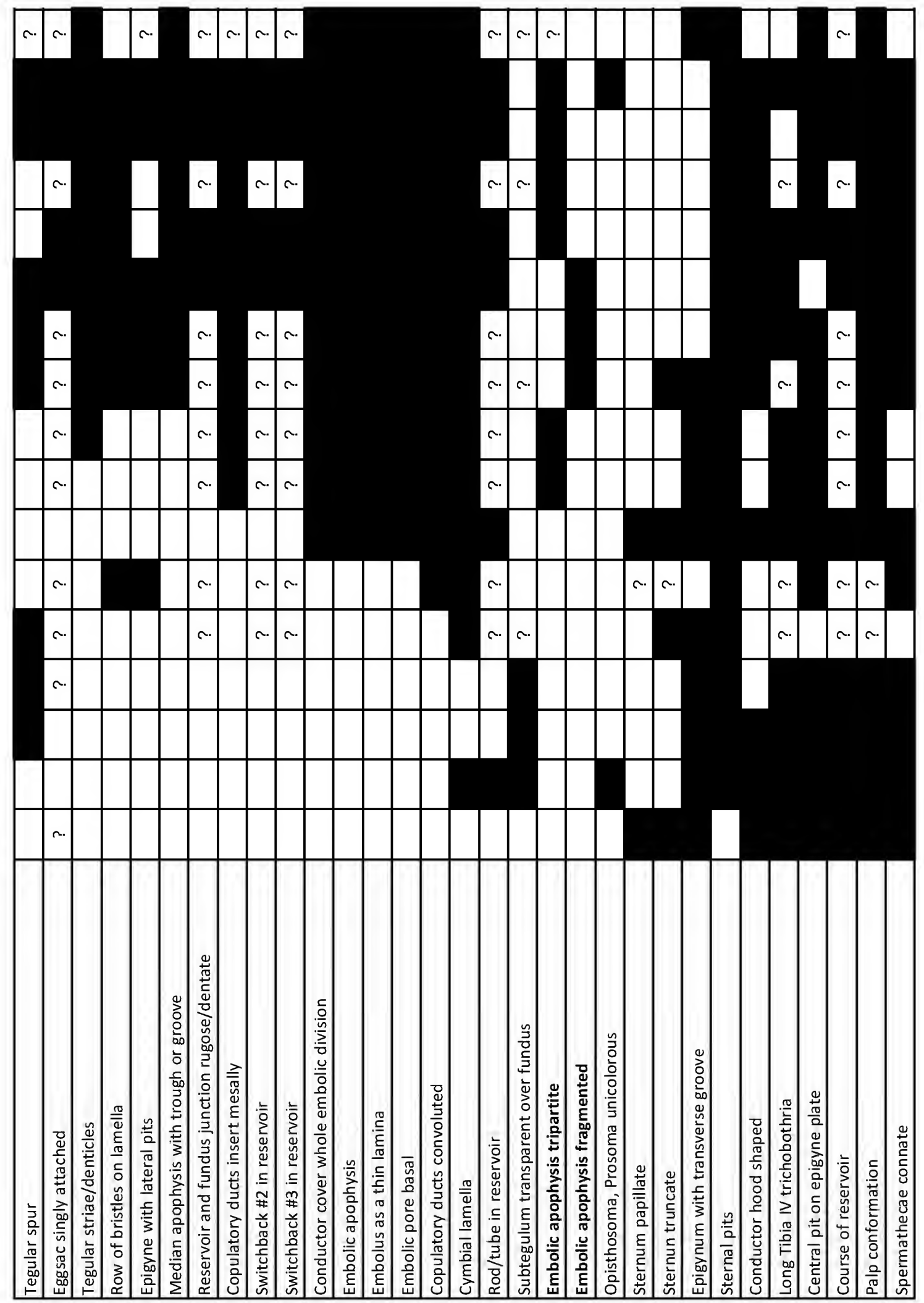
Coddingtonia and Tagalogonia gen. nov. can be distinguished from other genera of Theridiosomatidae by the opisthosoma sparsely covered with long and strong setae, the well-developed disk shaped conductor, the long and slender cymbium with a ventral groove where the conductor fits, and the long and thin copulatory ducts (Figs. 1A-D, 2A-F, 3A-F, 4A-F, 5A-F, 6A-F, 7A-F; figs. 8B, 11E-F Miller et al. 2009; fig. 3-7 Wunderlich 2011). Particularly, males of Coddingtonia and Tagalogonia gen. nov. resemble those of Baalzebub, Epilineutes, Karstia and Wendilgarda (all of them in Theridiosomatinae) by having a tripartite embolic apophysis (Figs. 1A, C, 2D-F, 4D-F, 5D-F; figs. 161-162, 191, 198 Coddington 1986; figs. 11, 25 Chen 2010;), whereas Ogulnius have the embolic apophysis bifurcated (fig. 100 Coddington 1986) and Theridiosoma, Zoma and Andasta have it fragmented (fig. 133 Coddington 1986; fig. 28D Zhao and Li, 2012). The embolic apophysis is not well documented in Chthonopes (figs. 18, 18c Wunderlich, 2011). However, Coddingtonia and Tagalogonia gen. nov. lack the characters that support the clade of Epilineutes and Wendilgarda, e.g., the epigynal scape and the sub-rectangular median apophysis with denticles (figs. 173, 189, 197, 213 Coddington 1986). On the other hand, females of Coddingtonia and Tagalogonia gen. nov. share with those of Platoninae, Epeirotypinae, Ogulninae, Chthonopes, Menglunia and Zoma the presence of a transverse posterior groove on the epigynum (Figs. 1B, D, 3D-F, 6D-F, 7D-F; figs. 25, 37, 50, 78 Coddington 1986; fig. 18f Wunderlich 2011; figs. 16B, 18D, 29B Zhao and Liu 2012), whereas this character is absent in the other Theridiosomatidae. Peculiarly, females of Coddingtonia and Tagalogonia gen. nov. share with those of Chthonopes and Menglunia the separated spermathecae (Figs. 1B, C, 3D-F, 6D-F, 7D-F; fig. $18 \mathrm{f}$ Wunderlich 2011; figs. 16B, 18D Zhao and Liu 2012), whereas these are juxtaposed or partially fused in the other Theridiosomatidae (Coddington 1986; Miller et al. 2009; Zhao and Liu 2012).

Alaria and Menglunia resemble Platoninae and Epeirotypinae having the embolus tube-like with a distal opening, and lacking the embolic division and apophysis (figs. 1A-D, 5A-B, 15A-B, 17A-B, 18A-B Zhao and Liu 2012). Menglunia also share with Platoninae and Epeirotypinae short copulatory ducts with a simple and acute turn (figs. 16B, 18D Zhao and Liu 2012), whereas Alaria share with Coddingtonia, Tagalogonia gen. nov., Theridiosomatinae and Ogulninae convoluted copulatory ducts (figs. 2A, 5D Zhao and Liu 2012). Females of Alaria (figs. 2A-B Zhao and Liu 2012) also share an epigynal scape with Chthonopes, Epilineutes and Wendilgarda (figs. 18d-e Wunderlich 2011; figs. 173, 213 Coddington 1986), while Alaria males lack all the Theridiosomatinae synapomorphies. Zhao and Liu (2012) suggested that Alaria is closely related to Chthonopes and Wendilgarda, but this seems unlikely. Taking into account all the former evidences, Menglunia and Alaria seems to be closely related to Platoninae and Epeirotypinae (Table 1).

\section{TAXONOMY}

\section{Genus Tagalogonia Labarque and Griswold, gen. nov.}

Type Species. - Tagalogonia banahaw Labarque and Griswold, sp. nov.

ETYMOLOGY.- The generic name is a noun in apposition that resembles the Austronesian language spoken as a first or second language in Philippines: Tagalog. The gender is feminine.

MonopHYLY.- Putative synapomorphy: Males of Tagalogonia gen. nov. have a median apophysis very small (minute), square and smooth (Figs. 1A, 2F, 4F).

Diagnosis. - Tagalogonia gen. nov. and Coddingtonia can be distinguished from other genera of Theridiosomatidae by the opisthosoma sparsely covered with long and strong setae, the welldeveloped disk shaped transparent conductor, the long and slender cymbium with a ventral groove where the conductor fits, and the long and thin copulatory ducts (Figs. 1A-D, 2A-F, 3A-F, 4A-F, 5A-F, 6A-F, 7A-F; figs. 8B, 11E-F Miller et al. 2009; figs. 3-5 Wunderlich 2011). Males of Taga- 


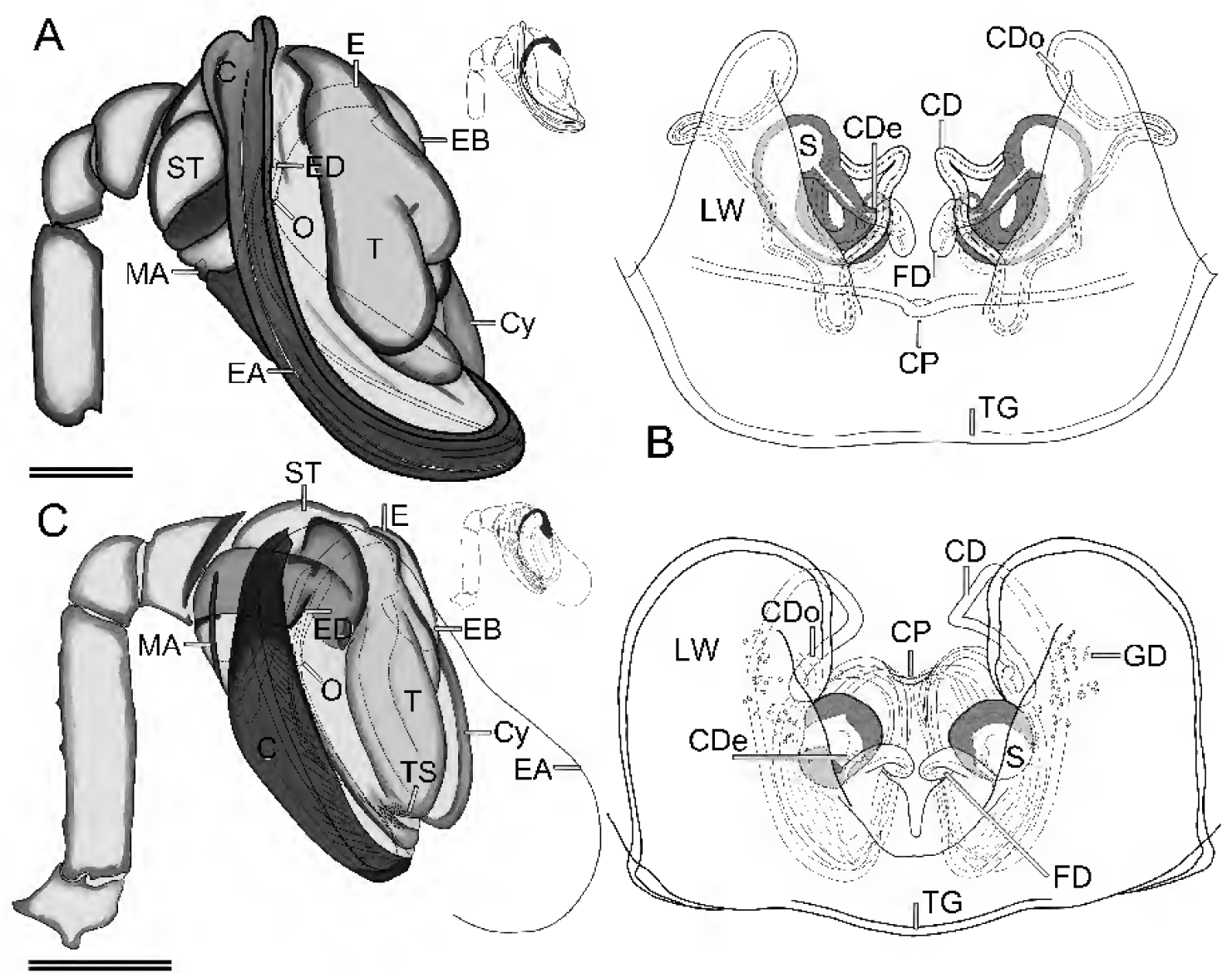

FIgURE 1A-D. Tagalogonia gen. nov. and Coddingtonia genitalia. A Tagalogonia isarog sp. nov. ( $\lesssim$, CASENT9043442). B Tagalogonia banahaw sp. nov. (ㅇ, CASENT9047558). C-D. Coddingtonia anaktakun sp. nov. (C ô, CASENT9048607; D $q$, CASENT9048606). A, C Left palp, retrolateral. Upper left reduced schemes showing embolus and embolic apophyses in black. B, D Vulva, dorsal. $(\mathrm{C}=$ conductor; $\mathrm{CD}=$ copulatory ducts; $\mathrm{CDe}=$ copulatory duct ending; $\mathrm{CDo}=$ copulatory duct opening; $\mathrm{CP}=$ central pit; $\mathrm{Cy}=$ cymbium; $\mathrm{E}=$ embolus; $\mathrm{EA}=$ embolic apophysis; $\mathrm{EB}=$ embolus base; $\mathrm{ED}=$ embolic division; $\mathrm{FD}=$ fertilization ducts; $\mathrm{MA}=$ median apophysis; $\mathrm{LW}=$ lateral wings; $\mathrm{O}=$ sperm duct opening; $\mathrm{S}=$ spermathecae; $\mathrm{ST}=$ subtegulum; $\mathrm{T}=$ tegulum; $\mathrm{TG}=$ transversal groove; $\mathrm{TS}=$ tegular striae). Scales: A, $0.125 \mathrm{~mm} ; \mathrm{C}, 0.2 \mathrm{~mm}$.

logonia gen. nov. can be distinguished by having the embolus and its apophysis covered by the conductor (Figs. 1A, 2E, 4F), and the median apophysis reduced and square (Figs. 1A, 2F, 4F), whereas Coddingtonia have the mesal bristle of the embolic apophysis protruding from beneath the conductor (Figs. 1C, 5D-E; fig. 3 Wunderlich 2011), and the median apophysis ovoid, elongated and distally acute (Figs. 1C, 5D; fig. 5 Wunderlich 2011). Females of Tagalogonia gen. nov. resemble those of Coddingtonia by the separated spermathecae, the epigynum with transverse ridges and a deep central transversal pit (Figs. 1B, D, 3D-F, 6D-F, 7D-F; figs. 11E-F Miller et al. 2009; figs. 6-7 Wunderlich 2011). However, Tagalogonia gen. nov. females can be distinguished by the pattern of the copulatory ducts that describes a lateral loop, then a posterior-median loop, and finally followed by an anterior-median loop which inserts on the reniform spermathecae mesally (Figs. 1B, 3D, F), by the lateral wings of the copulatory bursae soft, not swollen, without gland ductiles (Figs. 1B, 3D, F), and by the central pit of the epigynum in the middle line under the spermathecae, which are visible through the integument (Figs. 1B, 2D-E). In Coddingtonia the copulatory 
ducts describe a posterior-lateral loop, followed by a dorsal loop, and then by a posterior-median loop which coils more than four times before inserting on the round or oval spermathecae mesally (Figs. 1D, 6E, 7E; fig. 11F Miller et al. 2009), the lateral wings are well developed, round, swollen with dorso-median gland ductiles (Figs. 1D, 6E-F, 7E-F; fig. 11 F Miller et al. 2009; fig. 7 Wunderlich 2011), and the central pit is on the anterior third of the epigynum above the spermathecae (Figs. 1D, 6D, 7D; fig. 11E Miller et al. 2009).

SPECIES.- Tagalogonia banahaw sp. nov. and Tagalogonia isarog sp. nov.

Description. - Males total length between 1.43-1.47, females 1.75. Prosoma dark. Ocular area dark. Eyes nearly subequal, AME separated by about $1 / 2$ a diameter, PME separated by about $1 / 2$ a diameter (Figs. 2A-C, 3A-C, 4A-C). Sternum smooth and flat, olive-green circled by a dark line (Figs. 2C, 3C, 4C). Legs long, femora and patella olive-green, tibiae dark orange, metatarsi and tarsi tan; metatarsi shorter than tibiae (except legs III); tibiae III-IV with three to four rows of trichobothria that are longer than tibiae diameter; leg formula: 1243 (Figs. 2A-C, 3A-C, 4A-C). Opisthosoma ovoid, dark, with posterior tubercle, sparsely clothed with long, strong setae. Spinnerets light (Figs. 2A-C, 3A-C, 4A-C). Palp cymbium long, slender with a ventral groove where the conductor fits. Conductor well-developed, disk shaped, transparent, which retrolaterally covers the embolus and its apophysis, and delimits laterally and posteriorly the apical hematodocha (Figs. 1A, 2D-F, 4D-F). Median apophysis reduced, square (Figs. 1A, 2D-F, 4D-F). Epigynum sub-rectangular, flat, with well-developed transverse ridges, a deep central pit and a posterior transverse groove (Fig 3C, E). Vulva with soft lateral wings, not swollen, without gland ductiles; copulatory ducts very long, thin, describing a lateral loop, followed by a posterior-median loop, and then by an anterior-median loop inserted anterio-ventrally to the spermathecae (Figs. 1B, 3D-F).

\section{Tagalogonia banahaw Labarque and Griswold, sp. nov.}

Figures 1B, 2A-F, 3A-F

Type Material.- Holotype: $\widehat{\jmath}$ from Philippines, Luzon Island, Quezon Province, peak of Mt. Banahaw de Lucban, 6.4 km WSW Lucban, 14.0761, 121.51365, 19-22.May.2011, elev. 1852 $\mathrm{m}$, general collecting at night in forest, H. Wood, M. Yngente, N. Chousou Polydouri, C. Griswold, V. Knutson cols., preparation codes FML-01169-01170, (CASENT9047549), deposited in UPLB. PARATYPE: $\not$, same data as the type, (CASENT9048608) deposited in CAS; + , same data as the type, miniwinkler extraction of concentrated leaf litter in forest, (CASENT9047546), deposited in CAS; 69 and one immature, same data as the holotype, searching cryptic habitats in forest, C. Griswold col., preparation codes FML-01168, FML-01182-01183 [ㅇ], (CASENT 9047558), 2 ㅇ deposited in UPLB, remainder in CAS.

ETYMOLOGY.- The specific name is a noun in apposition for the volcano where the species was found: Mount Banahaw de Lucban. The volcano's name might have been derived from "Banaw" which means pool of water in Bisaya language.

Diagnosis.- Males of $T$. banahaw sp. nov. can be distinguished from those of $T$. isarog sp. nov. by having two strong macrosetae at the tip of the cymbium (Fig. 2D), and by the hematodocha exposed beneath the conductor posteriorly (Fig. $2 \mathrm{~F}$ ), whereas $T$. isarog sp. nov. lack those macrosetae, and the conductor covers the hematodocha completely (Fig. 4F). Females of T. banahaw sp. nov. can be distinguished by the copulatory ducts describing a lateral loop, followed by a posterior-median loop, and finally by an anterior-median loop which inserts ventrally in the spermathecae (Figs. 1B, 3D), by the reniform spermathecae (Figs. 1B, 3D-F), and by the epigynum with a deep transverse central groove in the middle line under the spermathecae, which are visible through the integument (Fig. 3D-E). 


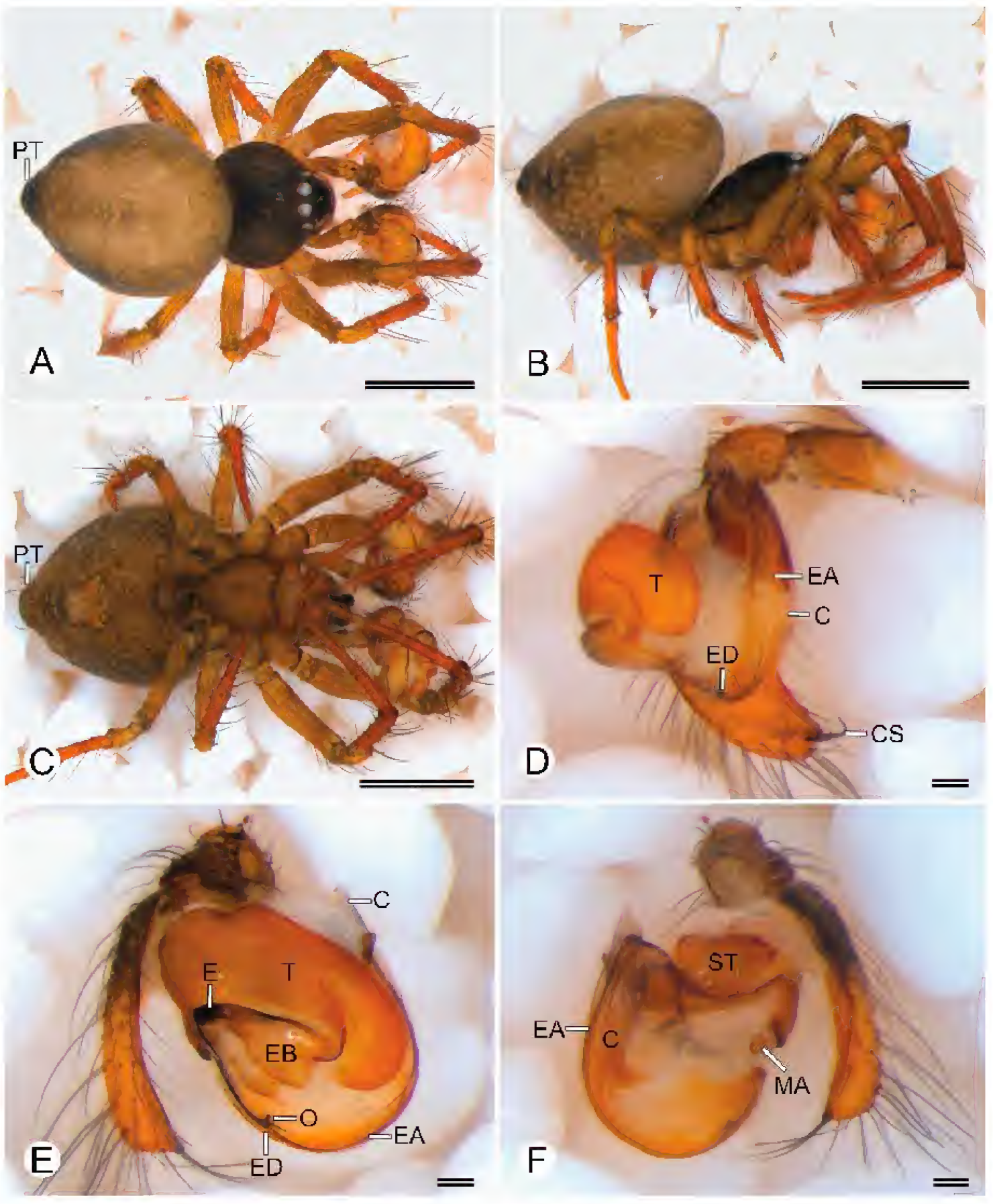

FIGURE 2A-F. Tagalogonia banahaw sp. nov. (ð̃, CASENT9047549). A-C Habitus (A dorsal, B lateral, C ventral). D-F Left palp (D retrolateral, E anterior, F posterior). $(\mathrm{C}=$ conductor; $\mathrm{CS}=$ cymbium setae; $\mathrm{E}=$ embolus; $\mathrm{EA}=\mathrm{embolic}$ apophysis; $\mathrm{EB}=$ embolus base; $\mathrm{ED}=$ embolic division; $\mathrm{MA}=$ median apophysis; $\mathrm{O}=$ sperm duct opening; $\mathrm{PT}=$ posterior tubercle; $\mathrm{ST}=$ subtegulum; $\mathrm{T}=$ tegulum). Scales: A-C, $0.5 \mathrm{~mm}$; D-F, $0.05 \mathrm{~mm}$. 


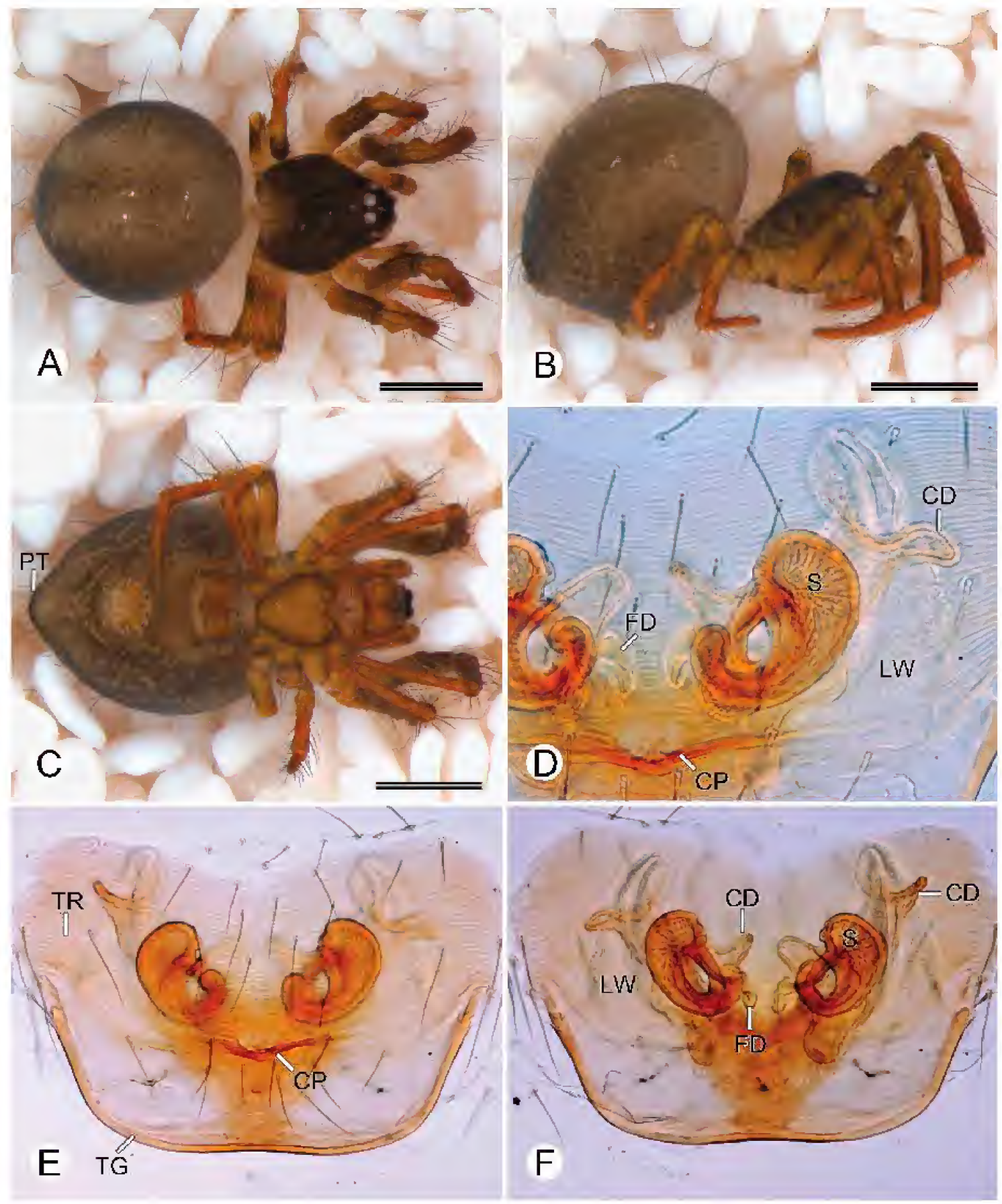

FiGURE 3A-F. Tagalogonia banahaw sp. nov. (․, CASENT9047558). A-C Habitus (A dorsal, B lateral, C ventral). D-F Epigynum (D-E ventral, $\mathrm{F}$ dorsal). $(\mathrm{CD}=$ copulatory ducts; $\mathrm{CP}=$ central pit; $\mathrm{FD}=$ fertilization ducts; $\mathrm{LW}=1$ ateral wings; $\mathrm{PT}=$ posterior tubercle; $\mathrm{S}=$ spermathecae; $\mathrm{TG}=$ transversal groove; $\mathrm{TR}=$ transversal ridges). Scales: $\mathrm{A}-\mathrm{C}, 0.5 \mathrm{~mm}$. 
Description.- Male (Holotype, CASENT9047549): Total length 1.43. Prosoma: Length 0.61 , width 0.58 , height 0.57 . Sternum: Length 0.35 , width 0.35 . Eye diameters and interdistances: AME 0.06, PME 0.07, AME-AME 0.03, AME-PME 0.07, PME-PME, 0.03. Leg formula: 1243. Opisthosoma: Length 1.01, width 0.79, height 0.75 . Dorsal shield of prosoma dark brown (Fig. 2A). Sternum olive-green circled by a dark line (Fig. 2C). Opisthosoma color overall olive-grey with numerous sparsely long, strong setae and a posterior tubercle (Fig. 2A-C). Epiandrum, booklungs, tracheal spiracles, and area behind the anal tubercle olive-grey (Fig. 2C). Spinnerets tan (Fig. 2C). Femora and patellae olive-green, tibiae dark orange, metatarsi and $\operatorname{tarsi} \tan$ (Fig. 2A-C). Palp: cymbium with a ventral groove and two strong macrosetae at the distal tip (Fig. 2D), conductor disk shaped, leaving hematodocha exposed in posterior view (Fig. $2 \mathrm{~F}$ ), median apophysis minute and square (Fig. 2F).

Female (Paratype, CASENT9047558): Total length 1.75. Prosoma: Length 0.70, width 0.58, height 0.58. Sternum: Length 0.36, width 0.36. Eye diameters and interdistances: AME 0.07, PME 0.07, AME-AME 0.03, AME-PME 0.07, PME-PME, 0.03. Leg formula: 1243. Opisthosoma: Length 1.23, width 0.98, height 0.99. Coloration as in male (Fig. 3A-C). Epigynum tan (Fig. 3C). Epigynum: transverse ridges well-developed and central pit deep (Fig. 2E). Vulva: lateral wings soft without gland ductiles, copulatory ducts describing a lateral loop, followed by a posteriormedian loop, and finally by an anterior-median loop which inserts ventrally in the comma-shaped spermathecae (Figs. 1B, 3D, F).

Distribution.- Philippines, Luzon Island, Quezon Province, Mt. Banahaw; known only from the type locality.

\section{Tagalogonia isarog Labarque and Griswold, sp. nov.}

Figures $1 \mathrm{~A}, 4 \mathrm{~A}-\mathrm{F}$

Type Material. - Holotype: 0 from Philippines, Luzon Island, Camarines Sur Province, Mt. Isarog, 11.2 km E Naga City, 13.663683, 123.371667, 1-2.Jun.2011, elev. 1760 m, general collecting at night in forest, M. Yngente, N. Chousou Polydouri cols., preparation codes FML-0117101172, (CASENT9043442), deposited in UPLB.

ETYMOLOGY.- The specific name is a noun in apposition for the volcano where the species was found: Mount Isarog. Isarog Agta is a nearly extinct Bikol language spoken by a semi-nomadic hunter-gatherer native people of the Philippines.

Diagnosis.- Males of $T$. isarog sp. nov. can be distinguished from those of T. banahaw sp. nov. by the well-developed conductor that covers completely one of the hematodocha posteriorly (Figs. 1A, 4F), whereas in T. banahaw sp. nov. the conductor does not cover it completely (Fig. 2F).

Description.- Male (Holotype, CASENT9043442): Total length 1.47. Prosoma: Length 0.61 , width 0.62 , height 0.56 . Sternum: Length 0.35 , width 0.35 . Eye diameters and interdistances: AME 0.08, PME 0.06, AME-AME 0.02, AME-PME 0.06, PME-PME, 0.03. Leg formula: 1243. Opisthosoma: Length 1.09 , width 0.78 , height 0.75 . Dorsal shield of prosoma dark brown (Fig. 4A). Sternum light olive-green circled by a dark line (Fig. 4C). Opisthosoma color overall olivegrey with numerous sparsely long, strong setae and a posterior tubercle (Fig. 4A-C), lighter grey at tracheal spiracles and behind the anal tubercle (Fig. 4C). Epiandrum, booklungs and spinnerefs $\tan$ (Fig. 4C). Femora and patellae olive-green, tibiae dark orange, metatarsi and tarsi tan (Fig. 4A-C). Palp: cymbium with a ventral groove, conductor disk shaped and completely covering the hematodocha (Figs. 1A, 4F), median apophysis minute and square (Figs. 1A, 4F).

Female: Unknown. 


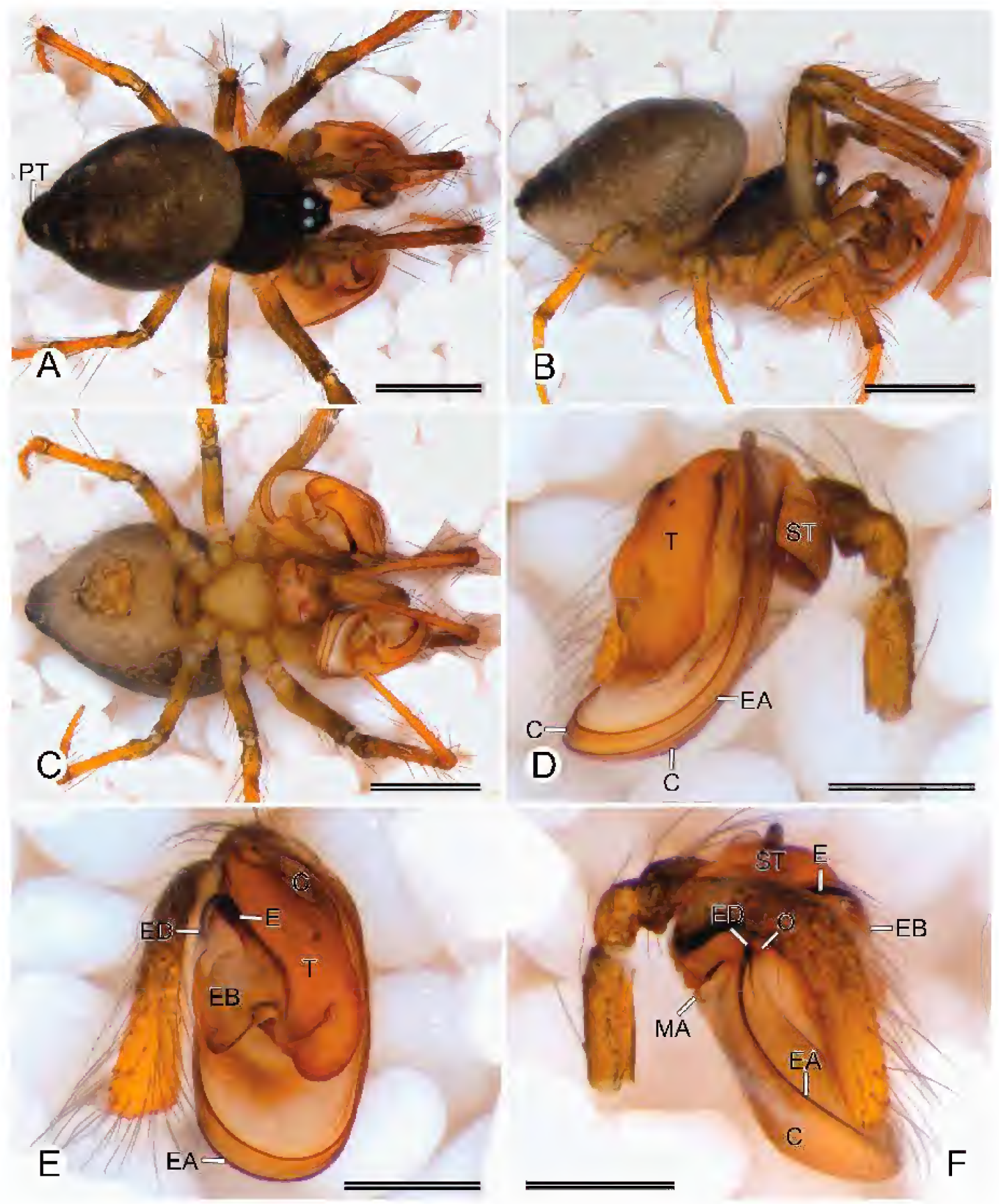

Figures 4A-F. Tagalogonia isarog sp. nov. (ð̂, CASENT9043442). A-C Habitus (A dorsal, B lateral, C ventral). D-F Left palp (D retrolateral, $\mathrm{E}$ anterior, $\mathrm{F}$ prolateral). $(\mathrm{C}=$ conductor; $\mathrm{E}=$ embolus; $\mathrm{EA}=$ embolic apophysis; $\mathrm{EB}=\mathrm{embo-}$ lus base; $\mathrm{ED}=$ embolic division; $\mathrm{MA}=$ median apophysis; $\mathrm{O}=$ sperm duct opening; $\mathrm{PT}=$ posterior tubercle; $\mathrm{ST}=$ subtegulum; $\mathrm{T}=$ tegulum). Scales: A-C, $0.5 \mathrm{~mm}$; D-F, $0.25 \mathrm{~mm}$. 
Distribution. - Philippines, Luzon Island, Camarines Sur Province, Mt. Isarog; known only from the type locality.

\section{Genus Coddingtonia Miller, Griswold and Yin, 2009}

Coddingtonia Miller, Griswold and Yin, 2009: 30, figs. 8B, 11E-F, 94. Type species Coddingtonia euryopoides Miller, Griswold and Yin [one 9 holotype (CASENT 9022403, HNU), one immature paratype (CASENT 9029336), from China, Yunnan Province, Longling Co., Mangkuan Township, Zaotang He at Baihualing village, examined]

Luangnam Wunderlich, 2011: 431. Type species by monotypy Luangnam discobulbus Wunderlich [one $\delta$ holotype (SMF), one $q$ paratype (SMF), one $\delta^{\lambda}$ and 5 q paratypes (SMF-62412), from Laos, Luang Nam Tha Province, Vieng Phou Kka, Phou Pasat, Tham Pasat Thia, examined] syn. nov.

SynONymy. - The female of Luangnam discobulbus Wunderlich agrees in every way with the diagnostic characters here described for Coddingtonia Miller, Griswold and Yin, 2009, and the male agrees in detail with the diagnostic characters of males of our new species, Coddingtonia anaktakun Labarque and Griswold.

MonophYLY.- Putative synapomorphies: Males of Coddingtonia have a median apophysis elongated, distally acute and basally ovoid (Figs. 1C, 5D, F; fig. 5 Wunderlich 2011), and the mesal bristle of the embolic apophysis protruding from beneath the conductor (Figs. 1C, 4D-E; figs. 3-5 Wunderlich 2011). The former is also shared with Wendilgarda (fig. 198 Coddington 1986). Females of Coddingtonia have lateral oblique pockets on the epigynum (Figs. 6D, 7D; fig. 11E Miller et al. 2009), different to the lateral round sclerotized pits found in Alaria and Theridiosomatinae (fig. 2B Zhao and Liu 2012; figs. 151, 173, 213 Coddington 1986).

Diagnosis.-Coddingtonia and Tagalogonia gen. nov. can be distinguished from other genera of Theridiosomatidae by the opisthosoma sparsely covered with long and strong setae, the welldeveloped disk shaped conductor, the long and slender cymbium with a ventral groove where the conductor fits and the long and thin copulatory ducts (Figs. 1A-D, 2A-F, 3A-F, 4A-F, 5A-F, 6A-F, 7A-F; figs. 8B, 11E-F Miller et al., 2009; fig. 3 Wunderlich, 2011). Males of Coddingtonia can be distinguished by having the mesal bristle of the embolic apophysis protruding from beneath the conductor (Figs. 1C, 5D-E; fig. 3 Wunderlich 2011), the median apophysis elongated, ovoid and distally acute (Figs. 1C, 5D, F; fig. 5 Wunderlich 2011), and the striated tegulum (Fig. 1C; fig. 4 Wunderlich 2011), while those of Tagalogonia gen. nov. have the embolus and its apophysis covered by the conductor (Figs. 1A, 2E, 4F), the median apophysis reduced and square (Figs. 1A, 2F, 4F), and lack denticules on the tegulum (Fig. 1A). Females of Coddingtonia resemble those of Tagalogonia gen. nov. by the separated spermathecae, the epigynum with transverse ridges and a deep central transversal pit (Figs. 1B, C, 3D-F, 6D-F, 7D-F; figs. 11E-F Miller et al. 2009; figs. 6-7 Wunderlich 2011). However, Coddingtonia females can be distinguished by the pattern of the copulatory ducts that describes a posterior-lateral loop, followed by a dorsal loop, and finally a posterior-median loop that coils more than four times before inserting on the round or oval spermathecae mesally (Figs. 1D, 6E, 7E; fig. 11F Miller et al. 2009), by the lateral wings of the copulatory bursae well developed, like round, swollen sacks, with dorso-median gland ductiles (Figs. 1D, 6E-F, 7E-F; fig. 11F Miller et al. 2009; fig. 7 Wunderlich 2011), and by the central pit on the anterior third of the epigynum above the spermathecae (Figs. 1D, 6D, 7D; fig. 11E Miller et al. 2009). In Tagalogonia gen. nov. the copulatory ducts describe a lateral loop, followed by a posterior-median loop, and finally an anterior-median loop that inserts on the reniform spermathecae mesally (Figs. 1B, 3D, F), the lateral wings are soft, not swollen, without gland ductiles (Figs. 1B, 3D, F), and the central pit of the epigynum is in the middle line under the spermathecae (Figs. 1B, 3D-E). 


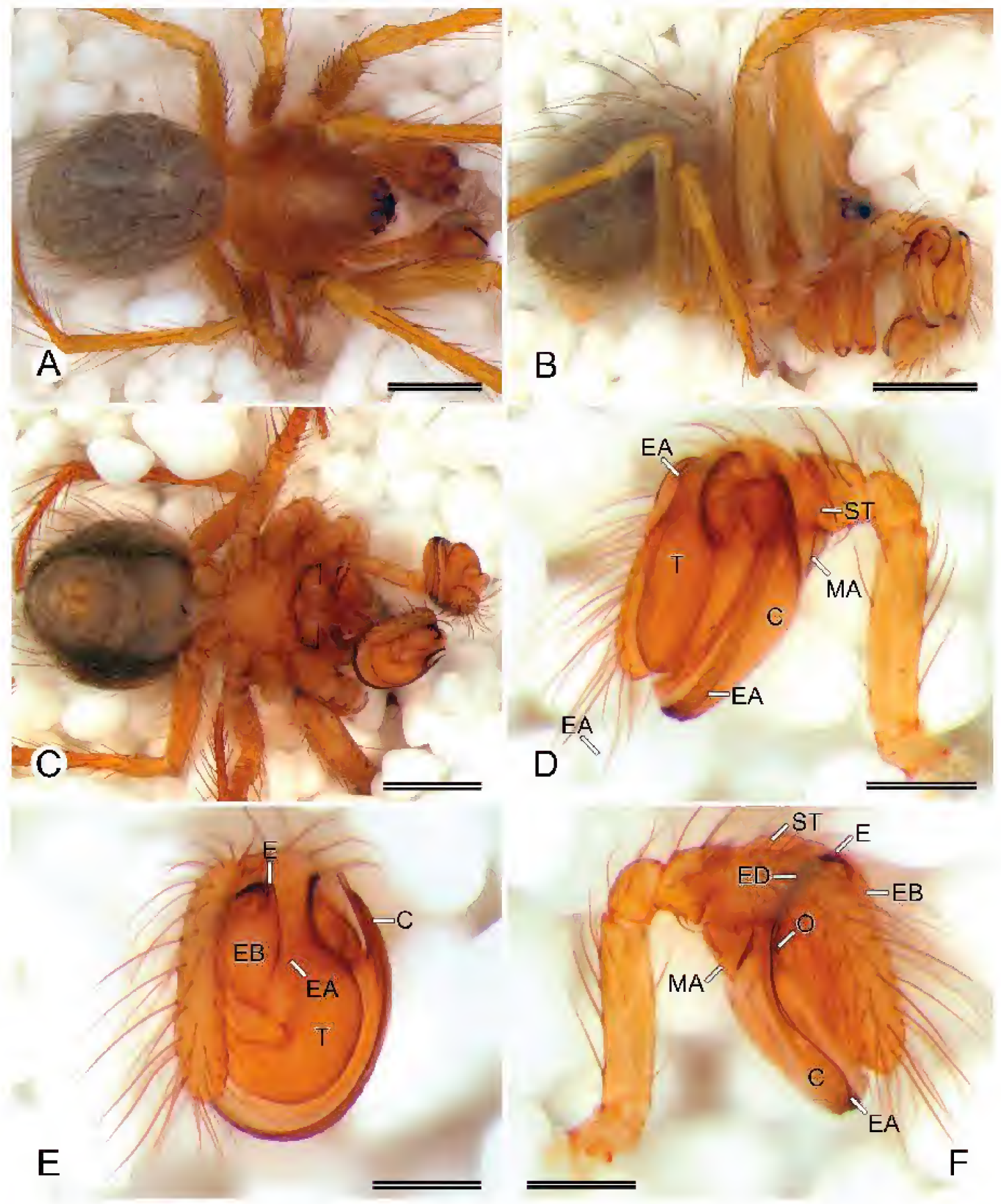

Figures 5A-F. Coddingtonia anaktakun sp. nov. (ô, CASENT9048607). A-C Habitus (A dorsal, B lateral, C ventral). D-F Left palp (D retrolateral, $\mathrm{E}$ anterior, $\mathrm{F}$ posterior). $(\mathrm{C}=$ conductor; $\mathrm{E}=$ embolus; $\mathrm{EA}=$ embolic apophysis; $\mathrm{EB}=\mathrm{embo-}$ lus base; $\mathrm{ED}=$ embolic division; $\mathrm{MA}=$ median apophysis; $\mathrm{O}=$ sperm duct opening; $\mathrm{ST}=$ subtegulum; $\mathrm{T}=$ tegulum). $\mathrm{Scales}$ : A-C, $0.5 \mathrm{~mm}$; D-F, $0.2 \mathrm{~mm}$. 


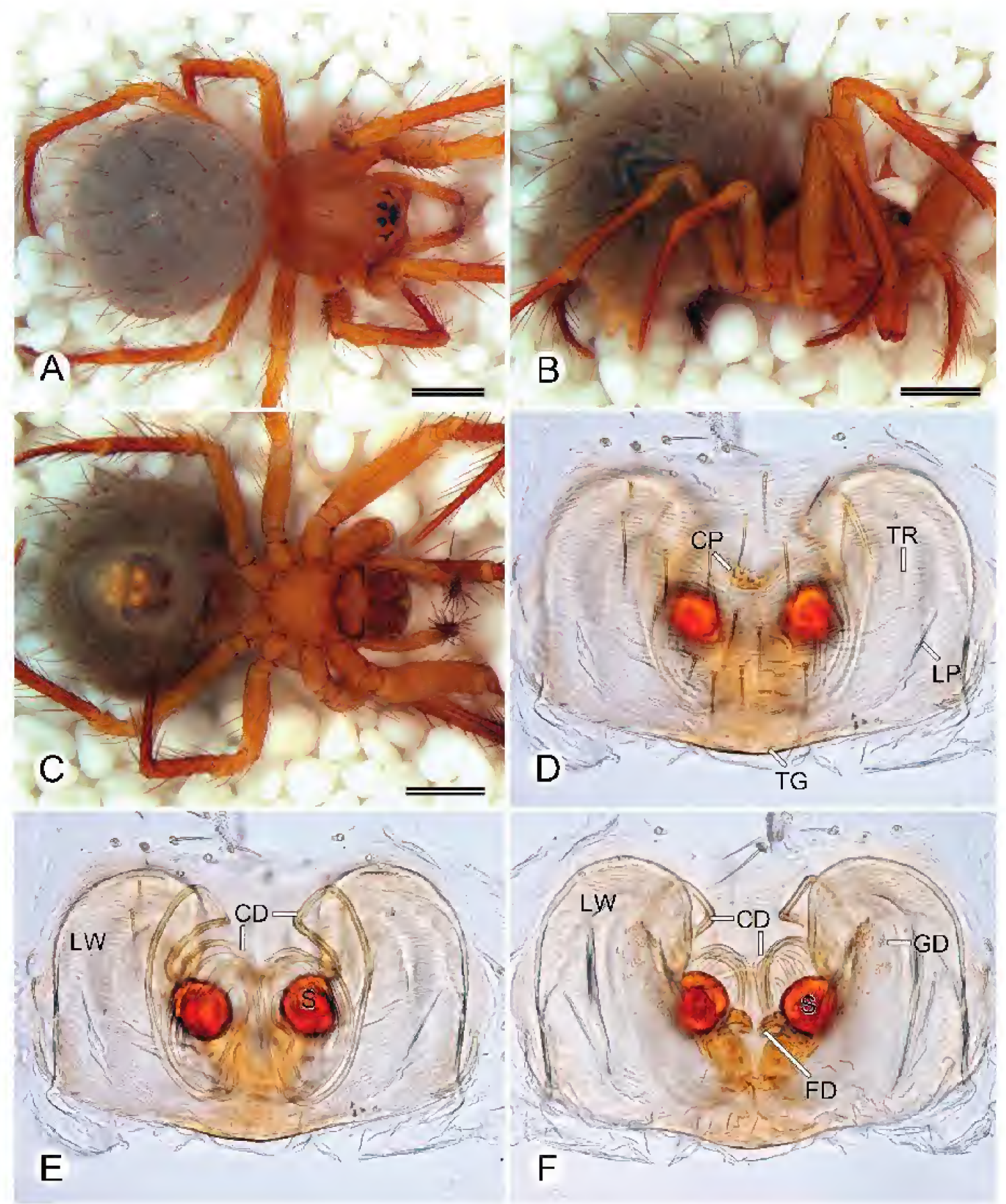

FIGURES 6A-F. Coddingtonia anaktakun sp. nov. (o, CASENT9048606). A-C Habitus (A dorsal, B lateral, C ventral). D-F Epigynum (D-E ventral, F dorsal). $(\mathrm{CD}=$ copulatory ducts; $\mathrm{CP}=$ central pit; $\mathrm{FD}=$ fertilization ducts; $\mathrm{GD}=$ gland ductiles; $\mathrm{LP}=$ lateral pockets; $\mathrm{LW}=$ lateral wings; $\mathrm{S}=$ spermathecae; $\mathrm{TG}=$ transversal groove; $\mathrm{TR}=$ transversal ridges). Scales: A-C, $0.5 \mathrm{~mm}$; D, $0.05 \mathrm{~mm}$. 
Species.- Coddingtonia euryopoides Miller, Griswold and Yin, 2009, Coddingtonia discobulbus (Wunderlich, 2011) comb. nov. and Coddingtonia anaktakun sp. nov.

Description.- Males total length between 1.6-1.95, females 1.8-2.36. Prosoma tan to dark. Ocular area tan to dark. AME nearly subequal or two times larger than the other eyes, AME separated by about or by less than $1 / 2$ a diameter, PME separated by about $1 / 2$ to 2 times their diameter (Figs. 5A-C, 6A-C, 7A-C). Sternum smooth and flat, tan or olive-green encircled by a dark line (Figs. 5C, 6C, 7C). Legs long, femora and patellae tan or olive-green, tibiae, metatarsi and tarsi tan; metatarsi shorter than tibiae (except legs III); tibiae III-IV with three to four rows of trichobothria that are longer than tibiae diameter; leg formula: 1243 (Figs. 5A-C, 6A-C, 7A-C). Opisthosoma ovoid, dark, with or without a posterior tubercle, sparsely clothed with long, strong setae (Figs. 5A-C, 6A-C, 7A-C). Spinnerets light (Figs. 5C, 6C, 7C). Palp cymbium long, slender with a ventral groove where the conductor fits. Conductor well-developed, disk shaped, laterally and posteriorly delimiting the apical hematodocha (Figs. 1C, 5D-F). Mesal bristle of the embolic apophysis protruding from beneath the conductor, convoluted, describing a semi-loop or a complete loop next to the embolus base, and a semi-loop around the bulb (Figs. 1C, 5D-E; fig. 3 Wunderlich 2011). Median apophysis elongated, ovoid and distally acute, sometimes with a dorsal projection (Figs. 1C, 5D, F). Epigynum sub-rectangular, flat, withwell-developed transverse ridges, a deep central pit on the anterior third of the epigynum and two lateral oblique pockets above the transversal groove (Figs. 1D, 6C-D, 7C-D). Vulva with lateral wings well developed as round swollen sacks with dorso-median gland ductiles, copulatory ducts very long, thin, describing a posterior-lateral loop, followed by a dorsal loop, and finally a posterior-median loop which coils between six and eleven times, inserted anterio-ventrally on the spermathecae (Figs. 1D, 6E-F, 7E-F).

\section{Coddingtonia anaktakun Labarque and Griswold, sp. nov.}

Figures $1 \mathrm{C}-\mathrm{D}, 5 \mathrm{~A}-\mathrm{F}, 6 \mathrm{~A}-\mathrm{F}$

Type Material. - Holotype: đ from Malaysia, Selangor State, Templer Park, Bukit Anak Takun, 12 mi. NW Kuala Lumpur, [3.298139, 101.637472], 13.Jun.1962, elev. 120 m, limestone cave, E.S. Ross, D. Cavagnaro cols., preparation codes FML-01187-01188, (CASENT9048607) deposited in CAS; PARATYPE: 2 \% , same data as the type, preparation codes FML-01184-01185 [우 and FML-01186 [ㅇ], (CASENT9048606); deposited in CAS; 6 9, same data as the type, (CASENT9048606), deposited in CAS.

Etymology.- The specific name is the union of two nouns that resemble the hill where the species was found: Bukit Anak Takun.

Diagnosis.- Males of C. anaktakun sp. nov. can be distinguished from those of C. discobulbus comb. nov. by the pattern of the mesal bristle of the embolic apophysis which describes a semiloop above the tegulum and cymbium and by the dorsal projection of the median apophysis (Figs. 1C, 5D-F); in C. discobulbus comb. nov. the embolic apophysis describes one complete loop next to the embolus base and a semi-loop around the bulb, and the median apophysis lacks the dorsal projection (figs. 3, 5 Wunderlich 2011). Females of $C$. anaktakun sp. nov. can be distinguished from those of $C$. euryopoides and $C$. discobulbus comb. nov. by the six coils of the copulatory ducts (Figs. 1D, 6E), whereas C. euryopoides have eight coils (fig. 11F Miller et al. 2009) and C. discobulbus comb. nov. have eleven coils (Fig. 7E). Also, females of $C$. anaktakun sp. nov. can be distinguished from those of $C$. discobulbus comb. nov. by the round spermathecae (Figs. 1D, 6E-F), whereas C. discobulbus comb. nov. have oval spermathecae (Fig. 7E-F; fig. 7 Wunderlich 2011).

DescriPTION. - Male (Holotype, CASENT9048607): Total length 1.95. Prosoma: Length 0.81 , width 0.80 , height 0.72 . Sternum: Length 0.35 , width 0.45 . Eye diameters and interdistances: 
AME 0.09, PME 0.05, AME-AME 0.04, AME-PME 0.06, PME-PME, 0.07. Leg formula: 1243. Opisthosoma: Length 1.18, width 0.88 , height 0.78 . Dorsal shield of prosoma tan (Fig. 5A). Sternum tan (Fig. 5C). Opisthosoma color overall olive-grey with numerous sparse, long, strong setae (Fig. 5A-C). Epiandrum, booklungs, tracheal spiracles, and area behind the anal tubercle pale (Fig. 5C). Spinnerets $\tan$ (Fig. 5C). Legs tan (Fig. 5A-C). Palp: cymbium with a ventral groove, conductor disk shaped, mesal embolic apophysis describing a semi-loop above the tegulum and cymbium, median apophysis elongated, distally acute with a dorsal projection (Figs. 1C, 5D-F).

Female (Paratype, CASENT9048606): Total length 2.36. Prosoma: Length 0.90, width 0.85, height 0.83 . Sternum: Length 0.43, width 0.49. Eye diameters and interdistances: AME 0.10, PME 0.04, AME-AME 0.05, AME-PME 0.08, PME-PME, 0.08. Leg formula: 1243. Opisthosoma: Length 1.57, width 1.40, height 1.38. Coloration as in male (Fig. 6A-C). Epigynum tan (Fig. 6C). Epigynum: transverse ridges well-developed, central pit deep, lateral oblique pockets above the transversal groove (Fig. 6E). Vulva: lateral wings well developed as round, swollen sacks with dorso-median gland ductiles, copulatory ducts describing a posterior-lateral loop, followed by a dorsal loop, and finally a posterior-median loop which coils six times and inserts ventrally on the round spermathecae (Figs. 1D, 6D, F).

Distribution.- Malaysia, Selangor State, Templer Park, Bukit Anak Takun; known only from the type locality.

\section{Coddingtonia discobulbus (Wunderlich, 2011), comb. nov.}

Figure 7A-F

Luangnam discobulbus Wunderlich, 2011: 431, figs. 1-7 [one $\sigma^{\Uparrow}$ holotype (SMF), one 9 paratype (SMF), one $\delta$ and 5 i paratypes (SMF-62412), from Laos, Luang Nam Tha Province, Vieng Phou Kka, Phou Pasat, Tham Pasat Thia, examined].

Material Examined.- Paratype: $\delta$ and $5 q$ from Laos, Luang Nam Tha Province, Vieng Phou Kka, Phou Pasat, Tham Pasat Thia, 20.777, 101.016722, 5.Mar.2008, elev. 750 m, P. Jäger col., preparation codes FML-01189-01190 [] and FML-01191 []], deposited in SMF (62412).

Diagnosis.- Males of $C$. discobulbus comb. nov. can be distinguished from those of C. anaktakun sp. nov. by the pattern of the mesal bristle of the embolic apophysis, which describes a complete loop next to the embolus base and a semi-loop around the bulb, and by the median apophysis without a dorsal projection (fig. 3, 5 Wunderlich 2011); in C. anaktakun sp. nov, the embolic apophysis describes a semi-loop above the tegulum and cymbium, and the median apophysis has a dorsal projection (Figs. 1C, 5D-F). Females of $C$. discobulbus comb. nov. can be distinguished from those of $C$. euryopoides and C. anaktakun sp. nov. by the eleven coils of the copulatory ducts (Fig. 7E), whereas C. euryopoides have eight coils (fig. 11F Miller et al. 2009) and C. anaktakun sp. nov. have six coils (Figs. 1D, 6E). Also, females of $C$. discobulbus comb. nov. can be distinguished from those of C. anaktakun sp. nov. by the oval spermathecae (Fig. 7E-F; fig. 7 Wunderlich 2011), whereas $C$. anaktakun sp. nov. have round spermathecae (Figs. 1D, 6E-F).

\section{ACKNOWLEDGMENTS}

This research was facilitated by a generous gift to the CAS from Will and Margaret Hearst for supporting the 2011 Filipino-American Hearst Biodiversity expedition to Luzon. We thank the other members of the Entomology Section, Terrestrial Team, from this expedition: Natalia Chousou Polydouri, Orlando "Daddyboy" Eusebio, Vanessa Knutson, Matt Lewin, Hannah Wood, Sheryl "Sheng" Yap, and Mark Yngente. We thank Gustavo Hormiga and Jeremy Miller for the revision and comments on this manuscript. FML wishes to thank a Postdoctoral Fellowship from the 


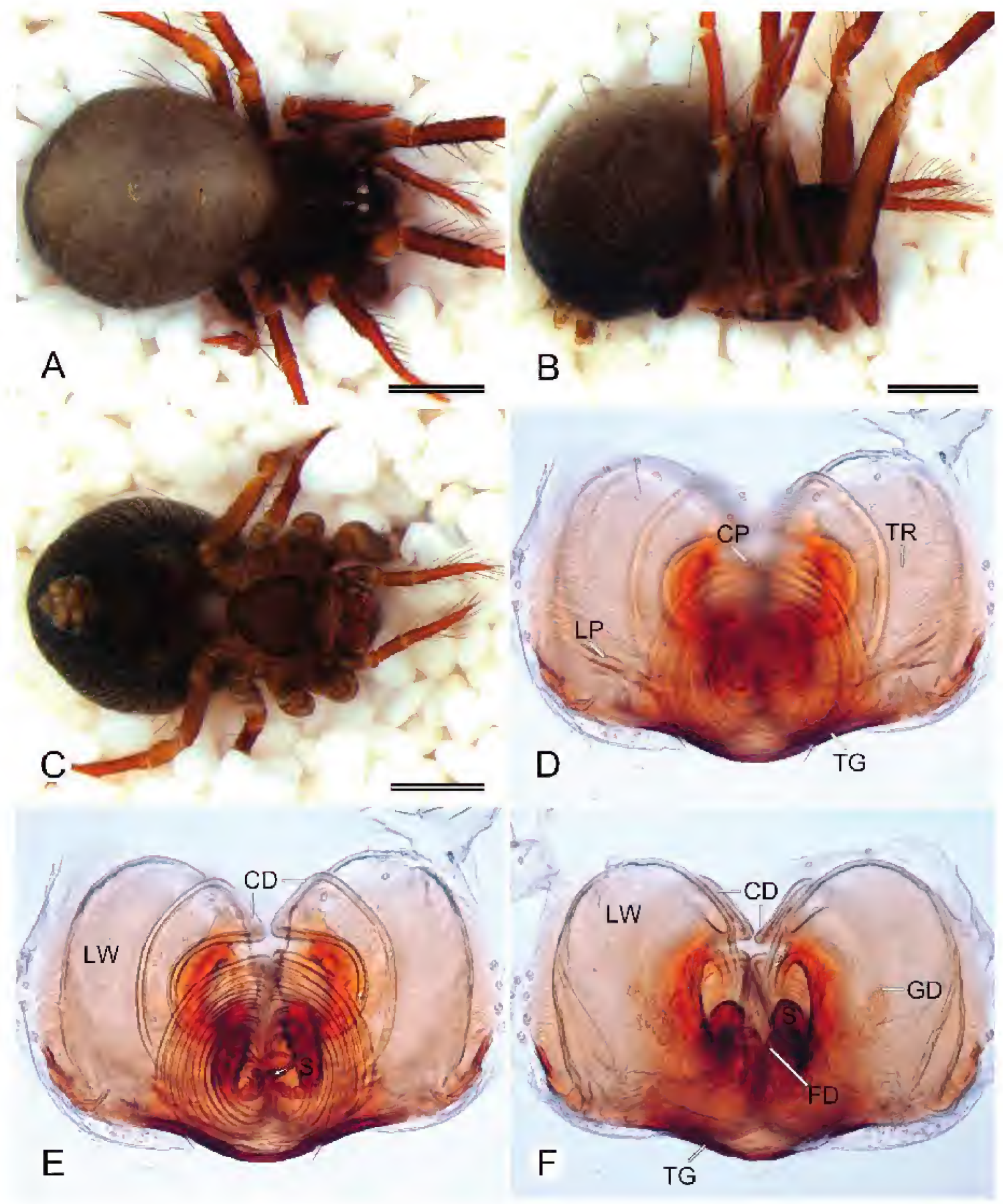

Figures 7A-F. Coddingtonia discobulbus Wunderlich, 2011 (, SMF62412). A-C Habitus (A dorsal, B lateral, C ventral). D-F Epigynum (D-E ventral, F dorsal). White arrows $C D$ path. $(C D=$ copulatory ducts; $C P=$ central pit; $F D=$ fertilization ducts; $\mathrm{GD}=$ gland ductiles; $\mathrm{LP}=$ lateral pockets; $\mathrm{LW}=$ lateral wings; $\mathrm{S}=$ spermathecae; $\mathrm{TG}=$ transversal groove; $\mathrm{TR}=$ transversal ridges). Scales: A-C, $0.5 \mathrm{~mm}$. 
Schlinger Chair of Arachnology at CAS. Additional support came from the Harriet Exline-Frizzell Fund of CAS and from the Schlinger Foundation.

\section{REFERENCES}

Chen, H. M. 2010. Karstia, a new genus of troglophilous theridiosomatid (Araneae, Theridiosomatidae) from southwestern China. Guizhou Science 28 (4):1-10.

Coddington, J. A. 1986. The genera of the spider family Theridiosomatidae. Smithsonian Contributions to Zoology 422:1-96.

Dou, L. A., AND Y. C. Lin. 2012. Description of Karstia cordata sp. nov. (Araneae, Theridiosomatidae) from caves in Chongqing, China. Acta Zootaxonomica Sinica 37:734-739.

Griswold, C. E., J. A. Coddington, G. Hormiga, and N. ScharfF. 1998. Phylogeny of the orb-web building spiders (Araneae, Orbiculariae: Deinopoidea, Araneoidea). Zoological Journal of the Linnean Society 123:1-99.

Khmelik, V. V., D. Kozub, And A. Glazunov. 2006. Helicon Focus version 4.70 Pro and $5.30<$ http://helicon.com.ula/heliconfocus/s

Miller, J. A., C. E. GRISwold, AND C. M. Yin. 2009. The symphytognathoid spiders of the Gaoligongshan, Yunnan, China (Araneae, Araneoidea): Systematics and diversity of micro-orbweavers. ZooKeys 11:9-195.

Lopardo, L., G. Giribet, AND G. Hormiga. 2010. Morphology to the rescue: molecular data and the signal of morphological characters in combined phylogenctic analyses - a case study from mysmenid spidcrs (Araneae, Mysmenidae), with comments on the evolution of web architecture. Cladistics 26:1-52.

Ono, H., And E. ShinKai. 2009. Theridiosomatidae, Symphytognathidae. Pages 394-398 in H. Ono, ed., The Spiders of Japan with Keys to the Families and Genera and Illustrations of the Species. Tokai University Press, Kanagawa, Japan.

Platnick, N. I. 2014. The World Spider Catalog, Version 14.5. American Museum of Natural History, New York. <http://research.amnh.org/entomology/spiders/catalog/> (accessed: 7.I.2014).

Rodrigues, E. N. L., AND R. OTt. 2005a. Nova espécie de Theridiosoma (Araneae, Theridiosomatidae) do sul do Brasil. Iheringia, Série Zoologia, Porto Alegre 95(1):79-81.

Rodrigues, E. N. L., AND R. OTT. 2005b. Aranhas da família Theridiosomatidae: espécie nova e novas ocorrências no Brasil. Iheringia, Série Zoologia, Porto Alegre 95(4):441-443.

Rodrigues, E. N. L., AND A. A. Lise. 2008. Description of two new species of Naatlo (Araneae: Theridiosomatidae) from Brazil. Revista brasileira de Zoologia 25:299-308.

Schüтt, K. 2003. Phylogeny of Symphytognathidae s.l. (Araneae, Araneoidea). Zoologica Scripta 32: $129-151$.

SHINKAI, E. 2009. Two new species of the genera Wendilgarda and Patu from Japan (Araneae: Theridiosomatidae and Symphytognathidae). Pages 75-77 in H. Ono, ed., The Spiders of Japan with Keys to the Families and Genera and Illustrations of the Species. Tokai University Press, Kanagawa, Japan.

Wunderlich, J. 2011. New extant taxa of the spider family Theridiosomatidac (Araneae) from Laos and some fossil taxa. Beiträge zur Araneologie 6:427-444.

Zhaо, Q. Y., AND S. Q. L. 2012. Eleven new species of theridiosomatid spiders from southern China (Araneae, Theridiosomatidae). ZooKeys 255:1-48. 


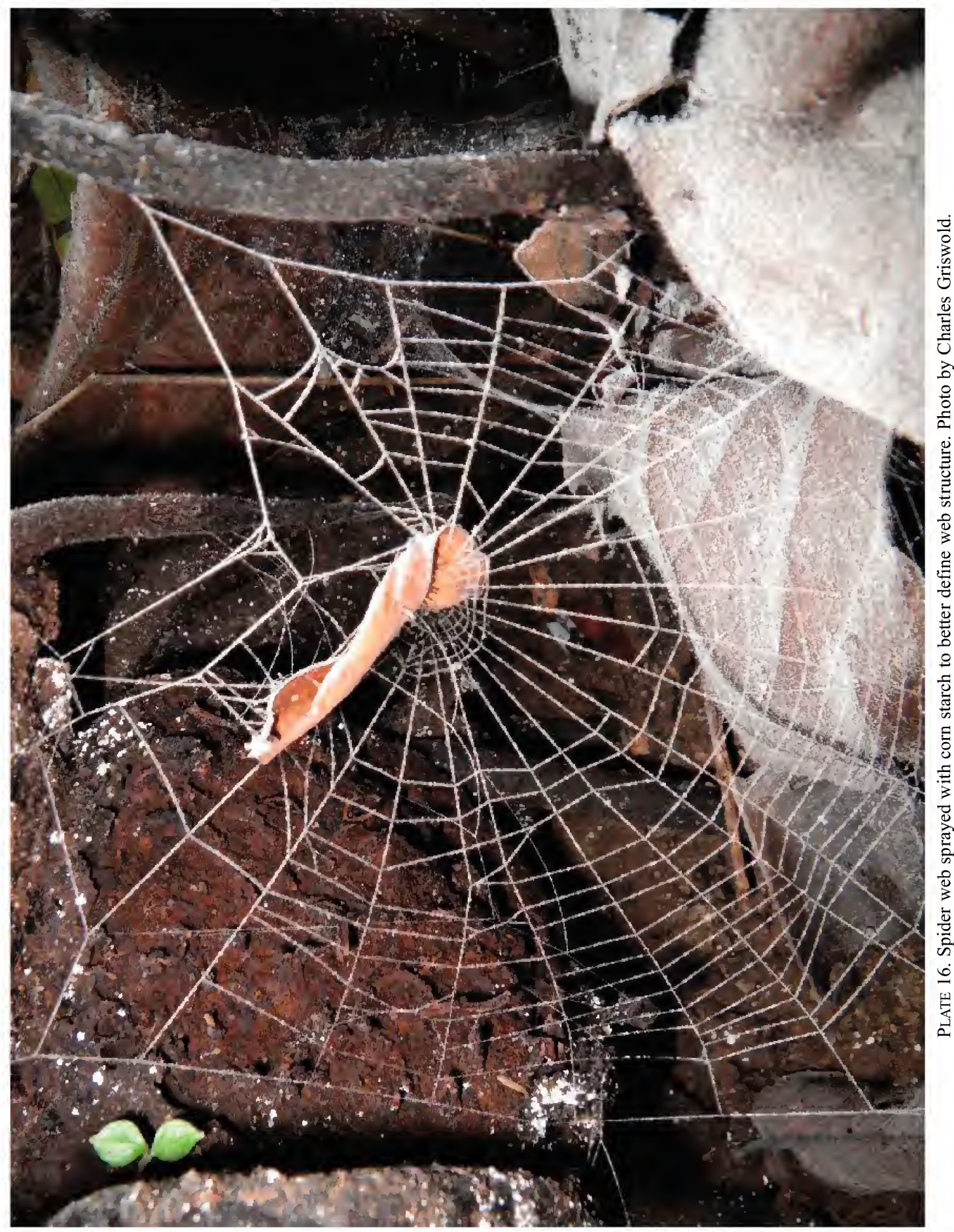




\title{
Redescription of the Flatbacked Millipede Ilodesmus margaritiferus (Gervais, 1836) (Diplopoda: Polydesmida: Platyrhacidae) from the Philippines
}

\author{
Facundo M. Labarque *, 1, Veverle D. A. San Juan 2-3, \\ Ireneo L. Lit, Jr. 2-3 and Charles E. Griswold 1, 4-6 \\ ${ }^{1}$ California Academy of Sciences, 55 Music Concourse Drive, San Francisco, CA 94118, USA; \\ 2 University of the Philippines Los Baños, College Los Baños, Laguna 4031, Philippines; \\ ${ }^{3}$ Museum of Natural History, University of the Philippines Los Baños, College Los Baños, \\ Laguna 4031, Philippines: ${ }^{4}$ Biology Department, San Francisco State University, \\ 1600 Holloway Ave, San Francisco, CA 94132, USA; ${ }^{5}$ Environmental Science, Policy \\ and Management, University of California, 101 Sproul Hall, Berkeley, CA 94704, USA; 6 Biology \\ Department, The George Washington University, 2121 I St NW, Washington, DC 20052, USA. \\ *Address correspondence to facundo.labarque@gmail.com
}

\begin{abstract}
Ilodesmus margaritiferus (Gervais, 1836) is redescribed based on several male and female specimens from Mount Makiling, Laguna Province, Luzon Island, Philippines. Detailed illustrations of the head, antennae, gnathochilarium, mandibles, various body rings, spiracles, legs, gonopods and eggs are provided. Platyrhacus philippinorum Chamberlin, 1921 and Polydesmus meyenti Brandt, 1839 are here considered junior synonyms of I. margaritiferus.
\end{abstract}

Keywords: alpha taxonomy; Indo-Malayan region; Platyrhacus philippinorum; Polydesmus meyenii.

Our knowledge on millipede morphology has increased rapidly through the use of scanning electron microscopy in the last decade (Akkari and Enghoff 2011; Golovatch 2003; Golovatch et al. 2008, 2009a-b, 2011; Mesibov 2003, 2005, 2008, 2009a-c, 2011, 2012; Rowe and Sierwald 2006). Even though identifications of millipede species are merely based on the morphology of the male copulatory organ, the gonopod, several recent works have documented morphological details in other structures such as: gonopores, fifth sternite lamella, spiracles, gnathochilarium and its palps, setae types, sensory cones (Rowe and Sierwald 2006), various tubercles processes, detail on the anal ring plates, spinnerets, limbus surface (Mesibov 2009a-b, 2012), sculpture of body rings and ozopores (Akkari and Enghoff 2011). The recent (2011) Filipino-American Hearst Biodiversity Expedition to the Philippines enabled the collection of numerous millipedes and other terrestrial arthropods, providing novel documentation of the remarkable species richness and endemism of Luzon. Among the specimens collected was new material of the flatbacked millipede Ilodesmus margaritiferus (Gervais, 1836), which enables us to redescribe the species and provide detailed illustrations of the head, antennae, gnathochilarium, mandibles, body rings, spiracles, legs, gonopods and eggs. These morphological features are described for the family Platyrhacidae for the first time.

\section{SYSTEMATICS}

The family Platyrhacidae Pocock, 1895 is a large and diverse group of millipedes with 32 genera and more than 250 species, distributed in the Neotropical region between Peru and Nicaragua, in the Indo-Malaysian region in the Philippine archipelago and in the Australasian region in the 
Papuan archipelago (Hoffman 1980, 1982, 2001). Members of the Platyrhacidae are distinguished by having wide discoid peritreme around their lateral ozopores, wide epiproct, setae tuft on the labrum and enlarged and elevated tracheal spiracles.

Male and female genitalia of Platyrhacidae follow the pattern of Polydesmida. The $1^{\text {st }}$ leg pair of the $7^{\text {th }}$ body ring of males is modified into the gonopods, and the $2^{\text {nd }}$ leg pair carries a simple gonopore ventrally on each coxa. Females carry a single genital opening ventrally between the sternite of the $2^{\text {nd }}$ body ring, which support the $2^{\text {nd }}$ leg pair, and the ring formed by the pleurites of the $3^{\text {rd }}$ body ring. The anterior ventral margin of this ring is called the epigyne. However, Platyrhacidae male gonopod are distinguished from other Polydesmida families by lacking additional processes on the coxae and prefemora, and by having in its terminal section, the acropodite, a slender solenomere and a large process, traditionally labeled tibiotarsus (see Hoffman 2011:405).

Gervais (1836) described Ilodesmus margaritiferus (Gervais, 1836) in the genus Polydesmus Latreille, 1803, based on a female specimen from Manila, Luzon Province, Philippines. Peters (1864:544, species 68) considered Polydesmus meyenii Brandt, 1839 and Platyrhacus fuscus Koch, 1987 (with question mark) as a junior synonyms of I. margaritiferus. Attems (1899) transferred I. margaritiferus to the genus Platyrhacus Koch, 1847 in the subgenus Platyrhacus, and redescribed P. fuscus in the subgenus Haplorhacus Attems 1914. Later, Attems (1938) synonymized Platyrhacus philippinorum Chamberlin, 1921 with I. margaritiferus based on at least a male specimen. He described the gonopod having the tibiotarsus pointed and toothed laterally ("[...] jagged knife blade"), and the solenomere with more than one curve ("[...] curved and hooked at the end") (Attems 1899, fig. 341; Attems 1838, fig. 249).

Wang (1951) made a key with illustrations to discriminate between Philippine species of Platyrhacus, including $P$. philippinorum and I. margaritiferus. He described the gonopod of P. philippinorum having the tibiotarsus pointed and toothed laterally, and the solenomere with more than one curve ("[...] acute tip of solenomerere curved") (Wang 1951, fig. 71), and P. margaritiferus, contrary to Attems (1938), having the tibiotarsus without tooth and the solenomere with one curve ("[...] lacks a secondary curvature") (Wang 1951, fig. 73). Wang (1951) never took formal action to elevate $P$. philippinorum to species level, despite the differences he found between P. philippinorum and I. margaritiferus. Since Wang (1951) never cited the work of Attems (1938), we assume that Wang may not have been aware of the synonymy proposed by Attems (1938). Furthermore, Wang (1951) revised several females and males of I. margaritiferus from the type locality and designated them as plesiotypes (i.e., topotypes), but he never had access to the material used by Gervais, Karsch and Attems. The evidence suggests that the species that Wang (1951) redescribed and illustrated as P. philippinorum is actually I. margaritiferus, and the one that he redescribed as I. margaritiferus is not conspecific, but instead represents a new or an already known species. The nomenclatural action and the taxonomic revision of the former species are beyond the scope of this contribution.

Jeekel (2007) transferred two species from Platyrhacus to Ilodesmus Cook, 1896 namely, Ilodesmus bakeri (Wang, 1951) and I. margaritiferus, in his Catalog of Indo-Australian Platyrhacidae (Jeekel, 2007). Ilodesmus meyenii (Brandt, 1839) remains the type species of the genus, even if it turns out to be a junior synonym. Peters (1864) synonymized I. margaritiferus and I. meyenii. Since Cook (1896) never cited the publication of Peters (1864), we assume that Cook may not have been aware of the synonymy proposed by Peters (1864). Jeekel (2007) considered P. philippinorum as a junior synonym of I. margaritiferus (following Attems 1938), and I. meyenii and I. margaritiferus as valid species, contrary to Peters (1864). In this contribution we examined P. philippinorum and $P$. meyenii male types, and confirm those species as junior synonyms of $I$. margaritiferus, as were considered by Attems (1938) and Peters (1894), respectively. 


\title{
Materials And Methods
}

The examined materials are deposited in the following institutions: Museum für Naturkunde, Universität Humboldt Berlin, Germany (ZMB, J. Dunlop); The Louis Agassiz Museum for Comparative Zoology, Massachusetts, USA (MCZ, G Giribet); California Academy of Sciences, California, USA (CAS, C. Griswold); Museum of Natural History, University of the Philippines Los Baños, Laguna, Philippines (UPLB, I. Lit, Jr.).

Morphological observations were made using a Leica MZ125 and a Motic SMZ-143 Series stereomicroscopes, all of them with a camera lucida. Pictures were taken with a Nikon DXM1200 digital camera mounted on a Leica DM4000 M compound microscope, and with a Leica DFC 500 digital camera mounted on a Leica M216 stereoscopic microscope. Extended focal range images were composed with Helicon Focus 4.70 Pro and 5.30 (Khmelik et al. 2006).

Scanning electron micrographs (SEM) were taken under high vacuum with a LEO 1450VP after paper drying and gold-platinum coating. Measurements were taken with a micrometric ocular and are given in millimeters. The gnathochilarium, head capsule, antennae, mandibles, gonopods and legs (feeding and walking) were dissected with fine-pointed forceps. Preparations were cleaned using a fine brush and a Bransonic 1510R MT ultrasonic cleaner for 10-20 minutes. Excess head tissues were digested overnight with a contact lens cleaner solution (ReNuß). Preparations were mounted on adhesive copper tape (Electron Microscopy Sciences, EMS 77802) affixed to a stub for SEM examination.

General terminology follows Attems (1899), Hoffman (1980) and Mesibov (2012), for mandibles, Seminyuk et al. (2011); see Hoffman (2001:406) for a discussion on the gonopod terminology and underlying homology assumptions. Abbreviations used throughout the text: Habitus: col, collum; epp, epiproct; hyp, hypoproct; pp, paraproct; tsn, telson. Head: cly, clypeus; to, tömösvary organ; vs, vertigial sulcus. Gnathochilarium and Mandible: pl: pectinate lamellae; et, external tooth; it, internal teeth; men, mentum; mp, molar plate; ll, lingual lobe; stp, stipites. Leg: cox, coxa; fem, femur; tar, tarsus; tib, tibia; por, postfemur; prf, prefemur. Gonopod: cnl, cannula; gcx, gonopodcoxa; pg, prostatic groove; sol, solenomere; tbtr, tibiotarsus; tub, tubercles. Epigyne: epi, epigyne; pro, prong; $2^{\text {nd }}$, second body ring, $3^{\text {rd }}$, third body ring; $4^{\text {th }}$, fourth body ring.

\section{RESULTS}

Taxonomy (taken in part from Hoffman 1980, 1998; Shelley 2003; Jeekel 2007; Shear 2011; Shelley and Martinez-Torres 2013)

\author{
Order Polydesmida Pocock, 1887 \\ Suborder Leptodesmidea Brölemann, 1916 \\ Superfamily Platyrhacoidea Pocock, 1895 \\ Family Platyrhacidae Pocock, 1895 \\ Tribe Erythrhacini Jeekel, 2007
}

Genus Ilodesmus Cook, 1896

\section{Ilodesmus margaritiferus (Gervais, 1836)}

Figures 1-8

Polydesmus margaritiferus Gervais, 1836:379. Female holotype from Philippines, Luzon Island, Manila, type specimen not examined.

Polydesmus margaritiferus:- Gervais, 1837:44 non vidi. 
Polydesmus margaritiferus:- Eydoux and Gervais, 1838: CL IX, page 3 plate 239, figs. 1-1d.

Polydesmus Meyenii Brandt, 1839:342. Male lectotype from Philippines, Luzon Island, Manila, deposited in ZMB (16), examined. [synonymized by Peters, 1864]

Polydesmus Meyenii:- Brandt, 1841:9.

Polydesmus margaritiferus:- Newport, 1844:266.

Polydesmus margaritifertus:- Gervais, 1847:102 non vidi.

Polydesmus Meyenii:- Gervais, 1847:102 non vidi.

Polydesmus (Stenonia) margaritiferus:- Peters, 1864:544.[Peters also synonymized Platyrhacus fuscus Koch under margaritiferus, with question mark]

Polydesmus (Stenonia) margaritiferus:- Humbert and DeSaussure, 1869:675 non vidi.

Polydesmus (Stenonia) meyenii:- Humbert and DeSaussure, 1869:675 non vidi.

Polydesmus (Platyrhachus) margaritiferus:- Karsch, 1881:27, plate 3, fig. 5.

Stenonia margaritifera:- Tömösvary, 1885:69.

Stenonia margaritifera:- Daday, 1889:138.

Platyrrhacus [sic!] naargaritiferus:- Attems, 1899:328, pl. 14, fig. 341. Males and females from Philippines, Luzon Island, Manila. [transferred from Polydesmus]

Ilodesnuls meyenii:- Cook, 1896:1. [overlooking the synonymy established by Peters, designated meyenii as the type species of Ilodesmus]

Platyrhacus margaritiferus:-Attems, 1914:251, 258 non vidi.

Platyrhacus philippinorum Chamberlin, 1921:85. Male holotype from Philippines, Luzon Island, Laguna Province, Mount Makiling, deposited in MCZ (4666), examined. [synonymized by Attems, 1938:224, with question mark]

Platyrhacus (Platyrhacus) margaritiferus:-Attems, 1938:204, 224, fig. 249.

Ilodesmus meyenii:-Attems, 1938:288.

Platyrhacus margaritiferus:- Wang, 1951:22, figs. 72-73.

Platyrhacus philippinorum:- Wang, 1951:21, figs. 70-71.

Platyrhacus margaritiferus:- Wang, 1953:3 non vidi.

Polydesmus meyenii:- Mortiz and Fischer,1978:122 non vidi. [overlooking the synonymy established by Peters]

Polydesmus meyenii:- Golovatch and Hoffman, 2000:237 non vidi. [overlooking the synonymy established by Peters]

Ilodesmus margaritiferus:- Jeekel, 2007:84 [lists Platyrhacus philippinorum as a synonym]

Ilodesmus meyenii:- Jeekel, 2007:84 [listed as a valid species, overlooking the synonymy established by Peters]

Note. - Whereas we have not examined the female type specimen of I. margaritiferus, and the male specimens described by Karsch (1881) and Attems (1899), we feel that species attribution is unproblematic. We have examined $P$. philippinorum and $P$. meyenii male types, considered junior synonyms of I. margaritiferus by Attems (1938) and Peters (1864), respectively, so we are confident that we understand their concept of I. margaritiferus Gervais, 1836.

TyPe Material. - Holotype (P. philippinorum): ô from Philippines, Luzon Island, Laguna Province, Mount Makiling, C.F. Baker col., deposited in MCZ (No. 4666). PARATYPE: $\widehat{\jmath}$, same data as holotype, deposited in MCZ (No. 4667). LeCtotyPe (P. meyenii): $\widehat{\jmath}$ from Philippines, Luzon Island, Manila, Meyen col., deposited in ZMB (16). Additional Material Examined: $\hat{\delta}$ and $2 q$, same locality as $P$. philippinorum holotype, Malaboo Camp, $3.46 \mathrm{~km} \mathrm{SSW}$ Los Baños, 673 m, 14.137, 121.205867, 10-12.May.2011, H. Wood, M. Yngente, N. Chousou Polydouri, C. Griswold, V. San Juan and V. Knutson cols., deposited in CAS (CASENT 9048616 [], CASENT 
9048615 [우, CASENT 9017860 [ठ]]); $3 \hat{0}$ and $q$, same locality as previous specimens, 6-8.May.2011, V. San Juan, M. Yngente, J. Vicarizas and S. De Guzman cols., deposited in UPLB (MYR 00134-00137).

Diagnosis.- Males of I. margaritiferus resembles those of $I$. bakeri by having the acropodite of gonopod with two branches (solenomere and tibiotarsus), solenomere extended anteriorly and curved postero-ventrally and tibiotarsus pointing dorsally with tubercles on posterior edge; but $I$. margaritiferus can be distinguished by the solenomere secondarily recurved dorsally (Figs. $7 \mathrm{~A}-\mathrm{D}$, $8 \mathrm{~A}-\mathrm{D}$ ) and by the tibiotarsus with four tubercles (Figs. 7 C-D, $8 \mathrm{~A}-\mathrm{D}$ ), while I. bakeri lack a second curvature in the solenomere and have five tubercles in the tibiotarsus (Wang, 1951, fig. 77).

REDESCRIPTION.- Color fresh specimen: Head, collum and dorsum brownish black (Figs. 1 A-B). Collum with four transverse rows of yellow tubercles (Fig. 1 B). Paranota yellow. Antennae pale orange, $6^{\text {th }}$ and last segments dark orange (Figs. $2 \mathrm{~A}-\mathrm{B}$ ). Coxa and prefemur pale yellow, rest of leg segments pale orange (Figs. 1 C-D). Prozonite brownish black dorsolaterally, dark orange ventrally (Figs.1 B-C, E). Metazonite brownish black with three transverse rows of yellow tubercles, posterior row conspicuous (Figs. 1 B-C, E). Sternite pale orange (Fig. 1 D). Telson brownish black with pale orange borders dorsally (Fig. $1 \mathrm{C}$ ), and pale orange ventrally (Fig. 1 D). Epiproct, paraproct and hypoproct dark orange (Fig. 1 D). Head and antennae: Head tuberculate, frons roughly at a 45 degree angle to the ground, covered by the collum with antennae and vertex visible dorsally (Figs. 1 A-B, E). Collum almond shaped (Figs. 1 A-B). Vertigial sulcus present, deepest at vertex, which extends from vertex to a point just above antennae (Figs. 1 A-B, 2 A), with a pair of lateral short seta. Antennal sockets oval (Fig. 2 A). Interantennal distance and socket diameter almost equal (Figs. 1 A, 2 A). Pair of Tömösvary organs behind antennal sockets, ovoid with longitudinal central ridge (Figs. $2 \mathrm{~A}, \mathrm{E}$ ). Border surface with several pores randomly distributed, internal surface smooth without pores (Figs. 2 F-G). Pores with single hole bordered by a suture (Fig. $2 \mathrm{G}$ ). Clypeus within a distinct trapezoid marked by four setae. Labrum with five supralabral and 15 to 17 sublabral setae tufts distributed transversally. Each setae tuft with eight to 14 setae (Figs. 2 H-I). Labrum with two teeth (Fig. 2 H). Labral pores alveolar with several holes, distributed irregularly (Fig. $2 \mathrm{~J}$ ). Antennal segment length formula: $7+8<1<2<3=4=5<6$ (Figs. 1 A, 2 B). Antennae with brush-tipped twisted setae (Figs. 2 C-D). Antennal surface with discrete cells (texture squamose) and several single pores, easily seen in the last segment. $6^{\text {th }}$ segment with disperse distal ventral filiform setae. Last segments $(7+8)$ with alveolar pores between the four sensory cones. Mandibles and Gnathochilarium: Mandibles with one external blunt tooth, and four internal blunt teeth forming a plate (Figs. 3 A-B). Pectinate lamellae with four rows of acute and long bristles (Fig. $3 \mathrm{C}$ ). Molar plate serrated forming the anterior fringe (Figs. 3 B, E). Membranous surfaces with spicules between pectinate lamellae and molar plate (Figs. 3 C-D). Gnathochilarium with several dorsal alveolar surfaces (Fig. 4 A). Alveolar patches formed by relatively big circular pits found on distal center of mentum, proximal inner sides of lingual lobes, and proximal inner and distal median sides of the stipites. Mentum heart-shaped, lingual lobes parallel thin plates, and stipites concave and distally wide plates (Fig. 4 A). Ventral surface of gnathochilarium with long filiform setae (Fig. 4 B). Anterior tips of palps with sensory cones (Figs. 4 C-D). Stipites and borders of lingual lobes with pair of spoon-like concavities transverse to midline axis (Fig. 4 A). Anterior tips of lingual lobes with peg in a semicircular depression (Figs. 4 E-F). Body rings (diplosegments): Surface sculpture of prozonite with spicules. Metazonite with three transverse tuberculate rows (Fig. 1 B), with 8-12 tubercles per row, posterior row conspicuous. Paranota extended posteriorly (Figs. 1 C, G), except for second and third segments which are produced anteriorly (Fig. $1 \mathrm{~B}$ ); with 5-9 marginal blunt tubercles and several anterior and posterior acute teeth (Figs. $5 \mathrm{~A}-\mathrm{C}$ ). Some metazonite tubercles have pores, especially marginal tubercles of paranota 
(Figs. 5 A-C). Ozopore formula as other Polydesmida: rings $5^{\text {th }}, 7^{\text {th }}, 9^{\text {th }}, 10^{\text {th }}, 12^{\text {th }}, 13^{\text {th }}, 15^{\text {th }}-19^{\text {th }}$. Ozopores simple, sub-circular, opening dorsally on paranota, posterior to transverse median line of metazonite (Figs. 6 A-B). Sternites as wide as long, with disperse brush-tipped twisted setae. Anterior tracheal spiracles opening anteriorly, and posterior tracheal spiracles opening posteriorly. Tracheal spiracles clavate, extending dorsally as long as the diameter of leg socket (Fig. 5 D). Spiracular filter coral-like (Figs. 5 D-E). Pre-anal ring: Epiproct well developed, wider than long, semicircular and flat; with seven marginal setae (Fig. 1 D), and four spinnerets. Paraprocts with two elongated and filiform setae each, which crosses median edge formed by paraprocts (Fig. $1 \mathrm{D}$ ). Dorsal edge of hypoproct truncated with two elongated filiform setae (Fig. 1 D). Legs: Legs covered with brush-tipped twisted setae, especially abundant on dorsal surface (Figs. 6 A, D, G-H). First and second leg prefemora with strong and filiform setae, which are as long as width of segments (Figs. 6 A, D). Length of first leg coxa and of prefemur to tarsus, $3 / 4$ times longer than other legs (Fig. $6 \mathrm{~A}$ ). Surface of first leg coxacoarse with dispersed small peaks (Fig. 6 C). Ventral surfaces of first and second coxae, pre-, femora and postfemora covered with long filiform and brushtipped twisted setae; tibiae to tarsi with short filiform setae (Figs. 6 A, D). Tarsal setae short (Figs. $6 \mathrm{~A}, \mathrm{D}, \mathrm{G}-\mathrm{H}$ ). Coxa of second leg bears a single smooth gonopore (Figs. 6 D-F). Legs of succeeding segments covered with short, brush-tipped twisted setae (Figs. $6 \mathrm{G}-\mathrm{H}$ ). Prefemur with single long proximal filiform setae (Fig. $6 \mathrm{G}$ ). Gonopod: Gonocoxae massive, twice as long as wide, slightly joined along their median edges, outside of $7^{\text {th }}$ segment trapezoidal aperture and with elongated brush-tipped twisted setae anteriorly and laterally (Figs. 7 A-D, 8 A-D). Prefemur with dense filiform, strong setae anteriorly, and with thin setae close to cannula (Figs. 7 B, D, 8 B, D). Telopodite pivoting on gonocoxae, twisted clockwise; with two branches (Figs. 7 A-D, 8 A-D). Solenomere extended anteriorly and curved posterioventrally, recurving dorsally; distally acute; tip pointing mesodorsally (Figs. 7 A, C, 8 A, C; "A" process in Hoffman, 2001). Tibiotarsus base wide, distally acute, pointing dorsally, with four bumps on posterior edge (Figs. $7 \mathrm{C}-\mathrm{D}, 8 \mathrm{C}-\mathrm{D}$; " $\mathrm{D}$ " process in Hoffman, 2001). Epigyne: Epigyne rectangular, with a sculptured edge, not rising above the ventral surface of ring 3 (Fig. 9 A). The center of the epygine extends ventrally on a roundedtriangular prong (Fig. 9 A).

REMARKs.- Eggs spherical, surface finely wrinkled (Figs. 9 B).

VARIATION. - Males $(n=4)$, Females $(n=3)$ : Body length/width between 6.5-7.3. Labium with two or three teeth.

Distribution.- - PhilipPines: Luzon Island: Mount Makiling, Los Baños (Laguna Province), and Manila. Wang (1951) described several males and females of I. margaritiferus from Mindanao Island, Philippines. However, as was mentioned in the Systematics section, what Wang (1951) redescribed and illustrated as $P$. philippinorum instead has the diagnostic characters of $I$. margaritiferus, i.e., a solenomere extended anteriorly, curved postero-ventrally and recurved dorsally, and a tibiotarsus pointing dorsally with four bumps on the posterior edge (toothed) (Wang 1951, fig. 71). In contrast, what Wang re-described as P. margaritiferus has a solenomere with a single curve (not secondary curvature), and the tibiotarsus lacks teeth (Wang 1951, fig. 73). Thus, Wang's P. margaritiferus specimens should not be considered in the distribution of $I$. margaritiferus. SuMATRA: Karsch (1881) described the gonopod from a male from Sumatra, which we did not examine. As Jeekel (2007) suggested, it seems doubtful that the specimen is a I. margaritiferus.

\section{ACKNOWLEDGMENTS}

This research was facilitated by a generous gift to the CAS from Will and Margaret Hearst supporting the 2011 Filipino-American Hearst Biodiversity expedition to Luzon. We thank the other 
members of the Entomology Section, Terrestrial Team, from this expedition: Natalia Chousou Polydouri, Orlando "Daddyboy" Eusebio, Vanessa Knutson, Matt Lewin, Hannah Wood, Sheryl "Sheng" Yap, and Mark Yngente. We thank Jason Dunlop, Gonzalo Giribet, Laura Leibensperger, Mary Sears, Hans Reip, Dave General, Zoltan Korsos and Petra Sierwald for type specimen loans, and for recommending and sharing literature; and to Scott Serata for helping on the SEM. We also thank the Lakeside Foundation for a travel and study grant to VSJ. FML wishes to thank a Postdoctoral Fellowship from the Schlinger Chair of Arachnology at CAS. Additional support came from the Harriet Exline-Frizzell Fund of CAS and from the Schlinger Foundation.

\section{REFERENCES}

AKKARI, N., AND H. ENGHOFF. 2011. On some surface structures of potential taxonomic importance in families of the suborders Polydesmidea and Dalodesmidea (Polydesmida, Diplopoda). In R. Mesibov and M. Short, eds., Proceedings of the 15th International Congress of Myriapodology, 18-22 July 2011, Brisbane, Australia. ZooKeys (156):1-24. (doi.103897/zookeys. 156.2134)

Aтtems, C. 1899. System der Polydesmiden. II. Theil. Denkschriftender kaiserlichen Akademie der Wissenschaften in Wien, mathematisch-naturwissenschaftliche Classe 68:251-436, pls. 12-17.

Aтtems, C. 1914. Die indo-australischen Myriapoden. Archiv für Naturgeschicthe 80A (4):1-398, plates 1-7. Atтемs, C. 1938. Polydesmoidea II. Fam. Leptodesmidac, Platyrhachidae, Oxydesmidae, Gomphodesmidae. Das Tierreich 69:i-xxviii, 1-487.

BRANDT, J. F. 1839. Note relative à la classification des espèces qui composent le genre Polydesmus, et suivi d'une caractéristique de dix espèces nouvelles, ainsi que de quelques remarques sur la distribution géographique des espèces em général. Bulletin Scientifique Académie des Sciences de Saint Petersbourg 5 (20):307-315.

BRANDT, J. F. 1841. Note supplémentaire sur les espèces qui composent le genre Polydesmus, suivie dúne caractéristique de deux espèces nouvelles. Bulletin Scientifique Académie des Sciences de Saint Petersbourg $9(1): 9-11$.

Chamberlin, R. V. 1921. New Chilopoda and Diplopoda from the East Indian region. Annals and Magazine of Natural History (9) 7:50-87.

DAdAy, E. 1889. Myriapoda extranea Musaei Nationalis Hungarici. Termeszetr. Füz. 12:115-165, plates 4-5.

Eydoux, F., AND P. Gervais. 1838. Myriapodes du Voyage de la Favorite. Magasin de Zoologie 8: Cj. IX, 1-4, plates 239-240.

Gervais, P. 1836. Note sur le genre Polydesmus de la classe des Myriapodes. Annales de la Societe Entomologique cle France 5:373-381.

GervaIS, P. 1837. Études pour servir à l'histoire naturelle des Myriapodes. Annales des Sciences Naturelles (2) 7:35-60, plate 4.

GervaIs, P. 1847. Myriapodes, in: Walckenaer and Gervais, Histoire naturelle des Insectes, Aptères, 4:1-133. Atlas: plates $37,39-45$.

Golovatch, S. I. 2003.A review of the volvatory Polydesmida, with special reference to the patterns of volvation (Diplopoda). African Invertebrates 44 (1):39-60.

Golovatch, S. I., J.-J. Geoffroy, J.-P. Mauriès, and D. Van Den Spiegel. 2008. The first new species of the millipede family Pyrgodesmidae to be recorded in Vanuatu, Melanesia, southwestern Pacific (Diplopoda: Polydesmida). Arthropoda Selecta 17 (3-4):145-151.

Golovatch, S. I., J.-J. Geoffroy, J.-P. Mauriés, and D. Van Den Spiegel. 2009a. Review of the millipede family Haplodesmidae Cook, 1895, with descriptions of some new or poorly known species (Diplopoda, Polydesmida). ZooKeys (7):1-53. (doi: 10.3897/zookeys.7.117)

Golovatch, S. I., J.-J. Geoffroy, J.-P. Mauriés, and D. Van Den Spiegel. 2009b. Review of the millipede genus Eutrichodesmus Silvestri, 1910 (Diplopoda, Polydesmida, Haplodesmidae), with descriptions of new species. ZooKeys (12):1-46. (doi: 10.3897/zookeys.12.167).

Golovatch, S.I., AND R.L. Hoffman. 2000. On the diplopod taxa and type material of J. F. Brandt, with some 
new descriptions and identities (Diplopoda). Fragmenta faunistica Supplement 43:229-249. (ISBN: 83-85192-96-4).

Golovatch, S. I., I.I. Semenyuk, D. Van Den Spiegel, and A. E. Ainchkin. 2011. Three new species of the millipede family Pyrgodesmidae from Nam Cat Tien National Park, Southern Vietnam (Diplopoda: Polydesmida). Arthropoda Selecta 20(1):1-9.

Hoffman, R. L. 1980. Classification of the Diplopoda. Museum of Geneve. 237 pp.

Hoffman, R. L. 1982. Diplopoda. Pages 689-724 in S.B. Parker, ed., Synopsis and Classification of Living Organisms, vol. 2. McGraw-Hill., New York, New York, USA.

Hoffman, R. L. 1998. A Reassessment of the Platyrhacidae, a family of polydesmidan millipeds. Myriapodologica 5:125-141.

Hoffman, R. L. 2001. A synopsis of the platyrhacid millipeds of Borneo (Diplopoda: Polydesmida: Platyrhacidae). Revue Suisse de Zoologie 108:403-440.

Humbert, A., AND H. De Desaussure. 1869. Description de divers Myriapodes du Musée de Vienne. Verhandlungen der K.-K Zoologisch-Botanischen Gesellschaftin Wien 19:669-692.

JeEKEL, C. A. W. 2007. An annotated bibliographical catalogue of the Indo-Australian Platyrhacidae (Diplopoda, Polydesmida). Myriapod Memoranda 10:49-101.

Karsch, F. 1881. Zum Studium der Myriapoda Polydesmia. Archiv Für Naturgeschicthe 47 (1):36-49, pl. 3.

Khmelik, V. V., D. Kozub, and A. Glazunov. 2006. Helicon Focus version 4.70 Pro http://helicon.com.ua/ heliconfocus/

Mesibov, R. 2012. External Anatomy of Polydesmida. http://www.polydesmida.info/polydesmida/ Last accessed 23.V.2013.

MEsiBov, R. 2003. Two new and unusual genera of millipedes (Diplopoda: Polydesmida) from Tasmania, Australia. Zootaxa 368:1-32.

Mesibov, R. 2005. A new genus of millipede (Diplopoda: Polydesmida: Dalodesmidae) from Tasmania with a pseudo-articulated gonopod telopoditc. Zootaxa 1064:39-49.

Mesibov, R. 2008. The millipede genera Gephyrodesmus Jeekel, 1983 and Orthorhachis Jeekel, 1985 in southeastern Australia, a new Lissodesmus Chamberlin, 1920 from Victoria, and observations on male leg setae, spinnerets and metatergite sculpture (Diplopoda: Polydesmida: Dalodesmidae). Zootaxa 1790:1-52.

Mesibov, R. 2009a. New and little-used morphological characters in Polydesmida (Diplopoda). Soil Organisms 81(3):531-542.

Mesibov, R. 2009b. Revision of Agathodesmus Silvestri, 1910 (Diplopoda, Polydesmida, Haplodesmidae). ZooKeys (12):87-110. (doi: 10.3897/zookeys. 12.206).

Mesibov, R. 2009c. A new millipede genus and a new species of Asphalidesmus Silvestri, 1910 (Diplopoda, Polydesmida, Dalodesmidea) from southern Tasmania, Australia. ZooKeys (7):55-74.

Mesibov, R. 2011. New species of Asphalidesmus Silvestri, 1910 from Australia (Diplopoda, Polydesmida, Dalodesmidea). ZooKeys (93):43-65. (doi: 10.3897/zookeys.93.1255).

Mesibov, R. 2012. The first native Pyrgodesmidae (Diplopoda, Polydesmida) from Australia. ZooKeys (217):63-85. (doi: 10.3897/zookeys.217.3809).

MoritZ, M., AND S. C. Fischer. 1978. Die Typen der Myriapoden-Sammlung des Zoologischen Museums Berlin. I. Diplopoda. Teil 4: Polydesmida (Paradoxosomatidea, Sphaeriodesmidea, Polydesmidea). Teil 5: Ergänzugen (Teile 1 bis 3). Mitteilungen aus dem Zoologischen Museum in Berlin 54;99-160.

Newrort, G. 1844. A list of the species of Myriapoda, Order Chilognatha, contained in the cabinets of the British Museum, with descriptions of a new genus and thirty-two new species. Annals and Magazine of Natural History 13:263-270.

Peters, W. 1864. Übersicht der im Königl. zoologischen Museum befindlichen Myriopodenaus der Familie der Polydesmi, so wie Beschreibungen einer neuen Gattung, Trachyjulus, der Juli und neuer Arten der Gattung Siphonophora. Monatsberichte der Königlichen Preussische Akademie des Wissenschaften zu Berlin, 529-551.

Rowe, M., ANd P. Sierwald. 2006. Morphological and systematic study of the tribe Australiosomatini (Diplopoda: Polydesmida: Paradoxosomatidea: Paradoxosomatidae) and a revision of the genus Aus- 
traliosoma Brölemann. Invertebrate Systematics 20:527-556.

Seminyuk, I. I., A. V. Tuinov, and S. I. Golovatch. 2011. Structure of mandibles in relation to trophic niche differentiation in a tropical millipede community. International Journal of Myriapodology 6:37-49.(doi: 10.3897/ijm.6.2214).

SheAR, W. A. 2011. Class Diplopoda de Blainville in Gervais, 1844. Pages 159-164 in Z.-Q. Zhang, ed., Animal biodiversity: An outline of higher-level classification and survey of taxonomic richness. Zootaxa 3148:1-237.

SHELLEY, R. M. 2003. A revised, annotated, family-level classification of the Diplopoda. Arthropoda Selecta 11 (3): 187-207.

Shelley, R. M., And D. Martinez-Torres. 2013. The millipede family Platyrhacidae (Polydesmida: Leptodesmidea) in the West Indies: Proposal of Hoffmanorhacus n. gen.; description and illustrations of males of Proaspisaitia Loomis, 1941; redescription of Nannorrhacus luciae (Pocock, 1894); hypotheses on origins and affinities; and an updated New World familial distribution. Zootaxa 3626 (4):477-498.

TÖMÖSVARY, Ö. 1885. Myriapoda a Joanne Xantus is Asia Orientali collecta. Termeszetr. Füz. 9:63-72, plates 3-5.

Wang, Y. H. M. 1951. The Myriapoda of the Philippine Islands. Ph.D. Dissertation, University of Utah. 80 pp.

WANG, Y. H. M. 1953. Supplement to the Myriapoda of the Philippine Islands. Entomological News 64:1-4. 

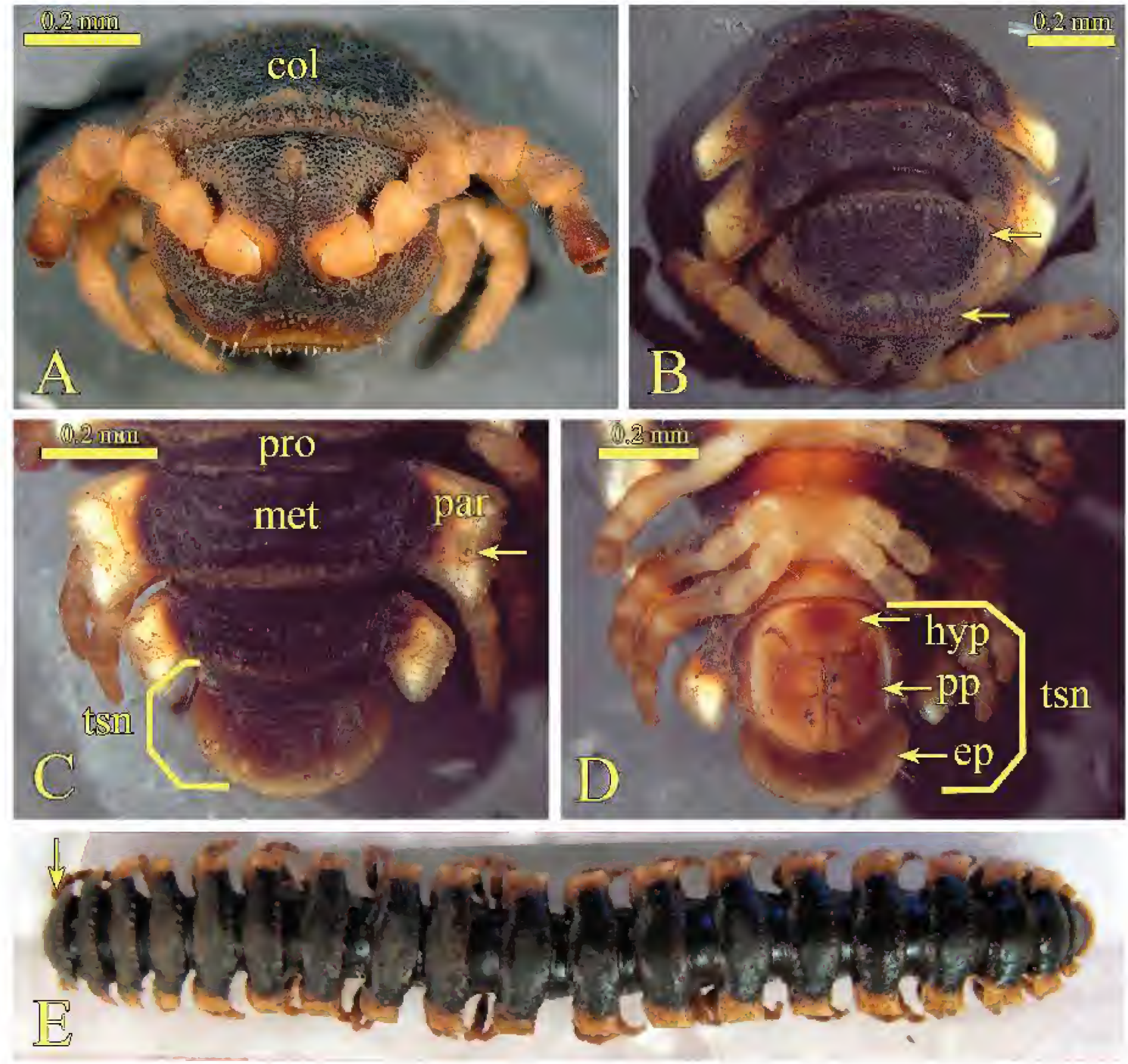

FIGURE 1. Ilodesmus margaritiferus (Gervais), preserved specimens (A, C, F ( $ત$, CASENT9017860); B, D, E (q, UPLB: MYR-00135); G ( $\hat{O}$, UPLB: MYR-00137)). A-B. Head and collum (A anterior, B dorsal - arrow to tubercles); C-D. Cauda (C dorsal - arrow to ozopore and paranota protruded posteriorly, D ventral); E. Habitus - arrow to head. Abbreviations: col, collum; ep, epiproct; pro, prozonite; met, metazonite; par, paranota; tsn, telson; hyp, hypoproct; pp, paraproct. 

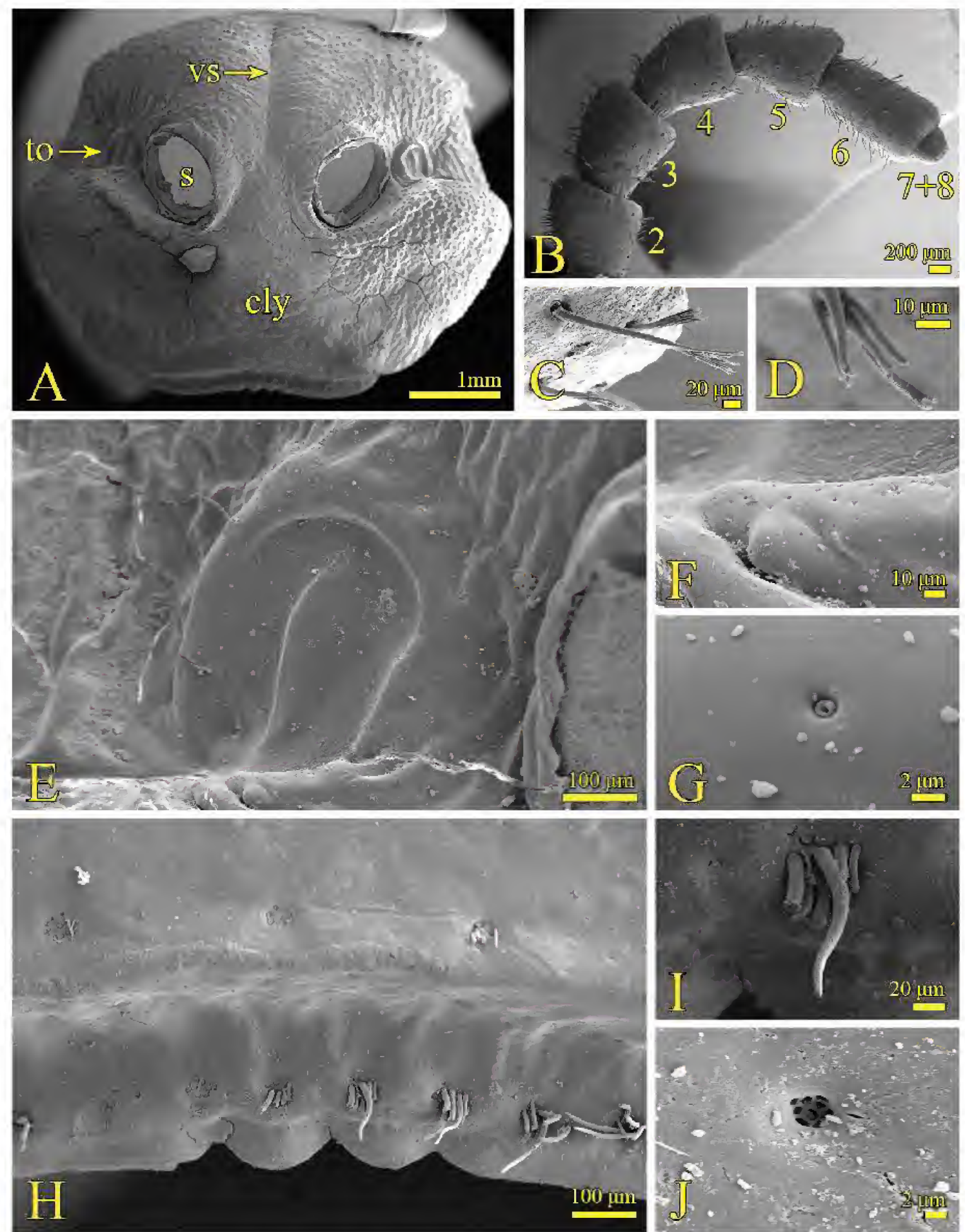

FIGURE 2. Ilodesmus margaritiferus (Gervais), head and antennae (A, E-J ( + , CASENT 9048615); B-D ( ${ }^{\lambda}$, CASENT 9017860)). A. Cephalic plate; B-D. Antennae (B right, C branched setae, D branch detail); E-G. Tömösvary organ (E right, F border detail, G single pore); H-J. Labrum, (H anterior, I setae tuft detail, J alveolar pore). Abbreviations: vs, vertigial sulcus; to, tömösvary organ; s, antennal socket; cly, clypeus. 

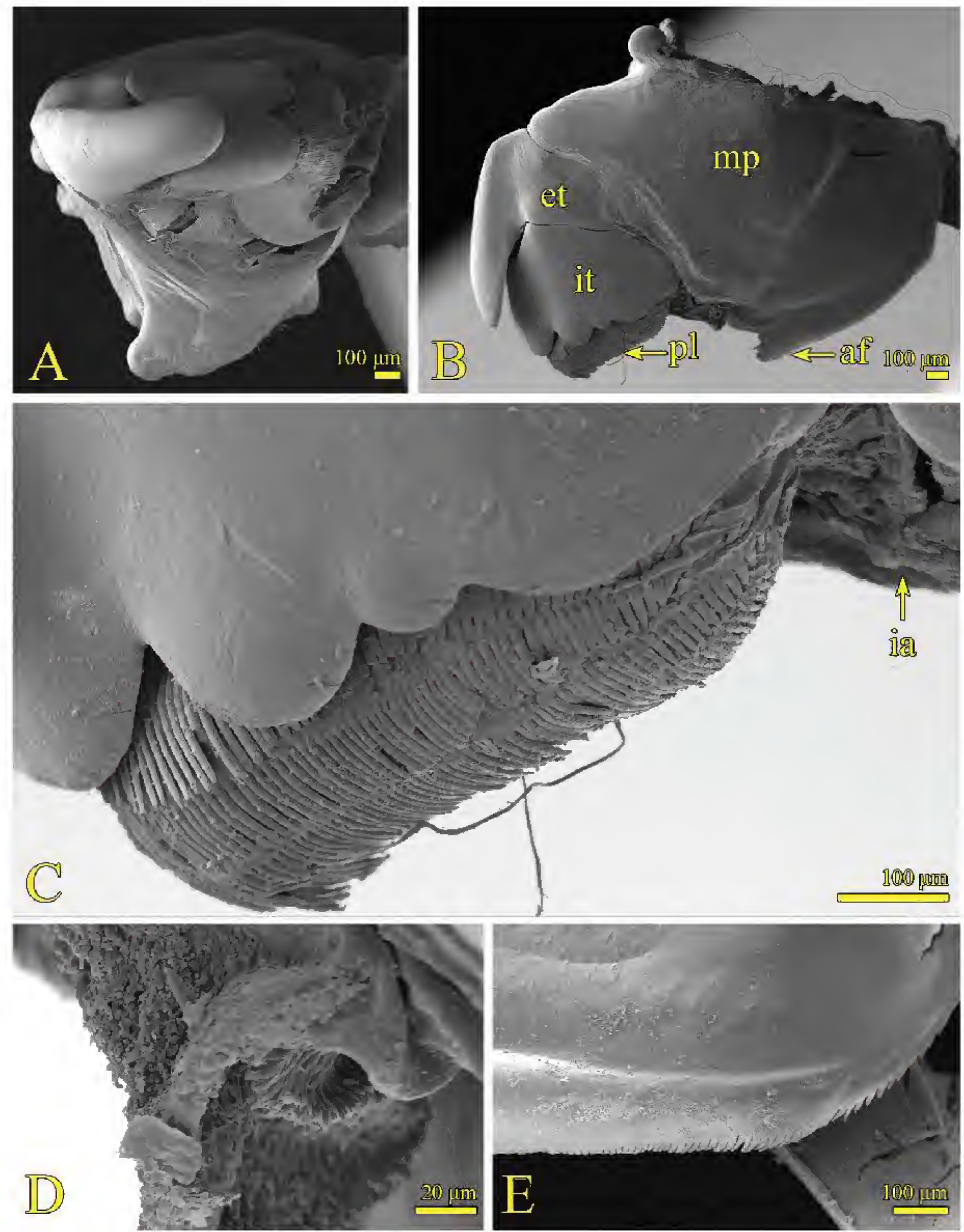

FIGURE 3. Ilodesmus margaritiferus(Gervais), mandible (ㅇ, CASENT 9048615). A-B. Right mandible (A anterior, B dorsal); C. Pectinate lamellae, internal teeth details and intermediate area; D. Intermediate area detail; E. Anterior fringe of molar plate. Abbreviations: et, external tooth; it, internal teeth; pl: pectinate lamellae; mp, molar plate; af, anterior fringe; ia, intermediate area. 

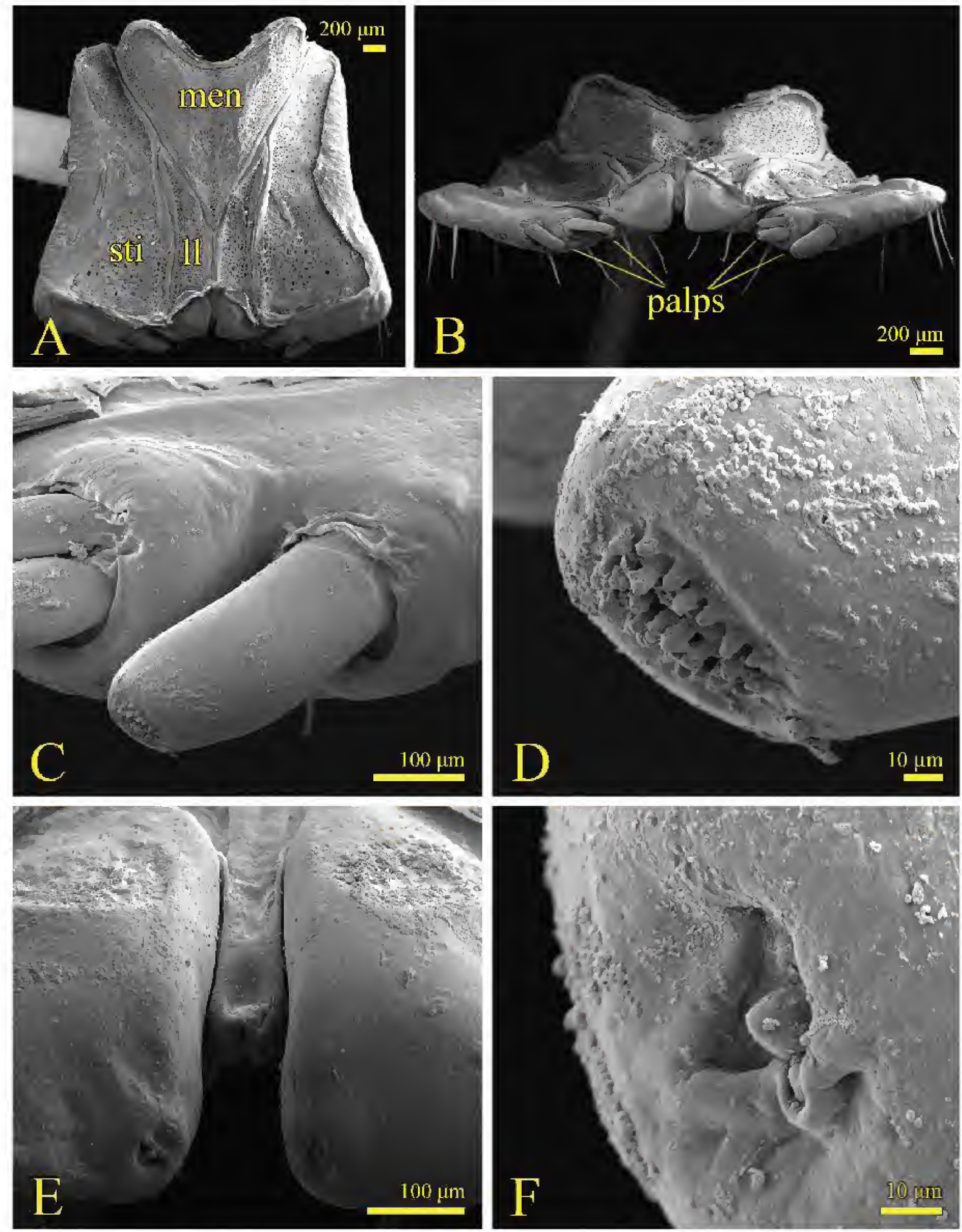

FIGURE 4. Ilodesmus margaritiferus (Gervais), gnathochilarium (ㅇ, CASENT 9048615). A-B. Gnathochilarium (A dorsal, B anterior); C-D. Left stipites palps (C external palp, D palp tip detail); E-F. Lingual lobe (E anterior, F left peg). Abbreviations: men, mentum; stp, stipites; 11, lingual lobe. 

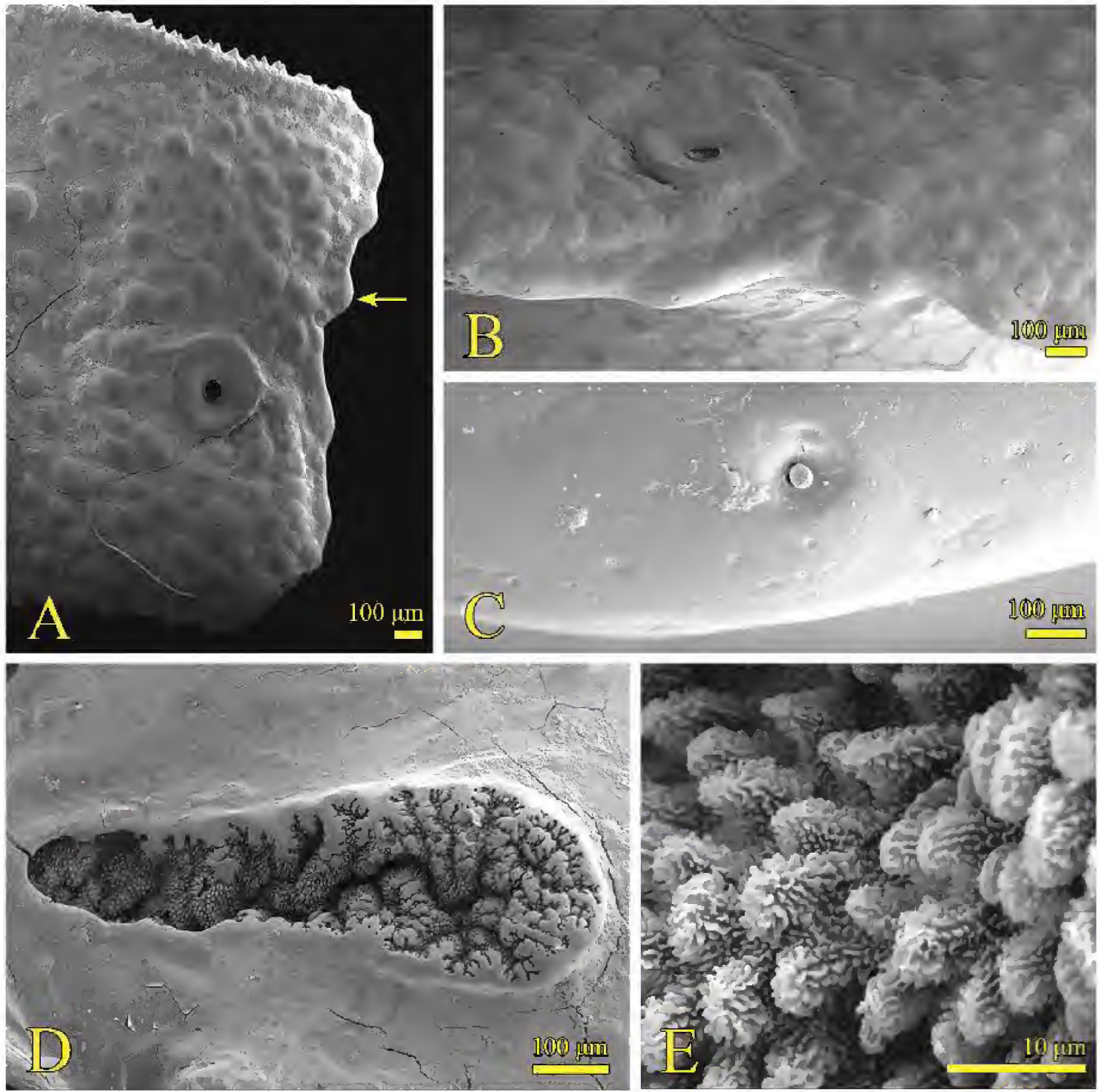

FIGURE 5. Ilodesmus margaritiferus (Gervais), paranota, ozopore and spiracle ( $\sigma^{\lambda}$, CASENT 9017860). A-C. Right paranota, $12^{\text {th }}$ segment (A dorsal - arrow to lateral tubercle, B lateral margin, C single pore); D-E. Left posterior spiracle (D lateral, E coral-like spiracular filter). 

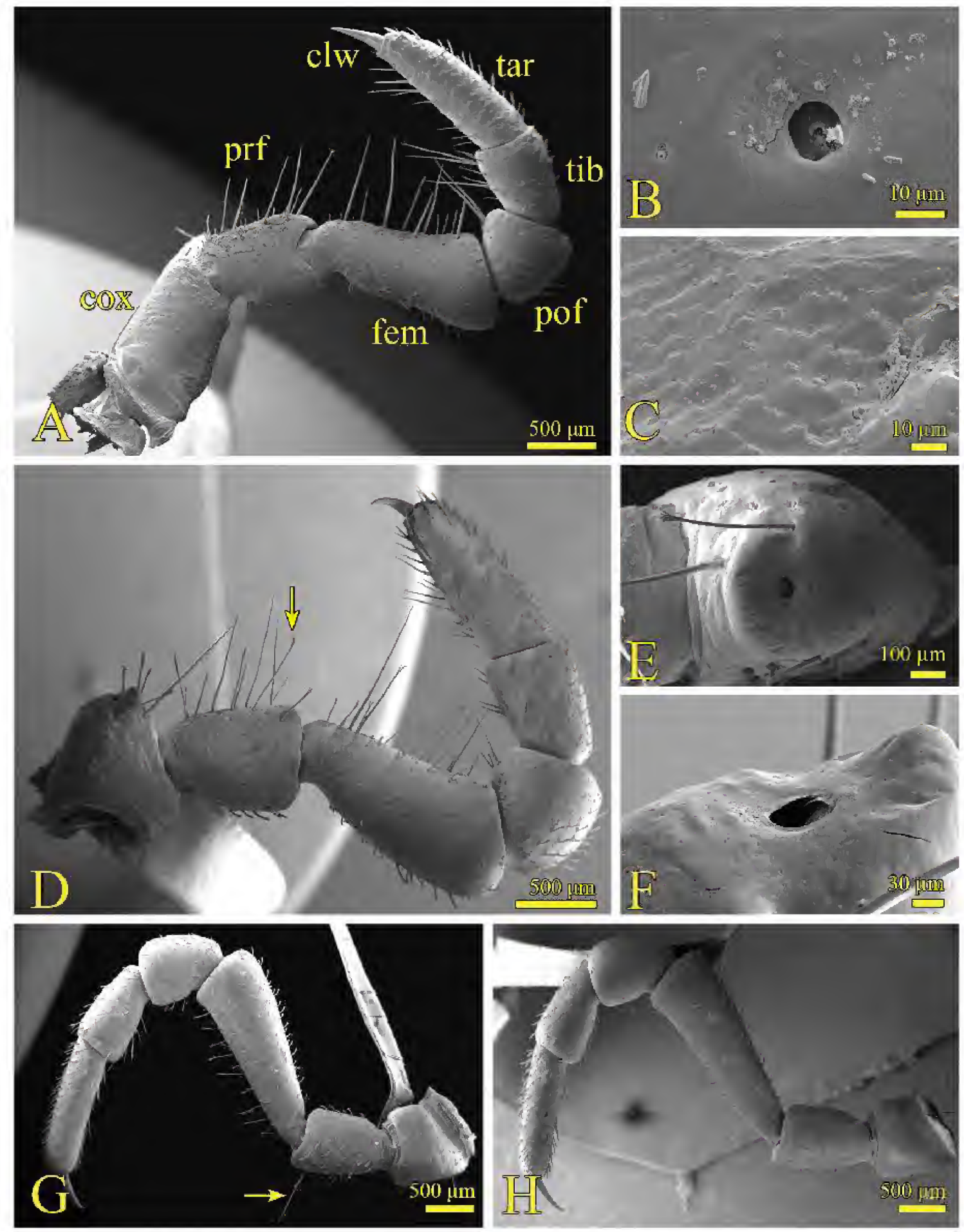

FIGURE 6. Ilodesmus margaritiferus (Gervais), male legs (O̊, CASENT 9017860). A-C. First left leg (A caudal view, B setal socket, C coxal surface detail); D-F. Second left leg (D caudal view-arrow to brush-tipped twisted setae patch -, E-F gonopore details); G-H. Legs of the $12^{\text {th }}$ ring, anterior view (G anterior left leg-arrow to filiform seta -, H posterior left leg). Abbreviations: cox, coxa; prf, prefemur; fem, femur; pof, postfemur; tib, tibia; tar, tarsus; clw, claw. Scale bars: $100 \mu \mathrm{m}$, unless stated otherwise. 


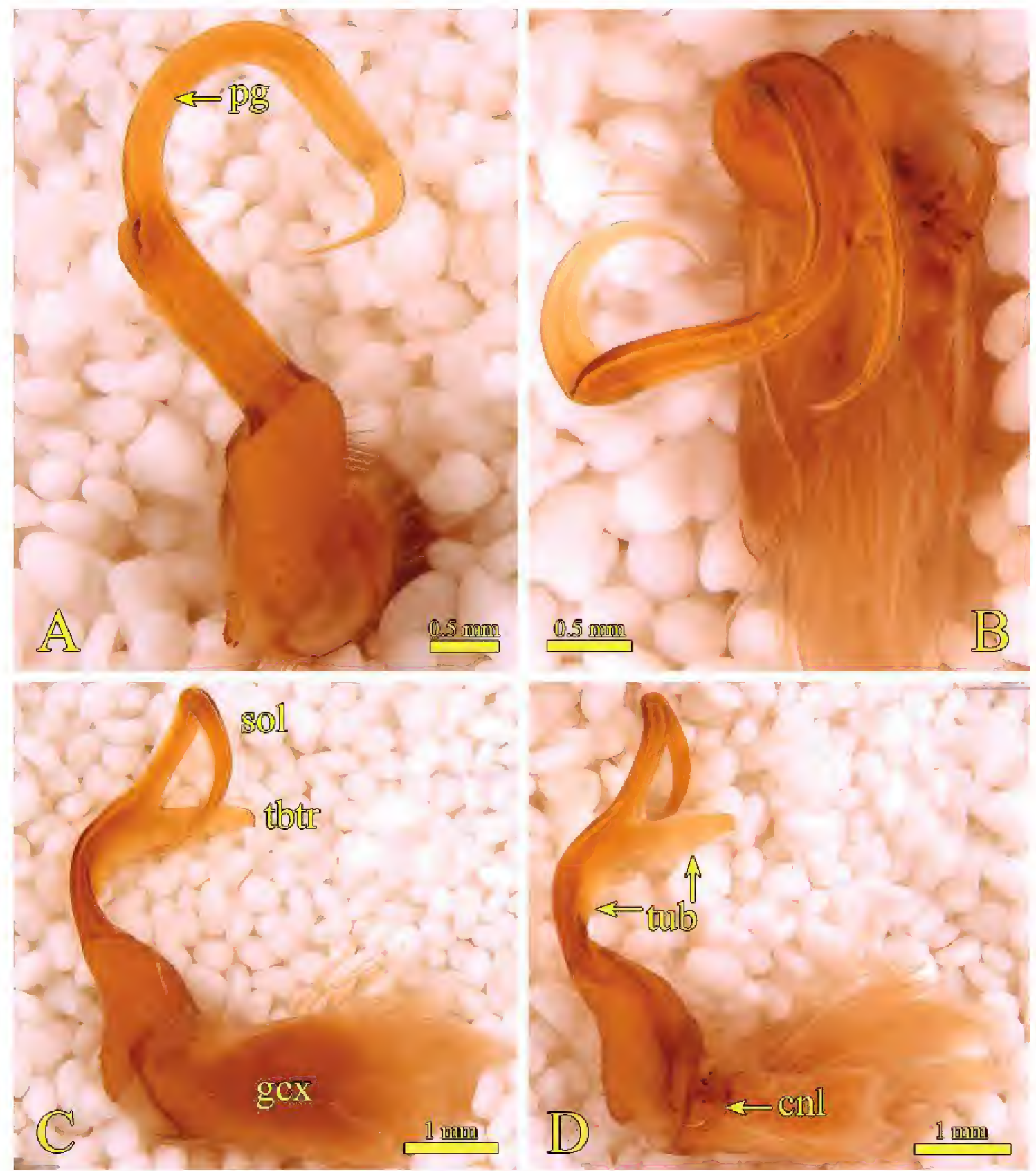

FIGURE 7. Ilodesmus margaritiferus (Gervais), gonopod ( $\delta$ holotype, Platyrhacus philippinorum, MCZ-4666). A-D. Left gonopod (A ventral, B apical, C lateral exterior view - arrow to posterior jagged edge, D lateral internal view). Abbreviations: cnl, cannula; gex, gonopodcoxa; pg, prostatic groove; sol, solenomere; tbtr, tibiotarsus; tub, tubercles. 

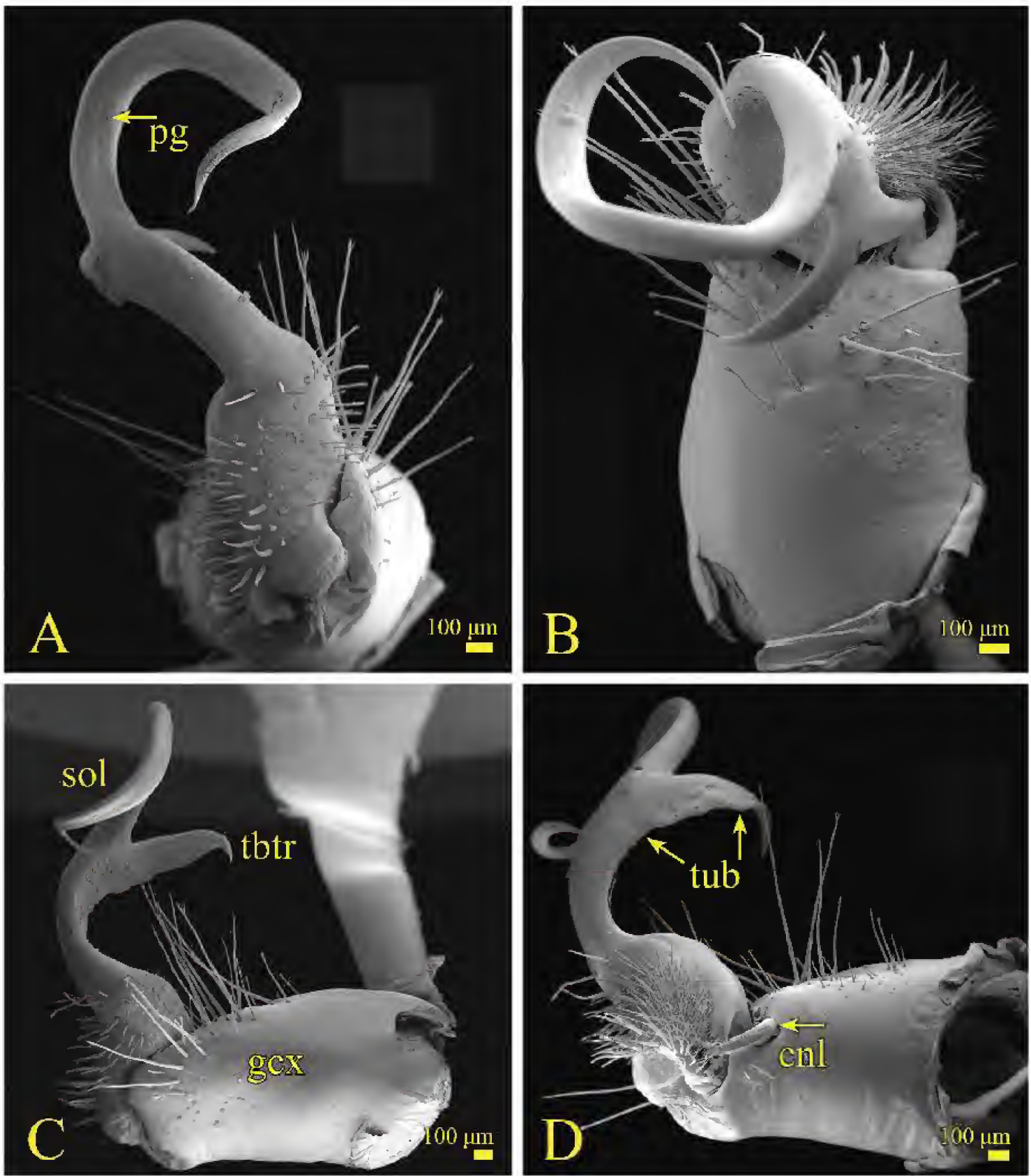

FIGURE 8. Ilodesmus margaritiferus (Gervais), gonopod (ð, CASENT 9017860). A-D. Left gonopod (A ventral, B apical, C lateral exterior view - arrow to posterior jagged edge, D lateral internal view). Abbreviations: cnl, cannula; gcx, gonopodcoxa; pg, prostatic groove; sol, solenomere; tbtr, tibiotarsus; tub, tubercles. 

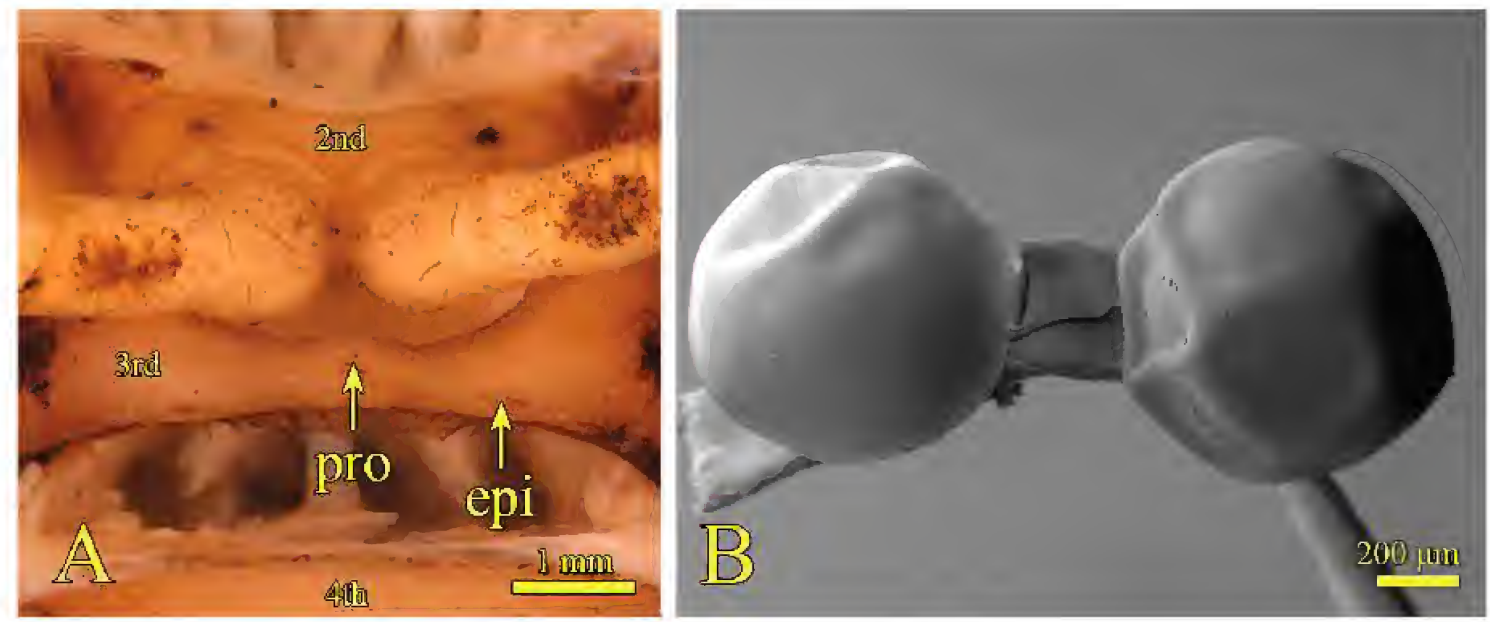

FIGURE 9. Ilodesmus margaritiferus (Gervais), epigyne ( + , CASENT 9048616) and eggs ( 9 , CASENT 9048615). A. Epigyne, ventral view. B. Eggs. Abbreviations: epi, epigyne; pro, prong; $2^{\text {nd }}$, second body ring, $3^{\text {rd }}$, third body ring; $4^{\text {th }}$, fourth body ring. 


\title{
An Annotated and Illustrated List of Carabid Beetles (Insecta: Coleoptera: Carabidae) from the California Academy of Sciences' 2011 Hearst Philippine Biodiversity Expedition
}

\author{
David H. Kavanaugh', Victor G. Smith, and Michael Krasnobrod \\ Department of Entomology, California Academy of Sciences, 55 Music Concourse Drive, \\ San Francisco 94118; 1Email: dkavanaugh@calacademy.org
}

\begin{abstract}
We present a list of carabid species represented in material collected by the international team of arthropod specialists in May-June, 2011 as part of the California Academy of Sciences' 2011 Hearst Philippine Expedition. A total of 234 specimens, representing 68 different morphologically distinct species (morphospecies), were studied and identified to the lowest taxonomic rank possible. Because the fauna of the Philippines is so diverse and remains so poorly known, many of these are identified only to genus and one only questionably to tribe. Digital images of dorsal habitus and collection data are also provided for each species to encourage study of this wonderful fauna.

KeY words: Coleoptera, Carabidae, Philippine Islands, biodiversity
\end{abstract}

The terrestrial component of the 2011 Hearst Philippine Expedition (see Williams, pp. 54-56, 62-65, this volume for details) included an experienced team of California Academy of Sciences (CAS) and Philippine arthropod specialists. Over a period of six weeks in May and June, 2011, this team sampled arthropod diversity in three areas in the southern part of Luzon Island (Fig. 1): (1) Mt. Makiling and adjacent lowland areas near Los Baños in Laguna Province; (2) the northeast base and slope of Mt. Banahaw de Lucban in Quezon Province; and (3) the northwest slope of Mt. Isarog in Camarines Sur Province. Collecting methods employed included hand collecting by day and at night with the aid of headlamps, attraction to both mercury vapor and ultraviolet lights at night, sifting of ground litter with subsequent sorting by hand or mass extraction using mini-Winkler traps, as well as pitfall traps, yellow pan traps, and Malaise traps. Although no specialists in beetle systematics participated in the expedition, the team collected more than 200 specimens representing the beetle family Carabidae using these diverse methods. Because study of this family is the principal research focus of the lead author [DHK], specimens from the Expedition were prepared for study and subsequent identification.

An attempt was made to identify all of the carabid specimens as far as possible, hopefully to the species level, but this proved to be quite difficult because the carabid fauna of the Oriental Region, and of the Philippines in particular, remains so poorly known. The last catalog of carabids of the Philippines was by Andrewes (1926), in which he recorded only 155 species and "varieties" for the entire archipelago, whereas the expedition team recorded slightly less than half of that number from just part of the southern end of Luzon Island in just six weeks. The carabid faunas of Japan to the north and New Guinea to the south are much better known, thanks largely to the extensive works by Akinobu Habu and by Philip J. Darlington, Jr. and Martin Baehr for these areas, respectively. However, the entire island region between these extremes has been very poorly sampled. Wiesner (1980) reviewed the tiger beetles (Cicindelini) of the Philippines, and a few other workers have dealt with certain genera or species groups represented in the archipelago (e.g., Baehr 2012 and Darlington 1959); but no comprehensive treatments of the Philippine carabid genera and species have been produced. It is likely that the known fauna represents only $10 \%$ or less of the true carabid fauna of this hyper-diverse archipelago. 
The purpose of this report is to provide a list of the species represented among specimens collected on the 2011 expedition. None of us has particular expertise with carabids of this region, nor have we had the opportunity to borrow representative identified material for species previously known to occur in the region. Consequently, this serves as a very preliminary report for which most identifications are necessarily incomplete and tentative, left only to the lowest taxonomic level for which we have some degree of confidence. In providing this checklist and accompanying annotations and illustrations, we hope to encourage researchers studying carabids from the region to make use of this material; and we also welcome any help with identifications based on the illustrations.

\section{Materials AND Methods}

This report is based on our study of 234 carabid beetle specimens collected on the 2011 Hearst Philippine Expedition. The three main areas where collecting of carabid specimens occurred are plotted on the map in Fig. 1, and locality data (including province, locality specifics, geographical coordinates and elevation) and collection event data (including date(s) of collection, collecting method, habitat and collector(s)) are provided in the Appendix. Each collecting event was assigned a unique code by the collecting team, and entries in the Appendix are arranged by collection event code for ease of information retrieval in using the checklist.

Specimens were sorted to species based on characters of external form and structure (i.e., morphospecies). Many identifications are only to the genus level, and for these we relied most heavily on Darlington's $(1952,1968)$ keys for the New Guinea fauna. One species could only be identified questionably to tribe (Platynini or Lachnophorini). All of the specimens from the expedition are deposited in the collection at CAS and are available for study on site or through loans. Digital images of dorsal habitus were taken of a representative member of each morphospecies using an Automontage imaging system from Synchroscopy with a JVC KY-F-75U digital camera and a Leica M420 dissecting microscope. The "CASENT" number associated with each image, as noted in figure captions, is a unique identifier that refers to the particular specimen photographed and its CAS database record.

\section{SPECIES LIST}

For the purposes of this checklist, we follow the classification, order and taxonomy provided by Lorenz (2005) except as specifically noted in the list. Our study of the material from the expedition leads us to recognize a total of 68 species represented in these samples and identified as in the following list.

\section{Ozaenini}

Eustra cf. hammondi Deuve (Fig. 2); 20 specimens; PH005, PH015; collected by mini-Winkler extraction of concentrated forest leaf litter

\section{Collyridini}

Tricondyla (Tricondyla) conicicollis Chaudoir (Fig. 3), 2 specimens; PH0001, NCP_3; collected by hand in daytime in forest

Tricondyla (Tricondyla) ventricosa ventricosas Schaum (Fig. 4), 1 specimen; PH0009; collected by hand in daytime in forest

Tricondyla (Stenotricondyla) cyanipes Gestro (Fig. 5), 1 specimen; NCP_3; collected by hand in daytime in forest

Neocollyris sp. (Fig. 6), 1 specimen; PH0054; collected by hand at night in forest 


\section{Cicindelini}

Prothyma sp. A (Fig. 7), 5 specimens; PH0054; collected by hand at night in forest

Prothyma sp. B (Fig. 8), 7 specimens; PH0042, PH0049, PH0050; collected by hand at night and in daytime in forest

Heptodonta melanopyga Schaum (Fig. 9), 1 specimen; PH0008; collected in malaise trap in open area in cultivated area near forest

Therates semperi Schaum (Fig. 10), 11 specimens; PH0003, PH0004, PH0012, PH0013, PH0057, NCP_3, MMHW_2; collected by hand in daytime and at night, in yellow pan traps, malaise traps and pitfall traps, all in forest

Thopeutica (Thopeutica) clara aenula (Horn) (Fig. 11), 1 specimen; PH0042; collected by hand at night in degraded forest

Thopeutica (Thopeutica) ef. conspicua (Schaum) (Fig. 12), 11 specimens; PH0035, LF_1, LF_2; collected by hand in daytime and at night and at mercury vapor light, all in forest

Lophyra (Spilodia) striolata (IIliger) (Fig. 13), 11 specimens; PH0043; collected at mercury vapor light in grassland

Cylindera (Conidera) mandibularis (Schaum) (Fig. 14), 1 specimen; PH0043; collected at mercury vapor light in grassland

Cylindera (Ifasina) viduata (Fabricius) (Fig. 15), 2 specimens; PH0043; collected at mercury vapor light in grassland

\section{Clivinini}

Clivina sp. (Fig. 16), 1 specimen; PH0028; collected by hand sorting of sifted forest litter

\section{Bembidiini}

Elaphropus (Tachyura) ceylonicus (Nietner) (Fig. 17), 1 specimen; PH0030; collected at mercury vapor light in forest

Polyderis impressipennis Motschulsky (Fig. 18), 2 specimens; PH0015; collected by mini-Winkler extraction of concentrated forest leaf litter

We follow Erwin et al. (2012) in considering Polyderis Motschulsky as a genus distinct from Tachys Dejean.

Sinechostictus (Pseudolinnaeum) cf. pendleburyi Andrewes (Fig. 19), 1 specimen; PH0025; collected by mini-Winkler extraction of concentrated forest leaf litter

We follow D.R. Maddison (personal communication) in recognizing Sinechostictus as a distinct genus. Our specimen agrees with Darlington's (1959) description of the females from Luzon Island that he studied and which differ from specimens from the type locality in northern Borneo.

\section{Pterostichini}

Metabacetus cf. arrowi Straneo (Fig. 20), 6 specimens; PH0004, PH0015; collected in pitfall traps in forest and by mini-Winkler extraction of concentrated forest leaf litter

Cosmodiscus cf. brunneus Darlington (Fig.21), 1 specimen; PH0011; collected in pitfall traps in forest

Lesticus sp. (Fig. 22), 1 specimen; PH0059; collected by hand in daytime in forest

\section{Oodini}

Oodes sp. (Fig.23), 7 specimens; PH0010, PH0011, PH0013, PH0014, PH0050; collected by hand in daytime and at night, in pitfall traps and in yellow pan traps, all in forest

\section{Chlaeniini}

Chlaenius (Haplochlaenius) sp. A (Fig. 24), 1 specimen; MHW_2; collected by hand at night in forest Chlaenius (Haplochlaenius) sp. B (Fig. 25), 1 specimen; PH0042; collected by hand at night in degraded forest 
This morphospecies, represented by a single female in our sample, may be conspecific with the preceding species, rcpresented by a singlc male; but we separate the two here because they have distinctly different elytral topographic, macrosculptural and microsculptural features (compare Figs. 24 and 25), and one species having so many gender-specific differences would be unusual.

Chlaenius (Lissauchenius) sp. (Fig. 26), 1 specimen; PH0051; collected at mercury vapor light in forest

\section{Harpalini}

Stenolophtus (Egadroma) sp. (Fig. 27), 2 specimens; PH0006, PH0015; collected by mini-Winkler extraction from concentrated leaf litter and at ultraviolet light, both in forest

Acupalpus sp. (Fig. 28), 1 specimen; PH0004; collected in pitfall traps in forest.

Coleolissus sp. A (Fig. 29), 1 specimen; PH0051; collected at mercury vapor light in forest

Coleolissus sp. B (Fig. 30), 1 specimen; PH0043; collected at mercury vapor light in grassland

Coleolissus sp. C (Fig. 31), 25 specimens; PH0009, PH0010, PH0011, PH0015; collected by hand in daytime, in pitfall traps and by mini-Winkler extraction from concentrated leaf litter, all in forest

Coleolissus sp. D (Fig. 32), 2 specimens; PH0006, PH0032; collected at ultraviolet and mercury vapor lights in forest

Trichotichnis sp. (Fig. 33), 1 specimen; PH0025; collected by mini-Winkler extraction from concentrated forest leaf litter

\section{Orthogoniini}

Orthogonius sp. A (Fig. 34), 1 specimen; PH0050; collecting by hand in daytime in forest.

Orthogonius sp. B (Fig. 35), 1 specimen; PH0020; collected by hand at night in forest

\section{Platynini}

Agonum muelleri Herbst (Fig. 36), 1 specimen; PH0027; collected in yellow pan traps in forest

This is a Palaearctic species, which has been introduced into North America on both coasts and continues to spread its range on that continent. To the best of our knowledge, it has not been recorded from anywhere in eastern Asia, so its occurrence in our samples is quite unexpected. If our identification is correct, then this must represent an introduction into the Philippines, perhaps even from North America; and it may or may not actually be established in the islands.

Altagonum sp. A (Fig. 37), 4 specimens; PH0021, PH0034, PH0037; collected by beating vegetation and at ultraviolet light, all in forest

Altagonum sp. B (Fig. 38), 2 specimens; PH0020, NCP_3; collected by hand in forest in daytime and at night

Altagonum sp. C (Fig. 39), 8 specimens; PH0021, PH0023, PH0034; collected by hand at night, by beating vegetation, and at ultraviolet light, all in forest

Altagonum sp. D (Fig. 40), 1 specimen; PH0061; collected by mini-Winkler extraction of concentrated forest leaf litter

Arhytinus minimus Jedlička (Fig. 41), 2 specimens; PH0015; collected by mini-Winkler extraction of concentrated forest leaf litter

Colpodes sp. A (Fig. 42), 2 specimens; PH0021; collected at ultraviolet light in forest

Colpodes sp. B (Fig. 43), 1 specimen; PH0021; collected at ultraviolet light in forest

Gastragonum sp. (Fig. 44), 19 specimens; PH0024, PH0055; collecting by hand in cryptic habitats in forest To the best of our knowledge, this genus has not been recorded previously outside of New Guinea.

This is onc of Darlington's (1952) "genera of convenience", based mainly on dorsal chaetotaxic features, so we assign this morphospecies to Gastragonum very tentatively and only because that's where it keys out in his key to genera.

Notagonum sp. A (Fig. 45), 10 specimens; PH0029, PH0054, PH0062, PH0063; collected by hand at night, in pitfall traps, and at ultraviolet light, all in forest

Notagonum sp. B (Fig. 46), 2 specimen; PH0001, PH0004; collected in daytime by hand and in pitfall traps, all in forest

Notagonum sp. C (Fig. 47), 2 specimens; PH0018; collected in daytime by hand in forest 
Notagonum sp. D (Fig. 48), 3 specimens; PH0018; collected in daytime by hand in forest

Notagonum sp. E (Fig. 49), 1 specimen; PH0020; collected by hand at night in forest

Notagonum sp. F (Fig. 50), 14 specimens; PH0021, PH0026, PH0027, PH0034; collected by hand at night, by beating vegetation, in yellow pan traps, and at ultraviolet light, all in forest, and in malaise trap in open area in forest

?platynine/ ?lachnophorine sp. (Fig. 51), 1 specimen; PH0002; collected by hand sorting of forest litter. The single specimen of this morphospecies, a female, has many features of a platyninc, and that is what we identified it as initially. However, its subtruncate elytra and elongate mandibles and maxillae are similar to those in some members of Neotropical lachnophorine genera, such as Aporesthus Bates. Most lachnophorines have the abdominal venter pubescent, but the specimen we examined is not pubescent, although it does have a few short setae across the last stcrnite near the apical margin. Curiously, a similar vestiture pattern is seen in Aporesthus (T.L. Erwin, personal communication). At present, the only lachnophorine genus recorded from the Oriental Region is Selina Motschulsky, members of which have markedly different body form and structural features; so if this specimen represents a lachnophorine species, it will be something either new or currently assigned to some other tribal taxon.

\section{Perigonini}

Perigona (s. str.) sp. (Fig. 52), 1 specimen; PH0025; collected by mini-Winkler extraction of concentrated forest leaf litter

Perigona (Trechicus) nigriceps (Dejean) (Fig. 53), 1 specimen; PH0051; collected at mercury vapor light in forcst

Perigona (Trechicus) sp. (Fig. 54), 4 specimens; PH0015, PH0047; collected by hand sorting of forest litter and by mini-Winkler extraction of concentrated forest leaf litter

\section{Odacanthini}

Dicraspeda brunnea Chaudoir (Fig. 55), 1 specimen; PH0051; collected at mercury vapor light in forest Mimocolliuris sp. (Fig. 56), 1 specimen; PH0054; collected by hand at night in forest

\section{Pentagonicini}

Pentagonica sp. A (Fig. 57), 15 specimens; PH0008, PH0015, PH0032, PH0047, PH0051, PH0064; collected by hand sorting of forest litter and by mini-Winkler extraction of concentrated forest leaf litter, at mercury vapor light in forest and in malaise trap in open cultivated area near forest

Pentagonica sp. B (Fig. 58), 2 specimens; PH0057, MHW_1; collected by hand sorting of forest litter and in yellow pan traps in forest

Pentagonica sp. C (Fig. 59), 15 specimens; PH0043, PH0049, PH0051, PH0054, PH0062; collecting by hand at night and at ultraviolet and mercury vapor lights, all in forest, and at mercury vapor light in grassland

\section{Lebiini}

Dolichoctis sp. A (Fig.60), 1 specimen; PH0051; collected at mercury vapor light in forest

Dolichoctis sp. B (Fig. 61), 2 specimens; PH0006; collected at ultraviolet light in forest

Dolichoctis sp. C (Fig. 62), 1 specimen; PH0039; collected in daytime by hand in grassland and degraded forest

Dolichoctis sp. D (Fig. 63), 1 spccimcn; PH0034; collccted by beating vegetation in forest

Syntomus sp. (Fig. 64), 1 specimen; PH0064; collected by hand sorting of forest litter

Lebia (Poecilothais) sp. (Fig. 65), I specimen; PH0051; collected at mercury vapor light in forest

Paraphaea philippinensis (Jedlička) (Fig. 66), 1 specimen; PH0048; collected by beating and sweeping vegetation in forest

The generic assignment of this species follows Shi et al. (2013). 


\section{Dryptini}

Dendrocellus coelestinus (Klug) (Fig. 67), 1 specimen; PH0040; collected by hand sorting of litter sifted from grassland and degraded forest

This represents a first record for this species in the Phillippine Islands (Liang and Kavanaugh 2007).

\section{Brachinini}

Brachinus sp. (Fig. 68), 2 specimens; MHW_2; collected by hand at night in forest Both published (Maddison et al 1999) and unpublished molecular data (D. R. Maddison, personal communication) strongly support the Brachininae as sister group to the huge subfamily Harpalinae. Hence, we place the brachinine species here in our list rather than with the Paussinae as done by Lorenz (2005).

\section{ACKNOWLEDGEMENTS}

First of all, we must thank Will and Margaret Hearst for their generosity in funding the Academy's 2011 Philippine Expedition. We gratefully acknowledge the many colleagues who collected the specimens on which this report is based. Among these are Natalia Chousou Polydouri, Charles Griswold, Vanessa Knutson, Matt Lewin and Hannah Wood of the California Academy of Sciences team, and O. Eusebio, V. San Juan, S. Yap, M. Yngente of the Philippine contingent. We also thank Alma Saucedo, who prepared the carabid specimens for this project, and Martin Baehr (Platynini, Pentagonicini and Lebiini), Terry Erwin (Tachyina and Brachinini), David Maddison (Bembidiini), and Kipling Will (Pterostichini) for their help with identifications.

\section{REFERENCES}

Andrewes, H. E. 1926. A catalogue of Philippine Carabidae. Philippine Journal of Science 31:345-361.

BAEHR, M. 2012. New species and new records of the genus Arhytinus Bates 2nd supplement to the "revision of the genus Arhytinus Bates". Koleopterogische Rundschau 82:41-64.

Darlington, P. J., JR. 1952. The carabid beetles of New Guinea. Part 2. The Agonini. Bulletin of the Museum of Comparative Zoology 107:87-252+ 4 plates.

Darlington, P. J., JR. 1959. The Bembidion and Trechus (Col.: Carabidae) of the Malay Archipelago. Pacific Insects 1:331-345.

DARlington, P. J., JR. 1968. The carabid beetles of New Guinea. Part III. Harpalinae (continued): Perigonini to Pseudomorphini. Bulletin of the Museum of Comparative Zoology 137:1-253.

Deuve, T. 2001. Le genre Eustra Schmidt-Goebel, 1846, insects (Coleoptera, Paussidae, Ozaeninae) à genitalia femelles orthoptiques. Zoostystema 23:547-578.

ERwin, T. L., C. J. Micheli, ANd G. F. Hevel. 2012. The beetle family Carabidae of Guyane (French Guyana): their tribes, genera, and number of species known, with notes on their ways of life. Le Coléoptériste 15(Supplement):1-88.

Liang, H. B., and D. H. Kavanaugh. 2007. Review of the genus Dendrocellus Schmidt-Göbel (Coleoptera: Carabidae: Dryptini), with descriptions of seven new species. Coleopterists Bulletin 61:1-39.

LoREnz, W. 2005. Systematic List of Extant Ground Beetles of the World (Insecta Coleoptera "Geadephaga": Trachypachidae and Carabidae incl. Paussinae, Cicindelinae, Rhysodinae). Second edition. W. Lorenz, Tutzing, $530 \mathrm{pp}$.

MAdDison, D. R., M. L. D. BAKER, AND K. N. OBER. 1999. Phylogeny of carabid beetles as inferred from 18S ribosomal DNA (Coleoptera: Carabidae). Systematic Entomology 24:103-138.

Rivalier, E. 1964. Le genre Prothyma Hope, revision et description de quatre espêces nouvelles. Revue Française d'Entomologie 31:127-164.

Shi, H. L., H. Z. Zhou, and H. B. Liang. 2013. Taxonomic synopsis of the subtribe Physoderina (Coleoptera, Carabidae, Lebiini), with species revisions of eight genera. ZooKeys 284:1-129.

WIESNER, J. 1980. Beiträge zur Kenntnis der philippinischen Cicindelidae (Coleoptera). Mitteilungen der Münchener Entomologischen Gesellscghaft 70:119-127. 


\section{APPENDIX}

A list of localities sampled (all on Luzon Island) and collection events, arranged by collection event codes. Code numbers missing from the sequential listing represent samples from which no carabids were recovered. The three general areas where collection localities, designated here by capital letters A through S, were concentrated are shown in Fig. 1.

A. Laguna Province, Mt. Makiling, Malaboo Camp, $3.46 \mathrm{~km} \mathrm{SSW}$ of Los Baños, $14.13700^{\circ} \mathrm{N}$, $121.20587^{\circ} \mathrm{E}, 673 \mathrm{~m}, 10-12$ May 2011

PH0001 General daytime collecting by hand in forest; H. Wood, M. Yngente, N. Chousou Polydouri, C. Griswold, V. San Juan and V. Knutson collectors

PH0002 Hand sorting of sifted forest litter; H. Wood and C. Griswold collectors

PH0003 Yellow pan traps in forest; H. Wood, M. Yngente, N. Chousou Polydouri, C. Griswold and V. Knutson collcctors

PH0004 Pitfall traps with polypropylene glycol in forest; H. Wood, M. Yngente, N. Chousou Polydouri, C. Griswold and V. Knutson collectors

PH0005 Mini-Winkler extraction of concentrated forest leaf litter; H. Wood, M. Yngente, N. Chousou Polydouri, C. Griswold and V. Knutson collectors

PH0006 Ultraviolet light in forest; S. Yap, V. Knutson, O. Eusebio and N. Chousou Polydouri collectors

B. Quezon Province, Mt. Banahaw de Lucban, $3.78 \mathrm{~km}$ WSW of Lucban, $14.10048^{\circ} \mathrm{N}, 121.52455^{\circ} \mathrm{E}, 747 \mathrm{~m}, 14-22$ May 2011

PH0008 Malaise trap in open cultivated area near forest; H. Wood, M. Yngente, N. Chousou Polydouri, C. Griswold and V. Knutson collectors

PH0009 General daytime collecting by hand in forest; H. Wood, M. Yngente, N. Chousou Polydouri, C. Griswold, V. San Juan and V. Knutson collectors

PH0010 Pitfall traps with soapy water in forest; H. Wood, M. Yngente, N. Chousou Polydouri, C. Griswold and V. Knutson collectors

PH0011 Pitfall traps with polypropylene glycol in forest; H. Wood, M. Yngente, N. Chousou Polydouri, C. Griswold and V. Knutson collectors

PH0012 Malaise trap in forest; H. Wood, M. Yngente, N. Chousou Polydouri, C. Griswold and V. Knutson collectors

PH0013 Yellow pan traps in forest; H. Wood, M. Yngente, N. Chousou Polydouri, C. Griswold and V. Knutson collectors

PH0014 General collecting by hand at night in forest; H. Wood, M. Yngente, N. Chousou Polydouri, C. Griswold and V. Knutson collectors

PH0015 Mini-Winkler extraction of concentrated forest leaf litter; H. Wood, M. Yngente, N. Chousou Polydouri, C. Griswold and V. Knutson collectors

C. Quezon Province, Taitai River, near Mt. Banahaw de Lucban, $5.3 \mathrm{~km} \mathrm{~W}$ of Lucban, $14.10740^{\circ} \mathrm{N}, 121.50740^{\circ} \mathrm{E}, 643 \mathrm{~m}, 16$ May 2011

PH0018 General daytime collecting by hand in forest; H. Wood, M. Yngente, N. Chousou Polydouri, C. Griswold and V. Knutson collectors

D. Quezon Province, Mt. Banahaw de Lucban, $3.78 \mathrm{~km}$ WSW of Lucban, $14.10048^{\circ} \mathrm{N}$, $121.52455^{\circ} \mathrm{E}, 747 \mathrm{~m}, 16$ May 2011

PH0020 General collecting by hand at night in forest; H. Wood, M. Yngente, N. Chousou Polydouri, C. Griswold, V. San Juan and V. Knutson collectors

E. Quezon Province, peak of Mt. Banahaw de Lucban, $6.4 \mathrm{~km}$ WSW of Lucban, $14.07610^{\circ} \mathrm{N}$, $121.51365^{\circ} \mathrm{E}, 1852 \mathrm{~m}, 19-22$ May 2011

PH0021 Ultraviolet light in forest; S. Yap, V. Knutson, O. Eusebio and N. Chousou Polydouri collectors 
PH0023 General collecting by hand at night in forest; H. Wood, M. Yngente, N. Chousou Polydouri, C. Griswold, V. San Juan and V. Knutson collectors

PH0024 General collecting by hand in cryptic habitats in forest; C. Criswold collector

PH0025 Mini-Winkler extraction of concentrated forest leaf litter; H. Wood, M. Yngente, N. Chousou Polydouri, C. Griswold and V. Knutson collectors

PH0026 Malaise trap in open area in forest; H. Wood, M. Yngente, N. Chousou Polydouri, C. Griswold and V. Knutson collectors

PH0027 Yellow pan traps in forest; H. Wood, M. Yngente, N. Chousou Polydouri, C. Griswold and V. Knutson collectors

PH0028 Hand sorting of sifted forest litter; H. Wood and C. Griswold collectors

F. Quezon Province, Mt. Banahaw de Lucban, $5.25 \mathrm{~km}$ WSW of Lucban, $14.08695^{\circ} \mathrm{N}$, $121.51727^{\circ} \mathrm{E}, 1279 \mathrm{~m}, 17-22$ May 2011

PH0029 Pitfall traps with polypropylene glycol in forest; H. Wood, M. Yngente, N. Chousou Polydouri, C. Griswold and V. Knutson collectors

G. Quezon Province, Mt. Banahaw de Lucban, $3.78 \mathrm{~km}$ WSW of Lucban, $14.10048^{\circ} \mathrm{N}$, $121.52455^{\circ} \mathrm{E}, 747 \mathrm{~m}, 14-15$ May 2011

PH0030 Mercury vapor light in forest; S. Yap, V. Knutson, O. Eusebio and N. Chousou Polydouri collectors

H. Quezon Province, near Mt. Banahaw de Lucban, $4.38 \mathrm{~km}$ W of Lucban, $14.10311^{\circ} \mathrm{N}$, $121.51764^{\circ} \mathrm{E}, 788 \mathrm{~m}, 16$ May 2011

PH0032 Mercury vapor light in forest; S. Yap, V. Knutson, O. Eusebio and N. Chousou Polydouri collectors

I. Quezon Province, peak of Mt. Banahaw de Lucban, $6.4 \mathrm{~km}$ WSW of Lucban, $14.07610^{\circ} \mathrm{N}$, $121.51365^{\circ} \mathrm{E}, 1852 \mathrm{~m}, 19-22$ May 2011

PH0034 Beating vegetation in forest; V. Knutson and N. Chousou Polydouri collectors

J. Quezon Province, Mt. Banahaw de Lucban, $5.25 \mathrm{~km}$ WSW of Lucban, $14.08695^{\circ} \mathrm{N}$, $121.51852^{\circ} \mathrm{E}, 1279 \mathrm{~m}, 17$ May 2011

PH0035 General daytime collecting by hand in forest; H. Wood, M. Yngente, N. Chousou Polydouri, C. Griswold and V. Knutson collectors

K. Quezon Province, peak of Mt. Banahaw de Lucban, $6.4 \mathrm{~km}$ WSW of Lucban, $14.07610^{\circ} \mathrm{N}$, $121.51365^{\circ} \mathrm{E}, 1852 \mathrm{~m}, 19-22$ May 2011

PH0037 Ultraviolet light in forest; V. Knutson, H. Wood, O. Eusebio and N. Chousou Polydouri collectors

L. Laguna Province, grassland on west slope of Mt. Makiling, $5.78 \mathrm{~km} \mathrm{WSW} \mathrm{of} \mathrm{Los} \mathrm{Baños,}$ $14.14873^{\circ} \mathrm{N}, 121.16652^{\circ} \mathrm{E}, 241 \mathrm{~m}, 25$ May 2011

PH0039 General daytime collecting by hand in grassland and degraded forest; H. Wood, M. Yngente, N. Chousou Polydouri, C. Griswold, V. San Juan and V. Knutson collectors

PH0040 Hand sorting of sifted grassland and degraded forest litter; H. Wood and C. Griswold collectors

PH0042 General collecting by hand at night in degraded forest; H. Wood, M. Yngente, N. Chousou Polydouri, C. Griswold, V. San Juan and V. Knutson collectors

PH0043 Mercury vapor light in grassland; S. Yap, V. Knutson, O. Eusebio and N. Chousou Polydouri collectors

M. Laguna Province, $2.5 \mathrm{~km}$ ESE of Los Baños, University of the Philippines Los Baños Campus, $14.15252^{\circ} \mathrm{N}, 121.23440^{\circ} \mathrm{E}, 138 \mathrm{~m}, 26-27$ May 2011

PH0047 Hand sorting of sifted forest litter; H. Wood and C. Griswold collectors

PH0048 Beating and sweeping vegetation in forest; H. Wood, N. Chousou Polydouri and V. Knutson collectors 
PH0049 General collecting by hand at night in forest; H. Wood, M. Yngente, N. Chousou Polydouri, C. Griswold, V. San Juan and V. Knutson collectors

PH0050 General daytime collecting by hand in forest; H. Wood, M. Yngente, N. Chousou Polydouri, C. Griswold, V. San Juan and V. Knutson collectors

PH0051 Mercury vapor light in forest; S. Yap, V. Knutson, O. Eusebio and N. Chousou Polydouri collectors

N. Camarines Sur Province, Mt. Isarog, $9.3 \mathrm{~km}$ E of Naga City, $13.66537^{\circ} \mathrm{N}, 123.35398^{\circ} \mathrm{E}, 918$ m, 31 May - 2 June 2011

PH0054 General collecting by hand at night in forest; M. Yngente, N. Chousou Polydouri and collectors

PH0055 General collecting by hand in cryptic habitats in forest; C. Criswold collector

PH0057 Yellow pan traps in forest; N. Chousou Polydouri and C. Griswold collectors

O. Camarines Sur Province, Mt. Isarog, $11.2 \mathrm{~km}$ E of Naga City, $13.66368^{\circ} \mathrm{N}, 123.37167^{\circ} \mathrm{E}, 1760$ m, 1-2 June 2011

PH0059 General daytime collecting by hand in forest; M. Yngente and N. Chousou Polydouri collectors

PH0061 Mini-Winkler extraction of concentrated forest leaf litter; M. Yngente, N. Chousou Polydouri and C. Griswold collectors

PH0062 Ultraviolet light in forest; S. Yap, O. Eusebio and N. Chousou Polydouri collectors

PH0063 General collecting by hand at night in forest; M. Yngente, N. Chousou Polydouri and collectors

PH0064 Hand sorting of sifted forest litter; N. Chousou Polydouri and M. Yngente collectors

P. Laguna Province, Mt. Makiling, $3.8 \mathrm{~km}$ WSW of Los Baños, University of the Philippines Los Baños Campus, $14.13892^{\circ} \mathrm{N}, 121.19861^{\circ} \mathrm{E}, 818 \mathrm{~m}, 11$ May 2011

NCP_3 General daytime collecting by hand in forest; H. Wood, M. Yngente, N. Chousou Polydouri, V. San Juan and V. Knutson collectors

Q. Laguna Province, peak of Mt. Makiling, $4.3 \mathrm{~km}$ WSW of Los Baños, $14.13567^{\circ} \mathrm{N}$, $121.19378^{\circ} \mathrm{E}, 1108 \mathrm{~m}, 11$ May 2011

MHW_1 Hand sorting of sifted forest litter; H. Wood collector

R. Laguna Province, Mt. Makiling, $3.8 \mathrm{~km}$ WSW of Los Baños, University of the Philippines Los Baños Campus, $14.13892^{\circ} \mathrm{N}, 121.19861^{\circ} \mathrm{E}, 818 \mathrm{~m}, 11$ May 2011

MHW_2 General collecting by hand at night in forest; M. Yngente, N. Chousou Polydouri and collectors

S. Quezon Province, Mt. Banahaw de Lucban, $4.9 \mathrm{~km}$ WSW of Lucban, $14.13567^{\circ} \mathrm{N}$, $121.19378^{\circ} \mathrm{E}, 1106 \mathrm{~m}, 17$ May 2011

LF_1 General collecting by hand at night in forest; H. Wood, M. Yngente, N. Chousou Polydouri, V. San Juan and V. Knutson collectors

LF_2 Mercury vapor light in forest; S. Yap, V. Knutson, O. Eusebio, H. Wood, M. Yngente and N. Chousou Polydouri collectors 
FIGURE 1. Map of the Philippine Islands, with enlargement of southern Luzon Island showing the three areas where collections of carabid beetles were made. I = Mt. Makiling area, localities A, L, M and P to S; II = Mt. Banahaw de Lucban area, localities B to K; and III = Mt. Isarog area, localities $\mathrm{N}$ and $\mathrm{O}$. Data for these localities and collection events at each are provided in the Appendix. The map used in this figure is from the Atlas of the Philippines, Wikimedia Commons, at the following URL:

https://www.google.com/search? $q=$ maps + of + the + Philippines\&rlz=1ClCHMO_enUS522US522\&espv=210\&es_sm=93 $\&$ tbm $=i$ isch \& $t b o=u \&$ source $=$ univ\&s $a=X \&$ ei=UIbHUtjYK4PsoASsrIKYBw\&ved = OCDAQs AQ\&biw=1153\&bih=876\#facr $c=$ \&imgdii=_\&imgrc=k7PSbYQ8z_ALEM\%3A\%3B1sNoxTHI7PRiBM\%3Bhttp\%253A\%252F\%252Fupload.wikimedia.org\%252Fwikipedia\%252Fcommons\%252F9\%252F93\%252FMap_of_the_Philippines_Demis.png\%3Bhttp\%253A\%2 $52 F \% 252 F$ commons.wikimedia.org\%252Fwiki\%252FAtlas_of_the_Philippines\%3B814\%3B 1228 


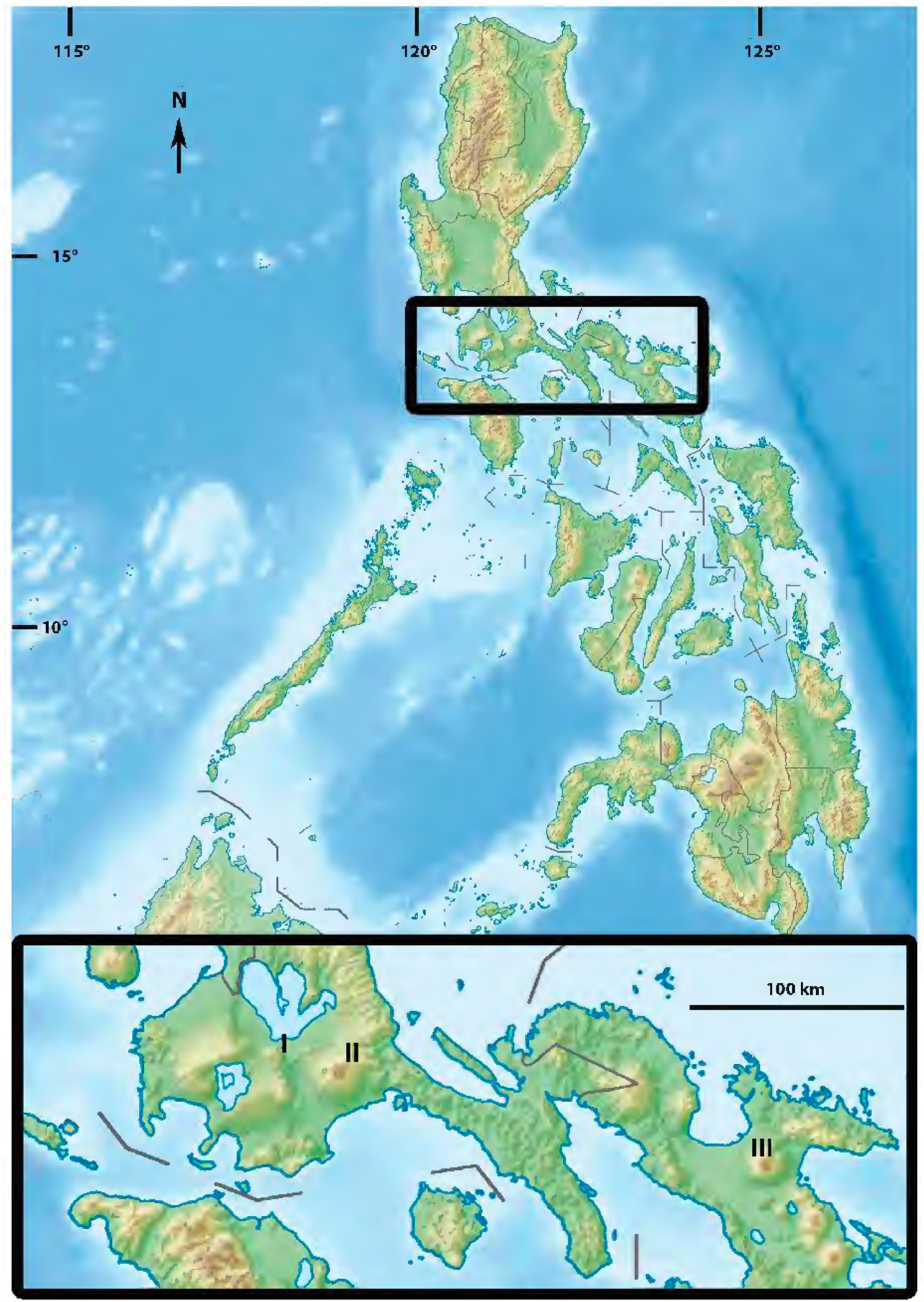



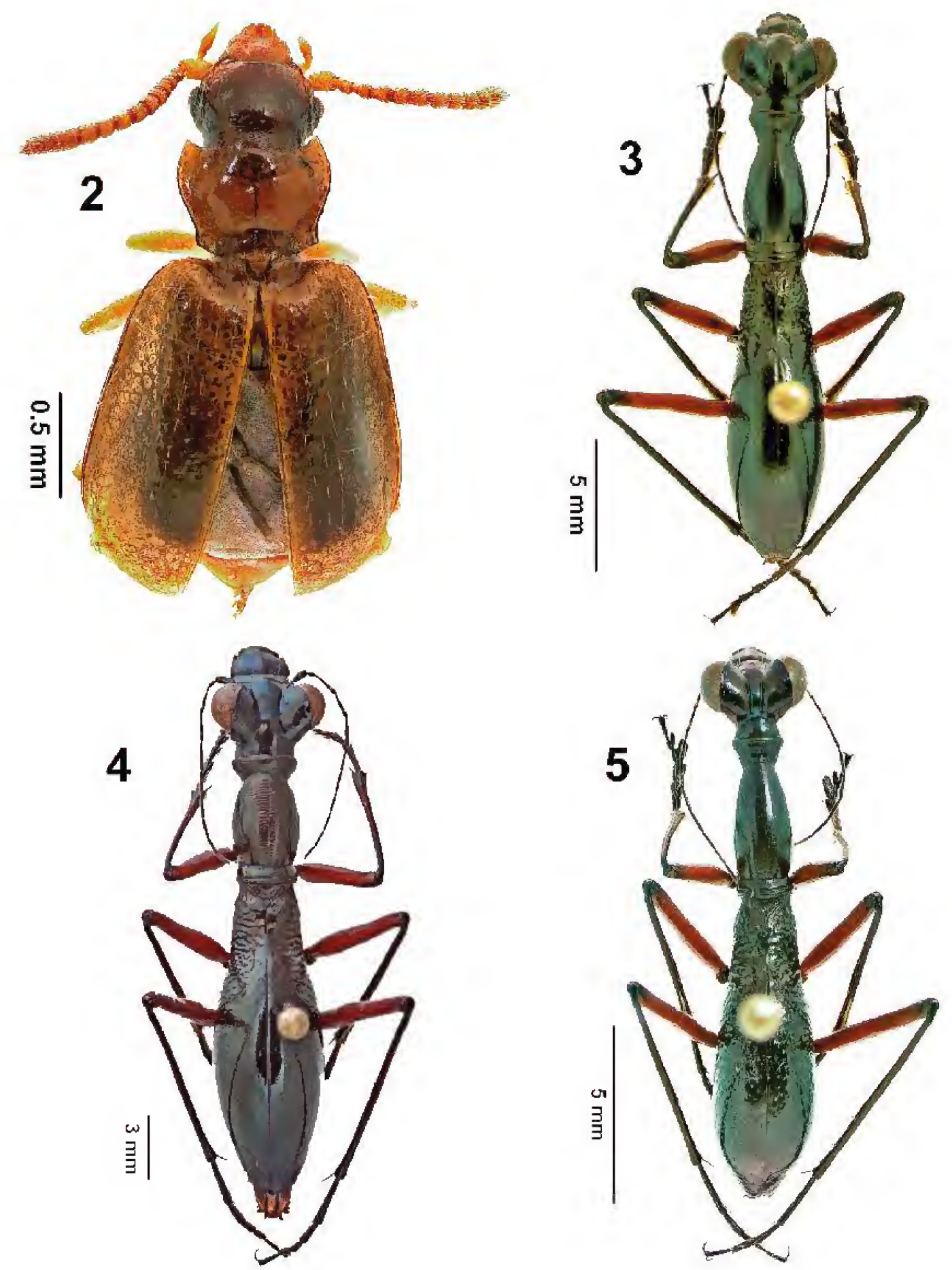

FIGURES 2-5. Digital photographs of dorsal habitus. Fig. 2. Eustra cf. hammondi Deuve (CASENT8144093). Fig. 3. Tricondyla (Tricondyla) conicicollis Chaudoir (CASENT8133486). Fig. 4. Tricondyla (Tricondyla) ventricosa ventricosas Schaum (CASENT8133567). Fig. 5. Tricondyla (Stenotricondyla) cyanipes Gestro (CASENT8133513). 

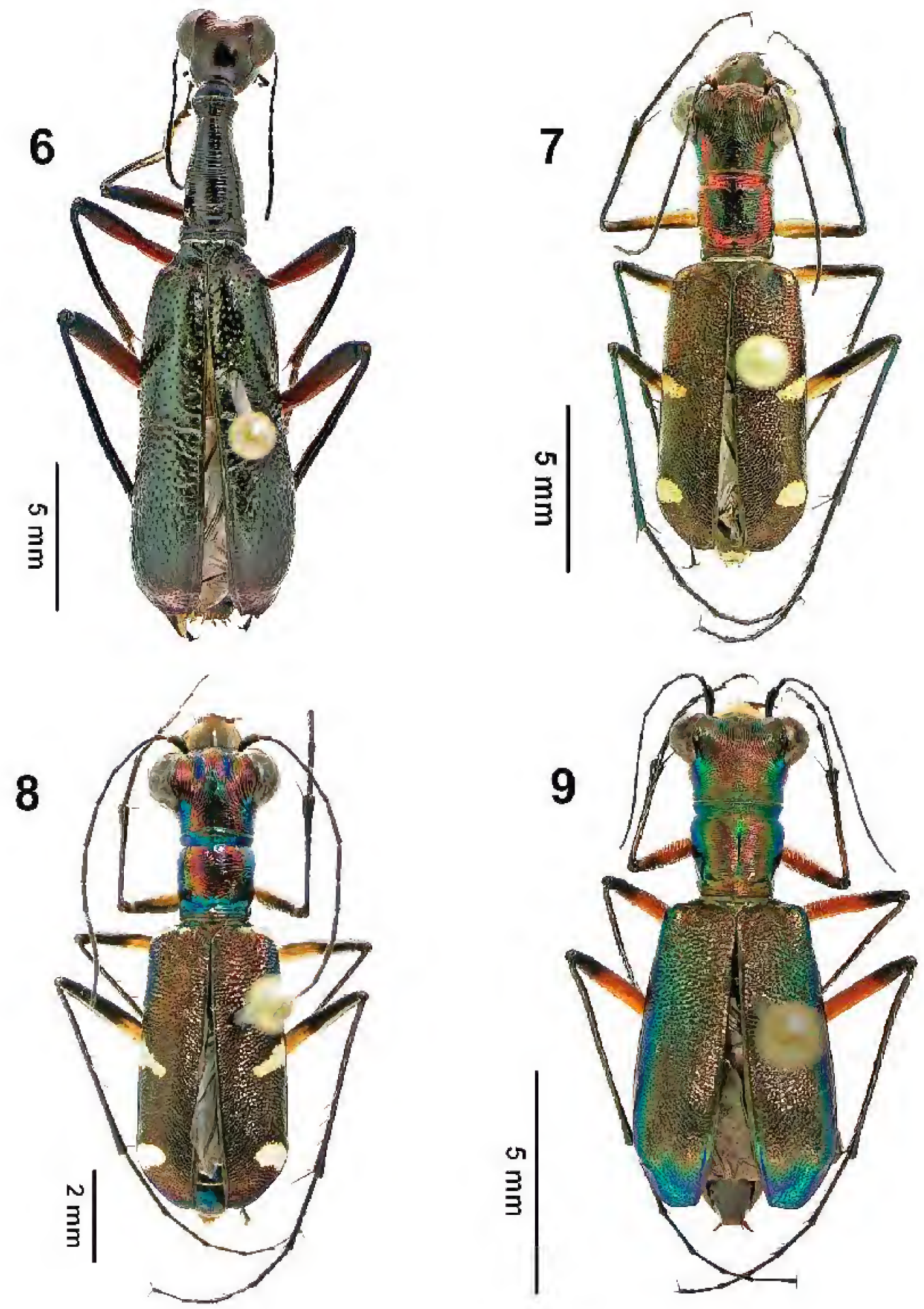

FIGURES 6-9. Digital photographs of dorsal habitus. Fig. 6. Neocollyris sp. (CASENT8133534). Fig. 7. Prothyma sp. A (CASENT8133491). Fig. 8. Prothyma sp. B (CASENT8133503). Fig. 9. Heptodonta melanopyga Schaum (CASENT 8144415). 

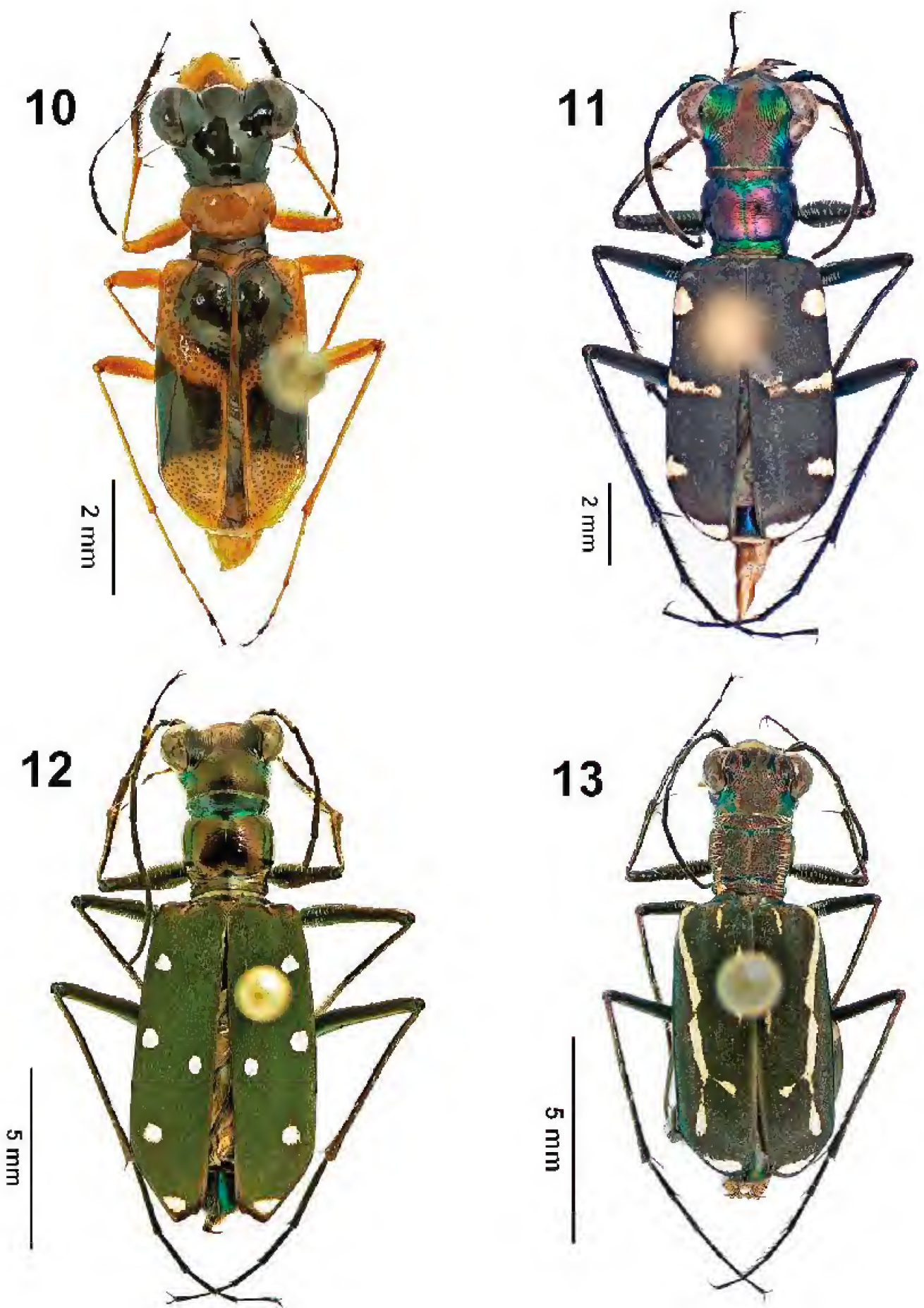

FIGURES 10-13. Digital photographs of dorsal habitus. Fig. 10. Therates semperi Schaum (CASENT8144057). Fig. 11. Thopeutica (Thopeutica) clara aenula (Horn) (CASENT8133505). Fig. 12. Thopeutica (Thopeutica) cf. conspicua (Schaum) (CASENT8133492). Fig. 13. Lophyra (Spilodia) striolata (Illiger) (CASENT8133498). 

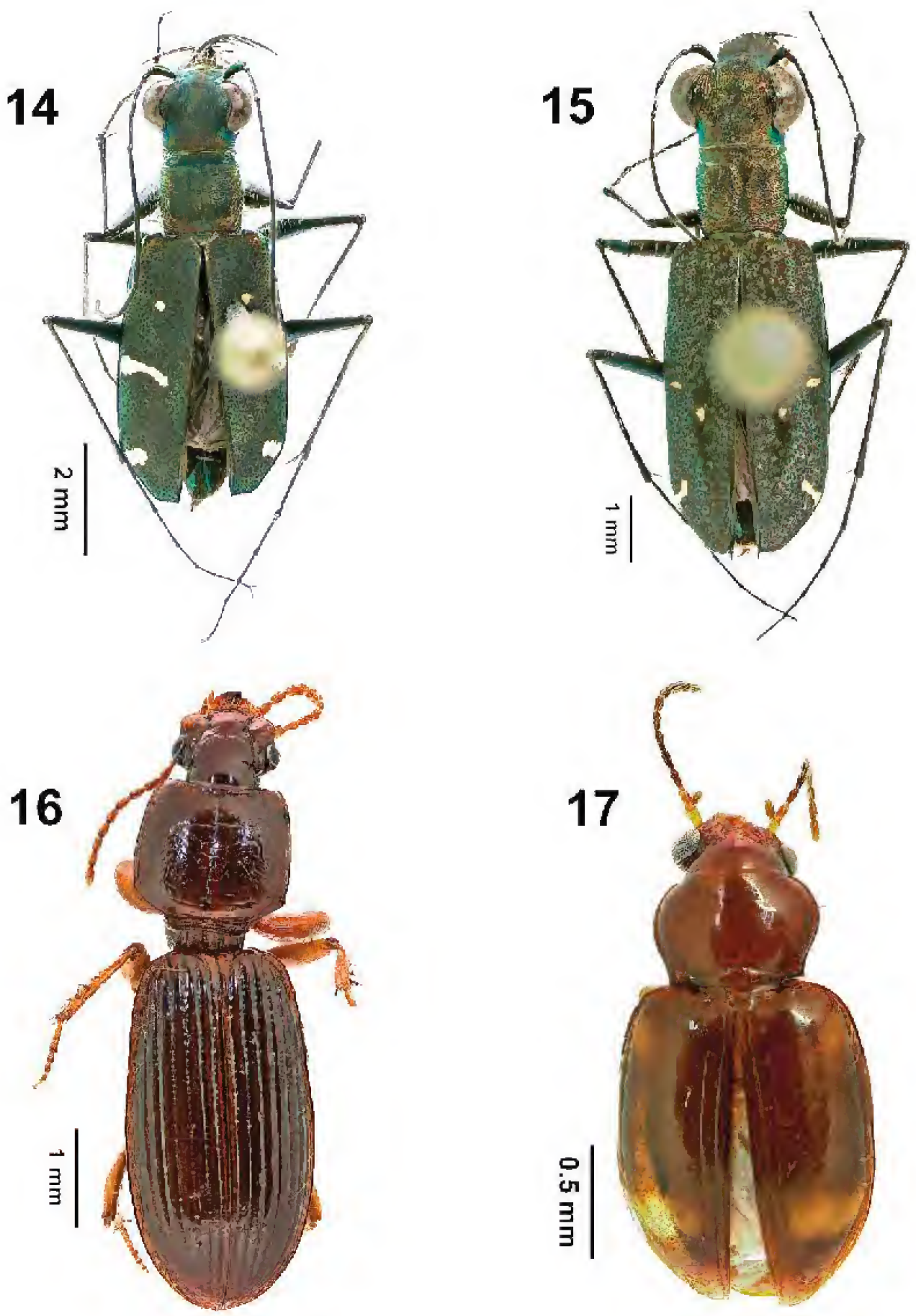

FIGURES 14-17. Digital photographs of dorsal habitus. Fig. 14. Cylindera (Conidera) mandibularis (Schaum) (CASENT8133501). Fig. 15. Cylindera (Ifasina) viduata (Fabricius) (CASENT8144050). Fig. 16. Clivina sp. (CASENT 8144418). Fig. 17. Elaphropus (Tachyura) ceylonicus (Nietner) (CASENT8144011). 

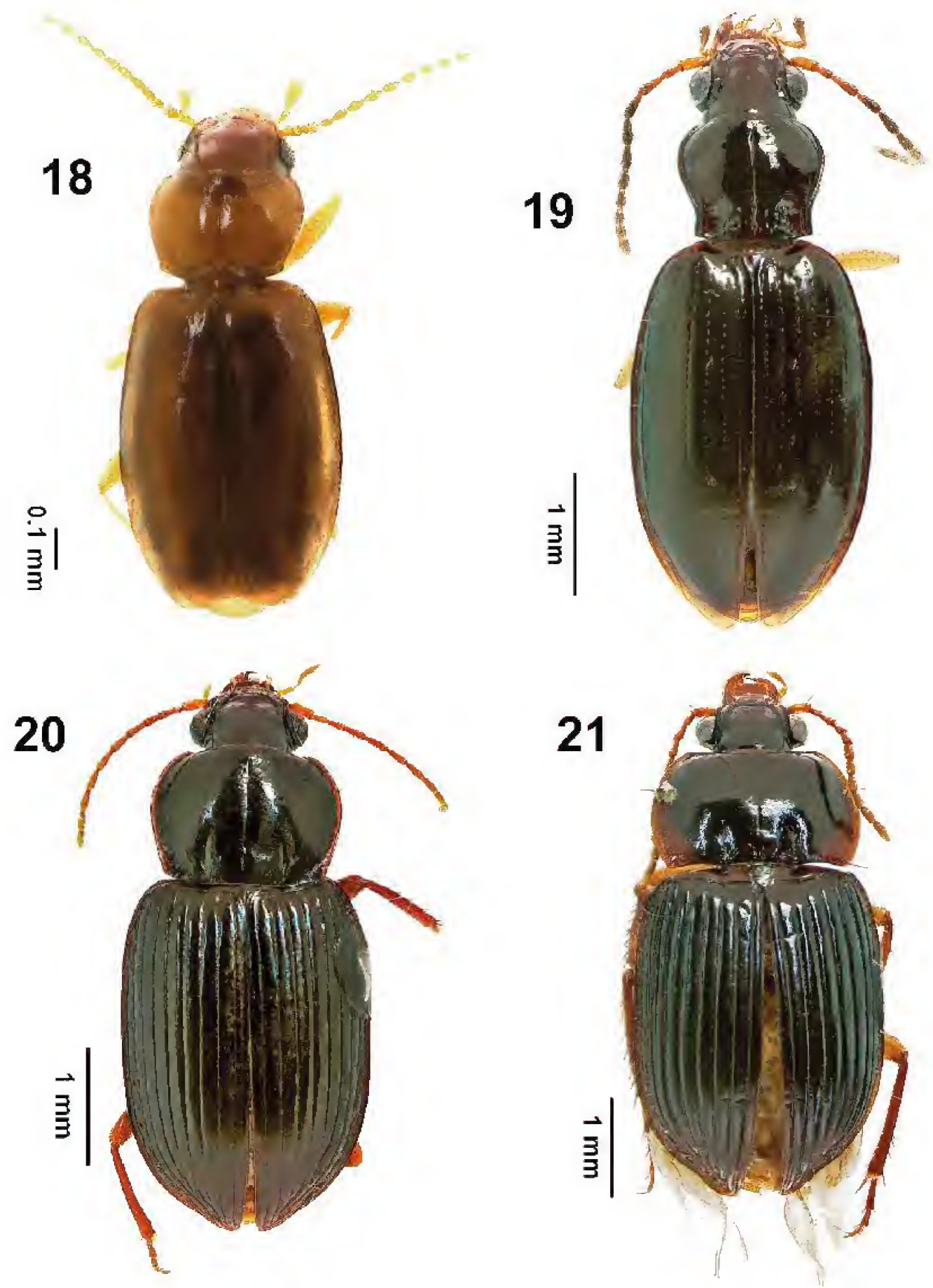

FIGURES 18-21. Digital photographs of dorsal habitus. Fig. 18. Polyderis impressipennis Motschulsky (CASENT 8144352). Fig. 19. Sinechostictus (Pseudolimnaeum) cf. pendleburyi Andrewes (CASENT8144025). Fig. 20. Metabacetus cf. arrowi Straneo (CASENT8144007). Fig. 21. Cosmodiscus cf. brunneus Darlington (CASENT8144414). 

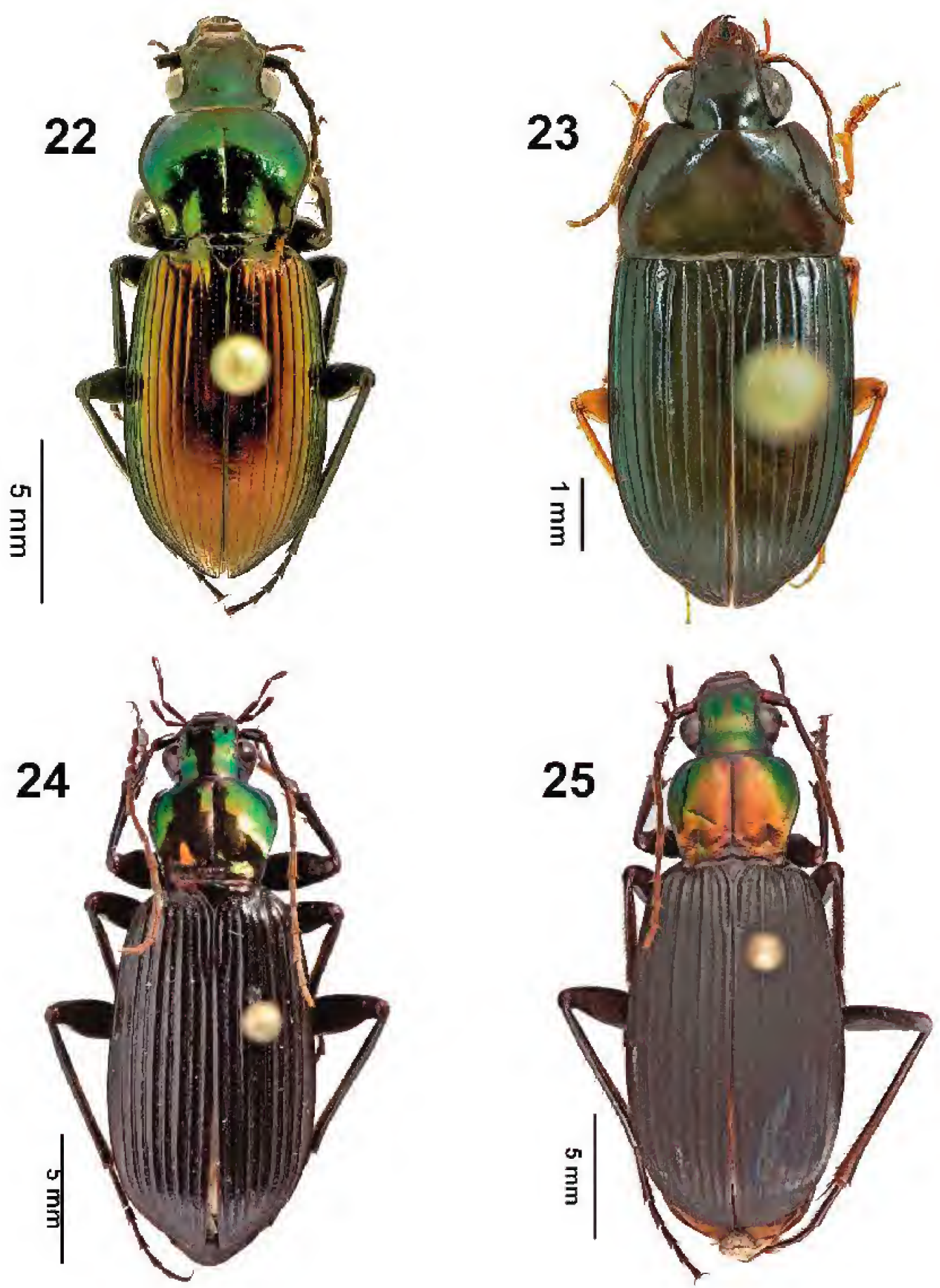

FIGURES 22-25. Digital photographs of dorsal habitus. Fig. 22. Lesticus sp. (CASENT8133488). Fig. 23. Oodes sp. (CASENT8133522). Fig. 24. Chlaenius (Haplochlaenius) sp. A (CASENT8133550). Fig. 25. Chlaenius (Haplochlaenius) sp. B (CASENT8133502). 

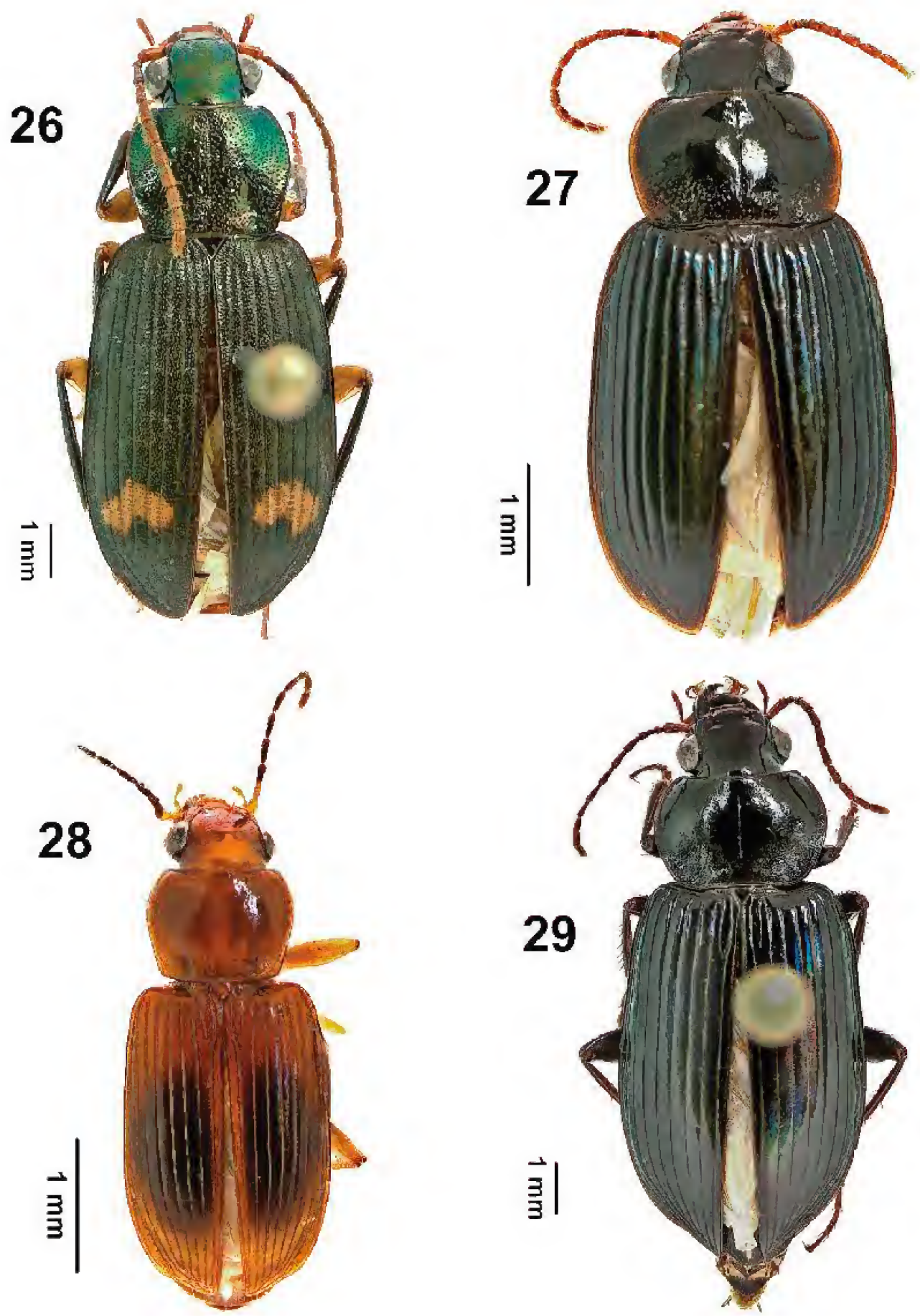

FIgUREs 26-29. Digital photographs of dorsal habitus. Fig. 26. Chlaenius (Lissauchenius) sp. (CASENT8144039). Fig. 27. Stenolophus (Egadroma) sp. (CASENT8144054). Fig. 28. Acupalpus sp. (CASENT8144417). Fig. 29. Coleolissus sp. A (CASENT8144012). 

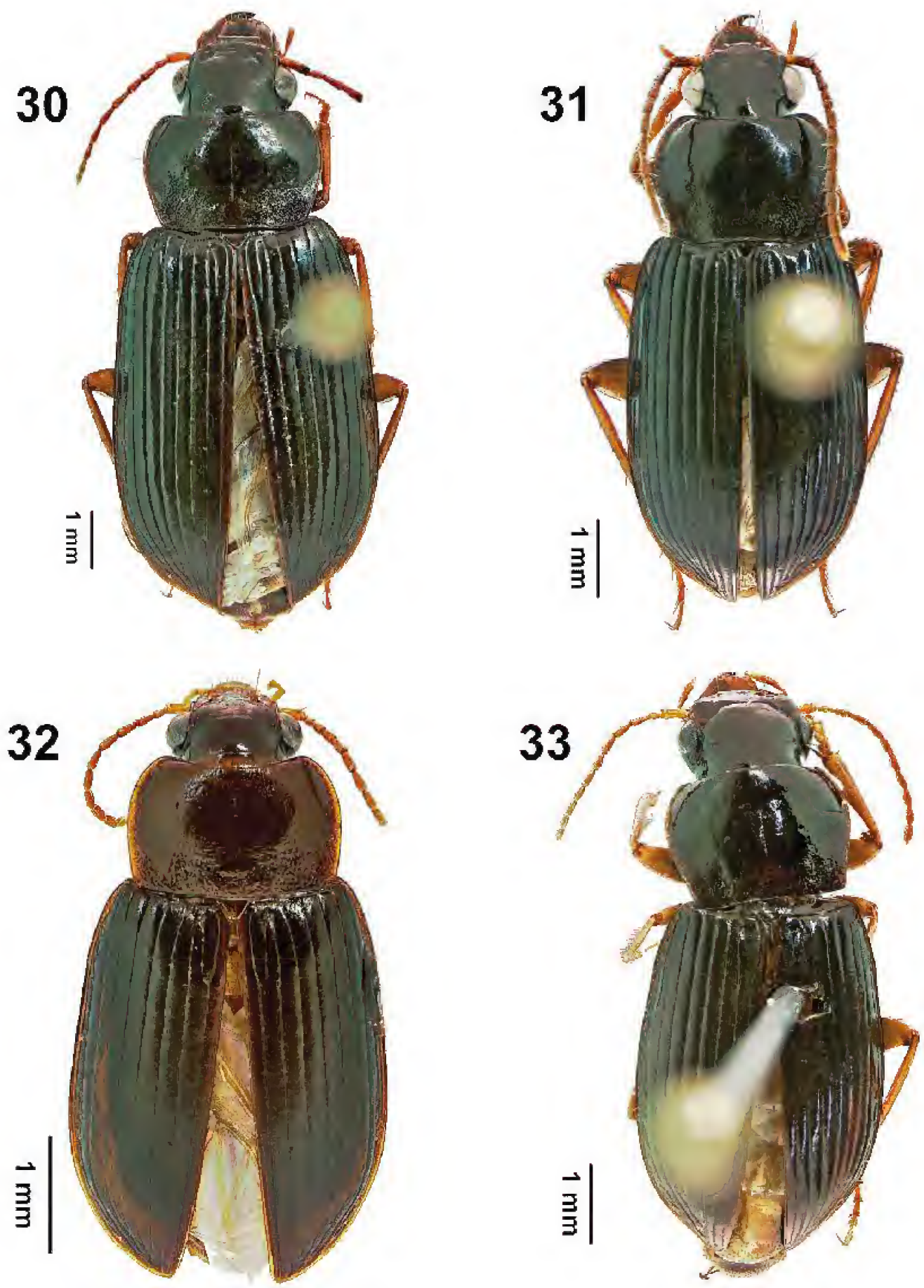

FIGURES 30-33. Digital photographs of dorsal habitus. Fig. 30. Coleolissus sp. B (CASENT8144051). Fig. 31. Coleolissus sp. C (CASENT8133541). Fig. 32. Coleolissus sp. D (CASENT8144053). Fig. 33. Trichotichnis sp. (CASENT 8144024). . 

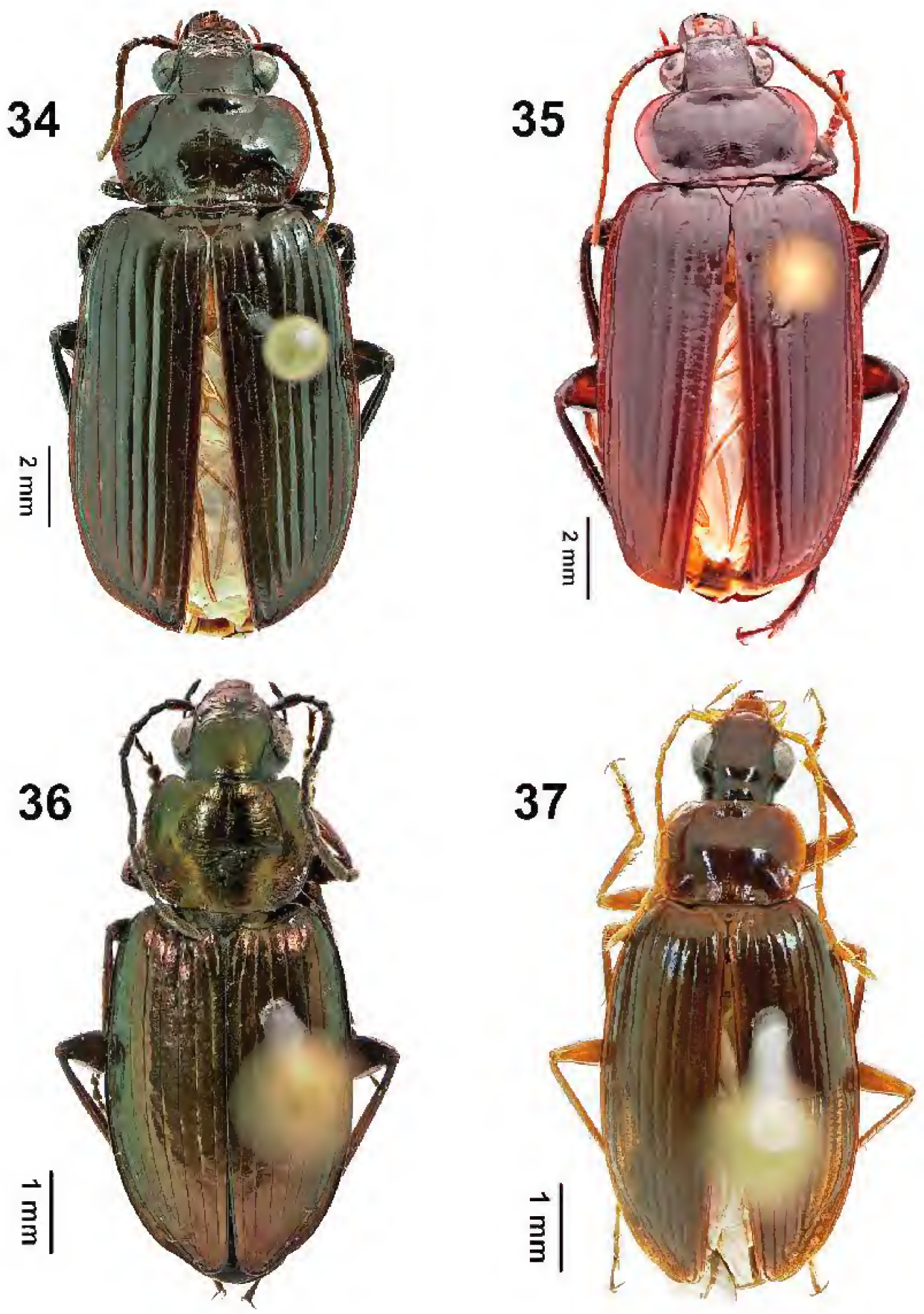

FIGURES 34-37. Digital photographs of dorsal habitus. Fig. 34. Orthogonius sp. A (CASENT8133517). Fig. 35. Orthogonius sp. B (CASENT8133538). Fig. 36. Agonum muelleri Herbst (CASENT81133572). Fig. 37. Altagonum sp. A (CASENT8133510). 

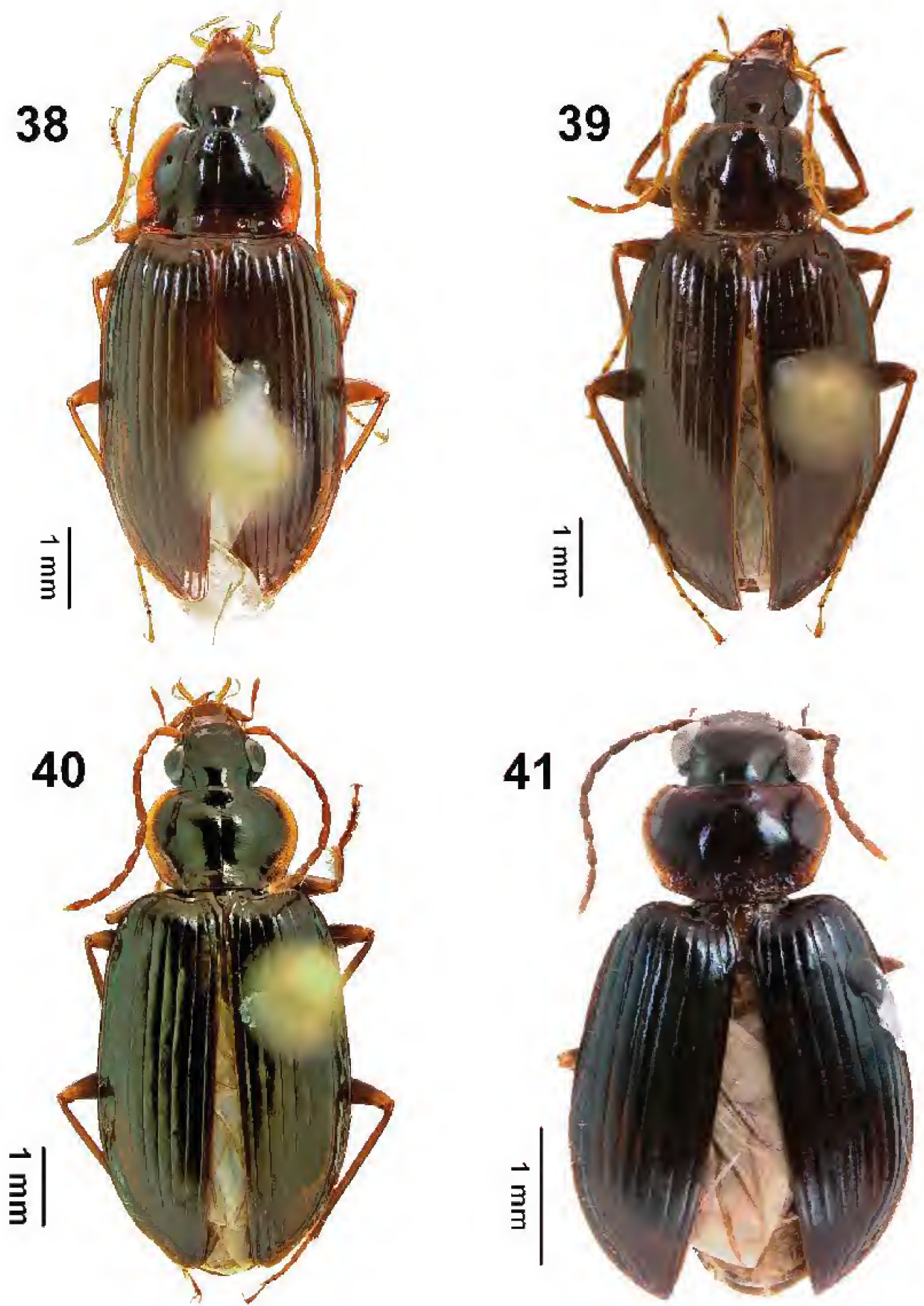

FIGURES 38-41. Digital photographs of dorsal habitus. Fig. 38. Altagonum sp. B (CASENT8133540). Fig. 39. Altagonum sp. C (CASENT8133571). Fig. 40. Altagonum sp. D (CASENT8133495). Fig. 41. Arhytinus minimus Jedlička. (CASENT8144077). 

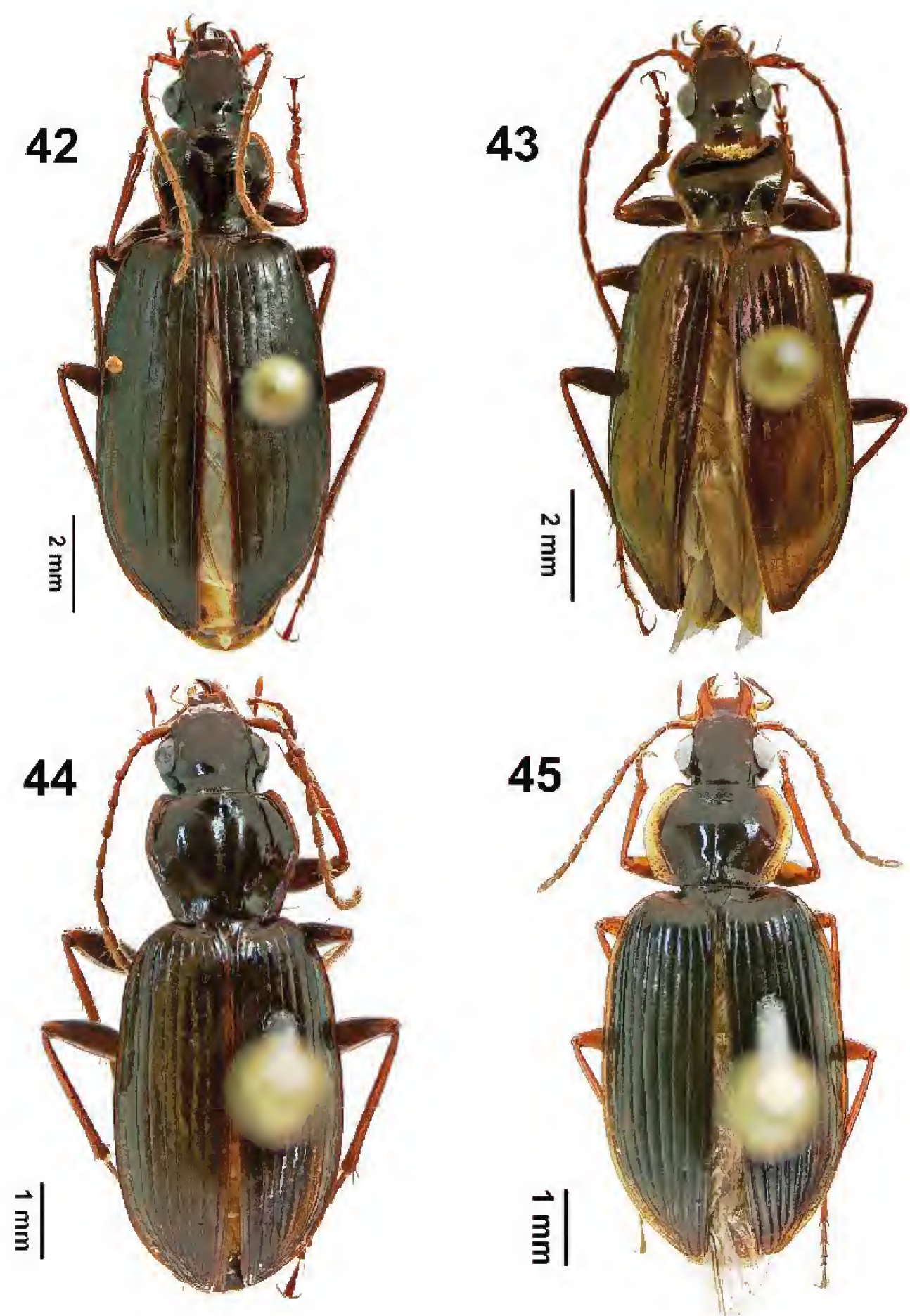

FIGURES 42-45. Digital photographs of dorsal habitus. Fig. 42. Colpodes sp. A (CASENT8144028). Fig. 43. Colpodes sp. B (CASENT8144029). Fig. 44. Gastragonum sp. (CASENT8133506). Fig. 45. Notagonum sp. A (CASENT8133559). 

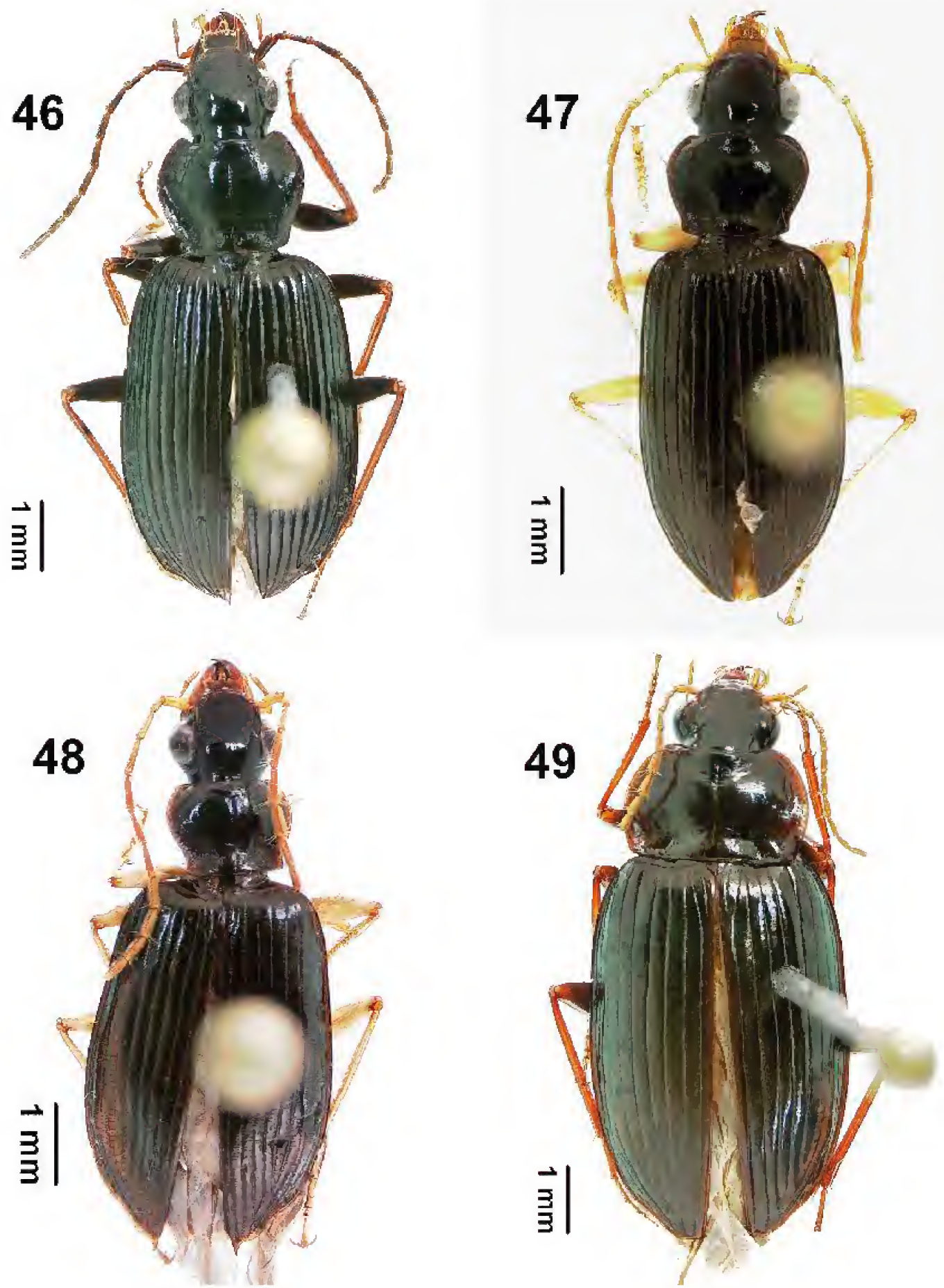

FigURES 46-49. Digital photographs of dorsal habitus. Fig. 46. Notagonum sp. B (CASENT8133494). Fig. 47. Notagonum sp. C (CASENT8144036). Fig. 48. Notagonum sp. D (CASENT8144034). Fig. 49. Notagonum sp. E (CASENT 8133539). 

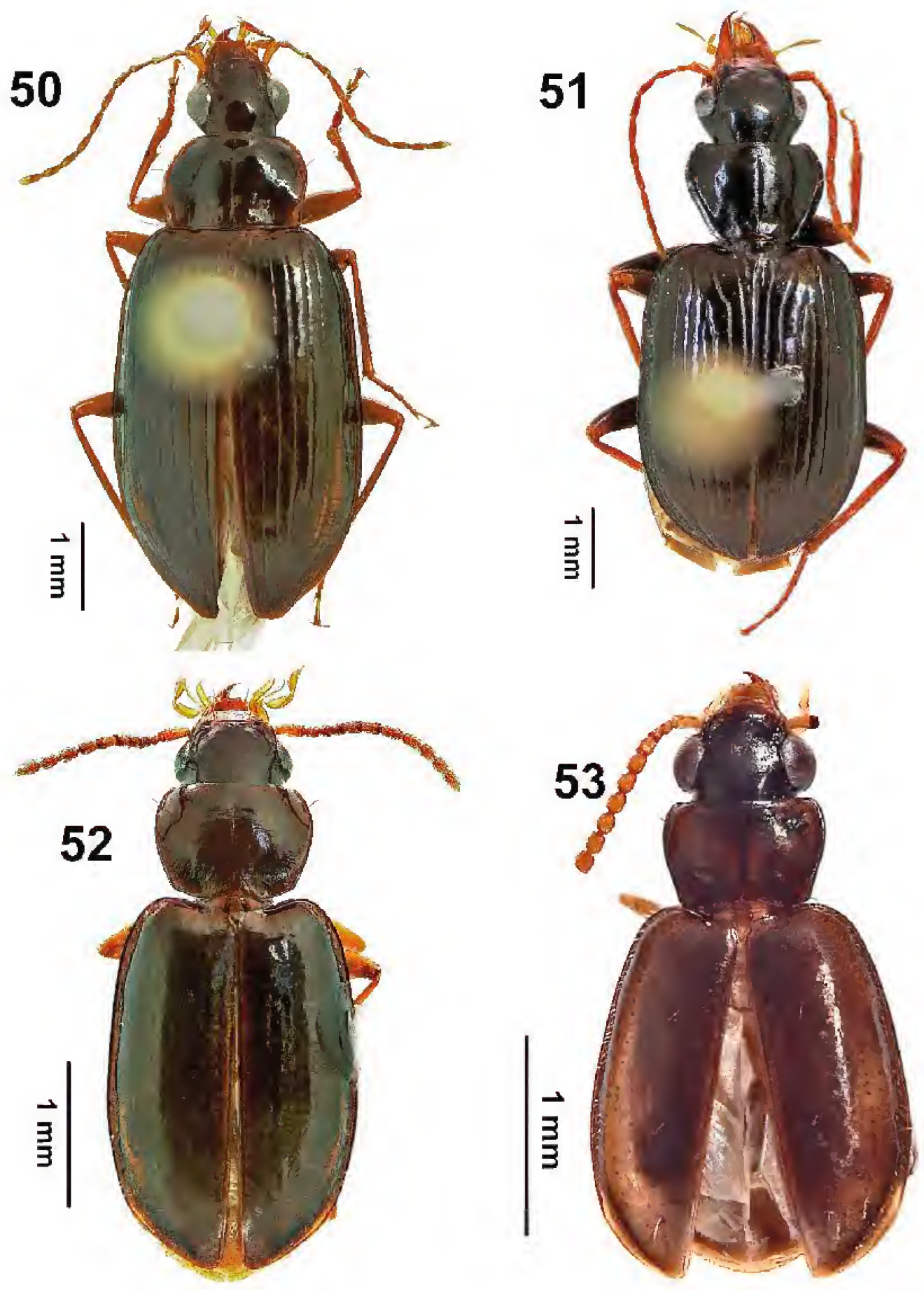

FIGURES 50-53. Digital photographs of dorsal habitus. Fig. 50. Notagonum sp. F (CASENT8144031). Fig. 51. ?platyrine/?lachnophorine sp. (CASENT8133569). Fig. 52. Perigona (s. str.) sp. (CASENT8144026). Fig. 53. Perigona (Trechicus) nigriceps (Dejean) (CASENT8144072). 

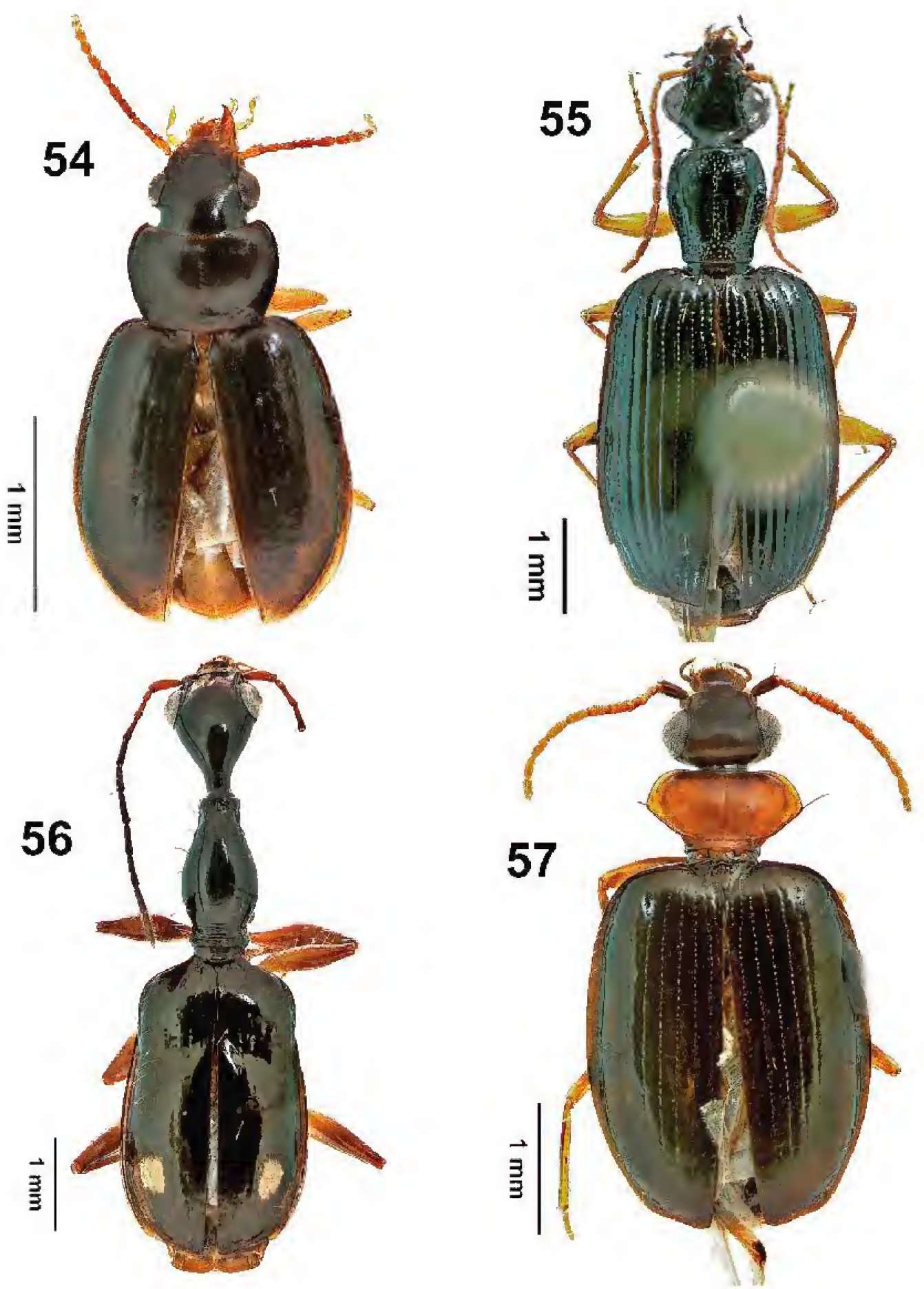

FIGURES 54-57. Digital photographs of dorsal habitus. Fig. 54. Perigona (Trechicus) sp. (CASENT814427). Fig. 55. Dicraspeda brunnea Chaudoir (CASENT8144040). Fig. 56. Mimocolliuris sp. (CASENT8144373). Fig. 57. Pentagonica sp. A (CASENT8144041). 

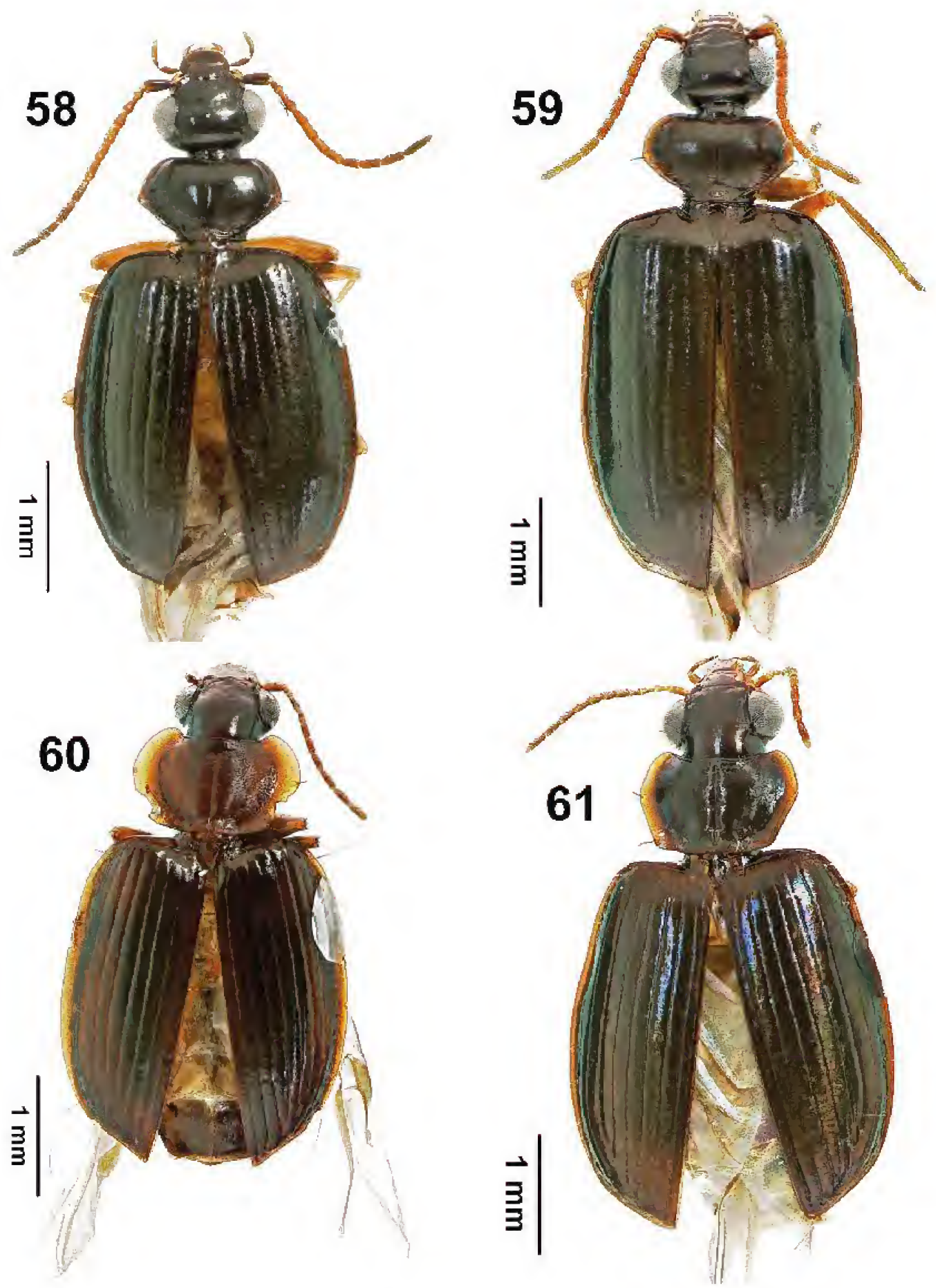

FIGURES 58-61. Digital photographs of dorsal habitus. Fig. 58. Pentagonica sp. B (CASENT8144058). Fig. 59. Pentagonica sp. C (CASENT8144380). Fig. 60. Dolichoctis sp. A (CASENT8144017). Fig. 61. Dolichoctis sp. B (CASENT 8144056). 

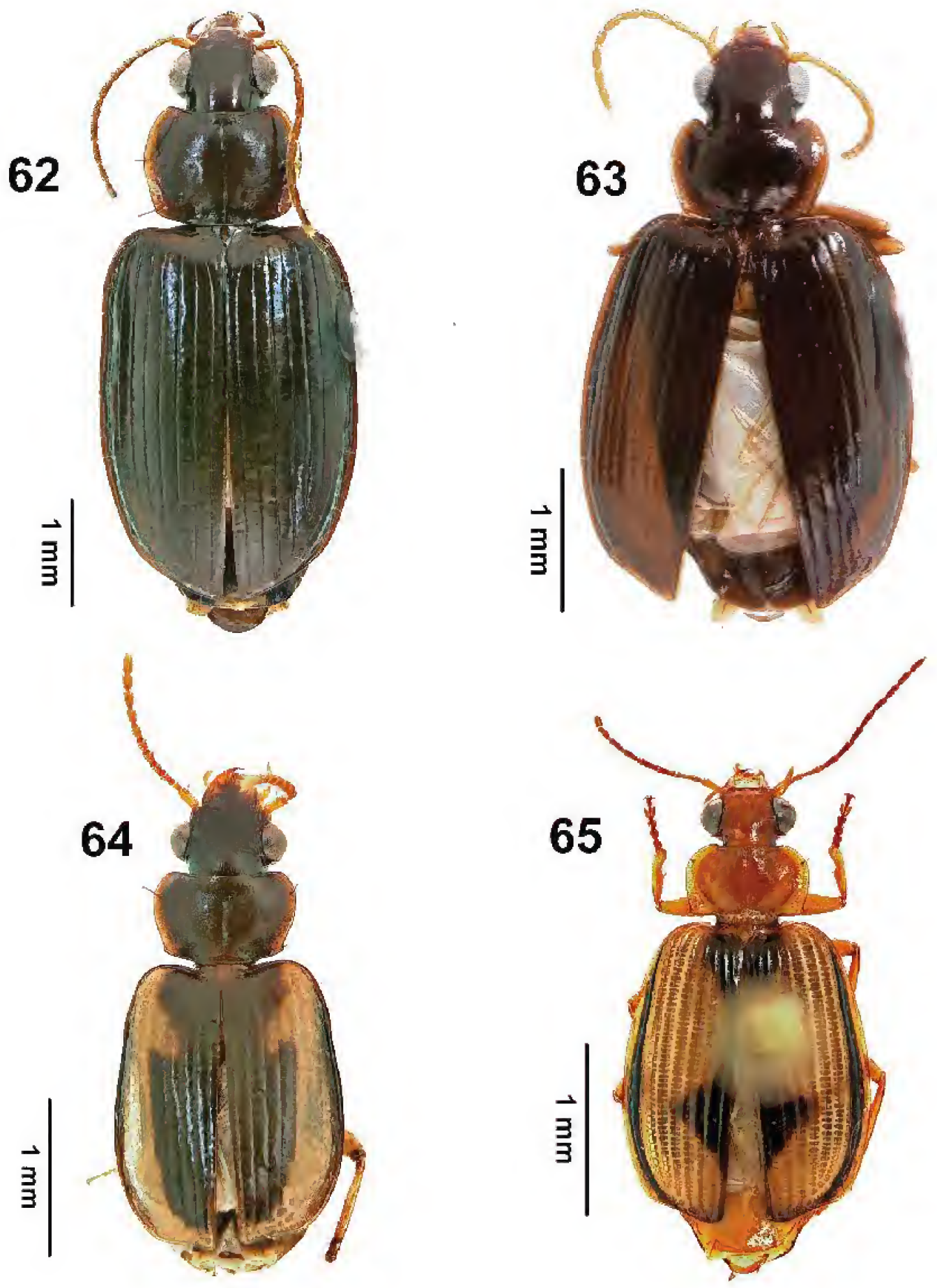

FIGURES 62-65. Digital photographs of dorsal habitus. Fig. 62. Dolichoctis sp. C (CASENT8144010). Fig. 63. Dolichoctis sp. D (CASENT8144370). Fig. 64. Syntomus sp. (CASENT8144069). Fig. 65. Lebia (Poecilothais) sp. (CASENT 8144013). 

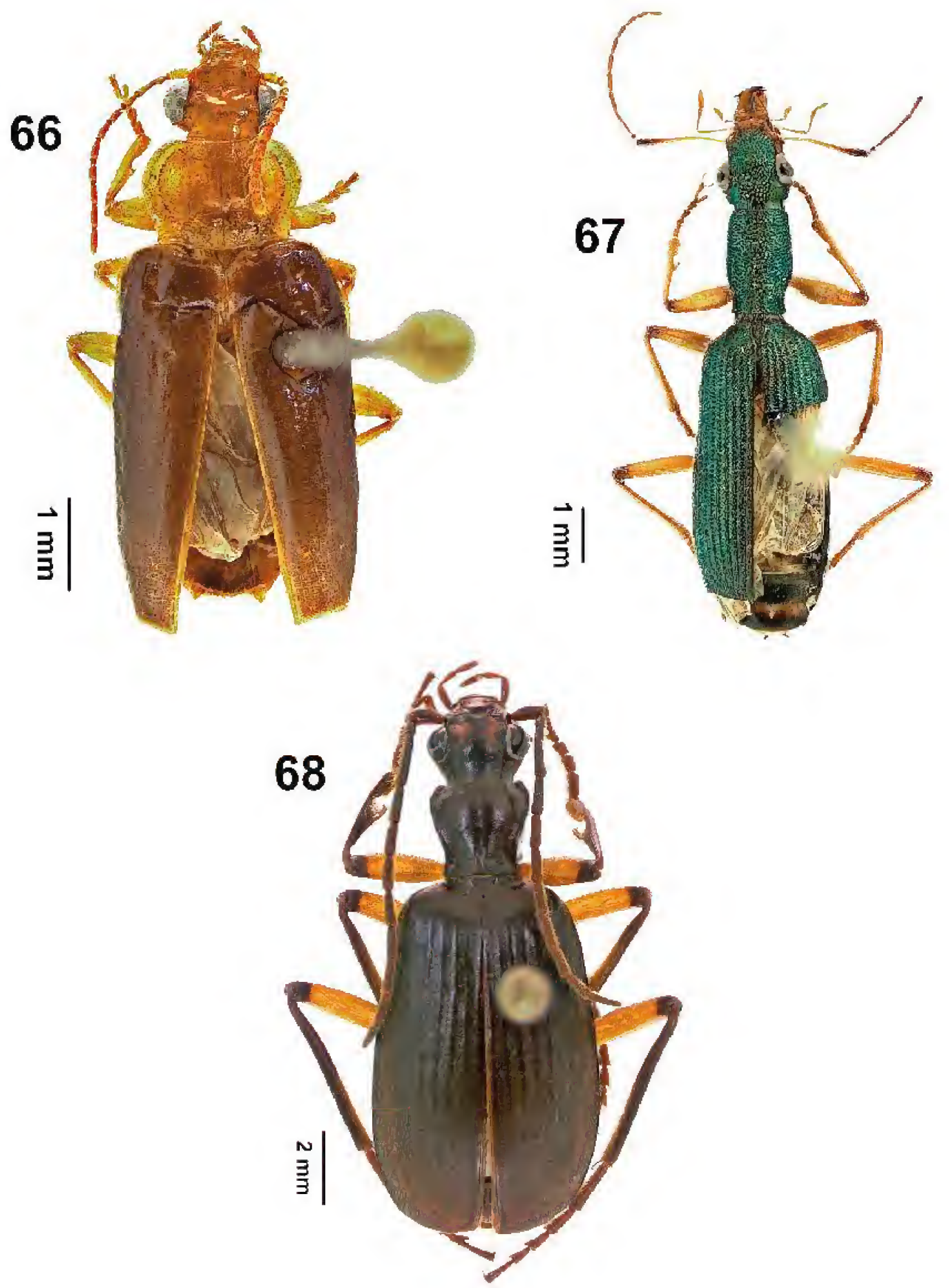

FIGURES 66-68. Digital photographs of dorsal habitus. Fig. 66. Paraphaea philippinensis (Jedlička) (CASENT 8133511). Fig. 67. Dendrocellus coelestinus (Klug) (CASENT8133493). Fig. 68. Brachinus sp. (CASENT8133551). 


\title{
The Dangerously Venomous Snakes of the Philippine Archipelago
}

with Identification Keys and Species Accounts

\author{
Alan E. Leviton 1, Rafe M. Brown 2, Cameron D. Siler ${ }^{3}$ \\ 1 Research Div., California Academy of Sciences, San Francisco, CA 94118 \& Research Associate, \\ Dept. Vertebrate Zoology, National Museum of Natural History, Smithsonian Institution, Washington, DC; \\ 2 Dept. Ecology \& Evolutionary Biology, University of Kansas, Lawrence, KS 66045-7593; 3 Dept. Biology \\ \& Sam Noble Oklahoma Museum of Natural History, University of Oklahoma, Norman, OK 73072-7029. \\ Email: 1 aleviton@calacademy.org; 2 rafe@ku.edu; ${ }^{3}$ camsiler@ou.edu

\section{Photographs by Rafe M. Brown, Arvin C. Diesmos, Dong Lin, Aaron Lobo, Cameron D. Siler, John Tashjian, Markus Oulehia, and Harold Voris Illustrations by Emily Eng and Michael Garfield}

\section{Table of Contents}

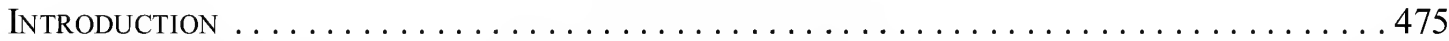

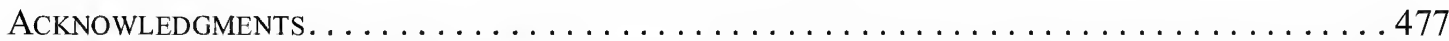

IDentification keys to the Dangerously venomous snakes of the Philippine Archipelago479

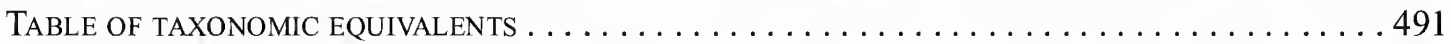

Species accounts for the dangerously venomous snakes of the Philippine Archipelago 493

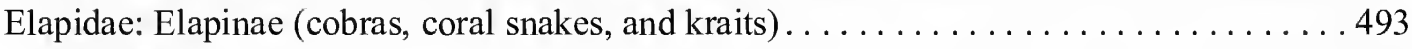

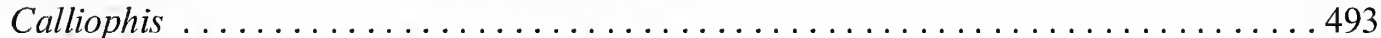

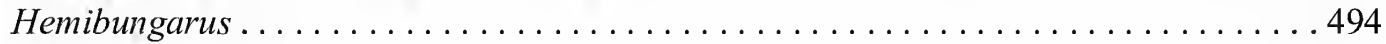

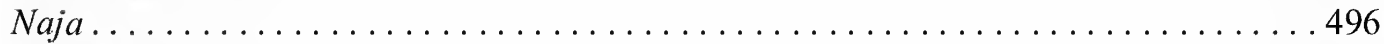

Ophiophagus ........................................ 497

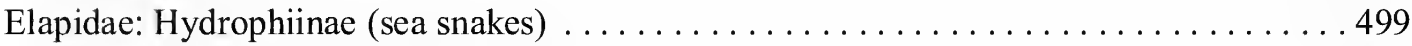

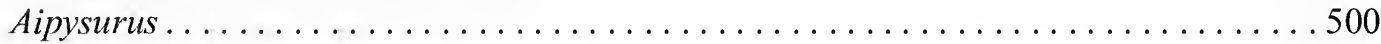

Emydocephalus ..................................... 501

Hydrophis (including Acalyptophis, Astrotia, Disteira, Enhydrina, Kerilia, Kolpophis,

Lapemis, Leioselasma, Pelamis, Praescutata, Thalassophis) . . . . . . . . . . 501

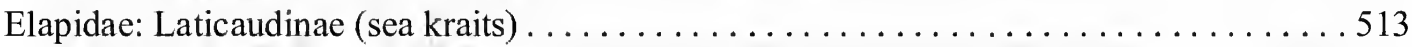

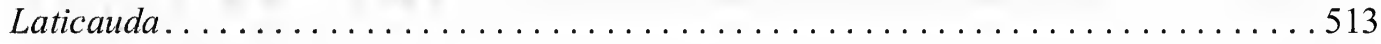

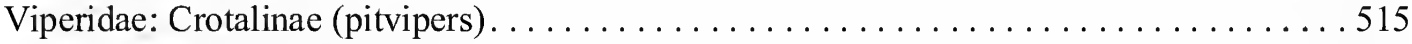

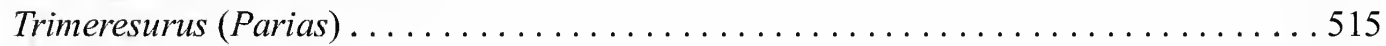

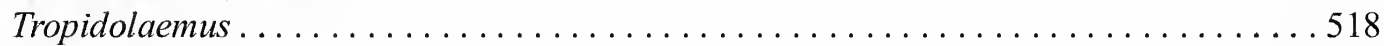

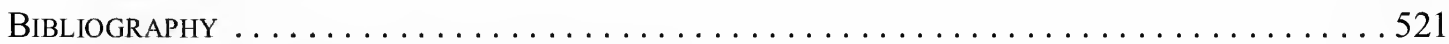

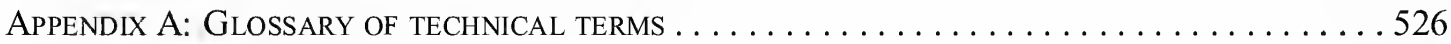

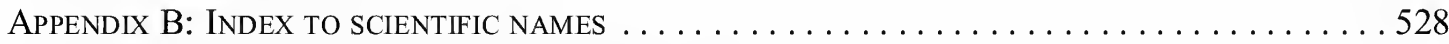

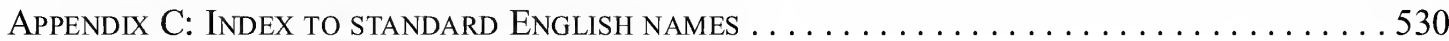




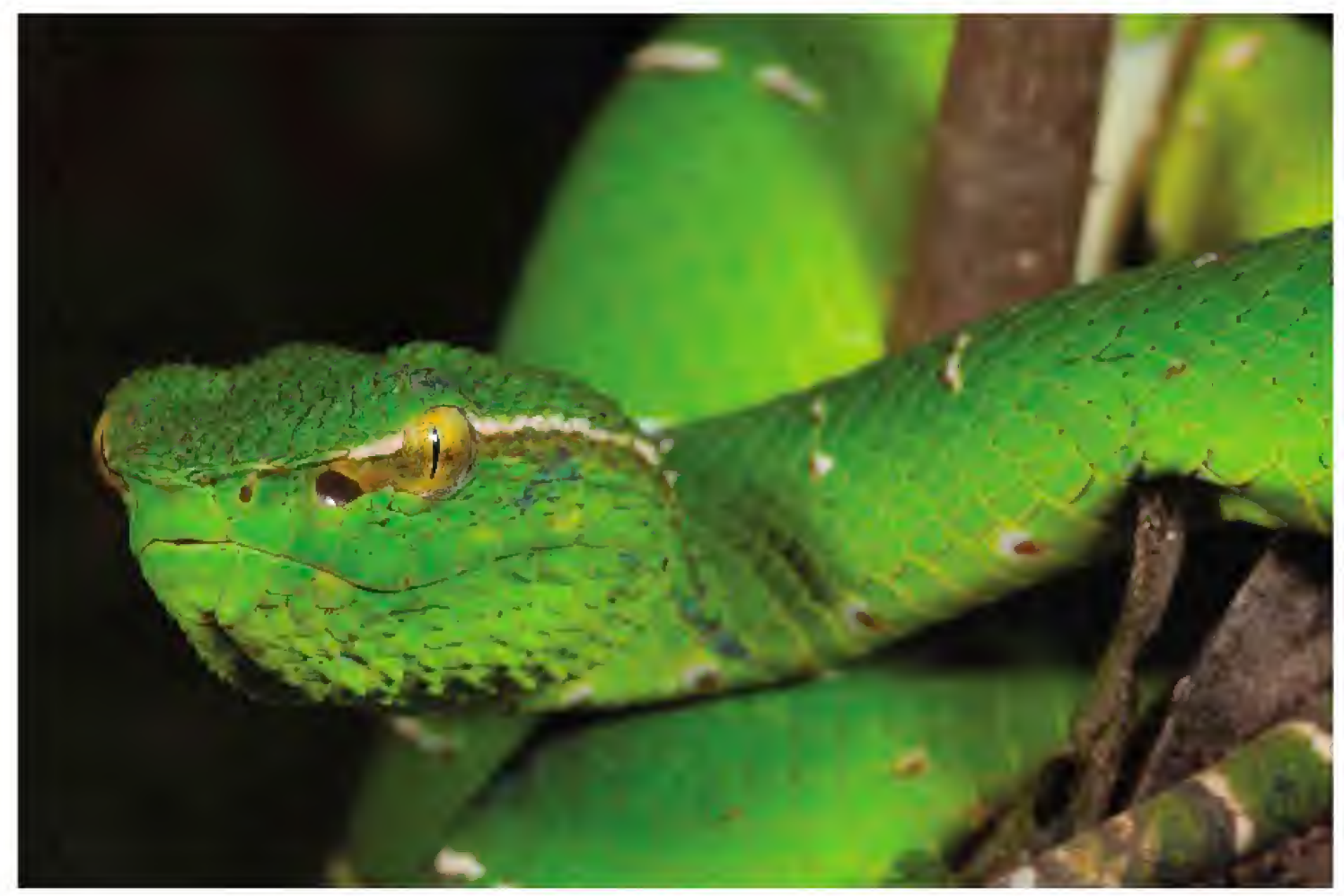

FIGURE 2. Tropidolaemus subannulatus Photo by Cameron D. Siler 


\section{The Dangerously Venomous Snakes of the Philippine Archipelago}

\section{INTRODUCTION}

To fewer than 33 species of dangerously venomous snakes inhabit the Philippine Islands 1 and the surrounding coastal waters (41, if one includes eight sea snakes that have yet to be found in Philippine coastal waters but are likely to occur there). Of the possible 41 species, 26 are sea snakes and except for two, Laticauda colubrina and L. laticaudata, none voluntarily come onto land (although some sea snakes may wash ashore during severe weather). The remaining 15 species are terrestrial living in various habitats on land and in freshwater. Several terrestrial species, such as Tropidolaemus [formerly Trimeresurus] subannulatus [formerly wagleri], favor arboreal habitats and seldom descend to the ground. All terrestrial species can swim, and some regularly occur near human habitations, in agricultural areas, and typically around sources of water such as flooded rice fields, rivers, and streams.

Two families of dangerously venomous snakes are represented in the Philippine herpetofauna, Elapidae (including sea snakes [subfamilies Hydrophiinae and Laticaudinae]), and Viperidae. A number of mildly venomous snakes occur in the archipelago as well, and most are members of the highly diverse snake family Colubridae; these include the rear-fanged Asian vine-snakes (Ahaetulla), cat-eyed snakes (Boiga), mock viper (Psammodynastes), and two aquatic and semi-aquatic snakes (Enhydris, Cerberus). How dangerous any of these are to humans is still an open matter for research. Several of the supposedly non-venomous Asian colubrids have been shown to have toxic salivas, and some can be considered mildly, if not dangerously, venomous. Some non-Philippine watersnakes (selected species of Tropidonophis and Rhabdophis) have been shown to be life threatening to humans but to date, in the Philippines none of these genera have been shown to be dangerous. What we do know is that we often underestimate the severity of many snakebites of both juvenile dangerously venomous and supposedly non-dangerously venomous snakes. Yet, bites of just such animals have been implicated in the deaths of several knowledgeable professional herpetologists, notably Karl Patterson Schmidt who, in 1957 at the age of 67, was bitten by a juvenile boomslang (Dispholidus typus), an African rear-fanged snake, and died a day later; in 1965, Fred Shannon, M.D., was bitten by Crotalus scutellatus, and a few years later, in 1975, Robert Mertens, was bitten by another African rear-fanged snake, Thelotornis capensis, and both died as a result of the bites. And, most recently, in 2001, Joseph Slowinski, at the age of 38, was bitten by a $30 \mathrm{~cm}$ long juvenile krait, Bungarus wanghaotingi, and died within 48 hours.

At this point we emphasize that extreme care should be exercised when handling any snake, even those that are supposedly non-venomous. It is not always possible to tell the difference between venomous and non-venomous species without careful inspection. In the Philippines, for instance, several snakes are black with white bandings; among these are Lycodon subcinctus, Calamaria lumbricoidea, juveniles of several species of Oxyrhabdion, Oligodon, and Chrysopelea, as well as the six species of venomous snakes that are referred to the genera Hemibungarus and Calliophis. The snakes of the first group are non-venomous, the latter two,

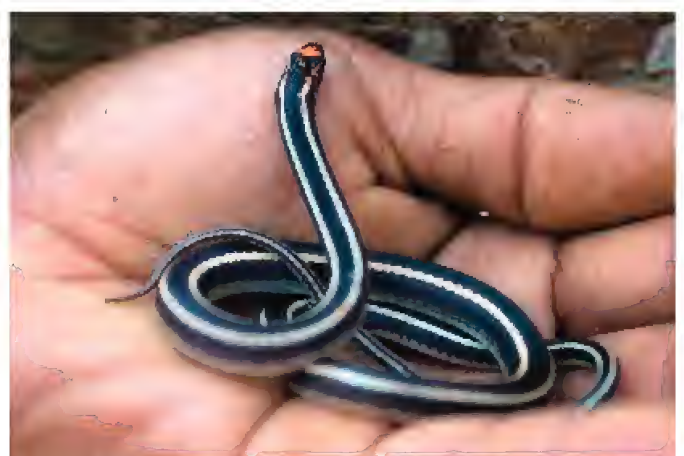

FIGURE 1. Looks can be deceiving. A field colleague recently picked up and photographed this innocentlooking snake in the belief it was a non-venomous species of Calamaria. It is, in fact, a coral snake, of the genus Calliophis. Photo by N. Antoque. 
Hemibungarus and Calliophis, dangerously venomous. The only definitive way to know whether a dark and light banded snake is a venomous or non-venomous species is to examine the side of the head just in front of the eye to see if a loreal scale (see fig. on p. 480) is present. If it is absent, the snake may well be a venomous species. In the illustrated keys that follow, these and other defining characters are clearly noted.

With respect to the treatment of snake-bites, again it cannot be overstated that all bites should be taken seriously. It is true that a large percentage of bites, even by dangerously venomous snakes, are "dry bites," that is bites in which no envenomation occurs. Because it is not always possible to know immediately following a bite whether or not envenomation has occurred, it is imperative to seek appropriate medical treatment as soon as possible. More complete instructions are available in other publications, several of which are given in the bibliography (see in particular WHO 1999 and Lewin [this volume]).

The snake fauna of the Philippines is reasonably well known, although there are areas of the country that have not been thoroughy investigated, especially parts of Luzon, Mindanao, and Palawan. It should be emphasized that precise knowledge of the kinds of venomous snakes present is imperative if one is going to receive effective medical treatment for a snakebite. For instance, in the Philippines, heretofore, only one species with three subspecies of the Philippine cobra was recognized, Naja naja, but extensive work by investigators demonstrated that in reality the three subspecies are quite distinct and are now recognized as full species. However, in the Philippines, only one antivenin is manufactured and readily available, for Naja philippinensis. The importance of this can be appreciated when one considers that to treat a snakebite one must often use speciesspecific antivenom in as much as the antivenom used to treat one kind of snakebite may not work for the bites of other species. Whether the species-specific antivenom for the Philippine cobra, Naja philippinensis, works for other cobra snakebites is not known.

The Philippines has a highly diverse fauna. And as a result of recent surveys, starting in the 1950s by the late Walter C. Brown of Menlo College, California, and and his colleague Angel Alcala, then at Silliman University, Dumaguete, and thanks to recent field work throughout the archipelago, knowledge of the faunal diversity has improved greatly. It is hoped that this contribution will enable those engaged in the study of the fauna in the field and the laboratory to recognize more readily the most dangerous components of that fauna.

The present work represents an effort with a single purpose, to aid in the identification of venomous snakes of the Philippines. Thus, we have made no attempt to provide inclusive synonymies, which are available in several of the works we cite, namely, Taylor (1922a), Leviton (1964a, 1964b), Golay et al. (1993), McDiarmid, Campbell and Touré (1999), and David and Ineich (1999). Where necessary, we provide additional references. DESCRIPTIONS of individual species are intentionally brief, but they include the data necessary for confirmation of identifications. The data for SIZE refer to known maximum lengths recorded for the species; when available, total and tail lengths for males and females are given separately. In the statements on DisTRIBUTION, we list only the country for non-Philippine localities and, where known, to Island and/or Province within the Philippines (see map, p. 492).

We accept names for all of the dangerously venomous snake species in the Philippines that represent the most current taxonomic arrangements, although with respect to sea snakes we have followed Sanders et al. (2013) (see also Pyron et al.2013) in the use of generic assignments of species and Rasmussen et al. (2011) for subfamily assignments. We provide a brief table of equivalencies (p. 487) so that those familiar with older names can quickly locate the species of interest. For instance, in the Philippines, snakes formerly referred to collectively as Trimeresurus wagleri, have been assigned to two different species under the genus name Tropidolaemus (i.e., T. philippensis 
and T. subannulatus); the annulated or barred coral snake, Calliophis calligaster, is now placed in the genus Hemibungarus, whereas the banded coral snake, Maticora intestinalis, is referred to as Calliophis intestinalis. In addition, in recent years, the pit vipers usually referred to the genus Trimeresurus have been subjected to intense scrutiny and at times have been reassigned to several genera, Trimeresurus, Parias, and, as already noted, Tropidolaemus. At the time of the writing of this report, the species of pit vipers assigned to the nominal genus Parias, have been returned to the genus Trimeresurus (e.g., T. flavomaculatus, T. mcgregori, and T. schultzei); however, some researchers recognize Parias as a subgenus of Trimeresurus, and we have adopted that assignment here, whereas Tropidolaenus is still valid as a distinct genus. These changes, though frequently confusing to the non-specialist, often represent significant advances to our understanding of the relationships and are important in leading to more effective treatment of snakebites by allowing for the selection and administration of appropriate species-specific antivenoms.

Lastly, we emphasize that whereas we believe all snakes should be treated with care, venomous or not, snakes are also highly beneficial to the ecosystem and should not be wantonly destroyed because of fear. The vast majority of the Philippines' $180+$ species of snakes are not dangerous to humans.

An early version of this publication titled "Keys to the dangerously venomous terrestrial snakes of the Philippines" was published in the Silliman Journal (Leviton 1961). That publication was followed by Angel Alcala's 1986 treatment of the venomous snakes of the Philippines in volume X, Amphibians and Reptiles, in the Guide to Philippine Flora and Fauna. Since these publications appeared, additional new information from both field and laboratory research has come to light. Indeed, a number of groups in Europe and the United States are actively engaged in research aimed at clarifying the taxonomy of the viperid genera Trimeresurus and Tropidolaemus, as well as the elapid snakes in the genera Calliophis and Hemibungarus and the sea snakes. As a result, we expect that the classification of the venomous snakes presented here will continue to change (see Bibliography for references, especially for authors David, Ineich, and Vogel, Rasmussen et al., Thorpe, Maholtra, and Wüster).

\section{ACKNOWLEDGMENTS}

The authors express their profound appreciation to Harold Voris, Doug Lin, and John Tashjian, who are responsible for several of the photographs that are reproduced here. Please note that in those figure legends where the words "Photo by" appear, copyright ownership of the images resides with the individual acknowledged and not the California Academy of Sciences.

We owe a special thanks to our friend and collaborator A. C. Diesmos (National Museum of the Philippines) for his continued support, past companionship in the field, for the use of photographs reproduced here, and for the logistical assistance he has generously provided through the years.

And, lest we forget, one of us (AEL) wants to express his appreciation again to the staff of the National Museum of Natural History, specifically George Zug, Addison Wynn, and Kenneth Tighe, for their ongoing assistance in locating specimens and providing onsite work space.

Lastly, we thank Dr. Michele L. Aldrich who perused an early version of the manuscript with extraordinary care and made substantive suggestions for improving the overall presentation. We are also indebted to the external reviewers for their thoughtful comments. Dr. George Zug, in particular, suggested a number of changes, most of which we heartily accepted. Having said this, the authors still bear full responsibility for their decisions to accept or reject specific recommendations as well as for errors of commission or omission. 
Fieldwork was supported partially by a National Science Foundation Doctoral Dissertation Improvement grant (DEB 0804115 to CDS), Fulbright and Fulbright-Hayes Fellowships (to CDS); and an NSF Biotic Surveys and Inventories grant (DEB 0743491 to RMB). We thank the Philippine government's Protected Areas and Wildlife Bureau (PAWB) of the Philippine Department of Environment and Natural Resources for facilitating field studies that involved numerous encounters with venomous snakes.

Alan E. Leviton, Rafe M. Brown, and Cameron D. Siler

06 January 2014 


\section{Identification Keys to the Species of Dangerously Venomous Snakes of the Philippine Archipelago}

General Note AND TAXonomic (NAME) Changes: This key has been formulated to accommodate only the dangerously venomous snakes known from the Philippine Islands. It should not be used, even at the generic or familial group levels, to identify venomous snakes from outside the archipelago. Colors mentioned in the keys are based on colors in life; in preservative, colors may be lost or changed, greens turn bluish, reds are lost, and other bright colors become dull. In preparing this key and the species accounts that follow, we have been guided by the latest revisionary studies, but we have also taken a conservative position because of the nature of the animals with which we are working (see below). The section of the key dealing with the sea snakes (couplets 17 et seq.) has been modified from Smith (1926 and 1943 and Rasmussen, Elmberg, Gravlund, and Ineich 2011). Furthermore, we have culled from the literature and adopted the most recent phylogenetic arrangement for the genera of viviparous sea snakes, notably that of Sanders et al. 2013, so that many heretofore familar generic names, such as Enhydrina, Lapemis, and Pelamis, and their included species, have been referred to the genus Hydrophis.

Also, we have, rather arbitrarily, chosen to accord all recognizably distinct allopatric subspecies full species status rather than get embroiled in arguments of why raise one subspecies to full species status but retain another as a subspecies, though both can be readily, though differentially, diagnosed taxonomically. Arguments as to what constititues a biological "species" versus "subspecies" are most often not fruitful and usually based on arbitrary assessments by a given worker on just how "important" a character or character state is in inferring the "closeness" of biological affinities, i.e., the genealogical relationships among the parties.

As we have already mentioned (pp. 472-473), in recent years the most significant nomenclatural changes have been in the allocation of species among genera of venomous snakes. Thus, we hasten to emphasize, many of these changes are not to be taken lightly inasmuch as they reflect important changes in our understanding of the relationships among these venomous snake species and are highly relevant because of the significant medical implications, vis-a-vis the production and use of antivenins in the treatment of snakebites.

Also, please note, many of the images have been provided by colleagues as a courtesy for the express use of members of the Hearst Philippine Expedition participants; the images are owned and copyrighted by the donors and must not be copied or otherwise distributed. 
A
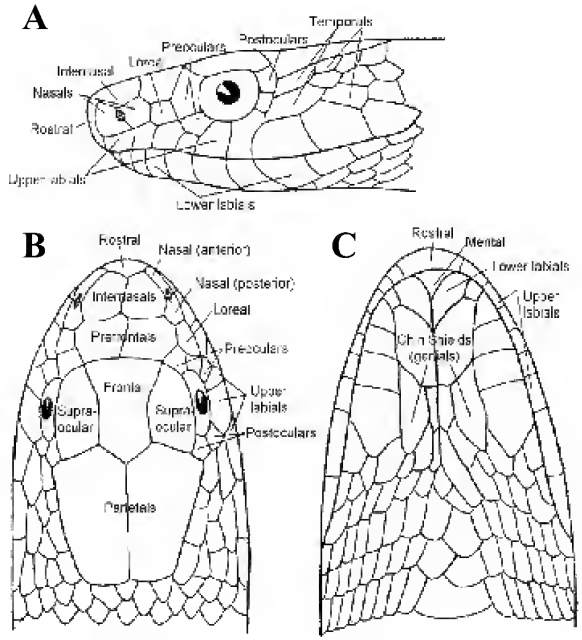

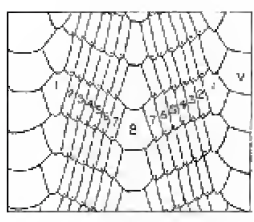

D

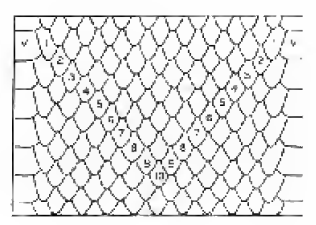

E
Diagrams of head and body scalation in a typical snake. Head scales: (A) lateral, (B) dorsal, and $(C)$ Ventral views.

Body scale patterns and how best to count scale rows. Body scales arranged in (D) oblique rows, and (E) parallel rows.

Diagrams modified from Smith (1943)

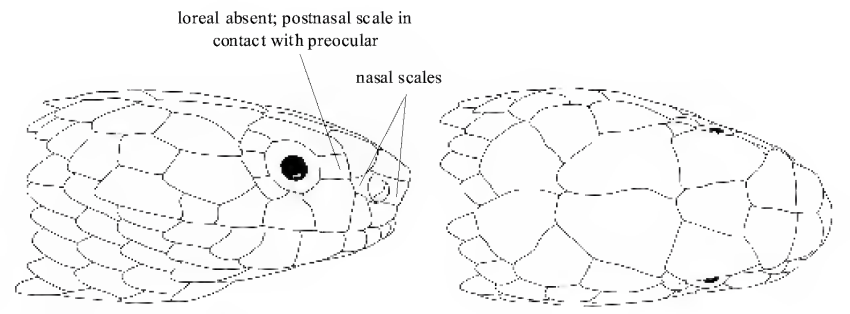

G
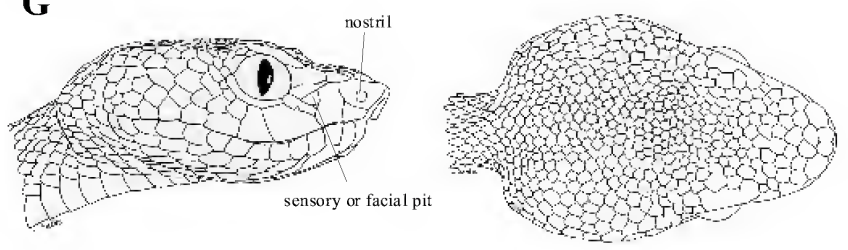

$\mathbf{H}$

G. Lateral and dorsal views of the head of a king cobra, Ophiophagus hannah. Note in particular the absence of the loreal scale between the postnasal and the preocular scales. This is characteristic of all elapine snakes, but the absence must be used with care because a number of non-venomous colubrine snakes also lack the loreal.

H. Lateral and dorsal view of a typical Philippine viperine snake, Trimeresurus (Parias) flavomaculatus. Note the position of the sensory pit located on the side of the head between the nostril and the eye.
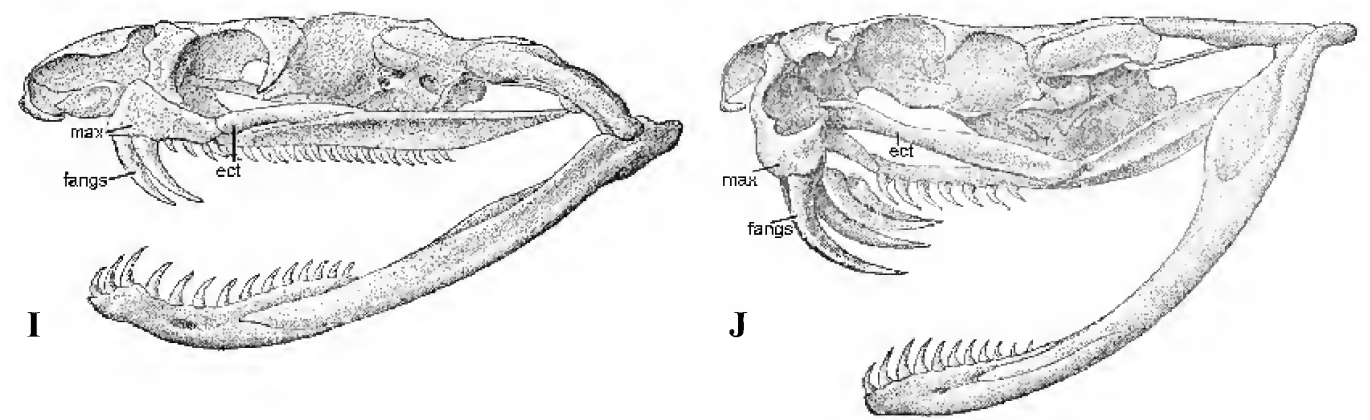

Diagrams of skulls of elapine (Naja naja) (I) and crotaline viper (Crotalus horridus) (J) skulls.

(I) maxilla is attached to ectopterygoid and cannot rotate; small post-fang maxillary teeth usually behind venom delivery fangs; $(\mathrm{J})$ Maxillary bone small, rotates against ectopterygoid; no teeth behind venom delivery fangs.

Diagrams from Boulenger (1893, 3:373 and 3:518)

$(\max =$ maxillary bone; ect $=$ ectoptygeroid bone $)$

FIGURES 3A-J. Diagrams of diagnostic scale and dental characters of Philippine snakes. 
1a. Pupil of eye round; loreal scale absent (Fig. 4); venom fangs short, permanently erect; maxillary bone elongate, usually with several small teeth behind front fangs (Family Elapidae,

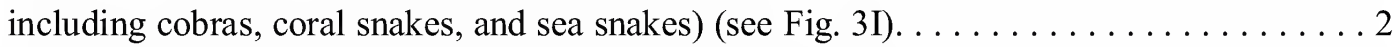

1b. Pupil of eye vertically elliptical (Fig. 5A); loreal scale absent; upper surface of head either covered by small scales (Fig. 5B) or large, symmetrical scales; a deep sensory pit present immediately behind the nostril (Fig. 5A); venom fangs variable in length, fixed to a short moveable maxillary bone that allows for rotation of the fangs backward when the mouth is closed; no

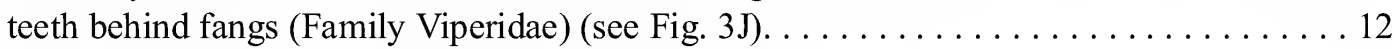

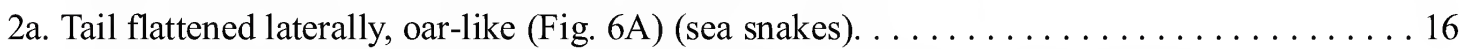

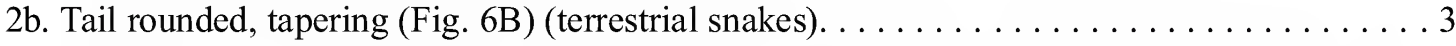

3a. Scales in 13-15 longitudinal rows at midbody; scales on sides of body variable, in either

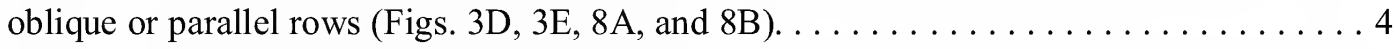

3b. Scales in 17-25 longitudinal rows at midbody; scales on sides of body in oblique rows [Fig. 3D, also Fig. 8A for Ophiophagus] (Genus Naja). . . . . . . . . . . . . . . . . . . 10

4a. Scales on sides of body in oblique rows (Figs. 3D, 8A); number of scales on posterior third of body at least two less than on anterior third (Balabac, Jolo, Luzon, Mindanao, Mindoro, Negros, Panay, Palawan, Polillo)............... Ophiophagus hannah (Fig. 7A)

4b. Scales on sides of body in parallel rows (Figs. 3E, 8B); number of scales on posterior third of

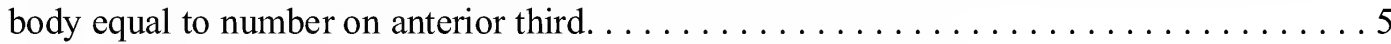

5a. Scales in 15 longitudinal rows at midhody (Genus Hemibungarus) $\ldots \ldots \ldots \ldots \ldots \ldots$

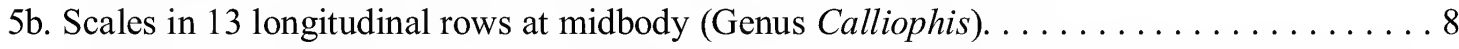

6a. Black rings on dorsum of body not divided by narrow white annuli; temporal region heavily pigmented with melanin; white annuli on dorsum usually less than $60 \ldots \ldots \ldots \ldots \ldots 7$

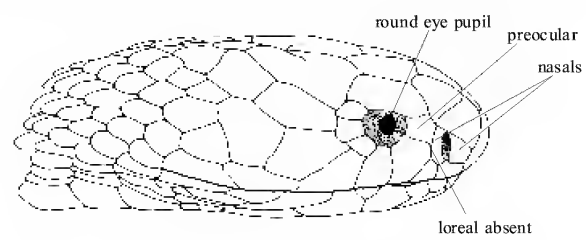

FIGURE 4. Pupil of eye of Naja philippinensis; loreal scale absent.
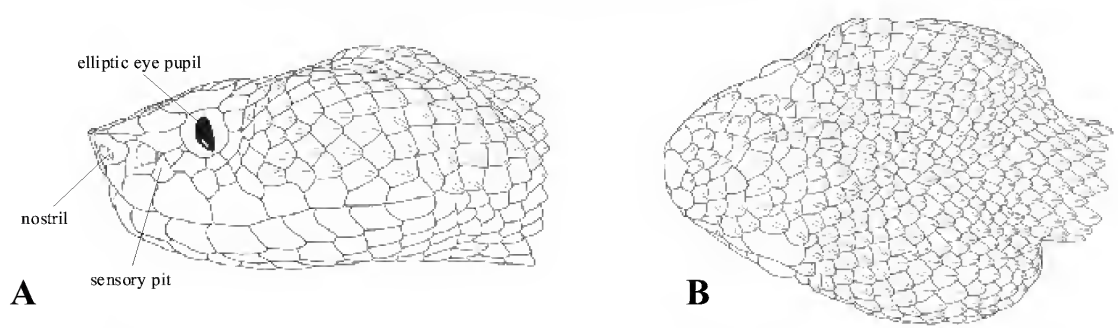

FIGURES 5A-B. Tropidolaemus subannulatus: (A) Lateral view of head (B) Dorsal view of head.

A

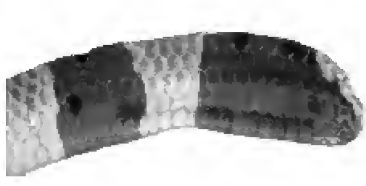

FIGURES 6A-B. Tails of sea snakes (A. laterally compressed, paddle-shaped) and terrestrial snakes (B. not compressed, rounded and tapering toward tip). 
6b. Black rings on dorsum of body divided by narrow white annuli; temporal region not heavily pigmented with melanin; white annuli on dorsum usually more than 60 ; ventral shields: $\left({ }^{\pi}\right)$ 197-216, (ㅇ) 218-227 (Cebu, Negros, Panay). . . . . . . . . . . . Hemibungarus gemianulis

7a. Ventral shields: (ठ઼) 223-233; (ㅇ) 252-259 (Luzon). . . . . . Hemibungarus calligaster (Fig. 9)

7b. Ventral shields: (ठ) 206 (two specimens) (Polillo and adjacent Aurora Prov., Luzon). . . . . . . $\ldots \ldots \ldots \ldots \ldots \ldots \ldots \ldots \ldots \ldots \ldots \ldots \ldots \ldots \ldots \ldots \ldots \ldots \ldots \ldots \ldots \ldots \ldots$ Hemibungarus melungi

8a. Black crossbars on venter do not come in contact with black of sides; a distinct white line present on sides occupying entire first scale row or parts of first and second rows (Balabac,

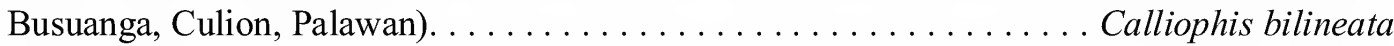

8b. Black crossbars on venter contact black of sides; no distinct white line along outer scale rows

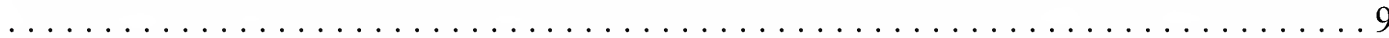

9a. Cream colored crossbars on venter do not extend on to side of body above first scale row (Jolo)

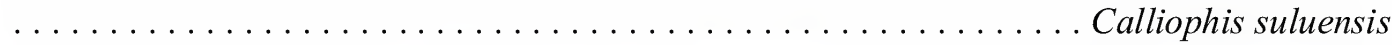

9b. Cream colored crossbars on venter extend onto side of body, often to fourth scale row (Mindanao, Samar) . . . . . . . . . . . . . . . . Calliophis philippina (Fig. 10)
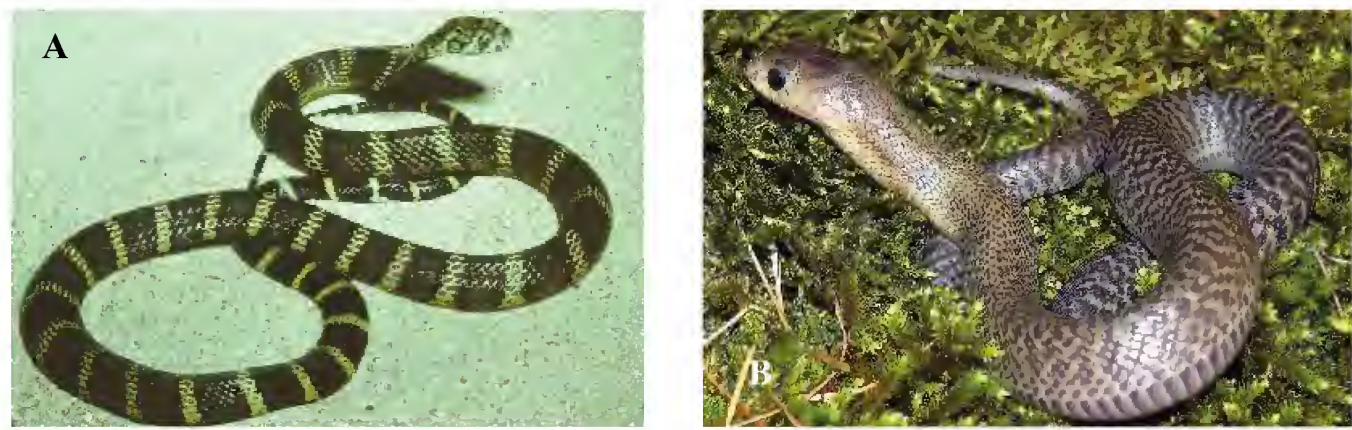

Figures 7A-B. Juneiles of (A) Ophiophagus hannah. and (B) Naja philippinensis. Photos.courtesy of (A) John Tashjian and (B) Markus Oulahla

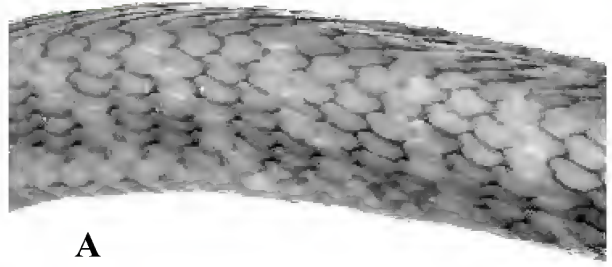

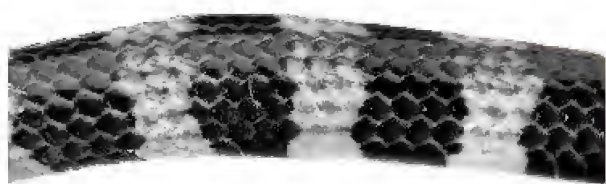

B

FIGURES 8A-B. Scales on sides of body: (A) slanting downward [oblique] (Ophiophagus hannah); (B) horizontal [parallel] (Hemibungarus calligaster).

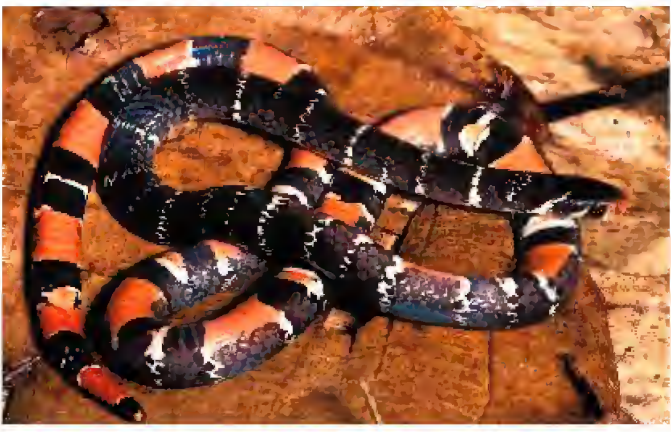

FIGURE 9. Hemibungarus calligaster. Photo by Rafe Brown.

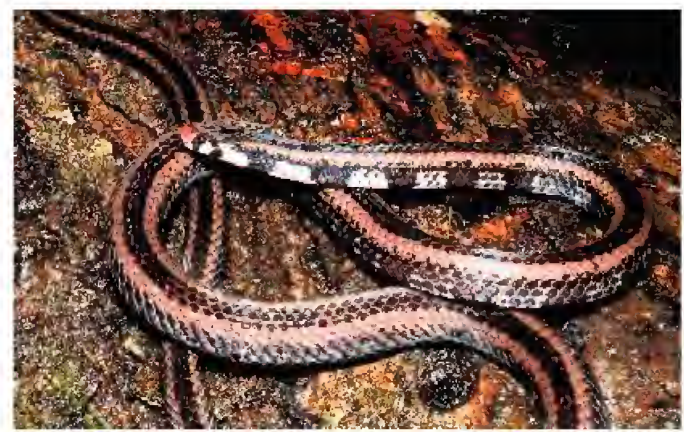

FIGURE 10. Calliophis philippina. Photo by Rafe Bown. 
10a. Scales at midbody in 17-19 longitudinal rows; ground color above black or dark brown. . . 11

10b. Scales at midbody in 21-23 longitudinal rows; above color uniform light brown or olive; ventrals 180-196 (Catanduanes, Luzon, Mindoro). .......... Naja philippinensis (Fig. 7B)

11a. A few anterior ventrals light yellow followed by band of black that gradually fades posteriorly; ventrals 162-178 (Bohol, Leyte, Mindanao, Samar). . . . . . . . . . . Naja samarensis

11b. Venter dark or light but without a distinctive black band on anterior portion; ventrals 178-189

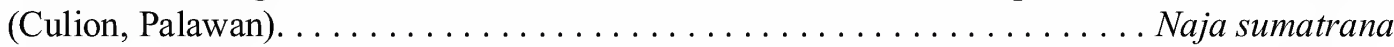

12a. Scales on head and chin smooth; second upper labial fused to scale forming anterior border of

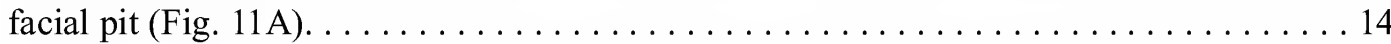

12b. Scales on head and chin strongly keeled; second upper labial separated from scale forming

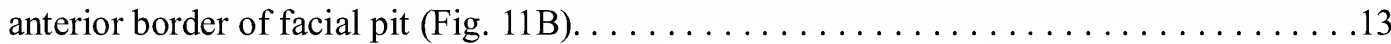
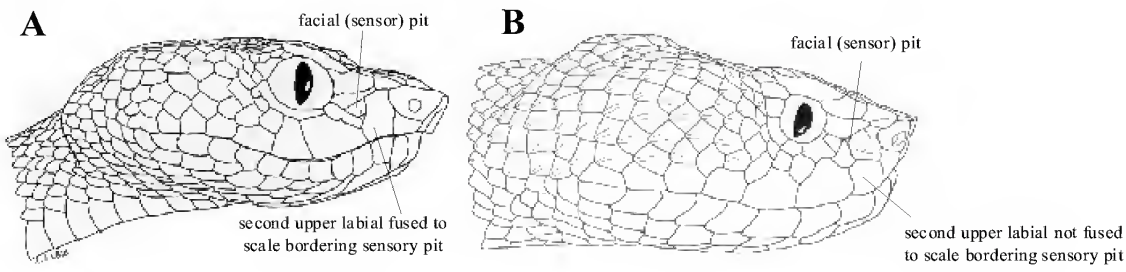

FIguRES 11A-B. Lateral view of heads of (A) Trimeresurus (Parias) flavomaculatus and (B) Tropidolaemus subannulatus.

13a. Scale rows at midbody, (ठ) 21-23, (ㅇ) 21-29; internasals separated by 2 (rarely 1) scales, never in contact; 3 rd upper labial usually separated from subocular by 1 or 2 scales; scales on snout along a straight line from rostral to level of supraoculars, ( $\left.\delta^{-1}\right) 4-7,(q)$ 5-8; scales on dorsum of head on a line between supraoculars 9-16; color variable, shades of green, blue or green and blue in females, green in males but blue in some Negros populations; crossbands around body blue and white, red and white, or blue, red and white; postocular stripe in females variable, in males white or red, and red in juveniles; ventrals (ठ) 128-148, (ㅇ) 127-147; subcaudals (ð) 45-53, (ㅇ) 40-54 (Balabac, Basilan, Bohol, Dinagat, Jolo, Leyte, Luzon, Mindanao, Negros, Palawan, Panay, Samar, Sibutu, Tumindao) . . . . . . . . . . . .

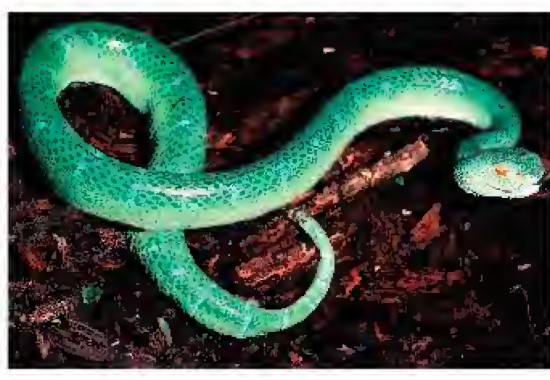

A
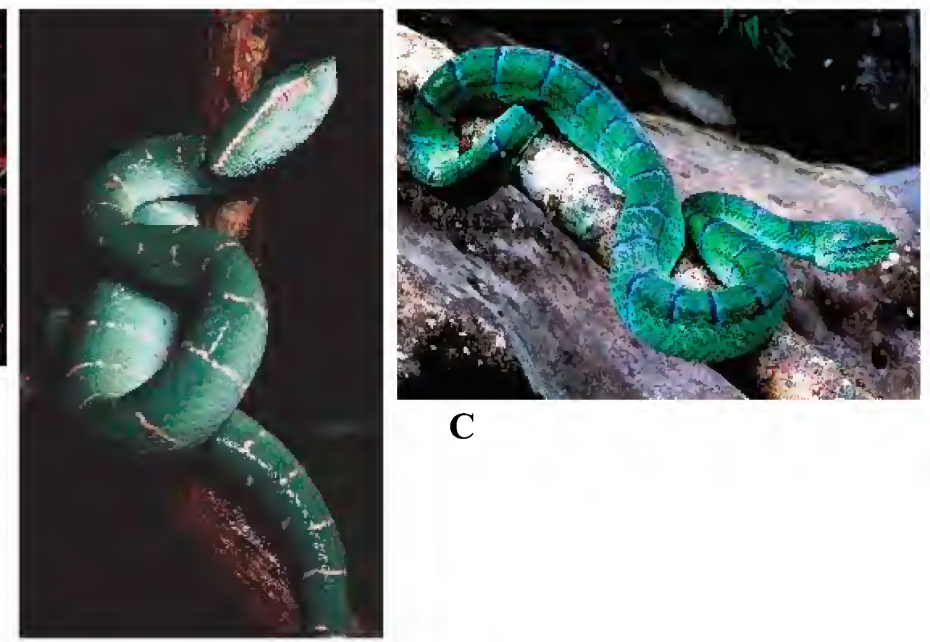

C

Figures 12A-C. Tropidolaemus subannulatus: (A) Luzon, female; (B) Luzon, male; (C) Negros, female. Photos by Rafe Brown. 
13b. Scale rows at midbody 18-19; internasals separated by 1 or 2 scales, never in contact; 3rd upper labial usually in contact with subocular or rarely separated by only 1 scale; scales on snout along a straight line from rostral to level of supraoculars $\left(\delta^{3}\right) 4-5$, (ㅇ) 5 ; scales on dorsum of head on line between supraoculars 6-8; color green-turquoise background color in males, green in females; postocular stripe in black, rarely white, in both females and males; ventrals (ð) 131-135, (ㅇ) 129; subcaudals (M) 45-46, (ㅇ) 44 (Leyte, Mindanao, Samar). . . .

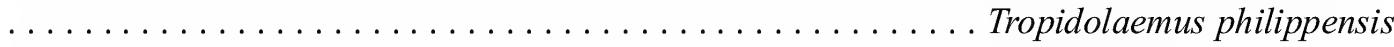

14a. Tail not distinctly differentiated from body by color; hemipenes without spines. . . . . . 15

14b. Tail distinctly differentiated from body by color; hemipenes spinose (Balabac, Palawan). ...

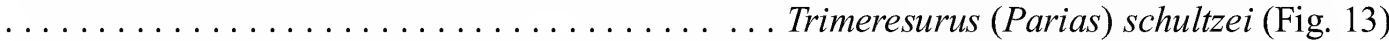

15a. Dorsal color lacks dark pigments except for a scattering of dark dorsal blotches; yellow in life (white in alcohol) (Batan Island). ............. Trimeresurus (Parias) mcgregori (Fig. 14)

15b. Dorsal color with dark pigments present, usually blue green, green or dark blue gray (Camiguin, Jolo, Luzon, Mindanao, Siquijor). ...... . Trimeresurus (Parias) flavomaculatus (Fig. 15)

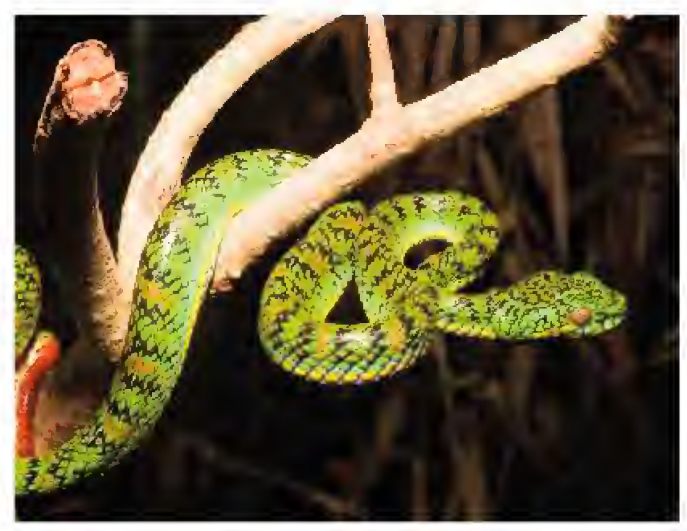

FIGURE 13. Trimeresurus (Parias) schultzei. Photo by Rafe Brown.

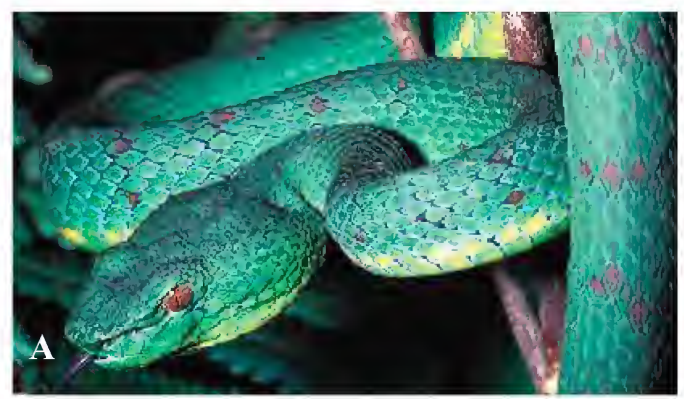

Figures 15A-B. Variation in color pattern in Trimeresurus (Parias) flavomaculatus. Photos by Rafe Brown.

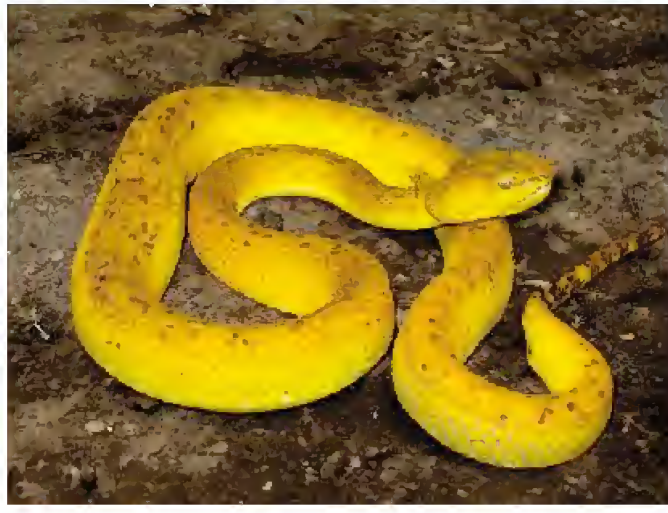

FiguRE 14. Trimeresurus (Parias) mcgregori. Photo by Rafe Brown.

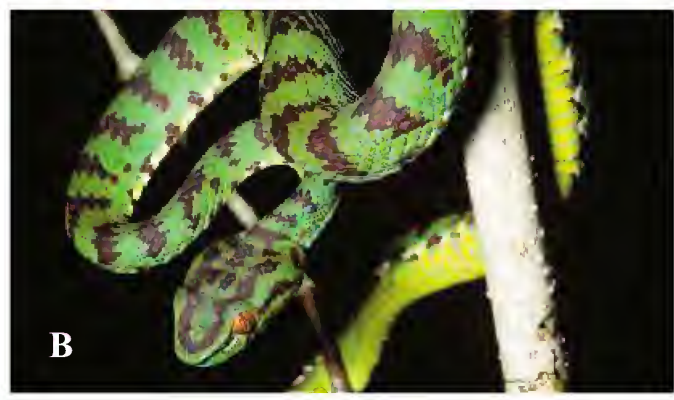




\section{Seasnakes}

(N.B. Several species included in this section of the keys have yet to be reported from Philippine waters but have been found in neighboring areas, off the coast of northern Borneo and/or elsewhere in the South China Sea region [indicated by boldface type]). Also, recent phylogenetic studies of the sea snake genus Hydrophis and allied genera, have resulted in major changes in the the generic assignment of species. Those changes are indicated here by enclosing formerly recognized genera in brackets [ ] following the now current name for the species, e.g., Hydrophis curtus, formerly Lapemis curtus, is shown below as Hydrophis [Lapemis] curtus.

16a. Ventral scales large, one-third to more than one-half the width of the body (Fig. 16A); nostrils lateral or superior, nasal scales in contact or separated separated by internasals. . . . . . 17

16b. Ventral scales small, less than one-fourth width of body, often smaller than or at least not larger than adjacent body scales (Fig. 16B); nostrils variable, internasal scales absent, nasal scales in contact with one another. . . . . . . . . . . . . . . . . . . . . . . 20

A

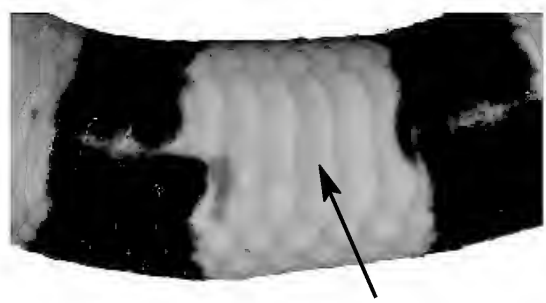

B

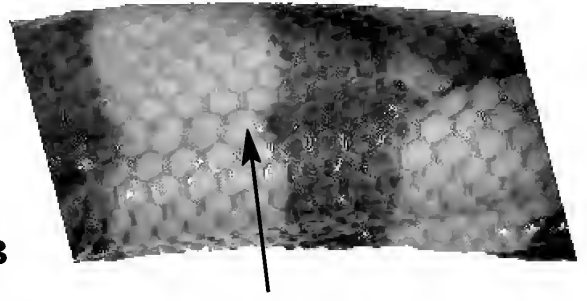

FIGURES 16A-B. Ventral scales in sea snakes: (A) large ventral scales in Laticauda (Laticauda colubrina); (B) small ventral scales in Hydrophis (Hydrophis atriceps) and other sea snakes.

17a. Nostrils lateral; nasals separated by internasals. . . . . . . . . . . . . . . . 18 17b. Nostrils superior; nasals in contact with one another. Aipysurus eydouxii

18a. Scales in 19 longitudinal rows at midbody; no azygous prefrontal scale (Fig. 17A); ventrals

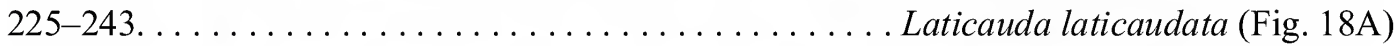
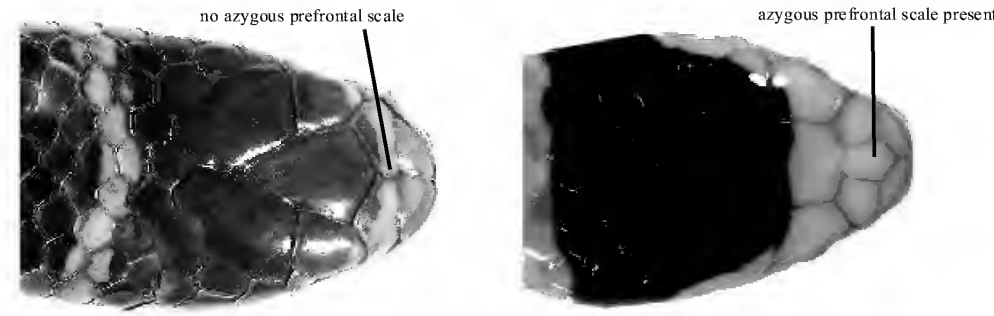

FiguRES 17A-B. Azygous prefrontal scale: (A) absent in Laticauda laticaudata; (B) present in Laticauda colubrina.

A

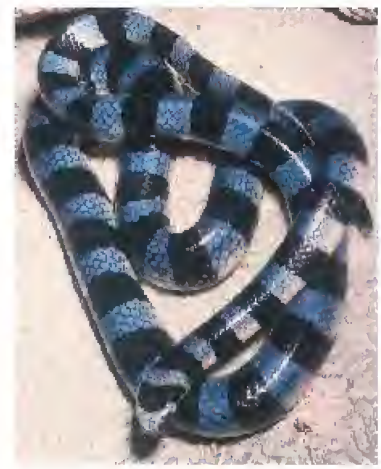

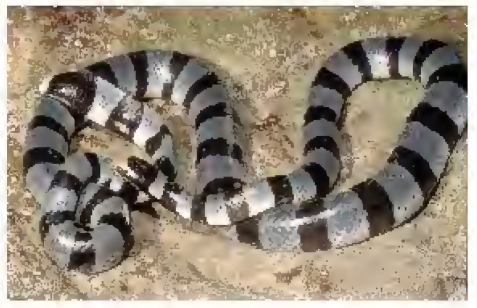

B

Figures 18A-B. (A) Laticauda laticaudata. Photo courtesy John Tashjian; (B) Laticauda colubrina. Photo by Dong Lin. 
18b. Scales in 21-25 longitudinal rows at midbody; an azygous prefrontal scale usually present (Fig. 17B). . . . . . . . . . . . . . . . . . . . . . . . . . 19

19a. Rostral not divided; upper lip yellow; ventrals $213-245 \ldots$. . . Laticauda colubrina (Fig. 18B)

19b. Rostral divided horizontally; upper lip brown; ventrals $195-205 ; 30-42$ bands on body. . . . . $\ldots \ldots \ldots \ldots \ldots \ldots \ldots \ldots \ldots \ldots \ldots \ldots \ldots \ldots \ldots \ldots \ldots \ldots \ldots \ldots \ldots \ldots \ldots \ldots \ldots \ldots$

20a. More than 72 scale rows around midbody. Hydrophis [Kolpophis] annandalei

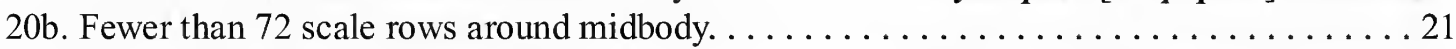

21a. Rostral scale fragmented into 4 or 5 smaller scales; dorsal head scales with thickened edges $\ldots \ldots \ldots \ldots \ldots \ldots \ldots \ldots \ldots \ldots \ldots$ Hydrophis $[$ Thalassophis] anomalus

21b. Not as above. . . . . . . . . . . . . . . . . . . . . . . 22

22a. Three supralabials only, second very elongate. . . . . . Emydocephalus annulatus

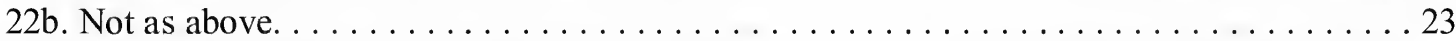

23a. Ventrals much broader anteriorly than posteriorly. . . . . Hydrophis [Praescutata] viperina

23b. Ventrals uniformily small. . . . . . . . . . . . . . . . . . . . . . 24

24a. Ventral scales small but distinct throughout, undivided by a median groove (Fig. 19B) or, if divided posteriorly (Fig. 19C), the two halves either apposed or alternating with one another, head very small and front half of body long and very slender. . . . . . . . . . . 25

24b. Ventral scales, if distinct, then either divided by a median groove (Fig. 19C) or smaller than

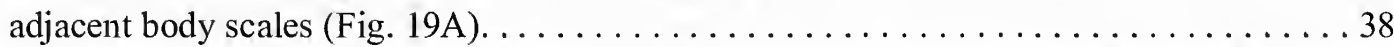

25a. Not more than 23 scales aboud the thickest part of body. ...... Hydrophis [Kerilia] jerdoni

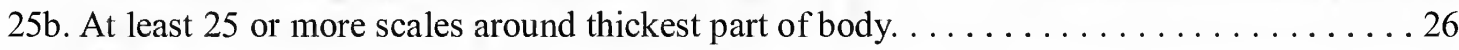

26a. Head scales regular, usually entire (Fig. 20A); nasal scales in contact with one another; pre-

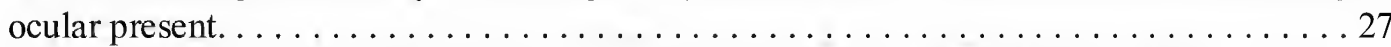

26b. Head scales, especially frontal and parietal, more or less fragmented (Fig. 20B) . . . . . . .

Hydrophis [Acalyptophis] peronii

27a. Mental scale normal (Fig. 21A), not hidden in symphysis grove; ventrals uniform in size; 1-18 maxillary teeth behind fangs. . . . . . . . . . . . . . . . . . . 28

27b. Mental scale elongate, partially hidden in groove in symphysis (Fig. 21B); ventrals uniform in size; 3-5 maxillary teeth behind fangs . . . . . Hydrophis [Enhydrina] schistosus (Fig. 22)

28a. Scales on thickest part of body hexagonal or quadrangular in shape, weakly imbricate or juxtaposed (Fig. 23A); 8-18 maxillary teeth behind fangs. . . . . . . . . . . . . . . 29

$28 \mathrm{~b}$. Scales on thickest part of body with rounded or bluntly pointed tips, distinctly or weakly

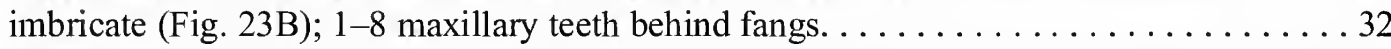

29a. Head very small, body long and very slender anteriorly (Fig. 24A); 5-6 maxillary teeth behind

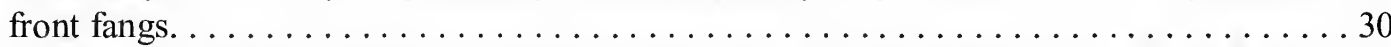

29b. Head not distinctly reduced, body not particularly slender anteriorly (Fig. 24B); head and body grayish above, white below; ventrals 195-281; 8-18 maxillary teeth behind fangs. . . 31

30a. Head black with yellowish spots; body grayish above, white below; scales in 25-30 longitudinal rows around neck, 39-49 around thickest part of body; ventrals $323-452 \ldots \ldots \ldots \ldots$ $\ldots \ldots \ldots \ldots \ldots \ldots \ldots \ldots \ldots \ldots \ldots \ldots \ldots \ldots \ldots \ldots \ldots \ldots \ldots$ Hydroph atriceps

30b. Head blackish with a curved yellow mark across snout and extending backwards along sides of head and sometimes a connecting yellow band or two across frontal and parietal region, body greyish above, yellowish while below, with 60-80 dark grey bands, usually encircling body anteriorly; markings often lost in older adults; $37-45$ scales around midbody; ventrals $328-414$.

Hydrophis brookii 


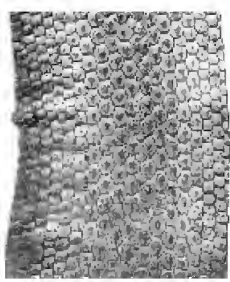

A

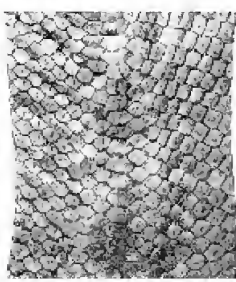

B

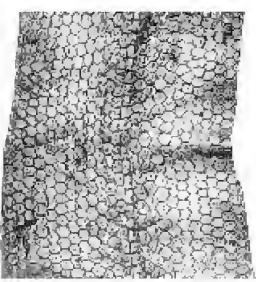

C

FIGURE 19. Ventral scales in hydrophiine sea snakes (adapted from Smith, 1926, pls. I and II ). (A) undivided and indistinguishable from adjacent scales (Hydrophis [Lapemis] curtus); (B) usually distinguishable from adjacent scales (Hydrophis cyanocinctus); (C) divided by a longitudinal groove (Hydrophis gracilis)

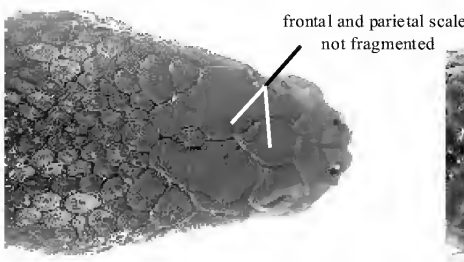

A

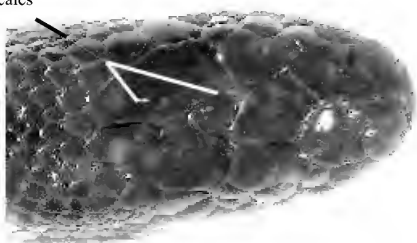

B

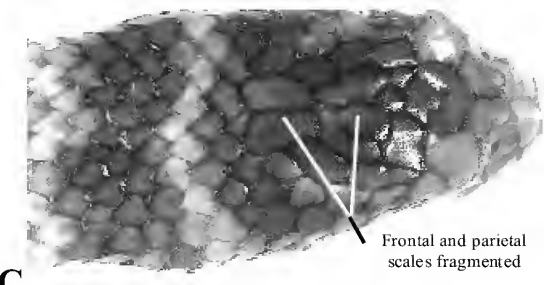

c

FIGURES 20A-C. Scales on dorsum of head: (A) scales unfragmented (Hydrophis [Enhydrina] schistosus) and (B) (Hydrophis cyanocinctus); (C) frontal and parietal head scales fragmented (Hydrophis [Acalyptophis] peronii).

A

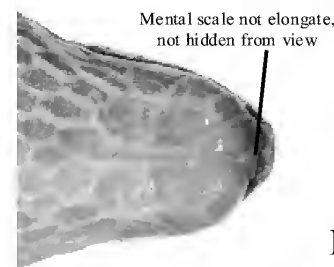

B

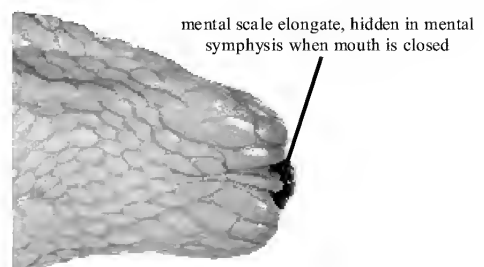

FiguRES 21A-B. Mental scale: (A) normal, neither elongate nor partially hidden from view in mental symphysis (Hydrophis); (B) elongate mental scale partially hidden in mental symphysis when mouth is closed (Hydrophis [Enhydrina] schistosus)

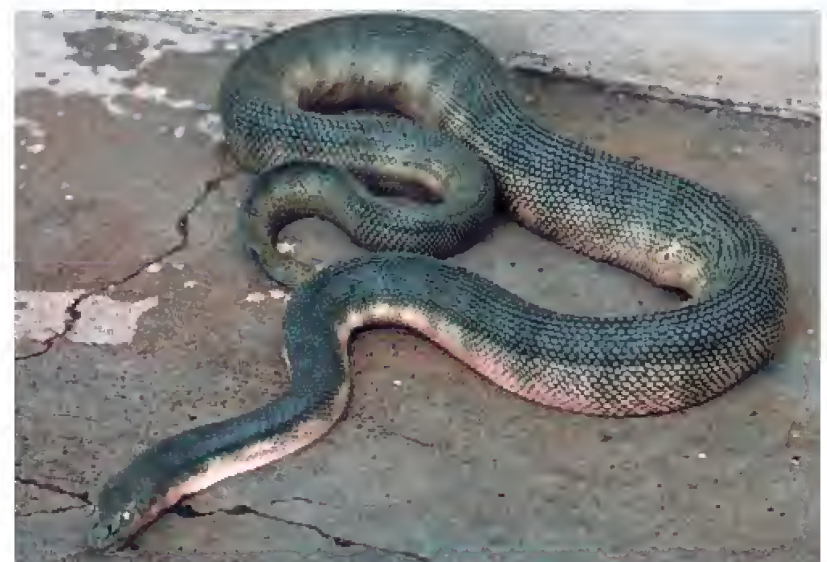

FIGURE 22. Hydrophis [Enhydrina] schistosus. Photo courtesy of Harold Voris.

31a. 26-36 dark middorsal blotches or bands on body; anteriorly interspaces between dorsal dark body bands more than 2 scale rows wide; 4-6 dark bands on tail; 37-45 scale rows around neck; ventral scales 258-306; 9-12 maxillary teeth behind front fangs. . . Hydrophis lamberti 
31b. 39-45 dark middorsal blotches or bands on body; anteriorly interspaces between dorsal dark body blotches or bands less than 2 scale rows wide; $8-11$ dark bands on tail; $31-39$ scale rows around neck; ventral scales 224-294; 9-12 maxillary teeth behind front fangs. . . . . . . . . . $\ldots \ldots \ldots \ldots \ldots \ldots \ldots \ldots \ldots \ldots \ldots \ldots \ldots \ldots \ldots \ldots \ldots \ldots \ldots \ldots \ldots \ldots$ Hydroph ornatus

32a. Usually one anterior temporal (Fig. 25A); 25-31 scale rows around neck; 6-8 upper labials

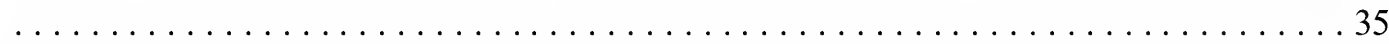

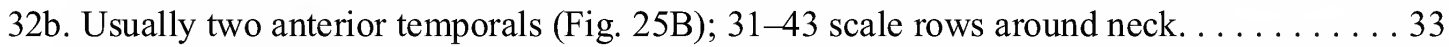

33a. 14-18 maxillary teeth behind front fangs; 31-43 scales around neck, 38-54 around midbody;

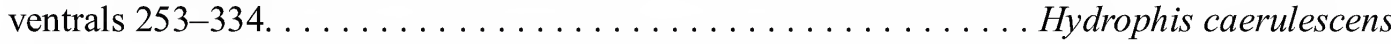

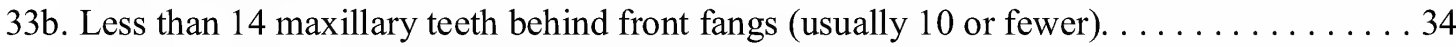

34a. Head in adult olive or yellowish (in young, head may be black or dark olive); black ventral stripe often present but less distinct in older adults; dorsal portions of black body annuli persist even in older adults; ventrals 290-390. . . . . . . Hydrophis cyanocinctus (Figs. 26A-B)

34b. Head in adult black; body black with 50 to 60 narrow whitish bands or annuli; ventrals usually black; ventrals 314-356 (restricted to Lake Taal [Bombon], Luzon). . Hydrophis semperi

35a. Usually 5 upper labials, rarely $6 ; 22-27$ scale rows around neck; ventrals $360-415$; one ante-

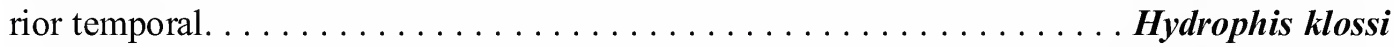

35b. Usually 6 or 7 upper labials, rarely $5 ; 23-31$ scale rows around neck, usually greater than 24 ; one anterior temporal, sometimes divided into two superimposed scales. . . . . . . 36

36a. Longitudinal rows of scales increases by $4-8$ rows from neck to midbody (25-29[neck]/ $33-38$ [midbody $]+4-8$ increase in rows) $1 \ldots \ldots \ldots \ldots$ Hydrophis spiralis (Figs. 26C-D)

$36 \mathrm{~b}$. Longitudinal rows of scales increases by $8-18$ rows from neck to midbody; body greatly com-

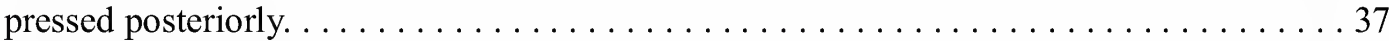

37a. Head black with yellow markings; head small, body long and slender anteriorly, compressed posteriorly; 40-55 dark bands on body; 23-27 scale rows around neck, 33-41 around midbody; $6-8$ maxillary teeth behind front fangs. . . . . . . . Hydrophis melanocephalus

$37 \mathrm{~b}$. Head black in young with or without a yellow curved mark above, greyish, olive, or yellowish in adult; head moderate, body elongate, compressed posteriorly; 25-31 scale rows around neck, 37-45 around midbody; 60-80 dark bands on body, fading in adults; 4-5 maxillary teeth behind front fangs. . . . . . . . . . . . . . . .

38a. Midbody scales in 25-43 rows around body; dorsal scales hexagonal, juxtaposed. . . . . . 39

38b. Midbody scales in 47-67 rows around body; dorsal scales juxtaposed, or imbricate. . . . . 40

39a. Head small, anteriorly body elongate and narrow; scale rows around neck 17-23; scales

A

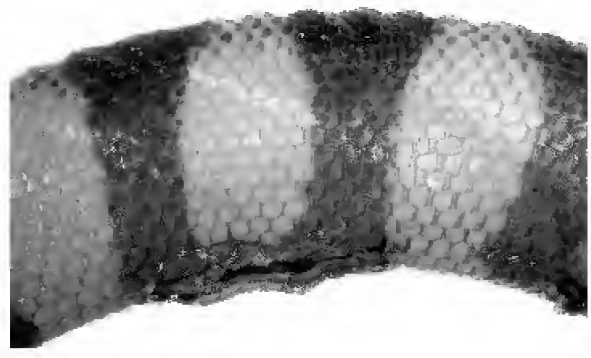

B

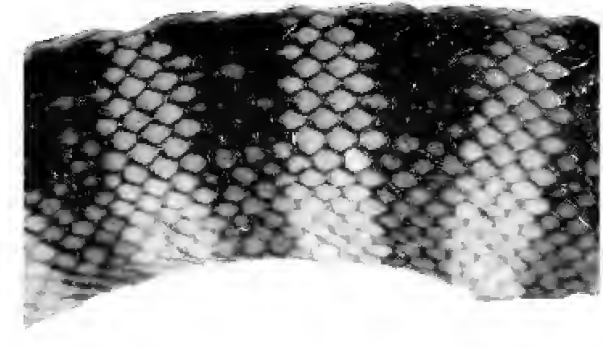

FIGURES 23A-B. Scales on thickest part of body: (A) hexagonal or quadrangular in shape (Hydrophis atriceps); (B) scales rounded or with bluntly pointed tips (Hydrophis cyanocinctus).

\footnotetext{
${ }^{1}$ After Smith (1926): "represents the number of scale rows on the neck and body, and the increase in the number of scale rows from neck to midbody."
} 
B

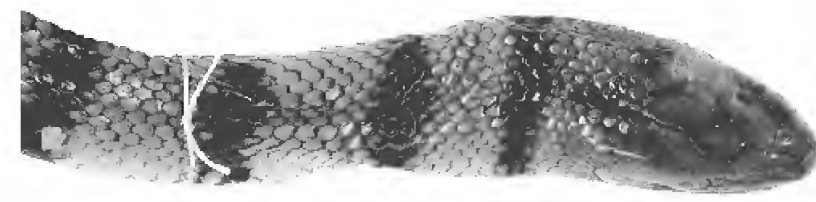

A

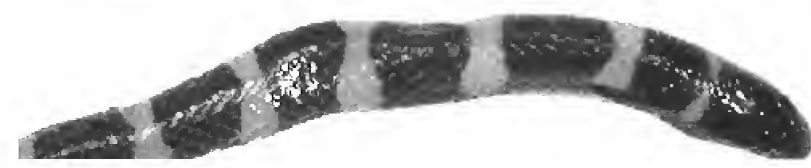

FIGURES 24A-B. Head and body dimensions: (A) head and anterior fourth of body slender (Hydrophis atriceps);

(B) head and anterior portion of body not distinctly narrowed (Hydrophis ornatus)

A

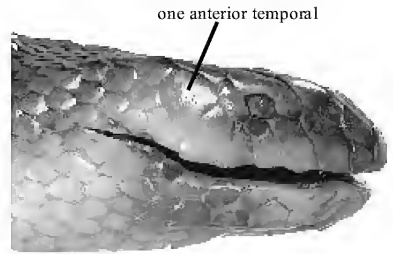

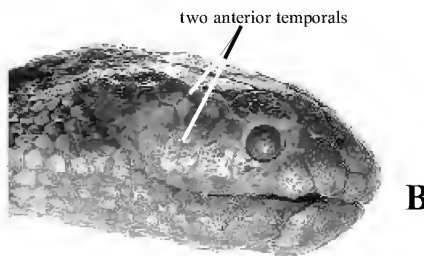

FigURES 25A-B. Anterior temporal scales: (A) one anterior temporal scale (Hydrophis spiralis); (B) two anterior temporals scales (Hydrophis cyanocinctus).
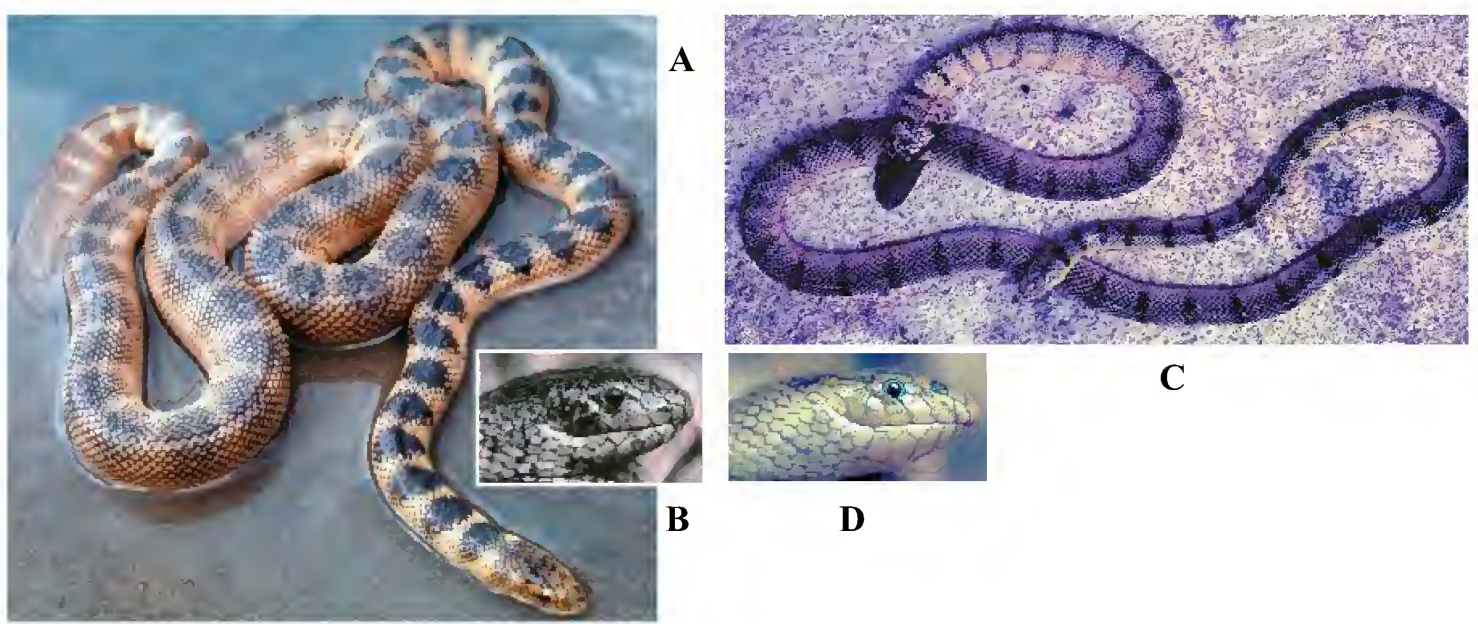

C

Figures 26A-D. (A-B) Hydrophis cyanocinctus; (C-D) Hydrophis spiralis. Photos courtesy of Harold Voris.

around midbody $30-43$; lowermost lateral scale rows slightly larger than upper lateral scales; dorsal scales posteriorly hexagonal, juxtaposed; ventrals usually distinct on anterior fourth of body, entire and broader than adjacent dorsal scales, posteriorly distinctly divided by a medi-

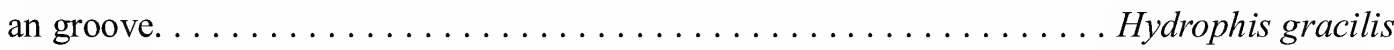

39b. Head and neck normal, not narrow (Fig. 28); scale rows around neck 23-31; scale around midbody 25-43; dorsal scales, lowermost lateral scale rows larger than upper lateral scales (Fig. 27D); ventrals usually distinct on anterior fourth of body, posteriorly barely larger than adjacent scales or not enlarged at all, not divided by a longitudinal groove; greenish or olive to gray above, whitish below, 35-55 narrow dark bands, occasionally uniform dark gray; 3-6 maxillary teeth behind each fang. ............ Hydrophis [Lapemis] curtus (Figs. 28-29)

40a. Dorsal scales pointed, strongly imbricate (Fig. 27B); ventrals in two halves; 6-7 maxillary teeth behind each fang. ..................... Hydrophis [Astrotia $]$ stokesii 
40b. Dorsal scales hexagonal, juxtaposed, lowermost lateral scale rows not larger than adjacent upper lateral scales (Fig. 27C); midventral scales, when distinct, divided by a longitudinal groove; bicolored, ordinarily black above, yellow below, with some variation in which yellow extends farther up on the sides and the black is confined to a wide middorsal stripe; sometimes black bars on belly; tail mottled yellow and black; 8-10 maxillary teeth behind front fangs. . .

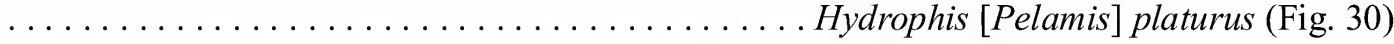

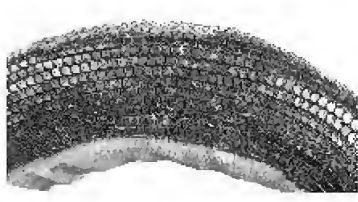

A

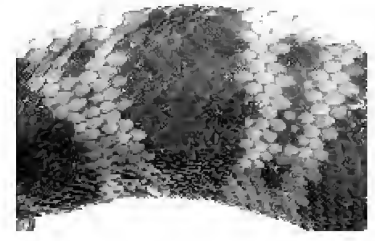

B

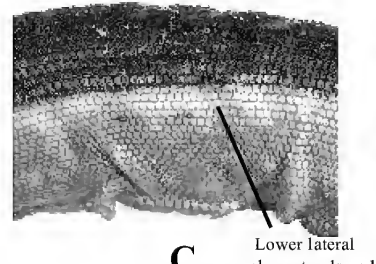

C scales not enlarge

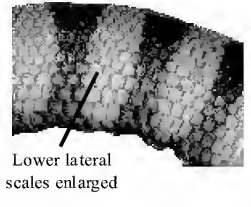

D

Figures 27A-D. Dorsal scales: (A) scales juxtaposted (Hydrophis [Pelamis] platurus); (B) scales imbricate (Hydrophis [Astrotia] stokesii); (C) lowermost 3 or 4 lateral rows not larger than adjacent upper lateral scales (Hydrophis [Pelamis] platurus); (D) lowermost 3 or 4 lateral rows larger than upper lateral scales (Hydrophis [Lapemis] curtus [hardwicki])

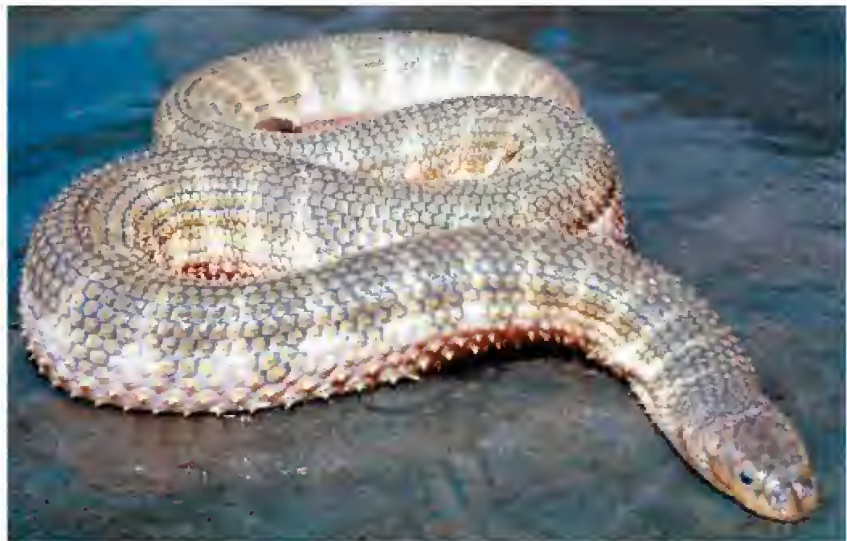

FIGURE 28. Hydrophis [Lapemis] curtus. Photo courtesy of Harold Voris

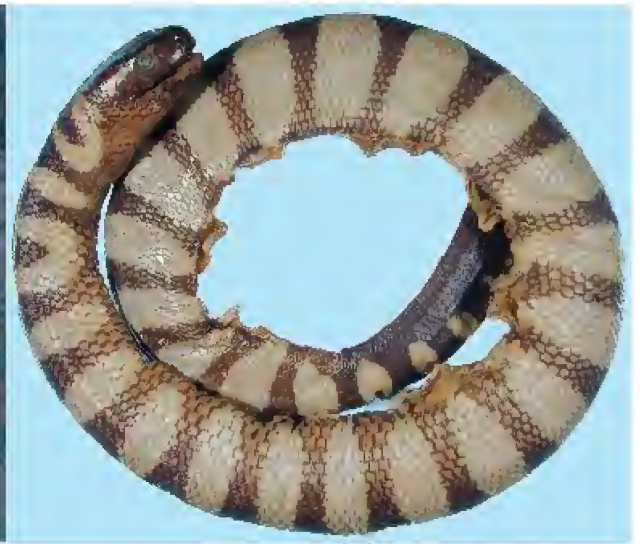

FIGURE 29. Hydrophis [Lapemis] curtus [hardwicki]. Photo of preserved specimen.

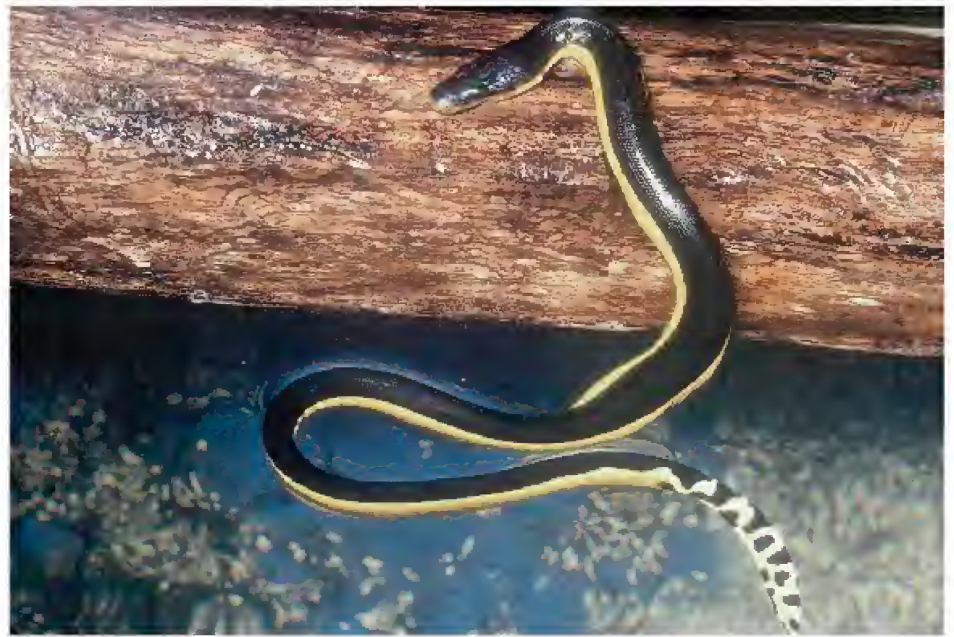

FIGURE 30. Hydrophis [Pelamis] platurus. Photo courtesy of John Tashjian. 


\section{Table of taxonomic equivalents for the Philippine venomous snakes}

\section{Current name}

Calliophis intestinalis

Calliophis bilineata

Calliophis philippina

Calliophis suluensis

Hemibungarus calligaster

Hemibungarus calligaster

Hemibungarus gemianulis

Hemibungarus mcclungi

Naja philippinensis

Naja samarensis

Naja suncatrana

Ophiophagus hannah

Trimeresurus (Parias) flavomaculatus

Trimeresurus (Parias) flavomaculatus

Trimeresurus (Parias) flavomaculatus

Titimeresurus (Parias) megregori

Trineresurus (Parias) schultzei

Tropidolaenus philippensis

Tropidolaemus subanmulatus

Aipysurus eydouxii

Emydocephalis annulatus

Hydrophis annandalei

Hydrophis anomalus

Hydrophis atriceps

Hydiophis belcheri

Hydrophis brookii

Hydrophis caerulescens

Hydrophis curtus

Hydrophis cyanocinctus

Hydrophis gracilis

Hydrophis jerdoni

Hydrophis klossi

Hydrophis lamberti

Hydrophis melanocephalus

Hydrophis ornatus

Hydrophis peronii

Hydrophis platurus

Hydrophis schistostus

Hydrophis semperi

Hydrophis spiralis

Hydrophis stokesii

Hydrophis viperinus

Laticanda colubrina

Laticauda laticaudata

Laticauda semifasciata

\section{Terrestrial snakes}

Maticora intestinalis

Maticora intestinalis bilineata; Doliophis bilineatus

Maticora intestinalis philippina; Doliophis philippinus

Maticora intestinalis suluensis

Calliophis calligaster

Calliophis calligaster calligaster

Calliophis calligaster gemianulis

Calliophis calligaster mcclungi; Hemibungarus mcclungi

Naja naja philippinensis

Naja naja samarensis

Naja naja miolepis

Naja hamnah

Trimeresurus flavomaculatus

Trimeresurus flavomaculatus flavomaculatus

Trimeresurus flavomaculatus halieus; T. (Parias) halieus; T. halieus

Trimeresurus flavomaculatus mcgregori; T. mcgregori

Trimeresurus schultzei

Trimeresurus wagleri philippensis [philippinensis]

Trimeresurus wagleri subannulatus

\section{Sea snakes}

Kolpophis annandalei

Thalassoph is anomalus

Hydrophis fasciatus (east of the Straits of Malacca)

(Lapemis curtus, Lapemis curtus hardwickii, also as L. hardwickii)

Leioselasma cyanocinctus; Disteira cyanocincta

Microcephalophis gracilis

Kerilia jerdoni

(formerly included in Hydrophis ornatus)

Leioselasma melanocephalus

(also includes Hydrophis inornatus from Philippines);

Disteira cyanosoma; Disteira ornata

Acalyptophis peronii

Pelamis platurus; Pelamydrus platurus; Pelamis platura

Disteira schistosa; Enhydrina schistosa

Leioselasma semperi

Leioselasma spiralis

Astrotia stokesii

Thalassophina viperina; Praescutata viperina

Pseudolaticauda semifasciata 


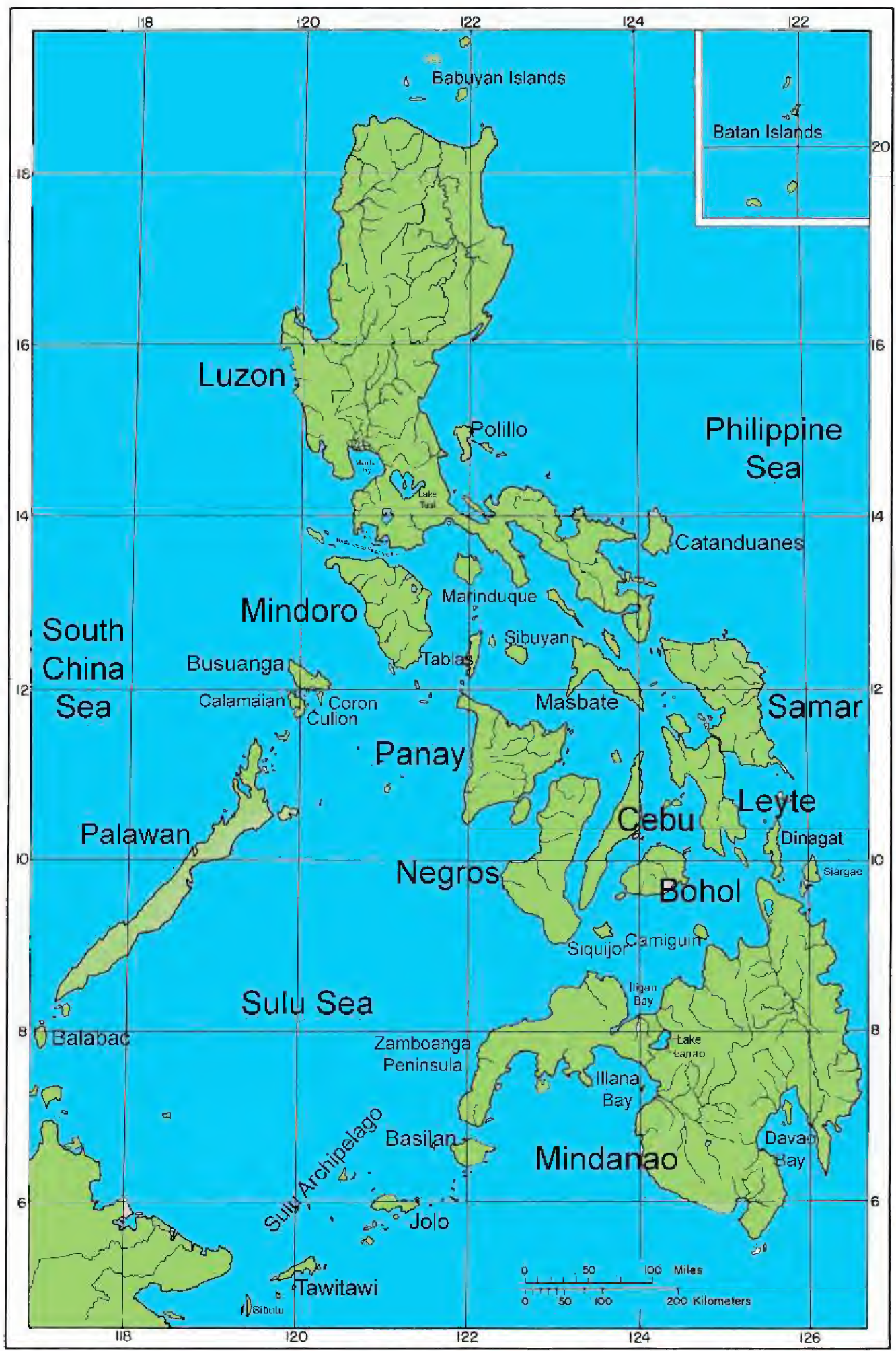

The PhilipPINe ArChIPELAGo 


\title{
SPECIES ACCOUNTS OF THE VENOMOUS SNAKES OF THE Philippine Archipelago
}

\author{
Family ElaPIDAE \\ Subfamily Elapinae
}

\section{Genus Calliophis Gray, 1834}

Calliophis Gray, 1834. (Type species: Aspis intestinalis Laurenti 1768).

Diagnosis. - Maxilla extends forward beyond palatine; venom fangs followed by a diastema and then by one small, solid tooth; head not distinct from neck; loreal absent; nostril between nasals; eye small, pupil round; body cylindrical, elongate; tail short; scales smooth, in 13 longitudinal rows at midbody; subcaudals paired; venom glands elongate, extending far back into body cavity and terminating in an elongate, club-shaped end; hypapophyses present throughout vertebral column.

General features of PhilipPine species. - Dorsal scales in 13 longitudinal rows except just behind the head where they are in 15 rows; precloacal scale undivided; venter usually with an alternating series of black and light crossbars; head, at least posteriorly, dark.

REMARKS.- The species included here in Calliophis were, until recently, placed in the genus Maticora. Apart from the reasignment of species formerly referred to Calliophis, Hemibungarus, and Maticora by earlier authors (e.g., Leviton 1964, Toriba 1993, David and Ineich 1999 [q.v. for additional references]) and contrary to previous analyses, Slowinski et al. (2001) demonstrated that the type species of Calliophis and Maticora had been improperly assigned and that the type species of Calliophis is Aspis intestinalis Laurenti, 1768, by monotypy and whose type locality is Java, Indonesia (restricted by Leviton 1964:529).

\section{Calliophis bilineata Peters, 1881}

Two Stripped Coral Snake

Figure 31

Calliophis bilineatus Peters, 1881:109 (type locality: "Pulauan" [=Palawan]).

Maticora intestinalis bilineata, Leviton, 1964:532.

DESCRIPTION.- Black crossbars on venter not in contact with black on sides of body; prefrontals, and usually internasals, rostral and first two upper labials white (in alcohol-preserved specimens); a distinct white line always present on side of body between first and second scale rows, or first scale row completely white; dorsum of tail with two or three black crossbars, otherwise red or cream; ventrals $(\lesssim)$ 232-260, (ㅇ) 266-285; subcaudals (ð) 24-31, () 23-25
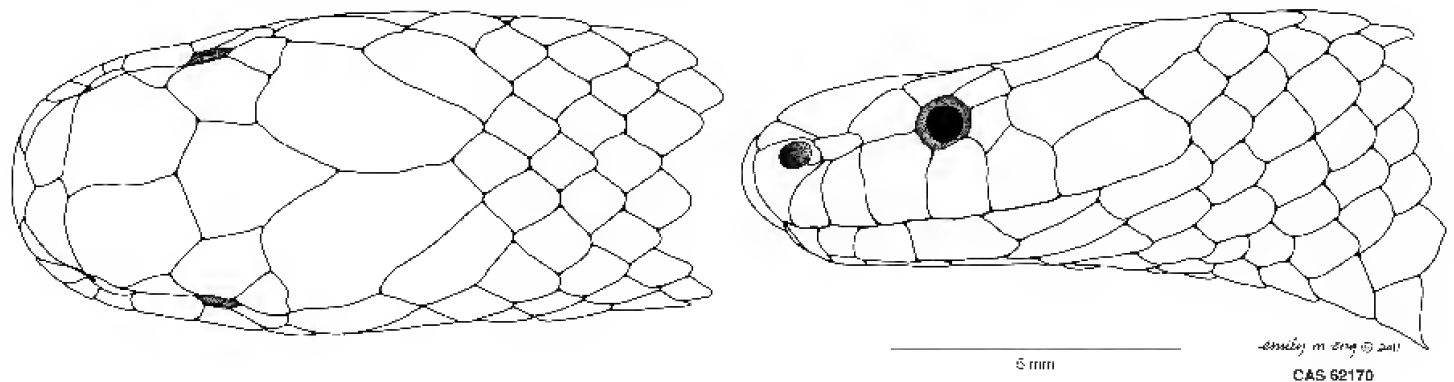

FIGURE 31. Calliophis bilineata. Illustrations by Emily M. Eng. 


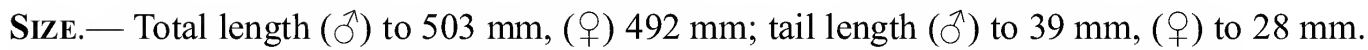

Distribution. - Endemic to Philippines (Balabac; Busuanga; Culion; Palawan).

\section{Calliophis philippina Günther, 1864 \\ Philippine [banded or striped] Coral Snake}

Figures 10,32A-B

Callophis intestinalis var. Philippina Günther, 1864:349 (type locality: Philippine Islands).

Maticora intestinalis philippina, Leviton, 1964:533.

DESCRIPTION.- Black crossbars on venter in contact with black on sides; dorsolateral stripe broad, tan or reddish brown; no distinct white line on sides of body along outer scale row; prefrontals colored as rest of head; cream crossbars on venter extend onto sides of body, often to fourth

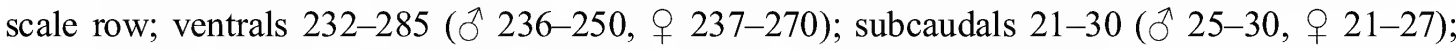
29-45 black crossbars on venter; 1-4 black crossbars on underside of tail.

SizE.— Total length (ð) to $625 \mathrm{~mm}$, (†) $545 \mathrm{~mm}$; tail length (ठ) to $47 \mathrm{~mm}$, (†) to $40 \mathrm{~mm}$.

Distribution.- Endemic to Philippines (Mindanao [Prov.: Agusan; Davao; Lanao; Misamis Occidental; Zamboanga]; Samar).
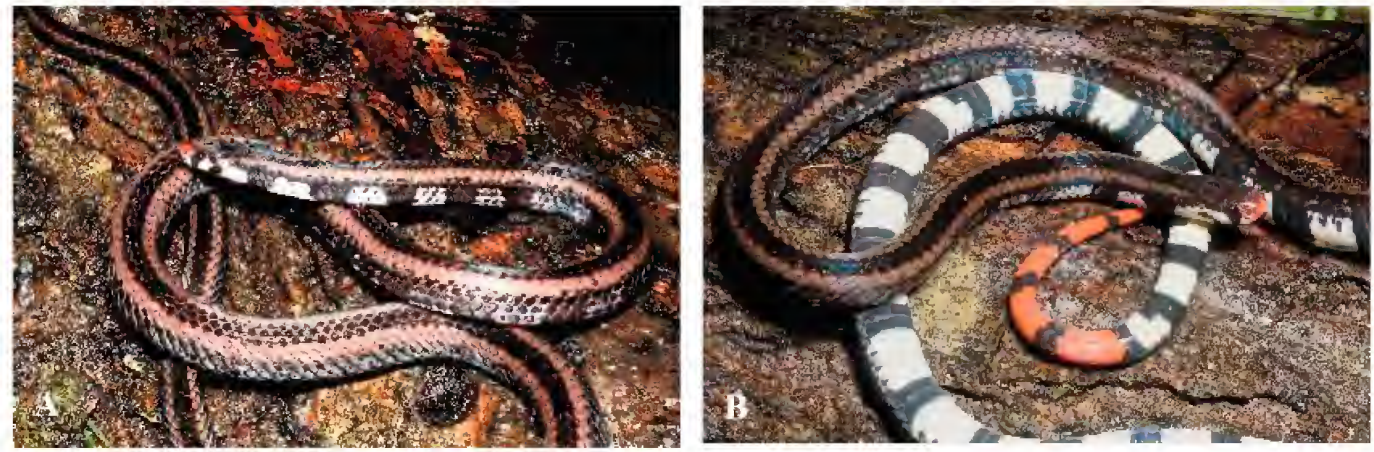

FIGURES 32A-B. Calliophis philippina from Western Mindanao Island. Photos by Rafe Brown.

\section{Calliophis suluensis Steindachner, 1891}

Sulu Islands Banded Coral Snake

Callophis intentinalis suluensis Steindachner, 1891:295 (Type locality: Sulu Archipelago).

Maticora intestinalis suluensis, Leviton, 1964:535.

DESCRIPTION.- Black crossbars on venter contact black on sides of body; dorsolateral stripe broad, tan or reddish brown; no distinct while line on sides along outer scale rows; prefrontals cream colored (specimen in alcohol), or at least lighter than rest of head; cream-colored crossbars on venter do not extend onto sides of body above first scale row; ventrals 197-218; subcaudals 24-33; 39 black crossbars on venter, 3 on underside of tail.

SizE.- Total length (ठ) to $405 \mathrm{~mm}$, + unknown; tail length (ठ) $33 \mathrm{~mm}$, + unknown.

Distribution.- Endemic to Philippines (Jolo).

\section{Genus Hemibungarus Peters, 1862}

Hemibungarus Peters, 1862:638 (Type species: Elaps calligaster Wiegmann, 1834).

Diagnosis.- Maxilla extends forward beyond palatine; venom fangs followed by a diastema and then by one small, solid tooth; head not distinct from neck; loreal absent; nostril between nasals; eye small, pupil round; body cylindrical, elongate; tail short; scales smooth, in 13 or 15 lon- 
gitudinal rows at midbody; subcaudals paired; venom glands confined to head region; hypapophyses present throughout vertebral column.

General features of Philippine species. - Scales in 15 longitudinal rows throughout; 6 upper labials, rarely 7; anterior temporal in contact with 2 upper labials; preocular in contact with nasal; color pattern consists of an alternating series of broad black and red rings that are separated by narrow white annuli (in adults both dorsal and lateral portions of red rings become heavily infused with black pigment).

REMARKS.- - See Remarks under Calliophis (above).

\section{Hemibungarus calligaster (Weigmann, 1834)}

[Annulated or Barred] Philippine Coral Snake

Figures 8B, 9, 33

Elaps calligaster Wiegmann, 1834:253, pl. 20, fig. 2 (Type locality: Manila, Luzon Island).

Hemibungarus calligaster, Taylor, 1922a:269, pl. 33, figs. 1-2, pl. 34, figs. 1-2.—Castoe et al., 2007

Calliophis calligaster calligaster, Leviton, 1964:543.

DESCRIPTION.- Black rings on body not divided by narrow white annuli; narrow white annuli on dorsum of body 44-75; temporal region more or less heavily pigmented with melanin, with a distinct light vertical postocular stripe and a diagonal nuchal chevron bordering the area; ventrals 223-259 (ठ 223-233, ㅇ 252-259); subcaudals 16-22 (ð 17-22, 우 13-30).

SizE. - Total length (ठ) $515 \mathrm{~mm}$, (ㅇ) 504 $\mathrm{mm}$; tail length (ठ) $28 \mathrm{~mm}$, (ㅇ) $28 \mathrm{~mm}$.

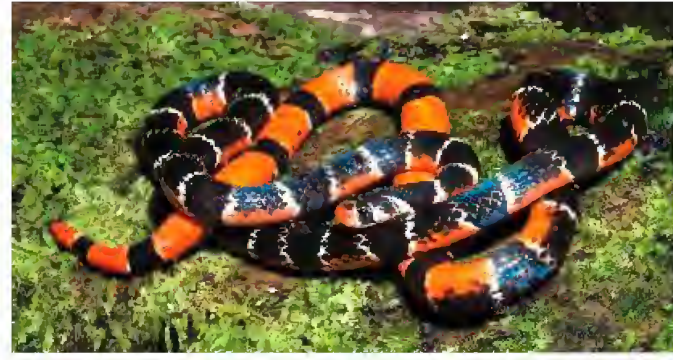

FIGURE 33. Hemibungarus calligaster. Photo by Cameron Siler.

Distribution.- Endemic to Philippines (Luzon [Prov.: Albay, Bataan, Camarines Sur, Laguna, Quezon, Rizal]; Mindoro).

\section{Hemibungarus gemianulis Peters, 1872}

[Double-barred] Philippine Coral Snake

Hemibungarus gemianulis Peters, 1872:587 (Type locality: "Philippine Ids.")

Hemibungarus calligaster (part) Taylor, 1922a:269.

Calliophis calligaster gemianulis, Leviton, 1964:545.

DESCRIPTION.- Black rings on body divided by narrow white annuli; white annuli on dorsum 60-83; temporal region either light (cream or reddish) or very lightly spotted with melanin; ventrals 196-227; subcaudals 15-21.

SizE.—- Total length (ð) $551 \mathrm{~mm}$, (ㅇ) $478 \mathrm{~mm}$; tail length (ð) $32 \mathrm{~mm}$, () $28 \mathrm{~mm}$.

Distribution. - Endemic to Philippines (Cebu; Negros; Panay).

\section{Hemibungarus mcclungi Taylor, 1922}

McClung's Philippine Coral Snake

Hemibungarus mcclungi Taylor, 1922a:272, pl. 33, pl. 34, figs. 3-4 (Type locality: Polillo). Calliophis calligaster mcclungi, Leviton, 1964:547.

DESCRIPTION.- Black rings on body not divided above by narrow white annuli; narrow white annuli on body 46 (but white often obscured by melanin pigmentation); temporal region pigmented; ventrals 206; subcaudals 23 . 
SizE.- Total length $293 \mathrm{~mm}$. (one §̋); tail length $23 \mathrm{~mm}$.

Distribution.- Endemic to Philippines (Luzon [Prov.: Aurora]; Polillo).

\section{Genus Naja \\ Cobras}

Naja Laurenti, 1768:90 (Type species: Naja lutescens Laurenti, $1768=$ Coluber naja Linnaeus, 1758 [see Williams and Wallach 1989:97; also David and Ineich 1999:156]).

Diagnosis. - Maxillary bone extends forward beyond palatine; venom fangs moderately short, followed by from 0 to 2 small teeth; eye moderate, pupil round; nostril large, between two nasal scales; loreal scale absent; body scales smooth, in 19-25 longitudinal rows at midbody (for Southeast Asian species only); hemipenes relatively short, forked for less than half their length, variously spinose throughout.

Naja philippinensis Taylor, 1922

Philippine Cobra; Northern Philippine Cobra

Figures 4, 34, 35A-B

Naja naja philippinensis Taylor, 1922a:265 (Type locality: Manila, Luzon Island)._Leviton, 1964:539.

Naja philippinensis, Wüster and Thorpe, 1990:336-341.— Toriba, 1993:191.—David and Ineich, 1999:166.

DESCRIPTION.- Color above light brown to olive brown, below lighter cream to yellowish brown, without any distinctive dark bands or other markings anteriorly; scales in 23-25 longitudinal rows around neck, 21 longitudinal rows at midbody, and 15 just before the vent (scale row reduction: 23[25]-21-15); ventrals 181-191; subcaudals 38-47; precloacal scale single.

SizE.— Snout-vent length (ð) $1223 \mathrm{~mm}$, (ㅇ) $960 \mathrm{~mm}$; tail length (ð) $189 \mathrm{~mm}$, (ㅇ) $195 \mathrm{~mm}$.

Distribution. - Endemic to Philippines (Luzon [Prov.: Aurora, Batangas, Bulacan, Cavite, Laguna, Pampanga, Pangasinan, Quezon, Rizal]; Marinduque; Mindoro).
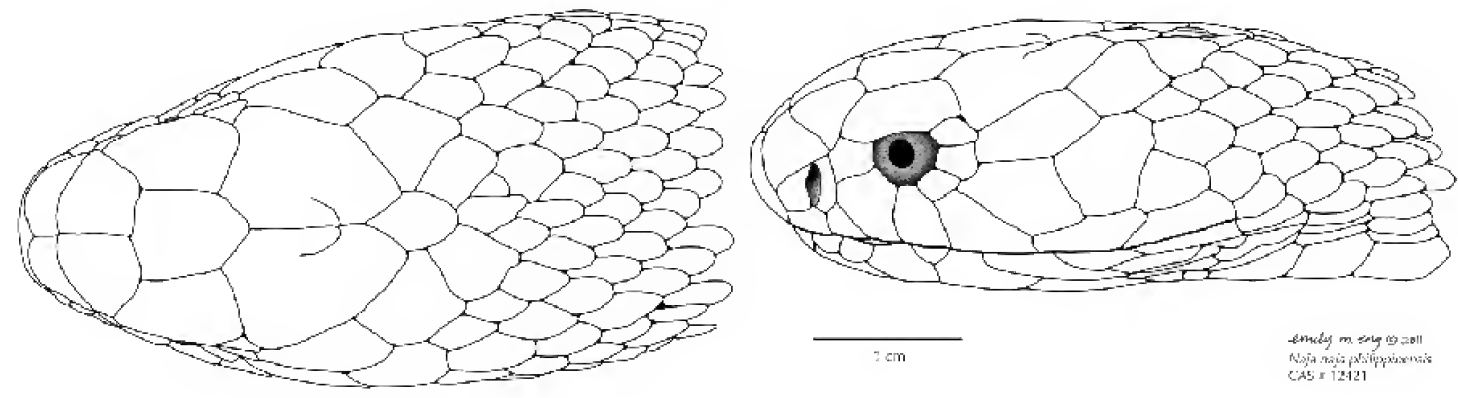

FigURE 34. Naja philippinensis Taylor, 1922. Illustrations by Emily M. Eng.

\section{Naja samarensis Peters, 1861}

Central Philippine Cobra

Figure 35C

Naja tripudians samarensis Peters, 1861:690 (Type locality: Samar Island).

Naja samarensis, Boulenger, 1896:385.- Taylor, 1922a:259.— Wüster and Thorpe, 1990:336-341.

Naja naja samarensis, Leviton, 1964:542.

DESCRIPTION.- Color above dark brown to black, usually with a trace of a light lateral line, at least anteriorly, on outer two scale rows; below, throat and first few ventrals yellowish followed by a distinct broad black band, which gradually fades to light gray; scales in 21-23 longitudinal rows around the neck, 19 longitudinal rows at midbody, and 13 longitudinal rows just before the 
vent (scale row reduction: 23[21]-19-13); ventrals 162-178; subcaudals 42-50; precloacal scale single.

SizE.- Snout-vent length (ठ) $843 \mathrm{~mm}$, () $921 \mathrm{~mm}$; tail length (ð) $158 \mathrm{~mm}$, (ㅇ) $155 \mathrm{~mm}$.

Distribution. - Endemic to Philippines (Bohol; Leyte; Mindanao [Prov.: Agusan, Bukidnon, Lanao, Misamis Occidental, Zamboanga]; Samar).

\section{Naja sumatrana F. Müller, 1887}

Equatorial or Sumatran spitting Cobra

Naja tripudians var. sumatrana Müller, 1887:277 (Type locality: Solok, Prov. Sumatera Barat, Sumatra, Indonesia.)

Naja naja miolepis, Taylor, 1922a:262.— Leviton, 1964:538.

Naja sumatrana, Wüster and Thorpe, 1989:336-341.— Toriba, 1993:192.— David and Ineich, 1999:168.

DESCRIPTION. - Color above black or dark brown, below dark or light but without a distinctive black band on anterior postion of bdy; scales in 23 longitudinal rows abound the neck, 17-19 longitudinal rows at midbody; and 13 rows longitudinal rows just before the vent (scale row reduction: 23-[17]19-13); ventrals 178-195; subcaudals 46-51; precloacal scale single.

Size. - Snout-vent length (ð) $1227 \mathrm{~mm}$, (Q) $1057 \mathrm{~mm}$; tail length (ठ) $177 \mathrm{~mm}$, (Q) $150 \mathrm{~mm}$.

Distribution.- Philippines (Culion; Palawan). Elsewhere: Thailand (southern), Malaysia (Peninsula, Borneo), Indonesia.

\section{Genus Ophiophagus Günther, 1864}

Ophiophagus Günther, 1864:340 (Type species: Hamadryas elaps Günther, 1864 [= Hamadryas hannah Cantor, 1836]).- Leviton, 1964:544.

Diagnosis. - Maxillary bone extends forward beyond palatine; venom fangs short, followed by three short teeth; head barely distinct from neck; nostril large, between two nasal scales; loreal scale absent; scales smooth, in 15 longitudinal rows at midbody; subcaudal scales partially single, partially divided; hemipenes very elongate, forked for most of their length; hypapophyses present on posterior vertebrate.

\section{Ophiophagus hannah (Cantor, 1836)}

King Cobra

Figures 7A-B, 36, 37

Ophiophagus hannah, Günther, 1864:341._- Leviton, 1964:544_—Alcala, 1986a:161; 1986b:161 _— Toriba, 1993:195. - David and Ineich, 1999:171.

Naja hannah, Taylor, 1922:256, pl. 31.—Smith, 1943:436.

DESCRIPTION.- Color variable, dorsum uniform olive to dark brown in adults, scales often with black borders, juveniles dark brown to black with yellow rings; ventral surface, chin and throat cream white, becomming darker posteriorly. Maxillary bone extends forward beyond palatine; venom fangs short, followed by three small teeth; pterygoid teeth 10-12; head barely distinct from neck; eye moderate, pupil round; nasal large, nostril between two nasals; loreal absent; scales smooth, in 15 longitudinal rows throughout; caudodorsal scales reduce: $6(2+3$ [43-46]) 6; subcaudals $90-116$.

SizE. - Snout-vent length (đ) $1610 \mathrm{~mm}$, () $1590 \mathrm{~mm}$; tail length (đ) $430 \mathrm{~mm}$, (†) $395 \mathrm{~mm}$

Distribution.- Philippines (Balabac; Jolo; Luzon [Prov. Aurora, Benguet, Bulacan, Isabela, Laguna]; Mindanao (southern); Mindoro; Negros [Prov.: Negros Oriental]; Palawan; Polillo). Elsewhere: Pakistan through South and Southeast Asia, southern China, Malaysia, Singapore, Indonesia. 

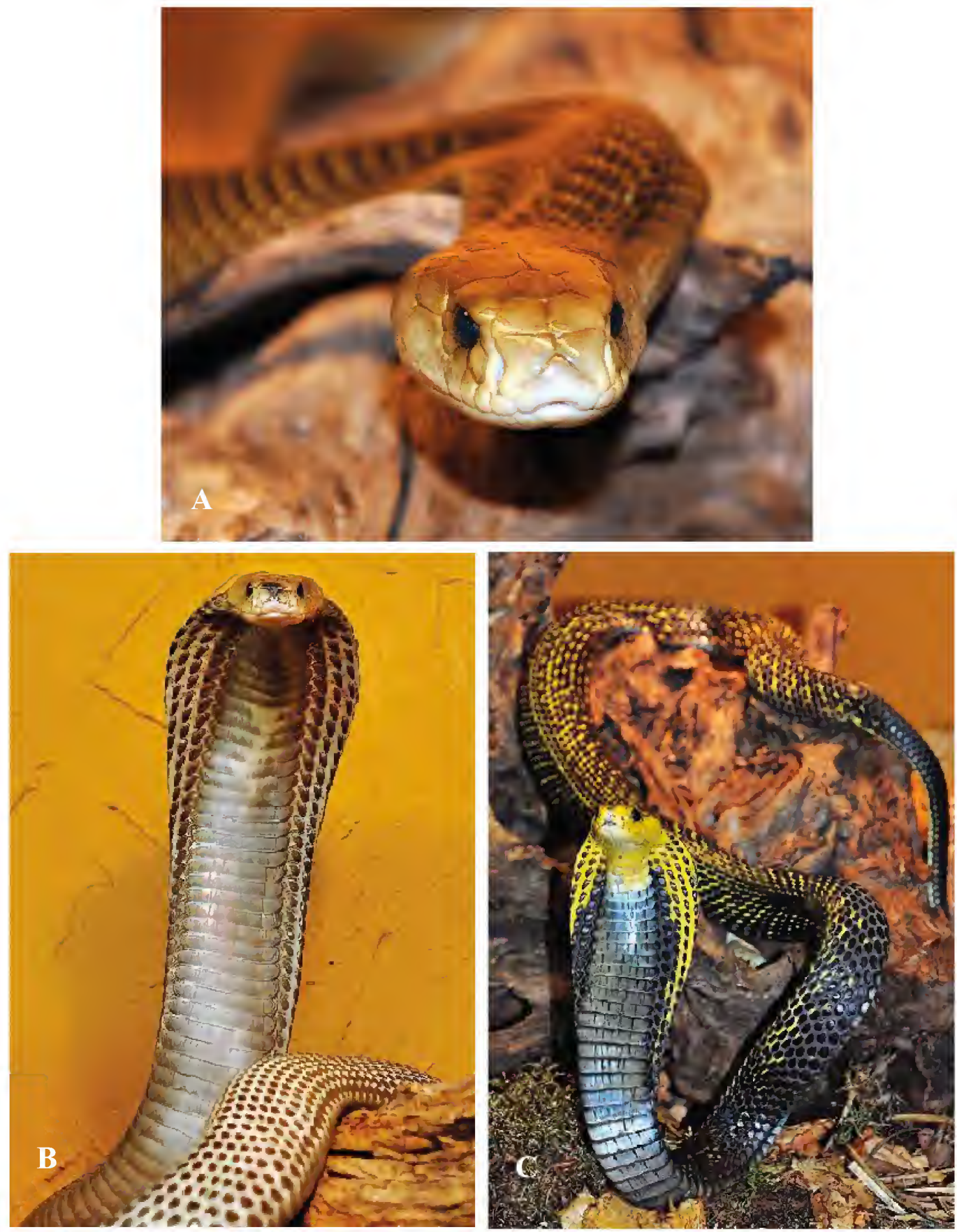

Figure 35A-C. A. Naja philippinensis. B. Naja philippinensis. C. Naja samarensis. Photos courtesy of Markus Oulehla. 

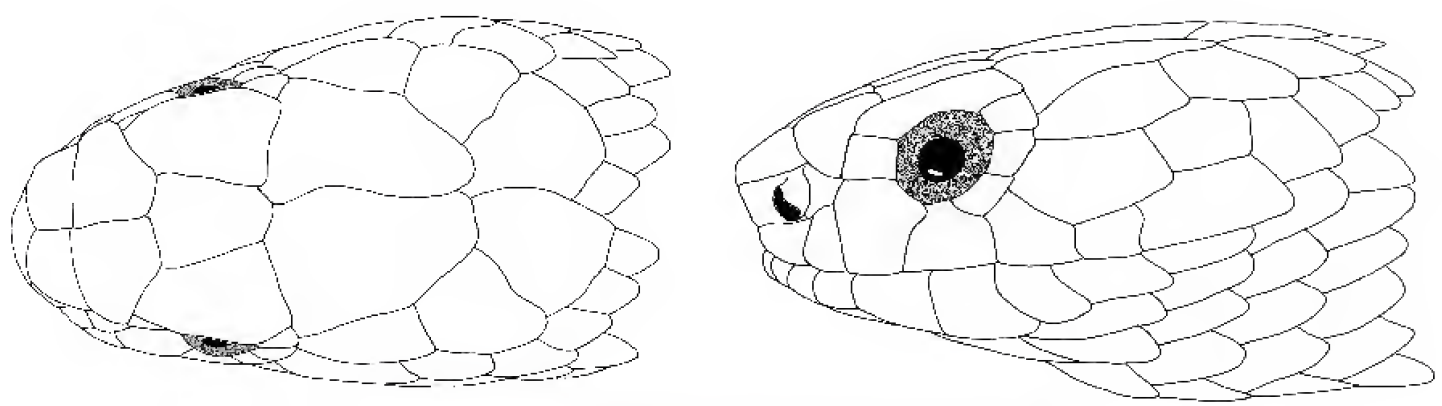

FIGURE 36. Ophiophagus hannah (Cantor, 1836). Illustrations by Marilyn Kramer.

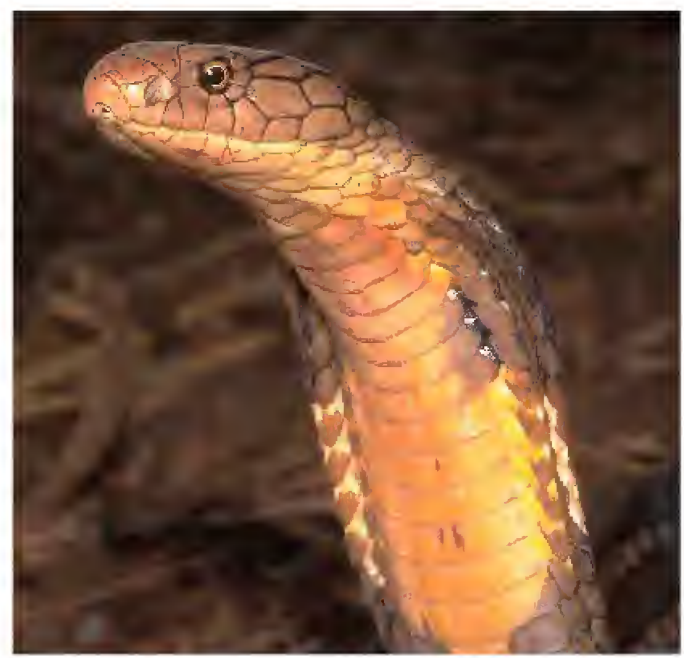

Figure 37. Ophiophagus hannah. Photo by Hla Tun.

\section{Subfamily Hydrophiinae}

REMARKS. - Sea snakes are, taxonomically, among the most poorly understood group of reptiles. In recent years, at least dating from McDowell's efforts in 1972 to redefine the major groups of hydrophine sea snakes, to 2013, with Sanders et al. multilocus phylogeny of viviparous sea snakes, rarely do two authors agree on the phylogenetic relations among the snakes let alone the reality of species that exist. However, significant strides have been made mostly through the efforts of Sanders et al. (2013), Rasmussen (e.g., 1989, 1997, 2010), Rasmussen et al. (2011), Heatwole, et al. (2005), Lukoschek and Keogh (2006), Voris (1977), and Voris and Voris (1983), and with the further application of molecular RNA/DNA studies, a clearer picture of sea snake diversity and relationships should emerge in the forseeable future. In the meantime, we have chosen to follow the recommendations of Sanders and co-authors to wit, "Division [of the sea snakes] into multiple poorly defined genera would ... fail to represent the history of recent rapid diversification of these taxa ... For these reasons, we recommend recognizing a single genus, Hydrophis Latreille 1802, for the core Hydrophis group [which includes Acalyptophis, Astrotia, Kerilia, Lapemis, Pelamis, Thalassophina]. The taxon Hydrophis is well known as comprising dangerously venomous sea snakes; hence, retaining this name (instead of adding multiple new genera) will create less confusion for conservationists, medical professionals, and fishing industries/communities as well as herpetologists." (Sanders et al. 2013:584.) 
Most sea snakes are obligate aquatic animals that rarely, if ever come onto land except when swept ashore by wind and waves. However, at least three species, often referred to a distinct subfamily, the Laticaudinae, Laticauda colubrina, L. laticaudata, and L. semifasciata, regularly come onto land to rest and lay eggs, but otherwise they feed in water. Also, "three of the most 'primitive' true sea snakes (Subfamily Hydrophiinae) (Ephalophis greyi, Hydrelaps darwiniensis, and Parahydrophis mertoni)" (Rasmussen 1992:57), none of which occur in Philippine waters, have been observed emerging to forage on land for small burrowing gobies and then taking refuge in small burrows until the next tide allows them to return to the water (Rasmussen 1992:57 and for references).

Description data accompanying each of the sea snake species have been culled largedly from details given in Smith (1926) and adjusted where necessary based on newer materials.

\section{Genus Aipysurus Lacepède, 1804}

Aipysurus Lacepède, 1804:197.— Smith, 1926:13.

Diagnosis. - Maxillary bone extends forward beyond palatine, as long as or longer than ectoptergyoid; 5-11 maxillary teeth behind front fangs; nostrils superior, nasal scales in contact with one another; head scales variable, either whole or broken into smaller scales; body scales imbricate, in 17-15 rows around body; ventrals large, $1 / 3$ to $1 / 2$ width of body, scales usually with medial keel, best developed posteriorly. (Modified after Smith 1926:13.)

REMARKs. - See comments about Aipysurus in Rasmussen (2002:56).

\section{Aipysurus eydouxii (Gray, 1849)}

Spine-tailed or Marbled Sea Snake

Tomogaster eydouxii Gray, 1849:59.

Aipysurus eydouxii, Smith, 1926:14.

DESCRIPTION. - Body nearly of uniform diameter throughout, cylindrical; 10-11 maxillary teeth behind fangs; body scales, imbricate, smooth, in 17 rows on neck and body, 15 rows just before vent; dorsal scales on head large, regular, frontal longer than its distance from tip of snout; prefrontals usually two but occasionally divided by transverse groves to four; one pre- and two postoculars; six upper labials, fourth bordering orbit of eye; six lower labials; ventrals (ठ) 129-137, (ㅇ) 135-146, each with a more or less developed median keel that in adult males ends in a strong spinous tubercle; subcaudals ( $\delta^{3}$ ) 30-32, (ㅇ) 23-27; brownish or olive above with 44-55 yellow, black-edged scales forming crossbands, usually broken along mid-dorsal line.

SizE. - Total length usually to $550 \mathrm{~mm}$ (but Smith [1926:15] records one $q$ from Java at 910 $\mathrm{mm})$.

Distribution. - Philippines (although reported for the Philippines, no verifiable records or voucher specimens ["I have seen no specimens. Both Boulenger \{1896:304\} and Wall \{1910:189\} give the Philippines as part of its range, and the species is included in the present work on their authority." \{Taylor, 1922a:227\}]; Smith [1926:16] also questions the authenticity of Boulenger's report.). Elsewhere: widely distributed in coastal waters off of Australia (Queensland, Northern Territory, Western Australia), New Guinea, Indonesia, Gulf of Thailand, Singapore, Malaysia, South China Sea. 


\section{Genus Emydocephalus Krefft, 1869}

Emydocephalus Krefft, 1869:321.—Smith, 1926:26.

Diagnosis. - Maxillary bone shorter than ectopterygoid and extends forward beyond palatine; no maxillary teeth present following the very small venom fangs; nostrils superior; nasal scales in contact with one another dorsally; scales in dorsum of head large; second upper labial scale very elongate; scales on body imbricate, in 15-19 longitudinal rows at midbody.

\section{Emydocephalus annulatus Krefft, 1869}

Annulated Sea Snake

Emydocephalus annulatus Krefft, 1869:322.- Smith, 1926:26.-Alcala, 1986a:162.—David and Ineich, 1999:91.

DESCRIPTION.- Body of nearly uniform diameter throughout; head short, above covered with large, regular scales; rostral five-sided, usually with a projecting spine; prefrontals not in contact with upper labials; one preocular, two postocular scales; temporals small, 2 anterior, three posterior; upper labials 3, second very elongate; 4 lower labials; body scales in 15 longitudinal rows on neck, 15-17 around midbody, strongly imbricate; ventrals distinct, 125-145, with small tubercles and usually with a median keel; subcaudals 20-40, undivided; precloacal (anal) scale single; body color variable, uniform dark grey, brown to black above or yellowish white with 23-35 variegated brown or black rings; head variable, creamy white, yellowish, or dark brown or black, with dark or light markings.

SizE.- Total length $910 \mathrm{~mm}$; tail length $110 \mathrm{~mm}$.

Distribution.- Philippines: according to Alcala (1986:163), "Probably all over Philippine seas" but without exact references. Elsewhere: Australia, Papua New Guinea, Indonesia (Irian), Loyalty Islands.

\section{Genus Hydrophis Latreille in Sonnini and Latreille, 1801}

Hydrophis Latrielle, 1802:193. - Smith, 1926:40; 1943:451.— McCarthy, 1993:229.

Pelamis Daudin, 1803:361. Disteira Lacepède, 1804:210.

Leioselasma Lacépède, 1804:210.

Lapemis Gray in Hardwicke and Gray, 1835, vol. 2, pl. 87, fig. 2.- Smith, 1926:108.- McCarthy, 1993:243.— Rasmussen, 1996:22.—David and Ineich, 1999:121.

Aturia Gray, 1842:61.

Enhydrina Gray, 1849:47.

Kerilia Gray, 1849:57. - Smith, 1926:31.— David and Ineich, 1999:120.

Thalassophis Schmidt, 1852:75. - Smith, 1926:103.—David and Ineich, 1999:197.

Astrotia Fischer, 1856:38. - Smith. 1926:113. — David and Ineich, 1999:63.

Acalyptophis Boulenger, 1896:269.- Smith, 1926:101.

Praescutata Wall, 1921:390.—David and Ineich, 1999:176.

Thalassophina Smith, 1926:33.- Rasmussen, 1997:23.

Kolpophis Smith, 1926:106. - Rasmussen, 1996:23.—David and Ineich, 1999:120.

Diagnosis. - Maxillary bone does not extend forward beyond palatine; 1-18 maxillary teeth behind venom fangs and separated by a small interval (diastema); nostrils superior; nasal scales in contact with one another or separated by elongate scales; dorsal head scales regular, large; body scales imbricate to juxtaposed; ventrals small, usually distinct and undivided.

REMARKs.- David and Ineich (1999:104) reviewed the controversy surrounding the use of the name Hydrophis to include several nominal taxa, Disteira, Leioselasma, and Aturia that had 
been recognized by various authors. In so doing, they followed Rasmussen (1996), who also recommended recognizing Astrotia and Enhydrina as distinct genera. More recently, several phylogenetic studies have led to the abandoment of at least 10 heretofore recognized genera by placing them and their included species in the genus Hydrophis (Sanders et al. 2013; Pyron et al. 2013). Although we have adopted the newly proposed taxonomic arrangements here, we have also indicated where those changes have occurred by including in brackets [ ] the genus name to which the respective species had been previously assigned. It should be noted that the bracketed name does not imply a subgenus designation..

In the descriptions that follow, body lengths, that is total lengths and tail lengths, are for the largest specimens we have found recorded, mostly as recorded by Smith (1926) but adjusted if more recent information were available.

\section{Hydrophis [Kolpophis] annandalei (Laidlaw, 1901) Annandale's Sea Snake}

Distira annandalei Laidlaw, 1901:579, pl. 35.

Kolpophis annandalei, Smith, 1926:106.—David and Ineich, 1999:121.

DESCRIPTION.- Body short, stout, greatest body diameter not quite twice that of neck; head large, with nasal and prefrontal scales usually divided; supraocular, frontal, and parietals entire, the latter usually separated by small scales; 9-11 upper labials, often fragmented; temporals small, irregular; lower labials, small or indistinct and separated from labial margin by small scales; scale rows: around neck 62-82, around midbody 74-93, hexagonal, juxtaposed or subimbricate, smooth or with short keel; ventrals distinct throughout, 320-368; precloacal scales enlarged. (After Smith 1926:106.)

SizE. - Total length (ठ゚) $910 \mathrm{~mm}$; tail length (ठ) $120 \mathrm{~mm}$.

Distribution. - Philippines (not yet reported from the Philippines but has been reported from coastal waters of northern Borneo [Brunei] and Vietnam in the South China Sea as well as the Gulf of Thailand). Elsewhere: Indonesia (Java), Singapore, Malaysia, and Thailand (see David and Ineich 1999:121 for references).

\section{Hydrophis [Thalassophis] anomalus Schmidt, 1852} Anomalous Sea Snake

Thalassophis anomalus Schmidt, 1852:81.-Smith, 1926:104.—David and Ineich, 1999:197.—Stuebing and Inger, 1999:221.

DESCRIPTION. - Head short; above, rostral fragmented into 4-5 small scales; nasals separated by elongate scales; frontal small, sometimes divided; one pre- and two postoculars; temporals 2 or 3 anterior, three posterior scales, small, scarcely larger than adjacent scales; $6-7$ upper labials, second usually in contact with prefrontal, 3-5 bordering orbit of eye; 4 lower labials in contact with sublabials; 27-30 scale rows around neck, 31-35 at midbody, posterior scales hexagonal in shape, juxtaposed and keeled; ventrals scarcely broader than adjacent scales, 210-256, bicarinate; precloacal scales slightly enlarged.

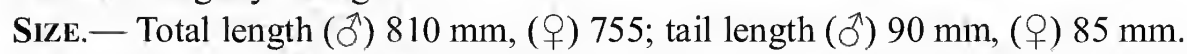

Distribution. - Philippines (not yet reported from coastal Philippine waters but one record for the northern coast of Borneo [Brunei] and elsewhere in the Gulf of Thailand). Elsewhere: Indonesia (Java, Kalimantan, Moluccas), Malaysia, Singapore, Thailand, Vietnam. 


\section{Hydrophis atriceps Günther, 1864}

Southeast Asian Sea Snake

Figure 19B, 23A, 24A

Hydrophis atriceps Günther, 1864:371, fig.—McCarthy, 1993:230.— David and Ineich, 1999:104.— Rasmussen 2001:4001, 1 fig.

Hydrophis fasciatus atriceps, Smith, 1926:97, fig. 27; 1943:465.

Diagnosis. - Head small, body long and slender anteriorly; scales on thickest part of body subquadrangular or hexagonal in shape, juxtaposed or slightly imbricate; 5-6 maxillary teeth behind fangs; 2 anterior temporals; body scales in 25-30 (usually 27-29) rows around the neck, 39-49 (usually 43-53) around midbody (increase in number of rows from neck to midbody 12-20); ventral scales 320-455 (average 366 or less); anterior part of body including head and neck dark olive to black with pale oval yellowish spots on sides, sometimes connected as crossbars; posterior, grayish; below whitish; dark rhomboidal spots may extend down the sides of the body and form complete annuli in young.

SizE.- Total length (ơ) $1100 \mathrm{~mm}$, (ㅇ) $990 \mathrm{~mm}$; tail length (ơ) $100 \mathrm{~mm}$, () $75 \mathrm{~mm}$.

Distribution.- Philippines (Mindanao; Samar; Sulu Archipelago; Visayan Sea). Elsewhere: coastal waters off the east coast of Malaysia, Gulf of Thailand,Vietnam, southern China, Indonesia to western New Guinea, and northern Australia.

REMARKS.- This species is so similar in appearance to $H$. fasciatus that the two have been regarded as conspecific, though treated as distinct subspecies (Smith 1926, 1943), but recent studies have treated tham as distinct species (see McCarthy 1993:230, 234; David and Ineich 1999:104, 109). Alcala (1986:164) referred to records from the Visayan Sea and areas around Samar, Mindanao, and the Sulu islands to H. fasciatus but David and Ineich (1999:105) noted that "According to A. R. Rasmussen (pers. commun., June 1996), all references of Hydrophis fasciatus based on specimens taken East of Malacca Strait, from Gulf of Thailand to southern China and to the north coast of Australia, belong to Hydrophis atriceps; we follow his interpretation." We accept this interpretation as well.

\section{Hydrophis belcheri (Gray, 1849)}

Belcher's Sea Snake

Aturia belcheri Gray, 1849:46.

Hydrophis belcheri, McCarthy, 1993:230._- David and Ineich, 1999:105.— Rasmussen et al., 2011:5.

DESCRIPTION.- Head moderate, body elongate, compressed posteriorly, two to four times the diameter of the neck; 7-8 [rarely 6 or 9] maxillary teeth behind venom fangs; normally one supralabial (4th, but occasionally two, $3^{\text {rd }}$ and $4^{\text {th }}$ or $4^{\text {th }}$ and $5^{\text {th }}$ ) borders eye; one anterior temporal, occasionally divided by a horizontal groove; 24-27 scales around neck, 32-37 around midbody; ventrals 278-313; body color yellow or grayish above, yellow-whitish below, 52-70 dark bands, head black in young, lighter in adults, with yellowish or olive markings. (After Rasmussen et al. 2011:5.)

SiZE.—Total length (ठ) $1240 \mathrm{~mm}$, (ㅇ) $1110 \mathrm{~mm}$; tail length (ठే) $120 \mathrm{~mm}$, (ㅇ) $90 \mathrm{~mm}$.

Distribution.- Philippines (unknown although Alcala (1986a:166) states that it "has been recorded from the central Philippine sea."; otherwise, it has been reported from the coastal waters off of Vietnam in the South China Sea [Rasmussen et al. 2011:5]). Elsewhere: Gulf of Thailand, Vietnam, Indonesia, and New Guinea (David and Ineich [1999:105] noting earlier discussions by McDowell [1972:217] and McCarthy and Warrell [1991:162-163], now refer the Australasian records to Hydrophis pacificus, but see also Kharin [2005:161], whose observations heighten the confusion regarding the identification of samples of populations supposedly belonging to $H$. belcheri. See also comments by Rasmussen (2001) relating to H. coggeri. 


\section{Hydrophis brookii Günther, 1872 \\ Brook's Sea Snake}

Hydrophis brookii Günther, 1872:597, fig. (Type locality: Sarawak [coast], Borneo, Malaysia).- Smith, 1926: 99.—David and Ineich, 1999:106.— Stuebing and Inger, 1999:207.— Rasmussen et al., 2011:5.

DESCRIPTION. - Head very small, body very slender anteriorly, compressed posteriory and two to three times diameter of neck; 4-5 maxillary teeth behind venom fangs; scales at midbody subimbricate, hexagonal in shape, often with a median tubercle or keel; 6 , occasionally only 5 , upper labials, 3rd and 4th border eye; scales in 23-31 rows around neck, 37-45 around midbody; ventrals 328-414, distinct throughout; color (live) bluish white (greyish in preserved specimens), with 60-80 dark grey (black) bands, anteriorly they encircle body and are about twice as broad as the interspaces, posteriorly they narrow on the sides and may be incomplete below; head black or dark grey with curved yellow horseshoe-shaped marking across snout and extending back along sides of head. (Modified from Smith 1926:100-101 and Rasmussen et al. 2011:5.)

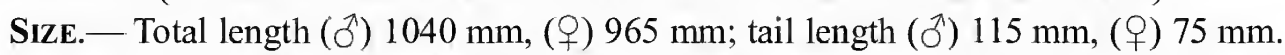

DisTRIBuTION. - Philippines (unknown, but it has been reported from South China Sea, along the coast of Sarawak, Borneo [Smith 1926:101; Stuebing and Inger 1999:207] and Vietnam [David and Ineich 1999:106; Rasmussen 2011:5]). Elsewhere: Thailand, Indonesia, Malaysia, Singapore, Vietnam, Sarawak coast of Borneo.

\section{Hydrophis coggeri (Kharin, 1984)}

Cogger's Sea Snake; Pacific Yellow-banded Seasnake

Leioselasma coggeri Kharin 1984a:1538, fig. b. — David and Ineich 1999:107.— Rasmussen 2001 :4002, figs.

DESCRIPTION.- Head and body variable, "small head and slender neck, others with more robust body" (Rasmussen, op. cit.); 5-8 maxillary teeth behind venom fangs; scales in 22-39 rows around neck, 29-35 around midbody; ventrals, 278-325; head uniformly dark brown to black, body olive with encircling dark bands on body and tail.

SizE.- Total length $1150 \mathrm{~mm}$.

Distribution.- Philippines (said to occur in the Philippines [Rasmussen 2001:4002 and distribution map; also Zug 2013:229] but most likely H. melanocephalus [see Rasmussen et al. 2011:6]). Elsewhere: north coast of Australia, New Caledonia, east to Vanuatu and Fiji.

\section{Hydrophis [Lapemis] curtus Shaw, 1802 \\ Short or Hardwicke's Sea Snake \\ Figures 27D, 28-29, 37-38}

Lapemis curtus Shaw, 1802:562.—Zhao and Adler, 1993:269.- Gritis and Voris, 1990: 1-11.- Whitaker and Captain, 2004:398, photo (p. 399). McCarthy, 1993:244.—David and Ineich, 1999:121.

Lapemis hardwickii Gray in Hardwicke and Gray, 1835, vol. 2, pl. 87.-Smith, 1926:108, fig. 32, pl. 1, fig. 3; $1943: 468$, figs. 148-149.

Lapemis curtus hardwickii, McCarthy, 1993:244.

DESCRIPTION.- Body short, stout, diameter of neck region at least half that of the midbody; head large, scales on dorsum of head regular (Fig. 37), entire, parietals occasionally divided, nostrils superior, nasals in contact with one another; prefrontal usually in contact with second upper labial, 7-8 upper labials, 3-4 bordering eye, 1 pre- and 1-2 postoculars, 2 , rarely 3 , anterior temporals; body scales squarish or hexagonal, juxtaposed, outer 3-4 rows larger than others, scale rows: around neck (ठ) 23-31, (ㅇ) 27-35, around midbody, (đ) 25-27, (ㅇ) 33-41; ventrals small, usually distinct anteriorly, not so posteriorly, (đ) 114-186, (q) 141-230; greenish or yellow-olive above, whitish below, 35-50 olive to dark gray dorsal bars, tapering to a point laterally, occasion- 


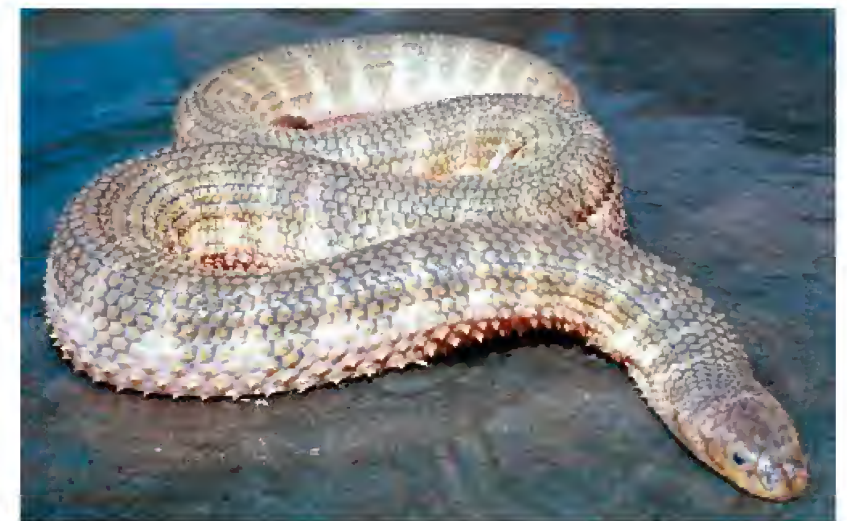

FIGURE 37. Hydrophis [Lapemis] curtus Shaw, 1802. Photo courtesy of Harold Voris.

ally encircling body, a narrow dark ventral stripe or broad irregular band occasionally present; adults often lack any pattern and are uniform olive to dark gray; head pale olive to black, yellow markings on snout present or not.

SizE.- Total length $850 \mathrm{~mm}$ (1100 mm, fide Rasmussen et al. 2011); tail length $85 \mathrm{~mm}$.

Distribution.- Philippines (reported from the Visayan Sea [fide Alcala 1986:170]). Elsewhere: southeast coast of India to Straits of Malacca, Indonesia, and Australia, and north to China, Taiwan, and Japan.

REMARKS.- Gritis and Voris (1990) do not recognize Lapemis hardwickii [now Hydrophis hardwicki] as a distinct species, placing it in the synonymy of L. curtus. McCarthy (1993) recognized it as a subspecies of $L$. curtus, allowing that the nominate form inhabits coastal waters from the Persian Gulf to the shores of western India, and L. curtus hardwickii ranges from the coastal waters of Sri Lanka and eastern India to New Guinea and Australia and north to the coast of China, the Philippines, and Japan (see also David and Ineich 1999:121-122). Smith (1926:113, 1943:471) argued that $L$. curtus ranges from the Persian Gulf to the west coast of India as far as Sri Lanka but that it is unknown along the east coast of India. We follow Gritis and Voris in this handbook inasmuch as theirs is the most comprehensive analysis of character variation done so far, and based on their study there are no mophological features that justify recognizing two species although we emphasize that recent phylogenetic studies (Sanders et al. 2013) place the genus Lapemis and its included species in the genus Hydrophis.

\section{Hydrophis cyanocinctus Daudin, 1803}

Annulated Sea Snake; Many-banded Sea Snake

Figures 19B, 20B, 23B, 25B, 26A-B, 39

Hydrophis cyanocinctus Daudin, 1803:383.- Smith, 1926:56; 1943:454.— Whitaker and Captain, 2004:392, photo (p. 303).

DESCRIPTION.- Head moderate, body elongate, not slender anteriorly; scales on thickest part of body overlapping (imbricate) throughout, with medial keel or broken into two or three tubercles; 5-8 maxillary teeth behind venom fangs; ordinarily two anterior temporals; scales in 27-35 rows on the neck, 37-47 around midbody (increase from neck to midbody 8-14); ventrals 290-390, distinct throughout, about twice as broad as adjacent scales; head in adult olive or yellowish, in young, head black or dark olive; young with black annuli that broaden dorsally and occasionally a black 
ventral stripe; in adults, ventral stripe and lower portions of annuli less distinct but dorsal portion of annuli remain distinct.

SizE. - Total length $\left({ }^{\pi}\right) 1500 \mathrm{~mm}$, () $1885 \mathrm{~mm}$; tail length $\left(\partial^{7}\right) 130 \mathrm{~mm}$, (P) $135 \mathrm{~mm}$.

Distribution.- - Philippines (Luzon; Visayan region) (fide Alcala 1986a:164). Elsewhere: Extensive range from Persian/Arabian Gulf east to Indonesia and north to the Idzu Sea, Japan (see David and Ineich [1999:108] for details).

\section{Hydrophis gracilis (Shaw, 1802)}

Common Small-headed Sea Snake Figure 19C

"Kadell nagam" Russel, 1801 :pl. 15, pl. 13.

Hydrus gracilis Shaw, 1802:560 (Type locality: unknown).

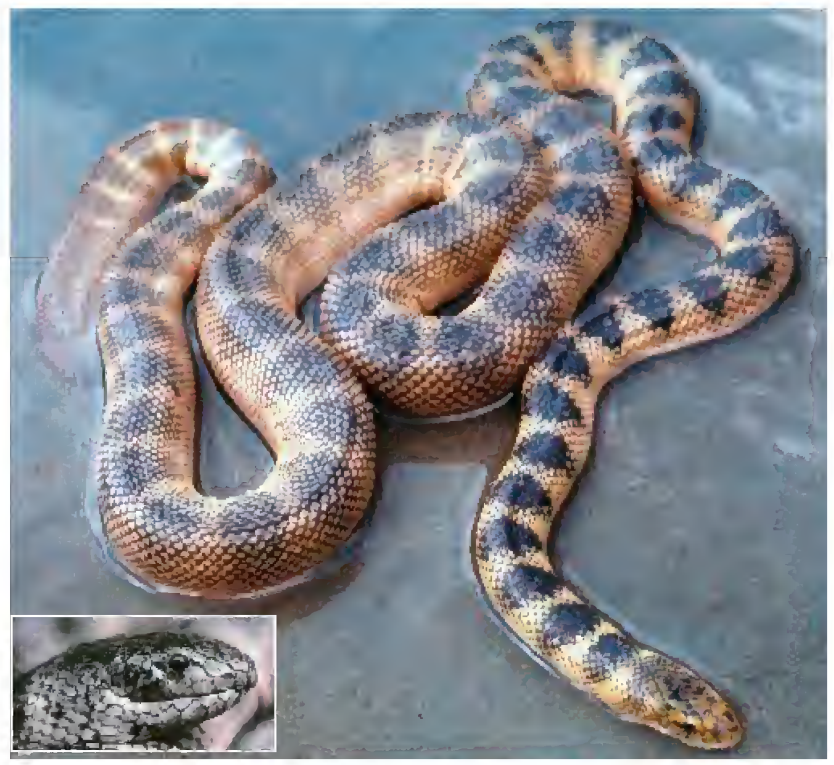

FIGURE 39. Hydrophis cyanocinctus Daudin, 1803 (inset: closeup view of head). Photos courtesy of Harold Voris Microcephalophis gracilis, Smith, 1926:121. — David and Ineich, 1999:110. - Rasmussen et al. 2011:6.

DESCRIPTION. - Head very small, elongate, snout projecting beyond lower jaw; body long and slender anteriorly, compressed posteriorly and four to five times the diameter of neck; 5-6 maxillary teeth behind front poison fangs; rostral scale large, extending well onto upper surface of snout; scale rows on neck 17-23, on body 30-43, posterior scales hexagonal, juxtaposed, broader than long, with two or three tubercles, one behind the other; ventrals 215-350, entire and broader than adjacent body scales on anterior slender portion of body, completely divided posteriorly by a median groove, the two halves apposed or alternating to one another; precloacal scales slightly enlarged; color in young black anteriorly with whitish dorsal bands or oval spots laterally, 40-60 more or less complete bands posteriorly, in adults markings lose definition and body becomes more uniformly greyish above, and paler below.

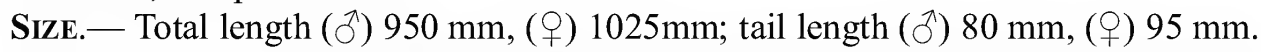

Distribution.- Philippines (this species has not been recorded from the Philippines but it has been found in the South China Sea off the coast of Vietnam and southern China). Elsewhere: widely distributed from Persian/Arabian Gulf (coastal Saudi Arabia, Kuwait, Iraq, Iran, and Oman) east to the Bay of Bengal, Gulf of Thailand, Malaya and Singapore, South China Sea, and Indonesia, to New Guinea (Gulf of Guinea).

REMARKS. - Smith (1943:473) provides information on the geographic variation in scale counts for this species.

\section{Hydrophis inornatus (Gray, 1849)}

REMARKS. - According to David and Ineich (1999:111), Rasmussen (1989) referred records of Philippine and Indonesian H. inornatus to H. ornatus (see Rasmussen synonymy, 1989:399, also comments on p. 410). Rasmussen also states, "However, the acceptance of H. inornatus as a separate species is explicitly preliminary and further study may show that the type specimen of H. inornatus is an abberant specimen of H. ornatus." (Rasmussen 1989:415.) 


\section{Hydrophis [Kerilia] jerdoni Gray, 1849 \\ Jerdon's Sea Snake}

Kerilia jerdoni Gray, 1849:57.- Smith, 1926:31.-David and Ineich, 1999:120.- Stuebing and Inger, 1999:214.- Rasmussen et al., 2011:8.

DESCRIPTION.- Head short, narrowed anteriorly; body robost, elongate; 7-9 maxillary teeth behind fangs; scales on body longer than broad, imbricate throughout, strongly keeled, in 15-17 rows around neck, 19-23 at mid-body; ventrals 200-273, distinct throughout but only slightly broader than adjacent scales; body yellow above, yellowish or whitish below, with black bands that are wider above and usually fade laterally.

SizE. - Total length $940 \mathrm{~mm}$; tail length $100 \mathrm{~mm}$.

Distribution.- Philippines (not yet reported from the Philippines but has been reported from coastal waters of northern Borneo and coastal waters elsewhere in the South China north to Taiwan). Elsewhere: widely distributed from coastal waters of southeast Indian Peninsula, Sri Lanka, Myanmar, Thailand, Mergui Archipelago, Malacca Straits, Singapore, and west and northwest coast of Borneo.

REMARKS.- Two subspecies of Kerilia jerdoni have been recognized, but not all authors agree on their status. Kerilia j. jerdoni is the form that would be encountered along in the Bay of Bengal along the coasts of southeast India, Sri Lanka, and Myanmar, whereas $K$. j. siamensis ranges from the east coast of Peninsular Thailand to the Borneo coast (Rasmussen and Anderson 1990).

Although not yet recorded from the Philippines, its occurrence in shallow coastal waters off the coast of northern Borneo suggests it will likely be found in coastal waters off of the Palawan Island group and perhaps in the Sulu Sea.

\section{Hydrophis klossi Boulenger, 1912}

\section{Kloss's Sea Snake}

Hydrophis klossi Boulenger, 1912:190.— Smith, 1926:68. — Stuebing and Inger, 1999:210.— David and Ineich, 1999:112.

DESCRIPTION.- Head small, body anteriorly slender, posteriorly two to three times diameter of neck, compressed; 5-6 maxillary teeth behind venom fangs; scale rows on neck 23-25 (27), at midbody 31-37 (39); ventrals distinct throughout, 360-413, less than twice as broad as adjacent body scalers; precloacal scales enlarged; Head dark olive to dark brown, sometimes with elongate whitish spots or indistinct horseshoe shaped marking; body above grey with 50-75 dark bands that encircle body, broadest above and broader than interspaces; below, underside of head dark and anterior portion of body dark, posteriorly sides of body and belly yellowish-white, posteriorly, greyish; tip of tail black. (After Smith 1926:68 and Stuebing and Inger 1999:210.)

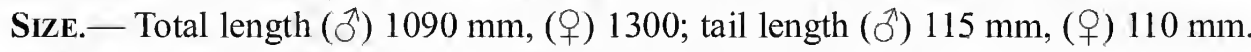

Distribution.- Philippines (not yet reported from Philippine waters; Stuebing and Inger [1999:210] report one specimen off the coast of northern Borneo). Elsewhere: east coast of Malay Peninsula, Thailand, Singapore, western Indonesia (Sumatra).

\section{Hydrophis lamberti Smith, 1917}

\section{Lambert's Sea Snake}

Hydrophis lamberti Smith, 1917:340.

Hydrophis ornatus, (part) Smith, 1926:81._ Dunson and Minton, 1978:281. - Minton, 1978:151.

Hydrophis lamberti, Rasmussen, 1989:410.—Rasmussen et al., 2011:6. 
DESCRIPTION.- Head large, robust; 9-12 maxillary teeth behind front fangs; scale rows on neck (ठ) 38-42, (ㅇ) 37-45, on body (ठ) 45-52, (우) 49-56; ventrals distinct throughout, anterior-

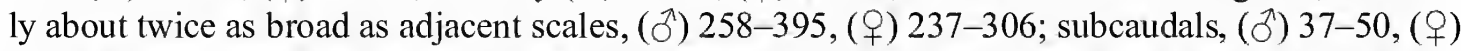
34-44; color, head greyish or brown above, whitish below; body with large oval-shaped bands anteriorly, replaced by cross-bands with broad interspaces posteriorly, dark bands both widest and darkest dorsally, lighter and narrower laterally; on tail,greyish black bands and broad whitish interspaces, 4-6 in (ठ), 5-6 in (ㅇ) . (After Rasmussen 1989:411.)

SizE. - Total length (ठ) 410-1220 mm, () 440-1040 mm.

Distribution.- Philippines (Iloilo Prov. [Gigante Ids.]; Luzon [Manila Bay]). Elsewhere: Singapore, Gulf of Thailand, Vietnam.

\section{Hydrophis melanocephalus Gray, 1849}

Black-headed Sea Snake

Hydrophis sublaevis var. melanocephalus Gray, 1849:53.

Hydrophis melanocephalus, Smith, 1926:64.- McCarthy, 1993:237.— David and Ineich, 1999:114.

DESCRIPTION.- Head small, body elongate and slender anteriorly, compressed posteriorly, the diameter two to three times greater than the neck; 6-8 maxillary teeth behind venom fangs; $23-27$ scale rows around neck, 33-41 around midbody (rows increase from 8-14, neck to midbody); ventrals 289-358, distinct throughout, bicarinate, almost twice as broad as adjacent body scales; precloacal scales enlarged; color, head black with yellow spot behind nostrils and a yellow streak behind eye, body olivaceous or greyish, yellowish or white below, with 40-55 black bands about as broad as the interspaces, usually expanding both dorsally and ventrally.

SizE. - Total length (ठ) $1130 \mathrm{~mm}$, () $1230 \mathrm{~mm}$; tail length (ठ) $95 \mathrm{~mm}$, () $90 \mathrm{~mm}$.

Distribution. - Philippines (fide Rasmussen 2011; David and Ineich 1999) but without locality details. Elsewhere: Vietnam, China, Taiwan, Japan (Ryukyu Ids.).

\section{Hydrophis ornatus (Gray, 1842)}

Ornate Sea Snake; Reef Sea Snake

Figures 24B, 40-41

Aturia ornata Gray, $1842 \mathrm{~b}: 61$.

Hydrophis ornatus, Smith, 1926:6.- David and Ineich, 1999:116.- Whitaker and Captain, 2004:394, photo (p. 395).

Hydrophis ornatus ornatus, Smith, 1943:460.—McCarthy, 1993: 239.

DESCRIPTION.- Scales on thickest part of body more or less hexagonal in shape, feebly imbricate or juxtaposed; 9-13 maxillary teeth behind fangs; head large; body robust, not elongate, greatest diameter posteriorly about twice that of the neck; one preocular; two postoculars; two anterior temporals; 7-8 upper labials; scale rows on neck: $\left(\partial^{\lambda}\right) 28-40$, (우) $31-45$, on thickest part of body, (ふ) 33-52, (ㅇ) 39-55 (increase from neck to midbody 4-12); ventrals distinct throughout, in (ठ) 209-273, in (ㅇ) 236-312, anteriorly ventrals about twice as large as adjacent scales, narrowing posteriorly; above grayish or light olive to almost white with broad dark bars or rhomboidal spots separated by narrow interspaces; below yellowish or whitish.

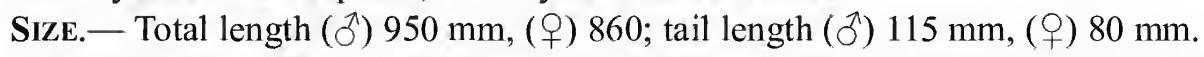

Distribution. - Philippines (Luzon; South Gigante Id.). Elsewhere: Persian [Arabian] Gulf to New Guinea and Australia and north along the coast of China to the Ryukyu Ids. (See also comments by Zug 2013:230 relating to reports of occurrence in the Gilbert Islands.)

REMARKs. - See comments under $H$. inornatus. 


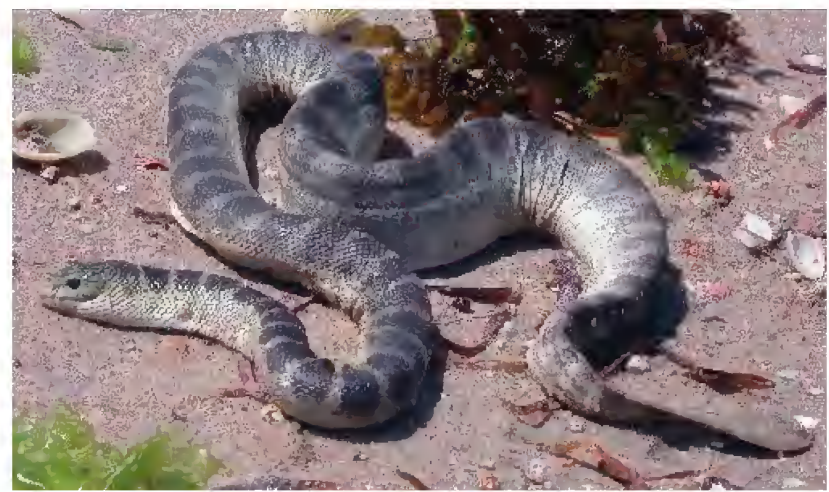

FIGURE 40. Hydrophis ornatus (Gray, 1842). Photo courtesy of Aaron Lobo
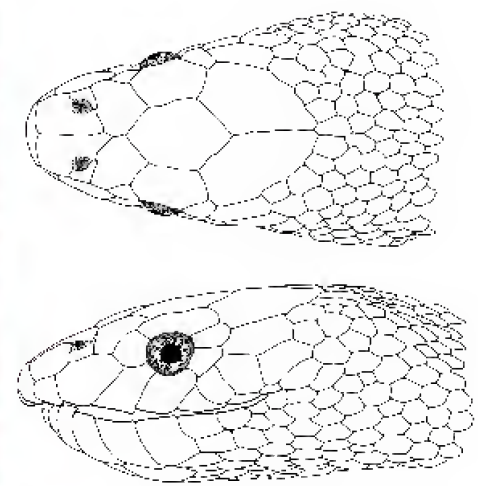

1 -

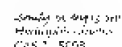

FIGURE 41. Hydrophis ornatus (Gray, 1842). Illustrations by Emily M. Eng

\section{Hydrophis [Acalyptophis] peronii (A.H.A. Duméril, 1853)}

Spiny-headed Sea Snake or Horned Sea Snake

Figures 20C, 42

Acalyptus peronii A.H.A. Duméril, 1853:522.

Acalyptophis peronii, Boulenger, 1896:269.- Smith, 1926:102.— McCarthy, 1993:221.—David and Ineich, 1999:55.

DESCRIPTION. - Head short, small, diameter of neck onethird to two-thirds that of the greatest diameter of body; rostril distinctly broader than deep; supraocular with raised, pointed posterior border; 19-23 scale rows on neck, 23-29 around body, with short keels, stronger and spinose in males; ventrals 142-206, as broad as or slightly narrower than adjacent body scales; greyish or pale brown above, whitish below, with or without dark dorsal bars tapering to points on sides; narrow ventral bands or spots may be present.

SizE.- Total length $1230 \mathrm{~mm}$; tail length $160 \mathrm{~mm}$.

Distribution.- Philippines (unknown, but it has been reported from coastal Malaysia and Vietnam in the South China Sea). Elsewhere: Gulf of Siam, including coastal Thailand, Vietnam, Malaysia, Indonesia, South China Sea north to Taiwan, and east to New Guinea, New Caledonia, and Australia.
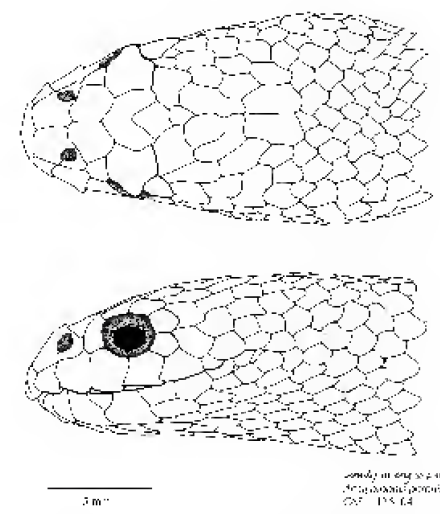

FIGURE 42. Hydrophis [Acalyptophis] peronii (A.H.A. Duméril, 1853). Illustrations by Emily M. Eng.

\section{Hydrophis [Pelamis] platurus (Linnaeus, 1758)}

Pelagic Sea Snake; Yellow-bellied Sea Snake

Figures 27A, 27C, 30, 43-44

Anguis platura Linnaeus, 1766:391.

Pelamis platurus, Smith, 1926:116, fig. 33; 1943:476.—McCarthy, 1993:245.-David and Ineich, 1999:174. - Whitaker and Captain, 2004:402, photo (p. 403). Pelamis platura, Rasumssen et al., 2011:9.

DESCRIPTION.- Body compressed, posteriorly more than twice the diameter of the neck; body scales juxtaposed, subquadrangular in shape, in 49-67 rows around thickest part of body; ventral scales, 264-406, very small and, if distinct, divided by a longitudinal groove, but usually indistin- 


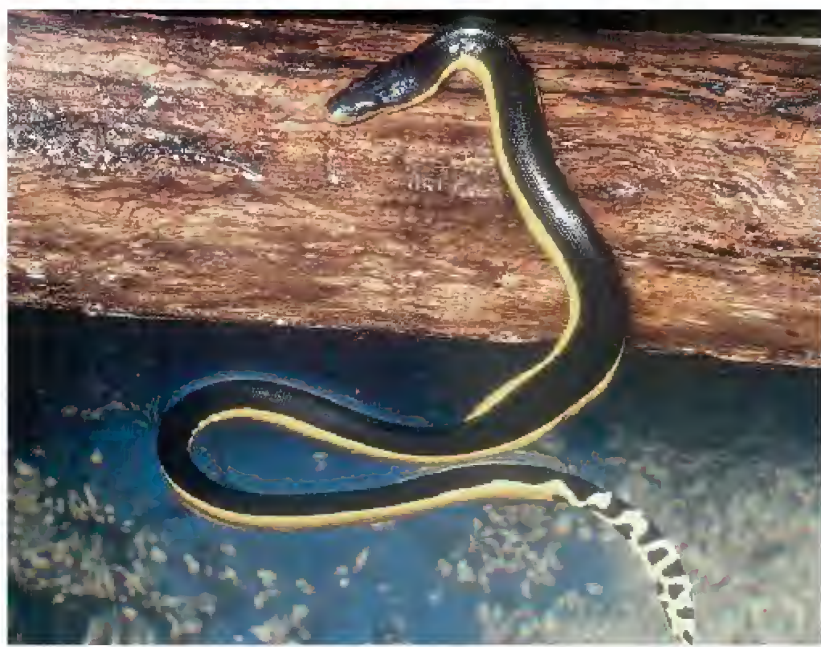

FIGURE 43. Hydrophis [Pelamis] platurus (Linnaeus, 1758). Photo courtesy of John Tashjian.
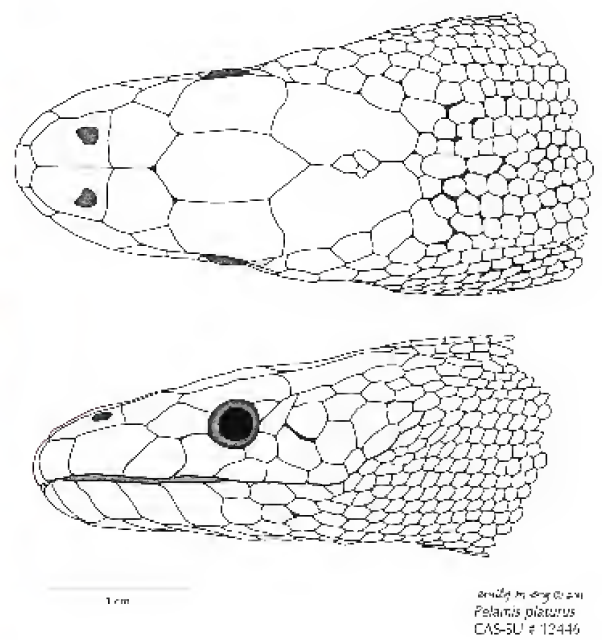

FIGURE 44. Hydrophis [Pelamis] platurus (Linnaeus, 1758). Illustrations by Emily M. Eng.

guishable from adjacent body scales; head narrow, snout elongate, head scales entire, nostrils superior, nasal scales in contact with one another; prefrontal in contact with $2^{\text {nd }}$ upper labial; $1-2$ preand 2-3 postoculars; $2-3$ small anterior temporals; $7-8$ upper labials, $4-5$ below eye but separated from border by subocular; color variable but most often distinctly bicolored, black above, yellow or brown below, the dorsal and ventral colors sharply demarked from one another; ventrally there may be a series of black spots or bars on the yellow or brown background, or the yellow may extend dorsally so that there is only a narrow middorsal black stripe, or a series of black crossbars (see Smith 1943:476-477 for a more complete description of the color pattern variants).

SizE.—-Total length (ð) $720 \mathrm{~mm}$, (ㅇ) 880; tail length (ð) $80 \mathrm{~mm}$, (우) $90 \mathrm{~mm}$.

Distribution. - Philippines (widely distributed). Elsewhere: most widely distributed of all sea snakes, from east coast of Africa throughout southern and eastern coastal Asia, as far north as southern Siberia, throughout Indonesia to Australia and Tasmania, also from Gulf of Panama north to Baja California in western North America and Hawaiian Islands.

\section{Hydrophis [Enhydrina] schistosus (Daudin, 1803)}

Beaked Sea Snake; Hooked-nosed Sea Snake

Figures 20A, 21B, 22, 45

Hydrophis schistosus Daudin, 1803:386.

Enhydrina schistosa, Smith, 1926:36, fig. 17; 1943:449, fig. 144.— McCarthy, 1993:227.—David and Ineich, 1999:92.-Whitaker and Captain, 2004:390, photo (p. 391).

Disteira schistosa, McDowell, 1972:239-244.

DESCRIPTION.- Mental scale small, partly concealed within mental groove; 3-4 maxillary teeth behind fangs; 5-6 palatine teeth, palatine teeth larger than pterygoid teeth; no suborbital stripe; young light brown to dark gray above, whitish below, with dark gray or black annuli; pattern disappears in adults which are uniform gray in color; scales around body variable, in Bay of Bengal, scales around neck, (ð) 40-52, (우) 42-55, scales around midbody, (ठ) 49-60, (우) 51-65, scales imbricate or subimbricate, with short central keel; ventrals 239-322, small, usually distinct throughout, occasionally missing on anterior part of body; precloacal scales slightly enlarged; color of young grey or bluish grey above, whitish below, with dark grey or black rings, broadest dorsally, that disappear in adults, which are usually uniformly greyish in color. 
Size. - Total length $1400 \mathrm{~mm}$; tail length $180 \mathrm{~mm}$ (but rarely exceeding $1100 \mathrm{~mm}$ total length).

Distribution.- Philippines (although there are no specific records, its wide range and occurrence in the South China Sea in muddy bottoms of coastal waters and at the mouths of streams, makes its occurrence in the coastal waters of southwestern Philippines likely). Elsewhere: Persian/ Arabian Gulf (Iraq, Iran), Oman, Pakistan, India, Myanmar, Thailand, Malaysia, Singapore, Indonesia, east to New Guinea and Australia (David and Ineich 1999:92).

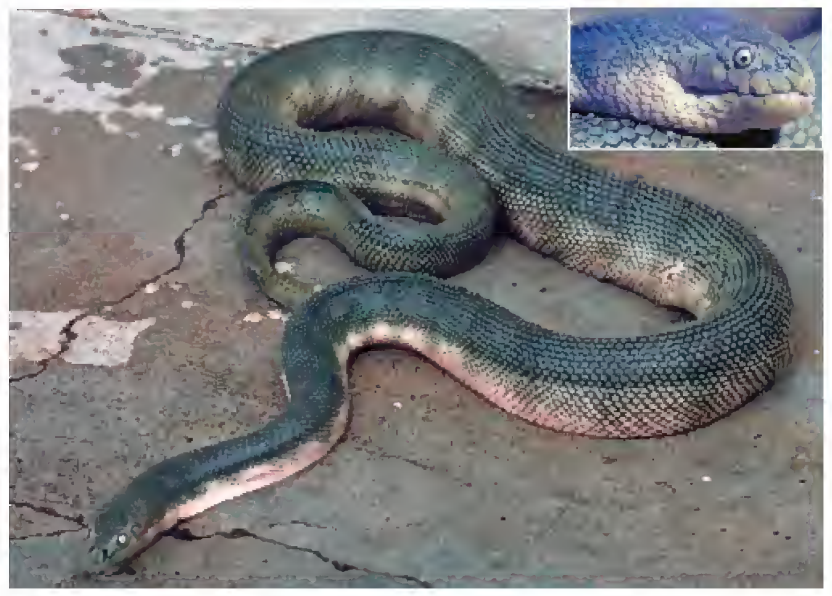

FIGURE 45. Hydrophis [Enhydrina] schistosus (Daudin, 1803) (inset: closeup view of head). Photos courtesy of Harold Voris.

REMARKS. - Stuebing and Inger note that "The Beaked Sea Snake is a dangerous species, with potent venom and a reputation in Peninsula Malaysia for biting fishermen. Because of its preference for muddy bottoms, it is sometimes trod upon in shallow tidal flats by people who wade barefoot while netting prawns." (Stuebing and Inger 1999:207.)

\section{Hydrophis semperi Garman, 1881}

Lake Taal Sea snake Figure 46

Hydrophis semperi Garman, 1881:85. - Smith, 1926:63.— McCarthy, 1993:240._ David and Ineich, 1999:118.

DESCRIPTION.- Head moderate, body not compressed anteriorly, greatest diameter about twice that of the neck; 6-8 maxillary teeth behind fangs; scales on body imbricate and with short keel, 29-21 around neck, 37-43 around body (increase of 10-12); ventrals 314-356, distinct throughout, bicarinate, about twice as broad as adjacent scales; precloacal scales enlarged; head black, body black with 50 to 60 narrow whitish bands of annuli, ventral scales usually black.

Size. - Total length $(\circlearrowleft) 550 \mathrm{~mm},($ (Q) 725 ; tail length $(ठ)$ $55 \mathrm{~mm}$, (q) $650 \mathrm{~mm}$.

Distribution.-Endemic to Philippines (Luzon [Prov.:
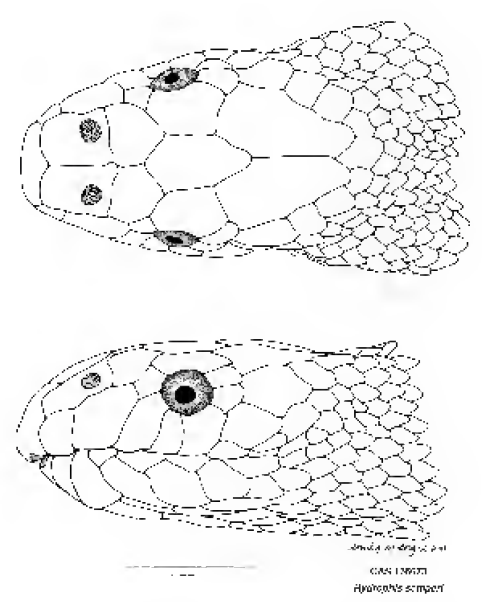

FIGURE 46. Hydrophis semperi Garman, 1881. Illustrations by Emily M. Eng. Batangas $\{$ Lake Taal $\}]$ ).

\section{Hydrophis spiralis (Shaw, 1802) \\ Yellow Sea Snake \\ Figures 25A, 26C-D}

Hydrus spiralis Shaw, 1802:564, pl. 125.

Hydrophis spiralis, Smith, 1926:48.

DESCRIPTION. - Head moderate, body elongate, body diameter posteriorly about twice that of neck; 6-7 maxillary teeth behind fangs; 25-31 scale rows around nexk, 33-38 at midbody, scales 
feebly imbricate, smooth or with small tubercle or keel; ventrals 295-362, distinct throughout, about twice as broad as adjacent body scales; precloacal scales enlarged.

SizE.- Total length (ठ) $1620 \mathrm{~mm}$, () 1830 ; tail length (ठ̋) $140 \mathrm{~mm}$, (q) $120 \mathrm{~mm}$. (after Smith 1926:49).

Distribution.- Philippines (a single record, juvenile, from Mergui [Smith 1926:50]) that has been repeatedly cited without further evidence of presence in Philippine coastal waters). Elsewhere: widely distributed from the Persian/Arabian Gulf east to Malaysia and Indonesia (see David and Ineich 1999:118).

\section{Hydrophis [Astrotia] stokesii (Gray, 1846) \\ Malayan [or Stokes'] Sea Snake \\ Figures 27B, 47}

Hydrus stokesii (part) Gray in Stokes, 1846:502.

Astrotia stokesi, Wall, 1909:250.

Astrotia stokesii, Smith, 1926:113.— Dunson and Minton, 1978:282.— David and Ineich, 1999:63.

DESCRIPTION.- Exceptionally thick-bodied sea snake with large head, covered by regular head scales, and thick neck, about one-half diameter of greatest diameter of body; 6 or 7 maxillary teeth behind fangs; body scales in 37-47 rows on neck, 47-59 around body, scales strongly imbricate, pointed, keeled or keels broken into tubercles; ventrals 226-286, anterior-most occasionall entire, all others divided, the two halves overlapping; color pattern, head dark olivaceous to yellowish, body yellowish to pale brown with broad black or dark brown bands or bars. (After Smith 1926:114.)

SizE.-Total length (đ) $1200 \mathrm{~mm}$, (†) $1600 \mathrm{~mm}$; tail length (ठ) $170 \mathrm{~mm}$, (ㅇ) $190 \mathrm{~mm}$.

Distribution.- Philippines: South Gigante Id. (Dunson and Minton 1978:282). Elsewhere: widely distributed from India to Australia and north into the South China Sea. (See David and Ineich [1999:63] for details.)

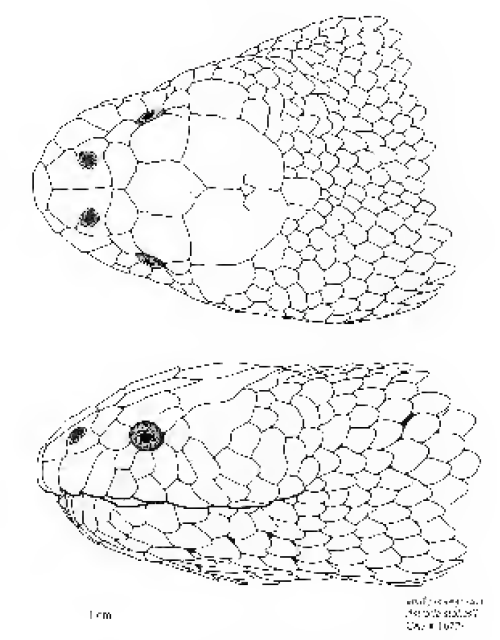

FIGURE 47. Hydrophis stokesii (Gray, 1846). Illustrations by Emily M. Eng.

\section{Hydrophis [Praescutata] viperinus (Schmidt, 1852) Grey Sea Snake}

Thalassophis viperina Schmidt, 1852:79, pl. 3.

Thalassophina viperina, Smith, 1926:33.- Rasmussen, 1997:23.

Praescutata viperina, David and Ineich, 1999:177.— Stuebing and Inger, 1999:220.

DESCRIPTION. - Head short, depressed, distinct from neck; nasal scales as broad as long; prefrontals much broader than long, not in contact with upper labials; frontal twice as large as supraocular; 1 (-2) preocular, 1-2 postoculars; 7-9 upper labials, usually 3-5 bordering orbit of eye, occasionally only two border orbit; temporals variable, usually only 1 , occasionally 2 or $3 ; 27-34$ scale rows around neck; 37-50 abound midbody; ventrals 226-274, anteriorly half the width of body, posteriorly narrowed, about twice width of adjacent scales; precloacal scale enlarged.

SizE.— Total length (ð) $925 \mathrm{~mm}$, (†) 820; tail length (ð) $100 \mathrm{~mm}$, (†) $80 \mathrm{~mm}$.

Distribution. - Philippines (not yet reported from coastal Philippine waters but present in the South China Sea and Gulf of Thailand). Elsewhere: widely distributed from Persian/Arabian 
Gulf to eastern Asia, including off the coasts of northern Borneo (Sarawak), Thailand, Vietnam, China, as far north as Taiwan (see David and Ineich 1999:177, also Stuebing and Inger 1999:220), as well as eastward to northern Australia and into the western Pacific (Zug 2013:231).

\section{Subfamily Laticaudinae}

REMARKS. - The genus Laticauda has in recent years been assigned variously to the subfamily Elapinae, which includes cobras, kraits, and coralsnakes, and to the subfamily Hydrophiinae, the sea-snakesand Australian terrestrial elapids. Recent work by Castoe, Smith, Brown, and Parkinson (2007) provides evidence for including the genus among the subfamily of sea snakes. However, others prefer to place the genus in a separate subfamily, the Laticaudinae, within the Family Elapidae (e.g., McCarthy 1986; David and Ineich 1999).

\section{Genus Laticauda Laurenti, 1768}

Sea Kraits

Laticauda Laurenti, 1768:109.— David and Ineich, 1999:122.

Pseudolaticauda Kharin, 1984b:134.

Diagnosis. - Maxillary bone shorter than ectopterygoid, extends forward beyond palatine; venom fangs followed by 1-3 maxillary teeth; head scales normal, large; nostrils lateral, nasals separated by internasals; body scales imbricate, smooth; ventrals large, at least half the width of body.

\section{Laticauda colubrina (Schneider, 1799)}

Yellow-lipped Sea Krait

Figures 16A, 17B, 18B, 48

Hydrus colubrinus Schneider, 1799:238.

Laticauda colubrina, Taylor, 1922a:231, pl. 29.—Smith, 1926:6; 1943:443.— McCarthy, 1993:146. — David and Ineich, 1999:123.—Whitaker and Captain, 2004:386, photo (p. 387).— Rasmussen et al., 2011:9.

DESCRIPTION. - Ventrals large, onethird to more than $1 / 2$ width of body; nostrils lateral; nasals separated by internasals; an azygous prefrontal scale usually present; rostral undivided; body scales imbricate, in 21-23 longitudinal rows aboud neck, 21-25 longitudinal rows at midbody; color above light or dark bluishgrey above, yellowish below, with 24-64 black bands of more or less uniform width above and somewhat narrower than the lighter interspaces, and sometimes narrowing across the belly, head black except for a well-defined yellow horseshoeshaped marking that originates on the

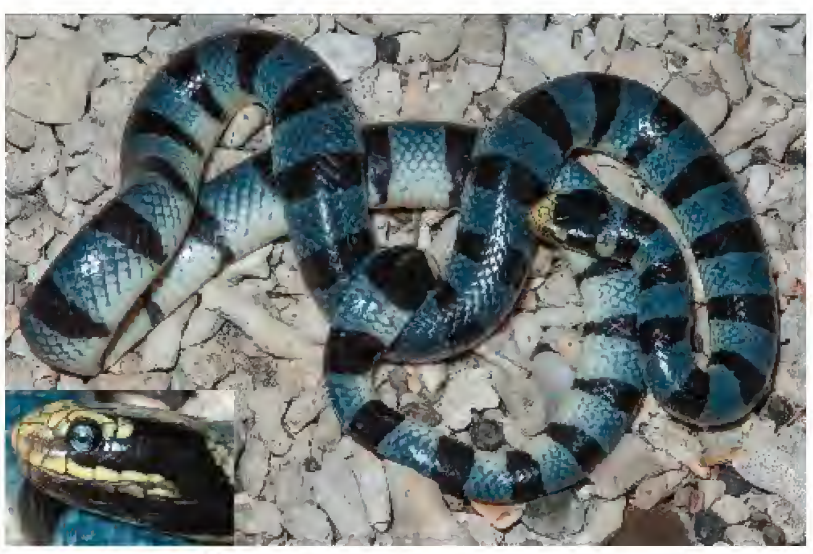

FIGURE 48. Laticauda colubrina (Schneider, 1799) (Insert showing color markings on side of head). Photos by Cameron Siler (from Mastre de Campo Island). snout and extends backwards beyond the eyes to the temporal region and yellow upper lips; ventrals 213-245. subcaudals paired, (ठ ) 37-47, () 29-37.

SizE.— Total length (ð) $875 \mathrm{~mm}$, (†) $1420 \mathrm{~mm}$; tail length (ð) $130 \mathrm{~mm}$, (†) $145 \mathrm{~mm}$.

Distribution.- Philippines (Bantayan; Jolo; Luzon [Manila Bay]). Elsewhere: Smith (1943:444) states that this species is not commonly met in "Indian and Indo-Chinese waters" 
though it is not uncommon at Singapore. Minton (1975: 26, Table 1) suggests that although rare in the Bay of Bengal, it may not be uncommon along the Myanmar coast and the west coast of the Malayasian Peninsula. Also coastal waters of Thailand, Malaysia, western Indonesia as far east as Polynesia and north along the east Asian coast to southern Japan.

\section{Laticauda laticaudata (Linnaeus, 1758)}

Brown-lipped Sea Krait; Black-banded Sea Krait

Figures 17A, 18A, 49

Coluber laticaudatus Linnaeus, 1758:222 (part).

Laticauda laticaudata, Taylor, 1922a:4.- Smith, 1926:4; 1943:442.— Toriba, 1993: 146.— David and Ineich, 1999:124.— Rasmussen et al., 2011:9.

DESCRIPTION. - Ventrals large, one-third to more than $1 / 2$ width of body; nostrils lateral; nasals separated by internasals; 19 longitudinal rows of imbricate scales around neck and at midbody, 17 rows posteriorly; no azygous prefrontal scale; rostral undivided; body color light or dark bluish-grey above, yellowish below, with black bands of more or less uniform width throughout, each separated from the next band by $2-4$ scale-row wide interspaces, head black with pale yellowish horseshoe-shaped yellow marking on snout extending along the upper sides of head to or beyond the eyes, upper lips dark brown; ventrals 225-243, subcaudals (ठ) $38-47$, (ㅇ) 30-35.

SizE.- Total length (ठ) $910 \mathrm{~mm},($ ( ) $1070 \mathrm{~mm}$; tail length $($ đ) $110 \mathrm{~mm},($ ( ) $110 \mathrm{~mm}$.

Distribution.- Philippines (Bantayan; Jolo; Luzon; Mindanao; Mindoro [northern]; Samar; Sulu Id.). Elsewhere: Smith (1943:443) states that it is "rare in the Oriental region (Calcutta and Little Nicobar Harbour)." On the other hand, Minton (1975:26, table

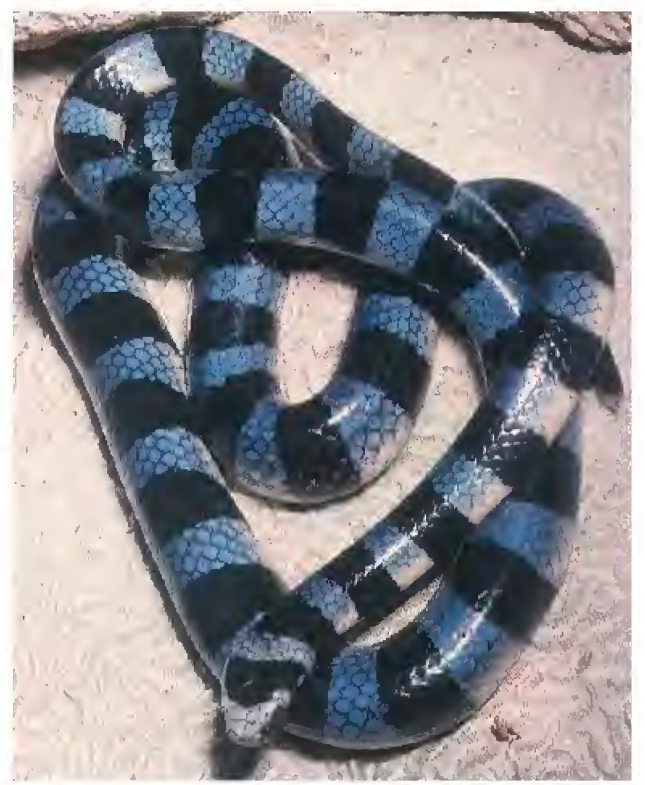

FIGURE 49. Laticauda laticaudata (Linnaeus, 1758). Photo courtesy of John Tashjian. 1) suggests that although rare in the Bay of Bengal, it may not be uncommon along the west coast of the Malayasian Peninsula. Also western Indonesia (Sumatra and Java) to Australia, Melanesia and Polynesia, and north along the east coast of Asia to southern Japan.

\section{Laticauda semifasciata (Reinwardt in Schlegel, 1837)}

Half-banded Sea Krait

Platurus semifasciatus Reinwardt in Schlegel, 1837:516.

Laticauda semifasciata, Taylor, 1922a:234, pl. 3, fig. 2, pl. 30.- Smith, 1926:10.-David and Ineich, 1999:125.- Rasmussen et al., 2011:9.

Pseudolaticauda semifasciata, Kharin, 1984b:135.

DESCRIPTION. - Ventrals large, one-third to more than $1 / 2$ width of body; nostrils lateral; nasals separated by internasals; an azygous prefrontal usually present; rostral divided by a horizontal groove; body scales imbricate, in 21-23 rows longitudinal rows at midbody; color above greenish, or bluish-grey, below yellowish, with 30-42 black bands that are broader than the lighter interspaces encircling body; head dark brown or black with a yellow curved mark above that connects 
posteriorly with the yellow band at the back of the head; in older individuals, markings become less distinct; upper lip brown; ventrals 195-205; subcaudals (ठో) 38-43, (우) 32-36.

Size. - Total length (đ) $920 \mathrm{~mm}$, (ㅇ) $1305 \mathrm{~mm}$; tail length (ठో) $115 \mathrm{~mm}$, (우) $115 \mathrm{~mm}$.

Distribution. - Philippines (Luzon [Prov.: Zambales, coast of]; Negros [Prov.: Negros Oriental]; Sulu Id.). Elsewhere: China, Taiwan, Japan, Russia (fide David and Ineich 1999:125; Rasmussen et al. 2011:9).

\section{Family Viperidae \\ Subfamily Crotalinae}

\section{Genus Trimeresurus Lacépède, 1804 \\ Pitvipers}

Trimeresurus Lacépède, 1804:209.

Parias Gray, 1849:11. - Malhotra and Thorpe, 2004:94-95.—David et al., 2011:43 (as a subgenus of Trimeresurus).

Diagnosis. - Hemipenes deeply forked, spinose and papillose; first upper labial not fused to nasal scale; second upper labial fused to scale forming anterior border of facial pit; scales on head and throat smooth.

REMARKS.- Malhotra and Thorpe (2004) present substantive molecular genetic data to justify a revised taxonomy for the nominal genus Trimeresurus at the generic level. However, more recently, David et al. (2011:41) argue in favor of recognizing the lineages of Trimeresurus (sensu lato) as subgenera of Trimeresurus rather than genera as proposed by Malhotra and Thorpe (2004). At this stage of inquiry with respect to the phylogenetic relationships among the included species, we are inclined to agree with David et al. and for the reasons they state, "if one considers Trimeresurus as a single genus, information on the phylogenetic relationships among the various 'clades' within the genus Trimeresurus is obscured, but the monophyly of the main 'clade' Trimeresurus is emphasized with regard to other Asian (Ovophis, Tropidolaemus) and American pitviper genera. ... It should also be emphasized that, on an external morphological basis, these subgenera are hardly diagnosable, and we think that recognizing 'genera' that cannot be diagnosed morphologically is not a help to practising taxonomists, especially when they do not have access to molecular facilities." (David et al. 2011:41.) Although we do not believe that the closing phrase is necessarily a justification for recognizing or not recognizing a taxon or clade, nonetheless, the current state of flux leads us to take a more conservative approach in handling the problem, in part so that those outside of the herpetological community, notably those in the medical profession who must deal with clinical concerns about snakebite, can more readily access information about the animals concerned.

\section{Trimeresurus (Parias) flavomaculatus (Gray, 1842)}

Yellow-spotted or Philippine Pitviper

Figures 11A, 15A-B, 50A-G

Magaera flavomaculata Gray, 1842:49.

Parias flavomaculata, Gray, 1849:11.

Trimeresurus flavomaculatus, Günther, 1879:79; Taylor, 1922a:288.—Leviton, 1964:257.— Gumprecht et al., 2004: 32, 25 col. photos (pp. 181-186).

Trimeresurus flavomaculatus flavomaculatus, Leviton, 1964:257.- Toriba, 1993:98. - David and Ineich, 1999: 284.

Trimeresurus halieus Griffin 1910:214 (Type locality: Polillo Islands).— Taylor, 1922a:286.

Trimeresurus flavomaculatus halieus, Leviton, 1964:262.- Toriba, 1993:98.- David and Ineich, 1999:284.

Trimeresurus schadenbergi Fischer, 1885:116 (Type locality: "Süd-Mindanao"). 

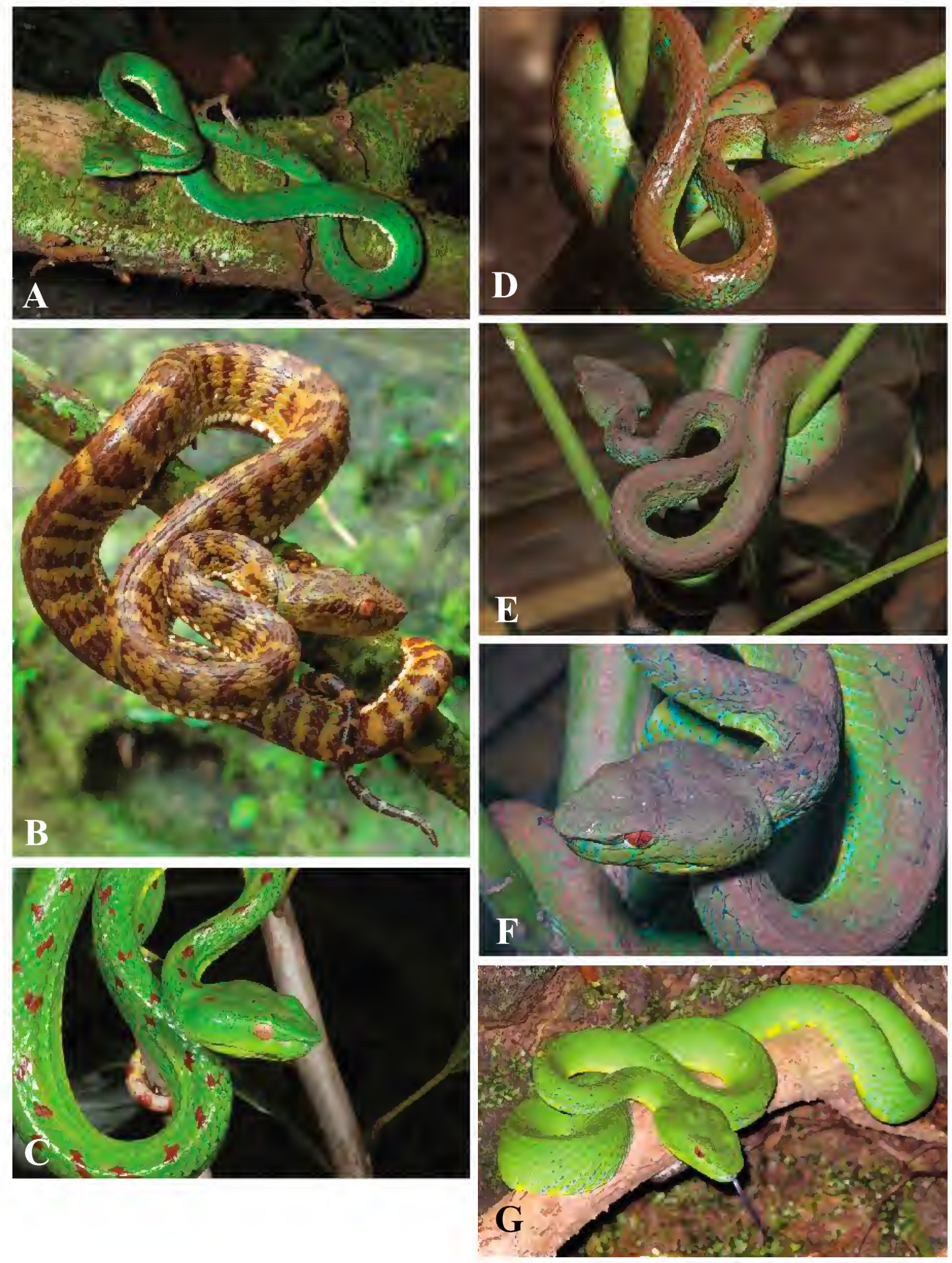

FIGURES 50A-F. Chromatic and pattern polymorphism among and within populations of Trimeresurus (Parias) flavomaculatus (A-B) Aurora, Luzon; (C) Zambales, Luzon; (D-F) Polillo; (G) Bicol. Photos A-F by Cameron D. Siler, G by Rafe Brown. 
DESCRIPTION.- Scales on head and chin smooth or irregularly keeled; second upper labial fused to scale forming forming anterior border of facial pit; body scales in 21 longitudinal rows around midbody, 29 rows around neck; a distinct light stripe, or at least a series of light spots, present along outer scale row; dorsal color highly variable, with dark pigments present, usally blue green, green, or dark blue gray, sometimes as scattered, irregular spots or blothches, also as distinct crossbars; tail not distinctly differentiated from body by color; hemipenes without spines; ventrals (ठ) 170-178, (ㅇ) 177-182, subcaudals (ठ) 62-71, (ㅇ) 58-63.

SizE.- Snout-vent length (ठ) $614 \mathrm{~mm}$, () $929 \mathrm{~mm}$; tail length (ठ) $151 \mathrm{~mm}$, (ㅇ) $163 \mathrm{~mm}$.

Distribution. - Endemic to Philippines (Camiguin; Jolo; Leyte; Luzon [Prov.: Aurora, Bataan, Bulacan, Cagayan, Camarines Norte, Ilocos Norte, Isabela, Kalinga, Laguna, Quezon]; Mindanao [Prov.: Davao, Lanao]; Mindoro).

REMARKS.- Gumprecht et al. (2004:32) chose not to recognize T. flavomaculatus halieus as a subspecies and elevated T. f. mcgregori to the rank of full species, as do David et al. (2011:43). With respect to T. f. halieus, we are inclined to agree with their handling of that taxon. Indeed, recent field observations by several of the authors indicate that there is a wide range of color and pattern polymorphism both within and among populations throughout the range of the species. We also agree with the elevation of $T$. mcgregori to the rank of full species. Furthermore, recent examination of material from Mindanao suggests that the population inhabiting that island is quite distinct from Luzon T. flavomaculatus and should possibly be accorded recognition as a full species for which the name T. schadenbergi Fischer, 1885, is available. According to Gernot Vogel and Patrick David (2007:37), this matter is under investigation and the results are scheduled to appear in due course; thus we refrain from making any changes at this time.

\section{Trimeresurus (Parias) mcgregori (Taylor, 1919) \\ McGregor's Pitviper \\ Figures 14, 51}

Trimeresurus mcgregori Taylor, 1919:110.- Taylor, 1922a:284.- Gumprecht et al., 2004: 35, 18 col. photos (pp. 246-250).

Trimeresurus flavomaculatus mcgregori, Leviton, 1964:261.- Toriba, 1993:98. - David and Ineich, 1999:284.

DESCRIPTION.- Scales on head and chin smooth or irregularly keeled; second upper labial fused to scale forming forming anterior border of facial pit; a distinct light stripe, or at least a series of light spots, present along outer scale row; dorsal color yellow to greenish yellow with darker pigments forming irregular spotted patches along middorsum; tail not distinctly differentiated from body by color; hemipenes without spines.

SizE. - Snout-vent length (ㅇ) $587 \mathrm{~mm}$; tail length (P) $97 \mathrm{~mm}$.

Distribution. - Endemic to Philippines (Batan, Sabtang, and Cagayan Ids.).

REMARKs.- See remarks above under T. flavomaculatus.

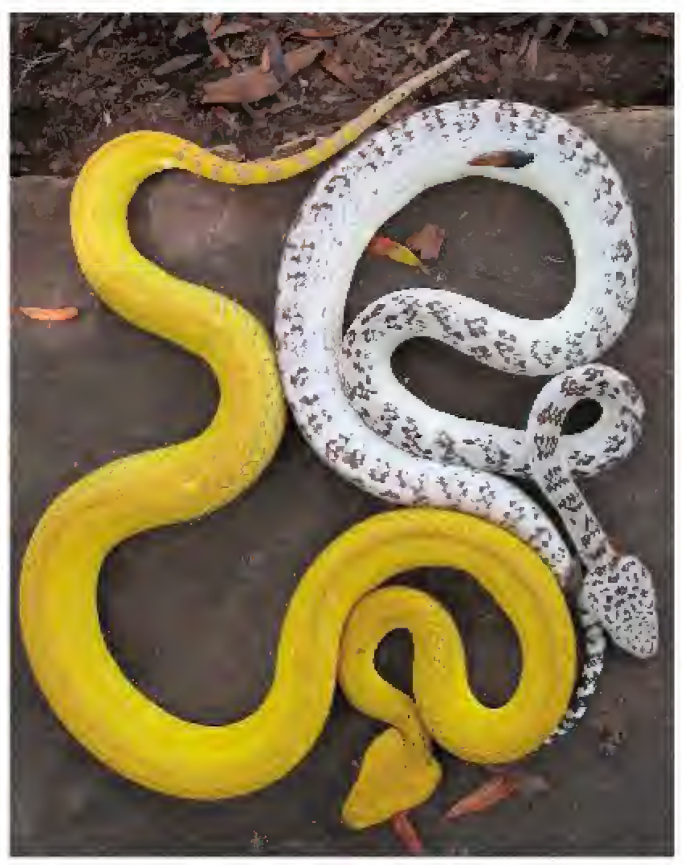

FiguRE 51. Trimeresurus (Parias) mcgregori, color and pattern variants. Photo by Rafe Brown. 


\section{Trimeresurus (Parias) schultzei (Griffin, 1909)}

Schultz's Philippine Pitviper

Figure 13

Trimeresurus schultzei Griffin, 1909:601.—Taylor, 1922a:292.— Leviton, 1964:263. Toriba, 1993:105.— David and Ineich, 1999:290.— Gumprecht et al., 2004: 37, 9 col. photos (pp. 288-289).

DESCRIPTION. - Scales on head and chin smooth or irregularly keeled; first upper labial separated from nasal by distinct suture; second upper labial fused to scale forming forming anterior border of facial pit; body scales in 21 [rarely 23] longitudinal rows at midbody; ventrals 187-203, subcaudals 66-82; a distinct light stripe, or at least a series of light spots, present along outer scale row; dorsal color greenish-brown to brown or purplish brown with 50-62 indistinct dark bars or zig-zag lines across dorsum, each 2-3 scale rows wide; a distinct yellow line along outer, ventrolateral scale row; ventrals edged with black; tail distinctly differentiated from body by its light color and without dorsal markings; hemipenes spinose.

SizE.- Snout-vent length (ठ゚) $706 \mathrm{~mm}$, () $1022 \mathrm{~mm}$; tail length (む) $162 \mathrm{~mm}$, () $198 \mathrm{~mm}$

Distribution. - Endemic to Philippines (Balabac; Palawan).

\section{Genus Tropidolaemus Wagler, 1830}

Pitvipers

Tropidolaemus Wagler, 1830:175 (Type species: Tropidolaemus wagleri Wagler, 1830:175).

Diagnosis.- Hemipenes long, slender, deeply forked, spinose; first upper labial not fused to nasal scale; second upper labial not fused to scale forming anterior border of facial pit; scales on dorsum of head and throat strongly keeled; body scales in 19-25 longitudinal rows at midbody.

Remarks. - See brief discussion in McDiarmid, Campbell, and Touré (1999:349), also David and Ineich (1999:294). Resurrected from the synonymy of Trimeresurus and then included as a subgenus by Brattstrom (1964:251), Burger (1971:109) and others but then recognized as a distinct genus following the studies of Kraus, Mink, and Brown (1996:769).

\section{Tropidolaemus philippensis (Gray, 1842)}

Philippine Temple Pitviper

Figure 52B, E-F

Trimeresurus philippensis Gray, 1842:48.-Taylor, 1922a:295, pl. 37, fig. 1.

Tropidolaemus hombronii Guichenot in Jacquinot and Guichenot, 1853:23, pl. 2, fig. 3.

Trimeresurus wagleri, Leviton, 1964:265.

Tropidolaemus wagleri, David and Ineich, 1999:295 (doubtfully included in T. wagleri).

Tropidolaemus philippensis, Vogel et al., 2007:31, figs. 25-26.

DESCRIPTION.- Scales on head strongly keeled; body scales in 18-19 longitudinal rows around midbody and 19-21 around neck; scales on snout along a straight line from rostral to level of supraoculars $(\delta) 4-5$, (ㅇ) 5; scales on dorsum of head on line between supraoculars 6-8; ventrals 129-135, subcaudals 44-46 (49); color green-turquoise background in males, green in females; postocular stripe black, rarely white in both males and females. (After Vogel et al. 2007:31 et seq.)

Size. - Total length (ठ) $455 \mathrm{~mm}$; tail length (ठ) $65 \mathrm{~mm}$.

Distribution.- Endemic to Philippines (Leyte; Mindanao [Prov.: Agusan Del Norte, Bukidnon, Cotabato, Davao del Sur]; Samar).

REMARKS.- Tropidolaemus philippensis and T. subannulatus were formerly included in the ubiquitous species $T$. wagleri. Recent studies have indicated that several recognizeable species 
have been inappropriately parading under that nominal taxon, T. philippensis among them, known from Leyte, Samar, and southern and northeastern Mindanao. However, on the large and topographically diverse island of Mindanao, and on careful examination, the Zamboanga and northern Sulu (Basilan) population also appears to be quite distinct from populations inhabiting other parts of the island, although Vogel et al. (2007) had referred them to T. philippensis. Recent unpublished studies by the authors suggest that it may be a distinct species for which the name T. hombronii Guichenot in Jacquinot and Guichenot, 1853 (type locality, Zamboanga) is available. Thus, this taxon will have to be resurrected from the synonymy of T. philippensis to accommodate the Zamboanga and northern Sulu (Basilan) population. Furthermore, a recently documented population of Tropidolaemus found on Leyte bears a strong resemblance to T. philippensis (Fig. 48B) but also T. subannulatus (see Vogel et al. 2007:30, fig. 24 from Negros Id.). We have refrained from suggesting any changes at this time because this also is said to be under study by Vogel and David (see also remarks under Trimeresurus flavomaculatus and Tropidolaemus subannulatus).

\section{Tropidolaemus subannulatus (Gray, 1842)}

Philippine Temple Pitviper

Figures $5 \mathrm{~A}-\mathrm{B}, 11,12 \mathrm{~A}-\mathrm{C}, 52 \mathrm{~A}, \mathrm{C}-\mathrm{D}$

Trimesurus subannualtus Gray, 1842:48.

Trimeresurus wagleri (part), Taylor, 1922a:296.—Leviton, 1964:265.— Toribe, 1993:108.— David and Ineich, 1999:295.

Tropidolaemus wagleri (part), Burger, 1971:110.- (part) Gumprecht et al., 2004:41-42, 8 col. photos (pp. 339-340).

Tropidolaemus subannulatus, Vogel et al., 2007:23.

DESCRIPTION. - Scales on head and chin strongly keeled; internasals not in contact, separated by 2 [rarely 1] scales; scales on snout along a straight line from rostral to level of supraoculars, (ふ) 4-7, (ㅇ) 5-8; scales on dorsum of head on a line between supraoculars 9-16; 3rd upper labial usually separated from subocular scale by 1 or 2 scales; body scales in 21-23 longitudinal rows at

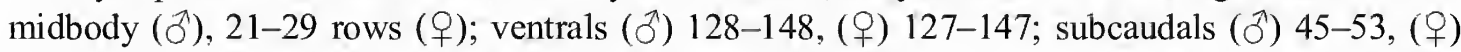
40-54; body color above, variable, green or blue in females, green in males and juveniles (but blue in some Negros populations), belly, (ㅇ) uniform or with blue or red blotches, $\left({ }^{\pi}\right)$ and juveniles uniform or with red spotting. (After Voget et al. 2007:23 et seq.)

Size.- Total length $963 \mathrm{~mm}$ (Snout-vent length $820 \mathrm{~mm}$; tail length $143 \mathrm{~mm}$.) for largest () and $463 \mathrm{~mm}$ (Snout-vent length $384 \mathrm{~mm}$; tail length $79 \mathrm{~mm}$.) for largest (ठ) reported by Vogel et al. (2007:23).

Distribution.- Philippines (Balabac; Basilan; Bohol; Dinagat; Jolo; Leyte; Luzon [Prov.: Albay, Bulacan, Cavite, Cagayan, Camarines Norte, Isabela, Quezon]; Mindanao [Prov.: Agusan del Norte, Agusan del Sur, Lanao del Norte, Zamboanga]; Negros [Prov.: Negros Occidental, Negros Oriental]; Palawan; Panay; Samar, Sibutu; Tumindao; Sulu Archipelago). Elsewhere: Malaysia (Borneo [Sabah, Sarawak]); Indonesia (Belitung, Borneo [Kalimantan], Buton, Sangihe Archipelago, Sulawesi) (see Vogel et al. [2007:23, 31] for details).

REMARKS.- Given the variation observed among samples of this species studied by Vogel et al. (2007), they concluded, "We refrain from giving a more detailed description here, as the variation among this species or complex of species will be discussed in the next and forthcoming paper of the series. A splitting into several taxa seems to be likely.” (Vogel et al. 2007:23.) 

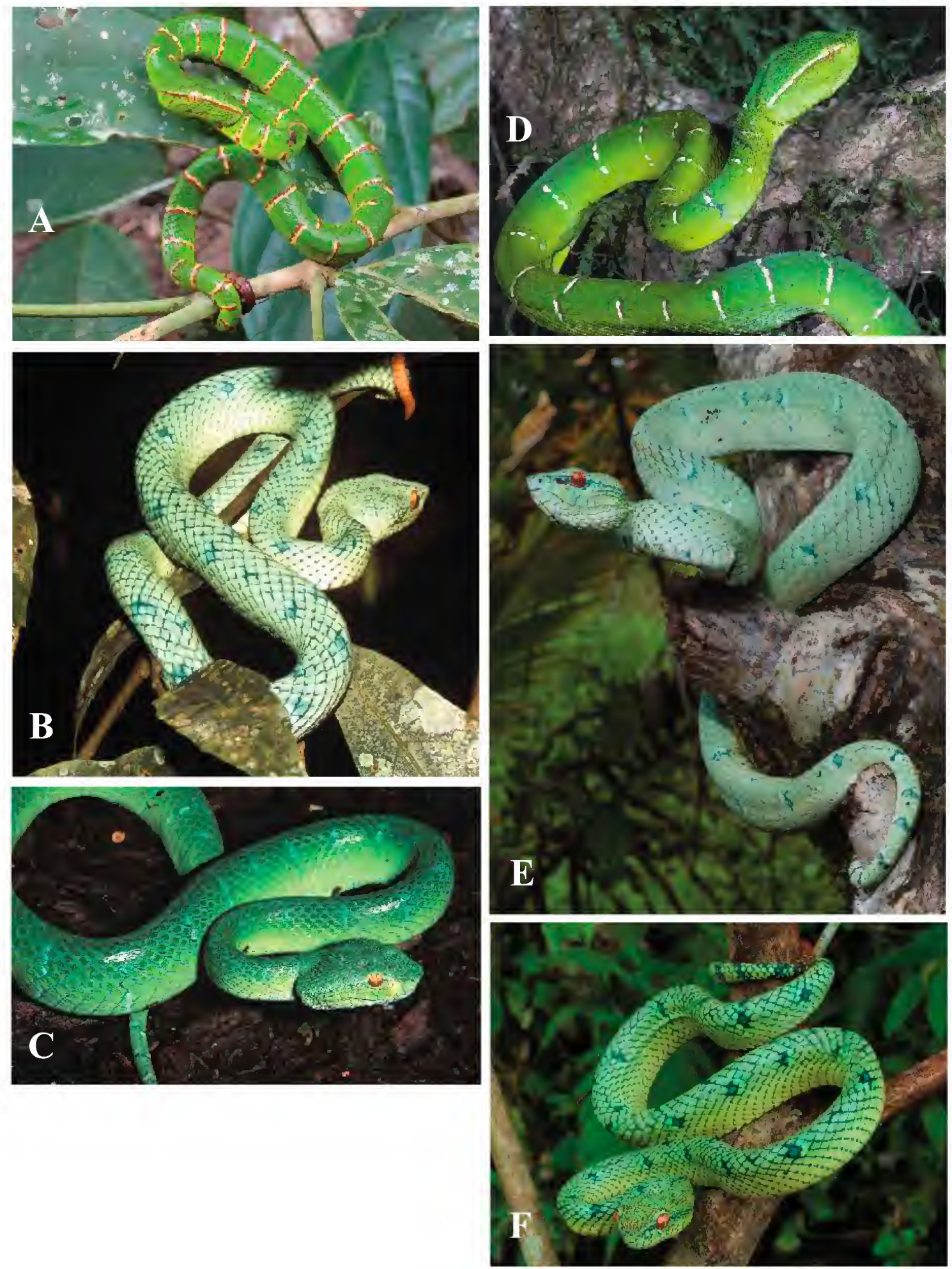

FIGURE 52. Tropidolaemus populations from: (A) Tropidolaemus ef. subannualtus from Makiling, Luzon (but likely a distinct species); (B) Leyte (T. philippensis) (but see Remarks); (C) Mt. Bulusan, Sorsogon Prov., Luzon (cf. T. subannulatus; female); (D) T. subannulatus; (E-F) Samar (T. philippensis). Photos A-C by Rafe Brown, D-F by Cameron D. Siler. 


\section{Selected references}

Alcala, Angel C. 1986a. Guide to Philippine Flora and Fauna. Vol. X. Amphibians and Reptiles. Natural Resources Management Center, Ministry of Natural Resources, and University of the Philippines, Manila, Philippines. xiv +195 .

Alcala, Angel C. 1986b. Guide to Philippine Flora and Fauna. Vol. XII. Poisonous Animals. Natural Resources Management Center, Ministry of Natural Resources, and University of the Philippines, Mani1a, Philippines. 77-158.

BARme, Michel. 1967. Venomous sea snakes (Hydrophiidae). Pages 285-308 in W. Bucherl, et al., eds., Venomous Animals and their Venoms, vol. 1. Academic Press, New York, New York, USA.

Bogert, Charles Mitchell. 1945. Hamadryas pre-occupied for the king cobra. Copeia 1945:47.

Brattstrom, Bayard H. 1964. Evolution of the pitvipers. Transactions of the San Diego Natural History Society 13(11): 185-268.

Broadley, Donald G., Jean-Claude Rage, and Michicisa Toriba. 1993. Naja Laurenti, 1768. Pages 184-193 in Philippe Golay et al., eds., Endoglyphs and other Major Venomous Snakes of the World. Azemiops S.A., Aïre-Geneva, Switzerland.

BROWN, RAFE M. 2006. A case of suspected coral snake (Hemibungarus calligaster) mimicry by lepidopteran larvae (Bracca sp.) from Luzon Island, Philippines. Raffles Bulletin of Zoology 54(2):225-227, fig. 1.

Brown, Rafe M., Carl H. Oliveros, Cameron D. Siler, Jason B. Fernandez, luke .J. Welton, Perry Archival C. Buenavente, Mae Lowe L. Diesmos, and Arvin C. Diesmos. 2012. Amphibians and reptiles of Luzon Island (Philippines), VII: Herpetofauna of Ilocos Norte Province, northern Cordillera Mountain Range. Checklist 83(3):469-490, figs. 1-48, table 1.

Brown, Rafe M., Cameron D. Siler, Carl H. Oliveros, Luke. J. Welton, A. Rock, J. Swab, M. Van Weerd, J. van Beinnen, E. Jose, D. Rodriguez, E. Jose, and Arvin C. Diesmos. 2013. The amphibians and reptiles of Luzon Island, Philippines, VIII: The herpetofauna of Cagayan and Isabela Provinces, northem Sierra Madre Mountain Range. Zookeys (266):1-120.

Burger, William Leslie. 1971. Genera of Pitvipers (Serpetnes: Crotsalidae). Ph.D. thesis. University of Kansas, Lawrence, Kansas, USA. 186 pp.

Castoe, Todd A., Eric N. Smith, Rafe M. Brown, and Christopher L. Parkinson. 2007. Higher-level phylogeny of Asian and American coralsnakes, their placement within the Elapidae (Squamata), and the systematic affinities of the enigmatic Asian coralsnake Hemibungarus calligaster (Wiegmann, 1834). Zoological Journal of the Linnean Society 151:809-831, figs. 1-3, tables 1-3, Appendices 1-3.

David, Patrick, and IVAN INeich. 1999. Les Serpents venimeux du monde: systématique et répartition. Dumerilia 3:3-499.

David, Patrick, Gernot Vogel, and Alain Dubois. 2011. On the need to follow rigorously the Rules of the Code for the subsequent designation of a nucleospecies (type species) for a nominal genus which lacked one: the case of the nominal genus Trimeresurus Lacépède, 1804 (Reptilia: Squamata: Viperidae). Zootaxa (2992): 1-51.

De LeON, WALFRIDO. 1946. Cobra venom - its possibilities in Philippine medicine. Journal of the Philippine Medical Association 22:1-6.

De Leon, Walfrido, and Enrique Salafranca. 1957 [1956]. Cobra-anti-venom seium production at the Alabang Serum and Vaccine Laboratories. Philippine Journal of Science 85:477-487.

Deraniyagala, Paulus Edward Pieris. 1960. The taxonomy of the cobras of Southeastern Asia. Spolia Zeylanica 29:41-63, 1 fig., pls. 1-4.

Dunson, William A., and Sherman A. Minton, JR. 1978, Diversity, distribution, and ecology of Philippine marine snakes (Reptilia, Serpentes). Journal of Herpetology 12(3): 281-286.

Gaulke, Maren, and Alexander V. Altenbach. 1994. Contribution to the knowledge of the snake fauna of Masbate (Philippines) (Squamata: Serpentes). Herpetozoa 7:63-66, fig. 1 [map]. (In English, with German abstract.)

Gaulke, Maren, Arnold Demegillo, Jochen Reiter, and Benjamin Tacud. 2003. Additions to the herpetofauna of Panay Island, Philippines. Salamandra 39:111-122, figs. 1-7.

Golay, Philippe, Hobart M. Smith, Donald G. Broadley, James R. Dixon, Colin McCarthy, Jean- 
Claude Rage, Beat Schätti, and Michihisa Toriba, eds. 1993. Endoglyphs and Other Major Venomous Snakes of the World: A Checklist. Azemiops S.A. Herpetological Data Center, Aire-Geneva, Switzerland. $\mathrm{xv}+478 \mathrm{pp}$.

Gritis, Paul, ANd Harold K. Voris. 1990. Variability and significance of parietal and ventral scales in the marine snakes of the genus Lapemis (Serpentes: Hydrophiidae), with coments on the occurrence of spiny scales in the genus. Fieldiana: Zoology, ser. New Series, i-iii, 1-13, figs. 1-4, 5-6 [maps], 7-8.

Gumprecht, Andreas. 2001. Die Bambusotter der Gattung Trimeresurus Lacépéde, Teil V: Die philippinischen Bambusotter Teil 1: Die Gelbflecken-Bambusotter Trimeresurus flavomaculatus (Gray, 1842). Sanria 23(3):3-14.

Gumprecht, Andreas, Frank Tillack, Nikolai L. Orlov, Ashok Captain, and Sergei Ryabov. 2004. Asian Pitvipers. GeiteBooks, Berlin, Germany. 368 pp. (pp. 43-354 col. photos.)

Kharin, Vladimir E. 1984a. A review of sea snakes of the group Hydrophis sensu lato (Serpentes, Hydrophiidae). 3. The genus Leioselasma. Zoologicheski'i Zhurnal 63(10):1535-1546.

KhARIN, Vladimir E. 1984b. [Revision of sea snakes of subfamily Laticaudinae Cope, 1879 sensu lato (Hydrophiidae)]. Pages 128-139 in Leo Borkin, ed., Ecology and Faunistics of Amphibians and Reptiles of the USSR and Adjacent Countries. Trudy Zoologicheskogo Instituta, Akademia Nauk, SSSR [Procecdings of the Zoological Institute, Leningrad], vol. 124. (In Russian, with brief abstract in English.)

Kharin, Vladimir E., and J. Hallermann (2009): Distribution of a Little-Known Sea Krait Pseudolaticauda schistorhynchus (Günther, 1874) (Serpentes: Laticaudidae). Rulssian Joulnal of Marine Biology 35(5):437-440

Kharin, VladmiR E. 2005. Distribution of a little-known sea snake Chitulia belcheri (Gray, 1849) and new records of rare species of the genus Leioselasma Lacepede, 1804 (Serpentes: Hydrophiidae). Russian Journal of Marine Biology 31(3):159-163, figs. 1-4, tables 1-2.

KLUSMEYER, Boris, AND BERnd FAUSTEN. 1994. Haltung und Nachzucht der Bambusotter Trimeresurus flavomaculatus halieus. Salamandra 30:174-184, figs. 1-10. (In German.)

Lacéptide, Bernard Germain Étienne. 1804. Mémoire. Sur plusieurs animaux de la Nouvelle Hollande dont la description n'a pas encore eté publiée. Amm. Mus, Paris 4:197.

LeViton, Alan EDWARD. 1961. Keys to the dangerously venomous terrestrial snakes of the Philippine Islands. Silliman Journal 8:98-106, figs. 1-2.

Leviton, Alan Edward. 1964 [1963]. Contributions to a review of Philippine snakes, III. The snakes of the genera Maticora and Calliophis, Philippine Journal of Science 92:523-550, fig. 1 [map].

Leviton, Alan Edward. 1964. Contributions to a review of Philippine snakes, V. The snakes of the genus Trimeresurus. Philippine Journal of Science 93:251-276, figs. 1-2 [maps].

Leviton, Alan Edward. (1968). The venomous terrestrial snakes of East Asia, India, Malaya, and Indonesia. Pages 529-576 in Wolfgang Bücherl, Eleanor E. Buckley, and Venancio Deulofeu, eds., Venomous Animals and their Venonts, vol. 1, Venonıous Vertebrates, Chap. 18. Academic Press, New York, New York, USA.

LuKoscheK, VimoksAlehi, AND J. Scott KeOGH. 2006. Molecular phylogeny of sea snakes reveals a rapidly diverged adaptive radiation. Biological Journal of the Linnean Society 89:523-539, figs. 1-3, tables 1-3, Appendix.

LutZ, Mario. 2006. Die Kobras des Philippinischen Archipels. Teil I: Die Philippinen-Kobra, Naja philippinensis Taylor, 1922. Saturia 28:5-11, figs. 1-10 (col.). (In German.)

Malhotra, ANitA, ANd Roger S. Thorpe. 2004. The phylogeny of four mitochondrial gene regions suggests a revised taxonomy for Asian pitvipers (Trimeresurus and Ovophis). Molecular Phylogenetics and Evolution 32:83-100.

McCarthy, Colin J. 1993. Laticauda Laurenti, 1768. Pages 145-148 in Philippe Golay et al., eds., Endoglypls and other Major Venomous Snakes of the World. Azemiops S.A., Aïre-Geneva, Switzerland.

McCarthy, Colin J. 1993. Acalyptophis Boulenger, 1896. Pages 221 in Philippe Golay ct al., eds., Endoglyphs and other Major Venomous Snakes of the World. Azemiops S.A., Aïre-Geneva, Switzerland.

McCarthy, Colin J. 993. Aipysurus Lacepede, 1804. Pages 221-224 in Philippe Golay et al., eds., Endoglyphs and other Major Venontous Snakes of the World. Azemiops S.A., Aïre-Geneva, Switzerland.

McCarthy, Colin J. 1993. Astrotia Fischer, 1855. Pages 224-225 in Philippe Golay et al., eds., Endoglyphs 
and other Major Venonous Snakes of the World. Azemiops S.A., Aïre-Geneva, Switzerland.

McCarthy, Colin J. 1993. Enhydrina Gray, 1849. Pages 227-228 in Philippe Golay et al., eds., Endoglyphs and other Major Venomous Snakes of the World. Azemiops S.A., Aïre-Geneva, Switzerland.

McCarthy, Colin J. 1993. Hydrophis Latrielle 1801. Pages 229-242 in Philippe Golay et al., eds., Endoglyphs and other Major Venontons Snakes of the World. Azemiops S.A., Aïre-Geneva, Switzerland.

McCarthy, Colin J. 1993. Lapemis Gray, 1834. Pages 243-245 in Philippe Golay et al., eds., Endoglyphs and other Major Venomous Snakes of the World. Azemiops S.A., Aïre-Geneva, Switzerland.

McCarthy, Colin J. 1993. Pelanis Gray, 1834, Pages 245-247 in Philippe Golay ct al., eds., Endoglyphs and other Major Venomous Snakes of the World. Azemiops S. A., Aïre-Geneva, Switzerland.

McCarthy, Colin J., aNd David A. Warrell. 1991. A collection of sea snakes from Thailand with new records of Hydrophis belcheri (Gray). Bulletin of the British Museum of Natural History., Zoology 57(2): $161-166$

McCoy, C. J., And Donald E. Hahn. 1979. The yellow-bellied sea snake, Pelamis platurus (Reptilia: Hydrophiidae), in the Philippines. Annals of the Carnegie Museum 48:231-234.

McDiarmid, Roy W., Jonathan A. Campbell, and T'Shaka A. Touré. 1999. Sinake Species of the World. A Taxonomic and Geographic Reference, Vol. 1. Herpetologists' League, Washington, DC. xi +511 pp.

MCDowell JR., SAMUel Booker. 1972. The genera of sea-snakes of the Hydrophis group (Serpentes: Elapidae). Transactions of the Zoological Society of London (32):189-247, 1 fig.

Minton Jr., Sherman A. 1975. Geographic distribution of sea snakes. Pages 21-31 in William A. Dunson, The Biology of Sea Snakes. University Park Press, Baltimore, Maryland, USA.

Minton JR., Sherman A. 1978. Serological relations of some Philippine sea snakes. Copeia 1978:151-154.

Minton JR., Sherman A., AND Milton S. DA Costa. 1975. Geographic distribution of sea snakes. Pages 33-55 in William A. Dunson, The Biology of Sea Snakes. University Park Press, Baltimore, Maryland, USA.

Mittleman, M. B. 1947. Geographic variation in the sea snake Hydrophis ornatus (Gray). Proceedings of the Biological Society of Washington 60:1-8.

Pope, Clifford Hillhouse, and Sarah Haydock Davis Pope. 1933. A study of the green pit vipers of S. E. Asia and Malaysia, commonly identified as Trimeresurus granineus (Shaw), with description of a new species from Peninsula India. American Museun Novitates :1-12.

Pyron, R. Alexander, Frank T. Burbrink, and John J. Wiens. 2013. A phylogeny and revised classification of Squamata, including 4161 species of lizards and snakes. BMC Evolutionary Biology 13(93):1-53, figs. 1-28. (<http://www.bionedcentral.com/1471-2148/13/93>)

RaSmussen, ARne RedSted. 1989. An analysis of Hydrophis ornatus (Gray), H. lamberti Smith, and H. inornatus (Gray) (Hydrophiidae, Serpentes) based on samples from localities, with remarks on feeding and breeding biology of H. ornatus. Amphibia-Reptilia 10:397-417, figs. 1-12.

Rasmussen, Arne Redsted. 1997. Systematics of sea snakes: a critical review. Pages 15-30 in R.S. Thorpe, W. Wüster, and A. Malhotra, eds., Venonıous snakes: Ecology, Evolution and Snakebite. Clarendon Press, Zoological Society of London \& Oxford, London, UK. Symp. Zool. Soc. London, vol. 70.

Rasmussen, Arne Redsted. 2001. Sea snakes. Pages 3987-4008 in K.E. Carpenter and V.H. Niem, eds., The Living Marine Resources of the Western Pacific. Vol. 6. Bony fishes part 4 (Labridae to Latimeriidae), estuarine crocodiles, sea turtles, sea snakes and marine mammals. FAO Species Identification Guide for Fishery Purposes. Rome, Italy: Food and Agriculture Organization of the United Nations.

Rasmussen, Arne Redsted. 2002. Phylogenetic analysis of the "true" aquatic elapid snakes Hydrophiinae (sensu Smith et al., 1977) indicates two independent radiations into water. Steenstrupia 27(1):47-63, figs. $1-3$.

Rasmussen, Arne Redsted, Johan Elmberg, Peter Gravlund, and Ivan Ineich. 2011. Sea snakes (Serpentes: subfamilies Hydrophiinae and Laticaudinae) in Vietnam: a comprehensive checklist and an updated identification key. Zootaxa (2894): 1-20, figs. 1-9.

Rasmussen, Arne Redsted, And Ivan Ineich. 2010. Species diversity in the genus Emydocephalus Kreft, 1869 (Serpentes, Elapidae, Hydrophiinae): Insight from morphology and anatomy. Herpetological Review 41:285-290.

ReID, H. AlistAir. 1975. Epidemiology and clinical aspects of sea snakebites. Pages 417-462 in William A. Dunson, The Biology of Sea Snakes. University Park Press, Baltimore, Maryland, USA. 
Reyes, A. C., and C. Lamana. 1955. Snakebite mortality in the Philippines. Philippine Journal of Science 84:189-194.

Sanders, Kate L., Michael S. Y. Lee, Mumpuni, Terry Bertozzi, and Arne R. Rasmussen. 2013. Multilocus phylogeny and recent rapid radiation of the viviparous sea snakes (Elapidae: Hydrophiinae). Molecular Phylogenetics and Evolution 66(2013):575-591, figs. 1-4, table 1, Appendices A and B.

Sawal, Y., K. Koba, T. Okonogi, S. Mishima, Y. Kawamura, H. Chinzel, Abu Bakar bin Ibrahim, T. Devaraj, Sriprapai Phong-Aksara, Chaloem Puranananda, E. S. Salafranca, J. S. Sumpaico, C, S. Tseng, J. F. TAylor, C. S. Wu, And T, P. Kuo, 1971. An epidemiological study of snakebites in the Southeast Asia. The Snake 3:97-128, figs. 1-17, maps 1-7, 28 tables.

Schättr, BeAt, AND Michel Guillod. 1990. Bemerkungen zur Rassengliederung bei der Philippinischen Bambusotter, Trimeresurus flavomaculatus (Gray, 1842). Herpetofauna (Weinstadt) 12:32-34. (In German, with English summary.)

Siler, Cameron D., ANd LuKe J. Welton. 2010. Geographic variation in Philippine mimicry system: hypothesized widespread coral snake (Hemibungarus calligaster) mimicry by lepidopteran larvae (Bracca sp.) on Luzon Island, Philippines. Herpetological Review 41(4):427-430, figs. 1-2.

Siler, Cameron D., Luke J. Welton, J. M. Siler, J. Brown, A. Bucol, Arvin C. Diesmos, and Rafe M. Brown. 2011. Amphibians and reptiles, Luzon Island, Aurora Province and Aurora Memorial National Park, Northern Philippines: New island distribution records. Check List 7:182-195.

Siler, Cameron D., J. C. Swab, C. H. Oliveros, Arvin C. Diesmos, L. Averia, A. C. Alcala, and Rafe M. BRown. 2012. Amphibians and reptiles, Romblon Island Group, central Philippines: Comprehensive herpetofaunal inventory. Check List 8:443-462.

Slowinski, Joseph BRUno, JefF Boundy, ANd Robin Lawson. 2001. The phylogenetic relationships of Asian coral snakes (Elapidae: Calliophis and Maticora based on morphological and molecular characters. Herpetologica 57:233-245, figs. 1-5.

Smith, Malcolm Arthur. 1926. Monograph of the Sea-Snakes (Hydrophiidae). Trustees of the British Museum, London, UK. $x x+130$ pp., figs. 1-35, pls. 1-2.

Stejneger, Leonhard. 1907. Herpetology of Japan and Adjacent Territories. Bulletin of the United States National Museum 58:xx +577 pp., 35 pls.

Stuebing, Robert B., and Roberf F. Inger. 1999. A Field Guide to the Snakes of Borneo. Natural History Publications (Bomeo), Kota Kinabalu, Sabah, Malaysia. viii $+254+$ [2], illus. [col. photos.].

SweEny, R. 1994. McGregor's pit viper, Trimeresurus flavomaculatus mcgregori. Herptile 19:71, 86-88, pl. (p. 71).

Taylor, Edward Harrison. 1922a. The Snakes of the Philippine Islands. Bureau of Science, Manila, Publication no. 16. Bureau of Science, Manila, Philippines. 312 pp., pls. 1-37.

TAYlor, Edward HARrison. 1922b. Additions to the herpetological fauna of the Philippine Islands, II. Philippine Journal of Science D 21(3, September):257-302, pls. 1-4.

TAYlor, EdWARd HARRISON. 1922c. Herpetological fauna of Mount Makiling. Philippine Agriculture 11(5, December):127-139.

TAYlor, Edward Harrison. 1923. Additions to the herpetological fauna of the Philippine Islands, III. Philippine Journal of Science 22:515-555, pls. 1-3.

Toriba, Michisica. 1990. Venomous snakes of medical importance in the Philippines. Pages 463-469 in P. Gopalakrishnakone, et al., eds., Snakes of Medical Importance (Asia-Pacific Region). (Includes col. figs. 1-3.) National University of Singapore and International Society on Toxicology (Asia-Pacific Section), Singapore.

Toriba, MichicisA. 1993. Tropidolaemus Wagler, 1830. Pages 108-109 in Philippe Golay et al., eds., Endoglyphs and other Major Venomous Snakes of the World. Azemiops S.A., Aïre-Geneva, Switzerland.

Toriba, Michicisa. 1993. Calliophis Gray, 1834. Pages 123-124 in Philippe Golay et al., eds., Endoglyphs and other Major Venomous Snakes of the World. Azemiops S.A., Aïre-Geneva, Switzerland.

Toriba, MichicisA. 1993. Hemibungarus W. Peters, 1862. Pages 139-143 in Philippe Golay et al., eds., Endoglyphs and other Major Venomous Snakes of the World. Azemiops S.A., Aïre-Geneva, Switzerland.

ToribA, Michicisa. 1993. Maticora Gray, 1834. Pages 150-154 in Philippe Golay et al., eds., Endoglyphs and other Major Venomous Snakes of the World. Azemiops S.A., Aïre-Geneva, Switzerland. 
Toriba, Michicisa. 1993. Ophiophagus Günther, 1864. Pages 195-196 in Philippe Golay et al., eds., Endoglyphs and other Major Venomous Snakes of the World. Azemiops S.A., Aïre-Geneva, Switzerland.

Vick, James A., Jurgen von Bredow, Marie M. Grenan, and George M. Pickwell. 1975. Sea snake antivenin and experimental envenomation therapy. Pages463-485 in William A. Dunson, The Biology of Sea Stakes. University Park Press, Baltimore, Maryland, USA.

Vogel, Gernot, Patrick David, Mario Lutz, Johan van Rooijen, and Nicholas Vidal. 2007. Revision of the Tropidolaemus wagleri-complex (Serpentes: Viperidae: Crotalinae). I. Definition of included taxa and redescription of Tiopidolaenus wagleri (Boie, 1827). Zootaxa (1644):1-40, figs. 1-30, tables 1-7.

Vogtman, Donald B. 1950. The relative efficiency of two types of anti-venom sera in neutralizing cobra venom. Copeia 1950:225-228.

Voris, Harold K. 1977. A phylogeny of the sea snakes (Hydrophiidae). Fieldiana: Zoology 70:79-166.

Voris, HAROLD K., AND HEATHER H. VORIS. 1983. Feeding strategies in marine snakes: an analysis of evolutionary, morphological, behavioral and ecological relationships. American Zoology 23:411-425.

WALl, Frank. 1909. A monograph of the sea snakes. Memoirs of the Asiatic Society of Bengal 2(8):250.

WALl, Frank. 1924. The hamadryad or king cobra, Naia hannah (Cangtor). Journal of the Bombay Natural History Society 30:189-195, I pl.

Watt, George, and R. David G. Theakson. 1985. Seasnakebites in a freshwater lake. American Journal of Tropical Medicine and Hygiene 34:770-773.

Wegner, A. M. R. 1954. The snakes of the genus Maticora Gray with special reference to Maticora bivirgata bivirgata (Boie) and M. intestinalis intestinalis (Laurenti). Penggemar Alam 34:55-58.

WÜster, Wolfgang. 1996. Taxonomic changes and toxinology: systematic revisions of the Asiatic cobras (Naja naja species complex). Toxicon 34:399-406.

Wüster, Wolfgang, and Roger S. Thorpe. 1989. Population affinities of the Asiatic cobra (Naja naja) species complex in south-east Asia: Reliability and random resampling. Linnean Society of London, Biological Journal 36:391-409.

Wüster, Wolfgang, And Roger S. ThorPe. 1990. Systematics and biogeography of the Asiatic cobra (Naja naja) species complex in the Philippines. Pages 333-344 in Gustav Peters and Tainer Hutterer, eds., Vertebrates in the Tropics. Proceedings of the International Symposium on Vertebrate Biogeography and Systematics in the Tropics, Bonn, June 5-8, 1989. Alexander Koenig Zoological Research Institute and Zoological Museum, Bonn, Bonn, Germany.

Wüster, Wolfgang, and Roger S. Thorpe. 1991. Asiatic cobras: Systematics and snakebite. Experimentia (Basel) 47:205-209.

WÜster, Wolfgang, And Roger S. Thorpe. 1992. Dentitional phenomena in cobras revisited: spitting and fang structure in Asiatic species of Naja (Serpentes: Elapidae). Herpetologica 48:424-434.

Zug, GEORge R. 2013. Reptiles and Amphibians of the Pacific Islands. University of California Press, Berkeley, California, USA. $x+306$ pp., text figs. 1-30, pls. 1-35. 


\begin{abstract}
APPENDIX A
Glossary

See also diagrams of head and body scalation in a typical snake on page 8

For additional terms, see Peters, James A. 1964. Dictionary of Herpetology. Hafner Publ. Co., New York. vii $+(1)+362+(30$ pp. figs. $)$
\end{abstract}

anal plate: (see precloacal scale).

anterior: in front or toward the front; the head as the most anterior portion of the body [its opposite, posterior $\{q . v\}$.$] .$

arboreal: inhabiting or frequenting trees, including animals that spend at least part of the time in trees or high bushes.

azygous: not one of a pair; a single scale, usually on the midline as a single, median head scale.

body scale rows: see scale rows (body).

caudal: tail.

clade: a group of phylogenetically related organisms that is defined by features exclusive to all its members and that distinguish the group from all others.

cloaca: chamber just anterior to the base of the tail; it receives all digestive, excretory, and reproductive materials prior to their exit to the outside through the vent.

distal: away from; behind the point of origin or attachment; e.g., behind and away from the front end or head region measured from a refernce point that is more forward.

dorsal (above): toward the back or upper side of head or body [its opposite, ventral $\{q . v$.$\} ].$

dorsum: the back or upper side of body.

hemipenis (plural, hemipenes): one of a pair of male copulatory organs; at rest, the hemipenes are stored in a cavity in the tail; during copulation, only one is everted; it appears like a bulbous finger of a glove, is often highly ornamented organ, and protrudes from the vent opening.

imbricate: overlapping [as opposed to juxtaposed $\{q . v$.$\} ], when one scale overlaps the one imme-$ diately behind. [its opposite, juxtaposed $\{q . v$.$\} ].$

juxtaposed: placed side by side, not overlapping [its opposite, imbricate $\{q . v$.$\} ].$

keels: raised elongate ridges on scales, usually in median position on head and/or body scales.

labial scales: scales bordering the lips of the mouth, those bordering the upper lip are upper or supralabials, the lower lip, lower, sub- or infralabials.

lateral: the side.

longitudinal: entending along the long axis of the body, from head to tail.

loreal scale: a scale on the side of the head placed between the eye and the nostril; usually separated from the anterior border of the eye orbit by a preocular scale [q.v.], which may be divided by a horizontal grove into two scales, and from the nostril by the posterior portion of the nasal scale $[q . v]$; in the absence of a loreal scale, the nasal and preocular scales are in contact with one another.

nasal scale(s): scale pierced by the nostril; scale may be divided by a suture into anterior and posterior segments.

occipital scale(s): usually a pair of enlarged scales at the rear end of the head behind the enlarged parietal scales $[q . v$.$] ; occasionally a single, small scale partially inserted betwen the parietals$ along their posterior edge or several small scales bordering the parietals behind.

parietal scales: a pair of enlarged scales on the posterior part of the dorsum of the head, usually the last of the enlarged head scales.

posterior: behind or toward the rear [its opposite, anterior $\{q . v$.$\} ].$

postocular scale(s): one or more scales that border the back edge of the eye orbit. 
precloacal scale (often termed anal scale or plate): enlarged scale following last ventral scale that overlies the cloacal or vent opening; scale may be single or paired.

preocular scale: one or more scales that border the front edge of the eye orbit (but see also loreal scale above).

proximal: next to or nearest to point of origin or attachment; toward the front end or head region from a refernce point that farther behind.

scales, scutes, shields: frequently used interchangeably. However, scutes and shields are usually larger structures than scales, which term is most often used to described the smaller structure that adorn the dorsum of the body. Scutes and shields are terms usually reserved to describe the belly scales as well as the scales on the head and chin. To avoid confusion, we have used the term scale(s) to describe all the epidermal structures on the snakes.

scale rows (body): scales on the upper and sides of the body, usually arranged in parallel longtiudinal rows; the number of transverse rows (rows across the body) are counted beginning with the first row on the side that is in contact with the enlarged ventrals and counting to the opposite side.

sensory pit: a deep depression on the side of the head between the nostril and the eye of some viperine snakes (pitvipers) that contains an infrared (heat) sensory receptor at its base; in pitvipers the pit occurs on each side in the loreal scale.

snout-vent length: straight-line distance measured from the tip of snout to the posterior edge of the anal orifice.

subcaudal scales: enlarged plate-like scales on the underside of the tail, usually paired but occasionally undivided.

subocular scale(s): one or more scales lying between eye and upper labial scales [q.v.].

tail length: straight-line distance measured from the vent to the tip of the tail.

temporal scales: scales on the sides of the head behind the eye and the postocular scale.

total length: straight-line distance from the front of the snout to the tip of the tail.

transverse (across): set crosswise, at right angles to the longitudinal or long axis of the body, extending from side to side.

vent: opening of the cloaca to the outside, covered by an enlarged precloacal scale [q.v.].

ventral (below): ventrum, underside, or toward the underside (see also ventral scales).

ventral scales: transversely enlarged plate-like scales on the underside of the trunk extending from the throat to the precloacal scale; among sea snakes, sometimes indistinguishable from adjacent scales.

ventrolateral: a narrow region along the lower side where ventrum and side of trunk meet.

ventrum: underside of trunk from neck to vent. 


\section{APPENDIX B: INDEX TO SCIENTIFIC NAMES}

(Images appear on pages that are boldfaced)

Acalyptus peronii.................5511

Acalyptophis . . 473, 486, 487, 491, 499, 501, 509

peronii ............... 491, 509

Ahaetulla ....................... 475

Aipysurus ............ . 473, 485, 491, 500

eydouxii ............ 485, 491, 500

Anguis platura . . . . . . . . . . . . . . . . . . . 509

Aspis intestinalis . . . . . . . . . . . . . . . . . . 493

Astrotia . . . 473, 489, 490, 491, 499, 501, 500, 512 stokesii................ 491, 512

Aturia .................... 501, 503, 508

belcheri .................. 503

ornata ................... 508

Boiga . . . . . . . . . . . . . . . . . . 475

Bungarus wanghaotingi.............. 475

Calamaria lumbricodea. . . . . . . . . . . 475

Calliophis ...... 473, 475, 476, 477, 481, 482,

491, 493, 494, 495

bilineata . . . . . . . . . 482, 491, 493

bilineatus ................... 493

calligaster ........... 476,491, 495

calligaster calligaster . . . . . . 491, 495

calligaster gemianulis . . . . . . . 491, 495

calligaster mcclungi . . . . . . . 491, 495

intestinalis .............447, 491

philippina ...........482, 491, 494

suluensis . ............4482, 491, 494

Callophis . . . . . . . . . . . . . . . . . . . . . . . . 494

intentinalis suluensis . . . . . . . . . . . . . . 494

intestinalis var. Philippina . . . . . . . . . . 494

Cerberus ........................4475

Chrysopelea.................... 4475

Coluber ...................4496, 514

laticaudatus . . . . . . . . . . . .514

naja ...................496

Colubridae . . . . . . . . . . . . . . . . 475

Crotalinae.................473, 515

Crotalus ..................475, 480

horridus .................4480

scutellatus ................. 475

Dispholidus typus . . . . . . . . . . . . . 475

Disteira ............ 473, 491, 501, 510

cyanocincta .................491

cyanosoma .................491

ornata .....................4491

schistosa ............. 491, 510

Distira annandalei ... . . . . . . . . . . 500

Doliophis . . . . . . . . . . . . . . . . . 491

bilineatus . . . . . . . . . . . . . . . 491 philippinus ................4491

Elapidae . . . . . . . . . . 473, 475, 481, 493, 513

Elapinae .............. 473, 493, 513

Elaps calligaster . . . . . . . . . . . . 494, 495

Emydocephalus .........443, 486, 491, 501 annulatus ............ 486, 491, 501

Enhydrina ........4473, 479, 485, 487, 491, $501,500,510,511$

schistosa .............4491, 510

Enhydris ..................... . 475

Ephalophis greyi ................ . 500

Hamadryas . . . . . . . . . . . . . . . . . . . . 497

elaps ...................... 497

hannah ................... 497

Hemibungarus ......473, 475, 476, 477, 481, 482, 491, 493, 494, 495

calligaster . . . . . . . . . . 482, 491, 495

gemianulis . . . . . . . . . . 482, 491, 495

mcclungi ........... 482, 491, 495

Hydrelaps darwiniensis . . . . . . . . . . 500

Hydrophis . . . . . . 473, 479, 485, 486, 487, 488, $489,490,491,499,501,500,503,504,505,506$, $507,508,509,510,511,512,545$

[Acalyptophis] peronii . . . . . . 486, 487, 509

[Astrotia] stokesii . . . . . . . 489, 490, 512

[Enhydrina] schistosus . . .486, 487, 510, 511

[Kerilia] jerdoni .......... . 486, 507

[Kolpophis] annandalei ........4486, 500

[Lapemis] curtus . . . 4 485, 489, 490, 504, 505

[Lapemis] curtus [hardwicki] . . . . . . . 490

[Pelanis] platurus ......... .490, 509, 510

[Praescutata] viperina . . . . . . . . . 486

[Praescutata] viperinus . . . . . . . . . 512

[Thalassophis] anomalus ...... 486, 500

annandalei ...................441

anomalus ....................491

atriceps .....4485, 486, 488, 489, 491, 503

belcheri ............ . 488, 491, 503

brookii ............. 486, 491, 504

caerulescens .............. 488, 491

coggeri ...............503, 504

curtus . . . . . . . . . . . . . . 485, 491

cyanocinctus . . 487, 488, 489, 491, 505, 506

fasciatus ............. 491, 503

fasciatus atriceps ........... . 503

gracilis .......... 487, 489, 491, 506

inornatus .............4491, 506

inornatus .............. 506, 508

klossi ............. . 488, 491, 507 
lamberti ............4487,491, 507 melanocephalus .........4 488, 491, 508 ornatus .... 488, 489, 491, 506, 507, 508, 509 ornatus ornatus ............. 508 pacificus .....................503 peronii .....................491 platurus .....................491 schistosus ....................491 semperi $\ldots \ldots \ldots \ldots \ldots \ldots 488,491, \mathbf{5 1 1}$ spiralis ............488, 489, 491, 511 stokesii ..................491, 512 sublaevis var. melanocephalus ........508 viperinus ..................491

Hydrophiinae . . . . . . . 473, 475, 499, 500, 513

Hydrus ................ 506, 511, 512,513 colubrinus ...................513

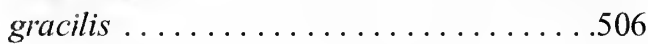
spiralis $\ldots \ldots \ldots \ldots \ldots \ldots \ldots \ldots \ldots 11$ stokesii ....................5512

Kerilia ........4473, 486, 491, 499, 501, 507 jerdoni ................. 491, 507

j. jerdoni .................. 507

j. siamensis ............... 507

Kolpophis .........473, 486, 491, 501, 500 annandalei ...............491, 500 Lapemis ...... 473, 479, 485, 487, 489, 490, 491, $499,501,504,505$

curtus .........4485, 487, 491, 504, 505 curtus hardwickii .......... 491, 504, 505 hardwickii ................... 491

Laticanda ...... . 473, 475, 485, 486, 491, 500, 513,514

colubrina .....4 475, 485, 486, 491, 500, 513 laticandata ......4.475, 485, 491, 500, 514 semifasciata . . . . . . . 486, 491, 500, 514

Laticaudinae .........4473,475, 500, 513

Leioselasma ............443, 491, 501,504 L(eioselasma) coggeri ............ 504 L(eioselasma) cyanocinctus . ......... 491 L(eioselasma) melanocephalus ......... 491 L(eioselasma) semperi . ............441 $L($ eioselasma $)$ spiralis . . . . . . . . . . 491 Lycodon subcinctus . ....................475 Magaera flavomaculata . ............ 515 Maticora .............477, 491, 493, 494 intestinalis ........4477, 491, 493, 494 intestinalis bilineata .......491, 493 intestinalis philippina .......491, 494 intestinalis suluensis . . . . . . 491, 494 Microcephalophisgracilis . ..........4491, 506 Naja . ....... 473, 475, 480, 481, 482, 483, 491, $496,497,498$ hannah..................4491, 497

lutescens ................. 496 naja .......... 476, 480, 491, 496, 497 naja miolepis ........... 491, 497 naja philippinensis . ....... 491, 496 naja samarensis . . .........491, 496 philippinensis ......476, 481, 482, 483, 491, 496, 498

samarensis ...........483, 491, 496, 498 sumatrana .............483, 491, 497 tripudians ..............4496, 497 tripudians samarensis . ......... 496 tripudians var. sumatrana . . . . . . . 497

Oligodon ...................... 475

Ophiophagus ......473, 480, 481, 482, 491, 497, 499,523

hannah ...... 480, 481, 482, 491, 497, 499

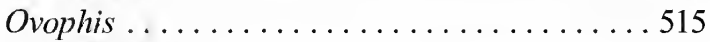

Oxyrhabdion ..................... 475

Parahydrophis mertoni .............. 500

Parias .......... 473, 477, 480, 483, 484, 491, $515,516,517,518$

flavomaculata ................ 515

Pelamis .... 473, 479, 490, 491, 499, 501, 509, 510 platura ...................4491, 509

platurus ..................4491, 509

Pelamydrus platurus . ............... 491

Platurus semifasciatus .............. 514

Praescutata .........473, 486, 491, 501, 512 viperina ............... 491, 512

Psammodynastes .................. 475

Pseudolaticauda ................4491, 513 semifasciata ...............4491, 514

Rhabdophis ..................... 475

Thalassophina ...........491, 499, 501, 512 viperina ................491, 512

Thalassophis .....473,486, 491, 501, 500, 512 anomalus ................491, 500 viperina ................... 512

Thelotornis capensis ............... 475

Tomogaster eydouxii . ................ 500

Trimeresurus ...... 473, 475, 476, 477, 480, 483, $484,491,515,516,517,518,519$

flavomaculatus ......477, 491, 515, 517, 519 flavomaculatus ...........491,515 halieus ............491, 515, 517 mcgregori ............4491, 517 halieus ..................4491, 515 mcgregori ...........447, 491, 517 philippensis .................. 518 schadenbergi .............5 515, 517 schultzei...............477, 518 
wagleri ..........446,491, 518, 519 philippensis [philippinensis] .......491 subannulatus ...............491

(Parias) .......... 473, 480, 483, 484, $491,515,516,517,518$

flavomaculatus .....480, 483, 484, 491, $515, \mathbf{5 1 6}$

halieus ................... 491

mcgregori ........484, 491, 517

schultzei..........484, 491, 518

Trimesurus subannualtus .............519
Tropidolaemus .....473, 475, 476, 477, 478, 481, $483,484,491,515,518,519,520$

cf. subannualtus ..............5520

hombronii ................5 518, 519

philippensis ......446,482, 491, 518, 520

subannulatus ......474, 477, 481, 483, 491,

$\mathbf{5 1 8}, 519,520$

wagleri ................ 518, 571

Tropidonophis .................. 475

Viperidae ...........4 473, 475, 481, 515

\section{ApPendix C: InDEX to Common ENGLish NAmES}

Cobras ...................473, 496

Central Philippine Cobra . . . . . . . . . . . . 496

Equitorial Spitting Cobra.............. . 497

King Cobra...................... . 497

Northern Philippine Cobra. . . . . . . . . . . . 496

Philippine Cobra. ................... 496

Sumatran Spitting Cobra . . . . . . . . . . 497

Coral snakes.................... 473

Annulated Philippine Coral Snake. . . . . . . 495

Barred Philippine Coral Snake. ...... 494, 495

Double-barred Philippine Coral Snake . . . . 495

McClung's Philippine Coral Snake . . . . . . . 496

Philippine Coral Snake. . . . . . . . . . . . . . . 494

Sulu Islands Banded Coral Snake . . . . . . . . 494

Two-striped Coral Snake . . . . . . . . . . . . 493

Pitvipers. ............... 473, 515, 517

McGregor's Philippine Pitviper. . . . . . . 517

Philippine Pitviper ................. 515

Philippine Temple Pitviper. . . . . . . 5 518, 519

Schultz's Philippine Pitviper ........... 518

Yellow-spotted Pitviper .............. 515

Sea snakes and sea kraits. . . . . . . . . . 475, 499

Annandale's Sea Snake . . . . . . . . . . . . . 502

Annulated Sea Snake ............. 501, 505

Anomalous Sea Snake . . . . . . . . . . . . 502

Beaked Sea Snake . . . . . . . . . . . . 510

Belcher's Sea Snake. . . . . . . . . . . . . . 503

Black-banded Sea Krait . . . . . . . . . . . 514

Black-headed Sea Snake . . . . . . . . . . . 508

Brook's Sea Snake ... . . . . . . . . . . . . . . . . 504

Brown-lipped Sea Krait . . . . . . . . . . . 514
Cogger's Sea Snake................ 504

Common small-headed Sea Snake. . . . . . . . 506

Grey Sea Snake ................ 512

Half-banded Sea Krait . . . . . . . . . . . . . 514

Hardwick's Sea Snake ... . . . . . . . . . . . 504

Hooked-nosed Sea Snake. . . . . . . . . . . . 510

Horned Sea Snake . . . . . . . . . . . . . . . 509

Jerdon's Sea Snake. . . . . . . . . . . . . . . . . 507

Kloss's Sea Snake . . . . . . . . . . . . . . . . 507

Lake Taal Sea Snake ............... 511

Lambert's Sea Snake . . . . . . . . . . . . . . 507

Malayan Sea Snake ............... 512

Many-banded Sea Snake . . . . . . . . . . . . . 505

Marbled Sea Snake. . . . . . . . . . . . . . . 500

Ornate Sea Snake................. 508

Pacific Yellow-banded Seasnake . . . . . . . . . 504

Pelagic Sea Snake ... . . . . . . . . . . . . . 509

Reef Sea Snake. . . . . . . . . . . . . . . . 508

Sea krait ....................... 513

Short Sea Snake .......... . . . . . . . . . 504

Southesast Asian Sea Snake. . . . . . . . . . . 503

Spiny-headed Sea Snake . . . . . . . . . . . 509

Spine-tailed Sea Snake. . . . . . . . . . . . . 500

Stokes Sea Snake . . . . . . . . . . . . . . 512

Yellow-bellied Sea Snake. . . . . . . . . . . . 509

Yellow-lipped Sea Krait. . . . . . . . . . . . 513

Yellow Sea Snake.................. 511 


\title{
How Expeditions Drive Clinical Research
}

\author{
Matthew Lewin \\ (Hearst Expedition Physician) \\ California Academy of Sciences, 55 Music Concourse Drive, San Francisco, California 94118 USA. \\ Email:MLewin@calacademy.org
}

Ever since I can remember I've wanted to see the world and have a portable skill. I was amazingly fortunate because my second grade classmate, Karl Gajdusek, brought his Uncle Carlton to school for "show-and-tell" one day shortly after his remarkable discovery of prions was awarded the 1976 Nobel Prize for Medicine. He told us about his expeditions to Papua New Guinea, kuru and then proceeded to dissect a brain and a heart for the class. I knew exactly what I wanted to do when I grew up.

Combined physician-scientist training programs are long, so it wasn't until 2003 that I finally joined the American Museum of Natural History on expeditions to Mongolia and then, having cut my teeth on those expeditions, joined the California Academy of Sciences in 2009. The Mongolian-American expeditions taught me a lot about the practicalities of expedition life and I published several original clinical research papers related to those experiences. Invariably interesting or quirky, they were all one-off projects. Nevertheless, each was the product of a practical problem encountered in the field [1-9].

It is the practical problems of life in the field that drive my research. Contrary to my expectation that my research would be the product of real-time reactions to crises and experiences, it has invariably been the product of preparation. I spend months preparing for expeditions, thinking about and researching the areas anticipated to be covered by the expedition. The research in preparation includes physical, political and medical geography, including disaster management, communications and evacuation options. This preparation also includes becoming familiar with the crews and their medical concerns, past present and future. Much of this effort is geared toward guessing the optimal medical kit for any given trip. Considerations for the assembly of the kit includes the number of people going, the duration of the trip, likely diseases to be encountered and evacuation options. Additionally, I have to anticipate what I will leave with the crews if I am leaving the field before they do - I can carry only so much stuff and that which I leave needs to be appropriate and safe in the hands of non-medically trained personnel.

The 2011 Hearst Philippines Biodiversity Expedition was unique in my experience for several reasons. The sheer size of the expedition was most notable, along with its decentralized structure - crews spread throughout the country in both marine and terrestrial divisions. Fortunately for me, Dr. Terry Gosliner simplified my task by admonishing me to focus on the hazards to be faced by the terrestrial group working in the mountains and rainforests of Luzon.

My general approach to emergency medicine, my clinical specialty, is to simplify the problems and this is how I approach each expedition's medical kit. For each situation and each patient I encounter in daily practice, I ask myself three questions:

1. What is the worst imaginable thing this could be?

2. What is the most likely thing?

3. If I delay or miss the diagnosis, will the patient be harmed?

For most situations, especially trauma, questions 1 and 2 are quickly resolved. The victim simply reports what happened. It is the answer to the third question that causes the most angst. Any computer, or even most third-year medical students, can tell you what is most likely and what is 
the worst imaginable, but there is little that can assist in answering question 3: If I blow the case, will the patient be harmed? Oftentimes, I am not onsite when these questions arise, so I am relying on the reporting of the patient or bystanders on satellite phone, for example. Some people minimize their symptoms and others can be very dramatic. Is the patient exhibiting anxiety because he's anxious or is he anxious because he is dying? This might sound funny, but it is a very real concern and the two can be confused. It is dangerous to make the patient prove he or she is sick, but it is also dangerous and disruptive to evacuate unnecessarily. This is just a brief description of the mindset with which I approach expedition medical care. To be a field scientist is inherently risky, but that does not mean accepting risk unconditionally and diagnostic uncertainty is certainly not expected in every situation.

Preparation for this expedition was different for me for the simple and odd reason that despite 8 years of field experience I had never actually been confronted by the specter of dangerously venomous snakes. Within a few breaths of inviting me on the expedition, Dr. Terry Gosliner indicated that I would be on the "Terrestrial" team and before finishing the sentence handed me a copy of the World Health Organization's (WHO) recommendations for the treatment of snakebite for Southeast Asia [10]. The recommendations are not massive or complicated. They are quite thorough, but they are not all that reassuring for a field scientist - remain calm (tell the victim to remain calm), seek medical attention and antivenom remains the cornerstone of treatment in the setting of venomous bites.

In the WHO recommendations there is a note that in some types of envenomation, a drug combination containing neostigmine and atropine or glycopyrrolate can be administered IV - and is thought to be useful in the setting of cobra bite. This caught my eye because neostigmine and glycopyrrolate can be given simultaneously in a 1:1 ratio and would be easy to administer, relatively safe and inexpensive and heat stable. The best of what little research is available on this type of drug combination came from the Philippines in a study of patients bitten by Philippine's cobra exactly the snake I was concemed about for the terrestrial group. So, with some relief I put together a kit with neostigmine, glycopyrrolate, some alcohol swabs, syringes and needles, with simple instructions for use.

Fortunately, we never had to use the snakebite kit. I left the Philippines about two weeks before the end of the expedition. It is customary to exchange photos and NataliyaPolydouri and I did this. She had taken several photographs of me explaining the kit to a herpetologist and it was on the plane home from the Philippines that I saw these. My recollection of the conversation was that the scientist with whom I was speaking was enthusiastic about the kit and the concept. Nevertheless, my perception of the same scientist in the photograph was that he was thinking, with some anxiety, about the possibility of having to administer such an antidote in a crisis. I have no idea what he was really thinking - likely just engaged — but it got me thinking: "There has to be a better way to do this. What if we just got rid of the needles?" I went to sleep and woke up in San Francisco thinking, "why not?".

The idea was lying fallow in my head for some time before I realized the implications of such an idea should it actually turn out to be a plausible approach. Months passed. The expedition had returned and there was no real practical pressure to think about it. In spring of 2012, there was a national shortage of midazolam and it was affecting the ambulance system. Midazolam and other drugs for seizures can be delivered through the nose and are safer to administer in a convulsing patient than those administered by IV or by any sort of injection. King-American's chief paramedic, Josh Nultemeier and I were spending a lot of time trying to find a source of these drugs and reviewing City protocols and our own to see how we could stretch out supplies much like every other ambulance service in the country. Time and again we came back to the nasal delivery as a 

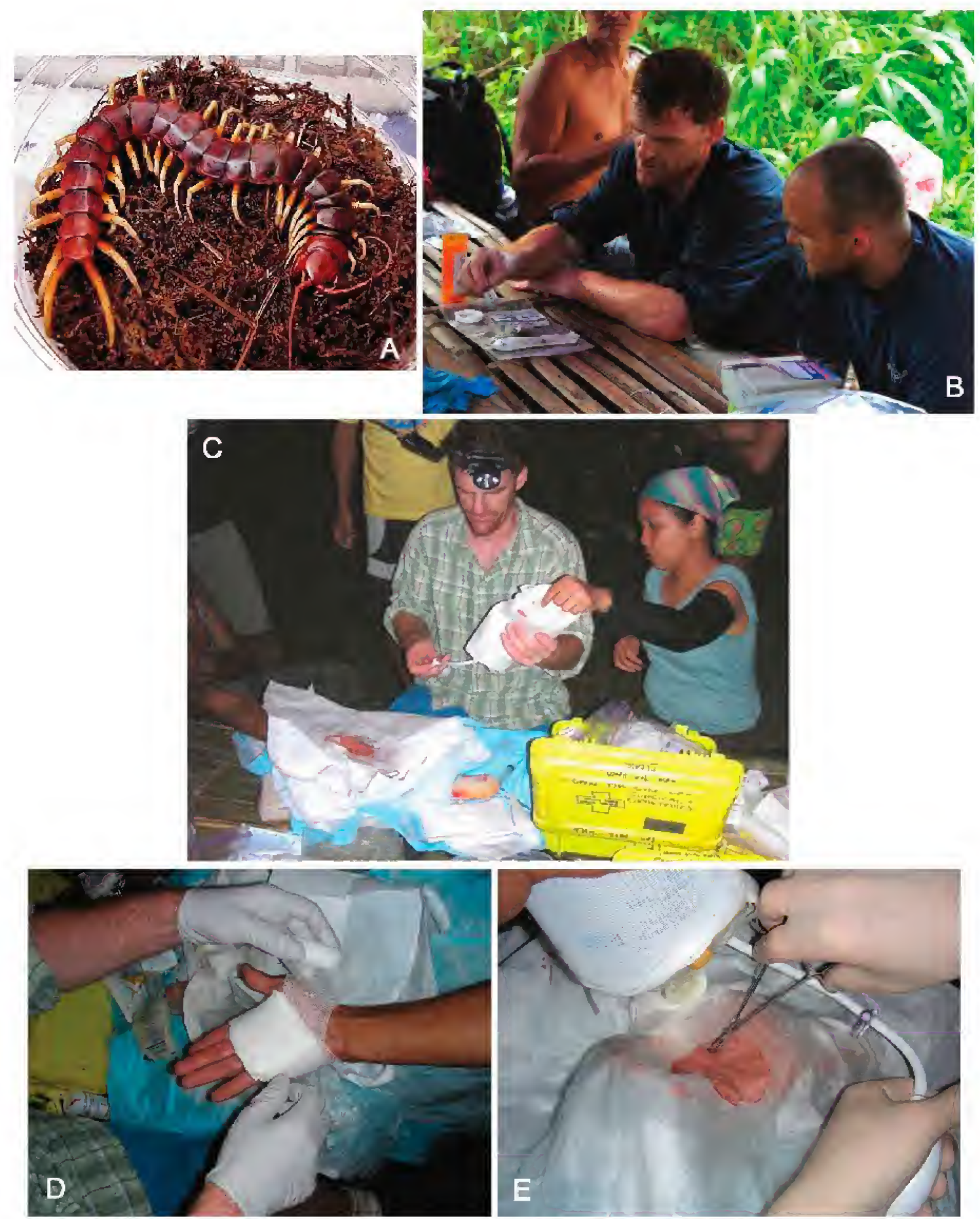

FIGURE 1. A: The centipede Scolopendra sp. can pack quite a powerful and painful bite, but the most likely complication is infection. B: Explaining the snakebite kit to one of the herpetologiosts, seemingly engaged by the concept of a nonvenom based amntidote. C-E: Machete injury. One porter tossed a machete to another and it was caught by its blade. It was dark by the time we got back to camp. Insects would fly into the wound and there was a high risk of infection 
means to administer the drugs because we could use diazepam or lorazepam for this same route of administration.

During this time, I perused (in the literal sense of thoroughly searching) the medical literature for research related to pre-hospital administration of nasal drugs, including those for seizures and neostigmine, as well. Nasal sprays and aerosols are used all the time to treat asthma and other lung diseases. Nasal sprays are used as decongestants and to deliver steroids for asthma and allergies and as cold remedies. To my amazement, nasal spray neostigmine had been used for the treatment of myasthenia gravis, a fairly rare cause of muscle weakness and fatigue, by a group of Italian neurologists in the late 1980s and early 1990s [11-13] . . . but never reported in the literature for use in anesthesia or snakebite or any other type of envenomation for that matter.

Some months later I really got a bee in my bonnet about testing this idea and two things happened. The first was that I mentioned the idea to friend, colleague and mentor, Dr. Phil Bickler, and he gave it some thought. Phil is an anesthesiologist at UCSF with a $\mathrm{PhD}$ in comparative anatomy. He has heard and (appeared to) seriously consider many of my wildest ideas over the years, but he was definitely paying attention when I mentioned this one. He didn't say much, just, "let me talk to John Feiner and Tom Heier." I had never met Tom Heier, but had heard of him. John, like Phil, is a friend and mentor from my UCSF days.

A short time later, Phil and I were commuting into San Francisco and he said that Tom and John had a research protocol that could be easily adapted to test my idea [14]. By this time, I had become familiar with the epidemiology of snakebite from a global perspective and appreciated that the idea of developing a needle-free, heat-stable kit had repercussions far beyond the occupational hazard of scientific expeditions, and my goal was to "beat the monsoon." The monsoon is the peak of snakebite season in India. It is estimated that as many as 35,000 to 50,000 people die each year in India, alone, as result of snakebite $[15,16]$. Of those deaths, the vast majority occurring during the 3 or 4 months of rainy season - a death toll approaching 10,000 a month - staggering, yet invisible. There are, additionally, an estimated 5,000,000 snakebites each year, resulting in up to 125,000 deaths $[17,18]$. This makes snakebite one of the leading causes of accidental death worldwide, but is a largely invisible epidemic in North America where there are fewer than a dozen snakebite related deaths in any given year and an abundance of emergency care facilities.

The fall and winter of 2012-2013 were dedicated to designing the experiment and gaining approval from the UCSF Committee on Human Research (CHR) to actually do it. Even the most mundane human research requires arduous review, including language that is as much directed toward the protection of human research subjects as it is to protecting the university from lawsuits should anything happen or be alleged to have happened. In this case, the reviewers were carefully scrutinizing the protocol - one requiring the attending anesthesiologists to awake-paralyze one or more human subjects and test if a neostigmine nasal spray could counteract the paralytic agent. The protocol was submitted several times and returned several times until finally being approved on my birthday in late February.

The idea of the experiment was to weaken the subject sufficiently that he or she could not move, but was still breathing. This requires careful titration of the paralytic agent and the ability to reverse it should the paralysis go too far. The shortest acting paralytic agent was used - mivacurium. Mivacurium is a derivative of curare.

Weakness induced by curare has long been recognized to have clinical similarities to cobra venom and, in fact, cobra venom is called a "curare-like" venom. The similarity between cobra toxin and curare was described, in detail, by Sir Joseph Fayrer in the 1870s and his experiments were neatly summarized in several treatises, "On the poison of venomous snakes and the methods of preventing death from their bite." [19-21]. In 1935, Mary Walker described the use of a neostig- 
mine-like drug to reverse muscle weakness resulting from myasthenia gravis [22-24] and in the 1970s radioactively labeled cobra and krait toxins were used to show that myasthenia gravis was a disorder of the acetylcholine receptor [25-27]. Banerjee first reported using intravenous neostigmine to reverse snakebite induced paralysis in 1972 [28] and 20 years later Sghirlanzoni and colleagues reported the safe use of nasal spray neostigmine in the treatment of myasthenia gravis [12]. The connections were not obvious - very different fields of medicine and science, but much to my surprise, it was all there - the final piece of the first puzzle being whether nasal spray neostigmine could reverse paralysis in the type of experiment Tom Heier and John Feiner had designed to look at perioperative complications related to the type of paralysis used in the operating theater [14].

On April $5^{\text {th }}$, after considerable planning and rehearsal, the experiment was performed at UCSF in an intensely monitored setting. The subject was slowly infused with mivacurium until stable clinical and electrophysiological deficits were established. 115 minutes after starting the infusion, the nasal spray neostigmine was administered with mivacurium being infused at a constant rate such that the only explanation for the subject's rapid return of muscle function was the nasal spray's effect. As described by Dr. Lance Montauk, one of four physicians present, "the effect was so quick and obvious we didn't even need to measure it." But, of course, we did [9].

To this point, the project was completely un-funded - everything the product of my and my friends' efforts during our own time. For me, though, it was already a full time job. From the day the experiment was approved, I closed my practice to all but neighborhood patients and occasional house calls. The day after the experiment, I started analyzing and writing the data. By coincidence, I had been invited to be one of the keynote speakers at the American Physician Scientist Association meeting in Chicago at the end of April. The invitation had come long before the idea for a needle-free snakebite treatment matured in my mind, but presented a great opportunity to discuss it in front of a knowledgeable audience and see how it would be received. Importantly, now that we had data, I could realistically start looking for a collaborator and funding. What better place than in front of a large group of physician scientists? Even so, the manuscript was only submitted and not accepted, so I was a little nervous about putting this idea out in the open. Jerry Harrison, who has been the Godfather of the project - details of how and why are outside the scope of this version of the story - encouraged me to speak about it and just a few hours before my lecture I did end up changing the entire talk to gear it toward the idea of a nasal spray for the early treatment of a broad range of neurotoxic venoms. His main argument was that I had had this idea so tightly held for so long that I should just get it off my chest and who knows who might be in the audience? In fact, the second part of the argument was prescient. Dr. Stephen Samuel of Trinity College Dublin, Ireland and a native of Tamil Nadu, India was in the audience. The talk was well received and he approached me afterwards to ask some questions and make some comments, including that he was jet-lagged and had come to the talk to force himselfout of that state. After several hours of discussion, it seemed pretty certain that we had a serious collaboration in the works. From a chance meeting on April 27th, we agreed to meet in India in June. I went to work raising funds for the trip and Stephen, in a flurry of unbelievable activity and coordination, arranged for us to use a certified animal lab in Hyderabad to perform mouse experiments - including all protocol approvals - and reestablished contact with a schoolmate, Dr. C. Soundara Raj, from medical school whose specialty is the treatment of snakebites and poisonings. Dr. Soundara Raj was a senior student at PSG Medical College when Dr. Samuel was a junior student. Stephen immigrated to Ireland for post-graduate studies and Dr. Soundara Raj returned to his hometown of Krishnagiri to found his own hospital, TCR Multispecialty Hospital. The motto of TCR Multispecialty Hospital is, "No patient should die from snakebite." Prior to performing the animal experiments in Hyderabad, I spent two weeks as an observer at TCR and was - and remain - truly 
amazed by the skill with which the most shockingly sick and apparently hopeless cases arrive in their ER and end up walking out of the hospital. During the two weeks I was there and the entire month that Stephen was there, there was not a single death or even complication resulting from treatment at the hospital. Amongst the many patients occupying the 100 beds of TCR Multispecialty Hospital were quite a few horrific snakebite cases. Virtually all the victims had similar stories and bite marks on an ankle or foot. Typically, the patient had gone to urinate in the pre-dawn hours or to a woodpile or some other innocuous activity and stepped on a snake. The snakes struck and very soon after, the victims were bleeding from every orifice, paralyzed or both bleeding and paralyzed by the time they arrived in the care of Dr. Soundara Raj and his staff five to ten hours after the bite. All received antivenom and IV neostigmine if there was a neurologic deficit. Many ended up on dialysis. All survived. Stephen (all month) and I (just under two weeks) slept in two rooms we occupied in the hospital day and night waiting for snakebites and discussing the future of our project over dinner with Soundara Raj in the "Tank Room". It wasn't always work - we also entertained ourselves with imaginary Bollywood movie scripts such as, "Snakes and Saris: Venom for Venom," a feature length film for which we are about 9 songs and 11 dance routines short. In one version, Angeline Saris, a bass player for Zepparella would play the theme song with a basssithar. Amala Paul would play the heroin and we hadn't agreed about the hero, villainous nephew or the blind fortuneteller because most of our discussions deviated back to the topic of finding novel approaches to the treatment of snakebite. One thing we are all in agreement about is that EARLY treatments would allow more people to get to hospitals alive. The most telling statistic about how horrific the problem of snakebite is that of the patients who die from snakebite, only $25 \%$ die in the hospital $[16,29]$. That means $75 \%$ of deaths occur without ever having made it to medical care. In the case of TCR Multispecialty Hospital, it is a good bet that if you arrive alive, you will live. Unfortunately, too many do not make it to the capable hands of physicians like Dr. Soundara Raj.

I left Krishnagiri the third week of June and headed for Hyderabad to do the mouse studies to test the neostigmine against cobra venom. The results of this pilot study were astonishing -10 of 15 mice survived to be completely normal receiving nasal neostigmine while 0 control mice survived the same dose of cobra venom. Needless to say, these results need to be replicated, but they are encouraging. What is most astonishing and a testament to Dr. Samuel and Dr. Soundara Raj's vision for this project is that on June $27^{\text {th }}-2$ months to the day - after I met Dr. Samuel in Chicago is that they actually treated a patient with a suspected krait bite using nasal neostigmine. I was working in the ER at Kaiser when I got a surprise e-mail headlined by "Complete reversal of ptosis!" that almost reduced me to tears. The patient, aged 50, had the horrifying experience of having woken up with a snake biting her arm. Her symptoms and signs all pointed toward a krait bite: Bitten while asleep, no fang marks, progressive paralysis. Briefly, she arrived at TCR Hospital about 9 hours after her bite, but still awake. While in the ER she became unresponsive as antivenom was being infused. Dr. Soundara Raj put her on life support without any sedation and she was brought to the ICU. She received maximum doses of antivenom, but her facial paralysis persisted and she could not lift her head or even open her eyes. Dr. Samuel and Dr. Soundara Raj report having treated her with a single dose of intranasal neostigmine and that she showed clinical improvement within 30 minutes - so much so that she insisted on leaving the hospital the next day. On his way home to Dublin, Ireland, two weeks after leaving Krishnagiri, Dr. Samuel stopped in San Francisco. We called the patient's brother in her village and he went to her residence. She had returned to her normal activities, remembered getting the nasal spray, how it felt and she asked quite adamantly, why she hadn't been sent home with a supply. That made us smile, but there is a lot to do and scattered cases can serve as proof of principle, but they are not proof. 
We have a long way to go, but it is without a doubt we have changed the way people are going to think about solving this ancient scourge and persistent modern tragedy.

\section{REFERENCES}

1. Lewin, M. R., D. H. Bouyer, D. H. WalKer, ANd D. M. Musher. 2003. Rickettsia sibirica infection in members of scientific expeditions to northern Asia. Lancet 362:1201-1202.

2. Lewin, M. R., P. Knott, And M. Lo. 2004. Seal finger. Lancet 364: 448.

3. Platts-Mills, T. F., M. R. Lewin, J. Wells, and P. Bickler. 2006. Improvised cricothyrotomy provides reliable airway access in an unembalmed human cadaver model. Wilderness and Environmental Medicine 17:81-86.

4. Platts-Mills, T. F., E. Stendell, M. R. Lewin, M. N. Moya, K. Dhah, et Al. 2007 An experimental study of warming intravenous fluid in a cold environment. Wilderness and Environmental Medicine 18:177-185.

5. Balanoff, A. M., M. A. Norell, G Grellet-Tinner, and M. R. Lewin. 2008. Digital preparation of a probable neoceratopsian preserved within an egg, with comments on microstructural anatomy of ornithischian eggshells. Naturwissenschaften 95:493-500.

6. Tonna, J. E., M. R. Lewin, I. H. Hahn, T. F. Platts-Mills, and M. A. Norell. 2009. A prospective, multiyear analysis of illness and injury during summer travel to arid environments. Wilderness and Environmental Medicine 20:107-112.

7. Tonna, J. E., A. M. Balanoff, M. R. Lewin, N. SaAndari, and M. Wintermark. 2010. Potentially low cost solution to extend use of early generation computed tomography. Western Journal of Emergency Medicine 11:463-469.

8. Tonna, J. E., M. R. Lewin, And B. Mensh. 2010. A case and review of noma. PLoS Neglected Tropical Diseases 4:e869.

9. Lewin, M. B., T. Heier, J. Feiner, L. Montauk, and B. D. Mensh. 2013 (In press). Reversal of Experimental Paralysis in a Human by Intranasal Neostigmine Aerosol Suggests a Novel Approach to the Early Treatment of Neurotoxic Envenomation. Clinical Case Reports.

10. WARrell, D. A. 2010. Guidelines for the Management of Snake-bites: South East Asia Region. New Delhi, India. $67 \mathrm{pp}$.

11. Brogigini, M., C. Benvenuti, V. Botta, A. Fossati, and M. Valenti. 1991. Bioavailability of intranasal neostigmine: comparison with intravenous route. Methods \& Findings in Experimental Clinical Pharmacology 13:193-198.

12. Sglilrlanzoni, A., D. Pareyson, C. Benvenuti, G. Cei, V. Cosi, et al. 1992. Efficacy of intranasal administration of neostigmine in myasthenic patients. Journal of Neurology 239:165-169.

13. Di Costanzo, A., A. Toriello, C. Mannara, C. Benvenuti, and G. Tedeschi. 1993. Intranasal versus intravenous neostigmine in myasthenia gravis: assessment by computer analysis of saccadic eye movements. Clinical Neuropharmacology 16:511-517.

14. Heier, T., J. E. Caldwell, J. R. Feiner, L. Liu, T. Ward, et al. 2010. Relationship between normalized adductor pollicis train-of-four ratio and manifestations of residual neuromuscular block: a study using acceleromyography during near steady-state concentrations of mivacurium. Anesthesiology 113: 825-832.

15. Kasturiratne, A., A. R. Wickremasinghe, N. de Silva, N. K. Gunawardena, A. Pathmeswaran, et al. 2008. The global burden of snakebite: a literature analysis and modelling based on regional estimates of envenoming and deaths. PLoS Medicine 5: e218.

16. Mohapatra, B., D. A. Warrell, W. Suraweera, P. Bhatia, N. Dhingra, et al. 2011. Snakebite mortality in India: a nationally representative mortality survey. PLoS Neglected Tropical Diseases 5:e1018.

17. Chippaux, J. P. 1998. Snake-bites: appraisal of the global situation. Bulletin of the World Health Organization 76:515-524.

18. ChIPpauX, J. P. 2008. Estimating the global burden of snakebite can help to improve management. PLoS Medicine 5:e221. 
19. Fayrer, J. 1884. An Address on the Nature of Snake-Poison; its Effects on Living Creatures, and the Present Aspect of Treatment of the Poisoned. British Medical Journal 1:205-210.

20. FAYrer, J. 1890. The Venomous Snakes of India. Eclectic Magazine 52:81-94.

21. Hawgood, B. J. 1996. Sir Joseph Fayrer MD FRS (1824-1907) Indian Medical Service: snakebite and mortality in British India. Toxicon 34:171-182.

22. Walker, M. B. 1935. Case showing the Effect of Prostigmin on Myasthenia Gravis. Proceedings of the Roval Society of Medicine, London 28:759-761.

23. WALKer, M. B. 1938. Myasthenia Gravis: A Case in which Fatigue of the Forearm Muscles could induce Paralysis of the Extra-ocular Muscles. Proceedings of the Royal Society of Medicine, London 31:722.

24. Pearce, J. M. 2005. Mary Broadfoot Walker (1888-1974): a historic discovery in myasthenia gravis. European Neurology 53:51-53.

25. Satyamurti, S, D. B. Drachman, and F. Slone. 1975. Blockade of acetylcholine receptors: a model of myasthenia gravis. Science 187:955-957.

26. Drachman, D. B. 1978. Myasthenia gravis (second of two parts). New England Journal of Medicine 298:186-193.

27. Drachman, D. B. 1978. Myasthenia gravis (first of two parts). New England Journal of Medicine 298:136-142.

28. Banerjee, R. N, A. L. Sahni, K. A. Chacko, and K. Vijay. 1972. Neostigmine in the treatment of Elapidae bites. Journal of the Association of Physicians of India 20:503-509.

29. MN SBSKPRP. 2012. Incidence of animal bite/attack cases in the state of Karnataka, India - EMS perspective. National Journal of Emergency Medicine (Abstracts). 


\title{
The Education Log of the 2011 Hearst Philippine Biodiversity Expedition
}

\author{
Meg Burke and Roberta Brett \\ Department of Teacher and Youth Education, California Academy of Sciences, 55 Music Concourse Drive, \\ Golden Gate Park, San Francisco, CA 94118; Email: mburke@calacademy.org, rbrett@calacademy.org
}

\begin{abstract}
The 2011 Hearst Philippine Biodiversity Expedition was not only taxonomically multi-disciplinary and the largest expedition ever mounted by the California Academy of Sciences and hosted by the Philippines, it also embedded extensive educational outreach and significant media coverage as priority goals from the beginning. During the course of the seven-week expedition, over 900 people in the Philippines participated in community outreach and teacher professional development workshops, conference sessions, and the capstone symposium. Countless others in the Philippines and the U.S. heard about the expedition through radio and television coverage and special events during and after the expedition. Three key factors contributed to the success of the in-country outreach: holding workshops near all of the communities where scientists were conducting thcir fieldwork; having both U.S. and Filipino scientists participate in the workshops; and showcasing live specimens wherever possible. The 2011 expedition has paved the way for ongoing research, education and conservation collaborations with the Philippines.
\end{abstract}

The goal of the 2011 Hearst Philippine Biodiversity Expedition was to document biodiversity in a variety of habitats (shallow-water reefs, deep water communities, and montane forests) on and surrounding Luzon Island and across multiple disciplines (invertebrate zoology, ichthyology, botany, entomology, herpetology and mammalogy). Educational outreach and media coverage were embedded in the planning and goals from the beginning, as were collaboration with and participation by Filipino colleagues. Not only was this the largest expedition (in terms of number of scientists, educators and media personnel) ever launched by the California Academy of Sciences (CAS), it was also the largest and most diverse expedition to ever take place in the Philippines. A total of 94 scientists, educators and media personnel participated, 49 of whom were Filipino. Another key distinguishing feature of this expedition was the intent and successful execution of publically sharing preliminary field results immediately, before even leaving the country. To date, over 500 new species have been documented from the expedition, over 900 people attended educational outreach events in the Philippines during the expedition, and thousands more have engaged with expedition programs, materials and results in the United States and at CAS. Extensive television, radio, online and print media coverage occurred during the expedition and continued afterward.

The Philippines was chosen for this historic expedition for a variety of reasons. First and foremost, it is a biodiversity hotspot as designated by Conservation International, with great species diversity, high levels of endemism, and significant threats to the diversity. Equally as important, much of the diversity is not well documented. CAS also has a strong, established network of collaborators in-country due to ongoing shallow-water reef research by Terry Gosliner and Gary Williams going back to 1992, primarily focused along the Verde Island Passage along the southern coast of Batangas Province. Since 2006, there have also been numerous trips to the Philippines by CAS staff for combined research, educational outreach and animal husbandry activities, supported by the 2004-2009, \$2.5 million NSF grant Water is Life: Immersing the Public in Aquatic Diversity (ESI-0229918) that also helped build the living Philippine coral reef exhibit for the complete- 
ly renovated Academy which opened in 2008. The coral reef exhibit and the grant helped forge strong connections to and collaborations with the San Francisco Bay Area Filipino community and Pusod, the Philippine environmental education and conservation non-profit whose efforts are centered in Batangas Province.

Gosliner and Burke (2013) detailed the value and impact of embedding extensive educational outreach and media coverage into the field expedition. This new article is a more detailed log of the planning, implementation, and impact of the expedition's educational outreach. The educational component of the expedition was led by Meg Burke, Director of Teacher and Youth Education, and Roberta Brett, Senior Science Specialist, with significant help from other expedition colleagues, both American and Filipino. A list of all expedition participants is provided in Appendix 1, Expedition Participants and Logistics (see Gosliner and Burke [this volume] 2014: 9-12). Goals of the outreach included having educational workshops in every community in which expedition scientists were doing their research, and having expedition scientists, both American and Filipino, participate in the workshops with live specimens whenever possible. Main messages of the community outreach workshops included what the scientists were doing, why it was important, the biodiversity of the area, the need for protecting that biodiversity, and what local people could do to help. Additional outreach activities consisted of teacher professional development workshops, presenting at a national sustainability conference, interviews for radio and television, writing blogs for the CAS website and the New York Times'Scientists at Work feature, and the public capstone symposium at the end of the expedition. Table 1 lists the various types of outreach conducted in the Philippines during the expedition, who participated, and the numbers reached, while Table 2 lists the media outreach events during the expedition. Table 3 documents the media requests for information in the first 10 weeks after the expedition ended, and Table 4 shows the educational outreach done at CAS during the expedition and through October 12, 2011, four months after the expedition.

\section{Pre-EXPEDITION PLANNING}

CAS Executive Director Greg Farrington announced at the CAS March 24, 2010 Science Council meeting that Will and Margaret Hearst had offered to fund a large-scale expedition for CAS. The Philippines biodiversity proposal was submitted at the end of May 2010, and was selected for funding in June 2010. Gosliner, Dean of Science and Research Collections, was the overall Principle Investigator (PI) and expedition leader, as well as the leader of the shallow-water component. Co-PIs were Rich Mooi, Curator of Invertebrate Zoology, leader of the deep-water component; Frank Almeda, Senior Curator of Botany, leader of the terrestrial component, later replaced by Peter Fritsch, Curator of Botany, due to scheduling conflicts; and Burke, leader of the educational outreach component.

Extensive planning was required within CAS and with Filipino partners to handle the complex logistics and permitting processes for such a large expedition with its wide diversity of disciplines and venues. Due to the many prior years of research and collaboration by Gosliner and other marine biologists, the groundwork was already laid for the shallow-water team with regard to permitting and operational logistics, and also helped inform and expedite the planning for the deepwater component. There was no similar background of recent research and collaboration on the terrestrial front, however, and logistical planning and obtaining permits proved more challenging for the terrestrial component. By the time all of the planning was done, seven Memoranda of Understanding and Agreement were in place to collaborate on scientific research, education and conservation related to Philippine natural resources, and two additional MOUs have been signed following the expedition (see Table 5). As noted in Gosliner and Burke (2013), the educational outreach component frequently helped secure the MOUs and permits. 
TABLE 1: Educational outreach in-country during the 2011 Philippine Biodiversity Expedition.

\begin{tabular}{|c|c|c|c|}
\hline Type of outreach & Date & Participants & Attendance \\
\hline \multicolumn{4}{|l|}{ Community outreach } \\
\hline \multirow[t]{2}{*}{ Club Ocellaris, Anilao } & $5 / 1 / 11$ & Mooi, Williams, Van Syoc, Horn, McGuire & 20 \\
\hline & $5 / 8 / 11$ & Burke, Brett arrive Manila & \\
\hline Taal Lake, Talisay & $5 / 11 / 11$ & $\begin{array}{l}\text { Burke, Brett, Piotrowski, Catania, McGuire, Sal- } \\
\text { cedo, Javier, Dumale }\end{array}$ & 33 \\
\hline Mt. Makiling, UPLB & $5 / 12 / 11$ & Burke, Brett, Lewin, Salcedo, Javier & 69 \\
\hline University of Batangas & $5 / 13 / 11$ & Burke, Brett, Piotrowski, Javier, Castillo & 62 \\
\hline Mt. Banahaw, SLSU, Lucban & $5 / 17 / 11$ & Burke, Brett, Griswold, Fernando, Salcedo, Javier & 58 \\
\hline Calatagan & $5 / 18 / 11$ & $\begin{array}{l}\text { Burke, Brett, Gosliner, Williams, Van Syoc, } \\
\text { Moore, Salcedo, Castillo }\end{array}$ & 37 \\
\hline Mabini/Tingloy & $5 / 23 / 11$ & $\begin{array}{l}\text { Burke, Brett, Hamilton, Stone, Olney, Isaacson, } \\
\text { Comendador, Javier, Castillo }\end{array}$ & 44 \\
\hline Mt. Isarog, ANU, Naga & $5 / 31 / 11$ & Burke, Brett, Almeda, Stone, Olney, Tan, Salcedo & 32 \\
\hline Subtotal & & & 355 \\
\hline \multicolumn{4}{|l|}{ Teacher Prof'l Development } \\
\hline Univ. Santo Tomas, Manila & $5 / 9 / 11$ & Burke, Brett, Salcedo, Castillo & 76 \\
\hline Philp. Sci. Centrum, Marikina & $5 / 20 / 11$ & Burke, Brett & 92 \\
\hline Subtotal & & & 168 \\
\hline \multicolumn{4}{|l|}{ Sustainability Conference } \\
\hline CEU, Manila & $5 / 27 / 11$ & Gosliner, Burke, Brett, Salcedo & 160 \\
\hline \multicolumn{4}{|l|}{ Expedition Symposium } \\
\hline UP Diliman & $6 / 8 / 11$ & $\begin{array}{l}\text { Farrington, Gosliner, Mooi, Catania, Piotrowski, } \\
\text { Van Syoc, Williams,Hamilton, Moore, Simison, } \\
\text { Iwamoto, McCosker, Griswold, Burke, Brett, } \\
\text { Chousou Polydouri, Salcedo, Javier, Castillo }\end{array}$ & 250 \\
\hline Total & & & 933 \\
\hline
\end{tabular}

Because the education team intended to deliver community outreach programs in as many of the research venues as possible, Burke created an expedition master calendar (see Gosliner and Burke [this volume] 2014, Appendix 2, pp. 14-18) to keep track of the locations, comings and goings of all the Academy participants, and the proposed outreach events. The calendar was a key resource for Mary Lou Salcedo, Expedition Project Manager, for Pusod staff helping organize logistics for the educational outreach, and for Marites Pastorfide, Sales Manager of Wayfair Tours Inc. and her team that organized all of the ground transportation and hotel accommodations for the expeditioners. Skype proved to be invaluable technology for finalizing details before the expedition and even during it since different participants were in different locations at any given time.

Beginning in December 2010, Burke and Brett met weekly to develop and finalize outreach content, deliverables, target audiences, logistics and schedule, and to contact potential Filipino 
TABLE 2: Media events in-country during the 2011 Philippine Biodiversity Expedition.

\begin{tabular}{|c|c|c|}
\hline Date & Event & Participants \\
\hline $5 / 2 / 11$ & UP press conference & $\begin{array}{l}\text { Gosliner, Fritsch, Penneys, Shevock, } \\
\text { Ong, UP Pres. Pascual }\end{array}$ \\
\hline $5 / 5 / 11$ & Expedition video shown at Academy Gala & Expedition team \\
\hline $5 / 11 / 11$ & ANC (ABS-CBN) "Future Perfect" interview & Gosliner, Ong, UP Pres. Pascual \\
\hline $5 / 21 / 11$ & GMA 7 "Born to be Wild" interview & Gosliner, Hamilton, Licuanan \\
\hline $5 / 28 / 11$ & GMA 7 "Born to be Wild" interview & Mooi, Piotrowski, Williams, Carpenter \\
\hline $6 / 6 / 11$ & Philippine Congressional dinner \& medal ceremony & Expedition team \\
\hline $6 / 7 / 11$ & GMA 7 "News to Go" interview (live TV) & Farrington, Gosliner, Burke \\
\hline multiple & Numerous interviews with ABS-CBN film crew & Most of expedition team \\
\hline multiple & New York Times "Scientist at Work" blogs (4) & Mooi \\
\hline multiple & CAS website blogs & Expedition team \\
\hline
\end{tabular}

partners. We created outreach templates to share in advance of the expedition with our various Filipino partners (see Appendix 1). Periodic Skype meetings were held with external partners in the Philippines, including Pusod, Philippine Science Centrum, and ABS-CBN, at critical junctures in the planning process. Multiple meetings were also held internally with a variety of CAS groups including the researchers, educational and public floor staff, Marketing and IT to provide information about the expedition in general and the educational outreach in particular, to discuss how expedition assets, digital or otherwise, could benefit programs during and beyond the expedition, as well as be applicable to future initiatives. To simplify field logistics, the four-person CAS media team spent most of their 16 days in the Philippines traveling in conjunction with Burke and Brett.

\section{Educational OUtreach in the PhilipPINES}

The goals of the educational outreach team were to explain the "what" and the "why" of the expedition to local audiences, share its scientific discoveries and preliminary results, provide resources and suggestions to participants for further involvement in locally relevant science and conservation opportunities, and help digitally document the processes of the expedition. The outreach efforts wound up falling in three basic categories: 1) community outreach presentations to local government officials, conservationists, educators, and interested members of the public; 2) professional development workshops for teachers, grades K-16, that included the basic biology, ecology, conservation and climate change challenges of Philippine coral reefs and montane forests; and 3) presentations at conferences and symposia. At the outreach sessions, hard copies and digital links were provided of a selected bibliography, including relevant CAS lesson plans (see Appen$\operatorname{dix} 2$ ).

Burke and Brett were in the Philippines for the last five weeks of the seven-week expedition, arriving in the Philippines on May 8, 2011, after the first contingents of CAS scientists (shallowwater arrival April 26, 2011; terrestrial arrival May 2,2011), but before all of the teams were at full strength. Because of the nature of the outreach and the desire to reach all communities where scientists were engaged in research during the expedition, the education team traveled more extensively than any other component of the expedition. During the five weeks, Burke and Brett conducted 11 outreach events, traveled by seven different modes of transportation (see Fig. 1), and changed localities 14 times, using the house of Malou Babilonia, daughter of Expedition Project 
TABLE 3: Media coverage of 2011 Philippines Biodiversity Expedition, through 8/18/11, 10 weeks post.

\begin{tabular}{|c|c|c|}
\hline Media & Count & Outlets \\
\hline \multirow{9}{*}{ TV/Radio } & 10 & 7Live on KGO \\
\hline & & ABS CBS - Philippines \\
\hline & & CNN International \\
\hline & & Filipino Channel - SF \\
\hline & & GMA 7 - Philippines \\
\hline & & KOFY-TV - Indiana \\
\hline & & KGO-TV - 4 stories (new species, sharks, botany, aquarium) \\
\hline & & KNTV \\
\hline & & National Public Radio - Wisconsin \\
\hline \multirow[t]{26}{*}{ Print/Online } & 47 & Advertiser - Australia \\
\hline & & Agence France-Presse - Asia \\
\hline & & Asian Correspondent \\
\hline & & Asian News International \\
\hline & & Balita \\
\hline & & Care2.com \\
\hline & & DailyIndia.com - India \\
\hline & & EarthSky.org \\
\hline & & Filipino Express \\
\hline & & Forbes.com \\
\hline & & Fox News \\
\hline & & Gizmodo \\
\hline & & Guardian Weekly - UK \\
\hline & & GulfNews.com \\
\hline & & Hindustan Times \\
\hline & & Illustreret Videnskab - Denmark \\
\hline & & IndiaTimes.com \\
\hline & & Inquisitr \\
\hline & & Inter Press Service \\
\hline & & International Business Times \\
\hline & & Korea Times - Korea \\
\hline & & La Tercera - Chile \\
\hline & & LiveScience \\
\hline & & Mongabay.com \\
\hline & & MSNBC.com \\
\hline & & MX - Australia \\
\hline
\end{tabular}


TABLE 3: Media coverage of 2011 Philippines Biodiversity Expedition, through 8/18/11, 10 weeks post (continued).

\begin{tabular}{|c|c|c|}
\hline Media & Count & Outlets \\
\hline & & National Geographic Indonesia \\
\hline & & NationalGeographic.com \\
\hline & & New York Daily News \\
\hline & & NYTimes.com \\
\hline & & Oman Daily Observer - Oman \\
\hline & & OurAmazingPlanet.com \\
\hline & & Philippine Daily Inquirer - Philippines \\
\hline & & Philippine Star \\
\hline & & Philippines Online Chronicles \\
\hline & & Practical Fishkeeping - UK \\
\hline & & San Francisco Chronicle \\
\hline & & Science \& Vie Decouvertes - France \\
\hline & & Scientific American \\
\hline & & Seattle Post Intelligencer \\
\hline & & Sin Chew Jit Poh - Malaysia \\
\hline & & Sun Star - Philippines \\
\hline & & Treehugger.com \\
\hline & & Vancouver Sun - Canada \\
\hline & & Washington Post \\
\hline & & Yahoo! News \\
\hline & & Yahoo.de \\
\hline
\end{tabular}

Manager Mary Lou Salcedo, in Ecology Village, Makati, Metro Manila, as their staging base until the end of the expedition when the Dusit Thani Hotel in Makati was used as the base of operations for the entire CAS team for the capstone symposium.

The following is a site-by-site, event-by-event description of the educational outreach workshops conducted during the expedition:

May 1, 2011:

Club Ocellaris, Anilao, Batangas Province

Prior to the arrival of Burke and Brett, CAS marine biologists Mooi, Williams and Bob Van Syoc conducted an outreach program for 20 members of the staff, their families, and neighbors of Club Ocellaris, the rustic dive resort serving as the base of operations for the shallow-water component of the expedition. They set out pans of seawater with live specimens they had collected and shared information about the species and the critical roles they play in coral reef ecosystems (see Figs. 2-3). As with all the outreach events, live specimens were the stars of the show; many coastal community members are unaware of the amazing diversity of marine life literally in their own backyards since they cannot afford the time or expense of scuba diving or snorkeling, and may not even know how to swim. This outreach event was captured on video by CAS videographers Tim 
TABLE 4: Educational outreach at CAS during and four months after the expedition.

\begin{tabular}{|c|c|c|}
\hline Date & Event & Participants \\
\hline $5 / 19-20 / 11$ & $\begin{array}{l}\text { Live Skype from Philippines to NightLife } \\
\text { Earth Update }\end{array}$ & Gosliner, Mooi \\
\hline $6 / 23 / 11$ & Presentation to Academy Leadership Team & Gosliner, Mooi, Fritsch, Burke \\
\hline $6 / 24 / 11$ & Panel discussion, Members' Curators Event & Gosliner, Burke, Shepherd, Stone \\
\hline $6 / 24 / 11$ & Research displays, Members' Curators Event & Expedition team \\
\hline $6 / 30 / 11$ & NightLife, Earth Update & Gosliner, Griswold \\
\hline $6 / 30 / 11$ & $\begin{array}{l}\text { Philippines NightLife, education \& research } \\
\text { tables }\end{array}$ & $\begin{array}{l}\text { Brett, Piotrowski, Van Syoc, Penneys, Lewin, } \\
\text { Griswold, Williams, Chousou Polydouri, Shevock }\end{array}$ \\
\hline $6 / 30 / 11$ & $\begin{array}{l}\text { Philippines NightLife, VIP attendees, hosted } \\
\text { by Burke, Gosliner }\end{array}$ & $\begin{array}{l}\text { Philp. Secretary of Tourism, SF Consul General, } \\
\text { Pres. Philip. Airlines }\end{array}$ \\
\hline $7 / 6 / 11$ & Presentation to Education Division staff & Burke, Brett \\
\hline $7 / 13 / 11$ & $\begin{array}{l}\text { Chat with an Academy Scientist (presenta- } \\
\text { tion at Science in Action) }\end{array}$ & Hamilton \\
\hline $7 / 19 / 11$ & Presentation to Building Operations team & Burke \\
\hline $7 / 20 / 11$ & Presentation at All-Staff meeting & Gosliner, Griswold, Burke \\
\hline $7 / 22 / 11$ & Presentation to TISS teachers & Gosliner \\
\hline $7 / 29 / 11$ & $\begin{array}{l}\text { Out of the Lab (presentation at the Project } \\
\text { Lab) }\end{array}$ & Griswold \\
\hline $8 / 5 / 11$ & $\begin{array}{l}\text { Out of the Lab (presentation at the Project } \\
\text { Lab) }\end{array}$ & Williams \\
\hline $8 / 10 / 11$ & $\begin{array}{l}\text { Chat with an Academy Scientist (presenta- } \\
\text { tion at Science in Action) }\end{array}$ & Burke \\
\hline 9/12/11 & Presentation to Will Hearst & $\begin{array}{l}\text { Gosliner, Mooi, Griswold, Burke, Shepherd, } \\
\text { Stone, Penny }\end{array}$ \\
\hline $9 / 13 / 11$ & Acdemy Pritzker lecture & Gosliner, Burke \\
\hline $10 / 7 / 11$ & $\begin{array}{l}\text { Science in Action video exhibit (Academy } \\
\text { research side) }\end{array}$ & Mooi \\
\hline $10 / 12 / 11$ & $\begin{array}{l}\text { Chat with an Academy Scientist (presenta- } \\
\text { tion at Science in Action) }\end{array}$ & Brett \\
\hline
\end{tabular}

Horn and David McGuire, digitally transmitted back to CAS with the help of the Nido Fortified Science Discovery Center Planetarium (SM Mall of Asia, Pasay City, Metro Manila) which had suitable bandwidth for the large files, and was included in the "Explore" video shown at the 2011 Annual Big Bang Gala fundraising event at CAS on the night of May 5, 2011. The international dateline was our friend in this case, giving CAS's Visualization Studio team essentially an extra day to receive the video file and incorporate it into the Gala video. 
TABlE 5: Memoranda of Understanding and Agreement between the California Academy of Sciences and various Filipino and international partners and agencies to support research, education and conservation of Philippine natural resources; presented in alphabetical order within each section.

In place before, and continuing beyond, the 2011 Philippine Biodiversity Expedition:

Philippine Bureau of Fisheries and Aquatic Resources (BFAR)

Philippine Science Centrum

Pusod, Inc.

Created for the expedition and continuing:

Ateneo de Naga University

Department of Agriculture of the Republic of the Philippines

Department of Environment and Natural Resources of the Republic of the Philippines (DENR), including the Protected Areas and Wildlife Bureau (PAWB) and the Regional Offices of the DENR.

National Museum of the Philippines

University of the Philippines System (all campuses)

Completed since the expedition, and continuing:

ABS-CBN Foundation, U.S. and Philippines

Conservation International

May 9, 2011:

University of Santo Tomás, Manila

The day after their arrival in the Philippines, Burke and Brett, assisted by Salcedo and Pusod Project Assistant Jovell Castillo, led an all-day professional development workshop for 76 university faculty, graduate students, and high school educators at the University of Santo Tomás, the oldest university in Asia. Entitled "Biodiversity Assessment and Conservation: The Hearst Expedition," the workshop included an overview of CAS and the expedition, content and hands-on activities related to tropical forests in general and Philippine forest in particular, and content and handson activities related to coral reefs in general and Philippine reefs in particular. The fact that the Philippines is both a terrestrial and marine biodiversity hotspot, with less than $10 \%$ of the Philippines' primary forests remaining and is the center of the center of coral reef diversity, makes for a compelling story and intense interest. In one activity (Carbon Cycle Role Play), participants exchanged ping pong balls representing carbon atoms cycling through the biotic and abiotic components of an ecosystem, to better understand the carbon cycle, climate change and what is meant by "carbon footprints," as well as the role of forests in the carbon cycle and climate change. In another activity, participants were asked to make careful observations of marine bivalve shells and record as many details of the external morphology as possible (see Fig. 4). They then placed all of the similar looking shells in a large pile and were asked to find their shell based on the description they had made of it. The shell activity helped participants better understand the scientific process and the importance of careful observation in the describing and naming of new species, a major focus of the expedition. Tropical Storm Bebeng prevented 40 other registered participants from other provinces and islands from attending.

May 11, 2011:

Taal Lake, Talisay, Batangas Province

At Taal Lake, the education team and CAS and Filipino researchers presented to a group of 33 elementary school teachers and local government officials, including the mayor of Talisay, one of 
the municipalities bordering the lake. Taal Lake is the third largest freshwater lake in the Philippines and has two unique aspects: it used to be connected directly to the ocean as an arm of Balayan Bay, and it has an island in the middle of it (Volcano Island) that has its own large crater lake. Eruptions in the $18^{\text {th }}$ century closed off direct access to the ocean and over time the lake became fresh water. This has resulted in biologically unique, endemic species such as the freshwater sea snake (Hydrophis semperi) and sardine (Sardinella tawilis). Expedition biologists David Catania, Chrissy Piotrowski, Van Syoc, Vanessa Knutson and Don Dumale were particularly interested in collecting Taal specimens, but the unusual electrolytes in the Taal waters interfered with attempts to use the electro-shocker to collect fish, and a heightened alert status for possible eruptions limited access on Volcano Island. Some specimens were successfully collected, however, with nets. The botany team's plan to conduct a survey of plants on Volcano Island, especially along the route of a proposed hiking path for tourists, had to be canceled due to the eruption alert. The Taal watershed is a protected area, but Taal is the center of controversy and conservation concerns due to the presence of tilapia fish pens (see Fig. 5), the introduction of an invasive species of piscivore fish, jaguar guapote (Parachromis managuensis), and the occurrence of significant kills of both native and aquaculture fish, the causes of which are attributed to both overstocking of fish pens, oxygen depletion in the water, and over-abundance of sulfur in the water due to volcanic activity. The educational outreach, in addition to the usual focus on the expedition, included discussions about the conservation challenges facing the lake and the communities surrounding it.

\section{May 12, 2011: Mt. Makiling, University of the Philippines, Los Baños, Batangas Province}

This university campus is situated in a lush, tropical forest and offered the ideal backdrop for the outreach, which focused primarily on the expedition fieldwork being conducted by botanists and entomologists on the slopes of Mount Makiling, an inactive volcano located $65 \mathrm{~km}$ southeast of Manila. The outreach was attended by 69 park officials, university faculty, students, and other educators. Participants learned about discoveries made at elevations not previously surveyed, especially for bryophytes, a group that had not been a focus of much previous fieldwork. Expedition physician Matt Lewin also provided field first aid tips (never leave home without a safety pin or two!) and described a mobile snakebite kit that he was developing and its potential value during fieldwork in remote terrestrial locations such as those being visited in the Philippines. Salcedo and Pusod Executive Director Ann Hazel Javier assisted Burke and Brett with the outreach.

May 13, 2011:

University of Batangas, Batangas City, Batangas Province

Hosted by Dr. Percy Showers, a faculty member at the University of Batangas (UB), this program reached 62 students and faculty. Burke and Brett were joined by Javier and Castillo from Pusod, and by CAS marine biologist Piotrowski, who deserved a Purple Heart for participating in the outreach while waiting for medical results from the Batangas Hospital for a recurring infection she was battling. Before the outreach session began, Burke and Brett had a courtesy call with Jesus Mayo, Vice President for Students and External Affairs, Florencio V. Reyes, Vice President of Publications, Research, Linkages and Liaison (PReLL) and Julio Romeo T. Chavez, FacultyResearcher, PReLL. It was at this meeting that CAS was invited to attend and present at the sustainability conference at Centro Escolar University later in the month.

May 17, 2011:

Southern Luzon State University, Lucban, Quezon Province

As the expedition progressed and more fieldwork was done and specimens collected, outreach events offered even greater opportunities to share information about the joint discoveries being 
made by CAS and Filipino scientists. The day before this outreach event, Burke and Brett joined the terrestrial biologists in the field, accompanying the entomologists on a collecting trip on Mt. Banahaw, providing an opportunity for first-hand field experience and documenting the fieldwork (see Fig. 6). The outreach had 58 participants ranging from local government officials and agency representatives to students and faculty. Salcedo warmed up the crowd with opening comments in Tagalog, and the resounding stars of the event were CAS entomologist Charles Griswold and Filipino botanist Edwino Fernando as they showed a large live spider, a laughing cicada, and other specimens that had been collected the day before (see Figs. 7-8).

May 18, 2011:

Calatagan, Batangas Province

This outreach was attended by 37 local government officials, including Sophia G. Palacio, the mayor of Calatagan, community members, and NGOs, including the troop leader and several youth from the Sea Scout program in Nasugbu (see Fig. 9). Sea Scouts is a joint program of the Boy Scouts of the Philippines and the Philippine Coast Guard and Auxiliary and is designed for young boys and girls ages 13 to 18 . It provides opportunities to learn swimming and water survival techniques, basic seamanship, and receive career mentoring; the Nasugbu chapter also has a strong focus on marine conservation and species identification. The outreach was held at CAP Ocean, a conservation non-profit and small hotel run by Jessie de los Reyes, who is helping restore mangroves and creating artificial reefs to restore corals. The expedition team and Jessie collected live marine animals to showcase during the outreach. Following the outreach, the Sea Scouts helped the biologists release the animals back into the ocean and the biologists got to experience first hand the knowledge, enthusiasm and keen eye sight of the scouts (see Fig. 10).

May 20, 2011:

Philippine Science Centrum, Marikina City, Metro Manila

As part of International Museum Day 2011, organized by the Philippine National Commission for Culture and the Arts and the National Committee on Museums, Sub-Committee on Science and Technology Museums, Burke and Brett delivered "A Workshop for the Ecology and Conservation of Philippine Tropical Forests and Coral Reefs" to 92 formal and informal educators (see Fig. 11). The workshop was by invitation only and was held at the Philippine Science Centrum (PSC), a hands-on science center in Marikina City. May Pagsinohin, the Executive Director of PSC, and Burke have known each other for many years, collaborating on visits of staff between the two institutions and sharing educational resources. The all-day workshop featured presentations on the expedition goals and scope, an overview of coral reef and montane ecosystems and their conservation issues, preliminary findings of the expedition's biodiversity surveys, and the carbon cycle role play lesson plan.

May 23, 2011:

Mabini/Tingloy, Batangas Province

Forty-four members of the Mabini and Tingloy communities, local government officials including Nilo Villanueva, the Mayor of Mabini, conservation advocates and NGOs including Conservation International, and teachers attended this outreach. The highlight was once again the display of living organisms, including a sea horse and pipe fissh collected on the nearby reefs. CAS ichthyologist Healy Hamilton and Filipino marine biologist Joseph Commendador participated in the outreach, as did the CAS media team. Burke and Brett were also assisted by Javier and Castillo of Pusod. During the discussions following the presentations, Mayor Villanueva made a public commitment to increase the number of permanent moorings at nearby popular dive sites, to help protect the reefs from damage caused by anchors. (N.B. In December 2013, many new moorings were installed.) 
May 27, 2011:

Centro Escolar University, Manila

Burke, Brett, Salcedo and expedition leader Gosliner were invited to speak at the Philippine Society for Educational Research and Evaluation, Inc. (PSERE) international conference on "Global Response to Sustainability through Research" which was part of PSERE's $19^{\text {th }}$ annual assembly. Hosted by Centro Escolar University, the CAS session reached an audience of over 160 professional scientists, students and university faculty. Angel Alcala, renowned marine biologist at the Philippine Council for Aquatic and Marine Research and former Secretary of DENR and Academy Fellow, gave the plenary session address.

May 31, 2011:

Ateneo de Naga University, Naga City, Camarines Sur Province

This outreach presentation was made to $32 \mathrm{Mt}$. Isarog National Park officials, university faculty and students, and high school educators. The program included an overview of local forest ecosystems and conservation issues of Mt. Isarog by Yolda Abante, Protected Area Superintendent for Mt. Isarog, an overview of the Hearst expedition and an education workshop for teachers by Burke and Brett, and preliminary findings of the terrestrial biodiversity survey of Mt. Isarog by CAS botanist Frank Almeda and Filipino botanist Benito Tan. Closing remarks were made by the Director of the Environmental Conservation and Research Department at Ateneo de Naga University. Stephanie Stone and Jennifer Olney of the CAS and U.S. media team and Salcedo also attended.

June 6, 2011:

Quezon City

While not technically an outreach event, it is worth noting that as a result of the expedition's science, education and conservation efforts, the Honorable Angelo B. Palmones, member of the House of Representatives, Republic of the Philippines, and members of his AGHM Party List, hosted a dinner for the CAS delegation and Filipino scientists, and presented each participant with a certificate and a Congressional Medal of Excellence in Research and Development. This honor demonstrated the high level of interest in and appreciation of the expedition and its collaborative, inclusive approach. Throughout the expedition, there was significant and consistent Philippine TV, radio and print media attention.

June 8, 2011:

Expedition Capstone Symposium, University of the Philippines Diliman, Quezon City, Metro Manila

The capstone symposium took place just two and three days after the expedition teams returned to Manila or their home Philippine institutions at the end of the fieldwork. The goal of the symposium was to present preliminary findings, lessons learned, and conservation recommendations based on those findings. Presentations were made by both CAS and Filipino expedition participants (see Fig. 12). This was an unprecedentedly quick and inclusive approach compared to most expedition communication techniques. The all-day symposium attracted the media and the participation of high-level officials, such as the President of the University of the Philippines, who hosted the event, the Executive Director of CAS, cabinet level Secretaries and Directors (see Fig. 13). Over 250 people attended the symposium.

\section{AFTER THE EXPEDITION}

As shown in Tables 3 and 4, interest in the expedition continued after CAS scientists returned home. Gosliner and Burke (2013) outlines the invited presentations and media coverage resulting from the expedition. Of special note is the June 30, 2011 CAS NightLife event that had the expedition as its theme, with expedition team members displaying specimens and images and talking to 
guests about the expedition. Almost 3,000 guests attended the NightLife, and the vast majority of them were Filipino, including the Consul General and staff from the San Francisco Philippine Consulate and the Secretary of Tourism, visiting from Manila. The event received rave reviews and remains the single largest Filipino outreach event in CAS history.

The impact of the expedition and CAS's connection to the Philippines continue. In November 2012, as a follow-up to the expedition and at the invitation of the University of the Philippines, Diliman, nine CAS staff, including Gosliner, Burke, Williams, Piotrowski, and Brian Simison from the expedition, spent a week at the university delivering and participating in multi-disciplinary workshops focused on integrating research, education, exhibits and conservation. Hundreds attended the event, from across the Philippines.

Most recently, Gosliner and Burke were invited guests and presenters at meetings of Mayor Villanueva of Mabini and his Council, and of the Batangas Provincial Government Board on November 12 and 13,2013, respectively. The focus of the meetings was creating sustainable coastal ecosystem development plans. CAS was honored to be asked to share its expertise and excited to be able to help play a role in helping conserve natural resources and securing sustainable livelihoods for coastal communities. These meetings took place in the context of the devastation brought by Super Typhoon Haiyan (Yolanda), which hit the central Philippines November 7-8. While Manila and Batangas Province were virtually unscathed by the typhoon, it was a wake up call to everyone about the increasing impacts of climate change and the necessity of preserving intact coral reef and mangrove ecosystems to help abate storm damage. The Batangas Provincial Government Board voted unanimously to proceed with a coastal ecosystem development plan after Gosliner's statement on the floor of the legislature. During this trip, Burke and Gosliner also learned of another impact of the 2011 expedition: KGO TV's award-winning documentary, Reefs to Rainforests: The Great Expedition, is being used in graduate classes at the Asian Institute of Management in Manila to help MBA students better understand the uniquely rich and valuable natural resources of the Philippines.

Many of the CAS and Filipino participants in the shallow-water and deep-water components of the 2011 expedition are now gearing up for two more field seasons of biodiversity surveying along the Verde Island Passage in the springs of 2014 and 2015, courtesy of the recent NSF grant (Collaborative Proposal: Documenting Diversity in the Apex of the Coral Triangle: Inventory of Philippine Marine Biodiversity, DEV-1257630) awarded to Gosliner. Following the successful 2011 expedition model, educational outreach will once again be embedded in the fieldwork.

\section{ACKNOWLEDGEMENTS}

We would like to thank all of our colleagues who helped make the expedition and its educational outreach such a success, before, during and after. From our funders, Will and Margaret Hearst, to each and every member of the expedition teams, our outreach partners, our planning and logistical supporters in the U.S. and the Philippines, and our enthusiastic audiences, we literally couldn't have done it without you. Maraming salamat po kayo.

\section{LiTERATURE CiTED}

GoSLinER, T. M., AND M. BURKE. 2013. From parachutes to partnerships: an "integrated" natural history museum expedition in the Philippines. Curator: The Museum Journal 56 (1):47-67.

Gosliner, T. M., AND M. BuRKe. 2014. Expedition participants and logistics. Pages 9-18 in G.C. Williams and T.M. Gosliner, eds., The Coral Triangle: The 2011 Hearst Biodiversity Philippine Expedition. California Academy of Sciences, San Francisco, California 94118, USA. 


\section{Photo Images}

Figures 1-13 


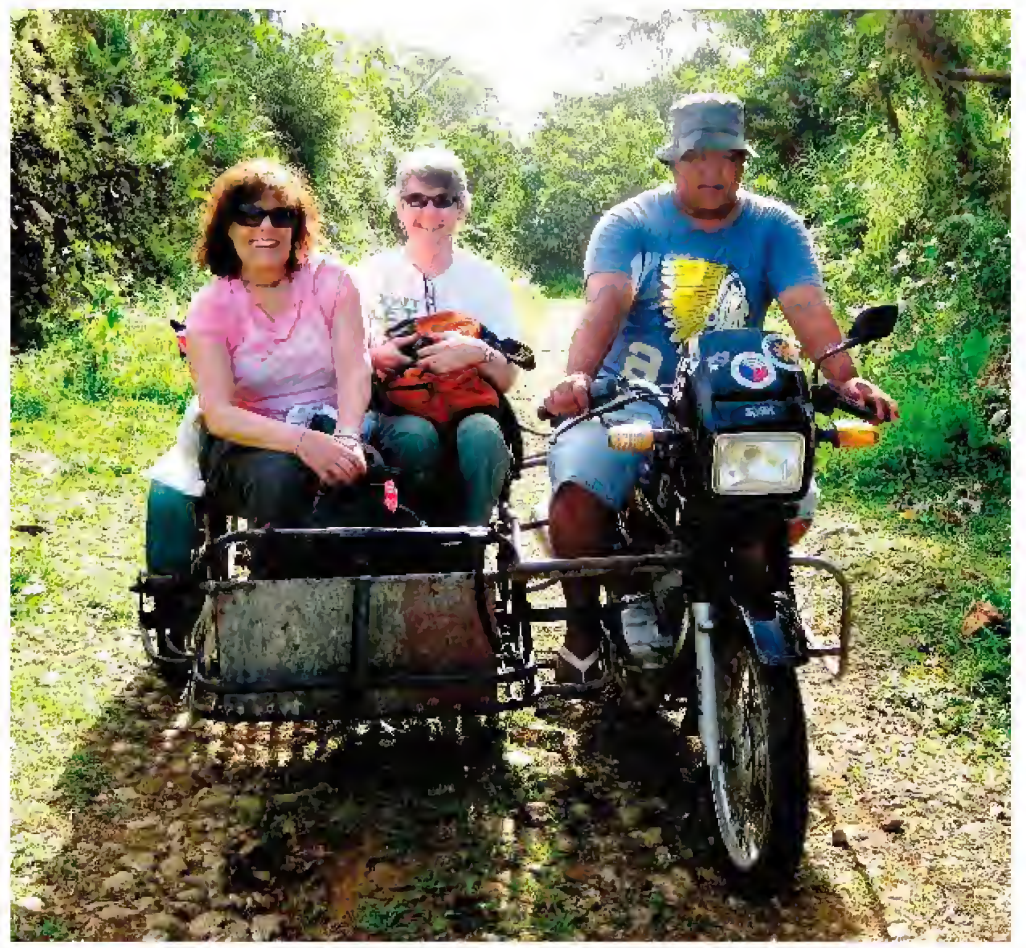

FIGURE 1: Brett and Burke arrive by tricycle to join the terrestrial team of botanists and entomologists at Mt. Banahaw during the 2011 Philippine Biodiversity Expedition. Photo by J. Edrial.

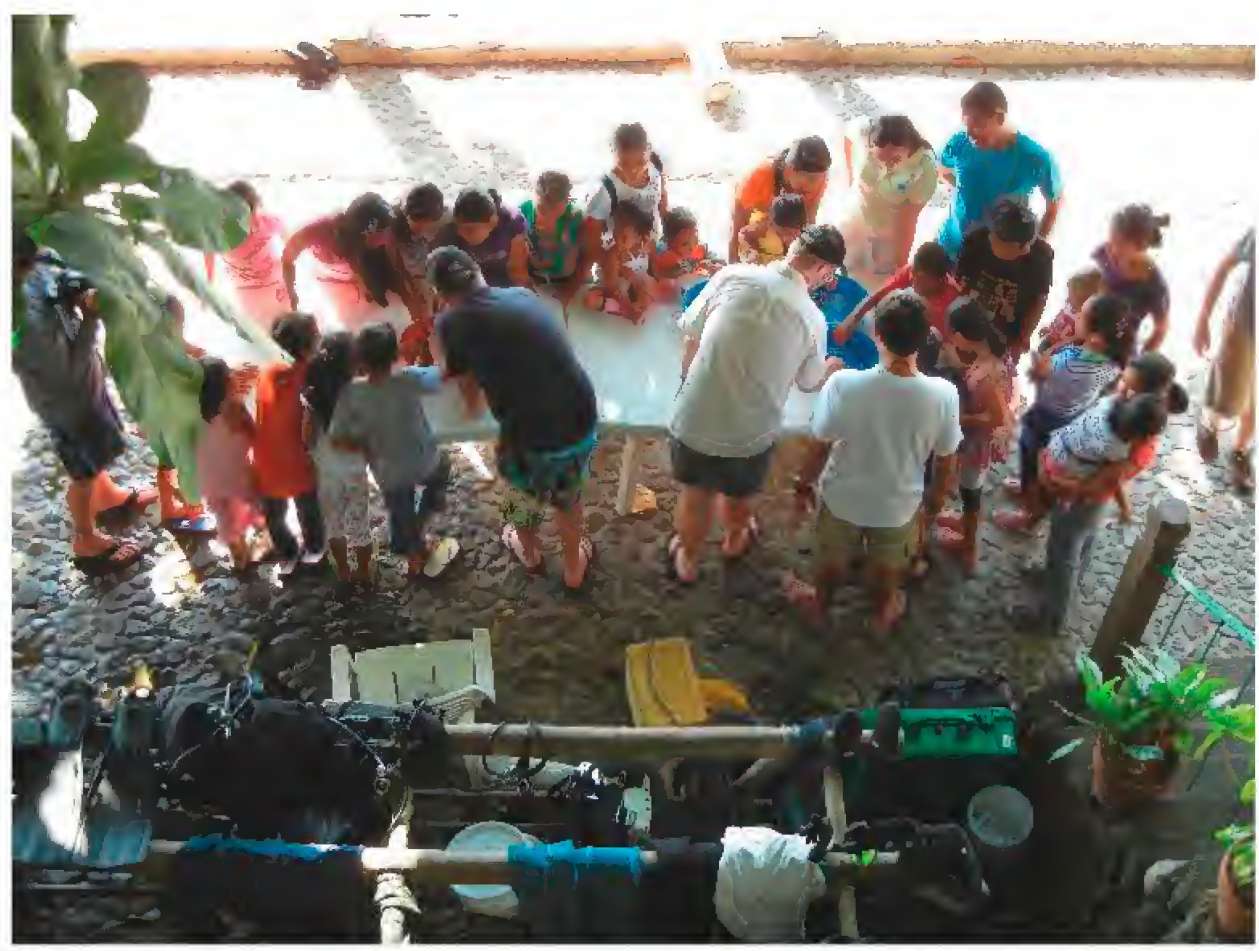

FIGURE 2: CAS marine biologists conducting outreach with live specimens for Club Ocellaris staff, families and neighbors. Photo by T. Horn. 


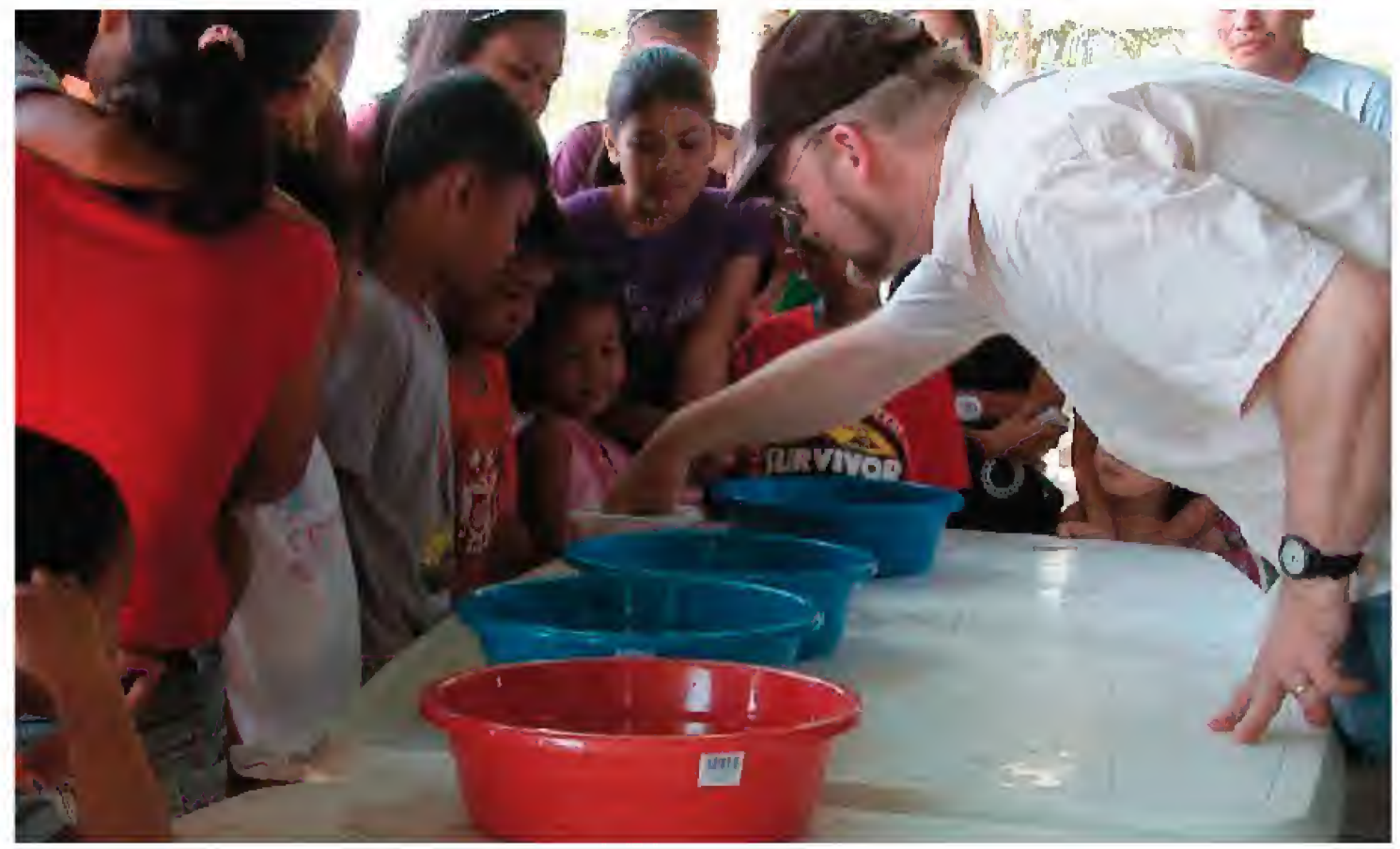

FIGURE 3: Club Ocellaris outreach with Rich Mooi wowing the crowd. Photo by D. McGuire.

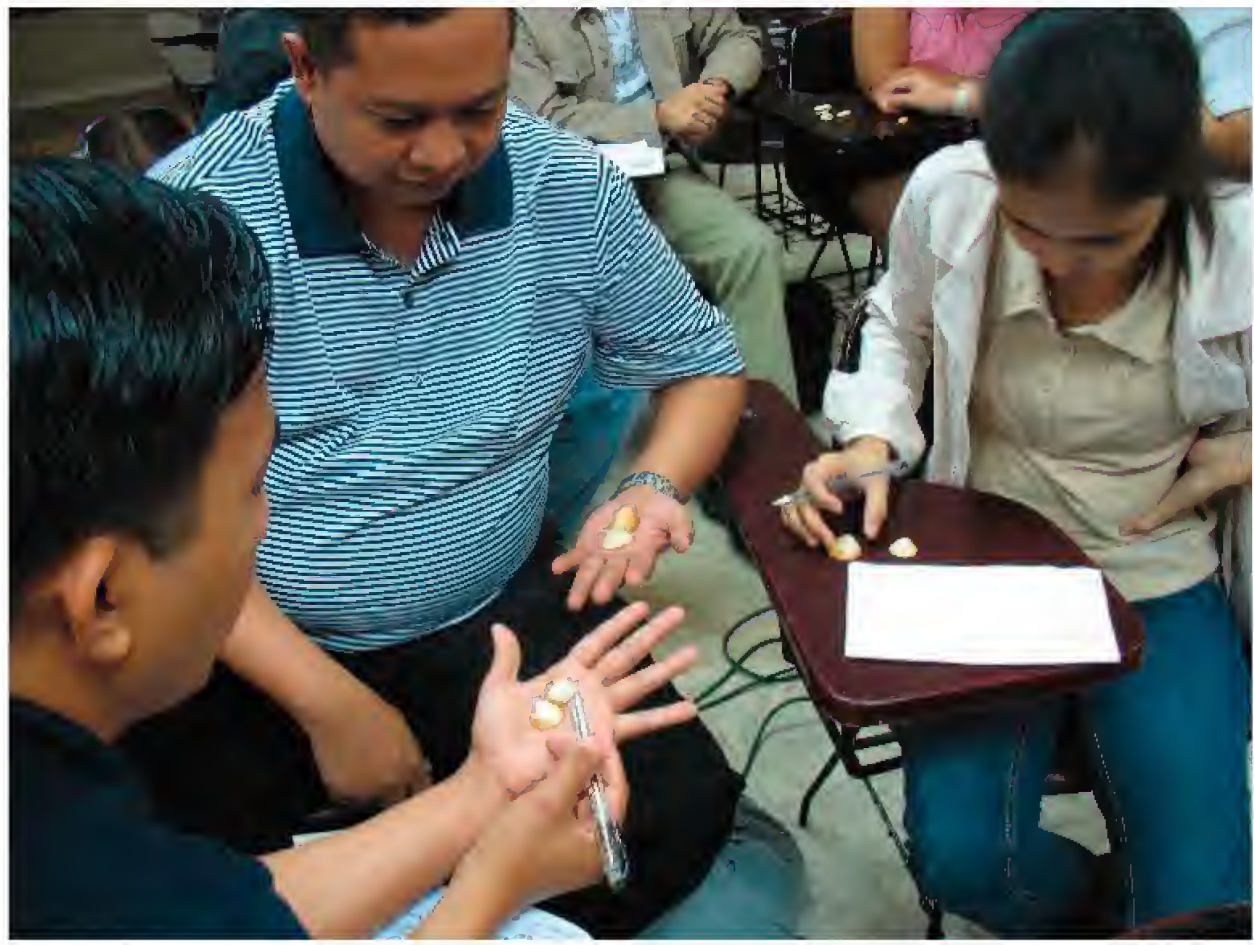

FIGURE 4: Teacher professional development workshop at the University of Santo Tomás, Manila. Teachers participating in an activity on observation and inquiry. Photo by R. Brett. 


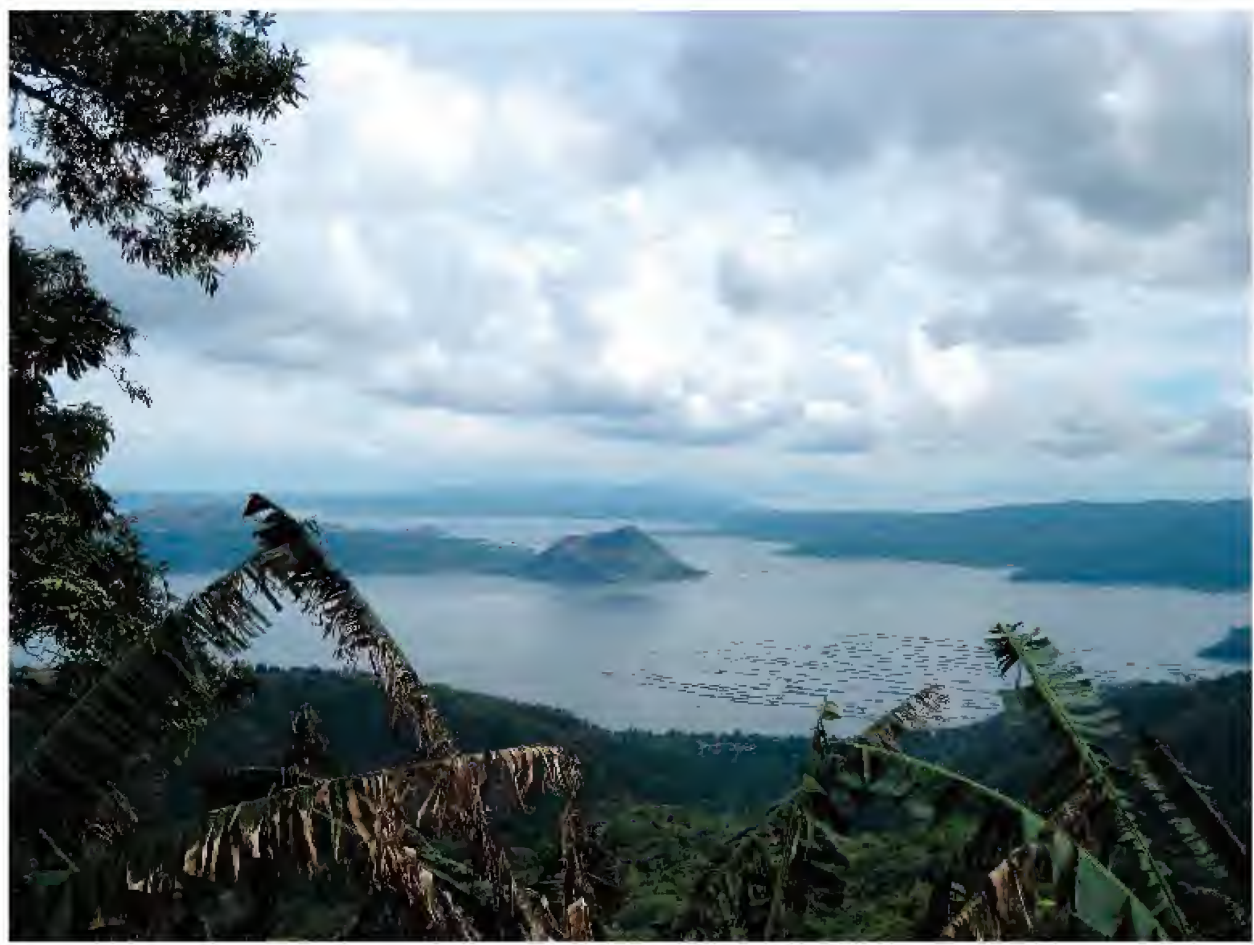

FIGURE 5: View of Taal Lake, showing Volcano Island within the lake and some of the many fish pens (foreground). Photo by M. Burke.

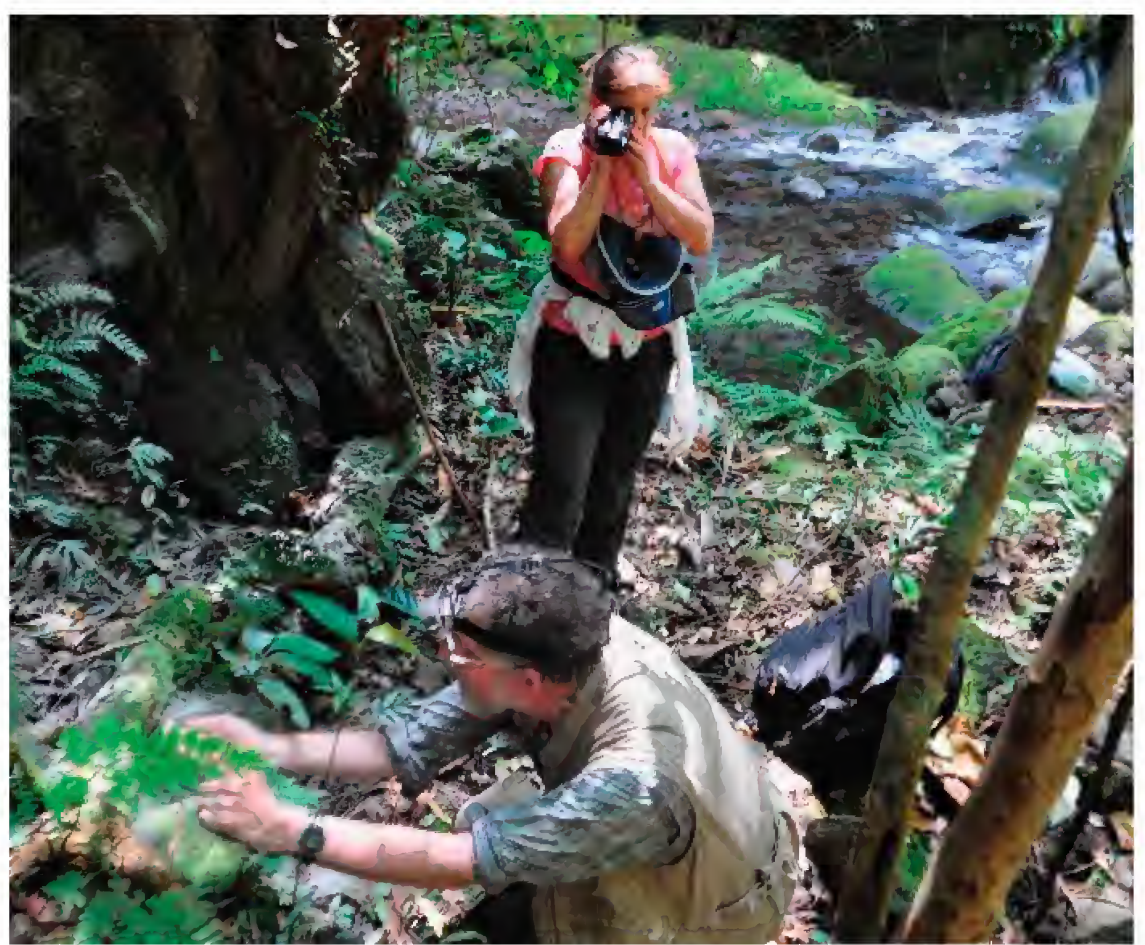

Figure 6: Brett video taping Charles Griswold collecting spiders on Mt. Banahaw. Photo by M. Burke. 


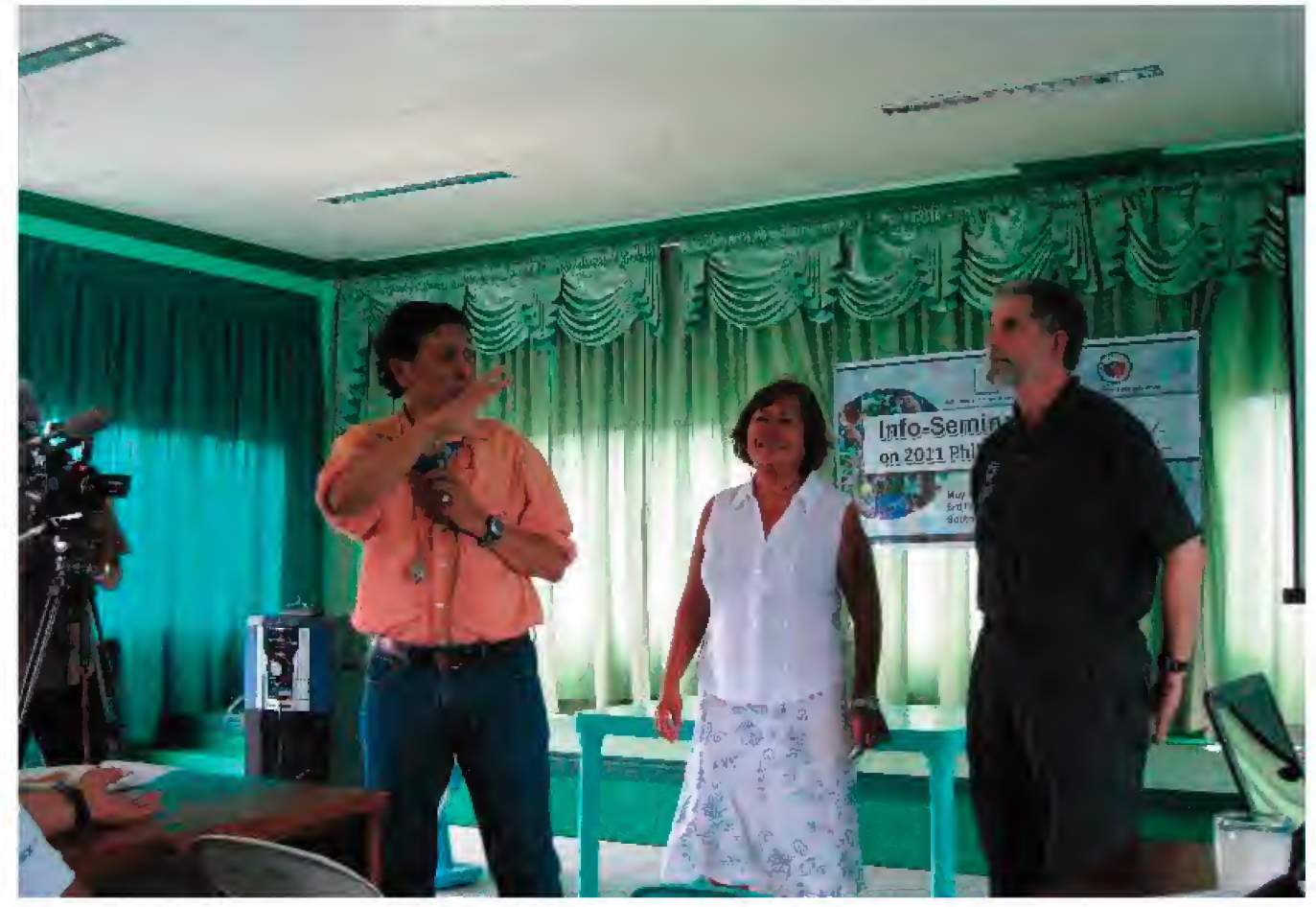

FIGURE 7: Outreach event at Southern Luzon State University. Filipino botanist Fernando, Expedition Project Manager Salcedo, and CAS entomologist Griswold discussing the expedition while being filmed by ABS-CBN. Photo by M. Burke.

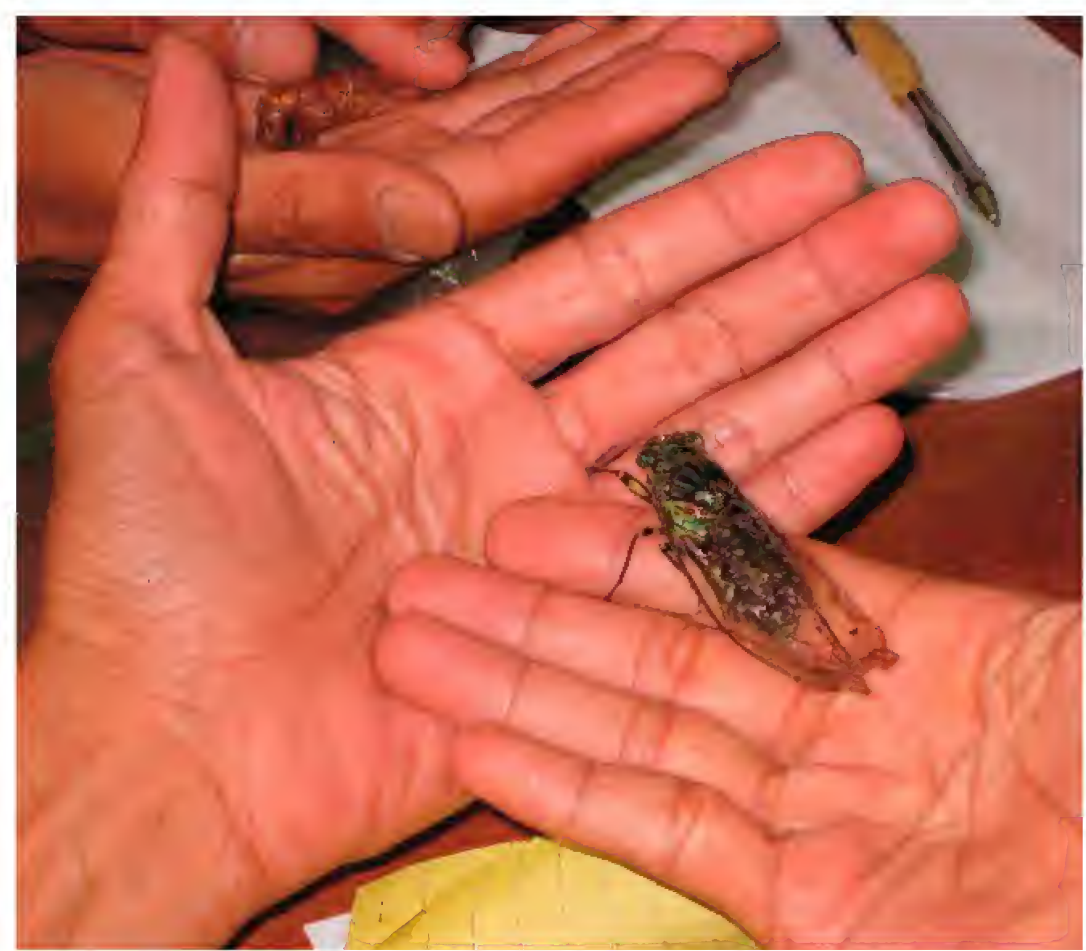

FIGURE 8: Outreach event at Southern Luzon State University. Hands-on encounter with a "whistling" cicada and a molt. Photo by M. Burke. 


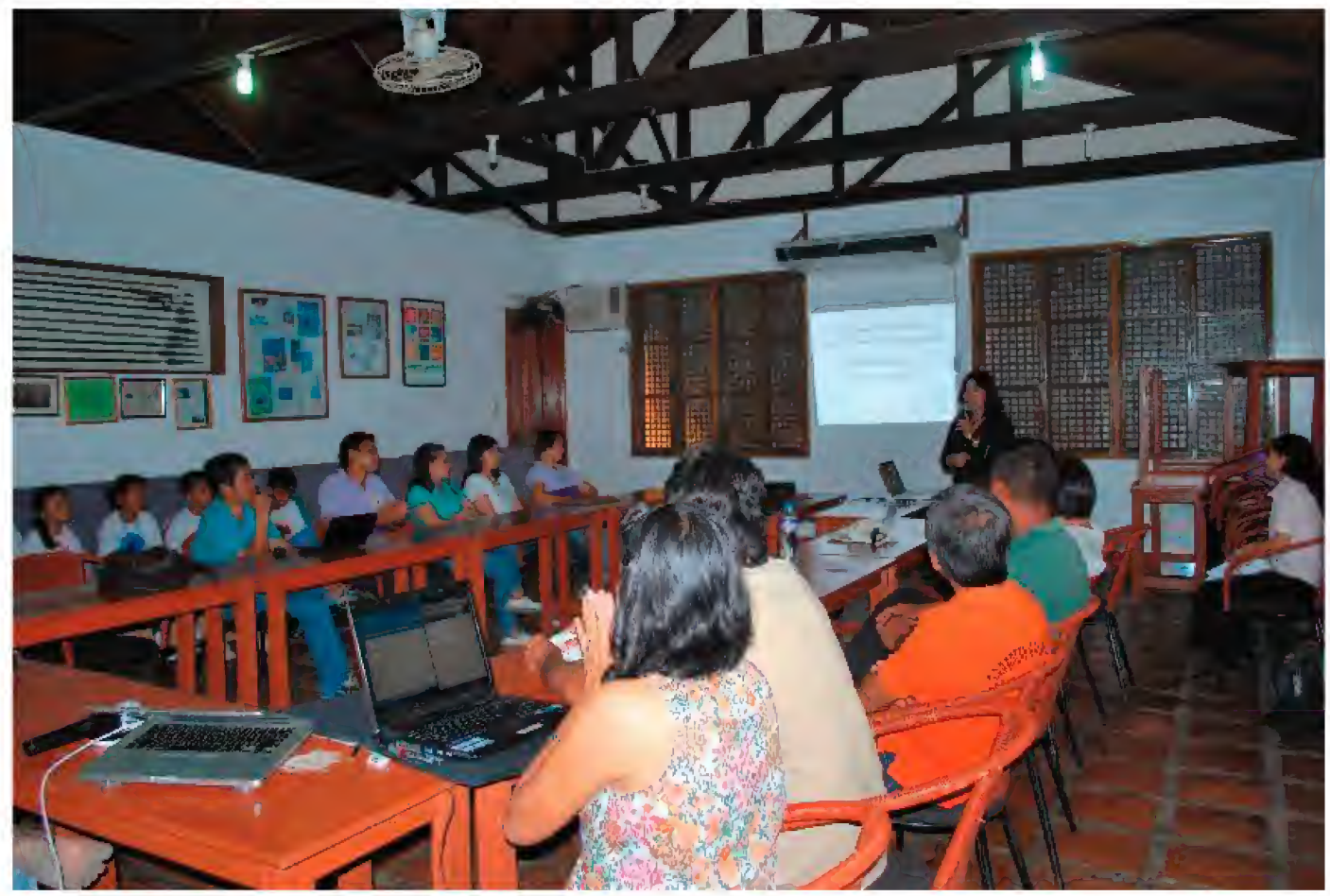

FIGURE 9: Outreach at Calatagan. Presentation, with Sea Scouts sitting along side wall. Photo by M. Burke.

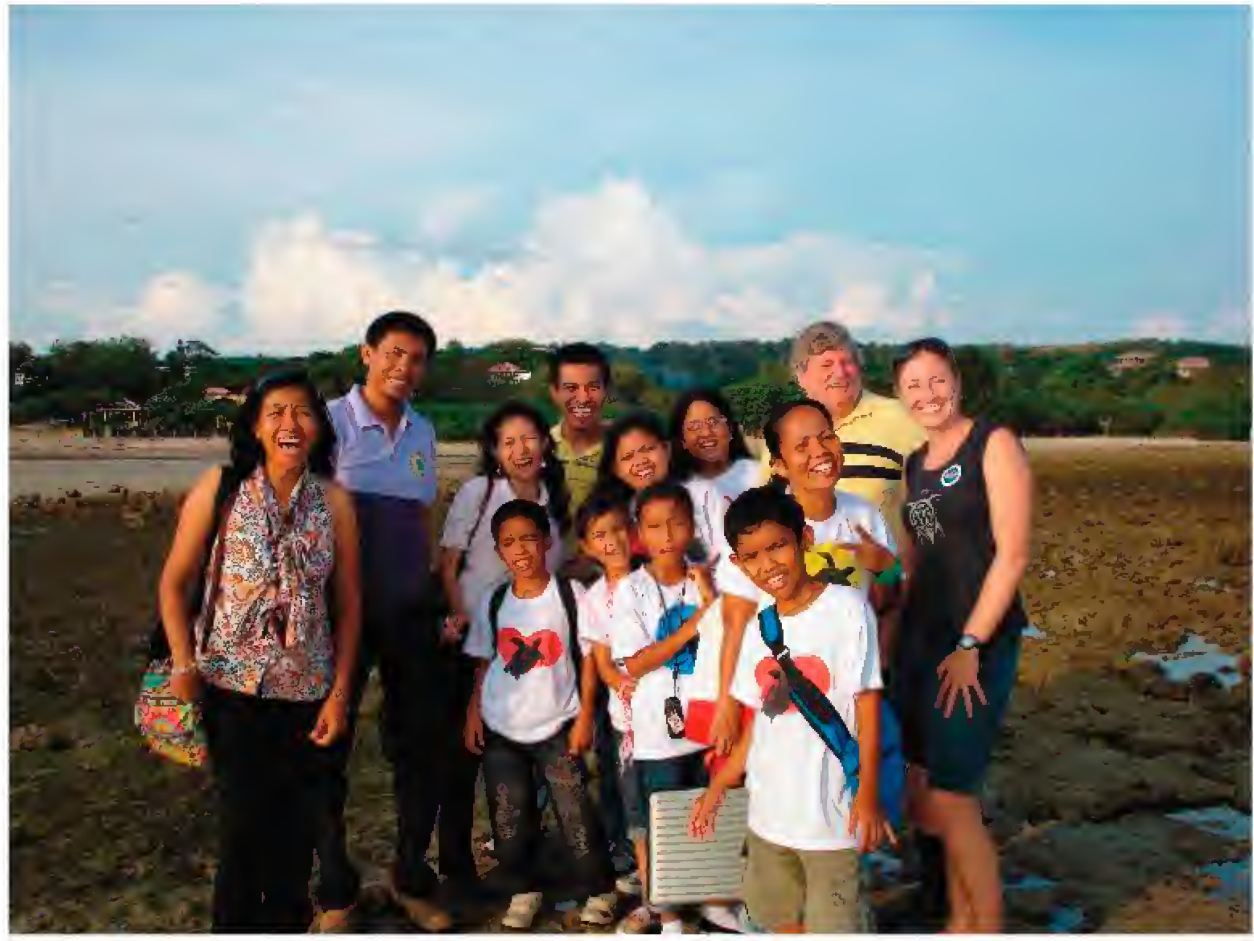

Figure 10: Outreach at Calatagan. Expedition members, Pusod staff, and Nasugbu Sea Scouts after returning live specimens to the sea after the outreach event. Expedition Leader Gosliner second from right. Photo by M. Burke 


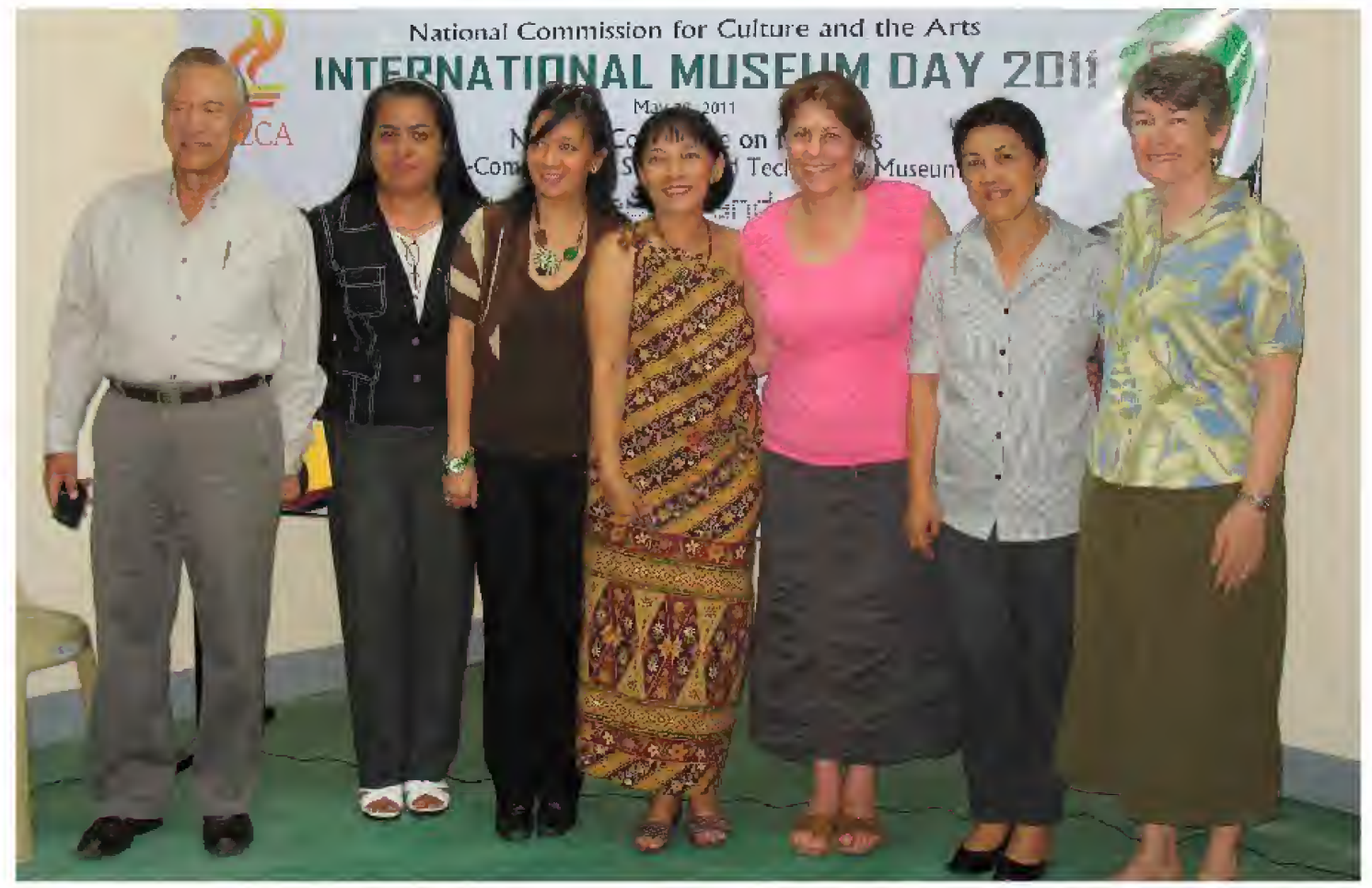

FIGURE 11: After the teacher professional development workshop at the Philippine Science Centrum (PSC), part of the International Museum Day Conference. From left to right: Filemon Jun Berber, Jr., President, Philippine Foundation of Science and Technology, PSC; May Pagsinohin, Executive Director, PSC; Theresa Mundita Lim, Director, Protected Areas and Wildlife Bureau, Department of Environment \& Natural Resources; Alice Pañares, Head, Subcommission on Cultural Dissemination, National Commission for Culture and the Arts; Roberta Brett, CAS; Myrna Jimenez, Executive Director, Sagip Ilog Pilipinas; Meg Burke, CAS. Photo by PSC staff.

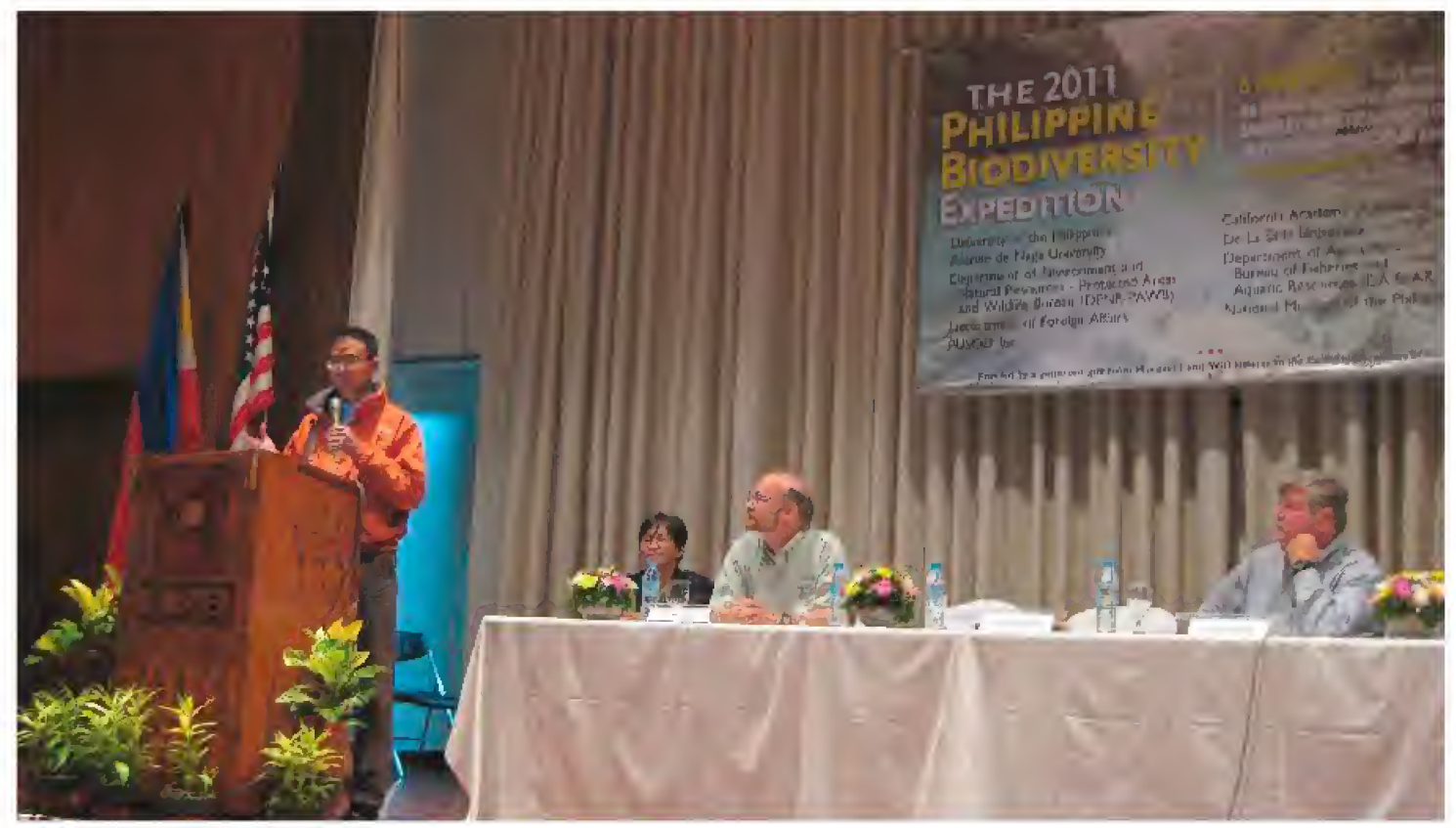

FIGURE 12: Wilfredo (A1) Licuanan presenting at the capstone symposium at the University of the Philippines, June 8 , 2011; Marilou Nicholas, Rich Mooi and Terry Gosliner at the table. Photo by M. Burke. 


\title{
PROGRAM
}

REGISTRATION $8: 00-8: 30$ a.m.

National Anthem

ii. Welcome Remarks

III. Messages

\author{
Alfredo E. Pascual \\ President, UP \\ Harry K. Thomas, Jr \\ Antoassador, USA \\ Gregory C. Farrington \\ Executive Director, CAS \\ Perry S. Ong \\ Director, IB, UPD
}

IV. Dedication to Two Biodiversity Sejentists:

V. Status of Philippine Biodiversity

$$
\text { Marine Realms: }
$$

Terrestrial Re:alms:

Edgardo D. Gomez

Angel $C$. Alcâla

BREAK 10:30-10:45

VI. Panel Discussions: Government Role/Action

Sec. Proceso J. Alcala

Dept of Agriculture
Sec. Ramon Jesus P. Paj

Dept of Environnent \& Natura' Resourccs

Senator Juan Miguel Zubiri

Scnatc Committce on Environment

Senator Edgardo J. Angara

Serate Committee on Science and Technology

Sec. Alberto A. Lim

Dept of Tourism

Sec. Mario G. Mantejo

Dept or Science and Techoogy

Sec. Alberto F. Del Rosario

Dept. of Forcign Affairs

OPEN FORUM 1 11:30-11:45

VII. The 2011 Phillppine Blodiversity Expedition:

Preliminary Results: Marine

- Shallow-water invertebrates

- Deep-water animals

Terrence Gosliner

Wilfredo Y. Licuanan

Richard Mooi

- Freshwater fishes

Rachel R. Gotanco

David A. Catania

LUNCH 12:45-1:45 p.m.

VIII. The 2011 Philippine Biodiversity Expedition: Terrestrial

- Terrestrial Plants:

- Terrestrial Invertebrates:

- Terrestrial Vertebrates:

Edwino S. Fernando

Charles Griswold

Ireneo l, Lit Jr.

Perry S. Ong

Philip Alviola

Rafe Brown

IX. Conservation Challenges: Panel

- Management Strategies

- Community Grassroots [ssues

- Legal lssues

- Educational Challenges

- Policy Challenges

- Internatlonal Perspective

Theresa Mundita S. Lim

Dircctor: PAWB

Ruperto Aleroza

Jose A. Canivel

Catherine G. B. Lagunzad

IR Nereus "Neric" O. Acosta

Rodrigo Fuentes

Director, Asean Center for Biodiversity

BREAK 3:30-3:45

$X$. Further Directions.

- Research:

- Education:

- Conservation:

Terrence Gosliner

Perry5. Ong

Meg Burke

Ann Hazel Javier

Asis G. Perez

OPEN FORUM 2 4:15-4:30

XI. Closing Remarks

Caesar A. Saloma

Chancellor, UP Ditiman

Marilou G. Nicolas $\quad$ Antoinette B. Hernandez
Moderator

FIGURE 13: Program of the expedition capstone symposium. 


\section{Appendix 1 \\ Educational outreach templates and descriptions}

\section{Terrestrial Education Outreach Component}

The educational outreach component of the California Academy of Sciences' 2011 Hearst Philippine Expedition will be led by Dr. Meg Burke, CAS Director of Teacher and Youth Education, and Ms. Roberta Brett, CAS Senior Science Content Specialist. Both Dr. Burke and Ms. Brett are field biologists as well as science educators. The terrestrial outreach program will include presentations by Academy and Filipino scientists, educators and conservationists. Presentation components will include:

An overview of the Hearst Expedition, its goals and scope.

An overview of local forest ecosystems and their conservation issues.

Preliminary expedition findings of the terrestrial biodiversity surveys of plants, insects,

spiders, and reptiles, with opportunity to observe specimens.

Discussion of conservation lessons and actions.

Question and answer period.

Ann Hazel Javier, Executive Director of Pusod, will coordinate outreach details with appropriate local representatives to help determine the best venue for the outreach program and the topics that will be of most interest and use to the audience. A diverse audience will be invited to attend the outreach program, including local government officials, other community members, conservation groups, teachers and youth.

\section{Taal Lake Education Outreach Component}

The educational outreach component of the California Academy of Sciences' 2011 Hearst Philippine Expedition will be led by Dr. Meg Burke, CAS Director of Teacher and Youth Education, and Ms. Roberta Brett, CAS Senior Science Content Specialist. Both Dr. Burke and Ms. Brett are field biologists as well as science educators. The Taal outreach program will take place at the Visitor Center and will include presentations by Academy and Filipino scientists, educators and conservationists. Presentation components will include:

An overview of the Hearst Expedition, its goals and scope.

An overview of the Taal ecosystem and its conservation issues.

The diversity and conservation issues of Taal fish species, with opportunity to observe live specimens.

Preliminary expedition findings of a botanical survey relative to a proposed footpath, with

opportunity to observe specimens.

Discussion of conservation lessons and actions.

Question and answer period.

A diverse audience will be invited to attend the outreach program, including local government officials, fisherfolk, women's groups, conservation groups, teachers and youth.

\section{Marine Education Outreach Component}

The educational outreach component of the California Academy of Sciences' 2011 Hearst Philippine Expedition will be led by Dr. Meg Burke, CAS Director of Teacher and Youth Education, and Ms. Roberta Brett, CAS Senior Science Content Specialist. Both Dr. Burke and Ms. Brett are field biologists as well as science educators. The marine outreach program will include presentations by Academy and Filipino scientists, educators and conservationists. Presentation components will include: 
An overview of the Hearst Expedition, its goals and scope.

An overview of local coral reef and deep-water ecosystems and their conservation issues.

Preliminary expedition findings of the marine biodiversity surveys, with opportunity to observe specimens.

Discussion of conservation lessons and actions.

Question and answer period.

Ann Hazel Javier, Executive Director of Pusod, will coordinate outreach details with appropriate local representatives to help determine the best venue and the topics that will be of most interest and use to the audience. A diverse audience will be invited to attend the outreach program, including local government officials, fisherfolk, women's groups, other community members, conservation groups, teachers and youth.

\section{Confirmation Letter for Teacher Professional Development Day at University of Santo Tomás, Manila}

The California Academy of Sciences is pleased and honored to be able to present an educational forum at the University of Santo Tomás on May 9, 2011. The workshop is being held concurrent with and will leverage the findings of the largest, multidisciplinary natural history expedition ever undertaken by the California Academy of Sciences in its 157-year history. Partnering closely with Filipino colleagues, Academy scientists will survey the biodiversity of shallow-water reef ecosystems, adjacent deep-water habitats, and terrestrial tropical forests and lakes. Results from the expedition will help inform conservation policy and resource management decisions.

Research is documenting that Philippine coral reefs are home to more species of organisms than any other marine ecosystem in the world. In addition, millions of people living in coastal communities around the world depend on healthy coral reefs for food and as an important resource for their livelihood. Similarly, tropical forests are known to be the richest terrestrial ecosystems on Earth, and are also among the most threatened. The Philippines are rich in this valuable and vulnerable natural resource, but much of its biodiversity has yet to be discovered.

This professional development workshop will help teachers and others understand the biology, ecology and conservation challenges of Philippine reefs and mountain forests, including their role as environmental indicators of global climate change. The workshop will provide this important background information, as well as provide ideas on how to incorporate key concepts and facts into classroom curriculum and community outreach to engage students and the community with locally relevant science. There will be opportunities to try hands-on activities that can be used to reinforce these concepts. Lesson plans and a list of bibliographic resources will also be provided to participants.

\section{University of Santo Tomás Presentation}

\section{"Biodiversity Assessment and Conservation: the 2011 Philippine Biodiversity Expedition" Professional Development Workshop University of Santo Tomás, Manila May 9, 2011}

I.. Welcome and introductions

II. Overview of the expedition and the California Academy of Sciences

III. Tropical forest species diversity, ecology and conservation

IV. Break

V. Forest lesson plans

a. Carbon cycle and climate change

b. Other lessons 


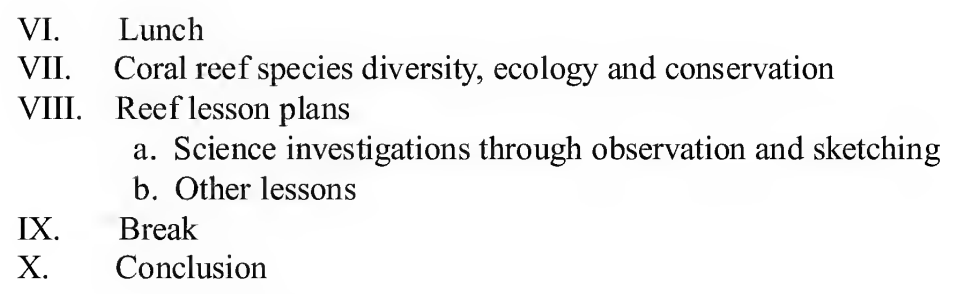

\section{Teacher Professional Development Workshops at the Philippine Science Centrum for International Museum Day}

\section{A) The Ecology and Conservation of Philippine Coral Reefs: A Workshop for High School Teachers}

Research is documenting that Philippine coral reefs are home to more species of organisms than any other marine ecosystems in the world! In addition, millions of people living in coastal communities around the world depend on healthy coral reefs for food and as an important resource for their livelihood. This professional development workshop will help teachers understand the biology, ecology and conservation challenges of Philippine reefs, including their role as environmental indicators of global climate change. The workshop will provide this important background information, as well as ideas on how to incorporate key concepts and facts into classroom curriculum and engage their students with locally relevant science. There will also be opportunities to try hands-on activities for the classroom that can be used to reinforce these concepts. A list of bibliographic resources will be also be provided to participants. The workshop is being held concurrent with and will leverage the findings of the largest, multidisciplinary natural history expedition ever undertaken by the California Academy of Sciences. Partnering closely with Filipino colleagues, Academy scientists will survey the biodiversity of shallow-water reef ecosystems, adjacent deepwater habitats and terrestrial tropical forests. Results from this expedition will help inform conservation policy and resource management decisions.

\section{B) The Ecology and Conservation of Philippine Tropical Forests: A Workshop for High School Teachers}

Tropical forests are known to be the richest terrestrial ecosystems on Earth, and also among the most threatened. The Philippines are rich in this valuable and vulnerable natural resource, but much of its biodiversity has yet to be discovered. This professional development workshop will help teachers understand the biology, ecology and conservation challenges of Philippine forests, including their role as environmental indicators of global climate change. The workshop will provide this important background information, as well as ideas on how to incorporate key concepts and facts into classroom curriculum and engage their students with locally relevant science. There will also be opportunities to try hands-on activities for the classroom that can be used to reinforce these concepts. A list of bibliographic resources will be also be provided to participants. The workshop is being held concurrent with and will leverage the findings of the largest, multidisciplinary natural history expedition ever undertaken by the California Academy of Sciences. Partnering closely with Filipino colleagues, Academy scientists will survey the biodiversity of shallow-water reef ecosystems, adjacent deep-water habitats and terrestrial tropical forests. Results from this expedition will help inform conservation policy and resource management decisions. 


\section{Template for Public Outreach}

Assume 2.5 hours for the program; may not have electricity at some sites; audience may be local politicians, naturalists, families, teachers, etc.

\section{Presentation portion:}

I. Intro

a. So glad to be here

b. Who we are

i. Educators

ii. Scientists

iii. Local reps and partners

II. Hearst expedition overview - what it is, why important

III. CAS overview

IV. Local habitat (marine or terrestrial)

a. Overview of the habitat

i. Include area in Philippines and globally

a. Biodiversity

b. Ecology

c. Conservation

i. Why the habitat is important

ii. Threats

iii. Solutions

V. Preliminary findings from the expedition scientists

a. Presentation or interview format with RB or MB

VI. Next steps

VII. Q\&A

\section{Activities portion (at tables):}

VIII. Audience-specific topic(s)

a. Meet the scientists and specimens

b. Lesson plans for teachers; activities for community groups; sustainable practices in everyday life; conservation activity (e.g., carbon cycle role

IX. Merienda play); handouts (if appropriate)

X. Continue with educational activities if there is interest and schedule permits. 


\section{Appendix 2 \\ Selected bibliography provided to participants at expedition outreach events}

California Academy of Sciences online lesson plans

http://www.calacademy.org/teachers/resources/

Selected lessons:

Carbon cycle role play

What contains carbon

Coral chemistry

Build a coral polyp

Sustainable fishing

Climate change and sea level

Rainforest locations
Rainforest products

Threatened biodiversity

Invent an Insect

Conservation Island

Tropical belt

Energy - a day in your life

Conservation International

Biodiversity Hotspots

http://www.biodiversityhotspots.org/xp/hotspots/philippines/Pages/default.aspx

Conservation International

Overview of Philippines

http://www.conservation.org/explore/asia-pacific/philippines/pages/overview.aspx

Conservation International

Sulu Sulawesi Seascape

http://www.conservation.org/sites/marine/initiatives/seascapes/sulu_sulawesi/Pages/sulusulawe-

$\underline{\text { si.aspx }}$

Sea Slug Forum

Website devoted to nudibranchs

http://www.seaslugforum.net/

Nudibranch Central

http://research.calacademy.org/redirect?url=http://researcharchive.calacademy.org/research/izg/nu dibranchs/index.html

The Hearst Expedition

http://www.calacademy.org/science/hearst/

The Coral Reef Alliance

International Organization for the protection of coral reefs

http://www.coral.org/

Biodiversity Hotspots map

http://www.conservation.org/Documents/cihotspotmap.pdf

Reef Check Philippines

http://reefcheckphilippines.org/philippine-summary-on-coral-reefs.php 


\section{Epilogue: The 2011 Hearst Philippine Biodiversity Expedition}

The early history of the California Academy of Sciences took place during the tumultuous and often flamboyant California Gold Rush in the mid nineteenth century. In the latter half of that century, the Academy's research, publications, and presentations were primarily focused on the natural history - geology, fossils, and the flora and fauna - of the young state of California (Ewan 1955; Leviton and Aldrich 1997; Leviton et al. 2010). By the early twentieth century, the geographic scope of research at the Academy had broadened to include other parts of western North America as well as the Galápagos Islands, and continued to expand to a global perspective throughout the century (Daniel 2008; McCosker 2007; Slevin 1959; Slevin and Leviton 1956; Williams 2007).

An example of the wide-ranging interests of scientists associated with the Academy in its first four decades as well as the early Academy as a center of scientific activity for the western United States is that of Alice Eastwood. In 1887, she was a twenty-eight year old high school teacher in Denver, Colorado and acted as a guide to visiting British naturalist Alfred Russel Wallace in an exploration of the highest peak in the Colorado Front Range during the alpine flowering season of that year. Five years later, she was appointed as a joint curator of Botany at the California Academy of Sciences with Mary Brandegee (Leviton and Aldrich 1997:337; Raby 2001).

The Hearst Philippine Biodiversity Expedition of 2011 (Fig. 1) is an affirmation of the stalwart nature of the Academy's continuously successful history as a research institution. The contemporary and unfortunate state of affairs affecting various museums and other similar facilities has resulted in the marked curtailing or even discontinuation of scientific research activities at numerous institutions worldwide. In spite of this, research endeavors such as the Hearst Philippine Biodiversity Expedition and the great variety of diligent and enthusiastic individuals responsible for its successful fulfillment, provide hope and confidence for a brighter future regarding research at institutions such as the California Academy of Sciences.

The expedition would not have been possible without the generous support of Will and Margaret Hearst. Their interest and dedication to scientific research at the Academy is greatly appreciated.

\section{LITERATURE CITED}

Daniel, Thomas F. 2008. One Hundred and Fifty Years of Botany at the California Academy of Sciences (1853-2003). Proceedings of the California Academy of Sciences, ser. 4, 59(7):215-305.

Ewan, Joseph. 1955. San Francisco as a Mecca of Nineteenth Century Naturalists, with a Roster of Biographical References to Visitors and Residents Pages 1-63 in E.R. Babcock, J. W. Durham, and G. S. Myers., eds., A Century of Progress in the Natural Sciences 1853-1953. California Academy of Sciences. San Francisco, Califomia, U.S.A. 807 pp.

Leviton, Alan E., and Michele L. Aldrich. 1997. The California Academy of Sciences, 1853-1906. California Academy of Sciences. San Francisco, California, U.S.A. 623 pp.

Leviton, Alan E., Michele L. Aldrich, Gary C. Willams, and Peter U. Rodda. 2010. Geology at the California Academy of Sciences, 1853-1907. Proceedings of the California Academy of Sciences, ser. 4, 61(7):547-574.

Raby, Peter, 2001. Alfred Russel Wallace, A Life. Princeton University Press, Princeton, U.S.A. 340 pp.

McCosker, John E. 2007. The History of Research at the California Academy of Sciences' Steinhart Aquarium and Department of Aquatic Biology. Proceedings of the California Academy of Sciences, ser. 4, 58(11):171-196.

Slevin, Joseph Richard. 1959. The Galápagos Islands, A History of Their Exploration. Occasional Papers of the California Academy of Sciences 25:1-150. 
Slevin, Joseph R., and Alan E. Leviton. 1956. Holotype Specimens of Reptiles and Amphibians in the Collection of the California Academy of Sciences. Proceedings of the California Academy of Sciences, ser. 4, 28:529-560.

Williams, Gary C. 2007. History of Invertebrate Zoology at the California Academy of Sciences. Proceedings of the California Academy of Sciences, ser. 4, 58(12):197-239.

Gary C. Williams

January 1,2014 

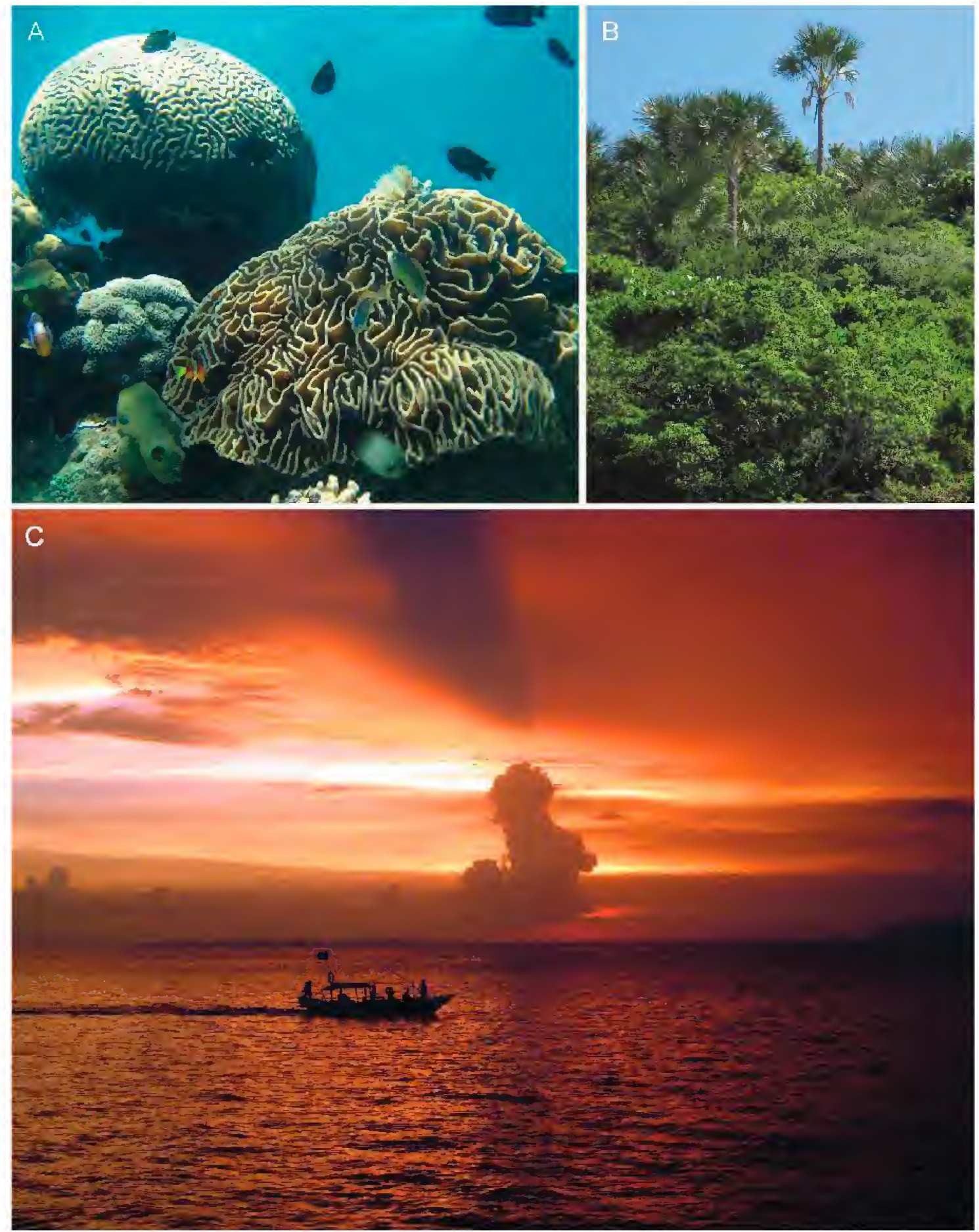

Figure 1. Southwestern Luzon, Philippines - region of the 2011 Hearst Philippine Biodiversity Expedition. A. Coral reef with the hard corals Pectinia lactuca (lower right) and Platygyra lamellina (upper left), Bethlehem dive site, Maricaban Island. B. Ridgetop vegetation with indigenous palms, southwestern coast of the Calumpan Peninsula. C. Sunset, Balayan Bay and the Verde Island Passage from the Calumpan Peninsula. Photos by G. C. Williams. 


\section{Index}

(Prepared by A. E. Leviton)

\section{A}

Abdophus .......................2244

Acabaria ... 72, 76, 98, 99, 173, 174, 179, 201, 209

Acalycigorgia .................. 77

Acalyptophis . 473, 486, 487, 491, 499, 501, 509, 528 peronii ..............4491, 509, 528 (see also as Hydrophis [Acalyptophis] peronii)

Acalyptus peronii ...............509, 528 Acanthaphritis ............251, 253, 254, 258 Acanthephyra ..............386, 387, 389 eximia ............386, 387, 389, 390 quadrispinosa .............. 387, 389 Acanthogorgia . . . . 73, 77, 101, 102, 201, 202, 209 truncata .................202,209

Acanthogorgiidae .............. 75, 77

Acanthomolgus ................. 81

Acasta . . 171, 172, 202, 203, 204, 205, 206, 207, 209

gregaria .................207, 209

hirsuta ................207, 209

purpurata ...............207, 209

vipensis . 171, 202, 203, 204, 205, 206, 207, 209

Acastinae ................ 172, 202, 207

Acritagasyllis ................... 145

Acropomatidae . . . . . . . . . . . . . . . 290

Acropora .................. 43, 44, 49

nobilis .................... 43

willisae .....................44

Acropora spp ......................557

Acupalpus sp. ................448, 462

Africa . . . 74, 75, 76, 77, 79, 80, 81, 82, 84, 85, 271,

$275,277,281,287,289,290,291,296,299,300$,

$385,388,389,392$

East Africa . . 74, 75, 76, 77, 281, 290, 296, 300 east coast .............. 385, 388, 392

Principé (Island) . . . . . . . . . . . 22

São Tome (Island) . . . . . . . . . . . 22

South Africa ...... 79, 80, 81, 82, 347, 348

southeastern Africa .............8 84, 85

Aglajidae .................... 351,381

Agonum muelleri ................448, 464

Ahaetulla ..................475, 528

Aipysurus ...........473, 485, 491, 500, 528

eydouxii ............4 485, 491, 500, 528

Alaria ...............4407, 410, 412, 419

Albatross (see U.S. Fish Commission Steamer Albatross)

Alcala, Angel $\ldots \ldots \ldots \ldots \ldots \ldots \ldots \ldots . \ldots 7$

Aldrovandia ..................271, 309 oleosa ........................271

phalacra ................2271,309

Alepocephalidae ....................2273

Alpheidae ..................... 388

Alpheus macroskeles ............ 386, 387, 388

Altagonum ...............448, 464, 465

sp. A . . . . . . . . . . . . . 448, 464

sp. B $\ldots \ldots \ldots \ldots \ldots \ldots \ldots 448,465$

sp. C $\ldots \ldots \ldots \ldots \ldots \ldots \ldots 448,465$

sp. D ................ 448, 465

American Museum of Natural History . . . . . . 531

American Samoas .................. 289

Amphioctopus . . . 46, 236, 237, 238, 239, 240, 243, 244, 245, 246, 247, 248, 249

marginatus .. 46, 236, 237, 238, 239, 240, 241, $243,244,245,246,247,248$

Analogium ..................... 134

Andaman Sea (see under Indian Ocean)

Andasta ............... 408, 409, 410, 412

cyclosina ..................4 408

Andrews, Roy Chapman . . . . . . . . . . . . 7

anemone ........................ 58

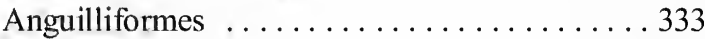

Angnis platura ................... 509

Annelida ....................... 145

Annella ................ 73, 75, 95, 96

mollis .................... 75,95

reticulata .............. 75, 95, 96

Antigonia ....................286, 321

capros .................... 286

malayana .................. 286

rubicunda ................286, 321

antipatharians ...........171, 172, 173

antivenom(s) ............... 476, 477

Aphanopora echinobrissoides ...........2231

Aphroditoidea ..................... 155

Apogonidae .................269, 291

Apristurus platyrhynchus ..........270, 307

Apterichtus klazingai ................ 339

Arachnida . ....................6. 63

Arachnoides placenta ................ 232

Arafura Sea ................283, 290, 294

Araneae ....................66, 63, 407

Arbaciidae .................... 218, 229

Arbacioida ................... 218, 229

Archaeobalanidae .............171, 173, 209

Archiacasta ..................... 207, 209

spinitergum ................207, 209

Arctic Ocean . . . . . . . . . . . . . . . . . 77 
Argentines ...................... 275

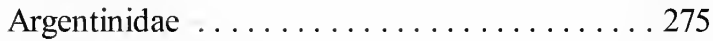

Argopatagus vitreus . ................ 234

Arhytinus minimus .............448, 465

Ariosoma anago .............. 272, 311

Aristaeidae ........................ 388

Aristaeopsis edwardsiana ........386, 387, 388

Aristeus virilis ................. 387, 388

Armored Searobins ................. 288

Armoreye dories ................. 286

Arnoglossus ..................297, 330

brunneus .....................297

elongatus . . . . . . . . . . . . . . . . . 297

japonicus ..................297, 330

oxyrhynchus ..............2929,330

Arothron immaculatus . . . . . . . . . . . . 300, 332

Aseraggodes .................. 298, 331

kobensis ..................298, 331

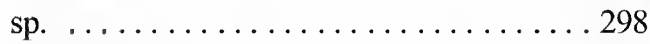

Asian vine-snakes . . . . . . . . . . . . . . . 475

Aspidodiadematidae ..............218, 229

Aspidodiadematoida .............. 218, 229

Aspis intestinalis . . .............. 493, 528

Astacidea ................... 385, 392

Asthenosoma ................. 215, 228

varium .................... 58

Astriclypeidae .............218, 231, 232

Astriclypeus manni ................231

Astrogorgia .......... 73, 78, 104, 105, 170

Astronesthes ...............274, 275, 313

chrysophekadion .................. 274

ijimai .....................2275, 313

lucifer ....................275, 313

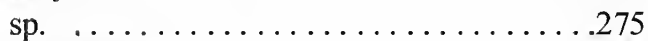

Astronesthidae ...................274

Astropyga .................220, 229

Astrotia . 473, 489, 490, 491, 499, 501, 502, 512, 528

stokesii ...............441, 512, 528

(see also as Hydrophis [Astrotia] stokesii)

Ateleopidae .....................285

Ateleopus japonicus . .............285, 320

Atlantic (Ocean) ...74, 81, 82, 83, 84, 85, 86, 273,

$276,277,286,295,388,389,392$

North Atlantic .................. 295

Western Atlantic . . . . . . . . . 74, 81

Aturia ...............501, 503, 508, 528

belcheri ................5503, 528

onnata ...................508,528

Australasian region ................ 427

Australia ... 74, 75, 78, 79, 80, 171, 201, 270, 271,

$272,275,277,279,280,281,282,283,285,286$,

$288,289,290,291,292,293,294,295,296,297$,
$298,299,300,347,348,349,352,379,381,388$, $389,392,500,501,503,504,505,508,509,510$, $511,512,514$

Australian Museum ............... 268

Great Barrier Reef ........ 74, 75, 76, 77

New South Wales ............... 388

northern Australia . . . 283, 288, 290, 292, 294, 296, 298

Northern Territory . . . . . . . . . . . 500

northwestern Australia . 171, 291, 292, 293, 297

Queensland ....................500

Victoria ....................... 389

Western Australia ... 270, 272, 279, 282, 283, $296,298,347,348,349,500$

Autolytinae .................. 145, 153

Autolytus triangulifer ............... 153

\section{B}

Baalzebub ............ 408, 409, 410, 412

Babilonia, Malou .................24, 36

Bajacalifornia erimoensis . . ........273, 312

Balanoidea ...................... 173

Balanomorpha ..................... 173

Balistidae ......................... 299

Barracudinas . . . . . . . . . . . . . . . . . 278

Barrel sponge ..................... 58

Bascanichthys myersi ................. 339

Batfishes ........................ 284

Bathyclupea..................293, 327

argentea ..................293,327

schroeder..................... 293

Bathyclupeidae .................... 293

Bathycongrus ...............273, 312

guttulatus ................273, 312

retrotinctus .................2273,312

Bathygadidae ....................2279

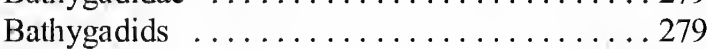

Bathygadus ....................2279, 315

Bathylagidae .................... 273

Bathynomus . . . . . . . . . . . . . . . 280

Bathynomus kensleyi ...........31, 61, 250

Bathypterois .............276, 313, 314

atricolor ...............276, 313

guentheri ...............276, 314

phenax .................... 276

Bay of Bengal .......299, 506, 507, 510,514

Bembidini ................. 447, 450

Bembrops .................... 294, 328

caudimacula ..............2294, 328

curvatura .......................... 294

nelsoni ....................294, 328

Benthenchelys cartieri ................. 339 
Benthosema fibulatum ..............2276

Bigeyes ......................... 291

Biodiversity inventory . . . . . . . 395, 397, 404

Bismarck Archipelago . . . . . . . . 67, 86, 89

black corals ................... 171

Blackchins . .................... 276

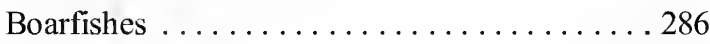

Boiga ..................... 475, 528

Bolinichthys...............276, 278

distofax ...................276

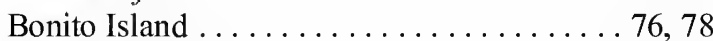

boomslang ...................... 475

Borneo ...................... . 70, 270

Brachinus sp. ...............4450, 472

Brachysomophis ..............334, 339

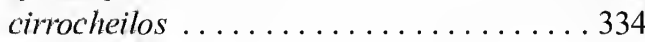

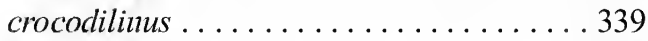

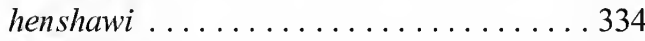

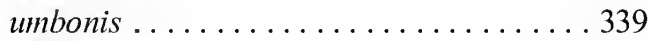

Branchiopsaron .................... 254

Brandegee, Mary . . . . . . . . . . . . . 565

Bregmaceros japonicus . ........... 279, 315

Bregmacerotidae ....................2 279

Brentidae ..........................6 64

Breynia elegans ................... 234

Briareum ............ 72, 74, 89, 91, 92

Brissalius vannoordenburgi . ..........2233

Brissidae ....................218, 233

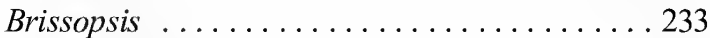

luzonica ....................233

micropetala ................... 233

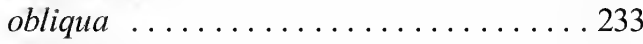

oldhami ..................... 233

similis ......................233

Brissus ........................2233

agassizii ....................233

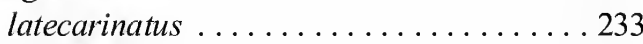

meridionalis .................233

Bristlemouths . . . . . . . . . . . . . 273

brittlestars ..................213, 214

Brotulas ....................... 282

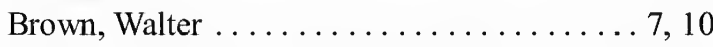

bryophytes $30,395,396,398,400,401,402,403,404$

Bulla aperta ................... 355

Bungarus wanghaotingi .......... 475, 528

\section{C}

Calamaria

475,528

lumbricoidea ....................4 475

California Academy of Sciences 7, 9, 19, 20, 22, 23, $28,34,39,43,44,45,47,51,53,55,56,67,71,72$, $86,125,129,130,131,145,146,148,153,155$,
$156,157,165,166,213,217,237,239,246,247$, $249,251,258,260,263,264,269,333,334,337$, $339,341,342,348,351,352,353,385,427,429$, $445,450,531,539,546,560,561,562,564,565$

Galápagos Expedition ............ 53

Steinhart Aquarium . . . 7, 23, 27, 29, 39, 41, 42, $44,45,46,47,51,237,239,241,242,243$, $244,245,246,249$

Summer Systematics Institute $\ldots . \ldots \ldots 23$

Teacher and Youth Education Department . . . 7

Callechelys ...................... 334

catostoma ....................... 334

marmorata ....................... 334

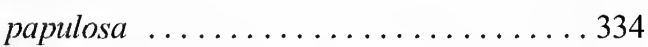

Callionymidae ....................... 296

Callionymus (Calliurichthys) japonicus . . . . . 296

Calliophis .....473, 475, 476, 477, 481, 482, 491, 493, 494, 495, 528

bilineata .......... 482, 491, 493, 528

bilineatus .................493, 528

calligaster .........477, 491, 495, 528

calligaster ..........4491, 495, 528

gemianulis .........4 491, 495, 528

meclungi ..........4491, 495, 528

intestinalis .............477, 491, 528

philippina ...........482, 491, 494, 528

suluensis .........4482, 491, 494, 528

Calliurichthys .................... 296

(see also Callionymus (Calliurichthys))

Callophis ......................... . 494

intentinalis suluensis . . . . . . . . . . . 494

intestinalis var. Philippina . . . . . . . . . 494

Camarodonta ............218, 229, 230, 231

camarodonts .............213, 217, 220

Cantherhines sp. ................... 299

Caproidae ...................... 286

carabid beetles ....445, 447, 449, 451, 453, 454, $455,457,459,461,463,465,467,469,471$

Carabidae ..................... 445

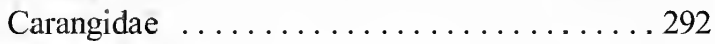

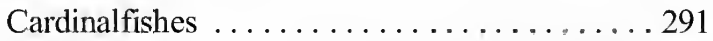

Caribbean ........39, 44, 45, 293, 359, 363, 379

Caribbean Sea ......74, 293, 388, 389, 392, 393

Caridea .................................. 388

Carideans ............................ 385

Cassidulidae ...............218, 231

Cassiduloida .................218, 231

Cat sharks ....................... 270

cat-eyed snakes . . . . . . . . . . . . . . . 475

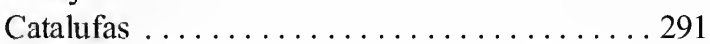

Caterpillar ........................6 64

Cavernulina ............. 72, 84, 124, 128 
cf. cylindrica ........... 84, 124, 128

Cenozoic .............................

centipede ..................... 533

Centipede ......................63

Cephalaspidea ...........................

Cephalopholis aurantia ...........290,325

Cephaloscyllium ................270, 308

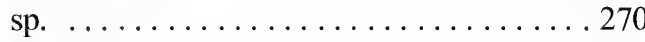

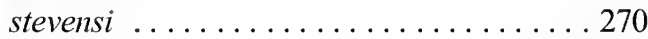

Cerberus ...................475, 528

Chaetodiadema ..............220,221, 229

granulatum ............220, 221, 229

Challenger Expedition ............... 165

Champsodon ........................293

atridorsalis ..................... 293

guentheri .......................293

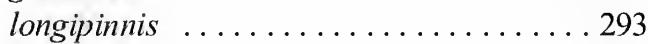

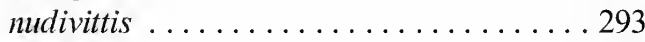

vorax ........................ 293

Champsodontidae ...................293

Chaunacidae .....................283

Chaunacops ....................283

cf. coloratus .................283

Chaunax ............283, 284, 318, 319

sp. $1 \ldots \ldots \ldots \ldots \ldots \ldots \ldots 283,318$

sp. $2 \ldots \ldots \ldots \ldots \ldots \ldots \ldots 284,319$

Chesterfield Islands $\ldots \ldots \ldots \ldots \ldots \ldots \ldots \ldots \ldots$

Chicago (Illinois) ................... 25

Chicago Shell Club .............. 25

Field Museum (of Natural History) . . . 25, 35

Shedd Aquarium . . . . . . . . . . . . . . . 25

Chilopoda ...........................6. 63

Chimaeridae .....................2270

China .....201, 202, 263, 270, 272, 274, 275, 276,

$277,280,281,282,283,285,286,287,288,289$,

296, 298, 299, 408, 419, 485, 497, 500, 502, 503, $504,505,506,507,508,509,511,512,513,515$

Hong Kong $\ldots \ldots \ldots \ldots \ldots \ldots 286,291$

Hunan Normal University, Changsha . . . . 408

Yunnan Province ................. 419

Chironephthya sp. .................6 60

Chlaeniini ..................... 447

Chlaenius ..............447, 448, 461, 462

(Haplochlaenius) sp. A ..........447, 461

(Haplochlaenius) sp. B ..........447, 461

(Lissauchenius) sp. ...........448, 462

Chlorophthalmidae .................276

Chlorophthalmus ................276, 313

acutifions..................276, 313

albatrossis ....................... 276

Chocolate Chip Starfish . . . . . . . . . . 243, 248

Chrionema chlorotaenia ............ 294, 328
Chromodoris magnifica ..............558

Chrysopelea ................475, 528

Chthonopes ............407, 409, 410, 412

Chthonos .....................4 408, 410

Cicada ...........................6 64

Cicadidae $\ldots \ldots \ldots \ldots \ldots \ldots \ldots \ldots 64$

Cicindelini .................. 445, 447

Cidaridae ................218, 227, 228

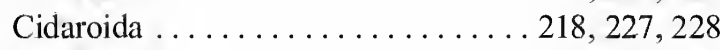

cidaroids $\ldots \ldots \ldots \ldots \ldots \ldots \ldots \ldots \ldots \ldots \ldots \ldots \ldots \ldots, 213,217,218$

Cirrhimuraena .......................... 339

chinensis ........................ 339

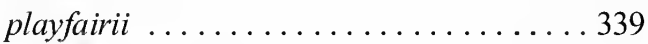

Cirripedia ..................171, 173

CITES (Convention on International Trade in Endangered Species of Wild Fauna and Flora) . . . . 4 47

Citharidae .......................296

Citharids .......................296

Citharoides macrolepidotus .........296, 329

Clathraria ........................ 76

Clivina sp. ................... 447, 459

Clivinini ........................447

Clypeaster ..................212, 232

annandalei ................... 232

fervens ..................... 232

humilis ..................... 232

latissimus .................. 232

pateriformis .................. 232

reticulatus ...............212, 232

virescens ....................... 232

Clypeasteridae ................. 218, 232

Clypeasteroida ..........218, 231, 232, 233

Cnidaria ..........................6 67

Anthozoa ....................667 67

Octocorallia ................667,84

cobra venom .................5534, 536

cobras ...........473, 481, 496, 513, 530

Coconut Octopus(es) (see also Octopus) . . 46, 237, $238,239,240,241,242,243,244,248$

Coddingtonia ...407, 408, 409, 410, 412, 413, 419, $420,421,422,423,424$

anaktakun ..... 407, 408, 413, 419, 420, 421, 422,423

discobulbus ......4407, 419, 422, 423, 424

euryopoides ............419, 422, 423

Codlets ..........................279

Coelorinchus ...................280, 316

acantholepis ..............280, 316

carinifer .................280, 316

kishinouyei .................280

smithi ...................280, 316

Coleolissus ..............448, 462, 463 
sp. A $\ldots \ldots \ldots \ldots \ldots \ldots \ldots 448,462$

sp. B . . . . . . . . . . . 4 448, 463

sp. C ................. 448, 463

sp. D . . . . . . . . . . . . . 448, 463

Coleoptera ..................64, 445

Collyridini ..................... 446

Coloconger scholesi .............. 272, 311

Colocongridae .................... 272

Colpodes ....................448, 466

sp. A ................ 448, 466

sp. B ................ 448, 466

Coluber .....................496, 514

laticaudatus ..................... 514

naja .......................... 496

Colubridae ................... 475,528

Commensal shrimp ................45, 46

Conger.....................272, 311

macrocephalus .............272,311

philippinus ..................272

Conger eels ....................272

Congridae ..................269, 272

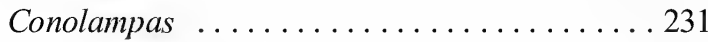

diomedeae .....................231

malayana .................... 231

murrayana .................. 231

Conopea . . 171, 172, 173, 175, 176, 177, 178, 179,

$180,181,182,183,184,185,186,187,188,189$, $190,191,192,193,194,196,197,198,199,200$, 207, 209

acuta ..............171, 196, 200, 201

arcuata ...................... 209

basicuneata .... 171, 192, 193, 194, 196, 200, 201, 207, 209

calceola ......................207

canaliculatus ............171, 201, 209

cornuta ...............171, 200, 209

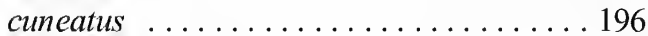

cymbiformis .................. 172

dentifer ..............171,202, 209

exothobasis ....171, 196, 197, 198, 199, 200, 201, 207, 209

fidelis ........................ 209

fragilis .............. 171, 202, 209

investita ........171, 196, 200, 202, 209

longibasis .............171, 201, 209

margaretae ....171, 177, 183, 184, 185, 186, 187, 190, 201, 207, 209

minyrostrum . . . 171, 187, 188, 189, 190, 191, $200,207,209$

mjobergi............172, 196, 200, 201

mjoebergi ...................209

proripiens ...... 172, 177, 187, 190, 201, 209 pygmaea .............172, 202, 209

sabangensis .... 171, 177, 179, 180, 181, 182,

$183,201,207,209$

saotomensis . . . . . . . . . . . . . . 209

scandens ............. 172, 201, 209

squamosa ..............172, 202, 209

willhearsti .....171, 173, 175, 176, 177, 178,

183, 190, 201, 207, 209

Conservation ....539, 540, 542, 546, 547, 548, 549, $550,560,561,562,563,564$

conservation biology . . . . . . . . . . . 396

Conservation International . . . . . . . 30,35

Coral reef ....................... . 567

Coral Restoration Foundation . . . . . . . . . 39, 40

coral snakes ...........473, 481, 524, 530

corals (partial listing) ...26, 29, 30, 39, 40, 43, 44,

$45,47,49,50,67,69,70,71,89,90$

coral larvae .................. 43

coral planula . . . . . . . . . . . . . 43

hard corals . .............67, 70,567

hermatypic corals ............. 70

octocoral(s) ...660,67, 70, 71, 72, 86, 89, 90 , $171,173,209$

Scleraxonian gorgonian $\ldots \ldots \ldots 660$

soft corals .............39, 45, 47, 67

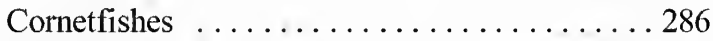

Coryphaenoides ..............280, 316

macrolophus .................281

marginatus ....................281

microps ................280, 316

semiscaber .....................281

tydemani .......................281

Corystus ........................2233

Corystusidae ................218, 233

Cosmodiscus cf. brunneus .........447, 460

Crangon shrimp ................... 244

Crangonidae ........................ 388

Craniata .......................... 341

Crocodile Toothfishes . . . . . . . . . . . . . 293

Crotalinae ..............4473, 515, 528

Crotalus scutellatus ............. 475, 528

crustaceans . ..................... 30

Ctenocella ................882, 201,209

Cubiceps whiteleggii ..............296, 329

Curculionidae ....................6. 64

Cusk-Eels . . . . . . . . . . . . . . . . . . . . 282

Cutthroat eels .................... 271

Cylindera....................444, 459

(Conidera) mandibularis ........4447,459

(Ifasina) viduata ............. 447, 459

Cynoglossidae . . . . . . . . . . . . . . . . . . 298

Cynoglossus . ................298, 299, 331 
abbreviatus ....................299

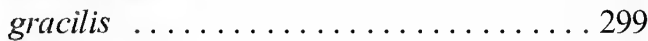

cf. gracilis ................... 298

mccullochi ....................299

microlepis .................... 299

sp. ...................... 299

\section{D}

Dactyloptena .................. 289, 324

orientalis ................289, 324

tiltoni ..................... 289, 324

Dactylopteridae ...................289

De La Salle University . . . . . . . . . . 12, 39, 45

Decapoda ....................... 388

Decapterus kurroides ............292, 327

Deep-sea smelts . . . . . . . . . . . . . . 273

Deepsea herrings . ................. 293

Deepwater Cardinalfishes . . . . . . . . . . . . 291

Dendrocellus coelestinus ..........4450,472

Desmechinus ......................231

rufis $\ldots \ldots \ldots \ldots \ldots \ldots \ldots \ldots 231$

versicolor ........................231

Diadema ................... 214, 220, 229

Diadematidae .................218,229

Diadematoida ..................218, 229

diadematoids . . . . . . . . . . . . . . . . . . 213

Diaphus ..................277, 278, 314

adenomus ................277, 314

elucens ......................277

fragilis .................277, 314

garmani ....................277

gigas ........................ 277

perspicillatus ..............277, 278

sp. ...................... 277, 278

suborbitalis ..............277, 314

watasei ..................277, 314

Dibranchus sp. ...................284

Dichotella ...... 74, 81, 120, 123, 192, 201, 209 gemmacea ...........81, 120, 123, 192

Dicraspeda brunnea . . . . . . . . . . . 449, 469

Dicrolene tristis . .................. 282

dinoflagellates .................. 71, 90

Dispholidus typus ..............475, 528

Disteira ..........473, 491, 501, 510, 528

cyanocincta ............... 491, 528

cyanosoma ................ 491, 528

ornata ................. 491, 528

schistosa ............4491, 510, 528

Distira annandalei .............. 502,528

Distorsio sp. . . . . . . . . . . . . . . . . . . . 384

DNA .................. 34, 353, 354, 363

Dogfish sharks .................270
Dolichoctis ...............444, 470, 471

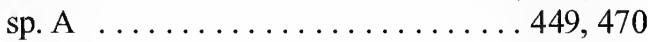

sp. B ............... 449, 470

sp. C $\ldots \ldots \ldots \ldots \ldots \ldots \ldots$ 449, 471

sp. D .................449, 471

Dolichosudis ...................... 278

Doliophis .................. 491, 528

bilineatus .................491, 528

philippinus ................491, 528

Dorid nudibranch $\ldots \ldots \ldots \ldots \ldots \ldots \ldots 58$

Doridicola .......................... 81

Dragonets .........................296

Driftfishes ........................ 296

drugs ..................... 532, 535

atropine $\ldots \ldots \ldots \ldots \ldots \ldots \ldots \ldots 532$

glycopyrrolate ................. 532

midazolam .................. 532

mivacurium .............. 534, 535

neostigmine $\ldots \ldots \ldots \ldots 532,534,535,536$

Duckbills ....................... 294

Dysomma anguillare ...........271, 310

\section{$\mathbf{E}$}

East Africa (see under Africa)

East China Sea .... 270, 274, 276, 277, 281, 283, $285,288,289,296,348$

Eastwood, Alice ................... 565

Ebosia bleekeri ...............286, 321

Echinocardium cordatum .............2234

Echinocyamidae ..............218, 232

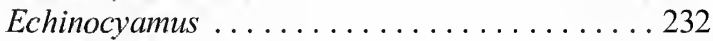

crispus .................... 232

megapetalus ..................232

provectus ................... 232

scaber ......................... 232

Echinodermata ...................2213

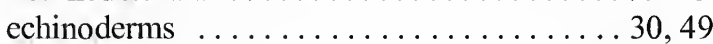

Echinodiscus ....................231, 232

auritus ......................2231

bisperforatus ................ 232

tenuissimus ................. 232

Echinogorgia .....73, 78, 80, 106, 107, 201, 209

Echinoidea .........213, 215, 216, 218, 226

echinoids .....213, 214, 215, 217, 218, 219, 220, 222, 223, 228, 233

Echinolampadidae .............218, 231

Echinolampadoida ..............218,231

Echinolampas ......................2231

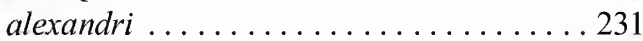

chuni .....................2231

ovata ......................231

sternopetala ..................231 
Echinonetra ............. . 214, 215, 229 mathaei .................. 215, 229

Echinometridae ............ 218, 229, 230

Echinomuricea . . . . . . 73, 78, 79, 80, 106, 108

Echinoneidae ............... . 218, 231

Echinoneoida ............... 218, 231

Echinoneus cyclostomus . . . . . . . . . . 231

Echinostrephus ................. . 230

aciculatus ................. 230

molaris .................... 230

Echinothrix .............. 215, 220, 229

Echinothuriidae . . . . . . . . . . . 218, 228

Echinothurioida . . . . . . . . . . . . . 218, 228

echinothurioids ............213, 214, 215

Ectreposebastes imus . . . . . . . . . . 286, 321

Ecuador . . . . . . . . . . . . . . . . . . . . . 348, 349

Galápagos (also as Galapagos) Islands . . . 22, $53,347,348,349,565$

San Cristobal Island . . . . . . . . . . 348

Galápagos Expedition (see under California Academy of Sciences)

Educational outreach (see under Hearst Philippine

Biodiversity Expedition)

Egadroma (see Stenolophus (Egadroma)) . . . . 462

Elaphropus (Tachyura) ceylonicus . . . . . 447, 459

Elapidae ....... 473, 475, 481, 493, 513, 528

Elapinae ............ . 473, 493, 513, 528

Elaps calligaster . . . . . . . . . 494, 495, 528

Ellisella .... 74, 82, 121, 123, 183, 192, 193, 196, 201, 209

sp. . . . . . 121, 123, 183, 192, 193, 196

ssp. . . . . . . . . . . . . . 82

Ellisellidae . . . . . . 171, 187, 188, 192, 207, 209

Emydocephalus ....... 473, 486, 491, 501, 528 annulatus ..........446, 491, 501, 528

Enalcyonium ................. 81

Enhydrina .... . 473, 479, 486, 487, 491, 501, 502, $510,511,528$

schistosa ............ 491, 510, 528 (see also as Hydrophis [Enhydrina] schistosus)

Enhydris .................475

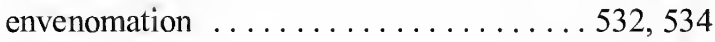

Epeirotypinae ............4408, 409, 412

Epeirotypus ................4408,410

Ephalophis greyi . . . . . . . . . . . . . . 500, 528

Epigamia .................. 145, 147

alexandri .................. 147

magna ...................... 147

Epigonidae ... . . . . . . . . . . . . . . . . 291

Epigonus ctenolepis . . . . . . . . . . . . 291, 326

Epilineutes .............. 408, 409, 410, 412

Epinephelus . . . . . . . . . . . . . . . . 290, 325 areolatus ................ 290, 325

fasciatus ................... 290

Eptatretus . . . 270, 307, 341, 342, 343, 344, 345,

$346,347,348,349$

chinensis .................. 347

fernholmi ....... 270, 341, 342, 343, 347

gomoni . . . . . . . . . . . . . . . 347, 348

indrambaryai . . . . . . . . . . . . 347, 348

luzonica .............. . . . 342, 343

luzonicus . . . . . 270, 307, 341, 342, 343, 344, $345,346,347,348$

mccoskeri .............. 347, 348

octatrema . . . . . . . . . . . . . 347, 348

okinoseanus . . . . . . . . . . 347, 348

strahani ............ . 347, 348, 349

wisneri . . . . . . . . . . . . . . . . 347, 349

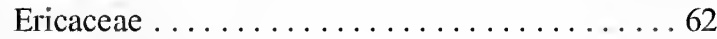

Erisphex ariarus . . . . . . . . . . . . . 287

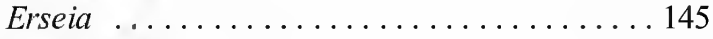

Erythrhacini . . . . . . . . . . . . . . . . . . . . 429

Escolars . . . . . . . . . . . . . . . . . . . . . 296

Etmopterus brachyurus . . . . . . . . . . 270, 308

Euacasta microforamina . . . . . . . . . 207, 209

Eucidaris metularia . . . . . . . . . . 222, 227

Eunicella ..................... 207, 209

kochi ..................... 209

verrucosa . . . . . . . . . . . . . . . . 207

Eupatagidae . . . . . . . . . . . . 218, 233

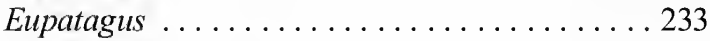

lymani ................... 233

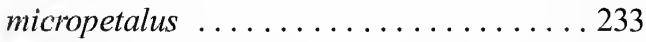

rubellus ..................... 233

Euplexaura .... . 73, 79, 80, 83, 109, 110, 207, 209

Eurypatagidae ................218, 234

Eurypatagus ovalis . . . . . . . . . . . . . . . 234

Eustra cf. hammondi . . . . . . . . . . . . 446, 456

\section{F}

Faorina chinensis . . . . . . . . . . . . . 235

Faroe Islands . . . . . . . . . . . . . . . . . . . . . . . . . . . . . . . . . . . 287

Fathead Sculpins . . . . . . . . . . . . . . . . . . . . 289

Feather Stars . . . . . . . . . . . . . . . . . . . 45

Fernandina Island . . . . . . . . . . . . . . . . . . 349

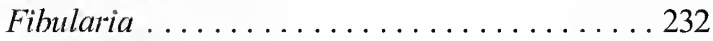

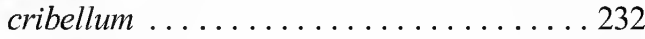

ovulum ................... . 232

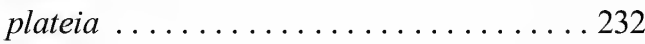

Fibulariella ................... 232

acuta .................. 232

angulipora ................ 232

volva ................... 232

Fibulariidae ............... 218, 232 
Fiji $\ldots \ldots \ldots \ldots 77,283,295,299,388,389,392$

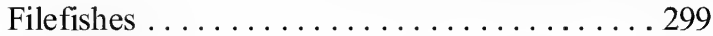

Fire Urchin

.58

fish $\ldots \ldots \ldots 22,23,29,30,251,263,333,341$

Fishery Researcher I (Taiwan fishery vessel) . . 268

Fistularia petimba .............286, 321

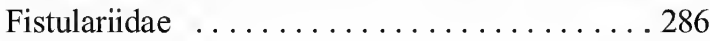

Flatfish .......................45

Flatheads ........................ 289

Florida . . . . . . . . . . . . . . . . . . . . 74

Florida Aquarium ................. 241, 249

Flying Gurnards . . . . . . . . . . . . . . . . . 289

Footballfishes ...................285

Formosa (see also Taiwan) .......... 70, 281

France ........................ 147

\section{G}

Gadomus .................279, 280, 315

colletti .....................2279

denticulatus ....................2279

multifilis ...............280, 315

Galápagos (see under Ecuador)

Gastragonum sp. ...............448, 466

Gecko gecko .........................665 65

Gemplylidae ........................ 296

Genyagnus monopterygius . . . . . . . . . . 295

Ghost Flatheads . . . . . . . . . . . . . . . . 289

Glossanodon sp. . .................. 275

Glyphocrangon ............. 386, 387, 388

gilesii ...................... 388

proxima ..............386, 387, 388

Glyphocrangonidae .................. 388

Glyphus marsupialis .............386, 389

Glyptophidium ...............282, 317

japonicum ...............282, 317

lucidum .....................282, 317

Gnathophausia zoea ............... 386, 388

Goatfishes . . . . . . . . . . . . . . . . . . . . 292

Gobies .......................... 295

Gobiidae ...................269, 295

goblin spider . .................... 30

Gonocephalus sophiae ..............665 65

Gonostomatidae .................. 273

Google Earth . . . . . . . . . . . . . . . . 397

Goosefishes .................. 283

Gorgonian(s) . . . 67, 70, 71, 72, 74, 75, 81, 83, 89, $90,113,123,171,172,200,201,202,203,207$, 209

Gorgoniidae

$81,207,209$

Greeneyes .........................2276

Grenadiers ....................... 280

Grideye Spiderfishes . . . . . . . . . . . . . 276
Gulf of Aden . . . . . . . . . . . . . . . 295

Gulf of Mexico . . 293, 359, 363, 388, 389, 392, 393

Gulf of Siam . . . . . . . . . . . . . . . . . . 509

Gulf of Thailand $\ldots \ldots \ldots \ldots \ldots \ldots \ldots 251$

Gulf of Tonkin . .................. 297

Gymnechinus epistichus . .............2231

Gymnodorididae ............... 129, 131

Gymnodoridinae ................... 129

Gymnodoris . . . . 129, 130, 131, 132, 133, 134, 135,

$136,137,138,139,140,141,142,143,144$

alba .................... 129, 138

aurita ................... 137, 138

brunnea ... 129, 131, 132, 133, 134, 135, 138, $140,141,142,143$

ceylonica ................ 138, 144

citrina ...................... 134

inariensis ................... 130

inornata .................... 138

marginata .................... 135

pattani ...................... 130

pseudobrunnea ..... 129, 135, 138, 139, 140, $141,142,143$

striata .................... 129

tuberculosa ....129,133, 135, 136, 137, 138

Gymnopatagus magnus .............. 234

Gymnothorax.................271, 309

albomaculatus .................2271

elegans .....................271

isingteena ..................271

johnsoni ....................271

cf. johnsoni ..............271, 309

cf. nuttingi ...............271, 309

punctatus ....................2271

\section{H}

hagfish .................. 341, 342, 348

Halicmetus sp. . . . . . . . . . . . . . . . . 284

Halieutaea ....................... 284, 319

sp. . . . . . . . . . . . . . . ... 284

cf. stellata . . . . . . . . . . 284, 319

Halieutopsis ...............284, 319, 320

sp. $1 \ldots \ldots \ldots \ldots \ldots \ldots \ldots \ldots$. . . . 284, 319

sp. $2 \ldots \ldots \ldots \ldots \ldots \ldots \ldots \ldots 284,320$

vermicularis $\ldots \ldots \ldots \ldots \ldots \ldots 284$

Halimeda . . . . . . . . . . . . . . . . . . 372

incrasita ................... 372

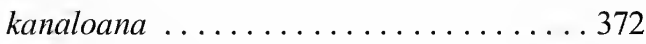

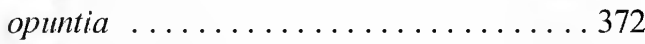

Haliporoides sibogae .............386, 390

Halosauridae . . . . . . . . . . . . . . . . . . 271

Halosaurs ....................... 271

Hamadryas .................. 497, 528 
elaps 497,528

hannah 497,528

Haplochlaenius (see Chaerius (Haplochlaenius)) 461

Haplorhacus . . . . . . . . . . . . . . . 428

Harpalinae . . . . . . . . . . . . . . . . . . . . 450

Harpalini . . . . . . . . . . . . . . . . . . . . . . . . . 448

Hawai'ian Islands (also as Hawaiian Islands) . . . . .

$271,272,275,286,290,351,352,353,372,510$

Hawai'i (also as Hawaii) . . . 76, 162, 271, 275, $277,281,287,288,289,290,372,385,389$

Maui .......... 354, 356, 372

Airport Beach ......... 372

Black Rock ... . . . 354, 356, 372

Makena Landing . . . . . . . . 356, 372

Hazeus . . . . . . . . . . . . . . . . . . . . . . . . 295, 329

Hearst, Will and Margaret (also as Margaret and Will

Hearst, William and Margaret Hearst, William Randolph and Margaret Hearst) . . . . 22, 36, 39, $45,223,241,330,336,360,405,432,450,540$, 550,565

Hearst Philippine Biodiversity Expedition (also as 2011 Hearst Philippine Biodiversity Expedition, Hearst Biodiversity Expedition, Hearst Biodiversity Expedition to the Philippines, Hearst Expedition, Hearst Philippine Expedition, Hearst Philippines Biodiversity Expedition, Philippine[s] Biodiversity Expedition) . . . . 7, 19, 20, 21, 27, 35, 36, $39,41,43,45,47,49,51,53,129,131,148,155$, $156,165,166,213,216,217,219,223,226,263$, $341,342,346,347,348,352,360,427,432,445$, $446,479,531,539,565,567$

Educational outreach . 539, 540, 541, 542, 544, $545,547,550,560$

heart urchins ...........214, 217, 220, 223

Heliopora . . . . . . . . . . . . . . . . 70

Hemerocoetes . . . . . . . . . . . . . . . . . 253

Hemerocoetinae . . . . . . . . . . . 251, 252, 258

Hemerorhinus heyningi . . . . . . . . . . . . . . . . 334

Hemiasteridae . . . . . . . . . . . . . . . 218, 234

Hemibungarus . . . . 473, 475, 476, 477, 481, 482, $491,493,494,495,528$

calligaster . . . . . . 482, 491, 495, 528

gemianulis . . . . . . . 482, 491, 495, 528

mcclungi ..........4482, 491, 495, 528

Hemigrapsus . . . . . . . . . . . . . . . . . . . . . . 244

Heptodonta melanopyga . . . . . . . . . 4 . . . . . . . . . 277,457

Herring smelts . . . . . . . . . . . . . . . . 275

Heterobranchia . . . . . . . . . . . . . . . . . . . . . 129

Heterobrissus niasicus . . . . . . . . . . . . 235

Heterocarpoides . . . . . . . . . . . . 386, 389

levicarina ................... 389

woodmasoni ................ 386
Heterocarpus . . . . . . . . . 386, 387, 389, 390, 391 dorsalis . . . . . . 386, 387, 389, 390, 391 gibbosus . . . . . . . . . 386, 387, 389, 390 sibogae ........... 386, 389, 390, 391 woodmasoni .............. 386, 389

Heterocentrotus . . . . . . . . . . . . . . . . 230

mamillatus ................. 230

trigonarius ............... 230

Heterodactyla hemprichii . . . . . . . . . . . . . . 49

Heteropoda sp. . . . . . . . . . . . . . . . . . . . . . . . . . . . . . . . . . .

Hexatrygon bickelli . . . . . . . . . . . . . 271, 309

Hexatrygonidae . . . . . . . . . . . . . . . 271

Himantolophidae . . . . . . . . . . . . . . . . . . . 285

Himantolophus appelii . . . . . . . . . . . . . . 285

Hippocampus . . . . . . . . . . . . . 44, 75, 77

bargibanti ............444, 75, 77

denise ................ 75

Histocidaridae . . . . . . . . . . . . . 218, 228

Holanthus expergitus . . . . . . . . . . . . . . . 234

Holasteroida . . . . . . . . . . . . . . . 218, 233

Holocentridae ... . . . . . . . . . . . . . . . 286

Homolampas lovenioides . . . . . . . . . . . . . . 234

Homoptera . . . . . . . . . . . . . . . . . . 64

Hoplichthyidae . . . . . . . . . . . . . . . . . . . 289

Hoplichthys langsdorfi . . . . . . . . . . 28 289, 324

Hoplobrotula armata . . . . . . . . 282, 317

Hoplostethus . . . . . . . . . . . 285, 320

elanopterus ............. 285, 320

ravurictus .................. 285

sp. . . . . . . . . . . . . . . . . 285

hornworts . . . . . . . . . . . . 395, 402

Husbandry . . . . . . . . . . . . 237, 239, 249

Hyclrelaps darwiniensis . . . . . . . . . . . . 500

hydrocoral .................... 70

Hydrolagus deani . . . . . . . . . . . . 270, 307

Hydrophiinae . . . . . 473, 475, 499, 500, 513, 528

Hydrophis . . . . 473, 479, 485, 486, 487, 488, 489, $490,491,499,501,502,503,504,505,506,507$, $508,509,510,511,512,528,547$

atriceps . . 485, 486, 488, 489, 491, 503, 528 belcheri ........ 4. 488, 491, 503, 528

brookii ........... . 486, 491, 504, 528 caerulescens ...........4488, 491, 528 coggeri..............503, 504, 528 curtus . . . . . . . . . . . . 485, 491, 528 cyanocinctus $487,488,489,491,505,506,528$ fasciatus . . . . . . . . . . 491, 503, 528 atriceps ............. 503, 528

gracilis ....... 4 487, 489, 491, 506, 528

inornatus . . . . . . . . . . 491, 506, 528

klossi ...........4488, 491, 507, 528

lamberti . . . . . . . . 487, 491, 507, 528 
melanocephalus . .......488, 491, 508, 528 ornatus . 488, 489, 491, 506, 507, 508, 509, 528 ornatus ..............508,528 pacificus ................503, 528 semperi ........448, 491, 511, 528, 547 spiralis ......... 488, 489, 491, 511, 528 sublaevis var. melanocephalus ........508 [Acalyptophis] peronii ....... 486, 487, 509 [Astrotia] stokesii .........489, 490, 512 [Enhydrina] schistosus . . . 486, 487, 510, 511 $[$ Kerilia $]$ jerdoni . ............486, 507 [Kolpophis] annandalei .........486, 502 [Lapemis] curtus . . . 4 485, 489, 490, 504, 505 [Pelamis] platurus ......... 490, 509, 510 [Praescutata $]$ viperina . . . . . . . . . 486 [Praescutata] viperinus . . . ........5512 [Thalassophis] anomalus .......4486, 502 Hydrus ...............506, 511, 512, 513 colubrinus .................. 513 gracilis .....................506

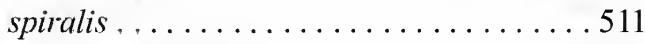
Hygophum proximum . . . . . . . . . . . 278

Hymenocephalus ...............281, 317 lethonemus ....................281 nascens .................2281, 317 striatissimus ................281 torvus $\ldots \ldots \ldots \ldots \ldots \ldots \ldots 281$

Hymenopenaeus propinquus . . . . . . . 387, 388 Hypselaster affinis ................. 235

\section{I}

Ichthyscopus ...................295

Ifasina (see Cylindera (Ifasina)) . ........4459 Ilodesmus . . . . 427, 428, 429, 430, 436, 437, 438, $439,440,441,442,443,444$

bakeri .................... 431 margaritiferus ... 427, 428, 429, 430, 431, 432, $436,437,438,439,440,441,442,443,444$

meyenii .................428, 430 Imajimaea ................. 145, 147 India . 78, 79, 172, 217, 505, 507, 511, 512, 534, 535 Indian Ocean . . . . 55, 56, 75, 77, 78, 81, 82, 83, 85, $157,160,219,271,272,276,277,280,281,283$, $286,287,288,289,290,291,292,294,295,296$, $298,348,385,388,389,392$

Andaman Islands . . . . . . . . . . 285 Andaman Sea . . . 286, 291, 348, 388, 389, 392 eastern Indian Ocean . . . . . . 272, 290, 292, 298 Eastem Indian Ocean . . . . . . . . 75, 82, 348 Rodriguez ................... 157 western Indian Ocean . . . . . . . . 78, 81, 83 Indo-Australian Archipelago . . . . . . . . . 287, 297
Indo-Malayan (Malaysian) region . . . . . . . 427 Indo-Pacific . . . . 71, 74, 75, 76, 77, 78, 82, 83, 86, $129,155,213,216,218,220,351,352,353,371$, 379,381

Tropical Indo-Pacific . . . . . . . . 351, 379 Indo-West Pacific 74, 75, 76, 77, 78, 79, 80, 81, $82,83,84,85,237$

Indonesia . . 67, 70, 74, 75, 76, 77, 78, 79, 80, 81, 85, $86,89,90,136,168,171,172,200,201,202,217$, $272,274,275,279,280,281,282,283,286,288$, 290, 291, 292, 293, 294, 295, 296, 298, 299, 300, $333,388,389,392,493,497,500,501,502,503$, $504,505,506,507,509,510,511,512,514,519$

Amboina Bay . . ............... 202

Bali .............. 70,86, 287, 294

Bali Straits . . . . . . . . . . . . . . . . 287

Belitung ..................... 519

Borneo (see under Borneo)

Buton ....................... 519

Celebes ...................... 70

Halmahera ...................... 389

Halmahera Sea . . . . . . . . . . . . . 287

Irian ...................... 501

Java $\ldots \ldots \ldots \ldots \ldots 493,500,502,514$

Java Sea .................... 297

Kalimantan ...............502, 519

Lombok . . . . . . . . . . . . . . . . . . . . 70

Madura ........................ 297

Moluccas ..................... 502

New Guinea (see separate listing; also see Irian above)

Raja Ampat ................... 136

Sangihe Archipelago . . . . . . . . . . . . . 519

Savu Sea . . . . . . . . . . . . . . . . . 287

Sulawesi .................70,519

Sumatra ..............497, 507, 514

Sumbawa .................... 287

Timor Sea ................... 287

Insecta ...................... 445

Iphione $\ldots \ldots \ldots 155,156,157,159,160,162,163$

coriolos ................... 162

fustis .................. 157, 160

henshawi ................... 162

hirta ................. 156, 162

malifera . . . 155, 156, 157, 159, 160, 162, 163

muricata ...........156, 157, 160, 162

ovata ............156, 157, 160, 162

reticulata $\ldots \ldots \ldots 155,156,157,160,162$

spinosa ..................... 157

treadwelli ........................ 162

Iphionidae .................. 155, 156

Ipnopidae ....................276 
Iran $\ldots \ldots \ldots \ldots \ldots \ldots \ldots \ldots \ldots \ldots, 511$

Iraq $\ldots \ldots \ldots \ldots \ldots \ldots \ldots \ldots \ldots \ldots, 511$

Irregularia ..................214, 220

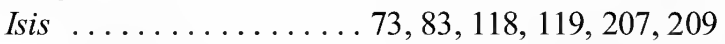

hippuris ..............83, 118, 119

Isopatagus obovatus ............... 234

isopod $\ldots \ldots \ldots \ldots \ldots \ldots \ldots \ldots, 30,31,61$

\section{$\mathbf{J}$}

Jacks and Pompanos . . . . . . . . . . . . . 292

Janicella spinicauda ........... 386, 387, 389

Japan . . . . 76, 77, 85, 130, 135, 171, 201, 202, 266, $270,271,272,273,274,275,276,277,279,280$, $281,282,283,284,285,286,287,288,289,290$, 291, 292, 293, 294, 295, 296, 297, 298, 299, 300, $347,348,385,388,389,392,445,505,506,508$, 514,515

Hokkaido . . . . . . . . . . . . . . . 277

Honshu .................201, 348

Idzu Sea .................... 506

Ryukyu Islands ........... 84, 296, 508

Okinawa Islands . . . . . . . . . . 273

Okinawa ..... 75, 273, 277, 282

Ryukyu Trench .................2273

Suruga Bay ....................274

Japan Sea ... . . . . . . . . . . . . . . . . 2280

Jaydia . . . . . . . . . . . . . . . . . 291,326

carinatus ................291,326

cf. poecilopterus .............291, 326

Jellynose . . . . . . . . . . . . . . . . 285

Junceella . . 73, 82, 89, 122, 123, 192, 193, 201, 209

fragilis ............82, 123, 192, 193

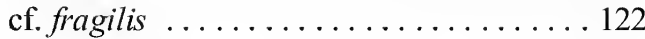

sp. . . . . . . . . . . . . . . 192, 201

\section{$\mathbf{K}$}

Kamoharaia megastoma .............297, 330

Karstia ................407, 409, 410,412

Kathetostoma sp. .................. 294

Keeling Island . . . . . . . . . . . . . . . 75

Kerilia ....473, 486, 491, 499, 501, 507, 528, 529

jerdoni ..............441, 507, 529

jerdoni .................. 507

siamensis ................ 507

Koehleraster abnormalis ............2231

Kolpophis ........473, 486, 491, 501, 502, 529

annandalei .............491, 502, 529

krait (sea kraits) . ........4 475, 513, 514, 530

Kuwait ........................506
Lachnophorini ..................... 446

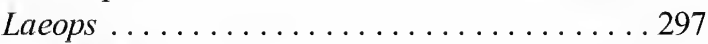

clarus ...................... 297

gracilis ..................... 297

kitaharae ...................... 297

sp. . . . . . . . . . . . . . . . . . . . 297

Laganidae ..............218, 232, 233

Laganum ......................... 232

decagonale .....................232

depressum ...................232

fudsiyama .................. 232

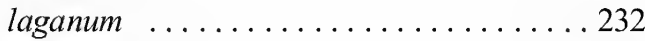

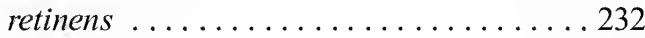

Lamnostoma ....................... 339

kampeni ...................... 339

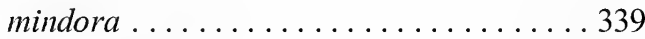

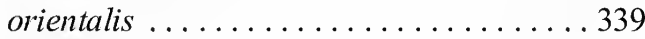

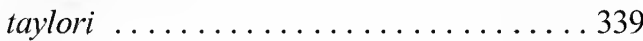

Lampanyctus ..................... 278

nobilis ..................... 278

sp. ......................... 278

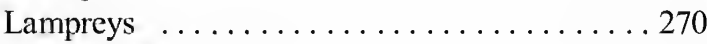

Lanternbellies ....................... 290

Lanternfishes . . . . . . . . . . . . . . . . . . . . 276

Laos ................... 408, 419, 423

Luang Nam Tha Province .... . 408, 419, 423

Lapemis . . . 473, 479, 485, 487, 489, 490, 491, 499, $501,504,505,529$

curtus ....... 485, 487, 491, 504, 505, 529

hardwickii .......4491, 504, 505, 529

hardwickii ................. 491

Laticauda 473, 475, 485, 486, 491, 500, 513, 514, 529

colubrina ...475, 485, 486, 491, 500, 513, 529

laticaudata .... . 475, 485, 491, 500, 514, 529

semifasciata ......4486, 491, 500, 514, 529

Laticaudinae ........473, 475, 500, 513, 529

Lebia (Poecilothais) sp. ...........4449, 471

Lebiini .....................449,450

Leioselasma ..........473, 491, 501, 504, 529

coggeri ................504, 529

cyanocinctus ...............491, 529

melanocephalus .............4491, 529

semperi ..................491, 529

spiralis ..................491, 529

Leiuranus ........................ 339

semicinctus ......................... 339

versicolor .......................... 339

Lepidoptera ...................... 64

Lepidotrigla abyssalis . . . . . . . . . . 288, 323 
Leptodesmidea ..................4.429

Leptodiadema purpureum .............. 220

Leptogorgia ....................... 209

Lesticus sp. .................447, 461

Levidorum ...................... 145

Lightfishes ..................... 273

Lim, Mundita $\ldots \ldots \ldots \ldots \ldots \ldots \ldots \ldots \ldots \ldots \ldots \ldots \ldots \ldots \ldots, 33,36$

Limacodidae ....................6 64

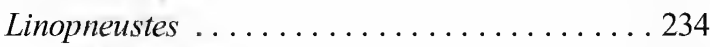

excentricus ..................234

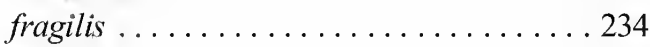

murrayi ....................234

spectabilis ..................2234

Lissodiadema ...............220, 221, 229 lorioli.................220, 221, 229

Lituaria ....................... 84

breve ..................... 84

liverworts ................ 395, 398, 402

Lizardfishes . . . . . . . . . . . . . . . . . 275

Lobsters ...................... 385

Lophiidac .................... 283

Lophiomus setigerus . ............283, 318

Lophogastrida . . . . . . . . . . . . . . . 388

Lophogastridae . . . . . . . . . . . . . 388

Lophyra (Spilodia) striolata . . . . . . . . 447, 458

Lovenia .........................234

doederleini ..................234

elongata .................... 234

gregalis ..................... 234

subcarinata ..................2234

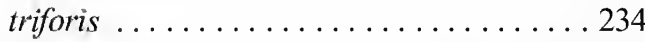

Loveniidae ................ 218, 234

Loyality Islands $\ldots \ldots \ldots \ldots \ldots \ldots \ldots . \ldots \ldots 1$

Luangnam ................4407, 419, 423

discobulbus ...............419, 423

Lucanidae ..........................6 64

Luciobrotula bartschi ................... 283

Luna, Ipat . . . . . . . . . . . . . . 25, 36

Lutjanidae . . . . . . . . . . . . . . . . . 292

Lycodon subcinctus . . . . . . . . . . 475, 529

Lycodontis johnsoni . ................. 271

\section{M}

Macropneustidae ..............218, 234

Macropus .....................244

Macrouridae .....................280

Macrourids ........................ 280

Macrurocyttidae . . . . . . . . . . . 286

Madagascar ....... 75, 76, 78, 79, 80, 290, 293

Madeira ........................ 147

flavomaculata ...............5515, 529

Malakichthys elegans . . . . . . . . . . . . . 290
Malay Archipelago . . . . . . . . . . 70, 287

Malay Peninsula . ............. 219, 507

Malaya ....................... 506

Malaysia . . . 74, 76, 77, 80, 81, 217, 296, 333, 407, $408,422,423,497,500,502,503,504,509,511$, $512,514,519$

Borneo .... 485, 497, 502, 504, 507, 513, 519

Brunei .................. 502

Sarawak ...........504, 513, 519

Selangor State ......... 408, 422, 423

Malaysian Peninsula . ................ 81

Malthopsis ...................285, 320

annulifera ..............285, 320

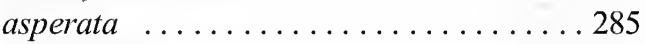

kobayashii ...............285, 320

lutea ........................285

tiarella ..................... 285

Mantis shrimp ..................... 58

Maretia planulata ................... 234

Maretiidae ..................218, 234

Margaret and Will Hearst (see under Hearst, Will and Margaret)

Marine hatchetfishes . . . . . . . . . . . . 274

Marshall Islands .......... 75, 129, 136, 289

Mary Lou Salcedo ..............24, 25, 36

Mataeocephalus ...............281, 317

acipenserinus .................. 281

cristatus .................281, 317

Maticora ...........447, 491, 493, 494, 529

intestinalis ......4477, 491, 493, 494, 529

bilineata ............441, 493,529

philippina ..........491, 494, 529

suluensis ...........4491, 494, 529

Matsubaraea setouchiensis . . . . . . . ......251

Mauritius .............76, 80, 157, 162

medical ..........5531,532, 534, 535, 536

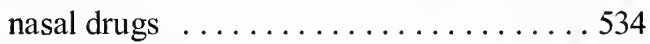

nasal sprays . . . . . . . . . . . . . 534

Medinilla teysmanii ...............6. 62

Mediterranean Sea ...... 82, 83, 84, 85, 86, 389

Melanesia ..................... 514

Melanostomiatidae .................275

Melastomataceae ..................6 62

Melithaea . . 72, 76, 98, 100, 173, 174, 179, 201, 209

Melithaeidae ..........76, 171, 207, 209

Menella ... 73, 78, 79, 80, 111, 112, 113, 202, 203, 207, 209

Menglunia ............... 407, 409, 412

Mergui Archipelago .................. 507

Mesopenaens mariae .............386, 387

Mesozoic ........................... 214

Mespilia globulus .................. 230 
Metabacetus cf. arrowi ............447, 460

Metalia .......................233

dicrana ......................233

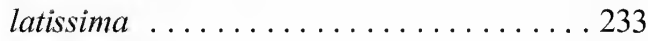

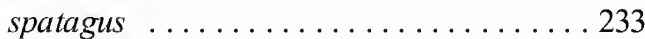

sternalis ................... 233

Metanephrops sinensis . ..... 386, 390, 391, 392

Metapenaeopis ..................... 388

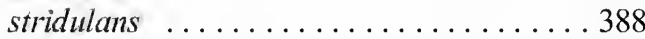

mogiensis $\ldots \ldots \ldots \ldots \ldots \ldots \ldots \ldots \ldots . \ldots \ldots$

Micrasteridae ................218, 234

Microcephalophis ...........4491, 506, 529 gracilis .............. 491, 506, 529

Microcyphus ....................2230 excentricus ...................2230

keiensis ...................... 230

Micronesia $\ldots \ldots \ldots \ldots \ldots \ldots \ldots \ldots 2$

Micropyga ............ 220, 222, 228, 229

violacea ..............220, 222, 229

Micropygidae $\ldots \ldots \ldots \ldots \ldots \ldots 218,228,229$

Micropygoida ............. 218, 228, 229

Millepora ...................... 70

millipedes ....................4 427

Flatbacked Millipede ............4 427

Mimocolliuris sp. ...............449, 469

Minous ...................287, 322

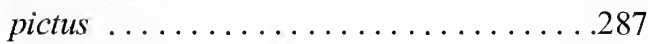

quincarinatus .............287, 322

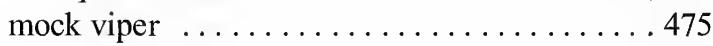

mollusks ..................23,30

Moluccas ...................... 81, 289

Monacanthidae ........................ 299

Mongolia ..................... 531

Monomitopus pallidus ..............2283, 318

Mopsella ............... 76, 173, 201, 209

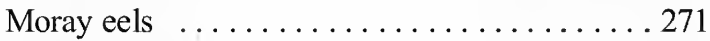

Morid Cods . . . . . . . . . . . . . . . . 279

Moridae ........................... 279

Mortonia australis ...............232

mosses ......................... 395

Mozambique ...................... 292

Mullidae ......................292

Muraena stellifer ...................271

Muraenichthys.................333, 339

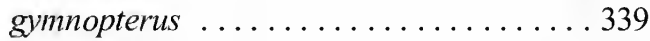

malaboensis ................333, 339

philippinensis ..............333,339

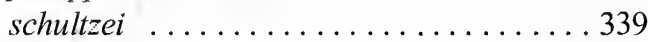

thompsoni .................333,339

Muraenidae ...................269,271

Muricella .............. 73, 75, 77, 101, 103

Muriceopsis tuberculata . . . . . . . . . . . . . 209
Muséum national d'Histoire naturelle, Paris . . 267

Myanmar ..............287, 507, 511, 514

Myctophidae ....................2276

Myctophum obtusirostre .............278

Myrianida .. 145, 146, 147, 148, 149, 151, 152, 153

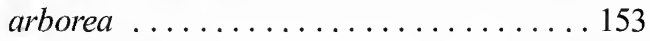

australiensis ..............147, 152

brachycephala ............. 147, 148

convoluta ................ 147, 152

dentalia ................. 147, 148

edwardsi .................147, 148

flava .................... 147, 148

gidholmi ............145, 147, 152, 153

hesperidium ............... 147, 152

inermis .................... 147, 148

langerhansi .............. 147, 148

longoprimicirrata ............ 147, 148

pachycera ............145, 147, 152, 153

pentadentata ............... 147, 148

pinnigera .................. 147, 148

prolifera ................. 147, 148

puladilaw ... 146, 147, 148, 149, 151, 152, 153

quindecimdentata ............147, 152

rubropunctata ................. 147

tereseta ...................... 153

Myrichthys .............34, 50, 333, 339

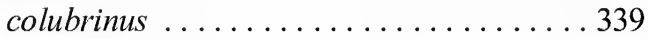

maculosus ..................... 339

paleracia .................... 50

paleracio ..............34, 36, 333, 339

Myripristis hexagona ...........286, 320

Myrophinae .................333, 337

Myrophis microchir .................. 339

Myxine .........2 270, 307, 341, 342, 347, 348

formosana ............2 270, 341, 348

cf. formosana .......2 270, 307, 341, 348

garmani ...................... 342

Myxinidae ...........269, 270, 341, 342

\section{$\mathbf{N}$}

Naatlo .....................4408, 410

Nacospatangus ....................234

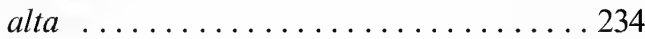

tylota .................. 234

Naja . . . . . 473, 476, 480, 481, 482, 483, 491, 496, $497,498,528,529$

hannah .............. 491, 497, 529

lutescens .................4496, 529

naja ........476, 480, 491, 496, 497, 529

miolepis ...........4 491, 497, 529

philippinensis .......4491, 496,529

samarensis ...........491, 496, 529 
philippinensis . . 476, 481, 482, 483, 491, 496, 498,529

samarensis .......483, 491, 496, 498, 529

sumatrana .........483, 491, 497, 529

tripudians ............ 496, 497, 529

samarensis .............496, 529

var. sumatrana .............. 497

Nansenia ardesiaca . . . . . . . . . 273, 312

Narcetes kamoharai ................ 273

National Muscum of Natural History (see under

Smithsonian Institution)

National Science Foundation (US) . . . . . . . . . 23

Nematocarcinidae ..................... 388

Nematocarcinus bituberculatus . . . . . 387, 388

Nemipteridae . . . . . . . . . . . . . . . 269, 292

Nemipterus . . . . . . . . . . . . . . . . 292, 327

bathybius ................292, 327

peronii ......................292

virgatus ..................... 292

Neobythites .................. 283, 318

macrops .................283, 318

nigromaculatus ............... 283

sivicola .................283, 318

unimaculatus ..............282, 318

Neocentropogon ..............287, 322

aeglefinus ................287, 322

affinis ................... 287, 322

Neocollyris sp............... 446, 457

Neoepinnula orientalis . . . . . . . . . 296, 329

Neolampadidae .................2218, 231

Neomerinthe sp. . .................. 287

Neoscopelidae . . . . . . . . . . . . . . . . . . 276

Neoscopelus ................2276, 314

microchir .................276, 314

porosus ....................2276

Neotropical region $\ldots \ldots \ldots \ldots \ldots \ldots . .427$

Nephila ........................6 63

Nephilidae ........................663

Nephropsis ensirostris . . . . . . . . . . 387, 392

New Caledonia . . 75, 76, 77, 78, 79, 80, 81, 82, 84, $162,274,275,279,281,285,290,295,297,298$, $300,385,388,389,392,504,509$

New Guinea $\quad .67,74,75,76,77,78,79,80,81,86$, $89,219,287,296,445,446,448,500,501,503$, $505,506,508,509,511$

(see also Papua New Guinea)

New Hebrides . . . . . . . . . . . . . . . . . . . . 389

New York Times . . . . . . . . . . . . 32, 540, 542

New Zealand ................. 147, 274, 295

Nezumia spinosa . . . . . . . . . . . . . . 281

Nicaragua . . . . . . ............. 427

Nomeidae . . . . . . . . . . . . . . . . . . 296
North America . . . . . . . . . . . . . . . . 448

Notagonum $\ldots \ldots \ldots \ldots 448,449,466,467,468$

sp. A $\ldots \ldots \ldots \ldots \ldots \ldots \ldots \ldots \ldots \ldots, 448,466$

sp. B $\ldots \ldots \ldots \ldots \ldots \ldots \ldots 448,467$

sp. C $\ldots \ldots \ldots \ldots \ldots \ldots \ldots 448,467$

sp. D ............... 449, 467

sp. E .................449, 467

sp. F . . . . . . . . . . . 449, 468

NSF (see National Science Foundation)

Nudechinus .....................231

stictus ....................2231

verruculatus ..................231

Nudibranchia . . . . . . . . . . . . . . . . . . . 129

nudibranchs . ................ 44, 49

\section{$\mathbf{O}$}

Obliquogobius ..............295, 296, 329

cirrifer ..................295, 296

cf. cirrifer ................... 296

megalops .................... 295

yamadai ......................295

Ocosia zaspilota ..............287, 322

octocorals (see under corals)

Octopus (see also Coconut octopus) . . . . 45, 46, 47

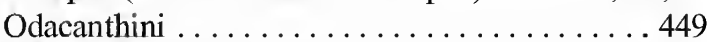

Odontodactylus scyllarus .............. 58

Ogcocephalidae ................. 269, 284

Ogulninae ...............4408, 409, 412

Ogulnius ................ 408, 410,412

yaginumai ................. 408

Okinawa (see under Japan, Ryukyu Islands)

Oligodon .....................475, 529

Oligopodia epigonus . . . . . . . . . . . . 231

Oman .......................506, 511

Oodes sp....................447, 461

Oodini ......................... 447

Ophichthidae ................272, 333

Ophichthus ...........272,310,333,339

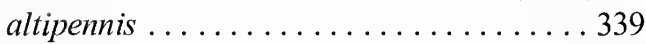

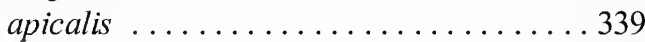

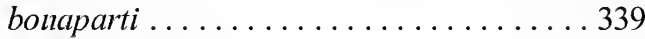

cephalozona .....................339

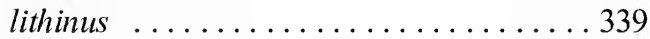

macrochir .....................339

manilensis .................333,339

mystacinus ...................... 339

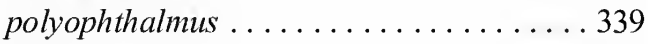

tomioi ....................... 339

urolophus ................272, 339

cf. urolophus . . . . . . . . . 272, 310

Ophidiidae ........................ 282

Ophiophagus ... 473, 480, 481, 482, 491, 497, 499, 
525,529 hannah ... 4 480, 481, 482, 491, 497, 499, 529

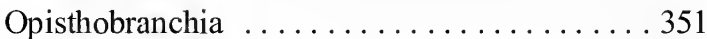

opisthobranchs ............. 351, 352

Oplophoridae . . . . . . . . . . . . . . . . . 389

Oriental Region . . . . . . . . . . . . . . 445, 449

ORSTOM (French cruises) . . . . . . . . . . . . . . . . . . . . . . 467

Orthogoniini . . . . . . . . . . . . . . 448

Orthogonius ..............448, 464

sp. A ............... . 448, 464

sp. B . . . . . . . . . . . . 448, 464

Osopsaron ............... 254, 258, 259

natalensis ................. 254

verecundum ................. . . 259

Ostichthys ................286, 321

japonicus . . . . . . . . . . . . . . 286

cf. japonicus ............286, 321

Ostorhinchus ................ 291, 326

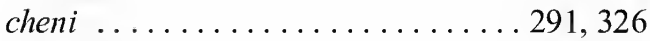

cf. cheni ...............291, 326

Oxyrhabdion ................445, 529

Ozaenini .....................4446

\section{P}

Pachyclavularia .................. 74

Pachyprocerastea ... . . . . . . . . . . . . . . 145

Pacific (Ocean/Region) (see also islands and groups, Fiji, Melanisia, Micronesia, etc.) . . . 67, 69, 71, $74,75,76,77,78,79,80,81,82,83,84,85,86$, $171,200,213,216,218,219,220,237,246,266$, $271,272,273,274,275,276,277,278,279,281$, $282,283,285,286,287,288,289,290,291,292$, $294,295,296,298,299,300,351,352,353,371$, $379,381,385,388,389,392$

Central Pacific 75,78

Eastern Pacific . . . . 285, 286, 295, 296, 385 , 389,392

Indo-West Pacific . . . 277, 281, 283, 285, 286, 287, 288, 289, 290, 291, 292, 299, 300

North Pacific . . . . . . . . . . . . . . . . . . 277

Northeastern Pacific . . . . . . . . . . . . . . 389

Northwestern Pacific . . . . . . . . . . . . . 282

South Pacific . . . . . . . . . . . . . . . . . 299

Wallis and Futuna Islands . . . . . . . . . . 388

Western Pacific . .67, 69, 75, 76, 77, 79, 80, 81, $82,83,271,272,273,275,276,277,281$, $283,285,286,288,290,291,292,294,295$, 296, 298, 385, 388, 389, 392

Markus-Necker Ridge . . . . . . . . . . . 281

Pacific striped octopus . . . . . . . . . . . . . . . 246

Pakistan ... . . . . . . . . . . . . . . 497, 511

Palaeostoma mirabile . . . . . . . . . . . . . . . . 234
Palaeostomatidae . . . . . . . . . . . . . . 218

Palacotropidae . . . . . . . . . . . . . 218, 234

Palau (Island[s]) . . . . . 74, 75, 76, 77, 78, 79, 81, 83

Paleopneustidae ........... 218, 234, 235

Paleotrema loveni . . . . . . . . . . . . . . . . . . 234

Palmones, Angelo . . . . . . . . . . . . . . 32

Palmyra . . . . . . . . . . . . . . . 74

Pandalidac . . . . . . . . . . . . . . . 385, 389

Papua New Guinea . . . . . 77, 80, 86, 129, 135, 136, $142,501,531$

Madang Province . . . . . . . . . . . . 136

Kranket Island . . . . . . . . . . . 136

Sek Island . . . . . . . . . . . . . . 136

Parabathymyrus brachyrhynchus . . . . . 272, 311

Parabothus ................. 297, 298, 330

sp. . . . . . . . . . . . . . . . . . . . . 298

taiwanensis . . . . . . . . . . 297, 330

Parachromis ............. . . . . . . . 547

managuensis ................ . . 547

Parahydrophis mertoni . . . . . . . . . . . 500, 529

Paralepididae ............... 278, 315

Paralepidonotus indicus . . . . . . . . . . . . . . . . . . . 162

Paramonacanthus . . . . . . . . . . . . 299, 332

curtorhynchos ............. 299, 300

cf. curtorhynchos . . . . . . . . 299, 332

japonicus .............279, 299, 300

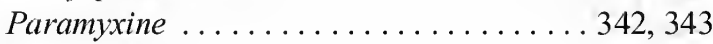

fernholmi ............... 342, 343

moki....................... 342

walkeri .................. 342

Parapenaeus sextuberculatus . . 386, 387, 388, 390

Parapercis sp. . . . . . . . . . . . . . . 293

Paraphaea philippinensis . . . . . . . . . 449, 472

Paraplexaura ........ 73, 78, 80, 113, 114, 115

Parapontocaris aspera ... . . . . . . . 387, 388

Paraproceraea ................... 145

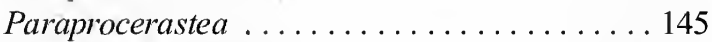

Parapterois heterurus . . . . . . . . . 287, 322

Parasalenia .............. . . . . . . . 230

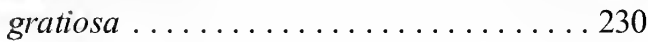

poehlii ................... 230

Parasaleniidae ............. 218, 224, 230

Parascolopsis inermis . . . . . . . . . . 292, 327

Paratrema doederleini ... . . . . . . . . . . . 230

Parias ....473, 477, 480, 483, 484, 491, 515, 516, $517,518,529$

flavomaculata ............ 515, 529

Pasiphaea japonica . . . . . . . . . . . . . 386, 389

Pasiphaeidae ... . . . . . . . . . . . . . . . . 389

Paussinae . . . . . . . . . . . . . . . . . . . . 450

Pectinia lactuca . . . . . . . . . . . . . . 567

Pedinidae . . . . . . . . . . . . . . . . . . . 218, 229 
Pedinoida ................. 218, 229

Pelamis . 473, 479, 490, 491, 499, 501, 509, 510, 529 platura ............... 491, 509, 529 platurus ..............4491,509, 529

Pelamydrus .................4491,529 platurus ...................491, 529

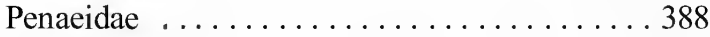

Penaeoidea ................... 385, 388

Pennatulacea . . . . . . . . . . . . . 83

Pennatulaceans . . . . . 67, 70, 71, 72, 74, 85, 124

Pennatulidae .................... 85

Pentagonica ................4449, 469, 470 sp. A . ............... 449, 469

sp. B ...............444, 470

sp. C .................449, 470

Pentagonicini ................... 449, 450

Perciformes .....................251

Percophidac ....................... 294

Peri Paleracio $\ldots \ldots \ldots \ldots \ldots \ldots \ldots . \ldots . \ldots . \ldots . \ldots, 36$

Pericosmidae ..................218, 235

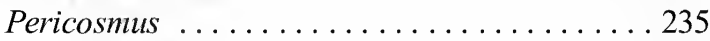

cordatus .....................235

keiensis ....................235

macronesius .................235

Perigona .................. 449, 468, 469

(s. str.) sp. . . . . . . . . . . 449, 468

(Trechicus) nigriceps . . . . . . . . 449, 468

(Trechicus) sp. ............. 449, 469

Perigonini ........................ 449

Peristedion cf. liorhynchus . . . . . . . . 28 288, 323

Peristidiidae .....................288

Peronella .......................... 233

lesueuri ....................... 233

macroproctes .................. 233

minuta .................... 233

orbicularis .................. 233

pellucida ................... 233

Persian/Arabian Gulf . . . . . 75, 290, 505, 506, 512

Peru ......................... 427

Pervagor sp....................... 300

Petersenaspis palpallatoci . . .......... 165

Philinacea ................351, 380, 381

Philine .....351, 352, 353, 354, 355, 356, 357, 358, $359,360,361,362,363,364,365,366,367,368$, $370,371,372,373,375,376,377,378,379,380$, 381,382

abyssicola ................... 352

acuticauda ....351, 354, 355, 356, 357, 358, $359,360,363,379,381$

alba ........ 351, 359, 360, 363, 379, 381 alboides ......351, 359, 360, 363, 379, 381 angasi ...................379, 381 aperta . . 351, 365, 367, 371, 375, 378, 379, 381 auriformis ..........354, 367, 379, 381 babai ................................ dentiphallus ...351, 354, 356, 363, 364, 365, $366,367,379,381$

elegans ..................... 375

fenestra ............... 352, 367, 381

finmarchica .................. 381

habei ....... 352, 354, 371, 378, 379, 381

hearstorum ....351, 354, 356, 360, 361, 362, $363,379,381$

multipapillata .. 351, 353, 354, 375, 376, 377, 378, 379

orca .................. 354, 379, 381

orientalis ...................354, 381

paucipapillata ............ 352, 379, 381

pittmani ....351, 354, 356, 367, 368, 369, 370 , $371,372,373,375,379,381,382$

puka ..............352, 371, 378, 379

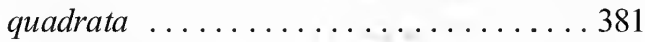

quadripartita ............... 379, 381

rubra ............... 371, 378, 379

rubrata...............354, 379, 381

sarcophaga ................. 352

verdensis . . .351, 354, 356, 367, 368, 370, 371, $378,379,381$

Philinidae ............. 351, 353, 355, 381

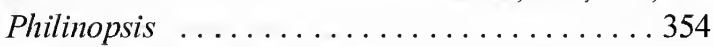

ctenophoraphaga .............. 354

Philippine Consulate in San Francisco . . . . . . 25

Philippine Consulate Genera ........... 134

Philippine Sea .................... 67

Philippines (also as Philippine Archipelago, Philippine Islands) . . . 7, 11, 19, 20, 21, 22, 23, 24, 25, $26,27,28,29,30,32,33,34,35,36,37,39,44,45$, $46,47,48,50,51,53,55,56,60,62,66,67,68,70$, $71,74,75,76,77,78,79,80,81,82,83,84,85,86$, $89,101,125,129,131,132,135,136,138,142$, $145,146,148,152,153,155,156,160,162,163$, $165,166,168,171,173,174,176,179,183,187$, $188,190,192,193,196,200,201,202,203,207$, $208,209,210,213,214,215,216,217,218,219$, $220,223,226,237,238,239,240,241,242,243$, $244,246,248,251,252,255,258,263,264,267$, $270,273,274,276,277,279,280,281,282,283$, $285,286,287,288,289,290,291,292,293,294$, $295,296,297,298,299,300,333,334,337,341$, $342,343,344,345,346,347,348,349,351,352$, $353,355,356,360,363,365,367,371,375,382$, $385,388,389,392,395,396,397,398,404,405$, $407,408,412,414,417,419,427,428,429,430$, $432,445,448,452,453,454,475,476,477,491$, 
494, 495, 496, 497, 500, 501, 502, 503, 504, 505, $506,507,508,509,510,511,512,513,514,515$, $517,518,519,531,532,539,540,542,543,544$, $545,546,547,548,549,550,558,561,562,563$, 564,567

Ateneo de Manila University . . . . . . . . 67

Balabac . 481, 482, 483, 484, 494, 497, 518, 519

Bantayan ................ 513,514

Batag Island $\ldots \ldots \ldots \ldots \ldots . \ldots 343,346$

Bohol ..........352, 375, 483, 497, 519

Panglao ....351, 352, 353, 354, 375, 382

Bureau of Fisheries and Aquatic Resources (BFAR) 9, 10, 11, 23, 25, 30, 31, 33, 36, 39, $45,55,239,242,243,251,253,263,268,546$ M/V DA-BFAR (Research vessel) . 18, 31, $55,61,220,221,222,223,251,252$, $253,260,263,264,265,266,270,305$, $333,334,337,340,341,343,348$

Busuanga ................... 78

Cabra Island .................... 387

Calamian Group .................. 78

Calavite Passage . . . . . . . . . . . . . . . 341

Caubian Island $\ldots \ldots \ldots \ldots \ldots \ldots \ldots 26 . \ldots \ldots$

Cebu ..................482, 495

Coral Gardens Reef .............. 78

Department of Agriculture . . ......... 546

Department of the Environment and Natural Resources (DENR) ..... 7, 25, 405, 546

Iloilo Prov. . . . . . . . . . . . . . 508

Gigante Ids. . . . . . . . . . . . . . 508

South Gigante Id. . . ......... 512

Leyte .... 483, 484, 497, 517, 518, 519, 520

Luzon (Luzón) . . . 7, 11, 20, 23, 25, 30, 32, 39, $45,53,55,67,74,75,76,77,78,79,80,81$, $82,83,84,85,86,125,131,132,135,136$, $138,145,148,152,156,157,166,171,183$, $188,192,196,202,203,239,251,252,255$, $263,268,279,281,282,286,287,289,297$, $333,341,343,355,360,363,365,367,369$, $385,386,388,389,408,414,417,419,423$, $427,428,429,430,432,445,447,451,454$, $476,481,482,483,484,488,495,496,497$, 506, 508, 511, 513, 514, 515, 516, 517, 519, $520,531,539,547,556,567$

Albay ............... 495, 519

Aurora ......4482, 496, 497, 516, 517

Bataan .............. 495, 517

Batangas Province ... 23, 24, 39, 45, 53, $74,75,76,77,78,79,80,81,82,83,84$, $85,86,131,132,135,136,138,146$, $148,156,157,173,174,183,188,192$, $196,202,203,239,355,360,363,365$,
$367,539,540,544,546,547,548,550$

Balayan .............. 263

Balayan Bay ...53, 79, 80, 131, 132, $138,166,173,174,183,188,202$, $203,355,385,386,567$

Ligpo Island . . . . . 79, 80

Batangas ...223, 24, 25, 30, 34, 131, $132,135,136,138,263,287,496$, 511,547

Batangas Bay ...... 85, 263, 386 Mainit Bubbles ......... 85

Bonito Island . . . . . . . . . 135

Caban Island ..... 59, 78, 79, 135 Kirby's Rock ........ 78, 79

Calatagan ....53, 54, 66, 360, 541, 548, 557

Calumpan Peninsula .... . 53, 59, 68, $71,79,80,81,82,83,85,146,148$, $173,183,192,196,202,567$

Anilao ...... 53, 129, 131, 132, $135,138,236,239,240,541,544$

Club Ocellaris ... . 29, 34, 40, 41, $42,45,47,48,50,53,239,240$, $249,541,544,553,554$

Culebra Island . . . . . . . . 173

Ligpo Island ....... 173, 174, 203

Lipa .................24

Mabini .... 23, 26, 34, 35, 239, 240, $541,548,550$

Mabini/Tingloy . .... 23, 541, 548

Maricaban Island ... 53, 59, 68, 71, $74,75,76,77,78,79,80,81,82$, $83,84,85,86,101,122,135,136$, $156,160,173,174,192,203,567$ Devil's Point . . 52, 74, 75, 76, 78, 79, 80, 101

Devil's Rock ........... 83

Gamao Point ...........83 83

Maricaban Strait . . 85, 183, 202, 203

Taal Lake .... 54, 55, 65, 541, 546, $547,555,560$

Talisay .............541, 546

Tingloy ...............239

University of Batangas ...5541, 547

Bulacan .........4496, 497, 517, 519

Camarines Sur ...........286, 495

Camarines Sur Province ...... 408, 417, 419, 445, 453, 549

Ateneo de Naga University . 546, 549

Mt. Isarog ..... 30, 54, 55, 62, 408, $417,419,445,453,454$

Naga City . . . . . . . . . . . 549 
Cavite ..............496, 519

Laguna (Province) ... 408, 427, 430, 432, $445,451,452,453,495,496,497,517$

Los Baños .......30, 408, 427, 429, $430,432,445,451,452,453,547$

Mount (Mt.) Makiling ... 30, 54, 55, $427,430,432,445,451,452,453$, $454,541,547$

Manila ... 7, 14, 23, 25, 29, 31, 32, 35, 36, $40,42,48,49,66,171,241,242,243$, $244,245,248,268,298,341,428,429$, $430,432,495,496,508,513,541,544$, $545,546,547,548,549,550,554,561$

Aquascapes ....... 242, 243, 244

Centro Escolar University . . 547, 549

Corregidor Island . . . . . . . . . 31

Museo Pambata .............. 35

National Committee on Museums 548

National Museum of the Philippines (also as Philippines National Museum) ... 11, 30, 36, 39, 45, 55, 171, $210,268,269,385,546$

Philippine National Commission for Culture and the Arts ...... 548

Philippine Science Centrum ... 12, $542,546,548,558,562$

Mt. Malarayat $\ldots \ldots \ldots \ldots 30,54,55$

Pagapas Bay ................ 386

Pampanga .................496

Pangasinan ...............4496

Quezon Province ... 408, 414, 417, 445, $451,452,453,547$

Lucban ....445, 451, 452, 453, 454, 541,547

Mt. Banahaw (de Lucban) ... 30, 54, $55,62,64,406,408,414,417,445$, $451,452,453,454,541,548,553$, 555

Quezon ......495, 496, 517, 519

Quezon City ...........14, 549

Southern Luzon State University. 547, 556

Rizal Province .......... 495, 496

Romblon Province..... 81, 83, 192, 193

Cobrador Island . . . . . . . 81, 83

San Bernardino Strait . . . . . . . . 251

Zambales ............... 515, 516

Marinduque .................. 496

Marine Protected Areas .......... 29, 33

Mindanao ... 70, 476, 481, 482, 483, 484, 494, $497,503,514,515,517,518,519$

Agusan ......... 494, 497, 518, 519
Agusan del Norte . . . . . . . . 518, 519

Agusan del Sur . . . . . . . . . . . . 519

Bukidnon ...............497, 518

Cotabato ................. 518

Davao ............494, 517, 518

Davao del Sur ............... 518

Lanao .......... 494, 497, 517, 519

Misamis Occidental .......4494, 497

Zamboanga ..........444, 497, 519

Zamboanga Peninsula .......... 70

Mindoro .... 7, 53, 67, 82, 84, 173, 179, 183, $193,202,251,252,255,263,333,341,343$, $356,365,369,481,483,495,496,497,514$, 517

Medio Island .........82, 183, 193

Mindoro Occidental . . . . . . . . . 356

Lubang Islands . . .53, 54, 55, 60, 61, $166,251,263,267$

Ambil Island . . 61, 166, 360, 387

Golo Island . . 166, 355, 363, 365

Lubang Island . . 6, 346, 347, 349, 367, 385, 386, 387

NW Passage of Puerta Galera ... . 82, 183

Puerto Galera . .......... 53, 54, 84

Sabang ..........173, 179, 183, 201

National Fisheries Research and Development Institute (NFRDI) . . . . . . . . . . 239

Negros .... 481, 482, 483, 495, 497, 515, 519

Silliman University . . . . . . 7, 12, 333

Palawan .....27, 37, 70, 476, 481, 482, 483, 484, 493, 494, 497, 507, 517, 518, 519

Puerto Princesa . . . . . . . . . . . 27

Panay ...........481, 482, 483, 495, 519

Philippine National Parks . . . . . . . . . . 35

Polillo ... . . 481, 482, 495, 496, 497, 515, 516

Pusod (PUSOD) .... 12, 24, 25, 540, 541, 542, 546, 547, 548, 557, 560, 561

REEF (Reaching out through Environmental Education to Filipinos) . . . . . . 24, 34

Samar .... 343, 346, 482, 483, 484, 494, 496, $497,503,514,518,519,520$

Sibutu ................ 483, 519

Sibuyan Sea .........67, 81, 83, 192, 193

Sulu Archipelago . . . . . . 389, 494, 503, 519 Jolo ... 481, 482, 483, 484, 494, 497, 513, $514,517,519$

Sulu Sea . . . . . . . . . . . 219, 274, 281

Tablas Island . . . . . . . . . . . . . . . . 192

Tumindao .................4483, 519

Typhoon Haiyan . . . . . . . . . . 550

University of Santo Tomás ... . 546, 554, 561

University of the Philippines (UP) . . 7, 11, 25, 
$27,30,33,34,39,45,53,55,56,66,67,84$, $223,239,267,408,452,453,546,547,549$, 550,558

Marine Science Institute (MSI) . . 23, 25, 84,146

Zoological Museum ........... 267

Verde Island Passage . . . 7, 25, 29, 30, 39, 45, $53,54,55,59,60,61,67,68,71,72,74,84$, $86,166,171,176,183,187,190,196,200$, $201,207,214,219,221,223,239,240,263$, $272,333,334,337,341,346,351,352,353$, $354,355,360,363,365,367,369,385,386$, $387,389,539,550,567$

Visayan Sea 503,505

Phormosomatidae ................218, 228

Photichthyidac ....................273

Photonectes albipennis .............275, 313

Phyllodesmium briareum ..............74

Phyllophichthus xenodontus ......... 334, 339

Physiculus ...................279, 315

longifilis ...................... 279

rhodopinnis ..............2279, 315

Pinguipedidae ..................... 293

Pisodonophis ...................... 339

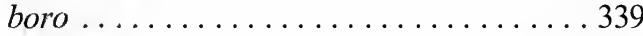

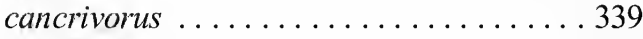

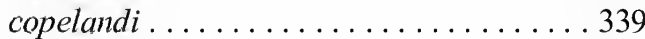

Pitcaim (Island) . . . . . . . . . . . . 289

pitvipers .........65, 473, 515, 518, 527, 530

Planicirrata ....................... 145

Plato ...................... 408, 410

Platoninae ............... 408, 409, 412

Platurus semifasciatus ............514, 529

Platybrissus roemeri ................. 234

Platycephalidae ...................... 289

Platygyra lamellina . ............... 567

Platymantis isarogi .................6 65

platynine/ ?lachnophorine sp. . . . . . . . . . . . 449

Platynini ..............446, 448, 450

Platyrhacidae .............427, 428, 429

Platyrhacoidea . . . . . . . . . . . . . . . 429

Platyrhacus ............4427, 428, 430, 442

fuscus ................. 428, 430

margaritiferus ...........428, 430, 432

meyenii ................44, 428, 430

philippinorum ...........4 428,430, 432

(Platyrhacus) margaritiferus ........ 430

Platyrhacus philippinorum .... 427, 428, 430, 442

Platyrhynchine ....................64 64

Platyrrhacus [sic!] margaritiferus . . . . . . . . 430

Plectranthias ..................... 290, 325

sagamiensis ...............290, 325

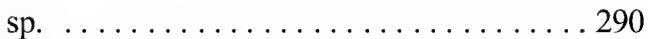

Pleistocene . .....................55

Plesionika .......... 386, 387, 389, 390, 391

edwardsii ............386, 387, 389, 391

hsuehyui .....................389

cf. kensleyi ................. 387

orientalis ............. 386, 389, 390

rostricrescentis ................. 386

sp. . . . . . . . . . . . . . . . 387

Plesiozonus ...............220, 221, 234

diomedeae .................... 234

hirsutus ..............220, 221, 234

tenuis ........................ 234

Pleurobranchella nicobarica .........661,350

Pleuronectidae . . . . . . . . . . . . . . . . . . . . 298

Plexauridae .............171, 202, 207, 209

Plexechinidae ................218, 233

Plexechinus spectabilis . .............. 233

Pocillopora sp. ....................5 57

Poecilopsetta ...................298, 331

colorata ...................298, 331

plinthus .................298, 331

Poecilothais (see Lebia (Poecilothais)) . . . . . 471

Pollichthys mauli ................... 273

Polyceridae ........................ 129

Polycerinae . . . . . . . . . . . . . . . . 129

Polychaeta . . . . . . . . . . . . 155, 165

polychaete (also as polychetes) . . 49, 155, 165, 166

Polycheles ....................386, 392

baccatus .................386, 392

helleri ................... 386, 392

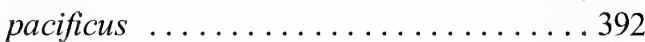

sculptus .................386, 392

Polychelida .................. 385, 392

Polyderis ....................447, 460

impressipennis . ............447, 460

Polydesmida . . ......... 427, 428, 429, 432

Polydesmus ............4 427, 428, 429, 430

margaritiferus ..............429, 430

meyenii .............427, 428, 430

(Platyrhachus) margaritiferus . . ...... 430

(Stenonia) margaritiferus . . .........440 430

(Stenonia) meyenii ............... 430

Polyipnus ....................274, 312

danae .......................274

soelae ........................... 274

spinifer ..................274, 312

tridentifer ....................274

triphanos ........................ 274

unispinus ....................... 274

Polymetme corythaeola . . . . . . . . . . . . 273

Polymixia berndti ..............278, 315 
Polymixiidae . . . . . . . . . . . . . 278

Polynesia ...................... 514

Polynoidae ...................... 155

Pontinus ..................287, 323

macrocephalus $\ldots \ldots \ldots \ldots \ldots \ldots 287,288$

rhodochrous ............287, 288, 323

tentacularis ................... 287

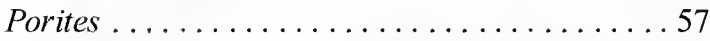

Praescutata ......473, 486, 491, 501, 512, 529 viperina ............491,512, 529

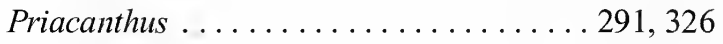

fitchi ..................291, 326

macracanthus ..............291, 326

Pricanthidae .................... 291

Principé (Island) (see under Africa)

Prionechinu .................s 220, 221, 231 forbesiamus ..............221, 231 sculptus ....................231

Pristigenys niphonia .............291, 326

Pristipomoides argyrogrammicus . . . . . . 292, 327

Proceraea ..................... 145, 147 albocephala ................... 147

madeirensis .................... 147

pleijeli ...................... 147

Procerastea ....................... 145

Procletes levicarina ..............387, 389

Promethichthys prometheus . . ....... 296, 329

Prothyma ..................447, 457

sp. A $\ldots \ldots \ldots \ldots \ldots \ldots \ldots . \ldots 44,457$

sp. B ................444, 457

Protoreaster nodosus .............. 243, 248

Prymnaster investigatoris . . . . . . . . . . . . . 235

Psammodynastes ................. 475, 529

Psettina gigantea ................298, 330

Pseudobalistes flavimarginatus . . . . . . . . . 299

Pseudoboletia .....................2231

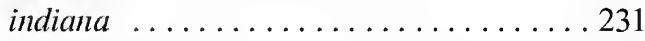

maculata ......................231

Pseudolaticauda .............4491, 513, 529 semifasciata .............491, 514, 529

Pseudolimnaeum (see Sinechostictus (Pseudolimnaetum) $\ldots \ldots \ldots \ldots \ldots \ldots \ldots \ldots . \ldots 460$

Psychocidaridae $\ldots \ldots \ldots \ldots \ldots \ldots 218,228$

Psychrolutes ..................289, 324

occidentalis ................... 289

cf. occidentalis . . . .............289

Psychrolutidae ...................... 289

Pteroeides ........... 72, 85, 86, 127, 128 sp. ....................... 128

spp. .................... 85, 127

Pterois ......................288, 323

antennata...............28 28, 323 lunulata ...............288, 323

Pteropsaron .... 251, 252, 253, 254, 255, 256, 257 , $258,259,260,293,294,327,328$

dabfar ....252, 253, 254, 255, 260, 293, 327

evolans..............251, 254, 259

formosensis ...............255, 259

heemstrai ................254, 259

incisum ................251, 259

levitoni ...255, 256, 257, 258, 259, 260, 294, 328

natalensis ........251, 254, 255, 258, 259

springeri $\ldots \ldots \ldots \ldots 251,260,294,328$

verecundum ......................259

Pterostichini .................444, 450

Pterygotrigla ................... 288, 323

hemisticta .................. 288

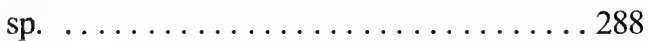

Puffers ........................ 300

Pylorobranchus .....333,334, 335, 336, 337, 339

hearstorum .... 272, 310, 333, 334, 335, 336, 337,339

hoi ..................334, 337

Pusod (PUSOD) (see under Philippines)

\section{$\mathbf{R}$}

Rafflesia maniliana ..................66 62

Rafflesiaceae ...................662

Rapa .......................... 289

Ratfishes $\ldots \ldots \ldots \ldots \ldots \ldots \ldots \ldots \ldots \ldots \ldots . .270$

Rattails ..................... 280

Red Sea ... 74, 77, 78, 79, 80, 81, 82, 85, 162, 217 , 219, 290, 291, 292, 295, 300

REEF (Reaching out through Environmental Education to Filipinos)(see under Philippines)

Rhabdophis ................475, 529

Rhynobrissus pyramidalis ............ 233

Righteye Flounders . . . . . . . . . . . . . . . 298

rockfishes .....................286

Rogadius welanderi ...........289, 323, 324

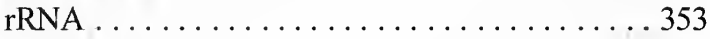

Rumphella ...........73, 81, 83, 118, 119

aggregata .................. 81

cf. aggregata $\ldots \ldots \ldots \ldots \ldots .81,118,119$

antipathes $\ldots \ldots \ldots \ldots \ldots \ldots \ldots \ldots 1$

Ryukyu Islands (see under Japan)

Ryukyu Trench ....................... 273

\section{S}

Saleniidae ....................218, 229

Salenioida ...................218, 229

Salmaciella ...................... 230 
dussumieri ..................2230

oligopora .................... 230

Salmacis ......................230

belli .......................230

bicolor......................230

sphaeroides ..................230

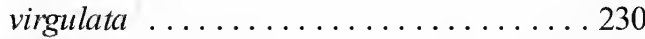

Samarus cristatus ..............298, 331

Samoa ......................291, 389

Samoan archipelago ............... 70

San Francisco . ....... 19, 20, 23, 25, 26, 35, 36

San Francisco Bay .................. 354

San Francisco Philippine Consulate ........ 550

sand dollars . . . . . . . . . . . . . . . . . . . 214

Sand-divers ........................ 293

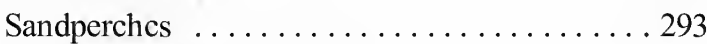

São Tome (see under Africa)

Sardinella tawilis .................. 547

Saudi Arabia . ................... 506

Saurida sp. .....................275

Scaleless black dragonfishes . . . . . . . . . 275

Scaleworm ...................... 155

Scaly dragonfishes $\ldots \ldots \ldots \ldots \ldots \ldots 274$

Scaphander ..............353, 354, 355, 381

mundus ................353, 354, 355

Schizaster lacunosus .................2235

Schizasteridae ................218, 235

Schultzidia johnstonensis . ............ 334

Schultzidia retropinnis . . . . . . . . . . . . 339

scleractinian corals . ................667

Scolecenchelys ................334, 339

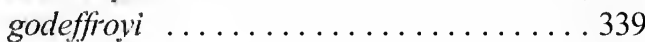

gymnota ...................... 339

laticandata ........................... 339

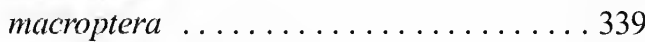

Scolecenchelys acutirostris . . ........... 334

Scolopendra .....................63 63

sp. ........................533

Scorpaenidae ...................286

Scorpionfishes . . . . . . . . . . . . . . 286

Scyliorhinidae . . . . . . . . . . . . . . . 270

Scytalium ................ 72, 85, 124, 128

cf. sarsi $\ldots \ldots \ldots \ldots \ldots \ldots . \ldots 5,124,128$

sea biscuits ...................... 214

sea cucumbers . . . . . . . . . . . . . . 213

Sea Fans $\ldots \ldots \ldots \ldots \ldots \ldots \ldots 6,80,171$

sea kraits ..............473, 513, 530

sea lilies ......................213

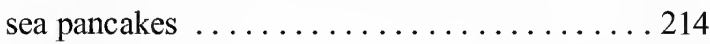

Sea pens $\ldots \ldots \ldots \ldots \ldots \ldots \ldots 60,67,89$

sea snakes ... 32, 473, 475, 476, 477, 479, 481, 485,

$487,491,499,500,510,513,527,530$
Sea Toads . . . . . . . . . . . . . . 283

Sea Whips $\ldots \ldots \ldots \ldots \ldots 67,82,83,122,171$

seahorses ................... 44, 45

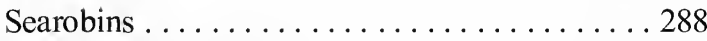

SECORE Foundation ...............241

Selenechinus armatus ................ 230

Semperina ..................... 75

Scnckenberg Forschungsinstitut und Naturmuseum 408

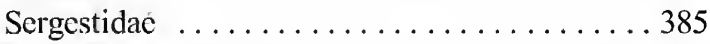

Sessilia .......................... 173

Setarches longimanus . . . . . . . . . . 288

Seychelles ......................22

sharks ....................44, 50

Shortnose chimaeras . . . . . . . . . . . . . . 270

Shrimps ......................... 385

Sigmops elongatum . . . . . . . . . . . . . 273

Simenchclyidae . .................. 272

Simenchelys parasitica ..........272, 310

Sinechostictus ................444, 460

(Pseudolimnaeum) cf. pendleburyi ... 447, 460

Singapore $\ldots .78,79,80,385,497,500,502,504$ $506,507,508,511,514$

Raffles Museum ................. 385

Sirembo imberbis . .............283, 318

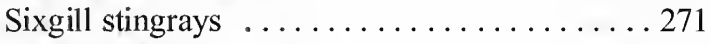

Skythrenchelys ..................... 339

macrostomus .................. 339

zabra ....................... 339

Slickheads ....................... 273

Slimeheads .....................285

Smithsonian Institution . . . . . . . 10, 213, 217

National Museum of Natural History .... 23, $213,217,333,337,339,385$

Snaggletooths . . . . . . . . . . . . . 274

Snake eel(s) .......... 34, 49, 50, 272, 333

Snake Mackerels . . . . . . . . . . . . . . 296

snakebite ...........532, 533, 534, 535, 536

Snappers ....................... 292

Snubnose parasitic eels . . . . . . . . . . . 2 272

Society Islands . . . . . . . . . . . . . 289

Soft coral ................... 58, 60

Soft Coral Anemone ....................49

Soleidae . . . . . . . . . . . . . . . . . . . . 298

Solenocaulon ......... 72, 74, 89, 90, 93, 94

cf. rubra ............. 74, 93,94

Solenoceridae ..................... 388

Solenostomus ....................44 44

cyanopterus .................... 44

Soles ............................. 298

Solomon Islands . . 67, 74, 75, 76, 77, 81, 86, 89, 274

South Africa (see under Africa) 
South China Sea . . . 67, 201, 202, 251, 263, 268, $270,272,274,280,281,282,283,285,286,287$, $296,298,386,387,388,389,485,500,502,503$, $504,506,509,511,512$

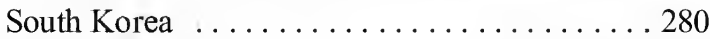

Southeast Asia . . . . . . . 29, 395, 407, 532

Spain ................... 145, 147, 148

Spanish American War ............... 22

Spatangidae ...................218, 235

Spatangoida ..........217, 218, 233, 234, 235

spatangoids ..................214, 216

Spatangus ........................2235

diomedeae ................... 235

pancituberculatus ..................2235

Sphagemacrurus pumiliceps ..........2281, 317

Sphoeroides pachygaster ........... 300, 332

spiders ........................30,407

Spikefishes .....................299

Spilodia (see Lophyra (Spilodia)) . . . . . . . . 458

Spinapsaron ..................251, 254

barbatus .....................251

sporophytes .................... 402

Squalidae .......................270

Squirrelfishes $\ldots \ldots \ldots \ldots \ldots \ldots \ldots 286$

Sri Lanka ............ 76, 78, 79, 505, 507

Stag beetle ...................... 64

starfish ........................ 213

Stargazers . . . . . . . . . . . . . . 294

Stenolophus (Egadroma) sp. . . . . . . . 448, 462

Stenonia ......................... . 430

margaritifera ...............4 430

Stenotricondyla (see Tricondyla (Stenotricondyla)) 456

Sternaspidae . . . . . . . . . . . . . . 165

Sternaspis ............ 165, 166, 167, 168 piotrowskiae .........165, 166, 167, 168 rietschi .................. 168

thorsoni ..................... 168

Sternoptychidae .................... 274

Sternoptyx diaphana ................ 274

Stick weevil . . . . . . . . . . . . . . . . 64

Stomias ....................274, 313

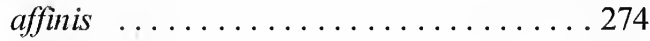

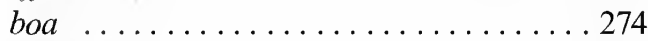

danae......................274

longibarbatus .................274

nebulosus ..................274, 313

sp. ........................274

Stomiidae ........................ 274

Stomopneustes variolaris . . . . . . . . . 220, 229

Stomopneustidae ................. 218, 229

Stomopneustoida ................ 218, 229
Straits of Malacca ...............491, 505

Stylodactyloides sp.............. 387, 392

Subergorgia ..........73, 75, 76, 89, 93, 97

appressa .................. 76

mollis ..................... 75

pulchra .................... 76

suberosa ............. 75, 76, 93, 97

Sweden ....................... 147

Syllidae .................. 145, 146, 153

Symbiodinium microadriaticum . . . . . . . . 71

Synagrops ..................290, 324, 325

bellus .......................... 290

japonicus ...................290, 324

philippinensis ..............290, 325

sp. ...........................290

Synaphobranchidae .................2271

Synaphobranchus kaupii ............271, 310

Syngnathidae ..................... 75

Synodontidae .......................275

Synodus ..................275, 276, 313

macrops ..................... 275

oculeus ...............275, 276, 313

sp. ..........................

Syntomus sp. ..................449, 471

Systellaspis debilis .......385, 386, 387, 389

\section{$\mathbf{T}$}

Taaningichthys sp. ............... 278

Tachyura (see Elaphropus (Tachyura)) . . . . . 459

Taeniopsetta ocellata ............298, 330

Tagalogonia ... 407, 408, 409, 410, 412, 413, 414, $415,416,417,418,419$

banahaw ...407, 408, 412, 413, 414, 415, 416, 417

isarog . . . . 407, 408, 413, 414, 417, 418, 419

Taiwan ... . 74, 75, 76, 77, 78, 79, 83, 85, 268, 270, $271,274,276,280,281,282,283,284,286,287$, $289,290,291,296,297,298,334,337,341,342$, $347,348,385,389,393,505,507,508,509,513$, 515

Academia Sinica . . . . . . . . . . . . . 268

Kaohsung .................. 268

Taiwan Fisheries Research Institute . . 268

National Museum of Marine Biology and Aquarium ..................... 284

Tasmania ....................295, 510

Teleostei ........................251

Temnopleuridae ...............218, 230

Temnopleurus ....................2230

decipiens ...................... 230

hardwickii .................... 230

reevesii ....................230 
toreumaticus .................2230

Temnotrema ....................230

pallescens ..................230

pulchellum ..................230

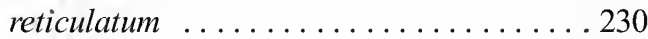

sculptum ..................230

siamense ................... 230

Tetraodontidae .............. 269, 300

Thailand ... .78, 79, 130, 347, 348, 497, 500, 502,

$503,504,506,507,508,509,511,512,513,514$

Gulf of Thailand 500, 502, 503, 506, 508, 512

Thalassophina .......4491, 499, 501, 512, 529 viperina .............491,512,529

Thalassophis ...473, 486, 491, 501, 502, 512, 529 anomalus ...............441,502, 529 viperina .................512,529

Thamnacornus tesselatus . ......... 300, 332

Thelephonida ...................6. 63

Thelotornis capensis . ............ 475, 529

Therates semperi ............... 447, 458

Theridiosoma ...........4408, 409, 410, 412 nebulosum ................. 408

Theridiosomatidae ... 407, 408, 409, 410, 412, 419

Theridiosomatinae ......4 408, 409, 410, 412, 419

Thompson, Joseph Cheesman . . . . . . . . . . 7

Thopeutica .................447, 458

(Thopentica) cf. conspicua .......447, 458

(Thopeutica) clara aenula .......447, 458

Thoracica ....................... 173

Threadfin Breams . . . . . . . . . . . . . . . . 292

Thysanophrys chiltonae ...........289, 324

tiger beetles . . . . . . . . . . . . . . . . . . . . 445

Tomogaster eydouxii .............. 500, 529

Tonga (Island) . . . . . . . . . . . . . . . . . . . . 389

Tonguefishes . . . . . . . . . . . . . . . . . . 298

Toxopneustes ................215, 231

pileolus ......................231

Toxopneustidae . . . . . . . . . . 218, 231

Trachichthyidae ............269, 285, 302

Trachonurus villosus ............282, 317

Triacanthodes ................299, 332

anomalu ........................ 299

ethiops ...................299, 332

Triacanthodidae ..................... 299

Trichinotidae . . . . . . . . . . . . . . . 293

Trichonotidae ............251,252, 258

Trichotichnis sp. ...............448, 463

Tricondyla .................. 446, 456

(Stenotricondyla) cyanipes . . . . . . 446, 456

(Tricondyla) conicicollis ......... 446, 456

(Tricondyla) ventricosa ventricosas . . 446, 456

Triggerfishes ...................... 299
Triglidae ..................269, 288

Trigonocidaridae ............218, 220, 231

trigonocidarids $\ldots \ldots \ldots \ldots \ldots \ldots \ldots 220$

Trimeresurus . . . .65, 473, 475, 476, 477, 480, 483, $484,491,515,516,517,518,519,529$

flavomaculatus . . 477, 491, 515, 517, 519, 529 flavomaculatus .......4491, 515, 529 mcgregori .........4491,517,529 halieus .........4491, 515, 517,529 halieus ............... 491, 515, 529 megregori ........447, 491, 517, 529 philippensis ...............518, 529 schadenbergi ..............5 515, 517 schultzei ............4 477, 518,529 (Parias) ... 473, 480, 483, 484, 491, 515, 516, $517,518,529$

flavomaculatus .......66, 480, 483, $484,491,515,516,529$

halieus ................... 491

mcgregori .......444, 491, 517, 529

schultzei .........484, 491, 518, 529

wagleri .........476, 491, 518, 519, 529 philippensis [philippinensis] .......441 subannulatus ............4491, 529

Trimesurns subannualtus ............. 519

Tripneustes gratilla ................ 231

Tropidolaemus .....473, 474, 475, 476, 477, 481, $483,484,491,515,518,519,520,529$

hombronii ............518, 519, 529

philippensis . . . . 476, 484, 491, 518, 519, 520, 529

subannulatus ... 474, 476, 481, 483, 491, 518, $519,520,529$

cf. subannualtus . ..............5520

wagleri............... 518, 519, 529

Tropidonophis ................475, 529

Tuamotus . . . . . . . . . . . . . . . . . . . . . . 299

Tubipora ........................ 70

Turbinaria ......................44

Tylerius spinosissimus .............. 300

\section{$\mathbf{U}$}

U.S. Fish and Fisheries Commission ........ 22

U.S. Fish Commission Steamer Albatross ... 7, $22,37,217,263,267,281,282,341,342$, $343,346,347,385$

Umbellula sp. ....................6 60

Umbellulifera sp. .................. 58

University of California Los Angeles . . . . . . . 10

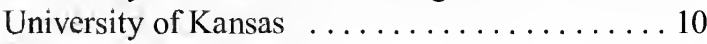

University of Singapore $\ldots \ldots \ldots \ldots \ldots \ldots 12$

University of the Philippines (see Under Philippines) 
Upeneus.....................292, 327

moluccensis . . . . . . . . . . . . . . 292

subvittatus . ...............292, 327

Uranoscopidae ...................294

Uranoscopus .............294, 295, 328, 329

bicinctus .....................295

chinensis ..................295

cognatus ....................295

japonicus .....................295

kaianus ......................295

sp. $2 \ldots \ldots \ldots \ldots \ldots \ldots \ldots 294,295,328$

sp. $3 \ldots \ldots \ldots \ldots \ldots \ldots 295,328,329$

urchins ........213, 214, 215, 217, 220, 223

fire urchins $\ldots \ldots \ldots \ldots \ldots 213,215$

flower urchin . . . . . . . . . . . . . 215

hair-spined urchin . ..............220

keyhole urchins ................. 214

lamp urchins $\ldots \ldots \ldots \ldots \ldots \ldots \ldots 214$

pea urchins $\ldots \ldots \ldots \ldots \ldots \ldots \ldots 214$

Sea Urchins .............. 213, 214

slate pencil urchins $\ldots \ldots \ldots \ldots \ldots 213,214$

USA $145,147,148$

\section{V}

Vaccinium sp. ...................662

Venerupis philippinarum . . . . . . . . . . . . . 244

Venomous snakes $\ldots \ldots \ldots \ldots \ldots . \ldots 32,473,531$

Ventrifossa ...................282, 317

longibarbata ..............282, 317

macroptera ..................282

saikaiensis ................2282, 317

sazonovi ...................282

Verde Island Passage (see under Philippines)

Veretillidae ....................883

Veretillum .............. 72, 83, 84, 125

Vietnam .... 282, 286, 293, 502, 503, 504, 506, 508,

509,513

Villanueva, Mayor................. 548, 550 Villogorgia ..............73, 80, 116, 117

Viminella . 74, 83, 120, 123, 183, 188, 200, 201, 209 gracilis ................201, 209 sp. ................183, 188, 201
Viperidae .........4473, 475, 481, 515, 529

Virchowia ...................145, 147

clavata...................... 147

Virgularia ................. 72, 85, 126

Virgulariidae .................... 85

voucher specimens $\ldots \ldots \ldots .396,397,400,404$

\section{W}

Wallace, Alfred Russel ..........70, 90, 565

Wallace's Line ...................... 70

Wallacea .................69, 70, 90

Weevil .......................... 64

Wendilgarda .........408, 409, 410, 412, 419

liliwensis ................... 408

West Indies . . . . . . . . . . . . . . . . 293

Leeward Islands . . . . . . . . . . . . . 293

Wood urchins . .................... 220

World Echinoidea Database ............. 213

World Health Organization (WHO) . . 532, 535, 536

Worm eels .................. 272, 333

worms ........................... 30

Wrightella ......................... 76

$\mathbf{X}$

Xestochilus nebulosus . ................. 334

Xestospongia testudinaria $\ldots \ldots \ldots \ldots \ldots 58$

Xyrias revulsus ..................... 339

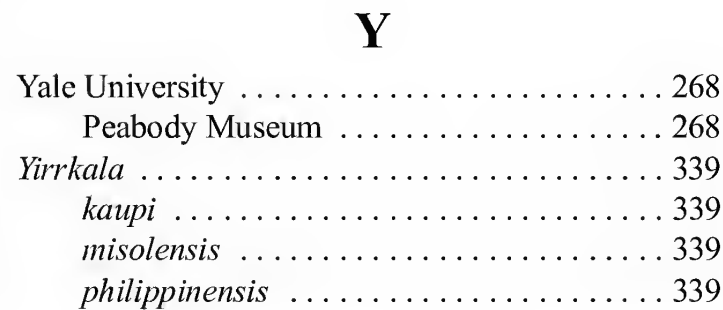

\section{$\mathbf{Z}$}

Zanzibar ...................... 76

Zenion hololepis . ...............286, 321

Zoma ...................409, 410,412

Zooxanthellae .... 71, 78, 79, 80, 84, 90, 122, 124 